\title{
TWELFTH ANNUAL REPORT
}

\author{
OF THE
}

UNITED STATES

\section{Geological and Geographical Survey or}

\section{THE TERRITORIES:}

A REPORT OF PROGRESS OF THE EXPLORATION IN

\section{WYOMING AND IDAHO' FOR THE YEAR 1878.}

IN TWO PARTS.

PART I.

Br F. V. HAYDEN, UNITED STATES GEOLOGIST.

CONDUCTED UNDER THE AUTHORITY OF THE SECRETARY OF THE INTERIOR.

W A SHINGTON:

GOVERNMENT PRINTING OFFICE.

1883 . 

TWELFTH ANNUAL REPORT OF THE UNITED STATES GEOLOGICAL AND GEOGRAPHICAL SURVEY.

\section{PART I.}

1

GEOLOGY, PALEONTOLOGY, AND ZOÖLOGY.

(iii) 



\section{TABLE OF CONTENTS.}

Title Page.

Table of contents ................................................... V

List of illustrations ..................................................... VII

Letter of transmittal................................................... XIII

\section{SECTION I.-GEOLOGY AND PALEONTOLOGY.}

REPORT OF C. A. WHITE, M. D...................................... 1

Letter of transmittal...............................................

Contributions to invertebrate paleontology:

No. 2. Cretaceous fossils of the Western States and Territories...........

No. 3. Tertiary mollusca from Colorado, Utah, and Wyoming ...........

No. 4. Fossils of the Laramie group ...................................

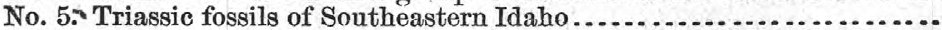

No. 6. Carboniferous fossils from the Western States and Territories ....

No. 7. Jurassic fossils from the Western Territories .....................

No. 8. Carboniferous fossils from the interior States ...................

REPORT OF ORESTES ST. JOHN:

Letter of transmittal

Report on the geology of the Wind River District..................... 175

CHAPTER I.-Area and boundaries................................ 175

CHAPTER II. -Wyoming Range ..................................... 178

CHAPTER III.-Hoback-Green River Basin ............................ 202

ChaPTER IV.-Gros Ventre Range ................................ 208

Chapter V.-Gros Ventre Basin ................................... 219

CHAPTER VI. -Wind River Range....................................... 228

Chapter VII. -Wind River Basin ................................ 255

REPORT OF SAMUEL H. SCUDDER:

The Tertiary Lake Basin at Florissant, Colo............................ 271

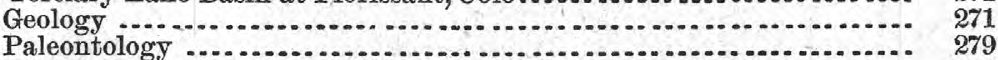

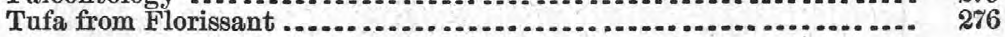

SECTION II.-ZOÖLOGY.

Report of A. S. PACKard, JR:

Monograph of Phyllopod crustacea:

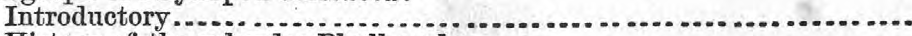

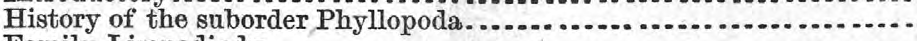

Family Limnadiadæ..............................................

Family Apodidæ

Geological succession of the Phyllopoda............................

Geological distribution of the Phyllopoda............................

Morphology and anatomy ........................................

Development, metamorphosis and genealogy ........................

Reproductive habits of Branchiopodidæ.............................

Systematic Position of the Order Phyllocarida ........................

Phyllocarida.......................................................

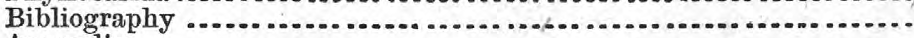

Appendix

REPORT OF R. W. SHUFELDT:

Osteology of Speotyto Cunicularia .................................... 593

Osteology of Eremophila Alpestris ..................................... 627

Osteology of North American Tetraonidæ.............................. 653

Osteology of Lanius luidovicianus excubitorides......................... 719

Osteology of Cathartidæx ........................................ 727 



\title{
LIST OF ILLUSTRATIONS.
}

PALEONTOLOGY.

\author{
ACCOMPANYING C. A. White's REPoRT.
}

Facing page.

Plates 11-18.-Fossil mollusca.

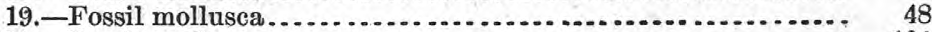

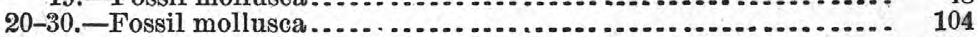

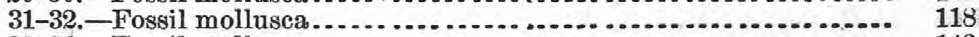

33-36. - Fossil mollusca ......................................... 142

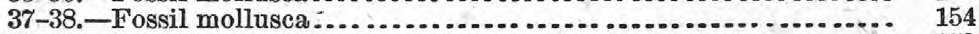

39-42.-Fossil mollusca ..................................... 172

\section{GEOLOGY.}

\section{Accompanying Orestes St. Jomn's Report.}

Plate

I.-Hoback Cañon

Facing page.

II-Upper Valley, Hoback River

III. - Panoramic view of the Gros Ventre Range ....................

IV.-Geologic sections, Hoback Cañon. . . . . . . . . . . . . . . . . ...

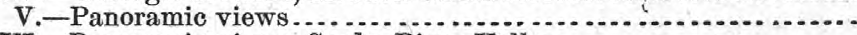

VI.-Panoramic views, Snake River Valley .....................

VII.-Geologic sections through Station XI .....................

VIII.-Panoramic views. . . . . . . . . . . . . . . . . . . . . . . . . . . .

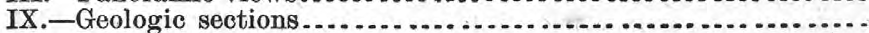

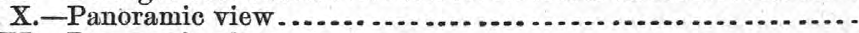

XI. - Panoramic view . . . . . . . . . .

XII. - View and section, Green River Valley .......................

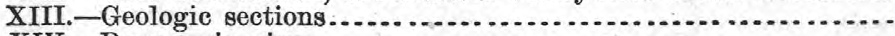

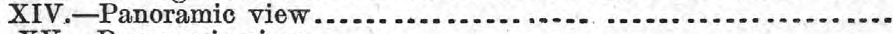

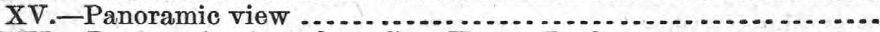

XVI.-Panoramic view, from Gros Ventre Peak . . . . . . . . . . . . . . . .

XVII. - North flank of the Gros Ventre Range......................

XVIII. - Gap between Wind River and Gros Ventre Ranges............ .

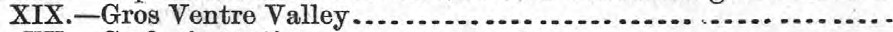

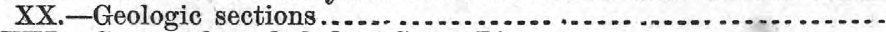

XXI. - Cañon of north fork of Green River . . . . . . . . . . . . . . . . . . .

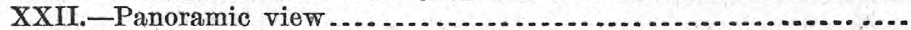

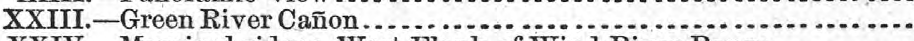

XXIV.-Morainal ridges, West Flank of Wind River Range...........

XXV.-Entrance to Green River Cañon ............................

XXVI.-Geologic sections, Wind River Range......................

XXVII. -West flank of Wind River Range ... . . . . . . . . . . . . . . . . . . . . .

XXVIII. -Geologic sections, Wind River Range......................

XXIX. - Geologic sections, Warm Spring Creek ......................

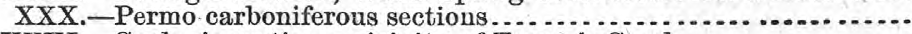

XXXI.-Geologic sections, vicinity of Torrey's Creek . . . . . . . . . . . . . .

XXXII. - Junction of North Fork and Wind River .... . . . . . . . . . . . . .

XXXIII. -Geologic section ....

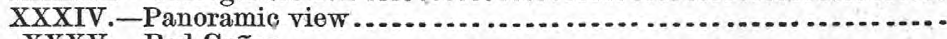

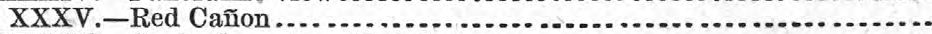

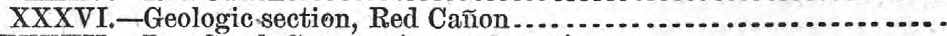

XXXVII.-Dry Creek Cañon, view and section . . . . . . . . . . . . . . . . . . .

XXXVIII.-Bull Lake Fork, view and section . . . . . . . . . . . . . . . . . . . . .

XXXIX.-Bull Lake Fork Cañon 
PLATE - XL.-Geologic section, north side of Bull Lake Fork

XLII.-Geologic sections, vicinity of Red Cañon................ 250

XLIII.-Cañon, North Fork of Little Wind River..................... 251

XLIV.-Geologic sections ....................................... 252

XLV.-Panoramic view and geologic sections ..................... 253

XLVI. -Wind River Valley and Togwotee Pass ...................... 255

XLVII. -Profile of Upper Wind River Valley . . . . . . . . . . . . . . . . . . . . 258

XLVIII. -Wind River Valley ..................................... 260

XLIX.-FIG. 1a. Orifice of Ancient Spring. FrG. 1'b. Section of Ancient Spring. Fig. 2. Arch, Warm Spring Cañon. Fig. 3. Section.

ACCOMPANYING S. H. SCUDDER'S RePORT.

Map of Tertiary Lake Basin at Florissant, Colorado ......................

\section{Accompanying A. S. Packard's Report.}

FIG. 1.-Limnetis gouldii..........................................

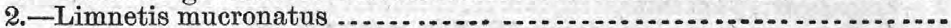

3.-Front of head of Limnetis mncronatus, \&c . . . . . . . . . . . . . . . . . . .

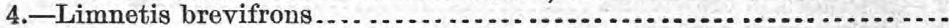

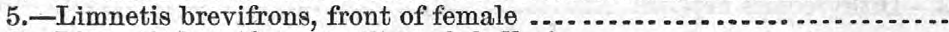

6.-Limnetis brevifrons, outline of shell, \&c.........................

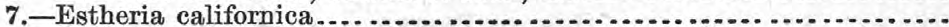

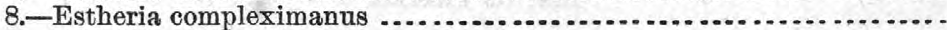

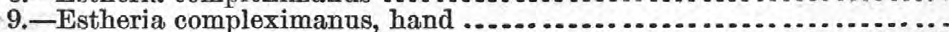

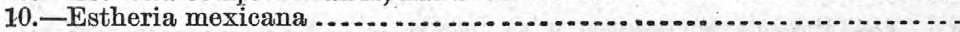

11. - Estheria belfragei . . . . . .

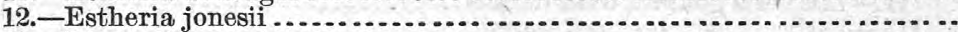

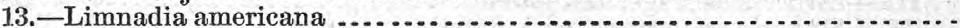

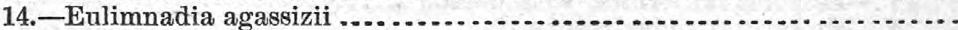

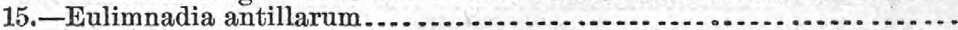

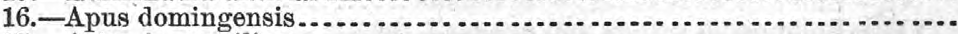

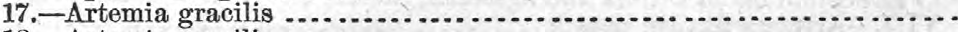

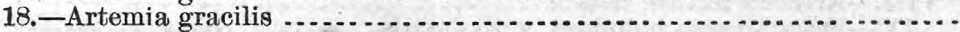

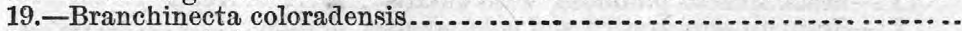

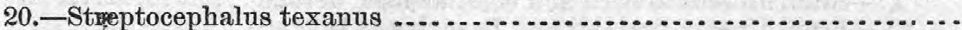

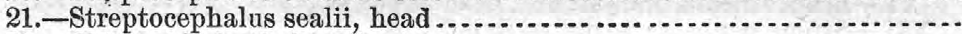

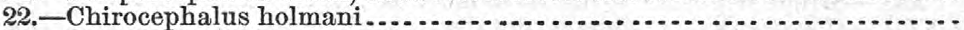

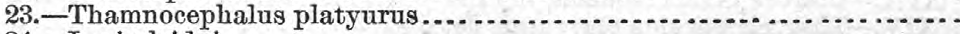

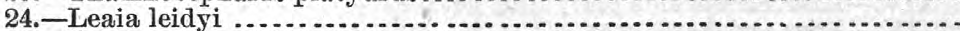

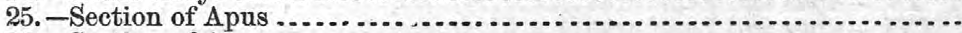

26. - Section of Apus . . . . . . . . .

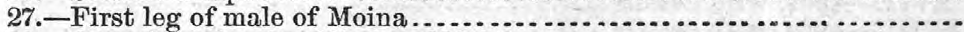

28. - One of third pair of limbs of Moina . . . . . . . . . . . . . . . . . . . . . .

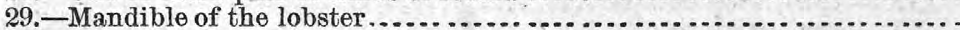

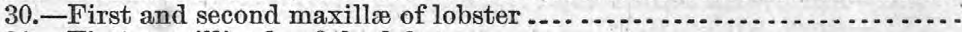

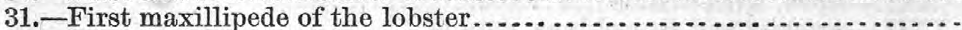

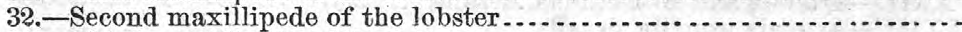

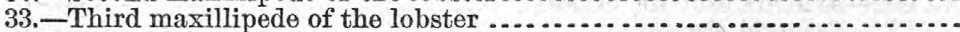

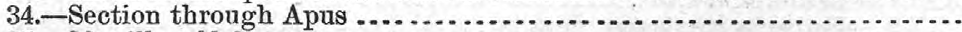

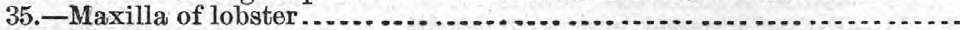

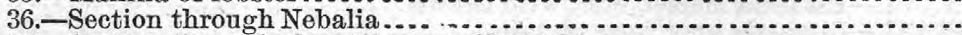

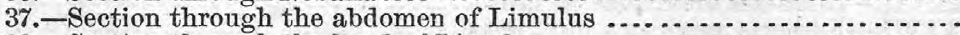

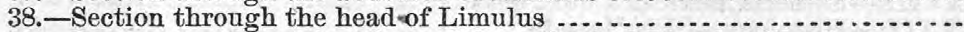

39.-Diagrammatic section through hypothetical Limulus-like form .......

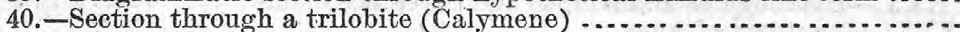

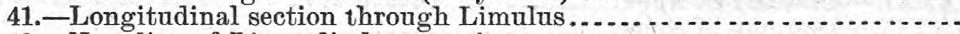

42. -Nauplius of Limnadia hermanni . . . . . . . . . . . . . . . . . . . . . . . . . .

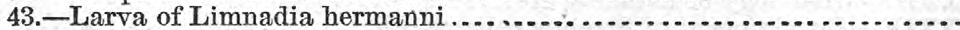

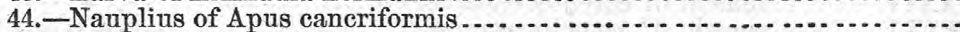

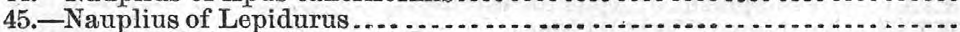

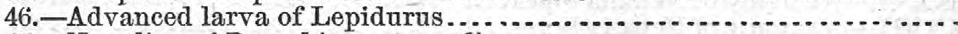

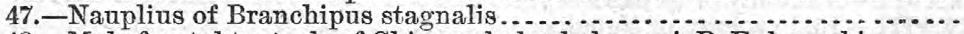

48. - Male frontal tentacle of Chirocephalus holmanni, B. Eubranchipus .....

49.-Female frontal tentacle of Chirocephalus holmanni, B. Eubranchipus..

50.-Left clasper of larva of Streptocephalus texanus.

Page.

299

300

301

301

302

303

304

306

306

308

309

310

310

311

314

325

330

331

338

345

348

352

354

358

361

390

404

405

406

406

406

406

407

409

409

409

409

410

410

410

411

415

416

416

416

417 
Fig. 51.-Right clasper of larva of Streptocephalus texanus .................

52.- Right clasper of larva of Streptocephalus texanus . . . . . . . . . . . . . .

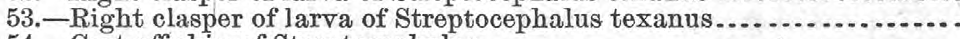

54.-Cast-off skin of Streptocephalus ...............................

55.-Bristles of second antennæ of larval Eubranchipus . . . . . . . . . . . . .

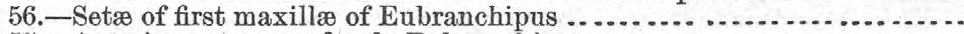

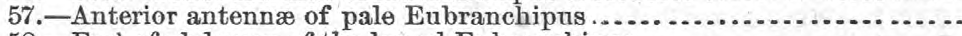

58. - End of abdomen of the larval Eubranchipus . . . . . . . . . . . . . . . . . . .

59. - Seta of first maxilla of the Streptocephalus . . . . . . . . . . . . . . . . . . .

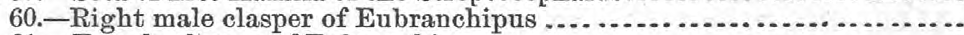

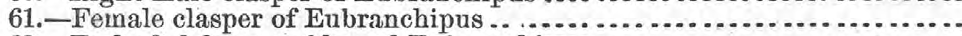

62. - End of abdomen of larval Eubranchipus . . . . . . . . . . . . . . . . . . .

63. - End of abdomen of larval Eubranchipus . . . . . . . . . . . . . . . . . . . .

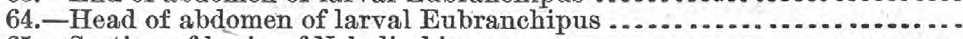

65. - Section of brain of Nebalia bipes . . . . . . . . . . . . . . . . . . . . . . . . .

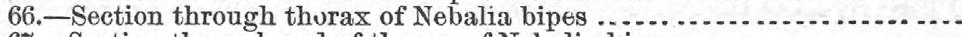

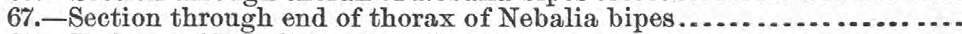

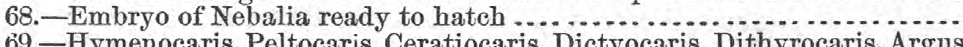

69.-Hymenocaris, Peltocaris, Ceratiocaris, Dictyocaris, Dithyrocaris, Argus

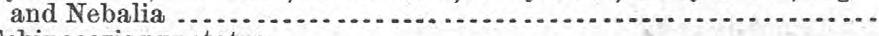

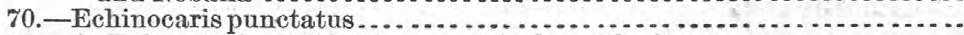

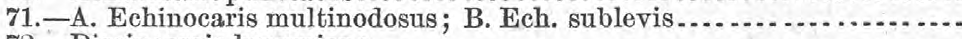

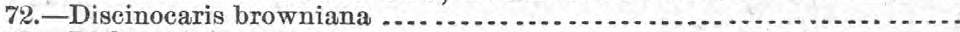

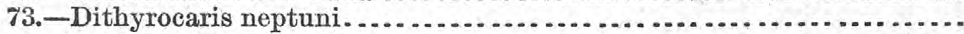

\section{List of Plates.}

Plate I.-Limnetis mucronatus, with details........................ Facing page 561

II. - Limnetis gouldii, with details ................................ 518

III.-Estheria belfragei and jonesii ................................. 520

IV.-Estheria californica, with details ............................ 522

V.-Estheria compleximanus...................................... 524

VI.-Eulimnadia texanus, wibh details .............................. 526

VII.-Eulimnadia texana and agassizii, details ..................... 528

VIII.-Artemia fertilìs, details....................................... 530

IX.-Branchinecta paludosa, with details .......................... 532

X.-Branchinecta arctica and coloradensis, details ................ 534

XI.-Branchinecta lindahli and Branchipus vernalis .................. 536

XII.-Streptocephalus texanus, details ............................ 538

XIII.-Chirocephalus holmani, details ............................. 540

XIV.-Thamnocephalus platyurus, details............................ 542

XV.-Apus and Lepidurus ...................................... 544

XVI._Apus and Lepidurus ........................................... 546

XVII._Apus, with details ............................................ 548

XVIII._Apus, with details............................................. 550

XIX.-Apus, with details................................................. 552

XX.-Apus, with details ............................................. 554

XXI.-Apus, with details .............................................. 556

XXII.-Artemia and Branchipus, details ............................. 558

XXIII.-Artemia gracilis, details ...................................... 560

XXIV._Estheria, details............................................... 562

XXV._Estheria mexicana, details..................................... 564

XXVI._Estheria morsei, etc., with details.......................... 566

XXVII._Limnetis brevifrons, details ..................................... 568

XXVIII.-Estheria mexicana, etc., details .............................. 570

XXIX.-Histology of Phyllopoda..................................... 572

XXX.-Histology of Branchipus and Streptocephalus ................. 574

XXXI._Anatomy of Apus......................................... 576

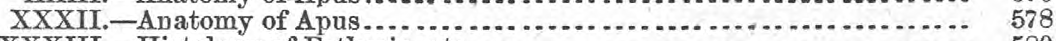

XXXIII.-Histology of Estheria, ete .................................. 580

XXXIV.-Development of Streptocephalus, etc....................... 582

XXXV.-Development of Apus Iucasanus.......................... 584

XXXVI.-Anatomy of Nebalia bipes................................... 586

XXXVII._Anatomy of Nebalia bipes.............................. 588

XXXVIII.-Embryology of Nebalia..................................... 590

XXXIX.-Transformation of Artemia and Branchipus ................. 592 And a Zoo-geographical colored map. 


\section{Accompanying DR. R. W. ShUHeldT's RePort.}

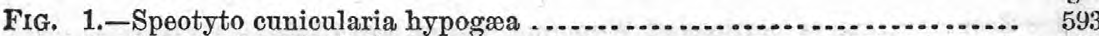

2.-Speotyto cunicularia hypogra $\ldots \ldots \ldots \ldots \ldots \ldots \ldots \ldots \ldots \ldots \ldots \ldots \ldots \ldots \ldots \ldots \ldots$

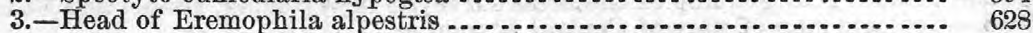

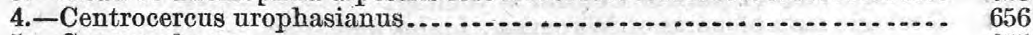

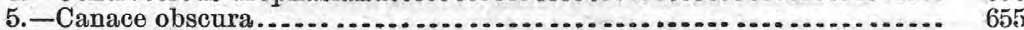

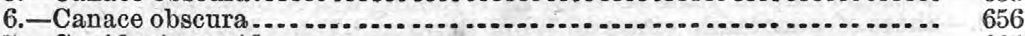

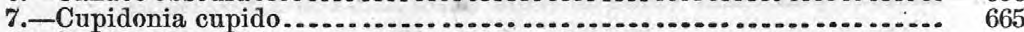

8._Cupidonia cupido ..... . . . .

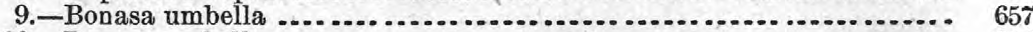

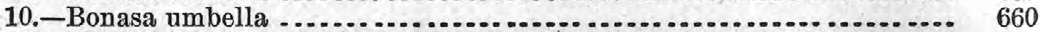

11. -Centrocercus urophasianus.................................... 672

12. - Pediæcetes phasianellus ......................................... 678

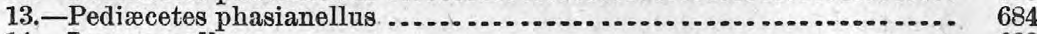

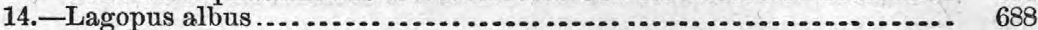

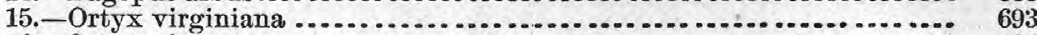

16._-Ortyx pieta ............

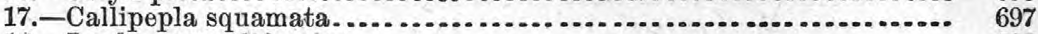

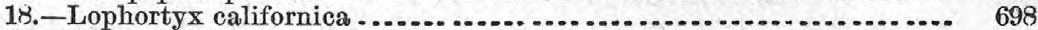

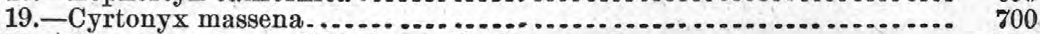

20. - Pseudogryphus californianus (facing page) $\ldots \ldots \ldots \ldots \ldots \ldots \ldots \ldots \ldots \ldots \ldots$ 727

21. - Pseudogryphus californianus.................................. 730

22. - Cathartes burrovianus................................... 733

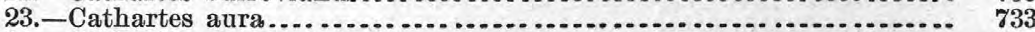

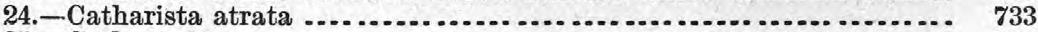

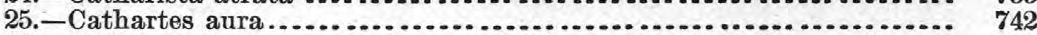

26. -Catharista atrata .......... $\ldots \ldots \ldots \ldots \ldots \ldots \ldots \ldots \ldots \ldots \ldots \ldots \ldots \ldots \ldots \ldots \ldots \ldots$

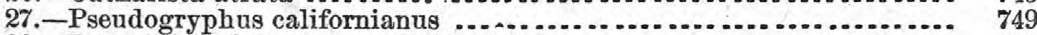

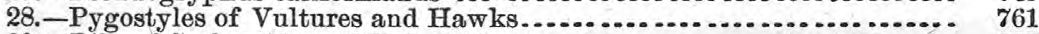

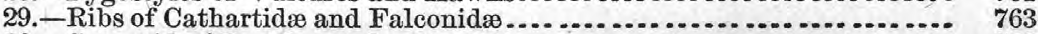

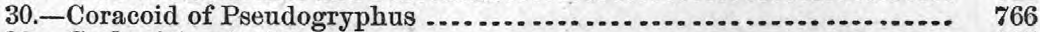

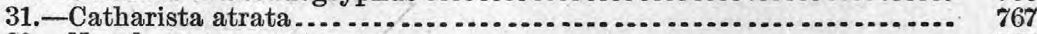

32. -Neophron percuopterus ....... . . . . . .

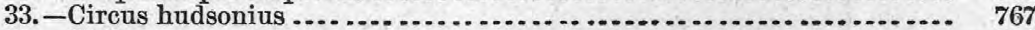

34. - Cathartes aura .... . . . . . . . . . .

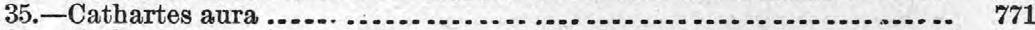

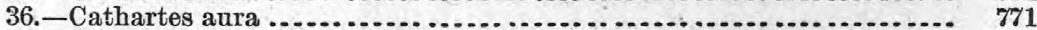

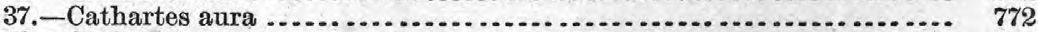

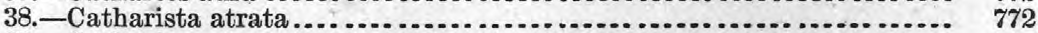

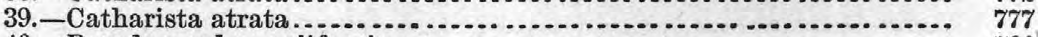

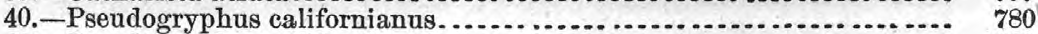

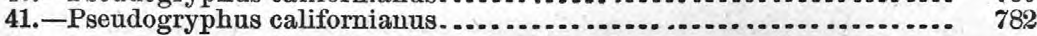

Facing page.

Plate I. -Skeleton of Speotyto cunicularia hypogæa................. 629

II. - Osteology of Speotyto cunicularia hypogra $\ldots \ldots \ldots \ldots \ldots \ldots \ldots \ldots . .624$

III. - Osteology of Speotyto cunicularia hypogæa $\ldots \ldots \ldots \ldots \ldots \ldots \ldots \ldots \ldots .626$

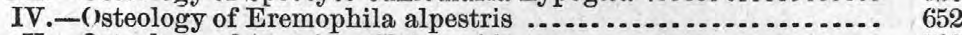

V.-Osteology of American Tetraonidær.......................... 702

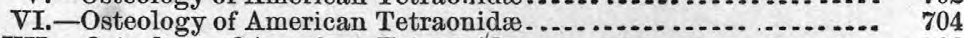

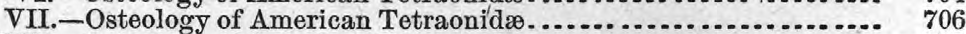

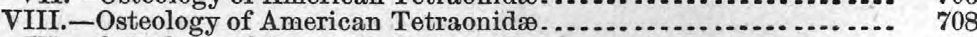

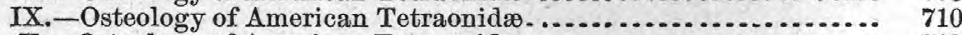

X. - Osteology of American Tetraonidæ ........................... $\quad 712$

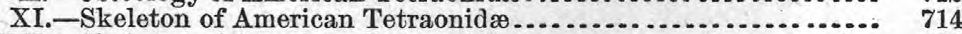

XII. - Skeleton of American Tetraonidæ $\ldots \ldots \ldots \ldots \ldots \ldots \ldots \ldots \ldots \ldots \ldots \ldots . \quad 716$

XIII. - Skeleton of American Tetraonidæ....................... 718

XIV.-Osteology of Lanius ludovicianus excubitorides . . . . . . . . . . $\quad 726$

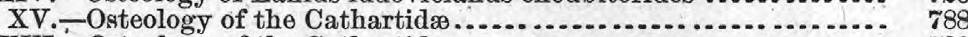

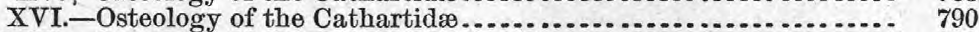

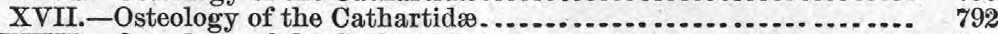

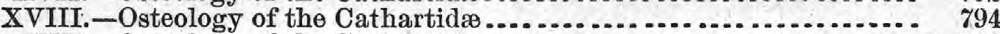

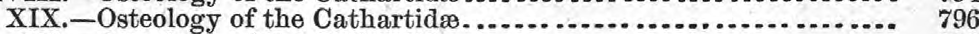

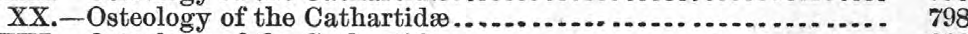

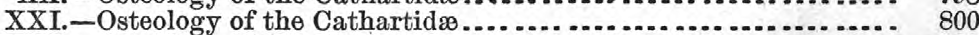

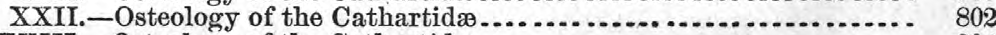

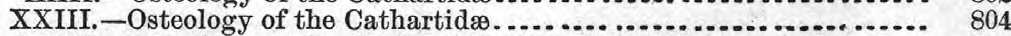

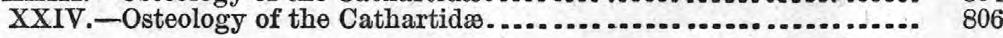


MAPS IN ACCOMPANYING POCKET.

1.-Ecomonic map of portions of Wyoming, Idaho, and Utah.

2.-General geologic map of the areas surveyed in Wyoming, Idaho, and Utah.

3.-Geologic map of part of Central Wyoming.

4.- Geologic map of parts of Wyoming, Idaho, and Utah.

5.-Geologic map of parts of Western Wyoming and Southeastern Idaho.

6.-Sheet of panoramic views of Wind River and Teton Mountains. 



\section{LETTER TO THE SECRETARY.}

\section{OfFice of the United States Geological and \\ Geographical SURVEY OF THE TerRitories, Washington, D. C., January 1, 1879.}

SIR: I have the honor to transmit for your consideration and for publication the twelfth and last Annual Report of the United States Geological and Geographical Survey of the Territories. This report includes the labors of the corps for the field season of 1878, and the office work until the close of the existence of the Survey by law June 30,1879. Several of the members have, however, performed very important work since that time in elaborating their individual reports, which has added greatly to their interest and value.

A general summary of the work for the season of 1878 will be appropriate in this connection. Owing to the length of the session, Congress did not pass the usual appropriation for the work of the Survey until July, and consequently the period for work in the field was comparatively short.

The headquarters of the Survey was at Cheyenne, Wyo., the same as the preceding season. Four parties were organized, but in such amanner that in case of necessity they could be divided for special duty. All our outfit and animals were transported from Cheyenne to Point of Rocks and Green River Stations, on the Union Pacific Railroad, and from thence the parties pursued their way northward to their respective fields of labor.

To the first division, in charge of A. D. Wilson, was confided the primary triangulations of the entire area to be surveyed. Eight of the most important peaks were employed as stations, with some minor points. Among the more important stations were Wind River, Frémont's, Grand Teton, and Sawtelle's Peaks (near Henry's Lake); also several of the most conspicuous points in the Yellowstone Park. This division was robbed, near Sawtelle's Peak, of all its animals and a portion of its outfit, so that at least half of the most valuable time for work during the season was lost. Had it not been for this misfortune at least double the work would have been accomplished. The Yellowstone Park at this time forms the most extensive unoccupied area in the West, and, surrounded by great ranges of mountains, becomes a resort for hostile bands of Indians when pursued by the troops. 
To the division of the Survey in charge of Mr. Henry Gannett was intrusted the work of making a specially-detailed geological and geographical survey of the Yellowstone National Park. The party was divided into two sections for the prosecution of this work; one section, consisting essentially of Mr. Gannett, topographer, and Mr. W. H. Holmes, geologist, made the general survey of the park, while the other, consisting of Dr. A. C. Peale and Mr. J. E. Mushbach, were occupied in making detailed studies and maps of the geyser and hot-spring localities, a work of the greatest interest and value to the scientific world.

Material was secured for a detailed map, on a scale of one mile to an inch, of the Yellowstone Park, an area of 3,500 square miles; and for maps on a large scale of all the principal geyser and hot-spring localities. In the survey of the park, forty-seven important stations were occupied for secondary triangulation and topography, besides a large number of lesser importance. On all the principal stations stone monuments were erected for future reference. Several groups of geysers and hot springs; not heretofore known, were discovered.

The area of the Yellowstone Park is, in round numbers, 3,500 square miles. Its surface is in large part level or rolling, with several groups and short ranges of mountains diversifying it. In the eastern part, extending its whole length and forming the watershed between the Yellowstone and the Bighorn, stand the rugged volcanic peaks of the Yellowstone Range. Nearly all of the park is covered with a dense growth of magnificent pine timber; indeed, west of the one hundredth meridian there is no area so densely timbered with the exception of Washington Territory. The mean elevation of the park above sea-level is between 7,000 and 8,000 feet, which implies too cold a climate to admit of agriculture, except in certain very limited localities. It is safe to say that not more than one per cent. of this area can, by any possibility, be used for agricultural purposes. Except along the northern border, grazing land exists only in small patches of a few acres each. There are not, so far as is known, any mines or mineral deposits within the park.

The only occupied buildings within the park are at the White Mountain Hot Springs, where Mr. J. C. McCartney has made some improvements. A good wagon-road extends from Bozeman, Mont., to this point. From these springs, which form the usual point of departure for excursionists, there are excellent trails to all points of interest within this region; to Amethyst Mountain, Yellowstone Falls and Lake, the Mud Geysers, and other objects of interest on Yellowstone River and the Geyser Basins. It is unnecessary to specify these trails, as they traverse the country in all directions. In his campaign against the Nez Percés, in 1877, General Howard constructed an excellent wagon-road up the Madison to the Lower Geyser Basin, and thence across to the Yellowstone. His road up the Yellowstone is impassable at present for wagons.

Mr. W. H. Holmes acted as geologist to the second division. The first month of the season he was with the fourth division, which pro- 
ceeded from Point of Rocks Station northward, along the west side of the Wind River Mountains, and up the Snake River Valley to the Yellowstone Park, where he joined the second division. In the mean time he was engaged in making sketches, panoramic views, and geological sections of the intermediate country, all of which will prove of the highest importance in illustrating the geological structure of this most interesting and complicated region.

The latter part of the summer was spent in making detailed geological examinations in the district that includes the National Park. The greater portion of the park was found to be covered with somewhat uniform flows of the ordinary volcanic rocks. Features of more than ordinary geologic interest occur, however, along the northern border of the park district. Here a small belt, not more than 15 by 30 miles in extent, contains a fair epitome of the geology of the Rocky Mountain region. The whole series of formations from the earliest to the most recent are almost typically developed. The only marked irregularity in the succession of geologic events occurred during the great mountain-building period of the Middle Tertiary. After that followed a number of inferior oscillations of the surface, during which an extensive series of recent Tertiary and volcanic rocks were deposited. Comnecting this period with the present are the deposits of a number of great lakes, which at the present time have their chief representative in Yellowstone Lake. Detailed investigations were made at many points of interest, and a fine mineralogical collection was made.

In the mean time Mr. Holmes made sketches covering every square mile of the Park, an area of 3,500 square miles. In such minute detail was the work done that the economic resources, as well as all the minor features of the geology, can be laid down on a map on a scale of one mile to an inch with the greatest care and minuteness. The great variety of forms which the mountains in and around the park assume can be presented to the eye by panoramic views with wonderful distinctness.

The third division, under Mr. F. A. Clark, surveyed the Wind River Mountains, a portion of the Wyoming Range, the Gros Ventre Range, with a large area in the Snake River Valley. Mr. Clark made 31 gradienter stations and 15 compass stations. The area lies between latitude $43^{\circ}$ and $44^{\circ}$ and longitude $109^{\circ} 15^{\prime}$ and $111^{\circ}$. This includes the upper portion of the Wind River Mountains, with portions of the Wyoming Range, the Gros Ventre Range, and portions of the Shoshone Mountains and the Owl Creek Range; also the sources of Green River, Hoback Basin, and upper waters of Wind River. Mr. St. John acted as geologist and Mr. N. W. Perry as mineralogist to this party. Their reports will prove of general interest. Mines of gold, silver, iron, and vast beds of gypsum, as well as many other minerals, were found.

In the prosecution of the field-work of the Survey during the past season a photographic division was again put in operation, after an interval of two years, under the leadership of Mr. W. H. Jackson, who 
has been connected with the Survey as its photographer during the past nine years.

Leaving Point of Rocks, on the Union Pacific Railroad, on July 24, the first points of interest were reached on the western flank of the Wind River Mountains. Two side trips, undertaken in connection with Mr. Wilson, in charge of the primary triangulation, were made to the crest of the range, and some grand views of that remarkable region were obtained. From the summit of Frémont's Peak views were made of an immense glacier now occupying its eastern slope. Fine views were also obtained of the great glaciated plateau lying between the plains and the crest of the range.

Proceeding next to the vicinity of the Grand Tetons, lying to the east of the headwaters of the Snake River, several magnificent views of the remarkable range in which they occur were made from the neighborhood of Jackson's Lake.

Reaching Shoshone Lake the 18th of August, the entire month following was devoted exclusively to the careful photography of all the remarkable phenomena connected with the hot springs and geysers of the various basins within the Park. Especial attention was paid to the almost unknown but exceedingly interesting features of the new Shoshone and Red Mountain Basins. The "Fire Hole" and "Mammoth Hot Spring" Basins were again gone over, and the experience derived from the work done here in former years shows its benefits in the remarkably effective views obtained this season. At this latter basin many detailed as well as general views were made with especial reference to the future production of an exact model in plaster of the whole group.

On the homeward route, which was by the way of the Upper Yellow. stone, across the headwaters of the Snake to the Wind River and thence via Camp Brown to the railroad, a number of very effective views were made, particularly about the Grand Falls and the cañon of the Yellowstone. At the Yellowstone Lake some very fine views were made, but that region was left somewhat incomplete in consequence of a prolonged snow storm.

At the Togwotee Pass some characteristic views were obtained of the remarkable breccia mountains, whose castellated forms adorn that portion of the continental divide, and also some of the curious "bad lands" farther down on Wind River. The season's work closed at Camp Brown, where some excellent portraits and groups were made of the Bannock prisoners in confinement at that post.

A brief summing up of the season's operations of three months, much of which time was characterized by extremely inclement weather, shows an increase to the already very extensive collection of the survey, of 45 negatives 11 by 14 inches in size, and 110 of smaller ones, 5 by 8 . The number was purposely kept small that a better quality might prevail in them.

The geologist in charge accompanied the photographic division, and 
the route pursued gave him an opportunity to secure a very accurate general knowledge of the geological structure of a large area. The Wind River Range proved one of remarkable interest. It has a trend about northwest and southeast, with a length of about 100 miles. On the west side all the sedimentary belts have been swept away, down to the Archæan, older than the Wahsatch, and the latter formation rests on the Archran rocks all along the base of the range, seldom inclining more than $5^{\circ}$ to $10^{\circ}$. On the east side of the range the series of sedimentary formations usually known to occur in the northwest are exposed from the Potslam sandstone, which rests upon the Archran rocks, to the Cretaceous inclusive.

Along the northwestern portion of the range the Wahsatch Group only is seen for some distance, but as we proceed down the Wind River Valley the formations appear one after the other, until at the lower end the entire series is exposed. The Wind River Range may be regarded as originally a vast anticlinal, of which one side has been entirely denuded of the sedimentary, except the Middle Tertiary. Un the same side of the range the morainal deposits and glaciated rocks are shown on a scale such as we have not known in any other portion of the West. Three genuine glaciers were discovered on the east base of Wind River and Frémont Peaks, the first known to exist east of the Pacific coast.

The morainal deposits are also found on a grand scale in the Snake River Valley, on the east side of the Teton Range. The numerous lakes have been the beds of glaciers, and the shores of the lakes are walled with morainal ridges. North of the Teton Mountains the prevailing rocks are of modern volcanic origin, and in the Yellowstone Park the hot springs and geysers are the later manifestations of the intense volcanic activity that once existerl. All these interesting features were studied with care, and the results have been elaborated for the present annual report.

It was with great pleasure that the geologist in charge reviewed the ground passed over in 1860 , over eighteen years previously. In the years 1859 and 1860 he acted as geologist to the exploring expedition under the command of Col. William F. Raynolds, now of the Engineer Corps, U.S. A. A geological map accompanies the report of the expedition, which embraces Dakota and Montana, with portions of Idaho, Wyoming, and Colorado.

In presenting the final annual report of the field-work of the survey, it seems proper to make a brief statement in regard to the causes which led to the delay in its publication. During the season of 1878 and 1879, Congress passed a law, discontinuing the three surveys then in existence, on the 30th of June, 1879, and and establishing the United States Geological Survey. The members of the Geological Survey of the Terri-

*Geological Report of the Exploration of the Yellowstone and Missouri Rivers, under the direction of Capt. (now Lieut. Col. and Brevet Brig. Gen.) W. F. Raynolds, Corps of Engineers, 1859-1860. By F. V. Hayden. 
tories were discharged, some remaining in Washington, having obtained positions in various departments of the government, others engaging in business in different parts of the country. These reports were, therefore, completed at such leisure intervals as could be spared from other duties. The great pressure of work on the Public Printing Office for several years past has also been a partial cause of delay.

Of the valuable memoirs embraced in the first part of this report, but little need be said. They comprise those of White, St. John and Scudder, on geology and paleontology, and those of Packard and Shufelt on natural history, and they will be found to be of the highest interest and eminently creditable to these authors.

The editorial work has been under the supervision of W. H. Holmes, who has also had general charge of the business of the survey in Washington for the last two years. He has bestowed much time and labor upon the preparation and revision of illustrations as well as upon other details of the work.

I take pleasure in acknowledging the important service of Mr. F. M. Pierson, formerly clerk of the survey, who rendered very efficient aid in closing the business affairs of the organization.

During the season of 1878 and 1879, Mr. James Stevenson, performed the duties of executive officer with his usual ability and fidelity.

The small appropriation which had been allowed by Congress for completing the office work of the United States Geological and Geographical Survey of the Territories was exhausted June 30, 1882. Five volumes of the quarto series of publications remained unpublished though far advanced towards completion. At my request, the Secretary of the Interior confided the general direction of completion and publication of these volumes to Maj. J. W. Powell, Director of the United States Geological Survey, who has assured me that he will render every facility in his power in bringing these final reports out in creditable shape.

The survey does not claim that its work is absolutely accurate in detail but rather preliminary to the more thorough study which is to come in the future. It is believed, however, that this report will be regarded as an important contribution to the geological and natural history resources of the region under examination.

Very respectfully, your obedient servant.

F. V. HAYDEN, United States Geologist.

To the Secretary of the INTERIOR. 


\section{PART I.}

\section{GEOLOGY AND PALEONTOLOGY.}





\section{REPORT OF C. A. WHITE, M. D.}

\section{LETTER OF TRANSMITTAL.}

Washington, D. C., April 7, 1880.

SIR: I have the honor to herewith transmit Contributions to Invertebrate Paleontology, Nos. 2-8, together with thirty-two plates of illustrations. The character of these articles is set forth in the remarks which precede each, respectively, and they have been made as complete as the circumstances attending the closing up of the affairs of the Survey hitherto under your direction would allow.

These articles are a portion of the series of "Contributions," No. 1 of which appeared in the Annual Report for 1877, for which you had made provision among the publications of the Survey, in addition to the less elaborate "Papers" and more exhaustive memoirs. While the circumstances referred to have rendered these articles less complete than could be desired, and less so than was originally intended, the illustration of nearly all the fossil species that have been hitherto described in the publications of the Survey is an important point gained.

Very respectfully,

Dr. F. V. HAYDEN,

C. A. WHITE.

United States Geologist in Charge. 



\title{
CONTRIBUTIONS TO INVERTEBRATE PALEONTOLOGY, N0. 2: CRETACEOUS FOSSILS OF THE WESTERN STATES AND TER. RIT0RIES.
}

\author{
By C. A. White, M. D.
}

The present article is a continuation of the one entitled Contributions to Invertebrate Paleontology, No. 1 (and bearing the same sub-title), which was published in the Annual Report of this Survey for 1877. The material upon which this article is based, like that which formed the basis of the former one just referred to, has been collected by different persons from Cretaceous strata, at different and widely-separated localities in the western portion of the national domain.

In connection with the establishment of this series of illustrated articles, under the general title of "Contributions to Invertebrate Paleontology," the hope was entertained that the subjects which they should involve might be treated philosophically and somewhat exhaustively; and that upon those subject's some important generalizations, both stratigraphical and zoölogical, might be based. Cireumstances required the publication of the former article without an opportunity for satisfactory discussion of the subjects which properly pertained to the fossil forms described and figured therein; and the abolishment by act of Congress of this Survey, as at present organized, without affording an opportunity to pursue any further studies in the field before its publications must cease, makes it necessary to publish this material, as well as that of the two following articles, in a similarly unsatisfactory manner with that of the first. The main object of this series of articles as originally planned has therefore not been attained, but as none of the species enubraced in any of them have ever before been illustrated, an important object will have been accomplished by the illustration of so considerable a number of species as is here represented by figures of typical specimens.

A part of the species embraced in this article were published in different reports of the Survey by Mr. Meek, before his death ; a part of them by the writer, in the Bulletin of the Survey and the Proceedings of the National Museum; and the remainder are here published for the first time. The greater part of the fossils were collected by persons connected with this Survey, but a part of them have been sent to the office of the Survey and the National Museum by private parties. Among these are the two corals which are first noticed on the following pages, and Pinna lakesii, which is described on a subsequent page. These three species were included in a collection of fossils which was sent for examination to the oftice of the Survey by Mr. Arthur Lakes, who collected them from the Cretaceous strata on Fossil Creek, 16 miles westward from Greeley, and 6 miles southward from Fort Collins, Colo.' These two corals present so conspicnously a Paleozoic facies that it is proper to call especial attention to their stratigraphical position. Mr. Lakes's known 
familiarity with the geology of that region would of itself incline me to refrain from questioning the correctness of his reference of these fossils to Cretaceous strata, notwithstanding their Paleozoic aspect; but, fortunately, he has made such questioning impossible, by sending pieces of rock in which both the corals and well-known forms of Cretaceous molluscan shells are imbedded together. Besides this, I have myself visited that locality and made collections from its strata, some forms of which I recognize as of the same species as a part of those sent by Mr. Lakes. I also recognize the strata there as belonging to the lower portion of the Fox Hills Group of the Cretaceous series, as that group is developed in Colorado; and they are doubtless equivalent with a portion of the Fort Pierre Group, or Cretaceous No. 4, of the Upper Missouri River region.

Remains of the Cœlenterata are exceedingly rare in all the Cretaceous rocks of Western North America, and therefore the discovery in them of any coralline form is of more than ordinary interest; but the interest concerning these two forms is greatly increased by their evident Paleozoic affinities. Being imbedded in sandstone, the condition of their preservation is not such as to give entirely satisfactory results from their study. I have therefore referred them provisionally to Paleozoic genera, because, in their visible characteristics, they correspond more nearly with those genera than with any others known to me.

Prof. H. Alleyne Nicholson, of the University of St. Andrews, Scotland, whose labors in the fossil Actinozoa and Polyzoa are so well known, has kindly examined specimens of both these forms at my solicitation, and to him I am indebted for valuable notes concerning them, from which I have drawn in the following remarks embraced in the descriptions of the species.

Several years ago, while examining the conglomerate beds of the Dakota Cretaceous Group in Western Iowa, I found among the pebbles, of which those beds are so largely composed, some fragments of Paleozoic corals. These coral-pebbles were water-worn like the others, and like them they were also siliceous. That region was traversed by the eastern shore-line of the earlier intercontinental Cretaceous sea, the waters of which washed the whole series of Paleozoic strata there. The fossils of those strata, especially the corals of Devonian and Upper Silurian age, are often silicified, and they doubtless reached that condition before Cretaceous times. It is, therefore, easy to understand that the corals found in the pebble-beds referred to are really Paleozoic corals which were redeposited in Cretaceous strata, and not Cretaceous corals of Paleozoic types.

The case, however, is quite different with the corals sent by Mr. Lakes from the Cretaceous strata of Northern Colorado. These corals are calcareous and not siliceous, and they are also comparatively fragile. They present no appearance of having ever been water-worn, nor does the stratum in which they were found, an ordinary slightly calcareous and slightly muddy sandstone, contain any water-worn masses of any kind larger than the grains of coarse sand. We therefore necessarily reach the conclusion that these corals are really of Cretaceous age, although having so much the aspect of Paleozoic forms.

I am indebted to the late Prof. B. F. Mudge for the types of two new forms from the Dakota Cretaceous of Kansas ; and a very interesting part of the following described species have been received from the Cretaceous strata of Texas, having been collected at different localities and forwarded by Mr. D. H. Walker, Mr. G. W. Marnoch, and Mr. S. W. Black, 
whose names are referred to in connection with the respective descriptions.

It has not been thought necessary to rewrite, nor in many cases to revise, the descriptions of the fossils embraced in these articles which were formerly published by Mr. Meek in the publications of this Survey; and I have, therefore, here copied his descriptions, and, to a great extent, tacitly followed his classification.

\section{ACTINOZOA. \\ Genus CH无TETES Fischer.}

\section{CHATETES ?? DIMISSUS White.}

Plate 12, fig. $14 a$.

Chatetes?? dimissus White, 1879, Bull. U. S. Geol. Sur. Terr., vol. v, p. 220.

Corallum ramose, dichotomously branching at irregular intervals; branches cylindrical or subcylindrical, solid, the successive branches diminishing in size; corallites small, not exceeding $\frac{1}{5}$ millimeter in diameter, closely compacted together, diverging from the axis of the corallum at an acute angle with it, and describing a slight upward curve as they are projected towards the surface. Character of the surface and of the corallites unknown, the specimens being firmly imbedded in sandstone. One corallum, at least, seems to have consisted of a central or basal mass, from which several stems diverged irregularly, each stem bearing several branches.

Diameter of the stems and branches varying from 2 millimeters to 6 millimeters.

While this coral has all the outward appearance, and apparently the general structure, of the ramose forms of Chcetetes or Monticulipora the corallites seem to be entirely destitute of tabulæ, even when viewed under the microscope in the section prepared for that purpose by Professor Nicholson. If the tabulæ are really absent, as they appear to be, this coral cannot be properly referred to Chotetes, nor to any other form of the Actinozoa, but it probably belongs to the Polyzoa. If it really belongs to the latter class, I do not know any genus to which it can be referred; and as the specimens are not sufficiently perfect to warrant a new generic diagnosis, I assign them provisionally to Chcetetes.

Only two examples of this coral have been discovered, and, like all other coralline forms in the Cretaceous rocks of the West, it is doubtless a rare one. The rarity of the remains of Cœlenterata in those rocks is no doubt due, not to a universal suppression at that time of those forms of life, but to the local or regional physical conditions which prevailed at the time those Western North American strata were deposited. It is a well-known fact that coral polyps require pure waters for vigorous and abundant growth; and as the Cretaceous strata of the West consist so largely of sand, it is evident that the waters in which they were deposited could not have been congenial for a large development of any of the forms of Cœlenterate life.

Position and locality.- Strata of the Fox Hills Group, of the Cretaceous series, at Fossil Ridge, 16 miles westward from Greeley, and 6 miles southward from Fort Collins, Colo., where it is associated with the coral next described, and also with various Cretaceous molluscan forms. 


\section{Genus BEAUMONTIA Edwards \& Haime.}

BEAUMONTIA ? solitaria (sp. nov.).

Plate 12, figs. $13 a, b$, and c.

Beaumontia? solitaria White, 1879, Bull. U. S. Geol. Sur. Terr., vol. v, p. 281.

Corallum massive, compact; corallites prismatic, readily cleaving from each other in the specimens discovered, unequal in size and also in the shape of the transverse section, some of them being more than twice as large as others, and the longer diameter of some being more than twice as great as the short diameter of the same; average diameter of the corallites not exceeding one millimeter; their walls thin, apparently marked only by the ordinary lines of growth; tabulæ plain, numerous, variously flexed, but never to a great degree. No trace of radiate septa or of longitudinal striation of the corallites has been detected.

This coral much resembles Favosites in the character of the corallum and the aspect of the corallites, but no traces of mural pores have been detected, not even in the section prepared by Professor Nicholson, when viewed under the microscope. In consequence of this, and of the irregular or flexed character of the tabulæ, I refer it to Beaumontia. Apparently the only known fact that suggests a doubt of the correctness of such a reference is that Beaumontia has hitherto been known only in Paleozoic rocks. This is also a rare form, and doubtless so for the reasons explained in connection with the description of the foregoing species.

Position and locality.-Associated with the preceding and various molluscan forms in Cretaceous strata of the Fox Hills Group, Northern Colorado.

ECHINODERMATA.

\section{Genus OPHIODERMA.}

\section{OPHIODERMA? BRIDGERENSIS Meek.}

Plate 12, fig. $12 a$.

Ophioderma? bridgerensis Meek, 1873, An. Rep. U. S. Geol. Sur. Terr. for 1872, p. 475.

The type specimen from which Mr. Meek drew his description, and from which the figure on plate 12 is drawn, is the only example of the species that, has ever been discovered. Therefore nothing more is known of it than was published (loc. cit.) by Mr. Meek. It was obtained by one of the parties of the Survey from the "last foot of Bridger Peak, 4 miles north of Fort Ellis, Mont.," where it is reported to be associated with certain imperfect molluscan remains, among which $\mathrm{Mr}$. Meek recognized the following genera, namely: Gryphoa, Avicula, Pinna, Inoceramus, Crassatella, Pholadomya, Turritella, and Gyrodes.

The following is Mr. Meek's brief description: "A small Ophiuran, with disk depressed, nearly circular, and only 0.17 inch in breadth, showing on the dorsal-side ten ovate-subtrigonal radial plates that are joined together over the inner ends of the arms, so as to form five pairs; arms small, only about 0.75 inch in length, and at their inner ends 0.06 inch in breadth; middle row of arm-pieces on the dorsal side slightly wider than long, and hexagonal in form; marginal pieces about as large as the middle ones, 
seen somewhat edgewise from above, and bearing a row of very small short spines. Ventral side unknown. The specimen is not well preserved ; perhaps I should eall it Ophiolepis bridgerensis."

\section{CONCHIFERA.}

\section{Genus OSTREA Linnæus.}

\section{Ostrea soleniscus Meek.}

Plate 11, figs. $2 a$ and $b$.

Ostrea soleniscus Meek, 1873, An. Rep. U. S. Geol. Sur. Terr. for 1872, p. 487.

The name of this species was given by Mr. Meek in a catalogne of fossils, on page 276 of the Annual Report of this Survey for 1871, but as no description or diagnosis then accompanied it, the name can date, only from 1873, when his description was first published (loc. cit.). The following is Mr. Meek's diagnosis of the species, together with his remarks upon it:

"Shell attaining a large size, becoming rather thick in adult examples, generally straight, greatly elongated, and comparatively very narrow, with parallel lateral margins. Lower valve with moderate internal cavity, and having the appearance of a little gutter or elongated trough; beak usually nearly straight, rather obtusely pointed, and more or less distorted by the scar of attachment; ligament-area of moderate size, strongly striated transversely, and provided with a large, deep, longitudinal furrow; surface apparently only with moderately distinct marks of growth. Upper valve almost flat externally, but nearly as concave as the other within; beak usually a little truncated; ligamentarea marked with strong transverse striæ, and having its mesial ridge very prominent, and occupying as much as one-third its breadth. Surface as in the other valve, or perhaps a little smoother.

"Length of sdult examples about 18 inches; breadth of the same about 2.50 to 3 inches.

"Although not a very uncommon species, I have seen no entire specimens of this remarkable shell. It will be readily known by its unusually narrow, elongated, and generally straight form. The shell is usually found broken into several pieces, but casts of the internal cavity are not unfrequently met with entrire. One of these now before me is nearly one foot in length and only two inches in breadth. It often had a curious habit of growing in groups of three shells, attached to each other by the backs of their beaks. I have seen large numbers of them closely arranged, or nearly in contact with each other, at Coalville, all with their beaks downward, or at right angles to the plane of the sandstone strata. When found where it has grown isolated, the shell is sometimes arched to one side.

"Locality and position.-This species ranges through nearly the whole thickness of the Cretaceous sandstones near Coalville, Utah, and is also found in the Cretaceous coal-bearing sandstones at Bear River City, Wyo., as well as in the sandstone ridge of the same age on the Union Pacific Railroad, a few miles east of the latter locality."

I have frequently collected specimens of this species in the region indieated by $\mathrm{Mr}$. Meek, and have verified all his observations as given above, but no specimens more perfect than his types have ever been discovered. While a large majority of the specimens have the long slender 
form described by Mr. Meek, there are many also which are not so much elongated, but which are evidently of the same species. This remark applies not only to the young, which were proportionally short, as shown. by the lines of growth upon the anterior portion of adult shells, but also to many that are massive and evidently of adult growth. Still, the species has always much more than the average proportionate length. The habit of this oyster, mentioned by Mr. Meek, of uniting its shells in groups of three, by their deeper valves, is not confined to this speeies alone. I have often observed it in the case of 0 . glabra M. \& H. of the Laramie Group. I suppose it to have been a not uneommon habit with oysters that-lived on sandy bottoms, because, in all the cases I have observed, the specimens were collected from soft sandstone strata; and yet in all these cases the majority of their associates of the same species were free. It is a common habit with oysters to attach themselves together, but why they should so often have been attached together in the manner described is not easy to understand.

Considerable variation in form is very common in all species of Ostrea proper, and some very elongate examples of the living 0 . virginica are occasionally brought into the markets from various places along the Atlantic coast. This fact was illustrated by a large labeled series prepared at the Smithsonian Institution by Mr. W. H. Dall for the Centennial Exposition in 1876. In reply to some inquiries, Mr. Dall writes me: "In the case of 0. virginica there is no doubt that a position where it is subjected to currents, and especially if the water carries a little sediment, will induce a long, thin growth, with parallel sides; while still waters tend to produce a rounded form. The normal is between the two. But there are normally long species and normally round, besides twig-climbing species, all of which, in a state of nature, may be differently affected from thinned and planted oysters."

There is no room for doubt that Ostrea soleniscus is a normally long and slender species. That its elongate form is not due to the same cause which elongates the specimens of $O$. virginica before referred to is shown by the fact that so many of the longest of them are found in a vertical position, evidently their natural one, in relation to the plane of the strata containing them, as mentioned by Mr. Meek, and also observed by $\mathrm{my}$ self. It is also contra-indicated by the fact that so many of them grew in clusters of three, attached together by their larger valves, and by the absence of any evidence in the character of the strata that they were deposited in water having a current of sufficient strength to produce such a result.

I know of no other American oyster, either fossil or recent, that need be confounded with this species The anterior portions of many of the specimens, as they are often found broken off, resemble corresponding portions of 0 . longirostris Lamarck, as figured by Goldfuss; but although that species is an elongate one, O. soleniscus is constantly a much more slender species.

\section{Ostrea ANOMIOIDES Meek.}

Plate 11, figs. $4 a$ and $b$.

Ostrea anomioides Meek, 1873, An. Rep. U. S. Geol. Sur. Terr. for 1872, p. 488.

No other examples of this species besides those of the original collection have ever been obtained. The figures on plate 11 are drawn from Mr. Meek's types, and the following is his description of the species, together with his remarks upon it:

"Shell rather small, very thin, depressed-plano-convex, and without 
any visible scar of attachment, varying from ovate to circular; rounded or sometimes a little straightened on the hinge-margin; beaks hardly projecting beyond the outline of the cardinal margin. Lower valve very shallow; cartilage-pit unusually small, shallow, and short. Upper valve almost perfectly flat; cartilage attachment even shorter than that of the other valre, and slightly convex on its inner margin. Muscular scars unknown; surface of both valves with small, regular concentric wrinkles most distinctly marked on the central region.

"Greatest diameter of one of the largest oval specimens, 1.70 inches; breadth, 1.40 inches; convexity, 0.23 inch.

"This species is remarkable for the thinness of the shell, the slight convexity of the under valve, and the flatness of the upper, as well as for its rounded or slightly straightened cardinal margin, and the absence of any sear of attachment, or of any traces of muscular impressions within. These external characters, and the regular small concentric wrinkles, give the exterior of lower valves of circular specimens somewhat the appearance of a Lucina or Dosinia, while in other individuals it looks more like an Anomia or Placuna.

"Locality and position.-Missouri River, below Gallatin City, Mont. Cretaceous."

The comparative smoothness of these shells is so unusual with mature shells of any of the Ostreidæ as to suggest the possibility that they are immature examples; but their considerable abundance, and the nearly uniform size of all the specimens, seems to indicate that they are adult shells. If so, they evidently do not belong to the typical section of the genus Ostrea; but without some knowledge of the character of the muscular markings, it is unprofitable to offer any suggestions as to their true generic affinities.

\section{Subgenus ALECTRYONIA Fiseher.}

\section{Ostrea (ALECTRYonia) BLACKII White.}

Plate 14, figs. $1 a$ and $b$; and Plate 17, fig. $4 a$.

Ostrea blackii White, May, 1880, Proc. U. S. National Museum, vol. ii, p. 293.

Shell irregularly subovate in marginal outline, moderately capacious; beaks small, sometimes obscure and sometimes moderately prominent, pointing a little backward, but not conspicuously so. Lower valve usually moderately deep and capacious, its convexity being more prom. inent about the middle than elsewhere, often subalate, but the latter feature is usually obscure; scar of attachment at the beak usually present, and often modeprately large; ligament-area usually short and rather small, but sometimes comparatively large and laterally extended; ligament-furrow well defined, and of the usual character. Upper valve nearly flat, and corresponding with the lower in other respects, except that it is not so broad at the hinge border, and never has there the subalations which sometimes mark the lower valve. The adductor scars are moderately large, and of the form common to Alectryonia, namely, curved spatulate. Surface of both valves marked by concentric lines and strong imbrications of growth, and each by a dozen or more radiating ribs or plications, which constitute a conspicuous feature of the shell, but they are usually somewhat less distinct upon the upper than upon the lower valve.

Length, 68 millimeters; greatest breadth, 62 millimeters; thickness, 32 millimeters. 
In form and general aspect this shell approaches that of a typical Ostrea, but in the character of its adductor scars, the extent of its plications, and the subalation of its cardinal border, it is properly referable to the section Alectryonia. The only shell with which it need be compared is that of 0 . bellaplicata Shumard, also from Texas. It differs from that shell in being constantly larger, proportionally less capacious, broader towards the base, and in having its hinge-border longer and more oblique.

Locality and position.-Cretaceous strata, Collin County, Texas, where it was collected by Mr. S. W. Black, and sent by him to the Smithsonian Institution. The specific name is given in his honor.

\section{Genus EXOGYRA Say.}

\section{EXOGYRA: WINCHELLI White.}

Plate 13, figs. $1 a, b, c$, and $d$.

Exogyra winchelli White, May, 1880, Proc. U. S. National Museum, vol. ii, p. 294.

Shell of medium size, irregularly subovate in marginal outline; sessile, or attached by a large part of the surface of the lower or left valve, being obliquely inclined so that the anterior border is very much higher than the posterior. Lower valve massive, moderately deep, its front side nearly perpendicular and of considerable height vertically; umbo vertically flattened continuously with the front side, and broadly eurving backward; beak closely incurved under the posterior border and concealed; ligamental groove long and narrow, occupying the whole curvature of the umbo. Upper valve nearly flat, thick, the anterior part being much thicker than the posterior; beak vertically thin or compressed, closely coiled in a plane with that of the valve, making a little more than one entire volution. Surface marked by coarse lines of growth, and, near the anterior borders of both valves, especially the upper, it is usually deeply laciniate.

Length, 90 millimeters; breadth, 66 millimeters; height in front, 55 millimeters.

This species belongs to the same section of the genus Exogyra with E. haliotoidea Sowerly sp. and E. walkeri White. The latter species is larger and proportionally broader than E. winchelli and not properly sessile, as the latter species is. $E$. haliotoidea, as figured by d'Orbigny in Pal. Française, t. iii, pl. 478, differs from $E$. winchelli in being proportionally higher in front and narrower in transverse diameter, and in not having the beak so much incurved. E. interrupta Conrad, from Mississippi, also belongs to the same section, but that species is described as having radiating ribs, which $E$. winchelli has not.

Position and locality.-Cretaceous strata, Collin County, Texas, where it was collected and sent to the Smithsonian Institution by Mr. S. W. Black. The collections of the Institution also contain a fine example sent by Prof. A. Winchell many years ago from Prairie Bluffs, Ala., which is believed to be specifically identical with the form here described, but it is proportionally more elongate, has a larger muscular scar, and the umbonal curve is a little more abrupt. The specific name is given in honor of Professor Winchell. 


\section{EXogTRA FORNICULATA White.}

Plate 14, figs. $2 a$ and $b$.

Gryphcea pitcheri Marcou, 1858 (not Morton), Geol. of N. A., pl. iv, figs. 5 and 6. Gryphara navia Gabb, 1861 (not Conrad), Proc. Acad. Nat. Sei. Philad., p. 22; ib., Paleont. California, vol. ii, p. 273.

Exogyra forniculata White, May, 1880, Proc. U. S. National Museum, vol. ii, p. 293.

Shell of moderate size, subtrihedral in lateral outline, somewhat compressed vertically; under or left valve thick, especially its umbonal half; beak curved strongly towards the posterior border and in the plane of the free margins of the valve, not forming so much as one complete volution, its point being free but closely approaching the posterior border of the valve; ligament-area irregularly triangular, moderately large, extending to the apex of the beak, its sulcus well developed; interior surface having the usual characteristics of the genus. A faint, illy.defined sulcus is apparent on the posterior portion of the surface, extending from the umbo to the basal border, between which sulcus and the laterally flattened-concave posterior border of the valve there is an equally indefined radiating curved ridge. The anterior portion of the valve is marked by a strong, angular, rough carina, or ridge, which extends from the beak to the basal border. The prominence of this ridge gives a flattened aspect to the outer surface of the valve and also produces a flattened space of considerable width between it and the anterior margin. Surface marked by the ordinary coarse lines and imbrications of grewth common to the Ostreidæ, and upon the ridge just described there are occasional nodes, or vaulted projections of portions of the shell. Upper valve flattened and having much the aspect of that of a Gryphcea.

Length, 70 millimeters; breadth across the base, where it is widest, 50 millimeters.

This shell is much like a Gryphowa in general aspect, but it is referred to Exogyra because of its laterally-curved umbo and beak. It is often difficult to point out clear distinctions between these two genera, but the lateral curvature of the beak appears to be the most constant and important characteristic of Exogyra, distinguishing it from Gryphcea. Specifically, this shell is well marked by the strong, rough, angular carina, its free beak, narrow umbonal region, and broad base. In these respects it differs too much from any described species except a variety of Gryphoea pitcheri, to make detailed comparison necessary.

Morton's Gryphaea pitcheri has, unfortunately, been the cause of much controversy among paleontologists, in which the species here described has been involved because of some general resemblance which it bears to some varieties of the former. It is not my purpose to add anything to that controversy, but to endeavor, by the following remarks, to free Exogyra forniculata from necessary connection with it.

Professor Marcou (loc. cit.) referred this species to G. pitcheri, and gave excellent figures of it, but it differs materially from any of the several varieties of $G$. pitcheri in (not to mention other features) the invariable lateral deflection of the beak. If Gryphoea be distinct from Exogyra, then this is a generic character; and, in any case, it is at least a strong specific one, and one which is constant and readily recognizable.

Mr. Gabb (loc. cit.) referred this species to G. navia Conrad; and on p. 274 of the last-cited work he gave a new name, G. mucronata, to the true $G$. navia, or to a form that its author cited as such. Mr. Conrad 
appears never to have known $E$. forniculata. His original figures, in Emory's Mex. Bound. Report, of G. navia, which he properly regarded as only a variety of $G$. pitcheri, are unmistakable in their identity, and illustrate a well-known form which, although in a general way resembling, is distinctly different from $\boldsymbol{E}$. forniculata. Besides this, Mr. Conrad, in his accompanying description, refers, as already intimated, to Rœmer's figures in Kreid. von Texas, pl. ix, fig. $1 a, b$, and $c$, as excellent representations of his $G$. navia, which are also very different from $E$. forniculata in their long vertically arched beaks. Mr. Gabb also refers to those figures of Rœmer as illustrations of his G. mucronata; and there is, therefore, no room for doubt as to the mutual identity of the forms to which these two names were respectively applied by Mr. Conrad and Mr. Gabb. The latter author discriminated correctly between the true G. navia, as represented by Conrad's and Rœmer's figures respectively, and $E$. forniculata, and he possibly intended to give a new name to the latter form instead of the former; but he did not, and the latter has gone without a correctly-applied name until I published it as E. forniculata in Proc. U. S. Nat. Museum, vol. ii, p. 293.

Position and locality.-Cretaceous strata, Bexar County, Texas, where it was collected. by G. W. Marnoch, esq., together with many well-known Cretaceous species of that region. It is also found at numerous other Texan localities.

\section{Genus ANOMIA Linnæus.}

\section{ANOMIA PROPATORIS (sp. nov).}

Plate 12, figs $15 a$ and $b$.

Shell rather small, irregularly and a little obliquely subovate or subcircular in marginal outline; test pearlaceous and moderately thin, as is usual in Anomia. Upper valve convex; beak small, depressed, not quite marginal; surfiace marked by somewhat coarse, irregular wrinkles of growth, by a few radiating wrinkles in the umbonal region, and by fine, close-set, raised, radiating striæ, the latter appearing more distinctly on the forward part of the shell than elsewhere. Under valve unknown.

Length of the most perfect example in the collection, 11 millimeters ; breadth, 10 millimeters ; convexity, 5 millimeters.

This shell resembles A.gryphorhynchus Meek, the typical examples of which are from the Laramie strata of the Bitter Creek series, Southern Wyoming, but it differs from that species in having a less prominent and rounded umbo; in possessing radiating and concentric wrinkles and radiating raised striæ, while that species is an unusually smooth one. In the possession of the radiating raised striæ it corresponds closely with $A$. micronema Meek, which is so commonly distributed throughout the Laramie Group. As this striation constitutes a more important characteristic than mere form, which is always variable in this genus, it strongly suggests an intimate genetic relation for our shell with $A$. micronema.

This species is a member of the estuary fauna which was discovered several years ago by Mr. Meek in the Cretaceous series of strata at Coalville, Utah, and which is more particularly mentioned on a subsequent page, in remarks which follow the description of Cyrena carletoni. Although all the species of that Cretaceous estuary fauna are different from any yet found in the Laramie Group, several of them are so closely related to certain Laramie forms as to strongly suggest the idea that 
the molluscan fauna of the Laramie period had mainly its genetic derivation from the estuary faunæ that were established along the continental shores of marine waters during the previous Cretaceous epochs. In view of what we already know of the history of the great Laramie deposit, this view of the genetic derivation of its molluscan fauna would seem to be the most natural one, even without the paleontological hints here mentioned.

In the marine strata of the Cretaceous series at Coalville examples of an Anomia are not unfrequently met with which closely resemble this one, and which may really belong to the same species. All the examples from the marine strata there which have come under my observation are, however, too imperfect to show the surface markings, and thus an important specific characteristic is wanting.

Position and locality.-The specimen figured on plate 12 is one which Mr. Meek obtained from the estuary strata of the Cretaceous series at Coalville, Utah.

\section{Genus PTERIA Scopoli.}

\section{Pteria?? stabilitatis (sp. nov.).}

Plate 17, fig. $3 a$.

Shell adherent by the whole surface of the right valve, suborbicular or transversely suboval in marginal outline; hinge-line straight, less in length than the breadth of the shell. Right valve thin, especially at, and near the margins; beak minute, hardly raised above the cardinal border; ears minute or obsolete; hinge-area narrow, ending somewhat acutely both anteriorly and posteriorly, its inner border prominent but plain; cartilage-pit small, pyramidal, turned obliquely forward. Upper or right valve unknown.

Breadth of the largest example discovered, 34 millimeters ; height of the same from base to cardinal border, 26 millimeters. Three or four of the examples are not above $1 \frac{1}{2}$ millimeters in diameter.

The only known representatives of this species are one adult and several small examples of the right valve adhering to the surface of a fragment of the shell of a large Inoceramus. It evidently belongs to the Aviculidr, but in being adherent by the whole surface of the right valve it differs from all other known members of that family, and when perfect examples of both valves are discovered it will probably be found to represent an unpublished genus. The shell-substance of the thin marginal portion of all these examples is loosely cellular, which condition is possibly due to some malady which affected the mollusk while living, but it seems to be connected with a prismatic-cellular structure of the thicker portion, such as is common to the Aviculidæ.

Position and locality.-Cretaceous strata, Collin County, Texas, where it was collected by Mr. S. W. Black, and sent by him to the Smithsonian Institution.

\section{Subgenus OXYTOMA Meek.}

\section{Pteria (Oxytoma) salinensis White.}

Plate 16, figs. $2 a$ and $b$.

Pteria (Oxytoma) salinensis White, May, 1880, Proc. U. S. National Museum, vol, ii, p. 296.

Shell rather large for a Cretaceous Pteria; the body, exclusive of the wings, being obliquely subovate, broad at base, moderately gibbous, dis- 
tinctly but not very greatly inequivalve; the left valve, as usual, more convex than the right, and its beak more prominent than the other; the convexity of the surface of the valves somewhat uniform, but increasing toward the umbonal region, where it is greatest; anterior wing moderately large, defined from the body of the shell by being laterally compressed, but not by any distinct auricular furrow ; the byssal sinus under the anterior wing of the right valve having the usual size and shape common to Oxytoma; posterior wing not proportionally large, and not distinctly defined from the body of the shell except by a somewhat gradual lateral compression; its posterior angle not greatly produced; hingeline less than the axial length of the shell; posterior adductor scars not distinct; anterior scars distinct for a shell of this genus, placed immediately in front of the beaks, that of the left valve being more distinct than the other.

This, like the following described species, is known only from natural casts in brown hematite of the interior of the shell, the imperfection of which will not allow of an accurate measurement of all its proportions. It is, however, known to have reached an axial length of more than 60 millimeters, a transverse width near its base of at least 50 millimeters, and a thickness of about 25 millimeters, when both valves were in natural position.

The character of the surface is not known, but it was evidently nearly smooth, as is usual with its congeners. It is related to Pteria (Oxytoma) nebrascana Evans \& Shumard, but it is a larger and more robust shell, having a proportionally larger anterior wing, more prominent beaks, and broader base.

Position and locality.-Strata of the Dakota Group, Saline County, Kansas, where it was discovered by Prof. B. F. Mudge, associated with the next following described species, and also with Cyrena dakotaensis Meek \& Hayden and Cardium kansasense Meek,

\section{Genus GERVILLIA Defrance.}

\section{Gervillia mudgeana White.}

Plate 14, figs. $3 a$ and $b$.

Gervillia mudgeana White, May, 1880, Proc. U. S. National Museum, vol. ii, p. 295.

This shell, like the last described, is known only from natural casts in brown hematite of the interior and of a few adhering fragments showing the character of the test. It is moderately large, laterally distorted; hinge-line comparatively long, very oblique with the axis of the shell, producing a somewhat prominent posterior alation, which is not distinctly defined from the body of the shell; cartilage-pits in the area of each valve six or seven, as shown by undulations upon the cast; beaks placed very near the anterior end, beyond which there appears to have been no distinct anterior ear; beak of the right valve more prominent than the other, although the right valve is less convex transversely than the left; right valve having a somewhat regular and strong longitudinal convexity, but its transverse convexity is very slight in the anterior half, while that of its posterior half is nearly flat; left valve nearly straight or even slightly concave longitudinally along the axis, but very strongly convex transversely in all parts, this convexity being more abrupt along the axis than elsewhere, but there is between the axis and the hingemargin a slightly raised rounded fold which extends from behind the beak to the posterior margin; adductor muscular impression large and 
distinct in each valve. A few fragments show the surface to have been marked by the ordinary concentric lines of growth, and also that the test, although firm, was not massive.

The dimensions cannot be definitely given, but the largest example discovered indieates a length of at least 80 millimeters.

This shell differs too much from any of the few known Cretaceous species of the genus to need detailed comparison, but it is related to $G$. $s u b$ tortuosa Meek \& Hayden, which it resembles in being tortuous. It differs, however, from that species in being a proportionally much shorter shell, in the shape and position of the adductor scars, and in the relative position and arrangement of the cartilage-pits. It is less tortuous than G. tortuosa Sowerby, and its proportions are different.

Position and locality.-Strata of the Dakota Group, Saline County, Kansas, where it was discovered, associated with the preceding species, by Prof. B. F. Mudge, in whose honor the specific name is given.

\title{
Genus PINNA Linnæus.
}

\section{PINNA LAKESII White.}

\author{
Plate 11, figs. $1 a$ and $b$.
}

Pinna lakesii White, 1879. An. Rep. U. S. Geol. Sur. Terr. for 1877, p. 181. Compare with Pinna restituta Hœninghaus.

Shell rather large, slender anteriorly but beeoming quite broad and somewhat compressed posteriorly ; sides not angular or otherwise conspicuously marked along the median line, nor very convex except near the anterior end, where the transverse thickness of the shell is about equal to its height from base to dorsal border; dorsal margin broadly concave from front to rear and longer than the basal margin ; posterior border convex, or rather truncated obliquely downward and a little backward from the dorsal border to a point a little below the median line, where it is abruptly rounded, and, by a long forward slope, blends with the basal border, which border is slightly conrex or nearly straight. Surface marked by the usual lines of growth and by some concentric wrinkles, which latter are more distinct below than above the median line. It is further marked by numerous slender, slightly raised, radiating ribs, which extend continuously from the anterior to the posterior end of the shell. Seven or eight of these ribs mark the whole space above the median line, and three or four are seen below it, leaving the lower half of the space below the median line free from ribs. The ribs are merely close-set raised lines upon the narrow front end of the shell but become stronger farther backward. They are there much narrower than the intervening spaces, because the width of the latter increases posteriorly much more rapidly than that of the ribs.

Full length of the specimen figured on plate 11, about 280 millimeters; width (vertical) of the same at the widest part, about 83 millimeters.

This species is in no danger of being coufounded with any other described and figured form from American rocks, but it somewhat resembles the $P$. decussata Hœninghaus as figured by Goldfuss. It differs from that species, however, by increasing more rapidly in size from front to rear, by the much less convexity of its basal margin, and by the character and direction of the posterior and postero-basal borders as described above.

Position and locality.-No examples of this species have been satisfactorily identified from any other region than that of Northern Colorado, 
east of the Rocky Mountains. The type specimens were obtained from Fossil Ridge, about 16 miles westward from Greeley, and about 6 miles southward from Fort Collins, Col. The best examples yet discovered, one of which is figured on plate 11, were obtained at that locality by Mr. A. Lakes, by whom they have since been sent to Princeton College, New Jersey.

\section{Genus VOLSELLA Scopoli.}

\section{Subgenus BRACHYDONTES Swainson.}

VOLSELLA (BRACHYDONTES) MULTHINIGERA Meek,

Plate 11, fig. $3 a$.

Modiola pedernalis Meek (not Rœmer), 1871, An. Rep. U. S. Geol. Sur. Torr. for 1870, p. 297.

Modiola (Brachydontes) multilinigera Meek, 1873, An. Rep. U. S. Geol. Sur. Terr. for 1872, p. 492.

In a catalogue of Cretaceous fossils, published in the Annual Report of this Survey for 1870, Mr. Meek (loc. cit.) referred this species to the Modiola pedernalis of Rœmer, but he afterward gave it the new specific name as above, together with the following description and remarks:

"Shell rather above medium size, obliquely arcuate-subovate; valves strongly convex along the umbonal slopes, thence cuneate posteriorly and abruptly curved inward below the middle in front; posterior margin forming a broad, regular convex curve from the end of the hinge downward to the anterior basal extremity, which is very narrowly and abruptly rounded; anterior margin ranging obliquely backward and downward to the narrow basal extremity, and strongly sinuous along the middle, above which it projects more or less beyond the umbonal ridge, so as to form a moderately prominent, somewhat compressed, protuberance; hinge margin nearly or quite straight, ranging at an angle of $50^{\circ}$ or $60^{\circ}$ above an imaginary line drawn from the beaks to the most prominent part of the basal outline, and equaling about one-half the greatest oblique length of the valves; beaks nearly terminal, rather compressed, very oblique, and scarcely rising above the hinge margin; umbonal slopes prominent and more or less strongly arcuate. Surface ornamented with fine lines of growth, crossed by regular radiating lines that are very fine and crowded on the anterior part of the valves, but become coarser above and behind the umbonal ridge, the largest being near the dorsal side, where they bifurcate so as to become very fine, and curve more or less upward before reaching the cardinal margin.

"Greatest length, measuring from the beaks obliquely to the most prominent part of the basal margin of a large specimen, 1.90 inches; greatest breadth at right angles to the same, 1 inch; convexity, 0.76 inch.

"On first examining some imperfect casts of this shell brought by Dr. Hayden from near Coalville, Utah, I was led to think it probably the form described by Dr. Romer from Texas under the name Modiola pedernalis, to which I referred it provisionally in making out the list of Cretaceous fossils for Dr. Hayden's report for 1870. Further comparisons of better specimens collected at the same locality during the past summer, however, have satisfied me that it presents well-marked and constant differences from the Texas shell. In the first place it is distinetly more arcuate, so much so that when placed with its hinge line in a horizontal position, the outline of its posterior margin, instead of form- 
ing an oblique, backward-descending curve, ranges nearly vertioally. Again, the most prominent part of its posterior basal margin is very narrowly rounded, instead of forming a regular curve. Its umbonal ridges are likewise more prominent, more arched, and extend down to the narrowly-rounded posterior-basal extremity. The lobe-like projection of the upper part of its anterior margin, under the beaks and in front of the umbonal ridge, also differs in being proportionally much smaller than in Dr. Rœmer's species, in which it forms about one-third of the entire valve, as seen in side view, while in our shell it scarcely forms more than one-sixth. Of course the specimens are more or less variable in these characters, but the two forms can always be readily distinguished when good examples can be had for comparison.

"In its more arcuate form our shell agrees more nearly with Modiola ornata Gabb, from the Cretaceous rocks of California; but that shell differs very markedly in having its beaks decidedly less nearly terminal, and a more decided and much more prominent lobe in front of them. Another important difference is to be observed in the radiating striæ, which on the anterior side of our shell are very minute and closely crowded, while on that part of Mr. Gabb's species they are as large and distant from each other as on any other part of the valves.

"If Scopoli's name, Volsella, should be adopted for this genus, as there are some reasons for believing may be the case, this change would require the name of this species to be written Volsella multilinigera.

"Locality and position.-Cretaceous sandstones near Coalville, Utah."

\section{Genus BARBATIA Gray.}

\section{Barbatia barbulata (sp. nov.).}

Plate 11, fig. 5 a.

Shell small, longitudinally oblong or subrhomboidal, a little more than twice as long as high; cardinal and basal margins nearly parallel, the former straight and the latter nearly so; anterior side short, rounded up obliquely from the base, and meeting the cardinal margin at an obtuse or bluntly rounded angle; posterior side, long; posterior margin, truncate obliquely downward and backward from the cardinal margin to the base, which it meets at a blunted angle, or it is there abruptly rounded; beaks distinct, but somewhat depressed and incurved, placed about onefifth the length of the shell from the front; cardinal area narrow, but it is not well shown in our examples. Surface showing fine crowded, raised, rounded, radiating striæ, which are crossed by fine lines of growth and also by numerous sharply raised concentric lines, some of which are more conspicuous than the radiating lines.

Length, about 25 millimeters ; height, about $11 \frac{1}{2}$ millimeters.

Only two or three imperfect examples of this species have been discovered, but in its shape and surface markings it presents such differences from any known form as to warrant the foregoing description under a new specific name.

Position and locality.-Cretaceous strata, apparently of the age of the Fox Hills Group, at Cimarron, New Mexico, where it was found by Prof. St. John, associated with Crassctella cimarronensis White, and other forms, some of which were deseribed and figured in Contributions to Invertebrate Paleontology No. 1, and published in the Annual Report of this Survey for 1877. 


\section{Genus CYRENA Lamarck.}

\section{Cyrena carletoni Meek.}

Plate 12, figs. $16 a$ and $b$.

Cyrena carletoni Meek, 1873, An. Rep., U. S. Geol. Sur. Terr. for 1872, p. 495.

The following is Mr. Meek's description of this interesting species, together with his remarks upon it:

"Shell small, thin, subcircular or with length a little greater than the height, moderately convex; anterior and posterior margins rounded from above regularly into the rounded basal outline, or with the posterior sometimes slightly straightened, both rounding more abruptly to the hinge above; beaks rather depressed, small, abruptly pointed, incurved, nearly contiguous, and placed slightly in advance of the middle; hinge line sloping very gradually from the beaks. Surface marked with moderately distinct concentric lines and furrows.

"Length of a medium-sized specimen, 0.55 inch; height of same, 0.49 inch; convexity, 0.32 inch.

"This shell is so very thin, and so nearly resembles a rather large Sphcerium in form and surface characters that I certainly should have referred it to that genus had not a lucky blow separated the hinge of a right valve from the matrix in such a manner as to expose the teeth quite satisfactorily. This shows its hinge to have the characters of a true Cyrena. For so thin a shell it has quite a stout hinge. Its cardinal teeth are rather diverging, the posterior two being well developed, and each a little furrowed along the middle, while the anterior one (in this right valve) is much smaller and conical in form. The lateral teeth are of moderate size, and certainly smooth, the posterior being remote from the cardinal teeth, and the linear anterior extending back to the latter. Internal casts show the muscular and pallial impressions to be well defined, and the latter to be a little straightened, or showing a very faint tendency to form a small sinus under the posterior (adductor scar).

"This is a rather small and an unusually thin shell for the genus Cyrena, being, as already remarked, much more like a Sphcerium in these characteristics. It is quite abundant at the locality, but, as it is only found in an indurated clay matrix, good specimens are with difficulty obtained, and from these the thin shell is very liable to break and scale off, leaving only the internal cast remaining.

"Among the specimens collected there are some of a more transversely oval form and somewhat larger size than those I have regarded as the types of the species here described. These may belong to a distinct species, but they agree so nearly in all other known characters that I am at present inclined to regard them as merely $a$ variety of the same.

Locality and position.-Carleton's coal mine, Coalville, Utah."

This species is one of an interesting estuary fauna which was discovered by Mr. Meek in connection with a portion of the coal-bearing strata in the Cretaceous series at Coalville, Utah. The figures on plate 12 have been drawn from his types, which are among the only examples that have ever been collected.

One of the species of this peculiar estuary fauna, namely, Physa carletoni, was illustrated on plate 7, fig. 12, of Contributions to Invertebrate Paleontology No. 1, in the Annual Report of the Survey for 1877, and all the remaining species of that estuary fauna which have yet been described are illustrated upon plate 12 of this article. They embrace the following 
species: Anomia propatoris, Corbicula carletoni, Melampus? antiquus, Neritina bannisteri, Neritina (Velatella) bellatula, $N$. (V.) carditoides, Turritella spironema, Eulimella? inconspicua, E.? chrysallis, and Valvata nana. The fauna also contains another Turritella, a Unio, and two or three other undetermined species. For Mr. Meek's remarks upon this fauna see the Annual Report of this Survey for 1872, pp. 442-445.

Peculiar interest attaches to this estuary fauna in different ways, but especially because some of its species indicate the existence of types at that early period which are found to characterize the fossil molluscan faunæ of later epochs as represented by North American strata; and of some that are also common among living North American forms. Especial reference is had in this remark to the fresh-water and land mollusca. The strata containing the fossil fauna in question were evidently deposited in the estuary of a stream, which, during at least a portion of the Cretaceous period, flowed into the sea from the narrow continental region of Mesozoic time, the eastern shore of which was evidently near that locality. There were doubtless other similar estuaries along that and other shores of the Cretaceous seas, but little is yet actually known of them. Unfortunately, also, the excavations which exposed the strata bearing the fauna in question, at Coalville, have been discontinued and covered with débris, and none of its species have yet been found elsewhere. Our present knowledge of this deposit is therefore confined to that one limited locality.

\section{Genus PHARELLA Gray.}

\section{Pharella? PEALei Meek.}

Plate 11, figs. $6 a$ and $6 b$.

Pharella? pealei Meek, 1873, An. Rep. U. S. Geol. Sur. Terr. for 1872, p. 496.

No other than the type specimens of this species have ever been discovered; the best one of which, although only a cast, is figured on plate 11. The following is Mr. Meek's description of it:

"Shell elongate or subrhombic, the length being about twice and a half the height, rather compressed; anterior margin slightly sinuous just in advance of the beaks above, and somewhat narrowly rounded below this faint sinuosity; posterior margin truncated, with a convex outline, very obliquely downward and backward from the posterior extremity of the hinge to the prominent and very narrowly-rounded or angular posterior -basal extremity; hinge-line proper, apparently comparatively short, and not forming any angularity of outline at its connection with the sloping posterior dorsal margin; beaks rising a little above the hinge margin, but rather depressed and placed about one-fifth the entire length of the valves from the anterior margin; basal margin long, slightly sinuous along most of its length; posterior dorsal slopes rather prominently rounded from the beaks obliquely to the posterior basal extremity. Surface only showing obscure lines of growth.

"Length, 1.20 inches; height, 0.48 inch; convexity, 0.28 inch.

"Knowing nothing of the hinge of this shell I only referit provisionally to Pharella. It does not seem to have had the extremities gaping as in that genus, but the specimen has evidently been accidentally compressed, and this may have given the valves the appearance of being closed. In general appearance it resembles Solen guerangeri d'Orbigny, which seems to belong to the genus Pharella. Our shell, however, evidently differs from d'Orbigny's specifically, at least, in not having the posterior margins of 
its valves near so abruptly truncated, but rounding and sloping forward gradually into the dorsal outline above. Possibly, I should call it Modiola pealei.

"Locality and position.-Missouri River, below Gallatin City, Mont. Cretaceous."

\section{Genus TAPES Mühlfeldt.}

\section{TAPES HILGARDI Shumard.}

Plates 16, figs. $3 a, b$, and $e$.

Tapes hilgardi Shumard, 1860, Trans. St. Louis Acad. Sci., Vol I, p. 601.

The following is Dr. Shumard's description of this species (loc. cit.).

"Shell ovate, transversely elongate, valves compressed, convex; extremities rounded, the anal end narrower than the buccal, and in adult specimens approaching to subtruncate; cardinal border long, curving gently from the beaks posteriorly; basal margin very gently convex; beaks situated about one-third the length of the shell from the anterior margin, rather short, nearly in contact; ligament area depressed, narrowlanceolate; pallial sinus linguæform, extending above the middle of the height of the shell. The surface markings are not well preserved in any of the specimens before me. They show merely fine concentric lines of growth near the basal margin.

"Length, 2 inches; width, 1.27; thickness, 0.66 .

Locality.-Bluffs of Red River, Lamar and Fannin counties (Texas), occurring in septaria of the marly clay, near the base of the Lower Cretaceous."

In the collections of the National Museum are some examples which I reter to this species, one of which is represented by fig. $3 b$ and another by fig. 3 c, plate 16 . These examples were sent by Mr. D. H. Walker, from Bell County, Texas, with other Cretaceous species. Fig. $3 a$ of the same plate is from a photograph of Dr. Shumard's original drawing which he had gren to the late Mr. Meek before his death. This species perhaps belongs to the genus Baroda Stoliczska, but as nothing is yet known of its hinge or interior markings I prefer to leave it where Shumard placed it.

\section{Genus PACHYMYA Sowerby.}

\section{PACHYMYa? COMPACTA White.}

Plate 17, figs. $4 a$ and $b$.

Pachymya? compacta White, Jan., 1880, Proc. U. S. National Museum, vol. ii, p. 297.

Shell small, narrower posteriorly than anteriorly, slightly gaping behind; beaks depressed, approximate, incurved, directed forward, their position being very near the front; basal margin broadly convex; posterior margin narrowly rounded; postero-dorsal margin forming an oblique downward and backward truncation of that part of the shell; cardinal margin nearly straight, subparallel with the basal margin, much shorter than the full length of the shell; ligament short, its area depressed and sharply defined; front very short, depressed beneath the beaks and narrowly rounded below; umbonal ridges prominent, angular or subangular; the space above and behind them moderately broad and flattened; the remainder of the valve somewhat regularly convex. Hinge and interior markings unknown. Surface marked by the ordinary concentric lines of growth. 
Length, 29 millimeters; height, 18 millimeters; thickness, both valves together, 14 millimeters.

This species is evidently congeneric with the shell which; in the An. Rep. U. S. Geol. Sur. Terr. for 1877, p. 298, I described as Pachymya herseyi and also with the Cypricardia texana of Rœemer; but knowing nothing of the hinge of either of these forms I am not satisfied that they are properly referable to Pachymya. They are, however, here referred to that genus because of the agreement of their external characteristics with those of Pachymya.

Position and locality.-Cretaceous strata, Bell County, Texas, where it was collected by Mr. D. H. Walker.

\section{Genus THRACIA Leach.}

\section{ThRACIA MYAFFORMIS White.}

Plate 17, figs. $2 a$ and $b$.

Thrácia myceformis White, Jan., 1880, Proc. U. S. National Museum, vol. ii, p. 297.

Shell transversely subovate in marginal outline; valves nearly equal; anterior end regularly rounded; wider and thicker anteriorly than posteriorly; posterior portion narrowed vertically and somewhat compressed laterally, but gaping at the extremity; basal border broadly convex; posterior border abruptly rounded; cardinal margin slightly convex; but the prominent umbones give the shell a concave appearance behind the beaks; a distinct linear depression is seen in the natural cast, on each side of the ligament; beaks prominent, incurved, and directed a little forward; muscular impressions not distinctly shown in our examples, which are natural casts in chalky limestone, but the pallial sinus appears to have been large and subangular at its anterior end. Surface marked by the ordinary lines of growth, and also by more or less distinct irregular concentric wrinkles.

Length, 57 millimeters; height, from base to umbo, 37 millimeters; thickness, both valves together, 24 millimeters.

This shell in general aspect, approaches T. prouti Meek \& Hayden, from the Upper Fox Hills Group of the Upper Missouri River region; but it differs in being proportionally narrower and more produced behind the beaks than that species, and in the greater prominence of the umbones.

Position and locality.-Cretaceous strata of Bell County, Texas, where it was collected by Mr. D. H. Walker.

\section{GASTEROPODA.}

\section{Genus MELAMPUS Montfort.}

\section{Melampus? ANTIQUUs Meek.}

Plate 12, figs. $11 a b, c$, and $d$.

Melampus antiquus Meek, 1873, An. Rep. U. S. Geol. Sur. Terr. for 1872, p. 507.

The following is Mr. Meek's description of this species, together with his remarks upon the same:

"Shell subovate, thin; spire moderately prominent, conical, and abruptly pointed; volutions about eight; those of the spire very short 
and nearly flat; last one large, widest above and tapering below; suture shallow, with a slightly impressed line a little below it, around the upper margin of each volution; aperture narrow; columella and inner lip provided with four very prominent laminæ or folds, with sometimes one or two smaller ones above these, near the top of the aperture; outer lip thin; and strengthened by a few transverse ridges within. Surface showing only fine obscure lines of growth and presenting a somewhat polished appearance.

"Height of a small specimen 0.43 inch; breadth, about 0.27 inch.

"I have only seen very imperfect specimens of this shell, but, taken together, they give a correct idea of nearly all of its characters. Some of them are three or four times the linear dimensions of that from which the above measurements were taken.

"Among the specimens from the same locality and bed there are some very large broken examples, too imperfect for detailed description, that seem to belong to a more elongated species, with a more produced spire than that described above. This form, however, as far as its characters can be made out, appears to agree with the foregoing in nearly all other respects. If distinct, it may be called $M$. elongatus.

"Locality and position.-Carleton's coal-mine, near Coalville, Utah. Cretaceous."

After a full examination of all the specimens collected by Mr. Meek, I am inclined to believe them to represent only one species, and that the differences which exist are due only to interspecific variation. Figures $11 a$ and $11 b$, on plate 12 , are drawn from the most perfect example discovered, although it is not more than one-third the size of some individuals which are represented in the collection by badly broken specimens.

The four folds upon the inner lip, mentioned by Mr. Meek, vary in size and character. The two middle ones are stronger and more prominent than the other two. The anterior one is narrow and ridge-like, and is not so distinctly seen from without as the others are, and it appears to be absent in the earlier stages of growth of the shell. The third one from the anterior end of the aperture, including the less conspicuous one just mentioned, is more transverse in its position than the others, and it is also hollowed upon its anterior side and a little flattened upon its outer side in shells of fully adult growth. They all rest upon a layer of callus, which forms the inner lip, and constitute an unusually conspicuous armature of the aperture. Figure $11 d$, plate 12 , shows this armature of a much broken, but very large example, natural size.

Upon carefully cutting the indurated clay matrix from around the spire of several of the specimens of the collection, I find the first volution of the minute apex to be reversed; or rather its axis is so turned as to have a different direction from that of the axis of the body of the shell. Usually the two axes are nearly at right angles. The reversed portion is very minute, and may easily escape detection, even under an ordinary lens. Figure $11 c$, plate 12, represents an enlarged view of the apex. This is an important feature, and suggests possible relationship of this shell to the Pyramidellidæ, with some members of which family it is faunally associated; but its form, as well as most of its other characteristics, are much more like those of the Auriculidæ. Instead, however, of regarding it as a true Melampus, I am more disposed to regard it as congeneric with Rhytophorus Meek, the type-species of which is found in the Bear River Laramie strata. The longitudinal varices, occupying the space immediately in advance of the narrow groove near the distal border of the volutions of the type of that genus, were regarded as of generic. importance by Mr. Meek, and suggested the name which 
he gave to the genus. These varices are not present on the shell here discussed; but to my mind the narrow groove situated near the distal border of the volutions in both shells is of greater generic value than the varices. Of equal or greater generic value also is the reversed apex of our shell, which is evidently a constant characteristic; but it is not yet known whether the apex of the type of Rhytophorus is also reversed. Until this question can be decided I prefer to leave this species where Mr. Meek originally placed it, in the genus Melampus, although it is quite certain that it does not strictly belong there, rather than to formally transfer it to Rhytophorus, or to propose a new generic name.

\section{Melamipus ? — ?}

Plate 12, fig. $6 a$.

Mॅlampus — ? Meek, 1873, An. Rep. U. S. Geol. Sur. Terr. for 1872, p. 439.

$\mathrm{Mr}$. Meek obtained from the marine strata at Coalville a single example of a shell, which is evidently congeneric with the Melampus antiquus, from the estuary beds there, and which has just been described. It is too imperfect to base a specific description upon; but it is probably distinct from the last-described species. All its associates are marine forms, and if it is a littoral pulmonate Gasteroporl, as it is supposed to be, it was probably drifted to its marine entombment from an adjacent shore, just as the Physa probably was, which was found in the same or associated strata, and which is figured on plate 7, fig. 13, of Contributions to Invertebrate Paleontology No. 1, in the annual report of this survey for 1877. The character of the specimen here referred to Melampus is well shown by fig. $6 a$, plate 12 , but it is thought best to wait for better examples before giving it a specific name.

\section{Genus NERITINA Lamarck.}

\section{Neritina BANNISTERI Meek.}

Plate 12, figs. $10 a, b$, and $c$.

Neritina (Neritella) bannisteri, Meek, 1873, An. Rep. U. S. Geol. Sur. Terr. for 1872, p. 499.

This species is one of the estuary Cretaceous fauna before referred to, which was discovered by Mr. Meek, at Coalville, Utah. The figures of it on plate 12 have been drawn from one of Mr. Meek's types, and the following is his description of the species, together with his remarks upon the same :

"Shell, subglobose; spire much depressed, or with its apex scarcely rising above the body-whorl; volutions three or four, rapidly increasing in size, so that the last one comprises neariy the entire shell, more or less flattened, and sometimes provided with an obscure linear revolving furrow above; aperture large, subovate, approaching semicircular, being a little straighter on the inner side; outer lip beveled to a thin edge; inner lip of moderate breadth, slightly concave, and flattened, with a steep inward slope, entirely smooth. Surface polished, and marked by crowded zigzag vertical bands of brown and light-yellowish colors; lines of growth moderately distinct.

"Height of a nearly medium-sized specimen 0.40 inch; breadth, 0.43 inch. Some examples are as much as twice these dimensions. 
"Although the specimens show the pattern or style of the original coloration of this shell quite distinctly, the colors themselves may, of course, have been different in the living shell. Usually the zigzag markings are quite distinct on the specimen as found, but on some examples the bands are blended, and become fainter, so that the surface merely presents a light brownish tinge. It is always polished, howover, on all the specimens seen.

"This species seems to be more nearly allied to $N$. nebrascensis M. \& H., from the Jurassic beds, near the head of Wind River, than to any other form with which I am acquainted. It may be readily distinguished, however, by its more depressed spire, and the slight flattening of its volutions above, as well as by its more flattened and more concave inner lip. It likewise attained a larger size than any of the specimens of that species I have seen. It is one of the most abundant shells observed at the locality, and is usually found in a better state of preservation than any of its associates.

"Position and locality.-Carleton's coal mine, Coalville, Utah."

This species is closely related to $N$. incompta White, from marine Cretaceous strata at Hilliard Station, about 40 miles northward from Coalville, and which is figured on plate 7 of Contributions to Invertebrate Paleontology No.1, Annual Report of this Survey for 1877; but its differences are pointed out in connection with the accompanying description of that species.

\section{NERITINA PISIFORMIS Meek.}

Plate 12, figs. $9 a, b$, and $c$.

Nerilina pisiformis Meek, 1873, An. Rep. U. S. Geol. Sur. Terr. for 1872, p. 500.

This shell is found associated with $N$. pisum Meek, which is figured on plate 7, accompanying Contributions to Invertebrate Paleontology No. 1, in the Annual Report of this Survey for 1877, and also with many other forms in the marine Cretaceous series of strata exposed at Coalville, Utah. The figures on plate 12 have been drawn from one of $\mathrm{Mr}$. Meek's types, enlarged two diameters, while those of $N$. pisum, just referred to, are of natural size. In size and general aspect the two species are closely alike, as may be seen by comparing the figures of both, and as has also been pointed out by Mr. Meek. The following is his description of this species:

"Shell small, subglobose, or obliquely rhombic, the height being slightly less than the oblique breadth; spire rather prominent for a species of this genus; volutions three to three and a half, convex; aperture subovate, considerably contracted by the flattened, moderately wide inner lip, which is nearly straight on its inner margin, and provided there with four small denticles, the upper one of which is largest; surface smooth.

"Height, 0.30 inch; greatest oblique breadth, 0.32 inch.

"This little shell agrees so nearly in size and form with the described species ( $N$. pisum) that they may be readily confounded, as they are found with the aperture filled with rock.

"A fortunate fracture of one of the specimens exposed the inner edge of its flattened columella, however, and thus enabled me to see that it is denticulated, and in this respect differs from Neritina pisum, which seems to be entirely without teeth. Further comparisons also show the two shells to differ in form, that under consideration having a more prominent spire and a more globose outline, being less oblique. 
"In size and general appearance it also closely resembles small examples of Neritina compacta Forbes, from the Cretaceous rocks of India, but it is less oblique, or more globose in form, and has four denticles instead of only three on its columella. It is possible that I should call it Nerita pisiformis, as the denticulations of its columella are rather strongly developed for a Neritina, in which genus the columella is usually smooth, or only finely crenate. Its general aspect, however, is more like species of the latter group.

"Locality and position.-Coalville, Utah, from the Cretaceous beds below the lower heavy bed of coal mined there.

\section{Subgenus VELATELLA Meek.}

No diagnosis of this type having yet been published, although Mr. Meek proposed a name for it on p. 499 An. Rep. U. S. Geol. Surv. Terr. for 1872, I propose the following diagnosis, which is drawn from all the yet known forms beionging to it, namely: Neritina (Velatella) bellatula and $N$. $(V$.$) carditoides Meek, from the estnary Cretaceous strata$ at Coalville, Utah; $N$. (V.) patelliformis Meek, and var. weberensis White, from the marine Cretaceous strata at the same place; and $N$. (V.) baptista White from the Laramie Group at Black Buttes Station, Wyoming.

Shell resembling both Dostia and Velates, suboval in outline, depressed convex above, flattened beneath; beak minute, incurved, turned a little to one side, and depressed nearly or quite to the posterior margin ; inner lip large, flattened or slightly convex, its border smooth or crenulate; outer lip usually a little thickened and sometimes crenulate within, and more or less continuous with the inner lip; aperture comparatively small ; surface smooth or radiately ribbed; usually polished. It differs from Dostia in its more nearly perfect bilateral symmetry and its minute apex; and from Velates in having its apex always depressed to the posterior border.

\section{Neritina (Velatella) Bellatula Meek.}

Plate 12, figs. $8 a$ and $b$.

Neritina (Dostia\%) bellatula Meek, 1873, An. Rep. U. S. Geol. Sur. Terr. for 1872, p. 497.

The type which in this article is represented by the two following described forms, while it is closely related to Dostia Gray, and Velates Montfort, is doubtless worthy of the subgeneric distinction suggested for it by Mr. Meek in connection with his specific description of them in the Annual Report of this Survey for 1872, pp. 197 and 198. The publication of a diagnosis of the type being necessary for its proper recognition, and Mr. Meek having failed to publish one, I have drawn the foregoing one from the characteristics presented by all the known forms which are referable to this type.

The two forms described in this article were discovered by Mr. Meek associated together, and forming a part of the estuary Cretaceous fauna at Coalville, Utah, which has already been mentioned. Another species of the same type $N .(\nabla$.$) patelliformis is found in the marine Cretaceous$ strata of the same neighborhood, and the only other known species belonging to it was discovered by the writer in the upper strata of the Laramie Group at Black Buttes Station, Wyoming. The latter form is figured, on plate 29 ; and $N$. ( $V$. ) patelliformis, together with a variety of the same, is figured on plate 7, accompanying Contributions to Inverte- 
brate Paleontology No. 1, in the Annual Report of this Survey for 1877. The following is Mr. Meek's description of this species, together with his remarks upon the same:

"Shell small, depressed-ovate, or broad slipper-shaped; apex very small, and depressed to the posterior margin, where it forms one or two minute, slightly oblique, compact turns, that do not project beyond the margin, but are sometimes even slightly overlapped by it; inner lip very broad, or shelf-like, and occupying more than half the under side, convex, and more or less thickened, with the inner margin concave in outline at the middle, and provided with a slight projection on each side, but not properly crenate or dentate; outer lip rather thick, obtuse, nearly or quite smooth, and continuous around the margins with the inuer one; aperture small and transversely semicircular. Surface polished, and ornamented by from fifteen to twenty light yellowish or cream-colored simple radiating costæ, separated by shallow, light brownish furrows of about the same breadth; * lines of growth moderately distinct.

"Length, 0. 31 inch; breadth, 0.25 inch; convexity, 0.12 inch.

"I am in some doubt in regard to the proper disposition to make of this little shell. In most of its characters it seems to conform pretty nearly with Dostia Gray, generally regarded as a subgenus under Neritina Lamarek (=Neritella Humphrey). It has a much smaller and less prominent spire, however, and a more convex and broader inner lip than the type of that group, and also wants the crenulations of the inner lip seen in the same. In its limpet-like form, tumid, greatly developed inner lip, and minutely coiled apex, it approaches Velates Montfort, and I am not quite sure that it would not be nearer right to call it Velates bellatula. Still it differs from the typical form of that genus in having its apex depressed to the posterior margin, instead of being elevated and nearly central, while the margin of its inner lip wants the distinct denticulations seen in that of that shell.

"Of course if Humphrey's catalogue genera are to be adopted on account of priority of date over those of Lamarck and others that were accompanied by diagnoses, the name of this shell, supposing the view here adopted in regard to its affinities to be correct, would become Neri. tella (Dostia) bellatula.

"Locality and position.-Carleton's coal mine, Coalville, Utah."

\section{NERITiNa (VELATELLA) CARDITOIDES Meek.}

Plate 12, fig. 7 a.

Neritina (Dostia?) carditoides Meek, 1873, An. Rep. U. S. Geol. Sur. Terr, for 1872, p. 499.

This form certainly belongs to the same type as the preceding, and there appears to be some ground for suspecting them to belong to one and the same species. All the specimens in the collection of both this and the other form are more or less imperfect, however, and I therefore prefer to treat them as separate species in this article, as Mr. Meek has done. The following is his diagnosis of this form:

"Shell attaining a moderately large size, broad, oval and depressed in form, apex posterior and nearly or quite depressed to the margin, apparently subspiral; inner lip very broad or forming more than half the under side, rather thick, smooth, and nearly flat, or somewhat convex, with its straight inner margin sharp and without teeth or crenulations;

* "Of course the colors mentioned are not known to present the same tints in the fossil shells that ornamented them when the animal was alive." 
outer lip thick, very obscurely crenate within, and apparently continuous with the margins of the inner one around behind; aperture transversely semicircular, and less than half the size of the under side of the shell. Surface ornamented by about fifteen simple, narrow, sharp, and subcrenate radiating costæ, separated by wider, rounded intermediate furrows; lines of growth distinct.

"Length about 0.87 inch; breadth, 0.70 inch; convexity, 0.35 inch.

"This is another curious form allied to the little species I have described under the name $N$. bellatula. When viewed from the dorsal side, as seen lying with the aperture downward, its form and strong radiating costæ give it much the appearance of the left valve of a Cardita or Cardium. The only specimen of it in the collection has its apex and posterior and lateral margins broken away, and its broad, smooth, shelf-like inner lips broken by pressure inward. Still, however, it gives a tolerably correct idea of the characters of the shell. In several respects it agrees with Velates, and possibly might without impropriety be called Velates carditoides. I suspect, however, that when better specimens can be examined it will be found tpyical of an undescribed section, including also the little species $N$. bellatula. If so, I would propose for the group the name Velatella. I know of no nearly allied type.

"Locality and position.-Carleton's coal-mine, Coalville, Utah. Cretaceous."

\title{
Genus EUSPIRA Agassiz.
}

\section{EUSPIRA UTAHENSIS White.}

This species was erroneously mentioned and described in the An. Rep. U. S. Geol. Sur. Terr. for 1877, under the name of $E$. coalvillensis. (See pages 237, 253, and 310; and also explanation of plate 4 of that volume.

\section{Genus TESSAROLAX Gabb.}

\section{Tessarolax HitziI (sp. nov.)}

\author{
Plate 15, fig. $2 a$.
}

Shell rather small; length of the spire about one-half that of the whole body of the shell exclusive of the canals; its apex a little blunted; volutions about five, that of the body bearing two revolving angles or narrow ridges which apparently end respectively upon the two slender spines of the outer lip; the whole spire covered with a layer of callus which obscures the sutures, and also the original surface of the volutions upon which there are apparently some revolving lines; outer lip bearing two long slender spines projecting from its border, each being grooved upon its under surface; the anterior labial spine directed outward and forward, and having near its middle a moderate enlargement, where it is also bent a little downward; the posterior labial spine gradually and uniformly tapering from base to point, directed outward and slightly curved backward; anterior canal long slender and spine like, flexed a little downward and to the left, its grooves being very narrow and linear; posterior canal also slender, its grooves being narrow and linear like that of the canal and the labial spines, extending from the aperture close alongside of the spire and projecting as a slender spine much beyond its apex, from which it gently curves to the right; the 
callus which covers the shell apparently little if any thickened upon the inner lip.

Length, from the base of the anterior canal to the apex of the spire, 19 millimeters; breadth of body-volution, exclusive of the aperture and outer lip, 9 millimeters; breadth, inclucing the aperture and outer lip, but excluding the labial spines, 14 millimeters.

The apices of both the anterior and posterior canals, and also of the posterior labial spine are broken off in the type specimen, but the anterior spine is entire, and the others are evidently nearly so, the anterior spine being 19 millimeters in length. The portion remaining of the posterior canal projects 5 millimeters beyond the apex of the spire, and that of the anterior canal projects 7 millimeters beyond the anterior border of the aperture. The anterior and posterior canal-spines and the posterior labial spine are each about $1 \frac{1}{2}$-millimeters in diameter, the anterior labial spine being about double that width at its mid-length where it is broadest.

This shell appears to have borne no varices or tubercles upon the callus-covering of the body-volution such as characterizes the type species of Tessarolax. Mr. Gabb appears to have regarded that feature as of generic importance, but I am disposed to consider it as only a specific character.

Perhaps no family of shells with which the paleontologist has to deal is more in need of careful revision than the Aporrhaidæ. Of the various genera and subgenera which have been proposed by different authors, some doubtless ought to be rejected, but that all should be discarded and the species all referred to Aporrhais, as is the custom of some authors, appears to be unadvisable. The covering of the whole shell with callus, as in Lispodesthes and Tessarolax seems necessarily to have been correlated with characters in the animal which would separate it generally from such forms as those which American authors generally refer to Anchura. The character of the anterior and posterior canals and labial spines of such forms as Tessarolax distorta and T. hitzii, seem also sufficient to separate them generically from Anchura, Lispodesthes, and other proposed genera of the Aporrhaidæ.

Tessarolax and Lispodesthes are both entirely callus-covered forms, and both are yet known only in Cretaceous strata; to which also other forms of the Aporrhaidæ seem to be restricted. Aside from zodlogical considerations, perhaps the strongest conventional reason for retaining the generic distinctions which have been recognized in at least a part of the Cretaceous forms of this family lies in the fact that they seem to be characteristic of the Cretaceous period.

Position and locality.- The species here described was obtained, according to the records of the United States National Mruseum, by Dr. R. B. Hitz, from the Fort Pierre Cretaceous Group, at Fort Shaw, near Muscleshell River, Montana. The specific name is given in his honor.

\section{Genus LISPODESTHES White.}

\section{LISPODESTHES? OBSCURATA (sp. nov.) \\ Plate 11, figs. $7 a$ and $b$.}

Shell subfusiform; spire rather short, tapering with nearly straight sides to the apex; volutions six or seven, convex; last or body volution rather large, without a revolving angle; suture impressed; outer lip or wing comparatively small, as indicated by all the known specimens, its 
outer border bearing a slender, tongue-like projection, which extends outward and forward from the anterior portion of the wing margin. The posterior portion of the wing is not accurately known, as all the specimens are more or less imperfect in that respect, but it seems not to have been prolonged backward in the form of a pointed projection, as it is in Anchura and the typical forms of Lispodesthes. That portion of the wing apparently formed a broad, short, blunt projection, which was broadly concave beneath, posteriorly; but there is in our examples no appearance of a true posterior canal such as characterizes the typical forms of Lispodesthes. Anterior canal comparatively broad and long; beak moderately broad, rounded at the anterior end, but with a shorter curve at the left side than at the right. Shell (the callus being removed) thin and delicate, its whole surface marked by very fine lines of growth, and also by very fine crowded raised revolving lines, which are a little more conspicuous than the former, but they all need a lens to render them distinctly visible. There is also a narrow, square shouldering of the distal border of the volutions of the spire at the suture.

Length, from the apex to the end of the anterior canal, 37 millimeters; breadth, across the body volution and wing, 18 milimeters.

Fig. 7 a, plate 11, represents a specimen with the entire callus removed, but with the shell proper remaining. Fig. $7 b$, of the same plate represents an imperfect example with the spire, and a portion of the body volution still covered with callus. The indications furnished by the other specimens of the collection, all of which are imperfect, are that the whole shell, when adult, was covered with callus, as in Lispodesthes White and Calyptraphorus Conrad. This shell certainly does not belong to the latter genus, and it also presents some important differences from the typical forms of Lispodesthes. For example, it has evidently no posterior canal hollowed out of the callus and extending along the spire nearly or quite to the apex, as in the latter genus. This seems to be an important difference. A lesser one is the apparent absence of a falciform projection of the posterior portion of the wing. It agrees with Lispodesthes in general form, in the callus-covering of the whole shell, and the anterior tongue-like projection from the wing. I therefore refer it provisionally to that genus, notwithstanding the differences before mentioned, because no other one of the numerons established genera of the A porrhaidæ will receive it; and because the examples yet known will not warrant a full generic diagnosis. For some general remarks on related genera, see paragraph following description of the preceding species.

Position and locality.-The only specimens yet known, which are certainly referable to this species, were collected by Dr. Hayden at "Dotlson's Ranch, near Pueblo, Colorado"; apparently from strata of the Fox Hills Group. A few imperfect examples found in the Cretaceous strata at Bear River City, Southern Wyoming, perhaps belong to this species, but they were found only in the condition of casts of the internal cavity.

\section{Genus TURRITELLA Lamarck.}

\section{TURRITELLA SPIRONEMA Meek.}

Plate 12, fig. $3 a$.

Turritella spironema Meek, 1873, An. Rep. U. S. Geol. Sur. Terr. for 1872, p. 503.

"Shell rather small, or scarcely attaining a medium size, elongateconical; volutions about fifteen, increasing very gradually in size, mod- 
erately convex, last one rounded in the middle; aperture apparently ovate; columella rather regularly arcuate. Surface ornamented by squarish, rather regular, revolving, thread-like lines, with nearly equal furrows between; about five to seven or eight of the lines and furrows are seen on each of the turns of the spire, and nearly twice as many on the body-whorl, where those below the middle become abruptly smaller and more crowded than those above; lines of growth obscure and gently arched in crossing the volution; suture moderately distinct.

"Length of the largest specimen found, 0.82 inch; breadth of bodyvolution, 0.23 inch; spire nearly regular, divergence of its slopes, about $17^{\circ}$.

"There is a slightly polished appearance of the surface of this shell that is not often seen in true Turritella, and gives origin to some doubts whether it may not belong to some group allied to Aclis or Menestho. As in size and general appearance, however, it seems to correspond more nearly to Turritella, I have concluded to refer it provisionally to that genus until better specimens can be obtained for study and comparison. None of those yet seen show satisfactorily the exact form of the aperture.

"Locality and position.-Carleton's coal-mine, Coalville, Utah. Cretaceous."

The foregoing is Mr. Meek's description of, and remarks upon, this species, to which no material addition can be made, because no other examples have ever been discovered. As already shown, in remarks following the description of Cyrena carletoni on a previous page, and also by Mr. Meek (loc. cit.), the estuary Cretaceous fauna at Coalville, Utah, contains some forms that must be regarded as marine, as well as some that we must necessarily regard as of fresh-water origin. It is also worthy of remark that some of the species of that fauna, whose living representatives usually characterize brackish waters, have congeneric representatives in the marine Cretaceous strata of the same neighborhood. In this remark more especial reference is made to the Neritidæ, but it may be suggested that the fauna of those strata was to some extent affected or modified by its proximity to the then existing coast. On the other hand, it is not quite so easy to account for the existence of so many forms that are regarded as wholly marine among the estuary forms, unless we assume that all the fresh-water and a part of the brackish-water forms were drifted from fresh and less saline waters to those in which the deposit was made.

\section{Genus EULIMELLA Forbes.}

\section{EULTMELLA? CHRYSALLIS Meek.}

Plate 12, fig. $4 a$.

Eulima ? chrysallis Meek, 1873, An. Rep. U. S. Geol. Sur. Terr. for 1872, p. 506.

No other examples of either this or the following species than those collected by Mr. Meek have ever been discovered. Therefore no material addition can be made to his description, which is as follows:

"Shell small, elongate-subconoid, or subfusiform; spire-conical; volutions about eight, flattened nearly to the slope of the spire; suture nearly linear; aperture subovate; inner lip a little reflected and moderately arched; outer lip unknown; surface smooth.

"Length about 0.29 inch; breadth 0.12 inch.

"I am by no means sure that this is a true Eulima, not having seen 
any specimen showing very clearly the form of the aperture or the nature of the outer lip. It has the general aspect of that genus, however, and may be placed there provisionally for the present until better specimens can be obtained for study. It will be at once distinguished from the last* by a less produced spire, less numerous volutions, and proportionally larger body-whorl.

"Locality and position.-Carleton's coal-mine, near Coalville, Utah. Cretaceous."

Among a considerable number of examples of the Eulima? funicula of Meek, which have been collected from the marine Cretaceous strata both at Coalville and at the North Fork of Virgin River, Utah, are some which indicate a nearer relation to Eulimella than to Eulima. I have, consequently, in other writings, $\dagger$ referred that species provisionally to the former rather than to the latter genus. The two species from the estuary beds at Coalville, described and figured in this article, seem to be congeneric with $E$. funicula, and I therefore refer these also to Eulimella, with similar doubt.

\section{EULTMELla ? inCONSPICUA Meek.}

Plate 12, fig. 5 a.

Eulima? inconspicua Meek, 1873, An. Rep. U. S. Geol. Sur. Terr. for 1872, p. 507.

"Shell small, conoid-subovate; spire conical; volutions eight or nine, a little convex, compactly coiled; suture distinct; aperture apparently subovate; surface smooth.

"Length 0.17 inch; breadth 0.07 inch; spire with straight slope that diverges at an angle of about $22^{\circ}$.

"This is another form that I only refer with great doubt to Eulima, the specimen not being in a condition to show the exact form and nature of the aperture. It will be readily distinguished-from the last by its more convex volutions, proportionally shorter spire, and more expanded body-whorl. It is probably not a Eulima.

"Locality and position.-Carleton's coal-mine, near Coalville, Utah. Cretaceous."

See remarks following the description of the preceding species.

\section{Genus VALVATA Müller.}

\section{Valvata nana Meek.}

Plate 12, figs. 17, $a$ and $b$.

Valvata nana Meek, 1873, An. Rep. U. S. Geol. Sur. Terr., for 1872, p. 507.

This also is one of the species embraced in the estuary fauna of the Cretaceous strata at Coalville, the only known examples of which were discovered by Mr. Meek. It seems to be a true Valvata, and as such its discovery adds another fact to those already known concerning the early differentiation of certain molluscan types which characterize more recent fossil, as well as existing, fresh-water faunæ. The following is Mr. Meek's description :

"Shell small, depressed subglobose, or subdiscoidal; spire depressed; volutions three and a half, rounded, suture deep; umbilicus compara-

* E. funicula, which is figured on plate 9, Cont. Pal. No. 1, An. Rep. for 1877.

+ See Expl. and Sur. West of the 100th Merid. (Wheeler), vol. iv, p. 197, pl. xviii, fig.

6. Also, An. Rep. U. S. Geol. Sur. Terr. for 1877, p. 316, pl. 9, fig. 10. 3 H 
tively small; aperture rounded-suboval; surface nearly smooth, or only showing fine, obscure lines of growth under a magnifier.

"Breadth of largest specimen, 0.12 inch; height about 0.08 inch.

"Compared with V. subumbilicata M. \& H., from the Tertiary lignites of the Upper Missouri country, this little shell will be readily distinguished by its smaller umbilicus, more prominent spire, and more oval aperture. It has also a smaller umbilicus and a less rounded aperture than the recent $V$. sincera. Its spire is more depressed, its aperture more oval, and umbilicus rather smaller than the living species, V. tricarinata, var. simplex Say.

"Locality and position.-Carleton's coal-mine, Coalville, Jtah. Cretaceous."

\section{Genus FUSUS Lamarck.}

\section{Fusus? utahensis Meek.}

Plate 12, fig. $2 a$.

Fusus (Neptunea) utahensis Meek, 1873, An. Rep. U. S. Geol. Sur. Terr., for 1872, p. 505.

"Shell of moderate size, short fusiform; spire rather depressed, conical; volutions four; those of the spire a little convex; last one large and ventricose, rounded or very slightly flattened around the middle, and contracted rather rapidly below into a narrow canal that is longer than the spire, and more or less bent to the left; aperture rhombic, angular above and narrowed and prolonged into the canal below surface, as determined from a cast in sandstone, with obscure vertical ridges, about twelve of which may be counted on the penultimate volution, while on the last or body-whorl they become nearly or quite obsolete. Revolving lines probably also marked the surface of the shell, though no traces of anything of the kind are seen on the cast, except a shallow furrow above the suture on the volutions of the spire.

"Length, including canal, about 1.90 inches; breadth, 0.91 inch ; angle of spire, about $67 \circ$.

"As in the last," we have not the means of determining the generic characters of this species with any degree of certainty, and merely place it provisionally in the genus Fusus with Neptunea in parenthesis, to indicate that it may be found to belong to that group. It is a rather decidedly larger shell than the last ( $F$. gabbi), with a distinctly less elevated spire, and more obscure vertical ribs or varices.

"Locality and position.-Coalville, Utah; from 'Chalk Hill,' considerably above the heavy bed of coal mined there. Cretaceous."

Only a single example, the one figured on plate 12, was found among the collections obtained and studied by Mr. Meek, but this was labeled in his handwriting, and is evidently his type. It is a well-marked species, but it is known only by imperfect casts in sandstone.

\section{Genus FASCIOLARIA Lamarck.}

\section{Subgenus PIESTOCHEILUS Meek.}

\section{Fasciolaria (PIESTOCheilus) alleni (sp. nov.)}

Plate 12, fig. 1 a.

Shell slender, fusiform; spire, from the distal end of the aperture to the apex, one-third longer than the aperture; volutions about eight,

* F. gabbi, figured on plate 9 of Contributions to Paleontology No. 1, published in the Annual Report of this Survey for 1877. 
moderately convex, increasing uniformly in size; last volution not expanded disproportionately with the other volutions, tapering gradually forward into a moderately long and somewhat stout beak, which is a little deflected to the left; aperture narrow, lance-ovate in outline, acutely angular at its distal end, and ending anteriorly in the canal formed by the beak before mentioned; columella nearly straight, its folds not seen; outer lip gently sinuous, its general direction approximately parallel with the axis of the shell. Surface, especially that of the last volution, marked by strong lines of growth and also by faint revolving lines. The distal border of the volutions is also marked by a ridge or narrow shoulder adjacent to the suture, which has the appearance of consisting of one or more strongly raised revolving lines.

Length, 80 millimeters; breadth of last volution, 20 millimeters; length of aperture, including canal, 33 millimeters.

This species is closely related to $F$. $(P$.) culbertsoni Meek \& Hayden, but it differs in the much greater proportionate length of the spire, and in the elevation or shouldering of the distal border of the volutions, upon the proximal side of the suture.

Position and locality.-Cretaceous strata, valley of Yellowstone River, Montana, where it was collected by Mr. J. A. Allen, and in whose honor the specifie name is given.

\section{CEPHALOPODA.}

\section{Genus PRIONOCYCLUS* Meek.}

\section{Prionocyolus wromingensis Meek.}

Plate 15, figs. $1 a, b, c, d$, and $e$.

Ammonites (Pleuroceras) serrato-carinatus Meek, 1871, An. Rep. U. S. Geol. Sur. Terr. for 1870, p. 298.

Prionocychus wyomingensis Meek, 1876, U. S. Geol. Sur. Terr., vol. ix, p. 452.

Shell discoidal; umbilicus broad; rolutions very slightly embracing or sometimes merely in contact, comparatively slender, the vertical diameter of the outer volutions about one-third greater than the transverse diameter, but this difference between these dimensions of the inner volutions is greater than that of the outer; outer sides of the volutions flattened, convex, and abruptly rounded to both the peripheral and umbilical sides, the former side bearing along the median line a sharply. raised, strong earina, the edge of which is studded with more or less distinct small tubercles or serrations; sides of the volutions marked with numerous transverse sharply-raised costæ, which become obsolete upor the umbilical side, and upon reaching the peripheral side they all bend abruptly forward, and become obsolete before quite reaching the carina. These costæ are small and of nearly uniform size in very young examples, but they gradually increase in size with the growth of the shell, and a part of them become stronger than the others, and usually every third or fourth costa is strengthened towards its inner end, and occasionally towards its outer end also, by the coalescence there with the adjacent costa in front of it.

At the points of the coalescence and also upon some others of the larger costæ, more or less distinct but somewhat irregular tubercles are

\footnotetext{
* For generic diagnosis of this genus and a subgenus Prionotropis, see U. S. Geol. Sur. Terr., vol. ix, pp. 452-455.
} 
formed in rows, one being near the outer and the other near the inner border of the side of the volution. Upon the outer volution of very large shells the stronger costæ become still stronger, the intermediate ones comparatively less distinct, and the plain space at each side of the carina becomes a narrow depression. Septa having complex sutures, showing one peripheral and two lateral lobes, besides the crenulations of the auxiliary series and the secondary lobe of the outer lateral cell; also two full lateral cells, one being large and double and the other small; peripheral lobe narrow, rudely wedge-shaped, the point being directed backward; first lateral cell broad, and made almost double by the presence of a secondary lobe at its middle; median or first lateral lobe large, but not so broad as the first lateral cell, including both its divisions; second lateral cell somewhat smaller than either of the divisions of the first lateral cell; second or inner lateral lobe smaller than second lateral cell, and scarcely larger than the secondary lobe at the middle of the first lateral cell; third or inner lateral cell not distinct as such except upon the side adjacent to the second lateral lobe, its outer end being continuous with the auxiliary series, which consists of an irregular crenulated suture, extendling not only to the next volution within, but also to the inner median line, the latter part of it, however, being covered by the embraced periphery of the next volution within.

The borders of both lobes and cells are studded with short branches, serations, and crenulations as shown in fig. $1 e$, plate 15. The first lateral cell might with propriety be regarded as two separate cells, and its secondary lobe as a small primary one, but I have followed this method of their description, because it is the one adopted by Mr. Meek, the anthor of the genus, in his description of species under it. The siphuncle is of ordinary size, and is placed at the base of the peripheral carina, having a part of its diameter projecting within the base of the carina, which it so weakens that the latter is usually broken off in the imbedding rock.

This shell often reached a large size, some of the examples indicating a diameter of coil little if any less than twenty-five centimeters.

Although Mr. Meek made this species the type of his genus Prionocycius, he never either described or figured it. The identity of the specimens upon which this description is based, and a part of which are repsented by figures upon plate 15 is, however, unquestionable, because he placed them in my hands as his types before his death. The specimens are somewhat numerous, but none of them are in a very satisfactory condition of preservation. No attempt will now be made to discuss the relation of this type to other proposed genera of Ammonitidæ, the principal object being, so far as practicable, to illustrate all the forms among the collections of the survey that have hitherto been described but not figured.

Position and locality.-Cretaceous strata; probably of the Colorado Group; Valley of Medicine Bow River, Wyoming. 


\section{ARTICULATA. CRUSTACEA.}

\section{Genus PARAMITHRAX Milne-Edwards.}

\section{Paramithrax ? WALKeRI Whitfield.}

Plate 16, fig. $1 a$; and Plate 17, fig. $1 a$.

Both description and figures of this Brachyuran have been furnished by Prof. R. P. Whitfield for this report, for which he is sole authority. It is an exceedingly interesting addition to our knowledge of the Cretaceous Crustacea; and especially so because remains of this class are so rare in American Cretaceous rocks.

"This species is represented only by the claw and part of the penultimate joint of the right anterior limb. The specimen is of a short, rather compact and robust form, and somewhat triangular in transverse section. The length of the hand, from its articulation with the preceding joint to the base of the fixed mandible, bears the proportion to the height and thickness that seven does to five and four; the latter measurement being exclusive of the nodes. The mandibles, both fixed and movable, are distinctly round, without any flattening or carination; are gently and nearly equally curved throughout their length, and the articulating processes strong and robust. The hand is somewhat flattened on the inside and angular on the outer surface; the angulation being rather below the middle of the height, giving it the triangular form. The next preceding joint is only preserved in part; it is strong, obliquely ovate in form, and provided with a large flattened basal projection near the inferior articulation.

"Surface of the specimen, with the exception of the inner face of the mandible, marked by numerous strong spine-like nodes or tubercles, which have probably been spines on the surface of the shell (the specimen being an internal cast). These nodes are arranged in longitudinal lines on the outside of the claw, and partly so on the inside; but on the latter there is also a line of large nodes extending obliquely downward from the upper edge, parallel to the margin of the socket of the movable mandible, and at a short distance from it, and continuing upon the mandible. The preceding joint is also marked by lines of strong nodes; a double transverse line on the inside parallel to the anterior margin, but divided from it by a broad, rounded channel, and a single line of stronger nodes on the outside. The flattened area forming the basal projection of the joint is also bordered by nodes.

"The specimen, being an internal cast only, does not furnish the exact features of the shell itself, and as there is only a part of the limb known it is difficult to determine the generic characters in a satisfactory manner. There would appear to be but little reason to doubt, from its spiny character and the round claws, its relations to the group commonly called spider-crabs. Still there are some features which seem to differ from, those of the generality of the species of that group, and it is therefore with some hesitation that I have referred it to the family Maiadæ, and still more doubtfully to the genus Paramithrax; but I am not able to find any genus of strictly fossil crustaceans to which it 
seems so nearly allied. The specimen is of interest on account of its large size, and also as being the first of this group of crustaceans yet recognized from the Cretaceous formations of this country.

"Locality and formation.-The specimen here described and figured was obtained from the Cretaceous rocks near San Antonio, Texas, by Mrs. N. S. Walker, of that place, and in honor of whom the specific name is given."

\section{APPENDIX TO CONTRIBUTIONS TO INVERTEBRATE PALEONTOL- OGY, NO. 2.}

The late Dr. B. F. Shumard had, before his death, prepared drawings of a part of the fossils which he had from time to time previously published in the Trans. Saint Louis Acad. Sci. and the Proc. Bost. Soc. Nat. Hist. These drawings were never published by him, but he procured photographic eopies of a part of them for the late Mr. F. B. Meek. The last-named gentleman, at the time of his death, left these copies in possession of this Survey. A few of them were reproduced among the illustrations of Cretaceous fossils in the annual report of this Survey for 1877. It is deemed of importance that the public should have, as far as possible, the means for identifying the species that have been described by Dr. Shumard, and therefore all the remaining figures that are available, as just stated, which represent Cretaceous species, are reproduced in this report. All the figures on plate 18 are thus reproduced, besides one of those on plate 16 .

It is not deemed expedient at this time to either republish Dr. Shumard's descriptions of these fossils, or to enter into any discussion of the subjects which they may suggest. Therefore, only a list of the names he gave them will be here given, together with references to the figures and to the places where the descriptions are published.

Cidaris HEMIGRaNosus Shumard.

Plate 18, figs. $2 a$ and $b$.

For description see Trans. Saint Louis Acad. Sci., vol. i, p. 609.

Gervillia Gregaria Shumard.

Plate 18, fig. $3 a$.

For description see Trans. Saint Louis Acad. Sci., vol. i, p. 606

Nucula Bellastriata Shumard.

Plate 18 , figs. $5 a, b$, and $c$.

For description see Proc. Bost. Soc. Nat. Hist., vol. viii, p. 202.

Nugula HAYdeni Shamard.

Plate 18, figs. $6 a$ and $b$.

For description see Trans. Saint Louis Acad. Sci., vol, i, p. 602. 
Cardium choctawense Shumard.

Plate 18, figs. $7 a, b$, and $c$.

For description see Trans. Saint Louis Acad. Sci., vol, i, p. 599.

Cytheria lamarensis Shumard.

Plate 18, figs. $4 a$ and $b$.

For description see Trans. Saint Louis Acad. Sci., vol. i, p. 600. Ancyloceras annulatum Shumard.

Plate 18, figs. $10 a$ and $b$.

For description see Trans. Saint Louis Acad. Sci., vol. i, p. 595.

SCAPHITES VERMICULUS Shamard.

Plate 18, fig. 8 a.

For description see Trans. Saint Louis Acad. Sci., vol. i, p. 594. AMMONITES GRAYSONENSIS Shumard. Plate 18, figs. $9 a$ and $b$.

For description see Trans. Saint Louis Acad. Sci., vol. i, p. 593. Ammonites swallovin Shumard.

Plate 18, fig. 1 a.

For description see Trans. Saint Louis Acad. Sci., vol. i, p. 591. See also Expl. and Sur. West of the 100th Meridian, vol. iv, p. 202, pl. XX, fig. $1 a, b$, and $c$. 


Fig. 1. PinNa lakesi.

$a$. Left side view; reduced to one-half diameter.

$b$. Transverse section of the same.

Fig. 2. Ostrea soleniscus

a. Upper valve of small example; natural size.

$b$. Portion of the upper valve of another example, showing by the lines of growth the gradual change from a rounded to an elongate form.

Fig. 3. VoJ'SElla (BRachydontes) MULTILINIGERA

a. View of left valve; natural size.

Fig. 4. Ostrea anomiomes

a. Lower valve; natural size.

b. Upper valve of another example.

Fig. 5. Barbatia barbatula

a. Right side view of an imperfect example; natural size.

Fig. 6. Pharella? pealei

a. Left side view of an internal cast; natural size.

$b$. Dorsal view of the same.

Fig. 7. Lispodesthes? OBSCURATA

a. Side view; natural size; showing the enveloping callus removed but the thin test remaining.

b. Similar view of another example, showing a portion of the callus remaining upon and covering the spire. 


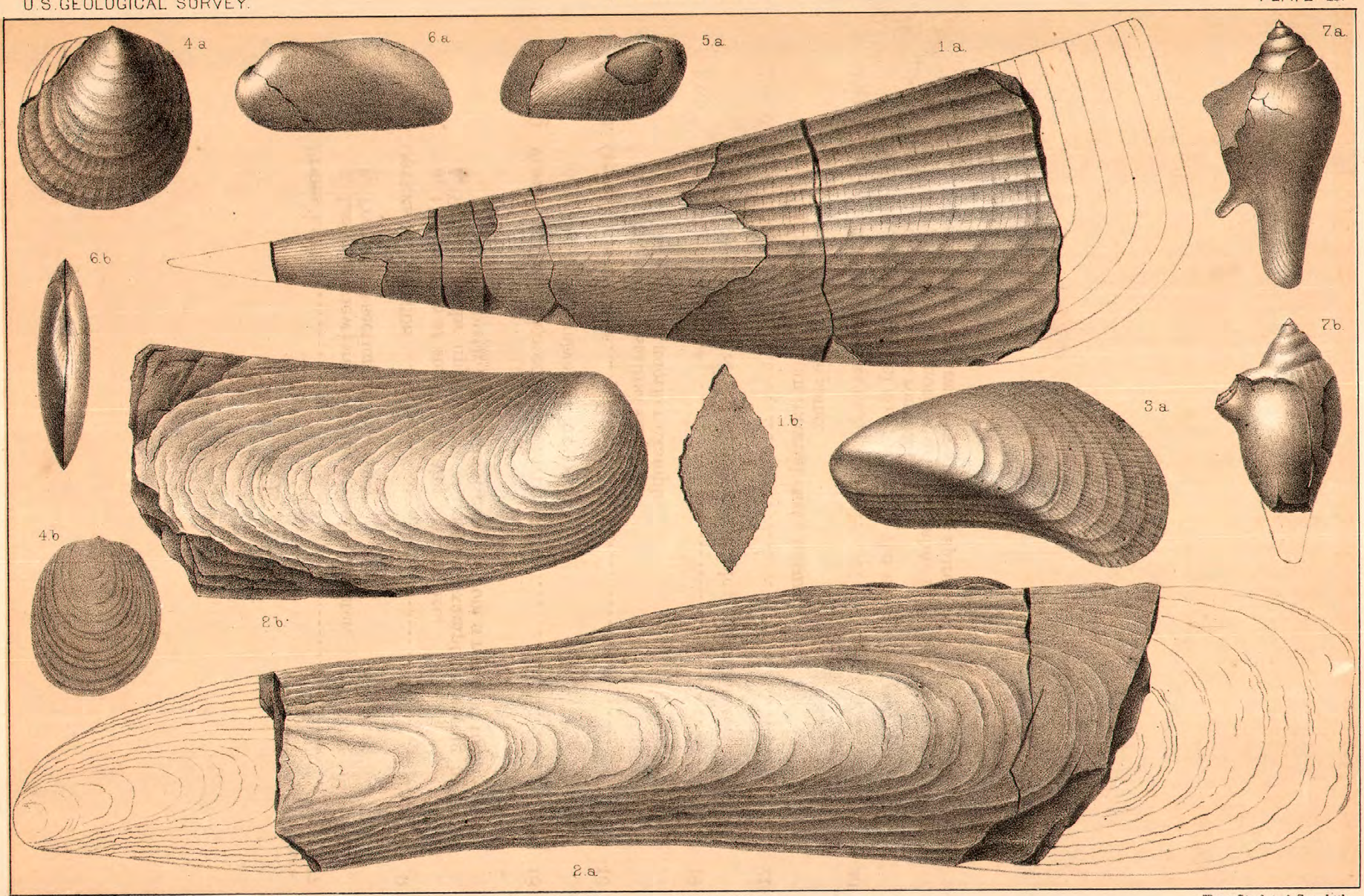






\section{PLATE 12.}

Fig. 1. Fasciolaria (Piestocheilus) alleni $\ldots \ldots \ldots \ldots \ldots \ldots \ldots \ldots \ldots \ldots . . . \ldots \ldots \ldots$

a. Side view; natural size.

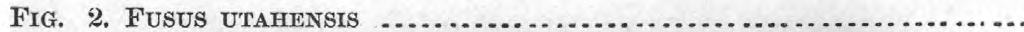

a. Side view of a natural cast in sandstone; natural size.

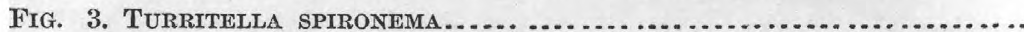

a. Side view; enlarged to two diameters.

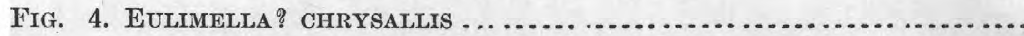

a. Side view; enlarged to four diameters.

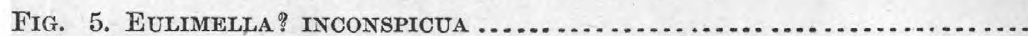

a. Side view; enlarged to four diameters.

Fig. 6. Melampus?

a. Side view of a cast in sandstone; natural size.

Fig. 7. Neritina (Velatella) Carditoides.

a. Dorsal view; natural size.

Fig. 8. Neritina (Velatella) bellatula.

a. Side view ; enlarged.

$b$. Dorsal view of another example; enlarged.

Fig. 9. Neritina PISIFormis................................

a. Side view; enlarged to two diameters.

b. Apical view of the same.

c. An example with a part of the outer volution broken away, showing the lip and its subdentate inner border.

Fig. 10. Neritina bannisteri

a. Side view ; natural size; showing pattern of color-marks.

$b$. Apical view of another example.

c. Apertural view of the same, showing the plain lip.

Fig. 11. Melampus? antiquUs.

a. Side view of a young example; enlarged to four diameters.

$b$. Apertural view of the same, showing armature of inner lip in the young state.

c. Summit of the spire; greatly enlarged; showing the reversed apex.

d. Fragment of a large example; natural size; showing full armature of inner lip of adult shell.

Fig. 12. OPHIODERMA? BRIDGERENSIS

a. View of Mr. Meek's type specimen; enlarged to $1 \frac{1}{2}$ diameters.

Fig. 13. Beaumontia? solitaria.

a. View of the cleft side of a fragment of a corallum; natural size.

$b$. Summit view of a group of corallites.

c. Side view of a section of a group of corallites; enlarged.

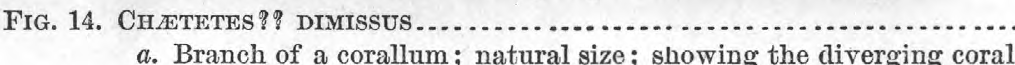
lites at broken ends of the branches.

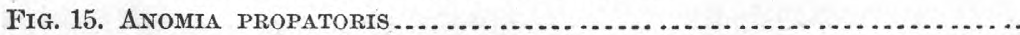

a. Exterior view of upper valve; natural size.

b. Lateral view of the same.

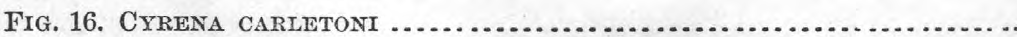

a. Left siçe view; natural size.

b. Dorsal view of the same.

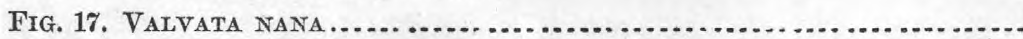

a. Lateral view; enlarged to five diameters.

$b$. Apical view of the same. 
CRETACEOUS.

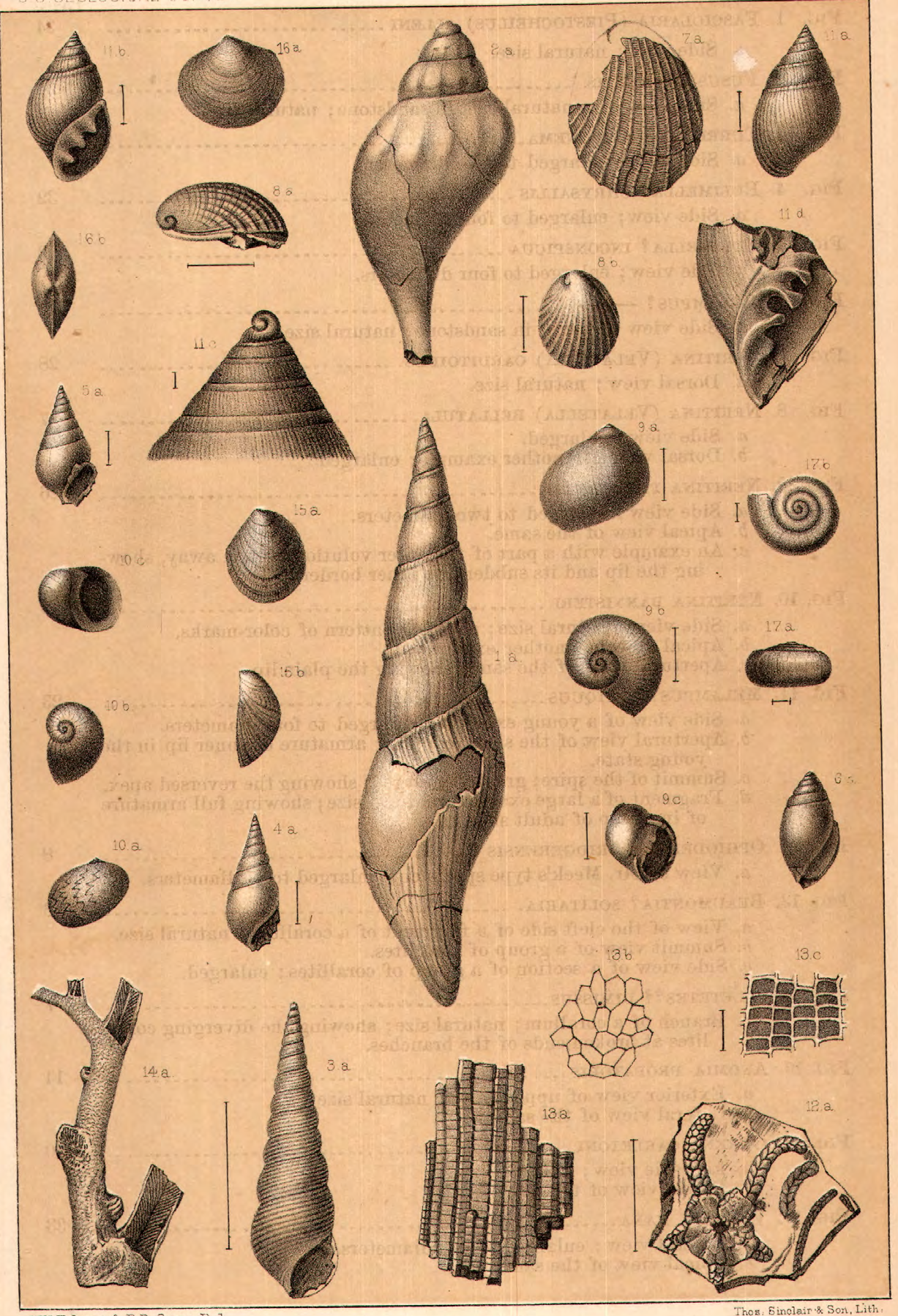

W.H.Holmes \& F. D Owen De] 




\section{PLATE 13.}

Fig. 1. Exogrra wincheln..

a. Interior view of the lower valve in its natural posture when adherent to a foreign body, the front side being much higher than the other; natural size.

b. View of the front side of the same, the right-hand border of the figure being that of the adherent surface of the valve.

c. Upper valve; exterior surface.

d Tnterior surface of the same. 


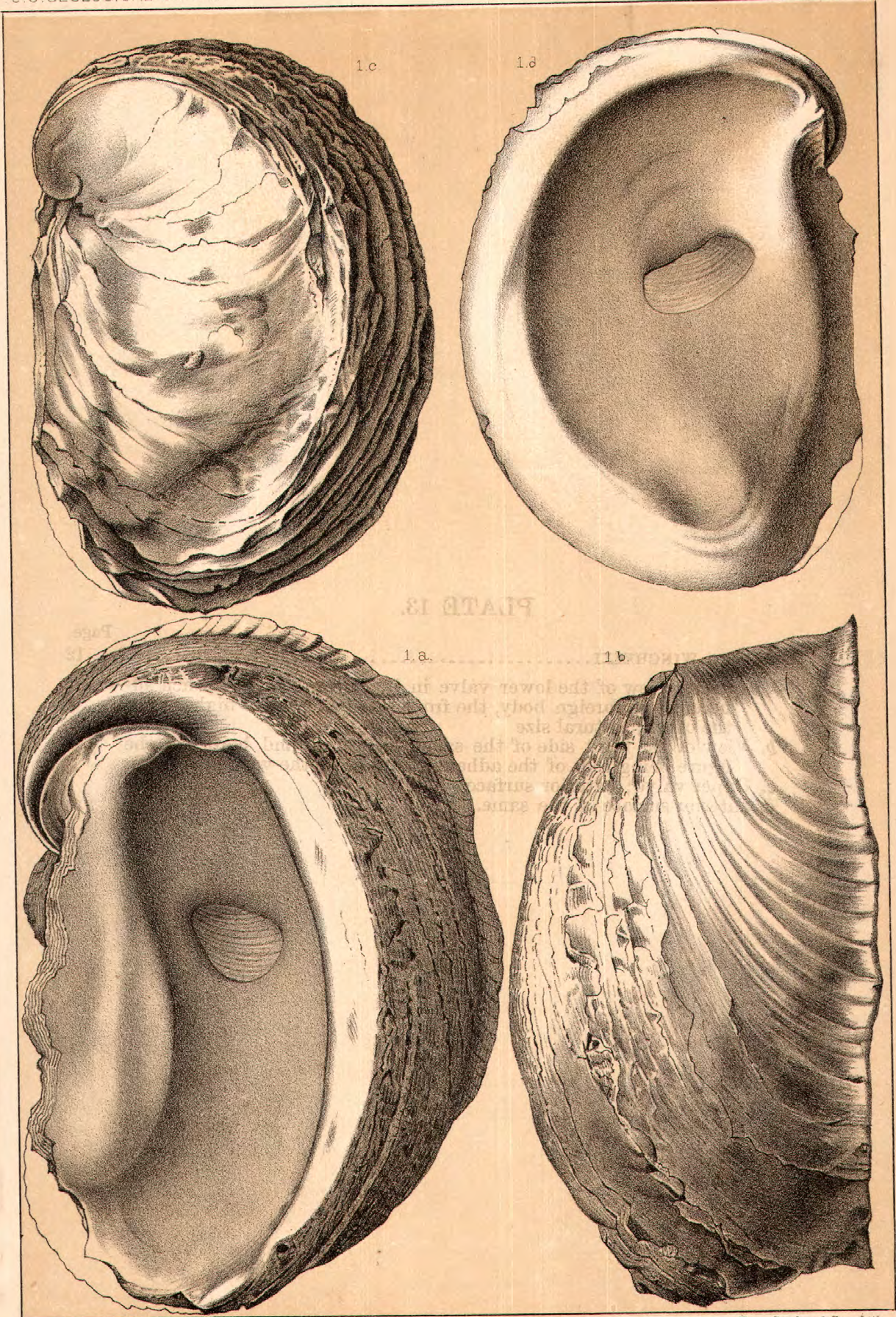

J.C.Mc Conne!l del. 


Frg. 1. Ostrea Blackir

a. Outer view of the lower valve of a large example; natural size.

b. Upper view of the same example.

For interior view of upper valve see plate 17.

Fig. 2. EXOGYRa ForNiculata

a. Outside view of lower valve; natural size.

b. Interior view of the same.

Fig. 3. Gervillia mudgeana

a. Left side view of a natural cast of the interior; natural size. b. Dorsal view of the same. 
CRETACEOUS.

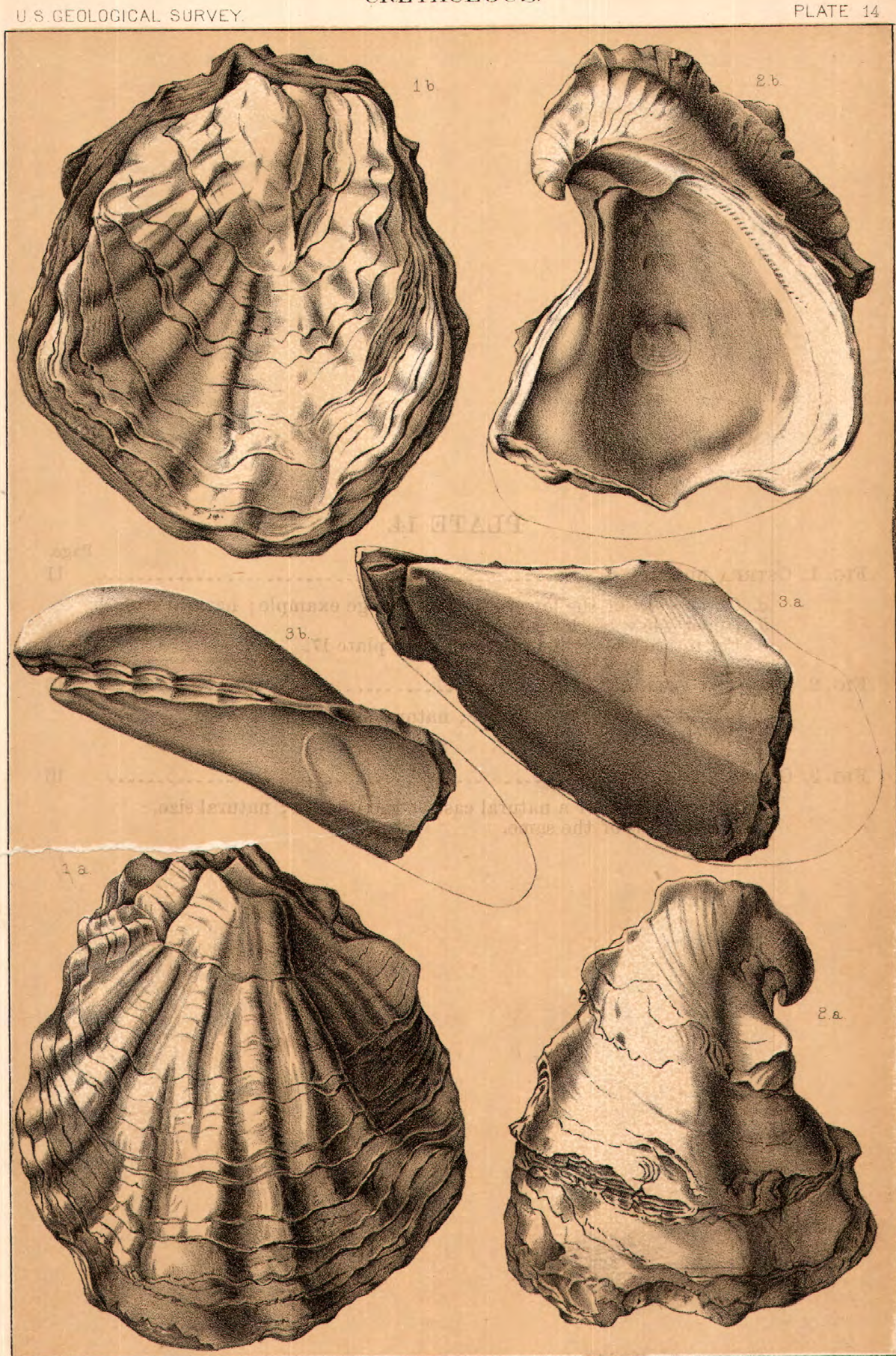

J.C.Me Connell del, 


Fig. 1. Prionocyclus wyomingensis

a. Fragment showing side view of portions of two volutions.

$\bar{b}$. Peripheral view of another example, the carina of which has been mostly broken away.

c. Side view of another example, showing the character of the earlier volutions.

d. Peripheral view of the same.

e. Septal suture; from fig. $1 \mathrm{~b}$. All of natural size.

Fig. 2 Tessarolax Hitzir ..........................................

a. Figure of a gutta-percha cast of the type specimen, showing the spire and the greater part of the under side of the shell, with its spines; natural size. 


\section{CRETACEOUS.}

U.S.GEOLOGICAL SURVEY.

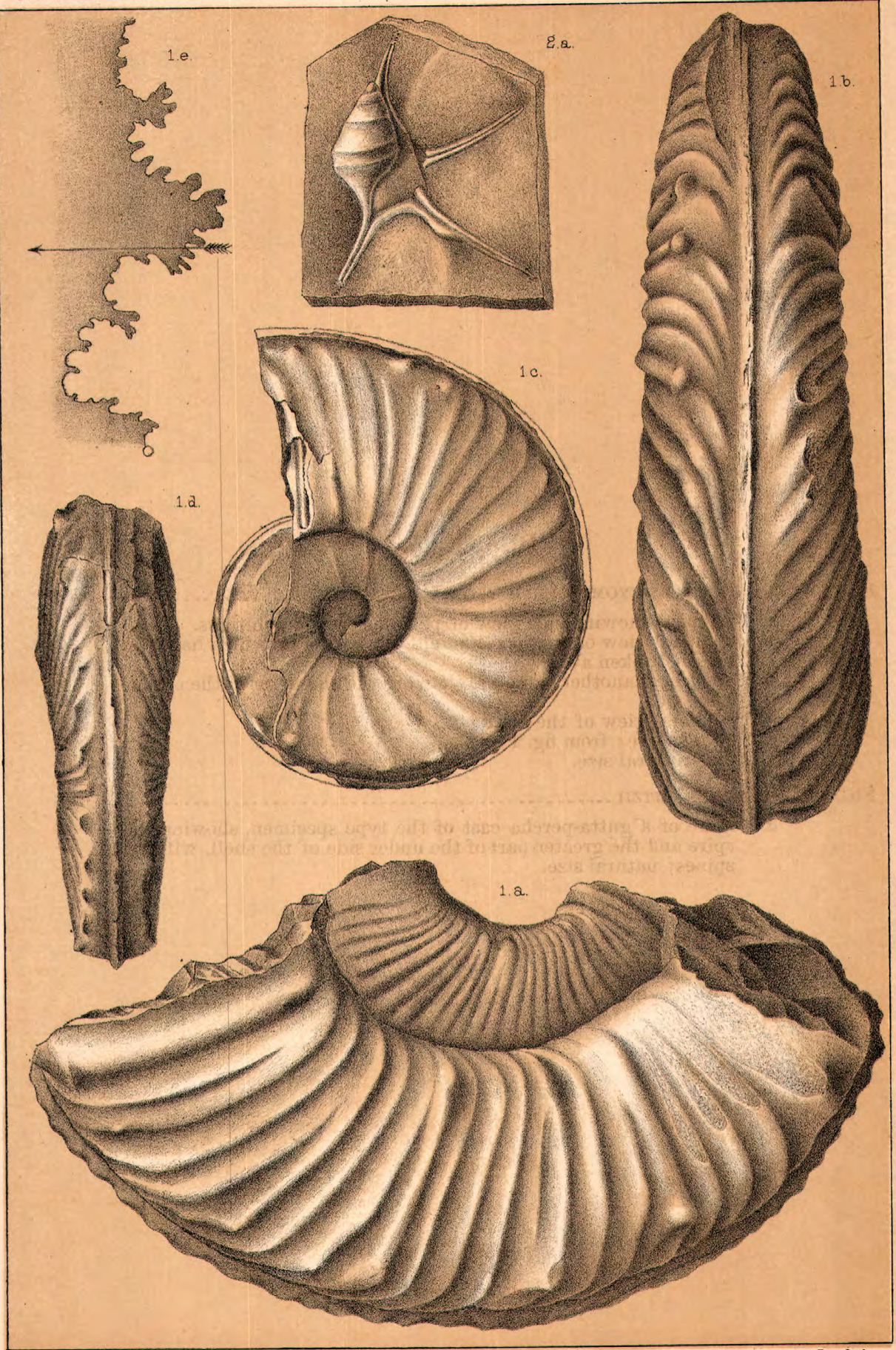




Fig. 1. Paramithrax walkeri.

a. Claw of right anterior limb; outer view; natural size.

$b$. Transverse section of fixed finger.

c. Transverse section of movable finger.

For opposite side view of the same see plate 17 .

Fig. 2. Pteria (Oxytoma) salinensis

a. Left side view of a natural cast of the interior; natural size.

$b$. Dorsal view of the same.

Nig. 3. TAPES hilgard

a. Copy of Dr. Shumard's original drawing.

b. Dorsal view of a smaller example from Bell County, Texas.

c. Left side view of another example from the same locality. All of natural size. 


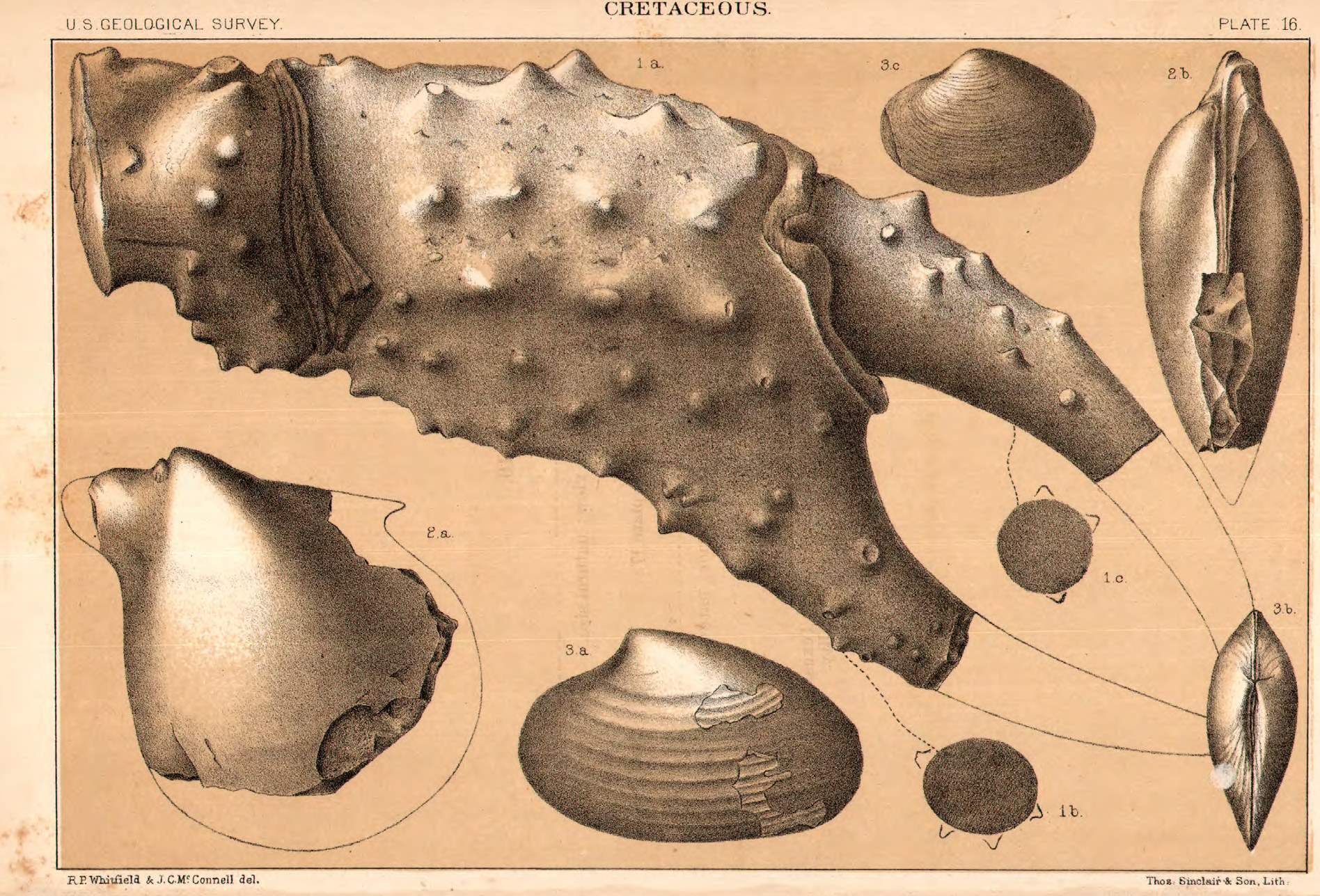




Fig. 1. Paramithrax walkeri

a. Claw of right anterior limb; inner view; natural size. For opposite view of the same see plate 16 .

Fig. 2. THRACIA MYAFORMIS

a. Right side view of a natural cast in chalky limestone; natural size.

b. Dorsal view of the same.

Fig. 3. Pteria?? stabilitatis.

a. View of one adult, and several smaller lower valves, attached to a fragment of the shell of an Inoceramus.

Fig. 4. PaChymya? Compacta

a. Right side view; natural size.

b. Dorsal view of the same.

Fig. 5. Ostrea BLACKII

a. Interior view of upper valve; natural size. For other figures of this species see plate 14. 


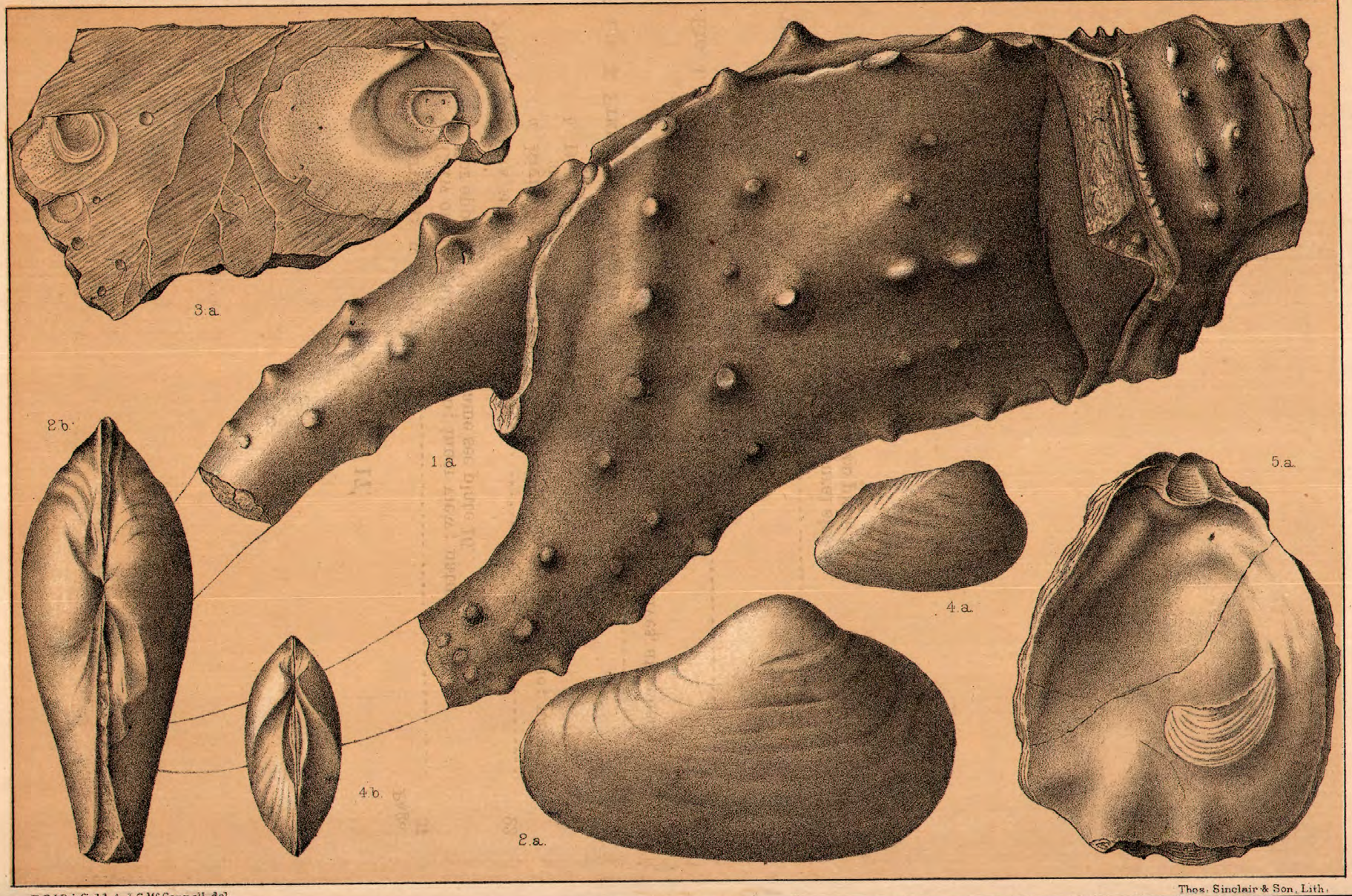






\section{PLATE 18.}

Fig. 1. Ammonites swallovir

a. Side view.

Fig. 2. Cidaris hemigranosus

a. Fragment showing body-plates and part of an ambulacral area.

$b$. Another fragment.

Fig. 3. Gervinlia gregaria

a. Left valve.

Fig. 4. Cytherea lamarensis.

a. Left side view.

$b$. Dorsal view of the same.

Fig. 5. Nucula bellastriata

a. Right side view.

$b$. Dorsal view of the same.

c. Dorsal view of a natural cast of the interior of a large example.

Fig. 6. NUCULA HAYDENI

a. Right side view.

b. Dorsal view of the same.

Fig. 7. Cardium choctawense

a. Side view.

$b$. Front view of the same.

c. Costæ and concentric lines enlarged.

Fig. 8. SCAPHITES Vermiculus.

a. Side view.

Fig. 9. AMmonites Graysonensis

a. Side view.

$b$. Peripheral view of the same.

Fig. 10. ANCYLOCERAS ANNULATUM.

a. Peripheral view of a fragment.

$b$. Side view of the same. 
CRETACEOUS.

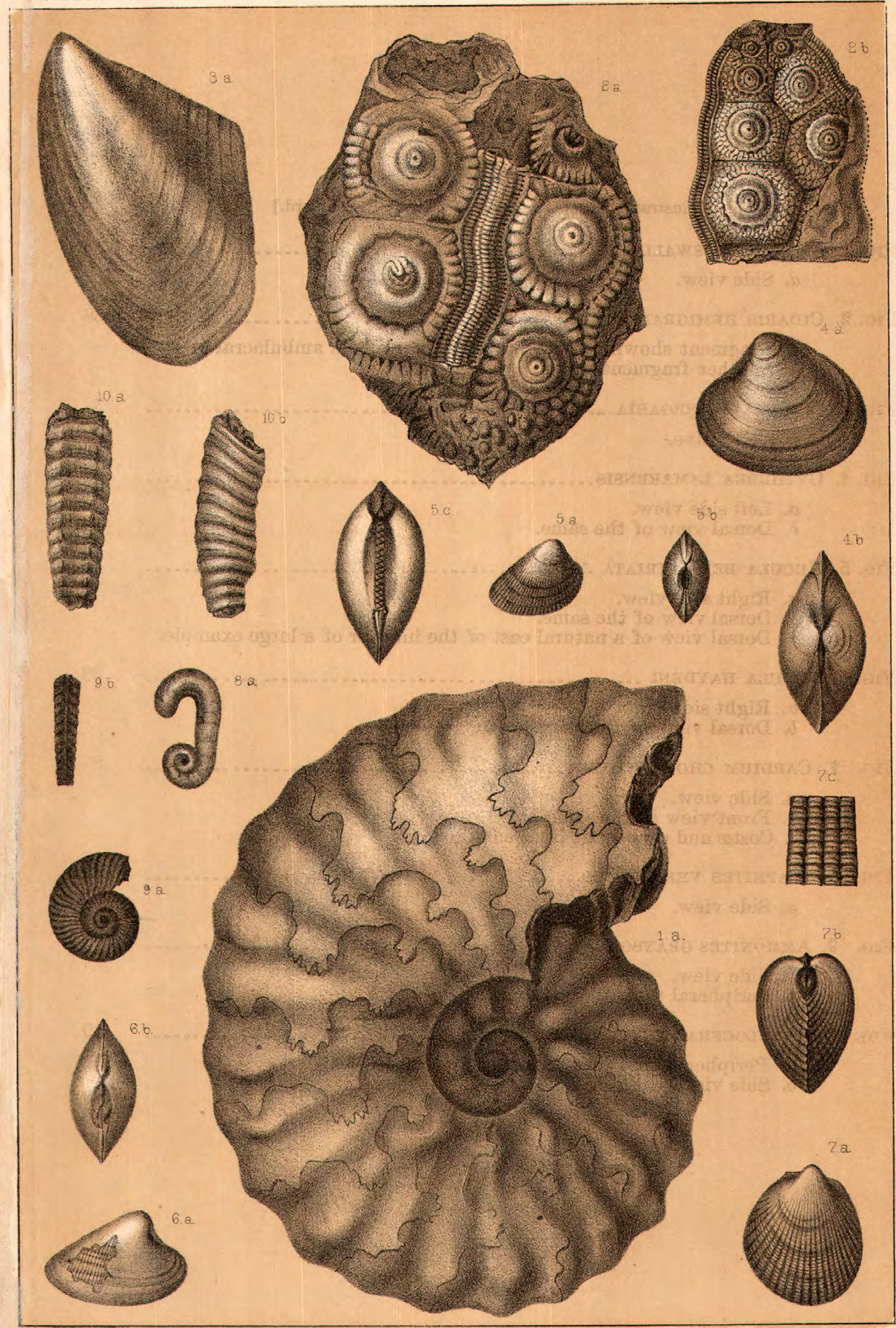

A.R. Roessler de? 



\title{
CONTRIBUTIONS TO INVERTEBRATE PALEONTOLOGY, NO. 3: CERTAIN 'IERTIARY MOLLUSCA FROM COLORAD0, UTAH, AND WYOMING.
}

\author{
By C. A. White, M. D.
}

The fossil mollusca herein described, and figured upon plate 13, have been collected at various times and by different persons connected with the two surveys which have heretofore been under the direction respectively of Dr. Hayden and Prof. Powell. Preliminary descriptions of all the species have before been published in different reports of those surveys, but none of them have before been figured. All the specimens figured on plate 13 are regarded as typical of the respective species, and the greater part of them are those from which the original descriptions were drawn. The type specimens-that is, those from which the original descriptions were drawn-have been used for illustration in all cases when they have been available; search for the types of a part of these species has, however, been hitherto unsuccessful, in consequence of their having been lost or mislaid. In these cases figures are given of specimens that have been carefully identified, and which have been collected from the same formations in which the original types were found, and at or near the original locality.

All the species presented in this article are from the great fresh-water series of strata, which is usually, and doubtless correctly, referred to the Eocene Tertiary epoch, and which is divided into the Wahsatch, Green River, and Bridger Groups. There seems to be sufficient reasons of a physical character for dividing that great series of strata into the three subordinate groups just named, for purposes of stratigraphical study, but it is evident that a large proportion of the molluscan species which they contain are common to more than one, and in some cases at least, to all three, of the groups. The general characteristics of the invertebrate faunæ of these groups is such also as to indicate their connection with, and proper reference to, a single epoch ; and such also as indicate not only a continuity of deposition over a very large area thronghout the whole of the triple series, but also a continuity of existence of specific forms of molluscan life in the waters in which the whole of that continuous deposition took place.

\section{CONCHIFERA.}

\section{Genus UNIO Retzius.}

\section{UNIO SHOSHONENSIS White.}

Plate 19, figs. $2 a$ and $b$.

Unio shoshonensis White, 1876, Powell's Rep. Geol. Uinta Mts., p. 126.

Shell subelliptical in marginal outline; valves moderately and somewhat regularly convex; test not massive; dorsal margin broadly convex; front margin regularly rounded; basal margin broadly and regularly convex; posterior margin somewhat abruptly rounded, the postero-dor- 
sal portion sometimes showing an oblique truncation or a sloping downward and backward of its border to a somewhat prominent posterior or postero-basal extremity; beaks well defined but not prominent, situated about one-quarter of the full length of the shell from the front, or sometimes less; umbonal slopes broadly convex. Surface marked by the ordinary concentric lines and imbrications of growth.

Length of one of the largest examples in the collection, the one which is represented by fig. $2 a$, plate 19, 65 millimeters; height of the same from base to dorsal margin, 43 millimeters; convexity of the single valve, 14 millimeters. Other examples have a greater proportional length, as shown by fig. $2 b$ of the same plate.

This species bears a closer resemblance to U. haydeni Meek, which has been reported from both the Green River and Bridger Groups, than to any other fossil form that has yet been published.

It differs from that species in its larger size, its convex instead of straight dorsal margin, its rather more prominent umbones, its somewhat stronger hinge, and in its greater proportionate height from base to hinge margin. It belongs to that general group of the Uniones which have an oval marginal ontline, the beaks submedially situated, and the surface plain; which group has several known representatives among the fossil Uniones of the western fresh-water tertiary deposits, and also a large number among living forms. In the latter respect it may be compared with $U$. fascinans and $U$. cope $i$ Lea, from the rivers of Virginia.

It is not improbable that this species is really identical with $U$. tellinoides (=Mya tellinoides Hall, Frémont's Expl. Oreg. and N. Cal., 1845). I have not had an opportunity, however, to examine Professor Hall's type specimens, and, in view of the fact that several closely related species exist in the fresh-water deposits of the region from which Professor Hall's types came, it is impracticable to determine from his figures and description alone to which species they were intended to apply. Fig. $2 a$, plate 19, represents a typical example of U. shoshonensis from the Upper Green River Group of Southern Wyoming, and fig. $2 b$, of the same plate, another more elongate example from the base of the Green River Group, or the top of the Wahsatch, in the valley of White River, Northwestern Colorado.

Position and locality.-This species has a wide geographical distribution and a considerable vertical range. Its present known range is from the base of the Lower to the top of the Upper Green River Group, and it probably extends into the Wahsatch Group below and into the Bridger above. I have collected examples of it from the Green River Group in the valleys of Snake and White Rivers and Vermilion Creek, and from the slopes of Dry Mountains in Northwestern Colorado; also from the same group in the valley of Henry's Fork, southward from Green River City, and near Alkali Stage Station, some twenty miles north of that place, in Southern Wyoming.

\section{UNIO WASHAKIENSIS Meek.}

Plate 19, figs. $3 a$ and $b$.

Unio washakiensis Meek, 1871, An. Rep. U. S. Geol. Sur. Terr. for 1870, p. 314.

The following is Mr. Meek's original description of this species (loc. cit.):

"Shell scarcely attaining a medium size, thin, depressed, rather compressed, longitudinally subovate; anterior side short, rounded; posterior side long, with a narrowly rounded or sometimes faintly subtruncated extremity, the most prominent point being below the middle, while above this there is usually an oblique slope from the posterior extremity 
of the hinge; basal margin forming a broad semi-elliptic or semi-ovate curve, in the latter case the most prominent part being a little in advance of the middle; dorsal or hinge margin straight from the beaks to the upper slope of the posterior margin; beaks depressed nearly to the dorsal margin, rather regularly convex, but not rentricose, and placed about one-fourth the length of the valves from the anterior extremity; umbonal slopes moderately and evenly convex. Surface smooth or only showing more or less distinct marks of growth, excepting near the immediate points of the beaks, where well-preserved specimens show traces of minute regular longitudinal wrinkles which terminate posteriorly at two faint, oblique, obsolescent linear ridges; hinge slender; cardinal teeth small, oblique, and apparently consisting of one in the right and two in the left valve; lateral teetl straight, rather long, two in the left and one or two in the right valve.

"Length of a large specimen 2.37 inches; height, 1.26 inches; convexity, 0.72 inch.

"This species is related to $U$. priscus M. and H., with which it agrees nearly in form and surface characters. It is constantly smaller, however, and distinctly thinner, while its hinge is weaker and its cardinal teeth smaller and much more oblique. The wrinkles on its beaks, and the two oblique linear ridges on their posterior dorsal sides, are similar to those on $U$. priscus, excepting that they are less distinctly defined and occupy a much smaller space only near the points instead of the whole surface of the umbones, being, in fact, so obscure and so near the points of the beaks as to be readily overlooked, and entirely obsolete in most cases.

"It will be distinguished from $U$. hayden $i$ mainly by its more depressed and more elongate form ; its stratigraphical position is also, according to Dr. Hayden's observations, one thousand to two thousand feet lower in the series than that of U. haydeni."

Mr. Meek does not expressly state from which of the three great freshwater groups of strata his type specimens came, but, judging from what is known of the strata at the localities he mentions (Washakie and Henry's Fork, Wyoming), they are all from the Green River Group. The vertical range of the species, however, is apparently from the base of the Green River Group to at least the lower part of the Bridger Group. The type specimens from which Mr. Meek drew his description seem to have been lost or mislaid, and I have, therefore, not been able to examine them. The one from which fig. $3 a$, plate 19, is drawn was found among other fossils that had been studied by him, and was labeled in his handwriting, "From Church Buttes, Wyoming." Church Buttes being composed of the strata of the Bridger Group, as well as the character of the stone embedding the shells, indicates that they came from that group, probably near its base. The specimen represented by fig. $2 b$, of the same plate, is from the base of the Green River Group, in White River Valley, Northwestern Colorado. The species is well characterized by Mr. Meek, and the specimens here figured, as well as the others associated with them, answer well to his description.

\section{UNIO MEEKII White.}

Plate 19, fig. 1 a.

Unio leanus Meek, 1871, An. Rep. U.S. Geol. Sur. Terr. for 1870, p. 313.

Unio meekii White, 1877, Bull. U. S. Geol. Sur. Terr., vol. iii, p. 665.

The original name of this species was changed by the writer, as above indicated, because it had been preoccupied by Gray many years ago. 
It is not a very rare species, but no examples have ever been obtained which are in a better condition than those are from which Mr. Meek drew his description, and which are all in the form of natural casts, mostly of the interior of the shell. Therefore a figure only of one of his type specimens is given on plate 19.

His original description is as follows:

"Shell attaining a medium size, or larger, rather thin; longitudinally ovate, being somewhat less than twice as long as high, with the widest (highest) point in advance of the middle; rather distinctly convex; anterior side wider than the other, and regularly rounded; posterior margin more narrowly rounded, or sometimes obliquely subtruncate above; basal outline forming a broad, semi-orate curve, with the most prominent part in advance of the middle; beaks moderately depressed and placed between one-third and one-fourth the length of the valves from the anterior margin ; surface smooth, or only showing marks of growth ; cardinal teeth prominent, and bearing, in internal casts, a very profound impression, ranging vertically just behind the anterior muscular scar; lateral teeth long and straight, two in the left and one in the right valve.

"Length, 3.80 inches; height, 2.20 inches; convexity, 1.40 inches.

"This will be readily distinguished from that I have provisionally referred to, U. tellenoides Hall, by its proportionally longer and more convex valves, stouter hinge, and particularly by having larger, thicker, and more prominent cardinal teeth, ranging vertically instead of very obliquely forward and downward.

"Locality and position.-Chureh Buttes, Wyoming Territory; miocene [eocene] tertiary, in a rather coarse greenish grit."

Figure $1 a$, on plate 19, is drawn from one of Mr. Meek's types, which, although so imperfect, is one of the best examples yet discovered.

Mr. Meek does not mention the group from which his specimens of this species were obtained, but as Church Buttes are composed of Bridger strata, they are doubtless from that group. The full characteristics of this species are not yet satisfactorily known, because its outer surface and complete external form have not been fully shown by any of the specimens yet discovered. It probably occurs at different horizons throughout the Green River Group also, but as the specimens of Unio found in all three of the Eocene fresh-water groups are so generally in the form of casts, the identity of the forms referred to with this species has not been satisfactorily determined. Some examples, also, that have been discovered in the Wahsatch Group appear to belong to this species; but these; too, have been found only in the form of casts.

\section{GASTEROPODA.}

\section{Genus PLANORBIS Müller.}

\section{Planorbis cirratus White.}

Plate 19, figs. $5 a, b$, and $c$.

Planorbis cirratus White, 1879, An. Rep. U. S. Geol. Sur. Terr. for 1877, p. 251.

Shell small, discoidal; volutions six or seven, very slender, their transverse diameter a little greater than their vertical, coiled closely and so nearly in a. plane that the upper and under sides respectively are distinguished mainly by the difference in the direction of the lines of growth upon the surface; the contact of the volutions is such as to produce a slight concavity upon the inner side of each, all the outer and exposed 
surface being regularly rounded and without revolving angles or lines. Surface smooth, or marked only by the ordinary striæ of growth.

Diameter of the coil of the largest example discovered, 8 millimeters; transverse diameter of the last volution, $1 \frac{1}{5}$ millimeters.

This species is remarkable for its numerous slender and plain volutions and small size. It differs materially from any other species known to me, either fossil or recent, in the slenderness of the volutions and the almost exact plane of its coil. The aperture is apparently without any thickening or reflexure of the peristome, even when fully adult.

Position and locality.-It has been found only in strata belonging to the basal portion of the Green River Group, or to the upper portion of the Wahsatch Group, about three miles east of Table Rock Station, Union Pacific Railroad, Wyoming.

\title{
Genus PHYSA Draparnaud.
}

\section{Physa BRIDGerensis Meek.}

Plate 19, figs. $10 a$ and $b$.

Physa bridgerensis Meek, 1873, An. Rep. U. S. Geol. Sur. Terr. for 1872, p. 516.

The specimens from which Mr. Meek drew his description of this species having been lost or mislaid, the figures illustrating it on plate 19 have been drawn from opposite views of two specimens which were obtained from the Bridger Group in the valley of Henry's Fork, a few miles east of Fort Bridger, by one of Professor Powell's parties in 1875. They do not strictly agree in all particulars with Mr. Meek's description, but the discrepancy is probably due to the fact that his types were less perfect than our examples are. He, however, recognized the identity of the latter with his species upon an examination which he gave them at my solicitation a short time before his death, and there is probably no reason to question it. The fact that both, his types and our examples are from the same formation and the same region, also favors this view. The following is Mr. Meek's description:

"Shell attaining a large size, subovate in form; spire prominent, conical; volutions four and a half to five, moderately convex, last one large but not very ventricose; suture well defined; aperture narrow-subovate, arcuate, acutely angular above, and about twice as long as the spire; columella twisted into a rather prominent fold. Surface with fine sharp lines of growth.

"Length about 1.15 inches; breadth, 0.66 inch.

"This is a fine large species, with a more prominent spire than any of our recent species resembling it in other respects. None of the specimens found are perfectly preserved.

"Locality and position.-Chureh Buttes, fourteen miles from Fort Bridger, Wyoming Territory. Tertiary."

\section{Genus SUCCINEA Draparnaud.}

\section{Subgenus BRACHYSPIRA Pfeiffer.}

\section{SUCCINEA (BRACHYSPIRA) PAPILLISPIRA White.}

\author{
Plate 19, fig. $4 a$.
}

Succinea papillispira White, 1876, Powell's Rep. Geol. Uinta Mts., p. 129.

Shell rather small, ovate or subelliptical in lateral outline; spire minute but prominent; last volution expanded and broadly convex; 
aperture large. Surface marked by the ordinary lines of growth, and, under the lens, faint, close-set, revolving striæ are seen crossing the fine lines of growth, giving the surface a fine cancellated appearance.

Length 11 millimeters; breadth accross the middle of the aperture 6 millimeters.

There are at best only a few salient specific characteristics observable in the shells of any species of Succinea, but this shell may be regarded as distinguished from all other species with which it is in any danger of being confounded by its minute spire, the very abrupt spreading of the body volution, or rather part of a volution, from those of the spire. Figure $4 a$, plate 19, is drawn from a gutta percha cast of a natural mould in fine-grained sandstone, the latter having been a little distorted by pressure.

This species was discovered by the writer in the summer of 1875 , and up to the present time no other fossil species of the genus Succinea has been discovered in North American strata. The discovery of a representative of this genus among the early Tertiary pulmonate mollusca is an interesting one; and the interest is increased also by the evidence which it affords that the subgenus Brachyspira of Pfeiffer was established as a subgeneric type as early, at least, as the Eocene epoch.

Position and locality.-U Uper Green River Group, Alkali Stage Station, some twenty miles northward from Green River City, Wyoming, at which locality alone the species has yet been discovered.

\section{Genus PUPA Lamarck.}

Pupa ARenula White.

Plate 19, figs. $8 a$ and $b$.

Pupa arenula White, 1876, Powell's Rep. Geol. Uinta Mts., p. 131.

Shell minute, ovate; spire obtasely rounded, its apex slightly prominent or merely convex; volutions, five or six, moderately convex; suture impressed; last volution contracted near the aperture; border of the aperture apparently reflexed, but its true shape, and the character of the armature, if any, of the aperture, unknown, in consequence of the imperfection of the specimens.

Length, 2 millimeters ; diameter, $1 \frac{1}{5}$ millimeters.

This shell, in shape, size, and general aspect, closely resembles Vertigo ovata Say, among living Pupidæ. It appears, however, to be either Pupa proper, or referable to the subgenus Pupilla.

Position and locality.-Upper Green River Group, valley of Henry's Fork, southward from Green River City, Wyoming, where it is associated with the two species next described, and also with Physa, Planorbis, \&c.

\section{Pupa atavuncula (sp. nov).}

\section{Plate 19, fig $9 a$.}

Shell minute, elongate subovate; the sides of the spire, for greater part of its length, subparallel; the distal portion of the spire, together with the apex, obtuse; volutions about five, convex, gradually increasing in size; suture impressed. Aperture unknown, but it is apparently not contracted.

Length about $1 \frac{4}{5}$ millimeters; diameter, 1 millimeter. 
This species very closely resembles, both in size and shape, Pupa californica Rowell, as figured and described by Binney and Bland in Land and Fresh-Water Shells of North America, part I (Smithsonian Miscellaneous Collections 194), p. 239, fig. 413. These authors give the diameter of that shell as one millimeter, which is the same as that of ours; but they state its length to be two and a half millimeters, which is one-fourth longer than the proportions of their figure indicate. I have never seen an example of that shell, but their figure (loc. cit.) probably correctly represents its proportions, which are therefore nearly the same as those of our shell. Indeed it is difficult to say, with the present knowledge only of our shell, wherein it differs from $P$. californica, but as no living species have been found in the strata from which the former comes, and as all its characteristics are not yet known, it would probably not be warrantable to refer it to a living species. It differs conspicuously from the last-described species, $P$. arenula, with which it is associated, and with which it corresponds approximately in size by being much less globose, and apparently in not having its aperture contracted. It has the aspect of the typical forms of Pupilla, and ought probably to be referred to that subgenus.

Position and locality.-Upper Green River Group, Henry's Fork, Wyoming, where it is associated with the following as well as with the preceding species, and also with other pulmonate gasteropods.

\section{Subgenus LEUCOCHEILA Albers.}

\section{Pupa (Leucocheila) incolata White.}

Plate 19, figs. $7 a, b$, and $c$.

Pupa incolata White, 1876, Powell's Rep. Geol. Uinta Mts., p. 130.

Shell small, elongate, distinetly rimate, sides somewhat regularly tapering along the greater part of the length of the shell, but more rapidly converging at the extremity to a slightly obtuse apex; volutions about six; convex regularly increasing from apex to aperture, the last one not contracted; suture impressed; aperture subovate in outline, its length a little more than one-third that of the whole length of the shell; onter lip thickened, prominent, reflexed; aperture apparently without either teeth or folds, but the condition of all the specimens in the collection is unsatisfactory in this respect.

Length, 5 millimeters; diameter of last volition, 2 millimeters.

This species closely resembles in size, form, and general characteristics, Pupa (Leucocheila) fallax Say, but the sides of our shell converge at a somewhat greater angle than they do in Say's species, and its peristome is also more thickened and expanded. It appears to possess all the characteristics of the subgenus Leucochcila; or at least it differs subgenerically from the typical forms of Pupa. The fact that we find two, and perhaps three, subgeneric forms of the Pupidæe in the Eocene strata of Western North America, is of great interest as regards the question of the early differention of existing types of pulmonate mollusks.

Position and locality.-Upper Green River Group, valley of Henry's Fork, southward from Green River City, Wyoming, where it was found associated with the two preceding species, and also with Helix, Planorbis, \&c. 
Genus BYTHINELLA Moquin-Tandon.

Bythinella gregaria Meek.

Plate 19, figs. $6 a$ and $6 b$.

Bythinella gregaria Meek, 1871, An. Rep. U. S. Geol. Sur. Terr. for 1870, p. 317.

The following description and remarks of Mr. Meek embrace all that has yet been learned concerning this species:

"Shell small, conoid-subovate; spire rather elevated; volutions five, rounded or very convex; suture strongly impressed; aperture ovate or slightly longer than wide, with the upper extremity subangular, and the lower rounded; inner lip not reflected, and leaving by its side a very small umbilical impression that seems not to perforate the axis. Surface smooth, or only showing, under a strong magnifier, very minute lines of growth.

"Length, $0.15 \mathrm{inch}$; breadth, 0.08 inch ; length of aperture, 0.06 inch; breadth of aperture scarcely 0.04 inch.

"This little shell so nearly resembles in form and proportions the figures of Bythinella tenuipes of Couper, that it is with some hesitation I have concluded to regard it as a distinct species. As that shell, however, is described as having its suture 'slightly impressed,' and as being 'subumbilicated' while that under consideration has its suture very deep, and could not be properly described as even subumbilicated, I do not feel warranted in referring our Tertiary form to the existing species.

"Of course we have no certain means of determining whether we ought not to call this shell Amnicola gregaria, or Pomatiopsis gregaria, instead of referring it to Bythinella, the distinction between these two groups being mainly based on characters not apparent in the shell. The fact, however, that it is found in vast numbers associated with a small Planorbis and millions of the carapace-valves of a minute Cypris, would seem to indicate that it was aquatic in its habits, like Bythinella and Amnicola. It is true terrestrial shells are often swept by streams into lakes, and deposited along with those of aquatic species; but it is exceedingly im. probable that millions of so small a shell as this would have been deposited all together, so as almost to form an entire bed of limestone, especially without some other terrestrial types.

"Locality and position.-Pacific Springs [Wyoming], Tertiary." 



\section{PLATE 19.}

FIG. 1. UNIO MEEKII.

a. Natural cast of the interior of the left valve; natural size.

Fig. 2. UnIo shoshonensis

a. Left valve; nataral size; from Southern Wyoming.

b. Left valve of another, mure elongate example; from White River Valley, Northwestern Colorado.

Fig. 3. Unio washakiensis

a. Left valve; natural size; from near Fort Bridger, Southern Wyoming.

b. Left valve of another example; a natural cast in sandstone; from White River Valley, Northwestern Colorado.

Fig. 4. Succinea papillispira

a. Lateral view; enlarged two diameters, of a gutta-percha cast of a natural mold in fine-grained sandstone. The specimen has been a little distorted by accidental pressure in its preservation.

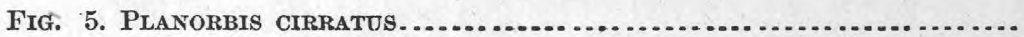

a. View of the upper side; enlarged to two diameters.

$b$. View of the under side of the same.

c. Peripheral view of the same, showing the outline of the aperture.

Fig. 6. Bythinella gregaria

a. Apertural view; enlarged to four diameters.

$b$. Opposite yiew of another example similarly enlarged.

Fig. 7. Pupa incolata

a. Apertural view; enlarged to four diameters; showing the aperture filled with a portion of the stony matrix.

b. Opposite view of the same.

$c$. Another view of the same, showing the thickened edge of the outer lip.

Fig. 8. Pupa arenula

a. Apertural view; enlarged to four and a half diameters; the peristome broken away.

b. Opposite view of the same.

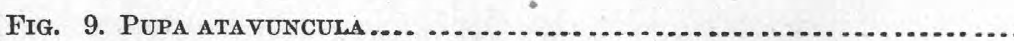

a. Lateral view; enlarged to six diameters.

Fig. 10. Physa BRIDGerensis.

a. Apertural view ; natural size; a part of the outer lip broken away.

b. Opposite view of another, more robust example. 


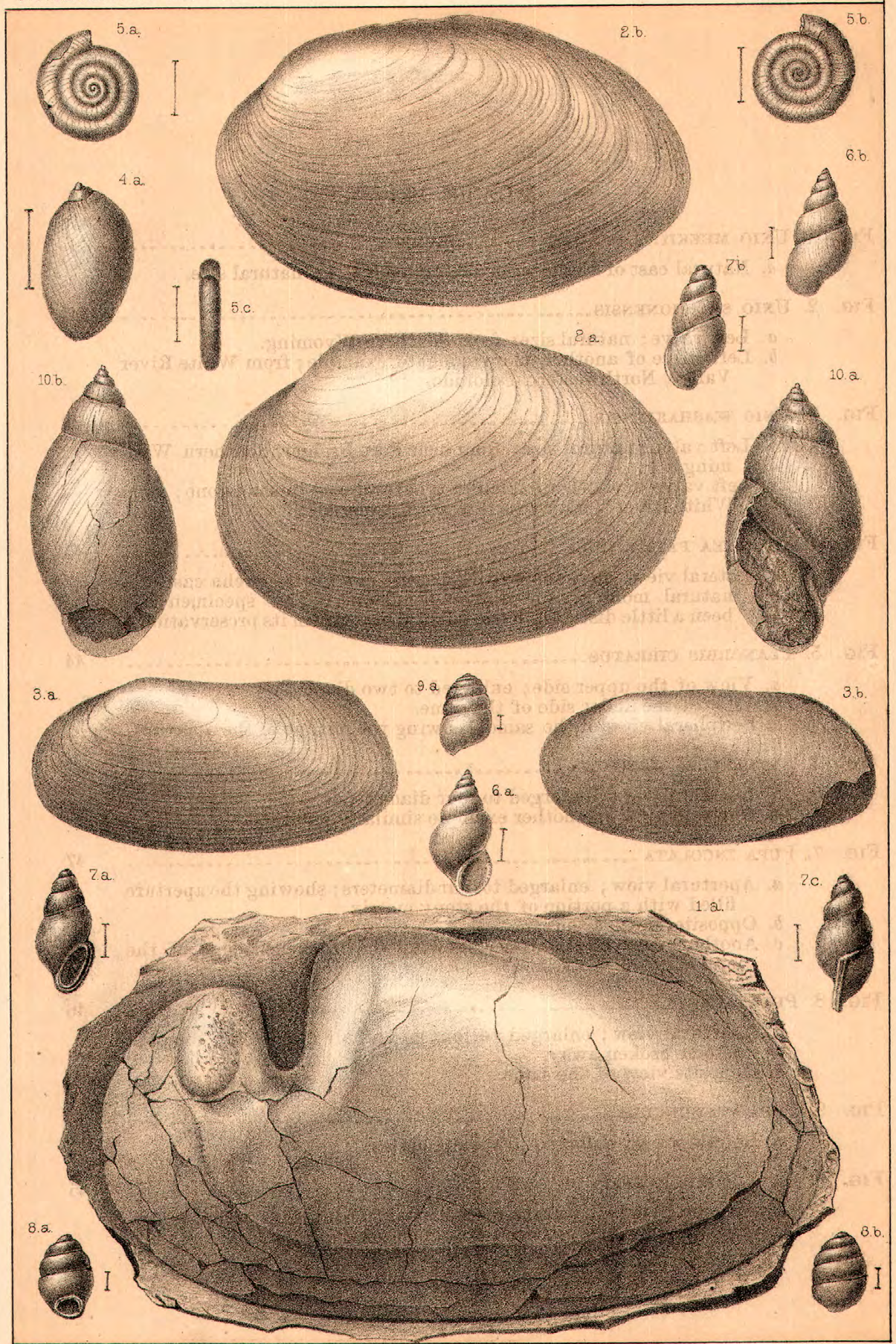

F.D. Owen \& W. H. Holmes del. 



\title{
CONTRIBUTIONS T0 INVERTEBRATE PALEONTOLOGY N0. 4: FOS- SILS OF THE LARAMIE GROUP.
}

\author{
By C. A. White, M. D.
}

The illustrations which accompany this article, on plates No. 20 to No 30 , inclusive, have from time to time been prepared to accompany a proposed monograph of the Laramie Group and its Invertebrate Fauna. A large amount of materials and the results of extended observations had been collected towards such a monograph up to the time that the fieldwork of this survey was discontinued, but the original plan of publication of these results has been abandoned because extended field investigations and large collections would be necessary to the completion of sueh a work upon a plan commensurate with its importance. The discontinuance of this survey having made it necessary to abandon the original plan, the material now accumulated is published in this article as one of the series of Contributions to Invertebrate Paleontology.

The Laramie Group and its invertebrate fossils have been frequently discussed by me in certain of the publications of this Survey during the past four years; and as there is some want of harmony in relation to some of the views expressed, or of inferences that may be drawn from statements made, or from methods of treating the subject in those published articles and reports, those publications may be taken to indicate the progress of our knowledge concerning the subject discussed. This was necessarily the case, because the field is so large and because the subject embraced the investigation of a great group of strata which has no known equivalent in other parts of the world. While future investigations will no doubt add greatly to our knowledge of the Laramie Group iand its invertebrate fossils, and perhaps considerably modify the views at present entertained, the two following-named publications besides this one may be taken as containing an exposition of my views at the present time: Pages 255-265 of the Annual Report of this Survey for 1877; and article xxxvi, volume iv of the Bulletin of this Survey. As the general subject has been somewhat fully discussed in these two publications, the present article will be confined to the following general summary, and to the enumeration of the known invertebrate fossils of the group, together with the description of those which are illustrated on the eleven accompanying plates before designated.

The geographical limits of the Laramie Group are not yet fully known, but strata bearing its characteristic invertebrate fossils have been found at various localities within a great area, whose northern limit is within the British Possessions, and whose southern limit is not further north than southern Utah and northern New Mexico. Its western limit, so far as known, may be stated as approximately upon the meridian of the Wahsatch range of mountains, but extending as far to the southwestward as the southwest corner of Utah, and its eastern limit is far out on the great plains, east of the Rocky Mountains, where it is covered from view by late formations and the prevailing débris of the 
plains. These limits indicate for the ancient Laramie sea a length of about one thousand miles north and south, and a maximum width of not less than five hundred miles. Its real dimensions were no doubt greater than those here indicated, especially its length ; and we may safely assume that this great brackish-water sea had an area of not less than fifty thousand square miles. The present range of the Rocky Mountains, which has been entirely raised as a mountain range since the close of the Laramie period, traverses almost the entire length of this great area, and far the greater part of the other extensive and numerous displacements which the strata of the different geological ages have suffered within that great area have also taken place since all the Laramie strata were deposited, although some of those changes thus especially referred to began before the close of the Laramie period. It is for these reasons that the great region within which the strata of the Laramie Group are found, however much they may be now displaced, is assumed to have been entirely covered by the Laramie sea during the whole of that period, except such portions as rose above the surface by stratigraphical displacements before its close, as before intimated.*

The invertebrate fauna of the Laramie Group consists almost wholly of brackish-water, fresh-water, and land mollusca. Species belonging to all three of these categories are often found commingled in the same strata, but it is also often the case that certain strata, sometimes only thin layers, which contain the fresh-water and land mollusks alternate with those which contain the brackish-water species. With the exception of one species of Axincea, one of Nuculana, and one or two of Odontobasis, no species usually regarded as of marine types have been found in any of the strata of the Laramie Group; $\dagger$ and even these are doubtless such as became inured to a brackish-water habitat as the waters were progressively freshened, just as certain marine types of fishes and other aqueous animals have become inured to brackish and even fresh waters both in past geological epochs and at the present time. Such brackishwater types, however, as Ostrea, Anomia, Corbula, Corbicula, and Neritina characterize the Laramie strata throughout their whole geographical extent, and from top to bottom of the group. Indeed this brackishwater fauna is the great distinguishing feature of the Laramie Group, so far as its remains of invertebrate life are concerned, and all the genera just named, except the last (the representatives of which are comparatively rare), are abundantly represented from the base to the top, or near the top, of the group.

All the species of fresh-water and land mollusca which prevailed during the Laramie period seem to have ceased with the disappearance of their contemporary brackish-water forms, although they were succeeded by other fresh-water and land species; so that we find it convenient and proper to fix the latest limit of the Laramie Group where the brackishwater forms disappear, especially so because no brackish-water forms are known in all that great western region in strata later than those of the Laramie Group. It is, however, quite proable that some species of the fresh-water and land mollusca of the Laramie period continued to live after its waters were fully freshened and all brackish-water forms had disappeared, but no instances of a commingling of those Laramie fresh

\footnotetext{
* The frequent alternation of strata in the Laramie Group which contain only freshwater molluscan forms with those which contain brackish-water forms, and the probable conditions which produced that result are discussed in the two publications cited on the preceding page.

t The reference of Inoceramus and other marine forms to strata of this group (= Point of Rocks Group of Powell), in chapter iii, Powell's Report on the Geology of the Uinta Mountains, was the result of error in stratigraphical determinations.
} 
water mollusks with the fresh-water forms which characterize the Wahsatch and other purely fresh-water groups above the Laramie have yet been observed. But if sedimentation was continuous from the Laramie, to the Wahsatch Group, as it is believed to have been, we may reasonably expect to find such a commingling of species at least in the lower strata of the Wahsatch Group or the top of the Laramie.

Paleontologically the Laramie Group stands out clearly and distinctly from the marine Fox Hills Cretaceous Group beneath, and the purely fresh-water formations above it, even though they may be connected by certain faunal types in the manner suggested. Its zoölogical characteristics are such also as to mark the Laramie as a well-defined period in geological history, apparently quite coördinate in importance with all that portion of the preceding Cretaceous period which is represented by any and all North American strata which have been referred to that period. The stratigraphical relations of the Laramie Group I have discussed at length in the works already cited, and I need only call attention here to the unique character of its invertebrate fauna, as exhibited in this article and the accompanying illustrations, not only as regards the relation of the latter to the faunæ of the formations which respectively underlie and overlie it, but as regards any other known faunæ. The unique character of this Laramie fauna is not affected by the fact that a large proportion of its types, especially those of its freshwater and land mollusks, are evidently the genetic precursors of some. of those now living in North American fresh-waters, because comparisons are made with that fauna in its entirety, and with it as regards its position in geological time. There are other brackish-water deposits among the strata of that great western region, especially those of Cretaceous age, but these are of comparatively small extent and contain limited faunæ the species of which at least are different from those of the Laramie Group, which latter fauna evidently livert in a great brackishwater sea. Those limited faunæ are mentioned here for the purpose of pointing out the fact that they are not to be confounded with the Laramie fauna, whatever genetic relations they may have sustained to it in fact, and in the order of time.

The evidence as to the true geological age of the Laramie Group has also been discussed in the two former publications before cited, and therefore only a brief summary of that question will be given in this article. Among the vertebrate remains that have hitherto been discovered in its strata are some of distinctively Cretaceous types as judged by European standard, namely, the Dinosaurian. Therefore vertebrate paleontologists have generally regarded the Laramie Group as of Cretaceous age. Paleobotanists, however, have quite as generally regarded the vegetable remains of the group as belonging to Tertiary types. Among all the invertebrate fossils which have yet been discovered in the strata of the Laramie Group, none of the types are distinctively characteristic of the Cretaceous period according to any hitherto recognized standard. Many of the molluscan types of this group still exist, although the species are of course extinct, and some of those types are known to have existed during the Cretaceous epochs preceding the Laramie. But on the other hand four or five molluscan genera and subgenera have been recognized in the fauna of the Laramie Group that are not known beyond its. limits. In view of the fact that the known Cretaceous flora of North America has near affinities with European Tertiary types, some persons regard the Tertiary facies of the Laramie flora as presenting little objection to a reference of that group to Cretaceous age. To those who hold such views the balance of paleontological evidence seems to be in favor of 
such a reference, especially as the strata immediately overlying that group contain an abundance of mammalian remains of Eocene-Tertiary types, while no such mainmalian types occur in the Laramie Group. The following facts, however, favor the view which I have advocated, that the Laramie is really a transitional group between the Cretaceous beneath and the Tertiary above.

We have yet no knowledge of the existence of any Cretaceous strata in North America which, according to European standards, are equivalent with any part of the Lower Cretaceous of Europe; all known Cretaceous strata of this continent being usually regarded as of the age of the Upper Cretaceous of that part of the world.

The Fox Hills Group has consequently been regarded as equivalent with the latest Cretaceous of Europe, a conclusion which is sustained by the character of its fossil fauna. The Fox Hills Group of Western North America is evidently exactly equivalent with the upper portion of the Cretaceous deposits of the Gulf and Atlantic States, where the marine Eocene deposits rest directly and conformably upon the Cretaceous, with no intervening strata that can be regarded as paleontologically equivalent with the Laramie Group. If, therefore, these parallelisms are correctly drawn, as they appear to be, the Laramie, as a complete group, cannot be as old as the latest recognized Cretaceous strata in either this or any other part of the world. Again, if those three groups of fresh-water strata which immediately overlie the Laramie Group, namely, the Wahsatch, Green River, and Bridger Groups, are really of Eocene-Tertiary age, as they are accepted by all paleontologists to be, then is there additional evidence of the correctness of the view that the Laramie is a transitional group between the Cretaceous and the Tertiary, partaking of the faunal characteristics of both periods. It should also be stated that paleontologists have generally agreed in referring the Wasatch, Green River, and Bridger Groups to the earlier Eocene.

In the two publications before cited I have shown that the strata of the Judith River and Fort Union series of the Upper Missouri River. region; the lignitic series east of the Rocky Mountains in Colorado and the adjacent region, and the Bitter Creek series and its equivalents west of the Rocky Mountains in Wyoming and Colorado, which were formerly treated as separate groups, are all merely regional divisions of the great Laramie Group, all being faunally connected together by the specific identity of a considerable proportion of their fossil remains.* In those publications I also included in the great Laramie Group that series of strata which have become well known as the Bear River series, its best known development being in the valley of Bear River, in the southwestern part of Wyoming, but equivalent strata being known many miles to the northward of that valley, and also at intervals in the region of the Wahsatch range of mountains as far south as Southwestern Utah. That portion of this Bear River series, that is, the lower portion, which is of brackish water origin, contains a molluscan fauna, every known species of which is distinct, not only from those of other formations, but different from any that are found in any of the other portions or regional divisions of the Laramie Group, before mentioned. This difference is evidently too great to be considered as a mere regional variation of the prevailing fauna of that period, and it becomes a serious question whether we ought not to regard that Bear River series and its

\footnotetext{
* Professor Cope's investigations of the vertebrate remains in these various regions have also shown that these regional divisions of the strata which are here referred to the Laramie Group all Welong to one great and important geological period.
} 
faunal equivalents as at least a separate division of the Laramie Group, if not, indeed, as a separate group.

The plan of the formerly-proposed monograph of the Laramie Group, which has already been mentioned, contemplated a separate discussion of the fauna of the Bear River series, but that plan cannot be strictly adhered to in this article, because its fauna has not yet been sufficiently investigated to reveal its true relation with that of the great remainder of the Laramie Group. Therefore only the following brief summary of our present knowledge of that portion of the subject will be given in this article, together with some suggestions which the facts stated seem to warrant. The consideration of this subject will be somewhat facilitated by reference to plate 30 , which contains illustrations of rossils of the Bear River series only, while the other plates pertaining to this article contain figures of such fossils only as are found in the typical portion of the Laramie Group.

The continuity of the strata of the Bear River series with those of the great body of the Laramie Group elsewhere has never been traced, and such continuity is not really known to exist; but that series has been referred to the Laramie Group, notwithstanding the contrastpresented by its fossil remains, mainly because it is, like the other, a great brackish-water deposit, and because it is everywhere found to be bounded, respectively, above and below, by the same formations that thus bound the typical portion of the group. All geologists are agreed that the Laramie Group is everywhere conformable with the Fox Hills Cretaceous Group, which lies beneath it, and none deny that in the production of the strata of the two groups sedimentation was or that it may have been continuous from the lower of these groups to the upper. With regard to the relation of the Laramie Group with the overlying Wahsatch Group of the Tertiary period, there is considerable diversity of opinion, some claiming that the two groups are everywhere uncomformable, and others, that they are in some places entirely conformable, and perhaps were there continuously deposited. I entertain this latter view, for which I have given my reasons in the former publications before cited.

This conformity of the upper strata of the Laramie Group with the lower strata of the Wahsateh has, however, been observed by myself only in the case of the Bitter Creek series and its equivalents, in Southern Wyoming and Northwestern Colorado, and in that of the lignitic series, east of the Rocky Mountains, in Colorado; while the Wahsatch strata that rest upon the Bear River Laramie series in the region of its typical exposures are known to be distinctly uneonformable, and in most places very greatly so. From all information, also, which I have been able to gather from the observations of other geologists in addition to my own, the strata which rest upon the equivalents of the Bear Rirer Laramie series, both northward and southward from the typical localities, are everywhere unconformable. The following facts, gathered from the sources referred to, lead me to believe that the great displacements which caused this unconformity took place before the close of the Laramie period, and not at its close, as claimed by some authors. I have never visited Central and Southern Utah in person, but the different parties counected with the surveys under the direction, respectively, of Lieutenant Wheeler and Professor Powell have brought in a number of species of Laramie fossils from different localities in that Territory, some of which are charasteristic of the Bear River series, and others are equally characteristic of other portions of the great Laramie Group. From the information which I have received in connection with these 
collections, I am led to believe that all the first mentioned species are from the highly disturbed Laramie strata, while the latter are from those which lie unconformably upon the disturbed strata, and which have been generally regarded as Lower Tertiary beds by the geologists who have examined that region. Whether this latter view is correct or not it is certain that the strata of the Bear River division of the Laramie Group, are found to be displaced to a greater extent than any of the other strata which are referred to that group.

The coal-bearing series near Evanston, Wyo., which in the report of this survey for 1877 I referred to the Laramie Group, appears, at that place, to rest conformably upon the brackish-water series, or the Bear River Laramie proper; but of this I was not then, and am not now, entirely satisfied. Those coal-bearing beds of the vicinity of Evanston are probably equiralent with the coal-bearing beds at Wales, Utah, which latter beds are understood to belong to a series of strata which are extensively developed in various parts of Utah, and which some geologists who have examined them regard as overlying more or less unconformably the equivalents of the Bear River Laramie series, and which are referred by them to the lowest Tertiary. Those Wales beds, however, contain at least two species, namely Goniobasis nebrascensis and G. tenuicarinata, which occur in the Laramie strata of the Upper Missouri River region, and also in those of Colorado east of the Rocky Mountains; and $I$ showed also in the report of this survey for 1877 that the Evanston coal-bearing series contains other Laramie species which were originally discovered in the Upper Missouri River region. As it is not my purpose, however, to discuss in this article the true character and relations of those coal-bearing beds at Evanston and Wales and the Upper Kanab beds, all of which contain at least some Laramie species, I shall give in addition to the list of well recognized Laramie fossils only separate unannotated lists of the supposed Laramie invertebrate fossils of other localities. The coal-bearing Evanston beds occurring at the only one of the supposed Laramie localities above mentioned which I have visited and examined in person, I give the lists from the other localities upon the authority of other observers.

It will thus be understood that I am omitting from this article the discussion of some of the most important questions pertaining to the Laramie period, namely, the question of its continuance after the occurrence of the great and extensive displacements which involved the strata of the Bear River brackish-water series and its equivalents; that of the original geographical continuity of the upper beds at Evanston, Wales, and Upper Kanab with the great body of the Laramie Group further eastward, and that of the continuity of deposition of the latter beds with the Wahsatch Group. The question of the true relation of the Bear River brackish-water beds with the great body of the Laramie Group has here also only a small part of the discussion which its importance demands. It is the great importance of these questions and the lack of sufficient opportunity to continue personal investigations of them in the field, that leads me to lay them aside now and wait for a suitable opportunity to prosecute their investigation in a proper manner.

The following is a list of the species that have been described from the coal-bearing beds of Bear River Valley in the vicinity of Evanston, Wyo., together with those which were originally described from other localities, but have been identified among the fossils of those beds. 
LIST OF FOSSILS FROM THE COAL-BEARING BEDS NEAR EVANSTON, WYO.

Pisidium saginatum White.

$\nmid$ Bulinus disjunctus White?

*B. subelongatus Meek \& Hayden.

*B. longiusculus M. \& H.

Helix evanstonensis White.

Macrocyclis spatiosa M. \& H.

* Columna teres M. \& H.

Hydrobia recta White.

Those marked with an asterisk were originally discovered in unquestioned Laramie strata. It will be seen that they are all Pulmonate Gasteropods, the significance of which fact I have pointed out in my former writings concerning the Laramie Group.

Among the collections brought from Southern Utah by Professor Powell are the following, which evidently belong to the Laramie Group, and they are believed to have been all collected from strata which overlie unconformably those strata in that region which are properly referable to the Bear River Laramie series. Only the first and second forms of this list are illustrated in this article.

\section{LIST OF FOSSILS FROM UPPER KANAB, UTAH.}

†Unio gonionotus White.

* Corbula undifera Meek, var. subundifera White.

Planorbis (Bathyomphalus) kanabensis White.

Physa kanabensis White.

Helix kanabensis White.

The collections of Professor Powell from the same neighborhood contained also some fossils that evidently came from strata referable to the Bear River series, and doubtless belonging beneath those which contain the fossils of the foregoing list. Among them Goniobasis cleburni and Pyrgulifera humerosa were recognized.

The collections brought in by one of the parties under the direction of Lieutenant Wheeler contain the following fossils, which are described and figured in Expl. \& Sur. West of the 100th Merid., vol. iv, part i, having been obtained from the coal-bearing beds at Wales, Utah. This collection is especially interesting, although so small, because it contains two species which are characteristic of the typical portion of the Laramie Group in Montana and Colorado.

LIST OF FOSSILS FROM THE COAL-BEARING STRATA AT WALES, UTAH.

Unio mendax White.

Goniobasis nebrascensis Meek \& Hayden.

G. tenuicarinata M. \& H.

Viviparus -

U. mendax was referred by me to U. vetustus Meek, in vol.iv, Exp]. \& Sur. West of the 100th Merid., but, afterward regarding it as a distinct species, I gave it the name U. mendax, in Bull. U. S. Geol. Sur. Terr., vol. iii, p. 605. This species, together with Goniobasis nebrascensis, and a Viviparus closely related to, if not identical with, $V$. trochiformis M. \& H., were also recognized among the fossils of a collection brought

t'These two species are illustrated in this article; the former on plate 20, and the latter on plate 23. 
from the Cañon of Desolation, Green River, Utah, by Professor Powell; the strata there being evidently equivalent with those at Wales.

Omitting special consideration of the fossils of the foregoing brief lists, although they are believed to really belong to the Laramie Group, the plan of the remainder of this article will embrace an enumeration of all the well-ascertained invertebrate species of the Laramie Group, including those of the Bear River series. Full descriptions, however, are given in this article of those species only which are illustrated upon the accompanying plates. For the purpose, however, of giving a full exhibit of the well-recognized molluscan fauna of the Laramie Group, the names of all the other species are given in systematic order, with references under each to the work or works in which descriptions and illustrations of them may be found. This article will thus present a synopsis of the invertebrate fauna of the Laramie Group, as it is known at the present time. It is a conspieuous fact that the invertebrate fauna thus presented consists wholly of mollusea. The only known examples of forms which do not belong to this class, that have been found in this group, are a few small Ostracoid Crustaceans, and some egg-masses of an insect described by Mr. Scudder under the name Corydalites fecundum, in 1878, in Bull. U. S. Geol. Sur. Terr., vol. iv, pp. 537-540.*

Besides the described species herein enumerated, there are known frag. ments of some others which are too imperfect for specific description; and in view of the fact that every season's examination of the strata of this great group in the field has brought to light new forms, we may safely conclude that many more will yet be added to the already interesting and important invertebrate fauna of the Laramie Group.

\section{CONCHIFERA.}

\section{Genus OSTREA Linnæus.}

\section{Ostrea Glabra Meek \& Hayden.}

Ostrea glabra Meek \& Hayden (1857), 1876, vol. ix, U. S. Geol. Sur. Terr. (4to ser.), p. 509 , plate 40 , figs. 2 , a, b, c, and d.

Ostrea wyomingensis Meek, 1873 , An. Rep. U. S. Geol. Sur. Terr. for 1872, p. 508 . Illustrated on plate 20 of this article.

Ostrea arcuatilis Meek, 1873, An. Rep. U. S. Geol. Sur. Terr. for 1872, p. 477.

Ostrea insecuris White, 1876, Powell's Rep. Geol. Uinta Mts., p. 112. Illustrated on plate 21 of this article.

Compare Ostrea subtrigonalis Evans \& Shumard, 1857 (redescribed and illustrated by Meek), vol. ix, U. S Feol. Sur. Terr. (4to ser.), p. 510, pl. 40, figs. 1, a, b, c, and d. (I)

By the foregoing synonymy it will be seen that I refer all the forms of Ostera yet described from the Laramie Group to one and the same species, except, perhaps, 0 . subtrigonalis, the reasons for which may be found stated upon pages 162,208 , and 217 of the report of this survey for 1877. The first and fifth forms are figured by Meek in vol. ix, pl. 40, U. S. Geol. Sur. (4to ser.). The second and fourth forms are illustrated on plates 20 and 21 , which accompany this article, but the third is not yet illustrated. It is plainly only a variety of the variety $\boldsymbol{O}$. woyomingensis, with typical forms of which it is associated.

A small Ostrea occurs not unfrequently in the Bear River Laramie series, which is probably a distinct species, but no examples sufficiently characteristic have yet been obtained.

* These interesting objects will be discussed by Mr. Scudder in his forthcoming work, Tertiary Insects of North America, and figured on plate 4, accompanying that work, figs. $4-7,13-16,18-21$, and 23. 


\title{
Genus ANOMIA Linnæus.
}

\author{
ANOMIA GRYPHORHYNCHUS Meek.
}

Plate 25, figs. 1, $a, b$, and $c$.

Anomia? gryphorhynchus Meek, 1872, An. Rep. U. S. Geol. Sur. Terr. for 1871, p. 375. Anomia (Placunopsis?) gryphorhynchus Meek, 1873, An. Rep. U. S. Geol. Sur. Terr. for 1872 , p. 509.

The following is Mr. Meek's description of this species, as given in the second place above cited:

"Shell, for an Anomia, of medium size,thin and pearaceous, a little obliquely subovate, or more or less orbicular in outline, usually somewhat narrowed towards the beak, and more broadly rounded at the opposite margin, often rather convex, but variable in this respect; cardinal margin arcuate transversely, or very slightly truncated, scarcely thicker than other parts of the shell, and without any proper marginal cardinal facet. Upper valve (assuming it to be an Anomia), in the more ventricose individuals, with umbo somewhat attenuated and eurved, so as to present the appearance of the under valve of Gryphcea, except that the obtuse immediate apex is not quite marginal. Surface usually appearing smooth, but in well-preserved specimens, especially those most depressed in form, sometimes very faint traces of fine radiating striæ, and thin, raised lamellse of growth may be seen. No scars of attachment observed on any of the specimens.

"Length and breadth of an orbicular specimen, 0.83 inch; convexity of same, 0.33 inch; breadth of an oval specimen of the same length, 0.63 inch; while there are all gradations between these extremes of form.

"In first describing this species I was unable to see any traces of muscular scars in any of the specimens then studied; but many of those since collected show them very clearly. They are precisely as in Anomia; that is, there are four impressions, one small one by the side of a little submarginal cartilage pit, close up under the beak, and three others near the middle of the valve, the largest one of the latter being. nearest the cardinal margin, and the two smaller ones just below the large one. These three central scars are more or less nearly circular or oval, and usually distinct from each other, but sometimes in contact or nearly blended together.

"Locality and position.-Two miles below Point of Rocks (Union Pacific Railroad), Wyoming, Bitter Creek series."

This species occurs quite abundantly at the limited locality, where it was originally discovered; but I have also frind it in Laramie strata holding a higher position in the Bitter Creek series, at Black Buttes Station, in Yampa Valley, near Cañon Park, and also in Crow Creek Valley, east of the Rocky Mountains, Northern Colorado. It is, however, a rare form, compared with the one next described, at all others than the firstnamed locality. Professor Powell also obtained a specimen, apparently of this species, from the cañon of Desolation, Green River, Utah.

\section{ANOMIA MICRONEMA Meek.}

Plate 25, figs. 2, $a, b, c$, and $d$.

Anomia micronema Meek, 1875, Bull. U. S. Geol. Sur. Terr., 2d Ser., No. 1, p. 43.

The following is Mr. Meek's original description of this species in the place above cited:

"Shell of medium size, thin, orbicular, subovate, or somewhat irregu. 
lar; upper valve moderately convex, more or less depressed, and nearly but not quite marginal; cardinal margin generally a little truncated, and slightly thickened; surface ornamented by very fine, regular, often deflected, radiating striæ, and small, sometimes regularly disposed concentric marks of growth. Under valve unknown.

"Diameter of well developed specimens, generally about one inch.

"This species is quite abundant, and generally moderately well preserved at the locality. As usual with fossil species of the genus, only upper valves were found. These show the muscular impressions to be exactly as in true Anomia.

"Locality and position.-From a shaft sunk on the Kansas Pacific Railroad, two hundred miles east of Denver, Colo., 45 feet below the surface, from beds of the age of the Wyoming Bitter Creek Coal series."

This Anomia has proved to be one of the most widely dispersed and abundant species of all that pertain to the Laramie Group, being especially common in the valleys of Bitter Creek and Yampa River, west of the Rocky Mountains; and also in the various fossil localities of that group east of the Rocky Mountains in Colorado. It is also known to range throughout the whole thickness of the group, a maximum of at least three thousand feet. The species shows not only the usual great variation of form common to all Anomias, but also as regards the character of the radiating lines which mark the surface. In some cases, even in well-preserved examples, the radiating lines are obsolete or wanting. Others have those lines much coarser than the average; and the examples thus varied are found associated with an abundance of those which are normally marked. The examples which are figured on plate 25 have been selected for the purpose of showing this variation of surface markings. Considerable difference in average size and in general form has also been observed at different localities, which differences were doubtless due to certain different conditions of environment while the mollusks were living. Thus, while at all the known localities of Laramie fossils east of the Rocky Mountains there is much variation as to the surface markings, there is comparatively little variation as to adult size and general form. But in the valleys of Yampa and White Rivers, west of those mountains, the specimens are generally much smaller; and in the strata at Rock Springs, in the valley of Bitter Creek, while the specimens are generally of the usual size, they have more than the average convexity of those found elsewhere. All these differences are, however, believed to be only varietal modifications of one species.

\section{Genus VOLSELLA Scopoli.}

\section{Subgenus BRACHYDONTES Swainson.}

\section{Volsella (Brachydontes) Regularis White.}

Plate 25, fig. $3 a$.

Volsella (Brachydontes) regularis White, 1878, Bull. U. S. Geol. Sur. Terr., vol. iv, p. 707.

Shell arcuate-subovate in marginal outline; valves moderately convex; upper margin more or less strongly arched from the beak to the posterior portion; thence, with a continuous but stronger curve to the postero-basal margin, which is somewhat abruptly rounded to the gently concave base; front moderately narrow, slightly projecting beyond the beaks, and abruptly rounded to the base; beaks depressed, scarcely perceptible as such, and nearly, but not quite, terminal; hinge margin short, nearly straight; umbonal slope somewhat prominent, but it is 
conspicuous only because it increases the apparent concavity of the basal portion of the valve. Surface marked by numerous, rather coarse. radiating lines or small costæ, which increase in size towards the free margins of the shell. These costæ have generally a somewhat crenulated aspect, which is due, in part, at least, to small sinuosities in their course, and in part to being frequently crossed by lines and undulations of growth; denticles or crenulations of the short front margin distinct, but not large.

Length of the type specimen, 36 millimeters; breadth at the widest part, 18 millimeters; but several less perfect examples which have been obtained at different localities indicate a much larger maximum size, the largest of which must have had a length of about 65 millimeters.

Position and locality.-The type specimen is from near the base of the Laramie Group in the valley of Crow Creek, Northern Colorado, about fifteen miles above the confluence of that creek with Platte River. Other examples are from Cañon Park, valley of Yampa River; Danforth Hills, near White River Indian Agency, Northwestern Colorado; and Rock Springs Station, Union Pacific Railroad, in the valley of Bitter Creek, Wyoming.

\title{
Volsella (Brachydontes) laticostata White.
}

\author{
Plate 25, fig. $4 a$.
}

Volsella (Brachydontes) laticostata White, 1878, Bull. U. S. Geol. Sur. Terr., vol. vi, p. 708.

Shell transversely elongate, arcuate-subelliptical; upperborder broadly and almost regularly arched; posterior border somewhat abruptly, but continuously rounded from the upper border to that of the base, which latter border is gently concave along its middle portion; front abrubtly rounded; beaks inconspicuous, situated near the front; hinge line short, nearly straight, not forming an angle with the remainder of the upper border; denticles or crenulations of the anterior border distinct but not large. Surface marked by the usual distinct lines of growth and also by fine radiating costæ, which are obsolete along the whole length of the median portion of each valve, and are more distinct upon and near the dorsal border than elsewhere.

Length, 50 millimeters; greatest width, 19 millimeters.

This species differs conspicuously from $V$. (B.) regularis, in having a greater proportionate length, straighter and less crenulate costæ, and in the absence or obsolescence of the latter upon the middle portion of the valves.

Position and locality.-Laramie strata, about four hundred feet from the base of the group; Danforth Hills, near White River Indian Agency, Northwestern Colorado.

\section{Genus AXIN EA Poli.}

\section{AXINAEA HOLMESIANA White.}

Plate 20, figs. $2 a$ and $b$.

Shell subcircular, the height and width being nearly equal; ligament area of moderate size, well defined, and marked upon each side of its median line by about seven distinctly divaricating linear grooves; beaks moderately gibbous, obtuse; hinge somewhat strongly arched; lateral teeth six or seven in number on each side, moderately strong, straight 
or only very slightly curved, their direction nearly transverse; the pits between them in all cases equaling the teeth in width; the teeth which occupy the median portion of the hinge, consisting only of numerous small but distinct crenulations. Surface marked by ordinary concentric lines of growth, and apparently by faint radiating lines, which correspond in position to the inner crenulations of the pallial border. The surface of neither of the only two examples in the collection is well preserved, but it is evidently nearly smooth and not radiately ribbed, as is usual in this genus. Upon weathered surfaces radiate lining is distinctly seen, but it is probable that it was less distinct upon the natural surface.

Height and width of the largest example, each about 47 millimeters.

The genus Axincea is regarded as a distinctively marine form, and the discovery of this species in the Laramie Group, especially so near its top as this form was found, was therefore quite unexpected. Upon its discovery the idea was first suggested that the specimens had been derived by erosion from strata of the pre-existing Fox Hills Group, but the conditions of their preservation and association were found to be such as to leave no doubt that the mollusks which formed them lived in Laramie waters. Their immediate associates are Ostrea glabra var. wyomingensis and Corbicula occidentalis, all being imbedded in the same layer. These two species are there abundant, and the only fresh-water form that was found among them was a single example of Viviparus. This is sufficient evidence that the waters in which they lived was at least in a good degree saline, for the single Viviparus may easily have drifted in among the others, while the latter are too numerous to suppose they had drifted into fresh waters. Besides which, currents of fresh waters go to saline waters, but not the reverse. The inference seems to be necessary, or at least natural, that this Axincea survived without generic change in the freshening waters of the Laramie period, while the marine associates of its progenitors failed to survive the changing conditions which wrought an almost complete faunal revolution in those waters. There are many known cases of survival analogous to this, and, even in this same Laramie Group, there are two other forms the congeners of which are generally regarded as of exclusively marine habitat or affinities, namely $\mathrm{Nu}$ culana and Odontobasis. That these forms really survived from former marine waters by adaptation to changed conditions, and that their presence where we have found them was not due to occasional incursions of true marine waters, is apparent from the fact that the localities at which they have been found are too distant from the then nearest oceanic waters for the latter to have reached them except by extensive subsidences of land which evidently did not occur.

Position and locality.-Only two examples of this shell have been found, one by myself, and the other by Mr. W. H. Holmes, in whose honor the specific name is given. They were both obtained at Point of Rocks Station, Bitter Creek Valley, Wyoming, from Laramie strata, near the top of the group.

\section{Genus NUCULANA Link.}

\section{NUCULANA INCLARA White.}

Plate 25, fig. $7 a$.

Nuculana inclara White, 1878, Bull. U. S. Geol Sur. Terr., vol. iv, p. 708.

Shell small, elongate subovate in marginal outline, gradually narrowing behind the beaks; valves only moderately convex even upon the 
anterior and umbonal portions, and without distinct umbonal ridges; beaks not prominent, situated about one-third the full length of the shell from the front; basal margin broadly semi-elliptical; anterior margin regularly rounded from the cardinal inargin to the base; postero-basal margin sloping upward to the posterior margin, which is sharply rounded to the cardinal margin; the latter margin slightly arched, or the anterior and posterior portions of it forming a very slight angle with each other ; denticles minute, numerous, twelve to fifteen or more in front of the beak, and a somewhat greater number behind it.

The very few examples of this species which have been discovered being in the form of natural casts in indurated shale, the true character of the surface is not accurately known, but it appears to have been marked only by ordinary concentric lines of growth. Character of the pallial and muscular impressions unknown.

Length, 11 millimeters ; height from base to beaks, 5 millimeters. No examples larger than this were discovered, but it is probable that it is larger at full adult size.

The occurrence of this genus within two hundred feet of the base of the group would not excite surprise, if it were not well known that the fresh and brackish water species which prevail in the Laramie Group are associated with it. The presence of the latter forms, however, in the same layers indicate that true marine conditions had ceased at the very beginning of the Laramie period.

Position and locality.-Laramie Group ; associated with Corbula undifera, Anomia micronema, Melania wyomingensis, \&c.; Danforth Hills, near White River Indian Agency, Northwestern Colorado.

\section{Genus ANODONTA Cuvier.}

\section{ANODONTA PROPATORIS White.}

Plate 24, figs. 2, $a, b, c$, and $d$.

Anodonta propatoris White, 1877, Bull. U. S. Geol. Sur. Terr., vol. iii, p. 601.

Shell elongate subelliptical in marginal outline; valves moderately and somewhat uniformly convex; beaks small, slightly elevated above the cardinal border; hinge-line long and straight; basal border broadly convex; front regularly rounded from the base up to the antero-dorsal border, which latter border is more abruptly rounded to the hinge-line; postero-dorsa: border oblique and slightly convex; postero ventral border somewhat abruptly rounded from the postero-dorsal to the basal border; cardinal margin slightly thickened but entirely plain and characteristic of the genus Anodonta.

Surface plain, or marked only by the usual lines and undulations of growth.

Length of the largest example in the collection, 62 millimeters ; height of the same from base to beaks, 36 millimeters; length of a partly grown example, 37 millimeters; height of the same, 20 millimeters.

This species is not only a true Anodonta, but in all its characteristics and its general aspect it very closely resembles several living American species of that genus. None of the examples are perfectly preserved, but the characteristics of the species are nevertheless well shown, and should perfect examples ever be discovered, it will probably be difficult to say how it differs from some one of the many closely similar living forms. It is not to be denied that in this case a separate specific iden- 
tity is assumed from its known antiquity, rather than proved by an assemblage of specific characteristics.

At the time of its discovery this was the only species of Anodonta that had ever been found in any strata of Western North America of either Mesozoic or Cenozoic age; and, with the exception of the next described species, it is the only known Anodonta yet known from any of the Western strata of the ages mentioned.

Position and locality.-Laramie strata of the Judith River series, Dog Creek, and also upon the north side of the Missouri River, near Birch Creek, Montana, where it was collected by Prof. E. D. Cope in the summer of 1876.

ANODONTA PARALLELA White.

Plate 24, fig. $3 a$.

Anodonta parallela White, 1878, Bull. U. S. Geol. Sur. Terr., vol. iv, p. 709.

Shell transversely much elongate, oblong or semi-elliptical in marginal outline; valves gently convex, apparently a little more so near the front than elsewhere; beaks situated about two-sevenths of the whole length of the shell from the front, depressed, the elevation of the whole umbonal region being very slight or hardly perceptible; hinge line long; the whole dorsal border nearly straight; both the anterior and posterior borders regularly rounded, that of the posterior end being a little more abruptly rounded than the front; base nearly straight, or perhaps very slightly emarginate along or a little in front of the mid-length; test thin ; surface smooth, or marked only by the usual lines of growth, and one or two faint linear ridges running from the beaks to the posterodorsal margin.

Length, 62 millimeters; breadth, 20 millimeters.

The extraordinary length of this shell compared with its width is an unusual feature in Anodonta, but all its other characteristics, so far as they can be observed on the only examples that have yet been discovered, indicate it to be a true Anodonta, the correctness of which reference is also suggested by the fact that all its immediate associates are freshwater forms. Only two examples have been discovered, both of which are imperfect, figure $3 a$ on plate 18 being a restoration drawn from both examples.

Position and locality.-Laramie Group, valley of Crow Creek, Northern Colorado, about ten miles above the confluence of that creek with Platte River.

\section{Genus UNIO Retzius.}

\section{UNIO ALDRICHI White.}

Plate 29, figs. $2 a$ and $b$.

Unio aldrichi White, 1878, Bull. U. S. Geol. Sur. Terr., vol. iv, p. 710.

Shell of medium size, transversely elongate, approximately oblong in marginal outline, height not diminishing posteriorily; valves moderately gibbous, especially alóng the umbonal slopes or ridges, and also forward of these; test moderately thick, becoming more so in old shells; beaks situated nearly one-third the full length of the shell from the front, incurved, broad but not very prominent, although the flattened umbo is raised above the hinge line; umbonal ridge prominent, subangular; 
postero dorsal portion of the shell behind the umbonal ridges compressed, and in young examples it is there subalate; front portion of the shell moderately gibbous, and between the front and the umbonal ridges the sides are flattened; anterior margin regularly but somewhat narrowly rounded down to the basal margin, which latter margin is straightened along its middle portion; postero-basal margin somewhat narrowly rounded, and extended upward and backward to the postero-dorsal margin; the latter margin sometimes truncated obliquely downward and backward and sometimes so rounded as to give an approximately square truncation to the posterior end of the shell; hinge line long and straight. Surface marked only by the ordinary lines of growth except all that portion which lies behind and above the umbonal ridges. This portion of the surface is marked by numerous sharply raised irregular lines or narrow ridges, with the intervening spaces wider than the ridges themselves, which, beginning almost imperceptibly just behind the umbonal ridge, extend backward with a greater or less upward curve to the dorsal and posterior borders. They usually constitute a conspicuous surface feature of the shell, but in the case of old examples they appear to have become obsolete. Their character is similar to that of markings upon corresponding parts of $U$. senectus, and U.primoevus, especially the latter.

Length of the largest discovered example, 82 millimeters; height of the same at mid-length, 48 millimeters; thickness, about 32 millimeters.

The specific name is given in honor of Mr. Charles Aldrich, formerly a member of this survey.

Position and locality.-Upper portion of the Laramie Group, Black Buttes Station, Union Pacific Railroad, Wyoming, where it is associated with a majority of the following-described species of Unio, and also with several other molluscan species.

\section{UNIO GONIAMBBONATUS White.}

Plate 29, figs. $1 a$ and $b$.

Unio goniambonatus White, 1878, Bull. U. S. Geol. Sur. Terr., vol. iv, p. 709.

Shell of medium size, transversely elongate, subtrihedral in marginal outline, being rapidly narrowed posteriorly from the anterior portion; valves moderately gibbous, their greatest convexity being in front of the mid-length and above the mid-height; test moderately thick; umbones prominent, but not much raised above the cardinal margin; beaks situated near the anterior end, depressed, a little flattened; umbonal ridge distinct, angular, and so prominent as to produce a flattened or even slightly concave space between it and the cardinal margin, giving the whole back of the shell a broadly flattened aspect; front margin regularly rounded from beneath the beaks to the basal margin, which latter margin is nearly straight in some examples, but in others broadly convex; postero-basal margin narrowly, and sometimes irregularly, rounded to the postero-dorsal margin; the latter margin forming a gentle slope downward and backward from the posterior end of the hinge; cardinal margin nearly straight, and occupying about two-thirds the whole length of the shell.

Surface marked only by the ordinary lines and imbrications of growth, but usually the angular umbonal ridges are each cut across by three or four short, distinct folds or ridges, and their intervening furrows, extending obliquely inward and backward, heing scarcely perceptible in front of the umbonal ridge, and becoming obsolete before reaching the postero-dorsal margin, or at least producing only slight undulations in it.

Length, 58 millimeters; height from base to umbones, 34 millimeters; thickness, both valves together, 28 millimeters. 
The elongate, subtrihedral outline, prominent, angular, and wrinkled umbonal ridges, and broad, flattened dorsum of this species, are features which separate it distinctly from all other known forms, whether fossil or recent, and, together with the last and the six or eight next described species, which are associated with it, shows an extent and diversity of differentiation among these earlier species of Unionidæ that is hardly surpassed among living forms of that family even in North American fresh waters.

Position and locality.--Upper part of the Laramie Group, Black Buttes Station, Union Pacific Railroad, Wyoming.

\section{UNIO BRACHYOPISTHUS White.}

Plate 22, figs. $2 a$ and $b$.

Unio brachyopisthus White, 1876, Powell's Rep. Geol. Uinta Mts., p. 126.

Shell small or of medium size, somewhat gibbous, subcircular in marginal outline, the length and height being about equal; umbones broad, not prominent; beaks depressed, situated near the middle of the dorsum; postero-dorsal portion of the shell broadly flattened, or so depressed that rounded or subangular umbonal ridges are formed, bounding the flattened or depressed posterior; cardinal margin short, and that portion of it behind the beaks is usually so depressed that the hinge ligament is hidden from sight by side view of the shell. Surface marked only by the ordinary concentric lines and laminations of growth.

Length and height of the largest example discovered, each 44 millimeters; but the example figured on plate 16 is much smaller.

This species may be readily distinguished by its subcircular outline and its very short, abruptly-sloping, and rounded posterior. The posterior portion of the young shell of this species is not proportionally so short as that of the adult, because the additions by growth are made more rapidly upon the basal border than upon that of the postero-basal region; as is commonly the case with shells of this genus.

Position and locality.-Upper strata of the Laramie Group, Black Buttes Station, Union Pacific Railroad, Wyoming, where it is associated with the preceding and most of the following-deseribed species:

\section{UNIO COUESI White:}

Plate 27, fig. 1 a.

Unio petrinus White (not Gould, 1855), 1876, Powell's Rep. Geol. Uinta Mts., p. 125. Unio couesi White 187\%, Bull. U. S. Geol. Sur. Terr., vol. iii, p. 605.

Shell very large, transversely elongate, moderately thick; test massive in fully adult shells; basal and dorsal margins subparallel, the latter broadly or slightly convex and the former more nearly straight or faintly emarginate a little behind the mid-length; front abruptly rounded; postero-dorsal and postero-basal margins both somewhat ahruptly rounded to the posterior margin, giving in most cases a subtruncated appearance to the posterior end of the shell; beaks depressed, scarcely distinguishable as such, situated in advance of the mid-length of the shell; umbones broad, not prominent; hinge massive, both cardinal and lateral teeth being strong and well developed. Surface marked only by the usual concentric lines and imbrications of growth, which become coarse and prominent in old shells. The outer prismatic layer is well preserved on some of the examples, and the same has been detected upon all the other 
species of Unio that have been found associated with it. Also, like all the species of Unio from the Mesozoic and Cenozoic strata of Western North America which I have examined, the umbones, even in the case of old shells, appear to have suffered no erosion, such as is common in the case of living Uniones of North American rivers.

Length of the largest example discovered, 150 millimeters; height of the same, 75 millimeters. The length of young shells, compared with their height, is proportionally greater.

This species was originally named U. petrinus (loc. cit.), but the name was subsequently changed to $U$. couesi, because the former name had been preoccupied by Gould for a living species of Unio.

It may be distinguished from all other species that are in any way likely to be confounded with it, by its very great size, elongate form, and subparallel dorsal and basal margins.

Position and locality.-Upper portion of the Laramie Group, Black Buttes Station, Union Pacific Railroad, Wyoming, where it is associated with the majority of the species of Unio described in this article; besides several species of Gasteropods.

\section{UNIO PROPHETICUS White.}

Plate 22, fig. $5 a$.

Unio propheticus White, 1876, Powell's Rep. Geol. Uinta Mts., p. 125.

Shell not above medium size, obliquely subovate in marginal outline, moderately thick, the greatest thickness being a little below the umbones; test moderately thick; umbones prominent; beaks reaching to or a little beyond the front of the shell, curved inward and a little forward; front nearly perpendicular; front margin slightly concave above, but abruptly rounded to the basal margin below; basal margin straightened or sometimes a little emarginate; posterior extremity abruptly rounded; dorsal margin broadly rounded, and forming, with the posterodorsal margin, a continuous curve from the beaks to the posterior extremity; the portion of each valve which bears the hinge is so inflexed as to produce a dorsal concavity that hides from sight the hinge ligament when the shell is seen by side view.

Surface marked by the ordinary lines of growth, and by numerous fine radiating striæ, which appear more distinctly in the substance of partly exfoliated portions of the test.

Length, 50 millimeters; height from base to umbones, 37 millimeters.

This fossil species is of the type of the living $U$. clavus Lamarck, which it much resembles in general aspect. It also resmebles, in some of its features, the next described species, $U$. proavitus, with which it is associated; but it is so different from any other known fossil Unio, from American strata that it cannot be mistaken for any of them.

Position and locality.-Laramie strata, near the top of the group, Black Buttes Station, Union Pacific Railroad, Wyoming, where it is associated with the preceding, and also with the majority of the species of Unio which are described in this article.

\section{UNIO PROAVIIUS White.}

Plate 22, figs. $3 a, b, c$, and $d$.

Unio proavitus White, 1877, U. S. Geol. Sur. Terr., vol.iii, p. 603.

Shell of medium size, moderately rentricose, irregularly oblong or subtetrahedral in marginal ontline; front moderately broad and trans- 
versely somewhat flattened below the beaks; test of ordinary thickness; basal and dorsal margins subparallel, the latter being broadly convex, and the former more nearly straight, or sometimes a little emarginate; front margin regularly rounded from beneath the beaks to the basal margin; posterior margin nearly straight or slightly convex, truncating the shell obliquely upward and backward, abruptly rounded to the basal margin and somewhat sharply rounded to the dorsal margin; beaks moderately strong, not elevated, but incurved and projecting beyond the front of the shell; the antero-dorsal and umbonal portions of each valve are sufficiently elevated to hide the cardinal ligament when the shell is seen by side view, but the postero-dorsal portion of each valve slopes away directly from the dorsal margin. Two obtuse ridges or elevations radiate from the beak of each valve to the margin. One of these, the umbonal ridge proper, ends at the junction of the posterior and basal margins, and the other at the junction of the posterior and dorsal margins. Between the latter ridge and the dorsal margin the space is narrow; between the two ridges the space is wider and distinctly flattened, and forward of the umboul ridge there is an umbonal flattening, or very broad and very shallow unbonal sinus, which, extending from the umbo to the basal margin, causes the slight emargination there that has been referred to. Cardinal teeth moderately strong; lateral teeth well developed. Surface marked by the ordinary lines and undulations of growth, and faint radiating lines are also usually observable, especially where the prismatic layer has been exfoliated.

Length from front to postero-dorsal prominence, 52 millimeters ; height from basal margin to dorsum, 35 millimeters; greatest thickness, both valves together, 31 millimeters.

This species is related to $U$. propheticus White, as alrearly noticed in connection with the description of that species, but the differences are well characterized in the description of each, and they are also well shown by the figures on plate 22 . The extreme anterior position of the beaks in these two species is a common characteristic among the fossil Uniones of Western North America, from the Jurassic to the Eocene strata inclusive. This feature is not unknown among living North American forms of Unio, but it is proportionally less common among them than among the fossil forms.

Position and locality.-Upper strata of the Laramie Group, Black Buttes Station, Union Pacific Railroad, Wyoming, where it is associated with all the previously described species of this article, and also with a part of the following.

\section{UNIO ENDLICHI White.}

Plate 26, figs. $1 a$ and $b$.

Unio endlichi White, 1877, Bull. U. S. Geol. Sur. Terr., vol. iii, p. 604.

Shell large, obliquely elongate, subovate in marginal outline, moderately thick, very short in front of the beaks and elongate and rapidly narrowed behind them; test strong, and massive in old shells; basal margin having a slight general convexity, but it is straightened, and sometimes a little emarginate at or a little behind the mid-length, regularly and continuously rounded to the front, and abruptly rounded to the postero-basal margin; dorsal margin proper rather short, broadly rounded from front to rear; postero-dorsal margin forming a long, gently convex downward slope to the posterior margin, which latter margin is very narrowly romnded; beaks much depressed, scarcely distinguishable 
as such, and the whole umbonal region only slightly prominent; hinge well developed; cardinal teeth strong; lateral teeth large and very long. Surface marked by the ordiuary concentric lines and imbrications of growth, which are coarse and rough on old shells.

Length of the largest example yet discovered, 130 millimeters ; greatest height of the same, 70 millimeters. These proportions, and consequently the marginal outline, varied somewhat with their growth, young examples being longer in proportion to their height. The fragments in the collection also show that the outline of adult forms was subject to considerable variation in proportional length.

This species resembles U. couesi, with which it is associated, in its large size, massive test, and simple surface; but it differs materially in outline, being much narrower posteriorly, and having its beak much nearer to the front of the shell than it is in that species. It bears some resemblance also to some of the varietal forms of $U$. dance, Meek \& Hayden, but it is constantly a more massive shell than that species; is always proportionally wider or higher at its highest part, which is near the front; and it also has its beaks placed farther forward, the front of $U$. endlichi projecting only very little beyond the beaks.

Position and locality.-Upper portion of the Laramie Group, Black Buttes Station, Union Pacific Railroad, Wyoming, where it is associated with the greater part of the species of Unio described in this article, as well as several species of Gasteropods.

\section{UNIO HoLmesianUs White.}

Plate 22, figs. $4 a, b, c, d$, and $e$.

Unio holmesianus White, 1877, Bull. U. S. Geol. Sur. Terr., vol. iii, p. 604.

Shell small, or of medium size, compact, moderately gibbous, subtrihedral in marginal outline, of ordinary length anteriorly for a short shell, but very short posteriorly; the postero-dorsal portion forming only a small narrow prominence upon the broad, abruptly truncated posterior; valves, in front of the umbonal sinus, regularly convex; umbonal sinus well defined but somewhat narrow, its posterior side a little higher or more distinctly defined than the anterior side, the sinus terminating at the base of the shell a little behind the middle; umbonal ridge prominent, forming a roughly rounded angle between the side of the valve and the posterior or postero-dorsal portion; cardinal margin very short; antero-dorsal margin sloping gently downward to the front of the shell, front and antero basal margins forming a regular and continuous curve, which extends to that portion of the basal margin where the umbonal sinus ends, where the base is a little emarginate; postero-basal margin a little roughened and abruptly rounded to the almost perpendicular or slightly oblique posterior margin; umbones somewhat prominent; beaks small, incurved; cardinal ligament moderately large. Until the shell had reached about one-third its full adult diameter the whole surface was marked by somewhat close-set rhombic papillæ, which are arranged in more or less distinct oblique lines, and which remain as the ornamentation of the upper and umbonal portions of the adult shell. All the surface below the portion thus marked by the papillæ and in front of the umbonal sinus is plain, or marked only by the ordinary distinct lines of growth. All the surface behind the umbonal sinus is marked by small, irregular, somewhat corrugated ridges, which are stronger upon the umbonal ridge than elsewhere, and from the median line of which they sometimes diverge downwards, and towards both the 
umbonal sinus and the posterior margin; but sometimes they radiate irregularly to the posterior and postero-basal margins.

Length of an adnlt example, 45 millimeters ; height from base to beaks, 42 millimeters.

This species presents a greater degree of differentiation from what may be regarded as the typical form of Unio than any other known fossil species, and fully as great as that of any species now living, even in North America fluvatile waters. It is of the same type as the living species $U$. rugosus Barnes, and in many respects it resembles that shell. Like many other fossil Uniones of the western portion of North America, it has representatives among living types that are now peculiar to this continent.

Position and locality.-Upper portion of the Laramie Group, Black Buttes Station, Union Pacific Railroad, Wyoming, where it is associated with all the preceding species of Unio herein described, and also with other fresh-water species, including several Gasteropods.

\section{UNIO DANAE Meek \& Hayden?}

Plate 27, Figs. $2 a$ and $b$.

Unio dance was originally discovered in strata of the Judith River series of the Upper Missouri River region by Dr. Hayden. It is figured and described by Meek in vol. ix, U. S. Geol. Sur. Terr. (4to ser.), p. 518 , plate 41, figs. $1 a$ and $b$. From the upper strata of the Laramie Group at Black Buttes Station, and associated with all the species of Unio that are described on the foregoing pages, some well preserved. examples have been. obtained which seem to belong to the species in question. Two examples are figured on plate 27, showing, respectively, the exterior and interior surfaces. All these examples show that the surface, even in the case of fully adult shells, was more than usually smooth; in which respect, as well as in others, it resembled the living species $U$. rectus Lamarck.

\section{UNIO CRYPTORHYNCHUS White.}

Plate 24, figs. $1 a$ and $b$.

Unio crypterhynchus White, 1877, Bull. U. S. Geol. Sur. Terr., vol. iii, p. 600.

Shell of medium size, ventricose, subelliptical in marginal outline; height a little greater forward of the mid-length than elsewhere; test moderately thick; dorsal margin nearly straight or slightly convex; basal margin broadly convex; posterior margin regularly rounded ; front margin also regularly rounded from beneath the beaks to the ventral margin; beaks rather large, distinctly defined from the body of the shell, not elevated, but projected forward and turned strongly inward, placed near the anterior end of the shell, but not reaching quite so far forward as the anterior border, between which and the beak there is a distinct sulcation; cardinal teeth strong; each valve having behind the cardinal teeth a moderately deep crypt or cavity of the beak; lateral teeth well developed, but thin and sharp. Surface marked only by the ordinary lines and lamellations of growth.

Length, 70 millimeters; greatest height from base to umbo, 45 millimeters.

This species bears some resemblance to $U$. proavitus White, which has been described on a foregoing page. That species was found in the 
upper strata of the Laramie Group at Black Buttes Station, Wyoming, where also some imperfect examples of a species apparently identical with $U$. cryptorhynchus have been found. This species differs from $U$. prowitus, however, in wanting the umbonal and postero-dorsal ridges and oblique posterior truncation of the last-named species, and also in having the front margin projecting a little beyond the beaks, instead of having the beaks projecting a little beyond the front margin as they do in $U$. proavitus.

Position and locality.-Prof. E. D. Cope discovered this species in 1876 in strata of the Judith River series of the Laramie Group, on Dog Creek; a tributary of the Upper Missouri River. As already stated, it apparently exists also in the upper strata of the Laramie Group at Black Buttes Station, Union Pacific Railroad, Wyoming. None of the specimens found at the latter locality are, however, sufficiently perfect for satisfactory determination.

\section{UNIO SENECTUS White.}

\section{Plate 28, figs. $1 a, b$, and $c$.}

Unio senectus White, 1877, Bull. U. S. Geol. Sur. Terr., vol. iii, p. 600.

Shell elongate-subelliptical in marginal ontline; convexity of the valves comparatively slight, and nearly uniform over the whole surface; test thin; both basal and dorsal margins broadly convex, or the former sometimes a little straightened; front regularly rounded; posterior margin also rounded, but sometimes more abruptly so than the front; beaks scarcely definable as such from the body of the shell, situated at about one-fifth the length of the shell from the front; hinge well developed; cardinal teeth prominent, but somewhat thin; lateral teeth long and well formed, having between their anterior end and the cardi-

- nal teeth a considerable plain space. Above and behind a line drawn from the beaks to the postero-basal margin, that is, along the line of the umbonal ridge, when one is present, the surface is marked by very numerous small crenulated undulations, which increase in number both by implantation and bifurcation with the increasing size of the shell; their general direction being backward, but along the dorsal portion of the valve they are flexed upward and end upon the dorsal margin. Below and in front of this line the surface is plain, being marked only by the ordinary lines of growth, except some fine radiating liness which appear in the substance of the shell when it has been exfoliated.

Length, 80 millimeters; height, 40 millimeters.

In its general form and surface characters, this species somewhat resembles the living Margaritana rugosa Barnes, but the undulations upon the postero-dorsal surface are much smaller, more numerous, and they occupy a proportionally broader space upon the surface of the shell than they do in that species; besides which the species here described is a true Unio, and not a Margaritana.

Position and locality.- Strata of the Judith River series of the Laramie Group, valley of Dog Creek, a tributary of the Upper Missouri River, Montana, where it was discovered by Prof. E. D. Cope in 1876. Mr. J. A. Allen also brought in examples of this species from the valley of Yellowstone River, Montana. 


\section{ONIO PRIMAEUS White.}

Plate 29, figs. $3 a$ and $b$.

Unio primavus White, 1877, Bull. U. S. Geol. Sur. Terr., vol. iii, p. 599.

Shell of medium size, broadly subovate in marginal outline when adult, but proportionally narrower when young; valves moderately convex, each having a faint umbonal sinus or radiating flattened space, which ends at the basal margin a little behind the mid-length of the shell; this sinus or flattened space is bordered posteriorly by a broad undefined, umbonal ridge, or slight radiating prominence which ends at the postero-basal border; beaks situated nearly equidistant from the anterior and posterior ends, or a little nearer to the anterior, prominent by reason of the sloping away from it of both the antero and postero dorsal borders as well as the sides; from the beaks to the postero-basal portion of the shell the margin is broadly convex; postero-basal margin abruptly rounded to the base, the latter margin being gently convex, or sometimes a little straightened where it is met by the umbonal sinus or flattened space; front regularly rounded; both cardinal and lateral teeth well developed; the cardinal tooth of the left valve passing into a pit in the right valve which is situated directly under the beak. The posterior end of the lateral portion of the hinge has a peculiar modification of the usual method of articulation in Unio, as shown by fig. $3 b$, plate 29 . It also ends by a thickening of the substance of the hinge and a rounding of its end, instead of having the lateral teeth ending sharply as is usual in shells of the genus Unio. Surface marked by the ordinary lines and undulations of growth, and the postero-dorsal portion is also marked by irregular raised linear ridges that have a somewhat corrugated appearance, their direction being from the beak towards the posterior and postero-basal borders. Besides these markings exfoliated portions of the test show fine radiating lines.

This shell may be readily distinguished by its broadly subovate outline and the peculiar irregular raised lines on the postero-dorsal surface. The peculiar character of the end of the lateral portion of the hinge which is seen in this shell is also to be observed in $U$. stewardi White, from the Jurassic strata of Northern Utah, but the hinges of the fossil Uniones that have hitherto been found in the Mesozoic and Cenozoic rocks of Western North America do not otherwise show any differences from those which prevail among the living Uniones of North American rivers.

Length of an adult example, 65 millimeters; height of the same from base to beaks, 49 millimeters.

Position and locality.-Ferruginous sandstones at the summit of the Judith River series of the Laramie Group; south of Cow Island, Upper Missouri River, Montana, where it was collected by Prof. E. D. Cope in 1876.

\section{Unio PRIscus Meek \& Hayden.}

This species was discovered by Dr. Hayden in strata of the Judith River series of the Laramie Group, in the valley of Yellowstone River, and it has hitherto been discovered nowhere else. It is described and figured in vol. ix, U. S. Geol. Sur. Terr. (4to ser.), p. 516, plate 43, figs. 8. $a, b, c$, and $d$. 


\section{Unio subspatulat'us Meek \& Hayden.}

\section{Unio Deweyanus Meek \& Havden.}

These two species were obtained by Dr. Hayden from the Judith River series of the Laramie Group, at the mouth of Judith River, Montana. They are described, respectively, on pages 518 and 519 of vol. ix, U. S. Geol. Sur. Terr. (4to ser.), and both are figured upon plate 41 of the same volume.

\section{Unio vetustus Meek.}

\section{Unio Belliplidatus Meek.}

Both of these species are described and figured in vol. iv, U. S. Geol. Sur. 40th Parallel (King), the former on p. 164, pl. 16, figs. 5 and $5 a, b$, and $c$; and the latter on p. 165, pl. 16 , figs. 4 and $4 a$. The former is also described and figured in Captain Simpson's report of the Great Basin of Utah, p. 361, pl. 5, figs. $12 a$ and $b$. They are both associated together in the Bear River series of the Laramie Group at several points in Bear River Valley, both above and below Evanston, Wyo. Dr. Peale has also brought fragments of the former from two or three localities still further northward.

\section{UnIo GoNIONOTUs* White.}

Plate 26, figs. $2 a, b, c, d$, and $e$.

Unio gonionotus White, 1876, Powell's Rep. Geol. Uinta Mts., p. 116.

Shell elongate subelliptical in marginal outline; flattened and thin when young, but becoming gibbous and even almost cylindrical when fully adult; dorsal margin broadly convex; base straightened in the adult, but broadly convex in the young shell; front regularly rounded; the rounding of the posterior end somewhat irregular in consequence of the presence there of the plications which end posteriorly; beaks obsolete, the umbonal surface of each valve so flattened that they form an acute angle at the dorsum of young shells, but the angle increases in degree with age so that it is very obtuse in the adult shell. Surface of the anterior portion of the shell marked only by the ordinary lines and laminations of growth, but the posterior portion, comprising more than half the length, is marked by a few strong, more or less irregularly radiating plications, which begin faintly a little forward of the middle, and increase gradually in strength to the posterior and postero-dorsal margins, the number being increased by a few bifurcations as the shell in creases in size. Curving upward and backward from the uppermost of the longer plications just mentioned there are several smaller, shorter ones that end at the postero-dorsal margin.

Length of the largest example in the collection 63, millimeters; height, 35 millimeters. Young examples have very different proportions and shape, as is shown by figures $2 c, d$, and $e$, on plate 26 .

This species differs conspicuously from any other fossil Unio known to me, although young examples of it bear some resemblance to those of the living species $U$. multiplicatus; but adult examples have a very

* This species is one of the collection made by Professor Powell at Upper Kanab, Southern Utah, and the only one of that collection which is illustrated in this article. 
different aspect. Although two or three species of Univ from strata of the Laramie Group have the surface partially rugose, this form, with the exception of $U$. belliplicatus, is the only distinctly plicate one that has yet been found in any American strata. It differs from $U$. belliplicatus in its general shape and in the position and distribution of the plications, which are most conspicuous on the anterior portion of that shell, while the corresponding portion of $U$. gonionotus is plain.

Position and locality.-Laramie strata, Upper Kanab, Southern Utah, where the only known examples of the species were collected by Professor Powell.

\title{
Genus SPHARIUM Scopoli.
}

\author{
SPHARruU PLANUM Meek \& Hayden. \\ SPHARIUM RECTICARDINALE M.\& H. \\ SPHAERUM FORMOSUM M. \& H. \\ SPHAERIUM SUBELLIPTICUM M. \&. H.
}

These four species of. Sphorium were collected from the Laramie strata of the Upper Missouri River region by Dr. Hayden-the two former from the Judith River series, and the two latter from the Fort Union series. They are all described in vol. ix, U. S. Geol. Sur. Terr. (4to ser.), pages 526 and 527, and figured on plate 43 of the same volume. No other examples of Sphcerium have been discovered in the Laramie Group, if we except a small undescribed form in the coal-bearing series near-Evanston, Wyo.

\section{Genus CORBICULA Megerle.}

\section{Corbicula obesa White.}

Plate 23, Figs. $3 a, b, c, d$, and $e$.

Corbicula obesa White, 1878, Bull. U. S. Geol. Sur. Terr., vol. iv, p. 712.

Shell small, or not above the average size common to this genus, inflated; sides somewhat regularly convex, suboval, or subtrihedral in marginal outline; transverse length somewhat greater than the height; basal margin almost regularly rounded, meeting both the posterior and anterior margins by regular and nearly equal curves; postero-dorsal portion of the shell, as seen by side view, regularly rounded from the beaks to the posterior margin; antero-cardinal margin short and straight, but the shell has the appearance of being concave in front of the beaks on account of the slight elevation and forward prominence of the latter; postero-dorsal margin very little, if any, depressed below the adjacent portions of the shell; beaks small, pointed, not prominent, directed a little forward, and situated only a little in advance of the midlength; lateral teeth well developed, slender, and apparently not crenulate, but none of the examples in the collection are in a condition to show the natural surface of the teeth clearly; cardinal teeth well developed, but not robust; pallial sinus small. Surface marked only by the usual lines of growth; and these being mostly very fine, the surface has a comparatively smooth, or sometimes even a polished, aspect in well preserved examples.

Length of the largest example in the collection, 38 millimeters; height of the same from base to umbo, 30 millimeters; thickness, both valves together, 25 millimeters. The average adult size is apparently considerably less. 
The distinctly subglobose form and comparatively smooth surface of this species are distinguishing features, and it differs too greatly from any described form of the germs to need detailed comparison with any.

While the greater part of the species found in strata of the Laramie Group that are referred to Corbicula vary in different characteristics and degrees from the typical forms of that genus, this one seems to possess the true typical characters. At least it is not referable to either of the subgenera that have been proposed, and which are noticed on following pages.

Position and locality.-Laramie Group, valleys of Crow and Bijou Creeks, Northern Colorado, at which localities alone it has yet been found, and where it is associated with other species of Corbicula.

CORBICULA CARDINI AFFORMIS White.

Plate 25, figs. $5 a$ and $b$.

Corbicula cardiniaformis White, 1878, Bull. U. S. Geol. Sur. Terr., vol. iv, p. 711.

Shell somewhat above medium size for a species of this genus, transversely subelliptical, moderately gibbous, especially a little forward of and above the middle, but somewhat compressed towards the free margins, especially in the posterior region; front and posterior margins both somewhat narrowly rounded, and the base broadly rounded, forming together nearly a semi-ellipse; cardinal margin broadly rounded, the postero-dorsal margin sloping gently downward from the beaks to the posterior margin ; antero-dorsal margin slightly concave just in front of the beaks, where the slight inflexion of the valves also produces a slight concavity in the'shell when both valves are together; umbonal portion of each valve prominent; beaks narrowed, distinctly defined, not much elevated, but pointing strongly forward and incurved. Hinge and interior markings unknown.

Length from front to rear, 59 millimeters; height from base to beaks, 38 millimeters; greatest thickness, both valves together, 28 millimeters.

In external form this species seems to occupy an intermediate position between the usual short or typical forms of Corbicula and that section of the genus which was separated from it by the late Mr. Meek under the subgeneric name of Leptesthes. In this respect it bears considerable resemblance to a form figured on plate 23 , figs. $2 a$ and $b$, which I regard as only a variety $C$. (L.) fracta Meek. It differs, however, from that form, and from all other species of Leptesthes known to me in the prominence and distinct definition of the beaks; the umbonal region being broadly flattened and the beaks depressed and illy defined in all the published species of the subgenus Leptesthes; which feature seems to be one of its distinguishing characteristics. It was found associated with $C$. cleburni, to which it bears some resemblance in general form, but it differs too greatly from it to need detailed comparison.

Position and locality.-Laramie Group, Valley of Crow Creek, 15 miles above the conflu ence of that creek with Platte River, Northern Colorado

\section{Corbicula CLEBURNI White.}

Plate 23, figs. $1 a, b$, and $c$.

Corbicula cleburni White, 1878, Bull. U. S. Geol. Sur. Terr., vol. iv, p. 711.

Shell rather large, subcircular or subtrihedral in marginal outline; height from base to umbo about equal to the extreme transverse length, 
moderately gibbous, the valves having a nearly regular convexity, flattened or a little concave along the postero-dorsal portion; moderately concave in front of the beaks, where there is an almost defined lunule; test thick or even somewhat massive in old shells; dorsal outline forming a somewhat regular convex curve from the beaks to the postero-dorsal portion, the border of which latter portion is abruptly, sometimes almost angularly, rounded to the lower margin; the latter margin forming an approximately true semicircular curve from the posterior to the anterocardinal margin, but the convexity of this curve is in old shells a little greatest about its middle; antero-cardinal margin straight or slightly concave, meeting the antero-basal margin at an obtuse angle or prominent, abrupt curve; beaks prominent, elevated, curving inward and forward, and, when well preserved, ending in a well-defined point; lateral teeth strong, well developed, and finely crenulate; cardinal teeth well developed, the outer posterior one showing, in one example at least, faint crenulations, but otherwise they are of the ordinary character; pallial line distinct, somewhat distant from the margin; pallial sinus small, directed strongly upward.

Surface marked only by the ordinary lines and undulations of growth.

Height of the largest example in the collection, 42 millimeters; extreme transverse length about the same; thickness, both valves together, 32 millimeters. The largest examples are all more or less broken; those figured on plate 23 being of smaller size.

This species bears, perhaps, more resemblance to C.cytheriformis Meek \& Hayden, than to any other published form; but it may be distinguished from the typical forms of that species by its more distinctly subtrihedral outline, its greater proportionate height and its concave, almost lunulate front. It bears some resemblance also to $C$. occidentalis, especially to some examples of the variety of that species which occurs in the valleys of Bitter Creek and Yampa Rivers, to be noticed on a following page.

Position and locality.-Laramie Group, valley of Crow Creek, Northern Colorado, about 15 miles above the confluence of that creek with Platte River.

\section{CoRbicula CyTHERTFormis Meek \& Hayden.}

Plate 21, figs. $4 a, b, c$, and $d$.

The type specimens of this species were discovered by Dr. Hayden in the Laramie strata of the Judith River series. It is described and figured by Meek in vol. ix U. S. Geol. Sur. Terr. (4to ser.), p. 520, pl. 40, figs. $5 a, b, c, d$, and $e$. It has been recognized also in the Bitter Creek series, the specimens which are illustrated on plate 21 having been obtained from a locality about two miles west of Point of Rocks Station, Union Pacific Railroad, Wyoming.

\section{Corbicula nebrascensis Meek \& Hayden.}

Dr. Hayden obtained this form also from the Laramie strata of the Upper Missouri River region; and it has not yet been recognized at any other locality. It is described and figured by Meek in vol. ix U. S. Geol. Sur. Terr. (4to ser.), p. 522, plate 43, figs. $2 a$ and $b$. 


\section{Corbicula occidentalis Meek \& Hayden.}

Plate 21, Figs. $3 a, b$, and $c$.

Corbicula occidentalis Meek \& Hayden, 1856, Proc. Acad. Nat. Sci. Philad., vol viii, p. 116 .

Corbicula (Veloritina) bannisteri Meek, 1873, An. Rep. U. S. Geol. Sur. Terr. for 1872, p. 513.

The collections of Dr. Hayden from the Laramie strata of the Judith River series contain the type specimens of this species, which are described and figured by Meek in vol. ix U. S. Geol. Sur. Terr. (4to ser.), p. 521, Pl. 40 , Figs. $6 a, b$, and $c$. The illustrations on plate 21, figs. $3 a, b$, and $c$, accompanying this article, are drawn from examples that were obtained in the valleys of Bitter Creek and Yampa River, and identified with this species. Figures $3 b$ and $3 c$ are drawn from the type specimen of $C$. bannisteri Meek, which is regarded as synonymous with $C$. occidentalis, because among the numerous examples of the variety of $C$. occidentalis which were obtained at and near the locality which furnished the type of $C$. bannisteri are many which show a direct gradation to that type from forms which cannot be separated from $C$. occidentalis.

Among the collections brought by Professor Powell from Upper Kanab, Southern Utah, is a single example which I am unable to distinguish from the forms that in the Bitter Creek series I refer to $C$. occidentalis.

\section{Subgenus LEPTESTHES* Meek.}

\section{Corbicula (Leptesthes) Fracta Meek.}

Plate 23, figs. $2 a, b, c, d$, and $e$; and plate 21, fig. $5 a$.

Corbicula? fracta Meek, 18i1, An. Rep. U. S. Geol. Sur. Terr. for 1870, p. 314.

Corbicula? fracta, var. crassiuscula Meek, 1873, An. Rep. U. S. Geol. Sur. Terr. for 1872, p. 512.

The following is Mr. Meek's original description of the species :

"Shell attaining a rather large size, longitudinally ovate, wider (higher) anteriorly, compressed, very thin and fragile; anterior margin rounded; pallial margin semi-ovate in outline; posterior margin narrower than the other and subtruncate; dorsal outline sloping gradually, with slight convexity behind the beaks, and more abruptly in front; beaks rather depressed, oblique, and placed about one-third the length of the valves from the anterior extremity; surface only showing very obseure lines and somewhat stronger ridges of growth.

"Length, 2.24 inches; height at the beaks, 1.48 inches; convexity, apparently about 0.40 inch.

"Specimens of this species are all more or less flattened by accidental compression, but show the outline and surface characters perfectly, even remains of their epidermis. With considerable difficulty I have succeeded in clearing away the matrix so far as to see that the hinge-margin is comparatively strong for so thin a shell. It shows apparently three diverging cardinal teeth in each valve, and a linear anterior lateral tooth extending parallel to anterior margin; while the posterior lateral teeth are somewhat remote from the cardinal, and rather elonrated. On these posterior lateral teeth I have seen transverse striæ, which, doubtless, also exist on the anterior lateral, though I have not seen a specimen in a condition to show them. Internal casts show the

*For a diagnosis of this subgenus see vol. ix U. S. Geol. Sur. Terr. (4to ser.) p. 161; und also remarks accompanying this description. 
anterior muscular impression to be ovate, and the posterior, broader, or more nearly circular, while the pallial line shows a shallow, rounded sinus, forming less than a semi-circle.

" Locality and position.-Hallville coal mines, just above a bed of coal, in a black, argillaceous, rather hard rock, that may be shaly at some other places."

Figure $2 a$ on plate 23 represents one of Mr. Meek's types, from which the foregoing description was drawn.* At the time he published that description the specimens with a much thicker test were not discovered. The latter specimens occur in a different condition of preservation, but in equivalent strata, near the top of the Laramie Group, at Black Buttes Station, only four miles from Hallville, on the Union Pacific Railroad, Wyoming. The species proves to be a much more variable one in form, and the natural thickness of the test much greater, than was anticipated by $\mathrm{Mr}$. Meek; and there are such good reasons for placing all the Hallville and Black Buttes forms under one specific name that I do not adopt his suggestion of a separate name for any of the forms of this type which are found at Black Buttes. Some of the latter forms are figured on plates 23 and 21 ; which figures show a good degree of variation, but not the full extent which prevails in the species.

The following are Mr. Meek's remarks on the Black Buttes forms which he discusses under the name Corbicula? fracta var. crassiuscula, two years after his first description was published; together with his original remarks on the characteristics of the subgenus Leptesthes, as given in the annual report of this survey for $1872, \mathrm{p} .512$. They are given at length because it is desirable to have the full discussion of this subgenus presented in connection with descriptions and illustrations of all its known species.

"This shell agrees so very closely in form and size, as well as in its hinge and pallial and muscular impressions, surface characters, \&c., with the species I have described from the shale over one of the Hallville beds [of coal] under the name Corbicula fracta that it hardly seems proper to separate it specifically. Yet in the thickness of the substance of these shells from the two localities and horizons, there is a very marked difference, those from Hallville being extremely thin, even in the largest specimens, the thickness not measuring more than from 0.02 to 0.03 inch, while in examples of corresponding size of those here under consideration it measures from 0.10 to 0.12 inch in thickness. The latter also seem to be more convex, but the Hallville specimens, being generally more or less flattened between the laminæ of the shale, it is difficult to know exactly how far this want of convexity may be due to accidental pressure.

"I am aware that shells found in argillaceous shales are usually thinner than examples of the same species from more calcareous deposits; but I have never seen a difference of this kind so strongly marked in specimens certainly known to belong to the same species. This thicker shell is therefore placed here provisionally as a variety of $C$. fracta, under the name crassiuscula, which it can retain if further comparisons should show it to be specifically distinet.

"In describing the species $C$. fracta, I noticed several points of difference between it and the characteristic forms of Corbicula and Cyrena, and suggested for the group of which it may be regarded as the type, the subgeneric name Leptesthes. The peculiarities mentioned were the

\footnotetext{
* The flexed outline of the posterior border is regarded as accidental to that specimen only, and not a specific character.
} 
extreme thinness of the shell and its very elongated depressed form. The specimens here under consideration show that the thinness of the shell is not a constant character, though they at the same time show that this type presents other more important differences, of which I had seen indications before, but which I did not mention especially because the specimens then seen were not sufficiently well preserved to permit these characters to be clearly defined. They are differences in the hinge. For instance, although the primary teeth do not differ materially from those of Corbicula and Cyrena, the anterior lateral tooth differs from that of Cyrena in being linear and elongated parallel to the hinge-margin, as wull as slightly striated, thus agreeing with the corresponding tooth of Corbicula. Its posterior lateral tooth, however, on the other hand, is more nearly as in Cyrena, being shorter than in Corbicula, and placed very remote from the cardinal teeth, while the intervening cardinal margins are wide, flat, and, when the valves are united, close fitting. Yet this tooth is also striated, as in Corbicula, though less distinctly. Again, the ligament is also decidedly longer than in Corbicula, or than is usual in Cyrena, and also less prominent, there being apparently no elevated fulcrum for its attachment. The pallial line shows a shallow subsemicircular sinus.

"It will thus be seen that these shells combine some of the characters of both Cyrena and Corbicula, without agreeing exactly with either. It is well known to paleontologists, however, who have studied fossil shells of these groups, that there are many species that show intermediate characters between these genera, so that some eminent authorities do not admit the genus Corbicula, but place the whole under Cyrena. Should this view prevail, the forms here under consideration might be so disposed of. Still, even in that case it would seem desirable and convenient to separate them subgenerically by writing the name Cyrena (Leptesthes) fracta. If the two groups, Cyrena and Corbicula, however, are to be regarded as distinct genera, there would be nearly or quite as good reasons for regarding Leptesthes as a genus."

In some remarks upon $C$. (L.) planumbona in the Bulletin of this survey, 2 series, No. 1, p. 45, Mr. Meek further notices the fact that the pedal muscular scar in this subgenus is detached from the anterior adductor scar, and not blended with the latter. This characteristic is shown in figure $4 e$, on plate 23 , accompanying this article. For other characteristics of Leptesthes, not mentioned by Mr. Meek, see remarks on a following page, following the description of $C$. (L.) macropistha.

\section{Corbicula (Leptesthes) Planumbona Meek.}

Plate 21, figs. $2 a, b, c$, and $d$.

Corbicula? (Leptesthes) planumbona Meek, 1875, Bull. U. S. Geol. Sur. Terr., $2 \mathrm{~d}$ ser., No. 1, p. 43.

This species, so far as it is yet known, is confined to the Laramie strata east of the Rocky Mountains in Colorado, where, however, it appears to be comparatively abundant and to have a considerable geographical range. The type specimens from which Mr. Meek drew the following description were all imperfect, and the illustrations on plate 21 are therefore drawn from some fine examples obtained by myself in the valley of Crow Creek, Colorado:

"Shell attaining a moderately large size, rather thick and strong, especially about the hinge of large specimens, generally of a short, transversely oval or subelliptic form but rather variable in outline, moder- 
ately and evenly gibbous, the greatest convexity being in the central region; anterior margin prominently and rather narrowly rounded; posterior vertically subtruncated; base forming a more or less nearly semi-elliptic or semi-ovate curve; dorsal outline sloping from the beaks, the anterior slope being more abrupt and concave in outline, while the posterior is generally convex; umbones subcentral, moderately prominent or somewhat depressed, usually eroded, and more or less flattened near the apices which are not strongly incurved, distinctly pointed, or raised much above the hinge margin; lunular region in the specimens with more gibbous umbones, somewhat excavated, but not distinctly impressed, or with defined margins; ligament narrow and not very prominent [in some well-preserved examples it is quite prominent]; anterior muscular impression ovate, well defined, and distinct from the small pedal scar under the hinge, above and behind its upper end; posterior muscular impression broader and more shallow; pallial line usually well defined and provided with a shallow, rounded, or semicircular sinus; hinge rather strong, with the three cardinal teeth well developed in each valve; the anterior two of the left valve and the posterior two of the right being more or less sulcated; anterior lateral teeth long, linear, and not very prominent; posterior shorter and very remote from the cardinals; both anterior and posterior laterals very nearly smooth or minutely granulo-striate.

"Length of a medium-sized adult specimen, 1.62 inches; height, 1.2S inches; convexity, 0.92 inch. Some fragments indicate one-third greater size for the largest.

"Locality and position.-Two hundred miles east of Denver City, on the Kansas Pacific Railroad, when they were found in a shaft at a depth of forty feet below the surface."

It also occurs in the Laramie strata of the valleys of Crow and Bijou Creeks, Northern Colorado. At the former locality many well-preserved examples were obtained, some of which are figured on plate 21 .

\section{CoRbicula (LEPTESTHES) MACROPISTHA White.}

Plate 23, figs. $4 a, b, c, d, e$, and $f$.

Corbicula (Leptesthes) macropistha White, 1878, Bull. U. S. Geol. Sur. Terr., vol. iv, p. 713.

Shell small, longitudinally subelliptical or subovate, broader (higher) posteriorly than anteriorly, slightly gibbous or somewhat compressed in the central portion; test strong, but not massive; basal margin broadly convex; posterior margin truncating the shell, its direction being almost perpendicular or inclining a little backward from below, and somewhat abruptly rounded to both the postero-dorsal and basal margins ; posterior cardinal margin broadly convex ; anterior cardinal margin nearly straight and directed obliquely downward and forward to the front, which is abruptly rounded to the base; beaks depressed, not well defined, not projecting above the hinge-margin, and situated about onethird the length of the shell from the front. Surface showing the usual lines and imbrications of growth; and well-preserved examples show that the former were so fine on a large part of the surface as to give it an almost polished aspect. Lateral teeth well developed and finely crenulate; cardinal teeth having the usual characteristics of the genus; pallial line somewhat distant from the margin; sinus shallow.

Length of an average sized example, as indicated by the twenty or thirty specimens in the collection, 21 millimeters; height of the same, 
15 millimeters; thickness, both valves together, 10 millimeters. There are two or three examples in the collection which were obtained from a layer separated by only a few feet from the one containing the typical specimens, at the Urow Creek locality, which seem to belong to this species, but, as they have some slight modifications of form besides their greater size, they are referred to it with doubt, and the size of the species is given as above.

This shell plainly belongs to the subgenus Leptesthes of Meek, but it is the smallest species yet known, as the type species is the largest. The species here described shows characteristics of the subgenus that were not mentioned by Meek in his diagnoses. The inner surface of each valve is marked by a somewhat broad, faintly raised, smooth ridge which traverses the valve nearly perpendicularly from beneath the beak to the basal border. This ridge is always faint, and in the species here considered it appears to be formed by a sudden thickening of the whole test forward of the median portion of the shell, rather than by a linear elevation of shell substance, such as constitutes the so-called internal rib of some shells. The beaks are also small, and the umbones not so prominent in the case of all species of this subgenus, as they are in the typical forms of the genus, and especially in the subgenus Veloritina. The peculiar flattening of the umbonal and upper and middle portions of the valves of $C$. ( $(\vec{V}$.$) macropistha, its greater width and equal if not$ greater thickness behind than in front, are characters by which the species may be readily recognized.

Position and locality.-Laramie Group; valleys of Crow and Bijou Creeks, Northern Colorado; associated with the last described and other species.

\section{Corbicula (Leptesthes) subelliptica Meek \& Hayden.}

The type specimens of this species were collected by Dr. Hayden from the Judith River series of the Upper Missouri River region; and Mr. Meek also recognized it among some collections that were brought in by one of the parties of this survey from the valley of Bijou Creek, Northern Colorado. I also collected it at the latter locality, where I found it associated with the preceding and other species. Mr. Meek described and figured it in vol. ix, U. S. Geol. Sur. Terr. (4to ser.), p. 523, plate 43.

\section{Subgenus VELORITINA* Meek.}

\section{Corbicula (Veloritina) DURKeei Meek.}

This species, which is the type of the subgenus Veloritina, has been found only in the Bear River series of the Laramie Group, where it is one of the most characteristic fossils. The typical examples were obtained in Bear River Valley, near the mouth of Sulphur Creek, but the species is known to range as far south as Southwestern Utah, some examples of it having been brought in by one of the parties under the direction of Lieutenant Wheeler; and figured and described by me in vol. iv, Expl. and Sur. West of the 100th Meridian. It is figured and described by Meek in vol. iv, U. S. Geol. Sur. 40th Parallel (King), p. 167, pl. xvi, figs. 6 and $6 a, b, c, d, e, f$, and $g$.

This species, the type of the subgenus Veloritina, seems to be suffi161.

* For a diagnosis of this subgenus see vol. ix, U. S. Geol. Sur. Terr. (4to ser.), p. 
ciently distinct from the typical forms of Corbicula to warrant its separation as proposed by Meek, but there are known forms that seem to connect the two types by direct gradation. $C$. cleburni, $C$. Occidentalis, and $C$. Oytheriformis seem to be such connecting forms, but perhaps they might with propriety be referred to Veloritina.

\title{
Genus CORBULA Bruguiere.
}

\author{
Corbula subtrigonalis Meek \& Hayden. \\ Corbula PERUNDATA Meek \& Hayden. \\ CoRBULA CRASSATELLTFORMIS Meek. \\ CORBULA TROPIDOPHORA MEEK.
}

In the annual report of this survey for 1877, p. 170, I placed all four of the above-named forms under one species, C. subtrigonalis, and I have since seen no cause to change my views upon that point, although it is true that selected examples of each form present differences that would be necessarily regarded as specific if no intermediate forms were known to connect them too nearly for specific separation. It is also true that at different localities this species presents recognizable varietal differences, but these are doubtless due to different environing conditions while the mollusks lived.

Dr. Hayden obtained the type specimens of the two first-named forms from the Judith River series of the Laramie Group, in the Upper Missouri River region. They are described by Meek in vol. ix, U. S. Geol. Sur. Ter. (4to ser.), pages 529 and 530, respectively, and figured on plate 40 of the same volume.

Mr. Meek originally described both $C$. crassatelliformis and $C$. tropidophora from strata of the Bitter Creek series of the Laramie Group, the latter holding a position a few hundred feet lower in the series than the former. The latter is described in the annual report of this survey for 1872, p. 514, and the former (under the name Corbicula? crassatelliformis) in the report for 1870, p. 315. Both these forms are figured on plate 25 , accompanying this article, together with others from Crow Creek, Colorado, east of the Rocky Mountains.

\section{Corbula mactriformis Meek \& Hayden.}

This species seems to be distinct from either of the four preceding forms, and yet it may perhaps prove to be only a variety. It has been found only in the Laramie strata near Fort Clark, in the Upper Missouri River region, where it was discovered by Dr. Hayden. It is described. and figured by Meek in vol. ix, U. S. Geol. Sur. Terr. (4to ser.), p. 528, plate 43 , figs. $7 a-f$.

\section{Corbula undifera Meek.}

Plate 29 figs $4 a, b, c, d, e$, and $f$.

Corbula undifera Meek, 1873, An. Rep. U. S. Geol Sur. Terr. for 1872, p. 513.

This well-marked species has proved to be a characteristic fossil of the Laramie Group west of the Rocky Mountains. The following is Mr. Meek's description:

"Shell of moderate size, trigonal subovate, rather convex, the inequality of the valves not being very strongly marked, although always 
obvious; beaks moderately prominent, that of the left valve being only a little more elevated than that of the other, located in advance of the middle, contiguous, incurved, with a scarcely perceptible, forward inclination; posterior extremity subangular at the connection of its margin with the base; posterior dorsal slope more or less convex in outline: anterior margin rather short and rounded; base semi-ovate in outline, being most prominent anteriorly, and somewhat straightened behind; left valve about one-fourth less convex than the other, with posterior umbonal slope less strongly angulated; surface of both valves ornamented with concentric ridges, generally small and regular on the umbonal region, but often swelling out into a few very prominent angular folds with rounded depressions marked by distinct lines of growth and some small ridges between on the lower half of the valves; all the ridges and folds generally becoming obsolete behind the angular posterior umbonal slope, but continued forward to the front.

"Length of a well-developed specimen, 0.76 inch; height to top of umbo of left valve, 0.56 inch; convexity of the two valves united, 0.41 inch.

"Locality and position.-Rock Springs Station, Central [Union] Pacific Railroad, Wyoming Territory. Upper part of the Bitter Creek series."

Typical forms of this species have been found in the valley of White River, Northwestern Colorado, near the base of the Laramie Group there, which shows it to range nearly or quite through the whole thickness of the group. Figs. $4 a$ and $b$, on plate 29 , are of an unusually large example, from Rock Springs.

\section{CORBULA UNDIFERA, var. SUBUNDIFERA.}

Plate 29, figs. $5 a, b$, and $c$.

Corbula subundifera White, 1876, Powell's Rep. Geol. Uinta Mts., p. 129.

This form was originally described by me as a distinct species, but it is so very nearly related to $C$. undifera, the form just described, that I am now disposed to regard it as only a variety of that species. I however give it a separate description and illustration in this article, because it is so constant in the minor differences which distinguish it from the typical form, and because those differences are recognizable at widely separated localities, examples of this variety having been brought by Professor Powell from Upper Kanab, Southern Utah.

Shell of ordinary size; marginal outline subtrihedral or subovate; valves only slightly unequal; beaks contiguous; umbones moderately prominent; beaks incurved and directed a little forward; front obliquely truncate, concave, producing indistinctly defined anterior umbonal ridges; abrùptly rounded below to the basal margin, which is broadly rounded; posterior extremity low, prominent, and sharply rounded; postero-dorsal margin sloping from the dorsum to the posterior extremity; this margin of each valve is bent abruptly inward and downward, producing a narrow, shallow furrow, bordered at each side by a somewhat prominent ridge, which extends from behind the beak to the posterior extremity of the shell. Surface marked by numerous more or less strongly elevated concentric folds, which disappear before reaching the posterior margin, and are usually less distinct in front than upon the sides. Between these folds, and upon those parts of the surface unmarked by them, there are ordinarily distinct concentric lines of growth.

Length, 25 millimeters; height, 18 millimeters.

Position and locality.-With the exception of the Southern Utah spec- 
imens before referred to, this form has been found only at Point of Rocks Station, Union Pacific Railroad, Wyoming, in the upper strata of the Bitter Creek series of the Laramie Group, a few hundred feet above those in which the Mr. Meek's types of $C$. undifera were discovered.

\section{Corbula PYRIformis Meek.}

This species is peculiar to the Bear River Laramie series, and at most of the known localities at which those strata are exposed it is one of the most abundant forms. C. englemanni Meek, an associated form, I regard as only a variety of $C$. pyriformis. Both forms are described in vol. iv, U. S. Geol. Sur. 40th Parallel (King), pages 170 and 174, respectively, and both are figured on plate xvii of the same volume.

\section{GASTEROPODA.}

\section{Genus RHYTOPHORUS* Meek.}

\section{RHYTOPHORUS PRISCUS Meek.}

The type specimens of this species, which are also the types of the genus, were obtained from the Bear River Laramie series, near the mouth of Sulphur Creek, in the valley of Bear River, Southwestern Wyoming, in which neighborhood only it has yet been discovered. It is described and figured in vol. iv, U. S. Geol. Sur. 40th Parallel (King), page 175, plate xvii. figs. 6 and $6 a$; and also in Captain Simpson's Report of the Great Basin of Utah, p. 364, plate v, figs. $4 a$ and $b$.

Under the head of Melampus antiquus, on page 24 of this volume, I have suggested that the species described by Meek under that name from the Oretaceous series at Coalville, Utah, may perhaps belong to this genus. Unless this shall prove to be the case, the genus Rhytophorus is yet known only in the Bear River Laramie series, and the only known species are $R$. priscus, the type of the genus, and $R$. meekii White, which is associated with it, and which is described in the next following paragraphs :

\section{RHYTOPHORUS MEEKII White.}

Plate 30 , figs. $8 a$ and $b$.

Shell subfusiform, spire moderately produced, nearly one-third the length of the entire shell; volutions about six, convex, the last one somewhat large, elongate, subterete, gently tapering from about its middle to the anterior end; suture impressed, and upon the proximal side of and near it there is an almost equally impressed revolving line or narrow furrow, having the appearance of a second suture; one fold of the columella moderately well developed, and another less so. Surface marked by the ordinary lines of growth; and also, upon the spire, by numerous small varices or longitudinal folds, which cross the volutions nearly parallel to the lines of growth, and which are slightly oblique to the axis of the shell. These varices appear only upon the distal portion of the last volution, while they cross the entire exposed portion of those of the spire.

Length of the largest example discovered, 25 millimeters; diameter of the body volution of the same, 12 millimeters.

${ }^{*}$ For Mr. Meek's diagnosis of this genus see vol. iv, U. S. Geol. Sur., 40th Parallel (King), p. 175 . 
This species differs from $R$. priscus Meek, with which it is associated, in the less robust and more elongate form of the shell, its proportionally longer spire, more delicate and finer surface markings, and the less abrupt convexity of the volutions upon the proximal side of the suture.

Position and locality.-This form has yet been found only in strata of the Bear River Laramie series, near the mouth of Sulphur Creek, Bear River Valley, Wyoming, where it is associated with $R$. priscus, and numerous other molluscan forms characteristic of that series.

\section{Genus ACROLOXUS Beck.}

\section{Acroloxus minutus Meek \& Hayden.}

This is the only species belonging to the Ancylidæ that has yet been discovered in any strata of the Laramie Group. It was obtained. by Dr. Hayden from the Laramie strata, near Fort Union, in the Upper Missouri River region, and is described and figured in vol. ix, U. S. Geol. Sur. Terr. (4to ser.), p. 543 plate 44, fig. 10.

\section{Genus PLANORBIS Müller.}

\section{Planorbis convolutus Meek \& Hayden.}

The Planorbis section of the Limnæidæ is not well represented among the pulmonate mollusca of the Laramie Group. Besides the three forms here noticed, all of which are from Laramie strata of the Upper Missouri River region, only one other form is yet known in the whole Laramie Group, although other fresh-water species of both pulmonate and branchiferous mollusks are common, and species of Planorbis are also common in the fresh-water formations that succeeded the Laramie Group. The excepted species referred to is a small undescribed form from the Bear River Laramie strata near the mouth of Sulphur Creek, in Bear River Valley, which is properly referable to the subgenus Gyraulus Agassiz. It should be remarked, however, that another form, Planorbis (Bathyomphalus) kanabensis White, has been discovered by Professor Powell in strata which he is understood to regard as equivalent to the Laramie Group, at Upper Kanab, Southern Utah; which species is noticed in the introductory remarks of this article. It is an interesting fact that the subgenus Bathyomphalus as well as Gyraulus was introduced thus early. Indeed it is probable that these two subgenera were introduced as early if not earlier than the form which is usually regarded as the typical of the genus.

$P$. convolutus is described and figured in vol. ix, U. S. Geol. Sur. Terr. (4to ser.), p. 536, plate 42, figs. $12 a$ and $b$.

\section{Subgenus BATHYOMPHALUS Agassiz.}

\section{Planorbis (Bathyomphalus) amplexus Meek \& Hayden.}

See vol. ix, U. S. Geol. Sur. Terr. (4to ser.), p. 539, plate 42, figs. 16 $a, b, c, d$, and $e$.

Planorbis (Bathyomphatus) Planoconvexus Meek \& Hayden.

See vol. ix, U. S. Geol. Sur. Terr. (4to ser.), p. 538, plate 44, figs. 9 $a, b$, and $c$. 


\section{Genus LIMN ÆA Lamarck}

\section{LIMNAEA NITIDULA Meek.}

In some of the layers of the Bear River Laramie series, near the mouth of Surphur Creek, Bear River Valley, Wyoming, this species occurs quite plentifully, where alone it has yet been discovered. It is described and figured in vol iv, U. S. Geol. Sur. 40th Parallel (King), p. 181, plate 17, figs. 5 and $5 a$.

\section{Subgenus Pleurolminara* Meek.}

Limnaea (PleurolimnaA tenuicostata Meek \& Hayden.

Dr. Hayden obtained the types of this species, which are also the types of the subgenus, from the Laramie strata near Fort Union, in the Upper Missouri River region, where alone it has ever been found. Mr. Meek established the subgenus for this species alone, no other having yet been discovered. It is described and figured in vol. ix, U. S, Geol. Sur, Terr. (4to ser.), p. 534, plate 44, figs. $13 a, b$, and $c$.

\section{Genus ACELLA Haldeman.}

Plate 30, figs. $9 a$ and $b$.

Acella haldemani White, 1878, Bull. U. S. Geol. Sur. Terr., vol. iv., p. 714.

Shell very small and very slender; spire longer than the aperture; volutions about six and very obliquely coiled, slightly convex; last one not very ventricose; aperture only slightly, if at all, expanded, its outer margin, as shown by the lines of growth, being nearly parallel with the axis of the shell. Surface marked numerous fine linear raised lines corresponding with lines of growth with spaces between them about equal to the lines, their direetion being nearly or quite parallel with the axis of the shell upon the volutions of the spire, as well as upon the body volution. These lines, owing to the minute size of the shell, are distinguishable only under a lens of considerable power.

Length, 6 millimeters; diameter of last volution, $1 \frac{1}{2}$ millimeters.

This form seems unmistakably to belong to Acella Haldeman. It is the only species of that genus that has yet been found fossil in American strata of any age, if we except an undescribed form in the Green River Eocene Group of Wyoming; and is especially interesting as showing the early establishment of that type among the Limnæidæ. Meek regarded Acella as only a subgenus under Limncea, and possibly he was right, but as the type has been so long established in nature, and the limits of genera are of very unequal distinctness and value, I prefer to regard it here as a full genus.

\section{Genus PHYSA Draparnaud.}

\section{Physa felix White.}

Plate 22, fig. 1 a.

Physa felix White, 1878, Bull. U. S. Geol. Sur. Terr., vol. iv, p. 714.

Shell large; body volution inflated, shouldered at the distal border by an abrupt rounding of that part from the outer surface, the shoul-

* For Mr. Meek's diagnosis of this subgenus, see vol. ix, U. S. Geol. Sur. Terr. (4 to ser.), p. 533. 
dered portion near the suture being at nearly right angles with the axis of the shell; spire comparatively small, and apparently only moderately elevated. Surface marked by the usual lines of growth, and upon the whole shouldered portion of the body volution, that is its distal portion, reaching to the suture, there are numerous small obliquely triangular papillæ, which are arranged in oblique rows that coincide nearly with the lines of growth.

Full length not accurately known, but the body volution of the type specimen was, when perfect, not less than 38 millimeters in length.

Only two fragments of this remarkable Physa have been discovered, but the characters shown by them, as recorded above and illustrated by figure $1 a$ on plate 22, are sufficient to distinguish it from any other species, either fossil or recent. When more perfect examples are found, it is not improbable they will show characters that will require it to be separated, at least subgenerically, from the typical forms of Physa, as well as from other recognized sections of the genus.

Position and locality.-Laramie Group; valley of Crow Creek, Northern Colorado, about ten miles above the confluence of that creek with Platte River; where it was found associated with numerous other freshwater mollusks, which are described in this article.

\section{Physa coper White.}

Plate 24, figs. $4 a$ and $b$.

Physa.copei White, 1877, Bull. U. S. Geol. Sur. Terr., vol. iii, p. 602.

Shell large, elongate subelliptical; volutions about four; body volution large and moderately inflated; spire short, less than one-third the entire length of the shell; suture distinct but not deep; aperture elongate subovate in outline; callus of the inner lip moderately thick; surface marked only by the ordinary faint lines of growth common to the genus.

Length, 50 millimeters; diameter of body volution, 25 millimeters.

This fine Physa is the largest species known to me except $P$. pleuromatis White, from the Wahsatch Group of Colorado, Wyoming, and Utah, some unusually large examples of which occur in the valley of White River, Northwestern Colorado.

Position and locality.-The only known examples of this species were discovered by Prof. E. D. Cope in Laramie strata, near Cow Island, Upper Missouri River, Montana.

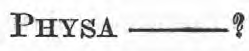

Plate 30, fig. $11 a$.

A single example, found in the strata of the Bear River Laramie series, is figured on plate 30 . It is the only specimen belonging to the Physidæ that has yet been found in that series, and is probably a new form, but it is too imperfect for specific description, especially as the species of all that family of shells have few salient characteristics. Perhaps it should be referred to Bulinus rather than to Physa. It is given a place in this article to show that the family is represented in the Bear River series, and to make this synopsis of the molluscan fauna of the Laramie Group as complete as possible. 


\title{
Genus BULINUS Adanson.
}

\author{
Bulinus atavus White.
}

Plate 24, figs. $5 a$ and $b$.

Bulinus atavus White, 1877, Bull. U. S. Geol. Sur. Terr., vol. iii, p. 601.

Shell large, much elongated; volutions about seven, increasing gradually in size; moderately convex; suture distinct but not deep; callus of the inner lip thin or absent; surface smooth, or marked only by very faint and very fine lines of growth. Some of the specimens have the appearance of having been naturally truncated or abruptly terminated at the apex, but it is more probable that this condition is the result of accident or erosion.

Length, 50 millimeters, or more if the apex of the example measured be restored; diameter of body volution, 26 millimeters; length of aperture, 24 millimeters; full length of the spire beyond the aperture about equal to that of the aperture.

This species is remarkable for its great size and unusually elongate form, which features render it so conspicuously different from any other known form as to make detailed comparison unnecessary. It is also so unusually elongate as to suggest that it may prove to be the type of a separate section of the genus Bulinus.

Position and locality._-Judith River series of the Laramie Group; valley of Dog Creek, a tributary of the Upper Missouri River, where it was discovered by Prof. E. D. Cope.

\section{BULINUS DISJUNCTUS White.}

Plate 24, figs $6 a$ and $b$.

Bulinus disjunctus White, 1879, An. Rep. U. S. Geol. Sur. Terr. for $1877,{ }^{*}$ p. 170.

Shell rather large and moderately elongated; volutions about six, those of the spire increasing gradually in size, but the body volution is proportionally more inflated than those of the spire; suture distinct, but not deep, and not conspicuous, because of the moderate convexity of the volutions; length of the spire a little more than half that of the whole shell; callus of the inner lip broad, its posterior half closely appressed against and adherent to the body; its anterior half deflected or disjoined from the body, so as to leave a kind of umbilical space between it and the body of the shell. This condition of the inner lip is evidently not accidental, as it is present upon all the examples, young and old, that have yet been found; aperture moderately large, its length a little more than half the full length of the shell. Surface marked only by the fine lines of growth peculiar to the Physidæ. ters.

Length, about 43 millimeters ; breadth of body volution, 20 millime-

This shell resembles B. subelongatus Meek \& Hayden, from the Laramie strata of the Judith River series, Upper Missouri River region;

\footnotetext{
* In the original description of this species I compared it with "B. elongatus Meek \& Hayden." B. subelongatus was intended, the error having occurred by copying from one of the labels accompanying the type specimens. I have elsewhere inadvertently made a few similar errors in cases where the originally labeled name was changed upon publication.
} 
but the spire is proportionally more elevated, and consequently the body volution, although large, is propertionally smaller.

Some examples of a Bulinus from the coal-bearing series near Evanston, Wyo., which I at one time supposed to be identical with this species, shows the same peculiarity of the inner lip, namely, the lifting of the anterior portion of the callus from the body of the shell. That, however, is probably a distinct species, and, if so, the peculiarity mentioned, would seem not to be confined to this specific form alone.

Position and locality.-Laramie Group valley of Urow Creek, Northern Colorado, about ten miles above the confluence of that creek with Platte River. An example brought in by one of the parties of this Survev from Separation Station, Union Pacific Railroad Wyoming, seems to belong to this species.

\section{Bulinus longiusculus Meek \& Hayden.}

\section{Bulinus? RHoMboideus Meek \& Hayden.}

These two species are from the Laramie strata near Fort Union on the Upper Missouri River, where the types were collected by Dr. Hayden. The former has been identified with a good degree of certainty in the coal-bearing strata near Evanston, Wyo., and examples of a species apparently identical with the latter have been found associated with it. Mr. Meek describes these two forms in vol. ix, U. S. Geol. Sur. Terr. (4to ser.), pages 441 and 442, respectively, and both of them are figured on plate 43 of the same volume.

Bulinus subelongatus Meek \& Hayden.

Dr. Hayden also obtained the types of this species from the Judith River series of the Laramie Group, in the Upper Missouri River region. It has been identified with a good degree of certainty among fossils collected from the coal-bearing strata.near Evanston, Wyo. It is described and figured in vol. ix, U. S. Geol. Sur. Terr. (4to ser.), p. 540, plate 42, figs. $13 a$ and $b$.

\section{Genus VITRINA Draparnaud.}

\section{Vitrina ? obliqua Meek \& Hayden.}

The type specimen of this form, which evidently represents a well defined species, although its true relations are not accurately known, was obtained by Dr. Hayden from the Laramie strata of the Judith River series with the large collections which he obtained many years ago in the Upper Missouri River region. It is described and figured in vol. ix U. S. Geol. Sur. Terr. (4to ser.), plate 42 , figs. $10 a$ and $b$.

\section{Genus HYALINA Férussac.}

\section{Hyalina? occidentalis Meek \& Hayden.}

\section{Hyalina? Evansi Meek \& Hayden.}

The types of these two species are also from the Judith River series of the Laramie Group; those discovered by Dr. Hayden being the only 
examples of either of these two forms yet known. They are described by Meek in vol. ix, U. S. Geol. Sur. Terr. (4to ser.), pages 547 and 548 , respectively. The former is illustrated on plate 42, figs. $6 a, b$, $c$, and $d$; and the latter is illustrated only by wood-cuts accompanying the description.

\section{Genus HELIX Linnæus.}

\section{Helix vetusta Meek \& Hayden.}

Dr. Hayden found this species associated with the precding and many other species in the Judith River series. It is described by Meek in vol. ix, U. S. Geol. Sur. Terr. (4to ser.), p. 552, and figured on plate 42 of the same volume. Although the Helicidæ were introduced at least as early as the Laramie period, and different divisions of the family were then distinctly differentiated, the family is not abundantly represented in that group.

\section{Genus THAUMASTUS Albers.}

\section{THAUMastus LIMNAEIFORMIS Meek \& Hayden.}

Discovered by Dr. Hayden in the Laramie strata near the mouth of Yellowstone River, Montana. It is described and figured in vol. ix, U. S. Geol. Sur. Terr. (4to ser.), p. 553, plate 44, figs. $8 a, b, c$, and $d$.

\section{Genus COLUMNA Perry.}

Columa teres Meek \& Hayden.

Columna vermicula Meek \& Hayden.

Both of these species were found associated together by Dr. Hayden in the Laramie strata, at the mouth of Judith River, Montana. They are described in vol. ix, U. S. Geol. Sur. Terr. (4to ser.), pages 555 and 556 , respectively, ând figured on plate 44 of the same volume.

\section{Genus NERITINA Lamarck.}

\section{Neritina VOLVILINEATA White.}

Plate 21, figs. $6 a$ and $b$.

Neritina volvilineata White, 1876, Powell's Rep. Geol. Uinta Mts., p. 131.

Shell small, subcircular in lateral outline; volutions three and a half or four; the last one regularly convex; spire short, but quite as prominent as is usual in species of this genus; suture slightly impressed; aperture semi-lunar; inner lip broad, plain, flat, its inner edge not clearly seen, but it is apparently plain. Surface marked by numerous raised revolving lines of unequal size, which increase in number by implantation as the shell increases in size, the lines also gradually increasing in size for a portion of their length after their origination; the spaces between the raised lines about equal to or a little less than the lines in width ; the revolving lines crossed by the usual lines of growth, which gives the surface, upon some parts at least, an indistinctly cancellated appearance under the lens.

Greatest diameter of the largest example among those first discovered at Black Buttes Station, 9 millimeters; height, the shell lying with its aperture upon the table, 5 millimeters. Some examples aiterward discovered in the valley of Yampa River are much larger. 
Position and locality.-Laramie strata, near the top of the group; Black Buttes Station, Union Pacific Railroad, Wyoming; and valley of Yampa River, near Cañon Park, Northwestern Colorado, where also its position is near the top of the group.

\section{Neritina NATICIFORMis White.}

Plate 30 , figs. $3 a$ and $b$.

Neritina naticiformis White, 1878, Bull. U. S. Geol. Sur. Terr., vol. iv, p. 715,

Shell very small, subglobose, its aspect being more nearly like that of Natica than that of the usual forms of Neritina; spire moderately prominent; rolutions three or four, increasing so rapidly in size that the last one comprises much the greater part of the bulk of the shell; all the volutions regularly convex; suture distinct; test not massive; aperture large, nearly straight on the inner side, the remainder of its border forruing a continuous and almost uniform curve, the whole comprising more than a semi-circle; edge of the outer lip thin; inner lip not very broad, flattened, apparently smooth both upon its surface and inner edge, sloping strongly inward, or away from the border of the aperture, its inner margin somewhat concave. Surface marked only by ordinary distinct lines of growth, except that in one or two instances traces of revolving striæ have been detected upon the proximal or lower portion.

Extreme length from apex to front margin, 6 millimeters; greatest diameter across the middle of the aperture, about the same.

In general aspect this little shell so closely resembles a Natica that, the aperture being filled with the imbedding material, the first suggestion whether it might not belong to that or a closely-related genus came from its association with fresh and brackish water forms. Upon breaking up some of the examples the inner lip was found to be more characteristic of Neritina than Natica, although it is not so broad and thick as it usually is in typical forms of the former genus; from which the shell in question also departs by the comparative thinness of the test.

The genus Neritina is not very well represented in the Laramie Group, no example of any species of it having yet been discovered in the Upper Missouri River region which has furnished so many other specific forms, and only three species have been found in the group elsewhere, including the next described form under the subgenus Velatella. It was more common in the preceding Fox Hills epoch, but it appears to have been entirely absent from the fresh waters in which the Tertiary deposits were made, that immediately succeeded those of the Laramie Group.

Position and locality.-Bear River, Laramie series, near the mouth of Sulphur Creek, Valley of Bear River, Wyoming, where it was found associated with Limncea vetusta, Acella haldemani, and other forms, in a layer both above and beneath which are those that contain an abundance of the characteristic brackish and fresh water species of that series.

\section{Subgenus VELATELLA* Meek.}

\section{Velatella Baptista White.}

Plate 29, figs. $6 a$ and $b$.

Velatella baptista White, 1878, Bnll. U. S. Geol. Sur. Terr., vol. iv, p. 715.

Shell small, elliptical in lateral outline, broadly convex above, the convexity of the postero-median portion being greater than it is elsewhere,

\footnotetext{
* For a diagnosis of this subgenus, see page 27 of this report.
} 
nearly flat beneath; umbo somewhat prominent, nucleus or apex posterior, minutely subspiral and depressed almost closely upon the posterior margin, small, closely incurved and turned towards the right side; inner lip broad, smooth, slightly convex in all directions, and occupying fully one-half of the whole under surface of the shell; outer lip apparently moderately thin, but this feature has not been clearly seen. Surface so nearly smooth as to give the shell an almost polished appearance, but under the lens minute striæ of growth are visible; and also near the borders minute radiating striæ are seen, apparently in the substance of the shell. There are, also, upon the only example yet discovered, seven or eight irregular radiating stripes of coloration of the test. These are now brownish in color, while the general surface is buff; both of which colors are doubtless now differ ent from those which characterized the shell while the mollusk was living, but the pattern of ornamentation is no doubt correctly preserved.

Length, 10 millimeters; breadth, 7 millimeters; height, 5 millimeters.

This species resembles in many respects, $N$. (V.) patelliformis Meek, especially the variety Weberensis White; but it differs from the former in shape, and from the latter in being without any trace of radiating raised lines or costæ, in the greater prominence of the umbonal portion, and its somewhat more conspicuous apex. Its coloration is not taken into account in this comparison because its preservation in this species and not in the other is thought to be only accidental.

Position and locality.-Laramie Group; Black Buttes Station, Union Pacific Railroad, where it was found associated with the majority of the species of Unio described in this article, besides Corbicula (Leptesthes) fracta, and other mollusks.

\section{Genus CERITHIDEA Swainson.}

\section{Subgenus PIRENELLA Gray.}

\section{Cerithidea (Pirenella) nebrascensis Meek \& Hayden.}

For description and illustration of this species, see vol. ix, U. S. Geol. Sur. Terr. (4to ser.), p. 559, pl. 43. Dr. Hayden obtained the types, which are the only examples yet discovered, from Laramie strata, near the head of Little Missouri River.

\section{Genus GONIOBASIS Lea.}

Thirteen or fourteen specific fossil forms have been obtained from the strata of the Laramie Group in different portions of the great region which it largely occupies, which authors have generally referred to the genus Goniobasis of Lea. These species may be separated into certain more or less distinct groups by characteristics which they respectively possess. Two or three of these suggested groups possess characteristics which may, perhaps, prove to be of at least subgeneric importance, but more material is necessary before such a study of them can be satisfactorily made. At present, three sections seem to be indicated, of which G. cleburni, G. nebrascensis, and $G$. gracilenta may be taken respectively as the types. Perhaps also the form which, in a following description, I have referred to Melania (M. wyomingensis) may be regarded as the type of only a section of Goniobasis co-ordinate with these, and not properly referable to Melania. At present, however, I prefer to make the following references of these forms, hoping at a future time to study them exhaustively. 


\section{Goniobasis Cleburni White.}

Plate 30, figs. $4 a, b, c$, and $d$.

Turbonilla (Chemnitzia) melanopsis White, 1875 (not Conrad), Expl. and Sur. West of the 100th Merid., vol. iv, p. 197, pl. xviii, fig. $10 a$.

Goniobasis eleburni White, 1876, Powell's Rep. Geol. Uinta Mts., p. 122.

Shell rather large, gradually tapering from the last volution to the apex, the sides of the spire being only slightly convex; volutions apparently nine or ten, gradually increasing in size, the last one not being proportionally larger than the others; suture slightly impressed; sides of the volutions of the spire nearly flat, or only slightly convex, but the outer and anterior sides of the last one having a broad and regular convexity; aperture, as indicated by the lines of growth, subovate in outline; outer lip kroadly sinuate. Surface of the spire marked by numerous strong longitudinal ridges or varices, extending from suture to suture, which are slightly flexed and slightly oblique to the axis of the shell, or approximately parallel with it; the proximal side of the last volution marked by several faint revolving lines, the longitudinal varices of the last volution ending before reaching that portion of the surface do not appear there. The lines of growth are usually stronger upon the last volution than elsewhere, and the varices are sometimes obsolete, at least upon a portion of its surface. Revolving lines have not been observed upon the surface of the spire, but sometimes the edges of the longitudinal varices are seen to be faintly crenulate, as if by incipient revolving lines.

Although a considerable number of specimens have been collected, none have been found with the apex complete, but the length of a fullgrown specimen is estimated from those obtained at about 50 millimeters; diameter of the last volution, 19 millimeters.

I now think that the shell, which in vol. iv, Expl. and Sur. West of the 100th Merid., p. 197 pl. xviii, fig $10 a$, I doubtfully referred to Turbonilla (Chemnitzia) melanopsis Conrad, and which was obtained from South. western Utah, really belongs to this species. This opinion is supported by the fact that Corbicula (Veloritina) durkeei Meek, was reported from the same locality, and which is also figured in the volume quoted; plate xxi. This being the fact, the geographical range of $G$. cleburni is seen to be very great.

Position and locality.-The types of this species were obtained from the Bear River Laramie series, near the mouth of Sulphur Creek, Bear River Valley, Wyoming. Examples of it, more or less perfect, have been found at all, or nearly all, the localities at which the Bear River Laramie series has been recognized. It is, therefore, one of the more characteristic species of that series of strata.

\section{Goniobasis chrysallis Meek.}

Plate 30, figs. $6 a$ and $b$.

Goniobasis chrysallis Meek, 1871, An. Rep. U. S. Geol. Sur. Terr. for 1870, p. 316.

The following is Mr. Meek's original description of this species:

"Shell generally almost cylindrical below the middle, but more abruptly tapering above; volutions six or seven, flattened, with the upper margin thickened, last one not angular, and scarcely larger than the next above it; suture well defined.

"Surface ornamented by distinct vertical costæ, often ranged nearly in the same line all the way up the spire; these are partly interrupted 
by an effort to form three, or rarely four, obscure revolving lines or ridges, the upper of which is larger and more prominent than the others, which character, with the slightly enlarged upper ends of the vertical costæ, causes the thickened appearance of the upper margins of the volutions; several other slender and more distinet revolving lines also occur on the under side of the last turn. Aperture somewhat rhombic-ovate.

"Length, about .60 inch; breadth, .18 inch."

This shell is plainly related to G. cleburni, with which it is associated, but its comparatively minute size and the details of its form show differences too great to require detailed comparison.

It has been found in considerable numbers in the Bear River Laramie series, near the mouth of Sulphur Creek, Bear River Valley, Wyoming; where it is associated with many other species, including those which are most characteristic of the series.

\section{Goniobasis ChRysalloidea White.}

Plate 30, figs. $5 a$ and $b$.

Goniobasis chrysalloidea White, 1876, Powell's Rep. Geol. Uinta Mts., p. 123.

Shell of medium size, gradually tapering from the last volution to the apex; volutions about seven or eight, those of the spire slightly convex, the last one broadly rounded to the anterior end; suture impressed, the apparent impression being increased by the projecting fold of the distal border of each volution, which is appressed against the next preceding one. Surface marked by more or less distinct longitudinal, slightly-bent ridges or varices, which are crossed by several revolving lines that appear only on the ridges, and not between them, giving the ridges a knotted or crenulated appearance; anterior surface of the last volution also marked by distinct raised revolving lines.

Length, 28 millimeters; diameter of the last volution, 9 millimeters.

This species is closely related to both G. cleburni and G. chrysallis, with both of which forms it is associated. It differs from the latter in its much larger size, much greater apical angle, straighter sides of the spire, and in the details of its ornamentation. It differs from G. cleburni in its smaller size, the more distinct crenulation of its longitudinal varices or folds, and in possessing the revolving fold-like projection of the distal border of its volutions.

Position and locality.-Bear River series of the Laramie Group, near the mouth of Sulphur Creek, Bear River Valley, Wyoming.

\section{GonIoBASIS ENDLICHI White.}

Plate 30, figs. $7 a, b$, and $c$.

Goniobasis endlichi White, 1878, Bull. U. S. Geol. Sur. Terr., vol. iv., p. 716.

Shell moderately elongate-conical; spire with straight or slightly concave sides; volutions six or seven, much, and nearly regularly, convex, the last one slightly inflated ; suture well defined, and appearing unusually deep on account of the convexity of the volutions; aperture subovate in outline, its distal end angular, its front somewhat narrowly rounded and without a sinus; outer lip apparently sharp; inner lip with a thin reflected callus, which is more developed anteriorly than posteriorly; columella gently arcuate.

Surface marked by fine but distinct lines of growth, which are erossed by very numerous fine, revolving, raised lines, giving it a cancellated 
appearance under the lens. In addition to these, there are usually from four to six much larger, nearly equidistant, revolving raised lines of nearly equal size upon the visible portion of the volutions of the spire, and ten or twelve of them upon the body volution. These larger revolving raised lines are sometimes absent or obsolete, but the smaller markings first mentioned are always present.

Length, about 22 millimeters; diameter of body volution, 11 millimeters.

This species is evidently nearly related to G. nebrascensis Meek \& Havden, and ought, perhaps, to be referred to Pachycheilus Lea, but the difficulty of learning the exact character of the outer lip leaves the matter in some doubt.

Position and locality.-Bear River series of the Laramie Group, seven miles northward from Evanston, in the valley of Bear River, where it is associated with many of the characteristic species of that series.

\title{
Goniobasis MaCILENTA White.
}

\author{
Plate 30, fig. $10 a$.
}

Goniobasis arcta White (not Meek), 1879, An. Rep. U. S. Geol. Sur. Terr. for 1877, p. 244.

Shell small, slender, terete; test thin; sides of the spire straight or a little concave; volutions, apparently ten or more, gradually increasing in size, their sides flat and forming the continuous surface of the straight sides of the shell; suture linear; surface marked by lines of growth, which cross the volutions with a slightly sinuous course, but nearly in line with the axis of the shell. Near the distal border of the volutions there is a revolving depressed line, which has the appearance of a second suture. There appears to be no tendency to form longitudinal varices such as mark G. cleburni, G. chrysallis, and other species, nor have other revolving lines than the one already mentioned been detected.

The length of the type specimen, when perfect, was about 12 millimeters; diameter of the last volution, a little more than 2 millimeters. A less perfect example, the largest in the collection, indicates about double that size.

Upon the first discovery of this species I supposed it to be identical with G. arcta Meek, which he described in Simpson's Report on the Great Basin of Utah, p. 366, as from the Tertiary strata of the valley of Ham's Fork, a tributary of Green River. That form is closely like the one in question in general aspect, and I was led to believe a mistake had occurred in giving its location similar to one made in regard to Limncea nitidula in the same connection, and which he afterward corrected. A careful study of our examples shows that they cannot be referred to that species, and I therefore apply to it a new specific name. The perfectly flattened sides of all the volutions of the spire, with the linear suture and its companion impressed line, distinguish it from all other known species.

The companion line of the suture of this species seems to have more significance than as a mere specific character, from the fact that it is more or less distinctly represented in both G. chrysallis and G. chrysalloides, both of which species are from the same series of strata and from the same locality that furnished the type specimens of this species.

Position and locality.-Bear River series of the Laramie Group, near the mouth of Sulphur Creek, valley of Bear River, Wyoming. 


\section{Goniobasis gracillenta Meek \& Hayden.}

The type specimens of this species were discovered by Dr. Hayden in the Judith River series of the Upper Missouri River region. It is described and figured in vol. ix, U. S. Geol. Sur. Terr. (4to ser.), p. 568, pl. 42, fig. 3. I have recognized the species among the Laramie fossils collected in the valley of Crow Creek, Northern Colorado; and among those of Black Buctes Station, in Southern Wyoming, is a form which, although rather more delicate than the type specimens of the species, appears to be identical with it.

\section{Goniobasis Convexa Meek and Hayden. \\ Goniobasis InVEnUSTA M. \& H. \\ GONIOBASIS SUBLAEVIS M. \& H. \\ Goniobasis? OMITTA M. \& H. \\ Goniobasis? sUbTORTUOAA M. \& H.}

These five species were collected by Dr. Hayden from the Judith River series of the Laramie Group, near the mouth of Judith River, Montana. They are deseribed in vol. ix, U. S. Geol. Sur. Terr. (4to ser.), pages 562, 564, 567, 568, and 569, respectively; and all are figured on plate 42 of the same volume. The last-named species is almost certainly not a Goniobasis, but it perhaps belongs to the genus Cassiopella White.

\section{Goniobasis Nebrascensis Meek \& Hayden.}

\section{Goniobasis tenuicarinata M. \& H.}

These two species were originally discovered by Dr. Hayden in the Fort Union series in the Laramie strata, in the Upper Missouri River region. They are described in vol. ix, U. S. Geol. Sur. Terr. (4to ser.), pages 565 and 566, respectively, and both are figured on plate 43 of the same volume. The former species has been obtained by myself from the Laramie strata of Crow Creek, Northern Colorado, and I identified it also among some fossils brought by Professor Powell from the Cañon of Desolation, Green River, Utah. Both species are also contained among Lieutenant Wheeler's collections from Wales, Utah, which were described and figured by me in vol. iv, Expl. and Sur. West of the 100th Merid., pages 212 and 213, pl. xxi, figs. 9 and 10.

\section{Genus MELANIA Lamarck.}

\section{Melanta ? InsculPta Meek.}

Plate 20, fig. $4 a$.

Melania? insculpta Meek, 1873, An. Rep. U. S. Geol. Sur. for 1872, p. 515.

The following is Mr. Meek's description of this species, together with his remarks upon it:

"Shell terete or elongate subconical; volutions apparently about ten, convex, or sometimes flattened convex, increasing gradually in size; last one not much enlarged and without an angle around the middle, sometimes slightly concave above in large specimens; suture well defined; aperture unknown. Surface ornamented with distinct, nearly straight or slightly arched vertical costæ, about sixteen of which may be counted on each volution, while crossing these are smaller, regular, deep revolving furrows that cut each rib into five or six little transverse nodes which, 
from the obsolescence of the vertical costæ on the lower part of the last turn, become more or less continuous revolving lines on that part of the shell.

"The specimens of this species ret obtained are too imperfect to afford the means of giving accurate measurements. Judging, however, from some of those in the collection, large adult individuals would seem to have attained a length of 1.40 inches, with a breadth of body volution of near 0.50 inch. Some of these larger specimens, consisting of three or four of the lower volutions, show but a very gradual decrease in breadth upward; while some of those composed of the upper part of the shell indicate a divergence of about $18^{\circ}$ for the angle of that portion of the spire.

"As none of the specimens show the aperture, it is not possible to determine from those yet seen whether this shell really belongs to the fresh-water genus Goniobasis or to some marine genus, although the species will be readily recognized by its sculpturing. Its only known associates are fragments of Ostrea and Modiola, with Corbula undifera, an association that would certainly favor the conclusion that it should be referred to a marine genus, in which case it would most probably fall into Bittium, and have to be called $B$. insculpta.

"We have, however, several examples of unquestionable fresh.water shells associated with marine types in some of the rocks of this region; while the general aspect of this shell seems, as far as known, to associate it with Goniobasis. The fact, too, that nearly all the specimens yet seen are fragmentary, seems to indicate that the species did not live in the same waters with the other forms found associated with it, but that the specimens may have been washed into the sea from streams on the neighboring shores.

"Locality and position.-Rock Springs, Wyoming; from a little above the main 10-foot bed of coal at that locality. Bitter Creek series."

While this shell is almost certainly a fresh-water form, there is no positively known reason for referring it to the genus Melania proper. It is, however, almost certainly genetically related to the next described species, as I suggested in the report of this survey for 1877; and in view of the form and ornamentation of the species referred to, I prefer at present to retain it with that species in the genus Melania; and this form being so related to that one, both seem to require the same generic assignment.

\section{Melania WYomingensis Meek.}

Plate 28, figs. $6 a$ and $b$.

Melania (Goniobasis?) wyomingensis Meek, 1873, An. Rep. U. S. Geol. Sur. for 1872, p. 516.

Melania larunda White, 1876, Powell's Rep. Geol. Uinta Mts., p. 131.

Shell large, elongate; volutions apparently eleven or twelve, uniformly increasing in size, moderately convex, the last five or six of them bearing about the middle or a little above it a revolving row of prominent, strong, outward-projecting, laterally compressed and somewhat sharpened tubercles. These tubercles are strongest upon the last volution and gradually diminish in size until they disappear among the crenulated lines that mark the volutions of the spire. They decrease in number also, there being about fifteen on the last volution, and about ten on that upon which they first appear. The upper volutions of the spire are marked by numerous crenulated longitudinal varices having a slight convex curve to the left side of the shell, the crenulations being caused 
by the crossing of the varices by about five revolving raised lines which are distince upon, but hardly appear between, the varices. The row of tubercles that mark the larger volutions begins by the gradual enlargement of the crenulations of the second revolving line forward of the suture. The other revolving lines of the smaller volutions are continued upon all the larger ones, but upon the latter they become more continuous and less distinctly crenulated; and the two lines upon the distal side of the row of tubercles are usually obsolete upon the last two volutions. Besides the three revolving lines upon the proximal side of the row of tubercles before mentioned, the last volution shows upon its proximal side four or five other somewhat stronger ones, which, in the volutions of the spire, are successively covered by the growth of the shell. Lines of growth rather distinct; suture linear; columella flexed; outer lip having a broad shallow notch, the retreating angle of which is opposite the row of tubercles; anterior portion of the lip moderately extended and abruptly rounded to the columella.

The length of a full-grown example, when entire, was probably not less than 100 millimeters; diameter of the last volution of the largest examples in the collection, 22 millimeters.

This description is drawn mainly from my type specimens of $M$. larunda, because they are much more perfect than Mr. Meek's types are, and more perfect than any others yet discovered. In its aspect and ornamentation this species is so much like an Old World Melania that I prefer to assign it to that genus rather than to Goniobasis, with some forms of which it agrees in general characteristies.

Position and locality.-Mr. Meek's types were discovered in the upper strata of the Laramie Group at Black Buttes Station, Union Pacific Railroad, Wyoming. Examples of it were also obtained by me from very near the base of the group at Danforth Hills, near White River Indian A gency, White River Valley, Northwestern Colorado. The types used in its description, under the name of $M$. larunda, were found in the valley of Crow Creek, Northern Colorado; and it has also been found at other places east of the Rocky Mountains in that State,

\section{Genus PYRGULIFERA* Meek.}

\section{Pyrgulifera humerosa Meek.}

The types of this species, which are also the types of the genus, were obtained from the Bear River series of Laramie strata, near the mouth of Sulphyr Creek, Bear River Valley, Wyoming, in which district it is one of the most abundant and characteristic species of that series. It is described and figured in vol. iv, U. S. Geol. Sur. 40th Parallel (King), p. 176, pl. xvii, figs. 19 and $19 a$; and also in Captain Simpson's Rep. Great Basin of Utah, p. 363, pl. 5, fig. $6 a, b$, and $c$.

\section{Genus CASSIOPELLA White.}

This genus was proposed in Bulletin U. S. Geological Survey of the Territories, vol. iii, p. 606 (1877), to include the species first published under the name Leioplax? turricula, in Powell's Report Geology of the Uinta Mountains, p. 133. The diagnosis is also given here, because it is at present known only in strata of the Laramie Group.

\footnotetext{
* For diagnosis of this genus, see vol. iv, U. S. Geol. Sur. 40th Parallel (King), p. 176.
} 
Shell resembling Goniobasis in form and in some of its other eharacteristies; but, unlike that genus, it is distinctly umbilicated; volutions more or less convex or angulated; aperture more or less produced in front; subovate or rhomboidal in outline; outer lip sinuous; inner lip having a more or less distinct layer of callus.

I have here placed this genus provisionally in the family Ceriphasiidre of Gill; but I am not entirely satisfied that it really belongs in that family. Being umbilicated, it bears a similar relation to Goniobasis that Cassiope Coqnand does to Turritella; but of course it is not regarded as having any near affinities with Cassiope, which is a marine genus.

\title{
Cassiopella turricula White.
}

$$
\text { Plate } 27 \text {, figs. } 3 a, b, c, d, e, f \text {, and } g \text {. }
$$

Leioplax? turricula White, 1876, Powell's Rep. Geol. Uinta Mts., p. 133.

Cassiopella turricula White, 1877, Bull. U. S. Geol. Sur. Terr., vol. iii, p. 606.

Shell elongate conical; the apical portion slender, the sides being slightly concave; volutions nine or ten, gradually increasing in size, prominent, angulated, the angle being prominent or subcarinated, and situated a little in advance of the middle of the exposed portion of the volutions of the spire; suture slightly impressed, but appearing deep in consequence of the prominence of the volutions; last volution broadly rounded from the prominent revolving angle to the verge of the umbilicus; umbilicus narrow, deep, and marked within by two or three revolving lines. Surface, upon both sides of the prominent angle of the volutions, marked more or less distinctly by two or three revolving raised lines; and the proximal surface of the last volution is also marked. by similar lines. Aperture subrhombic in outline.

Length, 34 millimeters ; diameter of the last volution, 15 millimeters.

Position and locality.-This is the type, and only known species of the genus; and it has hitherto been found only at Black Buttes Station, Union Pacific Railroad, Wyoming, in the upper portion of the Laramie Group. It is associated in the same layer with Viviparus plicapressus, Tulotoma thompsoni, Campeloma multistriata, Goniobasis gracilenta, and several species of Uino. It is therefore referred to a fresh-water habitat, although many young examples of Corbula subtrigonalis were also found immediately associated with it.

\section{Genus HYDROBIA Hartmann.}

\author{
Hydrobia ANTHonyi Meek \& Hayden. \\ Hydrobia warrenana Meek \& Hayden. \\ HYDRoBIA SUBCONICA Meek \& Hayden. \\ HybRobIa? enLIMoIdes Meek \& Hayden.
}

These four species were obtained by Dr. Hayden from the Laramie Group of the Upper Missouri River region, and none of them have yet been elsewhere identified. They are described on pages 571-573, vol. ix, U. S. Geol. Sur. Terr. (4to ser.), the two former being figured on plate 43 of that volume; but the two latter are illustrated by a wood-cut each, accompanying the descriptions.

The genus Hydrobia has not been recognized elsewhere in the Laramie Group, if we except a species which was described by myself from the coal-bearing series near Evanston, Wyo., and another from certain of tha strata exposed in the Cañon of Desolation, Green River, Utah. 
From the former I obtained $H$. recta White, and from the latter Professor Powell brought $H$. utahensis White. I have very little doubt that the strata of both those localities really belong to the Laramie Group, but, as before explained, they are not specially considered in this article, because more information concerning their stratigraphical relations is seeded.

\section{Genus MICROPYRGUS* Meek.}

\section{Mroropyrgus Minutulus Meek \& Hayden.}

This little shell is the type and only certainly known species of the genus. It was obtained by Dr. Hayden from the Laramie strata near Fort Union, on the Upper Missouri River, and is described and figured in vol. ix, U. S. Geol. Sur. Terr. (4to ser.), p. 575, plate 43, figs. 18 and b. I have seen fragments of a shell in the Green River Group of Southern Wyoming that may perhaps prove to be another, and.considerably larger, species of this genus.

\section{Genus VIVIPARUS Montfort.}

\section{VIVIPARUS PLICAPRESSUS White.}

Plate 28, figs. $3 a$ and $b$.

Viviparus plicapressus White, 1876; Powell's Rep. Geol. Uinta Mts., p. 133.

Shell rather under medium size; spire conical, its sides nearly straiglit; volutions about seven, moderately convex; the outer and anterior convexity of the last volution continuous and uniform; suture impressed. At the distal border of each volution there is a small, more or less distinct revolving groove or furrow; and the narrow border between the furrow and the suture is in the form of a fold, which is closely appressed. against the proximal side of the adjacent volution, the fold forming a slight projection or shoulder upon the proximal side of and bordering the suture. Surface marked by the ordinary lines of growth, and upon some examples there appears to be a faintly raised revolving line, or incipient angulation, near the middle of the outer side of the volutions.

None of the examples in the collection are entire, but the length is estimated from the most perfect examples at about 25 millimeters; breadth of last volution, 12 millimeters.

Position and locality.-Laramie Group, Black Buttes Station, Union Pacific Railroad, Wyoming; and also in the valley of Yampa River, near Cañon Park, Northwestern Colorado.

\section{VIVIPARUS PRUDENTIUS White.}

Plate 28, figs. $5 a$ and $b$.

Tiviparus prudentia White, 1878, Bull. U. S. Geol. Sur. Terr., vol. iv, p. 716.

Shell depressed, subconical; spire short, convex; volutions five and a half or six, including the minute ones of the apex, all regularly convex; last one considerably enlarged, and constituting the greater part of the shell, rounded by an almost uniform curve from the suture to the umbilicus; suture well defined, its apparent depth increased by the bold convexity of the volutions; umbilicus very small and deep; aperture short, subovate or subcircular in outline; obtusely angular at its distal

* For diagnosis of this genus see vol. ix, U. S. Geol. Sur. Ter., (4to ser., ) p. 574. 
side; its ontline a little straightened between the angle before mentioned and the verge of the umbilicus by contact with the body of the shell, but the remainder of the outline forming a continuous and almost regular curve. Surface smooth, and having an almost polished appearance; but it is marked by very fine lines of growth.

Length from the front margin of the aperture to the apex, 18 millimeters.

This shell more nearly resembles the living species $V$. intertexta Say than any other known form; but it differs from that species in its somewhat shorter spire, more distinct, though small, umbilicus, and the less prominently rounded distal side of the volutions. It also resembles $V$. leai M. \& H., but it is a much shorter shell.

Position and locality.-Laramie Group, valley of Crow Creek, ten miles above the confluence of that creek with Platte River, Northern Colorado.

\section{VIVIPARUS COUESI White.}

Plate 30, fig. 1 a.

Viviparus conesi White, 1878, Bull. U. S. Geol. Sur. Terr., vol iv, p. 717.

Shell very large when fully adult; volutions six or seven, convex, the distal side of the last one especially, abruptly rounded to the suture, giving it a somewhat shouldered aspect there, while the outer side is broadly convex and sloping gently forward and inward; suture deeply impressed, the apparent depth being increased by the great convexity of the volutions. Surface marked by the ordinary lines of growth, no revolving marks of any kind having been detected. The lines of growth indicate that the margin of the outer lip is nearly straight, as is usual with all species of this genus, and which feature distinguishes its shells from those of Campeloma, in which the outer lip is sinuous. Inner lip somewhat thickened by callus and reflexed at the proximal or anterior end, but not covering the umbilical fissure there, which is moderately large. The precise shape of the aperture is unknown, but it is probably subovate.

No entirely perfect examples have been discovered, but the largest one yet obtained would, if perfect, measure about 65 millimeters in length; full width of body volution, 38 millimeters.

This species is described by Meek, from an imperfect example, in U.S. Geol. Sur. 40th Parallel (King), vol. iv, p. 181, and figured on plate xvii, fig. 15, of the same volume; but it was not specifically named by him. He referred it to the genus Campeloma, but the numerous specimens that have been obtained from the same and other localities, as well as his own type specimen, show that the species possesses the true characters of Viviparus. It is distinguished from all other species of the genus known to me in American strata by its great size, and there are few other forms with which it is in any danger of being confounded. From $V$. paludinaformis Hall it differs in its more robust form, in the greater convexity of its volutions and the abrupt rounding of their distal side, and in the presence of a distinet umbilical fissure.

Position and locality.-Laramie Group, valley of Bear River, seven miles northward from Evanston, Wyo., and also near the mouth of Sulphur Creek, above Evanston. It is associated with other fresh-water forms, and also with many of the characteristic brackish-water species of that series. 


\author{
Viviparus Lear Meek \& Hayden. \\ VIVIPARUS RE'TUSUS M. \& H. \\ VIVIPARUS PECULIARIS M. \& H. \\ VIVIPARUS TRUCHIFORMIS M. \& H. \\ VIVIPARUS REYNOLDSIANUS M. \& H. \\ VIVIPARUS LIEIDYI M. \& H.
}

The types of the abore-named six species were collected by Dr. Hayden from the Fort Union series of the Laramie Group, in the Upper Missouri River region; they are described in vol. ix, U. S. Geol. Sur. Terr. (4to ser.), pages 577-582, and figured on plate 44 of the same volume, except the third, of which there is a wood-cut accompanying the description.

I think one cannot study these forms of Viviparus without becoming impressed with the belief that they are all genetically related. Indeed, it seems probable that further study of large collections of them will show that not more than two species ought to be made out of these six forms, even with the ordinary methods of discriminating study of fossil mollusca. From several localities in Utah examples of Viviparus have been brought in by different parties, some of which closely resemble the fourth, fifth, and sixth of the foregoing forms respectively. They are from strata that probably really belong to the Laramie Group, and are also probably related genetically with those forms.

\section{VIVIPARUS CONRADI Meek \& Hayden.}

This form was obtained by Dr. Hayden from the Judith River series of the Laramie Group, where alone it has yet been discovered; but Mr. Meek thought it probable that $V$. peculiaris of the Fort Union series is only a variety of it. It is described and figured in vol. ix, U. S. Geol. Sur. Terr. (4to ser.), p. 879, plate 42, figs. $15 a, b, c$, and $d$.

\section{Genus TULOTOMA Haldeman.}

\section{TULOTOMA THOMPSONI White.}

Plate 28, figs. $2 a, b, c, d, e, f, g$, and $h$.

Eulotoma thompsoni White, 1876, Powell's Rep. Geol. Uinta Mts., p. 134.

Shell moderately large, having somewhat the general aspect of $T$. magnifica, the type of this genus; spire elevated, its sides having a broad general convexity, and the apex being somewhat blunt; volutions six or sexen, their outer side flattened or slightly convex; proximal side of the last volution also flattened or slightly convex, producing a more or less prominent revolving angle between the proximal and outer sides of the last volution, but which is obscured in the spire by mutual contact of the volutions there; suture linear, or faintly impressed; umbilical perforation apparently wholly wanting in all cases. Surface of the three or four smaller volutions of the spire marked only by lines of growth and a few revolving lines, two of which are sometimes in the form of slight angulations; but the last two or three volutions are usually conspieuously marked by prominent tubercles, which are arranged in two or three revolving rows, which extend to the aperture, and which are usually connected together in their respective rows by raised revolving lines. The distal row of tubercles on each volution is stronger than 
either of the others, and the tubercles of this row are, when of full size, elongated, not in the direction of the row, but their axes are a little oblique to it. The proximal row (not the one which sometimes appears on the flattened proximal side of the last volution, but which is usually absent) is directly upon the angulation which is formed by the meeting of the flattened proximal and the outer sides of the volutions. There is sometimes another row of tubercles between these two, but it is often absent or reduced to only an obscure raised line. Sometimes the tubercles are so strong as to give the shell a conspicuously rugged appearance, but other examples are so slightly marked in this respect as to appear much like specimens of true Viviparus. Such examples very closely resemble $V$. trochiformis Meek \& Hayden, as may be seen by comparing figures of that form with figure $2 g$ on plate 28 . Indeed, notwithstanding the accepted generic differences between them, the two forms are probably genetically related. If so, one of the forms has gained a generic characteristic without losing all its specific ones. It should be remarked, however, that the opereulum of this species has not yet been discovered. This organ is quite characteristic in living forms of Tulntoma, and without a knowledge of it in the case of the fossil form we cannot be positively certain that it is generically separable from Viviparus.

Length of a large example, 38 millimeters; diameter of the last volution, 25 millimeters.

This species resembles the recent species T. magnifica Conrad, but it differs from that form in its less convex volutions, its faintly-impressed suture, and the different arrangement of its tubercles. It is the only known species of Tulotoma in American strata, but among European forms it may be compared with $T$. (Viviparus) strossmayerana Pilar.

Judging from Brusina's figures of that species, however, it differs in the less convexity of its rolutions, especially that of the proximal side, and in the different character and position of the tubercles that mark its surface.

The specific name is given in honor of Prof. A. H. Thompson, formerly geographer of the United States Survey of the Rocky Mountain Region.

Position and locality.-Laramie strata, near the top of the group, at Black Buttes Station, Union Pacific Railroad, Wyoming, and also in the valley of Crow Creek, east of the Rocky Mountains in Colorado.

\section{Genus CAMPELOMA Rafinesque. \\ Campeloma vétula Meek \& Hayden. CAMPELOMA MULTISTRIATA M. \& H. Campeloma multmineata M. \& H.}

Dr. Hayden obtained the types of these three species from the Laramie strata of the Upper Missouri River region. They are described and figured in vol. ix, U.S. Geol. Sur. Terr. (4to ser.). The first two forms have also been discovered in the Bitter Creek series west of the Rocky Mountains, and the third one in the Laramie strata, east of those mountains in Colorado. The latter examples are represented by figs. $4 a$ and $b$, plate 28. The examples show a more distinct shouldering of the distal border of the last volution than is shown by Meek's figured type; and some examples brought by Mr. J. A. Allen from the valley of the Yellowstone are still more robust and show a still more distinct shouldering of that border. 
Catipeloma MaCrospira Meek.

Plate 30, fig. $2 a$.

Mr. Meek describes this species in vol.iv, U. S. Geol. Sur. 40th Parallel (King), p. 179, and gives imperfect figures of it on plate xvii of that volume. It was originally described by Meek in the annual report of this survey for 1872, and fig. $2 a$, plate 24 , is drawn from the type from which he drew that description. Some other examples, collected from the same locality which furnished the types, indicate a much larger size than even the figure on plate 24 . It has been found only in the Bear River series of Bear River Valley, Southwestern Wyoming.

\section{Genus VALVATA Müller.}

\section{Valvata subumbilicata Meek \& Hayden. VALVATA PARVULA M. and H.}

Dr. Hayden's collections from the Fort Union series of the Laramie Group in the Upper Missouri River region contain the types of both these forms. They are described in vol. ix, U. S. Geol. Sur. Terr. (4to ser.), pages 290 and 291, respectively. The former is figured on plate 43 , but the latter is not illustrated. Mr. Meek expressed the belief that it is only a variety of the first.

\section{Valvata? montanaensis Meek.}

Mr. Meek describes this form from the Judith River series, Upper Missouri River region, in vol. ix, U. S. Geol. Sur. Terr. (4to ser.), p. 591, and gives three wood-cuts of it in connection with the description. It has not been discovered elsewhere in any part of the Laramie Group.

\section{Genus ODONTOBASIS Meek.}

\section{ODONTOBASIS BUCCINOIDES White.}

Plate 20, figs. $3 a$ and $b$.

Odontobasis buccinoides White, 1876, Powell's Rep. Geol. Uinta Mts., p. 124.

Shell of medium size, soméwhat robust; volutions six or seven, regularly convex; suture faintly impressed; surface marked by somewhat strong longitudinal folds or varices which end at the suture upon the proximal side of the volutions of the spire, but do not quite reach the suture upon the distal side, and upon the last volution they become obsolete before reaching the anterior end of the shell; the whole surface is also marked by somewhat coarse revolving raised lines, which, in crossing the longitudinal varices, give them a crenulated appearance. The revolving lines which traverse a narrow space upon the proximal side of the suture, and also the space in front of the revolving furrow of the columella, are finer than the others. Odontoid process of the base not very prominent, forming a small angular projection at the end of the revolving furrow of the columella.

Length, 37 millimeters; diameter of the last volution, 22 millimeters; but these proportions vary considerably in different examples, as is shown by the two figures on plate 20 . 
This is one of the few forms found in the strata of the Laramie Group, the only known closely-allied species to which are associated with marine species only.

Its immediate associates are Ostrea and Anomia in abundance, and a few imperfect examples of Melania? insculpta. Of itself, this species is suggestive of a marine habitat, but it is probable that, like the Nuculana and Axincea described in this article, it survived, without generic change, in the freshening waters of the Laramie period. This supposition is not at all an improbable one, as there is sufficient evidence, aside from the presence of these shells themselves, that the water in which they lived was in a considerable degree saline.

Position and locality.-Bitter Creek series of the Laramie Group, two miles west of the Point of Rocks Station, Union Pacific Railroad, Wyoming.

\section{ODONTOBASIS? FORMOSA White.}

Plate 28, fig. 7 a.

Goniobasis? formosa White, 1878, Bull. U. S. Geol. Sur. Terr., vol. iv, p. 718.

Shell rather small; spire equal to about one-half the entire length; volutions about six; the last one inflated, and those of the spire moderately convex; the distal part of each volution somewhat shouldered, and marked at that part by numerous small longitudinal varices that become obsolete towards the proximal part of the last volution; these varices are not more distinct upon the body volution than upon those of the spire; upon the latter spire there is also a small revolving furrow near to and upon the distal side of the suture, giving those volutions a slightly constricted aspect, but which furrow seems not to extend to the body volution. Surface marked only by lines of growth, with the exceptions already mentioned, and that of some faint revolving lines upon the proximal side of the body volution, near the columella.

Length, 12 millimeters; breadth of body volution, 7 millimeters.

Only one example of this species has been found, and this is a somewhat distorted natural cast, from the reddish shales of the Laramie Group, near its base. Neither the aperture nor the extremity of the beak is shown in the specimen, and I am not entirely satisfied that it belongs to the genus Odontobasis. It plainly does not belong to any described form, and it has the general aspect of a marine shell. I therefore refer it, provisionally, to that genus, because it approaches it more nearly in its characteristies than any other known genus which is likely to exist in the Laramie Group. With this view of its affinities it is interesting as adding another form to those found in the Laramie Group, which are regarded as marine types.

Position and locality.-Laramie Group, about 400 feet above its base, Danforth Hills, near White River Indian Agency, North western Colorado. 


Fig. 1. Ostrea wyomingensis

a. Lower valve; interior view; natural size.

$b$. Upper valve; exterior view; natural size.

c. Interior view of the same, showing hinge, pedal muscular scar, and area.

Fig. 2. Axiñea holmestaNa

a. Exterior view; natural size.

$b$. Interior view of the same, showing part of hinge and area.

Fig. 3. Odontobasis BUCCINOIDES

$a$. Side view of an imperfect example; natural size.

$b$. Similar view of another example, showing a variation of form.

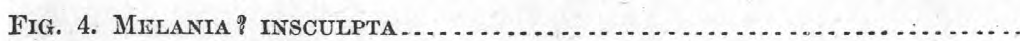

a. Side view of a fragment, which is one of Mr. Meek's types; natural size. 


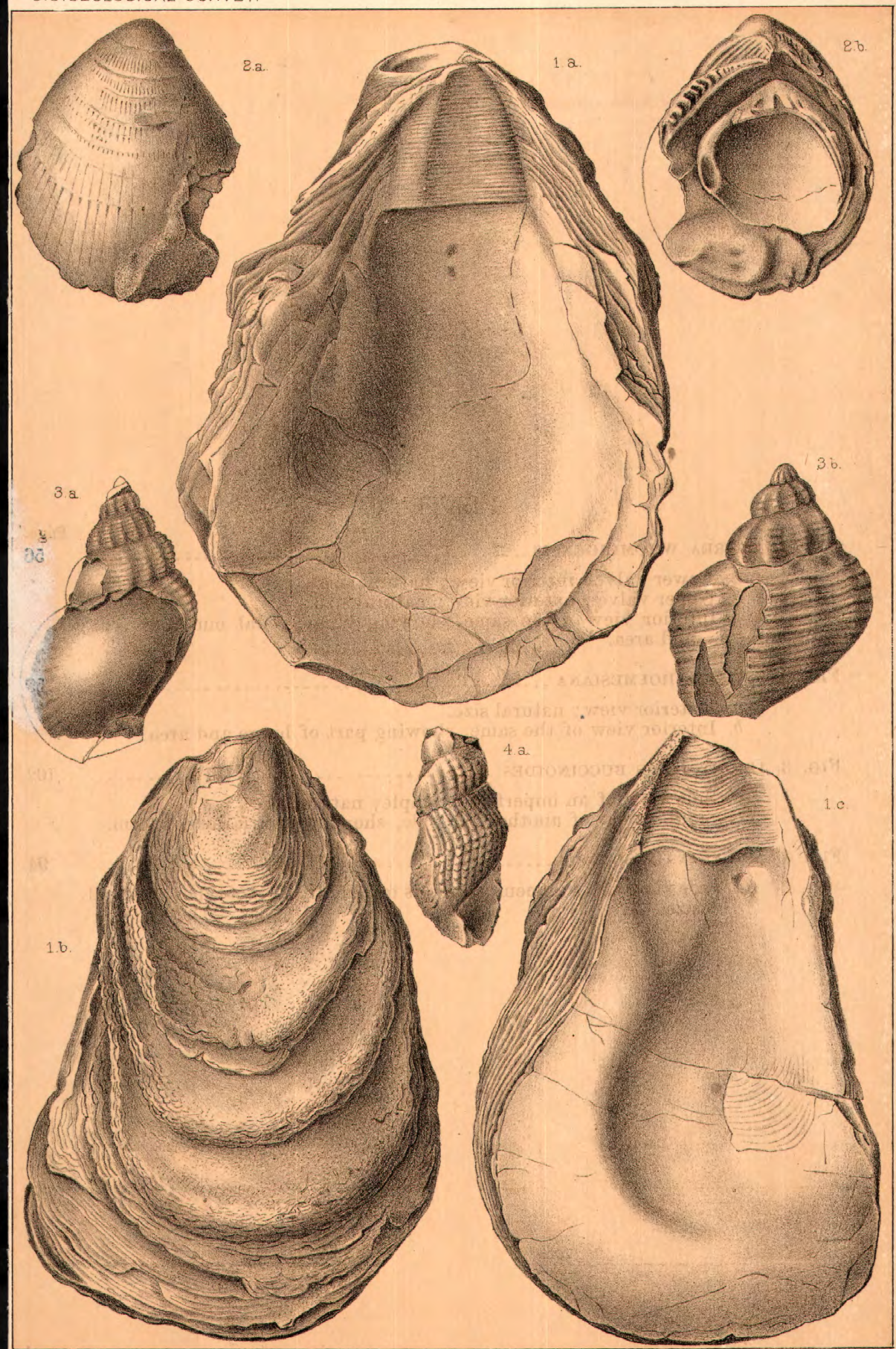

J. C. Mc Cornell, del,

Thos Sinclair \&s Son, Lith 


\section{PLATE 21.}

Fig. 1. Ostrea insecuris.................................... 56

a. Lower valve; exterior view; natural size.

$b$. Interior view of the same.

Fig. 2. Corbicula (Leptesthes) planumbona .

a. Right side view of an adult example; natural size.

b. Dorsal view of the same.

c. Right side view of another example.

d. Left side view of a large example.

Fig. 3. Corbicula occidentalis

a. Right side view of an example from Yampa Valley, Northwesteru Colorado; natural size.

$b$. Right side view of Mr. Meek's type of C. bannisteri.

c. Dorsal view of the same.

Fig. 4. Corbicula cytheriformis

a. Right side view ; natural size.

b. Dorsal view of the same example.

$c$. Interior view of a right valve.

d. Interior view of a left valve.

Fig. 5. Corbicula (Leptesthes) tracta

$a$. Left side view of an imperfect example, showing an unusually elongate form.

For other examples see plate 23 .

Fig. 6. Neritina volvilineata

$a$. Lateral view ; enlarged to one and a half diameters.

$b$. Apertural view of the same. 
US.GEOLOGICAL SURVEY

LARAMIE. PLATE 21.
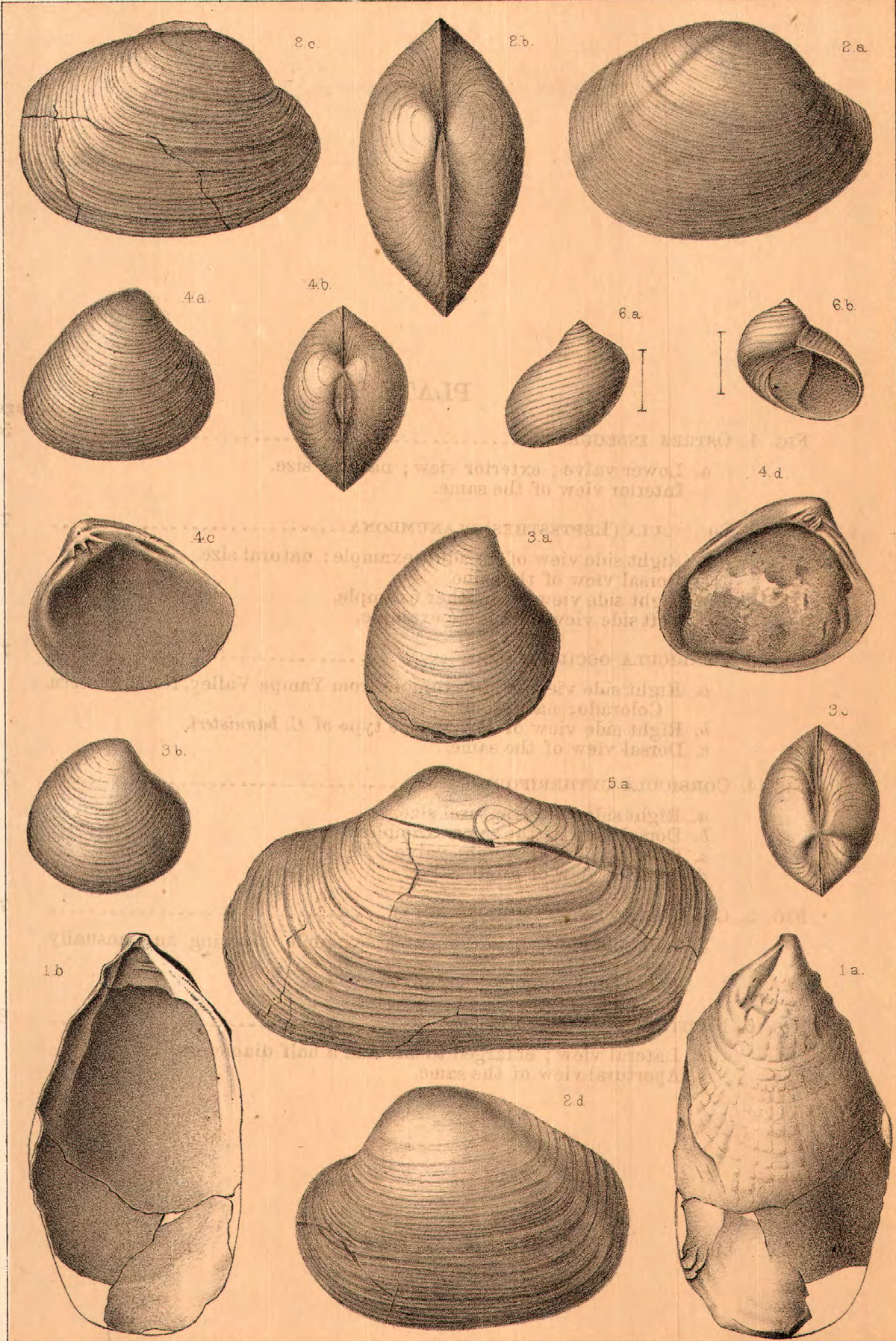

F. D. Owen \& J C.Mc Compll del.

Thog 5 inclair 8 Son Lith 

Fig. 1. Physa felix...

a. Side view of a fragment, the type specimen; natural size.

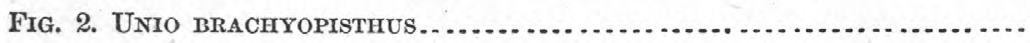

a. Exterior view, right valve; natural size; but this example is not fully adult.

b. Posterior view of the same; the valve having been a little distorted by pressure.

Fig. 3. UNIO PROAVITUS

a. Left valve; natural size.

b. Right valve of another example.

c. Front view of another example.

d. Interior view of a left valve.

Fig. 4. UNIO Holmesiands
a. Left side view; natural size.
b. Dorsal view of the same example.
c. Left side view of a young example.
d. Front view of the same.
e. Posterior view of the same. 

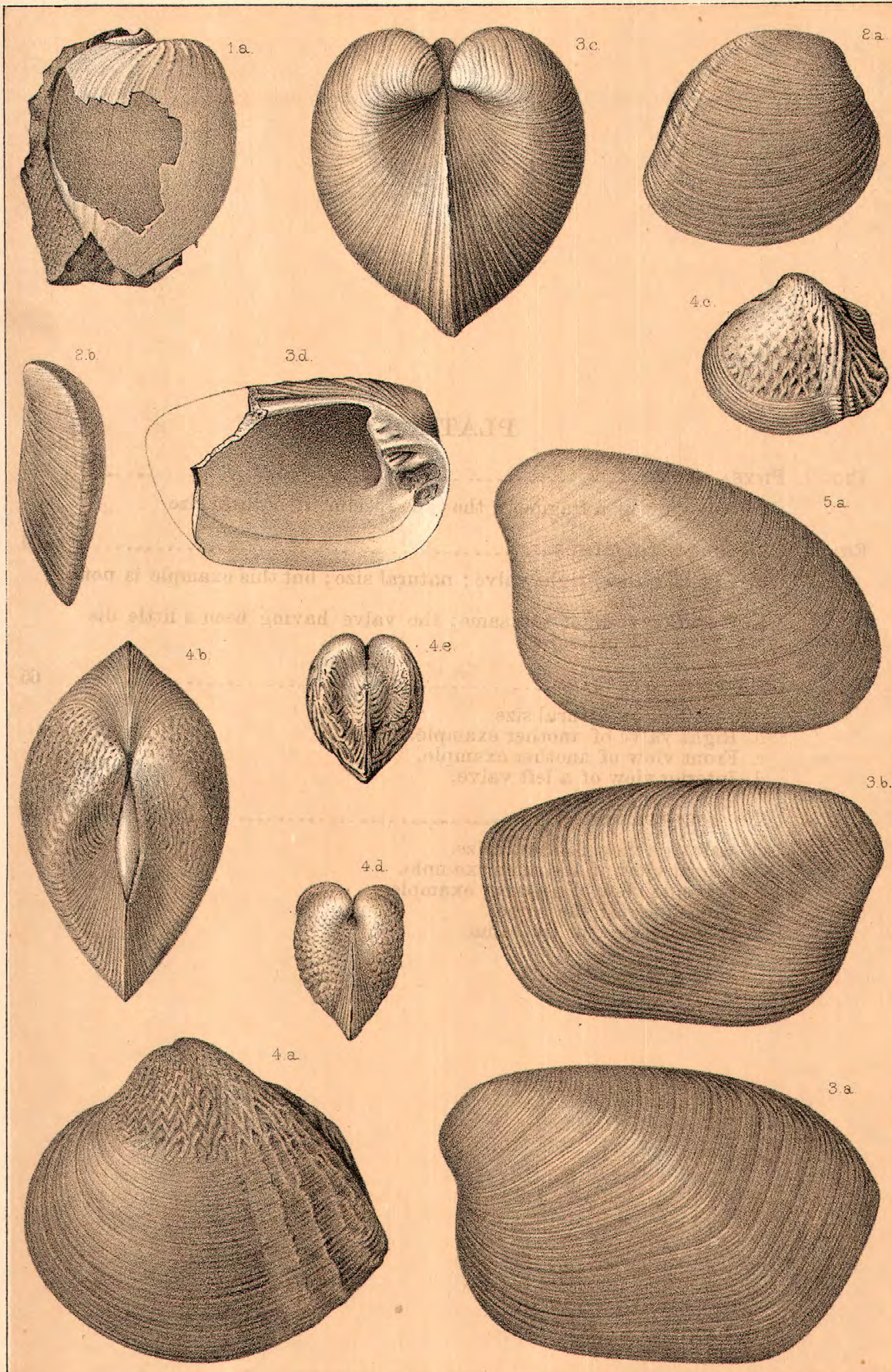

WH. Folmes Del 


Fig. 1. Corbicula cleburni.

a. Interior view, right valve; natural size.

$b$. Exterior view of the same.

c. Exterior view of another example.

All of natural size; but the species reaches a larger size than any of those figured.

Fig. 2. Corbicula (Leptesthes) Fracta . . . . . . . . . . . . . . . . . . . .

a. From a drawing by Mr. Meek of an example from Hallville.

b. Example from Black Buttes Station; left side view; natural size.

c. Dorsal view of the same.

d. Right side view of a young example; from the same locality.

e. Dorsal view of the same.

For another figure of this species see plate 21 .

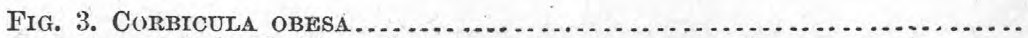

a. Left side viow of an example rather above the average size.

b. Dorsal view of the same.

c. Right side view of another example.

d. Front view of the same.

$e$. Dorsal view of the same. All of natural size.

Fig. 4. Cobricula (Leptesthes) macropistha

a. Left side view; natural size.

b. Dorsal view of the same.

c. Left side view of another example.

d. Dorsal view of the same.

$e$. Interior view of left valve.

$f$. Interior view of the right valve of another, a larger, example. 

Fig. 1. UNIO CRYPTORHYNCHUS.

a. Exterior view, right valve, of a broken example; natural size.

$b$. Interior view of the same, showing the hinge.

Fig. 2. AnOdonta propatoris

a. Left side view of a natural cast of the interior; natural size.

$b$. Left side view of a young example.

c. Dorsal view of the same.

d. Fragment of left.valve, showing the hinge.

Fig. 3. Anodonta parallela

a. Restoration figure from fragments of right valves; natural size.

Fig. 4. PhYsa COPEI .

a. Side view; natural size; the outer labial portion restored.

$b$. Apertural view of the same.

Fig. 5. Bulinus atavus

a. Side view; natural size.

$b$. Apertural view of the same.

Fig. 6. Bulinus disjunctus.

a. Side view; natural size; showing the disjoined and fiexed portion of the inner lip.

$b$. Apertural view of the same. 


Frg. 1. ANOMIA GRYPHORHYNCHUS

a. Exterior view of an upper valve; natural size.

6. Lateral view of the same.

c. Exterior view of two examples; upper valves.

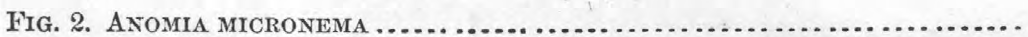

a. Exterior view of an upper valve, showing the radiating lines of the usual character; natural size.

b. Another example, showing coarser lines.

c. Another, larger, example, upon which the radiating lines are obsolete or absent.

d. Interior view of another example, showing the process beneath the beak for the attachment of muscles. All upper valves.

Fig. 3. Volsella (Brachydontes) regularis

a. Right valve; natural size.

Fig. 4. Volsella (Brachydontes) laticostata . . . . . . . . . . . . . ...

a. Right valve; natural size.

Fig. 5. Corbicula CARDINIAFormis

a. Left side view; natural size.

b. Dorsal view of the same.

Fig. 6. Corbula subtrigonalis

a. Left side view of an example from Crow Creek, Northern Colorado. $b$ and $c$. Left and dorsal views of another example from the same locality.

d. Meek's type of C. crassatelliformis, from Hallville.

$e$ and $f$. Different views of two of Meek's types of $C$. tropidophora; from near Point of Rocks Station, Wyo, 
LARAMIE.

PLATE 25.
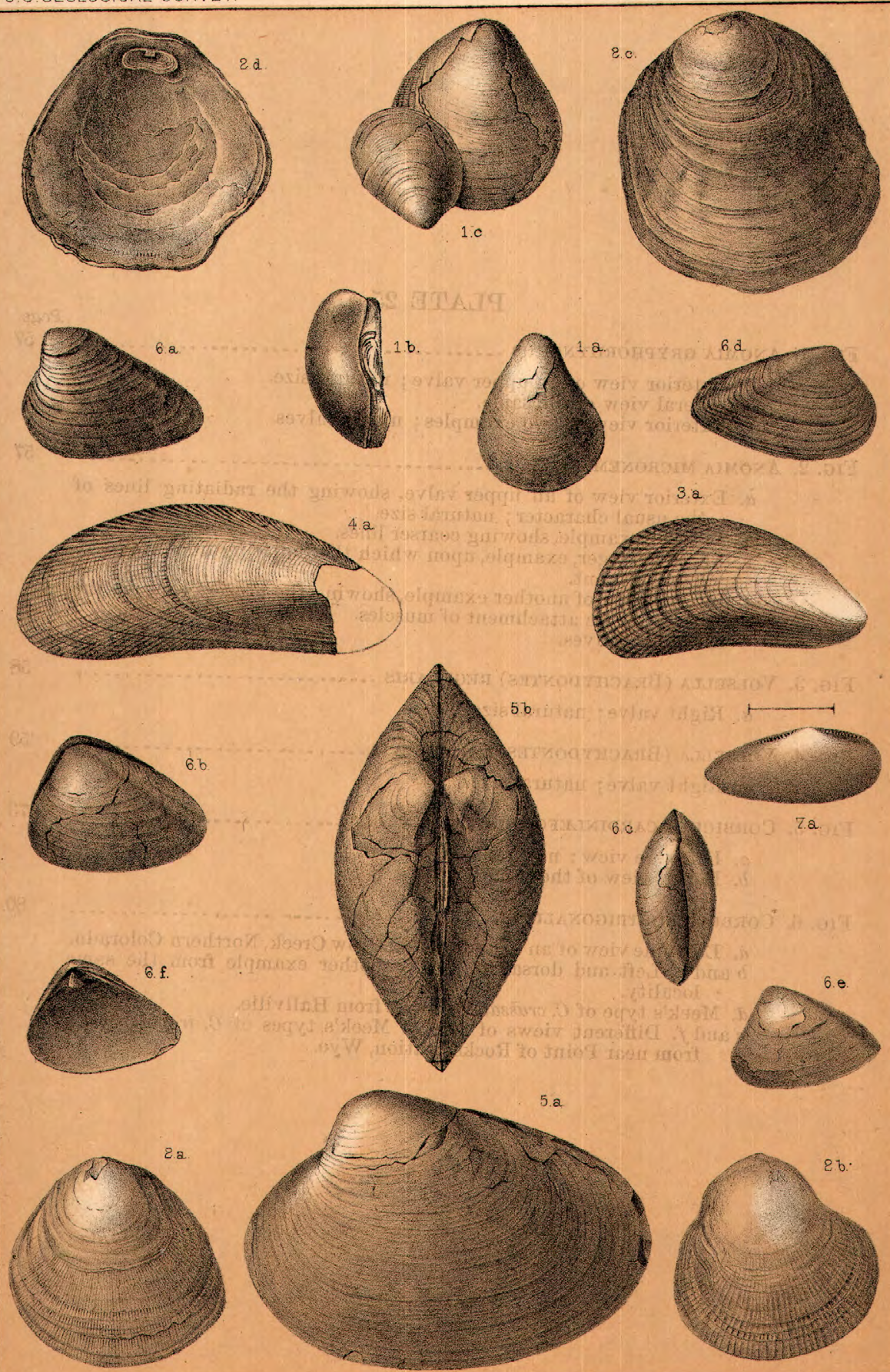

W.H. Holmes \& F D Owen $\mathrm{Del}$

Thos: Sincleir \& Son, Lith: 


Fig. 1. UNIO ENDLICHI

a. Right valve of large example; exterior view; natural size.

$b$. Interior view of a smaller left valve.

Fig. 2. Unio Gonionotus

a. Right side view; natural size.

$b$. Front view of the same example.

c. Left side view of a young example; natural size.

$d$. Right side view of the same.

e. Dorsal view of the same. 


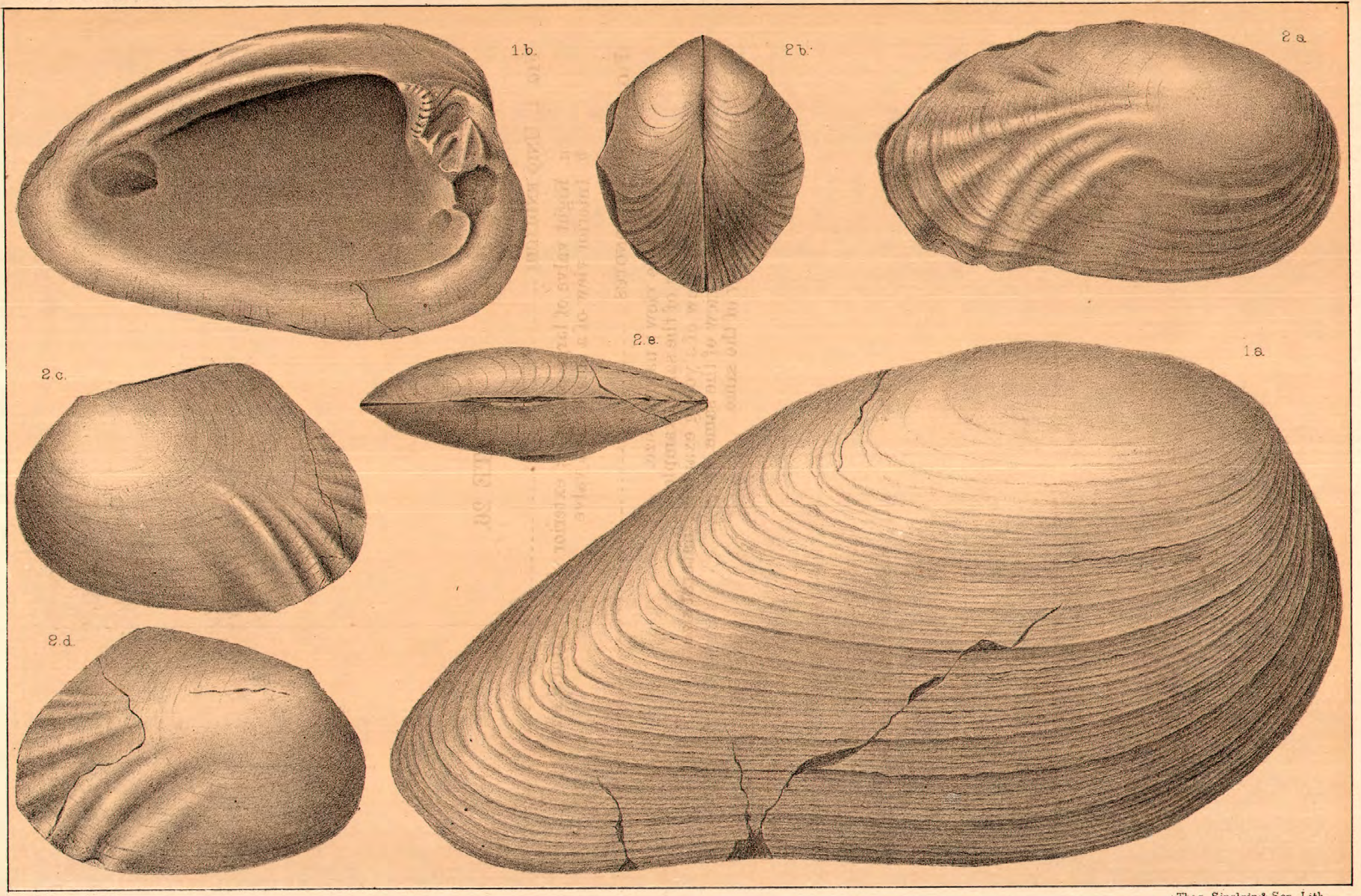



Fig. 1. UNIO COUESI

a. Left valve; natural size.

FIG. 2. UNIO DANAE?

a. Exterior view; right valve; natural size.

$b$. Interior view of a left valve.

Both examples are from Black Buttes Station, Wyo.

Frg. 3. Cassiopella turricula

$a, b, c$, and $d$. Lateral views of different examples; natural size. $e$ and $f$. Two examples, showing the aperture and small umbilicus. g. Basal view of another example, showing the umbilicus, the diameter of which is proportionately a little larger than the average. 


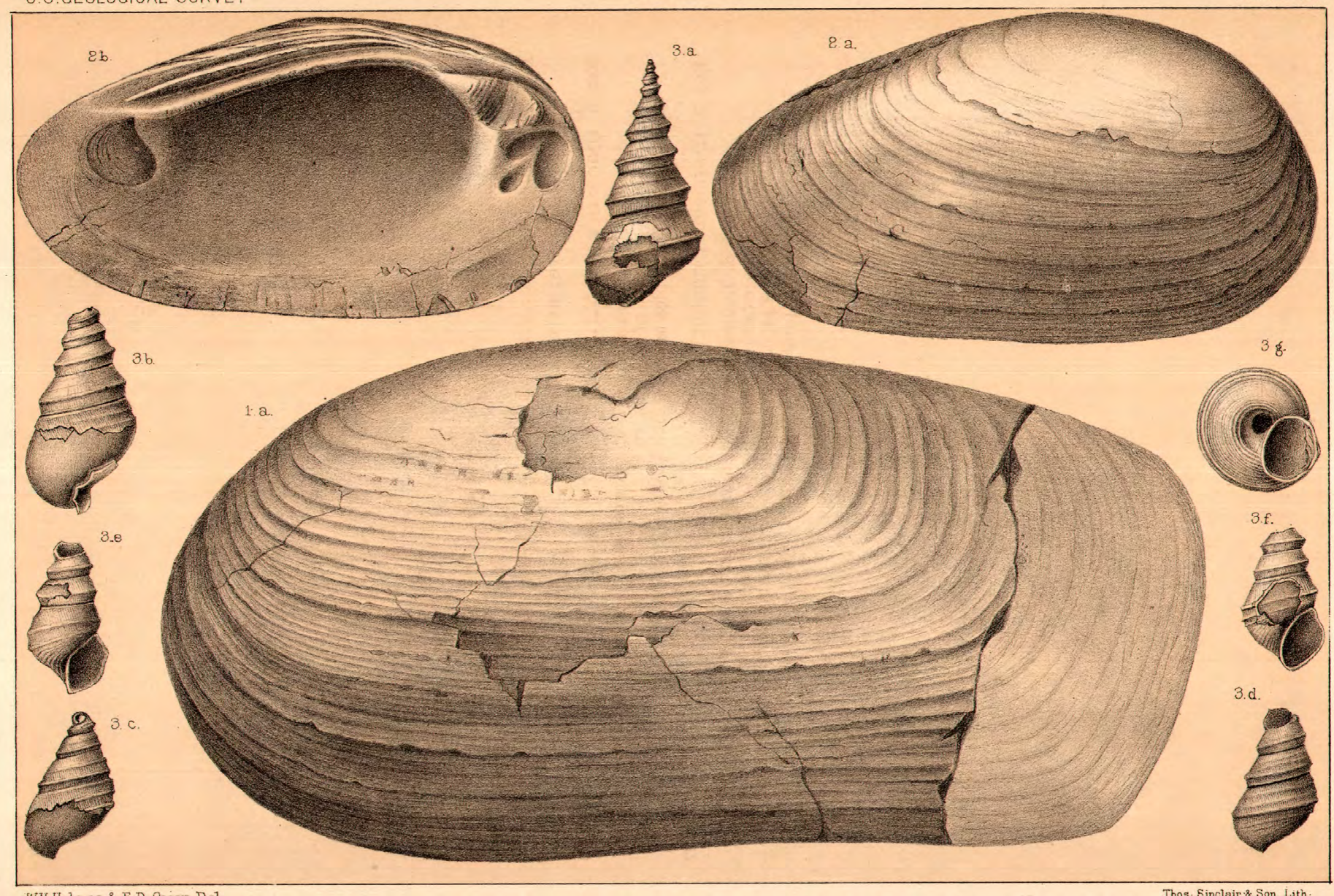



Fig. 1. UNIO SENECTUS

a. Right valve; natural size.

b. Anterior portion of a left valve.

c. Interior view of the same.

Fig. 2. Tulotoma thompsont.

a. Lateral view of an exam from Black Buttes Station, Wyo.; natural size.

$b, c, d, e, f$, and $g$. Examples from Crow Creek, Colorado, showing a wide range of variation in surface features.

$h$. Basal view of another example, showing the character of the inner lip.

Fig. 3. VIVIPARUS PLICAPRESSUS

a. Lateral view; natural size.

b. Similar view of another example.

Fig. 4. Campeloma multuineata

a. Side view of an example from Crow Creek, Colorado; natural size.

b. Another, more robust example, from the same locality.

Fig. 5. VIVIParUs PRUdentivgs

a. Side view ; natural size.

b. Apertural view of the same.

Fig. 6. Melania wyomingensis

a. Side view of a large example, showing the five last volutions; natural size.

b. Another example, showing some of the distal volutions of the spire and the beginning of the revolving row of tubercles. 

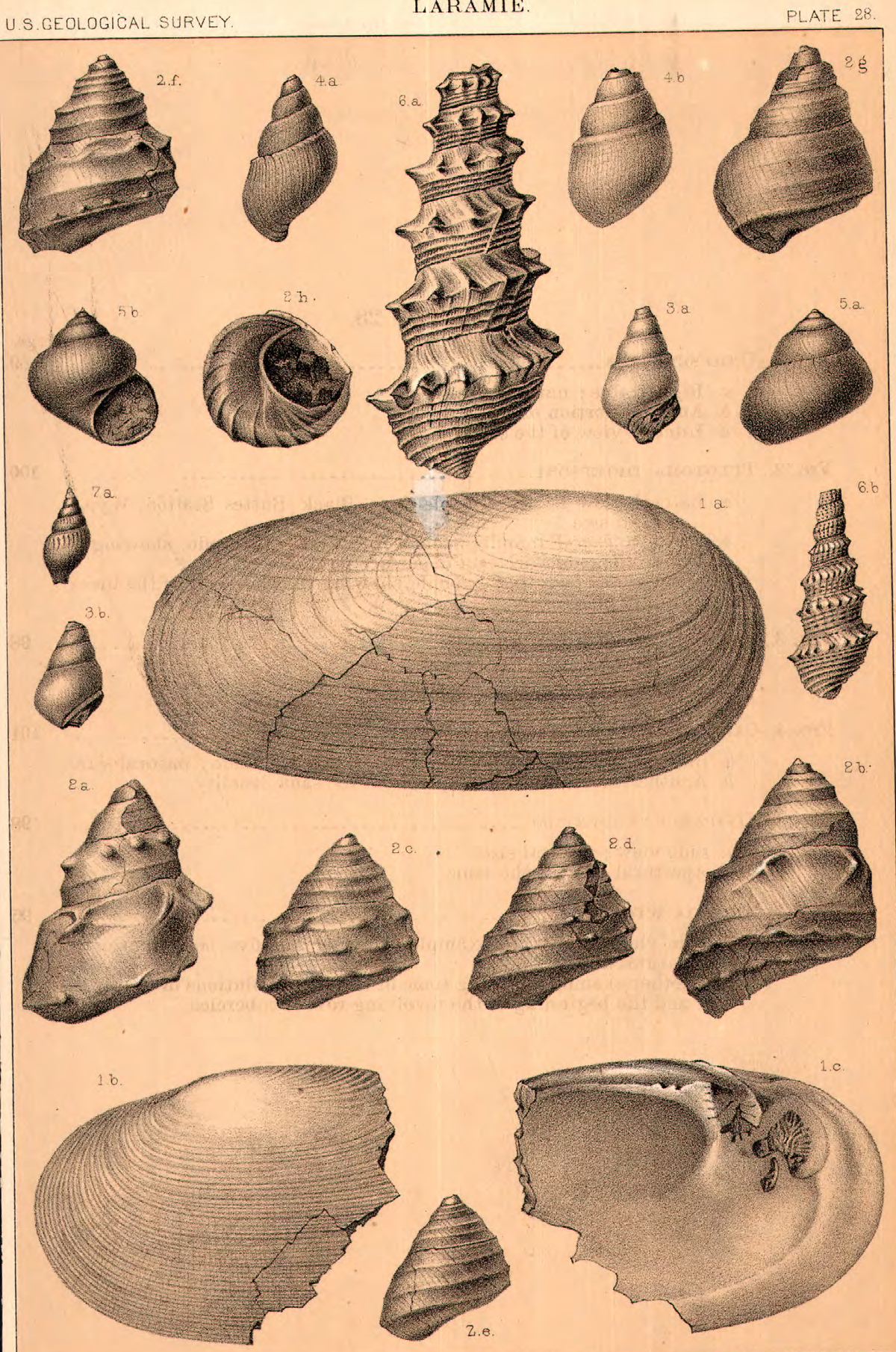

F D. Owen \& J C. Mc Comnell de

Thos Sinclair \& Son, Lith 


Fig. 1. Unio goniambonatus .

a. Left side view; natural size.

b. Dorsal view of the same example.

These figures are partial restorations as to form, the example having been somewhat distorted by accidental pressure.

FIG. 2. UNIO ALDRICHI

a. Left side view; natural size.

b. Dorsal view of the same.

FIG. 3. UNIO PRIMAVUS

a. Left side view of a small example.

b. Interior view of another example; both natural size.

Fig. 4. Corbula UNDIFERA

a. Right side view of a large example; natural size.

b. Dorsal view of the same.

c. Left side view of a smaller example.

d. Front view of the same.

$e$ and $f$. Side and front views of a young example, showing the manner of formation of the first of the larger coneentric valves or folds.

Fig. 5. Corbula undifera var. subundifera

a. Right side view; natural size.

$b$. Left view of the same.

c. Dorsal view of the same.

Fig. 6. Neritina (Velatella) Baptista . . . . . . . . . . . . . . . . . . . .

a. Dorsal view; enlarged to one and a half diameters.

b. Lateral view of the same. 
L. ARAMIE.

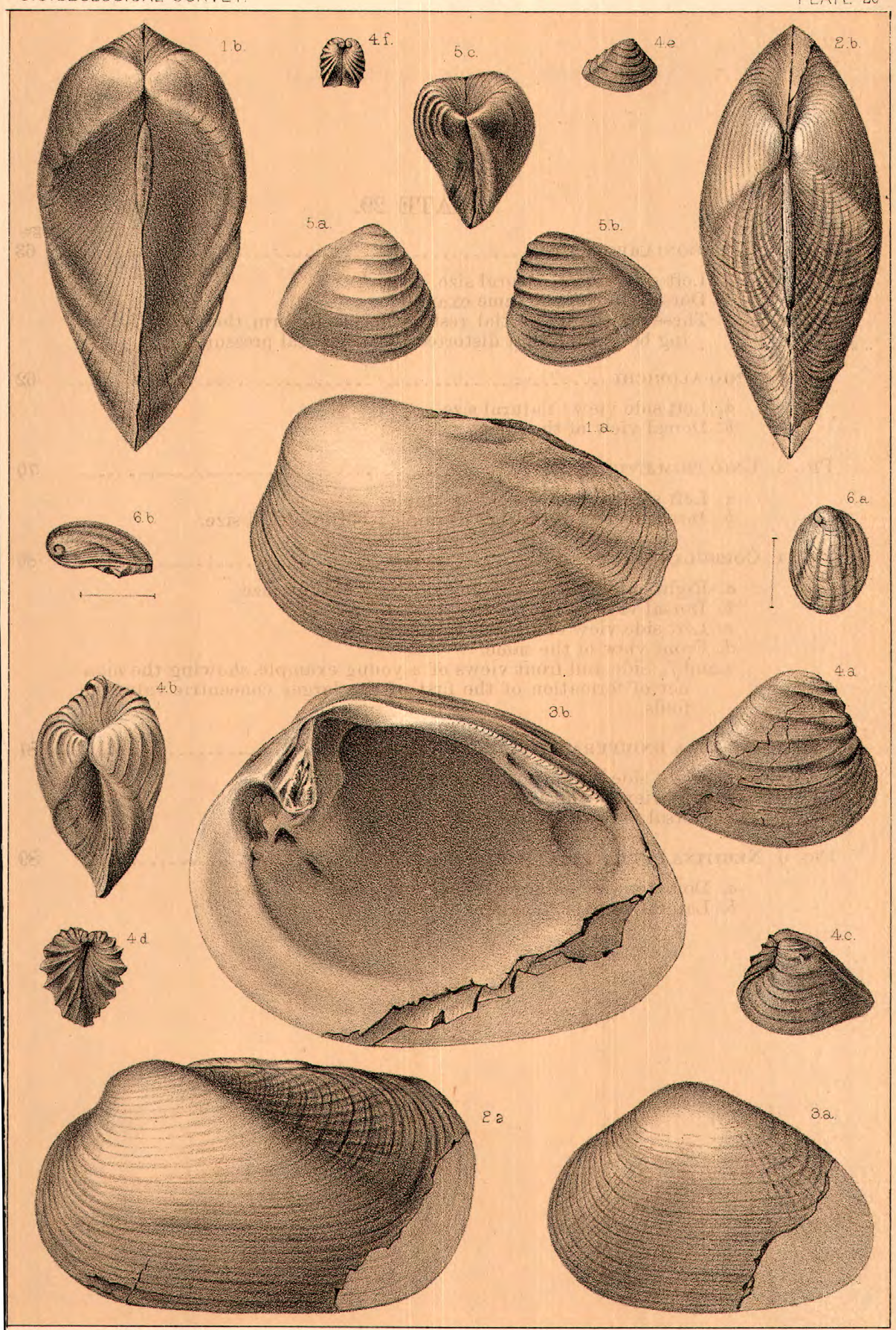

F. D. Owen \& J. C. Me Conrreil del.

Thos: Sinclatr \& Son, Lith 


Fig. 1. VIVIPARUS COUESI

a. Side view of the largest example discovered; natural size. The apex above the three last whorls has been restored from another example.

Fig. 2. Campeloma macrospira.

a. Side view, natural size, of Mr. Meek's type spccimen.

Fig. 3. Neritina Naticiformis

a. Side view; enlarged to four diameters.

$b$. Apertural view of the same. These figures are not very satisfactory.

Fig. 4. Gontobasis ClebURNI.

a. Side view of an averaged sized example; natural size.

$b$. Apertural view of the same.

c. Side view of another example.

d. Fragment of a large example.

Fig. 5. Goniobasis Chrysallomea

a. Side view of an imperfect example; natural size.

b. Similar view of another example.

Fig. 6. Goniobasis chrysallis

a. Side view; enlarged to two diameters.

$b$. Similar view, of another example, the spire of which is naturally or otherwise bent.

Fig. 7. Goniobasis ENDLICHI

a. Side view of an imperfect example, showing the revolving lines very distinctly.

b. Similar view of another example, showing the lines less distinctly.

c. Apertural view of another example, from which the lines have been removed by attrition.

All of natural size.

FIG. 8. RHYTOPHORUS MEEKI

a. Side view; natural size.

$b$. Apertural view of another less perfect example.

Fig. 9. Acella hatdemani

$a$. Side view; enlarged to four diameters.

b. Apertural view of the same.

Fig. 10. Goniobasis macilenta

a. Side view ; enlarged to one and a half diameters.

Fig. 11. PHYSA ?.

a. Side view; natural size. 

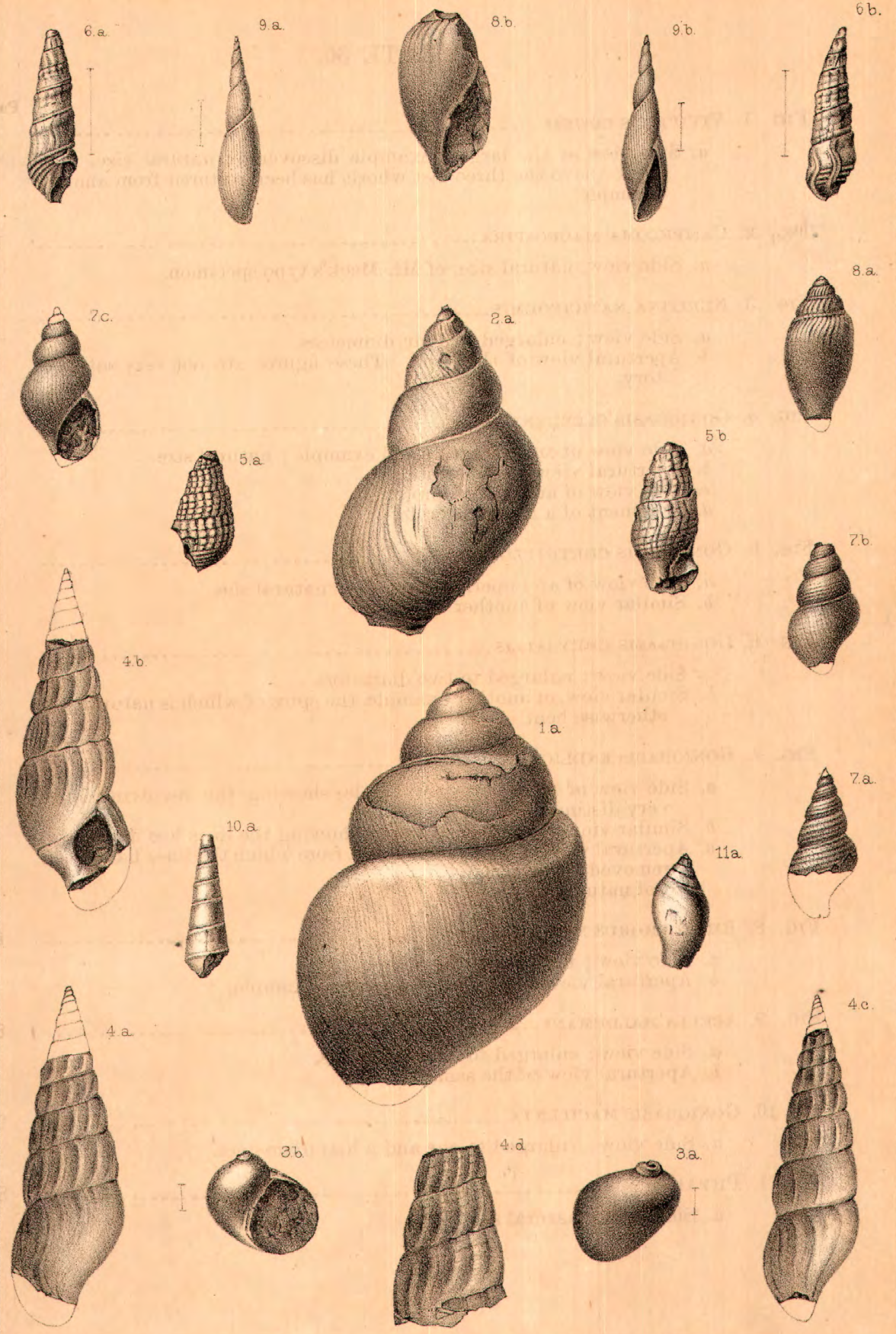

F. D. Owen \&. J C. Mc Conneli del 



\title{
CONTRIBUTIONS TO INVERTEBRATE PALEONTOLOGY N0. 5: TRIASSIC FOSSILS OF SOUTHEASTERN IDAHO.
}

\author{
By C. A. White, M. D.
}

The fossils discussed and illustrated in this paper are those which were under the designation of Fossils of the Jura-Trias, described in the Bulletin of this survey, vol. v, pp. 105-117; having all been collected by Dr. A. C. Peale, assisted in part by Mr. J. E. Mashbach, in 1877. The fossils in question were obtained in Southeastern Idaho; and a part of the species, especially the Cephalopods, have been found at no other than the localities which furnished the type specimens. A part of the Conchifers, however, had been previously found by Dr. Peale at other localities, not many miles distant, in Southeastern Idaho and the adjacent portion of Wyoming; and one of the species, Aviculopecten idahoensis, had been described by Mr. Meek. The strata of the localities last referred to had been by common consent assigned to the Jurassic period by the geologists who had visited them; or, latterly, to the Jura-Trias, in consequence of the growing opinion that no paleontological plane of demarkation exists between those series of strata which have hitherto been assigned respectively to the Jurassic and Triassic periods. I had adopted this latter view for the reason indicated, and in the first publication of these fossils I referred them to the Jura-Trias. The distinct Triassic character of this small fauna, however, as well as that of the one previously discovered in Nevada and California by King and Whitney respectively, seems to warrant the entire separation of the strata containing those founæ from the Jurassic, and their reference to the Triassic. This view finds support also in Dr. Peale's observations concerning the position of the strata from which he obtained these fossils, in relation to those which contain the undisputed Jurassic fossils above, and the Carboniferous strata beneath. I have, therefore, in the title of this article, referred the fossils of which it treats to the Triassie period.

Among the species which are generally regarded as characteristic of the true Jurassic strata of the West are Pentremites asteriscus, Belemnites densus and Camptonects bullistriatus of Meek \& Hayden, and Eumicrotis curta Hall; and these species were obtained from some localities in the region within which the fossils of this article were obtained; but not from the same strata, with the apparent exception of $E$. curta. Indeed the fauna of the strata which bear the fossils discussed in this article is quite distinct from any other known in that great region, and, according to the observations of Dr. Peale, they orcupy a distinct horizon much lower than that of the characteristic Jurassic fossils before mentioned. He places this horizon beneath the Red Beds, or the formerly accepted Triassic, and above the Carboniferous. The following remarks are based mainly upon his observations.

Among the exposures of Triassic strata in Southwestern Idaho and 
the district immediately adjacent (and they are numerous and comparatively small in consequence of the great disturbance which they, together with their associated strata, have suffered) there are three localties which are especially interesting because the strata there exposed not only contain a number of specific and generic forms not hitherto known, at least not certainly known, in America as regards the latter, but because some of the types in which those forms are expressed are such as in Europe are regarded as characteristic of the Middle Trias. For convenience of reference these localities are designated as Nos. 1,2, and 3.

Locality No. 1 is within the limits of Idaho, about sixty-five miles north of the boundary line between that Territory and Utah, about eighteen miles west of the boundary line between Idaho and Wyoming, and about five miles west of John Gray's lake. The lata for the following section at that locality have been furnished by Dr. Peale, who has also treated this subject at some length in the Bulletin of this survey, vol. v, pp. 119-123.

Section at locality No. 1.

A.-Uppermost member of the local series; alternating limestones and) arenaceous shales. Ontcrops obscure. The following fossils were obtained from near the top of this member: Terebratula semisimplex White; T. auqusta Hall \& Whitfield?; Aviculopecten idahoensis $\} 1,00$ feet. Meek; Gervillia —— ? and an undetermined conchifer..........

B.-Limestones; outerops somewhat obscure. The fossils are Eumicrotis curta and Aviculopecten idahoensis ...............................

C.-Greenish and reddish fossiliferous sandstones, followed by arenaceous ? shales and limestones. The fossils are Aviculopecten pealei White, 350 feet: and three or four undetermined species of conchifers..............

D.-Bluish-gray limestones, with fossils near their base. The fossils are Meekoceras gracilitatis White; M. mushbachanum W.; Arcestes? cirratus W.; Arcestes? ? ? ; Arcestes? (another species) and Eumicrotis curta Hall. ............................................

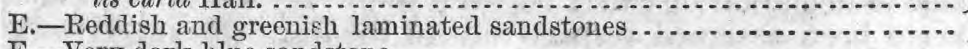

F.-Very dark-blue sandstone .......................................

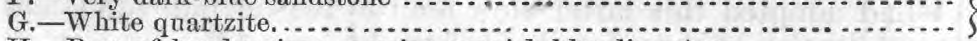

H.-Base of local series ; massive grayish-blue limestone.................. 400 feet,

The strata of this locality have been much displaced, the dip being to the southwestward, and at an angle of about 550 . At the southern portion of the exposures of the strata of this locality, however, the strike curves to the eastward, so that the dip is there to the southward, and the angle lessened.

At locality No. 2, which is about fifteen miles a little east of south from locality No. 1, occurs another limited exposure of limestone strata, which are equivalent in part with those of locality No. 1, and which there occupy a synelinal axis. From these strata Meekoceras aplanatum and $M$. gracilitatis were obtained. The presence there of the latter species seems to sufficiently indicate the equivalency of those strata with member D. of the foregoing section at locality No.1, because numerous examples of that species were obtained from that member of the section referred to.

About the same distance as before (fifteen miles), almost due west from locality No. 1, is locality No. 3, the strata there being calcareous sandstones. From these strata Dr. Peale obtained Aviculopecten idahoensis Meek, and A. altus White, examples of the former species being somewhat abundant and the latter rare. A. idahoensis also occurs in both $\mathrm{A}$ and $\mathrm{B}$ of the foregoing section, with which members of that section the strata of locality No. 3 are doubtless equivalent. Mr. Meek's types of this species, which he referred to the Jurassic period, were obtained several years ago by Dr. Peale in Lincoln Valley, near Fort Hall, about fifty miles northwestward from locality No. 1. So far as I am aware no other species were found associated with it there, and ithas been found atno 
other localities than those herein mentioned. It is reasonable therefore to regard it as peculiar to the horizon which furnishes the Cephalopods and other fossils pertaining to the peculiar fauna discussed in this article.

The following section is copied from Dr. Peale's article in the bulletin of this survey before mentioned, and is introduced here for the purpose of showing his views of the geology of the district in question after the very brief examination which he gave it in the autumu of 1877 .

General section of the Jura-Trias in Southeastern Idaho and Western Wyoming.

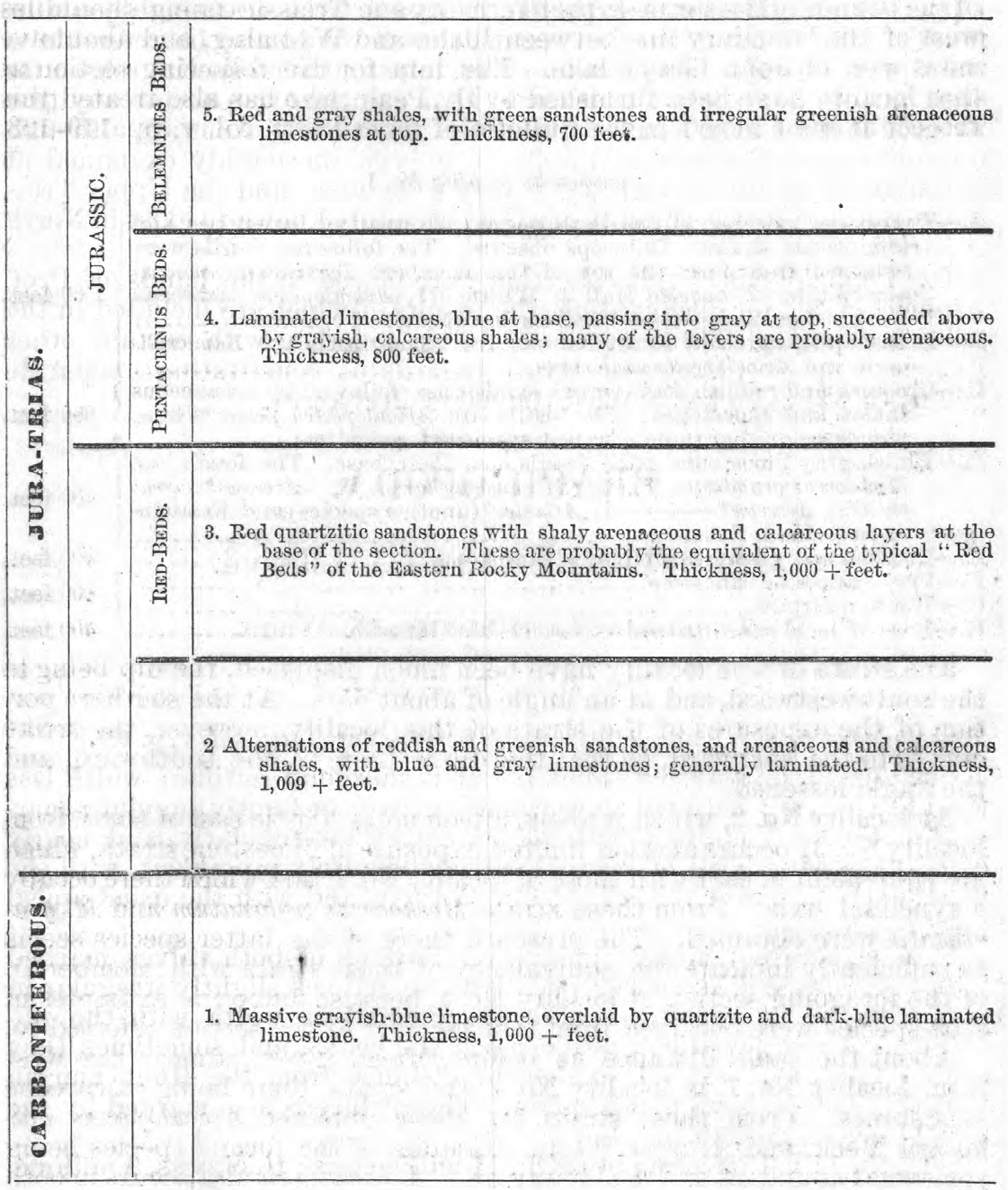

Nos. 1 and 2 of the foregoing section embrace the same strata which are represented by the previous section of locality No. 1 .

The fossiliferous strata of the three localities herein especially considered contain all the new fossil forms which are described in this paper, together with the three following identified species, namely Terebratula 
augusta Hall \& Whitfield, Aviculopecten idahoensis Meek, and Eumiorotis curta Hall. I am not entirely satisfied of the identity of the species here referred to $T$. augusta, and there is a possibility that the Eumicrotis is not $E$. curta ; but so far as can be at present determined, it is identical.

According to European standards the Cephalopods here described are unquestionably of Triassic types, and, as pointed out by Professor Hyatt in the following remarks, they have more resemblance to certain Cephalopods of the Muschelkalk or Middle Trias of Europe than to any other. The Triassic fauna discovered by King and Whitney respectively in Nerada and California was referied, and doubtless, correctly so, to the Upper Trias, and it was expected, in case a Triassic fauna should be found in the Rocky Mountain region, that it would also be referable to the Upper Trias. There was, however, apparently no special reason for such an opinion except that the evidence of the existence of any true Triassic fauna had so long escaped detection in North America, although the full series of strata had apparently been thoroughly examined at hundreds of localities, and over a very wide area; and the Upper Trias fauna referred to was the only one then certainly known to exist in North America.

The Cephalopods of this collection were placed in the hands of Prof. Alpheus Hyatt for examination, the results of which are included in the following pages. Three of these forms, together with certain other European species, Professor Hyatt regards as constituting a separate geuus, to which he has applied the name Meekoceras.

\section{BRACHIOPODA.}

\section{Genus TEREBRATULA Lihwyd.}

\section{Terebratula semismmetex White.}

Plate 31, figs. $3 a, b$, and $c$.

Terebratula semisimplex White, 1879, Bull. U. S. Geol. Snr. Terr., vol. v, p. 108.

Shell small, obovate or subelliptical in marginal outline; width less than the length; cardinal slopes gently convex or faintly angular ; margins of the shell obtuse; both valves somewhat regularly, and nearly equally convex; beak of ventral valve moderately prominent, with the usual curvature over that of the dorsal valve, and with the usual apical perforation.

Shell-structure minutely punctate. Surface of both valves marked by numerous small radiating plications, sometimes slightly irregular in size, with the intervening spaces about equal in width with the plications. These plications never reach the beaks, and sometimes they are so faint, and extend so short a distance from the front margin that the shell appears almost plain. The surface is also marked by the usual lines of growth. ters.

Length, 14 millimeters ; breadth, 11 millimeters ; thickness, 9 miliime-

The form, and more especially the plications, of this shell give it the appearance of certain forms of Rhynchonella, but its punctate structure forbids its reference to that genus. Perhaps it is really a Waldheimia; but as the internal structure is not known, it is at present referred to the typical genus of the Terebratulidæ. 
Position and locality.-Triassic strata; member $\mathbf{A}$ of the section at locality No. 1, Southeastern Idaho, where it is associated with Aviculopecten idahoensis and other species. Collected by Dr. A. C. Peale.

\section{gTf}

Associated with the preceding species at locality No. 1, is another species of Terebratula which may perhaps prove to be a new form, but it is too nearly like T. augusta Hall \& Whitfield and T. millipunctata Hall to warrant the application of a new specific name. The latter is a well-known Upper Coal Measure species of the Mississippi Valley; and the former is reported from Jurassic strata at Shoshone Springs, Augusta Mountains, Nevada.

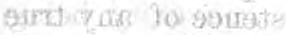

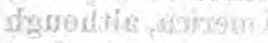

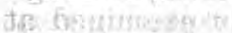 \\ CONCHIFERA. \\ Genus AVICULOPECTEN McCoy.}

\section{AVICULOPECTEN? PEALEI White.}

Plate 32, fig. $4 a$.

Aviculopecten pealei White, 1879, Bull. U. S. Geol. Sur. Terr., vol. v., p. 109.

Shell, exclusive of the ears, subovate in marginal outline; obliquity of the axis to the hinge-line backward, and forming with it an angle of about 70 degrees; hinge-margin not quite as long as the greatest transverse diameter of the body of the shell. Left valve moderately convex, the convexity being nearly uniform except in the umbonal region, where it is, as usual, greatest; beak moderately prominent, incurved and elevated slightly above the hinge-margin; anterior ear moderately large, prominent, extending as far forward as the front margin of the shell, distinet from the body of the shell, but not separated from it by a distinct auricular furrow; its antero-inferior border convex sloping backward to a moderately deep, angular byssal notch; front margin of the valve regularly convex in outline; antero-basal margin also conrex, but not quite so much so as the front; postero-basal margin somewhat abruptly rounded up to the nearly straight posterior margin. Posterior ear moderately large, but not quite so prominent as the anterior ear, moderately distinct from the body of the shell.

Surface marked by numerous raised radiating lines and small costæ, the latter being less numerous than the former, and differing from them only in being larger; all of them being slightly undulating in their direction from the umbo towards the margins. Near the margins three or four of the lines occupy each of the spaces between the costre. Both ears are marked by radiating raised lines similar to those on the body of the valve, but they are more numerous and finer on the posterior ear than on the anterior. No ribs appear on the ears, and the lines referred to are not quite so distinet as they are on the body of the valie. Crossing the radiating lines and costr there are numerous fine but distinct concentric lines, and some larger wrinkles of growth. Right valve and hinge unknown.

Height from base to beak, 37 millimeters; antero-posterior diameter of the body of the shell, 33 millimeters; length of hinge-margin, 28 millimeters.

The hinge of this shell being unknown, it cannot with absolute certainty be referred to Aviculopecten, but its form and external characters 
indicate its place in that genus, to which it is provisionally referred, together with the two following species, which are all evidently eongeneric. Position and locality.-Triassic strata; member $\mathrm{C}$ of the foregoing: section at locality No. 1, Sontheastern Idaho. Collected by Dr. Peale.

\section{Aviculopecten? altus White.}

Plate 32, fig. $3 a$.

Aviculopecten altus White, 1879, Bull. U. S. Geol. Sur. Terr., vol. v, p. 110.

Shell, exclusive of the ears, subovate in marginal outline; axis almost perpendicular to the hinge-margin, or having a very slight forward obli. quity; hinge-margin shorter than the greatest transverse diameter ofthe body of the shell. Left valve depressed-convex, the convexity being nearly uniform in all parts, except the umbonal region, where itis, as usual, greatest; beak small, moderately narrow, pointed, and projecting very slightly abore the hinge-margin; posterior ear moderately large, its posterior point extending about as far backward as the body of the shell, not very distinctly separated from the body of the shell, its posterior border broadly and not deeply notched; hinder margin nearly straight from the shallow noteh of the posterior ear to a point a little below the mid-height of the shell, from which point the margin is rounded with considerable regularity to the anterior side; from that side to the base of the anterior ear the margin is a little more abruptly rounded; outer margin of the anterior ear apparently forming a nearly right angle with the hinge-margin. Anterior ear apparently small, distinct from the body of the shell, but not separated from it by an auricular furrow. Surface marked by numerous radiating lines and costæe, which are somewhat irregularly undulating in their direetion; the latter, being more numerous than the lines, the two differing from each other only in size. The surface of the anterior ear is faintly marked by numerous fine radiating raised lines, but that of the posterior ear is apparently marked only by fine lines of growth. Crossing the radiating lines and costæ there are concentric lines and wrinkles of growth. Right valve and hinge unknown.

Height from base to beak, 55 millimeters; antero-posterior diameter, 43 millimeters; length of hinge-margin, 28 millimeters.

This species is congeneric with, and bears considerable resemblance to, A. pealei, just described, but it differs from that form in its much greater proportionate height, its almost perpendicular axis, its shorter hinge-margin, smaller anterior ear, ${ }^{*}$ and in having the heavier radiating lines or costæ more numerous in proportion to the smaller lines.

Position and locality.-Triassic strata, Southeastern Idaho, where Dr. Peale collected it from locality No. 3 , mentioned on a previous page of this article.

\section{AVICULOPECTEN? IDAHOENSIS Meek.}

Plate 32, fig. $2 a$.

Aviculopecten (Pseudomonotis?) idahoensis, Meek, 1872, An, Rep. U. S. Geol. Sur. Terr. for 1871, p. 374.

Associated with the species last described, and also with other forms in members $\mathrm{A}$ and $\mathrm{B}$ of the section at locality No. 1, Dr. Peale found a

* The condition of the only example discovered would not allow of an entirely satisfactory determination of the character of the anterior ear, but it is doubtless as represented by the artist in plate 32 , fig. $3 a$. The slight forward obliquity, if it be such, makes it somewhat doubtful whether it is really a left valve, as its other characteristics indicate it to be. 
number of examples of $A$. idahoensis Meek. The type specimens of this species, as before stated, were obtained at a locality in Lincoln Valley, about 50 miles northwestward from locality No.1. His description of it was published in the work already cited, and the strata from which the type specimens were obtained were then referred to the Jurassic. This form is sufficiently distinct as a species from either of the other two that have just been described, but they are all three clearly congeneric. Although in outward characters and appearance they are like the typical forms of Aviculopecten, the hinge is not known. All the specimens of all three of the species are preserved only in the form of casts of the left valve, and no trace of the right valve of either species, nor any hinge markings of any kind, have been detected. It is probable, as Meek has suggested in relation to $A$. idahoensis, that neither of the three species will, when their characters are completely known, be found to agree strictly with the typical forms of Aviculopecten. Their reference to that genus is therefore to be regarded as provisional only. The following is Mr. Meek's original description :

"Shell suborbicular, very slightly oblique, hinge distinctly shorter than the valves. Left valve rather compressed; posterior [anterior] ear very short or nearly obsolete, and scarcely angular at the extremity, the posterior [anterior] margin below being convex in outline instead of sinuous; anterior [posterior] ear longer and more angular, compressed but more distinct from the slight swell of the umbo than the other, and having its margin below broadly and rather slightly sinuous ; surface ornamented by compressed, generally simple, alternately smaller and larger, radiating costæ, only the latter of which reach the beak, while those of both series become nearly or quite obsolete on the ears, particularly on the posterior one; lines of growth small, rather regular and obscure. Right valve unknown.

"This is probably neither a true Pseudomonotis nor an Aviculopecten; but as I know nothing of the nature of its hinge, nor of its right valve, its true generic characters remain doubtful. Many paleontologists refer such forms to the genus Pecten, but they are evidently distinct from that group as typified by the existing P. maximus."

Among the fossils described in Contributions to Invertebrate Paleontology No. 7, upon a following page as Jurassic, and figured among: Jurassic fossils on plate 37, is another species, A. superstrictus, evidently congeneric with the three foregoing species; and among them is also another shell, Vulsella (Modiolinu) macronota, which occurs associated in the same strata with it. It is quite probable that the strata from which these two species were obtained may prove to be equivalent with those strata from which the fossils came that form the basis of this article. If so, they are of Triassic and not Jurassic age. This supposition is the more probable because both the types represented by the two species referred to occur in the Triassic, and are not yet known in the Jurassic of that region.

\section{CEPHALOPODA.}

Five species of Cephalopods, and perhaps six, are represented among the collections brought in from localities No. 1 and No. 2 , three of which belong to the genus here proposed by Professor Hyatt, and the others probably to Arcestes. The following are Professor Hyatt's diagnostic remarks upon the proposed new genus; and following those are remarks upon each of the species, all of which are indicated by quotation marks, and followed by his initials in brackets. 


\section{Genus MEEKOCERAS* Hyatt.}

"These species, so far as they go, are unlike the Ceratites of any foreign locality, but have more resemblance to the Muschelkalk than to the St. Cassian or Hallstadt faunas. They possess in common one characteristic which separates every species from the typical forms of European Ceratites. There are but three distinct lateral cells and two lateral lobes besides the finer anxiliary lobes and cells. This oceurs in the most involute species, ' $\mathrm{C}$ ' $[M$. gracizitatis $]$, as well as in the least involute [M. aplanatum]. This characteristic would be of no small value in any group, but in this one it is unusually constant in spite of the great differences of form and the variations in breadth of the sides of the whorls between the different species. The typical Ceratites. the $C$. nodosus and $C$. semipartitus have at least four distinet lateral cells and lobes besides the auxiliary ones, and the distinction is slight between the two series. In this genus, on the contrary, the auxiliary series, when present, is not divided from the third lateral cell by a distinct lobe as in Ceratites, and the aspect of the third lateral cell is often like that of a Goniatites. The auxiliary series is of course not present in the less involute and narrower sided forms, such as ' $\mathrm{A}$ ' [M. aplanatum], and A mm. parcus, Amm. boydanus, and Amm. ottonis, as tigured by von Buch; and Ceratites carbonarius Waagen. These and the Goniatites lcevidorsatus Gabb (which I have in Meek's report on the Paleontology of the Geol. Expl. 40th Parallel, erroneously referred to Clydonites), are quite distinct, but the adult sutures of the latter are not known, and its position is theretore uncertain.

"The compressed whorls of all the species is of course a characteristic which is obvious when they are contrasted with typical Ceratites, as is also the absence or merely transient appearance of heavy nodes or ribs, except, perhaps, in the least involute species, if lcevidorsatus be found to belong to this genus. The young shells appear to be quite distinct from the young shells of true Ceratites, so far as these have been compared, though no exact observations could be made for want of good specimens of the young of the true Ceratites." - (A. H.)

\section{MEEKOCERAS APLANTUM White.}

Plate 31, figs. $1 a, b, c$, and $d$.

Meekoceras aptanatum White, 1879, Bull. U. S. Geol. Sur. Terr., vol. v, p. 112.

Shell compressed, discoidal, having the peripheral or siphonal side of the outer volution flattened, that of the inner volution being a little rounded, and although narrow, its breadth is considerable as compared with the small transverse diameter of the volutions ; umbilicus open, shallow, its width in the adult being about equal to that of the greatest vertical diameter of the outer volution, but it appears to have been proportionally wider in young examples; volutions flattened, convex on their sides, but their inner edges are abruptly rounded inward to meet the next volution; all the rolutions slightly embracing; the inner ones somewhat less so than the outer. Siphonal cell of the septa small, and upon the inner volutions it is very small; in the outer septa it occupies the whole width of the flattened portion of the periphery, bringing the small outer lobes upon the angle between the sides and the fattened periphery; outer and middle cells of nearly the same width, the outer regularly, and

* "Dedicated to the memory of my friend, F. B. Meek, as some slight testimony of my respect for his works and regret for his loss."-[A. H. ] 
the middle a little obliquely rounded, inner cell incomplete; the outer lobes very small, usually notched at the end, pointing directly backward in the inner volutions, but in the outer septa they diverge a little from each other; middle lateral lobes of about the same width as the outer cell, bearing at its end about five small digitations; inner lobe smaller than the middle one, but similar to it and bearing about four small digitations; auxiliary lobes and cells apparently entirely wanting. Surface of the outer volution nearly plain, or bearing faint indications of transverse nodes or ribs, which upon the inner volutions are numerous and more distinct.

Diameter of the coil of the largest example in the collection, 60 mitlimeters; extreme vertical diameter of the outer volution, 22 millimeters; transverse diameter of the same, 12 millimeters.

Position and locality.-Triassic strata; locality No. 2 of the preceding pages; Southeastern Idaho, where they were collected by Dr. A. C. Peale.

Professor Hyatt makes the following remarks upon $M$. aplanatum :

"This species belongs to that group of this genus in which the shells have but a slight amount of involution, and possess also the narrow and numerous whorls which are the invariable accompaniments of this characteristic in all the Ammonitoids and Nantiloids. The resemblance to Amm. pareus von Buch* is very close so far as the outlines of the sutures are concerned, but the sides are too flat, the umbilical shoulder very abrupt, and the siphonal side flattened. There is an equally close resemblance to Ceratites carbonarius Waagent, but here again the siphonal side is flatter and the involution greater, the last whorl at the same size as in the largest one figured, being broader on the side. The septal sutures are, however, very similar.

"The young, when of the same size, are very similar to the figure of Goniatites lwvidorsatus Gabb, $\ddagger$ but when larger, as in Meek's figure, $\S$ very considerable differences appear. The lovidorsatus being a heavily ribbed shell, even when quite large, with a rounded abdominal side; though here again I doubt if the sutures differ much.

"The young shell of species 'A' [M. aplanatum $]$ has rounded smooth whorls, which increase very slowly by growth, and are full half an inch in diameter before the sides and abdomen (siphonal side) begin to show the flatness which characterizes the adult. At about this size also the whorls grow perceptibly broader in proportion on the sides, and the amount of involution increases gradually until it covers about one-third of the side, in a specimen about two and a half inches in diameter; the umbilical shoulder also changes at the same time, becoming abrupt and subangular.

"In some specimens there are indications of nodes on the sides, and in some the young until a late period are distinctly ribbed, the ribs being thick straight folds, reaching across the sides, but not up on to the siphonal side (abdomen).

"The age at which the serrations of the lobes appear could not be seen, but great caution should be exercised in this group in describing these characteristics, since they are liable to disappear with the removal of the shell on account of their shallowness. Thus, a full-grown shell may be readily mistaken for a Goniatite; or the young, before the serrations appear, for one of that genus."-(A. H.)

\footnotetext{
*Ueber Ceratiten. Abhand. Akad. d. Wissensch, 1848, pl. 4.

† Memoirs Geol. Sur. India, Pal., vol. iv, art. 4, pl. 1.

$\ddagger$ Pal. Geol. Surv., California, vol. i, pl. 3.

§ Geol. Expl. 40th Parallel, vol. iv, pl. 10.
} 


\section{MeEkoceras mushbachianum White.}

Plate 32, figs. $1 a, b, c$, and $d$.

Meekaceras mushbachanus White, 1879, Bull. U. S. Geol. Sur. Terr., vol. v, p. 113.

Shell compressed-discoidal, having the peripheral side abruptly rounded; umbilicus open, shallow, about two-thirds as wide as the full breadth of the outer volution in the adult and proportionally narrower in the young; volutions flattened-convex on their sides, the convexity merging gradually into that of the peripheral side, but upon the umbilical side the volutions, especially the outer one, are abruptly shouldered; volutions in the young shell distinctly embracing, but the amount of involution increasing with its growth, so that the outer one embraces nearly one-half of the next adjacent one. Siphonal cell of the septa, at or near adult size of the shell, small, slightly notched at the end; middle and outer lateral cells of nearly equal size, a little larger than either of the lobes, except in some cases the middle one, somewhat regularly rounded in front; inner lateral cell smaller than either of the others, its inner anterior border a little more abruptly rounded than elsewhere, bnt the inner side not defined for want of another lobe; middle and outer lateral lobes nearly. equal in size, but the former a little the longer; each bearing from six to eight prominent narrow digitations; the inner lateral lobe about half as wide as the outer lateral one, but of similar length, and bearing three or four digitations; auxiliary lobes and cells between theinner lateral cell and the inner edge of the volution indistinctly defined, but adjacent to the inner lateral cell there are three or four digitations such as mark the ends of the lobes, between which and the inner margin of the volution the edge of the septum merely describes a flexed or sigmoid line. This line and the adjacent serrations seem to represent respectively an incipient lobe and cell which, if developed, would be co-ordinate with the principal lobes and cells. Surface in adult shells showing the usual lines of growth and strong transverse wrinkles, some of which assume a slight degree of regularity as transverse ridges; but in the case of the young shell these ridges, although not prominent, are distinct, and quite similar to those in the young of M. apalantum.

Diameter of the coil of the largest example in the collection, 118 millimeters; that of a smaller but more perfect one, 95 millimeters; breadth, or vertical diameter, of the outer volution of the same, 43 millimeters; transverse diameter of the same, 22 millimeters.

Position and locality.-Triassic strata; member D of the section shown on a previous page of locality No 1, Southeastern Idaho, where it was collected by Dr. A. O. Peale and Mr. J. E. Mushbach.

The following are Professor Hyatt's remarks upon $M$. mushbachanum:

"This species differs from ' $A$ ' $[M$. aplanatum $]$ in never having a flattened abdomen. This is rounded. The sides in the young and the aspect of the shell are precisely the same as in 'A' [M. aplanatum], but the increase of the whorls by growth is much more rapid, so that at the diameter of an inch, or even somewhat less, they begin to flatten on the sides, show an abrupt umbilical shoulder, and cover up one-third of the whorl by involution. In consequence of the rounding of the abdomeis, however, the sides actually appear, in the full-grown, to be more gibbous than in ' $A$ ' $[M$. aplanatum $]$. One specimen at the total diameter of two and a half inches has one-half of the adjacent internal whorl covered by the outer one, an amount of involution which occurred much earlier in the history of the shell than at the diameter measured. Large, coarse folds are present in some of the specimens.

"This species in some cases has a strong resemblance to Arcestes? perplanus Meek, but is less involute."-(A. H.) 


\section{MEeKoceras GRACILITATIS White.}

Plate 31, figs. 2, $a, b, c$, and $d$.

Meekoceras gracilitatis White, 1879, Bull. U. S. Geol. Sur. Terr,, vol. v, p. 114.

Shell compressed-discoidal or sublenticular; siphonal side of the volutions flattened, the flattening being very distinct upon the inner volutions, even upon the very small ones, but sometimes less so upon the living-chamber of full-grown specimens; umbilicus shallow, in consequence of the small transverse diameter of the shell, but it is somewhat open, although narrower than that of either of the two species just described, its width in the adult being not more than one-half the greatest vertical diameter of the outer volution, and in the young it is proportionally much less; volutions flattened-convex on their sides, rounded somewhat abruptly inward to meet the next volution within, but they are not so distinctly shouldered there as in the two preceding species, except perhaps in the young volutions ; the amount of involution being so great in the young shell that the earliest volutions are nearly or quite covered, but it so diminishes with the growth of the shell that in fully adult specimens the outer volution does not embrace more than one-half the width of the next one within.

Siphonal cell of the septa, near the outer portion of an adult example, small; the outer, middle, and inner lateral cells larger, and both of nearly equal width; the outer cell regularly rounded at the end; the inner one more abruptly rounded at the inner side of the end than elsewhere; the inner cell not defined upon its inner side for want of another full lobe there, but its width between the auxiliary series and the inner full lobe is nearly as great as that of the other cells; ventral or outer lobe small, bearing two or three small digitations at its end; midale lobe largest, its width being nearly equal to that of the lateral cells, bearing at its rounded extremity five or six small digitations of nearly uniform size; inner lateral lobe small and narrow, bearing two or three, rarely four, small digitations at its end; auxiliary lobes and cells occupying a space adjacent to the next inner volution about as wide as that of the outer lateral lobe, and constituting a finelyundulated or serrated suture. In the more distinct examples the lobes appear minute and pointed, and the cells a little larger, and rounded at their ends, the one adjacent to the inner border being a little larger than the others. Surface of young examples nearly or quite plain, but in fully adult shells there is a teedency to form nodes or ribs, the latter sometimes crossing the periphery; but they do not appear to assume that regularity which we find in typical Ceratites.

Diameter of the coil of the largest example in the collection, 100 millimeters; vertical diameter of the outer portion of the living-chamber, 45 millimeters; transverse diameter of the same, 20 millimeters.

Position and locality.-Triassic strata; member D of the section at locality No. 1, shown on a previous page, Southeastern Idaho, where it was collected by Dr. A. C. Peale.

The following are Professor Hyatt's remarks upon M. gracilitatis :

"This species differs from ' $\mathrm{B}$ ' [M. mushbachianum] in about the same way that ' $\mathrm{B}$ ' differs from ' $\mathrm{A}$ ' $[M$. aplanatum $]$, except in so far as it approximates more closely to ' $A$ ' in having a similar flattened abdomen. This flattened abdomen appears at a much earlier age than in the less. involute form 'A.' In fact, before the shell reaches the diameter of three-sixteenths of an inch, not only is the abdomen flattened, but the sides also; and the increase by growth is so rapid that the sides of the 
internal whorls, even before this period, are almost hidden. This is, therefore, similar to those forms among Ammonites, which I have so often described as accelerated types; those which display in the earlier periods of growth and development, in quick succession, characteristies which come out in slower* succession in other species. Like many of those forms, also, a kind of premature degeneration appears, even before the animal can be said to have reached its adult condition. Thus at the diameter of an inch and a half, or even less sometimes, the sides of the whorls no longer increase by growth with the same rapidity as in the young. The amount of involution, consequently, is not maintained at the same rate, and the sides of the internal whorls become more exposed, until in some old specimens they are only about half eovered up.

"Thick folds or ribs are present in some old specimens, and a tendency to form nodes. In some large specimens the ribs eross the abdomen, and in one fragment a curious effect is produced by the retention of the contrictions formed by the transient mouths of the shell. These make depressions with swellings between, which give the abdomen a scalloped appearance, amply sufficient to found a new genus upon if economically used. There may be two rows of slight nodes on either side of the abdomen, giving this shell a slight resemblance to Trachyceras in some cases.

"The forward part of the living-chamber seems to be more rounded or gibbous than the after part, which has the square abdomen, even in old specimens, though I think that in extreme old age the whole shell would exhibit a round abdomen and more gibbous sides. These peculiarities and its flattened abdomen might readily mislead an observer to identify this species with Amm. semipartitus von Buch, but a glance at the septa would satisfy any one that they are distinct."-(A. H.)

\section{MEeKoceras GRACILITATIS Var.}

Among the examples of $M$. gracilitatis, which were obtained at locality No. 1 , is one which shows a considerable modification in the character of the septa. These appear to be in all respects like those of the typical forms, except as regards the inner lateral cell and the auxiliary series. The inner lateral cell is smaller than in the typical forms, and its inner border is not as abruptly defined from the auxiliary series. This series occupies a wider space, and consists of more numerous serrations than in the typical forms, appearing, indeed, to consist of a finely serrated, nearly straight suture. The umbilical shoulder is also less abrupt than in the typical forms. In all other respects this specimen appears to conform to the typical specimens of the species, and for this reason a separate specific name is not proposed.

\section{Genus ARCESTES Suess.}

\section{Arcestes? CIRRATUS White.}

Arcestes? cirratus White, 1879, Bull. U. S. Geol. Sur. Terr., vol. v, p. 116.

In his notes upon the Cephalopods of this article Professor Hyatt refers this form provisionally to the genus Arcestes with the following re-marks :

* "This expression, of course, is relative; applying not to the absolute amount of time occupied in the growth, but to the age at which the characteristics appear." 
"The specimens are too fragmentary to tell with any certainty the species; and even the genus ought perhaps to be considered doubtful, because the whole outline of the suture was not seen. "The runzelschicht,' however, was so marked that this appeared to show them to be identical with Arcestes. The septal sutures are, however, not entirely unlike those of Gymnotoceras."

There are only two specimens of this species in the collection, both of which, it is true, are too imperfect to afford means for the satisfactory characterization of the species. The characters which are shown, however, are quite sufficient for its identification and its discrimination from other forms. For the convenience of future teference and the characterization of the strata from which it comes, I have therefore applied the above specific name.

This shell, like those of the three species of Meekoceras herein described, is compressed-discoidal; the siphonal side rounded in the young and apparently a little angular in the aduit, but the latter feature is not plainly shown in either of the specimens; umbilicus open, but comparatively narrow; sides of the volutions flattened, those of the outer one of fully adult shells almost flat or only slightly convex, except near the outer and inner sides; inner border abruptly shouldered to the next inner volution; involution very great in the young, but it so lessens with the growth of the shell that the outer portion of the living-chamber of adults does not embrace by more than one-fifth its own width that of the next volution within. The examples do not show the character of the sutures satisfactorily, but the lobes and cells are both seen to be constricted about the middle, the ends of the former oblique, but digitate, as in Meekoceras, and the latter plain as in both that genus and Ceratites. Surface conspicuously marked by numerous longitudinal or revolving abruptly raised lines, which enlarge into ridges in the adult and which are separated by spaces a little wider than themselves at medium growth of the shell, but becoming wider in the fully adult.

This species is much larger than either of the other Cephalopods described in this article; the extreme diameter of the coil at fully adult size being not less than 180 to 200 millimeters, and the vertical diameter of the outer portion of the living chamber about 80 or 85 millimeters.

Position and locality.-Triassic strata, member D of the section at locality No. 1, shown on a previous page, Southeastern Idaho; collected by Dr. A. C. Peale.

\section{ARCESTES - ?}

Fragments of young examples of two more species of Cephalopods were obtained by Dr. Peale from member D of the section at locality No. 1, which are too imperfect for specific determination, but which seem to be referable to Arcestes. One of these forms is so very like young examples of $A$. gabbi Meek, vol. iv, U. S. Geol. Sur. 40th Parallel, p. 121, pl. X, figs. $6,6 a$, and $6 b$, as to leave upon the mind a strong impression of their identity. Such identity, however, would seem to necessitate a reference of the strata containing these forms to the same horizon as that of the Trias of Nevada and California, of which we have no other fact in support of, and many against such a reference.

The species embraced in the foregoing descriptions are far the most important of those that have been yet found in the horizon which is in. this article referred to the Middle Trias. Indeed the only other known forms or indications of other species are some fragments among the 
collections brought by Dr. Peale from locality No. 1. Among these is one fragment of a Spirifer or Spiriferina, one or two that belong either to Gervillia or Pteria, and one or two other forms of which the most that can be said is that they are Conchifers. This is all that is at present known of this very interesting fauna, and careful investigation of that region can hardly fail to be rewarded with many and important additions to it. 



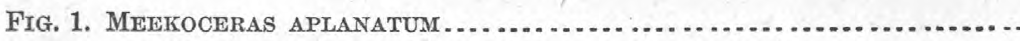

a. Side view of the largest example discovered.

$b$. Peripheral view of the same.

c. Side view of another example, the volutions being somewhat more slender, and bearing faint transverse folds.

d. Septum of Fig. $1 a$, near the living-chamber. All of natural size.

Eig. 2. Meekoceras gracilitatis

a. Side view of a medium-sized example.

$b$. Side view of a smaller example.

c. Peripheral view of the same.

d. Septum of an example larger than that of Fig. $2 a$. All of natural size.

Fig. 3. Terebratula semismplex

a. Ventral view; enlarged to one and a half diameters.

$b$. Dorsal view of the same.

c. Lateral view of the same. 
U.S.GEOLOGICAL SURVंEY.

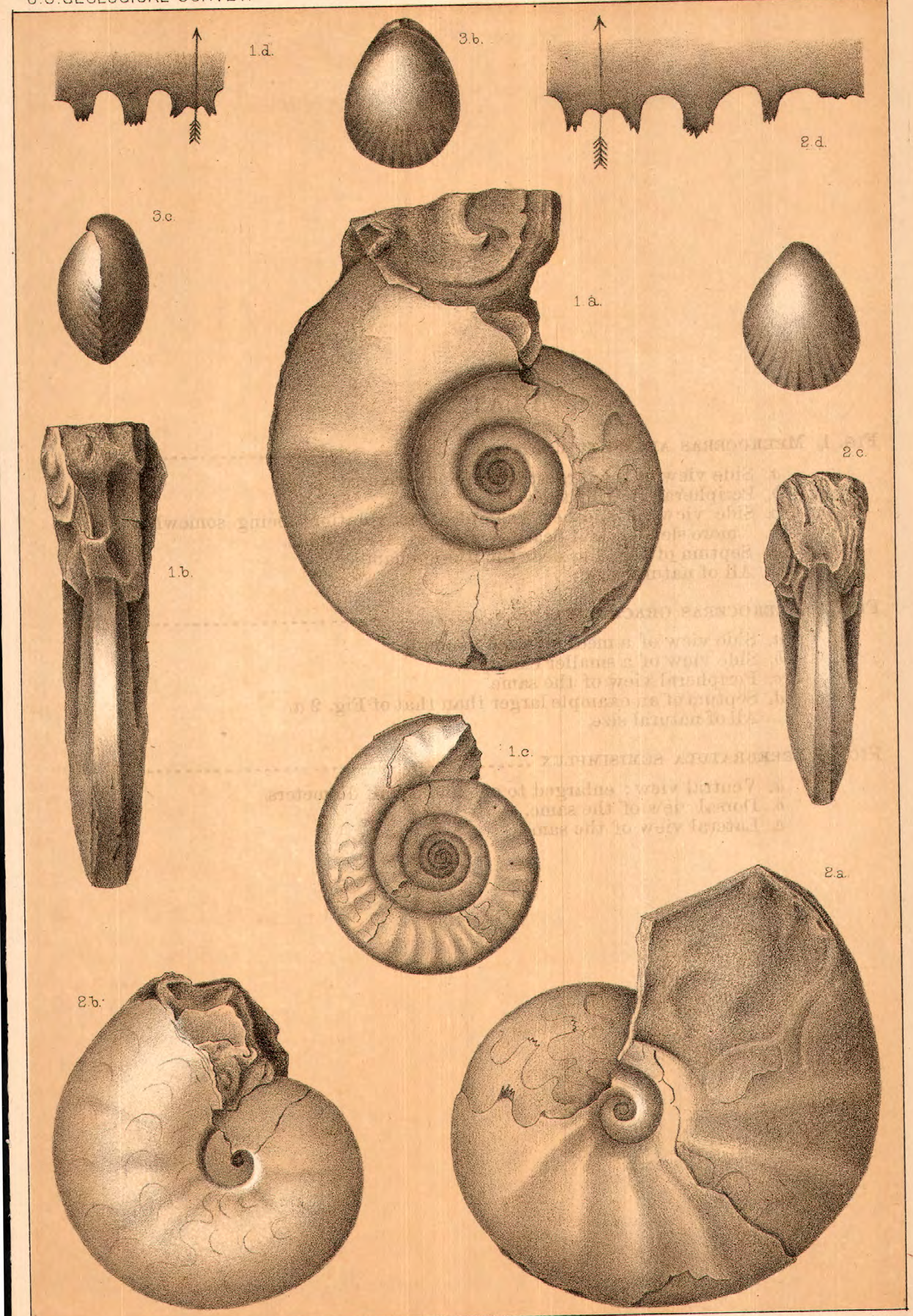

J. C. Me Conneli del

PLATE 31

TRIASSIC. 


Fig. 1. Meeroceras mushbachanum

a. Lateral view; natural size.

$b$. Peripheral view of the same.

c. Section of the same along the perpendicular line of fracture shown in Fig. $1 a_{\text {。 }}$

d. Septum of a large example, near the living-chamber.

Fig, 2. AviculopeCteN IDAHOENSIS

a. Left valve; natural size; from a natural cast in hard sandstone.

Fig. 3. Aviculopecten altus

a. Left valve; natural size; from a natural cast in sandstone.

Fig. 4. Aviculopecten PEALEI

a. Left valve; natural size; from a natural cast in sandstone. 


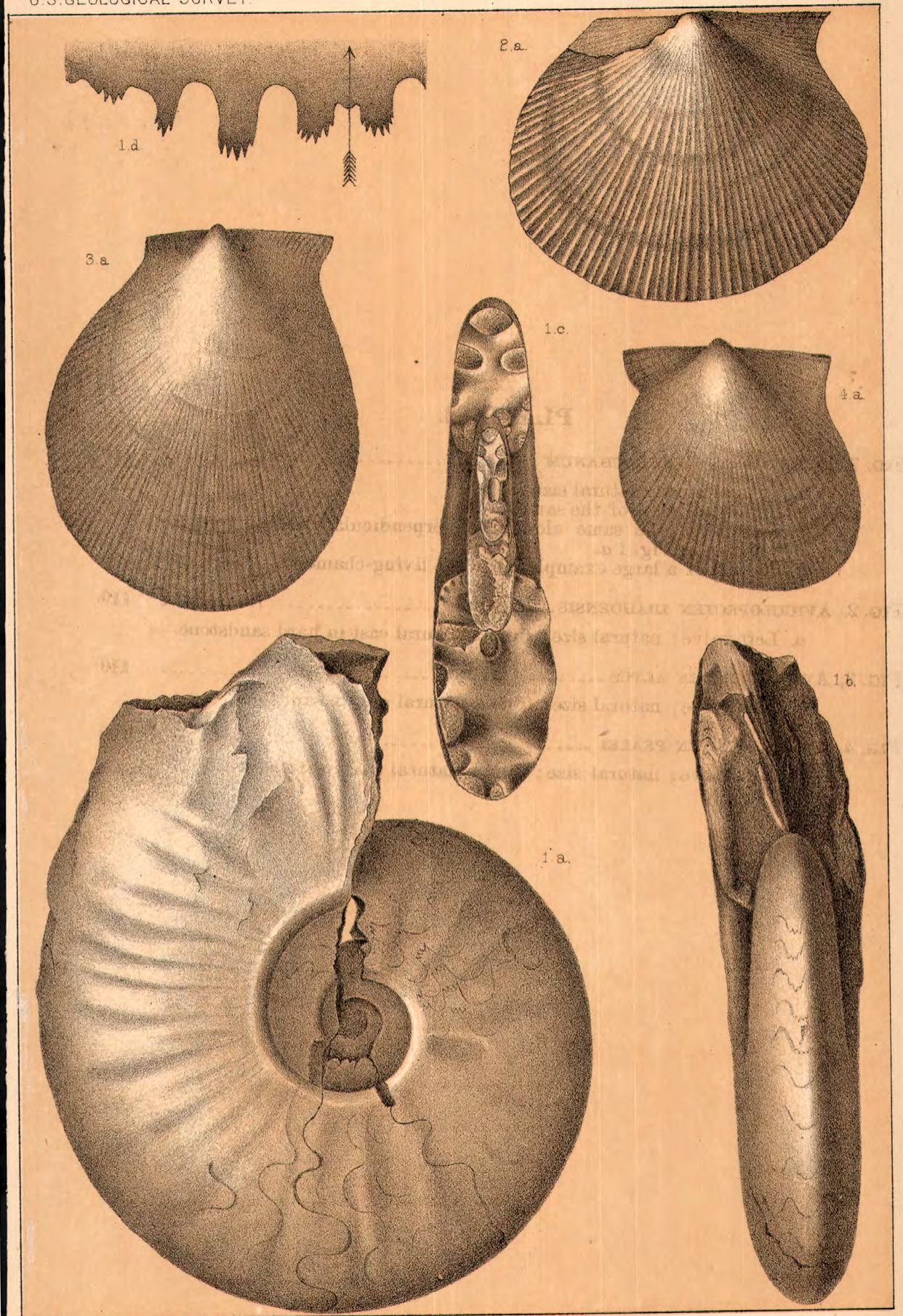

J C.MC Cunneil de 

CONTRIBUTIONS TO INVERTEBRATE PALEONTOLOGY NO. 6 : CERTAIN CARBONIFEROUS FOSSILS FROM THE WESTERN STATES AND TERRITORIES.

\author{
By C. A. White, M. D.
}

Among the collections of fossils pertaining to this survey, and in part also to that which has hitherto been under the direction of Professor Powell, there are the types of a considerable number of invertebrate species, preliminary descriptions of which have from time to time been published by the late Mr. Meek and the writer of this article respectively, in certain of the publications of the two surveys; but none of which were illustrated before the commencement of this brief series of illustrated articles. A large proportion of the species referred to have already been illustrated in the five first articles of this series, namely, Contributions to Inverte'srate Paleontology Nos. 1, 2, 3, 4, and 5, and the present article is devoted to the remainder. A few, however, are necessarily yet omitted because it has been impracticable to either discover the types among the older collections or to satisfactorily identify the species among the new ones. Those of the five former articles were devoted to Cretaceous, Tertiary, Laramie, and Triassic fossils respectively, but those of the present one are all Carboniferous.

As has been stated in introductory paragraphs to former articles of this series, it was originally intended that this illustrated series should embrace philosophical discussions of the topies suggested by the fossils upon which they are based; but eircumstances have prevented the fulfillment of this portion of that plan. Therefore this article, like the others of its brief series, will be devoted almost exclusively to the description and illustration of the fossil species.

Some general discussions of the questions pertaining to the great Carboniferous series of the West have been elsewhere published by the writer, but as so very much yet remains to be determined by future investigations in the field, it is not thought desirable to repeat them here. They may be found in the following-named publications: Explorations and Surveys. West of the 100th Meridian (Wheeler), vol. iv, part I, p. 16; Geology of the Uinta Mountains (Powell), p. 80; Bulletin U. S. Geol. Sur. Territories, vol. v, p. 209; and Annual Report U. S. Geol. Sur. Territories for 1876 (Hayden), p. 24.

A large proportion of the fossils of this article are from the collections of the survey under the direction of Professor Powell, having been collected by himself and Mr. G. K. Gilbert, to whom they are respectively credited in connection with each description; as has also been done in the former articles of this series. A few have been sent to the office of the survey, and others to the National Museum, by members of the United States Fish Commission, and by private parties, whose names are mentioned in connection with the descriptions so far as they are known; and the remainder have been collected by various persons connected with this survey. 


\section{ACTINOZOA.}

\section{Genus AMPLEXUS Sowerby.}

\section{AMPLEXUS ZAPHRENTIFORMIS White.}

Plate 33, figs. $1 a, b, c$, and $d$.

Amplexus zaphrentiformis White, 1876, Powell's Rep. Geol. Uinta Mts., p. 107.

Corallum having the external aspect of Zaphrentis, elongate-conical in form, more or less curved and tapering to a point or a small basal pedicel; epitheca well developed, having its surface marked by the usual concentric wrinkles and lines of growth, and with longitudinal lines which mark the position of the septa, the latter not being very distinct; calyx circular or subcircular, the plain portion of the surface at its bottom equal to one-third or more of the diameter of its rim; septal fosset well developed, usually situated at the concave side of the corallum, but not always; septa thirty or forty in number, rather strong; transverse plates numerous, well developed, somewhat irregular in direction, as well as in their distance apart, and ending exteriorly against a moderately well developed external wall, which is distinct from or of greater thickness than the epitheca proper. This external wall apparently contains no vesicles, but appears to consist of solid coralline substance.

The largest example in the collection is about ninety millimeters in length, the calyx having a diameter of twenty-five millimeters; but the average size of the nearly one hundred examples in the collection is considerably less.

This differs from all other American species of Amplexus known to me, in its zaphrentoid form; but its plain calyx-bottom, its broad transverse plates, and the absence of a vesicular zone, leave no doubt as to the propriety of referring it to the genus Amplexus. Although the corallum is somewhat stronger, proportionally shorter, and its sides less nearly parallel than is usual with Amplexus, it is not proportionally so short as that of $A$. henslowi Edwards \& Haine, from the Carboniferour rocks of Belgium. That species, according to those authors, has a compact, massive form, six centimeters in height, and a diameter of calyx equal to four or five centimeters. Our species may be compared. with this, as to the zaphrentoid form of both, but the differences between them in other respects are too great to need comparison as to specific identity.

Position and locality.-This species has yet been discovered only in the Uinta Mountain region. All the examples in the collection were collected by Professor Powell from the middle division of the Carboniferous series, designated by him as the Lower Aubrey Group, in Split Mountain Cañon, and near Echo Park, Green River, where that stream traverses the Uinta Mountain chain.

\section{Genus ACERVULARIA Schweigger.}

\section{ACERVUlaria ADJUNCTIVA Whíte.}

Plate 35, figs. $1 a, b, c$, and $d$.

Acervularia adjunctiva White, May, 1880, Proc. U. S. National Museum, vol. ii, p. 255.

Corallum massive or subdiscoidal, composed of compactly united corallites of somewhat unequal size; corallites approximately straight, 
irregularly polygonal, averaging about five millimeters in diameter, their outer surfaces faintly marked by vertical lines indicating the places of the septa, but they are not sufficiently distinct to give a crenulated border to the calyx ; the outer surfaces also present more or less distinct irregular transverse wrinkles or undulations; outer wall of the corallites distinct, but not thick; inner wall well developed, diameter of the space inclosed by the inner wall equal to about one-half the full diameter of the corallite; transverse tabulæ of this central space well developed, distinctly separate from each other, their number being about ten to each centimeter of length of the corallite. The space between the outer and inner walls is oceupied by numerous, more or less complete, shallow, infundibuliform plates, not quite so numerous as the central tabulæ, which, springing from the inner wall, and which wall they successively help to form, arch upward and outward to the outer wall. These infundibuliform plates are the successively abandoned floors of the outer portion of the calyces. They appear to have been usually, but not always complete, either as regards their extension to the outer wall or their construction of a symmetrical cup, but they are generally approximately perfect in these respects.

The condition of the only specimens discovered is not such as to show any of the calyces in their natural condition, and the structure of the corallites has therefore been determined by polished sections, both longitudinal and transverse. While the parts already described are thus distinctly shown, the rass are discovered with difficulty, and they were evidently only slightly developed. Their number appears to have been sixteen or seventeen.

Acervularia has been regarded as characteristic of Devonian strata; but as related genera are common to both Devonian and Carboniferous strata, there seems to be no reason why Acervularia may not be so. This species, however, differs somewhat from the typical examples of the genus, but the difference is apparently no greater than we should expect it to be in the case of related forms occurring in strata of so much later date than those which contain the typical forms.

Position and locality.-Carboniferous strata, Blackfoot range, south of the Yellowstone National Park, where it was discovered and collected by Prof. O. St. John.

\section{Genus LEPTOPORA Winchell.}

\section{LEPTOPORA WINCHELLI White.}

Plate 34, fig. 11 a.

Leptopora winchelli White, 1879, Bull. U. S. Geol. Sur. Terr., vol. v, p. 211.

Among some collections which were brought in by Dr. A. C. Peale, in the autumn of 1877, from near the forks of Logan River, in Bear River range, near the northern boundary of Utah, are a few specimens of Leptopora. This genus of corals was proposed by Prof. Winchell in Proc. Acad. Nat. Sci. Philad., 1863, p. 2, for a peculiar form, the first, and hitherto the only, known species of which occurs in the Kinderhook division of the Subcarboniferous Group, at Burlington, Iowa. This form is so rare and consequently so little known, that I quote here Prof. Winchell's generic diagnosis as a necessary aid in the description of the species.

"Corallum occurring in thin discoidal masses; cells very shallow, crowded, polygonal, separated by a common cell-wall, which is vertically 
striated; interior of cells filled with a finely vesicular tissue; cups polygonal, concave, elevated in the center, and displaying numerous radial lamellæ."

The calyces of the specimens discovered by Dr. Peale are a little smaller, and somewhat more irregular than those of the type specimens of L. typa used by Prof. Winchell in his description, and also of others which I have collected at the typical locality, near Burlington, Iowa, and the whole corallum is also a little more delicate. The differences between the two forms are very slight, however, but under the circumstances it is thought advisable to give a new specific designation to the form here especially considered, and in its selection to honor the name of the founder of the genus. It is proper to remark here that the corallum of this form appears to have been entirely free, as Dr. Winchell states his typical examples to have been, since the limestone matrix is in immediate contact with its under surface. A small example of this coral in the collection is evidently a young corallum. It consists of two minute calyces, and one large one, surrounded by ten or eleven others of nearly full size. This seems to indicate that the increase of the corallum by added calyces was in all directions from the center, and that the natural tendency to increase was no greater in one direction than in another.

Dr. Peale found only a part of the full Carboniferous series spored, or present, at the locality from which these specimens of Leptopora were obtained, and the fossils were found in strata near the base of that local series. He thinks the strata of that locality belong near the base of the full Carboniferous series; but, aside from the presence of Leptopora there is no paleontological evidence that they represent the Subcarboniferous Group, as separable from the remainder of the great Carboniferous series. On the contrary, some of the associated species have hitherto been found only in the Coal-measure strata of the Mississippi Valley.

Figs. $12 a$ and $b$, on plate 34, are drawn from an authentic example of L. typa; and are introduced here for comparison, and to illustrate generic characters.

The fossils found by Dr. Peale associated with the Leptopora here described, consist of a single example of Retzia (Eumetria) uta Mareon, a small plicated, ondetermined species of Rhynchonella, a broken stipe of Glauconome, like G. nereidis White or G. trilineata Meek, and a few segments of crinoid stems.

In this instance there is plainly a commingling of Subcarboniferous and Coal-measure types; and, so far as the paleontological evidence yet obtained is concerned, we are not justified in referring the strata from which these fossils were obtained to either of those groups exclusively.

\section{ECHINODERMATA.}

\section{Genus PLATYCRINUS Miller.}

Platiyorinus haydeni Meek.

Plate 33, fig. $7 a$.

Platycrinites haydeni Meek, 1873, An. Rep. U. S. Geol. Sur. Terr. for 1872, p. 469.

Only a single example of this species has been discovered, which Mr. Meek described as follows :

"A small species with a cup-shaped body, rounded below to a circular 
attachment for the column; body plates smooth or obseurely granular, and joined by slightly grooved sutures; arms twenty, slender, each dividing once on the second piece above their origin on the very small second radials, composed each of a single series of small pieces (as in P. nodobrachiatus Hall, Iowa Report, p.542), bearing pinnules alternately on their inner ends."

Position and locality.-Mr. Meek places this species (loc. cit.) in a list of Carboniferous fossils from the mountain called "Old Baldy," near Virginia City, Mont.

\section{Genus LECYTHIOCRINUS White.}

This genus was proposed in the Proceedings of the National Museum, vol. ii, p. 256, May, 1880, but it is desirable to repeat the generic diagnosis in this connection.

Generic formula.

Basal pieces ...................................... 3

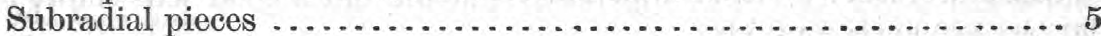

First radial pieces ................................. 5

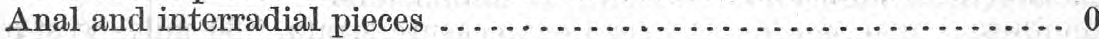

The basal subradial and first radial pieces are all well developed, those of neither set being minute. The dome is not known, but it was very small. The facet for the attachment of the column is small and round, but the column is not known. The facets for the attachment of the arms are small ; the arms are not known, but they were evidently small and five in number. The character, arrangement, and shapes of the three basal pieces is precisely as in Platycrinus, and the arrangement of the five subradial pieces upon them is the same as that of the first radials upon the basals in Platycrinus. The arrangement of the first radial pieces upon the subradials is essentially the same as that of Erisocrinus; that is, they alternate regularly with them, and have no anal or interradial pieces intervening. The body, which is the only portion of the animal yet known, is thus composed of thirteen pieces, the arrangement of which is essentially that of five first radial pieces, all in close contact with each other, superimposed upon the calyx structure of Platycrinus. Or, if it be assumed that the basal eycle of pieces in the body of every true crinoid contains the elements of five pieces, and that in case there are only three apparent in the adult state, as in Actinocrinus and Platycrinus, there has been an early anchylosis of two adjacent pieces in two cases, we may regard Lecythiocrinus as a Cyathocrinid thus modified. I am disposed to take this view, and consequently to refer the new genus to the Cyathocrinidæ. It is thought to be not improbable that if other species of this genus are discovered, the base may be found to be composed of five separate pieces, instead of three; but no trace of the fourth and fifth sutures can be discovered in the base of the form here described. In case other examples should prove to possess a five-parted base, the other characteristics of this form are still sufficient to hold it as a new generie form among the Crinoidea.

Only one example of this interesting crinoid, consisting of the body alone, has been discovered. It is small and delicate in structure, the delicacy of the pieces composing it being similar to that of certain species of Platycrinus and Dichocrinus found in the Burlington limestone. In this respect it differs from all known crinoids of the Upper Coalmeasures, the pieces composing the bodies of which are thick and often massive. This delicacy of structure will probably be found to be characteristic of other species of the genus, should any ever be discovered. 


\section{LECYTHIOCRINUS OLLICULAEFORMIS White.}

Plate 35, figs. $2 a$ and $b$.

Lecythiocrinus olliculaformis White, May, 1880, Proc. U. S. National Museum, vol. ii, p. $25 \%$.

Body small, subovoid or pot shaped, higher than broad, broadest a little below the middle, composed of thin pieces; base convex; basal pieces rather small but not minute; subradial pieces larger than any of the others, their vertical length a little greater than half the full height of the body and greater than their breadth, not materially varying in size or shape among themselves; first radial pieces smaller than the subradials but larger than the basals, broader below than above, height and greatest breadth about equal; at top, on both sides of the small prominent arm-facet, the upper border of each first radial is bent inward, constricting the already narrow interbrachial space at top, which was probably covered by a dome of minute pieces. Sutures not impressed, surface to ordinary vision apparently smooth, but a good lens shows it to be very finely granular.

Height, 9 millimeters ; breadth, $7 \frac{1}{2}$ millimeters.

Position and locality.-Upper Coal-measure strata, "30 miles west of Humboldt, Kansas." The type specimen is among the collections of the National Museum, but record of the collector's name has been destroyed by accident.

\section{Genus EUPACHYCRINUS Meek \& Worthen.}

\section{EUPACHYCRINUS PLATYBASIS White.}

Plate 33, fig. $8 a$.

Eupachycrinus platybasis White, 1876, Powell's Rep. Geol. Unita Mts., p. 108.

Calyx nearly flat; basal pieces small, concealed by the first joint of the column, which is proportionally large; subradial pieces rather small or of medium size; their inner ends also covered by the first joint of the column, all of nearly the same size and shape, judging from the visible portion of them; but the posterior one and the next adjacent on its right are a little modified in shape by the proximity of the anal series; first radial pieces much broader than long, broadly convex from side to side, and more abruptly convex from within outward; all of them ending with a regular obtuse angle between the subradial pieces, except the left posterior one, the angle of which is truncated or made a little irregular by the interposition of the first anal piece; first anal piece apparently nearly as large as the posterior subradial between which and the left posterior first radial piece it is interposed, reaching nearly as far inward as the first radial piece does, and at which inner point it ends with an acute angle; remainder of the anal series unknown; plates all massive, so that the body cavity, as inclosed by the calyx, is exceedingly small. Sutures all linear. Surface nearly or quite smooth. Remainder of structure unknown.

Diameter of calyx 18 millimeters, including the full thickness of the first radial pieces; height, 5 millimeters.

This species differs from the typical forms of the genus in the extreme flatness of the calyx, but the number, arrangement, and general charac. ter of the pieces composing its calyx leave little or no doubt as to the propriety of referring it to the genus Eupachycrinus Meek \& Worthen. 
Position and locality.-The only known example of this species was obtained by Professer Powell from the Lower Aubrey, or middle group of the Carboniferous series, at the coufluence of Grand and Green rivers, Utah.

\title{
Genus CYATHOCRINUS Miller.
}

\section{Cyathocrinus stmlativus White.}

\author{
Plate 35, figs. $3 a$, and $b$.
}

Cyathoorinus stillativus White, May, 1880, Proc. U. S. National Museum, vol. ii, p. 258

Body below the upper border of the first radial pieces shallow basinshaped, much wider than high, having a narrow, moderately deep, abrupt, five-sided depression at the middle of the base, at the bottom of which is the facet for the attachment of the column; composed of 18 moderately thick and strong pieces, all of which, except the basals, are more or less tumid in their middle portion; some of them presenting an uneven, irregular surface, which, with the impressed sutures and more deeply impressed corners of the pieces, give the surface a rugose appearance; basal pieces very small, occupying the bottom of the depression of the base, the greater part of each being covered by the first joint of the column; subradial pieces having their height and width about equal, four of them pentagonal, and one, that which is next below the first anal piece, hexagonal, there being no appreciable angle upon that side of any of them which adjoins the basal pieces; first radial pieces much larger than the subradials, wider than their full height, including the arm facet; the two adjacent to the anal pieces being very little if any narrower than the others; arm facets large, about one-third wider than high, their plane being nearly vertical, notched at their npper border, and marked transversely by the double ridge or raised line common to many of the Cyathocrinidre; anal pieces three known, nearly equal in size, or the first a little larger than the others, each having a prominent tuburcle at the centre; first anal-piece five-sided, abutting against one subradial, two first radials, and two second anals; the two second anal pieces abut against the first anal, each other, and each against a first radial.

Diameter of calyx, 14 millimeters; height of the same, 6 millimeters.

This is the first and only species of true Cyathocrinus yet known to me that has been found in strata of the Upper Coal-measures; $C$. inflexus Geinitz and $O$. hemisphericus Shumard not being regarded as species of that genus, but are more nearly related to Erisocrinus as shown in a following paragraph. Our species belongs to a type that is more characteristic of the Burlington limestone division of the Subcarboniferous than of any other division of the great Carboniferous series; and, together with the Rhodocrinus described on a following page, it shows the crinoidal fauna of the Upper Coal-measures to be more intimately related to that of the Subcarboniferous than it has hitherto been thought to be.

Position and locality.-Upper Coal-measures, "30 miles west of Humboldt, Kansas." The type of this species is among the collection of the National Museum, but the record of the collector's name has been destroyed by accident. 


\title{
Genus ERISOCRINUS Meek \& Worthen.
}

\section{ERISOCRINUS TYPUs Meek \& Worthen.}

\author{
Plate 33, fig. $5 a$.
}

\begin{abstract}
Erisocrinus typus Meek \& Worthen, 1866, Illinois Geol. Rep., vol. ii, p. 317.
Erisocrinus typus Meek, 1873, U. S. Geol. Sur.oNebraska, p. 146.

Erisocrinus typus White, 1876, Powell's Rep. Geol. Uinta Mts., p. 89.
\end{abstract}

The following is Mr. Meek's description of this species, together with his remarks upon it, as copied from the Nebraska report above cited :

"Body below the summit of the first radials, basin-shaped, rounded below, and obscurely pentagonal in outline as seen from above or below, composed of thick, smooth, slightly convex plates. Basal pieces small, occupying a shallow concavity of the under side, about half hidden by the column, all pentagonal in external form. First radial pieces four or five times as large as the subradials, wider than long, equal, and all pentagonal; supporting upon their broadly and evenly truncated superior sides the second primary radials, which are nearly of the same size and form as the first, but have their sloping sides above, instead of below, while they each support above two first brachials, or a series of secondary radials yet unknown. Surface smooth.

" Breadth of the body below the summit of the first primary radials, 0.72 inch; height of the same, 0.35 inch.

"From the slightly larger proportional size of the subradial pieces, I was at one time led to believe this specifically distinct from the Illinois specimens upon which the genus and species E. typus were founded. Further comparisons of additional specimens from the original locality near Springfield, however, showed clearly that no separation could be made on this character.

"Locality and position.-The specimen figured on plate I [loc. cit.] was found by Dr. Hayden eight or nine years since at Bellevue, Nebr. The species was first described from the Upper Coalmeasures at Spring. field, Ill. We also have fragments of apparently this crinoid from Division B, at Nebraska City."

Among the collections brought by Professor Powell from the middle division of the Carboniferous series, at the confluence of Grand and Green Rivers, Utah, is one example, evidently belonging to this species, although it is somewhat crushed, and its subradial pieces are proportionally a little larger than even those of the Nebraska specimen described by Mr. Meek. This Utah specimen is valuable because it possesses about one centimeter in length of the column, adjacent to the calyx, and also about two and a half centimeters in length of the arms, parts which have never before been known. The column is comparatively small, round, and composed of plates of moderate thickness, alternating with others which are thinner and slightly less in diameter, giving it the appearance of being composed of segments having convex or rounded edges. The arms are strong, ten in number, very sligntly tapering upwards, flattened or slightly convex on their backs, consisting each of a double row of interlocking pieces, except the first one, which rests obliquely upon the second primary radial piece, and occupies the whole width of the arm. When the arms are closed they all so fit together, side by side, that there is only a linear or slightly impressed suture between them, the adjustment being as perfect between the outer sides of arms upon adjacent rays as it is between the inner sides of the two 
arms of one and the same ray; these interbrachial sutures being similar in aspect to those which separate the pieces composing the calyx. The pinnules of the arms are thus wholly obscured from view when the arms are closed.

The arms of this genus, as shown by our example of E. typus, are more nearly like those of Graphiocrinus de Koninck \& Lehon than those of Encrinus Miller, although, as Mr. Meek pointed out (loc. cit.), it is in some respects closely related to the latter genus.

\section{ERISOCRINUs (CERIOCRINUS) PLANUS White.}

Plate 35, figs. $5 a$ and $b$.

Erisocrin $u$ planus White, May, 1880, Proc. U. S. National Museum, vol. ii, p. $25 \%$.

Body rather small, subcircular or obscurely pentahedral in lateral outlines as viewed from above or below, shallow basin-shaped below the top of the first radial pieces; base rounded and somewhat deeply impressed at the middle, the depression gradually rounding outward to the sides; basal pieces very small, occupying the bottom of the depression of the base, and almost covered by the first joint of the column; subradial pieces moderately large, their inner ends inflexed by the depression of the base to meet the basal pieces at its bottom, their outer ends extending outward and upward, so as to be more or less plainly visible by side view of the body; first radial pieces comparatively large, convex vertically, their upper edges rounded inward to the suture between them and the second radials, their lower angles extending downward almost to the lower surface of the body as it is seen by side view. The other characters are those common to the genus. One minute piece remains attached to the upper border of the calyx of the example from which this description is drawn, at the junction of two of the first radial pieces. This is doulbtless an anal piece, but it does not in any degree enter between the two posterior first radials upon the borders of which it rests, although it evidently rested betwen the two corresponding second radials.

Transverse diameter of the calyx, 14 millimeters; height of the same, 5 millimeters.

This species differs from E. typus in having a shallower and more rounded, basin-shaped calyx, proportionally smaller basal and larger subradial pieces, a more deeply impressed base, and, also, in possessing the minute anal piece before described. It very closely resembles the Poteriocrinus hemisphericus of Shumard, examples of which are associated with it in the collection from 30 miles west of Humboldt, Kans. Indeed, so far as the characteristics of the calyx alone are concerned, which are in part well shown by fig. $5 c$, plate 35 , there appears to be no essential difference except in the relative position of the small anal piece.

In Erisocrinus proper the anal series of pieces is entirely wanting, so far at least as their appearance at the outer surface is concerned. In $E$. planus there is one small anal piece visible between the two posterior second radial pieces, but it does not extend downward between the two corresponding first radial pieces of the calyx. In this species, therefore, the calyx is precisely as it is in true Erisocrinus. In the case of the form described by Shumard as Poteriocrinus hemisphericus, and also the Cyathocrinus inflexus of Geinitz, there is likewise a single anal piece; and it occupies the same relative position in both those forms that it does in $E$. planus, except that it is longer and extends downward between the two posterior first radial pieces, as well as upward between 
the two corresponding second radials. The possession of an anal piece by these three forms, while it is at present the only known feature by which they are separable from Erisocrinus proper, is, in my opinion, of subgeneric importance. I therefore propose Ceriocrinus: as the name of a subgenus under Erisocrinus, which will include these three forms, and all similar ones which have the general characteristics of Erisocrinus, with the addition of one anal piece.

Position and locality.-Upper Coalmeasures; "30 miles west of Humboldt, Kans." The type here described is among the collections of the National Museum, but the record of the name of the collector has been destroyed by accident.

\section{Erisocrinus (Ceriocrinus) inflexus Geinitz.}

Plate 34, figs. $9 a$ and $b$.

Cyathocrinus inflexus Geinitz, 1866, Carb. und Dyas in Nebraska, p. 62.

Scaphiocrinus? hemisphericus (Shumard sp.) Meek, 1872, U. S. Geol. Sur. Nebraska, p. 147. Scaphiocrinus carbonarius White, 1876 (not Meek \& Worthen), Powell's Rep. Geol. Uinta Mts., p. 89.

Body basin-shaped below the upper border of the first radial pieces, its basal portion deeply impressed, at the bottom of which depression is the facet for the attachment of the column; basal pieces very small, entirely covered by the first joints of the column, and occupying the deep depression of the base; subradial pieces large, longer than wide, flexed deeply into the depression of the base and extending upward to about mid-height of the calyx at their upper angles; the one which bears the first anal piece being a little longer than the others, and narrowly truncated at top; first anal piece small, and, in the example here described, nearly twice as high as wide, placed between the two posterior first radial pieces, its upper end projecting above them and between the corresponding second radials; first radial pieces not materially larger than the subradials, about twice as wide as high, differing but little from each other in size and shape. Surface apparently quite smooth.

Height of calyx, 11 millimeters; diameter at top, 21 millimeters.

Only a single example, and that of the calyx only, is contained in the collections of the survey. It is, however, quite a perfect example, and its specific identity with the $C$. inflexus of Geinitz, and not with the Poteriocrinus hemisphericus of Shumard, is evident from the relative size and position of the basal and subradial pieces.

This form, although not specifically identical, is strictly congeneric with the $P$. hemisphericus of Shumard, which, together with that species and Erisocrinus planus, I have above referred to a separate subgenus, under the name Ceriocrinus.

Position and locality. - The example from which this description is drawn, and which is figured on plate 28, was obtained by Prof. J. W. Powell from the middle division of the great Carboniferous series, at the confluence of Grand and Green Rivers, Utah, where it is associated with Erisocrinus typus and Eupachycrinus platybasis.

\section{Genus POTERIOCRINUS Miller.}

\section{Poteriocrinus montanaensis Meek.}

Plate 33, fig. $6 a$.

Poteriocrinus montanaensis Meek, 1873, An. Rep. U. S. Geol. Sur. Terr. for 1872, p. 469 The following is Mr. Meek's brief description of this species:

"A small species, with an elongate obconical body, composed of smooth

${ }^{*} \mathrm{~K} \eta \hat{i}^{\circ} \mathrm{v}$; a cake of wax. 
plates, and supported on a round column; arms long, slender, apparently simple above their origin on the last radials, and composed of small pieces, every third one of which bears, alternately on opposite sides, a long pinnule."

To this description may be added that of the following characteristies as observed in Mr. Meek's type specimen, the only one yet discovered. Sides of the calyx nearly straight and continuous with the upper part of the column, which increases a little in size from below, to meet the full width of the base of the calyx; basal pieces comparatively large, extending upward from the first segment of the column to about onethird the height of the calyx; subradial pieces also comparatively large, being the largest of those which compose the calyx; first radial pieces smaller than the subradials, their height being less than onethira the height of the calyx ; first bifurcation of the right posterior arm, the only one known, upon the fourth radial piece; the anal series rather large and extending as far up, at least, as the fourth primary radial piece.

Height of calyx, 6 millimeters; diameter at top, 5 millimeters; at base, 2 millimeters. The slender arms extend 30 to 35 millimeters above the ealyx.

Position and locality.-Mr. Meek reports this species from Carboniferous strata of the mountain known as "Old Baldy," near Virginia City, Mont.

\section{Genus RHODOCRINUS Miller.}

\section{RHODOCRINUS VESPERALIS White.}

Plate 35, figs. $4 a$ and $b$.

Rhodocrinus resperalis White, May, 1880, Proc. U. S. National Museum, vol. ii, p. 259.

Body subglobose, the sides and outer portion of the base being convex; the base having a deep, sharply-defined, five-sider pit which contains the whole of the five basal pieces, and the sharply inflexed inner ends of the five subradial pieces; the latter pieces moderately large, but not much larger than some of the radials and interradials; first radials varying in size in the different rays, the larger ones nearly or quite as large as the subradials; second radials much smaller than the first, and the third radials still much smaller than the second, the difference in size being more in their vertical than in their transverse diameter; the third radial, which is very narrow vertically, supports two brachial pieces, and they in turn support each another brachial piece, beyond which the structure is unknown; interradial pieces up to a line with the bases of the arms, three for four of the interradial spaces, and four for that of the anal side; the first or lower interradials are of about the same size as the first radials, but the two upper ones are somewhat smaller; vault moderately convex, prominent opposite the arms, and somewhat depressed between them, composed of numerous rather small pieces; proboscis subcentral, its length unknown. All the pieces of the body, except those of the base, are slightly tumid, their surfaces being rugose, or wrinkled, and in some cases marked by obscure lines which radiate from the center of each piece in groups of threes and become continuous with similar lines on adjoining pieces.

Height from the base of the body to the base of its proboscis, 12 millimeters; breadth of the same, 16 millimeters.

Although this species servestas a very suggestive link between the crinoidal faunæ of the Upper Coalmeasures and the Subcarboniferous, 
especially with the Burlington division of that series, it differs too much specifically from any described form of that genus to need detailed comparisons.

Position and locality.-Upper Coalmeasures, "30 miles west of Humboldt, Kans." The type of this species is among the collections of the National Museum, but the record of the narne of the collector has been destroyed by accident.

\section{Genus ARCH ÆOCIDARIS McCoy.}

\section{ARCHAOCIDARIS CRATIS White.}

Plate 33, fig. $2 a$.

Archceocidaris cratis White, 1876, Powell's Rep. Geol. Uinta Mts., p. 109.

Compare Archceocidaris mucronatus Meek \& Worthen, Illinois Geol. Survey, vol. ii, p. 295, pl. 23 , fig. 3.

Among the collections brought by Professor Powell from the middle division of the great Carboniferous series at the confluence of Grand and Green Rivers, Utah, is a single spine only of this species. The collections of the geological survey of Nebraska, in the cabinet of the Smithsonian Institution, also contain another spine. These are all that are known of the remains of this species, but as they are so characteristic, and so different from those of any described species, it is thought best to base a specific description upon them.

Spines slender, gradually tapering from base to point; shaft ornamented with sharp, distant spinules, each about one and a half millimeters long, and pointing strongly upward; basal ring prominent, plain, except the fine crenulation of its edge, and situated very near the proximal end of the spine. Surface apparently smooth.

Length, about 60 millimeters; diameter jnst above the basal ring, about 4 millimeters.

This species is certainly very closely related to A. mucronatus Meek \& Worthen (loc. cit.) from the Chester limestone of the Subcarboniferous series of Illinois, as shown by the only parts of the animal yet discovered; so closely indeed that we should hardly feel warranted in referring oar examples to any other than that species if they had been found associated, or even in formations that are geologieally equivalent. It is true that there exist between considerable portions of the faunæ of the Chester limestone and the Upper Coalmeasures, respectively, very close relationships. Furthermore, certain of the brachiopoda found in the first-named formation are not specifically distinguishable from certain species found in the last-named one. The difference, however, in the Echinodermic faunæ of the two formations is quite marked, the species here described presenting a closer relationship with a Chester limestone form than does any other known Echinoderm. Not only is there a marked difference between the Echinodermic fauna of the Chester limestone and that of the Upper Coalmeasures, but there is almost as great a difference between the Echinoderms of the different members of the Subcarboniferous series. In other words, the vertical range of fossil species of Echinoderms is perhaps more restricted than that of any other class of fossils. It is certainly much more limited than that of the Brachiopoda.

With these facts in view, it is thought best to give a new specific name to the fossil here described, although it is so similar in general character with $A$. mucronatus. Compared with that species, the spines of this one are more slender, more directly tapering from base to point; the basal ring is a little more prominent, and the spinules less numerous. 


\section{ARCHALOCIDARIS DININNII White.}

Plate 35, figs. $6 a, b$, and $c$.

Archococidaris dininnii White, May, 1880, Proc. U. S. National Museum, vol. ii, p. 260.

Principal spines fusiform, strong, 50 or 60 millimeters long, the greatest diameter being about the mid-length, and about 5 millimeters. The diameter of the basal ring of such a specimen is about $3 \frac{1}{2}$ millimeters, and the short neck or plain space above it is scarcely $2 \frac{1}{2}$ millimeters in diameter; above the short, plain neck the whole spine is studded with many irregularly disposed spinules, one to two millimeters long, which stand out at nearly right angles with the axis of the spine, except near its point, where they are directed upward. The spinules are usually more numerous and stronger upon the lower portion of the spine, and upon the middle portion of some of them the spinules are obsolete, apparently from some other cause than accident. The smaller spines are usually more slender or less fusiform than the larger, and some of them seem to have been without a basal ring. Nothing is satisfactorily known concerning the body plates.

A marked peculiarity of this -species, and one which makes it easily recognizable, although the other parts are unknown, is the abundance of spinules upon the spines, especially the lower portion, and the position of most of them being at nearly right angles to the axis of the spine.

Position and locality.-Upper Coalmeasures, near Tecumseh, Nebr., whence they were sent by Mr. F. M. Dininny, together with several other well-known Upper Coalmeasure forms. It is in his honor that the specific name is given. This species has also been recognized by myself at several localities in Iowa and Nebraska.

\section{POLYZOA.}

\section{Genus PTILODYCTIA Lonsdale.}

\section{Ptilodyctia triangulata White.}

Plate 33, figs. $3 a, b, c, d$, and $e$.

Ptilodyctia triangulata White, 1878, Proc. Acad. Nat. Sci. Philad., 1878, p. 35.

Ptilodyctia triangulata White, 1879, Bull. U. S. Geol. Sur. Terr., vol. v, p. 214.

The type specimens of this species were obtained from the Coal-measure strata at Danville, Ill., by Mr. William Gurley, and described by me in the place above cited. Some examples in the collections of the survey were obtained by myself from the middle division of the Carboniferous series on Yampa Plateau, Northwestern Colorado, and others were obtained by Mr. W. H. Holmes in the region southward from the Yellowstone National Park. These examples show that the corallum is ramose, as it was supposed to be when the species was originally described, although that fact was not clearly shown by the type specimens. The characteristics of the Colorado examples are in all respects like those of the type specimens, except that parts of the corallum are more slender, their sides having a breadth of from 2 to $2 \frac{1}{2}$ millimeters instead of from 3 to 5 millimeters, as in the type specimens; but this is 
not thought to indicate even a permanent varietal difference. The details of all these far western examples being the same as those of the type specimens, the original description is here repeated with only slight change.

Corallum ramose, the branches comparatively few and not varying materially in size from that of the portions from which they spring; transverse section triangular; all three sides poriferous; the edges moderately sharp and sometimes a little irregular; the laminar axis consisting of three divisions which end respectively at the three edges and meet and blend at the center of the corallum; pores well developed, but they are not arranged in the regular order that is common in this genus, nor are they bounded by any longitudinal or transverse lines or ridges. Their mouths are moderately prominent, slightly oval, the direction of the longer diameter of each being subject to no regularity.

This species differs from typical forms of Ptilodyctia in having three flat or concave sides instead of two convex ones, in the axis being consequently tripartite, and in the irregular disposition of the pores upon the surface.

\title{
BRACHIOPODA.
}

\section{Genus PRODUCTUS Sowerby.}

\author{
Productus Giganteus Martin. \\ Plate 36 , figs. $1 a, b$, and $c$
}

Among a small collection of fossils sent to the National Museum by Mr. Ludwig Kumlein, of the United States Fish Commission, from the valley of McCloud River, Shasta County, California, are three or four examples of a very large Productus which I am unable to distinguish from $P$.giganteus, the well-known type species of the genus, as it is extensively known in European strata. They are preserved in a hard, darkcolored argillaceous rock, which is partly metamorphosed, and they are, therefore, somewhat imperfect; but some portions of them show the characteristics of the species very plainly. The largest of these California examples was, when perfect, quite equal in size to the larger European examples of $P$. giganteus, having had a transverse diameter, near the hinge border of not less than 140 millimeters, or $5 \frac{1}{2}$ inches.

The other fossils associated with them are too imperfectly preserved for specific determination, but the genera Streptorhynchus, Fenestella, Spiregera, Camarophoria, Allorisma, and Euomphalus were more or less satisfactorily recognized. The Streptorhynchus is apparently S. crinistria Phillips sp. Besides the specimens of $P$. giganteus there are two or three examples of a smaller Productus which closely resemble $P$. nebrascensis Owen, but they are very imperfect. They all together plainly indicate the Carboniferous age of the strata from which they come; which fact) was also previously known through the reports of Trask and Whitney.

This, so far as I am aware, is the first discovery of $\boldsymbol{P}$. giganteus in American strata: It is not a little remarkable that it should be found in the western portion of the continent, and not in the middle and eastern portions, where the Carboniferous system is so well developed, and where several European species of brachiopoda are recognized. 


\section{Genus RHYNCHONELLA Fischer.}

\section{RHYNCHONELLA ENDLICHI Meek.}

Plate 33, figs. $4 a$ and $b$; and Plate 36, figs. $2 a$ and $b$.

Rhynchonella endlichi Meek, 1875, Bull. U. S. Geol. Sur. Terr., 2d ser., No. 1, p. 47.

Although Mr. Meek, when he originally described this species, believed it to have been derived from strata of Upper Devonian age, subsequently ascertained facts lead me to believe that those strata really belong to the lower portion of the Carboniferous series. I therefore include it among the Carboniferous fossils of this article. The following is Mr. Meek's description of the species, together with his remarks upon it:

"Shell attaining a rather large size, subtrigonal, with breadth nearly or quite equaling the length, the widest part being in advance of the middle, becoming very convex anteriorly with age; posterior lateral margins straight or but slightly convex in outline, laterally compressed. or flattened, and diverging from the beaks, in adult specimens, usually at about right angles or less; anterior lateral margins rounding to the front, which is generally more or less produced, and, as seen in direct view from above or below, transversly truncated, or a little sinuous at the middle, the elevation increasing rapidly to the front, which is raised so as to form a very prominent, broad, rounded, or somewhat flattened and slightly defined mesial fold, rarely traceable back to the central region, while on each side the lateral slopes descend abruptly to connect with those of the other valve; beak moderately prominent, and incurved more or less nearly at right angles to the general plane of the valves; interior with a prominent mesial septum extending forward nearly hali way to the front. Ventral valve flattened at the umbo, and so broadly and profoundly sinuous from near the same, anteriorly, as to leave onlya prominent angular margin on each side, the sinus being broadly flattened along the middle, and increasing rapidly in depth to the front margin, which is curved upward more or less nearly at right angles to the plane of the valves, and produced in the middle, in the form of a large extension, fitting into a corresponding sinuosity in the middle of the front of the other valve; anterior lateral margins on each side of the sinus meeting those of the other valve at acute angles; posterior lateral margins very abruptly deflected, and rectangularly deflected along each side of the sinus, to meet those of the other valve; beak comparatively small.

"Surface of both valves ornamented by numerous radiating costæ, which, on the umbones, are merely distinct raised lines, but increase in size anteriorly, particularly those in the sinus and on the mesial fold, where, toward the front of adult specimens, they become moderate sized, rounded ribs, of which four or six to seven may be counted in the immediate flattened bottom of the sinus and two or three more on the fold, while those on the lateral slopes bifurcate and continue of smaller size to the anterior and antero-lateral margins. Finer surface markings unknown.

"Length of an adult specimen, 1.78 inches; breadth, 1.53 inches; convexity, about 1.24 inches.

"This is a fine species, more nearly resembling some Devonian and Upper Silurian forms than the usual Carboniferous types. Its most marked features are the large size of its mesial sinus, formed by the 
abrupt flexure of those margins to meet those of the other valve. This inflection of the posterior lateral margins gives this part of the shell a peculiar truncated rectangular appearance, contrasting strongly with. he very acute angles formed by the connection of the antero-lateralt margins of the valves.

"Locality and position.-East of Animas River, Colorado, where it occurs associated with a small productus of the type of $P$. subaculeatus. According to Dr. Endlich's sections, as well as from its affinities, it would seem to be most probably an Upper Devonian species. Fragments of it have been brought in from other localities in the Rocky Mountains."

\section{Genus RETZIA King.}

\section{RETZIA WOOSTERI White.}

Plate 34 , figs. $8 a$ and $b$.

Retzia woosteri White, 1879, Bull. U. S. Geol. Sur. Terr., vol. จ, p. 215.

Shell of medium size, moderately gibbous, both valves being nearly equally convex; hinge short; ears only slightly prominent; ventral valve having a moderately broad, very shallow sinus, which is scarcely apparent at and near the umbonal region, and produces merely a broad sinuosity in the front margin ; longitudinal convexity of the valve regular, but greater between the middle and umbo than elsewhere; umbo prominent and somewhat strongly arched. Dorsal valve considerably shorter than the ventral, regularly convex, showing only a slight, if any, elevation corresponding with the shallow sinus of the ventral valve. Surface marked by about twenty-eight simple plications upon each valve, which extend from beak to base, being separated by grooves of about equal width with the plications. Six or seven of these plications occupy the shallow sinus of the ventral valve. They are all of nearly uniform size and occupy the whole surface except a small plain space on each side of the umbo of the ventral valve, and a still smaller adjacent space on each side of the umbo of the dorsal valve.

Length from ventral umbo to front margin, 20 millimeters; greatest width, which is in front of the middle, 18 millimeters; greatest thickness, both valves together, $10 \frac{1}{2}$ millimeters.

In general form and character of surface markings this species is related to $R$. uta Marcou (=R. punctilifera Shumard); but, besides being a much larger and comparatively less gibbous species, it bears nearly or quite double the number of plications upon each valve that is borne by $R$. uta.

Associated with it are Spirifer rockymontanus Marcou, Spiriferina octoplicata Sowerby, Spirigera subtilita Hall, Hemipronites crenistria Phillips, Axophyllum rudis White \& St. John,? and an undetermined small Gasteropod. They were all collected by Prof. L. C. Wooster, who, in a private communication, says: "They were obtained from some pebblr"s in a conglomerate resting upon the eroded face of the granite, 32 miles west and 18 miles north of Greeley, Colorado. A portion of the pebbles of this conglomerate was evidently derived from the granite upon which it rests." He found no Carboniferous strata in situ in that region, but it is evident that the "pebbles" which contain the fossils here noticed have not been transported to any considerable distance from the ledges from which they were derived. The fossils all belong to types which are eommon in the Coal-measure strata, and most of them are well known Coal-measure species. 


\title{
Genus SPIRIFER Sowerby.
}

\author{
SPIRIFER AGELAIUs Meek.
}

Plate 34, figs. $10 a$ and $b$.

Spirifer triradialis Phillips? Meek, 1873, An. Rep. U. S. Geol. Sur. Terr. for 1872, p. 470. spirifer agelaius Meek ib., in a foot-note.

Shell small, somewhat inflated, breadth a little greater than the length; hinge margin never longer than the greatest breadth of the shell, and usually shorter; anterior and lateral margins, except to little straightening at the front, forming an approximately regular curve, which comprises more than a semicircle.

Ventral valve somewhat more convex than the dorsal; umbo prominent, and from it the sides of the valve slope by a gentle convexity to the margins, the convexity being less at the sides than at the front; beak prominent, curved, and projecting backward over the hinge margin; area rather small, moderately high, arched, its lateral margins not well defined from the sides of the valve; mesial sinus rather narrow, but traceable from the front to the umbo, and bordered on each side by a moderately large, prominent, rounded rib, rather shallow, and having a faint ridge along its middle, which is perceptible only near the front, or it is only a little flattened at the bottom; upon each side of the sinus there are three and sometimes four ribs, which are smaller than the two that border the sinus, and which successively diminish in size and distinctness outwards, so that the fourth one is never very distinct.

Dorsal valve nearly regularly convex; beak not prominent, a little incurved, and projecting very slightly, if at all, over the hinge margin ; mesial lobe distinct, broader than the sinus of the other valve, with a faint median groove, or the lobe is a little flattened along its middle, bounded by grooves which are a little deejer than those which separate the ribs from each other; ribs three or four on each side of the mesial lobe, answering in character respectively to those of the other valve. Besides the ribs, the markings of the surface are only the usual concentric lines of growth.

Length of the largest dorsal valve in the collection, $6 \frac{1}{2}$ millimeters; breadth of the same, 9 millimeters. All the other examples in the collection, which are somewhat numerous, are smaller.

This species is reported from the Carboniferous strata of "Old Baldy" mountain, near Virginia City, Mont. The following are Mr. Meek's remarks upon it:

"A very abundant, gregarious little shell, closely resembling S. triradialis (Phillips) var. sexradialis, as illustrated by Mr. Davidson, excepting that the largest of hundreds of specimens are less than onefourth the size of well-developed individuals of that form. It also differs in being constantly wider than long, instead of the reverse, and in having the back of its ventral valve always proportionally shorter; while it shows a faint suleus along the mesial fold towards the front, and a corresponding very slight ridge in the bottom of the sinus of the dorsal valve. I think it probably a new species. If so, it may be called s. agelaius."

The differences between this shell and the $S$. triradialis var. sexradialis of Davidson are evidently incompatible with specific identity, and I therefore treat it in this article as a distinct species under the specific name proposed by Mr. Meek. 


\section{CONCHIFERA.}

\section{Genus NUCULA Lamarck.}

\section{NuCUla PERUMBonata White.}

Plate 34, figs. $7 a$ and $b$.

Nucula perumbonata White, 1879, Bull. U. S. Geol. Sur. Terr., vol. v, p. 217.

Shell small, compact, ventricose; posterior end obliquely truncated from the beaks to the postero-basal border, its plane forming an acute angle with that border and the sides of the shell; basal border broadly convex, front abruptly rounded; umbones large, much elevated; beaks situated about mid-length of the shell, incurved, pointing a little downward and backward; umbonal ridges forming a right and left angular border to the broad, concave postero-dorsal space. Surface marked by fine, raised concentric lines with spaces of like width between them.

Length, 9 millimeters; height from base to umbo, $6 \frac{1}{2}$ millimeters; thickness, both ralves together, $6 \frac{1}{2}$ millimeters.

Only one specimen of this species has been discovered, but it is so nearly perfect, and its characteristics are so well marked, and so different from those of any known forms, that I have ventured to give it a new specific name. In some of its characteristics this shell resembles the young of the next species described, namely, Nuculana obesa, especially in the character of the surface lines; but it is not prolonged posteriorly like Nuculana; besides which it is much more ventricose than the young of Nuculana obesa could have been. It differs from other known Carboniferous species of Nucula in the subcentral position of its beaks, its large prominent umbones, and the broad concave space between its umbonal ridges.

Position and locality.- This, together with most of the following species, was collected by Mr. G. K. Gilbert at Wild Band Pockets, Northern Arizona, 15 miles southward from Pipe Spring, from Carboniferous strata which he regards as holding a position near the top of the series.

\section{Genus NUCULANA Link.}

\section{NuCulana oBesa White.}

Plate 34, figs. $2 a, b$, and $c$.

Nuculana obesa White, 1879, Bull; U. S. Geol. Sur. Terr., vol. v, p. 216.

Shell subovate in marginal outline, except that the dorsum is concave behind the beaks, moderately gibbous in front, but attenuated behind; basal margin regularly and broadly convex; front regularly rounded, the curvature of the margin only slightly lessening between the front and the beaks; postero-dorsal margin concave, the posterior portion of the shell narrow, and the posterior margin subangular or sharply rounded from the postero-dorsal to the postero-basal margin; umbonal ridges sharply defined and placed so bigh as to form angular lateral borders to the concave dorsum behind the beaks ; these borders being more sharply defined near the beaks than they are further posteriorly; beaks well detined, incurved, and pointed backward, their average distance from the front being somewhat more than two-fifths the full leugth of the 
shell; but this proportion varies with the varying proportional length of the posterior portion of the shell in different examples. Surface marked by fine, regular, raised concentric striæ, which are obsolete, or less conspicuous, on the postero-dorsal space between the umbonal ridges. Cardinal teeth, about wwelve on each side of the beak; cartilage pit moderately large. Interior markings unknown.

Length of the most perfect example in the collection, 30 millimeters; height from base to beaks, 18 millimeters; thickness, both valves together, 12 millimeters. Some less perfect examples indicate a greater size and a proportionally greater elongation posteriorly.

This species is closely related to the Leda bellistriata of Stevens; but, besides being a larger and more robust form, it differs conspicuously in its laterally flattened and longitudinally strongly concave postero-dorsal area.

There can be no reasonable doubt that this form is genetically related to $N$. bellistriata Stevens sp.; but the differences here pointed out are evidently constant, and therefore deserve recognition; and the most convenient form of expressing such recognition is thought to be in the use of a separate specific name.

Position and locality.-Mr. Gilbert obtained this species from the uppermost of the Carboniferous strata at Wild Band Pockets, Northern Arizona, 15 miles southward from Pipe Spring, where it is associated with the species last described, and also with all except two of the following:

\section{Genus ALLORISMA King}

\section{ALLORISMA? GILBERTI White.}

Plate 33, figs. $9 a$ and $b$.

Allorisma? gilberti White, 1879, Bull. U. S. Geol. Sur. Terr., vol v, p. $21 \%$.

Shell rather small, elongate, broadly reflexed when adult, but less so while young; posterior portion compressed, and apparently slightly gaping; valves broadly convex, except posteriorly, where they are vertically flattened or compressed; nowhere gibbous; antero-dorsal portion of the shell obliquely truncated downward and forward directly from the beaks to the front; front margin rounded with a regular curve to the base; basal margin broadly convex; posterior margin short, abruptly truncating that portion of the shell downward and backward, forming a distinct but slightly obtuse angle with the dorsal margin; the latter margin broadly concave from the beaks to the posterior margin; beaks small, placed near the anterior end of the shell, slightly elevated, and turned a little forward; surface marked by concentric lines and wrinkles of growth. Also, extending from behind the beaks to the narrow posterior end of the shell, there are upon each valve two narrow, obscure folds, which increase a little in width with their extension posteriorly, and have a shallow groove between them. The lower one of these folds is the broader, and it ends at the postero basal angle; and the upper, which is involved with the inflexed dorsal border, ends at the postero-dorsal angle.

Length, 29 inillimeters; height, from base to beaks, 12 millimeters; thickness, both valves together, $7 \frac{1}{2}$ millimeters.

This shell departs somewhat widely, in general aspect, from the typical forms of Allorisma, and it perhaps does not strictly belong to that 
genus, although it corresponds in all essential respects with the generic diagnosis given by Professor King. It is evidently congeneric with the species described by Meek in the final report on the geology of Nebraska, p. 217, pl. x, fig. 15, under the name Allorisma (Sedgwickia) reflexa. That species is from the Upper Coal-measure strata at Nebraska City, Nebr., and it has also been found in the Lower Coal-measures of Illinois, as stated by Meek. Compared with that shell, ours is much more elongated, and the beaks are placed proportionally nearer the front.

Position and locality.-Carboniferous strata at Wild Band Pockets, Northern Arizona, 15 miles south of Pipe Spring. Collected by Mr. G. $\mathrm{K}$. Gilbert, in whose honor the specific name is given.

\section{GASTEROPODA.}

\section{Genus BELLEROPHON Montfort.}

\section{Bellerophon subPapillosus White.}

Plate 34, fig. $3 a$.

Bellerophon subpapillosus White, 1879, Bull. U. S. Geol. Sur. Terr., vol. v, p. 218.

Among the fossils here described, which Mr. Gilbert obtained from Wild Band Pockets, Northern Arizona, are some imperfect specimens of a Bellerophon which is closely related to $B$. urii Fleming and B. carbonarius Cox. In Powell's Report on the Geology of the Uinta Mountains, p. 92, I gave a brief description of this form under the name of B. carbonarius var. subpapillosus; the specimens then examined having been obtained from near the top of the Carboniferous series at several localities in Northwestern Colorado. In view of the constancy of the characteristics by which this form differs from the typical forms of $B$. carbonarius, I have decided to treat it as a distinct species, although I have no doubt of its genetic relation to $B$. carbonarius; and it probably bears the same relation to $B$. urii also.

Among the differences between this species and B. carbonarius is that the former is constantly of larger size than the latter as it is known throughout the Mississippi Valley and through the whole of its great vertical range in the Coal-measures there. The other characteristies which distinguish the two species from each other are also constant throughout their range and distribution respectively. The more conspicuous of these characteristics as regards B. subpapillosus, aside from its greater size, consists in the studding of the surface of the outer part of the last volution, which is entirely plain in B. carbonarius, with slightly raised papillæ, arranged in rows corresponding to and continuous with the revolving striæ which mark the remainder of the surface of both shells.

B. subpapillosus is characteristic of the upper strata of the Carboniferous series in Northwestern Colorado and the adjacent region, and its presence among the collections made by Mr. Gilbert in Northern Arizona seems to indicate a similar horizon for the strata from which the latter were obtained. 


\title{
Genus NATICOPSIS McCoy.
}

\section{NATICOPSIS REMEX White.}

\author{
Plate 34, fig. $6 a$.
}

Naticopsis remex White, 1876, Powell's Rep. Geol. Uinta Mts., p. 109.

Shell of ordinary size, very oblique when adult, by the elongation and enlargement of the last volution; volutions about four, convex, increasing rapidly in size, the last one large and much produced; spire small and short; suture impressed. Surface marked by the usual lines of growth, and upon the specimens which are best preserved there are very faint indications of the presence of revolving striæ also.

Length across the longest diameter of the volution and the remainder of the body volution of an average sized specimen, 23 millimeters; the short diameter of the aperture, 17 millimeters.

Position and locality.-The only known examples of this species were obtained by Professor Powell from the middle division of the Carboniferous series at the confluence of Grand and Green Rivers, Utah.

\section{Genus MURCHISONIA d'Archiac.}

\section{MURCHISONIA TEREBRA White.}

Plate 34, fig. $4 a$.

Murchisonia terebra White, 1879, Bull. U. S. Geol. Sur. Terr.', vol. v, p. 219.

Shell slender; apical angle $16^{\circ}$ or $17^{\circ}$; full number of rolutions in adult examples, not less than seventeen or eighteen; volutions strongly angulated, with only one angle, which is slightly carinated, the carina befinely nodulated or crenulate; the position of the angle much nearer to the proximal than the distal border of the volutions; outer side of the volution, between the distal border and the carinated angle, straight, and slightly concave between that angle and the proximal border; suture slightly impressed, moderately distinct. The whole outer surface of the volutions, on both sides of the angle, marked by fine revelving raised. lines of nearly uniform size, and separated by spaces of about equal width with the lines.

The full length of the largest example would be, if perfect, not less than 45 millimeters; width of the last volution, 10 inillimeters.

This species differs conspicuously from any published form of Murchisonia in the possession of the single prominent angle situated near the proximal border of the volutions, and in the broad flattened outer side of the volution between the angle and the distal border. It is perhaps more nearly related to M. marconiana Geinitz, from the Upper Coal Measure limestone of Eastern Nebraska, than to any other published form; but it differs from that species in the more anterior position of the revolving angle, in having a more slender spire, and in wanting the numerous uniform revolving raised lines which mark the whole outer surface of $M$. terebra. The collections from the Upper Coal Measure strata in the cabinet of the Smithsonian Institution contain some fragments of an undescribed species of Murchisonia which is closely related to ours in general form, and also in having only one prominent carinated revolving angle upon its volutions, the carina being likewise finely nod- 
ulated. That species differs from ours, however, in having its angle further from the proximal border of the volutions, and in wanting the numerous uniform revolving lines upon all the exposed surface of the volutions.

Position and locality.--Carboniferous strata at the Wild Band Pockets, Northern Arizona, 15 miles southward from Pipe Spring, where Mr. Gilbert found it associated with Nuculana obesa, Allorisma gilberti, \&c.

\title{
Genus PLEUROTOMARIA Defrahce.
}

\section{Pleurotomaria tagGerti Meek.}

Plate 34, figs. $1 a$ and $b$.

Pleurotomaria taggerti Meek, 1874, An. Rep. U. S. Geol. Sur. Terr. for 1873, p. 271 (foot note).

This species was collected by Dr. A. C. Peale from Carboniferous strata near Horseshoe Mountain, South Park, Colorado, where he found it associated with Productus semireticulatus, $P$. nebrascensis, $P$. prattenianus, \&c. The following is Mr. Meek's description:

"Shell attaining a large size, turbinate, very thin, slightly longer than wide; spire depressed conical, a little shorter than the length of the aperture; volutions five to five and a half, flattened above to the slope of the spire, last one very prominent and angular around the middle, with the under side slightly convex and sloping inward nearly at right angles to the flattened slope of the upper side above the peripheral angle; suture nearly linear; umbilical region very slightly excavated and imperforate; aperture rather large, subquadrate, with height and breadth apparently nearly equal; spiral band extremely narrow, occupying the peripheral angle of the body volution, and passing around only about its own breadth above the suture on those of the spire; surface nearly smooth, or showing only obscure lines of growth, with apparently merely the faintest possible traces of revolving striæ.

"Height, about 2.60 inches; breadth, about 2.49 inches.

"In size and general appearance this fine species somewhat resembles P. missouriensis (Trochus missouriensis Swallow), but it may be at once distinguished by having its body volution, below the periphery, longer than the height of the spire above it, instead of flattened, as well as by wanting the distinct revolving lines of that species."

The above statement, that the body volution below the periphery is longer than the height of the spire above it, is likely to be misunderstood. Mr. Meek's type specimen, the only one yet discovered, has the width of the body volution, as measured across the aperture in line with the axis of the shell, a little greater than the length of the spire beyond the upper or distal portion of the aperture.

\section{Pleurotomaria grayvillensis Norwood \& Pratten.}

\author{
Plate 34, fig. 5 a.
}

Pleurotomaria grayvillensis Norwood \& Pratten, 1855, Jour. Acad. Nat Sci., Philad., vol. iii, p. 75.

Pleurotomaria grayvillensis White, 1879, Bull. U. S. Geol. Sur. Terr., vol. v, p. 219.

Among the fossils brought by Mr. Gilbert from the Carboniferous strata at Wild Band Pockets, Northern Arizona, are a couple of imperfect examples of a small Pleurotomaria, which corresponds, so far as can 
be observed, too nearly with the description and figures of $P$. grayvillensis, as given by Norwood \& Pratten, in the work above cited, to warrant their separation under a new specific name. The principal differences presented by these examples are the greater prominence of the bandbearing carina, the more distinct furrow separating the carina from the proximal portion of the volution, and the greater prominence of the revolving lines which cover the surface. These differences, so far as they are observable upon our examples, seem not to be incompatible with specific identity. If these examples are specifically identical with $P$. grayvillensis, as they are believed to be, their discovery in Arizona adds another to the interesting facts already known, showing the wide geographical distribution of Carboniferous species. 


a. Lateral view of the largest discovered example; natural size.

b. Similar view of a smaller broken example.

c. Calyx of another example.

d. Section, showing tabulæ.

Fig. 2. ARCheocidaris cratis

a. Lateral view of one of the principal spines; natural size.

Fig. 3. Ptilodyctia triangulata

a. A group of fragments; natural size; from Northwestern Colorado.

b. One of the type specimens of the species; from Danville, Ill.; natural size.

c. Transverse section of the same.

$d$. View of one side of the same; much enlarged.

$e$. Diagram of $3 c$; enlarged; showing the manner of radiation of the cells from the tripartite axis.

Fig. 4. Rhynchonella Endichi

a. Dorsal view of a natural cast of a large example; natural size.

b. View of an imperfect ventral valve. For other figures of this species see plate 36 .

Fig. 5. ERISOCRINUTS TYPUS

a. Side view; natural size; showing a portion of the stem and arms.

Fig. 6. Poteriocrinus montanaensis

a. View of anal side of Mr. Meek's type specimen; natural size.

Fig. 7. Platycrinus haydeni

a. Side view of Mr. Meek's type specimen; natural size.

Fig. 8. EUPAChycrinus platybasis

a. Basal view; natural size.

Fig. 9. ALLORISMA GILBERTI

a. Right side view; natural size.

$b$. Dorsal view of the same. 


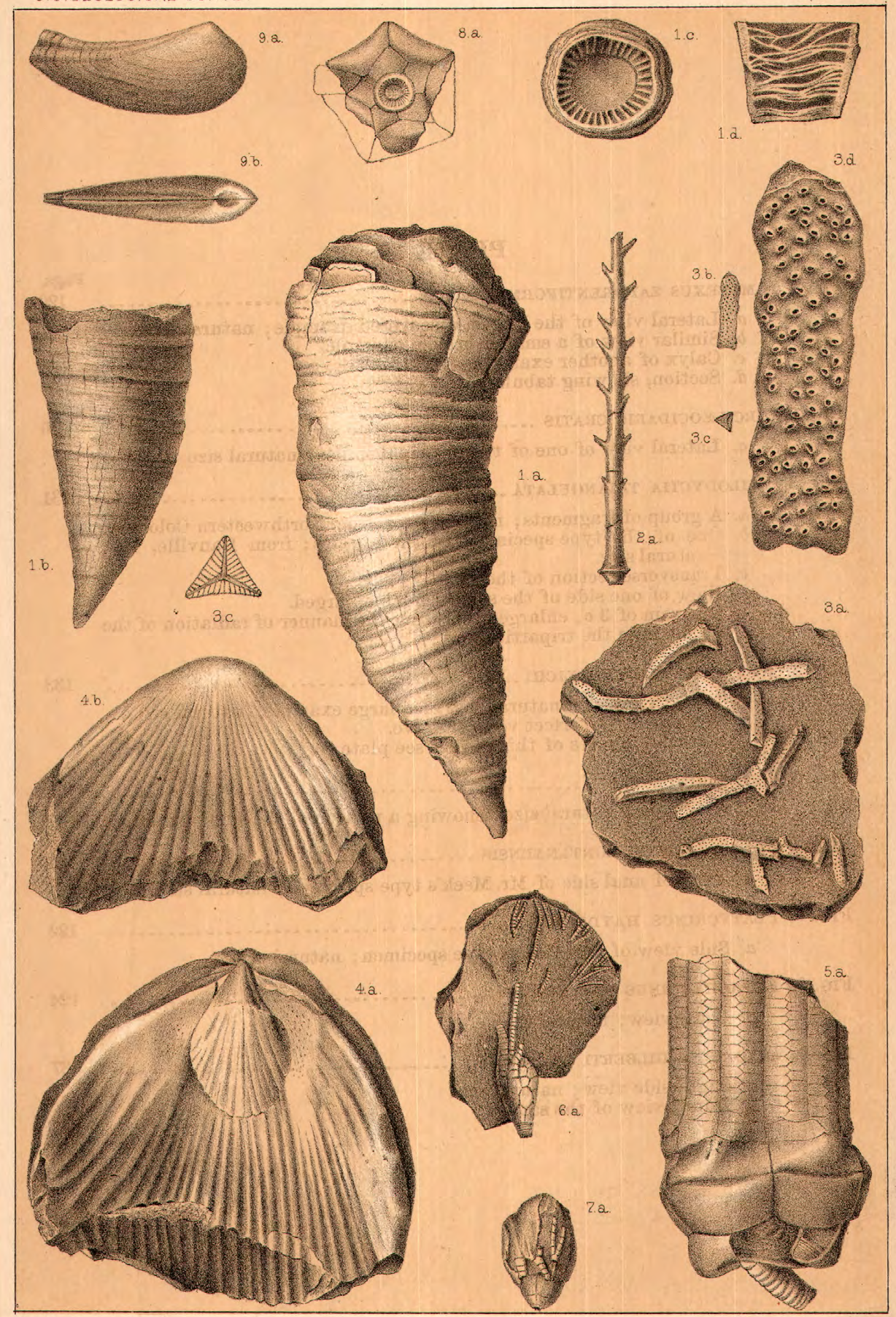






\section{PLATE 34.}

Fig. 1. Pleurotomaria taggerti

$a$. Side view; natural size.

$b$. Oblique view of the same, showing the base.

FIg. 2. NUCULANA OBESA

a. Left side view; natural size.

$b$. Dorsal view of the same.

c. Another example, showing the hinge.

Fig. 3. Bellerophon subpapillosus

a. Dorsal view ; natural size. Surface not quite perfectly preserved.

Fig. 4. Murchisonia terebra

a. Lateral view; natural size.

Fig. 5. Pleurotomaria grayvillensis

a. Side view; natural size. The upper, light portion of the figure is drawn from one example, and the lower portion from another.

Fig. 6. Naticopsis REMEX

a. Side view; natural size.

Fig. 7. NUCULA PERUMbonata

a. Right side view; enlarged to one and a half diameters.

$b$. Dorsal view of the same.

Fig. 8. Retzia woosteri

a. Ventral view; natural sizo

$b$. Lateral view of the same.

Fig. 9. Erisocrinus (Ceriocrinus) inflexus

a. View of anal side, natural size, of an example from Utah.

$b$. Basal view of the same.

Fig. 10. Spirifer agelaius

a. Ventral valve; enlarged to two diameters.

.b. Dorsal valve; enlarged to one and a half diameters.

Fig. 11. LePtopora wiNCHELLI...

a. Fragment of corallum, showing calyces; natural size.

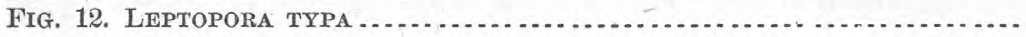

a. Upper view of an entire calyx and portions of other adjoining ones; enlarged to one and a half diameters.

$b$. Lateral view of the same, showing the depth of the calyces and of the corallum.

These examples are from the Subcarboniferous rocks of Burlington, Iowa, and are introduced here for comparison. 

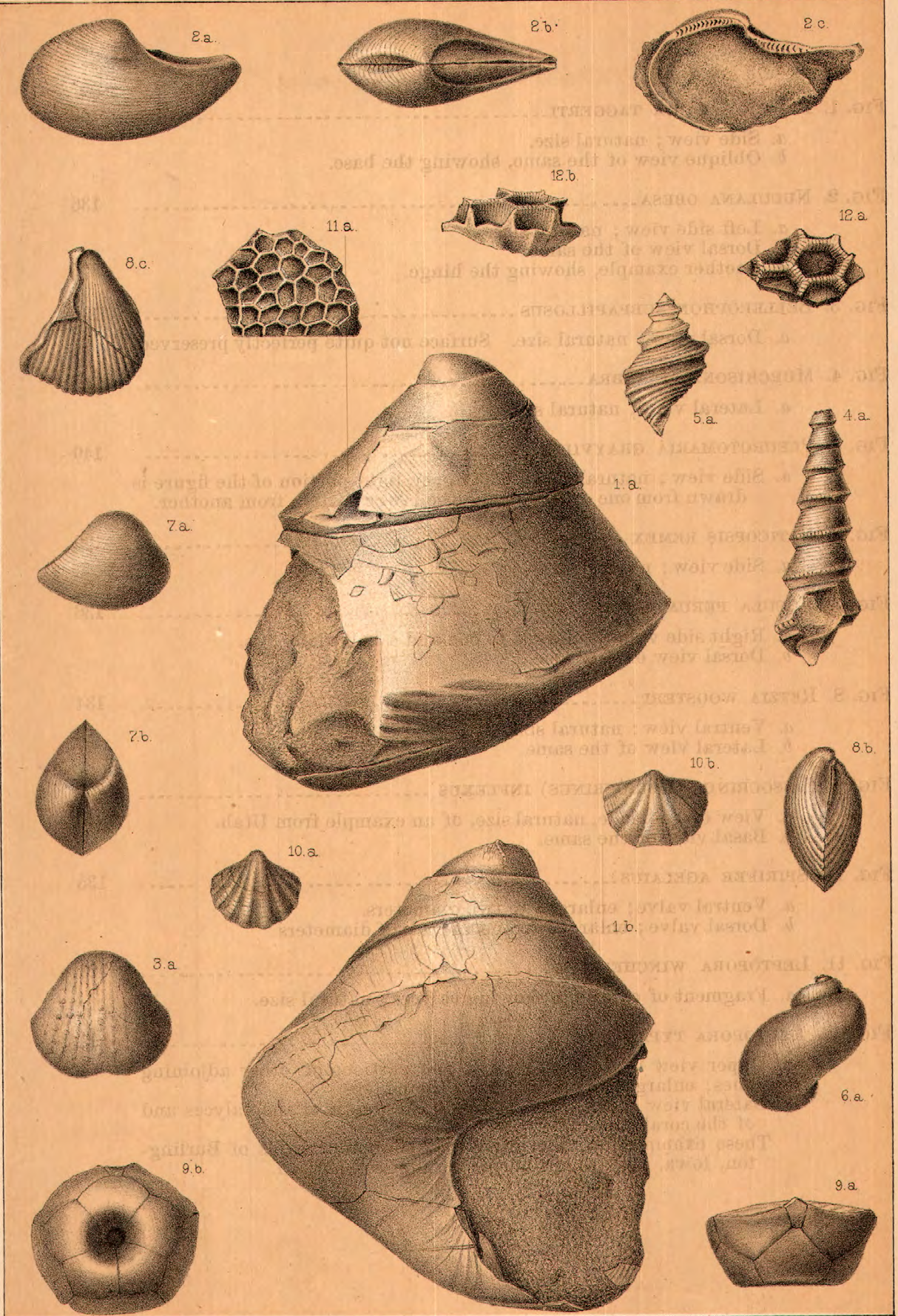

J. C. MC Comnell \& E. D. Owen Del 


Frg. 1. ACervularia adjunCtiva

a. Fragment of a corallum, showing the compacted corallites somewhat distorted by pressure.

b. A smaller fragment.

c. Transverse section of the same; partly diagramatic.

d. Longitudinal section of a corallite; partly diagramatic. All natural size.

Fig. 2. LECYTHIOCRINUS OLLICULAEFORMIS

a. Side view of the body; enlarged to one and a half diameters.

$b$. Diagram of the same; similarly enlarged.

Fig. 3. Cyathocrinus stillatives

a. Side view of the body; natural size.

$b$. Basal view of the same.

Fig. 4. RHODCCRINUS VESPERALIS

a. Side view of the body; natural size.

b. Basal view of the same.

Fig. 5. HRISOcrinus (CEriocrinus) planus

$a$. Side view of the body; natural size; showing minute anal piece.

$b$. Basal view of the same.

c. An example of the Potereocrinus hemisphericus of Shumard, introduced for comparison.

Fig. 6. ARCHAOCIDARIS DININNII

$a, b$, and $c$. Views of three different spines; natural size. 

Fig. 1. Productus giganteus

a. View of a natural cast of the concave surface of the dorsal valve, with a fragment of the ventral valve attached; natural size.

$b$. Gutta-percha cast of a portion of Fig. $1 a$, showing the natural surface of the dorsal valve, except that the numerous small spinules are not well shown. They are represented by the dots upon Fig. $1 a$.

c. Outline of section of the shell along the median line, showing the length of the shell from beak to front, which Fig. $1 a$ does not show because of the posture of the specimen when drawn. This figure is partly diagramatic, but the proportions are taken from measurements of specimens in the collection.

Fig. 2. Ritynchonella endichi

a. Dorsal view of a nearly perfect example, less than full adult size; the test partly extoliated.

b. Latera! view of the same.

For other figures of this species see plate 33. 


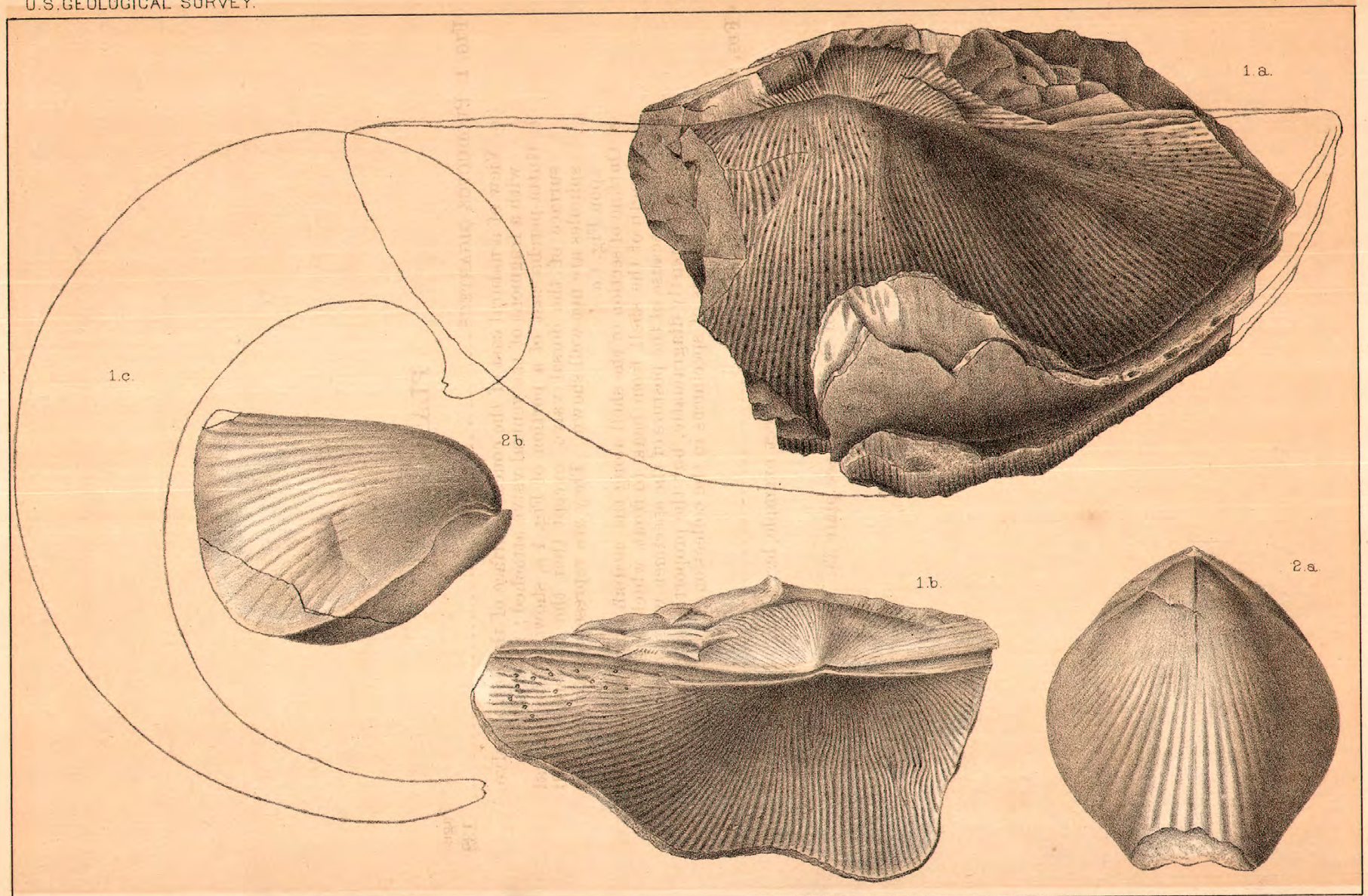



CONTRIBUTIONS TO INVERTEBRATE PALEONTOLOGY. NO. \%; JURASSIC FOSSILS FROM THE WESTERN TERRITORIES.

Bу C. A. Wніте, M. D.

The fossils embraced in this article have been collected by different persons who have been connected with the various government surveys in the western portion of the national domain. Six of the species are here described for the first time, and two of them were described by the writer in Professor Powell's Report on the Geology of the Uinta Mountains. The remainder were named by the late Mr. Meek in a catalogue of fossils which he published in the annual report of this survey for 1872 . The brief characterization which he there gave of them in the form of foot-notes is insufficient for their identification, but the type-specimens have all been recognized by means of the registered numbers which they bear in the records of the National Museum, and his names are therefore retained.

The specimens have all been reported as from the Jurassic by those who collected them. All but two of the species are believed to be from strata of unquestionable Jurassic age. These two, Aviculopecten superstrictus and Volsella (Modiolina) platynota, are possibly from the horizon of the Triassic fossils which form the basis of Contributions to Invertebrate Paleontology No. 5, already given on preceeding pages. The reasons for entertaining this opinion are presented in connection with the description on following pages of the two species named.

\title{
Genus CAMPTONECTES (Agassiz) Meek.
}

\section{CAMPTONECTES PLATESSIFORMIS White.}

\author{
Plate 37, fig. $5 a$.
}

Camptonectes platessiformis White, 1876, Powell's Rep. Geol. Uinta Mts., p. 93.

Camptonectes extenuatus Whittield, 1877 (not Meek \& Hayden), Prelim. Rep. Paleont. Black Hills, p. 47.

Shell, exclusive of the ears, subelliptic in marginal outline, the height being considerably greater than the width; the whole border below the ears forming a continuous and almost true elliptic curve; hinge line moderately long. Left valve gently convex; the ears moderately large, nearly rectangular, subequal, the anterior one perhaps slightly larger and a little more prominent than the other, defined from the body of the shell by their flattening and not by distinct auricular furrows; umbonal portion of the valve well defined by its straightened sides converging to the beak, which is small and projects little, if any, beyond the cardinal border. Surface marked by numerous comparatively coarse, radiating, crenulated, raised lines, which, near the base, begin to be curved outward to the margins, the curvature of the lines increasing towards 
the upper portion of the sides so that upon the space just below each ear they have a distinctly backward curvature. Right valve unknown.

Height from base to beak, 30 millimeters; breadth, 26 millimeters.

Position and locality.-The type of this species was discovered in Jurassic strata at the north base of Aquarins Plateau, Southern Utah. Professor Whitfield also reports its existence (loc. cit.) in Jurassic strata of the Black Hills, but refers it to the O. extemuatus of Meek \& Hayden The last-named species, however, as described and figured by its anthors is a smooth or nearly smooth one, and has a different marginal outline

\section{Genus AVICULOPECTEN McCoy.}

\section{AVICULOPECTEN? SUPERSTRICTUS (sp. nov.).}

Plate 37, figs. $4 a$ and $b$.

Shell suborbicular in marginal outline; cardinal border rather long, straight, and at nearly right angles with the axis of the shell; the free margins below the ears forming the greater part of a nearly perfect circle. Left valve moderately gibbous, the convexity being nearly uniform below but narrowing laterally toward the umbo, which is somewhat prominent and arched; beak small and projecting only slightly beyond the hinge margin; ears moderately large and well defined, but not separated from the body of the shell by auricular furrows; posterior ear having its outer margin slightly concave and its outer angle somewhat acute; anterior ear a little more abruptly flattened than the other, its margin forming a concavity with that of the body of the shell and being a little convex at the outer extremity. The body of the valve bears from twelve to fifteen slender radiating ribs between which each space is occupied by from five to seven radiating, thread-like, raised lines, which increase in number by implantation with the growth of the shell, and the first-formed lines also increase slightly in size. Indeed, the ribs themselves in their origin consist of just such lines as are formed between them in the after growth of the shell. Both ears are marked by lines similar to those between the ribs. Right valve and hinge unknown.

Height from base to cardinal border, 29 millimeters ; transverse diameter, 30 millimeters; length of hinge line, about 26 millimeters.

This shell is probably not a true Aviculopecten, but in external characteristics it closely resembles certain forms of that genus; and as nothing is yet known of its hinge, it is referred provisionally to Aviculopecten in consequence of those external characteristics. It is doubtless congeneric with the three Triassic species which, in Contributions to Invertebrate Paleontology No. 5, on previous pages of this volume, I have referred provisionally to that genus. It agrees with those three species in the character of its surface markings, but its hinge margin is not perceptibly oblique with the axis of the shell. This latter character distinguishes it from $A$. idahoensis and A. pealei. A. altus is very slightly, if any, oblique, but that species differs from the form here described in being proportionally much higher from base to beak, and also in having its left valve less convex and its hinge line proportionally shorter. The shell here described comes from the same region in which the Triassic fossils just referred to were discovered, and it is possible that it comes also from Triassic strata; but from information received I at present refer it to the Jurassic.

Position and locality.-Head of Lincoln Valley; from strata supposed to be of Jurassic age, where it was discovered by Prof. 0 . St. Jolin, in 1877. 


\title{
Genus GERVILLIA Defrance.
}

\author{
Gervillia montanaensis Meek.
}

Plate 37, figs. $1 a$ and $b$.

Gervillia montanaensis Meek, 1873, An. Rep. U. S. Geol. Sur. Terr. for 1872, p. 472.

Shell of medium size, distinctly inequivalve, not distorted, the body portion rather -lender, generally curved and very oblique with the cardinal border; anterior ear small; posterior ear rather large, flattened, and produced at the extremity; cardinal border long and straight; front and basal borders forming a continuous and almost regular curve; posterior extremity abruptly rounded; postero-auricular border gently curved, with a forward and upward direction of its lower portion, and ending with an abrupt backward curve, meeting the cardinal border at the extremity of the narrow projection of the posterior ear. Left valve more convex than the right, the umbonal portion narrow, and ending in an inconspicuous beak; anterior ear forming a small lobe-like projection in front of the umbo, from which it is defined by a faint furrow. Right valve corresponding with the left, but it is less convex, and in some cases apparently nearly flat. Surface marked by distinct concentric lines and some coarser wrinkles of growth; and the median portion of the body is also marked by from four to six more or less distinet, slender, radiating costæ, which extend from the umbo to the postero-basal: border, being separated by spaces of unequal width, but all wider than the slender costæ. These costæ are less distinct upon some examples than others, and they are sometimes obsolete or even wanting upon the right valve.

The length of the largest example in the collection was, when perfect, about 110 millimeters, measured along its axis, and its hinge line not far from 70 millimeters long.

None of the examples is in a condition to show the character of the hinge, and it is, therefore, not certain that this species is a true Gervillia. There are upon some of the examples indications of the presence of a slender longitudinal ridge near the cardinal border of the posterior ear, such as characterizes Pteroperna Morris \& Lycett; but this feature is obscure. If the hinge was really free from a longer or shorter series of cartilage pits, the shell can be referred neither to Gervillia nor Pteroperna, but should doubtless be referred to Pteria. In the absence, however, of any accurate knowledge of the character of the hinge, I prefer to leave it with Gervillia, where it was placed by Mr. Meek.

Position and locality. - Near the lower cañon of Yellowstone River, Montana, where it was collected by Dr. A. C. Peale, who found it associated with Trigonia americana, T. montanaensis, Myacites subcómpressus, and other Jurassic forms.

\section{Genus VOLSELLA Scopoli.}

\section{Volsella SUBIMBRICATA Meek.}

Plate 37, figs. $2 a, b$, and $c$.

Modiola ( Tulsella) subimbricata Meek, 1873, An. Rep. U. S. Geol. Sur. Terr. for 1872, p: 472.

Shell arcuate-subtrihedral in marginal outline when adult, but more elongate when young; basal margin concave; front margin short, ab-- 
ruptly rounded up to the beaks; posterior margin narrowly rounded to the postero-dorsal margin; dorsal margin nearly straight or a little convex and moderately long; postero-dorsal margin gently convex and forming a steep slope to the posterior margin; valves strongly convex, especially about the middle; umbones compressed and very slightly elevated; beaks proper, minute, and nearly terminal. The valves meet at a sharp angle along the postero dorsal slope, and both of them bend so abruptly inward below that the middle portion of the shell, when both valves are together, is nearly flat upon the under side. An illdefined radiating furrow or depression upon each valve separates a small antero-basal portion from the remainder of the shell, behind which furrows or depressions its transverse thickness is greater than elsewhere. Surface marked by abundant, distinct, concentric lines and some coarser wrinkles of growth, but by no radiating lines. Its hinge has not been clearly seen, but it seems to be a true Volsella, and apparently does not belong to the subgenus Brachydontes of Swanison.

Length, 58 millimeters; greatest width, which is about mid-length of the shell, 25 millimeters. 'This is the measurement of one of Mr. Meek's types. The following is that of an example, less than adult size, from near Vermilion Cañon, Northwestern Colorado: Length, 36 millimeters; greatest width, 15 millimeters; greatest thickness, both valves together, 15 millimeters. This species, as pointed out by Mr. Meek, is very like the Modiola imbricata of Sowerby, "excepting that its anterior ventral portion, in front of the umbonal ridges, is more prominent, and its posterior basal extremity is more produced and narrowed."

Position and locality.- Several specimens of this species were obtained by Dr. Peale from near the lower cañon of the Yellowstone River, and at Spring Cañon, in Montana; and a fine example, not quite adult, was obtained by the writer of this article from near Vermilion Cañon, Northwestern Colorado.

VolsElla (Modiolina) PLATYNota (sp. nov.).

Plate 37, figs. $3 a$ and $b$.

Shell transversely subovate in marginal outline, prominently convex in the central and umbonal regions, in consequence of which the dorsal portion of each valve is so flattened horizontally as to give the shell a broad flattened back; basal margin broadly convex; posterior margin rounded, the postero-basal portion being most prominent, and the postero-dorsal portion sloping upward and forward to the dorsal margin, which it meets with a moderate curve; dorsal margin nearly straight, its length being a little greater than half the full length of the shell; antero-basal portion of the shell a little compressed, its margin projecting a little in advance of the beaks and somewhat abruptly rounded to the front; umbones narrow and moderately prominent; beaks projecting very slightly beyond the immediately adjacent portion of the front border.

Length, 35 millimeters; height at mid-length of the shell, 24 millimeters; greatest thickness, both valvest ogether, which is about mid-length of the shell, 18 millimeters.

This shell is evidently not a true Volsella, but it is believed to be congeneric with the two species of Triassic shells which are deseribed by Meek in vol. iv, p. 103, U. S. Geol. Sur. 40th Parallel (King), and doubtfully referred by him to the Paleozoic genus Modiomorpha Hall \& Whitfield. It is doubtless possible that a genus of conchifers should range from 
paleozoic to mesozoic strata, but such a difference in age is strong presumptive evidence that there is also a difference of generic characters between shells from the strata of each respectively, even though they may agree in external form. Therefore, in absence of any knowledge of the hinge of the species here described, I think it unadvisable to refer it to Modiomorpha; and thinking the suggestion of Mr. Meek a correct one, that these shells probably represent a new genus, for which he proposed the name Modiotina, I have here used that name in parenthesis as a provisional generic reference.

Position and locality.-This shell was discovered by Prof. O. St. John, associated with Aviculopecten superstrictus and a few other obscure forms, at the head of Lincoln Valley, Southeastern Idaho. Although both this species and A. superstrictus are here referred to strata of Jurassic age, it is, as has already been stated, not certain that they are not of Triassic age, especially since both species have close congeners in the strata of the latter period in the same region from which these were obtained.

\title{
Genus MYTILUS Linnæus.
}

\section{Mrtulus whrter Whitfield.}

\author{
Plate 37 , fig. 9 a.
}

Mytilus whitei Whitfield, 1877, Prelim. Rep. on the Pal. Black Hills, p. 18.

Shell much higher than wide; basal margin regularly rounded; posterior margin long, gently convex; front margin slightly convex below and concave above by the forward projection of the umbonal portion of the shell ; anterior portion of the dorsal margin straight, but the hinder portion sloping gently to the posterior margin; umbonal portion of the shell somewhat narrow and projecting beyond the front margin. Left valve moderately convex; surface marked by the usual lines of growth. Right valve and hinge unknown.

Height from base to cardinal margin, 55 millimeters; breadth of the body of the shell at about its mid-height, 32 millimeters.

This shell is perhaps not a true Mytilus, but it is doubtless specifically identical with the shell described by Professor Whitfield (loc. cit.) as $M$. whitei, the more elongate form being regarded as due to increased growth in that direction by age.

Position and locality.--Jurassic strata from near Fontanelle Cañon, upon the west side of Green River Basin, Western Wyoming, where it was collected by Dr. A. C. Peale.

\section{Genus TRIGONIA Bruguiere.}

\section{Trigonia montanamesis Meek.}

Plate 38, fig. $2 a$.

Trigonia montanaensis Meek, 1873, An. Rep. U. S. Geol. Sur. Terr. for 1872, p. 472.

Shell transversely elongate, somewhat arcuate and rudely subtetrahe. dral in marginal outline, gibbous anteriorly and narrowed and compressed behind; umbones elevated; from the umbo to the middle of the base the margin, as seen by side view, forms a continuous and almost true senicircular curve; from the middle of the base to the posterobasal angle the margin is slightly concave; posteriur margin nearly. 
straight or very slightly convex, forming, with the dorsal margin, a distinct, slightly obtuse angle; dorsal margin concave, the appearance of convexity being increased by the elevation of the umbones; umbonal ridge distinct and prominent below, but becoming obsolete towards the beak. Surface in front of the umbonal ridge marked by ten or twelve curved varices, which start from near the umbonal ridge and extend to the front and basal margins, the concavity of their curve being upward and forward. The first six or seven of these varices become broken up into distinct nodules a short space in front of the ridge. The forward ones of each varix or transverse row of nodules are larger than the others, and are ranged in a vertical row of strong nodules, which form a conspicuous feature of the shell. The corselet, or space behind and above the umbonal ridge, is marked only by numerous distinct, nearly vertical, lines of growtl.

Length, 44 millimeters; height from base to beak, 35 millimeters; height of posterior portion, 20 millimeters.

This species resembles T. signata Agassiz, from the lower Jura of Europe, but it differs in the character of the noduliferous varices, in having a vertical row of large nodules, in the character of the umbonal ridge, and in other particulars. In the possession of the vertical row of nodules it resembles $T$. navis Lamarck, from the Lias of Alsace, but it differs from that species too much in other particulars to need comparison.

Position and locality.-Jurassic strata near the Lower Cañon of the Yellowstone, Montana, where it was collected by Dr. A. C. Peale.

\section{Trigonia americana Meek.}

Plate 38, figs. $1 a$ and $b$.

Trigonia americana Meek, 1873, An. Rep. U. S. Geol. Sur. Terr. for 1872, p. 472.

Shell subtetrahedral in marginal outline, gibbous in front of the umbonal ridge and compressed behind it; the margin from the beak all the way to the postero-basal angle forming a continuous and almost regular curve; posterior margin nearly straight, truncating the shell downward and backward; dorsal margin gently concave; beaks somewhat elevated and having the appearance of being directed slightly backward; umbonal ridge forming a somewhat prominent crenulated carina, which very gradually increases in size towards and ending at the postero-basal angle. Surface in front of the umbonal ridge marked by 15 to 18 sharplyraised concentric varices, which become suddenly obsolete just before reaching the umbonal ridge. The surface behind that ridge is marked by numerous raised, radiating, finely crenulated lines, which are nearly uniform in size; but the spaces separating the five or six lower ones are a little wider than the others.

Length from front to posterior margin, 34 millimeters; height from base to beaks, 31 millimeters.

This species is of the type of $T$. costata Lamarck, from the Lower Oolite of Europe, but it differs conspicuonsly from that and nearly related species by the uniform character of the radiating markings of the corselet.

Position and locality.-Jurassic strata near the Lower Cañon of Yellowstone River, Montana, where it was collected by Dr. A. C. Peale, who found it associated with $T$. montanaensis, Gervillia montanaensis, and Myacites subcompressus. 


\title{
Genus ASTARTE Sowerby.
}

\author{
Astarte PACKardi (sp. nov.).
}

Plate 37, fig, $6 a$ and $b$.

Shell subcircular in marginal outline, moderately and almost règularly convex; its length and full height almost equal, or the latter a trifle less than the former; margin forming a continuous subelliptic curve all the way around from the posterior end of the hinge to the lower end of the lunule; hinge margin short and gently convex; beaks placed subcentrally, rather small but prominent, and turned forward; lunule moderately large, rather deeply impressed and clearly defined, its abruptlyinflected borders giving a concave appearance to that portion of the shell as seen by lateral view. Surface marked by somewhat numerous and regular concentric undulations and, between these, by minute striæ of growth. Hinge unknown.

Transverse length, 20 millimeters; height from base to beaks nearly one millimeter less.

This shell is probably not a true Astarte as that genus is recognized among living forms, but it probably belongs to a section to which Gabb gave the name Eriphyla. As the hinge is unknown, however, I prefer to assign it to Astarte, since its visible characters indicate it to be closely related to, if notidentieal with, that genus. It resembles the A.ventricosa of Meek from the Jurassic rocks of California, as described and figured in the Paleontology of California, vol. 1, p. 50, pl. 8 , fig. 5 , but it is more nearly circular in marginal outline than that shell, less narrowly rounded in front, and the beaks are smaller and more pointed.

Position and locality.-Jurassic strata, near Como Station, on the Union Pacific Railroad, Wyoming, where it was discovered by Prof. A. S. Packard, jr., in whose honor the specific name is given. He found it associated with Eumicrotis curta, Belemnites densus, and other well-known Jurassic forms.

\section{Genus CARDINIA Agassiz.}

\section{Cardinia pratcisa (sp. nov.).}

Plate 37 , figs. $7 a$ and $b$.

Shell subovate in marginal outline, moderately and somewhat regularly couvex; beaks small, approximate, situated near the front, and turned slightly inward and forward; front slightly concave below the beaks, giving ari obliquely truncated appearance to the upper anterior portion; dorsum gently envex longitudinally from beaks to the pos. tero-dorsal portion, but concave laterally so as to nearly or quite obscure the ligament from side view; ligament external, well developed, but small and rather short. From front to rear, below a horizontal line drawn through the mid height of the shell, its border forms an almost true semi-ellipse; posterior border somewhat regularly rounded. Surface marked by concentric lines and undulations of growth.

Length, 38 millimeters; height, 28 millimeters; thickuess, both valves together, 18 millimeters.

This shell seems to be a true Cardinia, but it is the first species of that genus that has, to my knowledge, been found in American Jurassic 
strata. It is distinguished from other known species by its inconspieuous beaks and its obliquely downward and forward truncation of the - upper portion of the front.

Position and locality.-Jurassic strata near the lower cañon of Yellowstone River, Montana; where it was collected by Dr. A. C. Peale.

\section{Genus TANCREDIA Lycett.}

\section{TANCRedia extensa (sp. nov.).}

Plate 38, fig. $4 a$.

Shell transversely elongate, the length being about double the height; moderately and somewhat regularly convex, but the umbones are somewhat prominent, and there is a slight lateral flattening of the posterodorsal portion of each valve; basal margin forming a broadly-convex curve; both anterior and posterior margins narrowly rounded; posterodorsal margin sloping downward and backward from the beaks with a very gentle convexity; antero-dorsal margin concave in front of the beaks and gently convex further forward; beaks situated at about midlength of the shell. Surface marked by concentric lines of growth.

Length, 58 millimeters; height from base to beaks, 29 millimeters.

The only examples of this species that have been discovered are in the form of natural casts in sandstone. It is doubtless congeneric with those American Jurassic species which have been very generally referred to Tancredia, but this reference of it is made wholly from external characters, the hinge and interior markings being unknown. It somewhat resembles $T$. inornata (= Astarte inornata Meek \& Hayden), but it is a larger and much more elongate form.

Position and locality.-Jurassic rocks, north side of Bull Lake Fork, Southeastern Idaho, where it was discovered by Prof. O. St. John, in the season of 1878 .

\section{Genus PHOLADOMYA Sowerby.}

\section{Pholadomya kingir Meek.}

Plate 38 , figs. $3 a$ and $b$.

Pholadomya kingii Meek, 1873, An. Rep. U. S. Geol. Sur. Terr. for 1872, p. 473.

Shell elongate-oblong in marginal outline, excluding the elerated umbones, moderateiy inflated, laterally constricted behind and slightly gaping; basal margin broadly convex or slightly flattened a little in front of its mid-length; front and posterior margins both regulariy rounded; dorsal margin nearly straight, but the dorsum appears to be strongly concave because of the conspicuous elevation of the umbones; beaks incurved, approximate, and situated very near the front. Surface of each valve, except a short space at the front and the whole postero-dorsal space, marked by twelve or fourteen slender radiating costæ of the usual character, the first one being vertical, and the others successively increasing in obliquity of direction to the last, which ends at the posterobasal margin.

Length, 46 millimeters; height from base to dersal margin, not in- 
cluding the elevated umbones, 23 millimeters; thickness, both valres together, 23 milliméters.

Position and locality.-Jurassic strata near the Lower Cañon of the Yellowstone river, Montana, where it was collected, together with other Jurassic fossils, by Dr. A. C. Peale.

\title{
Genus GONIOMYA Agassiz. \\ Goniomya montanaensis Meek. \\ Plate 37, fig. 8 a.
}

Goniomya montanaensis Meek, 1873, An. Rep. U. S. Geol. Sur. Terr. for 1872, p. 473.

The type specimen of this species, which is the only one discovered, is imperfect, and its full form is not shown; by means, however, of the figure on plate 37, and the following description by Mr. Meek, it may be readily recognized: "Shell elongate-oblong, moderately convex; anterior margin regularly rounded; posterior truncated; dorsal and ventral margins nearly parallel; beaks depressed and placed near the anterior end. Surface having wrinkles or costæ starting from before the beaks and passing obliquely backward and near half way to the base, where they die out or become very obscure, and curve horizontally backward to meet others passing down to the posterior dorsal slopes."

Length, about 47 millimeters; height from base to umbo, about 24 millimeters.

Position and locality.-Jurassic strata near the Lower Cañon of Yellowstone River, Montana, where it was collected, with other Jurassic fossils, by Dr. A. C. Peale.

\section{Genus MYACITES (Schlotheim) Munster.}

\author{
MyaCITES sUBCOMPREssus Meek. \\ Plate 38 , figs. $5 \dot{a}, b, c, d$, and $e$.
}

Myacites (Pleuromya) subcompressa Meek, 1873, An. Rep. U. S. Geol. Sur. Terr. for 1872, p. 472.

Myacites (Pleuromya) subcompressa Meek, 1877, U. S. Geol. Sur. 40th Parallel, vol iv, p. 136.

The collection of specimens of this species, made by parties connected with this survey, show it to be a more variable one than would appear from Meek's original full description of it in the second volume above cited. A selection of the principal varieties of form have therefore been illustrated on plate 38, and Mr. Meek's description is here repeated. Fig. $5 e$ is that of a form which may perhaps prove to be a different spe. cies, but it is at present regarded as only a variety of $M$. subcompressus. It is not associated with any of the other specimens of $M$. subcompressus: figured on that plate, but comes from Devil's Slide, Cinnabar Mountain, Montana. "Shell of medium size, oblong-subovate, moderately convex, the greatest convexity being nearest and above the middle of the anterior end; valves nearly closed, or but slightly gaping behind; posterior margin somewhat abruptly cuneate, rounded in outline, though slightly prominent below the middle; basal margin with a moderately convex outline, rounding up more gradually behind than in front; anterior end short, subtruncated; dorsal margin rather short, rounding off gradually into the posterior margin; beaks gibbous, but somewhat 
flattened on the outer side, rather prominent, and located about half way between the middle and the anterior end; anterior umbonal slopes prominently rounded, or forming a rounded undefined ridge, which descends nearly vertically from the anterior side of each beak to the antero-basal margin; the sides behind this ridge being a little flattened, or possibly sometimes slightly concave below. Surface marked by small, rather regular, but not strongly defined, concentrie ridges that become nearly obsolete on the posterior dorsal region and near the front.

"Length, 1.27 inches; height, 0.92 inch; convexity, 0.66 inch.

"This shell closely resembles some varieties of Pleuromya ferruginea and $P$. impressa Agassiz, but has the anterior end shorter and more truncated, the concentric ridges of less regularity, and the concavity extending from the beaks to the anterior basal margins of the valves either entirely wanting or very feebly marked."

Fosition and locality.-This species has a wide geographical range in the Rocky Mountain region, it having been recognized in Jurassic strata of Colorado, Utah, Wyoming, Dakota, Montana, and Idaho. The specimens figured by Meek came from Utah, while those figured on plate 38 are from Montana, mostly from near the Lower Cañon of Yellowstone River.

\section{Genus LYOSOMA White.}

\section{Etym: $\Lambda v \omega$, to loosen, and $\sigma \tilde{\omega} \mu a$, the body.}

Shell resembling certain forms of Neritina and Nerita in general aspect; volutions few, the last one much expanded; outer lip moderately thin; inner lip not thickened and apparently without any callus; the portion of the body, exclusive of the last volution, very small and without a proper columella. Both of the only two species yet known have a slight flattening or lessening of the convexity of both the upper and outer sides of the last volution; the upper side having a more or less distinct but shallow revolving depression along its middle portion.

The only two species which are yet assigned to this genus are the Neritina? phaseolaris and Neritina?? powelli of White, both of which are from the Jurassic strata of Utah. The family relations of this genus are doubtful, but they are probably with the Velutinidce. They are apparently both marine forms; but in view of the fact that sereral species of fresh-water mollusca have been found in the Jurassic strata of Western North America, it is proper to state that the forms here under discussion have considerable similarity to Pompholyx Lea, a fresh water genus.

Lyosoma phaseolaris was described and figured in vol. ir, Expl. \& Sur. West of the 100 th Merid., p. 167, pl. xiii, figs $1 a, b, c, d$, and $e$, published in 1876. At that time I had not fully determined the character of the inner lip, but I have since become satisfied that it has no such thickening as eharacterizes the Neritida. L. powelli was described in Powell's Report on the Geology of the Uinta Mountains, page 110; and although I then ascertained beyond doubt that no thickening of the inner lip exists upon any of the specimens that had been collected up to that time, I hesitated then to do more than suggest for that form provisionally the generic name Lyosoma. This hesitation was caused by the publication of Binkhorst's discovery that the callus of the inner lip of certain fossil species of Nerita has been dissolved away during the condition of its fossilization, leaving the substance of all the remainder of the shell 
intact, and appearing as if it had never borne a callus. I am now convinced, however, from the character of the shells and also of the imbedding matrix, that they never had any such thickening of the inner lip as characterizes the Neritidoe.

\section{LYOSOMA POWELLI White.}

Plate 38, figs. $6 a, b, c$, and $d$.

Neritina?? powelli White, 1876, Powell's Rep. Geol. Uinta Mts., p. 110.

Shell obliquely subovate in outline by apertural view; volutions about three or three and a half, rapidly increasing, in size, the last one much expanded; spire depressed, the apex scarcely appearing by side view of the shell; suture slightly impressed; aperture large, broadly subcircular or obscurely subtetrahedral; a shallow revolving depression marks the median portion of the upper side of the outer volution, and between it and the suture there is a corresponding revolving convexity. Another revolving prominence outside of the depression gives the volution a good degree of obtuse angularity there.

Surface marked by ordinary lines of growth and also by somewhat prominent folds parallel with them, the folds being stronger upon the revolving prominences than elsewhere and especially upon the outer one, below which they are obsolete or absent.

Greatest diameter of the largest example, 28 millimeters; breadth of the same, 20 millimeters; height, the aperture resting upon the table, 15 millimeters.

Position and locality.-_Jurassic strata, mouth of Thistle Creek, Spanish Fork Cañon, Utah, where it was collected by Prof. J. W. Powell. 




\section{PLATE 37.}

Fig. 1. Gervillia montanaensis

a. Right valve; large example; natural size.

b. Left valve of a smaller example.

Frg. 2. Volsella subimbricata

a. Left valve of one of Mr. Meek's types; natural size.

$b$. Left side view of a smaller example from Northwestern Colorado.

c. Dorsal view of the same.

Fig. 3. Volsella (Modiolina) platynota

a. Side view of a natural cast of the right valve; natural size.

$b$. Outline of transverse section, showing the great convexity of the valves at about midlength.

Fig. 4. AviculopecteN SUPERSTRICTUS

a. Left valve; natural size.

$b$. Outline, showing convexity of the same.

Fig. 5. Camptonectes platessiformis

a. Left valve; natural size.

Fig. 6. Astarte Packardi

a. Left valve; natural size.

$b$. Outline, showing convexity of the valves.

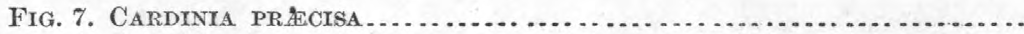

a. Right side view; natural size.

$b$. Dorsal view of the same.

Fig. 8. Goniomya montanaensis

a. View of Mr. Meek's type specimen; natural size.

Fig. 9. Mytilus whitei

a. Left valve; aceidentally somewhat compressed; natural size. 
JURASSIC.

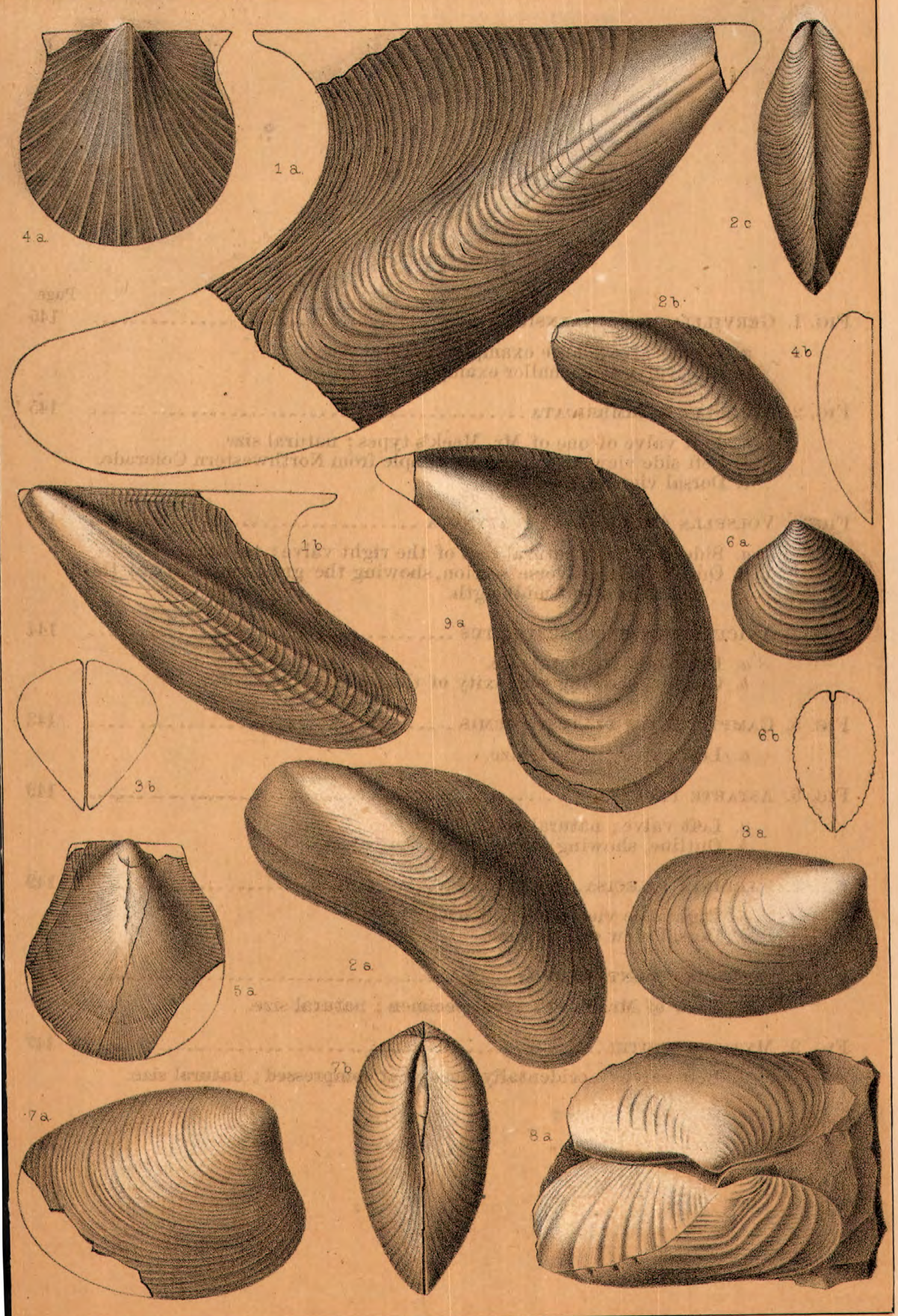

J.C.Me Connell del. 


Fig. 1. TrigonIA AMERICANA

a. Right valve; natural size.

b. Left valve.

Fig. 2. Trigonia montanaEnsis

a. Right valve; natural size.

Fig. 3. Pholadomya kingir

a. Right side view; natural size.

b. Dorsal view of the same.

Fig. 4. TANCREDIA EXtensa

a. Left side view of a natural east in sandstone; natural size.

Fig. 5. Myacites subcompressus.

a. Right side view of a short form, like Mr. Meek's figured type; natural size.

b. Left side view of another similar example.

$c$. Right side view of a more elongate example.

d. Dorsal view of the same.

e. Left side view of another example, from another locality; probably a variety of the same species.

EIG. 6. LyOSOMA POWELLI

a. Apertural view of a large example; natural size.

b. Outer view of the same.

c. Similar view of another example.

d. Apical view of the same. 

CONTRIBUTIONS TO INVERTEBRATE PALEONTOLOGY NO. 8 : FOSSILS FROM THE CARBONIFEROUS ROCKS OF THE INTERIOR STATES.

\author{
BY C. A. White, M. D.
}

The fossils which form the subject of this article have been collected by different persons, and at various localities, from both the lower and upper Carboniferous rocks. A part of them were collected by Prof. G. C. Broadhead, late State geologist of Missouri, at different localities in that State, and the type specimens belong to his private cabinet. A part belong to the private cabinet of Mr. William Gurley, and were collected by him at different localities in Illinois and Indiana; a part to Mr. Charles Wachsmuth, of Burlington, Iowa; and the remainder were collected by myself in Iowa.

A large proportion of all these species are new, and none of them except Lithostiotion mamillare have before been illustrated. A part of them, however, were described by myself at different times in the Proceedings of the Academy of Natural Sciences of Philadelphia, and of the Boston Society of Natural History.

The close relationship of the Carboniferous fauna of the Interior States with that of the western portion of the national domain makes a full knowledge of the former desirable in the investigation of the latter. Therefore, the illustration of these species is regarded as properly pertaining to the elucidation of the geology of the Western Territories.

\title{
RADIATA. ACTINARIA. \\ Genus ZAPHRENTIS Rafinesque.
}

\section{ZAPHRENTIS ELLIPTICA White.}

Plate 39, figs. $4 a$ and $b$.

Zaphrentis elliptica White, 1862, Proc. Bost. Soc. Nat. Hist., vol. ix, p. 31.

Corallum rather small, gently curved, laterally compressed, more so below the middle than near the calyx; sometimes this compression is slight, but sometimes so great as to produce a distinct carina along the lower portion of the outer curve; calyx moderately deep, its margin subcircular or sometimes subelliptical; septal fossett moderately large, situated upon the concave side of the corallum; rays well developed, numbering at the margin from thirty-two to forty. Surface marked by the usual lines of growth, but seldom by such distinct wrinkles as often mark species of this genus.

Length, 21 millimeters; diameter of calyx, 14 millimeters. 
This form is characterized by the lateral compression of the lower portion of the corallum, a feature not possessed by any other Zaphrentis so far as I am aware.

Position and locality.-Burlington limestone division of the Subearboniferous series, Burlington, Iowa, its position being at the base of that division, in strata which contain several invertebrate species which are common to the Kinderhook strata beneath.

\section{ZAPHRENTIS CALCEOLA White \& Whitfield.}

Plate 39, figs. $6 a, b, c$, and $d$.

Lophophyllum calceola White \& Whitfield, 1862, Proc. Bost. Soc. Nat. Hist., vol. viii, p. 305.

Corallum small, subturbinate, more or less curved, moderately but irregularly expanding from the base or apex upward, flattened on the outer side of the curvature, especially at the lower portion, but elsewhere somewhat regularly rounded; apex small, pointed; exterior surface rugose from unequal growth; calyx moderately deep; fossett situated subcentrally, but extending towards the side of the convex curve of the corallum; principal rays about thirty; secondary rays about equal in number with the principal ones. but they are usually very small and inconspicuous.

Extreme length of an average example, 18 millimeters; diameter of calyx, about 9 millimeters.

The flattening of the corallum mpon the outer surfare is more conspicuous upon some examples than upon others, but is always sufficient to serve as a ready means of recognizing the species. When the original description of this species was written it was referred to Lophophyllum, but more careful examination of other and more perfect examples shows that it does not possess the characteristics of that genus.

Position and locality. - The original type specimens of this species were obtained from the very base of the Burlington limestone division of the Subcarboniferous series, where it is associated with the preceding species, and where also it is found to range down into the underlying strata of the Kinder hook division. It is also among the collections sent to the United Statess National Museum by Professor Broadhead, who obtained it from the top of the Choutean limestone (Kinderhook division of the Subcarboniferous) at Sedalia, Mo. (See remarks following description of Lithostiotion microstylum, on a sulosequent page.)

\section{Genus HADROPHYLLUM Edwards \& Haime.}

\section{HADROPHYLLUM GLANS White.}

Plate 39, figs. $5 a$ and $b$.

Zaphrentis glans White, 1862, Proc. Bost. Soc. Nat. Hist., vol. ix, p. 32.

Corallum small, general form depressed-subglobose; apex small, prominent; calyx nerer distinctly concave, but often convex, with a receding but distinct margin, which is short-oval in outline and very oblique to the axis of the corallum; septal fossett moderately large but not deep, ranging with the long diameter of the calyx, its outer end reaching nearly to the distal calycular border; rays well developed, the principal ones being from thirty to forty in number, besides numerous rudimentary rays alternating with the lormer. 
Extreme length of an average-sized example, 17 millimeters ; long diameter of the calyx, 14 millimeters; short diameter of the same, $12 \frac{1}{2}$ millimeters.

Position and locality.-This speries is quite a common one in the upper portion of the Burlington limestone division of the Subcarboniferous series at and in the vicinity of Burlington, Iowa.

\section{Genus LOPHOPHYLLUM Edwards \& Haime.}

\section{LOPHOPHYLLUM EXPANSUM White.}

Plate 39, figs. $4 a$ and $b$.

Lophophyllum expansum White, 1876, Proc. Acad. Nat. Sci. Philad., p. 27.

Corallum broadly conical, slightly curved, transverse section subcircular; calyx broad, not deep; rays numerous; septal fossett not very distinct, situated at the convex side of the corallum; columella prominent but not large, laterally flattened so as to form a more or less sharp edge along its crest. Surface more or less rugose.

Height of corallum and diameter of its calyx each about 20 millimeters.

This species is proportionally much broader than $L$. proliferum McChesney sp. of the Coal Measures, but not much more so than the typical forms of Lophophyllum. It has somewhat the aspect of certain forms of Axophyllum, but as its internal structure is not yet fully known, it is referred to Lophophyllum because of its apparent external characters.

Position and locality.-Keokuk limestone division of the Subcarboniferous series, Henry County; Iowa.

\section{Genus CHONOPHYLLUM Edwards \& Haime.}

\section{Chonophyllum SEDALIENSE (sp. nov.):}

Plate 39, fig. 1 a.

Corallum moderately large, approximately straight, the angle of divergence of its sides being quite small; calyx apparently rather shallow; rays numerous; surface rough by the presence of numerous projecting successive calyx-borders, and by coarse, irregular longitudinal striæ. Only one example has been obtained, and that has been broken off at the lower end, and also somewhat crushed. Its full length was probably about 130 millimeters, and the diameter of the calyx about 30 millimeters.

Position and locality.-Near the top of the Choutean limestone (Kinderhook division of the Subearboniferous series), Sedalia, Mo.. where it was obtained by Prof. G. C. Broadhead. See remarks on this coralhorizon following description of Lithostiotion microstylum, on a subsequent page.

\section{Genus MICHILINIA de Koninek.}

MichiLINIA ? Placenta (sp. nov.).

Plate 39, figs. $1 a, b, c$, and $d$.

Corallum depressed or flattened, broadly convex above, flat or slightly concave below, free, or attached only in the young condition; corallites moderately large, subequal in size, nearly regularly hexagonal; calyces 
shallow, the bottom of each being slightly convex; the whole surface of the calyx coarsely granulate; rays numerous but slightly developed, consisting only of granular raised radiating strix, apparently existing only upon the sides of the shallow calyx and not upon its rather broad bottom; transverse plates or tabulæ few, and all of them appear to have extended all the way across the corallite. Under surface of the corallum covered with a distinct epitheca, and marked by strong concentric wrinkles. The largest example collected contains about forty corallites, and the smallest nineteen. Diameter of the larger calyces of the former about 12 millimeters; of the latter about 9 millimeters.

This species is known only by silicified examples, which do not show very clearly the details of internal structure, and it is probable that it does not strictly belong to the genus Michilinia; but I am not acquainted with any published genus to which it can be more satisfactorily referred. The tabulæ are few, and they seem to extend all the way across the corallites in all cases, without a tendency to form vescicles in the central space, as is common in the genus Michilinia. The communicating pores are numerous, as indicated by the silicious casts of the spaces between the tabulæ. It is probably congeneric with the Favosites divergens of White \& Whitfield, and it seems also to be congeneric with the next described species, all three of which belong to the same geological borizon. Remarks upon this interesting coral horizon are made in connection with the description of Lithostrotion microstylum, on a following page.

Position and locality.-Top of the Chouteau limestone (Kinderhook division of the Subcarboniferous series) at Sedalia, Mo. where it was obtained by Prof: G. C. Broadhead.

\section{MTOHILINIA EXPANSA (sp. nov.)}

Plate 39, figs. $2 a$ and $b$.

Corallum forming broadly expanded masses, which are less symmetrical than those of the last described species; upper surface irregular, but flattened; under surface unknown; corallites moderately large, more or less irregular in shape in consequence of some inequality in size; calyces averaging 8 or 9 millimeters in diameter, moderately deep; rays numerous, but not prominent; walls well developed; tabulæ having the usual character of those of this genus.

This species, like the last described, is known only by silicified specimens, all of which are more imperfect than those of the last described form. The walls appear to be unusually thick for a Michilinia, but this is probably due to their silicified condition. This condition has also obscured the radiate markings of the calyces, and also rendered the tabulæ somewhat obscure. It differs from the last deseribed species, with which it is associated, in the greater irregularity of the corallum and of the corallites, in the greater depth of the calyces and the less granular character of the calycular surfaces. The largest example discovered measures more than a hundred millimeters across the top of the corallum.

Position and locality.-Top of the Choutean limestone (Kinderhook division of the Subcarboniferous series), Sedalia, Mo., where it was obtained by Professor Broadhead, and where it is associated with several other coral species. See remarks following description of the next species. 


\title{
Genus LITHOSTROTION Fleming.
}

LITHOSTROTION MICROSTYLUM. (sp. nov.).

\author{
Plate 40, fig. 7 a.
}

Among the fossils obtained by Professor Broadhead from the top of the Chouteau limestone, a member of the Kinderhook division of the Subcarboniferous series, at Sedalia, Mo., are five species of corals, four of which are new. Four of them have just been herein described, and the remaining one is here noticed. Only one example of this species was obtained, which is silicified, and otherwise too imperfect for complete description, but it evidently belongs to the genus Lithostrotion, and is evidently a new form. The corallum is ten or twelve centimeters across the top, and in general aspect and in size and shallowness of the corallites resembles examples of the well-known Devonian coral Acervularia davidsoni. The calyces have, howerer, in the bottom of the small central pit, a very small prominent columella. The example is too imperfect for a full specific description, but it is found to differ materially from any other species of Lithostrotion with which it is in any danger of being confounded in the flatness or shallowness of the calyces, the smallness of the central pit, and of the columella.

Corals have hitherto been frequently met with in the Burfington, Keokuk, and Saint Louis divisions of the Subcarboniferous series of the Mississippi Valley, but with the exception of Lithostrotion mamillare, which is in some places plentiful, and found only in the Saint Louis division, they have been confined mainly to the Zaphrentidæ. In the upper and lower members of the Subcarboniferous series, however, namely in the Kinderhook and Chester divisions, Actinoid corals of any kind have hitherto been rarely found. The discovery, therefore, of four new forms in the Kinderhook division is a matter of much interest. This interest is also increased by the fact that they are all of types which are unusual in at least American Carboniferous strata; and although there is no a priori reason why the presence of these types might not be expected in Carboniferous strata, according to our present knowledge such a group of corals is not without a certain Devonian facies. It is also an interesting fact that these corals occupy a very narrow horizon at the top of the Kinderhook division, just beneath the Burlington limestone, and that in all the remainder of the Kinderhook division corals are rare, if not altogether absent. This coral horizon seems to be a wellmarked one; and from the fact that the only corals which have ret been found in that division in Iowa and Illinois occupy an exactly similar horizon with that here referred to in Missouri, it will probably prove to be one of considerable geographical extent. Up to this time the following ten species of corals have been found in that horizon in Missouri, Iowa, and Illinois : Zaphrentis calceola and Z. acuta White \& Whitfield; Z. elliptica White; Chonophyllum sedaliense n. s.; Syringopora harveyi White; Favosites (Michilinia?) divergens White \& Whittield; Michilinia placenta n. s.; M. expansa n. s.; Lepidopora typa Winchell; and Lithostrotion microstylum n. s.

Lithostrótion mamillare Castelnau.

Plate 40, figs. $6 a$ and $b$.

An example of this well-known coral from the Saint Louis division of the Sub arboniferous series in Monroe County, Indiana, contains three 
or four double corallites. In each of the double calyces there are two columellæ, from which the rays diverge as usual, the border of the calyx being elongate or suboblong, and having only a slight coustriction at the middle to indicate its double character. Upon the calycular side of the corallum these double corallites appear to have been cases of spontaneous fission, and they possibly were such; but the under side of the example (which contains about 60 millimeters length of the distal portion of the corallites and not the earliest or basal portions) shows them to have possessed the same general character at that stage of their growth which they do at their termination. In other words, they seem to have made no progress in separation into two distinct corallites while they were growing 60 millimeters in length. Figs. $6 a$ and $6 b$ show the upper and under sides, respectively, of that portion of the example in question which contains the three double corallites.

\section{ECHINODERMATA.}

\section{Genus PLATYCRINUS Miller.}

\section{Platycrinus bonoensis White.}

Plate 40, fig. $5 a$.

Platyorinus bonoensis White, 1878, Proc. Acad. Nat. Sci. Philad., p. 30.

Borly of the ordinary cup-shape, moderately deep; base shallow basinshaped, concave at the middle of the under side, or appearing to be so in consequence of the presence of a moderately broad and strong circular ridge which surrounds the central portion of the base, but which does not extend outward quite to the borders of the base. First radial pieces about as long as wide, having the shape and characteristics of outline usual in cup-shaped bodies of this genus, scarcely more convex than the general convexity of the body; facet for the articulation of the second radial pieces shallow; second radial pieces very small, and transversely subrhombic in outline. Upon the second radial pieces the rays divide into two secondary rays, the first piece of each secondary ray artic ulating upon the second radial, but also abutting in part upon the upjer border of the first radial. The secondary rays consist of two pieces each, upon the upper one of which they again divide, the outer arms of each division from that point upward continuing simple to the end, while the two minor subdivisions of the ray again divide into two arms each upon the second piece above the first division, beyond which all the arms of the whole ray, six in number, are simple, making thirty arms for the whole body. The arms are moderately slender, comparatively short, and for the first two or three pieces above the last bifurcation they consist of single wedge-shaped pieces. The only examples yet discovered have their arms so closely folded together that the pinnules are hidden from view. With the arms thus folded the whole animal had an obovate form. The stem, near the body, is moderately strong and slightly elliptical in outline of transverse section; surface nearly smooth, or faintly corrugated; the part of the body above the calyx and within the arms unknown.

Height of calyx to the top of the first radial pieces, 8 millimeters; greatest breadth of the same, 10 millimeters; height from the base of the calyx to the top of the arms, 26 millimeters.

This species resembles $P$. aequalis Hall, as figured by Meek \& Worthen 
in rol. $\nabla$, Illinois Geological Reports ; but it differs from that species in having the base of the caly $x$ concave instead of protuberant, in the proportions of the calyx, the comparative shortness of the arms, and in wanting the peculiar geniculation of the pieces of the double series composing the arms of that species. It resembles P. lcevis Miller, as figured by de Koninck \& Le Hon on plate vi, Recherches sur les Crinoides du Terraine Carbonifère de la Belgique, but it differs in having only two instead of three primary radial pieces to each ray, and also in other details of structure.

Position and locality.-Subcarboniferous strata; probably equivalent with those of the Keokuk division, Bono, Lawrence County, Ind.

\section{Genus SCAPHIOCRINUS Hall.}

\section{SCAPHIOCRINUS GIBSONI White.}

Plate 40, fig. $4 a$.

Scaphiocrinus gibsoni White, 1878, Proc. Acad. Nat. Sci. Philad., p. 31.

Body small or not above medium size for a species of this genus; calyx roughly cup-shaped, the pieces composing it moderately thick and protuberant, especially the first radial, subradial, and first anal pieces ; base small, nearly or quite covered by the first joint of the column; subradial pieces comparatively large, tumid; first radial pieces broader, but scarcely larger than the subradials; sutures between the pieces of the calyx impressed, especially at the points where the angles meet, and where there are pit-like depressions, which increase the tumid appearance of the pieces and give the calyx a somewhat shriveled aspect; anal spare comparatively large. The postero-lateral rays consist of three pieces, including the first radials, and upon each of the third radials the first bifurcation of the ray takes place, and above this the posterior secondary division of the ray only bifurcates, this third bifurcation taking place on the eighth piece above the second bifurcation, giving five simple arms for each of the postero-lateral rays beyond all the bifurcations. All the pieces of the rays, including those of both the primary and subordinate divisions, have a tendency to become angular upon the back, especially at the upper side of each. This, together with the apparent corrugation of the calyx and the zigzag articulation of the joints of the arms near their upper ends, gives the whole specimen a good degree of asperity of aspect, which, however, the artist has not fully represented in the figure on plate 40. Pinnules strong and somewhat angular, one arising from each joint of the arms and subordinate divisions of the rays, upon alternate sides of the joints. The other rays are not fully known, but they apparently bifurcate in nearly the same manner as the posterolateral ones. Column moderately large, composed of irregularly alternating larger and smaller pieces. "Ihe whole surface of body, arms, and column minutely but distinctly granular, as seen under a lens:

Breadth of body, 7 millimeters; height of the same from base to top

of the first radial pieces, 4 millimeters; height from base of the calyx to the extremities of the arms, 35 millimeters.

This species resembles $S$. arqualis Hall, as figured in volume $\nabla$ of the Illinois Ceological Reports, more nearly than any other known to me, but it differs from that species in the much greater proportionate length of the arms, as well as their number and the manner of their bifurcation, besides the difference in the character of thesurface. A conspicuous dif$11 \mathrm{H}$ 
ference is also seen in the divisions of the rays, S. coqualis having eight arms by the ultimate division of each postero-lateral ray, while S. gibsoni has only five. In the former species also the joints of the upper part of the arms lack that zigzag arrangement which they have in the latter; and the general asperity of aspect of the latter is wanting in the former.

Position and locality.-Subcarboniferous strata, probably equivalent with those of the Keokuk division, Crawfordsville, Ind.

\title{
SCAPHIOCRINUS GURLEYI White.
}

Plate 40, fig. $3 a$.

Scaphiocrinus gurleyi White, 1878, Proc. Acad. Nat. Sci. Philad., p. 32.

Body of medium size, or somewhat less; calyx roughly cup-shaped; subradial, first anal, and first radial pieces prominent, the sutures being deeply impressed; base nearly eorered by the last joint of the column; subradial and first anal pieces as large as, or a little larger than, the first radials; the anterior and the two antero-lateral rays only are known. These rays consist of three pieces each, including the first radials, already mentioned as a part of the calyx, and upon the third ray the first bifurcation takes place, each secondary division being once more bifurcated at varying distances from the first. In the anterior ray the second bifurcation takes place upon the eleventh piece from the first. In the antero-lateral rays the second bifurcation takes place upon the ninth piece of the anterior branch of each of those rays above the first bifurcation; and upon the seventh piece in the case of the posterior branches of the same, rerespectively. Near the tips of some of the arms there is still another bifurcation, the division of which, being very small, may be easily overlooked or confounded with the coarse pinnules. The pinnules are large, long, angular, and alternately arranged upon each side of the arms; each piece of all the divisions of the arms above the first bifurcation of the rays bearing only one pinnule. The backs of all the divisions of the rays are rounded, and have little or no tendency to become angular, except perhaps toward the extremities of the arms. Column composed of irregularly alternating larger and smaller pieces. Surface finely granular.

Height of calyx, from base to top of the first radials, 3 millimeters; breadth of the same at the top of the first radials, 4 millimeters; height of the type specimen from the base to the extremities of the arms, 28 millimeters.

The calyx of this species closely resembles that of S. gibsoni, especially in the tumidity of the subradial and first anal pieces and in the character of the column, but it differs conspicuously from it in the number of arms and the character of their bifurcations, as well as in the surface markings and other details.

Position and locality.-Subcarboniferous strata, probably equivalent with those of the Keokuk division Crawfordsville, Ind.*

\section{Genus ACTINOCRINUS Miller.}

\section{ACTINOCRINUS WACHSMUTHI (sp. nov.).}

\author{
Plate 40, figs. $1 a$ and $b$.
}

Body rudely subturbinate below the arms, the sides expanding gradually and with slight convexity up to near the arm-bases, where there is a more abrupt expansion; base broader than high, rather deeply notched

* In the original description the locality was inadvertently given as Illinois insteac of Indiana. 
at the sutnres by the prominence of the middle portion of each basal piece; column-facet large; first radial pieces nearly equal in size with the basals, and, with that exception, they are the largest pieces in the body; second and third radials about equal to each other in size, and not more than half as large as the first radials; each third radial piece bearing two secondary rays consisting of two pieces each, both of which are smaller than the second and third radials; each second secondary radial piece bearing two brachial pieces, and each brachial piece giving origin to an arm, making twenty arms in all.* Arms long and slender, and above the first four or five brachial pieces, which are single, they are composed of a double series of minute pieces which meet along the median line of the arm, forming there a zigzag suture. Anal pieces eight or nine; the first one being of about the same size as the first radials; the next three pieces above are about half as large as the first, and above these the other pieces are quite small; interradial pieces three or four, the first one being somewhat larger than the second radials, and occupying about half the interradial space. Vault convex or subconical, more than half as high as the height of the body below the arms, composed of irregular pieces of moderate size, all of which are more or less sharply tumid in the middle, and ending at the summit in a long, strong proboseis, which is composed of similar sharply tumid pieces. All the body plates are strongly tumid, the lower ones bearing each a strong transverse projection.

The specific name is given in honor of Mr. Charles Wachs cuth, whose excellent labors among the Crinoidea are well known.

Position and locality. - Subcarboniferous strata probably equivalent with those of the Keokuk division, Crawfordsville, Ind., where it was obtained by Mr. William Gurley.

\title{
Genus LEPIDESTHES Meek \& Worthem.
}

\section{LEPIDESTHES COLLETTI White.}

\author{
Plate 40, figs. $2 a$ and $b$.
}

Lepidesthes colletti White, 1878, Proc. Acad. Nat. Sci. Philad., p. 33.

General form apparently ovate. Interambulacral areas very narrow, linear, slightly convex from side to side, composed of four or five row's of small pieces, which rows do not apparently decrease in number, except perhaps near each extremity. Ambulacral areas broad, partaking of the convexity of the body, lance-oval in outline, and five or six times as broad as the interambulacral areas are. Ambulacral areas made up of very numerous small rhombic pieces, the transverse diameter of which is a little greater than the vertical; their lateral angles moderately acute, and interlocking so that they appear to be arranged in oblique rows; size of the pieces nearly uniform throughout the field, except that they all become a little smaller near both the upper and lower extremities. The number of vertical rows of pieces in each field is apparently 18 or 20 . Each ambulacral piece has two distinct round pores near each other and near the upper angle of the piecê; but they are sometimes obscured by the overlapping of adjacent pieces. Surface granules small, more distinct upon the interambulacral than upon the ambulacral pieces.

Two examples of this species have been discovered, both of which are

* The example represented by fig. $1 b$ on plate 40 has an extra arm-base immediately ver the center of the anal space, and it also has an extra basal piece about one-third as large as each of the other three basal pieces. 
crushed and otherwise in a much damaged condition. The best example, which is represented by fig. $2 a$ on plate 40 , shows that the original height of the body was about 45 millimeters, and its transverse diameter probably considerably less.

The crushed condition of the specimens causes some doubt as to the true number of longitudinal rows of interambulacral pieces, but they evidently do not exceed five. There seems to be only four rows to each area, one row of comparatively large pieces, with two smaller rows upon the right-hand side of it, and one row on the left. This want of bilateral symmetry of the best preserved area in the example figured suggests the possibility that one row of smaller pieces on the left-hand side of the row of larger ones has been forced beneath the others by pressure, but a careful examination fails to demonstrate it.

This species is clearly distinguished from $L$. coreyi M. \& W., the only other known species of the genus, by the very much narrower interambulacral areas, the different and varying proportions of the pieces composing those areas, as well as some other important but less conspicuous differences.

Position and locality.-Subcarboniferous strata, probably equivalent with those of the Keokuk division, Salem, Washington County, Ind.

\title{
MOLLUSCA.
}

\section{(MOLLUSCOIDEA.)}

\section{BRACHIOPODA.}

\section{(Genus ORTHIS Dalman.)}

\section{ORTHIS THIEMEI White.}

\author{
Plate 41, figs. $4 a, b, c$, and $d$.
}

\section{Orthis thiemei White, 1860, Jour. Bost. Soc. Nat. Hist., vol. vii, p. 231.}

Shell depressed, orbicular, usually a little wider than long, widest in front of the middle; hinge line short. Dorsal valve deeper than the ventral valve, regularly convex, with the general exception of a very shallow median sinus which extends from front to about midlength of the shell where it becomes obsolete; beak projecting a little beyond the hinge line and slightly eurving towards the beak of the opposite valve; cardinal process strong, with a strong blunt-edged median septum extending from it nearly half the length of the valve; brachial processes strong, slightly notched at the ends; margin crenulate in front.

Ventral valve convex near the umbo, depressed in front, which, with the depression on the opposite valve, considerably flattens the front border; beak short, elevated and incurved, leaving but little space between the two beaks when both valves are in position; width and height of foramen about equal, nearly filled by the strong cardinal process of the dorsal valve; muscular eavity large, heart-shaped, with a more or less distinct forked septum occupying its middle.

Surface marked with fine raised striæ, which have occasional minute tubular openings upon them; the striæ increasing in number by implantation, and traversed by the ordinary striæ of growth and a few coarser imbricating lines.

Length from 10 to 14 millimeters. 
This shell is somewhat variable in the convexity of the dorsal valve, the distinctness of the dorsal sinus, and the strength of the cardinal and brachial processes.

Position and locality.-The upper portion of the Kinderhook division of the Subcarboniferous series at Burlington, Iowa. A closely similar form exists in the upper portion of the Burlington limestone, and another in the Keokuk division, but they are at present regarded as distinct.

\title{
Genus RHYNCHONELLA Fischer.
}

\section{BHYNCHONELLA OTRUMWA White.}

\author{
Plate 41 , figs. $5 a, b$, and $c$.
}

Rynchonella otturoma White, 1862, Proc. Bost. Soc. Nat. Hist., vol. ix, p. 23.

Shell rather small, variable in ontline from subtriangular to subovoid; valves nearly equally convex. Ventral valve regularly convex along the middle from beak to front, broadly convex across the middle from side to side; beak prominent, projecting backward and with an upward curve; the space beneath it a little flattened, which gives it somewhat the appearance of an ared; deltidial pieces occupying a rather large equilateral triangular space, with a moderately large, oval foramen. Dorsal valve broadly convex, umbo depressed. Surface marked by from nine to eleven somewhat angular plications on each valve, which are absent or: become obsolete on the posterior third of the shell; two of these plications occupy the mesial sinus of the ventral valve and three of them the mesial fold of the dorsal valve; the mesial sinus is deep, and forms a more conspicuous feature than the mesial fold. Young examples of this shell are nearly plain, but the plications on the older ones ane well marked.

Length from ventral beak to front, 12 millimeters; greatest breadth, which is in front of the middle, about the same.

Position and locality.-Saint Louis division of the Subcarboniferous series, Ottumwa, Iow and various other localities in Iowa, Illinois, and Missouri.

\section{Genus SPIRIFER Sowerby.}

\section{SPIRIFER SUBCARDHFORMTS Hall.}

Plate 41 , figs $2 a, b$, and $c_{0}$

Spirifer subcardîformis Hall, 1858, Iowa Geol. Rep., vol. i, part ii, p. 660 .

Shell subelliptical in marginal outline, a little wider than long; hin line shorter than the greatest width of the shell. Dorsal valve a little less convex than the ventral, its beak somewhat prominent and projecting beyond the hinge line; mesial fold rather broad in front, slightly elevated, marked by four plications which all coalesce at the beak; a very slight elevation appears in the bottom of the groove which separates the two middle plications of the fold, and the two grooves which separate the fold from the lateral portions of the valve are broader than any of the others; from seven to nine simple, rounded plications mark the space on each side of the fold, the inner ones being strong and the outer ones becoming obsolete. Ventral valve having its beak prominent, incurved, and projecting back further than that of the dorsal valve; mesial sinus broad, not deep, bearing three plications; from seven to 
ten plications on each side of the mesial sinus, which correspond in character with those upon the other valve; the postero-lateral portions of the valve rounded into the area, which is very short and its limits ill-defined; foramen moderately large, triangular, and nearly equilateral.

Length from ventral beak to front, 28 millimeters; greatest breadth, 32 millimeters; greatest thickness, both valves together, 18 millimeters.

This species was originally described from an imperfect example which was obtained from the Warsaw limestone near Alton, Ill. Antong a collection of fossils obtained by Mr. William Gurley, from equivalent strata at Spergen Hill, Ind., is a more perfect example, which has served as the basis for the description and illustrations herein given.

Position and locality.-Subcarboniferous strata, Warsaw division, Alton, Ill., and Spergen Hill, Monroe County, Indiana.

\title{
(MOLLUSCA VERA.)
}

\section{CONCHIFERA.}

\section{Genus ANTHRACOP'TERA Salter.}

\author{
ANTHRACOPTERA POLITA (sp. nOv.).
}

Plate 42, figs. $5 a$ and $b$.

Shell rather small, aviculoid, moderately gibbous, height greater than the breadth from front to rear; test thin; valves subequal; hinge margin short, straight, terminating posteriorly in a somewhat obtusely angular wing, but not extending in front of the beaks; basal and front margins forming a nearly regular curve from beneath the beaks to the postero-basal extremity, which is more narrowly rounded; between that extremity and the posterior angle of the wing the margin is slightly concave; umbo prominent, or having the appearance of being somewhat inflated; beak elevated a little above the hinge line; the ear is distinct, but no well-defined auricular groove separates it from the body of the shell in either valve. Surface having a smooth aspect, but it is marked by numerous fine lines of growth, which are plainly visible under a lens.

Height from base to hinge line, 20 millimeters; length from umbo to posterior basal extremity, 24 millimeters.

This shell seems evidently referable to Anthracoptera of Sulter, although nothing is known of the character of its hinge or of its interior markings. It differs too materially from any known species to need detailed comparison.

Position and locality._-Coal-measure strata, Major's Mill, Vermillion County, Ill., where it was discovered by Mr. William Gurley.

\section{Genus ASTRARTELLA Hall.}

\section{Astarterla GURLEYI White.}

Plate 42, figs. $6 a$ and $b$.

Astartella garleyi White, 1878, Proc. Acad. Nat. Sci. Philad., p. 35.

Shell small, not very gibbous, subtetrahedral in outline; anterior end truncated from the beaks obliquely downward and forward to about 
midheight of the shell, where the front is sharply rounded to the somewhat broadly rounded basal margin; posterior margin broadly convex or sometimes almost straight and perpendicular, and joining both the basal and dorsal margins by abrupt curves; dorsal margin compara tively short, nearly straight; beaks small; umbones not elevated nor very prominent. An indistinctly defined umbonal ridge extends from each of the umbones to the postero-basal margin, behind which ridge the shell is slightly compressed. Surface marked by concentric furrows, which are separated by sharp linear ridges.

Length of an average-sized example, 7 millimeters; height from baso to beaks, $4 \frac{1}{2}$ millimeters.

This species differs from A. vera Hall, from the same formation, in its smaller size, in the slight prominence and want of elevation of the umbones, the greater proportional projection of the front beyond the beaks, and in being wider behind than in front, the reverse being the case with A. vera.

Position and locality.-Coal-measure strata, Danville, Il., where it was obtained by Mr. William Gurley.

\section{Genus ALLORISMA King.}

\section{ALLORISMA MARIONENSIS White.}

Plate 41, figs. $3 a$ and $b$.

Allorisma marionensis White, 1876, Proc. Acad. Nat. Sci. Philad., p. 31.

Shell small, elongate, ventricose anteriorly, and laterally flattened behind, where it is usually a little broader from base to dorsal margin than the anterior portion is; umbones prominent, elevated; beaks incurved, placed far forward; dorsal margin straight or slightly concave; postero-dorsal margin sloping backward to the posterior extremity, the greatest prominence of which is at, or a little below, midheight of the adult shell; base broadly rounded or st raight ned about mid way, where the slight umbonal flattening of each valve meets it. Surface marked by the ordinary concentric lines and undulations of growth.

Length, 28 millimeters; height, 13 millimeters. A few examples have been obtained which are about one-third larger than that of which the dimensions are here giren, but it is an unusually small species.

Position and locality.-Saint Louis division of the Subcarboniferous series, Marion and Mahaska Counties, Iowa, where it sometimes occurs quite plentifully in both the calcareous and magnesian layers of that formation.

\section{GASTEROPODA.}

\section{Genus EUOMPHALUS Sowerby.}

\section{Euomphalus springValensis White.}

Plate 41, figs. $1 a$ and $b$.

Enomphalus springvalensis White, 1876, Proc. Acad. Nat. Sci. Philad., p. 32.

Shell rather large; spire much extended for a species of this genus; volutions six or seven, gradually increasing in size from the apex to the aperture; moderately flattened upon the distal or upper side, regularly 
and continuously rounded from that side all the way around to the contact with the next volution; aperture therefore nearly circular, its outline being modified only by the slight flattening of the distal side of the volutions and their short contact with each other.

Length, or height, about $5 \tilde{5}$ millimeters; breadth of coil of last volution, 70 millimeters; diameter of aperture, 23 millimeters.

Position and locality.-Kinderhook division of the Subcarboniferous series, Springvale, Humboldt County, Iowa.

\section{Genus PLATYCERAS Conrad.}

\section{Platyceras tribulosum (sp. nov.).}

Plate 41, figs. $b a$ and $b$.

Shell of medium size, very obliquely and rudely conical, curved but not coiled; apex free, slender, pointed, incurved, and turned a little to the left side; body expanded; aperture very irregular in marginal outline, expanded in front, narrower behind, and having a prominent double lobe beneath the umbonal portion of the shell. Surface marked by the ordinary lines of growth, and also by three longitudinal rows of hollow spines arranged upon the dorsal aspect of the shell, the rows extending back more than half the length of the shell and containing five or six spines each.

Length of the shell from beak to front margin, 28 millimeters; breadth of its aperture, 21 millimeters.

This species is especially characterized by its spines, arranged in three rows, and the irregular character of its margin. It differs too much from any described species to need detailed comparison, but it may be compared with the two spinous species, $P$. biserialis Hall, from the same formation, and $P$. dumosum Conrad, from the Devonian rocks of New York.

Position and locality.-Burlington limestone division of the Subcarboniferous series, Burlington, Iowa, where it was obtained by Mr. Charles Wachsmuth.

\section{Genus NATICOPSIS McCoy.}

NATICOPSIS MONILIFERA (sp. nov.).

Plate 42, figs. $3 a, b$, and $c$.

Shell small, subglobose; spire short, obtuse, and its immediate apex flattened; volutions about six, but the apical ones are very small, the last one constituting the greater part of the shell, broadest upon its basal or proximal portion, the proximal side of which is somewhat abruptly rounded inward to the aperture; the small volutions of the apex are plain, but uron the distal border of the two last ones, adjacent to the suture, there is a conspicuous row of small nodes, constituting a pretty ornamentation of the shell; the remainder of the surface is smooth and has a polished aspect, upon which a good lens reveals fine striæ of growth; aperture suboval in outline; inner lip having a distinct callus, especially in front; outer lip thin, its border sinuate, having an almost distinct noteh just in front of the row of nodes.

Extreme length, 10 millimeters; extreme diameter of the last volution nearly the same.

Position and locality.-Upper Coal Measures, Pleasant Hill, Cass County Mo., where it was obtained by Prof. G. C. Broadhead. 


\title{
Genus PLEUROTOMARIA Defrance
}

\section{Pleurotomaria broadheadi (sp. nov.).}

\author{
Plate 42, figs. $1 a$ and $b$.
}

Shell large, narrowly umbilicated; spire somewhat extended, its length not quite half the full length of the shell; volutions about seven, strongly convex from suture to suture, gradually increasing in size; last volution large, somewhat produced on its proximal side, especially near the aperture, and abruptly rounded in to the umbilicus, but otherwise regularly convex; aperture subovate in outline, angular at its proximal end, straight upon its inner side; the straight inner lip thin, its edge ranging in line with the axis of the shell, so curved laterally as to give continuity to the narrow umbilicus almost to the proximal extremity of the last volution; outer lip sinuous, its notch small and shallow, situated at about the middle of the prominent convexity of the lip ; revolving band narrow and somewhat obscure. Surface marked by numerons slightly impressed revolving lines, which are more distinct upon the proximal than upon the distal side of the spiral band, and still more distinct within and upon the borders of the umbilicus; spaces between the depressed lines narrow, plain, and somewhat unequal in width.

Full length, 88 millimeters; length of aperture, 50 millimeters; breadth of the same, 49 millimeters; full diameter of the last volution, including aperture, 75 millimeters.

This large, fine shell differs too materially from any of the numerous forms of Pleurotomaria that have been obtained from the Carboniferous strata to need detailed eomparison.

Position and locality.-Coal Measure limestone, Kansas City, Mo., where it was obtained by Prof. G. C. Broadhead, and in whose honor the specific name is given.

\section{Pleurotomaria newPortensis (sp. not.).}

Plate 42, figs. $2 a$ and $b$.

Shell of medium size; spire moderately short, less in height than the vertical diameter of the aperture; volutions about five, regularly and prominently convex from suture to suture, gradually increasing in size; the last volution continuously rounded from the suture to the axial center; aperture subcircular in outline, its margin oblique; outer lip having a broad notch a little above its middle, at the bottom of which the spiral band ends; inner lip apparently thickened; spiral band consisting of an elevated, narrow, roughened ridge, which is either wholly or partly obscured upon the volutions of the spire by the subsequent volutions. Surface marked with numerous, somewhat irregular, raised revolving lines, the concave spaces between which are somewhat wider than the lines.

Extreme height of the shell, 39 millimeters; height of aperture, about 25 millimeters; transverse diameter about the same; extreme transverse diameter of the shell, 39 millimeters.

This shell resembles P. carbonaria Norwood \& Pratten, but it differs in having its revolving band simple and raised instead of concave, with revolving lines within it, as in that species; and also in having its aperture subcircular instead of nearly semicircular.

Position and locality.-Coal Measure strata, Newport, Ind., where it was obtained by Mr. William Gurley. 


\section{PTEROPODA.}

\section{Genus CONULARIA Miller.}

Conularia crustula (sp. nov.).

Plate 42, fig. $4 a$.

Shell rather small, having the usual four-sided pyramidal form; the four sides being equal, and flat or nearly so near the apex, but slightly convex towards the aperture; the four angles distinctly furrowed, and a slender furrow also marks the median line of each side, which furrow is more distinct upon the cast of the interior of the shell than upon the external surface of the test. Surface marked by the numerous transverse raised striæ common to this genus, which arch gently forward from each of the four angles; the majority of the striæ are continuous across the median line of the sides, and also across the angle-furrows, in crossing which they bend slightly backward.

Length, 31 millimeters; diameter of aperture, about 16 millimeters.

This shell is closely like several other known forms, but it possesses peculiar interest from the fact that it is the only. species known to me to occur in the Coal Measure strata of the Mississippi Valley, although several species are known in the Subcarboniferous strata of that region. It is, therefore, the most recent known American species, and adds to our knowledge another feature of close relationship between the faunæ of the upper and lower Carboniferous series.

Position and locality.-Coal Measure strata near Kansas City, where it was obtained by Professor Broadhead. Among some Carboniferous fossils trought'by Prof. E. D. Cope from near Taos, New Mexico, are a couple of fragments apparently of this species.

\section{CEPHALOPODA.}

\section{Genus NAUTILUS Breynius.}

\section{NaUtulus DaNVILLENSIS White.}

Plate 42, fig. 7 a.

Nautilus danvillensis White, 1878, Proc. Acad. Nat. Sci. Philad., p. 36.

Shell moderately large; umbilicus deep but not very broad, showing all the volutions, at least in large part; volutions apparently four, increasing rapidly in size, very slightly embracing, subtrihedral in cross-section, the two sides of the volution forming two sides of that outline, while the inner side of the volution forms its third principal side; sides of the volution plain, nearly flat or slightly convex; peripheral side very narrow, concave, and marked at either edge, where it joins the side, by a row of longitudinally compressed nodes. The sides are rounded abruptly into the umbilicus, which is unusually deepened by the transverse diameter of the volutions being greater at the inner side than elsewhere. Septa plain, somewhat deeply concave dorso-ventrally, but less so transversely; siphuncle subcentral, a little nearer to the peripheral than to the inner side. Surface smooth except the ordinary lines of growth and the two rows of dorsal nodes before referred to. Test thin. 
The only discovered specimens of this species being crushed or otherwise imperfect, it has not been practicable to illustrate it by any other figures than the transverse section given on plate 42, although the characters above given have been well ascertained. The exact form of the aperture, however, is not accurately known, but the lines of growth show the lateral margins to have been sigmoid or sinuous, and the peripheral margin concave. These lines also indicate that the aperture was oblique to the diameter of the plane of the shell, the peripheral portion retreating and the inner projecting.

Transverse diameter of a volution of less than full adult size from edge to edge of the umbilicus, 40 millimeters; width of its sides, 50 millimeters; breadth of peripheral side, 16 millimeters; the full diameter of the plane of the largest example discovered, about 130 millimeters.

The narrow concave periphery, with its two marginal rows of compressed nodes, and the plain, flattened sides of the volutions, which expand towards the umbilicus, are characters which distinguish this species from all others known to me.

Position and locality.-Coal Measure strata, Danville, Ill., where it was obtained by Mr. William Gurley.

\section{ARTICULATA. VERMES.}

\section{Genus SERPULA Linnæus.}

SERPULA INSITA White.

Plate 42, fig. $8 a$.

Serpula insita White, 1878, Proc. Acad. Nat. Sci. Philad., p. 37.

Scattered through an earthy, Carbonaceous layer of Coal Measure strata at Newport, Vermillion County, Ind., are abundant examples and fragments of a very small Serpula, which evidently burrowed in the mass when it was in the condition of mud. Also sessile upon some imbedded molluscan shells are found occasional nearly perfect examples of the same species. The species of the genus Serpula are so devoid of distinguishing characteristics that a specific diagnosis is often difficult or impossible. This species, however, is not likely to be mistaken for any other, because of its very small size, and because no other form has been recognized in the strata of that age in that region. It is here named, mainly, for the purpose of aiding in the classification of the rich fauna of the Carboniferous rocks. The species may be characterized as minute, sessile or free, tortuous, and subcylindrical. 


Fig. 1. Michilinia? placenta

a. Calycular view of a large example; natural size.

b. Lateral view of the same.

c. Calycular view of a small example; natural size.

$d$. Under side of tho same, showing the concentrically wrinkled epitheca.

Fig. 2. Mrchulnia expansa.

a. Calycular view of a small, imperfect, silicified example; natural size.

$b$ : Lateral view of the same.

Fig. 3. Chonophyllum sedaltense

a. Side view of a partially crushed and broken example; natural size.

Fig. 4. LOPHOPHYLLUM EXPANSUM

a. Side view of a type specimen; natural size.

$b$. Calycular view of the same.

The spots near the columella are accidental; and the figure does not show the full prominence of the columella.

Fig. 5. HADROPHYLLUM GLANS

a. Calycular view; natural size.

$b$. Lateral view of the same.

Fig. 6. Zaphrentis CALCEOLA

a. Lateral view of a specimen from Sedalia, Mo.; natural size; showing a minimum degree of flattening upon the lower portion of the convex side.

b. Calycular view of the same. The edge of the calyx of this specimen is constricted, giving it the appearance of being thickened. It is usually thin and sharp.

c. View of the convex side of another example, from Burlington, Iowa, showing a maximum degree of flattening of the lower portion of the convex side.

d. Calycular view of the same, showing the border of the usual character, except that its lower portion has been broken away.

Fig. 7. Zaphrentis Elliptica

$a$. Side view; natural size.

b. Calycular view of the same. 


a. Side view of a crushed example, showing the proboscis and a part of the arms; natural size.

$b$. Side view of the body of another example, only slightly distorted by pressure.

Fig. 2. LePIDESTHES COLletTI

a. Side view of a specimen somewhat smaller than the type; natural size.

b. Diagram of a single piece of the ambulacral series, with adjacent borders of others, showing the two pores; enlarged.

FIG. 3. SCAPHIOCRINUS GURLEYI.

$a$. Side view of the type specimen; natural size.

The black spots at the junction of the column with the body are accidental.

Fig. 4. SCAPHIOCRINUS GIBSONI

a. Side view of the type specimen; natural size. The slight zigzag arrangement of the smaller divisions of the arms is not distinctly shown in the figure, and it does not quite clearly represent the angular aspect of all the small pieces composing the arms.

Fig. 5. Platycrinus bonoensis

a. Side view of the type specimen; natural size.

Fig. 6. Lithostrotion mamillare

a. Calycular view of a portion of a large corallum, showing three double corallites.

b. Under view of the same, showing that portion of the same double corallites.

Fig. 7. Lithostrotion micnostylum ...............................

a. Calycular view of two or three corallites; natural size. The details are partially obscured by the bad state of preservation of the specimen. 



\section{PLATE 41.}

Fig. 1. EUOMPHALUS SPRINGVALENSIS

a. Lateral view of the type specimen; natural size; the outer portion of the spire being iniperfect by erosion.

$b$. Umbilical view of the same.

Fig. 2. SPIRIFER SUBCARDIIFORMIS

a. Ventral view of an example from Spergen Hill, Ind.; natural size.

$b$. Dorsal view of the same.

c. Lateral view of the same.

Frg. 3. Allorisma marionensis.

a. Lateral view; natural size.

b. Dorsal view of another example.

Fig. 4. ORTHIS THIEMEI

a. Ventral view of an example from Mr. Wachsmuth's collection; natural size.

b. Dorsal view of the same.

c. Lateral view of the same.

d. Interior view of the ventral valve of another example, showing the large muscular scar.

FIG. 5.. RHYNCHONELLA OTTUMWA

a. Ventral view; natural size.

$b$. Dorsal view of the same.

c. Lateral view of the same.

Fig. 6. Platyceras tribulosum

a. Dorsal view of the type specimen; from Mr. Wachsmuth's collection; natural size.

b. Lateral view of the same. 
SUBCARBONIFEROUS.

U.S.GEOLOGICAL SURVEY

PLATE 41
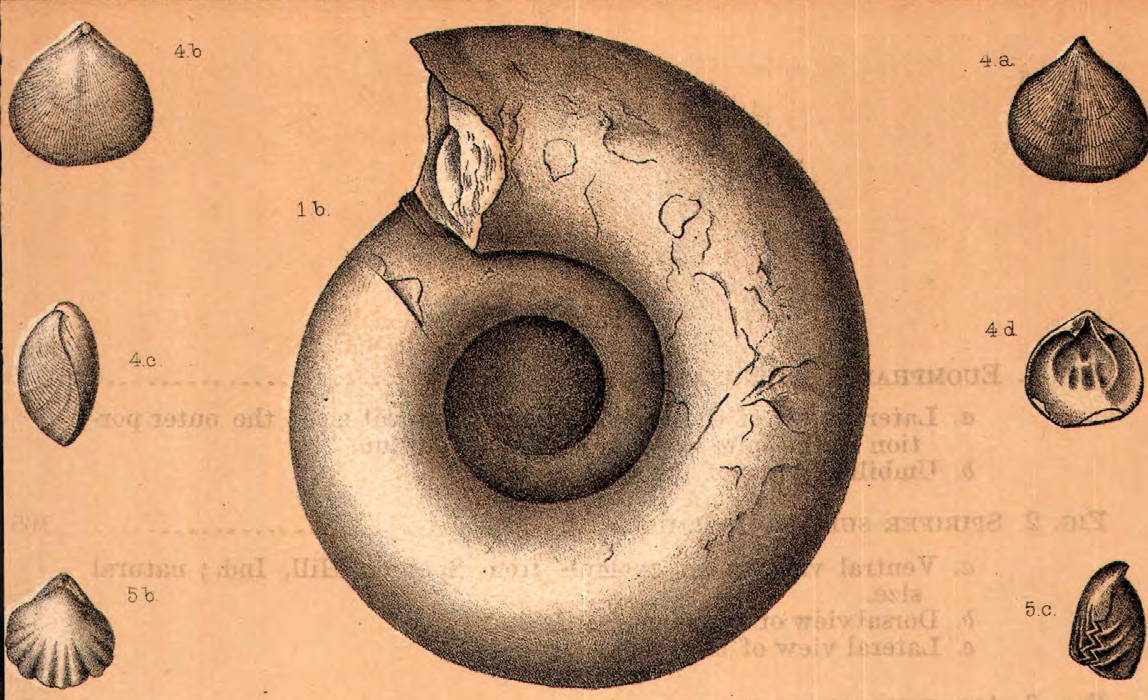

Q
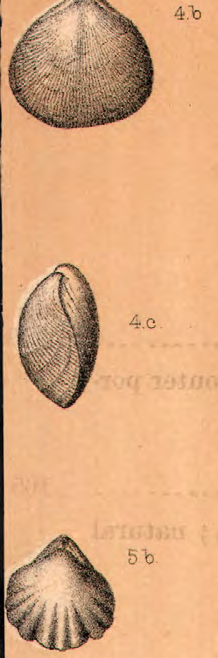

(2007 795
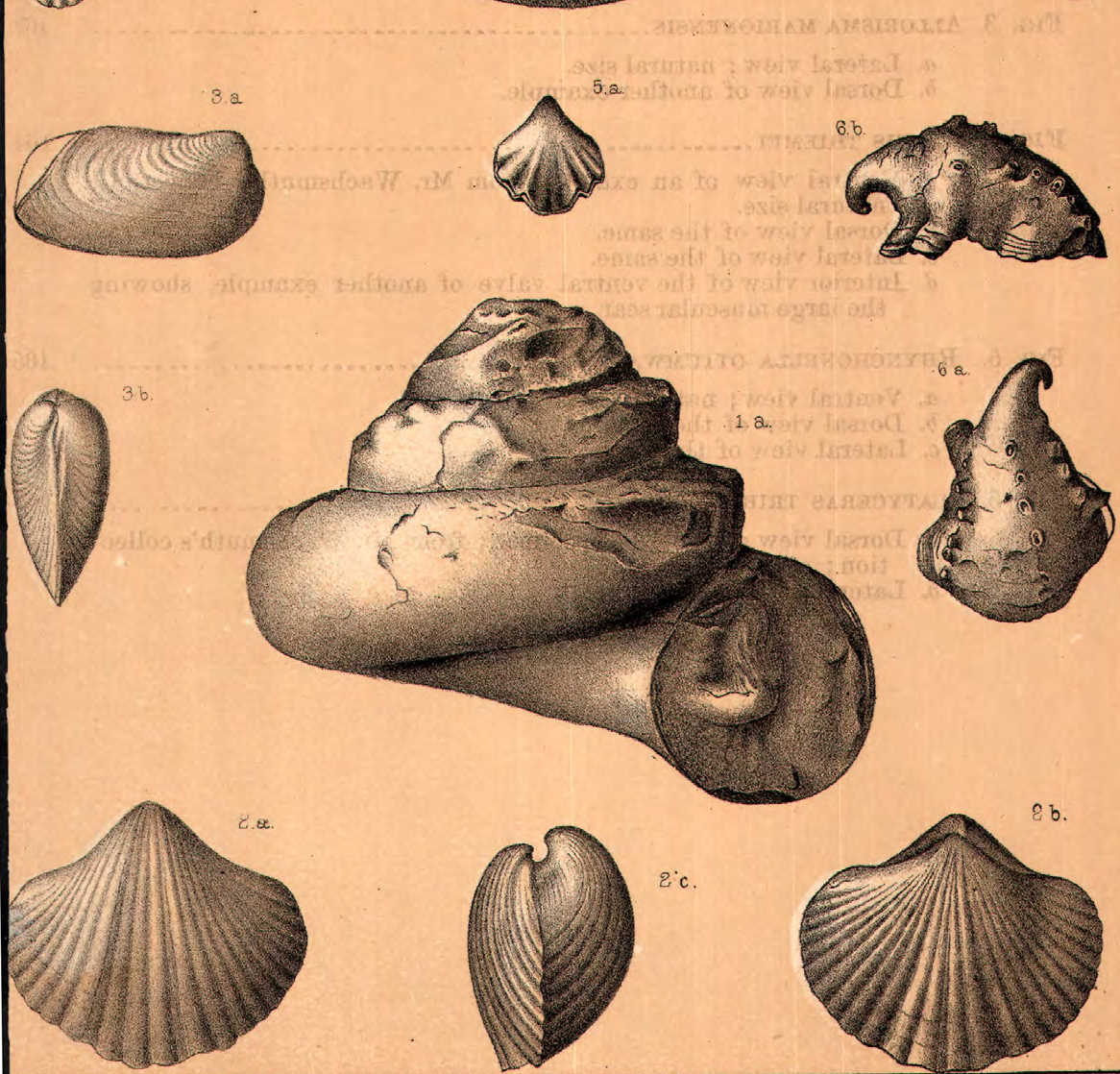

C.Mৎ Connell del,
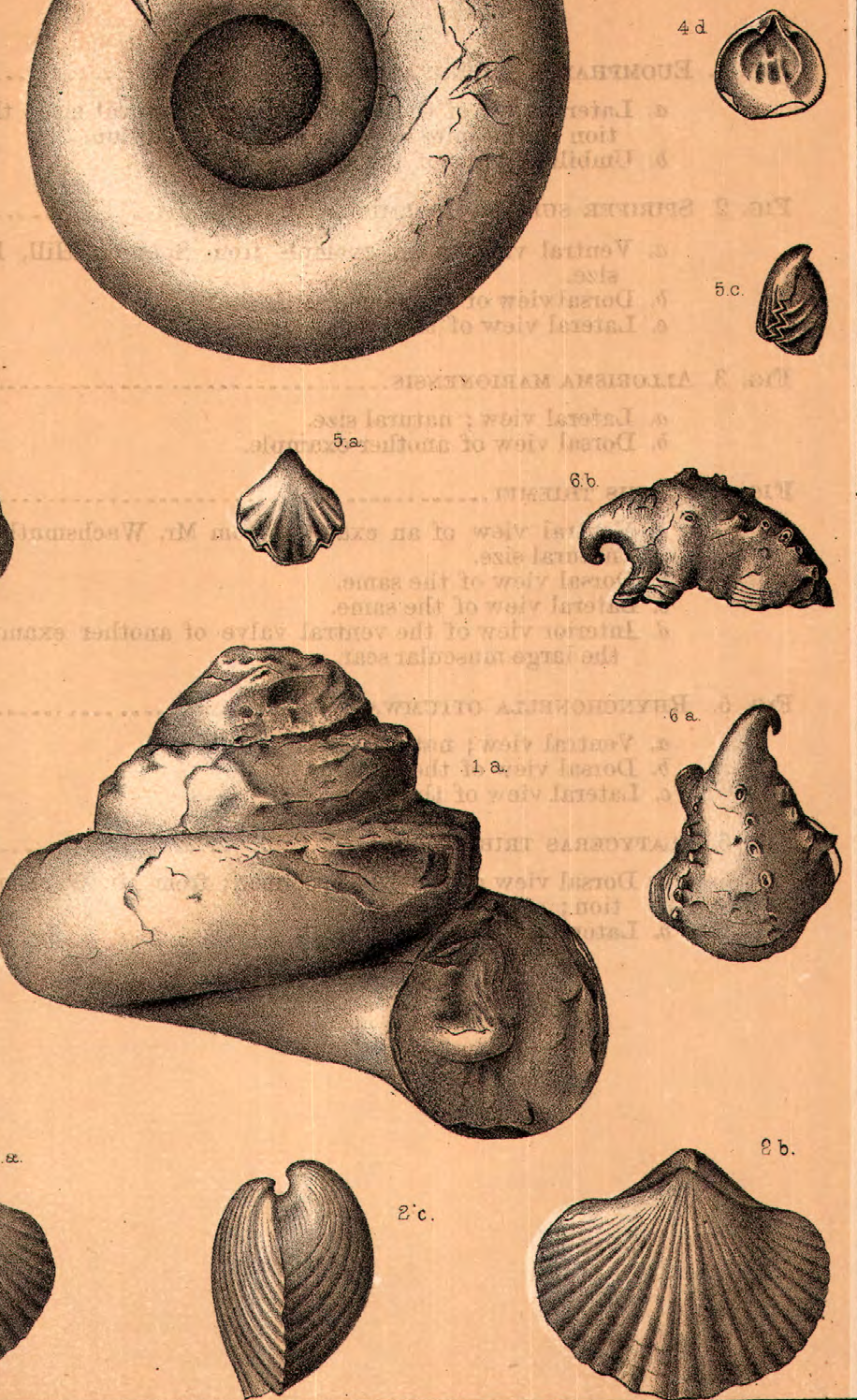

Thos Sincleir \& Son, Lith 

Fig. 1. Pleurotomaria broadheadi.

a. Lateral view; natural size.

$b$. View of the opposite side of the same, showing the aperture, Portions of the shell on this side have been a little crushed by pressure. Fragments have also been broken out of both sides, as shown by the outlines upon both the figures.

Fig. 2. Pleurotomaria newportensis

a. Lateral view; natural size.

b. Apertural view of the same.

Fig. 3. NATICOPSIS MONILIFERA

a. Lateral view; enlarged.

b. Apical view of the same.

c. Portion of the surface enlarged; the striæ of growth showing the character of the border of the outer lip.

Fig. 4. Conularia crustula.

a. Lateral view; natural size.

Fig. 5. ANthracoptera polita

a. Right valve; natural size.

b. Left valve. Both valves have been slightly distorted by pressure.

c. Diagram showing convexity of the valves.

Fig. 6. Astartella gurleyi

a. Lateral view; enlarged.

b. Dorsal view of the same.

Fig. 7. NaUtilus DaNVILlensis

a. Outline of a cross-section of a volution near the outer chamber; natural size.

Fig. 8. Serpula insita

a. A cluster of shells, attached to a fragment of a molluscan shell; enlarged. 
COAL MEASURES

U S.GEOLOGICAL. SURVEY

PLATE 48

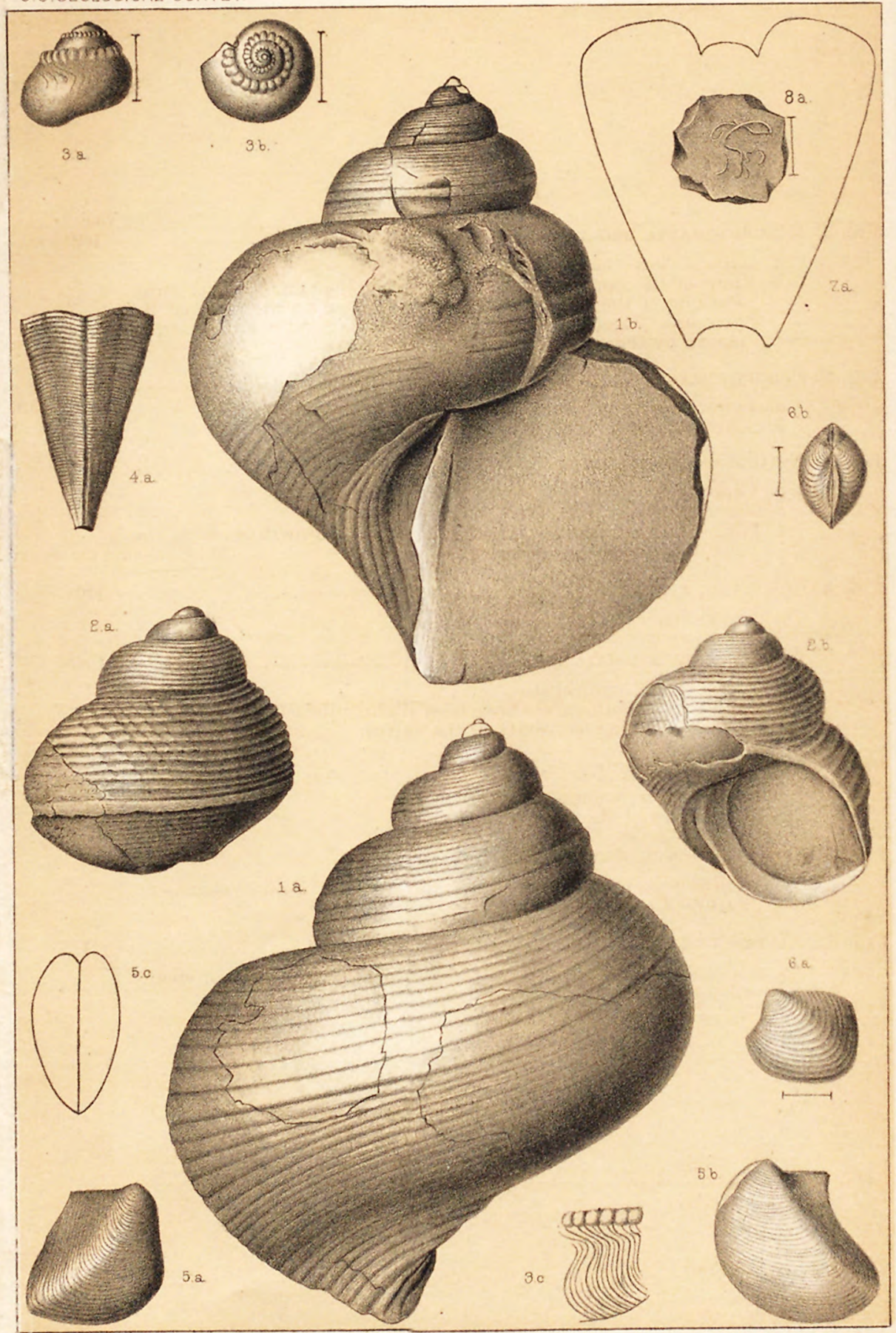

C. Me Conneil del.

Thos Etncinis of Son. Lith 



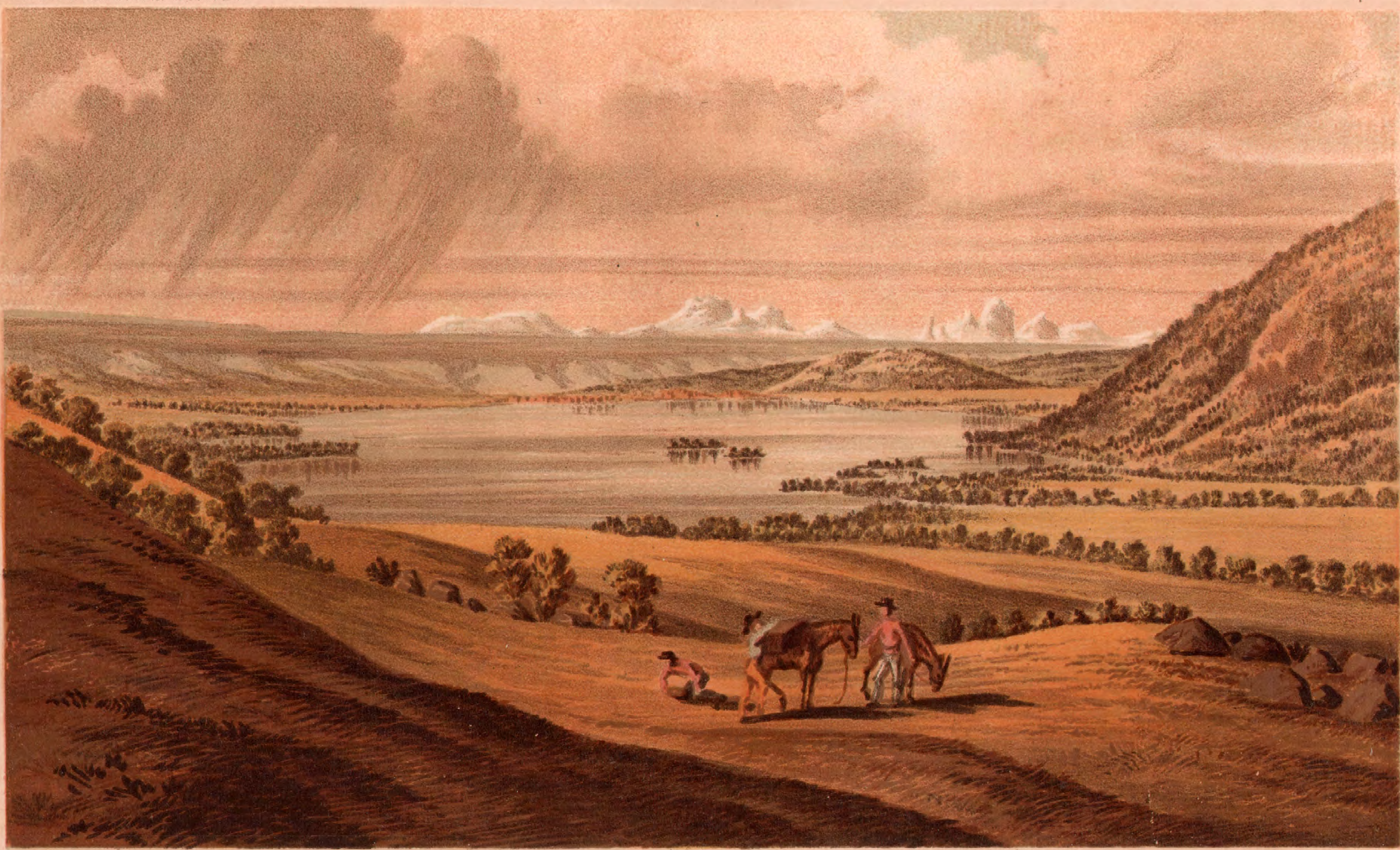




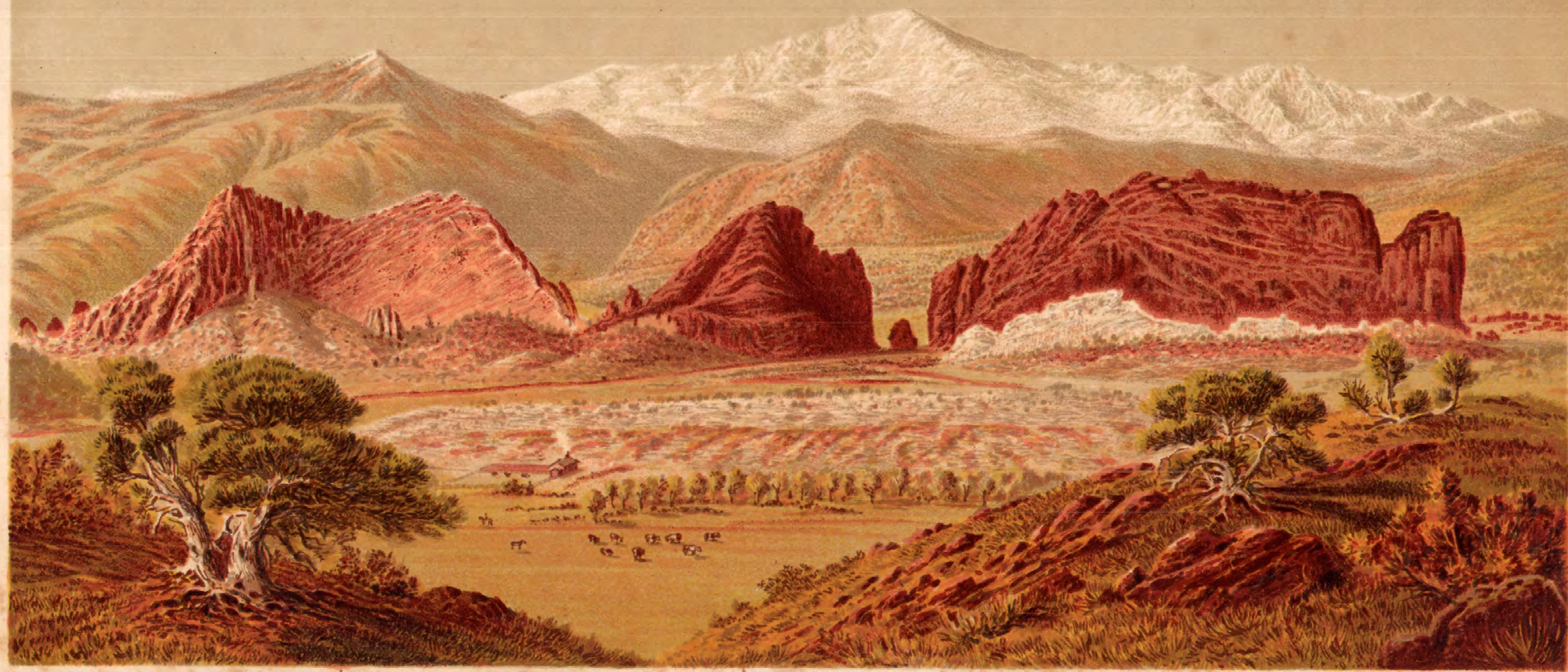

PIKES PEAK AND GARDEN OF THE GODS IN THE FOREGROUND COLORADO. MED SANDSTONE OF JURA TRIAS. 


\title{
REPORT OF ORESTES ST. JOHN.
}

\author{
LETTER OF TRANSMITTAL. \\ Office United States Geological $4 \mathrm{ND}$ \\ GeOGRAPHICAL SURVEY OF the Territories, \\ Washington, D. C., September, 1879.
}

SIR: I submit herewith my report on the geology of the district assigned to the Wind River division of the survey during the season 1878, together with a copy of the map of the territory visited by myself during the seasons 1877 and 1878, on which the distribution of the geological formations is indicated by appropriate colors.

The party to which I was assigned as geologist the past season was in charge of Mr. Frederick C. Clark, topographer, accompanied by Mr. Nelson Perry, mineralogist, Mr. Wells, topographical assistant, George and Mac, packers, and the cook, Henry. Outfitting at Cheyenne, the party was transported by rail to Granger Station on the Union Pacific Railway, whence in company with Messrs. Gannett and Peale's party we moved up the valley of the Green River, arriving on the southern confines of our territory on the 31st July.

The first work performed was in the northern extremity of the Wyoming Mountains, in the southwest corner of the district. We thence moved along the southern foot of the Gros Ventre Range to the west flank of the Wind River Mountains. Later in the season the northern half of the eastern slope of this range was visited, the work extending to a rapid survey of the eastern portion of the Gros Ventre Basin, over to Buffalo Fork. In the latter quarter, about the middle of October, just as we reached Pacific Creek, a heavy fall of snow virtually closed the season's field-work. The return was via Togwotee Pass, where the snow lay to the depth of above a foot, descending Wind River to Camp Brown, from which place I returned by stage to Green River Station, on the Union Pacific Railway. The time actually spent in the field was about ten weeks, during which time our movements were harassed by inclement weather, and latterly by that peculiar mental condition consequent on the uncertain and exaggerated rumors relative to the movements of hostile Bannacks by whom the country was said to be overrun, but of whose presence we saw no more than the traces of some days' old trails.

In relation to the geological map, a copy of which is herewith transmitted, so far as it records actual examinations it is believed to be in the main correct. But it embraces tracts which were either not visited, the geological features being viewed at a distance, or other sections where the data derived in the course of a hasty visit failed to aftord the means of determining the exact age of the rock formations found therein. In the former case is included the belt traversing the central portion of the Snake River Mountains, whose rather complicated geological structure it was impossible to satisfactorily make out from such examinations at a distance, with which we had to be content; and in the latter instance are included the several areas indicated by the common color 
employed to represent the distribution of those post-Jurassic formations occupying the positions of the Cretaceous and Laramie formations in the geologic scale. In the latter instances, although the occurrences were visited, the evidence of their age in the majority of cases depends entirely on sequence or their stratigraphic position in reference to welldetermined earlier formations in their neighborhood; the organic remains which these horizons afforded unfortunately were in so indifferent state of preservation as not to be recognizable with that degree of certainty desirable in defining the age of the deposits whence they came. It was therefore deemed adrisable not to attempt the definition of Cretaceous and Laramie formations on grounds purely lithological, and this, too, in a region where apparently there exists no unconformity between the various members of the great Mesozoic series; and hence the areas alluded to are given a single color with, however, queries and other legendary signs in accord with the impressions arrived at as to the probable stratigraphical relations of the deposits therein met with. The familiarity acquired during a season's hasty examination of large territories, if it could be supplemented by revisiting special localities, would result in exact knowledge such as it may not be possible to arrive at in any other manner. As it is, the work recorded on this map materially amplifies that of earlier explorations in this region, the differences and corrections being such as might be expected from the somewhat better facilities accorded the parties of this survey.

It is with pleasure and a due sense of my indebtedness I here acknowledge the favors I have received at the hands of Dr. White, who, in my absence, kindly examined my palæontological collections whose determinations have given me greatest aids in preparing my report. Also to Dr. Peale and Professor Lesquereux I am under many obligations for the favor of important information.

Very respectfully, your obedient servant,

Dr. F. V. HAYPEN,

ORESTES ST. JOHN.

United States Geologist, in charge. 


\section{REPORT ON THE GEOLOGY OF THE WIND RIVER DISTRICT.}

By Orestes St. John.

CHA PTER I.

AREA AND BOUNDARIES.

The country examined during the past season by the Wind River division of the survey includes an area of, approximately, 4,000 square miles. The region is triangular in shape, the base corresponding to the forty-third parallel north latitude, extending from the one hundred and eleventh meridian, west longitude, east abont 100 miles. The two sides are respectively defined, on the west by a line passing northeastwardly from the upper entrance to the Grand Cañon of the Snake, east of Jackson's Basin, to Togwotee Pass on the east of the continental watershed, $43^{\circ} 45^{\prime}$ north, and on the east by a southeasterly line, conforming, in a general way, to the course of Wind River; the meridian $109^{\circ} 30^{\prime}$, however, forms the eastern boundary line of the mapped area embracing the district especially alluded to.

\section{GENERAL SURFACE FEATURES.}

Drainage.-The region embraced within the above-mentioned limits mainly lies on the west slope of the continental watershed, its drainage belonging to three great river systems, viz, the Columbia, Colorado, and the Missouri. To the former belongs the drainage of the western border, which is gathered by the eastern tributaries of Snake River. Of the latter, the Elk Horn and Gros Ventre rise in the watershed, while to the south Hoback's and John Day's Rivers have their sources in the water-divide between the Snake and Green rivers. The ultimate source of Wind River originates in Togwotee Pass, its western tributaries draining the eastern slope of the great water-shed, their waters finally gaining the Missouri by the circuitous channels of the Big Horn and Yellowstone, far to the north and east. The southern half of the western slope of the watershed, in this district, belongs to the Colorado system, the sources of Green River rising in the most elevated portion of the Wind River Mountains.

Mountain Ranges.-By far the greater portion of the region surveyed may be denominated mountainous, although extensive tracts of the broken country may properly be considered in connection with the hydrographic basin areas. The continental watershed in the eastern portion of the district has a general south-southeast and north-northwest course of about 60 miles in extent. About two-thirds, or 40 miles, of the watershed is formed by the northern half of the Wind River Range, whose axial peaks, culminating near our southern border and dominating the district, are among the most lofty mountain heights of the great central Cordilleran region. To the northwest of Union Pass, and thence to Togwotee Pass, it entirely changes its Alpine character as also its geologic 
structure, becoming a wooded divide, ranging from 9,000 to 10,500 feet altitude.

Near the middle of the district lies the Gros Ventre range, a peculiar isolated mountain zone about 30 miles in northwest-southeast extent, culminating in altitudes between 11,000 and 12,000 feet above sea-level. This range forms a sort of link connecting the Wind River and Téton ranges, although topographically and geologically it is quite distinct from either of these ranges, possessing its own separate history. Jackson's Basin intervenes between its western end and the Téton Range, while a moderately elevated divide spans the interral between its eastern extremity and the Wind River Mountains. The Mt. Leidy highlands form an exceedingly rugged belt projecting westward from the watershed into the interval lying between the Gros Ventre and Buffalo Fork, and which is scarcely less in altitude than this portion of the great divide itself, with which, indeed, it is geologically intimately connected. Southwest of the Gros Ventre Range, occupying the extreme southwest corner of the district, the northern portion of the Wyoming Range is suddenly limited by the Grand Cañon of the Snake, beyond which the range is continued in the chain known as the Snake River Range, and which together make up one of the longest mountain ranges, a unit in geological structure, in this region.

Basin areas.-The basin areas which have to be considered in this connection correspond to the principal drainage depressions of the district. They are the Hoback, Gros Ventre, and Green River basins on the west slope, and on the east side of the watershed the Wind River Valley. An interesting conclusion arrived at in the course of the examinations in this region is that of the intimate geological relations existing between these depressed areas, especially with reference to the Gros Ventre and Wind River basins. The water divides separating these areas one from the other are generally low and composed of deposits pertaining to the Tertiary age. This is shown in the character of the divide between Hoback's and Green River basins, as also that between the latter and the Gros Ventre basin. In the latter quarter, however, the surface is heavily covered with Quaternary materials, in part dispersed by glacial agents, which hide from view the older deposits upon which they rest. That section of the great watershed lying between Union and Togwotee passes is essentially of the same geological character, though here the Tertian $y$ deposits were buried beneath a rastaccumulation of volcanic ejectamenta, which has served to protract the degradation of these soft deposits, maintaining them as a conspicuous barrier along the continental divide. In the details of their topographic and geological features there are marked contrasts in the several basin areas above briefly alluded to, and which will receive further notice in another place.

The extremes in altitude within the region under consideration, as determined by hypsometric observations made by this survey during several seasons subsequent to the expedition of 1872, show a range of about 8,400 feet. The lowest point, at the foot of the Grand Cañon of Snake River, has an altitude of 5,400 feet above the sea, and Fremont's Peak, one of the dominating summits of the Wind River Range, according to Mr. Wilson, attains an actual altitude of 13,790 feet. East of the watershed, that part of the Wind River Basin lying within the limits of the present district ranges from about 6,600 feet to 8,000 feet in altitude. On the west slope, within our limits, the altitudes of the several basin areas occurring therein are as follows: Green River Valley, 7,500 to about 8,000 feet; Hoback's Basin, 6,000 to 7,000; the Gros Ventre Basin, 6,500 to 8,500 feet. 
While the foregoing hypsometric data may convey some notion of the general surface reliefs of the district and its drainage depressions, a closer examination reveals great diversity, the mountain ranges presenting broad contrasts, which may also be said of the basin areas. With the exception of the Green River Valley, the alluvial tracts bordering the streams are of limited extent, usually confined to narrow strips of gravelly bottom land. In the Tertiary basins of the Hoback and Gros Ventre, the tributaries of the main streams generally occupy deep, narrow valleys eroded out of the soft strata, while along those which rise in the neighboring mountains is met some of the wildest and often sublime cañon scenery. The region on the west slope is generally well covered with forests of pine and fir trees, the lower hilly country being fairly covered with good grazing herbage. Perennial streams are everywhere encountered in this quarter. But on the east slope, beyond Wind River, the country presents some of the aspects of "bad lands"; only the larger streams are filled with flowing water the whole year, and extensive benchplateaus are covered with a sparce growth of herbage, and no forests.

$12 \mathrm{H}$ 


\section{CHA PTER II.}

\section{WYOMING RANGE.}

\section{TOPOGRAPHIC FEATURES, \&C.}

In the country to the south the Wyoming Range forms the waterdivide between the Green on the east and the drainage of Bear and Snake rivers on the west; but within the present territory its drainage is effected by numerous water courses tributary to Snake River. On the west it is defined by the valley of Salt River, and on the east by Hoback's Basin. The intermediate space is penetrated by John Day's River, and the southern affluents of the Hoback, a comparatively narrow belt along the north side draining directly into the Snake along that part of its course known as the Grand Cañon. To the northwest the same mountain belt is continued, scarcely diminished in relative altitude, under the name of the Snake River Range into the region partially explored the preceding season by the Téton division of the survey. In its passage across this mountain chain Snake River follows a southwesterly direction in a direct line from the mouth of Hoback's River, where the cañon may be said to begin, to the confluence of John Day's River, where it enters its lower valley, of about 20 miles. It forms a rift through the mountains the upper portion of which is occupied by terraces and occasional tracts of gravelly intervals continuous with the benches in the lower part of Jackson's Basin; but the lower half is said to bé scarcely wider than the bed of the river.

The main ridge of the range lies between John Day's and Salt rivers on the extreme western border, occupying a space about 10 miles across, east-west, and which has received in the district to the south the name "Salt River Range." From either side it presents a bold, rugged mountain barrier, attaining 10,400 feet actual altitude, and is known to be largely made up of Carboniferous strata. Towards the north end the John Day's has excavated a deep passage across the ridge parallel with and only about 4 miles south of the lower portion of the Grand Cañon, joining the Snake just below the debouchure from the mountains. Above this gorge the stream forks, sending off a fine tributary to the eastward whose sources lie in the crest of the Hoback Cañon, or easternmost mountain ridge of the range, the main stream from the forks pursuing a southerly course and confined to a narrow valley in that part passing through our territory.

The central portion of this highland belt is traversed in a nearly northsouth direction by a narrow ridge, the north half constituting a barrier between the drainage flowing directly into the Snake on the west and that of the Hoback on the east. To the south, however, this ridge is cut across by the East Fork John Day's River, in an exceedingly wild, narrow cañon, whose adjacent slopes are densely wooded with coniferous forests. South of the cañon the ridge reaches its maximum elevation, 
10,450 feet, at Station VII near our south line. For convenience sake this ridge has been designated by the name John Day's ridge.

East of the latter point a high, undulating mountain plateau extends over to the Hoback Cañon ridge some 4 miles distant, and which forms a part of the mountain basin in which rise the East Fork John Day's River and one of the tributary sources of the main Hoback. Geologic. ally, this basin forms the southern continuation of the valley between the middle and Hoback Cañon ridges and is principally drained north by a lower south tributary of the Hoback, which gains the latter stream 2 or 3 miles below the cañon. Thus limited it forms a narrow trough 20 miles in length gradually widening to the north where it is about 6 miles across, and is mainly occupied by Mesozoic and Tertiary deposits. The basin area to the west occupying the interval betweeil the Salt River and John Day's ridges, although much wider-10 to 12 miles east-west-is very similar in geologic structure to that just mentioned.

The eastern barrier ridge of the range, which we have designated as the Hoback Cañon ridge, stretches due south from the south flask of the Gros Ventre Mountains to the south line of the district, a distance of 38 miles. Although narrow, averaging 4 or 5 miles in width, it constitutes one of the most important topographic and geological features of the range in this region. In the northern half the Hoback River has opened a narrow way across the ridge nearly at right angles to its course, in which the geological structure of the ridge is well displayed. Between Hoback's Cañon and the south flank of the Gros Ventre Mountains the ridge has an altitude of 10,000 feet; to the south of the cañon it gradually rises, culminating in Hoback's Peak (Station VI), a few miles north of the south line of the district, at an altitude of 10,800 feet above the sea. In the latter quarter it is broken by the cañoned sources of Hoback's River, and thence southward the water-divide is transferred to the middle or John Day's ridge, which soon constitutes the main divide limiting the west side drainage of the Green River Basin in the district to the south. Throughout its extent this ridge presents from either side a very broken appearance, with steep, often precipitous, rocky acclivities, diversified by the rich color-contrasts imparted by the deep reds and arab browns of the Jura-Trias, the grays of the Carboniferous limestone, and the dark and light shades of the forest-covered and grassy slopes.

For so comparatively small area as that occupied by the Wyoming Range within this district, being only about 25 miles across and of an average north-south distance even less, it presents an exceedingly diversified surface and intricate drainage, with which are associated equally varied and interesting geological phenomena, which will be briefly discussed in the following section.

\section{HOBACK CAÑON RIDGE.}

Along the eastern flank of the Wyoming Range there occurs a low outlying ridge parallel with and 3 or 4 miles distant from the Hoback Cañon ridge, from which latter it is separated by the valley of tributaries which gain the Hoback a few miles above the cañon. This ridge is quite persistent to a point perhaps 7 miles north of our south line, where it is completely enveloped by the Tertiary deposits which here sweep high up on the eastern flank of the range, as will be noticed in a subsequent chapter devoted to the Green River-Hoback Basin. To the north of the Hoback the ridge, as such, is less well marked, being much eroded by Hoback tributaries descending from the south flank of the Gros Ventre Range, east of Station XII. 
The nucleus of this outer ridge is apparently almost exclusively made up of Mesozoic strata, excepting a small angle in the vicinity of the junction of this south affluent with the main stream, where strata of later date compose its bulk. Structurally, it presents a somewhat variable present condition that was determined by a sharp fold in the older strata, which locally exhibit the appearance of a regular anticlinal. In the sonthern portion, 6 or 8 miles above the mouth of the stream, the ridge shows a monoclinal structure, the stream occupying a synclinal from which the strata rise to the eastward into the narrow, picturesquelyweathered crest, 1,000 to 1,200 feet high. The east side is sharply broken down, and on the upturned edges of the nucleal strata rest the unconformable Tertiary deposits, dipping off to the eastward. Whether the condition of things here represents a fault with down throw on the east, or is attributable to denudation along the shore line of the Tertiary sea, was not clearly apparent. In the latter case the tilting of the Tertiary deposits would indicate a late-continued elevatory movement within the area of this western mountain border of the Hoback Basin sufficient to account for the present position of the Tertiary deposits which slope off into the basin at an angle of variable steepness.

Eight miles south of the Hoback this ridge is made up of hard reddish-buff sandstone and brecciated silicious beds, steeply tilted and rising along the crest into picturesque, ruin-like crags. Two or three miles lower down the stream, the west slope is flagged with drab, sparseamed limestone, containing a small Ostrea and Pentacrinites. These beds dip about WNW. at angles of $35^{\circ}$ to $65^{\circ}$, and are overlaid by limestones and indurated calcareous shales containing abundance of Gryphoca calceola, which, however, are soon concealed beneath the débris lower in the slope. Below the latter point the reddish or flesh-colored Triassic sandstones descend lower in the west slope, and as the course of the stream bears more to the east it crosses these beds, cutting a narrow gorge in which their anticlinal structure is well brought out. Below the gorge the valley is less confined, and is bordered on the east by beantifully rounded hills based on the soft gray deposits-alternations of sandstones and shales-of the Tertiary, which continue thence below the confluence of the Hoback. The latter deposits show a thickness of perhaps 1,00? feet, dipping eastward at an angle of $30^{\circ}$ to $45^{\circ}$, and at the confluence of the streams forming a low outlying hill on the west side of the valley. Similar remnants occur below the junction for some distance, forming benches low in the slope resting upon the westerly-dipping Triassic red sandstones, which form the crest of the west side border ridge. The Tertiary slopes are partially wooded with conifers, as also are the more rugged Triassic acclivities.

The main Hoback here pursues a northwesterly course, and a mile or so below the junction it has formed a narrow passage across the Triassic monoclinal ridge. The typical red sandstones show picturesque expos. ures, dipping west at an angle of $35^{\circ}$, the outlying ridges on the east being made up of the Tertiary deposits. In the angle formed by a considerable inflowing branch from the north, a high castellated mass of red sandstone fills the east side of the valley, sharply turning the stream west. The west slope of this hill is faced with heavy ledges of red sandstone, ineluding a drab calcareous or limestone deposit, steeply inclined westward. The summit is crowned by apparently nearly horizontal ledges of the same character, as though the strata had been partially severed and broken down or dragged on the west side of the fold, leaving the crest intact. In the west side of the narrow valley the strata again rise, but a little lower down thes are seen to form a perfect arch 

Plate I.

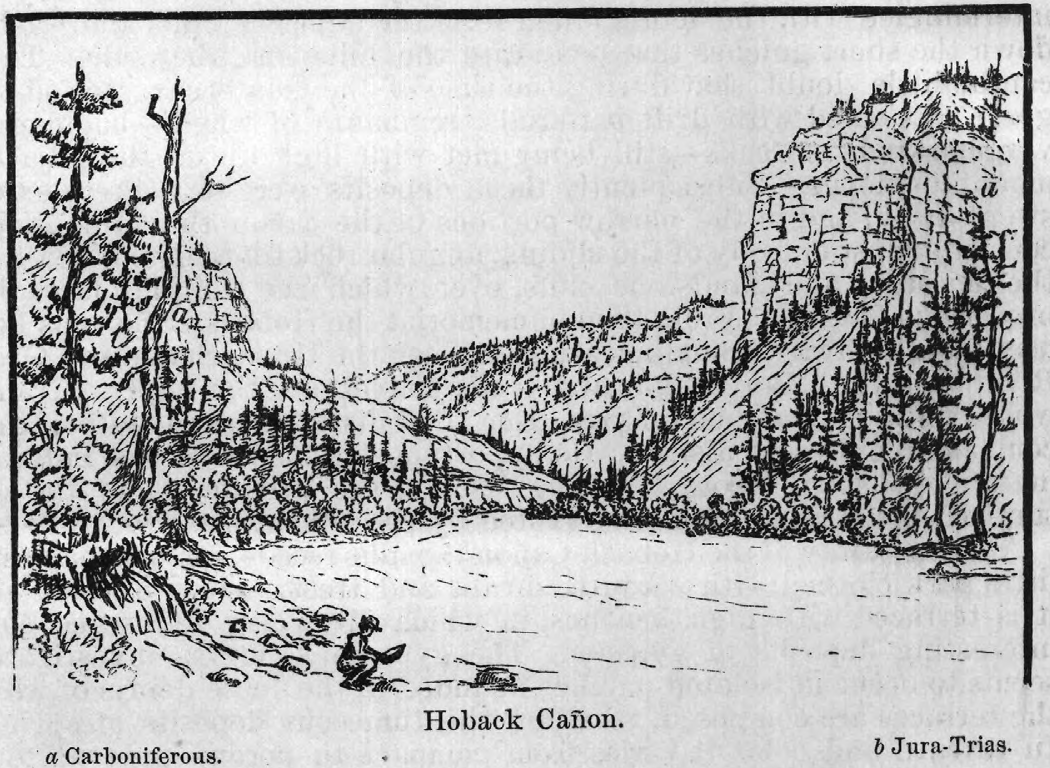


plated by the Jura. The "red beds" appear in force on the west side of the cañon above, exhibiting a thickness of above 1,000 feet, dipping westward, in which direction they merge into the broken outlying slopes of the Hoback Cañon ridge. North of the Hoback, as before mentioned, the continuity of this ridge is much broken by the streams here descending from the Gros Ventre Mountains, and it is not improbable that, in its geologic structure, it is also complicated by proximity to the latter mountain range.

The valley of the tributary separating the above outlying ridge from the main ridge south of Hoback Cañon is generally narrow and fre. quently walled in by precipitous rocky slopes. The narrow intervale expansions show well-defined terraces, and the stream-bed is paved with water-worn fragments of red sandstone and drab limestone, derived from the environing Jura-Trias deposits. However, on gaining the Hoback, the Quaternary deposits which fill the valley-bed are largely composed of Archæan and Palæozoic débris, from the Gros Ventre Mountains on the north. These materials extend through the cañon, where they are intermingled with the débris fallen from the adjacent cliffis and washed down the short gulches that penetrate the hills on either side. There can be little doubt that during the time of the Quaternary period this gorge was filled with drift materials, remnants of which-boulders of various kinds of rocks-still being met with high up on the adjacent mountain slopes. Subsequently these deposits were to a great extent swept away, and in the narrow portions of the cañon the talus slopes consist almost entirely of the sliding, angular rock fragments fallen from the limestone and sandstone cliffs, over which the trail, in places, has precarious footing. From time immemorial the Hoback Cañon has been used as a highway, communicating between the Upper Suake and Green River valleys. Many well-beaten trails converge at the upper entrance, whose antiquity may be inferred from their distinctness in spite of their comparative present disuse. Its importance in this respect is, indeed, a matter of historic record, reaching back to the first decade of the century when the region was first visited by the adventurous fur-traders.

Abont midway of the Hoback Cañon the hills recede, inclosing a pretty little park clothed with verdure, shrubs and trees. On the north side it is terraced with high benches, in which Mr. Perry discovered some interesting deposits of gypsum. The gypsum, so far as investigated, seems to occur in isolated patches included in the loose débris of which the terraces are composed, recalling the tufaceous deposits of springs. In texture and color it varies from compact to porous, pure white to grayish or soiled white, and apparently forms quite extensive deposits. That examined appears in the steep slope of the terrace near the brink, at an elevation of about 115 feet above the stream, and shows a thickness of 4 feet. Lower down, or just within the lower entrance to the cañon, a powerful sulphur spring issues along the north bank at the edge of the water for a distance of 30 or 40 yards, emitting the odor of sulphureted hydrogen. The spring water is not umpleasant to the taste; the temperature at $7 \mathrm{a}$. m. ( 7 th August) indicated 470 . F. The spring is seated immediately over an anticlinal fold, whose axis is here composed of Carboniferous-possibly Niagara-limestone. In favorable situations, the pebbles in the way of the spring currents are coated with a sulphur precipitate, and the inflowing spring water discolors that of the river for the distance of several hundred yards below with a strip of beautiful green. This unquestionably is the sulphur spring described by Rev. Samuel Parker, who journeyed down the Hoback in 1834. It may be well to remark,

\footnotetext{
* Journal of an exploring tour beyond the Rocky Mountains. Ithaca, N. Y., 1844.
} 
however, that at the time of onr visit gaseous emissions were far less noticeable than one would be led to infer was the case fifty years ago at the time of Mr. Parker's observations.

For a few miles south of the Hoback Cañon the main mountain ridge presents a sort of double crest, although the eastern and more prominent is the main drainage crest, the western one having the relations of huge buttress-spurs with outlying eminences but little inferior in height to the main ridge. Its structure throughout is that of two parallel folds separated by a shallow synclinal trough. The eastern, or Station II ridge, presents an abrupt and often escarped wall 500 to 800 feet high, facing the Hoback Basin, in which the edges of the westerly dipping strata are exposed. These consist chiefly of red and flesh-colored Triassic sandstones, capped by leaden shales and drab limestones of the lower measures of the Jura. From the foot of the escarpment on the east, a rugged wooded belt steeply descends into the parallel valley, in which the strata, though much disturbed and complicated, apparently form the eastern flank of an anticlinal fold. The above state of things is plainly indicated in the vicinity of Station II, where outlying hog-back ridges facing the monoclinal crest are made up of the Triassic red sandstones. dipping steeply to the east. Lower in the slope there are indications of a second lower fold, also archerl by the Trias, whose east flank declines into the synclinal trongh occupied by the parallel valley, and which is partially filled with Jurassic deposits. The eastern flank of this synclinal is the same as the outer barrier ridge already described. The relative position of the folds and their component strata are indicated in the section diagram across this part of the ridge. But while the above-mentioned structural features may be regarded as normal in this part of the east slope of the Hoback Cañon ridge, it was undoubtedly subject to greater or less local variation, recording the variable action of the dynamical forces which uplifted and folded the strata into a broad north-south mountain zone.

From the Hoback Dasin, looking up the valley of the main stream towards its sources, a comprehensive view is gained of the eastern wall of the ridge extending ifrom 'Station VI to the south line of the district, and which affords a fair knowledge of its geological structure. The outlying eastern slope is largely if not entirely enveloped by the Tertiary deposits of the basin, which a little farther to the sonth extend high up on the mountain ridge. Nothing could more strongly contrast with the abrupt, broken mountain declivity than do the long sloping benches that liere descend the mountain flank, reaching far out into the middle of the basin area. Even to the north, where the Tertiary deposits have been much more eroded by the streams, they still retain to no inconsiderable extent their distinctive bench features. But at a distance what may appear to be uninterrupted, smooth slopes, on nearer approach generally prove to be high benches, whose almost inaccessible sides are scored by the wildest gullies, while the comparative levels above are densely clothed with pine and spruce amongst which the fires have wrought wide-spread devastation, the interlacing of the fallen treetrunks erecting almost insurmountable barriers to travel.

As seen from this point of view, the ridge in the neighborhood of Station VI shows a broad synclinal or sag in the component strata, based upon heavy deposits of red sandstone. The trough of the depression is filled with variegated chocolate-drab beds, which are separated from the "red beds" by an intermediate buff-colored deposit forming escarpments in either flank of the sag, remnants of reddish sandstone occurring above the drab beds. The basis rocks of the exposed section 


\section{Plate II.}

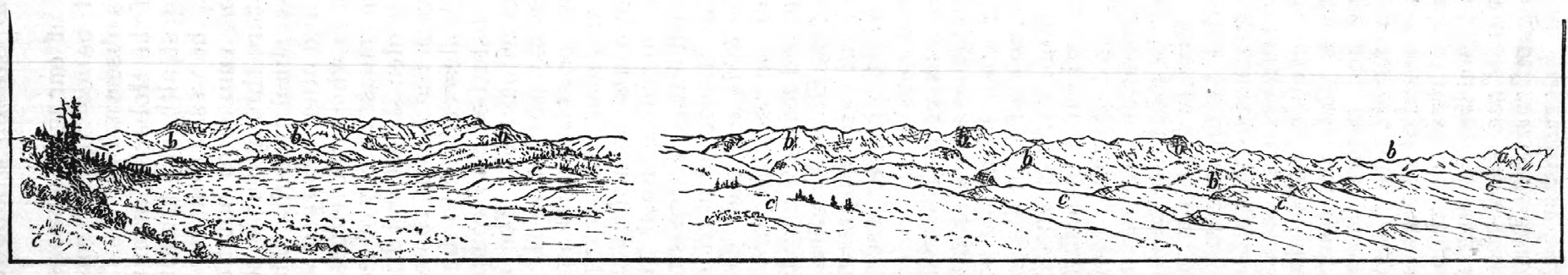

East flank of Hoback Cañon Ridge, from Upper Hoback Basin. $a$ Archæan, Sta. XII Gros Ventre Range. $b$ Jura-Trias.

$c$ Tertiary foreland, 

here referred to are clearly of Triassic age, while the overlying drab and variegated deposits are undoubtedly referable to the Jura. The depression alluded to is believed to be merely a sag in the strata between two points of maximum elevation, as it appears to be in line with, and not transverse to, the general north-south direction of the mountain folds. The same is further indicated from points of view foreshortening the mountain wall and bringing into profile the great headlands defining its amphitheaters, where the strata uniformly incline westward.

But at Station VI the mountain ridge presents a very marked synclinal fold, on a high point on the eastern flank of which the station was located, at an altitude of 10,800 feet. In an east-west direction the ridge is, perhaps, a mile across, either flank exhibiting the upturned strata in the position of monoclinals due to erosion. On the west side the strata rise much more steeply than on the opposite, and from certain points of view they appear to be almost vertical. The axial portion or crest of the west-side fold, however, has been removed by erosion at this point, but to the south it presents the appearance of a rather low, broad arch flagged with the variegated chocolate-drab Jurassic deposits, the same that fill the synclinal and constitute the greater height of the flanking ridges. The Jura is here made up of drab limestone layers and chocolate-drab shales including reddish arenaceous deposits, the whole, exclusive of the dirty buff deposits below, attaining a thickness of probably, at least, 1,500 feet.

A few miles north of Station VI, in the neighborhood of Station V, the ridge assumes its double character, the latter station being locaved on the western ridge, 10,050 feet above sea-level. The above-mentioned broad-spanned anticlinal fold southwest of Station VI is not recognized at this locality, unless it prove to be identical with the sharp fold of the western ridge occupied by Station V. The western ridge rises abruptly from the valley of the lower fork of the Hoback, its crest nearly corresponding to the axis of a sharp anticlinal fold in the Carboniferous limestones, which is preserved as far north as the lower entrance to the Hobach Cañon. The upper portion of the western slope is faced by the westerly-dipping Carboniferous limestones, succeeded by the buff and flesh-colored hard sandstones lower in the slope, which is covered with angular siliceous débris. The latter horizon holds the brecciated layers, composed of angular fragments of the quartzitic sandstone and drab limestone, recalling conglomeritic horizons in the Carboniferous in the region of. Ross Fork basin south of Fort Hall, Idaho. These deposits reach well down the slope, where they are in turn overlaid by typical red sandstones of the Trias, which form the first bench rising on the east of the little valley. From the crest of the ridge the inner synclinal is overlooked, occupying a belt about one and a half miles across extending over to Station II ridge, and which is eroded into irregular sharp ridges more or less parallel to the border mountain ridges. This synclinal trough is filled with the Triassic "red beds" overlaid by a few hundred feet thickness of the drab-colored Jurassic limestones and shales; the latter being mainly confined to the eastern portion of the depression, rising into the crest of the east or Station II ridge. The latter mountain, however, is principally composed of the inferior "red bed" series, which also reaches well up on the eastern flank of the west or Station V ridge, upon which it is steeply inclined.

The continuity of the western ridge is interrupted by deep gorges cut by tributaries flowing west into the lower south fork of the Hoback, contrasting with the east ridge in this respect, which forms the water-divide as far south as station VI. These cañons afford natural sections in 
which the structure of the ridge is fully revealed, besides affording excellent facilities for detail stratigraphical examinations.

One of the most interesting sections across this mountain belt is that presented in the sides of Hoback Cañon. This gorge traverses the ridge in a direction a little north of west, and that portion here alluded to is about five miles in length. The Hoback flows in narrow defiles at intervals, several miles above this point. Throughout this distance the south side of the cañon is closely hemmed in by steep mountain slopes, which are frequently broken by mural esearpments several hundred feet high, in which the strata are well exposed.

At the upper entrance to this stretch of cañon stands the before-mentioned eastern border ridge, in which the Triassic red sandstones are steeply tilted, dipping westward into a synclinal depression, whose axis apparently is but a few hundred yards distant. The west flank of this synclinal rises with a more gradual ascent, bearing a heavy series of Jurassic deposits, which consist of a rather heavy deposit of rusty buff limestone, resting upon hard reddish sandstone, probably belonging to the upper portion of the Trias. Then succeed heary ledges of drab limestone, associated with drab nodular and indurated calcareons shales, charged with quantities of Gryphrea calceola, the whole dipping a little north of east at angles of $30^{\circ}$ to $35^{\circ}$. The latter deposits are overlaid by a series of chocolate-red and gray, more or less arenaceous shales. In the latter series, at a point on the north side of the stream, a short distance above the upper entrance to the cañon, a thick bed of brownishdrab limestone forms a rather prominent outcrop in the slope, rising to the westward at an angle of $45^{\circ}$, finally curving over past verticality in the crest of the low ridge. The same flexure is also noticeable in inferior ledges lower down the cañon, though less marked than in the above instance. Although no fossils are detected in these higher strata, they are presumed to belong to the Jura, with the lower fossiliferous beds of which they are conformable. On the east flank of the synclinal the latter beds reappear, afiording abundance ot their characteristic fossils.

Just east of the debonchure of a gulch heading in the north end of Station II ridge, the Triassic red sandstones rise up and curve over in a fold with sharp, in places almost vertical, inclination on the west side, the same deposits in the east slope of the fold dipping at an angle of $25^{\circ}$ north of east. Higher up the gulch the steeply-tilted ledges have been weathered into narrow walls, presenting interesting examples of atmospheric erosion. The outer plating of this west-side slope consists of gray ledges, probably of the age of the Jura. On the north side of the cañon these horizons are not as well exposed, the slopes being strewn with red sandstone débris. In the opposite side of the gulch, a few hundred yards below, a heavy series of buff or pale flesh.colored and gray, very hard sandstone, including layers of siliceous limestone, occurs, which rises up into a fold with rather steep inclination in the east flank. The strata descend much more gently on the west flank of the fold, the ledges as seen in the exposures along the south side of the caũon gently undulating, until reaching a point half to three-fourths of a mile below the above-mentioned gulch, where they again more steeply rise to the westward, as shown in the nural exposures which rise 500 to 800 feet above the stream on either side. The upper siliceous deposits here oecupy the crests of the ridges, and are underlaid by a heavy series of grayish-drab, more or less cherty limestone, containing Zaphrentis, crinoidal remains, Polyzoans, Hemipronites, Spirifer, \&c. The latter beds rise descending the cañon, presenting marked inequalities or undulations, and finally make up the bulk of the cañon walls, and show- 
ing a thickness of a thousand feet, perhaps more. Approaching the debouchure of the cañon, where these strata exhibit their greatest vertical exposure, the limestones are crumpled into two low anticlinals, the axis of the lower fold, or that forming the west flank of the Hoback Cañon mountain belt, exposing a nucleus of brownish-gray magnesian limestone, which lithologically resembles the so-called Niagara horizon. A short distance within the mouth of the cañon a small cave has been fashioned out of this bed in the wall rising over the north side of the stream ; and just below this issues the sulphnr spring previously mentioned. The west flank of the cañon ridge is here much eroded, the ledges in the steep slope farther south showing their basset edges, dipping westward. Higher up the cañon the limestone beds exhibit interesting examples of irregular deposition, in places a heavy bed wedging out, so that subjacent and overlying beds elsewhere separated by many feet thickness of intervening layers are brought into immediate contact.

The above-described limestones, which compose the walls throughout the lower reaches of the cañon, are unquestionably Carboniferous, as shown by the fossils they contain, while the heavy series of conformably superimposed siliceous and limestone deposits agree in relative position with identical deposits occurring in the Snake River Mountains and elsewhere, which have been referred to the later epochs of the same age. No fossils, however, were here observed in these beds, and the demarkation between them and the typical "red beds" of the Trias is obscure in the cañon section. But from the adjacent heights the Triassic "red. beds" are seen to be well developed, occupying the synclinal in the central portion of the mountain belt.

The eastern border of the Carboniferous belt in the above described cañon section presents an interesting flexure, which, in connection with that observed in the early Mesozoic strata just above, exhibits anomalous results in the action of the dynamical forces in this part of the Hoback Cañon ridge which may be of local significance. In the elevation and folding of the strata over this mountain belt the Carboniferons beds were forced up into the position they now occupy, the strata in the eastern fold remaining intact, although there is evidence that along the eastern flank of the west fold the beds were subjected to excessive tension, which might have resulted in the severance of the superimposed and perhaps less tenacious Mesozoic strata, the latter appearing in the corresponding parallel fold directly opposite the upper siliceous horizons of the Carboniferous, the before-mentioned gulch descending from Station II, marking the line of disruption. The facts, such as were observed, are reproduced in the diagram of the cañon section.

Six miles north of Hoback Cañon the monntain ridge is crossed by a small tributary of the Snake, which rises in the southern slope of the Gros Ventre.Mountains, in the vicinity of Station XII, whose picturesque valley exhibits essentially the same structural features above noted. The narrow debouchure of the cañon is marked on either side by walls composed of massive gray limestone and pale reddish siliceous beds of the Carboniferous, dipping at a moderate angle northeastward. Ascending the cañon, the same ledges outcrop in mural exposures, the inclination changing a mile or so above the entrance to a westerly one at an angle of $10^{\circ}$ to $15^{\circ}$, and gradually steepening higher up the valley, which opens outinto prettylittle meadow intervales; the narrow portions of the valley walled by limestone clifis and steep taluses of débris; the mountain slopes furrowed by exceedingly steep ravines and clothed with beautiful evergreen forests. The bed of the stream is filled with a variety of 
bowlders, including metamorphic fragments, which were derived from the Gros Ventre Mountains. The expansions of the valley receive considerable affuents from the north, and this section marks the axis of a synclinal depression which is filled with the Triassic "red beds." A few miles above the entrance to the cañon the strata are much disturbed, and in the space beyond, lying between this ridge and the southern foot of the Gros Ventre Mountains, the continuity of the Mesozoies is lost beneath accumulations of more recent origin.

In the low northern continuation of the ridge the sedimentary formations apparently trend round more to the west, where they approach nearest to the south flank of the Gros Ventre Mountains. There is evidence of much disturbance in this quarter, the Triassic "red beds" being steeply upraised and resting upon deposits referred to the Upper Carboniferous. The latter here show a heavy ledge of gray, rusty weathered, fragmentary limestone, locally showing a tendency to concretionary structure, as also magnesian in composition. The bed outerops in a sharp ridge between two northern affuents of the above-mentioned stream, and dips southwestwardly at angles varying from $45^{\circ}$ to $80^{\circ}$. In lithological character and composition the ledge resembles horizons in the uppermost or Permo-Carboniferous division, as elsewhere developed in this region, although no fossils were recognized at this locality. The "red beds" here show 500 to 1,000 feet of the inferior portion of the series, consisting of alternations of deep red and thinner gray, laminated arenaceous shales and sandstones. These deposits inclose bands of reddish-stained, vesicular calcareous rock, which weathers with a rough surface, recalling the tufaceous-like limestone lavers interbedded in the Triassic sandstones on the east flank of the Wind River Mountains. The latter "red bed" series forms a belt, the trend of which apparently identifies the fold at the present locality with the first abrupt break on the east of the Carboniferous belt in the Hoback Cañon section already noticed. The position of this red belt is indicated in the steep slopes, both by the red color imparted to the soil by the disintegration of the red arenaceous deposits and the luxuriant herbaceous growth which this soil sustains in mountainous regions.

As already intimated, the eastern flank of the latter Mesozoic fold north of the little stream above described is obscured by later deposits. But in the section between this stream and Hoback Cañon, ascending to Station III, which occupies an eminence in the midst of this area nearly 10,000 feet in altitude, the following observations were made: West of the outflanking eastern anticlinal ridge, on crossing the synclinal, the calcareous indurated shales, drab limestones, and chocolate-red arenaceous shales composing the Jura, succeeded below by the Triassic sandstones, ontcrop at intervals in the outlying spur ridges at the foot of Station III. These deposits dip to the eastward, but in the space lying between the abrupt spur ridges and the main mountain group the strata are obscurely exposed; so that it is not clear how intimate the western border of the Mlesozoic fold here corresponds to its appearance 3 or 4 miles to the south in the Hoback Cañon section.

In the summit of Station III the strata dip southwest at an angle of $30^{\circ}$, the direction and angle of inclination varying considerably even within short distances. The crest shows a ledge of gray sandstone, in places slightly calcareous and laminated, underlaid by red, indurated arenaceous deposits. The high shoulder on the east, however, exposes similar gray and brownish red sandstones, dipping $25^{\circ}$ northeastward, and a few hundred yards south of the station the same ledges incline northwest at the same angle. It is apparent that Station III ridge is 


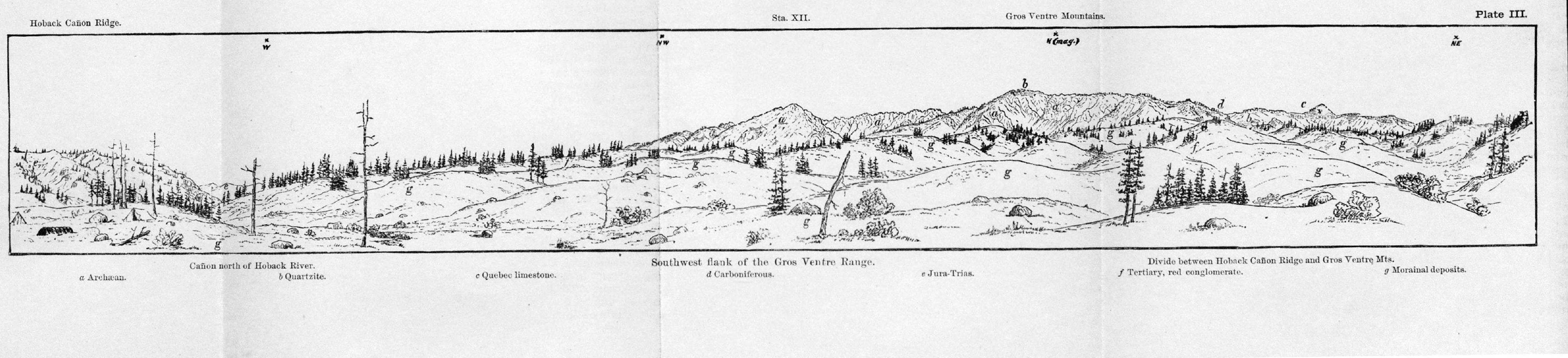


geologically the same as that on which Station II was located; that is, the eastern flank of the synclinal trough, which is here also filled with the "red beds," and probably remnants of the Jura. The eastern verge of the synclinal probably lies at least a mile east of the station, where it is marked by prominent red pyramidal heights overlooking the high morainal benches in the foot of the Gros Ventre Mountains, and which here constitute the divide between the upper north affluents of the Hoback and the little stream that joins the Snake a mile or so above the mouth of Hoback's River. The heavy upper "red beds" rest upon a series of grayish buff limestones and red drab and chocolate banded arenaceous deposits, occurring in heavy alternating beds, with a vertical exposure of near 1,000 feet in the south side of the cañon north of the Hoback. The latter deposits bear marked resemblance, lithologically, to the Permo Carboniferous horizon in the Snake River Mountains; but in the absence of fossils, none having been noticed in these beds, the data is as yet insufficient to establish their identity beyond question.

As regards the geological character of the ontlying strip on the southwest flank of the Gros Ventre Mountains, and extending well over to the Snake River south of the basin course of the Little Gros Ventre Creek, the only data gained was that presented in the view from Station III. This mainly diseloses the red and gray deposits of the Jura-Trias, from beneath which the Palæozoic formations rise up on the south flank of the great Archran spur of the Gros Ventre Mountains, which abruptly terminates on the Little Gros Ventre in Jackson's Basin, to the northwest of Station XII. To what extent the strata in this belt have been disturbed is not elearly made out. Nor is the contact of the Hoback Cañon ridge with the southern flank of the Gros Ventre Mountains in this quarter better displayed, though the two undoubtedly belong to entirely distinct areas of mountain upheaval, as will be further noticed in another place.

The Carboniferous series in the Hoback Cañon ridge offers striking resemblances to the same series as developed in the Snake River Range to the northwest of the Grand Cañon; the upper measures consisting of gray, buff, and flesh-tinted hard sandstones and red arenaceous deposits, including beds of more or less siliceous and sometimes magnesian limestones. This upper siliceous member is of great thickness (the exact measurement in feet would be difficult to determine after so hasty exploration), and in the deeper gulches and eañon it has contributed immense quantities of fragmentary materials to the steep taluses. With the inferior and perhaps heavier limestone member the whole series probably attains a thickness abore 3,000 feet in this area.

\section{JOHN D $A$ Y RIDGE.}

West of the Hoback Cañon ridge a nearly parallel mountain ridge extends from the southern line of the district, where it is identified with the Green and Snake River water-divide, northwards in a nearly direct course a distance of 22 miles, terminating in the angle at the junction of the Hoback and Snake Rivers, and which may be distinguished by the above appellation.

The belt intervening between the Hoback Cañon and John Day ridges is partly drained by the lower south fork of the Hoback, and north of the latter stream the area here alluded to merges into the valley of the Snake above the Grand Cañon. To the sonth a high divide separates the Hoback drainage from the sources of the East Fork John Day's River, south of which one of the upper tributaries of the main Hoback takes 
its rise within the same basin on the extreme southern boundary of the district. This north-south valley belt has a length of about 25 miles from our south line to where it finally merges into the Snake Valley, in east-west extent ranging from 3 to 6 miles, approximately. It is entirely occupied by Mesozoic and Cenozoic formations, which uniformly incline off the Carboniferous in the west flank of the Hoback Cañon ridge. Along the western border of the basin, or high up on the east flank of the John Day ridge, the strata have been faulted with downthrow on the east amounting to several thousand feet, so that the uppermost or latest of the geologic deposits impinge against the Carboniferous, which latter forms the crest of the ridge.

South of the East Fork John Day's River, which crosses this central mountain ridge in a deep cañon 4 or 5 miles north of our south line, the interspace between the two ridges is apparently occupied by Laramie, possibly also Cretaceous, deposits, which here hold a much higher actual altitude than is the case farther north, the later formations having been removed to a large extent, at least, in this quarter. The exact line of the fault probably passes well to the east of the monoclinal erest of that part of the ridge south of the East Fork John Day's River, which is made up of heary deposits of hard light-reddish sandstone and gray limestones of the Upper Carboniferons. These deposits, which were identified from specimens obtained at Station VII by Mr. Clark, dip at a moderate and steepening angle of inclination to the westward, presenting rugged escarpments on the east several hundred feet in height. East of the heights the inferior limestone ledges rise up more gently in the same direction, appearing in long lines of step-like exposures in the high plateau of this part of the basin.

In the divide north of the East Fork, however, in the line extending across from Hoback's Peak (Station VI) to Station VIII on the John Day ridge, the section discloses the entire Mesozoic series, as developed in this region, including above a heavy series of soft buff and gray sandstones and arenaceous clays probably referable to the Laramie. Two or three miles to the northeastward of Station VIII a high outlying ridge, between the forks of the lower south branch of the Hoback, about midway between the Hoback Cañon and John Day ridges, is here crested with strata of the age of the Bear River Laramie. These consist of browuish gray and buff sandstones, dark blue, drab, and chocolate-red shales, with more or less indurated layers and occasional ledges of dark siliceous limestone. The latter beds at one point in this vicinity afforded a few fossils, Goniobasis macilenta White, Corbula pyriformis Meek? Pyrgulifera humerosa Meek, Unio vetusta M., Se., and obseure vertebrate remains, which identify the strata with the Bear River division. It is very difficult to estimate the exact vertical extent of this member, owing to the soft character of the beds, which readily yield to atmospheric erosion, and althongh the belt it occupies is exceedingly broken, few good exposures are to be met with. However, it probably reaches a thickness of several thousand feet, and is apparently conformable to the Jurassic beds beneath. At the above locality the dip is westwardly at an angle of $35^{\circ}$, the intervening depression on the east being occupied by the Jura-Trias which rises up on the west flank of the Hoback Cañon ridge, and which apparently folds round the south extremity of the ridge on which Station V was located. On the west, in the saddle reaching over to the John Day ridge in the vicinity of Station VIII, a heavy series of greenish gray and light buff sandstones and soft elayey deposits succeeds, dipping uniformly westward, and reaching within 200 or 300 feet of the crest of the latter ridge, in abrupt 
John Day Ridge.

Hoback Cañon Ridge.

Plate IV.

Sta. $\mathrm{V}$ ridge.

Sta. II ridge.

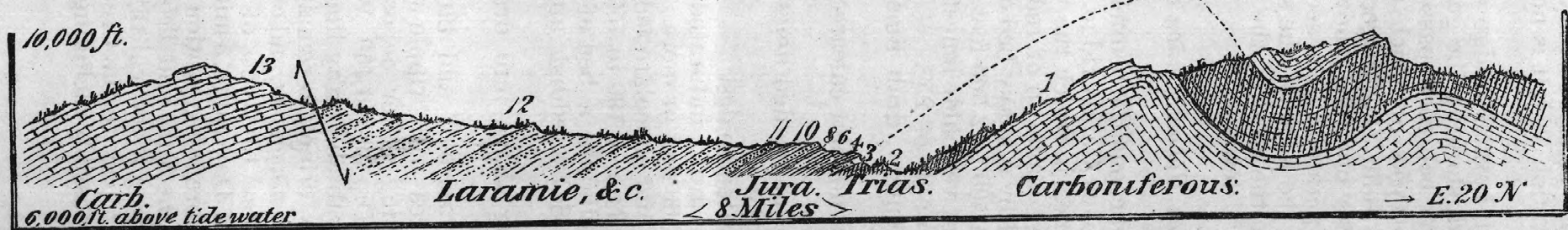

Section of Mesozoic formations betreen Hoback Cañon and John Day Ridges. 
spurs defining beautiful amphitheaters eroded out of the Carboniferous limestones which constitute the main mountain ridge. The position of the fault may be closely located at this locality, but to the sonth, in the undulating plateau east of Station VI, it is not so clearly indicated, as seen from this point.

From the above mentioned Laramie ridge an extensive view of the surrounding country is gained, showing the general geological features most clearly. The Bear River belt soon passes to the west side of the Hoback tributary, below the forks of which it is dimly traced in the rough slopes rising up on the John Day ridge. In the latter quarter a somewhat detailed section was obtained, showing the Jura-Trias and later deposits, which is incorporated in the section through Station V. This section commences near the forks of the stream, and is thence carried westward up the slope to the crest of the John Day ridge, presenting the following stratigraphic details:

\section{Section across basin between Hoback Cañon and John Day ridges.}

No. 1. Reddish and buff siliceous Carboniferous deposits, plating the west slope of Station V, Hoback Cañon ridge.

No. 2. Triassic red sandstones, in which the valley of the creek is here excavated. This series is here made up of red sandstones and grayish red arenaceous shales, capped by a heavy bed of buff sandstone, dipping WSW., at an angle of $35^{\circ} ; 1,500$ to 2,500 feet.

No. 3. Soft, buff, brecciated, vesicular limestone, with calcite, forming a heavy ledge. Dip WSW., angle of $25^{\circ}$.

No. 4. Rather hard, fragmentary, drab limestone, with Jurassic fossils. A heavy bed.

No. 5. Drab, indurated and nodular calcareous shales, with Pentacrinus, Gryphaca, \&c.

No. 6. Blue, fragmentary, even-bedled limestone, with shaly partings, Jurassic fossils. Dip 320 , WSW.

No. 7. Red, partially indurated shales.

No. 8. Blue limestone and drab, indurated calcareous shales, with Camptonectes, Gryphar, \&c., 300 feet or more.

No. 9. Greenish sandstone and chocolate-red streaked shales, capped by gray, rusty-weathered saudstone, 100 to 150 feet.

No. 10. Reddish shales, including a bed of light drab limestone and rusty indurated clay, overlaid by reddish and light gray sandstones, 300 to 500 feet.

No. 11. Dark shale, passing above into drab shales with indurated bands, 300 to 500 feet.

No. 12. Heavy series of gray, buff and bluish, rusty and reddishweathered sandstone, in places with ripple-markings, outcropping in ledges separated by intervening softer deposits, and exposed over an extent above a mile across. Dip $30^{\circ}$ to $45^{\circ}$, WSW.

No. 13. Light and dark drab and gray limestone, cherty and sparseamed, containing Zuphrentis, crinoidal remains, Orthoceras, upper layers, charged with Zaplerentis, Syringopora, and other Carboniferous fossils. Dip $10^{\circ}$ to $40^{\circ}$, WSW., a vertical thickness of about 800 feet exposed in east face and crest of the John Day ridge, 5 miles north of Station VIII.

The lower members of the foregoing section are clearly referable, by their fossils and lithology, to the Juma and Trias. But the series above the black clays, No.11, including a vertical thickness of a few thousand feet, are doubtfully referred in part to the Cretaceous, but mainly to a later period, or the Laramie, possibly including early Cenozoic deposits. 
There appears to be no break in the coniormity of the earlier and later deposits of this series of strata, and this fact, notwithstanding the modern appearance of the upper sandstones, suggests their identity with the Laramie formation. The impingement of the late sandstone deposits against the Carboniferous limestones in the foot of the sharp rise culminating in the crest of the John Day ridge is shown in the section diagram, and needs no further explanation. The junction of the Laramie and Carboniferous beds marks the position of the fracture in which resulted the fault, the downthrow of which probably amounts to not less than 6,000 feet at its locality. The crest of the John Day ridge was followed from this point, south, as far as the heights overlooking the gorge of the East Fork John Day's River, the Carboniferous limestones forming a marked monoclinal the whole distance. To the north, although this part of the ridge was not visited, except at its extreme northern end, where it terminates on Snake River, the appearances indicate precisely the same state of things.

Between the line of the last section and the Hoback the earlier Mesozoic formations again pass to the east side of the valley basin, where the later or Bear River beds are tolerably well exposed in clayey slopes and tilted ledges to the north and in the vicinity of Station IV. But in this quarter the earlier members are less well exposed in the outlying slopes on the west foot of the Hoback Cañon ridge. At Station IV, which occupies an eminence of a few hundred feet elevation, and between two and three miles south of the confluence of the Lower South Fork and the Hoback, obscure ledges of grayish buff and reddish laminated sandstone interbedded with bluish shales appear, and in the summit underlying a similar sandstone ledge occurs a considerable thickness of dark-blue indurated clays. Below the latter, arenaceous indmated layers afforded a few fossils, amongst which Dr. White has recognized Limncea vetusta, Meek, Compeloma megaspira, Meek? Corbicula (Veloritina) Durkeii, Meek? and a fragment of reptilian bone. These deposits incline westwardly at an angle of $30^{\circ}$. On the opposite, west, side of the stream similar deposits appear in stee] bluff slopes, presenting more or less distinctly banded dark leaden and gray exposures along the line of strike, which may be traced several miles up and down the stream, and rising up in the east flank of the John Day ridge, where they pass into the beforementioned yellow-weathered sandstones and clays. Above the station the valley narrows, the Bear River ledges appearing in hog-back ridges, male up of blueish, brown-weathered sandstones, and more or less arenaceous clays, including layers of light drab limestone, associated with variegated chocolate-red, shaly calcareous sandstone, all dipping south of west at angles of $30^{\circ}$ to $45^{\circ}$. Higher up the valley widens into a beautiful terraced intervale, the adjacent slopes wooded with pine and fir trees, although vast tracts have been devastated by forest fires. Below the caũon the Hoback flows through a fine terraced basin-valley, closing up a little lower down, but retaining its valley character to the confluence of the Snake, four or five miles below.

To the east, south, and west the view as seen from Station IV is limited by the bordering mountain ridges, but to the north, looking out into the lower part of Jackson's Basin, the southern half of the Téton Range rises boldly into view. In the latter direction are observed some interesting phenomena in relation to the position of the geological deposits occurring in the northern portion of the present basin area. Along the course of the little stream 3 to 5 miles north of the Hoback, and in the bordering hills, there appears a rather heavy deposit of dull- 


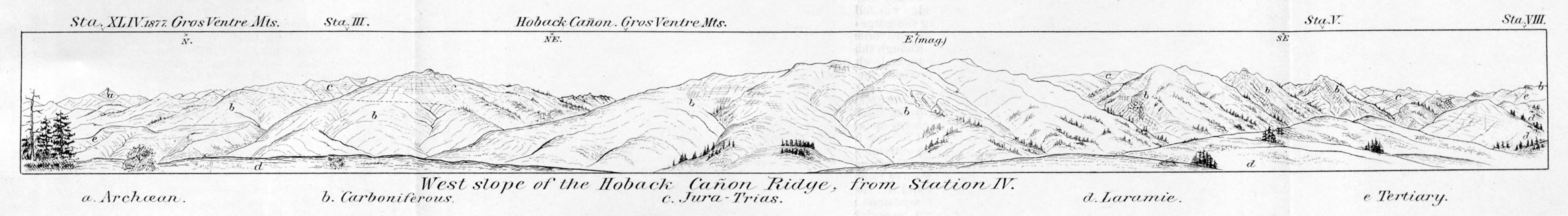

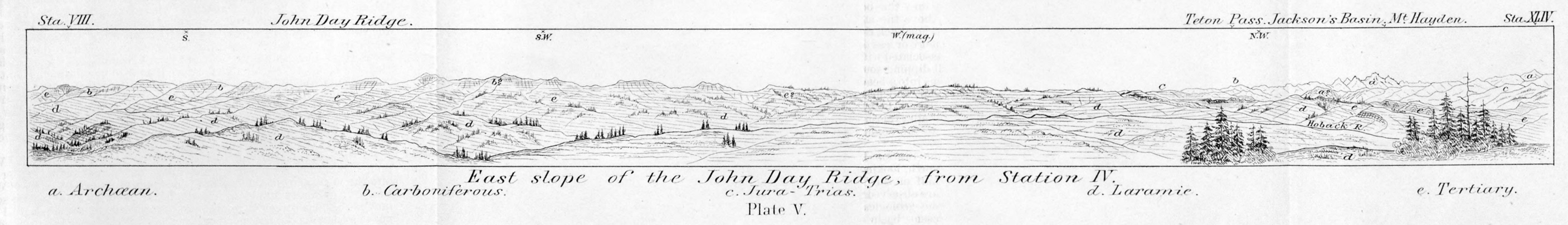




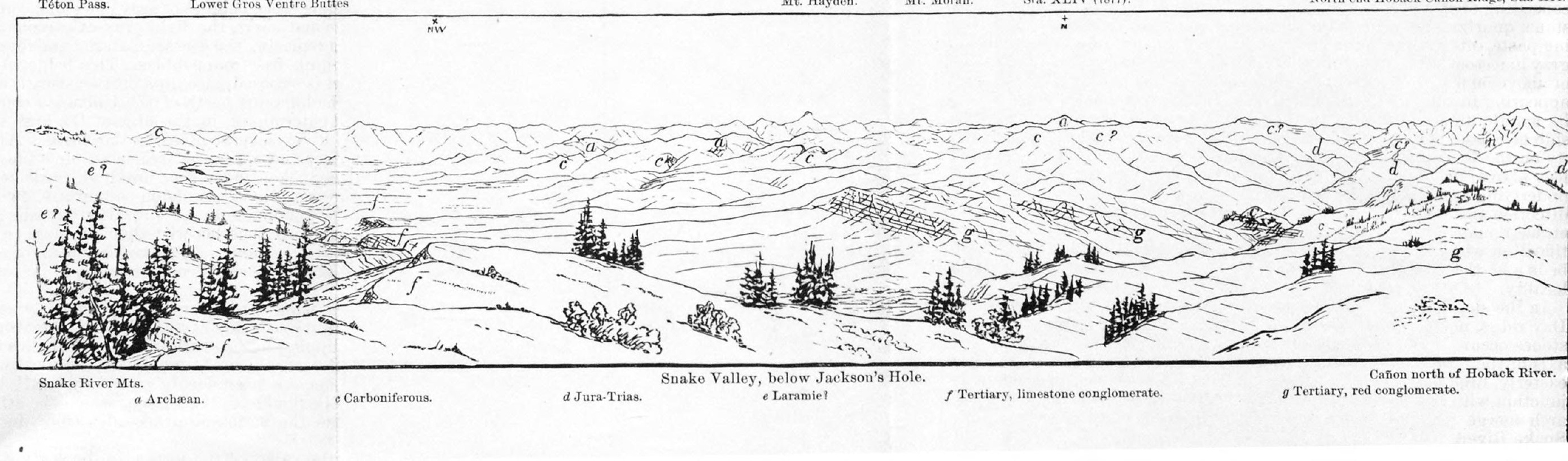


red, soft, gritty, slightly calcareous clays, holding quantities of lime. stone and red sandstone bowlders, also fragments of gray sandstone identical with beds occurring in the Laramie. These deposits incline quite uniformly to the notheastward at an angle of about $15^{\circ}$, abutting against the Carboniferous ledges in the Hoback Cañon ridge along the eastern margin of the basin. At the latter point the juxtaposition of the stratigraphically widely separated formations is not as clearly displayed as could be wished, yet it is sate to infer from their relative position either the existence of a fault by which the Carboniferous beds are brought up to the level of the Tertiary conglomerate, or the latter beds, which were originally laid down horizontally, have been upraised into their present position by subsequent disturbances situated in the central portion of this mountain range.

The conglomerate deposits may be traced in beautifully weathered exposures in the outlying slopes along the west foot of the Hoback Cañon ridge to the north and south of the little stream, where they were also examined by Mr. Perry. To the west they are underlaid by a gray ledge, consisting of water-worn pebbles of gray limestone, varions kinds of sandstone, quartzite and chert, the light-gray calcareous matrix, or cementing paste, often replacing the coarser material and forming a coarse lightgray limestone quit free from pebbles. This ledge, of which a thickness of above 50 feet is exposed, also dips northeastward at an angle of $20^{\circ}$, appearing in the hills just north of the Hoback a couple of miles above its mouth, and outcropping in the edge of the high terrace on the east side of Snake River several miles to the north. At the former locality on the Hoback the exposures reach an elevation of 1,500 or 1,600 feet above the Snake, and a few hundred yards to the west a heavy underlying series of grayish sandstone outcrop, showing about the same direction and rate of inclination. The latter deposits afford obscure vegetable remains, which, together with their lithology, warrants their identification with the Laramie. If there be nonconformity between these beds and the gray calcareous conglomerate, it is not apparent at this locality.

In the slopes rising into the more rugged outlying lills of the John Day ridge, on the south side of the Hoback, the same series of sandstones occur, dipping to the southwestward at angles of $15 \circ$ to $200^{\circ}$. The axis of the fold here indicated, extending in a northwesterly and southeasterly direction, has been deeply eroded by the Hoback just above its junction with the Snake, to the west of which the strata composing the arch merge into the series elsewhere described, in the section along: Snake River.

How far up the valley of the Snake, to the north, the gray calcareous and red conglomerates extend was not ascertained. However, their extension in that direction suggests the possible identity of at least the gray calcareous deposit with the soft calcareous and earthy late Tertiary or Pliocene beds known to exist in the mountain-locked basin east of the Tétons. That these deposits belong to a very late geological time is abundantly indicated by the nature and derivation of the component materials-the coarse detrital materials plainly having been derived from. the Palæozoic and Mesozoic strata occurring in the adjacent mountains. Their apparent conformity and nonconformity in relation to the supposed Laramie deposits which they immediately overlie and the Carboniferous formations against which they impinge in the foot of the Hoback Cañon ridge complicate the determination of their exact position in the geological series. 


\section{JOHN DAY BASIN.}

The area drained by John Day's River comprises the extreme southwestern portion of the district, the examination of which was limited, for want of time, to the eastern portion, or that drained by the East Fork. On the west a rather high and rugged mountain ridge (the Salt River ridge) intervenes between John Day's and Salt rivers, shutting out the view of the valley of the latter stream. Along the crest banks of snow sill lingered in shaded ravines as late as the middle of August. A few miles south of the Grand Cañon of the Snake and south of the water pass of the John Day's the high crest abruptly falls to a lower mountain ridge, which forms its continuation northward; to the south the mountain gradually rises in altitude, presenting a uniform ridge 10,000 to 10,800 feet in height in the district explored the previous season by Messrs. Gannett and Peale. The belt between this ridge aud John Day's ridge is occu, ied by a hilly basin holding many pretty little valleys and meadow basins. Both the John Day's and its East Fork flow through willowy intervales hemmed by steep slopes.

Descending the west flank of the John Day ridge, the upper siliceous deposits of the Carboniferous fall steeply, their debris strewing the slopes and burying the foot of the mountain beneath great piles of fragmentary materials. In the edge of the parallel depression more or less well-exposed Jura-Trias deposits may be traced both to the north and south, dipping uniformly westward, and occupying a belt one or two miles in width. Beyond lies a wider belt, 4 to 5 miles or more across, in which a heavy series of sandstone and clay deposits is met with, also dipping westwardly at angles of varying inclination.

On the western border of the latter belt, in the vicinity of the ridge lying between the forks of the John Day's, on which Statious X and XI were made, this series of beds, together with the Jura (?), is elevate 1 into a sharp anticlinal fold, with northeasterly dips of $50^{\circ}$, more or less, and much less steep westerly inclination. But ascending to Station XI ridge, the strata resume their westerly inclination, and from the crest they descend into a depression where the series impinge against the abrupt mountain barrier whose basis rocks consist of the heavy gray limestone ledges of the Carboniferous, overlaid by red sandstones probably belonging to the middle member of the same series. The latter deposits also dip westward in the direction of Salt River Valley, though in places they have been described as being much disturbed, as noticed by Professor Frank Bradley in the lower portion of the Grand Cañon of the Snake.*

To the north, along the Snake, the Jura-Trias outflanks the John Day ridge, the Jurassic member of the group appearing in fine exposures made up of variegated clays, sandstone and limestone ledges, in the abrupt mountain slopes hemming the right bank of the river. Both formations occur along a little stream which rises in a lakelet on the west foot of the John Day ridge, a few miles to the north of Station VIII, gaining the Snake just below the last bend in its course through the Grand Cañon. The Trias here exhibits its typical lithology, consisting of buff and red sandstones, dipping off the Carboniferous mountain ridge. The Jura near the confluence of the streams exposes heavy beds of more or less indurated light drab calcareous shales and limestone, which afford abundance of Gryphea calceola.

\footnotetext{
*Hayden's United States Geological Survey, Montana, Idaho, and Wyoming, 1872, p. 268 .
} 

Plate VII.

Sta. XI.

John Day Ridge.

22

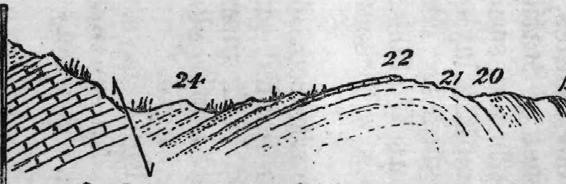

carb.

dNile $\rightarrow$

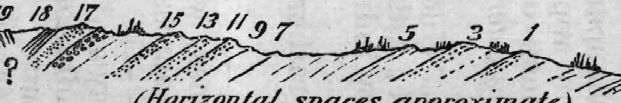
Section through Station XI. 
From the divide at the head of the west branch of this stream and a shallow meadow-valley tributary to the East Fork of John Day's River, a section was hastily examined extending over to Station XI ridge in the vicinity of Station 1X, a distance of about 4 miles, or between 6 and 7 miles west of the crest of the John Day ridge. 'The section alluded to, a diagram of which is given on an accompanying plate, is described below:

\section{Section east of Station IX.}

No. 1. Carboniferous limestone, in crest of Station VIII, or the John Day ridge.

No. 2. Heavy deposit of red or flesh-colored and white quartzitic sandstone, much broken up, corresponding to the upper siliceous member of the Carboniferous.

No. 3. Imperfectly exposed series of reddish and buff laminated sandstones and arenaceous shales, dip WSW. at angles of $35^{\circ}$ to $45^{\circ}$, occupying a belt half a mile or more across. This series is the equivalent of the Trias, its outcrop for a large part of the distance forming a well defined and, in places, rugged outlying ridge along the west foot of the mountain. Probably 2,000 feet thick.

No. 4. Clays and chocolate-red sandstone.

No. 5. Light weathered, bluish, spar-seamed, and cherty limestone, a thickness of 5 feet exposed of an apparently heavy bed, dipping westward. Contains obscure fragments of fossils, a small gasteropod, referred provisionally to Lioplacodes veternus M. and H., being most numerous and best preserved.

No. 6. Space, probably shales. (150 yards, +- .)

No. 7. Buff and rusty colored; rather hard fragmentary sandstone, associated with ferruginous gritty indurated deposits.

No. 8. Space. (100 yards, +-.)

No. 9. Dirty gray, laminated, rather hard sandstone; dip 400, about W. $100 \mathrm{~S}$.

No. 10. Space. (300 yards, +-.)

No. 11. Reddish buff sandstones, with traces of vegetable remains, forming a heavy ledge, 50 yards across the exposure.

No. 12. Space. (150 vards, +- .)

No. 13. Heavy bed of light gray and buff, reddish tinted, fragmentary sandstone, overlaid by grayish indurated clay and a band of light colored chert, 50 yards across the exposure.

No. 14. Dark blue, indurated clay shales, exposed in steep bluff slopes on the east side of East Fork, east of Station IX.

No. 15. Gray, dark rusty weathered sandstone, forming a heavy bed overlaid by greenish-gray and reddish layers with bands of flesh-colored chert and dark indurated clay shales. Exposed in bluffs on the west side of East Fork; dip $30^{\circ}$, about W. $30^{\circ}$ S.

No. 16. Yeliow and drab shales, with seams of white calcite, underlaid by gray, shaly sandstone.

No. 17. Gray and buff, dirty weathered, obliquely laminated sandstone.

No. 18. Gray and reddish thin-bedded sandstone, including a ledge of conglomerate composed of water-worn quartz pebbles, together forming a heavy bed outcropping in the broken slopes east of Stations IX and $\mathrm{X}$; dip westward at a moderate angle.

No. 19. Gray sandstones and light clays, exposed at intervals over a space 500 yards or more across; dip south westward.

No. 20. Rusty gray sandstone, obscurely exposed ledge, tilted nearly vertical. 
No. 21. Similar grayish sandstones containing plant impressions, exposed in ontlying slopes descending east from Station IX, over a space three-quarters to one mile across; dip westward.

A similar section was observed a few miles to the north, in passing along the ridge separating the East Fork and the Snake drainage, on the way to Station XI, which, while it is made up of the same series of deposits described above, exhibits some additional stratigraphic details not seen at the above locality. The eastern portion of the present section corresponds to Nos. 1 to 6 of the above section, and thence westward such exposures as occur over a belt about three miles wide are noted below.

\section{Section through Station XI.}

No. 1. Reddish gray sandstone, including chocolate-red shales.

No. 2. Space. (400 yards, + - .)

No. 3. Reddish-gray sandstone.

No. 4. Space. (300 yards, + - .)

No. 5. Reddish sandstone, dip $20^{\circ}$ to $25^{\circ}$, WSW.

No. 6. Space, with ledges of gray sandstone. (700 yards, + - .)

No. 7. Dark-blue shales, resembling Bear River deposits west of Hoback Cañon ridge.

No. 8. Space. (200 yards, +- .)

No. 9. Coarse and rather friable gray sandstone.

No. 10. Space. (150 yards, +- .)

No. 11. Heary ledge of gray laminated sandstone, containing obscure plant remains; dip WSW.

No. 12. Space. (200 yards, + -.)

No. 13. Light greenish-gray, shaly sandstone.

No. 14. Space (100 yards, +- ), with darkish indurated and soft lightcolored shales interbedded with sandstones.

No. 15. Gray and reddish tinted laminated sandstone, containing fragments of fossil wood and holding a band of partially oolitic light and greenish tinted chert; dip $25^{\circ}$ about W. $200 \mathrm{~S}$.

No. 16. Space (900 yards, + - ), with ledge of brownish-gray sandstone containing fragments of endogenous wood, and in the upper and westerly portion ledges of conglomeritic sandstone apparently interbedded with soft clays and arenaceous deposits; dip WSW.

No. 17. Sandstone; dip WSW.

No. 18. Dark shales.

No. 19. Space, with obseure ledges of grayish brown-stained sandstone; nearly vertical.

No. 20. Gray and brown shaly sandstone, overlaid by dark-blue shales, like No. 18; dip northeastward at an angle of 500 and less. Exposed in east flank of slope rising into Station XI, over a space between the conglomerate, No. 16, and summit, about 900 yards across.

No. 21. Greenish-gray sandstone and chocolate-red shales, apparently making a heavy deposit.

No. 2.2. Drab fragmentary limestone, associated with chocolate-red shales containing calcareons nodules. The limestone which contains a small gasteropod too imperfect for specific determination, appears in the sammit of the ridge at Station XI (8,549 feet altitude) dipping at a moderate angle of inclination westwardly.

No. 23. Rusty-weathered chocolate-red shales and indurated arenaceous beds, exposed in the west slope of Station XI ridge; dip westward.

No. 24. Drab shales and indurated arenaceous beds; dip westward 
into deep ravine, apparently impinging against the faulted Carboniferous deposits in the east flank of the Salt River ridge.

The conglomerate ledges mentioned under No.16 of the foregoing section are undoubtedly identical with bed No. 18 of the preceding section east of Station IX; also the vertically-upraised sandstone beds, 19 and 20 respectively of the two sections, are doubtless the same ledge. The latter horizon marks the site of a sharp synclinal flexure, into which the strata are wedged and so crushed together as to render the determination of the exact character of the fold extremely difficult. The darkblue shales included in No. 20 are not dissimilar to the supposed Bear River Laramie shales, No. 7, farther east, while the limestone, No. 22, found on the summit contains a small univalve shell resembling similar imperfectly-preserved forms occurring in Jurassic limestone beds described under the preceding section. The latter inference and surmised identity of the deposits in question, if well founded in fact, indicate a fracture or fault in the strata at this point, which must have taken place during the folding of the beds into the anticlinal of Station XI, and which latter movement was probably closely synchronous with that eoncerned in the upheaval of the neighboring parallel ridges of this mountain belt.

The western slope of Station XI descends with steepening abruptness into a deep depression largely filled with grayish deposits (No. 24), on the farther side of which rises, a more prominent mountain mass belonging to the ridge bordering the east side of Salt River Valley and properly considered as the northern terminus of the mountain ridge bearing the same name. In the abrupt eastern face of the latter mountain a fine section is exhibited, the lower two-thirds or more, based on the Carboniferous gray limestones, capped by a few hundred feet thickness of red arenaceous deposits, constituting the summit. Although the latter deposits bear lithologic resemblance to the "red beds" of the Trias, they may prove to belong to the red sandstone horizon forming the middle member of the Carboniferous series of the region. The strata in the latter mountain ridge dip to the westward, the general exposure as seen from Station XI being along the strike of the strata, and in places extensively barred, though much eroded, by drainage action. Between this mountain and the confluence of John Day's River and the Snake, at the lower entrance to the Grand Cañon, a belt some 5 miles across intervenes, which is known to be composed largely, if not entirely, of Carboniferous deposits, an account of which was given by Professor Bradley in the report of this survey for 1872. To the south, in the adjoining district, Dr. Peale found the same deposits extensively developed in the southern continuation of this mountain ridge, where they form a synelinal depression.

There can be little doubt that the strata composing the latter mountain ridge are faulted, the Carboniferous beds having been forced up into a position high above those pertaining to the Mesozoic and Laramie epochs which flank the ridges west of Stations IX and XI, descending into the valley of John Day's River. The condition of things referred to is sufficiently clearly interpreted in the diagram of the foregoing section, which, together with the diagrams of sections farther to the east, aftord a comprehensive view of the structural features of this mountain zone in the territory immediately south of the Grand Cañon of the Snake.

From the above account of the observations made in this region, it will have appeared that the work of exploration was carried nearly across the Wyoming Range; indeed, the results practically give a connected section across this portion of the range, between the upper basin of the 
Hoback and Salt River Valley. But, unfortunately, the facilities were entirely insufficient for acquiring a knowledge of the mountain tract forming the continuation of this range in the region north of the Grand Cañon of Suake River, it being impossible to trace out in a satisfactory manner the complicated structural features, which obtain with equal force in that quarter, from such distant points of view afforded by the mountain eminences on the sonth side of the Grand Cañon. The obser. vations of Professor Bradley, in 1872, disclosed several folds and extraordinary local disturbance in the strata comprising the natural section exposed in the walls of the Grand Cañon, and which doubtless bear intimate connection with the facts observed during the perhaps more detailed work of the present season briefly alluded to above. The region north of the Grand Cañon is excessively cut up by the combined effects * resulting from geologic disturbance and subsequent aqueous erosion, some idea of which may be gathered from inspection of the topographic charts prepared by the survey; and while the one state of things offers exceptionably favorable facilities for the detail study of local sections, the other renders a more general study, especially at this distance, extremely hazardous and unsatisfactory. In certain instances the identity of formations may be confidently recognized, but, in other cases, color or lithological appearances are insufficient criteria upon which to affirm the stratigraphical position and age of extensive deposits prevalent in that quarter. The ontlying gray ridge on the west, which forms the eastern barrier of the lower valley of Snake and Salt rivers, is unmistakably Carboniferous. Then succeeds a wide belt, out of which huge ridges have been sculptured by the elements from pale-red and buff beds, which seem to hold a position high above the latter, possibly forming part of the Laramie series, which appears to be much better developed (probably due to its being less extensively denuded) in that quarter than in the region visited the present season. And to the east of the latter, extending over to the Upper Snake in the vicinity of the lower portion of Jackson's Basin, the mountain escarpments exhibit all the lithological appearances familiarly ascribed to the Jura-Trias and post-Jurassic formations of the region. More than this the nature of the facts perhaps do not warrant. But a brief summary of the examinations of that part of the latter belt lying along: a part of the course of the Grand Cañon visited the present season is here appended.

Our route brought us to the Snake, at the confluence of a small tributary draining part of the west flank of the John Day ridge, about seven miles in a direct line sonth of the mouth of Hoback's River. This little valley is wholly excavated in the westerly-dipping Jura-Trias deposits, the Grsphæa bed of the former being well developed in the immediate neighborhood of the confluence. Below this point the Snake enters that part of its course more properly designated by the term cañon. We here found on the terraced intervale indications of old placer workings, which had been opened eight years ago by a party of miners associated with Jeff. Stantiford, a well-known prospector and explorer of this region. The enterprise was, however, interfered with by the Indians, since when no organized mining operations have been resumed in this quarter. The locality, which is wonderfully interesting, both in its scenic and geologic surroundings, was carefully examined by my companion, Mr. Perry, with especial reference to the placer deposits and warm and mineral springs. A mile or so above this place the Snake changes its southerly course to a westerly direction, which it pursues thence to the debouchure of the Grand Cañon. The steep hills on the west side of the river, opposite and for some distance above the abandoned placer mines, present fine 


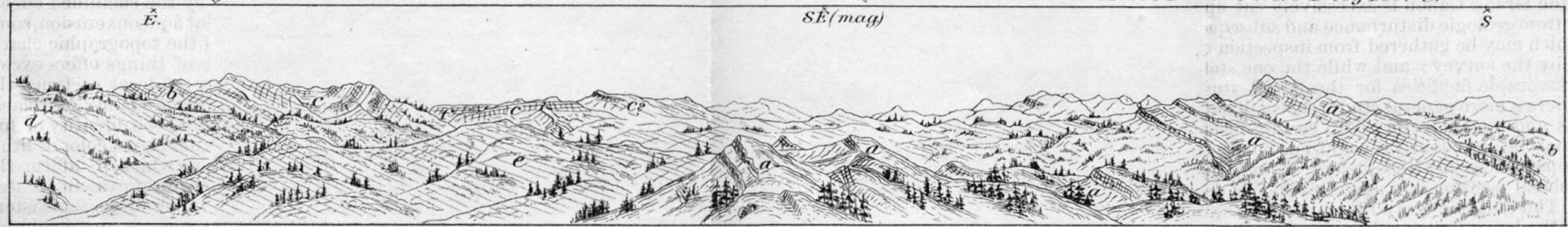

\section{Wyoming Mountains.}

\section{From Station VIII (John Day) Ridge}

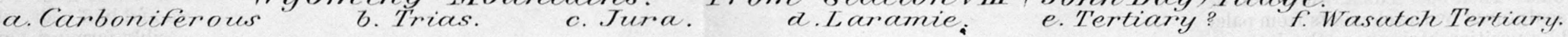

Sta.X. Caribou Mtn:

Snatse River Mountains

Téton Pass. Téton Mts

Salt Rividge. JohñDas Cañon. Sta.XI.

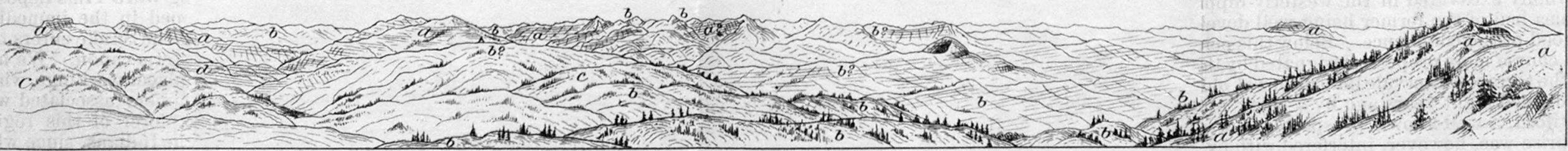

Snake River and Wyoming Mountains. From Sta. VIII (John Day) ridge. a. Carboniferous. 
exposures of probable Jurassic strata, showing alternations of variegated clays and indurated beds resting upon the Triassic red sandstones, the whole uniformly dipping south of west. The exposures, however, for some distance, appear along the strike of the strata, the section presenting the following lithologic appearance, as seen from the east side of the river, the vertical spaces being roughly estimated:

\section{Section west side of Snake River, in the Grand Cañon.}

No. 1. Red sandstones; Trias.

No. 2. Drab clays, a heavy bed, 200 feet or more; Jura.

No. 3. Ledge of dirty gray rock, probably limestone.

No. 4. Clays, with indurated layers, 100 teet.

No. 5. Drab and chocolate-red clays, alternating with brown and gray sandstone and limestone layers, 100 feet.

No. 6. Chocolate-red and urab clays, 100 feet.

No. 7. Heavy ledge of light gray rock, probably limestone, 40 feet.

No. 8. Drab and chocolate-red clays, 40 feet, with a bed of gray limestone (?), 15 feet.

The exposures along the east side of the river in this vicinity are much less satisfactorily revealed. In the neighborhood of the placer mines along the little stream draining the west slope of John Day ridge, the following Jurassic strata underlying the Gryphoca bed appear: Half a mile above the debouchure of the gulch there appears a ledge of drab, fragmentary limestone, containing fragments of Ostrea (?), a small gasteropod, and segments of the the column of Pentacrinites, underlail by drab and chocolate-red rariegated shales and earthy buff-weathered limestone, dipping about W. $15^{\circ} \mathrm{S}$., at an angle of $38^{\circ}$. Underlying the above occurs a heavy bed of drab indurated calcareous shales, with fragments of a chambered shell resembling Ammonites, also fragments of a conchifer, Pentacrinites, \&c. Then follows a ledge of softish butf-gray, magnesian (?) limestone, with pink ealcite seams, dip $43^{\circ}$ southwest, followed by a heavy bed of gray, reddish tinted quartzitic sandstone, weatherin 9 rusty reddish, and changing to red, laminated sandstone below, dip 370 to $40^{\circ}, \mathrm{W} .20^{\circ} \mathrm{S}$. The latter red sandstones belong to the Trias. They occur in a belt of rugged, outlying ridges along the foot of the John Day ridge, whose crest, as already stated, is composed of Carboniferous rocks, the limestone and siliceous débris of which is plentifully scattered over the lower slopes and incorporated with the soil, which is largely derived from the breaking up of the Jura-Trias deposits.

'The latter section of strata is the same as that mentioned in connee. tion with the sections east of Stations IX and XI ridge. In the extension north of the Grand Cañon it probably constitutes a belt of Mesozoic strata continuous with that noticed the previous season at Station XL, in the Snake River Mountains. Further, as was at that time surmised, it appears highly probable that these formations are faulted in the lat. ter quarter-the western border ridge of the Snake River Mountains corresponding in geologic structure and in its disturbed condition to the John Day ridge in the southwest portion of the present district. The Mesozoics were there found to be overlaid by a great thickness of drab, buff, and variegated pale red deposits, the same as above noticed west of Station XI, and there as here the deposits apparently abut against the Carboniferous along the line of the fault. It will thus be seen that this faulted condition, in the areas here alluded to north and south of the Grand Cañon, has an extent of at least 60 miles; its southeasterly extension in the Wyoming Range was defined by Dr. Peale the previous 
season. It is not improbable that the exceedingly complicated belt mentioned by Professor Bradley* in the Grand Cañon, in which the strata are tiited and disturbed in an extraordinary manner, involving Carboniferous and Mesozoic beds, was caused by proximity to the disturbances that produced the great faults of the John Day and Salt River ridges. But it will have been made apparent from the observations along the divide between John Day's and Salt rivers, in the neighborhood and east of Station XI, recorded in foregoing pages, that only one well defined anticlinal arch was found in the region lying between the John Day ridge and the similarly faulted Carboniterous monoclinal mountain that forms the northern terminus of the Salt River ridge.

The ground traversed in ascending the Snake Valley to the mouth of Hoback's River has already been reported upon by Professor Bradley, who accompanied the Snake River expedition of this survey in 1872. This part of the valley has a general northerly direction, and though lemmed by hills it hardly deserves the name cañon. At intervals the valley expands, aftording narrow tracts of gravelly bottom-land, covered with willows and grass plots, and beautiful clumps of Menzies spruce, aspens, and cottonwood; the hillsides being clothed with pine and the ordinary fir-trees. Interesting examples of terrace formations are also met with in these valley expansions, the highest reaching 250 feet above the river-level. At one point the terrace declivity shows a thickuess of 15 feet of horizontally stratified pebbles and bowlders at an elevation of about 100 feet above the intervale, which is cemented into a quite firn conglomerate. The terraces slope gently torvards the center of the valley, their steep declivities being strewn with the thoroughly water-worn rock fragments which are inlentical wich the materials pav: ing the present sho il river-bed. These consist chiefly of quartz, with some granitic and other rocks, rarely a volcanic bowlder. Pieces of obsidian were found mixed with the terrace gravel, which were doubtless derived from the region of the Upper Snake or from the watershed, many miles to the northeastward. The Snake in this part of its course often occupies a wide, shoal bed, which at this season (August) exposes extensive bars of shingle and cobble-stones, amidst which the stream winds in many channels. The views from the higher terraces, commanding long reaches of the river hemmed by disconnected terraces and the more rugged low mountain borders, are extremely beautiful. The trail along the left bank was found in good condition for the pack-train, and, save at one or two points, without serious obstacles in the way of nraking a wagon road. For railway purposes the valley and Grand Cañon offers a feasible route between the lower valley of the Snake and Jackson's Basin.

For three or four miles the valley is bounded on the east by the John Day ridge, in which the Carboniferous ledges are steeply tilted, inclining at an angle of $50^{\circ}$ to $70^{\circ}$ south of west. The mountain-foot terminates in a steep talus composed of light and flesh-tinted quartzitic sandstone and gray limestone débris. In the outlying slopes occurs a brownweathered gray shaly limestone, containing a few obscure fossils, which Dr. White refers to the young of Ostrea. From this evidence it would appear that these beds probably beloug to a remnant of the Jura, or possibly a later formation, the stratigraphical relations of which are not well made out at this locality, more than that they overlie the Carboniferous. At a locality a short distance higher up the valley, the foot of the mountain is covered with rusty red and brown weathered, bluish and greenish gray sandstone débris, which probably belongs to the same

* U. S. Geol. Survey, Hayden, report 1872, p. 268. 
horizon. The light reddish siliceous beds of the Carboniferous appear in castellated masses high up on the mountain side, and above these, in the crest of the ridge, occurs a series of light grayish deposits of doubtful age. A short distance below, where the valley changes to a north-south course, the Triassic quartzitic sandstones appear in force, forming a rocky point jutting into the river. These strata hold the same southwesterly inclination as do the older formations in the mountain ridge, the strike carrying them along the foot of the hills bordering the opposite side of the rirer for some distance above this point. They here probably attain a thickness of above 2,000 feet, with the same deep-red shaly arenaceous layers below. These deposits continue to a point where the valley course again trends northeasterly. The hills on the east side are well wooded and roughly scored by short drainage gulches, but those on the opposite side are comparatively bare, presenting gentler slopes, in which appears a heavy series of chocolate-red and drab-colored sand- stones and clays, which resemble and apparently hold the position of the Jura. The latter deposits continue in the bordering hills a couple of miles or more, extending inland, northwards, as far as could be seen.

Passing round the north end of the John Day ridge, in the neighborhood of the bend in the valley, about 3 miles below the mouth of Hoback's River, extraordinary exhibitions of disturbance are introduced into the geologic section of this part of the valley. As yet, no clew is obtained of the character of the extreme northern portion of this mountain range, except that the western flank is heavily mailed by the steeply upraised Carboniferous beds. The trend of the main crest, however, veers round east of north, and, from the manner of weathering, it is evident that this portion of the ridge is composed of different materials from those making up the Uarboniferous crest farther south, and which probably represent Post.Cretaceous formations. But in the neighborhood of the tule marsh (which is caused by the overflow of lime-charged warm springs that issue in the south side of the Snake) the slopes are strewn with drab, spar-seamed limestone débris, also fragments of hard, reddish sandstone, recalling the Carboniferous, although no fossils were found by which to establish their identity beyond doubt. In the opposite side of the river, however, the general structural features are well displayed, and beyond the necessary explanatory notes on the accompanying section diagram of this locality, I shall not repeat the observations here made by Professor Bradley in 1872.

\section{Section in right bank of the Snake, below the mouth of Hobacli's River.}

a. b. Dark reddish sandstones (Trias) and chocolate-red and drab sandstones and shales (Jura?).

c. Brownish-red ledge; dip southwestward.

d. Black shales, interbedded with light colored indurated bed; dip northeasterly.

e. Dirty jellow siliceous beds. In the ridge above apparently horizontal, light colored, unconsolidated deposits appear, possibly Quaternary or lake beds.

$f$. Red-colored beds, dipping off flank of spur ridge, southwesterly.

g. Rusty weathered beds, probably gray sandstones; dip southwestward at a steep angle.

h. Apparently soft drab or ash-colored beds, obscurely exposed.

$i$. Rusty weathered, greenish-gray sandstones.

$j$. Chocolate-red beds, apparently indurated clays, curving over and dipping steeply northeastward.

$k$. Indurated drab beds, dip very steep to the southeastward and 
curving up to the west where the chocolate-red beds are seen to form part of arch.

l. Dark rusty-weathered beds, probably gray sandstone, forming jagged crest of spur, with undulating inclination northeastward.

m. Soft, ash-drab deposits, apparently upraised into a low arch, but not clearly made out at a clistance.

$n$. Dark rusty-weathered, probably bluish-gray sandstones and argillaceous beds.

The deposits $a, b$, of the foregoing section unquestionably belong to the west flank of the John Day ridge uplift. The lower arch represented. in the section, on the east flank of which occur the black earbonaceous clays, $d$, may possibly be the northern continuation of the above ridge, and which, in the latter event, was not here fanlted. The reddishbrown ledge, $c$, the sole vestige of the west flank of the fold, strikingly resembles the earthy sandstones associated with the before-mentioned Ostrea? shaly beds found in the west foot of the ridge a few " south. Should the identity sought prove well founded, it would app

that the John Day ridge here sinks sufficiently to allow the Mesozo to completely mantle the arch. The carbonaceous deposits alluded are the same visited by Professor Bradley, and in his notice he refers to the exposure as consisting of "two or three heavy beds of black, calcareous shale and friable clay, with some harder bituminous mud-stones, * * * containing fragments of teeth and bones, probably belonging to amphibians." These deposits are overlaid by a thick bed of chert, probably represented by $c$ of the above section.

The fold represented next above the last described, constitutes the axis of the more elevated, rugged portion of the ridge which here closely borders the stream, and which is believed to lie to the east of the axial trend of the John Day ridge proper. This fold was also mentioned by Professor Bradley, who describes it as being of mountainous proportions, with a nucleus of limestone. Opposite these exposures, as already mentionel, quantities of spar-seamed drab limestone and hard reddish sandstone débris occur in the steep declivities, but in the absence of fossils their age remains in doubt. A short distance above the latter occurrence, however, and opposite this uplift, the trail passes a succession of steeply inclined gray, rusty-weathered, thin-bedded sandstones, with which are associated fragmentary light chert berls, whose ensemble certainly bears close resemblance to horizons is a plant-bearing beds east of Station XT, which were compared with the Laramie. The latter beds are donbtless the same shown at $l$, and if their stratigraphical identity, as above inferred, be correct, the underlying strata composing the axis of the fold may not include deposits of earlier date than the Jura. To the north, however, in the more mountainous region occupying the bend of the Snake below Jackson's Basin, and constituting the extreme eastern flank of the Snake River Range south of Téton Pass, the prevalent rock formations apparently belong to a later or Post-Jurassic age. The latter quarter, however, was not visited, and the inferences arrived at are founded upon lithological appearances made out at a distance.

The deposits $n$ appear in more or less interrupted exposures in the bluff-bank of the terrace, the evenly leveled-off tilted strata bearing the Quaternary deposits which constitute an important element in the composition of the terraces that now fill the valley. These strata contimue as far as the mouth of Hoback River, where good exposures recur in the banks of the latter stream, a short distance abore the confluence. At this locality a thickness of 20 to 30 feet is made up of bluish-gray, thiubedded to shaly, sometimes concretionary, sandstone and fine argillo-are- 
SECTION ACROSS THE WYOMING RANGE, NORTH OF HOBACK CAÑON.

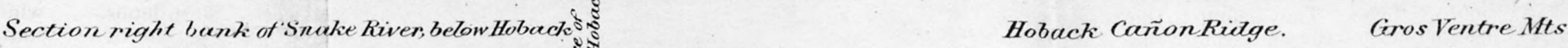

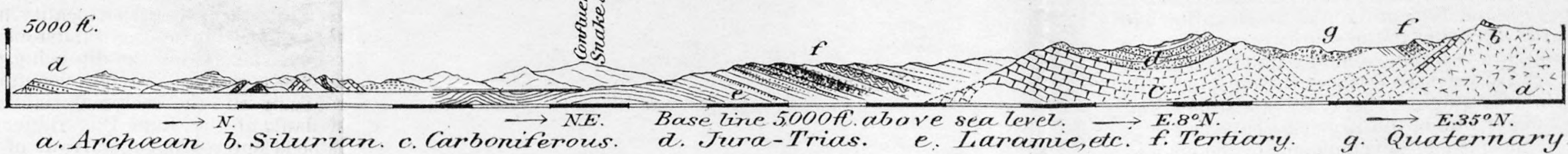

SECTION ACROSS THE WYOMING RANGE, THROUGH STATIONS VI, VIII AND IX.

\section{Salt River Ridge.}

SaltRiverValtey

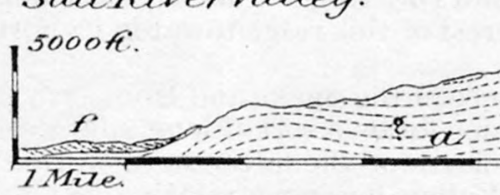

a. Carboniferous.

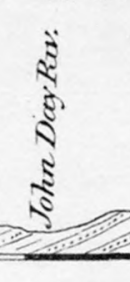

c. Turassic.
Sta. $T X$.
Tohn Day Rerdge

Sta. VIII.

Hoback Cañon Ridge.

Hoback(Sta.VT) PFAK.Hoback
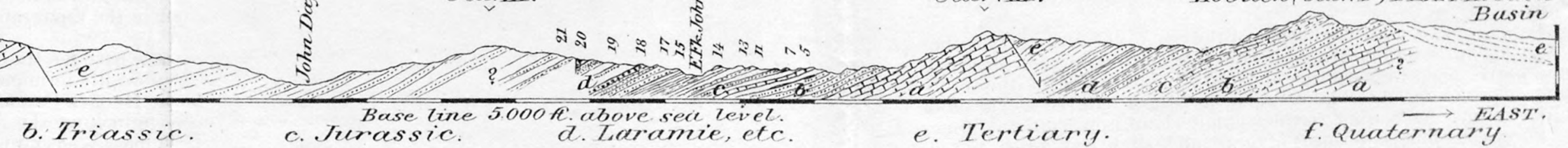

d. Lhove seit zevel.

e. Tertiary.

f: Quaternary

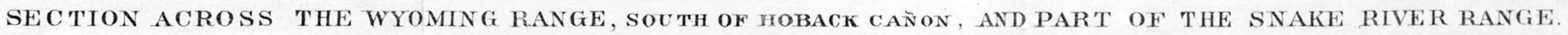
Snate River Range.

Mt.Baird ridge.
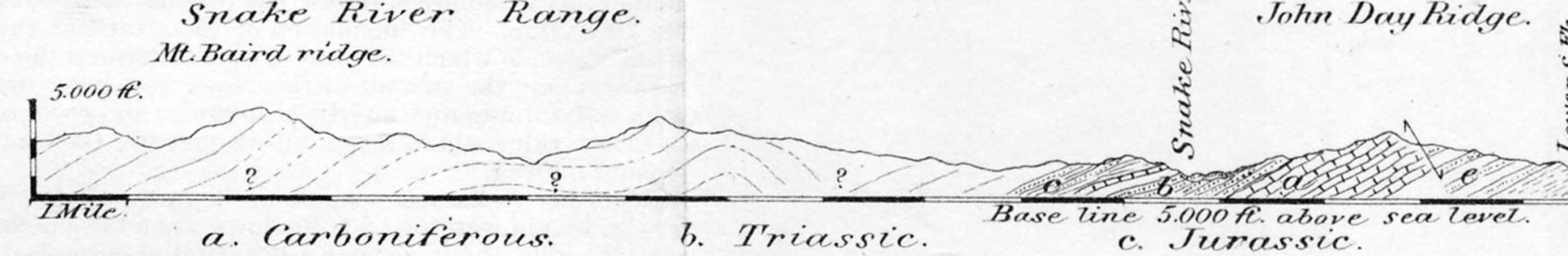

John Dou Ridge.

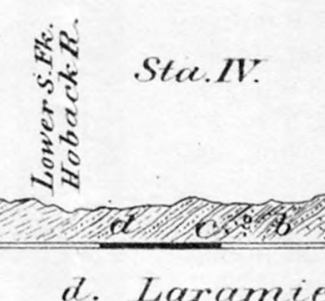

Hoback Cañon Ridge

d. Laramie, etc

e. Tertiary

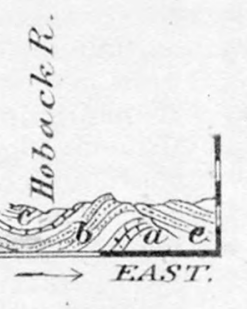

SECTION ACROSS THE WYOMING RANGE, THROUGH STATIONS V AND XI. Salt River Riage.
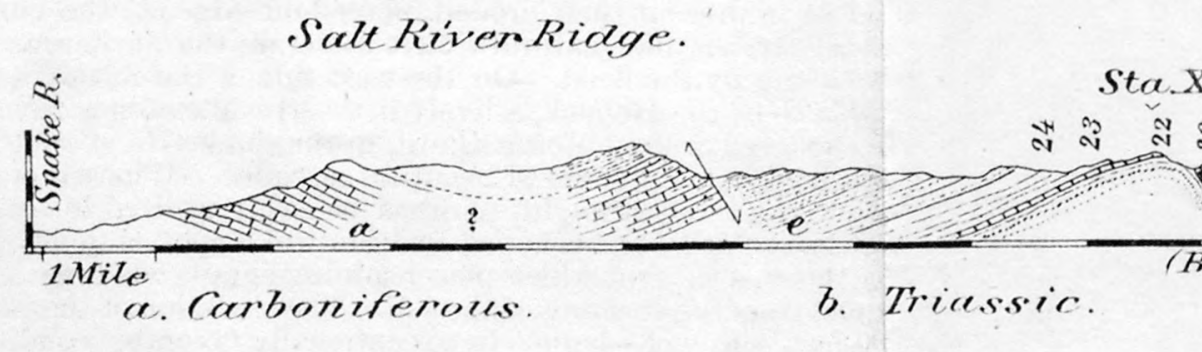
Sta.XI. John Day Ridge. Hoback Cant Sta.V.

Hoback Cañon Ridge.

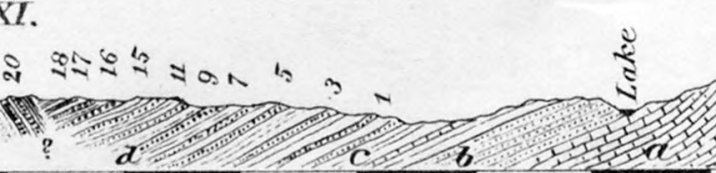
d. C

c. Jurassic

d. Laramie, etr.

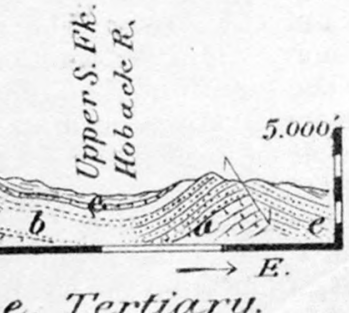

Plate IX. 
naceous layers, with partings of dark, almost fissile, shale chargeo with charcoal particles. These deposits, in which the argillaceous element predominates, incline at an angle of $17^{\circ}$ about W. $18^{\circ} \mathrm{S}$. They belong to the series $n$ of the foregoing section. In the high bluffs on the south side of the Hoback, just above the last noticed locality, heavy ledges of rather coarsegrained, thin-bedded, bluish-gray sandstone outerop at an elevation 175 to 200 feet above the stream, the dip being to the southwest at an angle of 200 . The beds afford only obscure vegetable remains, like tree-trunks. They enter largely into the rock materials composing the outlying hills on the east flank of the John Day ridge. The gray sandstones and argillaceous beds outerop in the narrows of the Hoback above as far as could be seen; but there are no conspicuous developments of red-colored strata along this part of the course of the Hoback, or between the cañon and the Spake. On the contrary, as has already been stated in relation to the valley of the lower south tributary of the Hovack, lving between the Hoback Cañon and John Day ridges, the grayish deposits constitute an important stratigraphical feature in this part of the Hoback Valley, especially in the east flank of the John Day ridge. Indeed, these deposits may appear in the topographical erest of this ridge towards its northern extremity.

In the angle between the confluence of the Snake and Hoback, a rather high ridge abruptly terminates, which forms a sort of long spur descending from the Hoback Cañon ridge north of the latter stream, the terminal point overlooking the Snake Valley having a relative elevation of about 1,600 feet. Ascending to the summit there appear in the upper part of the west slope exposures of gray and slightly reddish tinted, coarse-grained and shaly sandstones, interbedded with more or less indurated drab clays, dipping variably northeastward at angles of $16^{\circ}$ to 25०. The sandstones hold indistinct plant impressions, and are in all respects identical with the great series that reaches up on the east flank of the John Day ridge. The inclination of the strata at this locality shows a low anticlinal, of which the present exposures form the east slope. To the eastward, along the summit of the ridge, newer deposits successively appear, maintaining an easterly inclination, and reaching over to the Hoback Cañon ridge where they abut against the Carboniferous, as has been already noticed.

The Hoback is here a fine stream, about 50 yards wide, with a brisk current of sweet, limpid water. Looking down upon the shadowed pools from the adjacent hills, the water has a beautiful green reflection. The stream bed is paved with water-worn boulders and pebbles identical with the materials found in the bed of the adjacent Snake River. The gravels in the river side afforded Mr. Perry a few scales of gold. In this connection may be mentioned the favorable facilities for placer prospecting along the river banks in this vicinity. The sandstones and clays incline in such way as to present their eroded, planed-off edges to the current of the ancient stream, like natural riffles, to retain the auriferous particles borne along by the flood. On the west side of the Snake, a mile below the mouth of the Hoback, a lively little stream emerges from the mountains clustered around Mount Baird, in the Snake River range, its lower course broken into a series of beautiful cascades. Where it crosses the terraces in the valley it might, perhaps, be easily utilized in sluicing operations, though it is to be hoped so beautiful a spot may never be invaded by the chaotic ruin which placer mining entails wherever profit may be gained from the washing of the soil. The elevation of the valley, about 6,000 feet, may not conduce to exceptionally favorable conditions for agriculture, but the valleys and adjacent hills are well stocked with grasses, and no doubt the hardier farm products would thrive. 


\section{CHAPTER III.}

\section{HOBACK-GREEN RIVER BASIN.}

The region occupied by the principal drainage of Hoback's River and that of Green River after it leaves the Wind River Mountains is here considered under one head, since it presents a general uniform depression defined on three sides by mountain barriers. But its actual condition presents some interesting features, especially its hydrography, the development of which is due to the topographical department of the survey.

The basin as such opens to the south so that in ascending Green River the entire drainage of the great recess, bounded by the Wyoming Range on the west, the Gros Ventre Mountains to the north, and the Wind River range on the east, might be readily supposed to be tributary to this stream. Near the south line of the district, the Green River Valley proper, which here has an altitude of about 7,500 leet above tide-water, is narrowed to a width of about 20 miles, its western rim resting upon a low divide which curves round with its convexity to the southeast from the Wyoming Range north of Lead Creek where the width of the basin is augmented abont one-third to the eastern extremity of the Gros Ventre Mountains. The most depressed point of the divide, which has a length of about 30 miles, occurs about midway, where its elevation is something less than 8,000 feet. To the northwest lies the basin of Hoback's River. The descent in that direction is comparatively rapid, soon reaching the general basin-level of 7,000 feet, and thence gradually declining to the lowest portion of the basin, 6,325 feet, where the collected waters of the Hoback enter the cañon through the eastern ridge of the Wyoming Range on the way to the Snake.

Sufficient has been detailed to draw attention to the leading physical features of this basin area as a whole, and the somewhat pronounced contrasts presented by its dual drainage system when compared one with the other. It may, however, be difficult to comprehend the processes which have maintained the present state of things, to explain the causes which have been concerned in originating its.system of drainage; especially since there exists no natural orographic definition by which the waters of the Green might have been held to their present course instead of flowing into the more depressed area drained by the Hoback. Were the requisite data forthcoming this subject might properly be relegated to the section reviewing the dynamical geology of the district. However, brief allusion to some of the conclusions arrived at in this connection may be admissible in this place.

In the description of the eastern or Hoback Cañon ridge of the Wyoming Hountains, in a preceding section, occasion was had to notice the disturbed condition of nonconformable Tertiary deposits in the immediate vicinity of the folded Mesozoies of that mountain ridge. During the brief examinations along the foot of the Wind River Range on the east202 


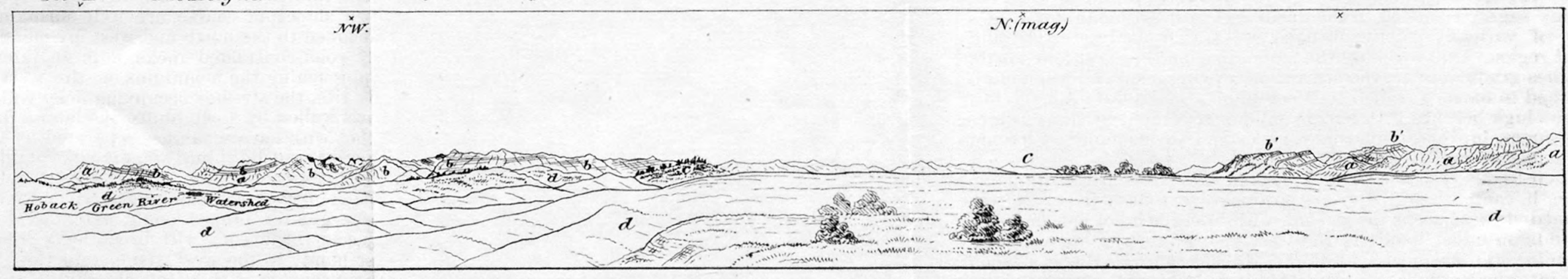

SOITH FLANK OF GROS VENTRE RANGE: FROM STATION I, ABOVE CONELUENCE OF LEAD CR. AND GREEN RIV. a.Archocar. b. Paloozoic Patoeozic south of Greer
Plate X. 
ern border of the basin, similar Tertiary deposits were also met with which appear to have been little if at all disturbed from their normal position. Along the Gros Ventre side of the basin perhaps the same observations, in part, hold good, with, however, certain exceptions in the neighborhood of the convergence of the Hoback Cañon ridge where the inclination of presumably Cenozoic strata is towards the mountain. The facts, therefore, imply dynamical movements within the area of the Wyoming Range and along the western border of the basin during a time subsequent to the deposition of the Tertiaries of the basin area; and was the tendency of these movements a downward one within the basin area aud an upward one in the western mountain border, the subsidence in the one place would encroach on the former drainage planes and originate a new system tributary to that of the depressed area. In this manner might have originated the Hoback, and at a time relatively recent compared with the inception of the Green River drainage. The extent of the movements above alluded to cannot at present be defined; the appearances, however, indicate for them rather a local character, centering in the region of convergence of the Wyoming-Snake, Téton, and Gros Ventre ranges.

The area embraced in the Hoback drainage is diversified by intervale. bordered streams and terraces, covered with herbage, aspen and evergreen groves; the open slopes, of course, are well sprinkled with the ubiquitous sage. Hemmed to the north and west by mountain ridges built up of variously color-contrasted rocks, it is an interesting and beautiful region. Approaching the mountains on the west and north, the benches gradually rise, the streams occupying deep valleys, and often confined to narrows walled by steep blufís, the lateral drainage furrowing the high benches with narrow ravines separated by sharp ridges or steep slopes, broken by landslides into step-like inequalities, having rhe semblance of rude terraces.

The almost equally extensive area belonging to Green River drainage, to the sonth, contains a greater proportionate extent of level bottom land immediately adjacent the stream, with broad belts of low, undulating uplands on either hand; to the west, rising into the low water-divide, heading the basin sources of the Hoback, and to the east soon merging into the foot hills and morainal ridges lying at the western base of the Wind River Range. To the north this portion of the basin is more broken, the tributary drainage which here reaches around the eastern extremity of the Gros Ventre Mountains draining a small portion of their northern slope, having fashioned a few broad-topped spurs reaching from that mountain axis, with gradually diminishing elevation, far out into the valley. While still farther to the north, a broad, undulating saddle-ridge, at least 15 miles in east-west length, stretches across from the northern slopes of the Gros Ventre Mountains to the west flank of the Wind River Range, forming the water-divide separating the Green from the Gros Ventre River. The divide is about 9,000 feet in actual altitude, comprising a beautiful park-like region of open, grassy prairies, dotted with aspen thickets and more or less extensive tracts of evergreen forests. The Green, after holding a nearly north-south course of 26 miles within the limits of this district, here sharply bends upon itself, and a few miles above, to the southeast, emerges from its mountain course through one of the grandest gorges penetrating this side of the Wind River Range.

This basin area is almost exclusively occupied by Tertiary deposits belonging to and continuous with the great Green River series of that age. 'The low water-divide separating the Green from Hoback's River, 
is made up of alternations of soft, in places friable, sandstones of a grayish-buff color, including coarse-grained and conglomeritic layers, interbedded in the soft drab or blue and variegated dull chocolate-red clays, in quite horizontal position. The nature of the deposits, which readily decompose at the surface, renders their outerop obscure save along the streams, where they appear in low bluff exposures. The inferior portion of the series, as it is here developed, becomes more clayey, like Wasatch deposits lower down the Green. The same beds reappear along Lead Creek, and they apparently constitute the great sloping benches that rise high up on and even invest the broad summit of the eastern portion of the Wyoming Range in the vicinity of the south line of the district. The benches here alluded to constitute the divide between Lead Creek, which flows into Green-River near our south line, and the ultimate source of Hoback's River, which rises just south of Hoback's Peak (Station VI), in the Wyoming Momntains, and hence they belong to the before-mentioned water-divide. The whole upland region, as also the terraces and stream-beds, are strewn with drift materials mainly composed of quartz rock with occasional granitic and lime. stone bowlders. But these superficial deposits become less prevalent in the western portion of the basin in proportion to the greater distance the remove from the loftier mountain elevations that lie to the east.

The view from the divide-ridge looking towards the western mountainborder south of Hoback Cañon, shows the Tertiary gently upraised along the eastern outlying ridge of the Wyoming Range. As has been elsewhere stated, these deposits, here constituted of light grayish slightly calcareous sandstones and clays, incline off the monoclinal ridge of steeply dipping, non-conformable Jura-Trias at angles of inclination varying from $15^{\circ}$ to $45^{\circ}$ eastward, gradually flattening out towards the center of the basin. The soft deposits are seldom well exposed, the comparatively smooth, herbaceous-covered slopes here as elsewhere contrasting with the densely timbered surface of the more rugged mountain declivities. The unconformity of these deposits is well displayed at the forks of the Hoback 3 or 4 miles above the cañon, where their most westerly exposures are reached. In the west side of the valley the Triassic red sandstones appear, dipping to the southwestward, while in the same side low outliers of the later deposits cling to the foot of the mountain slopes, and on the opposite side of the stream they form a considerable elevation in the bluff face of which several hundred foet thickness of the soft sandstones and clays are seen, dipping eastward at angles of $30^{\circ}$ to $45^{\circ}$.

South of the latter locality, the Tertiary deposits rapidly rise in elevation, and finally surmount the mountain summit, in the neighborhood of the south boundary of the district. In the latter quarter, these deposits incline eastward at a much gentler angle; but as this part of the Wyoming Range was not visited, their relations to the underlying Laramie formations, which Dr. Peale recognized still farther south, was not determined. It is improbable that the latter formation appears in the central portion of the Hoback Basin ; not, however, that it does not ex. ist there, but because it is concealed beneath the equally vast accumulations of Tertiary strata that fill the basin. Neither are the limits of the Tertiary deposits well-defined in the angle between the Hoback Cañon ridge and the Gros Ventre Mountains, where they are covered by erratic materials that in places deeply bury the foot of the mountain and outlying slopes. But the slopes soon merge into the benches descend. ing into the lower level of the basin, which in places disclose the Tertiary strata apparently inclined in a northerly direction or towards the mountain. 


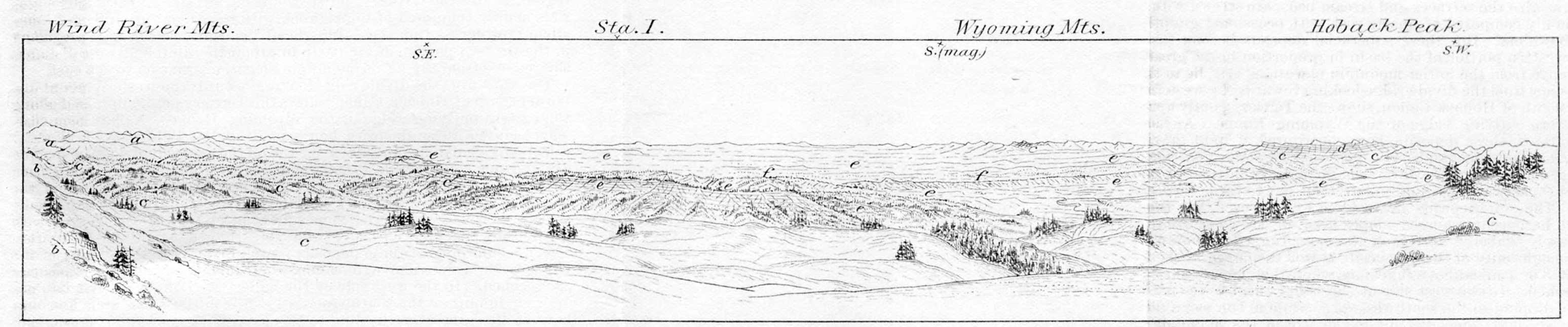

a. Archoean

b. Carboniferous.

From Gros Ventre Peak Ridge. Plate XI 
Although the immediate mountain border of the basin may be with equal propriety considered in connection with the description of the mountain areas for the sake of bringing together under one head all the data relating to the basin deposits, the observed occurrences in the border region are briefly reviewed in this place. In the narrow belt or saddle intervening between the Hoback Cañon ridge and the southern foot of the Gros Ventre Mountains, a set of imperfectly exposed beds oceur, whose like was not elsewhere observed, unless they prove to be a recurrence of the Tertiary (?) conglomerate before mentioned, as occurring in the depression lying at the west foot of the Hoback Cañon ridge, and thence extending north into the lower portion of Jackson's Basin on the Snake. These deposits consist mainly of water-worn fragments of gray and bluish limestone, red and gray shaly sandstone, inclosed in a more or less calcareous arenaceous matrix, the exposures having a pale reddish color. The coarse materials vary from mediumsized bowlders to smail pebbles. Their deriration may be traced to the neighboring mountains, the red sandstones having been furnished by the Triassic deposits, the gray shaly sandstone pebbles are apparently identical with beds occurring in the Cretaceous or Laramie, and the limestone fragments may have come from either the Jura, Carboniferons, or Quebec formations, all of which are in situ near at hand. The more conglomeritic portions show a homogeneous mass with obscure lines of deposition, best seen in the partially bared slopes where the bedding usually may be readily made ont.

The latter deposits occupying the outlying slopes $(9,000$ to 10,000 feet altitude) at the foot of the mountain wall, a mile or so southeast of Station XII. The outcrop forms a belt several hundred yards in width, to the south of which and perhaps less than a mile distant, the southwesterly dipping Triassic red sandstones appear in the opposite side of the saddle, within the area of the Hoback Cañon ridge. The conglom. erate dips at angles of $50^{\circ}$ to $75^{\circ}$ northward, or towards the Gros Ventre Mountains, in whose flank at this place the Paleozoic formations are much complicated and overtopped by the Archæan in the crest of the mountain. To the southeast of the above locality, and still clinging high up on the mountain foot, the conglomeritic deposits appear in the grassy slopes of the much eroded divide which here separates Upper Hoback and Snake River drainage.' It is here readily identified by its reddish color, though apparently less disturbed, indeed in places gently dipping away from the mountain and then gently rising, until it is lost to view a mile or so to the south. It was not recognized to the east of the stream descending from the divide to the Hoback, where its place appears to be occupied by the light drab and yellowish Tertiary sandstones and clays. In the divide it appears only in the ravines, tire slopes next the mountain being generally enveloped in morainal deposits brought from the immediately arjacent Archæan and Paleozoic mountains, in the vicinity of Station XII, and which are piled in characteristic ridges, whose inequalities afford numerous receptacles for water, form: ing diminutive lakelets amidst the partially wooded and open herbaceous slopes.

East of the divide beyond the limits of the mountain débris, the Tertiary deposits immediately appear in the sloping benches thiat make out into the basin to the south, a very broken region which, however, is traversed by beautiful terraced valleys of Hoback tributaries flowing out from the mountains to the north. The summits of the Tertiary benches often present wide, flat surfaces, through which wind swale-like drainage depressions, and covered with gneiss, quartzite, and limestone 
bowlders. The nature of the erratic materials is determined to a discernible extent by the prevalent rocks composing the nearest mountain wall. Paleozoic quartzite and limestone masses occurring at one place, and Archæan bowlders predominating at other localities.

Still farther east, and reaching over to the angle in the mountains at Gros Ventre Peak, the Tertiary deposits are much eroded by the streams that issue from the range, from whose foot they are here separated by a narrow intervening belt of Mesozoic formations, which properly pertain to the mountain area. A few miles to the eastward of Gros Ventre Peak these deposits reach high up in an outlying shoulder, about 10,000 feet altitude, where they rest unconformably upon deep red arenaceous beds holding the position of the Trias, and thence southward they compose the bulk of the water-divide between the Green and Hoback. At the latter locality, about south of Gros Ventre Peak, the Tertiary is chiefly made up of light buff or yellow and drab sandstones and arenaceous clays, dipping gently sonthward or southwestward into the basin where they merge into the long lines of terraces or benches that form a characteristic topographic feature of this area. The occasional exposures in the bluff escarpments along the water courses and ravines reveal the bedding with tolerable distinctness and often the beantiful effects of weather action peculiar to these soft deposits. No indications of coal were observed in connection with these deposits, although the observations made during a hasty visit hardly warrant the assertion that it does not exist.

In the region east of the water-divide, the middle, and perhaps later, Mesozoic formations have been denuded over a considerable area of the rolling high lands at the eastern terminus of the Gros Ventre range, where the Tertiary has been swept away. But farther south the latter deposits are again encountered, and thence they constitute the superficial rocks, filling the Green River portion of the basin; extending over to the great morainal accumulations that bury the western foot of the Wind River Mountains and reach well out into the more level basin uplands, where the erratic materials conceal the underlying deposits over extensive areas. However, exposures sufficient to show the identity and distribution of the Tertiary formation are not wanting, though to the action of fluvial, and to a less degree glacial, agencies, they have been generally leveled and covered with soil. South of Lac d'Auralia, the light drab, soft Tertiary deposits, nearly horizontal, fill a rather wide bay-like recess, extending in towards the mountain foot from the lower portions of the valley at a point on the south line of the district. This recess is defined on the north and south hy great morainal ridges, so that it is impossible to ascertain the condition of the Tertiary deposits. near the mountain border. These deposits probably extend not above 8 or 10 miles north of the $43 \mathrm{~d}$ parallel along the river, where they give way to the Mesozoics which cross the valley in a low fold extending over from the Gros Ventre to the Wind River Mountains, south of the great bend of the Green, and which will receive fuller notice under the head of the formerrange. Although the valley extends 15 to 20 miles farther north, the geological limits of the common basin area occupied by the Tertiary sediments, may be defined by a line projected southeasterly from Gros Ventre Peak across Green River Valley. Tertiary beds may occur north of this line, but they are to be regarded as remnants which. have escaped demolition in the process of erosion of the valley. Indeed these deposits may once have extended over the above mentioned geological fold, uniting and forming an uninterrupted belt with the Tertiary formations occurring in the otherwise well-defined basin area of the Gros 

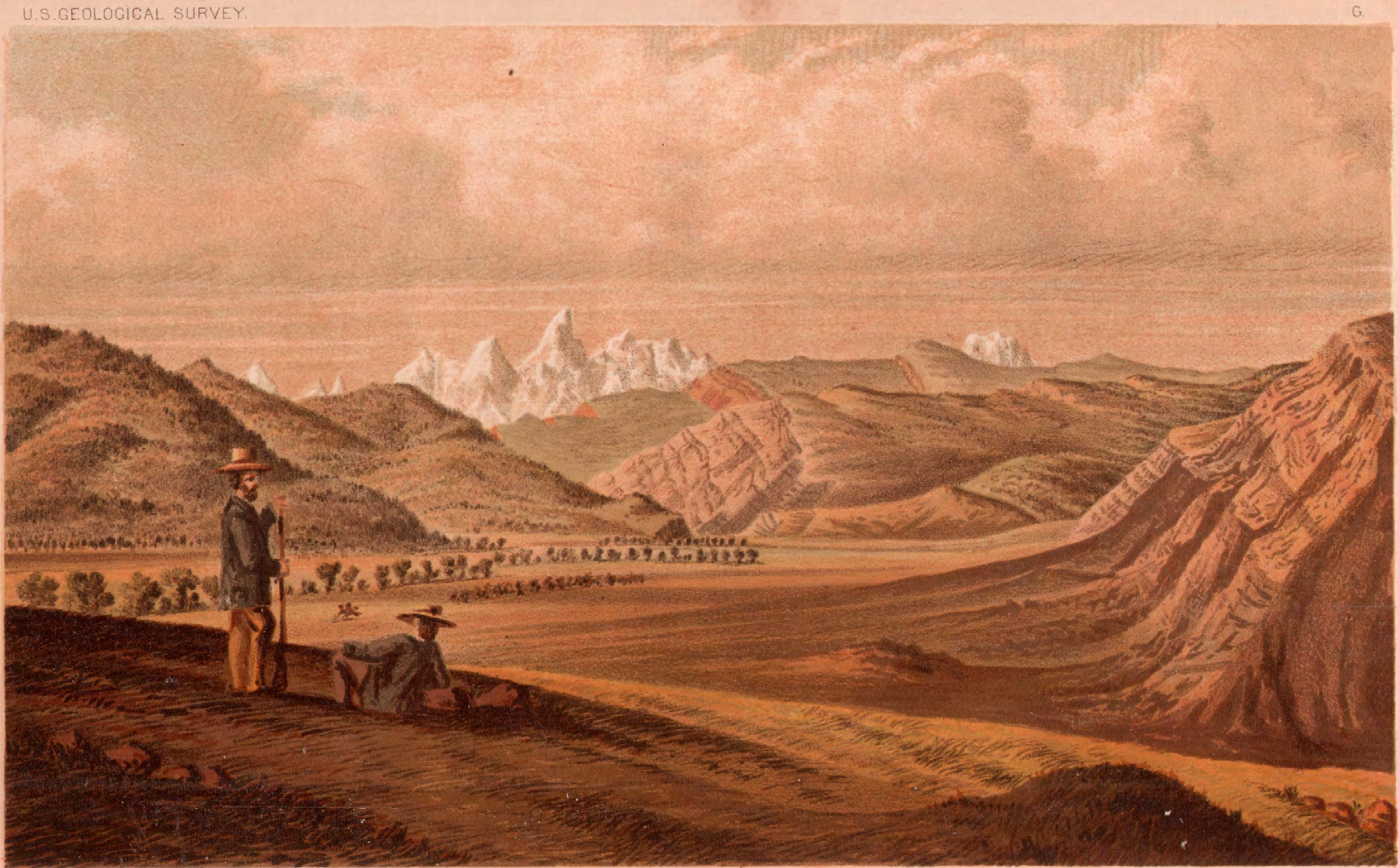

THE TETONS LOOKING DOWN GROS VENTREE FORK GREY AND RED BEDS OF THE JURA TRIAS IN THE FOREGROUND. 




\section{Plate XII.}

Wind River Mts.

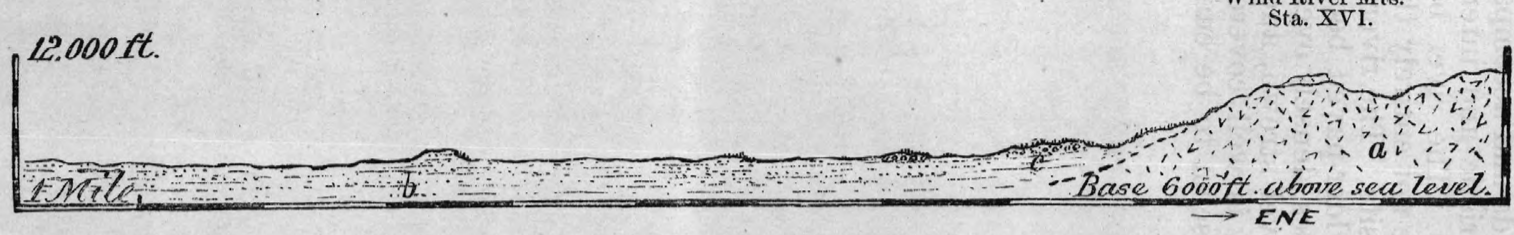

Profile of Green River Valley, Vicinity Station XVI.

a Archæan. $b$ Tertiary.

$c$ Tertiary conglomerate.

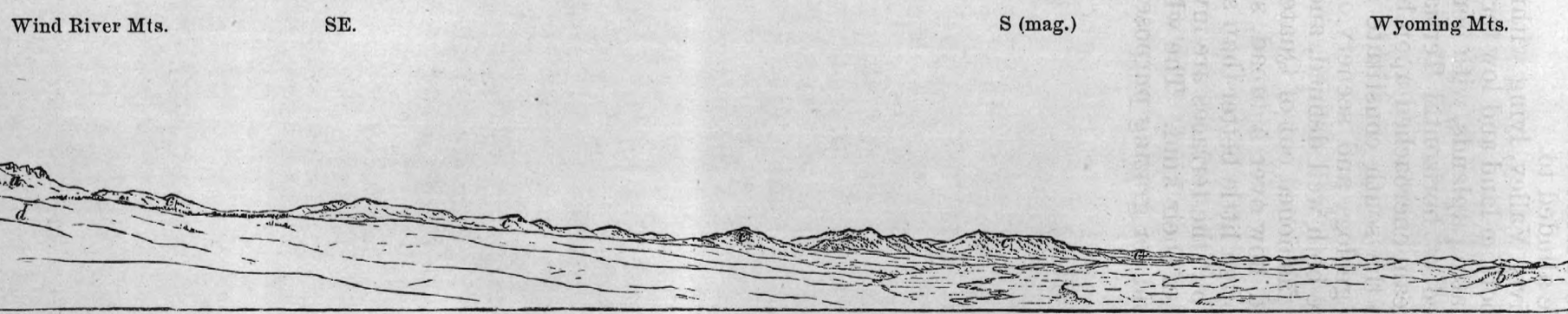

Sta. XVII.

Upper Green River Valley.

a Archæan.

$b$ Laramie (?)

$c$ Tertiary.

$d$ Moraines. 
Ventre drainage. But the meager facts in our possession are not deemed sufficient to establish beyond question so intimate stratigraphical synchronism in the Tertiaries of the at present topographically distinet basin areas here alluded to.

The Green River Valley, lying within this district, shows a broad expanse of level bottom-land and low terraces, giving place on either hand to gently undulating uplands, with here and there low hills and isolated buttes composed of horizontal Tertiary strat:. Not till beyond our limits is the stream encroached upon by the uplands and accompanying bluffs, which to the sonth constitute so characteristic and interesting features in the geology and scenery of the valley. The river bottoms and terraces are both well defined, and if they are not entirely they are at least largely fashioned out of Quaternary deposits. The river generally has a rapid flow over a broad, shallow, bowlder-paved bed. The intervales are often little better than spongy mosses, densely overgrown with willows; but the terraces are invariable gravel strewn, and beautiful examples of their kind. The whole country is well covered with bunch grass, and for grazing purposes it would seem to be eminently adapted. 


\section{CHAPTER IV.}

\section{GROS VENTRE RANGE.}

The Gros Ventre Mountains constitute a well defined range with a trend approximately ESE. and WNW., stretching from the foot of Jackson's Basin, east of the southern terminus of the Tétons, over to the Wind River range, nearly opposite the debouchure of Green River Cañon. Hence, its longer axis is little more than 40 miles, with a transverse breadth of somewhat less distinctly marked limits ranging from 8 to 14 miles. The western end of the range was visited the previous season, an account of which, together with a general account of the range, was given in the report on the Téton district, United States Geological and Geographical Survey of the Territories, 1877. Notwithstanding the haste -with which the present season's explorations were conducted, it is believed a sufficiency of data was secured by means of which a general understanding of its geological structure may be arrived at.

It is apparent that the present condition of the range does not preserve its original proportions; that in Pre-Cenozoic times it was subjected to erosive agents whose action has degraded and removed an enormous quantity of rock materials over its whole extent, but especially active were these degrading influences in the western portion of the uplift where half its original bulk has been swept away and the comminuted materials intermingled with the thou-ands of feet thickness of Tertiary sediments filling the neighboring basin areas. Although the vertical displacement varied considerably, being greatest in the western half, erosion has reduced the crest of the range to a nearly uniform average height of 11,000 feet. The highest point, $12,200 \mathrm{f}^{\circ} \mathrm{t}$, lies about 12 miles to the northwestward of Gros Ventre Peak; at Station XII in the western part of the range the altitude is 11,196 feet above the sea.

For the better understanding of the account of detail geology given in the following pages, a brief summary of the general structural features of the range, such as they are understood to be, is here introduced. Although the trend of the range, topographically, is as above stated, ESE. and WNW., the axis of elevation lies more nearly in a SE, and NW. direction. The upheaval, which was evidently an event closely following the close of the Mesozoic age and probably extending into Cenozoic time, was accompanied by at least two principal mountain corrugations parallel with one another, and perhaps not more than 5 miles apart. Besides the principal folds there were other minor undulations, whose extent and relations can only be worked out by a careful detail survey. The respective extent of the longer axis of the prineipal folds cannot at this time be determined, but the amount of ver. tical displacement in the southern fold was at least a few hundred feet in excess of that in the northern one. In the eastern half of the range, however, the southern fold has been entirely removed by erosion, so that the south flank of the mountain in the latter quarter is formed by 


\section{GROS VENTRE RANGE: SECTION EIGHT MILES N.W. OF GROS VENTRE PEAK.

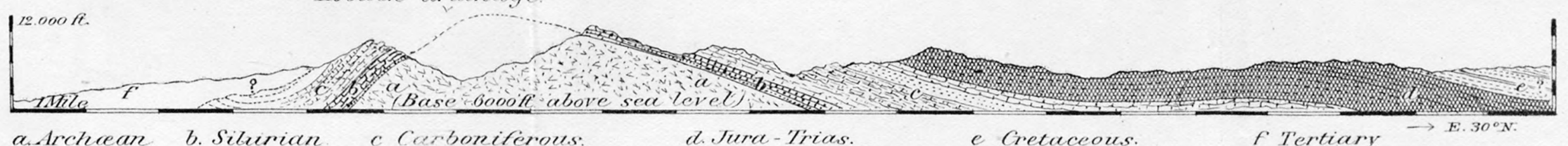

GROS VENTRE RANGE: SECTION FIVE MHES N.W. OF GROS VENTRE PEAK. Forkis Hoback R.
Hoback Busin

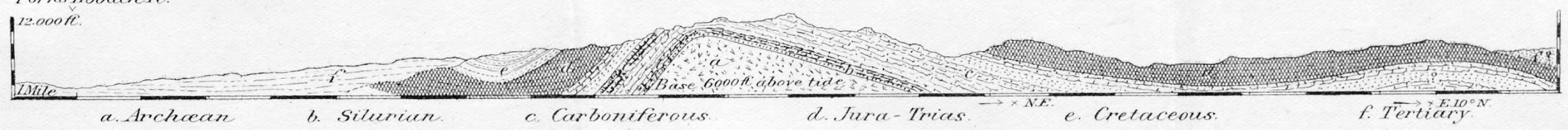

GROS VENTRE RANGE Hoback Rivez

\section{Hobact Basin.}

12.000 t:
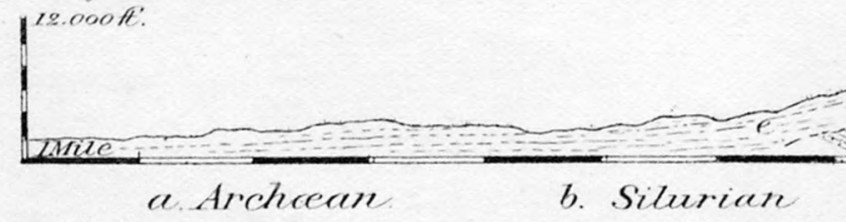
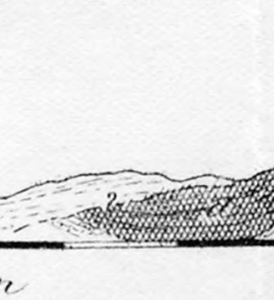

SECTIO Sta:XIII.

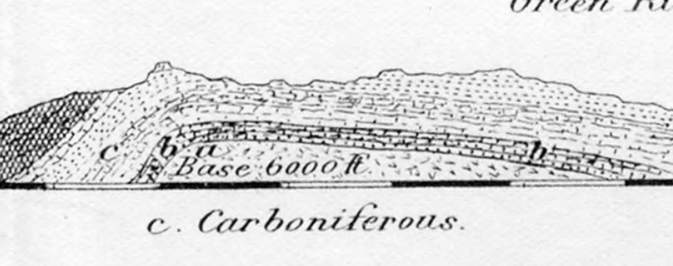

Grcen River drainage

Gros Ventre Basin

GROS VENTRE RANGE: SECTION ALONG A LINE S.W. FROM STATION XXIX.

Hoback Basin. Hoback drainage

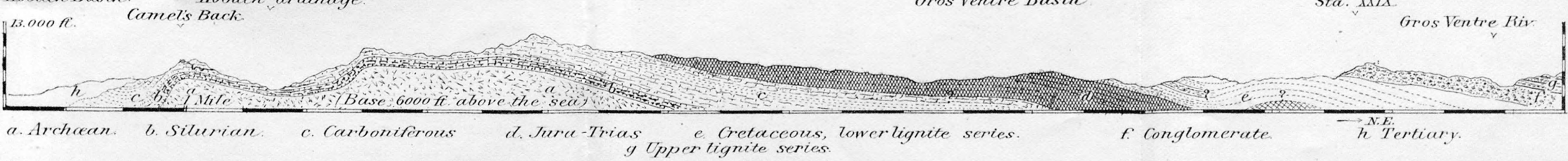
Plate XIII. 
SECTION THROUGH STATIONS XLIV, XLVI (1877.)

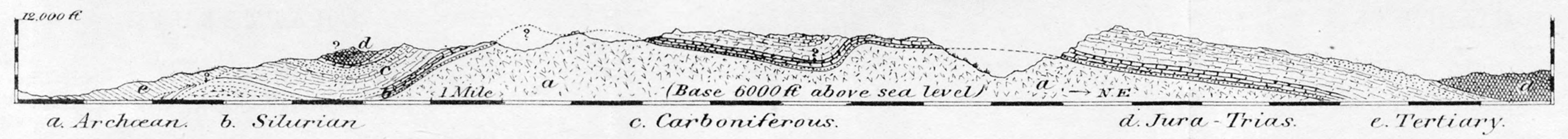

\section{GROS VENTRE RANGE : SECTION BETWEFN STATIONS XII AND XLIV (1877)}

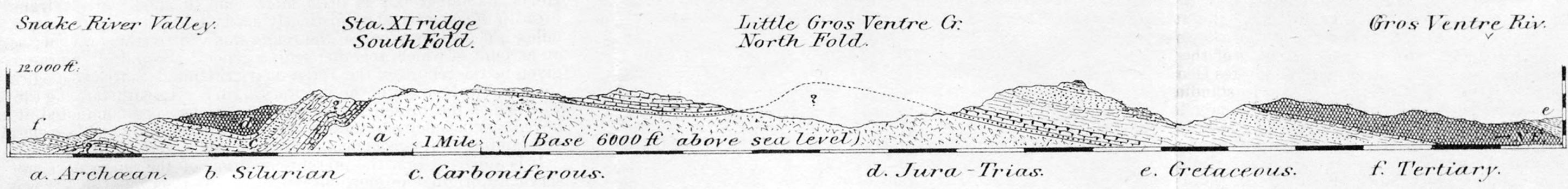

a. Archaean. b. Silurian carboniferous.

\section{GROS VENTRE: RANGE: SFCTION THROUGH STATION XII.}

\section{Hoback Ridge.}

Central plateau.

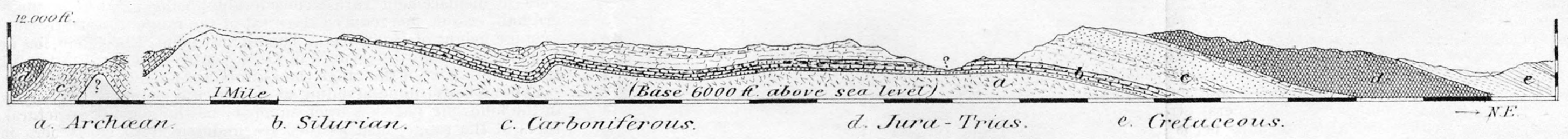

GROS VENTRE RANGE: SFCTION ALONG A LINE W.S.W. FROM STATION XXIX.

\section{Hoback Cañon Ridge. South Fold. North Fold} Hoback Basin. Hoback drainage.
Gros Ventre drainage
Gros Ventre Basin

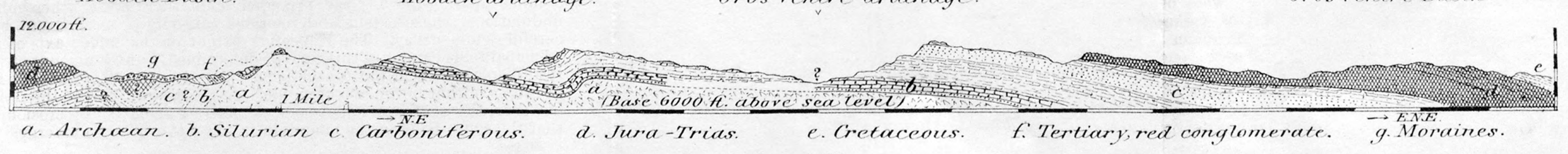

Plate XIII. 
the abrupt south slope of the northern fold. South of Gros Ventre Peak the site of the greater fold is concealed by Tertiary deposits, which reach high up on the mountain flank at this point and thence incline off gently into the Hoback-Green River Basin.

Both the principal folds closely correspond in contour, and which is retained in a marked degree in the present configuration of the great ridges. It consists of long gentle slopes on the north, with abrupt flexure on the south, which latter was apparently, in places, accompanied by the rupture and complete severance of the sedimentary strata. Of the latter manifestations, such as were observed will be described farther on. Both termini of the range are masked by late geological deposits, and hence it is not clear what relation the Gros Ventre uplift holds to that of the Wind River Mountains on the one hand and the Téton Range on the other. An interesting and inportant coincidence in this connection is the existence of strongly marked, broad, deep gaps at either extremity of the range in the vicinity of the junction of the three great uplifts. The upper course of the Green, after it bends south, on leaving its mountain gorge, crosses the present uplitt, which has declined sufficiently to carry the Carboniferous to the level of the river, where it is seen in a low fold with comparatively gentle inclinations of the component strata on either flank. From this it appears that the uplift was much less emphasized in the region approaching the west flank of the Wind River Mountains than was the case at the opposite extremity, where the metamorphic nucleus has a much more abrupt termination on the borders of Jackson's Basin, fronting the Téton Range. But here our resources fail; the interval separating the two ranges is occupied by a deep valley filled with late Tertiary sediments, which are pierced at only two points by insular remnants of the older sedimentary rocks that enter so largely into the composition of the mountain folds. Yet the evidence, meager and incomplete as it is, points to a more intimate relation of the present uplift with those of the Téton and Wyoming ranges than with that of the Wind River Mountains, though the whole may be said to be tied together by the transverse elevation of the Gros Ventre Mountains.

The southern flank of the Gros Ventre Range, in the extreme northwest, was not approached nearer than Station XII, 8 or 10 miles to the eastward. It is known, however, that the Archæan ridge of the south fold, on whose loftiest peak Station XII was located, extends through to a point opposite the Lower Gros Ventre Buttes in Jackson's Basin. It carries in its western part a mantle of Paleozoic strata of variable thickness, through which the Archæan nucleal rocks here and there protrude and at one point, 5 miles northwest of Station XII, rising into a symmetrical cone overlooking Jackson's Basin, on which was made Station XLIV of the Téton division the previous season. To the south of this ridge the surface falls in broken ridges, in which are discernible apparently the full Paleozoic series steeply inclining off' the south flauk into the Snake Valley. A little to the east high benches sweep up from the terraces bordering the Snake into the broken hills at the north end of the Hoback Cañon ridge, in which, as has been already noticed, northerly dipping Tertiary deposits occur, the higher mountainous belt beyond being made up of Carboniferous and the Jura-Trias. The latter belong to the Hoback Cañon ridge of the Wyoming Range, under which head they have been noticed in preceding pages.

The ridge which culminates in Station XII corresponds to the crest of the south fold, of which about 3 miles linear extent is made up of the metamorphics, with remnants of the Lower Silurian quartzite still capping high points. The latter show dull buff and rusty exposures, the $14 \mathrm{H}$ 
ledges inclining northeastward. Their reappearance was not observed on the steep southwest flank of the mountain immediately under the station, where the only sedimentary beds found are Carboniferous limestones with characteristic fossils, which outcrop in low, glaciated bosses, and dipping toward the mountain, whose foot is here buried in the débris. West of this, however, the quartzite, succeeded by the rusty-drab, evenbedded Quebec group limestones, is seen rising upon the mountain flank, and in outlying ridges the gray Carboniferous limestones recur. It is in the interval lying between the latter and the Triassic " red beds" occurring in the Hoback Cañon ridge, that the singular red conglomeritic deposits occur, also dipping toward the mountain, and which hide from view the older rocks. This conglomerate is made up of abraded rock fragments, contributions from all the older rocks, including those of as late date as the Jura-Trias, and possibly the Laramie formations, from which its relatively recent age is inferred. It seems highly probable that the interval alluded to marks the site of extraordinary geological disturbance, such as might occur along the line of impingement of two distinct axes of upheaval.

The mountain is here much eroded, showing peculiarly weathered precipitous Archæan ledges terminated in extensive taluses of sliding débris. It is an exceedingly picturesque locality, presenting those typical forms in mountain sculpture strikingly in contrast with the architectural forms into which the later sedimentary formations are wrought. Mr. Clark brought from the peak of Station XII fragments of quartzite, showing that even on this height the Archran is barely denuded of its Primordial covering. Mr. Perry, who also ascended the mountain, reported it made up of contorted gneissic rocks, quartz, feldspathic and hornblendic, traversed by quartz veins, and showing a well-marked anticlinal, strike east-west, trending round to northwest and southeast, with inclination of $25^{\circ}$ to the horizon. To the northeast the slopes are comparatively gentle, descending into the depression intervening between this and the north fold-a region filled with denuded, rocky inclines and sloping sedimentary tables, the same as described in the report on the Téton District, 1877. This depression drains southeast into the Hoback and north into the Little Gros Ventre. The latter quarter was reported upon the previous season.

A couple of miles to the southeast of Station XII this south ridge is crested by Silurian formations, dipping gently northeastward, and a little farther on a heavy mass of Carboniferous limestone rises high up on a short spur in the south flank, the strata dipping toward the mountain, or N. $37^{\circ} \mathrm{E}$., at angles of $20^{\circ}$ to $30^{\circ}$, or more. The latter show bluishgray, spar-seamed, chertv limestone and light buff, brecciated, impure limestone layers, containing numerous examples of a small zaphrentoid coral, a large Syringopora, and crinoidal remains. In the opposite side of the amphitheater, to the east, the quartzites and Quebec limestones are seen steeply inclined off the foot of the mountain and crowning the crest in isolated, monumental masses which have been but little disturbed from their horizontal position in the elevation of the mountain. The middle portion of the abrupt south front of the ridge shows a belt of denuded Archæan rocks separating the lower and upper sedimentary occurrences. At this point the Carboniferous limestones have been swept away, but the remnant of Quebec limestone is flexed up in a sharp synclinal, a mere fragment of the south flank of the trough remaining.

The Primordial quartzite here exhibits the same appearance noted in this horizon to the west. It is a dark brownish-red to rusty buff, laminated rock, steeply dipping southward, and rests immediately upon the 


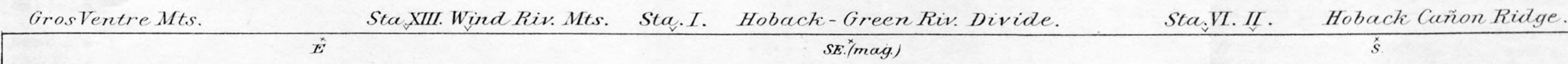

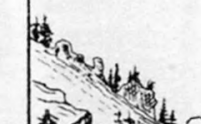

1.
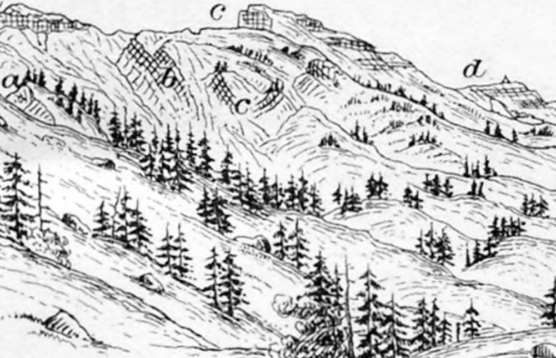

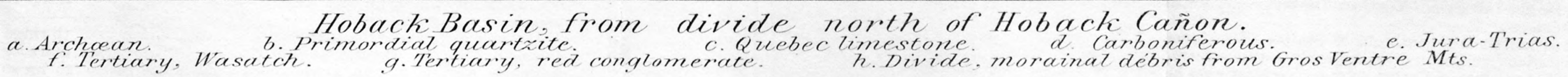
Plate XIV. 
gneissic ledges. The Quebec limestones also here show typical exposures, consisting of usually even, thin-bedded layers of a dark gray and dirty yellow color, weathered in rough surfaces, with brecciated and oölitic layers, the whole attaining an exposed thickness of 300 to 400 feet, more or less.

A mile or so to the southeast of the above locality, the quartzite composes the south-facing mountain wall. Intermingled with the débris in the talus slopes are huge blocks of quartzite, containing fucoidal markings. In the vicinity the Quebec limestones, also, are seen folding over the steep south face of the ridge, and in the summit they are overlaid by a heavy bed, 200 to 400 feet in thickness, of heavy-bedded light buff-gray, vesicular, rough-weathered magnesian limestone. The latter agreês well with what elsewhere has been referred to the Niagara epoch, although search failed to detect confirmatory paleontological evidence going to establish this identity. Indications of the above-mentioned synclinal were not again met with in the mountain flank, whose slopes are heavily loaded with the sedimentary rock débris fallen from the ledges perched along the summit of the ridge, concealing even the morainal deposits which are detected in many of the high benches outlying the mouths of gulches. Thence to the debouchure of the Hoback tributary that drains a considerable area of mountain basin on the northeast of Station XII ridge, the south slope of this ridge is heavily plated with sedimentary deposits.

In the angle on the west side of the debouchure of the latter stream, the mountain flank facing southward is composed of the drab or gray limestone of the Carboniferous, steeply rising into the relatively low crest in which they fold over, again descending northeast into the depression of the mountain course of this stream. The mountain in the opposite angle of the debouchure has the appearance of a huge block of Carboniferous strata which has been bodily uplifted and but slightly tilted from the horizontal. The south slope does not distinctly reveal the southerly flank of the fold, which was here eroded and concealed beneath the basin Tertiary deposits. The Carboniferous deposits in the present mountain reveal a thickness of several hundred feet of dark gray limestones with distinct reddish tint above-the latter color-feature being quite prevalent in these beds in this part of the range.

The exit of this first considerable Hoback tributary shows a rather wide cañon-debouchure, bordered on either hand by mountains sculptured out of the Carboniferous ledges, which appear in escarped slopes and picturesquely-weathered pinnacles. These deposits are traced well up the cañon to the northeast, as far as could be seen, forming the heights along the mountainous northeast side of the valley. Below the exit, the stream, on entering the softer deposits of the basin Tertiary, presently forms a low intervale bordered by well-defined terraces. It carries a good volume of swift-flowing water, and its bed is composed of water-worn fragments of Archæan, quartzite and limestone.

Although it was not with absolute certainty so determined, yet, both from the relatively low elevation and nearly horizontal position of the block of Carboniferous strata composing the mountain in the east angle of the above-mentioned stream, it may be that this mass belongs to the north slope of the great south anticlinal fold. This explanation is suggested by the position of sedimentary occurrences in the loftier crests to the northeast, with which this mountain forms an outlying prominent spur. In the latter mountain ridge, which may be more or less parallel with that of Station XII, the strata are bent up in a great flexure, of which the southeast face is that seen from this point of view. This is 
doubtless identical with the north fold into which the strata over the area of this mountain range were uplifted. Along the broken crest of this ridge, the reddish drab-gray Carboniferous and light buff-gray Niagara (?) limestones hold a prominent place in the rugged mountain masses and isolated peaks. But in the southeasterly continuation of the ridge the sedimentaries are, in places, removed, revealing a narrow belt of the Archæan nucleal rocks, so indicated by the peculiar mode of weathering exhibited by the rocks in the south face of the ridge and the presence of quantities of gneissic débris in the outlying slopes and stream-beds that emerge opposite this spot. This supposed Archæan ridge, in places bears along the crest dirty yellowish deposits, recalling the lithologic appearance of exposures of the Primordial horizon to the west. But the outlying flanks on the south are plated by Carboniferous and Silurian strata, which rise up steeply on the lower half or more of the height of the mountain ridge.

The above mentioned ridge terminates in a prominent mountain between the forks of the stream whose eastern and lesser branch drains a part of the northeast flank of the north fold, and which lies to the westnorthwest of Gros Ventre Peak between 8 and 9 miles distant. On the south the slope falls in an even and slightly bulging curve, corresponding to the planes of the flexed strata into the border of the basin, while on the west, north, and east the mountain breaks down in precipices, showing hundreds of feet thickness of the component strata. The ex. posures are mainly, if not entirely, of Carboniferous rocks, the upper part showing characteristic outcrops of harder and softer limestone beds alternating in mural exposures and steep, bare slopes that reach up to the summit. The basis rocks may belong to Silurian horizons. The denuded Archrean ridge lies less than a mile to the north, and although considerably lower than the summit of the terminal mountain, its crest rises above the actual altitude of the lowermost sedimentary exposures in the precipitous north wall of the mountain. The presence of this mountain mass of sedimentary rocks brings out in the most vivid manner all these relationships and the enormous extent of erosive action necessary to uncover the metamorphic core of the north fold. The vertical displacement in the fold at this point is probably not less than 3,000 feet. Its abrupt southern flank may be traced nearly its whole extent from the heights in the western part of the range, sometimes exhibiting the flexed strata, in situ, on the steep mountain sides, and then, again, eroded so as to appear in monoclinal ridges capped here and there by red beds possibly of Triassic age, whose gentle northerly declination forms the broad plateau reaching over to the culminating mountain crest overlooking the Gros Ventre Basin. This part of the range is deeply eroded by a considerable Gros Ventre tributary, in whose bed the Archæan may be revealed similar to the occurrence in the mountain basin of the sources of the cascade tributary flowing into the Hoback.

A couple of miles southeast of the last-mentioned cañon the sources of a small, independent Hoback tributary have excavated a deep amphi. theater extending back into the mountains 2 or 3 miles from the south border. Where it emerges, its course is interrupted by a beautiful cascade, the stream tumbling or sliding many feet lown the steep incline over Carboniferous ledges, which throw a heavy belt across the mouth of the recess and rise high up in the mountain elevations on either side. On the east of this amphitheater the Archæan is denuded, forming another spur which bears atop the whole of the Primordial quartzite capped by remuants of Quebee limestone, which latter appears in undulating low mural masses, weathered dark brownish gray. The south 


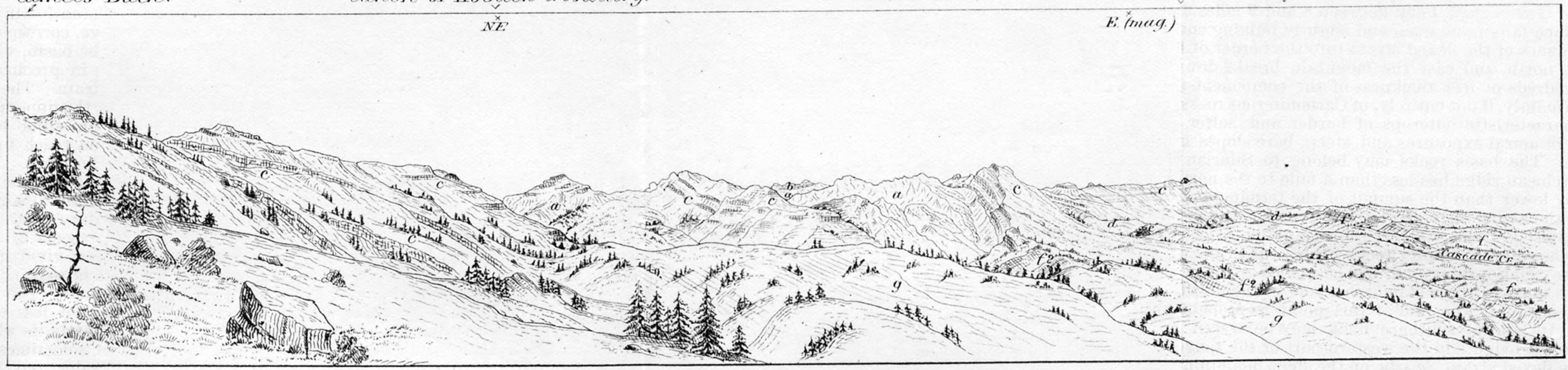

South Front of the Gros. Ventre Range, between Camet's Bach and Gros Ventre Peak (Sta. XIII). a. Archaean
f. Tentiary of Hobackis River:

Plate XV.

d. Tura-Trias.
g. Tertiary-red conglomerate. e. Laramie. 
side of the easterly continuation of this ridge fronting the basin is also plated by the uplifted sedimentaries, while looking up the cañon, the Archæan is conspicuously displayed, making up the greater height of the mountain walls in the sides of the amphitheater. The latter mountain ridge sweeps round to the north where it merges into the main north ridge of the range 8 miles to the northwest of Gros Ventre Peak. The former described axial ridge that forms the west wall of the amphitheater has a much more involved relationship in consequence of its median position between the two principal topographical ridges of the range in the region of the sources of Gros Ventre and Hoback tributaries and forming what may be termed a third mountain ridge with spurs connecting both with the south and north ridges, with the former in the vicinity of Station XII, northeast, and with the latter at a point about 11 miles northwest of Gros Ventre Peak.

These connecting spurs are but remnants left by erosion of the broad summit of the principal north fold, which indeed still retains much of its distinctive features in the elevated mountain plateau into which the central topographic ridge expands a few miles to the northwest in the direction of Station XLVI (1877) with which it forms a circuitous but almost uninterrupted chain of mountain tables from the point northeast of Station XII, where this ridge veers round from the axial line of the fold easterly and then northwesterly, finally forming the northern barrier towards the northwest extremity of the range

In the outlying slopes in the vicinity of the cascade unmistakable and most interesting exhibitions of Mesozoic strata are eneountered, the first of these rocks observed on this side of the range east of Hoback Cañon ridge. Drab and bluish indurated arenaceous clays, associated with buff sandstone, containing obscure vegetable remains, outcrop in the divide west of the cascade, dipping northeastward toward the mountain at an angle of $20^{\circ}$ to $45^{\circ}$. There are indications of a fold in these deposits with more gentle inclination on the southerly flank. These deposits bear a strong resemblance to Laramie horizons occurring in the Wyoming Mountains. Their exposure is also here accompanied by the browndrab soil and inmerous spring sources that are the concomitants of the outcrop of certain Laramie deposits in the latter region; and further, the presence of ferruginous-stained impressions of plants in some of the sandstone layers furnish additional evidence of their probable stratigraphical identity with those deposits. On the stream below the debonchure limited exposures of dark colored limestone were seen which recall similar layers that were found in lower member of the Laramie west of the Hoback Cañon ridge. Next the mountain occurs a set of beds resembling the Jura-Trias conformably superimposed on the southerly dipping Carboniferous. At the base of the Jura occurs a heavy bed of buff Magnesian limestone abounding with calcite. The "red beds," however, seem to be attenuated as compared with their thickness in the Wyoming Mountains. These deposits at this locality reach well up on the foot of the mountain, where they are much obscured by accumulations of rock débris.

Outlying the Jura-Trias belt, in the extremely broken slopes rising into the high bench on the southeast side of the stream, perhaps a couple of miles below the cascade, an interesting oyster-bed exposure occurs within the limits of the previously mentioned outlying fold. The bed shows a thickness of about 2 feet, closely packed with fossil Ostrea, included in a thin-bedded grayish buff sandstone which inclines northward at an angle of $50^{\circ}$, more or less, at the point examined. The exact stratigraphical relations of this bed to the before-mentioned Lara- 
mie deposits of similar lithological appearance is not clearly discernible at this locality. Dr. White refers the most prevalent Ostrea to O. soleniscus Meek, of the Upper' Cretaceous sandstones near Coalville, Utah. Associated with the above form there were also recognized Barbatia coalvillensis White, and a small Ostrea which resembles $O$. insecura White, of the Bitter Creek Laramie series, although it may be the young of the first-named species. The strata are so generally concealed by loose materials in the surface as not to afford the means for determining either their vertical thickness nor the extent of their outcrops. The occurrences are confined to the high benches well beyond the foot of the $\mathrm{Pa}$ leozoic-plated mountain, in the upheaval of which they evidently partook, although at no point do they probably remain on the high ridges of the range. The above stratigraphical occurrences probably occupy the synclinal trough intervening between the north and south folds of the range, the latter exposures pertaining to the remnant of the north flank of the south fold which here exhibits extraordinary abruptness of declivity.

Two or three miles below the cascade the brook enters a pretty int $\mathrm{r}$ vale and terrace bordered valley eroded out of the soft basin deposits. The hill-sides are covered with large tracts of vigorous young pines from a foot and upwards in height, amidst which rise the stark trunks $r$ their burned predecessors. Not unfrequently the same phenomenon was observed at other places in this region, which seems to prove that the conditions for forest growth are as favorable to-day as at any ime in the past. At, a locality north of Hoback Cañon, a tract of b cned spruce forests occupying a northwesterly slope was renewed by a dense growth of young pines.

Just below the valley expansion, well defined lateral moraines are developed, rising 75 feet, more or less, above the stream, and clinging to the steep slopes. There are two or three of these ridges one above the other. Lower down the moraines decline and spread laterally over the more gentle declivities, in the hollows of which wet meadows frequently oceur. The lowermost one finally converges, throwing a low embankment in the shape of a terminal moraine clear across the valley, through which the stream has eroded a narrow channel to the depth of 25 feet. How far below this the moraines extend was not ascertained. The one described was the most perfect example of terminal moraine observed during the visit to these mountains, although it probably does not mark the ultimate distance the ancient glacier traveled beyonds its mountain limits. The position of these morainal deposits conclusively shows that the glacier which transported their materials flowed down a pre-existing valley of nearly the same spaciousness as the present trough, and which possibly had almost equal preglacial extent within the mountain area as that which it there presents to-day. There was noted no unmistakable glaciation on the sedimentary mountain flanks in the debouchure, although the limestone-incline over which the cascade glides was bared and smoothed by the effects of the ice-fall. But within the cañon, doubtless, all the concomitant phenomena of glacial action would reward a more careful exploration than it was possible to undertake during the present visit.

To the east the mountain wall curves ronnd into a shallow recess, which is drained by another tributary of the Hoback. Oceasional exposures of gray Laramie (?) sandstone were met with in the high sloping basin benches that here reach close up to the foot of the abrupt mountain declivity. The east side of the recess is defined by the ridge reaching north from the angle of Gros Ventre Peak, which here, as in the south 


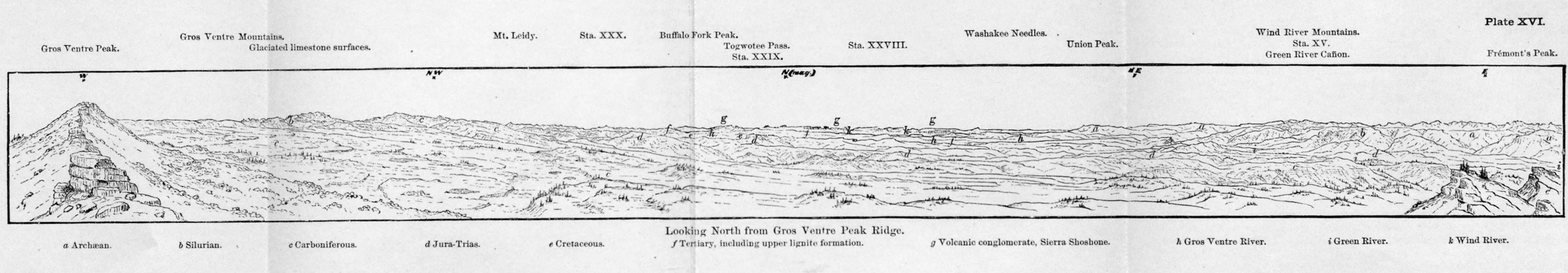


face of the east arm of this mountain ridge, forms long, steep talus slopes of loose débris, terminated above in a grand line of escarped ledges that rise up into the crest. Gros Ventre Peak is a conspicuous object viewed from the south, having the appearance of a bulky quadrangular mass of sedimentary rocks lifted bodily to the height of nearly 11,500 feet above sea-level. A low wedge of compressed pyramidal shape near the southwest angle of the mountain was selected for Station XIII, and which also served the purposes of a primary station for $\mathrm{Mr}$. Wilson the previous season. The west and south fronts break down abruptly from elevations 2,000 to 3,000 feet above the basin benches at their foot. Near the angle, the heavy bedded light buff magnesian limestone, elsewhere provisionally identified with the Niagara, rises up steeply in the mountain foot, forming a sharp flexure with southwesterly inclination at a high angle. These beds are succeeded by the thinner-bedded gray and reddish-stained limestones of the Carboniferous, which curve over and at a higher elevation from the escarped monoclinal heights of the ridge. The crest of this mountain was found to consist of a narrow ridge; that to the east wrought out of sandstones into a jagged, almost impassable, comb. On the north the descent is precipitous, broken by vast piles of angular débris, in 300 to 500 feet, reaching the limestone floor of an extensive, glaciated mountain basin. On this side the Carboniferous strata everywhere slope off to the northeastward, at a comparatively moderate angle of inclination. In the upper portion of the basin the limestone plane is burdened with low piles and ridges of débris, probably of morainal origin, and dotted with lakelets. The drainage flows east into the Green, and at the western end of the depression a south affluent of the Gros Ventre rises, flowing out to the northward across a wide belt of Jura-Trias.

A section of nearly 1,000 feet vertical thickness of Carboniferous strata is exposed in the east arm of Gros Ventre Peak. The upper 500 feet consists of a heavy deposit of buff-gray and reddish tinted, laminated sandstone, with obliquely laminated and quartzitic layers, and thin bands of deeper red color. The inferior half of the exposure is made up of numerous ledges of drab and gray limestones, the upper part containing layers stained chocolate-red, and containing characteristic Carboniferous fossils-Zaphrentis, crinoidal remains, Hemipronites crenistria, \&c. The beds incline northward, at an angle not exceeding $10^{\circ}$, and generally not more than $5^{\circ}$ to the horizon. As before stated, the sandstone forms a mere wall along the crest, which gradually declines to the east, where its appearance will be again referred to further on. To the north, in low southerly-facing declivities, defining that side of the mountain basin, the sandstone horizon reappearis, where it is overlaid by several hundred feet thickness of drab limestones, sandstones, and shales, alternating. Beyond the latter, in similar abrupt terminating benches, typical exposures of the Triassic " red beds" occur, occupying a wide belt sloping off the gently inclined north flank of the range into the basin area, drained by Gros Ventre River. The occurrences above noted bear a strong likeness to the stratigraphical sequence of the Carboniferous observed the previous season in the Téton Range and in the Snake River Mountains, to the west. Indeed, the resemblance is so marked that it may be regarded as conclusive evidence of the identity of the strata of these horizons in the regions mentioned. This middle Carboniferous sandstone, however, in the present mountain range, perhaps attains a somewhat greater development and differs lithologically in its generally paler tints from the equivalent horizon in the Téton Mountains. 
East of Station XIII the southern flank of the north flexure has been almost entirely removed by erosion, only limited exposures in the foot of the mountain preserving part of the curved strata. Along this part of the mountain the high outlying slopes show here and there limited exposures of the arenaceous "red beds" that form a belt continuous with the Triassic deposits occurring a few miles to the westward of Gros Ventre Peak, of which mention has already been made. At the present locality these deposits appear to be little disturbed; their inclination, although varying from northerly to southerly, perhaps does not exceed an angle of $10^{\circ}$. Their position at the foot of the mountain is not favorable to the determination of their relations to the Carboniferous deposits occurring in the latter, while on the south they are soon concealed beneath the Tertiary deposits that here gently rise up in the northern terminus of the Green and Hoback water-divide. It is possible that the uplift at this point was accompanied by a fault, with downthrow on the south, amounting in vertical extent to about the thickness of the carboniferous formations.

Soon after crossing the Hoback-Green divide, in the vicinity of the lake source of a stream flowing south into Green River, the Carboniferous limestone, here highly siliceous, forms a low, broad arch, with gentle inclination both north and southwards. The limestone appears over a considerable area in the low, hilly and undulating wooded country immediately south of the sandstone-capped eastern prolongation of Gros Ventre Peak ridge, at the foot of which lies the above-mentioned little lake-basin, partially environed by the sandstone and limestone cliffs. Thence eastward, this ridge steadily declines, flattening out into one of the low divides terminating on the west side of Green River Valley, about 8 miles distant. The Station XIII, or north fold of the range, is not traced with certainty but a short distance east of the lake, and it seems probable that it also dies out in that direction.

The west side of the stream flowing south into Green River is bordered above by bluffs composed of the "red beds," and lower down by the rather abrupt east face of the main divide separating the drainage of the Green from that tributary to the Hoback, and which is here made up of Tertiary deposits. Perhaps 3 miles south of the lake limited exposures of Jurassic sandstone and calcareous deposits appear in the gentle slopes on the east side of the valley, dipping about $25^{\circ}$ south, and containing Pentacrinus, Ostrea, and Belemnites. The way thence leads southeasterly over low, undulating divides in the country intervening between this stream and the Green. The only rock exposures met with in this section consisted of occasional outerops of drab clays and reddish-buff, thin-bedded, rather hard sandstone. These rusty-weathered sandstones continued nearly to the Green, forming low ledges here and there in the grassy slopes, and uniformly inclined about south, at angles of $20^{\circ}$ to $35^{\circ}$. Lithologically they bear intimate resemblance to, and are probably identical with, horizons elsewhere referred to the Laramie. They are apparently in conformable superposition to the Jurassic deposits occurring to the north, which further suggests the aboveinferred identity, unless they prove to belong to an intermediate Cretaeeous formation. But the latter formation was not recognized here, and in the absence of fossils our acquaintance with its stratigraphical composition is too imperfect to warrant its recognition in obscure outcrops.

The most southerly observed exposures of the above-mentioned Laramie (?) sandstones occur in the uplands on the west of Green River, about 3 miles northwest of an isolated Tertiary butte that rises from the plain on the opposite side of the river, or about 11 miles above the 
mouth of Lead Creek. Ascending the valley of Green River from this point the east side of the stream is closely bordered for several miles by a low, outlying ridge at the western base of the Wind River Mountains, which is composed of gently-inclined Jura-Trias deposits. About 11 miles north of the butte a low arch of Carboniferous limestone rises a few feet above the river-level, the strata gently inclining north and south at an angle not to exceed $10 \circ$, with which the superimposed Mesozoic formations conform, as displayed in the exposures on both sides of the valley. The axis of this arch lies a little north of east of Gros Ventre Peak ridge, and in its physical character it offers little by which it may be distinguished from the low arch immediately south of the eastern terminus of the above-named ridge, as mentioned above. In case of their identity the trend of the Gros Ventre Peak, or north fold of the range, curves round from a southeasterly course, which it has hitherto held, to an easterly direction on approaching the Wind River uplift. The beforementioned outlying ridge on the western foot of the latter range bears the record of dynamical disturbances that transpired in both zones of mountain elevation.

The north flank of the Gros Ventre Range was not approached nearer than the outlying and probably geologically parallel low ridges that lie within the Gros Ventre Basin. But from the latter and more distant mountain peaks situated in the northern part of the Wind River Range and in the Mount Leidy highlands, to the northeast and north, respectively, a general knowledge of its geological structure was acquired. From the points of view above designated the great north fold of the range more or less closely corresponds to the prominent mountain crest that constitutes the eastern half of the northern barrier. To the west the tributary drainage of the Gros Ventre River has eroded the north flank of the fold forming the culminating mountain ridge that makes a slight north deflection from the eastern portion of the ridge with which its topographical relations are most intimate. This ridge throughout ranges in actual elevation between 10,000 and 12,000 feet, bearing a grand chain of architectural peaks sculptured out of the uplifted sedimentaries.

As has been already stated, the north flank of the range presents a comparatively gradual and remarkably uniform declivity descending into the basin area of the Gros Ventre. Its component geological formations embrace the entire sedimentary series of the region, from the Silurian to the Jura-Trias, inclusive. In the eastern half only the Paleozoic formations, chiefly the Carboniferous, remain along the main mountain crest, while to the west, in the before-mentioned north deflection of this topographic crest, the Triassic "red beds" hold a prominent place on the flank of the monoclinal ridge. But what is regarded as the westerly continuation of the geological ridge or north fold, which was excessively eroded by the sources of the previously-mentioned south affluent of the Gros Ventre, which rises 5 or 6 miles to the northeast of Station XII, exists as a mere remnant, on the southwest flank of which low outliers of nearly vertical strata were seen from Station XLIV at the west end of the range the previous season. The erosion of the Little Gros Ventre, which heads in this quarter, has stripped the sedimentaries from the axis of the fold, revealing the quartzite and possibly also a belt of the metamorphic nucleus of undetermined extent along the course' of its cañon. The mountain ridge lying between Gros Ventre River and Little Gros Ventre Creek, and which constitutes the extreme northwest extremity of the range, exhibits the lower limestone and middle reddish-tinted sandstone members of the Carboniferous in long lines of monoclinal 
exposures lying a little to the north of the axis of the north fold and sloping off to the northeastward at a moderate angle of inclination.

The middle sandstone member of the Carboniferous, which is welldeveloped in the latter quarter, is conspicuous on account of its red color. In this respect it presents a marked contrast to the lithologic appearance of the same horizon noted towards the opposite extrem ty of the range, in the vicinity of Gros Ventre Peak, and which might lead to its being mistaken for the Triassic "red beds," were its stratigraphical associations locally masked or not recognizable in distant views, such with which the geologist too often has to be content.

The Jura-Trias occupies a relatively wide belt on the north flank of the range, even rising into quite prominent tables and foreland benches, descending in long inclines, and merging into the area of the basin proper. The Jura was hardly touched at a single locality in this quarter, its presence being determined chiefly from the lithological appearance and sequence of its exposures. It seems to be in part made up of deep drab and chocolate-red variegated clays, sandstones, marly indurated layers, and drab limestone. Owing to the prevalence of clayey constituents the exposures are seldom satisfactory. On the contrary, the deep-red arenaceous shales and sandstones of the Trias are exposed in numerous and extensive escarpments, and wherever in the region of its occurrence the soil from one cause or other has been disturbed, a gleaming spot of red color, may be contrasted with the deep-green of herbage-clothed slopes, discloses its presence. 


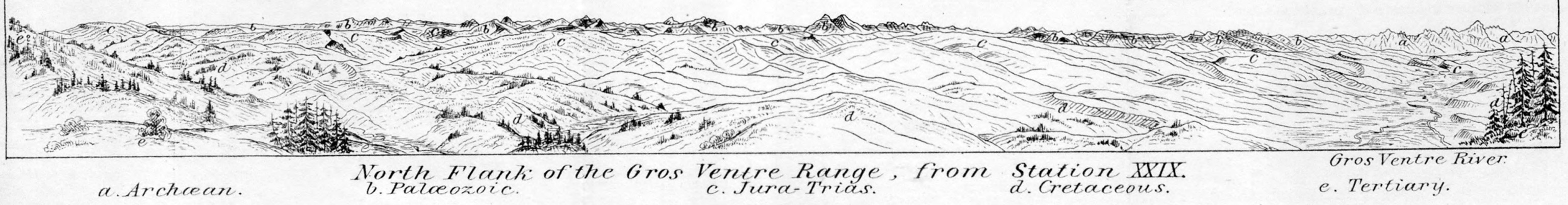
Plate XVII. 


\section{CHA P TER V.}

\section{GROS VENTRE BASIN.}

Gros Ventre River drains a large basin tract lying to the north of the mountain range bearing the same name, and which is about twice the superficial extent of the upper basin of the Hoback on the south of that range. To the southeast it is defined by the low, inconspicuous divide stretching over from the north slope of the Gros Ventre Range, east, to the great foreland bench on the west flank of the Wind River Range south of Union Peak; the elevated water-shed that spans the gap between Union Peak at the northern terminus of the latter range and the great sedimented volcanic mountains in the vicinity of Towotee Pass, a distance of 24 miles, constitutes the barrier on the east between this drainage and the upper course of Wind River; while it is separated from the valley of Buffalo Fork by the low mountainous highlands dominated by Mount Leidy, which form the northern boundary of this special drainage basin. Thus defined, the Gros Ventre Basin has an area of 500 square miles, approximately.

The main stream rises in a glaciated defile a few miles south of Union Peak, and once it emerges upon the elevated park-like slopes at the foot of the latter mountain, it pursues a general course a little north of west for the distance of about 42 miles to the point where it gains the plain of Jackson's Basin. It receives several good-sized tributaries from the surrounding highlands, and is of additional importance from the fact that it affords easy communication with the Wind River Valley via Union Pass at the north end of the Wind River Range. Chiefly occupied by easily eroded tertiary deposits, the general superficial contour of the basin is exceedingly broken, especially in the central and northern portion. The streams generally flow in narrow valleys, often deserving the name "cañons"; lower down the main valley expands, affording small tracts of intervale and terrace land. The uplands present pleasing variety of forest and herbaceous openings in the undulating southeastern quarter, where the wonds and meadows were found stocked with numerous bands of elk and deer. But in economic importance it scarcely equals the beautiful basin of the Hoback (its general elevation being in the neighborhood of a thousand feet higher), save in one particular, its extensive deposits of coal.

Geologically, the area above alluded to constitutes but a part of the great Cenozoic basin that stretches north intil it is lost beneath the lava flows and volcanic ejectamenta that mask the whole country around Yellowstone Lake. Its present orographic boundaries are, on the west, the Téton Range; south, the Gros Ventre Mountains and the northern end of the Wind River Range; to the north and east, except for the presence of the probably isolated uplift on Buffalo Fork, described in the report on the Téton district the previous season, it has an extent reaching far beyond the limits of the present district.

It is not the province of this special report to attempt the definition 
of the original boundaries of this great Tertiary basin. Within the area of this particular district observation seems almost to warrant the conclusion, if it fails to establish the fact, that the waters of that time communicated with the basin area of Green River, although denudation has interrupted the continuity of the sediments then accumulated in the intervening straits between the Wind River and Gros Ventre Ranges. But in the latter quarter the vertical displacement or upheaval, in the region of the eastern extremity of the latter range, was not sufficient to erect an insurmountable barrier to the encroachments of the waters on either hand and the eventual union of the north and south expansions of the Cenozoic sea. From a geological point of view the evidence is somewhat conflicting, inasmuch as it is not yet known with that certainty necessary to well-founded generalization to what extent the Cenozoic deposits themselves have been disturbed by forces acting within the present orographical boundaries, and, until the latter problem shall have reached solution, the original extent of surface occupied by these sediments must remain more or less a matter of conjecture. In the Wyoming Mountains they are known to reach high up on the summit in places, where they rest unconformably upon older geological formations ; at the same time their inclination, although moderate, shows that disturbing influences had not ceased subsequent to their deposition. Although in the Gros Ventre and Buffalo Fork uplifts these deposits at no point were observed in the more elevated portions of the mountains, yet they are more or less disturbed wherever they appear on the mountain flank. Whether their disturbed condition is due to elevatory movements within the mountain zones or to subsidence in the outlying basin areas is not so evident, although within the present topographically-defined basin area these beds exhibit marked evidence of disturbance, which resulted in their being uplifted into more or less well marked folds, whose parallelism with one or other of the bordering mountain uplifts may be readily recognized.

The northerly or northeast inclination of the Paleozoic and Mesozoic formations off the north flank of the Gros Ventre Mountains, as has been indicated in the preceding chapter, extends along the entire south border of the Gros Ventre Basin, so that it is difficult to draw the exact line defining on the one side the basin limits from the mountain foot on the other. Of the above formations only the Mesozoics enter the basin area proper, where they occupy a rather wide belt in the southeastern border portion. In the westerly-rising declivity of the Gros-Ventre-Green divide, at a point perhaps 8 miles about north-northeast of Gros Ventre Peak, the Triassic "red beds" arch partially over a low fold, the eastern flank of which has been eroded and is at present covered with dense forests. East of the latter fold the channels of streams flowing down either side of the divide reveal the presence of the soft yellowish sandstones and light-drab clays of the Tertiary(?); but on the declivity rising up on the Wind River Mountains to the east, the surface is composed of drift materials evidently derived from that range. West of the Triassic fold, in the gentle slopes descending the north flank of the Gros Ventre Range into the shallow intervening depression, the same deposits outcrop in low bluffs, the northerly inclination of the surface conforming to the dip of the strata. This low arch was not again recognized to the northwest, and it may be of merely local extent.

In the southwestern half of the basin the strata are complicated by a series of flexures lying quite within the basin limits, although, of course, intimately related to the mountain upheaval culminating in the north fold of the Gros Ventre Range. This belt of flexed basin deposits extends 
Plate XVIII.

Wind River Mts.

S.S.E.
S. (mag.) Gros Ventre Mts.

Sta. XIII.

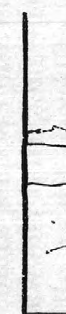

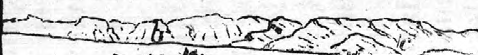

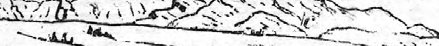

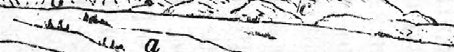

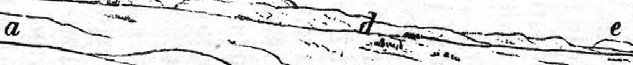

$-2 \frac{1}{\cdots+2}$

Gap between Wind River and Gros Ventre Ranges. h Archæan, south of Green River Cañon. $\quad c$ Palæozoic.

h Archæan, south of Green River Caño
(From Station XXVIII.)

e Tertiary. 

a distance of 5 miles or more along the Gros Ventre, or from the upper main forks to the valley of a considerable south tributary that skirts the foot of the Carboniferous plated mountain ridge which here forms the northernmost culminating crest of the range. The exposures are well displayed but for occasional interruptions in the continuity of their visible outcrops in the terrace bluff along the southeast side of the stream. The rocks involved in the flexures are of Cretaceous age, according to the specific identity of the few fossils here obtained, as kindly determined by Dr. White. The northeast-facing mountain slope to the west of the before-mentioned Gros Ventre south tributary is heavily plated by the Jura-Trias, the outlying lower slopes in places showing low ridges of light-buff deposits, which are presumably referable to the Cretaceous. The strata are again exposed in the east side of the valley, and thence to the main forks of the Gros Ventre they are exhibited in a well-defined synclinal and anticlinal fold, the axial trend of which is in a direction a few degrees east of south and west of north, changing farther east to about southeast-northwest. A diagram of the geological section here alluded to is given in an accompanying plate, the horizontal distances being rough approximations, in explanation of which is appended the following description:

\section{Section along Gros Ventre River.}

No. 1-4. The formations, Carboniferous to Cretaceous, inclusive, that rise up on the northeast flank of the Gros Ventre Range have been already mentioned. The outer border of the Cretaceous, No. 4, at the mountain foot is concealed by morainal deposits, No. 5, and alluvial materials in the valley. It may be that in this space the Cretaceous strata have been eroded over the site of a low fold corresponding to a previously mentioned broad low arch in the "red beds" immediately outlying the foot of the range to the northeast of Gros Ventre Peak.

No. 6. Gray, indurated argillaceous beds and drab clays, and soft gray sandstone, with thin seams of cannel-like coal. Dip northeastward.

No. 7. Gray, argillo-calcareous, indurated beds, gray sandstones and drab clays, with obscure plant-remains, and thin layers of lignite. Dip $20^{\circ}$, about E. $30^{\circ} \mathrm{N}$.

No. 8. Space, showing only obscure rock exposures of similar character to above and following.

No. 9. Indurated drab shales and drab and brown clays, and gray sandstone, underlaid by a thick deposit of heavy-bedded, gray, buffweathered, soft sandstone. In the overlying drab shales, which also form a heary deposit, at one place a thirty-inch bed of coal was observed, below which other thinner seams were seen, the outcrop crumbling on exposure to the weather; dip $55^{\circ}$, about W. $10^{\circ} \mathrm{S}$. Overlying the coal, a small ovate leaf with crenate margins occurs in a drab indurated argillaceous bed, together with comminuted vegetable remains, the sandstone also affording what appear to have been large stems of trees, but very imperfectly preserved.

No. 10. Gray sandstone, dip little south of west at an angle of about $60^{\circ}$. This is probably identical with the sandstone next mentioned below, having arched over a sharp anticlinal fold, the axis of which has been eroded or otherwise concealed at this point.

No. 11. Half a mile or thereabout below the main forks of the Gros Ventre, a heavy deposit of gray and buff-gray, coarse-grained, heavy and thin-bedded sandstone appears in the bluft's along the left side of the stream, and lower down underlaid by dark or brown drab clays showing 
only obscure exposure; dip E. $8^{\circ}$ N., at an angle of $50^{\circ}$. At one point the saudstones, which are in places calcareous, afforded a few imperfectlypreserved fossils, amongst which Dr. White has determined the follow. ing Cretaceous forms: Mactra arenaria Meek?, Ostrea sp.?, Inoceramus erectus Meek?, and other undetermined conchifers. The Inocerami have a considerable vertical range in the heavy sandstone deposit, although its presence is chiefly determined from mere fragments showing the peculiar shell structure.

No. 12. The steep hills in the immediate vicinity of the main forks of the stream are made up of gray, buff-weathered sandstones and drab clays, inclined at an angle of $55^{\circ} \mathrm{E} .33^{\circ} \mathrm{N}$.

No fossils were observed in the latter beds of the above section, but there is no doubt of their conformable superposition to the strata described under No. 11, and which, together with No. 4-11, inclusive, constitute a heavy series of light gray and yellowish-weathered sandstones and drab clays occurring within the basin area proper, and whose disturbed condition is apparently attributable to, and synchronous with, the disturbances that folded the strata over the region of what is now the Gros Ventre Range.

Station XXIX was located on a commanding crest of the ridge just west of the main branch of the Gros Ventre, about 6 miles southeast of the forks. The view from this point commanded nearly the whole northeastern front of the Gros Ventre Range, besides nearly the entire extent of the basin from a nearly central position. The nature of the strata composing the ridge itself, in the main soft sandstones and clays, dipping northeastward, affords few rock exposures of any considerable vertical extent. But the surface of the whole region, reaching up to and crowning the sharp ridge on which the topographical station was made, is strewn with the remnants of a remarkable conglomeritic deposit, whose origin might at first be mistaken for Quaternary, as indeed the degradation and dispersion of its component materials was affected during that period. Approaching the valley of the Gros Ventre, the Cretaceous deposits have been extensively eroded, but to the southeast they rise up into higher ridges, which still farther in that direction have been denuded, bringing to view the Triassic " red beds" and drab vari. egated deposits of the Jura in the before-mentioned low arch to the northeast of Gros Ventre Peak. This arch is about southeast of Station XXIX, to the east of which the Cretaceous deposits, if they still exist in that quarter, merge into the undulating drainage divide defining the southern limits of the basin.

In this connection may be mentioned limited occurrences, in the direct line of the south-southeasterly strike of the deposits above noticed, that were examined along Green River just above the great bend. There here occurs an exposure of gray and bluish clays with bluish indurated fine arenaceous layers, which break into narrow slabs or post-like masses, the dip of the beds being about N. $40^{\circ} \mathrm{E}$., at an angle of $30^{\circ}$. The isolation of the exposures and the absence of fossils renders the determination of their stratigraphical position a difficult question. But there is certainly a somewhat striking coincidence in the direction of their strike, which, at least, suggests a possible identity with the above-mentioned deposits in Station XXIX ridge.

The general northwesterly strike of the Cretaceous deposits, in the Gros Ventre section above described, apparently veers round more to the west on passing into the region north of this stream. This is indicated by the occurrence of very similar lithological manifestations in the broken slopes midway between Mount Leidy and the Gros Ventre, 



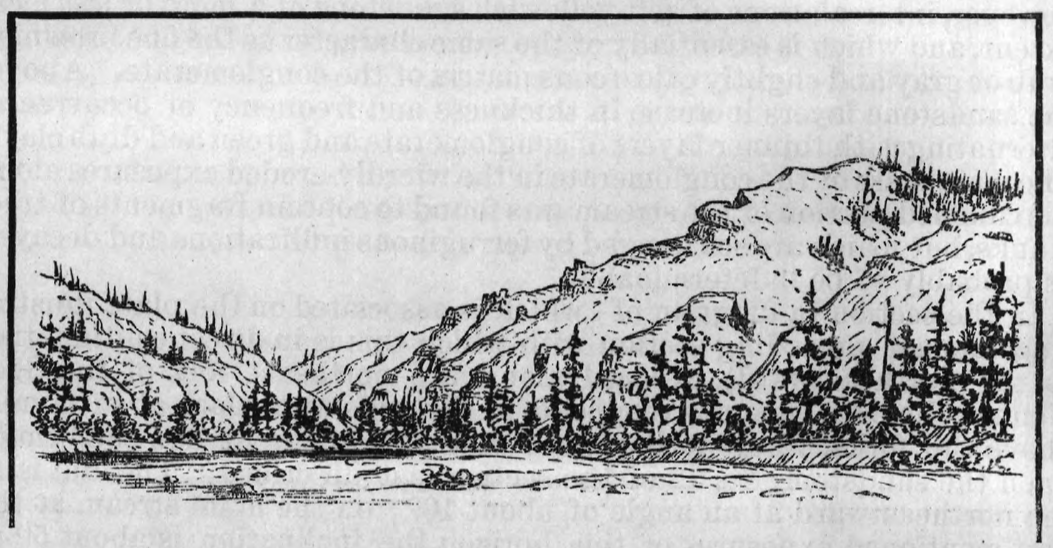

a Conglomerate.

Gros Ventre River: Cañon in conglomerate.

(Looking N. W.)

$b$ Upper lignite. 
and in the regular order of stratigraphical superposition to the variegated Jura and unmistakable "red beds" of the Trias, all of which, so far as can be made out at a distance, belong to the northerly-inclined flank of the northwestern extremity of the Gros Ventre Range. But these deposits appear over a comparatively narrow belt in this northern slope of the basin, at least not of greater width than along the Gros Ventre, while in the crest of the Mount Leidy highlands they are superseded by later deposits, presently to be mentioned.

The main branch of the Gros Ventre, after leaving the elevated mountain flats, flows in a gradually deepening narrow valley, in whose sides fine exhibitions of the Tertiary are met with, extending as far down as a point about 4 miles above the two principal forks, where the stream enters the above-mentioned Upper Cretaceous horizons. The Tertiary deposits are based upon a heavy accumulation of brownish-drab conglomerate, several hundred feet in thickness, and which is composed of thoroughly water-worn and rounded pebbles and small bowlders consisting almost exclusively of variously-colored quartz and quartzitic fragments, rarely a metamorphic pebble being seen. The conglomeritic character predominates through a great vertical extent of the horizon, with, however, intercalations of soft yellowish sandstone of a more or less local extent, and which is essentially of the same character as the fine brownish drab or gray and slightly calcareous matrix of the conglomerate. Above, the sandstone layers increase in thickness and frequency of occurrence, alternating with thinner layers of conglomerate and green and drab clays. The main mass of the conglomerate in the wierdly-eroded exposures along the cañoned portion of the stream was found to contain fragments of treetrunks, but which are so changed by ferruginous infiltrations and decayed. as probably to be indeterminable.

In the section (a diagram of which is associated on the plate illustrating the last preceding section with which this is in direct continuation to the northeastward) exposed along the northeast fork of the Gros Ventre, the conglomerate reappears in the hills at a place about a mile above the forks, where it is seen to rest with apparent non-conformity upon the sandstone No. 12 of the section last described. The dip is to the northeastward at an angle of about $10^{\circ}$; on the main stream at the first-mentioned exposures of this horizon the inclination is about $5^{\circ}$ in the same direction. The exposures continue about a mile before they finally pass beneath the level of the stream, the inclination gradually lessening, ascending the valley to the northeast. This horizon is represented by No. 13 of section diagram referred to.

The conglomerate is conformably overlaid by a still greater thickness of soft yellowish sandstones, light and drab clays, forming broken hills and slide-benches, in which the strata are usually more or less concealed by the soil derived from their degradation. The latter deposits also incline gently northeastwardly, occurring along the valley for the distance of perhaps a couple of miles. This series is also finely developed on and to the east of the southeast fork, where, at a point about 8 miles above the forks, Mr. Perry secured a very interesting detail.section. In a vertical thickness of about 1,000 feet, made up of generally light buff calcareous sandstones and clay shales in about the proportion 2 to 1 , and including five beds of limestone aggregating 40 feet in thickness, there were found eighteen distinct lignite horizons, composed of 47 layers, varying from thin seams up to beds $2 \frac{1}{2}$ feet thick, and aggregating about 28 feet. The exposed outcrops of the coal beds usually are more or less decomposed, and while, in the main, the beds are thin seams from less than 1 inch to 8 inches thick, there are at least 11 showing a thick- 
ness of 10 inches and upwards each; several of the thinner seams separated by thin partings of clay might be mined as one bed, many of them showing an aggregate thickness of 20 to 30 inches of coal. Comminuted vegetable remains occur throughout, and at one carbonaceous horizon in the middle portion of the series a few imperfectly preserved. fossils were found belonging to the genera Unio, Hydrobia?, Sphcerium, which Dr. White provisionally refers to Bear River Laramie forms. In nearly horizontal sandstones in the upper part of the section examined. by Mr. Perry a species of Viviparus closely allied to, if not identical with, $V$. paludinaformis Hall, was obtained, which, according to Dr. White, indicates the Wahsatch age of the supralignitic horizons.

The latter deposits, on the before-mentioned northeast fork of Gros Ventre River, continue for a distance of $1 \frac{1}{2}$ to 2 miles; the exact thickness attained by them is difficult to determine. The upper.portion may be destitute of coal deposits, although presenting great uniformity in composition and lithologic characters. Overlooking a more or less extended belt of the outcrops of this series, it presents a light buff color that readily distinguishes it from the brownish inferior conglomerate, as also from the overlying series. But it would be premature at this time to attempt to draw the line of demarkation between the lignite-bearing inferior portion with its supposed Laramie invertebrate fauna and the apparently conformable upper portion characterized by the Viviparus paludinceformis (?), except arbitrarily; while the non-conformity between the basis conglomerate and the subjacent Cretaceous deposits is unmistakable.

The above horizon is succeeded to the east by a series of variegated pale red or pinkish clays (No. 15), in apparently conformable superposition, and inclined gently northeastward. The outcrop of this member is traced as a somewhat narrower belt, distinguishable by its peculiar color at long distances. It frequently appears in bluffs and denuded slopes, in which respect, as also the banded disposition of the coloring matter, pink and light drab, forcibly recalls the peculiar deposits so prominently developed in the Wind River Valley, east of the present basin. To the south these deposits are not so distinctly traced, so that at present it would be impossible to define their areal extent in that quarter. In the opposite direction, however, they are seen to rise up in the broken slopes culminating in the Mount Leidy highlands on the north border of the basin, beyond which again they were not with certainty recognized.

A considerably thicker series of very light drab and buff deposits, probably arenaceous clays and soft sandstone, including pale, orangecolored horizons (No. 16), overlies the last preceding deposits, rising up into and forming the bulk of the sedimentary deposits in the crest of the watershed separating this basin from the upper valley of Wind River on the east. They are but slightly disturbed from their original horizontal position, as appears from such exposures occurring along the streams descending either slope of the watershed. About midway between Union and Togwotee passes, where the watershed is most depressed, 9,800 feet altitude, these deposits are clearly continuous with those occurring on the headwaters of Wind River. This region is generally well wooded, and but for the barred bluffs along the drainage channels intersecting the watershed, its geological structure might not be so easily made out in the course of a hasty examination. No fossils were found in these deposits by which they might be compared with elsewhere well-determined Tertiary formations.

To the south they are hidden beneath Quaternary débris over exten- 


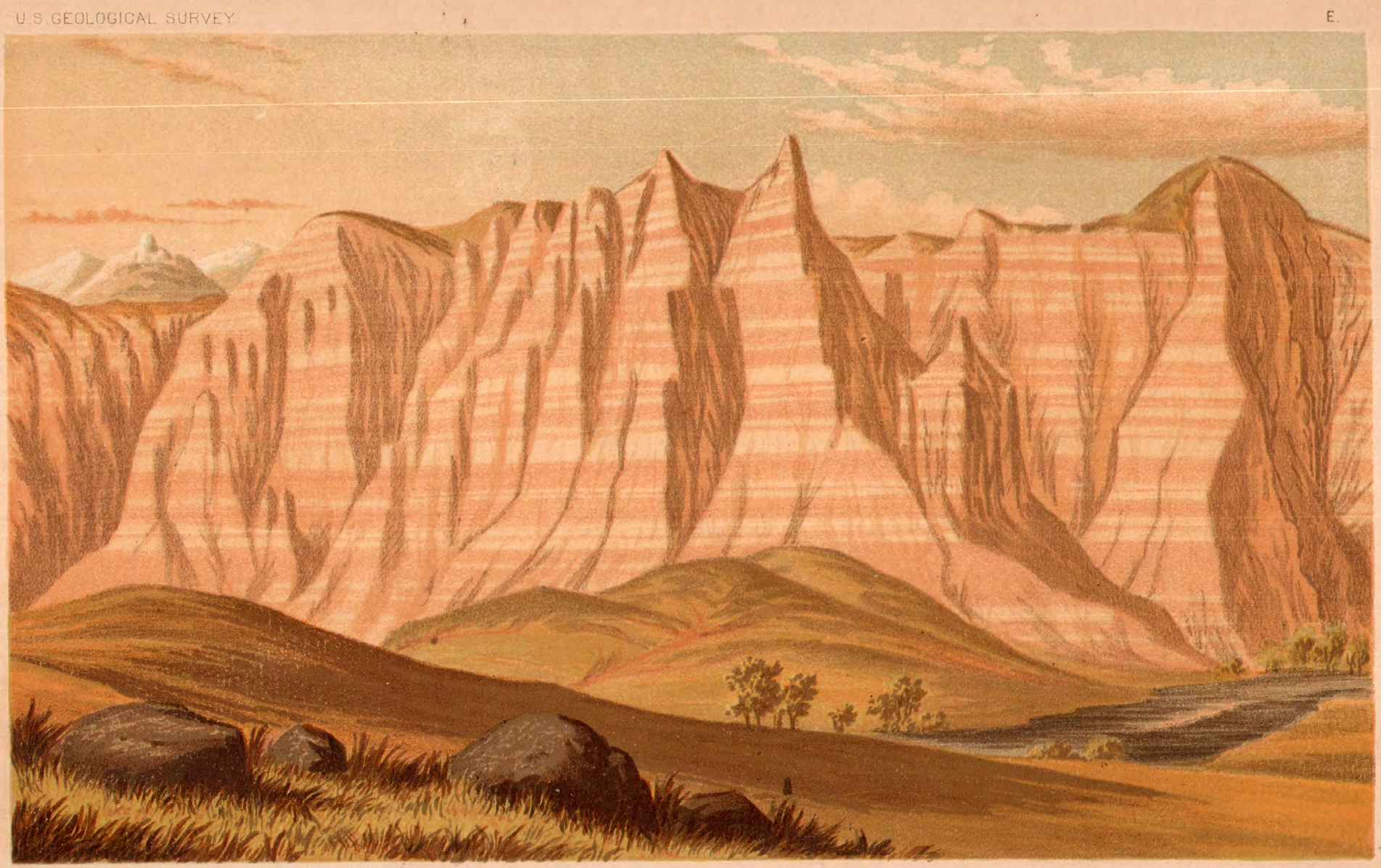

WASHED BLUFFS ON WIND RIVER. WASATCH GROUP 

sive areas in the slopes in the vicinity of Union Pass. Just north, however, on the head of Warm Spring Creek and upper drainage flowing to the Gros Ventre, they appear in the bluft's, showing nearly horizontal strata of yellow and brown sandy elays and soft yellow sandstones. The ridges separating the drainage are here often overspread by quan. tities of water-worn and rounded quartz pebbles, strikingly like the material derived from the degradation of the before-mentioned conglomerate lower down the Gros Ventre. But the surface is generally enveloped in the morainic débris consisting chiefly of Archæan bowlders. Approaching Station XXVIII, a low conical eminence rising on the summit of the watershed 11 miles to the northwest of Union Peak, attaining an altitude of 10,142 feet, the drift material shows constantly-increasing accessions of voleanic fragments and chalcedony. The station eminence is composed of a brownish-green easily-weathered deposit, intermingled with which, at the surface at least, occur quantities of basalt, red to brown and dark scoriaceous lavas, drab, brown, and pink trachyte, volcanic conglomerate and green-stained quartz conglomerate, such as occurs in Togwotee Pass, together with beautiful green volcanic glass and chalcedony, and fragments of fossil wood. Indeed, the hill would seem to be made up of fragmentary volcanic products of a kind identical with the great voleanic deposits in the neighborhood of Togwotee Pass. The green-stained basis deposit, also, is like that occurring beneath the great volcanic conglomerates at the latter locality, and which, the previous sf ason, was found to extend some distance from the summit of the pass along the upper course of Wind River, where it in turn rested upon light buff and drab Tertiary deposits, probably identical with those noticed above. A few miles to the north of the latter locality the flowed lavas connected with the high volcanic plateau that culminates in a low dome (the same occupied as Station LI by the Téton division of the survey the preceding season), 6 miles south-southeast of Togwotee Pass, first appear in situ (No. 17 of the section diagram), and thence round by way of that pass the watershed bears a heavy mantle of volcanic rocks. The stratigraphical appearance of these deposits in the latter quarter were noticed in the report upon the Téton district, 1877.

The range of hills separating this basin from Buffalo Fork drainage is apparently largely made up of the above-mentioned formations. This highland belt was crossed at a point about 10 miles east of Mount Leidy, in the vicinity of one of its culminating peaks, Station XXX, which has an altitude of 10,338 feet above the sea. The divide is here capped by the conglomerate, No. 13, composing several hundred feet thickness of the summit strata, and inclined about S. $12^{\circ}$ E., at an angle of $10^{\circ}$ or less. The conglomerate is here interbedded with hardish, gray, dirty-buff weathered sandstone containing fragments of twigs and tree trunks. The rock in the high summits weathers in precipitous slopes and steep taluses, through which protrude sharp arête-like buttresses which give to the weather sculpture of these eminences so peculiar and striking an appearance seen from a distance. East of this point the conglomerate is overlaid by the same succession of formations as noticed in Gros Ventre River section, 10 miles to the south, with which, indeed, these exposures have uninterrupted continuity. At the time of our visit the present season (October 11) the country was covered with snow; but in the 1:umerous abrupt hillsides the geological formations could be readily recognized, and especially so in the case of the great interlignitic conglomerate, which rises up into the heights that mark the irregular crest of the Mount Leidy highlands.

The inferior coal-bearing series, composed of softer materials, was not 
so markedly displayed in escarpment exposures, although it also doubtless largely enters into the basis deposits of this highland region. It is not impossible that the lignite seams reported the previous season on Elkhorn Creek, at the northern foot of Mount Leidy, belong to the latter series, in which case they should, together with their accompanying strata, be referred to the Cretaceous instead of the Tertiary as in the report upon the Téton district, 1877. The strata of a widish belt upon the western and southern flank of the highlands, which quarter, for want of time, was not visited, are also probably referable to the same age.

The conglomerate reappears in characteristically weathered summits north of Buffalo Fork, and it is very probable that the vast accumulations of drift-like débris, noticed by Professor Bradley in the high divide between the latter stream and the sources of Snake river, were derived from the breaking up of this deposit. It has contributed an immense amount of loose materials to fluviatile deposits in all the valleys of both the Buffalo Fork and the Gros Ventre basins, and most probably the water-worn and rounded quartz pebhles that enter so largely into the composition of the bars in the bed of Snake River along many miles of its course through Jackson's Basin, and even in its lower valley below the Grand Oañon, are attributable to this conglomerate formation. The streams south of the Gros Ventre Range are bedded with different and greater variety of rock materials, which may be traced to ledges in the surrounding mountains. It is said by old prospectors that this deposit affords gold, invariably in very minute particles.

In the Buffalo Fork region the deposit descends to the northeastward at a gentle rate of inclination, as shown in the fine exposures north side of Pacific Creek, a few miles above its month. This northerly inclination was also observed within the Mount Leidy belt, where the coniglomerate seems to form a very low, broad, undulating swell. Above the mouth of Blackrock Creek, five or six miles, a limited exposure of a conglomerate ledge appears in the south bank of the river, the relations of which to the higher occurring exposures could not be ascertained. If the latter ledge is in situ it shows that these strata also partook in the disturbances of the Buffalo Fork Peak uplift, low on the flanks of which Prof. Theodore Comstock found highly inclined lignite-bearing ing deposits. The latter, I am now prepared to believe, are of Cretaceous age, as was originally stated by Professor Comstock in his report to Captain Jones (Yellowstone Expedition, 1873). It was the intention the present season to carefully examine the borders of Buffalo Fork Peak uplift with the view of gathering as complete data as possible regarding the coal deposits known to occur there; but the early approach of winter snows forced the party to withdraw, leaving the northern part of the district unworked.

In the right bank of Buffalo Fork, near the confluence of Blackrock Creek, exposures of bluish-drab indurated argillaceous beds and shales, with gray and buff weathered sandstones appear, inclining at an angle of about $10^{\circ}$ to the northward. The shale here afforded abundant vegetable remains, among which a small long ovate leaf resembling the plum was most numerous. These plant remains, which were the only palæontological evidence obtained bearing on the age of these deposits have not been determined, so that we have to depend on stratagraphical data to determine this question. A mile or less to the north on the Blackrock, apparently identical strata incline northeastwardly at an angle of 15 to $20^{\circ}$, which would appear to show a nonconformity with the conglomerate similar to that noticed on the Gros Ventre. Apparextly the same series of deposits constitute the bulk of the hills north of Buffalo Fork, and extend west to the border of Jackson's Basin. 


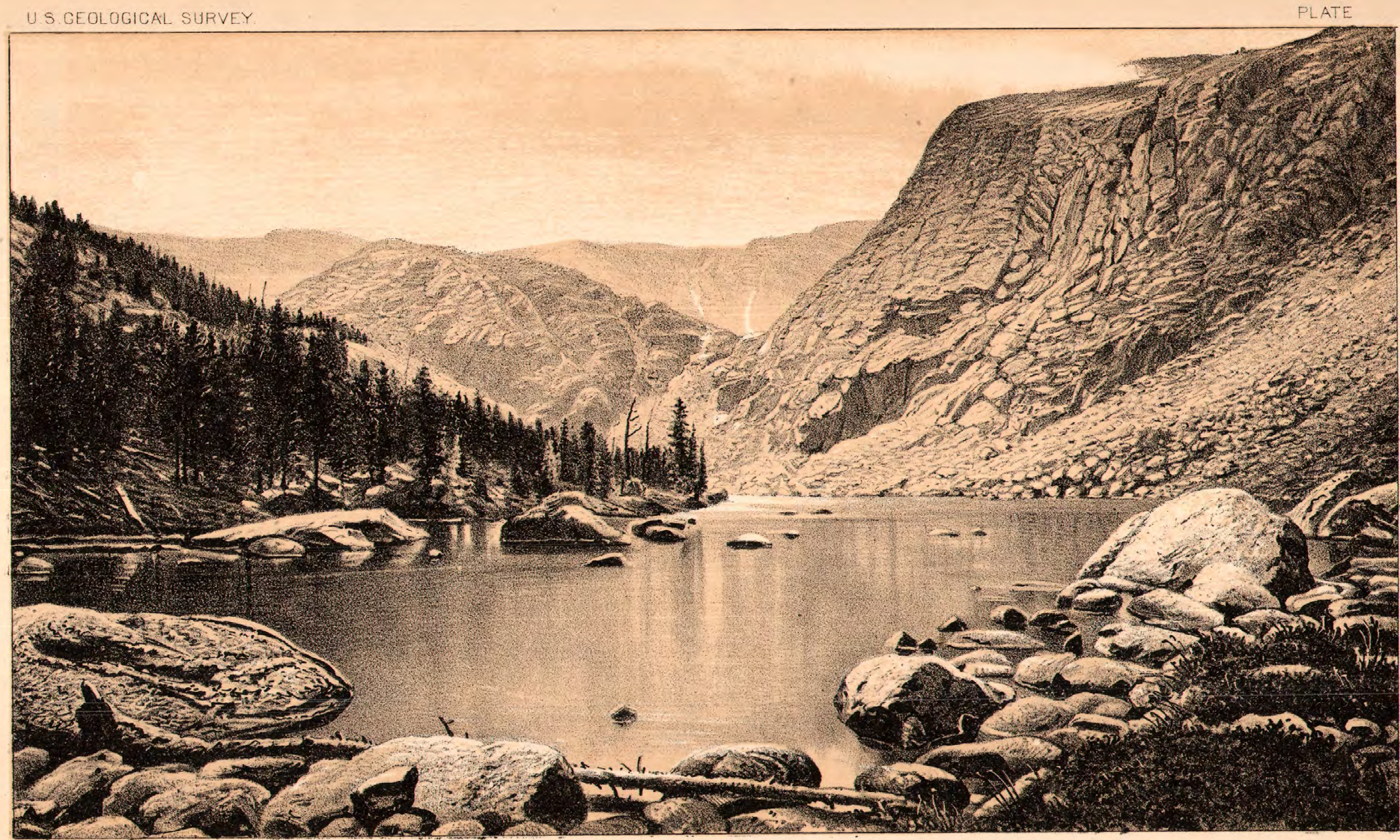





\section{SECTIONS ACROSS GROS VENTRE-BUFFALO FORK BASIN}

Sta $X X X$

Buffato For\% P'eak

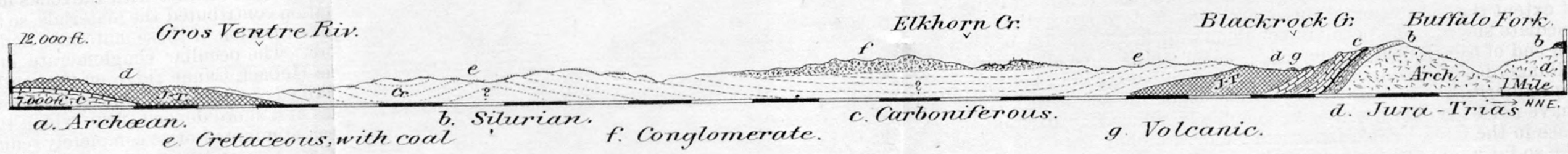

Gros Ventre Mts

Gros Ventre

Basin

Watershed

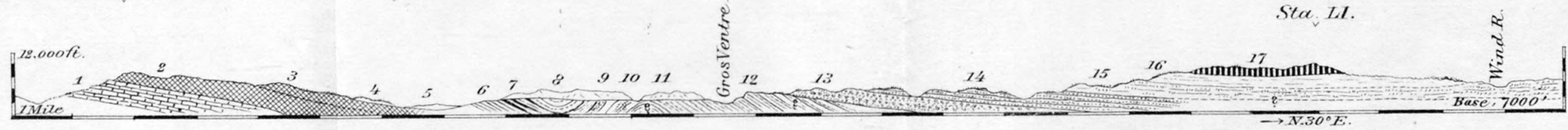

Gros Ventre Mts.

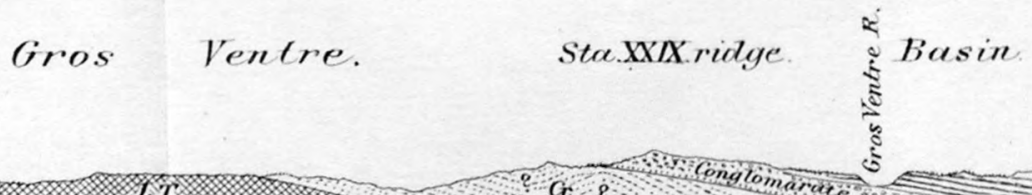

Sta.XXIX ridge

$17.000 \mathrm{t}$

11.0007.

ic Mue :

Continental Watershed

$$
\text { Stax XVIII. }
$$

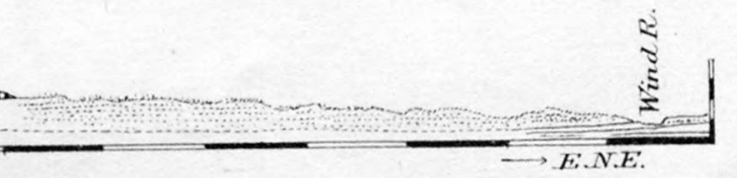


The apparent local occurrence of the conglomerate, which is, so far as known, restricted to the region north of Gros Ventre Mountains, would suggest the environing mountain ranges, the Teton, Gros Ventre, and Wind River, as the sources whence its component materials were derived. Observation, as yet, is too limited for the purposes of tracing the physical history of the horizon and noting the changes in the component materials remote from the ancient shores of the basin in which they were deposited. The beautifully rounded condition of the hard quartz fragments and the thorough comminution of the softer rocks which are mingled with the deposit in the condition of fine sand and limy cement, evidently show the work of wave action. At present the deposit has not been observed in immediate contact with the rocks in the mountain borders whose degradation contributed the materials, so that it is not known to what extent the trituration of these materials had progressed along the immediate shore. The peculiar conglomerate in the region of the northern end of the Hoback Cañon ridge on the south slope of the Gros Ventre Range, described on a preceeding page, possesses in a marked manner the peculiarities of a shore deposit, from which the softer rock fragments have not been eliminated or so completely reduced by attrition as is the case in the Gros Ventre Basin conglomerate; but here the data in hands, so far as relates to tracing identity with the latter formation cease, although that deposit is also of Tertiary age, but presumably of later date, or Pliocene. 


\section{CHAPTER VI.}

\section{WIND RIVER RANGE.}

The Wind River Range has a general course a little west of north and east of south of about 88 miles, and a breadth of from 12 to 32 miles. Within the present district there lies some 36 miles of the northern portion of the range, of which it forms by far the most prominent orographic feature. The southeast corner of the district lies in the heart of the mountains a few miles to the east of New Fork Peak; and thence the east boundary line descends north, gaining the Wind River Valley at the eastern foot at a point nearly due east of Union Peak, the most northerly eminence of the range. Circumstances beyond our control prevented the party penetrating the Alpine region, except at the northern extremity of the range. But to the south, Mr. Wilson, the previous season, succeeded in carrying the primary triangulation to the dominating summits at Fremont's and, I believe, New Fork Peak, revisiting in company with Dr. Hayden, at an earlier date the present season, the same region; so that the topographic features of the heart of the range, with its rock structure and interesting glacial phenomena within the district, have been subjects of investigation by several members of the survey. Our own work, however, was mainly confined to the flanks of the range, and chiefly within the belt oceupied by the uplifted sedimentary formations, the exhibition of which, as displayed in the gorges through which the streams descend on their way to the plains, is of extreme simplicity.

Archoean area.-The summit of the range within this district is composed of Archæan rocks, forming a broad wedge-shaped area with the apex resting on Union Peak and expanding to the south-southeast, where along the forty-third parallel it may reach a maximum width of 30 miles. The watershed and main topographic crest lies to the west of the central line of this area, forming a massive ridge to the south out of which erosion has sculptured the huge mountain summits dominating the range. The whole summit is lifted above timber-line between 2,000 and 3,000 feet. To the north the summit widens into a plateau, its surface paved with weathered blocks of granite and rising here and there into broad-based domes or craggy ridges a few hundred feet in eleration. This is the character of the range from Union Peak south to near the line of $43^{\circ} 15^{\prime}$.

The eastern face of the main ridge, from a point opposite the sources of 'Torrey's Creek, south at least as far as Little Wind River, breaks down precipitously, the stream sources draining this side of the range rising in elevated rugged basins and amphitheaters along the foot of the summit ridge. The united waters of these streams generally take a direct course transverse to the general direction of the range, and soon enters the broad belt of uplifted sedimentary formations reclining on the flank of the range, in erossing which they have eroded deep, picturesque cañons displaying the complete Palæozoic and the lower members of the Mesozoic series of formations. This belt of uplifted 228 
s. W.

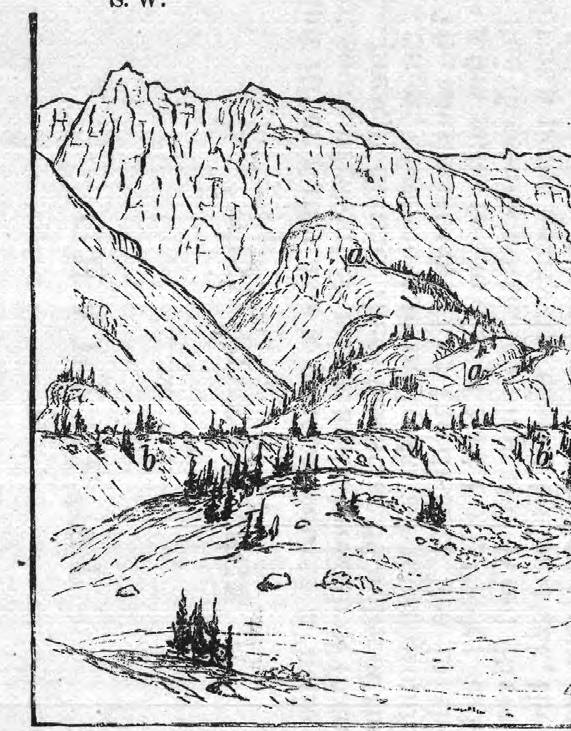

Gros Ventre Mountains.

W. (mag.)

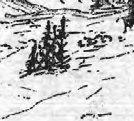

trinty
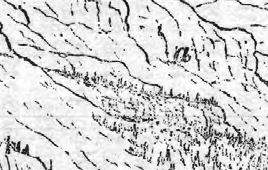

$=2 \sin ^{\circ}$

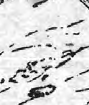

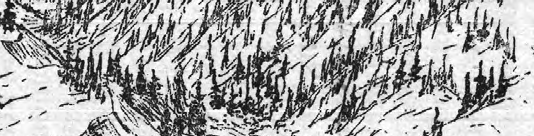

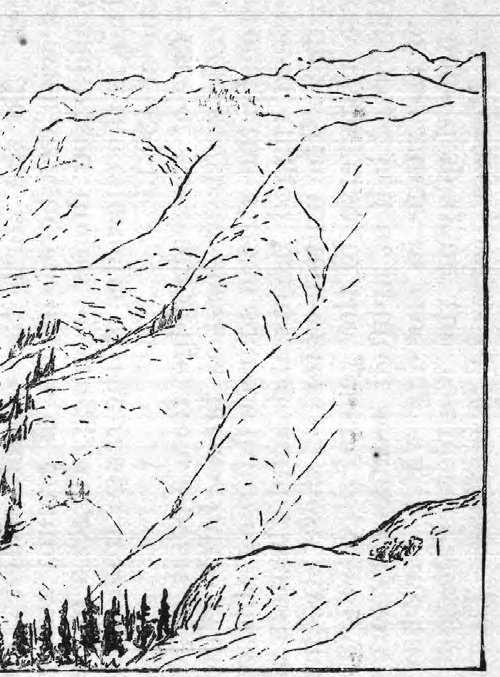

Cañon of North Fork of Green River.

a Glaciated Arohaan ledges.

b Moraines. 



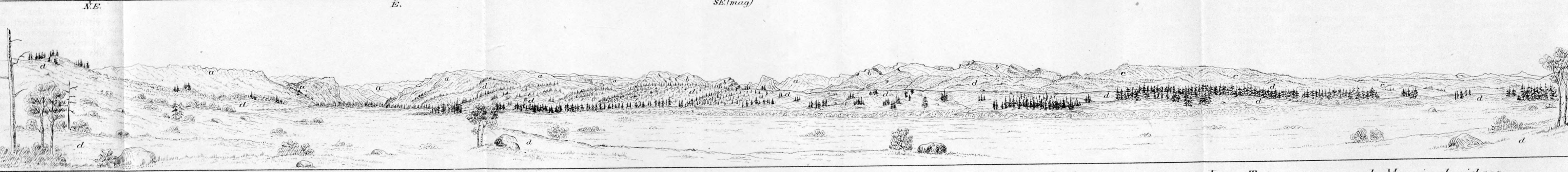


sedimentary rocks locally forms two or more distinct subordinate parallel ridges whose aggregate makes up an outlying mountain ridge that may be traced nearly the entire length of the range. The latter, as seen from the valley, forms the prominent orographic feature of the range, the high Archæan summit only appearing here and there up through the openings formed by the cañons of the descending streams; but from the higher or inner erests of the sedimentary belt the broken Archæan basin area is overlooked, terminated by the precipitous eastern wall of the culminating summit ridge only a few miles distant. The appearance of this lofty mountain barrier is indescribably varied and sublime. The stream beds are choked with confused piles of bowlders, and the rock surfaces everywhere bear unmistakable evidence of glacial action. The basins of all the streams that rise within the Archæan area present more or less perfect examples of roches moutonues; indeed the whole region s replete in these most interesting and varied phenomena.

On the west, the summit ridge is flanked by an exceedingly rugged elevated Archæan plateau or bench several miles in width. The streams that penetrate to the main crest flow in profound gorges walled by granite often many miles in length, as is the case with Fremont's Creek and Green River. The lesser drainage channels, rising in the outer edge of the outlying mountain plateau, often head in a cul de sac hemmed in between precipitous granite escarpments hundreds of feet in height, and flow out through cañons scarcely inferior in the grandeur of their scenic surroundings to those eroded by the principal water courses that drain the western flank of the range. Throughout nearly its entire extent within this district, the western edge of the Alpine plateau presents the appearance of a huge terrace escarpment which abruptly breaks down to the comparatively low, narrow belt of foot hills that slope into the valley of the Green River. Ancient glacial phenomena are here met with on a scale of great magnitude. Indeed the proper investigation of this branch of the geology of the mountains would profitably occupy many months.

Although little opportunity was presented for the systematic study of the central area of the mountains, such observations as were made in the northern portion of the range sustain the inference that the nucleal rocks are largely metamorphic. This is clearly the case along the west flank in the vicinity of Green River Cañon, as also at Union Peak, and along the eastern flank, where these rocks are revealed in the mountain valleys of Little Wind River and the streams of the north, whereever the latter were ascended beyond the limits of the unconformably superimposed Paleozoic formations. But with the meager data in hands, it would be impossible to attempt to define the lithologic and structural features of the rocks of this area, the successful elucidation of which would require a liberal allowance of time and facilities such as were beyond our means of supplying.

Along the mountain course of the tributary four or five miles north of Green River the gray banded gneissose ledges, associated with feldspar and talcose belts, have a general westernly inclination, the rock presenting locally a brecciated appearance, with angular hornblendic inclusions. The feldspar constituents weather into a soft, white earth, which may in part account for the milky discoloration of the waters of the Green above the lakes. Ascending this stream to its sources in the summit plateau 8 miles south of Union Peak, the same gneissic rocks were still prevalent, the glaciated surface bringing out the contorted lamination and ramifleations of quartz and feldspar veins with which the rock is traversed. Just above a narrow rock-hemmed gorge, down 
which the stream plunges, the schistose ledges curve over in an anticlinal, on the east flank of which the inclination is $30^{\circ},+-$. In the vicinity a well marked porphyry dike appears on the north side of the stream, and may be traced at intervals to the ESE. and WNW., along its line of strike, a distance of a few miles. The dike is perhaps 100 feet across, and has a slight southerly inclination from the vertical; to the east Mr. Perry reports it divided into three distinct branches, holding the same general course. In texture and lithology it varies from coarse mottled to dark green chloritic hue, weathering dark rusty, like trap. Its appearance is exactly similar to the dikes occurring in Mt. Hayden and Mt. Moran in the Téton range.

On the summit of the range between the above-mentioned tributary of Green River and Campbell's Fork of Wind River, knobby outliers of feldspathic granitoid gneiss rise above the plateau that here forms the summit. The rock weathers in blocks, recalling the granite knobs on the summit of the Laramie Range in the vicinity of Sherman Station, on the Union Pacific Railway. The gneiss, which is traversed by quartz veins, is represented by many varieties, including chloritic talcose and mica schists, the latter sometimes garnetiferous. The quartz veins have every appearance of segregated origin, resembling auriferous lodes; but the gravel deposits of the west side streams revealed no gold. South of Green River Cañon the west flank of the mountain appears to be largely made up of a coarse feldspathic granitoid rock, the relations of which to the gneissic ledges was not ascertained; but judging from the evidence afforded by the erratic materials composing the great morainic ridges along this mountain foot the latter ledges must occur in the interior of the range.

All along the east side of the Wind River Range, wherever we penetrated to the Archran area, these rocks were found to be composed of gneissic and various schistose rocks, including hornblende, upon which the upraised Palæozoic formations rest, forming a more or less wellmarked outer mountain ridge with escarped face towards the main summit crest. Union Peak, the most northerly eminence of the range, nearly 11,600 feet altitude, is made up of beautifully laminated and much contorted gray, rusty-weathered gneissic ledges, including hornblende and mica schists, showing a general westerly inclination at rariable angles. On the northeast shoulder of the mountain, a short distance from the summit, feldspathic granite appears in characteristic blocky exposures, identical with the knobs previously mentioned occurring in the plateau summit 6 miles to the SSE. Perhaps a couple of huudred yards south (?) of the peak a well marked granite dike, 30 yards in width, crosses a high shoulder of the mountain, strike about east-west, and dipping southwards at an angle of $45^{\circ},+-$, which is inclosed between gray gueissic walls, similar to that forming the summit. The dike consists of flesh-colored feldspar with segregations of mica and quartz, the latter sometimes replacing the silvery mica as pseudomorphs. Five miles to the north, in the vicinity of the trail over Union Pass, low, rugged exposures of feld-spathic granite outcrop, forming the most northerly observed exhibitions of the nucleal rocks of the range.

In the upper mountain basin of Warm Water Creek, above the cañon at Clarke's Camp, placer mines have been recently worked. At the time of our visit the mines were temporarily abandoned, nor could definite information be gained as to the character and richness of the deposits. From time to time considerable prospecting has been performed in this vicinity, test-pits having been carried high up on the summit of the pass. Mr. Charles Blackburn, who accompanied the party, describes 


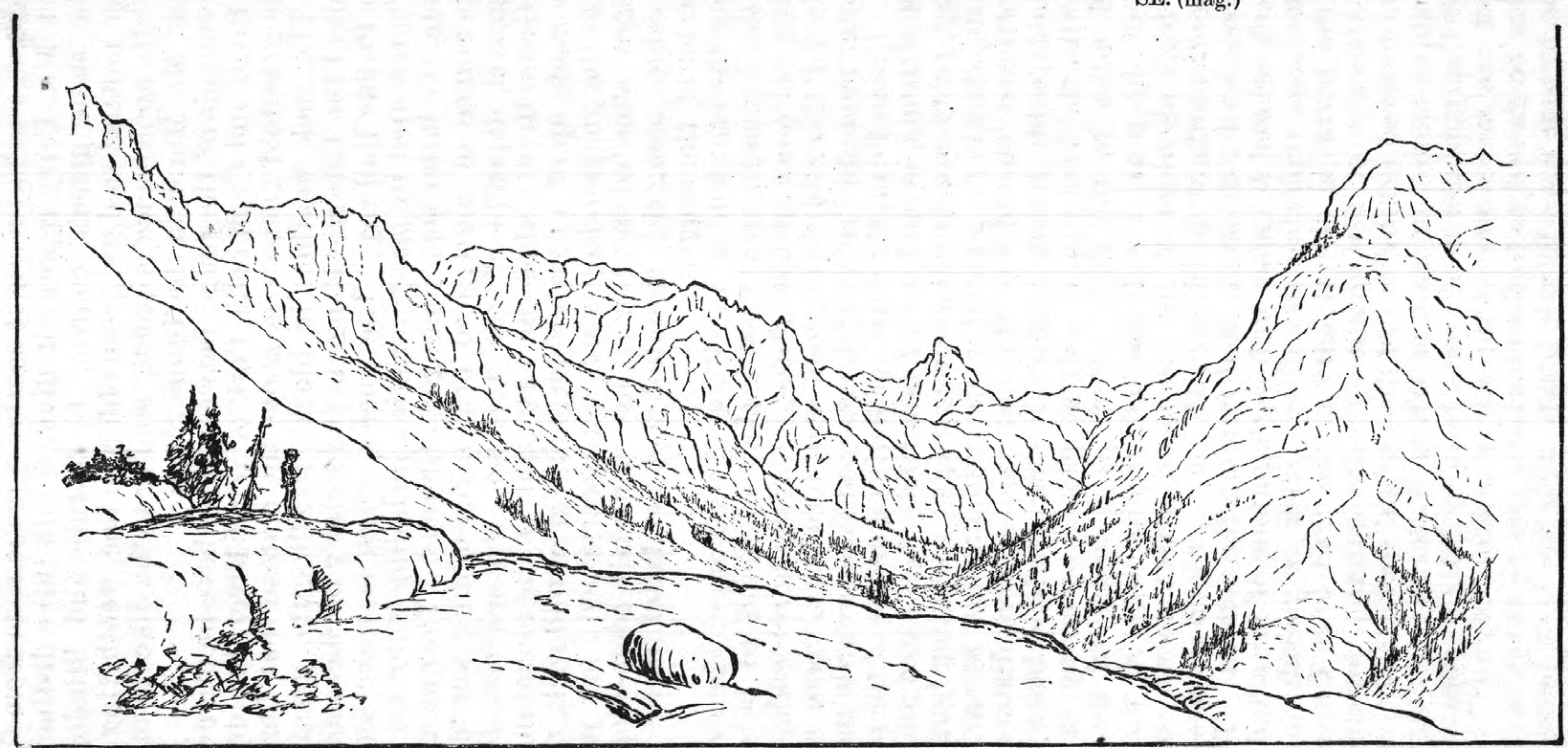

Green River Cañon, above the lakes. Glacial-polished Archæan ledges. 



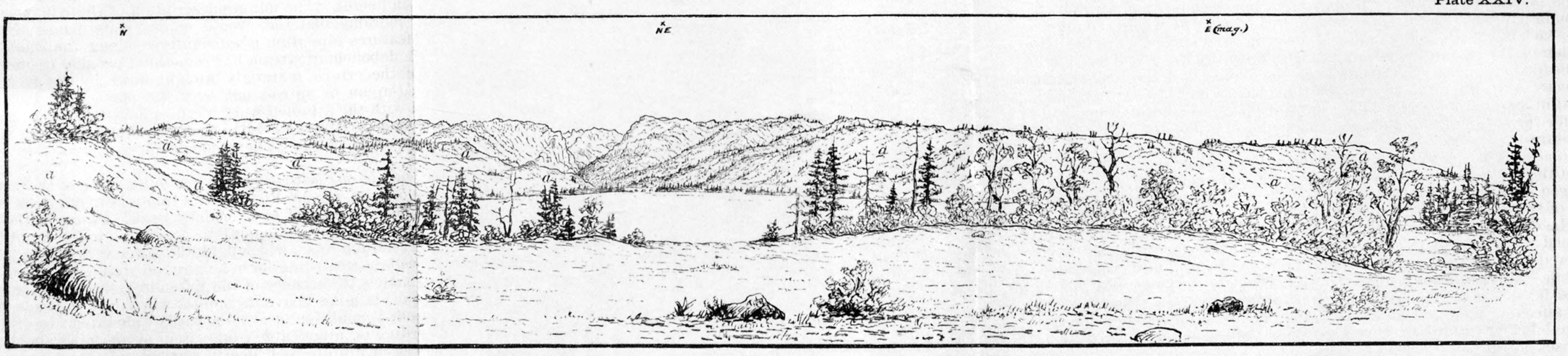

Morainal ridges $(a)$ debonchure Lac d'Amalia Cañon, west flank Wind River Range. 
the placer gold occurring hereabout as exceedingly finely comminuted and in consequence difficult to save by the ordinary processes employed in working the auriferous gravels.

Fifteen to eighteen miles of the western mountain front north of the debouchure of Frémont's Creek is denuded to the crystalline rocks, and the streams that flow down from the mountains, with the exception of Frémont's Creek, which issues on the south line, are small and rise in the beforementioned Alpine bench. They all show wonderful exhibitions of glacial action in the rock-polished surfaces of t:e cañon-walls and the enormous quantities of débris built up into moraines outlying their debouchures. The latter materials are spread well out over the low slopes, effectually concealing from view the Tertiary deposits along the margin of the Green River Valley. Within this Archæan west front lies one of the grandest cañons, that by which Frémont's Creek emerges, whose sources cluster about the mountain peak bearing the same name. This stream issues from the aforesaid Alpine bench, through a profound gorge hemmed in between precipitous glacial-polished walls of granite, its exit flanked by ridges of morainal origin a thousand feet and more in height. The minute description of these immense accumulations of morainic materials would require many pages; and while in the main features repetition is encountered along the whole mountain front, each debouching stream has something peculiar to offer in the disposition of the erratic materials brought down by the great ice rivers and heaped up on or spread out over the plain. All the phenomena connected with the attained work of the glaciers is both striking and beautiful, and perhaps no field in the west ofiers so favorable opportunity for the study of these phenomena as does that of the Wind River Mountains.

Sedimentary border belts. - Twenty-one miles north of the south boundary of the district, Green River issues from the mountains at a point eighteen miles northwest of Frémonts' Peak. Rising in the neighborhood of the latter peak, its mountain course is eroded hundreds of feet into the crystalline rocks which flank the gorge with precipitous glacialpolished walls scarcely inferior in height and grandeur to those that have rendered famous the scenery of the Yosemite. The cañon was ascended a distance of six miles above its mouth, where the way was obstructed by the flooded condition of the few-yards-wide intervales, the adjacent rocks afíording no practicable trail. Four or five miles above the inouth a huge block of granite with nearly vertical sides and truncated summit, rises on the south side of the stream to a height of perhaps two thousand feet. Below this mountain the valley expands, and is occupied by a pair of beautiful lakes. The upper and smaller lake is perhaps a mile in length and half a mile wide, its waters of a milky green from sediment brought down by the main stream, and margined by low willowy bogs and tlats. The lower lake, a mile or so to the northeast, is about twice the length of the upper, its half mile breadth of deep green water nearly filling the narrow valley. The contrast in the color of the water in the upper and lower lakes was very marked, as though all the sediment had been caught and retained in the upper basin and the water perfectly filtered ou its passage the nce to the larger lake.

A very interesting geological feature of this locality, and one which is so far as known unique on this side of the range, is the occurrence of a considerable remnant of Palæozoic formations adhering to and lifted high up on the mountain flank on either side of the debouchure of the Green. These great tables of seidmentary strata, in places flexed and shattered, present a peculiar feature in the topographical aspeet of this 
part of the range and which is conspicuously displayed from long distance to the southwest, west, and north. The area occupied by these rocks is probably included within a northeast-southwest belt eight miles long and not exceeding four miles in width, the bulk of the oceurrences lying to the south of the Green where they also attain, perhaps, their greatest altitude. The outer mountain barrier crowned by these deposits is planed off level irrespective of the inclined position of the strata, a result attributable to glacial action.

The nucleal rocks hereabout show gneissoid granite, the ledges more or less feldspathic and of a pale red color, at one point near head of lower lake dipping gently westward. Higher up the cañon, the rock changes to a gray color, is laminated and much complicated by joint or eleavage structure. The mountain walls on either side of the entrance to the cañon reveal the uplifted sedimentaries, which probably represent the complete Palæozoic series of the region. These consist in the first place, of typical exposures of buff, gray, and reddish stained carboniferous limestone and a buff hard sandstone, 2,000 feet or more in thickness, and which are apparently identical with the rocks composing the great ridge of Gros Ventre Peak that lie twenty miles due west of this locality. Below the above ledge appears a heavy bed of grayish buff rusty-weathered maguesian limestone, 200 to 400 feet in thickness, and in all respects identical with the ledge elsewhere referred provisionally to the Niagara epoch, although no fossils were detected in the rock at this locality. Below the latter occurs a few hundred feet thickness of dark drab and gray rough weathered limestone, even-bedded and in places brecciated, resting upon a heavier series of jellowish-buff silicious beds, which probably are the equivalents of the Quebec and Potsdam formations. The thickness of the sedimentary series above alluded to based upon rough estimates may not exceed 3,000 feet, of which twothirds, perhaps more, belong to the carboniferous.

The outer mountain declivity bears a heavy plating of carboniferous strata, the beds dipping north of west at an angle of $25^{\circ}+-$. On both sides of the cañon these deposits, together with the Niagara, are carried up forming escarped and peculiarly weathered mountain peaks or ridges. Between the lakes a sharp flexure arches the sedimentary formations, the axis of the fold being occupied by an Archæan ridge that gradually rises to the south or south west, in which quarter it was found to be quite denuded of the former rocks. Ascending the cañon, east, the sedimentaries again rise quite uniformly or with gentle undulations, so that the lowest members of the series are carried to the highest elevations within perhaps a couple of miles above the upper lake on the north side and a less distance on the south side, beyond which the Archæan is denuded over the remainder of the mountain plateau to the summit.

A low outflanking ridge lies close along the foot of the range, extending from the great bend of the Green 10 miles south, where it dies out in an uneven benched area. Beyond this point to the south line of the district the Tertiary deposits of Green River Basin impinge against the Archæan mountain flank without intervention of older sedimentary for. mations. Throughout the greater length of the ridge the Triassic "red beds" are displayed in frequent exposures in the slope descending to Green River, the interrupted section along this north-and-south line showing a broad, low undulation, in the axis of which Carboniferous limestones are brought to view, as has been elsewhere mentioned. In the benched area at the south end of the ridge the surface is broken by numerous sinks, the greater number of which are grassed over, although 


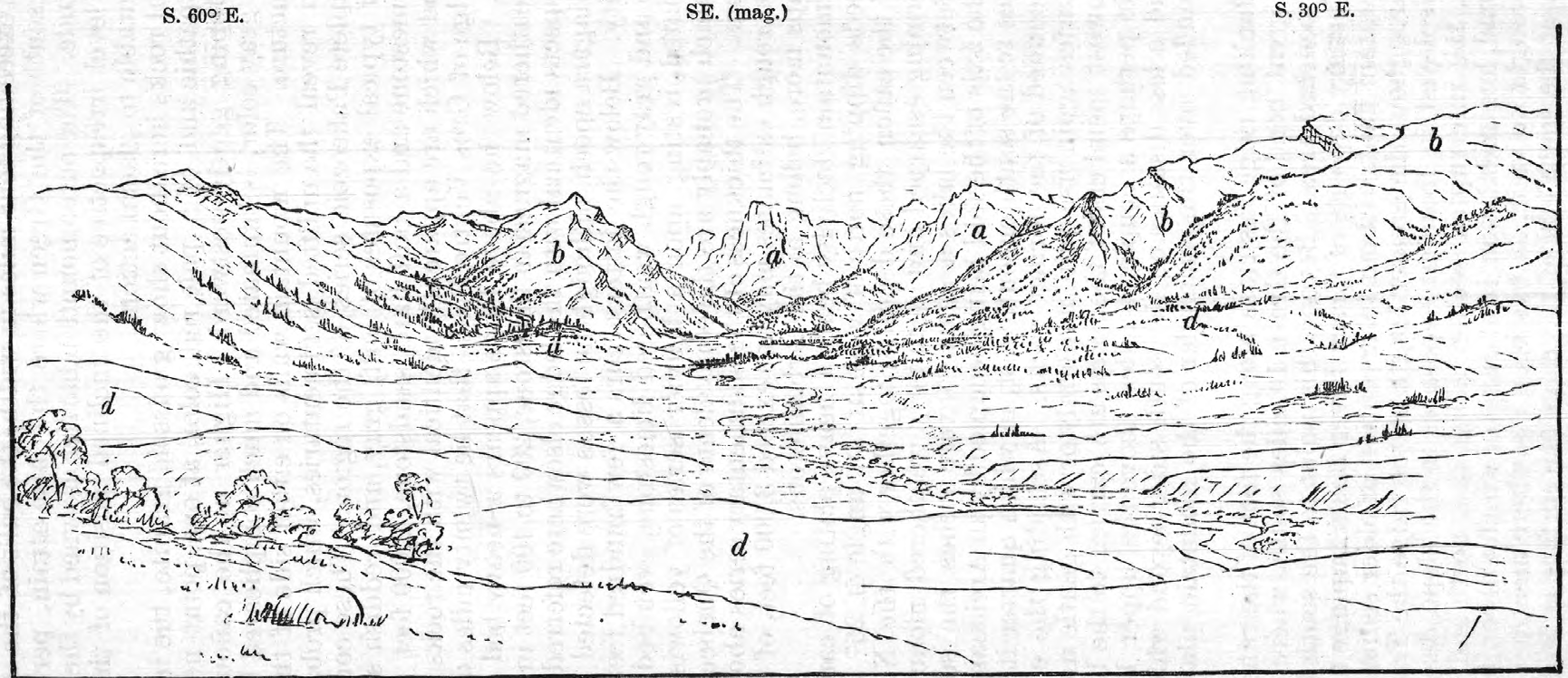

a Archæan. 


-Watershed Green and Gros Ventre Basins. Green River. N. Fork.

Upper Lake.

Archæan Platean.

$12000 \mathrm{ft}$

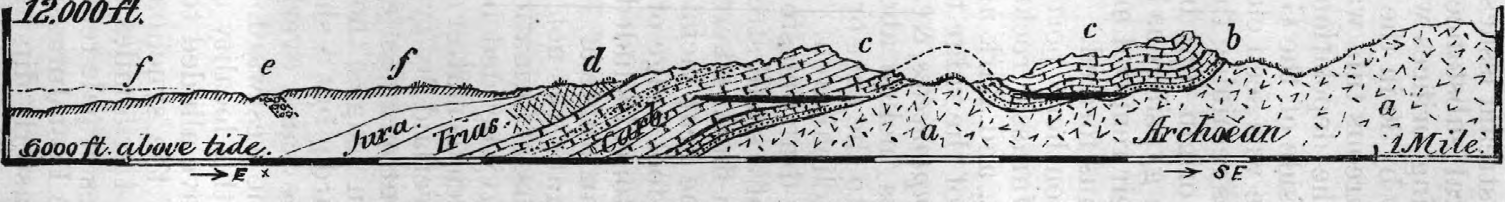

Wind River Range: Section worth side Green River Cañon.

$a$ Archæan. $b$ Silurian. $\quad c$ Carboniferous. $\quad d$ Trias. $\quad e$ Tertiary, red conglomerate. $f$ Morainal deposits.

East end Gros Ventre Mts. Green River.

West flank Wind River Range.

$12000 \mathrm{ft}$

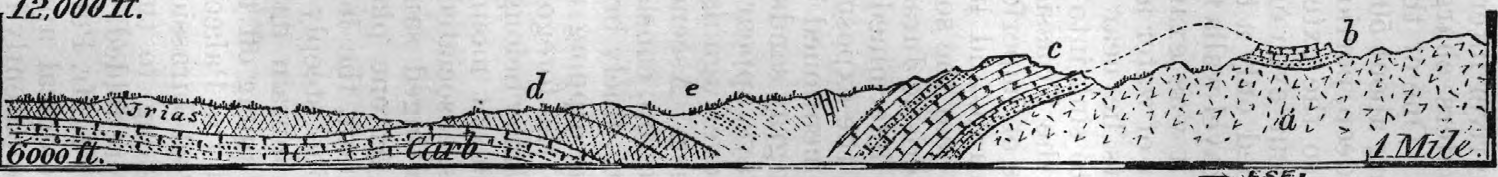

Section three miles SW. of Green River Cañon.

a Archæan. $b$ Silurian. $c$ Carboniferous.

d Jura-Trias.

e Cretaceous, \&c 
some are apparently of recent date. Occasionally limited rock exposures are seen in the sides of the sinks, showing alternations of usually white to gray gypsum in layers from a few inches to 5 feet and more in thickness, and variegated reddish and drab clays and indurated layers. In the immediate neighborhood more or less extensive accumulations of calcareous spring deposits are met with, and at one point in the low luff bordering the river intervale a copious stream issues from subterranean sources, its waters charged with mineral substances that render them unfit for use. One of the ancient spring orifices was examined, its dimensions being about 50 yards one way by 30 in the other direction and 10 to 15 feet deep, portions of the calcareous tufa walls remaining quite perfect, as also the exterior limits of the deposition from the overflow. The sinks occur even on the opposite side of the Green, where one apparently formed only a few days before was seen close beside the road, the terrace gravel-walls forming its sides retaining their vertical position at the time it was examined. Their origin may be attributed to the solvent power of water acting upon the gypsiferous beds, and where the latter deposits lie near the surface their removal may cause the superjacent earth to sink into the cavities thus formed.

Overlying the Triassic beds in the southern portion of the ridge are found a series of imperfectly-exposed Jurassic rocks made up of varie. gated pink, drab, and light-drab clays, and dark and light limestones. At a locality near the south extremity of the ridge the latter beds yield a few characteristic Jurassic fossils, Camptonectes, \&c., by which their age is definitely determined. The deposits incline about southeast at an angle of $16^{\circ}$, the exposures belonging to the east or southeast declivity of the before-mentioned broad, low anticlinal arch. A short distance to the northeast gray sandstones and light-drab limestones, associated with variegated clays, appear in the slopes of a small stream draining the interval lying over agaiust the mountain flank, where they show a dip of $25^{\circ}$ about east. Ascending east to the near vicinity of the mountain, a limited outcrop, consisting of a four-foot ledge of hard, pinkish gray and dirty buff, finely brecciated limestone, included in pale-red shales, was met with, dipping about east at an angle of $70^{\circ}$. 'The relation of the latter to the foregoing Jurassic strata was not satisfactorily determined, but it may belong to a Post-Jurassic formation.

In the adjacent mountain slope heavy-bedded buff magnesian limestone appears, associated with much silicious matter or passing into lightgray reddish-tinged sandstone and overlaid by typical Carboniferous limestones. At one place, near the southernmost exposures of the Palæozoic remnant, the heavy magnesian ledges, though the bedding is obscure, incline steeply to the eastward; but a short distance to the north the mountain flank exhibits the same overlying Carboniferous limestones dipping off the range to the westward. The steep easterly inclination of the Palæozoic strata at this localicy may have some relation to the Post-Jurassic exposures above alluded to, although it is possible they belong to the west flank of the synclinal trough into which these beds were folded. To the south, 4 or 5 miles, in the neighborhood of Station XVI, Mr. Perry found a series of pale-reddish deposits similar in their lithological appearance to the Post-Jurassic above referred to, and which apparently impinge with easterly dip against the Archæan wall that here forms the abrupt western flank of the range. The state of things observed in this quarter apparently indicates a fracture or fault extending parallel with and immediately along the foot of this part of the range, and which carried the Palæozoic series down a vertical distance amounting to several thousand feet, subsequent erosion having 
only uncovered later Mesozoic deposits along the downthrow side of the fracture-line, above which towers the denuded Archæan in escarped mountain walls a thousand feet and more in height. That these disturbances occurred prior to the deposition of the supposed Wahsatch Tertiary strata is evident from the fact of the occurrence of the latter in their original horizontal position only a few miles to the south, well up in the slopes outlying the Archrean wall that there defines the western border of the range.

The sections on an accompanying plate present the general facts relating to the above-mentioned Palæozoic remnant occurring on the west flank of the range vicinity of Green River Cañon, while the extent of area which they at present occupy is approximately shown on the geological map. But in respect to the outlying Mesozoic ridge, it is evident that the deposits occurring therein have still intimate connection with the Mesozoic area filling the depression between the Gros Ventre and Wind River Ranges in the interval just south of the great bend of the Green. Apparently the same series of "red beds" recurs on the outlying slopes of the latter range immediately north of the debouchure of Green River, where, however, they are concealed for the most part beneath the morainal materials that heavily cover the divide between the main stream and a smaller tributary that issues from the mountains four miles to the north. At the latter locality "red beds" are seen resting directly on the Archæan border of the mountain, recalling the previously-mentioned similar occurrences observed by Mr. Perry in the mountain flank seven or eight miles south of Green River Cañon, in the vicinity of Station XVI. Along the lower abrupt descent of the tributary that crosses this outlying morainal bench, red conglomerate deposits were observed, dipping steeply northwards, which strikingly resemble the Tertiary conglomerate along the south flank of the Gros Ventre Range at the intersection of Hoback Cañon ridge, described in a preceding chapter. To the nonth, still, the Quaternary deposits increase in importance as an element in the superficial geology of the broad outlying slopes that descend to the west and form the watershed between the Green and Gros Ventre drainages. This divide region is apparently largely made up of Tertiary formations, and their presence here seems to justify the inference of the former connection of the waters, in which at least the earlier Cenozoic measures were contemporaneously deposited over the ground that now belongs to two separate drainage systems.

It is difficult to say to what extent the Mesozoic barrier has been eroded within the time belonging to the present era or the Quaternary, and in view of the geological movements that are known to have continued into late Cenozoic time, the meager knowledge at present possessed hardly warrants conclusive statements as to the relations of the present physical conditions to what obtained during the deposition of the early Tertiary formations in the area above alluded to. This will be understood, perhaps, with greater clearness from the following statement of facts: The Carboniferous ocourring in.the axis of the low inter-mountain fold on the Green has an altitude of about 7,800 feet, or 1,100 feet lower than the divide between the Green and Gros Ventre 8 miles north, and only about 2,300 feet below the highest altitude of the latest Tertiary deposits oc. curring in the great watershed north of Union Peak. If we assume the whole Mesozoic series of the region to have been intact at the commencement of the Wasatch epoch, the interval now occupied by the bed of Green River must have presented a barrier of equal if not greater actual elevation than that of the Gros Ventre Mountains to-day, which may well have isolated, then as now, the drainage basins occupied respectively by 
Plate XXVII.

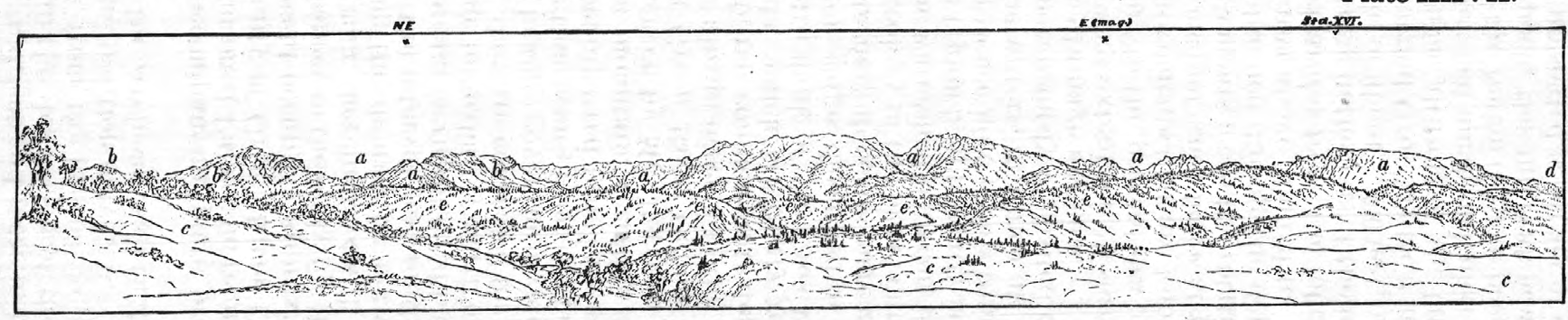

West flank Wind River Range south of Green River Cañon.

$a$ Archæan.

$b$ Palæozoic.

$c$ Mesozoic.

$d$ Tertiary.

$e$ Moraines. 



\section{$b$}

Section across north end of Wind River Range. $c$ Carboniferous. $\quad d$ Jura-Trias. $e$ Wind River Tertiary.

$f$ Tertiary and Morainal deposits.

Union Peak.

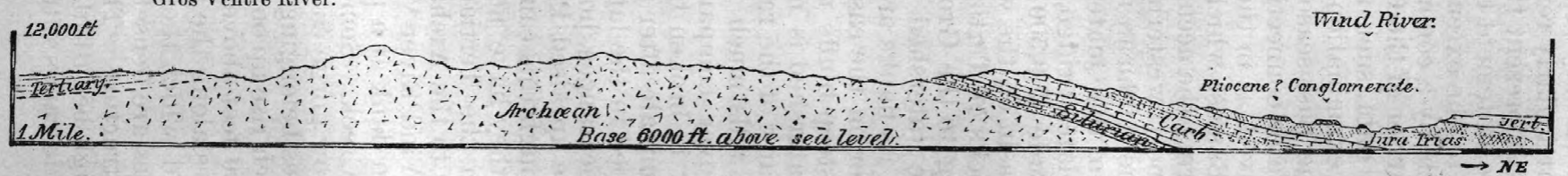

Section across Wind River Rauge through Union Peak. 
the Upper Green and Gros Ventre Rivers. But to the south it is well known that a long interval of time elapsed subsequent to the deposition of the later Mesozoic and Post-Cretaceous deposits common to the region, whose elevation and folding and subsequent erosion prepared the surface upon which the Tertiary beds were unconformably laid down. So, in the quarter here particularly referred to, a similar state of things may have transpired, but at present the evidence might not be deemed as justifying a conclusive statement to the effect that the same physical conditions here prevailed to the extent of uniting the early Tertiary basins of the north and south by a common sheet of water in the straits of what is now the low barrier of the Green and Gros Ventre water-divide. With more complete data, such as it were doubtless possible to acquire by more extended examinations in this divide region than it was possible to make during the past season, the facts bearing on this question of the continuity of water connection between these great Tertiary areas might be as easily solved as in the case of the Wind River and Gros VentreBuffalo Fork Basins, which latter undoubtedly originally formed one great basin during the accumulation of the Cenozoic formations.

Around the northwestern extremity of the Wind River Range proper the flanks of the Archæan nucleus are buried beneath immense detrital accumulations of the Quaternary period, and which are spread out over an extensive plateau ridge, across which Union or Warm Spring Pass lies, at an altitude of 9,500 feet above the sea. The descent into the Gros Ventre Basin on the west is over comparatively gentle declivities, whose basis rocks of Tertiary age have already heen described in the chapter relating to the Gros Ventre-Buffalo Fork Basin. The plateau character of the watershed continues thence to the vicinity of Togwotee Pass, although its flanks are deeply scored by the streams flowing down into Wind River on the east and the Gros Ventre on the opposite side, and in whose steep bluffs more or less complete sections of the strata of which the watershed is made up are displayed. But on gaining the northeastern flank of the range the declivity descending into the valley of Wind River falls much more steeply, and in the place of the long gentle slopes over comparatively undisturbed Tertiary deposits, the mountain flank is broken by great ridges of upraised Palæozoic rocks, which only terminate after passing Warm Spring Creek, when they are in turn enveloped in the later-formed sediments constituting the watershed. The appearances, however, strongly indicate a hemiquaquaversal condition of the upraised Palæozoic strata at the northern extremity of the range, although this cannot be proved from the fact that these earlier formations, if they have not been removed by erosion, are so deeply buried beneath the Tertiary deposits as completely to conceal their former relation to the Archæan nucleus in this quarter.

On leaving Wind River Valley, the Union Pass trail begins the ascent of the mountain flank at a point perhaps 3 miles above the confluence of Warm Spring Creek. Some distance below this point Wind River flows through a narrow gorge cut into northeasterly dipping rusty weathered sandstone ledges belonging to the middle division of the Carboniferous series, and which rise up on the mountain side forming a sort of hog-back ridge 500 or 600 feet above the stream. The same set of strata appear in similar ridges along the mountain side above this point perhaps 2 or 3 miles, beyond which the mountain flank trends round to the west, where the slopes are densely clothed with forests concealing the nature of their rock structure. The ascent of the trail is almost a continuous climb up through beantiful forests of pine for the distance of 4 or 5 miles, when it again descends into the upper mountain basin of Warm Spring 
Creek. The way thus far has passed successively over the hidden ledges of the Lower Carboniferous limestones and Silurian formations, the latter appearing as low ledges of rusty weathered limestone in the high ridge crests off to the eastward either side of the Warm Spring Cañon. In the south-side slopes rising from the Warm Spring Basin we encountered along the trail much débris of coarse buff and red sandstone, probably Potsdam, which extends some 2 or 3 miles, reaching an altitude of near 9,400 feet. Here we first met with Archæan exposures, occurring in low combs on the eastern edge of the elevated grassy plateau that stretches across the summit in the vicinity of the pass. To the west of this point the surface is deeply buried beneath the Quaternary gravels; meager exposures of yellow and drab sandy clays, possibly referable to the Tertiary, occasionally appear in shallow valleys occupied by the southern sources of Warm Spring Creek.

Above Warm Spring Creek the course of Wind River for 8 to 10 miles is east-westerly. About midway it is joined by a small affluent heading in the watershed a few miles to the northwest of Union Pass summit, and which, it is believed, defines the limits of the Palæozoic belt around the northern extremity of the Wind River uplift. Vestiges of "red beds" holding the stratigraphical position of the Trias were observed in the slopes descending to Wind River between the confluence of this stream and Warm Spring Creek, but the surface configuration of the valley slopes, after the stream enters the hills, shows them to be wrought out of the comparatively soft deposits of Tertiary age. This is indicated by the benched and densely wooded slopes, contrasting with the long declivities characteristic of the Palæozoic mountain flank, as seen in the vicinity of Warm Spring Creek, and thence extending south nearly the entire length of the range along its eastern front.

Warm Spring Creek, as before mentioned, rises in the elevated watershed to the northwest of Union Pass, flowing in a general direction about east-northeast, in a direct course about 12 miles. The sources lie within the Tertiary area, its middle course occupying a rather wide mountain basin excavated out of the Palæozoic belt. Four or five miles above its mouth the stream enters a narrow defile which it has excavated across the upraised Palæozoic belt, its bed at the upper entrance to the cañon being eroded several hundred feet into the Arehæan basis rocks. Lower down the sedimentary formations close in upon the stream, forming cliffs on either hand several hundred feet in height. In a distance of 4 miles the stream descends about 600 feet, the course being nearly in the direction of the inclination of the strata across which it flows, the cañon becoming shal lower and finally emerging in the Triassic "red beds" as the stream leaves the mountain and crosses the narrow terrace bordering the right bank of Wind River. The geological section exposed in the cañon walls is roughly reproduced in one of the accompanying plates of section diagrams, a description of which follows :

\section{Section in Warm Spring Creek Cañon.}

No. 1. Archæan basis rocks, belong to the principal core-mass of the range.

No. 2. Dark, rusty weathered outcrop, probably representing the Potsdam sandstone, and forming the lowest member of the Palæozoic series. This ledge rises high up on the wooded Archæan ridges that sweep round on either hand, and plates the declivity on the south side of the moutain basin above the cañon.

No. 3. Position of the Quebec formation, not clearly distinguishable 


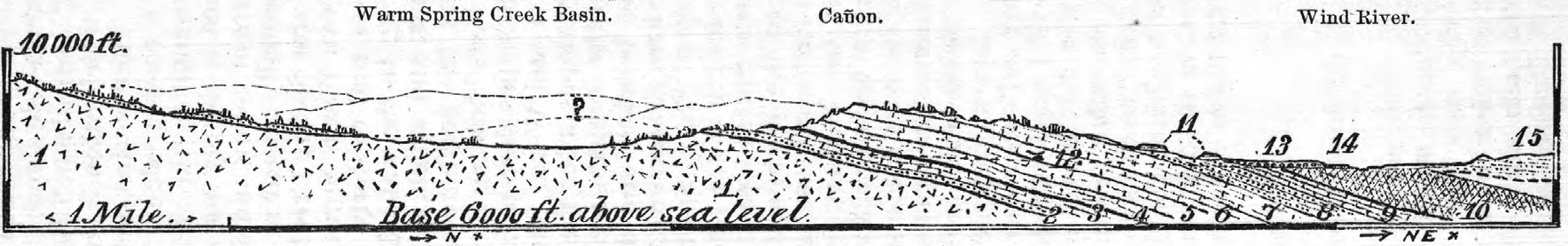

\section{$\rightarrow N \times$ Section in Warm Spring Creek Cañon.}

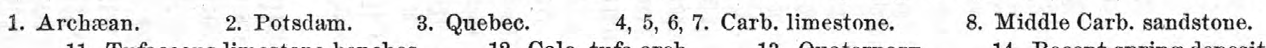
11. Tufaceous limestone benches.
12. Calc. tufa arch. 14. Recent spring deposits.
9. Permo-Carb. 10. Triassic. 15. Wind River Tertiary.
East flank Wind River Mts.

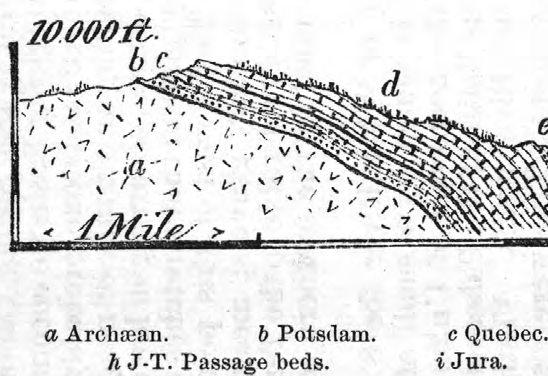
$h$ J.T. Passage beds.
Wind River. Sta. LIII (1877).
Wind River Basin.
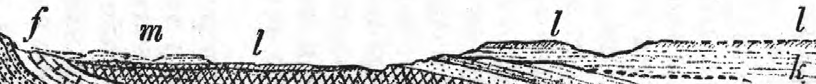

$l$

Base 6000 ft. chone tide

Section below Warm Spring Creek.

$d$ Carboniferous limestone.

$k$ Wind River Tertiary. e Middle Carb. sandstone.

$l$ Quaternary gravels. $f$ Permo-Carb. $g$ Triassic. $m$ Tufaceous spring deposits. 

in the talus slopes at foot of cañon walls. In the high crest of the sedimentary foreland ridge to the south this horizon recurs, where it shows ledges of even-bedded, dark-drab weathered limestone.

No. 4. Buff weathered limestone, probably magnesian, holding a stratigraphical position inferior to the Carboniferous, and doubtfully referred to the Niagara, forms castellated cliffs towards upper end of cañon.

No. 5. Heavy ledge of grayish-buff, red-stained limestone, separated from the preceding and overlying ledges by narrow talus slopes.

No. 6. Gray, drab, and dirty-buff weathered limestone, with which cherty bands are associated, dip $20^{\circ} \pm$ northeasterly; forms a heavy ledge rising up into promontory overlooking the upper basin of Warm Spring Creek.

No. 7. Heavy deposit of buff magnesian limestone interbedded with drab limestone and chert, overlaid by fragmentary, fine-grained, drabbuff, cherty limestone, with a prominent band of deep-red sandstone and sandy shales several feet in thickness, dip $15^{\circ}$ to $20^{\circ}$ northeastwardly. The lower limestone layers contain Carboniferous forms of Athyris, \&c.

No. 8. Buff, pink, and reddish stained sandstone, of variable hardness, with obliquely laminated layers, forming a heavy deposit, of which, however, only about one hundred feet thickness is exposed in bluffs on right bank of the creek below the cañon. This horizon belongs to the middle member of the Carboniferous series.

No. 9. Gray limestone layers, with Produotus, Spirifer, \&c., overlaid by rusty-brown weathered, indurated, argillaceous beds, passing up into light-drab partially indurated clays, all imperfectly exposed exhibitions of upper Carboniferous horizons, including the Permo-Carboniferous argillaceous deposits above.

No. 10. Triassic "red beds," consisting of more or less indurated red arenaceous shales and sandstones, with thin bands of gray sandstone appearing in terrace along south side of Wind River, where the edges of the moderately tilted strata have been evenly planed off, upon which rests a Quaternary deposit, cemented by calcareous infiltrations from adjacent springs into a sort of conglomerate, in places 30 feet thick.

No. 11. Calcareous tufa, in places holding water-worn drift pebbles formed by ancient springs, and crowning benches at various levels along the mountain-foot south side of Wind River Valley.

No. 12. Calcareous tufa arch spanning the stream in the cañon, origin same as above deposits.

No attempt was made to secure measurements of the thickness of the various members described in the above section, though they appear to conform in all respects to the same series as met with along this side of the range to the southeast, where their appearance will be noted in detail farther on. The section is reproduced here because it is the most northerly locality where the complete Palæozoic series is revealed to view, displaying a connected section from base to top along the course of this wild and picturesque mountain gorge. The geological examinations were carried along the brink of the north wall of the cañon, from which the general geologic structure, as displayed in the opposite cañon wall, could be most satisfactorily made out, and which may in a measure compensate for the lack of stratigraphic details, which are not to be acquired in the course of a hasty visit.

From Warm Spring Creek all along the east front of the range the Palæozoic formations present a uniform and rather steep foreland acclivity, culminating in the before-mentioned outer mountain ridge, the crest of which attains an altitude ranging from 10,000 to 11,000 feet. The slope, which always closely conforms in inclination to the dip of the 
strata, is pierced by numerous water-courses, whose deeply eroded cañons break the continuity of the great sedimentary ridge, revealing its structural features in a series of most remarkable natural rock sections. The meager observations made above Warm Spring Creek have already received brief mention, and the following notes are based on observations made along the mountain front below that locality, extending to the eastern boundary of the district a few miles below the mouth of Torrey's Creek. However, much interesting data was gained relating to the detail geology of the great eastern foreland between the latter point and Camp Brown, which, although outside the limits of this district, will be introduced in the order of their occurrence in journeying southwards along this side of the mountains.

A few miles below Warm Spring Oreek and about a mile distant from Wind River the foreland slope is interrupted by a rather prominent ledge of rusty weathered rock, having the appearance of a trap-dike as seen from a distance. It was found, however, to consist of a steeply tilted mass of middle Carboniferous sandstone, at one point dipping about northeast at an angle of $80^{\circ}$. It is made up of buff and reddish partially metamorphosed sandstones, including softer portions. The steep slope below is strewn with fragments of dark buff and drab limestones and chert, containing Productus and Spirifer, belonging to the upper division of the Carboniferous. On reaching the foot of the steep declivity the Triassic "red beds" are encountered, extending thence in the terrace bench to Wind River, where they form low mural exposures. The gentle inclination of the latter deposits might almost be regarded as evidence of non-conformity, an appearance which is doubtless due to the abrupt flexure of the strata at this point, and the erosion of the softer superimposed deposits over the steep acclivity down to or below the line defining the abrupt spring of the uplift.

Just below, on the opposite side of Wind River, and perhaps three or four miles below Warm Spring Creek, Station LII of 1877 was located on an eminence of the Wind River Tertiary, which here closely approaches the stream. The above-mentioned Trias "red beds" reappear in the outlying bench at the foot of the Tertiary plateau, where they are in turn overlaid by a few feet thickness of the inferior strata of the Jura, resting upon the soft light-colored sandstones, \&c., composing the beds of passage between the Jurassic and the typical "red beds" of the Trias. The Jura appears in a bench about 300 feet above the river, and is unconformably overlaid by the variegated or banded pale-red and greenishdrab arenaceous clays of the Wind River Tertiary, which culminate in the before-mentioned station promontory at an elevation of 600 to 650 feet above the stream. The Jura and inferior strata at this locality present the following section:

\section{Section at Station LII (1877), north side of Wind River.}

a. Triassic "red beds," consisting of deep-red and greenish-drab indurated gritty layers, upper measures concealed in terrace surface.

$b$. Green clays, with thin streaks of deep-red indurated gritty layers, 10 feet exposed, at elevation of about 275 feet above river.

c. Soft, thin-bedded yellow sandstone, with red and gray streaks, 30 feet; overlaid by soft whitish sandstone, 40 to 50 feet.

$d$. Greenish-blue marly clays, with layers of dirty gray-buff laminated and thin shaly limestone, 25 feet \pm .

e. Drab-gray, heavy bedded fragmentary limestone, 4 to 5 feet.

$f$. Light marly shales, 25 feet \pm . 


East flank Wind River Mts. Sta. XXVI.
Torrey's Lake.

$12.000 f^{t}$

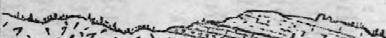

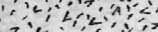

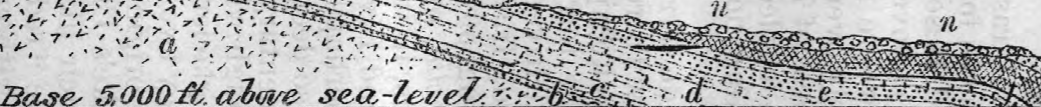

Base $5,000 \mathrm{ft}$ above se

a Archran. $b$ Potstam. $i$ Cretaceous?

c Quebec.

$d$ Carb. limestone.

Middle Carb. sandstone. $l$ Brown beds.

Wind River Mts.

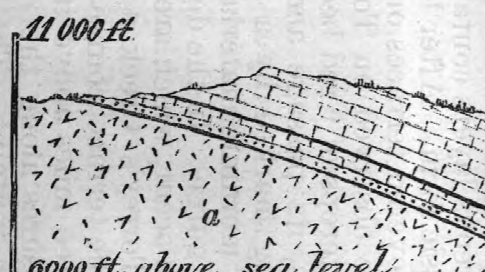

Wind Rirer Basin.

Horse Creek a Archæan. b Potsdam. $c$ Quebec.
Wind River.

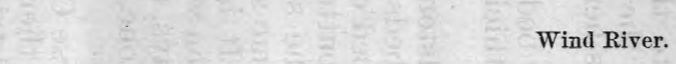

$g$ Triassic. $h$ Jurassic. $n$ Morainal deposits.

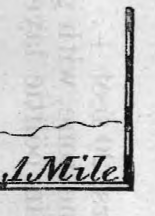


g. Gray even and thin-bedded pure limestone, 2 feet \pm ; dip, $15^{\circ}$ N. $39 \circ \mathrm{E}$.

$h$. Yellow marly clays with light shaly layers, 20 feet \pm .

$i$. Very hard, rusty-buff weathered, gray limestone, with gritty layers containing small pebble and calcite, and thin oölitic layers above, 5 feet \pm , exposed.

A profile of the mountain flank at this locality is given in an accompanying plate of illustrations, in which the above-mentioned stratigraphic features are presented with an approximation to accuracy, together with exhibitions of Quaternary and modern spring deposits, which latter will be noticed in the following chapter under the head of Wind River Valley.

Below the above-mentioned locality, on the south side of the river, the Triassic "red beds" appear in quite extensive surface exposures, extending down along the stream to a point opposite Horse Creek, reaching back perhaps a mile to the foot of the mountains. The locality derives much interest from the fact of its exhibiting the Jura-Trias passage beds. This horizon is here seen to be made up of the following strata:

a. Greenish-ochery sandy beds and variegated chocolate-red arenaceous clays, 50 to 100 feet \pm in thickness, resting upon typical Triassic " red beds."

$b$. Soft light or buff sandstones, 100 to 200 feet.

$c$. Marly clays and thin beds of limestone with Jurassic fossils.

The inferior limestone bed of the Jura in places forms the capping ledge of low, broad-based buttes in the denuded Mesozoic area on the south side of the river. The sandstone $b$ of the above section appears in the river bluff on the same side lower down, where it shows 50 to 60 feet of its upper portion. It is here immediately overlaid by 5 feet or more of brick-red clays, upon which rest a thickness of 7 feet of greenishdrab nodular calcareous clays, capped by a 3 to 4 foot ledge of drab, fragmentary, brecciated limestone, the strata inclining northeastwardly at an angle of 70 to $10^{\circ}$.

Below the mouth of Horse Creek the south-side terrace is covered by morainic bowlder deposits, thence to a point below Torrey's Creek, on the eastern boundary of the district, only meager rock exposures cropping out here and there. Such an one appears in the terrace bluffs on the lower side of Torrey's Creek where it joins Wind River, showing a limited exposure of gray or buff, rusty-weathered, friable, even-bedded sandstone, with firmer calcareous layers, dipping $50^{\circ}$ about N. $65^{\circ} \mathrm{E}$. The calcareous layers contain a small Rhynchonella, probably referable to a Jurassic form. After leaving the mountains, in its passage across the drift-covered terraces on the way to join Wind River, no rock exposures were observed on Torrey's Creek, with perhaps the exception of limited outcrops of "red beds." This stream also deeply penetrates the mountains, its passage across the great sedimentary outer mountain ridge being marked by a profound cleft, through which an immense amount of morainic materials was borne by the glacier that once flowed down this gorge. In the debouchure of the valley two or more beautiful little lakes occur, which are doubtless of glacial origin.

Above Torrey's Creek a couple of miles, Jake's Creek gains Wind River. The terrace course of this stream is much like the former, but two or three miles above its mouth the Triassic "red beds" appear in bluff exposures along the north side and just without its debouchure from the mountains. The lower portion of the cañon cuts the uplifted Palæozoic formations to their foundation, the upper seven or eight miles 
being walled by Archæan rocks. In the debonchure of the cañon Mr. Perry found limited exposures of gray and brownish-gray soft sandstones in horizontal position, containing obscure fossils of apparently Tertiary facies. These presumably Tertiary occurrences seem to indicate the pre-Tertiary existence of the mountain gorge in which these strata were deposited, and which latter were subsequently subjected to extensive glacial and fluviatile erosion, so that the present exposures may well be regarded as mere remnants of an originally extensively distributed Cenozoic formation. Some analogy may be recognized between the above exposures and the upper lignitic formation occurring in the Gros Ventre Basin, but the evidence, unfortunately, is too meager to more than suggest their possible identity with the latter horizons.

Station XXVI was located on the uplifted Palæozoic ridge, midway between Jake's and Torrey's Creeks, at an actual altitude computed at 10,269 feet, the crest culminating at a somewhat higher elevation a little to the south, or nearer Torrey's Creek Cañon. A fine view of the western or inner abrupt declivity of this mountain ridge was gained from the summit of Union Peak, extending southeast as far as Station XXV, south of Campbell's Fork Cañon, a distance of fourteen miles. The greater elevation of the abrupt west-facing break is composed of Archæan rocks, bearing above characteristic exposures of the Silurian and Carboniferous formations. The latter outcrops in long lines of low mural exposures, separated by intervals of more or less gentle talus slopes. As seen from the eastern edge of the summit platean two or three miles north of Station XV, and overlooking the profound depression in the bottom of which lies the glacier-fed lakelet that forms the source of Campbell's Fork, the great sedimentary mountain ridge is shut out from view by lofty intervening Archæan walls. This part of the range is frightfully gashed by erosive agents, and in the chasms that reach up into the high' summit still linger not insignificant remnants of glaciers, which above emerge into the snow-fields that envelop extensive areas over the northeast slope of the summit.

Between Torrey's Creek and Little Wind River Cañons the mountain flank preserves the same geological character as noted to the northwest of the former stream. But the cañons that pierce this part of the range afford more complete sections of the Mesozoic rocks, owing to the fact that the mountain border to the south has suffered to a much less degree from the effects of the denuding agents, which to the north, in places, barred the Palæozoies to the base of the mountain. Although lying to the east of the limits of the present district, opportunity was offered for visiting some of the more important cañons cutting the great sedimentary ridge, and the securing of an amount of interesting data bearing on the general structure of the mountain flank. In compliance with the request of Dr. Hayden, a brief account of the observations in this quarter, incliding both the mountain flank and such portions of the basin area as came under hasty examination, is subjoined.

Eight miles southeast of 'Torrey's Creek, Campbell's Fork issues from the mountains. Its sources, which have already been alluded to, lie well within the territory of this district, and flowing north of east it joins Wind River, after a course of about sixteen miles, at a point six miles below the mouth of North Fork. For fully three-fourths of this distance the stream traverses a deep mountain gorge, the upper half lying exclusively in the Archæan area, the lower portion cutting across the outer mountain ridge, where the uplifted sedimentaries are shown in escarpments hundreds of feet in height. Just below the debouchure the stream is dammed by low, transverse barriers, doubtless of glacial 


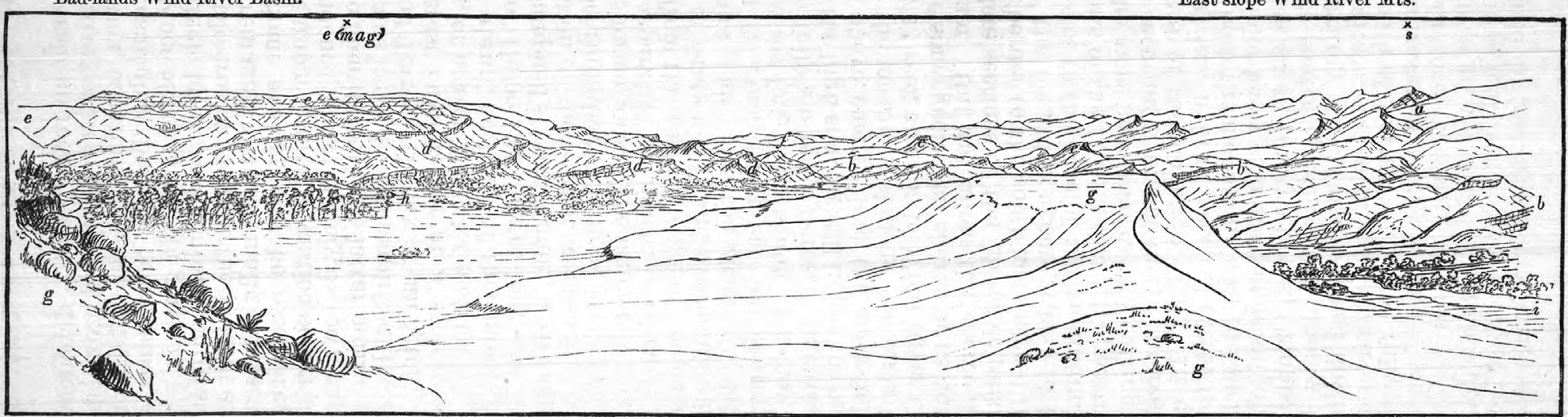

(Non-conformable Tertiary and Jura.) a Carboniferous.

Confluence of North Fork and Wind River. $c$ Yellow passage beds.

$f$ Campbell's Fork Moraine. $d$ Jurassic, limestone, sandstone, variegated shales

$g$ Drift-covered beuches, $h$ North Fork.
(Flexure in Jura-Trias.)

$i$ Wind River,

(n) C... 


Plate XXXIII.

TERTIARY AND MORAINAL DEPOSITS, DEBOUGHURE CAMPBELL'S FORK.

Grest Wind River Mts.

Wind River Basin. 13,200 ft.

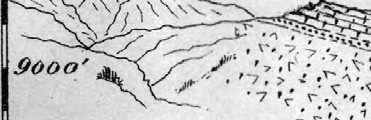

Tunnel TakeDinwiddie.

Wind River:

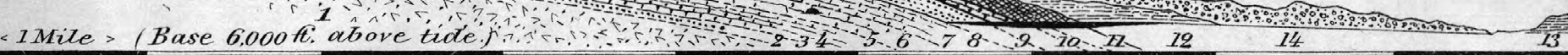

1. Archoean 2. Potsdam 3,4.quebec. 5,6,7,8, Carboniferous limestone.

9. Middle Carb. sandstone. 10. Permo-Carb. 11. Triassic "red beds."

12. Tertidry sandstone.

13. Wind River Tertiary.

14. Morainal deposits: 


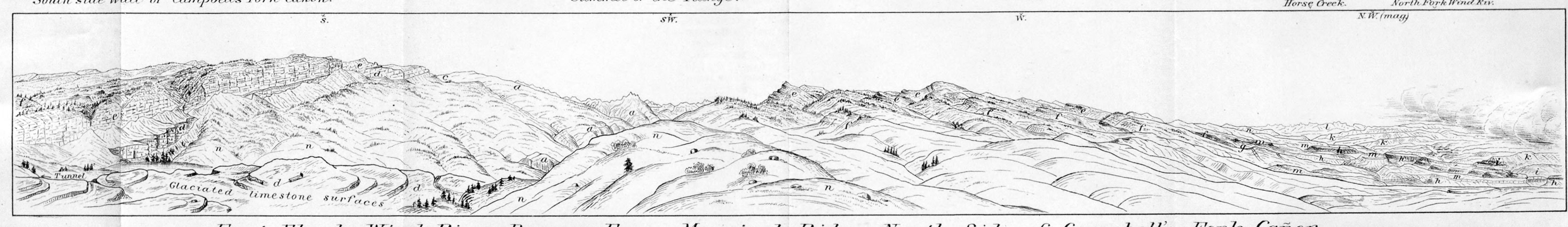

East Flank Wind River Range, From Morainal Ridge North Side of Campbell's Fork Cañon.

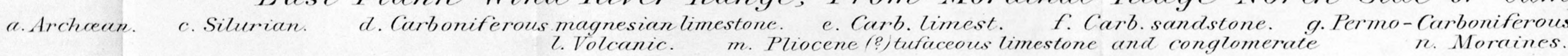


origin, forming a long, irregular lake, or chain of lakes, perhaps a couple of miles in length, nestled between high, steep bluffs, crowned by morainal materials. A mile above the lake, or just within the entrance to the cañon, the stream has for a short distance tunneled the Carboniferous limestone that here spans the bed of the cañon perhaps 50 feet above the present water-level in the subterranean passage. Above this smaller lake expansions occur, much silted up from the deposition of sediment.

The section revealed in the lower portion of the cañon includes the complete series of Palæozoic formations. The Primordial horizons, including the Potsdam quartzitic sandstones and Quebec limestones, are in the main concealed beneath the accumulations of débris in the taluses, so that the exposed portion of the cañon walls are entirely formed by the Carboniferous limestones. Towards the exit, however, the great sandstone horizon forming the middle division of the Carboniferous appears in the cañon walls, and rising well up on the mountain flank, where it forms a well-marked topographic feature. The sandstone is succeeded by the limestone and shaly Permo-Carboniferous deposits, which, however, are much obscured by débris. To the latter succeed the Triassic "red beds," upon which rests an unconformable series of soft, dirty yellow and drab Tertiary sandstones that appear in the bluffs bordering the course of the stream for a couple of miles below the cañon.

The geological section, of which a diagram illustration has been prepared, consists of the following members at this locality, the thickness of the various beds being roughly estimated:

\section{Section in Campbell's Fork Cañon.}

No. 1. Archæan.

No. 2. Potsdam quartzitic sandstones.

No. 3. Drab shaly passage beds.

No. 4. Quebec; drab, rusty-weathered, even-bedded limestones.

No. 5. Buff, reddish-stained limestone, 300 feet \pm . Carboniferous.

No. 6. Grayish-buff heavy-bedded magnesian limestone, 300 feet \pm .

No. 7. Buff-drab limestone, magnesian below, with a conspicuous red band above, 200 feet \pm .

No. 8. Drab cherty limestone, with reddish shaly limestones and clays, 400 feet \pm . Contains $\$ y$ ringopora.

No. 9. Generally buff sandstones, 200 to 400 feet.

No. 10. Limestones and shales, Permo-Carboniferous, 200 feet \pm .

No. 11. Trias. Red sandstone and arenaceous clays.

No. 12. Tertiary. Dirty buff and drab sandstones and clays, unconformably overlying the Triassic, and dipping slightly down stream or northeastward.

No. 13. Morainal deposits.

Between Torrey's Creek and Campbell's Fork the outlying bench at the foot of the mountain shows a low bulging area which is denuded to the Trias over the greater portion of its extent, in which the dips after leaving the spring of the mountain flank are generally quite moderate. But in the narrow area lying immediately along the left side of Wind River the strata are more sharply inclined, in places at an angle of $50^{\circ}$ or $60^{\circ}$. In the latter quarter, or in the immediate vicinity of the confluence of North Fork of Wind River, the section displayed in the abrupt barren bluff slopes is made up of the variegated and buff sandstone deposits of the inter-Jura-Trias horizon, and above occurs a considerable thickness, probably amounting to a few hundred feet, of beautifully variegated clays, rusty sandstones, and bands of limestone 
belonging to the Jura proper, and which in turn are unconformably overlaid by the pale-red and drab banded Tertiary deposits that a little farther back rise up into the general upland level of the basin region. The exposures here displayed would doubtless afford interesting and valuable data bearing on the detail stratigraphy of that portion of the Messozoic series represented. Such observations as were necessarily hastily made at this locality are embodied in an accompanying sketch, to which is added a brief explanatory legend of the geological deposits shown therein.

On the south edge of the above-mentioned outlying Mesozoic platform, only a short distance from Campbell's Fork, the gently inclined Triassic "red beds" are much eroded, the drainage channels having excavated shallow picturesque cañons on their passage to Wind River. A small stream about two miles above Campbell's Fork, and which rises in the outer flank of the great sedimentary border ridge, issues from a deep, narrow gorge in the foot of the mountain, where the junction of the upper Carboniferous and Triassic deposits is most clearly revealed. Below is given a detail section of the upper division of the Carboniferous series, including the Permo-Carboniferous horizon at the top, and which embraces all the strata at this locality lying between the middle Carboniferous sandstone below and the Triassic "red beds" and conformably associated deposits above. The diagram, in which the abovereferred-to strata are incorporated, is extended down the cañon to the northeast and a mile along the left bank of Wind River to the border of the Tertiary formations occupying the basin area to the north of that stream.

\section{Section of Permo-Carboniferous horizon, \&c., in cañon two miles northwest of Campbell's Fork.}

No. 1. Middle divisioñ Carboniferous: Light gray, buff, and reddish sandstones, with oblique bedded layers, dip $10^{\circ}$ about N. $60^{\circ} \mathrm{E}$., and rising up on mountain flank at a somewhat steeper angle.

No. 2. Gray and brownish, in places nodular limestone layers interbedded with shales, imperfectly exposed 25 feet \pm .

No. 3. Unexposed space, 22 feet \pm .

No. 4. Gray earthy limestone, exposed 3 feet.

No. 5. Unexposed space, 35 feet \pm .

No. 6. Hard, bluish-gray limestone, with chert, exposed 15 feet \pm .

No. 7. $a$, gray limestone ledge; $b$, indurated nodular calcareous shales, filled with Productus, sp.?, recalling P. horridus, \&c.; c, fragmentary gray, greenish-stained limestone, charged with Productus punctatus? ?, Rhynchonella, Retzia, Spirifer, Syringopora, with Discina in brown shaly layers above; all 15 feet \pm .

No. 8. Dark drab and brown indurated gritty shales; numerous individuals of a small Nucula ( $N$. beyrichii?) are weathered out on surface of this horizon, also fragments of Petalodus ?; 30 feet \pm .

No. 9. $a$, gray, fragmentary limestone, 2 feet exposed; $b$, cherty bed, with geodes discolored with bitumen and green stained, also some gypsum; $c$, fragmentary, grayish-drab limestone, mainly chert above; $d$, gray limestone, green stained, with more or less chert and chalcedony, containing crinoidal remains, Fistulipora?, Chcetetes making up a layer, Hemipronites, Retzia, Spirifer, Productus, \&c.; all 50 feet \pm .

No. 10. Gray, gritty, slightly calcareous, indurated argillaceous deposit, with thin sheets of limestone, containing in upper part a small Pleurophorus, Schizodus?, Lingula, pyrite crystals and nodules, and thin gypsum laminæ; 60 to 75 feet \pm . 
Plate XXXV.

NE.

Owl Creek Mts.

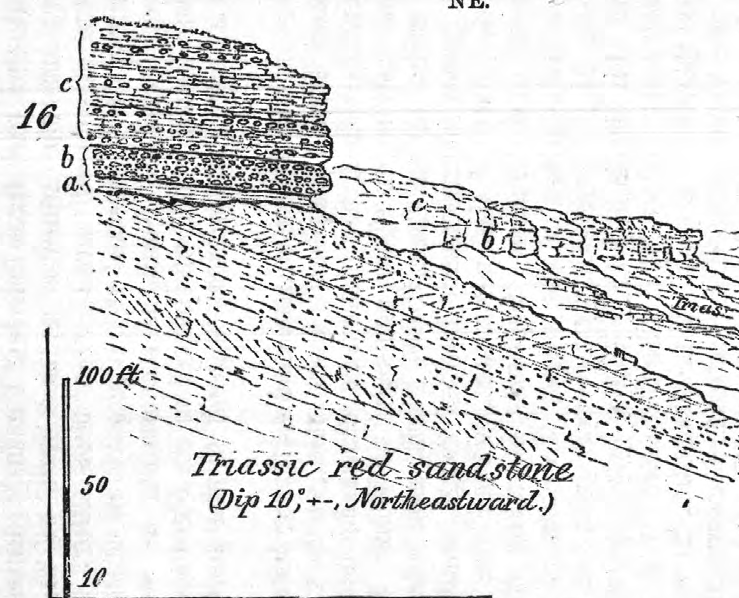

Wind River Basin.

Section of tufaceous limestone and conglomerate (looking down Red Cañon). 




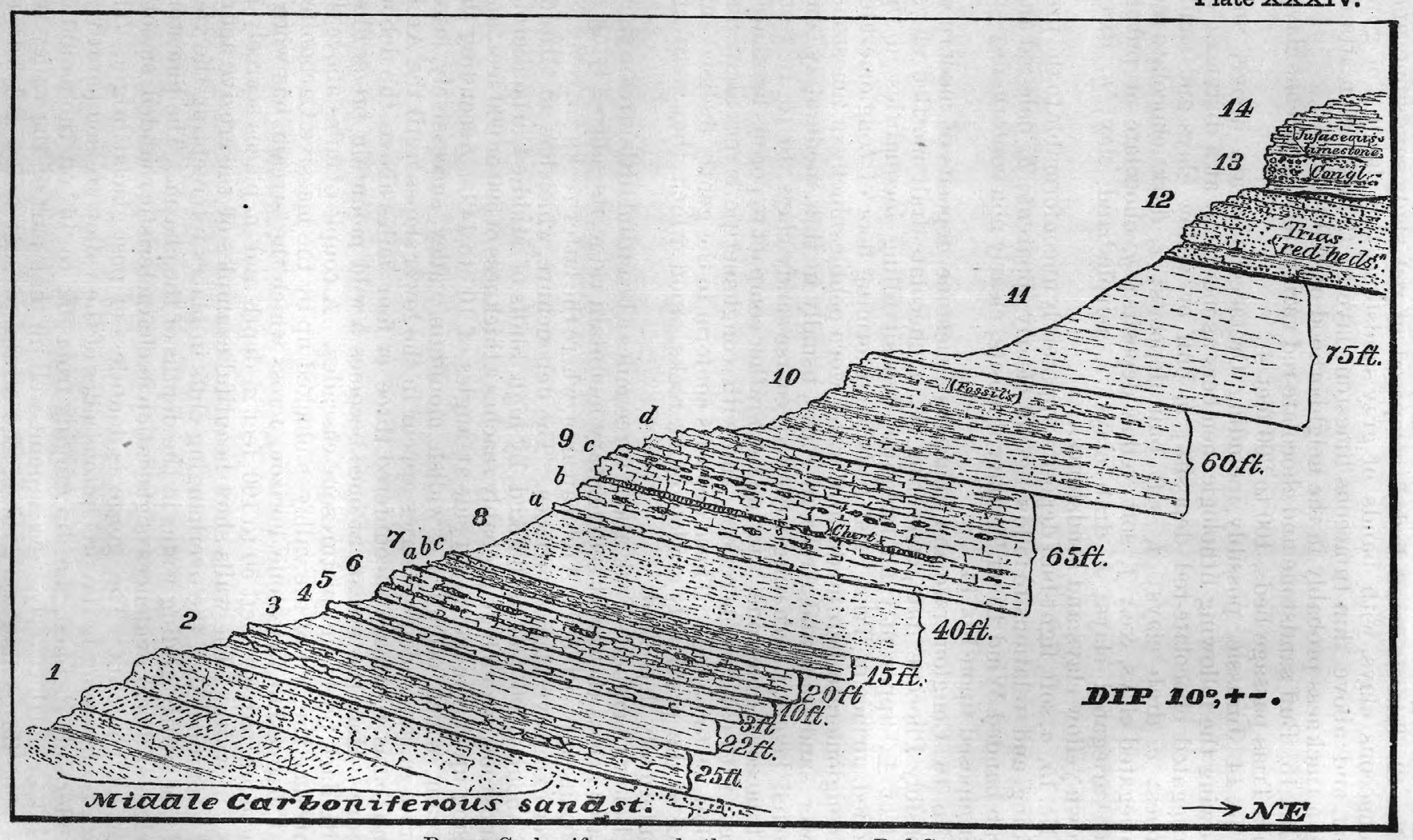

Permo-Carboniferous and other exposures; Red Cañon. 
No. 11. Light-drab arenaceous clays, 75 to 100 feet.

No. 12. Triassic "red beds," composed of red shaly sandstone and arenaceous clays, with bands of gray sandstone, thin laminæ of gypsum, and above thin tufaceous limestone layers; the formation attaining a thickness probably in the neighborhood of 800 feet.

No. 13. Buff sandstone and chocolate-red variegated arenaceous clays, Jura-Trias passage beds, 100 to 200 feet \pm .

No. 14. Jurassic, possibly including Cretaceous strata above, and showing the following lithologic members as made out at a distance: $a$, variegated chocolate-red deposits; $b$, buff or yellow clays and sandstones; $c$, drab clays; $d$, soft buff deposits; $e$, dark chocolate-red variegated clays, \&c.; $f$, soft yellow deposits; $g$, chocolate or purple red variegated clays; $h$, drab clays; $i$, purple-band clay; $k$, dirty brown-yellow clays and sandstones.

No. 15. $a$, soft, light-buff deposits, apparently unconformable to the preceding, and relations to following not clearly apparent; $b$, pale-red and drab banded Wind River Tertiary deposits, clearly non-conformably superimposed upon No. 14 .

No. 16. Conglomerate and tufaceous limestone deposits of modern or possibly Pliocene date, consisting of : $a$, chocolate-drab mottled clays, 5 feet \pm , apparently an irregular deposit filling inequalities in the eroded surface of Trias "red beds" and forming floor of conglomerate; $b$, conglomerate, here made up of water-worn pebbles chiefly of limestone, fewer sandstone and Archæan rocks, usually in thin, moderately compacted layers, alternating with red, coarse-sandy clays, 10 to 15 feet; $c$, tufaceous limestone, varying from rather compact to porous laminated rock, with calcite concretions, and with conglomeritic layers above and below, 50 to 55 feet. These deposits conform to the gently inclined surface of the previously eroded older rocks, upon which they were unconformally deposited.

Below Campbell's Fork about three miles a beautiful little stream penetrates across the great sedimentary mountain ridge, its sources lying in a basin well within the Archran area, where the latter rocks are revealed over extensive glacial surfaces. The debouchure, which has an altitude of about 7,600 feet, is flanked by high bluffs of Middle Carboniferous sandstone, which here probably reaches a thickness of 500 or 600 feet, and rising up on the mountain side at angles of $10^{\circ}$ to $14{ }^{\circ}$. Ascending the stream, which occupies a widish mountain valley, successively lower strata in the geological series appear in the lower slopes until the Archæan basis rocks are encountered three or four miles above the debouchure. Here the stream at once becomes a wild mountain brook filled with dark pools and picturesque cascades. A couple of miles above the entrance the bed of the valley is blocked up by the massive Carboniferous magnesian limestone horizon, across which the stream has worn a tortuous narrow cleft 50 to 100 feet in depth and in places scarcely 10 feet in width. The walls show beautiful examples of the erosive action of running water, the overhanging cliff's in places intercepting the view of the swiftly gliding water in the depths of the chasm. The limestone ledges still bear evidences of glaciation in characteristic rounded, smoothsurface contours. The gorge is doubtless of post-glacial origin. The strata appearing in the precipitous sides of the valley are comparatively moderately inclined, the dip ranging from $10^{\circ}$ to $15^{\circ}$ off the mountain flank or northeasterly. At a point well up that part of the valley traversing the sedimentary ridge, the strata present a low subordinate flexure, the recurrence of which farther south will be noticed farther on. The mountain-foot is denuded of the upper members of the Carbonifer- 
ous as also the Mesozoic formations, which, however, appear in the slopes to the north and south of this stream. Below the debouchure the valley is bordered by well-defined morainal ridges, that on the north side extending high up the mountain valley in a strictly characteristic high bench resting on the steep slope. The observations at this locality are embodied in the following section, the details being derived from the isolated outcrops along the stream, but which form heavy ledges in the cliff on either side.

\section{Section in cañon three miles south of Campbell's Fork.}

No. 1. Archæan; rusty weathered gneissic ledges.

No. 2. Potsdam; reddish, gray and variousle tinted and mottled, coarse and fine grained sandstones, in places partially quartzitic, with oblique laminated layers, dip $10^{\circ}$ to $15^{\circ}$ northeastwardly, 100 feet, \pm , exposed.

No. 3. Quebec; brownish limestone, with thin-bedded arenaceous layers interbedded with drab shales below, 25 feet exposed to level of stream, but much thicker.

No. 4. Drab shales, 15 feet \pm .

No. 5. Dark drab, Jellow mottled, fragmentary, thin-bedded limestone, in places showing brecciated structure, outcrops brown weathered, exposed 15 feet, but evidently thicker. Resembles Upper Quebec limestone.

No. 6. Unexposed space.

No. 7. Drab, brownish-buff and gray, fragmentary, thin-bedded limestone, rough weathered surfaces resembling lower magnesian limestone of the Carboniferous and so-called Niagara horizon of other localities in the region, 10 feet \pm .

No. 8. Greenish-drab shales, including thin layers of limestone, 30 feet \pm .

No. 9. Drab and gray, thin-bedded, fragmentary limestone, of which a thickness of 5 feet is exposed, but belonging to a thicker bed, underlaid by greenish gray disintregrated limestone. Contains Fistulipora? Crinoid remains, Hemipronites, \&c.

No. 10. Unexposed space probably occupied by the preceding bed and additional layers, forming a well-marked horizon 150 feet, $t$, in thickness in the mountain ridge, consisting of even-bedded, buff reddish weathered limestone.

No. 11. Dirty buff reddish tinted, rough weathered, even-bedded magnesian limestone, in places a breccia consisting of flesh-colored limestone fragments embedded in buff matrix, and belonging to a heavy ledge of which 200 feet \pm , are exposed in the neighborhood of the chasm which the stream has worn into its mass. Contains crinoidal remains.

No. 12. Unexposed space.

No. 13. a, gray or drab, reddish tinted limestone, a heavy bed as seen in cliffs bordering the valley; $b$, blue shaly layers, 10 feet, \pm ; $c$ drab reddish tinted limestone, more or less magnesian below, 200 to 300 feet; $d$, drab, reddish stained, dirty buff weathered fragmentary limestone in thick layers with calc. spar lined cavities, 100 feet \pm . Dips $10^{\circ}$ to $15^{\circ}$.

No. 14. Middle Carboniferous; gray, reddish stained sandstone, with obliquely bedded layers, sand concretions and seams of clay. The weathered ledges show shallow cavities. 600 feet, \pm .

The mountain flank for the next sixteen miles to the southeast presents a nearly uniform, moderate, grassy slope, the lower half of which is composed of the middle Carboniferous sandstone and more or less per- 


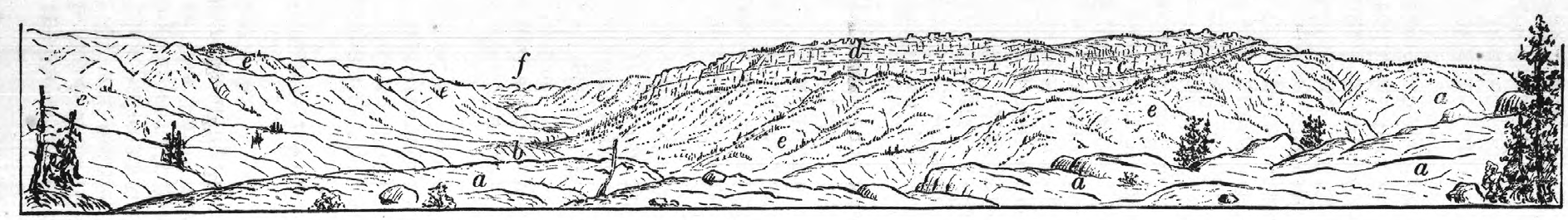

Dry Creek Cañon, looking toward Wind River Basin.
$a$ Metamorphic, glaciated surfaces.
$b$ Quebec limestone.
$c$ Carb. magnesian limestone.
$d$ Carb. limestone.
$e$ Morainal deposits.
$f$ Owl Creek Mts.

Sta. $X X V$.

Gorge.

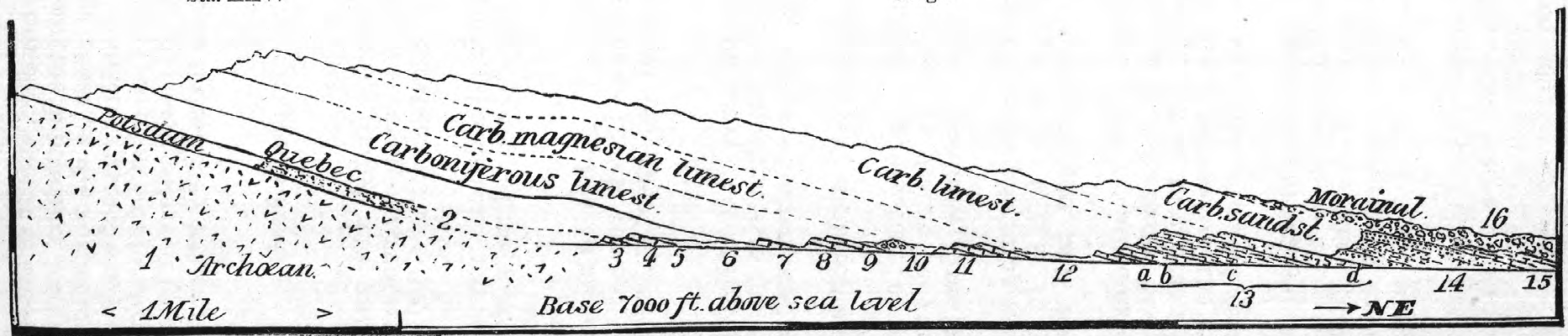

East flank Wind River Mts, ; Section in Dry Creek Cañon. 


Plate XXXVII.

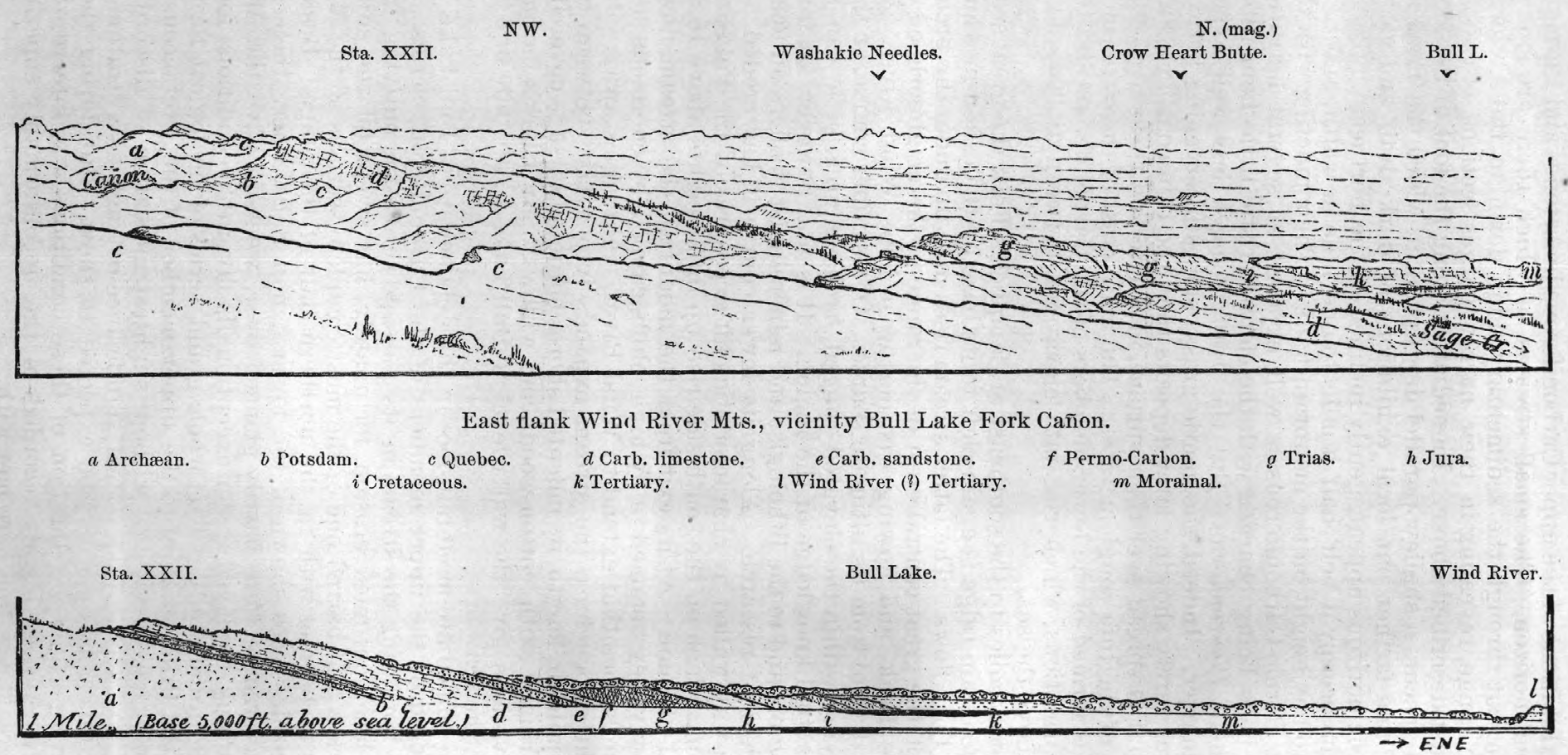

Section along Bull Lake Fork. 
fect exhibitions of the upper Carboniferous limestones and Permo-Carboniferous horizon. The small streams, of which there are four in this section, cut through the sedimentary ridge down to the Archæan core of the range, revealing in their narrow gorges sections esisentially like that last described above. Immediately along the foot of the mountain usually occurs a shallow parallel depression, in which the Triassic "red béds," and farther out local exhibitions of dark drab and variegated Jurassic horizons appear, gently inclined to the northeast. The former deposits occupy a belt half a mile to one mile in width, and never extend to any height on the mountain flank. Their junction with the subjacent Permo-Carboniferous is well exposed at several localities, the latter beds being charged with the characteristic little Lamellibranchiate shell, Pleurophorus. But the Jura is much less well exposed in this quarter. Indeed, the gentle grassy slopes intervening between the streams rarely showing later deposits than the thin coating of drift and soil that is spread over their surface, and here and there mesa-like remnants of the tufa-conglomerates. The main crest of the outer mountain ridge is formed of the lower members of the Carboniferous and the Silurian formations, which rise into elevations between 10,000 and 11,000 feet above the sea.

Twenty miles to the southeast of Campbell's Fork the great sedimentary mountain ridge is again cleft to its base by the cañon in which Bull Lake Fork flows. The latter stream rises high up under the precipitous wall of the great central crest of the range in the neighborhood of Fremont's Peak, and flowing east-northeast joins Wind River, 25 to 30 miles distant from its ultimate source. Of its upper course, or that portion lying within the elevated rugged Archæan area, little can be said from actual knowledge of the region. It is not, however, an inaccessible region, and to the lithologist and mineralogist it offers an absolutely new field of research. Along its lower course it has eroded a broad cañon-way walled by characteristic cliff exposures of the Palæozoic formations, which on the south side rise up into heights above 10,800 feet actual altitude. At its exit from the mountain the stream flows in a narrow valley hemmed in by high bluffs capped by enormous morainal accumulations that extend to Wind River, eight miles away. Just below the debouchure the stream expands into a lake between two and three miles in length, its indented shores bordered by sage-covered slopes and fringed with cotton-woods and willows. Mr. Clark's barometrical observations give the water-level of Bull Lake an altitude of 5,911 feet above the sea.

The immediate mountain-foot in the debouchure of Bull Lake Fork is composed of the upper members of the Carboniferous series. In the bluff's bordering the stream in its passage across the outlying benched area, late continued erosion, fortunately, has swept off the superficial materials and barred one of the most complete sections of the Mesozoic series to be met with in the northern half of the range. Besides the Palæozoic series shown in the lower cañon walls, where their general characteristics were hastily glanced over, we here have the Mesozoic formations displayed under exceptionally favorable conditions for detail stratigraphic study. This whole grand series of geological formations from the Primordial up to the upper member of the Cretaceous of the region, are here revealed without slightest indication of discordance of deposition of more than local significance or such as a stratum of any subordinate member may be expected to show. But during the PostCretaceous time the duration of these conditions was interrupted, and the evidence is legibly recorded in the unconformably superimposed Cenozoic deposition here met with. 


\section{Section on Bull Lake Fork.}

No. 1. Archæan.

No. 2. Primordial quartzitic sandstone.

No. 3. Quebec limestone formations.

No. 4. Buff or drab reddish stained limestones, apparently forming a distinct horizon underlying the buff magnesian limestone, as seen in the great cliff exposures in the cañon walls. This limestone holds the horizon of the Niagara, but it is regarded as probably belonging to the Carboniferous.

No. 5. Carboniferous magnesian limestone, 300 feet, \pm .

No. 6. Drab and gray rusty-weathered limestones, more or less cherty, with magnesian layers 400 feet \pm . Contains characteristic Carboniferous fossils, and is here referred to the lower division of the series of which it forms the upper member.

No. 7. Middle Carboniferous division, light gray, reddish buff, weathered, even-bedded sandstones, 400 feet, \pm .

No. 8. $a$, buff or light-gray limestones, with occasional shaly layers and bands of chert, with calcite and gypsum, 40 feet, $\pm ; b$, chert band with fibrous gypsum, 4 feet; $c$, gray limestone, with cherty layers in middle containing nodules of chalcedony with a black bitumen mineral and calcite geodes, 15 feet, $\pm ; d$, dark and light-gray limestones, cherty and nodular, alternating with shaly layers, with a 6-inch layer charged with black bitumen or carbonaceous matter, contains obscure fossils; 15 to 20 feet; $e$, gray limestone, with calcite, 8 feet.

No. 9. Drab clays and brown indurated shales, 50 feet, \pm .

No. 10. Gray magnesian (?) limestone, with calcite 15 feet, \pm .

No. 11. a, gray, nodular limestone with clay partings, and chert, numerous fossils of same species occurring in No. 14, 35 feet, $\pm ; b$, blue nodular limestone and shales underlaid by indurated dark drab calcareous shales containing cavities lined with calc. spar, 40 feet, \pm .

No. 12. Chert band, made up of uneven layers, 8 feet, \pm .

No. 13. Gray limestone, in places brecciated, with flint nodules, contains Chcetetes (?) Bryozoa, \&c., 20 to 30 feet.

No. 14. Permo-Carboniferous horizon; $a$, light-drab clays with nodules of flint and calcite, and thin layers of gritty brown and gray limestone containing casts of a small Pleurophorus, Balevillia, \&e., and in lower part thin irregular layers of limestone alternating with clays containing numerous fossils, Productus costatus? P. punctatus (?) Spirifer, two species, \&c., 65 to 70 feet; $b$, gray, thin-bedded, gritty limestone, more or less concretionary and magnesian (?) with ripple markings, 25 feet \pm ; dip $15^{\circ}$ to $20^{\circ}$ northeast.

No. 15. Light-drab clays with thin indurated layers, imperfectly exposed, 30 to 50 feet.

No. 16. Triassic red sandstones and arenaceous shales, with thin gray sandstone layers 1,000 to 1,400 feet; dip to the northeast, and at angles of $15^{\circ}$ to $20^{\circ}$.

No. 17. White gypsum, more or less regularly bedded, including one or two thin layers of sandstone, the outcrop somewhat fractured by tendency to joint structure. This bed shows a thickness of 25 to 40 feet, forming the crest of an outlying spur-ridge in the north side bluffs, some distance above the head of Bull Lake.

No. 18. $a$, red, greenish, and chocolate-colored shales with thin layers of white gypsum, and gray and drab indurated layers; $b$, red and gray banded shales, the outcrop presenting a beautifully variegated band wherever seen, 100 feet, \pm .

No. 19. Drab, fragmentary limestone, 6 feet, \pm ; dip $23 \circ$, N. $42^{\circ}$ E. 


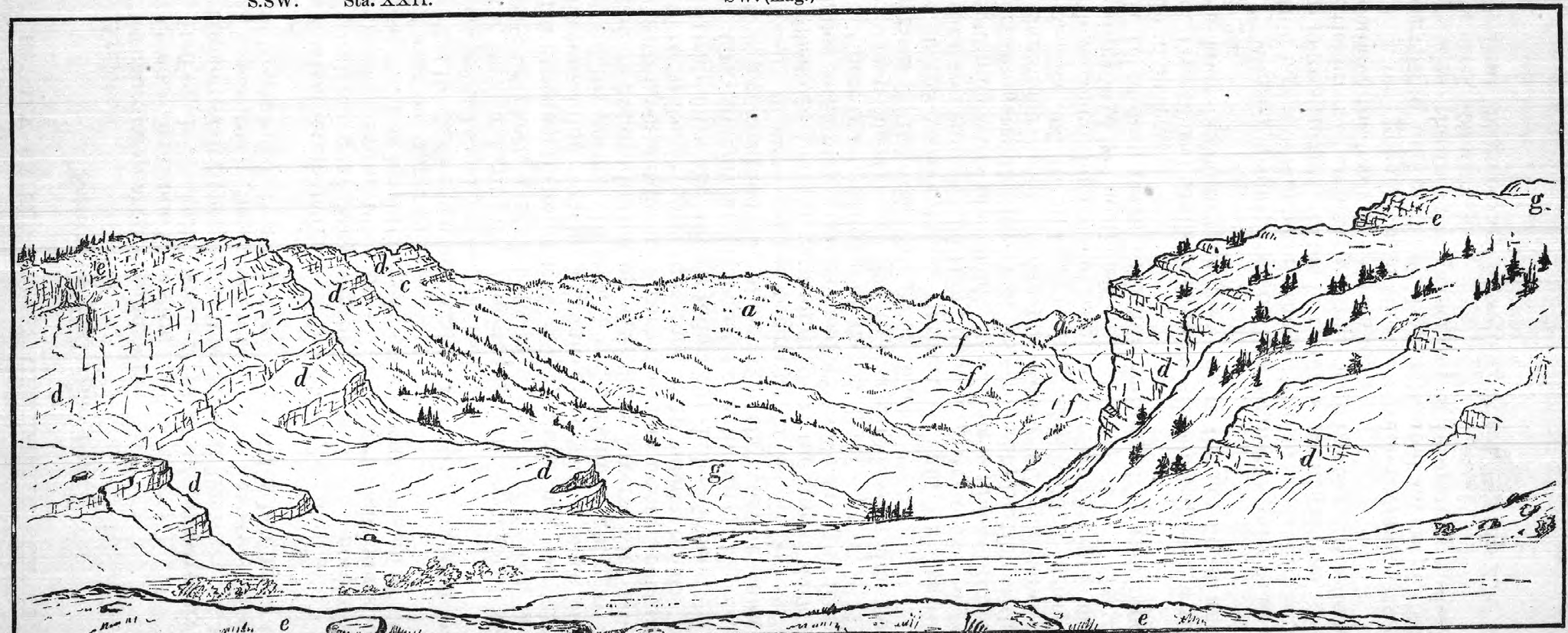

$\sum_{n=1}-1$

Bull Lake Fork Cañon.

a Archæan.

$c$ Quebec.

$d$ Carb. limestone.

c Middle Carb. sandstone. 

No. 20. Drab shales, 15 to 20 feet.

No. 21. Dark gray fragmentary limestone, with obscure remains of fossils, 1 foot, \pm .

No. 22. Drab clays with laminæ of calcite or gypsum, 15 to 20 feet.

No. 23. Dark gray fragmentary limestone, 4 feet, \pm .

No. 24. Drab shales with thin beds of light-gray sandstone, 170 feet, \pm .

No. 25. Gray, buff weathered soft sandstone, in part thin-bedded, with soft flagging layers, forming mural exposures in crest of spur-ridge, showing a thickness of 20 to 30 feet, dip $19^{\circ}$ to $23 \circ$, N. $42^{\circ}$ E. Upper layers contain casts of several Lanullibranchiate shells, probably representatives of Jurassic forms.

No. 26. $a$, red and drab shales, alternating; $b$, pale-red shales; $c$, chocolate-red shales and thin sandstone layers, alternating. This horizon presents a beautiful variegated belt in the steep slopes of spurridge, and probably attains a thickness of 300 feet, \pm .

No. 27. Soft-white or light-buff sandstone, 10 to 15 feet.

No. 28. Light and chocolate-drab shales, banded with thin indurated layers resting upon red shales, 250 feet, \pm .

No. 29. Buff sandstone, forming a heavy ledge in crest of spur-ridge, 25 feet, \pm .

No. 30. $a$, alternating layers buff sandstone and drab clays, with fucoidal (\%) impressions, 20 feet, \pm ; $b$, brownish-drab shales, with selenite; $c$, banded brown, yellow, blue, and dark, gritty shales and thin sandstone layers, 200 feet, \pm .

No. 31. Rather firm, light-gray, buff-weathered sandstone, 5 feet, \pm ; $\operatorname{dip} 18^{\circ}$ N. $23 \circ$ E.

No. 32. Dark-drab and bluish shales with selenite and thin bands of efflorescence, and in lower part a dark fragmentary calcareous layer perhaps 2 feet thick, 400 feet, \pm .

No. 33. Shaly and concretionary, fragmentary, dark-blue limestone, 5 to 10 feet. Contains fragmentary remains of Teliost fish-scales, \&c., resembling and probably identical with forms elsewhere occurring in the Colorado group of the Cretaceous.

No. 34. Drab clays and thin indurated layers, containing fish remains like those in No. 33, 110 feet, \pm .

No. 35. Rusty weathered, gray sandstone with clay partings, 60 feet, \pm , exposed in bluffs about opposite the head of Bull Lake. Locally shows the following subdivisions: $a$, at base bluish-gray sandstone, 5 feet exposed; $b$, space with drab shales, 15 feet; $c$, thin-bedded gray sandstone, 5 feet; $d$, space, 15 feet; $e$, bluish-gray sandstone, 5 feet, \pm ; $f$, brown shales, 5 feet; $g$, gray sandstone with fucoid-like markings, 10 feet, \pm .

No. 36. Rusty-yellow sandstone, and sandy and brown gritty shales, dark flint nodules in upper layer, 30 to 40 feet.

No. 37. White, very fine clays, 8 feet, \pm , forming, a conspicuous band in the bluff exposures.

No. 38. Drab shales with layers of rusty sandstone below, selenite and white efflorescence above, 30 feet, \pm .

No. 39. Yellow buff, soft sandstone, heavy bed, dip 150, N. $42^{\circ}$ E., 80 feet, \pm .

No. 40. Light-drab clays with white efflorescence, imperfectly exposed, 40 feet, \pm .

No. 41. Light-gray, thin-bedded sandstone, 6 feet, \pm .

No. 42. $a$, Light-drab clay, with white efflorescence; $b$, banded darkdrab clay, with brown carbonaceous, shaly bands; $c$, light-drab sandy clay. 175 feet, \pm . 
No. 43. Brownish-gray sanistone, thin layer.

No. 44. Bluish arenaceous clays, with thin, indurated layers, 300 feet, \pm .

No. 45 . Soft, bufi-gray sandstone, dip $15^{\circ}$ N. $52^{\circ}$ E., 30 feet, $\neq$.

No. 46. $a$, reddish-drab and brownish clays; $b$, lignite coal, 8 to 10 inches, drab clay 12 inches, lignite 3 inches, drab clay 12 inches, lignite 6 to 10 inches, total 4 feet; $c$, brown clays with selenite, 15 feet; total 30 feet, \pm .

No. 47. soft, light yellow sandstone, 20 feet, \pm .

No. 48. $a$, soft, grayish yellow, shaly sandstone and brown clays, exposed 10 feet; $b$, drab-brown shales, with minute flakes of mica and selenite, 3 feet; $c$, brown, gritty shales, with selenite, 30 feet, \pm ; total, 60 feet, \pm .

No. 49. Rusty brown and buff calcareous sandstone, 8 feet \pm , with numerous fossils in upper part, Inoceramus and several other conchifers, gasteropods, and Ammonites, probably identical with Fox Hills Cretaceous forms.

No. 50. Soft, yellowish sandstone and clays, imperfectly exposed, and belonging to a heavy bed at the top of the Mesozoic series here exposed.

No. 51. Tertiary. Buff sandstones with more or less argillaceous matter, resting unconformably upon the preceding sandstones, No. 50, in nearly horizontal strata.

No. 52. Yellowish clays, slightly brownish or reddish tinted above; possibly Pliocene or Post-Tertiary.

No. 53. Morainal bowlder deposits crowning ridge 800 feet above the level of Bull Lake.

The few hours devoted to the examination at the above locality necessarily left the results less complete than could be desired. It is impossible to draw the line of demarkation between the Jurassic and Cretaceous horizons, also between the former and the Trias. In the latter case, however, the great gypsum deposit affords a convenient horizon, but since this is evidently an excessive local development it might not subserve even the purpose of convenience. A comparison of this part of the section with the equivalent horizon to the northwest exhibits a marked change in the lithology of the inter-Jura-Trias strata. We here lose entirely the well-developed yellowish or buff sandstone that occurs in this horizon at the confluence of North Fork and Wind River, although the lower limestones correspond stratigraphically with occurrences at that locality, except for the pancity of organic remains in the present beds. It is hardly necessary to add that not the vestige of an organism was observed in the characteristically "red beds" of the Trias. The Jura, however, is recognized in the fossils occurring in the sandstones No. 25. But the limits of the formation above in the present state of knowledge must be arbitrarily assigned to some one of the lithologically conspicuous horizons interposed between No. 25 and No. 30. One or more of the sandstone and shale horizons occupying this space may prove to be identical with the Dakota or inferior formation of the Cretaceous. The heavy clayey measures No. 32-34, inclusive, doubtless represent the middle or Colorado group, while in the upper portion of the remainder of the conformable deposits, extending up to No. 50 and embracing a vertical thickness of strata probably in the neighborhood of 900 feet, a stratum occurs eharged with a molluscan fauna eminently characteristic of the Fox Hills division of the Cretaceous series. The lithology of these upper strata alone would strongly suggest the above inference. Although not a unique occurrence, the presence of lignitic deposits in these undoubted upper Cretaceous rocks at the present locality is an in- 
East foot Wind River Mts. 



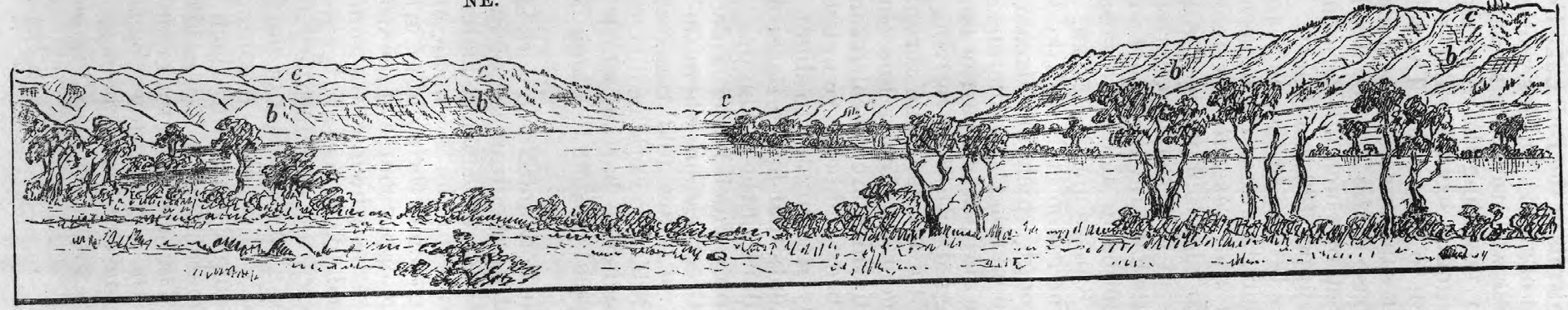
Bull Lake. $a$ Cretaceous, with coal. 
teresting fact, and deserves to be thoroughly investigated with the view to determining their economic value.

The Palæozoic series exposed in the walls of the Bull Lake Fork cañon is of no less interest in a geological point of view. But for want of time only the upper member of the Carboniferous was studied with any pretension to minuteness. Of the latter member, including the uppermost and distinctively Permian horizon, the foregoing section exhibits the detail stratigraphy with close approximation to the truth. The full thickness of the strata lying between the great sandstone of the middle division of the Carboniferous, No. 7, and the base of the Triassic "red beds," No. 16, reaches a maximum of about 400 feet, of which the Permian or PermoCarboniferous horizon comprises the upper 120 to 150 feet. The fossils of the lower strata of this upper series belong, in the main, to characteristic upper Carboniferous types. Their absence in the uppermost strata, in which such forms as Pleurophorus and Bakevillia exclusively occur, presents a striking faunal contrast to what obtains in the lower beds, and one that unmistakably indicates in this remote quarter a state of things analogous if not identical with what prevailed at the close of the Carboniferous period in the Mississippi basin along the western border of these occurrences in the States of Kansas and Nebraska.

Just within the lower entrance to the cañon of Bull Lake Fork a singular low ridge spans the valley, through which the stream has forced a wide passage. It is made up of the middle Carboniferous sandstones whose tilted edges are presented in an abrupt bluff barrier facing up the valley, the opposite side, which is flagged with the overlying limestone, declining more gently with the dip of the strata. The abrupt bluff-face of the ridge gives a section of the sandstone along a line closely corresponding to the strike of the strata, in which are revealed some interest ing minor undulations, as though the beds had been crumpled by a force acting laterally, but which is probably attributable to slight inequality in the intensity of the vertical movements that forced the strata up into their present inclined position on the flank of the mountain. Mr. Perry observed similar phenomena, though on a much larger scale, in the uplifted Palæozoic formations in Jake's Creek Cañon, where the strata are described as having the appearance of a low fold transverse to the mountain upheaval. In regard to the Bull Lake Fork locality, it is difficult to account for the existence of the sandstone barrier, which has maintained itself in spite of fluvial and glacial erosion to which it has been exposed for ages.

The mountain flank between Bull Lake Fork and North Fork Little Wind River, 10 miles to the south, is gashed by the drainage of Sage Creek, whose sources, to judge from the character of the erratic materials swept down by the stream, scarcely penetrate to the Archran area. This little stream debouches from a narrow cañon in the middle Carboniferous sandstone and overlying limestones, the upper course of the stream being defined by the earlier members of the series which, in the summit of the ridge, attain altitudes between 9,000 and 10,000 feet above the sea. The Carboniferous sandstone and dark-wreathed fragmentary limestones everywhere appear in the grassy slopes along the foot of the mountain, the edges of the various upraised geological members breaking down in abrupt declivities facing the great inclined planes in which the outer slope rises over successively lower formations until it culminates in the crest overlooking the Archæan area. The summit of the mountain ridge is formed by the Silurian limestones; to the north the lower member of the Carboniferous or so-called Niagara magnesian limestone may constitute the coping ledge. The latter horizon is often weathered in picturesque 
cliffs and huge outlying masses in the slopes a few hundred yards below the summit, while the outcrop of the Potsdam sandstone is traced here and there in the débris-covered inner slope descending to the Archæan basis rocks, rounded elevations of which still retain isolated remnants of the Primordial strata.

The Triassic "red-beds" appear over an outlying parallel belt, half to three-quarters of a mile wide, forming picturesque highly-colored low bluffs bordering the little valley below the debouchure which widens out into the basin through which the stream winds lower down. A considerable belt of darkish drab deposits succeeds the "red beds" and variegated Jura horizons, which is probably referable to the Colorado group of the Cretaceous series. Beyond the latter, to the eastward, the upland slopes merge into the Tertiary benches of the basin region, in the midst of which occurs the sharp subordinate fold that runs parallel with and 8 to 12 miles distant from the foot of the mountains. The section of the Mesozoic series exposed along tributary drainage depressions north of Sage Creek, of which an account is subjoined, affords many interesting details illustrative of the variable character of the depositions at localities removed but a few miles from one another, contrasting with the uniformity of the conditions prevalent over extended areas during the formation of the Palæozoic series.

\section{Section vicinity of Sage Creek.}

No. 1. Archæan. Rusty-weathered gneiss, schists, \&c.

No. 2. Potsdam sandstone.

No. 3. Quebee group limestones.

No. 4. Buff limestone, Niagara?

No. 5. Carboniferous. Magnesian limestone.

No. 6. Drab and gray limestones.

No. 7. Middle Carboniferous. Buff, reddish-stained sandstone.

No. 8. Upper Carboniferous division, including Permo-Carboniferous horizon. Gray, rusty-weathered limestones, and drab shales.

No. 9. Trias. $a$, deep red arenaceous shales and shaly sandstone, with thin layers of gray, greenish-stained sandstone; $b$, drab, fragmentary limestone, 5 feet, $\pm ; c$, reddish arenaceous shales and sandstone, with gray layers; $d$, drab limestone, obscure ledge; e, yellowish, greenstained and reddish sandstones, in places conglomeritic.

No. 10. Drab limestones and chocolate-red shales, forming a wellmarked horizon.

No. 11. Buff and reddish variegated sandstones, not clearly exposed.

No. 12. Jura. a, fragmentary drab limestone, exposed 4 feet, dip. $15^{\circ}$, N.E., containing numerous imperfectly preserved specimens of small conchifers; $b$, similar, darker-weathered limestone ledge ; no fossils observed.

No. 13. Dirty yellow and bluish soft sandstones, capped by a thin layer of rusty-gray calcareous sandstone charged with Camptonectes, Trigonia (?) Rhynchonella, Dentalium (?) \&c. Dip, 16॰ N. $63^{\circ}$ E.

No. 14. Drab and reddish shales, in beautiful variegated exposures.

No. 15. Yellowish sandstones, with concretions, forming a rather thick bed, followed above by unexposed space.

No. 16. Gray, rusty-weathered, and buff sandstone, a heavy ledge.

No. 17. Cretaceous. Dark drab and bluish clays, belonging to a heavy deposit conformable to the preceding and dipping in the same direction.

No. 18-20, inclusive. Variegated pale red and greenish drab clavey deposits, and dirty yellow weathered horizontal sandstones, belonging to 
Plate XIII.

East flank Wind River Mts.
$11000 \mathrm{ft}$.

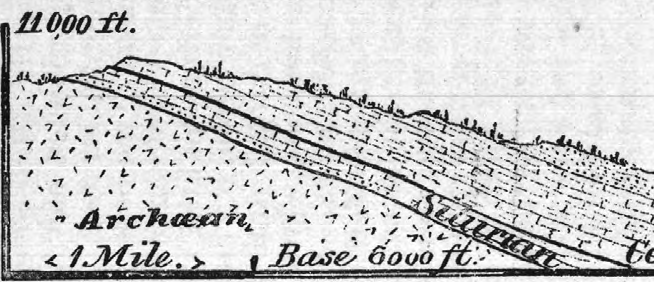

Wind River Basin

Wind River.

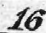

12

15
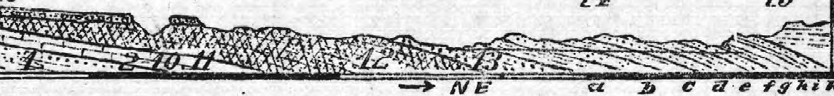

Section vicinity of Rea Cañon, NW. of Camploll's Fork.

1. Middle Carb. sandstune.

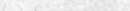

14. Jura, \&c. $(a-k)$.

15. Wind River Tertiary, \&c.
2-11. Permo-Carb.
12. Trias.
13. J.-T. Passage beds.
mest one and conglomerate.

East flank Wind River Mts.

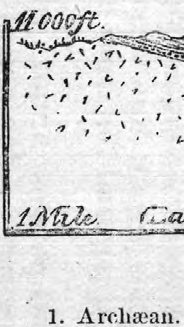

7. Carb. sandstone.
2. Potsilam.
8. Permo-Car

3. Quebec.

9. Trias.
Section north of Sage Creek.

4. Niagara (?) magnesian limestone. 10-12. Jura. 13-17. Cretaccous.
5. Carb. magnesian limestone 18-20. Tertiary (?).
Tind River Basin

21
21

$18 \div$




W.SW

Sta. XXI.

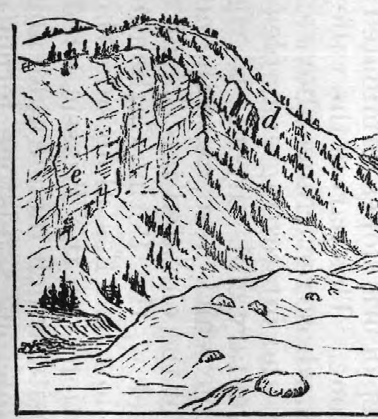

a Archæan. $c$ Quebec

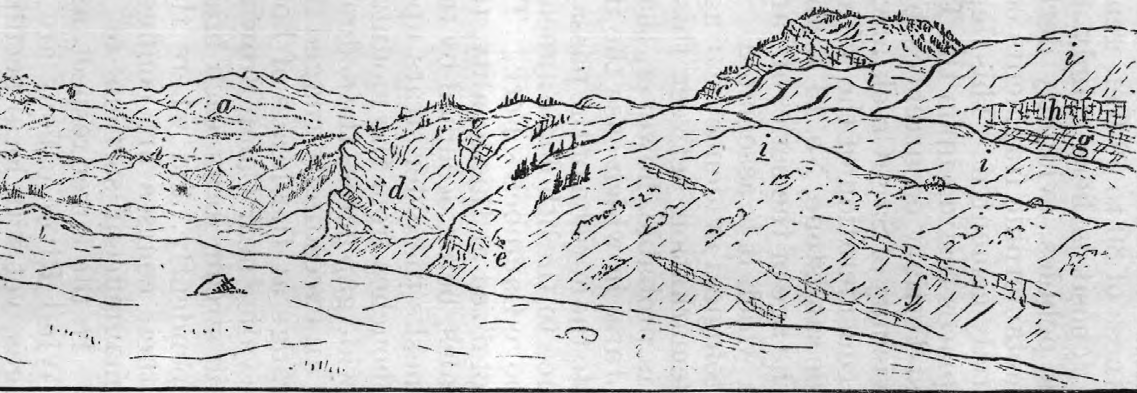

Cañon on North Fork Little Wind River $d$ Carb. limestone. $\quad e$ Carb. sandstone.
$h$ Pliocene (?) conglomerate. $i$ Moraines.
W. (mag.)

Sta. XX.
Plate XIII.

$g$ Triassic "red beds." $f$ Permo-Carb. 
the basin Tertiary series described, in following pages under the head of Wind River Basin.

No: 21. Pliocene, or possibly Post-Tertiary, conglomerate, resting upon the planed-off edges of the unconformable subjacent Mesozoic strata, attaining a thickness of 30 to 50 feet, gently sloping in the direction of the basin. The deposit is here mainly made up of water-worn limestone and sandstone pebbles, evidently derived from the adjacent mountain, few, if any, metamorphic fragments occurring in the deposit, which is more or less firmly cemented. This deposit reaches well up on the outlying slopes, in places resting upon the Trias.

The Tertiary and Post-Tertiary occurrences briefly alluded to in the foregoing section in the vicinity of Sage Creek, are further mentioned in the chapter devoted to the consideration of the Wind River Basin deposits. The fossiliferous Jurassic sandstone, No. 13, is an interesting occurrence, definitely establishing the age of the series of variegated arenaceous and argillaceous strata with which it is associated. It is impossible in the present lack of palæontological evidence bearing on the question to decide where the line of demarkation between this series and the Triassie should be drawn. It is probable, however, that the upper limestone, No. 10, pertains to the Jura, in which case the inferior buff and reddish sandstones would fall into the horizon of the passage beds, offering a somewhat marked resemblance to the lithologic appearances remarked in this horizon in the region above Campbell's Fork. The upper member of the Cretaceous was not recognized at this locality, the uplands lying to the east of the Colorado shales, being occupied by the Pliocene (?) conglomerate formation which masks the older strata upon which it rests.

Little Wind River debonches from the mountains a little north of the parallel $43^{\circ}$, opening a wide gap across the sedimentary plated mountain ridge, exposing to view an exceedingly rugged Archæan region outlying the main crest of the range at the heads of both the North and South Forks, as seen from the valley near Camp Brown. Just without the foot of the mountain the main stream forks, each branch penetrating the interior of the range independently, and where they break through the outer mountain ridge their courses are confined between stupendous walls, which disclose magnificent sections of the upraised Palæozoic series from top to base. In the latter respect, as also in the scenic concomitants, the Little Wind River cañons are much like those mentioned in preceding pages, yet with local peculiarities sufficiently striking to arrest the attention and stimulate the desire for more intimate acquaintance with the locality.

The cañon of the South Fork, which lies mainly south of $43 \mathrm{~d}$ parallel, appears to be the narrower of the two, though the mountain basin in which their sources lie is much the same. About three miles above the debouchure of the North Fork the stream is confined to a narrow defile hemmed in by steep débris slopes terminated above in vertical walls of Carboniferous limestone. This part of the valley is swept nearly clean of the morainal deposits, whose recurrence above and below exhibits some of the most stupendous and interesting examples of their kind. Above the narrows the sedimentary cliffs diverge to right and left, rising up into the crest of the ridge which here, as to the north, forms a rim defining the Archæan area of the elevated interior of the range. At the entrance to the cañon below, the Permo-Carboniferous and upper limestones outcrop in the low benches alongside the stream, but no good exhibitions of the junction with the Triassic "red beds" were met with. Underlying these deposits, which incline at an angle of about $12^{\circ}, \mathrm{N} .52^{\circ}$ E., the middle Carboniferous sandstone formation appears, gradually 
rising on the mountain flank; but immediately bordering the valley on the north side, to which the present examinations were confined, it has been much eroded and heavily loaded with morainal deposits which reach high up on the mountain foot in the debouchure. In the opposite side, however, this horizon is well displayed together with its relations to subjacent formations. About opposite the narrows a sudden flexure or up-bending in the lower limestone formations takes place, where the strata are tilted at a high angle, the tension accompanying their abrupt displacement manifesting its intensity by the rupture and faulting of certain beds, while the continuity of other and less refractory strata was unaffected. As seen from the summit of the ridge, looking down along the mountain flank to the north, a slight undulation in the declining strata was the only evidence of the continuation in that direction of the flexure which forms so marked a feature in the cañon-walls. Above the flexure the strata resume their former moderate inclination thence to the summit of the ridge. This highland region abounds in excellent pasturage, and along the streams considerable tracts of mountain meadow are met with. The rugged slopes are well stocked with evergreen forests up to a line nearly corresponding to the altitude 11,000 feet above the sea.

After leaving the mountains Wind River flows through a broad fertile valley, in the midst of which Camp Brown and the Shoshone Indian Agency are located. The altitude at the debouchure of North Fork is about 6,730 feet, the stream descending to 5,700 feet at the military post, in a distance of about twelve miles. The north side of this valley is bounded by the outlying uplands which break down in grassy declivities, in which the geological formations are in the main concealed from view by the loose soil. Here and there, however, over comparatively limited areas, the component strata crop out, and with care a detail section might possibly be made connecting the basin deposits with those more clearly shown along the foot of the mountains. Two or three miles below Camp Brown, and perhaps twelve or fourteen miles distant from the mountain foot, there appears an anticlinal fold with indications of a sharp synclinal on the west flank, which has brought up a series of variegated arenaceous and clayey deposits which, lithologically, bear striking resemblance to lower horizons occurring in the Jura of this region. On the west slope of this anticlinal the occurrence of drab fragmentary limestones, red and drab clays, and soft buff and grayish sandstones are certainly more in concordance with the stratigraphy of the Jura than with that of the Cretaceous members met with farther north, as described in foregoing pages. At the locality examined the axis of the sharp synclinal fold is occupied by an apparently heavy deposit of reddish and drab clays with associated sandstones, to the west of which obscure exposures of drab clays and soft arenaceous deposits, inclining eastwardly, seem to merge into the dark drab Colorado shales that appear in their proper stratigraphical order in the upland bench rising up against the foot of the mountains. The broad, shallow depression through which the Sage Creek drainage seeks Little Wind River marks the axis of the auticlinal fold, in the crest of which is located the bitumen spring which was described by Dr. Endlich in the Report of the United States Geological Survey for the season 1877. The flow of water is feeble, bubbling up in several hardly discernable vents, around which the bitumen is deposited, forming sheets whose consistency in the margin of the overflow becomes the hardness of an asphalt pavement. The spring is slightly raised above the general level of the plain, averaging perhaps 50 yards in diameter, and is partially overgrown with tall grass. . Birds and small Indians, frequenting the place for water and sport, not infrequently become entangled and 
Plate XIIV.

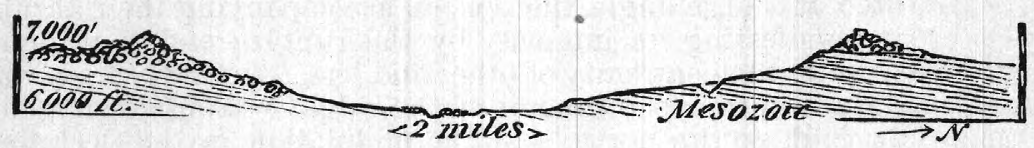

Lateral moraines debouchure Bull Lake Fork.

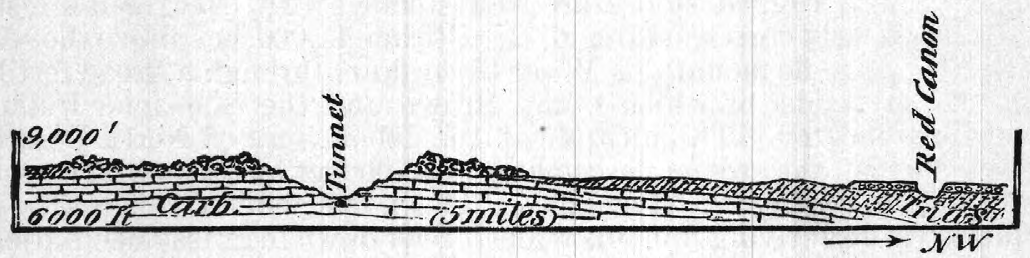

Lateral moraines debouchure Campbell's Fork.

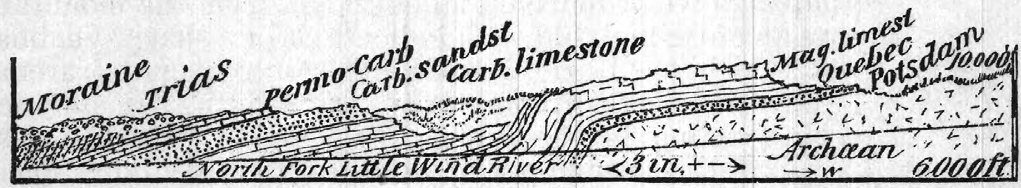

Flexure in Paleozoic strata, south side N. Fork Little Wind River.

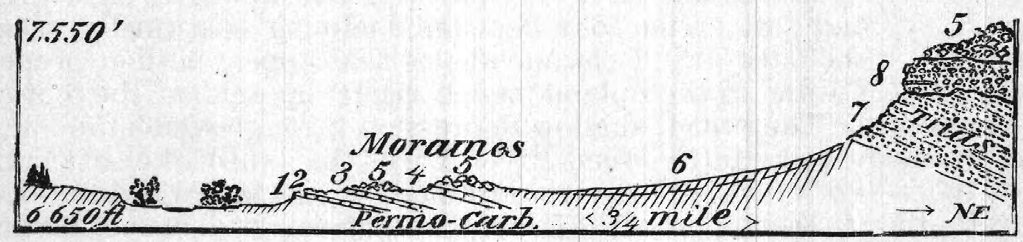

Section north side debouchure N. Fork Little Wind River. 



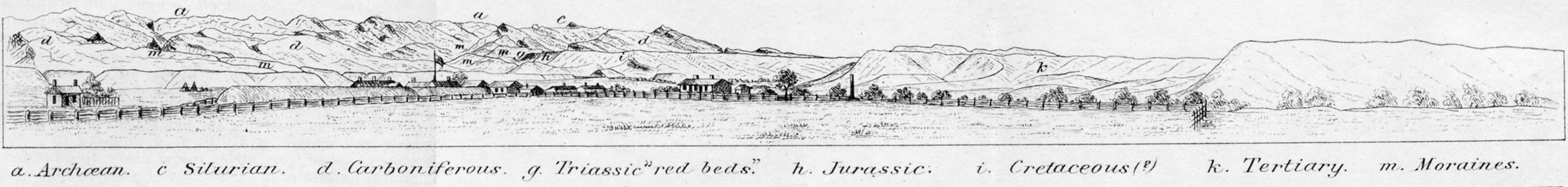

SECTION VICINITY OF NORTH FORK LITTLE WIND RIVER.

EAST FLANK WIND RIVER MTS. Sta.XX.
BASIN FOLD.

CampBrown. Bitumen Spring.
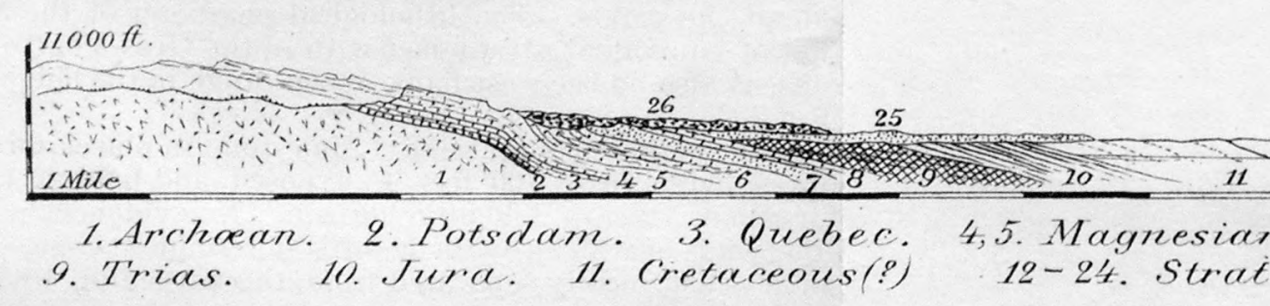

9. Trias. 10. Jura. 11. Cretaceous(?)

4,5. Magnesian limest. 6. Carb. limest. 12-24. Strata involved in Basin Fold.

\section{Plate 45.}


besmeared in the soft, viscous substance. On the east side of the repression the successive ranges of low, parallel bluffs that appear fartier out in the basin show sandstones and variegated clays, and finally a heavier mass of brownish drab clays, all dipping gently eastward. The latter deposits may be identical with the Colorado group. The abovementioned anticlinal was traced but a few miles to the north of Little Wind River, but to the south, where it was examined by Dr. Endlich during the previous season, it assumes a more important topographical position, where its geological structure may be studied under less unfavorable circumstances than those attending its exhibition in the present quarter.

The geologie section in the vicinity of North Fork of Little Wind River is given below, together with notice of the few observations made in the basin area to the east, supplemented by the diagram illustration of an accompanving plate, with which closes the account of the too briefly executed observations in this important mountain range.

\section{Section vicinity of North Fork of Little Wind River.}

No. 1. Archran. Mainly schistose rocks.

No. 2. Potsdam. Coarse-grained, grayish-buff, reddish-stained, in places of a dark-red color, thin-bedded saudstone, with oblique laminated layers, and locally quartzitic. The greatest exposed thickness of this ledge probably does not exceed 50 feet, but it is probably much thicker. Its contact with the metamorphic rocks was not revealed, and the nature of the overlying deposits, which readily yield to atmospheric erosion, are not conducive to the exposure of the full vertical extent of the horizon. In the isolated outliers crowning the heights north of North Fork drain. age, the beds incline about N.570 E., at an angle of $10^{\circ}$.

No. 3. Quebec. Ledges of drab, fragmentary, thin-bedded limestone, showing mural exposures of 10 to 25 feet at top, where at one point it appears in the summit of the mountain ridge, showing a heavy bed of drab-gray, yellow-mottled, even-bedded limestone, with brecciated and oölitic layers, containing fucoid-like markings in relief, in form also resembling certain ramose forms of the coral Chotetes, and the glabella of a large Trilobite. These occurrences, which are separated from the preceding sandstone, No. 2, by a space probably occupied by shaly passagebeds, are met with in a vertical space not exceeding 400 feet. The ledge in the summit of the ridge dips $100, \mathrm{~N} .52 \circ \mathrm{E}$. The horizon appears in a long line of rusty-weathered mural exposures in the escarpment on the south side of the cañon. The lithological character of the rock is precisely that of equivalent strata met with in the Gros Ventre and Téton Mountains, as also on the west flank of the range in the neighborhood of Green River Cañon.

No. 4. Buff-weathered maguesian (?) limestone, in places, forms a rather well-marked ledge, 75 to 100 feet \pm , exposed, and holding the position. of the so-called Niagara dolomitic horizon. - No evidence, however, was gained by means of which to satisfactorily determine its age. The above ledge is, at least, locally separated from the preceding by slopes over soft dirty-buff deposits.

No. 5. Carboniferous. Grayish-buff, rough-weathered, heavy-bedded magnesian limestone, with small jasper nodules and iron concretions, weathered in castellated shapes and forming a prominent ledge in the escarpments either side of the cañon, 200 feet, more or less, in height. Contains Zaphrentis, crinoidal fragments, Bellerophon, \&c., apparently referable to Carboniferous forms. 
No. 6. Drab and gray limestone, forming a heavy deposit several hundred feet in thickness, as seen in cliffs on the south side of the cañon.

No. 7. Buff-gray sandstone, with obliquely-bedded layers, exposed in the lower escarpments, especially on the south side of the cañon and in adjacent mountain flank, 300 feet \pm .

No. 8. Upper Carboniferous limestones and Permo-Carboniferous horizon, the latter showing at one place in the debouchure of the cañon, below : Light-gray, in places, magnesian limestone, 5 to 10 feet exposed; dark-gray, shaly sandstone with silicified fossils, exposed 4 feet; drab and dark-gray, compact and porous, thin-bedded limestone, exposed 5 feet, containing numerous casts of a small Pleurophorus, besides a large Bellerophon, \&c.; light-gray, thin-bedded cherty limestone.

No. 9. Triassic "red beds," composed of deep-red shaly sandstones and arenaceous shales, and reddish-buff or gray soft sandstone with ripple-markings. The exposures in the bluff just without the cañon show a thickness of several hundred feet (700 to 1,000) of this horizon, the strata (iipping at an angle of $13 \circ, \mathrm{N} .27^{\circ}$ to $42^{\circ} \mathrm{E}$.

No. 10. Jura. Variegated pale-reddish and drab deposits, as seen at a distance in obscure exposures occurring in grassy slopes. These deposits occupy a wide belt outlying the Triassic "red beds," and may reach a thickness of 1,000 feet.

No. 11. Cretaceous. Dark-drab (clays), and above light-buff (sandstones and clays) deposits appearing in more or less distinct belts lying beyond the preceding, and probably including the Colorado and Fox Hills members of the series.

No. 12. Drab clays, in bluff north side of Little Wind River, just below Camp Brown.

No. 13. Greenish-gray, coarse-grained, rather friable sandstone, with layers of reddish-brown weathered firmer sandstone, associated with reddish-drab clays and light-drab indurated clay shales. The above deposits outcrop in low, upland declivities to the northeast and 200 feet above Camp Brown, where they incline to the northeast at an angle of $30^{\circ}$ to 340. The sandstone contains partially silicified fragments of fossil wood.

No. 14. Soft buff sandstone, dip steep to the northeast.

No. 15. Reddish and drab elays.

No. 16. Drab fragmentary limestone, 5 feet \pm , dip $70^{\circ}, \mathrm{SW}$.

No. 17. Red shales and soft sandstone.

No. 18. Gray and yellowish, cross-bedded, soft sandstone, 50 feet \pm , $\operatorname{dip} 40^{\circ}$ northwestward.

No. 19. Reddish and drab clays.

No. 20. Drab fragmentary limestone, exposed 4 feet.

No. 21. Greenish-gray, reddish-stained, soft sandstone, associated with red and drab clays, dip $410, \mathrm{~W} .52^{\circ} \mathrm{N}$.

No. 22. Soft, greenish-buff, reddish-stained sandstone, and red arenaceous shales, exposed 50 feet \pm , dipping gently northeastward.

No. 23. Gray sandstones, as seen at a distance, in low bluffs.

No. 24. Heavy deposit of drab clays and indurated layers, compared with the Colorado group of the Cretaceous, appearing in "bad-land" bluff slopes.

No. 25. Loosely compacted conglomerate, consisting of rounded Archran bowlders and pebbles, with local thin layers of soft buff sandstone, the general appearance of the exposures showing obscure stratification, nearly horizontal, deposited upon the eroded edges of the inclined Mesozoic formations and reaching up nearly to the mountain foot. Compared to modern or possibly Pliocene accumulations. It is overspread with later morainal deposits.

No. 26. Morainal deposits. 



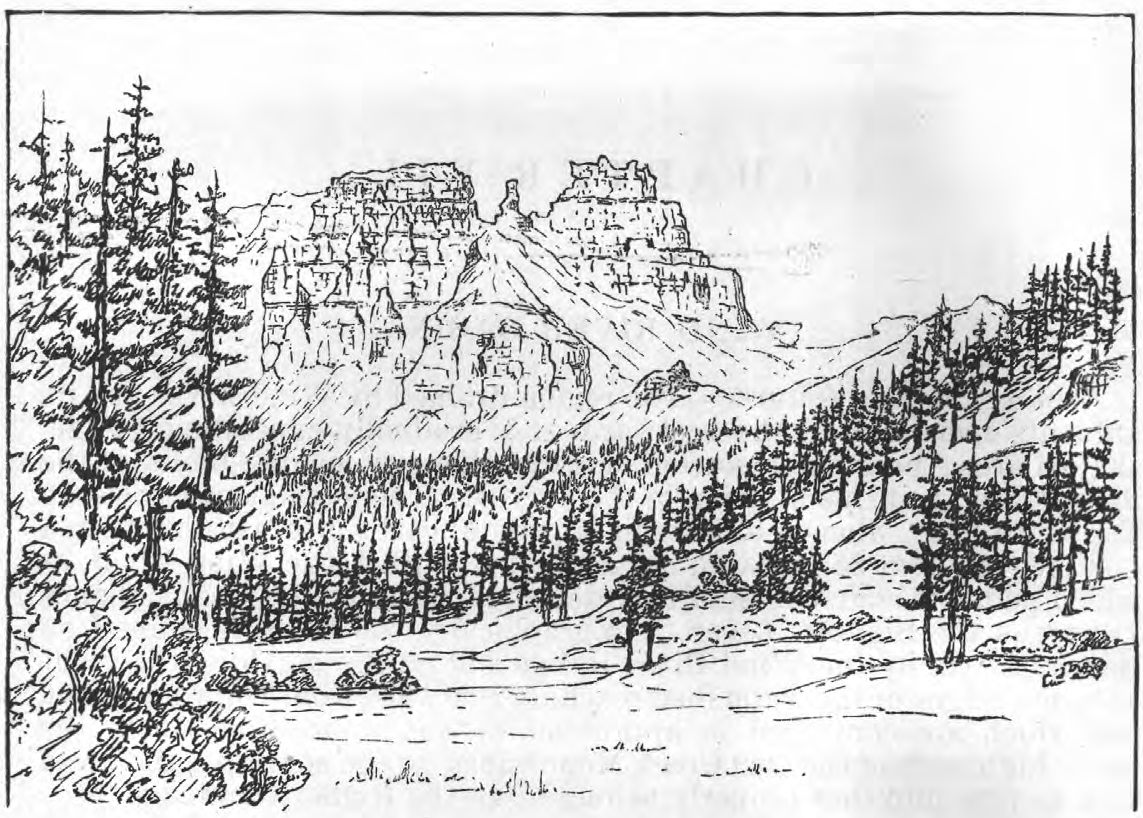

Statue Butte.

Wind River Valley.

Sierra Shoshone, NW.

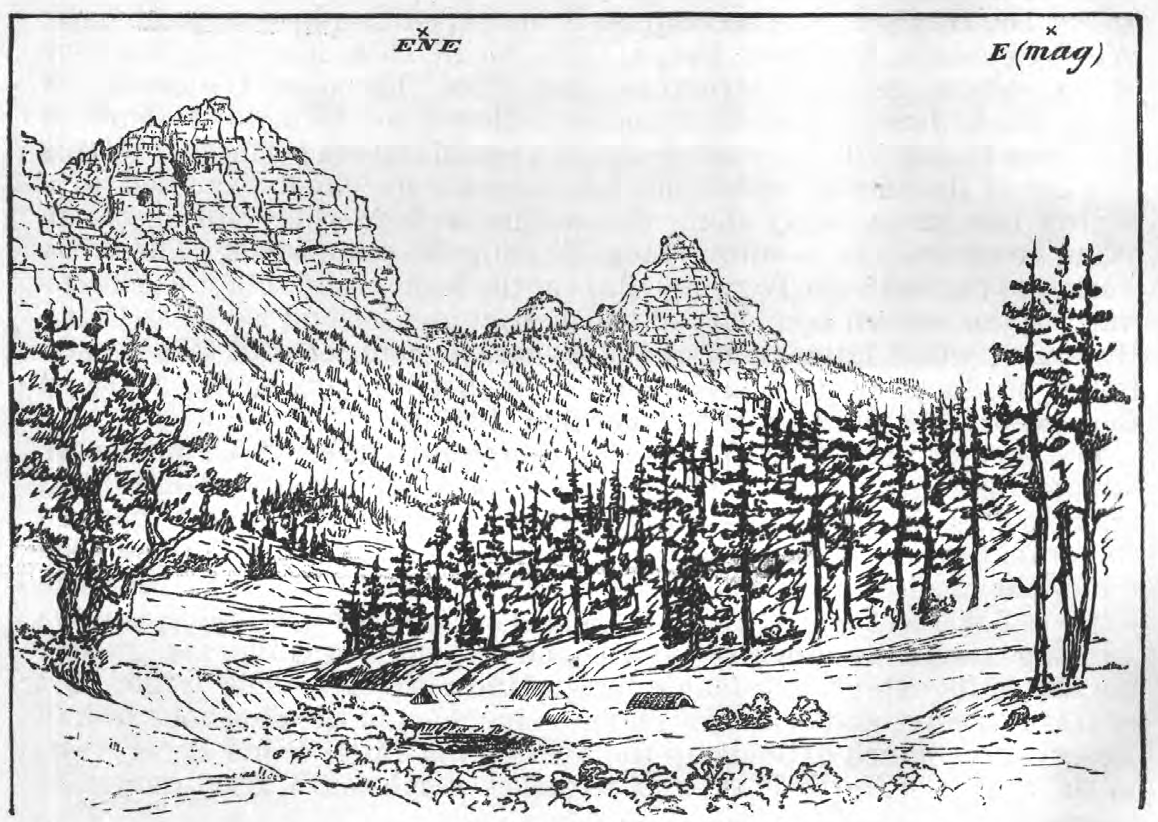

Togwotee Pass.

Clover flats.

Source Wind River.

Volcanic tuff, sunds, breccia, and conglomerate. 


\section{H A P T E R V I I}

\section{WIND RIVER BASIN.}

Area andsurface features.-The region drained by Wind River and its affluents opens out to the eastward in a gradually expanding wedgeshaped area, the greater portion of which lies beyond the limits of the district assigned this division of the survey. The main stream rises in Togwotee Pass, whence it flows in a general east-southeast direction, a distance of about 85 miles, to its confluence with Little Wind River, at which point its course is suddenly deflected northwards, and is thence known as the Bighorn River. Orographically the basin is defined on the southwest by the Wind River Range and on the north by the great volcanic ridges of the watershed reaching eastward from Togwotee Pass, and which are continued in approximately the same direction in the lower highlands of the Owl Creek Mountains ; to the southeast the basin area merges into that properly belonging to the Bighorn drainage.

The region above outlined has in years past been visited by various expeditions conducted under the auspices of the United States War Department, and to the published reports of these explorations we owe the most authentic accounts of its general topographic and geological features. Dr. Hayden, who accompanied the expedition in charge of Capt. W. F. Reynolds, Engineer Corps, U. S. A., in 1859, has giren account of its salient geologic structure, and Prof. Theodore Comstock, of Capt. W. A. Jones's expedition to the Yellowstone, 1873, has elaborated the same theme. The actual geological examinations performed by this division of the survey within this basin area were chiefly confined to a narrow belt immediately along the southwest border, or lying between Wind River and the mountain range bearing the same name. The latter work was carried from Togwotee Pass at the head of the valley southeastward to the eastern boundary of the district and beyond as far as Camp Brown, at which latter point the observations connect with those made by Dr. Endlich the previous season in the district lying to the south of the parallel $43^{\circ}$ and east of the meridian $109^{\circ} 30^{\prime}$.

The greater portion of the basin is thoroughly watered by numerous streams that rise in the bordering mountains, its terraced valleys and upland plateaus being generally clothed with nutritious herbage. In the lower portion of this area, however, more or less of its surface falls under the head of "bad lands." Its general surface lies at an altitude 5,000 to 7,000 feet above the sea ; the lower valleys in favorable seasons yielding abundant crops of cereals and vegetables, while the greater portion of its extent is valuable for grazing purposes. The larger part of this extensive and beautiful region is included in the Shoshone Indian Reservation, which extends up the valley from Little Wind River west, to the mouth of North Fork, and stretches north-south, from mountain to mountain.

Geological features.-In that portion of its course lying within the present district, Wind River flows close along the foot of the southwest bor- 
der range, the lands on the north rising in great upland benches that oceupy the wider interval lying between the main stream and the mountains on that side of the basin. The upper half of the course of the main stream is eroded out of the soft Tertiary strata, the remainder of its course to a point below the mouth of North Fork elosely conforms to the demarkation between the Mesozoic and Tertiary formations, the latter oceupying the whole of the basin area lying to the north of the river. At one point, in the neighborhood of $\mathrm{Du}$ Noir or Willow Creek, the stream touches the Paleozoic mountain flank, where for a short distance it flows in a narrow gorge walled by Carboniferous sandstone.

This narrow belt of Mesozoic and Paleozoic strata along the southwest border of the basin has already been noticed in the account of the geology of the eastern flank of the Wind River Range, to which it properly pertains, geologically. The stratigraphical relations of the two sections are uninterrupted and most intimate; erosion in preglacial time having swept away the unconformable Tertiary deposits, exposing to view the older formations over quite e:tensive areas in the interval lying betwecn the river and the mountain flank. During the glacial epoch, when the mourtain gorges were filled to the brim with moving bodies of ice, vast quantities of erratic materials were transported from the interior of the mountains and spread out in orderly disorder over the bared sedimentary formations in the slopes along their foot. The latter accumulations are conspicuously displayed in the embouchures of all the streams that rise in the interior of the range as far south, at lerst, as Little Wind River. But, perhaps, their most extensive exhibition is found in the debouchures of Bull Lake and Campbell's Forks, and on Torrey's Creek, where the drift lies scattered over broad areas and reaching perhaps a thousand feet up on the mountain side, their occurrence everywhere clearly displaying their origin. Besides the huge morainal ridges flanking either side of the debouching mountain valleys, the adjacent mountain slopes are corrugated with the peculiar short ridges composed of loose materials which were borne to their present resting: places by glacial agents.

Concerning, therefore, the remaining geologic characteristics of the basin area, there only remains to be noticed the great Tertiary formations that are known to outcrop over the greater portion of its surface, and such Quaternary and modern deposits as were observed the present season.

In a previous report, as also in preceding pages of the present report, allusion has been made to the great volcanic-capped watershed in the vicinity of Togwotee Pass, and in the chapter devoted to the Gros Ventre Basin, brief mention was made of the geologic components of that portion of the watershed lying between Togwotee and Union passes. The latter forms a low mountain barrier, separating Wind River from Gros Ventre drainage, and, as previously stated, it is almost entirely made up of Tertiary formations. The ridge, however, retains the volcanic capping to a point perhaps 10 miles south-southeast of Tog'rotee Pass, and remnants of the same sedimented volcanic ejectamenta were found crowning low eminences on the summit still farther south to within 6 miles of Union Pass trail. On one of the latter points Station XXVIII was made, which has an altitude of 10,142 feet above the sea.

Soon after leaving the summit of Togwotee Pass, the nascent stream begins to erode its bed into the soft deposits that underlie the great volcanic accumulations, and which appear in bluffs of gradually increasing height as low down as the confluence of the first considerable affluent from the north, just below which, or some 12 miles from its ulti- 
mate source, the stream emerges into a meadow-intervale, at which point the valley proper may be said to begin. In this distance the stream has made a descent of about,1,800 feet. Towards its source the bluff-banks show limited exposures of brownish green arenaceous deposits, with indurated streaks of sand and pebbles, dipping at a slight angle northwards. At one point these deposits are seen to overlie a conglomerate ledge composed of water-worn quartz pebbles held in a fine arenaceous paste, the whole being stained a green tint probably by iron infiltrations. This conglomerate is identical with similar occurrences along Black Rock Creek on the opposite side of the watershed, rem nants of which were found on the summit of the watershed to within a few miles of Union Pass. In all, save its green color, it bears close physical resemblance to the great conglomerate elsewhere noticed as occurring in the Tertiary area of the Gros Ventre Buffalo Fork Basin. Its relation to the great volcanic deposits that make up a thousand feet and more of the heights on either side of the pass is not clearly manifest, nor are its relations to the beforementioned conglomerate of the Gros Ventre Basin any better displayed.

Lower down the stream the greenish arenaceous deposits continue to appear, often forming bluff's of an hundred feet and more in height, and apparently gently inclined in the direction of the stream. At a locality 6 or 7 miles from the summit of the pass and about 1.100 feet lower, the abrupt terrace-face shows practically horizontal layers of greenish-gray, . coarse and fine grained earthy sandstone with thin seams of dark carbonaceous clay, the earthy layers yielding imperfectly-preserved leaves and stems of plants. Amongst these remains Professor Lesquerenx doubtfully recognizes a Ficus, whose relations seem to be rather with forms prevalent in the Green River Tertiary group than with those occurring in the Laramie formation. The greenish arenaceous deposits are here associated with lighter-colored strata of similar composition, which latter increase in relative importance as we descend the stream.

A mile or so below the above locality, the steep bluffs bordering the north side of the stream show a ledge of coarse conglomerate interbedded with thin, irregular layers of greenish-gray, soft sandstone, overlaid by yellowish sandstones. The conglomerate outcrops 40 feet above the water, and in lithological appearance it bears marked resemblance to the Tertiary conglomerate on the Gros Ventre and Buffalo Fork. Above the confluence of the first considerable north affluent, the bluffs on the main stream show 100 to 200 feet thickness of light-yellow soft sandstone, and gritty clays with shaly gray sandstone above, the whole aprently in nearly horizontal position.

The north side of the stream for several miles, both above and below the confluence of the north tributary, is bordered by a high bench or terrace, which is made up of the abore-mentioned stratigraphic exhibitions. The slope on the opposite side is more gradual, and for the most part densely wooded. At a point perhaps a couple of miles below the confluence, or 13 miles distant from the summit of Togwotee Pass, the terrace, which is here 500 feet above the stream, exhibits several ledges of soft buffgray and greenish-tinted coarse-grained sandstone, in places shaly or thin-bedded, with pebble layers, and interbedded with soft arenaceous clays. No fossils were observed in these beds, which have a slighteasterly or northeast inclination. A little lower down the valley, which here opens out into a considerable meadow tract, the gentle lower slope of the bluff's reveals obscure exposures of pale-red clays, forming thin bands seldom more than a few inches in thickness included in greenishdrab clays. A mere glance, without reference to their associated strati- 
graphic relations, might lead the observer to identify these horizons with the Triassic " red-beds," the first authentic exposures of which, however, are only met with at a point several miles lower down the va!ley in the neighborhood of Warm Spring Creek.

From the summit of the terrace a broad, shallow depression, occupied by a small stream flowing eastward, and probably tributary to the milky affluent that joins Wind River a few miles above Du Noir Creek, is overlooked, beyond which rises a considerably higher outlying bench on the flank of the great volcanic mountains whose sedimented horizontal ledges tower hundreds of feet above in magnificent architectural mountain forms. The abrupt southern declivity of this outlying bench, as seen from a distance, appears to be composed of more or less indurated. deposits, including a heavy bed of dull brick-red color, and above a rusty weathered ledge which is in turn overlaid by light ash-colored earth reaching up into the summit. The vertical extent of these deposits, which are nearly horizontal, is estimated at 500 to 800 feet, while both from their position and lithologic characters they are doubtless ideutical with the greenish arenaceous beds met with along the upper course of Wind River. Their relations to the volcanic mountain borders both to the north and southwest, and the inferior creamy-yellow sandstones is shown in an accompanying profile section of the valley along a line extending northeast from Station LI (1877) on the watershed on the south side of the valley.

North of the point where the small parallel tributary leaves the first terrace bench and enters the undulating, grassy region lying just to the east, a considerable thickness of banded bluish-drab and red deposits appears in low bluff's along the broken eastern edge of the terrace. The above exposures occupy a sort of recess in the lower terrace level, to the west and north of which the acclivities rise up into the higher bench, which here shows obscure, pinkish-(lral, red-streaked exposures. The probable stratigraphical relations of the banded variegated beds here alluded to will be referred to further on. To the northeast, brownish earthy deposits appear in a somewhat higher bench, and in the lower slopes, descending from the volcanic mountain ridge, quite extensive tracts are occupied by light drab, clayey deposits in the region of the upper course of Du Nioir Creek.

The above mentioned terrace is continued along the north side of Wind River, east, to within perhaps 3 or 4 miles of the mouth of Du Noir Creek, where it assumes the character of a high morainal bench, jutting into the valley. It is, however, somewhat lower, interrupted by short drainage depressions, and at a point perhaps 4 or 5 miles above Du Noir Creek it is cut by a smaller affluent whose waters are charged with milky-colored sediment. The latter phenomenon is doubtless attributable to the wash of white earthy deposits which were observed to occupy a considerable area some miles to the north, or northwest, in the region of the sources of this stream. But as we descend the valley, the blutf's gradually increase in elevation, frequent exposures of the component strata appearing in the more or less steep slopes facing the valley. At a point some distance above the confluence of the sediment-discolored stream, where the blufis approach the river, a thin seam of lignite ontcrops a few feet above the water-level, associated with chocolate-red and bluish-drab clays, overlaid by rusty yellow and grayish shaly sandstones in bluff-face, 150 feet above the stream. The sandstones were observed all along the bluff-face before reaching this locality, appearing in nearly horizontal ledges separated by soil-covered slopes, though in places apparently gently rising to the eastward as the 
Sta L.

Wind River.
Plate XIVII

Togwotee Pass.

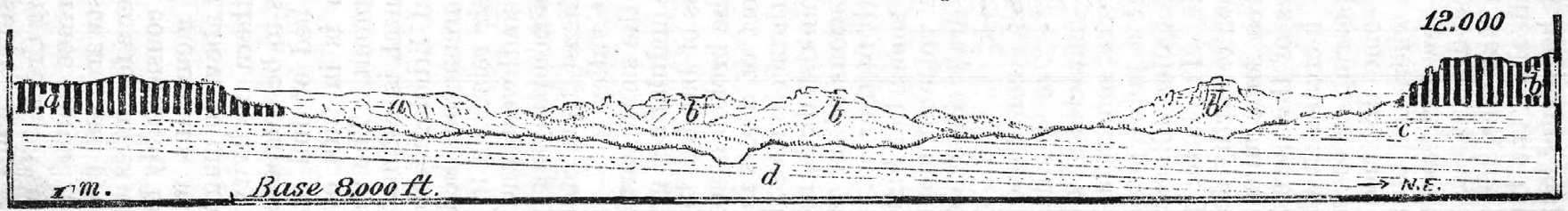

Profile of Upper Wind River Valley and Togwotee Watershed (looking NW.).

$a$ Flowed lavas, \&c. $b$ Sedimented volcanic ejectamenta.

$c$ Green, dull-red, and ash-colored deposits.

$d$ Sandstone, clay, lignite-Tertiary (?). 

stream deepens its bed. Between the latter stream and Du Noir Creek, the north side bluffs exhibit the same series of strata, consisting of rusty-buff sandstones, drab and yellow sandy clays with streaks of red clay, of which a thickness of 250 feet are here exposed. These deposits are overlaid by variegated or banded pale-red and drab clays, showing a thickness of 50 feet or more in the top of the blufts, the whole sloping off to the northeastward at a very gentle angle of inclination.

It was impossible at this locality to determine whether the superposition of the latter deposits is conformable to the inferior lignite-bearing formation, nor was opportunity afterward afforded for the satisfactory settlement of the question. I have also to regret the uncertainty as to the stratigraphic relations of the above geological formations with the previously noticed greenish arenaceous deposits occurring towards the head of Wind River. Indeed, lithologic data, which are quite persistent and reliable in the Gros Ventre region just over the watershed to the west, seem to be confused and less trustworthy guides to the identification of portions of the Cenozoic series as we approach that part of the divide which is surmounted by the great volcanic deposits. The comparatively undisturbed condition of all the geological products, including even the sedimented volcanics, occurring in the region about the sources of Wind River, renders the detection of nonconformities an extremely delicate operation; and when we take into consideration the action of thermic agents accompanying the great volcanic accumulations that were spread out over so vast an extent of the Cenozoic area in this region, we may well hesitate, in interpreting meager data, to assign the appearances here met with to changes akin to those induced by metamorphic agents, or to those other potent agents of geologic change, erosion, and deposition of distinct and unconformable materials. The conglomerates noticed on Wind River certainly bear close analogy to the great conglomerate horizon underlying the upper or Teritary lignitebearing series on the Gros Ventre, 15 miles to the westward. Yet, with the paucity of facts at present in hands, bearing on the detail stratigraphy of the Wind River section, it might be deemed presumptuous to assert the identity of the above occurrences. But when we come to the correlating of the supralignite series represented by the pale-red and drab .variegated or banded deposits, the occurrences in the above-mentioned regions are so alike as regards both their stratigraphic constitution and geological position, that little or no doubt can be entertained respecting the actual identity of the latter deposits in the regions of the Gros Ventre and Wind River basins. The few fossils found in the lignite series of the Gros Ventre Basin here referred to were provisionally compared by Dr. White with Bear River Laramie forms; while the immediately superimposed conformable strata afford a Viviparus paludinoformis (?) which elsewhere characterizes Wasatch Tertiary horizons. Hence, the variegated deposits to which Dr. Hayden gave the name Wind River Group, recognizing their probable Miocene age, are either emphasized variegated upper Wasatch strata or a much later and actually nonconformable member of the Tertiary series peculiar to the region north of the Gros Ventre Mountains, and east of the Wind River Range, in which quarter as yet no Green River Tertiary equivalents have positively been recognized, unless the plant-bearing beds above noticed prove to be of that age. The attempts hitherto made to correlate the Wind River Group have been based on supposed lithological resemblances, I believe, without the aid of palæontological evidence.

Du Noir Creek occupies a fine valley eroded out of Tertiary deposits, in the east side of which variegated red and drab exposures are seen. 
In the uplands to the east the same variegated series occurs over a wide belt extending down the middle of the basin, and is overlaid by obscurely exposed deposits of drab clays and soft yellow sandstones. Just below the Du Noir, the north side terrace closely approaches the stream which has eut a narrow gorge in the tilted Carboniferous sandstones reclining on the flank of the Wind River Mountains, as described in a preceding page. The relations of the basin Tertiary deposits to the Palæozic series in the mountain-flank at this loeality are concealed by drift accumulations mantling the terrace. But in the north side of the expansion into which the valley opens below the narrows, the variegated deposits are exposed on an extensive scale in the deep recess which here penetrates the upland; the soft materials of which they are composed readily yielding to the elements, which have wrought with wonderfully intricate picturesque effects in the sculpture of the barren bluffs that inclose this side of the valley.

A few miles below the narrows, the uplands again approach the stream which here traverses a narrow passage cut into the dark red sandstones of the Trias, which latter form the basis of the outlying terrace along: the foot of the Wind River Mountains. A limited exposure of Jurassic strata occurs in the bench on the north side of the stream, upon which rest the nonconformable variegated Tertiary beds. The latter here rise up into a prominent headland, 600 feet or more in height, which was utilized for topographic purposes the previous season (Station LII, Téton division). These deposits here consist of alternating bands of palered and greenish-drab clays, with irregular or local thin layers of gray and yellow sandstone. The eminence is covered with a thickness of 10 to 30 feet of brown earth and drift materials resting upon the planedoff surface of the variegated beds. The latter here incline to the northeastward at an angle not exceeding $5^{\circ}$; the underlying Jurassie beds dip in the same direction at an angle of $15^{\circ}$ to $20^{\circ}$, the nonconformity being marked as seen in the natural exposures at a distance. It is probable a thickness of at least 1,000 feet of these deposits is seen in the picturesquely eroded area of their occurrence here alluded to, while their total vertical extent may be found to exceed this estimate. The comparatively limited unexposed space intervening between the Jura and variegated Tertiary at this locality is wholly insufficient to admit the heavy series of yellow sandstones and clays of the lignitic series which higher up the valley were found underlying the variegated deposits. Hence, it is reasonably inferred that the lignitic formation was here denuded prior to the deposition of the variegated beds, which at this locality rest immediately upon the unconformable and also extensively denuded Juarissic strata.

Some notion of the distribution of the various geologic formations of the region may be gained from the eminence on which Station LII (1877) was located. The banded Tertiary deposits have extensive areal distribution to the north and east. The great sedimented volcanic ridge, constituting the Sierra Shoshone of Captain Jones, is traced from Togwotee Pass, eastward, along the northern rim of the basin, terminating in a group of lofty pinnaeles lying to the east of the sources of North Fork Wind River, and which are probably the Washakee Needles. From the latter mountain ridge, the $\mathrm{Owl}$ Creek Mountains are separated by a gap, and at their base lies a massive outlying bench in which an enormous thickness of similar variegated deposits is visible. The valleys of Horse Creek and North Fork are excavated in these deposits-their fringes of cottonwood and green shrubs presenting a pleasing contrast to the environing red-striped barren hillsides, in appearance a semibadland region, destitute of more than scant pasturage. 


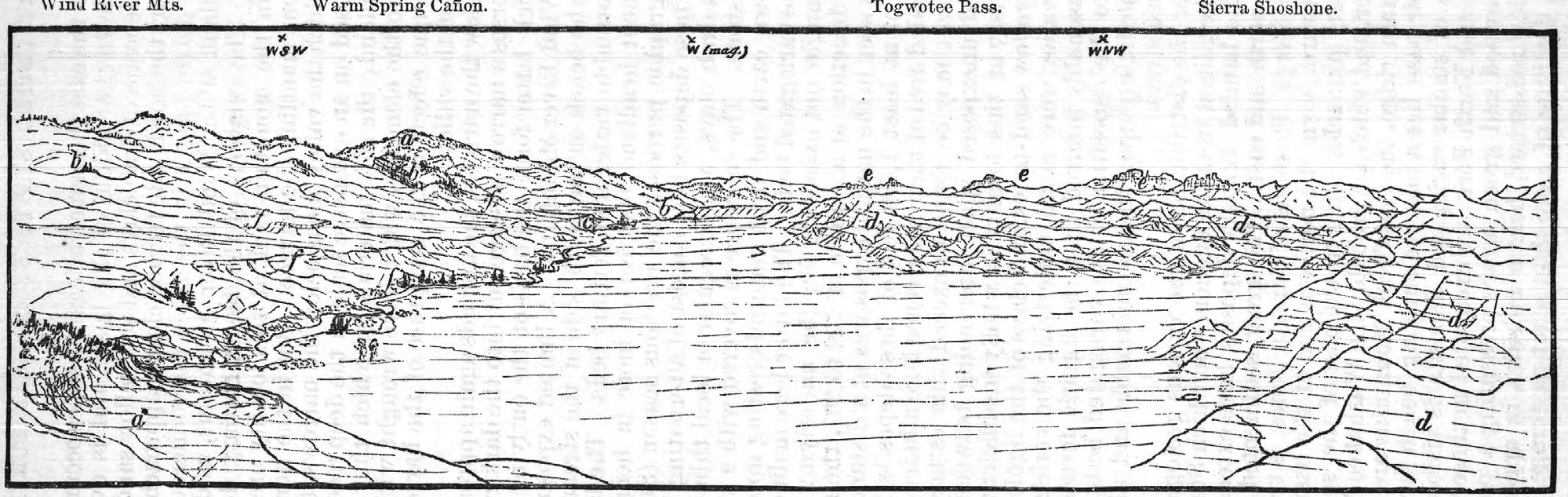
$a$ Silurian.
$b$ Carboniferous.
c Jura-Trias.
Wind River Tertiary.
$e$ Volcanic tuff, breccia, conglomerate.

$f$ Spring deposits-calc. tufa, gravel concrete. 

Below Horse Creek the variegated Tertiary skirts the stream, forming beautifully eroded bluffs 300 feet or more in height, the lower portion showing some discordance in deposition, but not in constituents and general appearance. The coloring matter appears not to have been distributed with perfect regularity, the belts of red becoming locally intensified by the merging of several narrow bands in one, and associated with frequent indurated arenaceous bands, which give rise to a great variety of monumental forms in the weather-sculptured bluff-face. These deposits continue thence along the north side of Wind River to near the eastern boundary of the district. In the vicinity of the confluence of North Fork they are again crowded back some distance from the stream and rest unconformably on the Jura, which at this place crosses to the north side of the river, forming a rather high shoulder outlying the Tertiary uplands east of North Fork.

Above Campbell's Fork, on the north side of the river, there occurs a heavy series of dirty-yellow and drab clays or arenaceous deposits, the stratigraphical relations of which, for lack of time, could not be satisfactorily determined, although they apparently underlie the banded Tertiary, The latter again reaches the stream opposite the confluence of Campbell's Fork, where it forms bluffs 200 to 300 feet high. It is made up of alternating pale-red and bluish-drab layers, often of considerable thickness, the disintegration of which produces a drab soil covering the talus slopes for more than half the height of the bluffs. A couple of miles or so below Camploell's Fork the variegated deposits appear in the terrace on the south side of the river, the red and drab bands alternating with yellow sandstones. The terrace bordering the opposite side of the valley exhibits frequent though rather obscure exposures of the same deposits, showing a preponderance of sandstone layers as we advance, and which are gently inclined in the direction of the descent of the valley, though locally varying in the direction and amount of inclination.

A few miles below the confluence of Crow Creek an isolated hill rises nearly a thousand feet above the level of the valley, forming a prominent landmark, which is known as Crow-Heart Butte. This eminence, which was detached by erosion from a high terrace level lying a few miles to the north, is based upon obscurely exposed variegated deposits, overlaid by a heavy deposit of rusty-yellow sandstones and drab clays forming the middle portion of the butte, upon which rests a somewhat less thickness of similar clays with reddish layers, the summit capped with a heavy ledge of rusty-yellow sandstone. The summit sandstone belongs to a heavy ledge that recurs in the above-mentioned high terrace, while the middle sandstone horizon is the same that constitutes the main terrace bordering the valley. The inferior basis deposits resemble the variegated horizon noticed higher up the valley, as mentioned above. Wherever this region was overlooked from the mountain border on the southwest the above-mentioned deposits always had the appearance of gently rising to the northwest in ascending the valley. Yet these appearances should be taken with due allowance when it comes to determining the geologic relations of the horizons here alluded to.

Below Crow-Heart Butte, as far as the stream was followed, the border bluffs on either side revealed frequent exposures of greenish-yellow soft sandstomes and arenaceous shales with layers of blue clay. The concentrated clayey portions of the rock are often weathered away, forming shallow caverns in the mural exposures. In the vicinity of Dry Creek, a few miles below Bull Lake Fork, rusty buff-weathered sandstones appear in the bluffs on the north side of the ralley, where they are gently upraised to the southwest and overlaid by a considerable 
thickness of variegated chocolate-red and drab deposits. But in the uplands on the opposite side of the valley, over which the road to Camp Brown leads, the horizontal Tertiary sandstones are again met with.

Mention has already been made of some fossiliferous sandstone occurrences, of probable Tertiary age, in the debouchure of Jake's Creek. These exposures are practically horizontal and fill a depression eroded out of the tilted Jura-Trias at the foot of the Wind River Mountains. Below this the Tertiary area is crowded to the north side of Wind River and is not again met with on the south side of the stream until reaching. Campbell's Fork, nine or ten miles to the east-southeast. At the latter locality a series of nearly horizontal drab and dirty-yellow soft sandstones appears in the bluffs bordering the stream for a mile or more, and which extend up the valley to a place nearly opposite the head of the lake, where they abut against the upraised Triassic "red beds" in the mountain flank. The same deposits occur in the bluff borders along all the deeper drainage channels that flow down from the Wind River Mountains between Campbell's and Bull Lake Forks, where they hold the same unconformable relations to the outlying Mesozoic belt at the foot of the mountains. But in the interval between North Fork and Campbell's Fork, where the outlying Mesozoics are projected beyond the mountain-foot in a sort of broad, low arch, across the outer edge of which the main stream has eroded its channel for several miles, the variegated red and drab deposits rest immediately upon the unconformable older formations without intervention of the above-described Tertiary sandstones. It may be urged that the latter sandstones hold a stratigraphic position superior to the variegated deposits, in which case it is evident that the heavy lignite-bearing series of supposed Wasatch Tertiary occurring in the Gros Ventre Basin just over the watershed at the head of Wind River, if not wanting, is so attenuated as to escape recognition in the denuded borders of the lower Wind River Basin.

Bull Lake Fork, immediately it leaves the mountains, exhibits an unusally clear section of the Tertiary sandstones. They here occur very much in the same manner as on Campbell's Fork, impinging at a sharp angle against the inclined Cretaceous strata occurring in the outlying bench at the foot of the mountains. The highest exhibitions of these strata occur in the bluffs about opposite the head of Bull Lake and between 600 and 700 feet above the water-level, the beds showing slight easterly inclination in the direction of the basin. Perhaps a mile lower down, on the north side of the lake, a section showing a vertical thickness of about 400 feet in this horizon was examined.

\section{Section of Tertiary strata on Bull Lake.}

No. 1. Unexposed slope to level of Bull Lake, 145 feet.

No. 2. Coarse, dirty-yellow sandstone, containing pebbles of metamorphic rocks and pockets of green clay, exposed 25 feet \pm .

No. 3. Soft, almost incoherent dirty-yellow sandstone, with thin layers of green clay and small concretions; fragments of fossil-wood in upper part, 250 seet \pm .

No. 4. Buff, coarse-grained, soft sandstone, with greenish arenaceous clays below, heavy-bedded above, and containing regular and irregular shaped sand and ferruginous sand concretions, 125 feet exposed.

No. 5. Brownish-yellow clay or soil, 20 feet \pm .

No. 6. Slope occupied by irregular parallel ridges of morainal materials reaching up into summit 700 feet above level of Bull Lake.

The Tertiary beds are planed off even with the tilted edges of the 
Mesozoic series, forming a gently sloping plane loaded with morainal deposits. The south-side bluffs exhibit less perfect exposures of the same rocks, which extend but a short distance below the lake, whence the border slopes and uplands alike are covered with the loose drift materials all the way to Wind Rirer.

A high bench projects into the basin between Bull Lake Fork and Sage Creek, traversed by two or more narrow drainage channels, in the steep bluffs of which similar exhibitions of horizontal Tertiary strata are met with. In the borders of one of these ravine-like depressions about two miles south of Bull Lake Fork and as far again from Wind River, the exposures consist of soft yellowish sandstones containing vegetable remains like compressed stems, and which are weathered into curious monumental forms by atmospheric erosion. Higher beds apparently belonging to the same series were observed in the divide between Wind River and Sage Creek, in the south slope of which to the west of the depression down which the road passes into the valley of the latter stream, the same soft yellow sandstones reappear, in horizontal position, on the west flank of the outer mountain fold in which the Mesozoics are brought to view.

A few miles to the west-northwest of the last locality, in the high outlying bench, pale red variegated deposits overlaid by drab and greenish arenaceous clay appear in the east side of a wide shallow drainage depression tributary to Sage Creek above the bend. These deposits, constituting here well-marked horizons gently inclined in the direction of Wind River, hold a position superior to the dark drab clays of the Oretaceous Colorado Group, and to the northeast they pass beneath the abovementioned soft yellow sandstones that occupy the interval extending over to Wind River. The geological relations of these horizons are obscured along the line of contact with the subjacent Colorado shales, where they have been eroded and overlaid by the unconformable conglomerate of Pliocene, or possibly Post-Tertiary age. This interval may well embrace the horizon of the Fox Hills Cretaceous, which shows characteristic exposures in the bluffis above Bull Lake. Lithologically, the deposits here alluded to recall the exposures on Wind River in the vicinity of Dry Creek, where. as has been stated in a preceding page, similar reddish and drab horizons occur, resting upon a heavy ledge of buff sandstone, which is gently upraised to the southwest. The local appearance of the above-mentioned deposits is shown in the profile section representing the mountain flank in the vicinity of Sage Creek Cañon. At the time of the examinations in this quarter it was the impression that the reddish variegated beds here alluded to were one and the same with the great formation of similarly colored variegated deposits that constitute so important a geologie feature in the mid-basin area a little higher up Wind River.

Post-Tertiary.-In the area of the basin region, even including the mountain border, it is probable that comparatively slight changes in the pre-glacial surface contours have been effected by the erosive agents that have wrought during and since the glacial epoch. Speaking in general terms, the conntry here alluded to has probably suffered to greater extent changes in its surface configuration due to fluviatile and those other potent atmospherical denuding agents than that produced by glacial action. The latter has evidently acted with greater effect as a degrading force in the high mountain regions, while.in the lower border region it was chiefly confined to a transporting function. In this latter respect the results are grouped about the debouching cañons, where they may be advantageously studied as so many local exhibitions of a part of the phenomena of glacial action. The great ice-flows naturally sought the 
depressions already existing, down which they slowly moved bearing and pushing along their burden of detrital materials, which were unloaded and built into the huge morainal ridges filling lateral depressions along the mountain course of the glacier and piled up on the surface in the edge of the plain. These occurrences furnish the most legible evidence of the magnitude of the individual glaciers descending along the eastern lank of the Wind River Range, which in some instances extended beyond the mountain foot a distance of several miles out into the basin.

While denuding agencies of one kind or other have wrought with startling effects, carving out stupendous mountain forms and broad valley depressions, the phenomena resulting from these actions, as seen to-day in the region of the sources of Wind River, present comparatively small evidence of glacial origin. This may be attributable to the soft nature of the geological formations in that region, but the glacial deposits which were here found are much less conspicuous than those met with along the foot of the Wind River Mountains. However, the occurrences along the upper course of Wind River present the same evidence of the local extent of the glaciers as those met in the mountain borders to the south. The erratic materials along the stream as far down as Warm-Spring Creek may be traced to the conglomerate and great volcanic conglomerate and lava formations, that encircle the head of the valley. The materials consist almost exelusively of the various sorts of volcanic rocks, basalt and trachytic lavas, found in situ in the mountain summit about Togwotee Pass. They have been distributed by transporting agents as far down the valley as North Fork, at least, though below the confluence of Warm-Spring Creek they are mingled with other kinds of rock débris derived from the Wind River Mountains, becoming less and less conspicuous and finally disappearing as a component of the superficial detrital deposits along the stream.

Above Du Noir Creek, the upland benches a few miles north of Wind River are sparsely covered with water-worn erratics consisting chiefly of volcanic rocks, and sparingly of fragments of reddish-white laminated quartzite and dark drab limestone resembling ledges occurring in Carboniferous and Jurassic horizons, and which evidently were brought down from the mountains lying to the north. But for the most part these upland slopes are covered with light sandy soil derived from the disintegration of the subjacent soft arenaceous Tertiary deposits. Above Du Noir Creek the uplands are more thickly strewn with water-worn volcanic bowlders which embrace all the varieties of these rocks occurring in the watershed around Togwotee Pass, the deposit having much the appearance of morainic origin. The wide intervale at the confluence of $\mathrm{Du}$ Noir and Wind River is paved with these erratics.

Just below in the neighborhood of Warm-Spring Creek, glacial phenomena, so far as they are dependent on morainal deposits for their recognition, are perhaps not of the most conclusive character. The mountain side at an elevation of 600 feet above the valley is strewn with unevenly dispersed accumulations of probable glacial origin. The loose materials consist of a rariety of metamorphic rocks such as occur in the interior portion of the range, together with limestone fragments from the outer flank of the mountain. But lower on the slopes or in the benches bordering the basin, these abraded erratics are spread out in well-defined terraces where they have been transformed into a sort of conglomerate by calcareous infiltrations from springs, with which are associated a variety of interesting phenomena.

It is difficult to decide the relations of the bowlder deposits in the 
terraces vicinity of Warm-Spring Creek to the undouloted glacial deposits. They appear in terraces along the south side of the river, at elevations of 150 feet or more. The deposit is composed of well-rounded fragments of volcanic rocks, limestone, quartzite, and occasional granitic pebbles, obscurely bedded, with thin sheets of sand. The impression derived in the course of hastily made examinations was that these deposits antedate the glacial epoch, in which event they might properiy be relegated to the Plioceno. Their consolidation might have taken place at a much later date from calcareous matter deposited by percolating spring-water.

In the vicinity of Jake's and Torrey's Creeks, the morainal deposits are on a scale of great magnitude, presenting all the characteristic phenomena usually associated with glacial accumulations. The outlying terraces are strewn over a wide area with this vast accumulation of erratic materials, reaching from the river back to the mountain where they oceur at an elevation of several hundred feet above the valley. In the constitution of the deposit metamorphic bowlders largely predominate, with which are sparingly associated fragments of limestone and quartzitic sandstone belonging to readily recognizable formations plating the neighboring mountain flank. The region occupied by these deposits forms a sort of high bench either side of the debouchures of the streams, the surface roughly furrowed just as the material was discharged from the glacier. Remnants of the glacial deposits occur on the north side of W'ind River below the mouth of Torrey's Creek, where they are seen clinging to the steep bluff slopes over the variegated Tertiary formation.

To the southeast the mountain slope is again unmasked until reaching Campbell's Fork, where similar morainal deposits are met with, though on a less extensive scale. At the latter locality the erratic materials are piled up in well-defined lateral morains on either side of the stream as it leaves the mountain, and which extend all the way to Wind River a distance of nearly 4 miles, where they are spread out in irregular low benches. The moraines rise up on the foot of the mountain attaining an elevation of near 8,400 feet, or 1,000 feet above Wind River. In the gorge across the sedimentary ridge the Carboniferous limestones at one point form a natural bridge, and everywhere in the barred surfaces the rock still retains in legible characters the record engraved by the glacier in the smoothed and polished ledges. This is the more remarkable considering the exposure to which these rock surfaces have been subjected. The cañon has been swept clean of these materials, but within the rugged mountain basin they recur under a variety of local aspects.

The streams to the south that rise in the more elevated portion of the range all exhibit in their debouchures interesting evidence of former glacial occupancy. But none of the smaller streams show morainal deposits of near the magnitude of those above noticed. This is evidenty due to the fact that the present streams do not penetrate so deeply into the more elevated regions, and hence the glaciers that once descended along their valleys were smaller and derived their products from less abundant sources. The lateral moraines on Dry Creek below the debouchure are quite as perfect examples of their kind as any to be met with on this side of the range. They reach well out into the sloping plain, presenting in their surface contour the several bench levels in the steep valley declivities marking the stages in diminution in the volume of the glacier and on the opposite side the furrowed gentler slopes descending to the general upland level. Between these streams the mountain side reveals the sedimentary formations in great upraised benches which form a characteristic feature in the surface configuration of the flank of the range. 
The Bull Lake Fork moraines are precisely like those above described, being heaped up on the planed-off surfaces of the Mesozoic and Tertiary deposits and reaching well up on the foot of the mountain to an elevation of 1,200 feet or more above the stream. They reach out into the basin as far as Wind River, or a distance of nearly 10 miles, the deposits apparently increasing in magnitude in that direction, where they soon conceal from view the subjacent geological deposits. The lake was formed by a low barrier which marks the site of a terminal moraine, similar occurrences being met with lower down the stream giving rise to a chain of water-expansions or lakelets. One of these low terminal moraines crosses the valley haif a mile or so above the lake, which the stream has broken through, forming a narrow passage where it shorws a height above the water of about 30 feet and a breadth of 75 yards. Looking up into the mountain basin the Archæan ledges present extensive glaciated surfaces and huge ridges of morainic origin.

Allusion has already been made to the glacial phenomena prevalent on Little Wind River. The two nain branches of this stream cross the outer mountain ridge by independent cañons, uniting in the plains below. Their exits from the mountains are accompanied by morainal ridges constituting prominent features in the magnificent view of the mountains as seen from the valley in the vicinity of Camp Brown. The barred sedimentaries appear on the mountain side in the interval between the two streams. In the bed of the valley of the North Fork, just below where it leaves the mountains, low parallel ridges of morainic origin are met with which may be remnants of medial moraines merged with terminal deposits. In th" high bluff's on the north side the lateral moraine rests upon a heavy bed of Pliocene (?) conglomerate which interposes a hundred feet between the glacial deposits and the tilted Mesozoic strata. The north-side lateral moraine attains an elevation of about 1,500 feet above the stream, rising up on a high shoulder which breaks down in a precipice several hundred feet in height on the caũon side. Within the broad and rugged mountain basin moraines of even greater magnitude were built up along the principal tributaries. The latter in places traverse beautiful tracts of grassy, forest-environed intervales, the region indeed abounding in scenic contrasts the most beautiful and sublime.

Tufaceous deposits, \&c.-Along the northeastern foot of the Wind River Mountains some interesting occurrences attributable chiefly to depositions from springs issuing in the immediate border of the basin were met with, of which a brief account is embodied in the following pages. The first of these deposits occurs in the immediate neighborhood of Warm Spring Creek, where their origin is perhaps most clearly revealed. They extend to the southeast as far, at least, as Campbell's Fork, and certain conglomeritic deposits with which they are here associated have similar, if not identical, recurrences still farther south to the neighborhood of Little Wind River.

In the south side of Wind River, at Warm Spring Creek confluence and a few miles below, recent deposits of calcareous matter have been made by springs which have not yet altogether ceased flowing. Their deposit forms a light, porous rock retaining impressions of leaves and land snails of living forms, and of comparatively limited extent in the low terrace bordering the intervale, 15 to 35 feet above the stream. Ascending Warm Spring Creek it is presently shut in by the bluffs of higher terraces that rise in two distinct levels. In the edge of the higher bench, perhaps half a mile above the mouth, the creek has cut through a mass of tufaceous limestone, where, on the east side, at an 



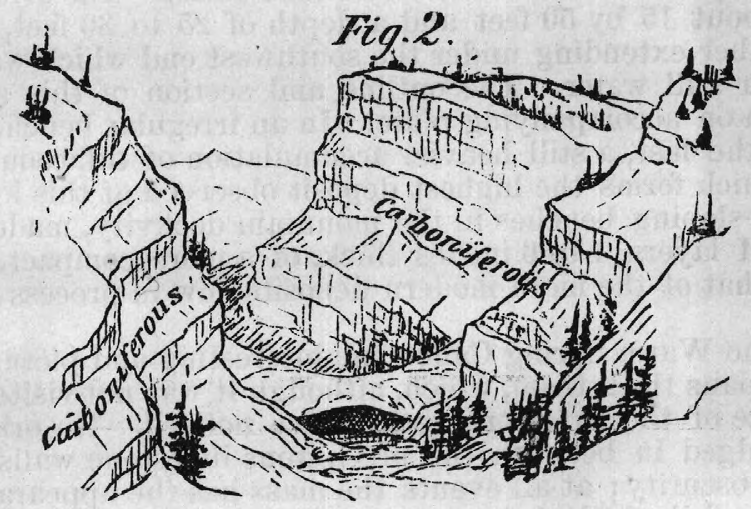

Arch in calcareous tufa, Warm Spring Cañon.
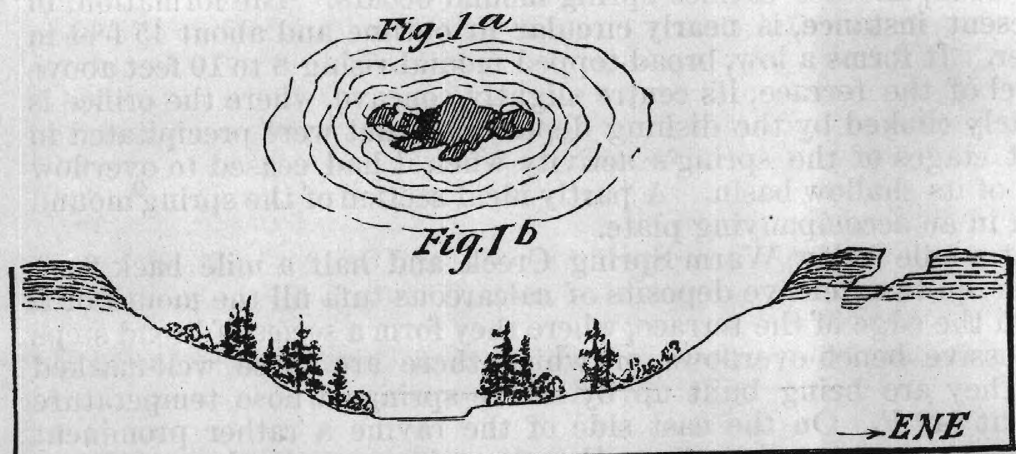

Profile of spring deposits on Warm Spring Creek.

Fig. 1a. Outline of orifice of ancient spring, 15 by 50 feet.

Fig. $1 b$. Section of ancient spring, partially filled with water.

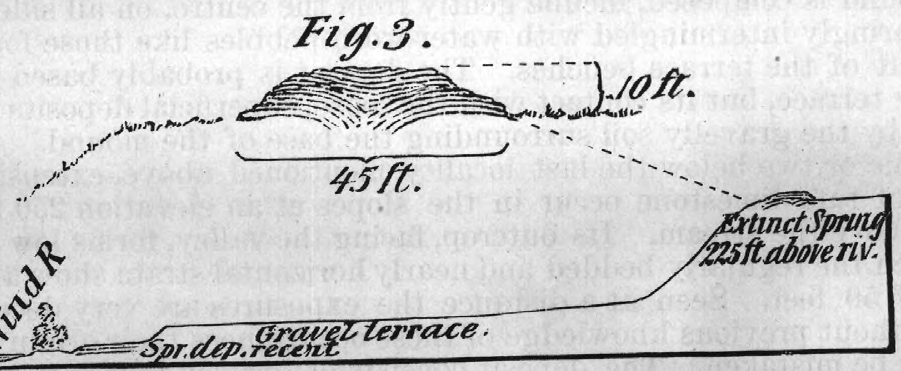


elevation of, perhaps, 150 feet above the river, it is surmounted by a broad, low cone or mound, in the centre of which occurs the irregular orifice of the spring. The spring has long since ceased to overflow, and, if it is not extinct, its waters seek subterranean outlet. The orifice has a diameter of about 15 by 50 feet and a depth of 25 to 30 feet, with a cavernous chamber extending under the southwest end which was partially filled with still water. The outline and section of this ancient spring is shown on accompanying plate. In an irregular bench, about 250 feet above the last, a still heavier accumulation of tufaceous limestone occurs, which forms the highest deposit observed at this locality. The mass forms sloping benches in the mountain declivity, made up of thin laminæ and layers, 4 to 6 inches thick, of a more compact, dense structure than that of the more modern deposits now in process of formation.

Looking up the Warm Spring Cañon an interesting and picturesque natural bridge spans the stream, which, although it was not visited, has every appearance of the tufaceous rock above noticed. Its origin at this locality, wedged in between the precipitous limestone walls, is involved in some obscurity; at all events the mass has the appearance of once having choked the bed of the cañon, the stream subsequently cutting a channel beneath without undermining the deposit. A short distance below the above-mentioned spring orifice, in the east-side angle of terrace bluff, another extinct spring mound occurs. The formation, in the present instance, is nearly circular in outline and about 45 feet in diameter. It forms a low, broad-topped mound rising 8 to 10 feet above the level of the terrace, its centre slightly concave, where the orifice is completely choked by the dishing depositions that were precipitated in the last stages of the spring's activity when it had ceased to overflow the rim of its shallow basin. A partly ideal section of the spring mound is given in accompanying plate.

About a mile below Warm Spring Creek and half a mile back from the river quite extensive deposits of calcareous tufa fill the mouth of a ravine in the edge of the terrace, where they form a series of broad steps or successive bench-overflows, of which there are three well-marked ones. They are being built up by active springs whose temperature was about $84^{\circ} \mathrm{F}$. On the east side of the ravine a rather prominent extinct spring crater rises from the slope, its summit about 200 feet above the wide bench descending to the river. The crater, which is surrounded by irregular, vertical walls, is about 1.5 feet in its longest diameter by 10 feet in the shorter, and a depth of 20 feet, the bottom filled with débris. The thin layers of porous tufa limestone, of which the mound is composed, incline gently from the centre, on all sides, and are sparingly intermingled with water-worn pebbles like those found in the drift of the terrace benches. The deposit is probably based on the sloping terrace, but its contact with the loose, superficial deposits is concealed by the gravelly soil surrounding the base of the mound.

A mile or two below the last locality mentioned above, extensive deposits of tufa limestone occur in the slopes at an elevation 250 feet or more above the stream. Its outcrop, facing the valley, forms low bluffs, in which the regularly bedded and nearly horizontal strata show a thickness of 50 feet. Seen at a distance the exposures are very deceptive, and without previous knowledge of these occurrences their origin might readily be mistaken. The deposit consists of grayish-buff, more or less compact and porous, even-bedded calcareous tufa, very gently inclined to the west, in one place apparently conforming to the declivity of the terrace bench upon which it rests. In texture the rock is firmer and 
more dense than the modern formations, though, so far as the evidence goes, it is difficult to assign these more ancient deposits a definite relative date as compared with the glacial drift.

In a preceding page has been mentioned the occurrence of the partially-cemented gravels in the first high bench bordering Wind River on the sonth for several miles below the narrows above Warm Spring Creek. These ancient gravel beds appear to have been intimately associated with the spring deposits, and if, as is inferred, these old bench deposits antedate the glacial drift, it removes a part of the tufaceous limestone formations to a remote period as compared with the similar deposits whose accumulation by accessions of living springs has not ceased. Of the latter deposits frequent occurrences were met with in ravines traversing the benches opposite Horse Creek confluence, and in the bordering bluff's, resting upon the Triassic "red beds," the terrace conglomerate reappears. It is here made up of limestone, sandstone, and metamorphic pebbles, usually firmly cemented by calcareous matter, forming an extensive deposit rising up to the foot of the mountain and spread out over ancient terrace levels. In comparatively recent times the bench slopes have been subjected to erosion, which has, in some instances, at this locality, isolated the conglomerate sheet in the midst of the barred "redbed" surfaces. Below this the morainal deposits, distributed by the Jake's Creek glacier, are encountered, and which are piled up on the earlier terraces in irregular ridges, completely masking the subjacent deposits.

In the mouth of Jake's Creek Cañon, Mr. Perry visited some interesting and extensive spring deposits which are still in process of formation. The springs have built up cones rising in the midst of platforms that were formed in the earlier stages of their flow. The water had a temperature of $68^{\circ} \mathrm{F}$., that of the atmosphere $44^{\circ}$ (2d October).

Between Torrey's Creek and Campbell's Fork perhaps even more extensive exhibitions of conglomerate and tufaceous limestone deposits are met with, the prevalent conditions being the same as noted in the region opposite Horse Creek. The Red Cañon occurrences may be taken as typical of the others found in the latter quarter. Here, upon old terraces moulded in the "red beds," heavy deposits of conglomerate and tufaceous limestones occur, interbedded. These deposits were noticed in detail in the section of the rocks occurring in the mountain flank at this locality, given in a preceding page and accompanying plate of illustrations. The deposits measured about 60 feet, the members locally varying in thickness. It consists of, below, $(\mathbf{1 6} a)$ variegated clays, 5 feet \pm , resting upon the uneven surface of the Triassic "red beds," and forming the floor upon which the succeeding beds were deposited; (16b) conglomeratic bed, 10 to 15 feet, composed of pebbles of varions kinds of rock occurring in the adjacent mountain, alternating with coarse sandy red clays, more or less local; $(16 c)$ tufaceous limestone, varying from rather compact to porous laminated or thin-bedded rock, with calcite concretions, interbedded with layers of pebbles above and below, attaining a thickness of ' 50 to 55 feet, locally. The deposit is quite variable throughout, in places the conglomeritic character prevailing. The pebbles consist chiefly of water-worn limestone fragments, with fewer sandstone and metamorphic pebbles. The deposit conforms to the surface contour of pre-existing sloping benches upon which it was laid down in an uninterrupted sheet. This character is clearly shown in the natural sections along the streams and over the denuded Triassic area lying between the mountains and Wind River, where tufaceous and conglomeritic beds are seen at two or more levels rising up on the foot 
of the mountains. Its outerop forms a mural coping in the bluffs hemming the drainage depressions and in the summits of the isolated mesas with which this region is diversified. The highest benches in this region may reach an elevation 1,000 to 1,200 feet above Wind River; the aneroid indicating nearly the same actual altitude for the deposits at this locality and in the vicinity of Warm Spring Creek, 16 miles above.

South of Campbell's Fork, 6 miles, a deposit evidently of the same origin appears in the low bluff's bordering a little stream that here crosses the foreland slope, and resting nearly horizontally upon upraised Carboniferous and Triassic horizons. It is a coarse or partially consolidated gray limestone, in rather even thin layers, with small siliceous pebbles. No fossils were detected, and the rock resembles some of the limestone layers of the Pliocene "lake-beds" of lower Bear River Valley, Utah. It was not detected on Bull Lake Fork, but just to the south of the latter stream, in the outlying bench slopes belonging to the Sage Creek drainage, apparently quite an extensive conglomeritic deposit was met with, which is probably synchronous with the above-mentioned occurrences. The conglomerate is chiefly composed.of. water-worn limestone fragments and sandstone, more or less firmly cemented with calcareous matter. The bed reaches a thickness of at least 50 feet, and rests upon various members of the Mesozoic series occurring in the belt along the foot of the mountains. The same formation recurs in the bluffs north side of North Fork Little Wind River, where it rests upon the Triassie "red beds," at an elevation of 800 feet above the stream. Metamorphic pebbles and small bowlders enter largely into the components of the deposit at this locality, interbedded with thin local sheets of soft buff sandstone, the whole loosely cemented and obsenrely stratified. Conclusive evidence of the preglacial origin of the deposit is not wanting at the present locality; the ridge above being loader with the morainal materials brought down by the Little Wind River glacier. There can be no question as to the identity of the latter occurences with those briefly described in foregoing pages; the only contrast they present is the absence of the tufaceous limestone which at other localities forms an important member of the formation. 



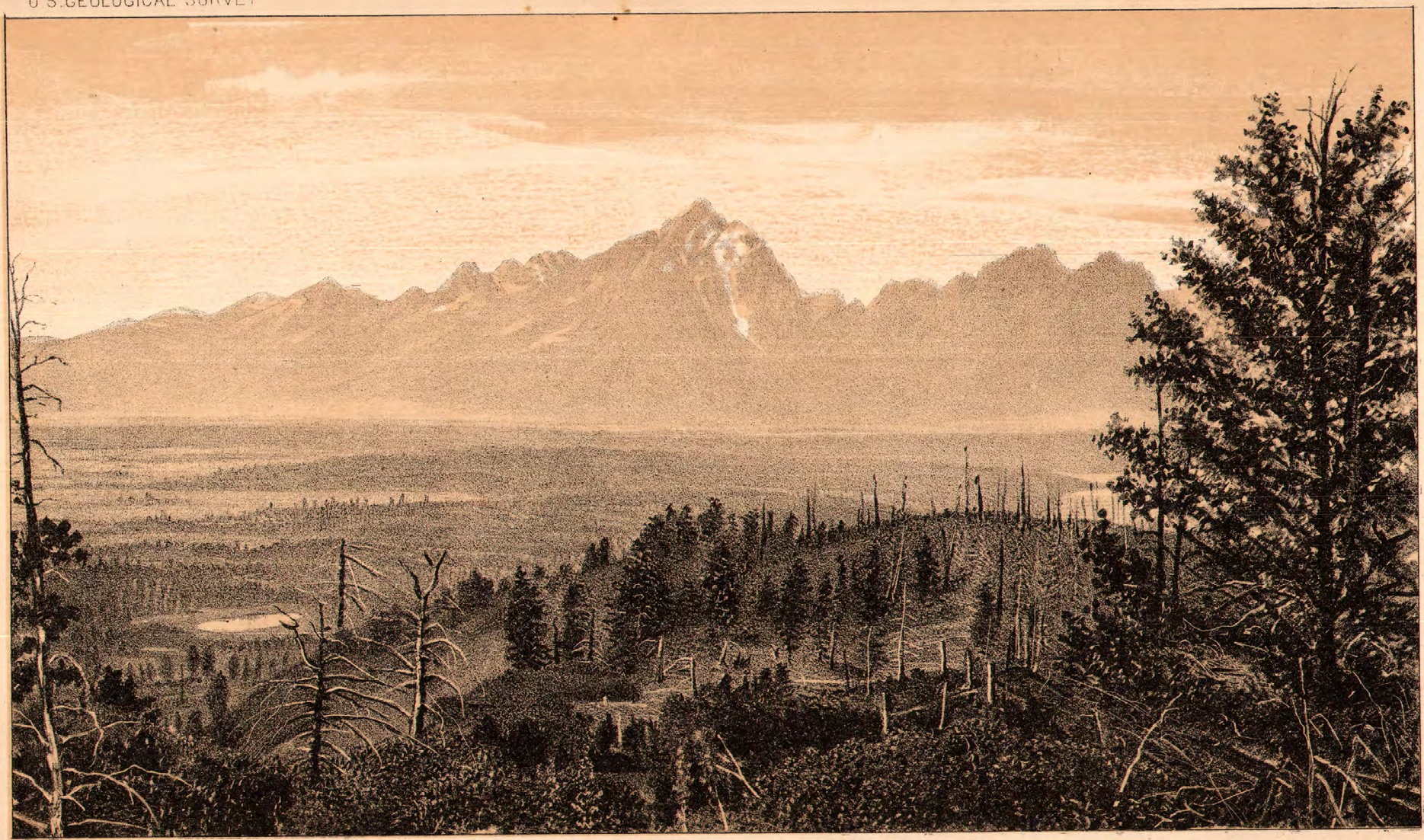




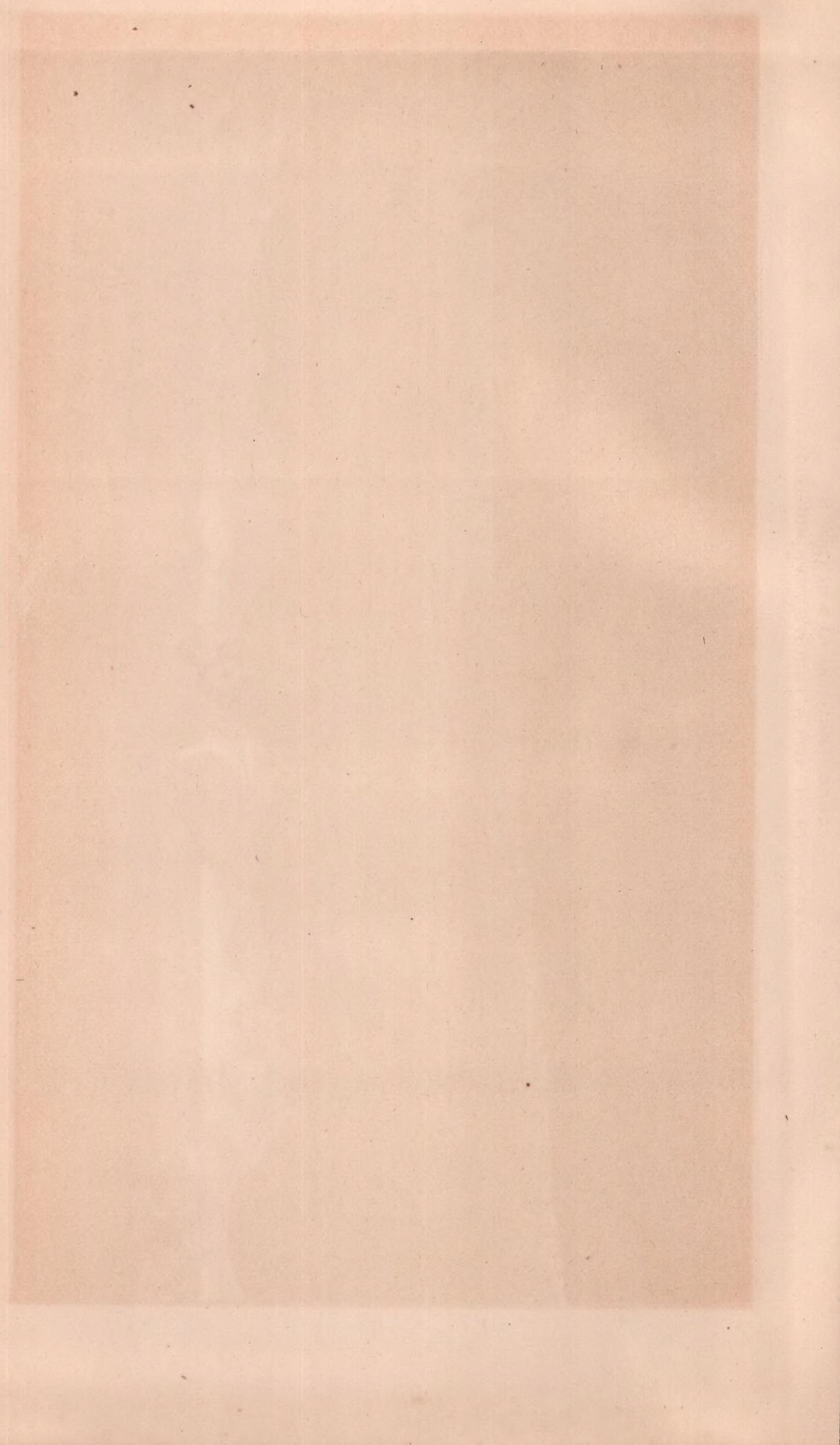




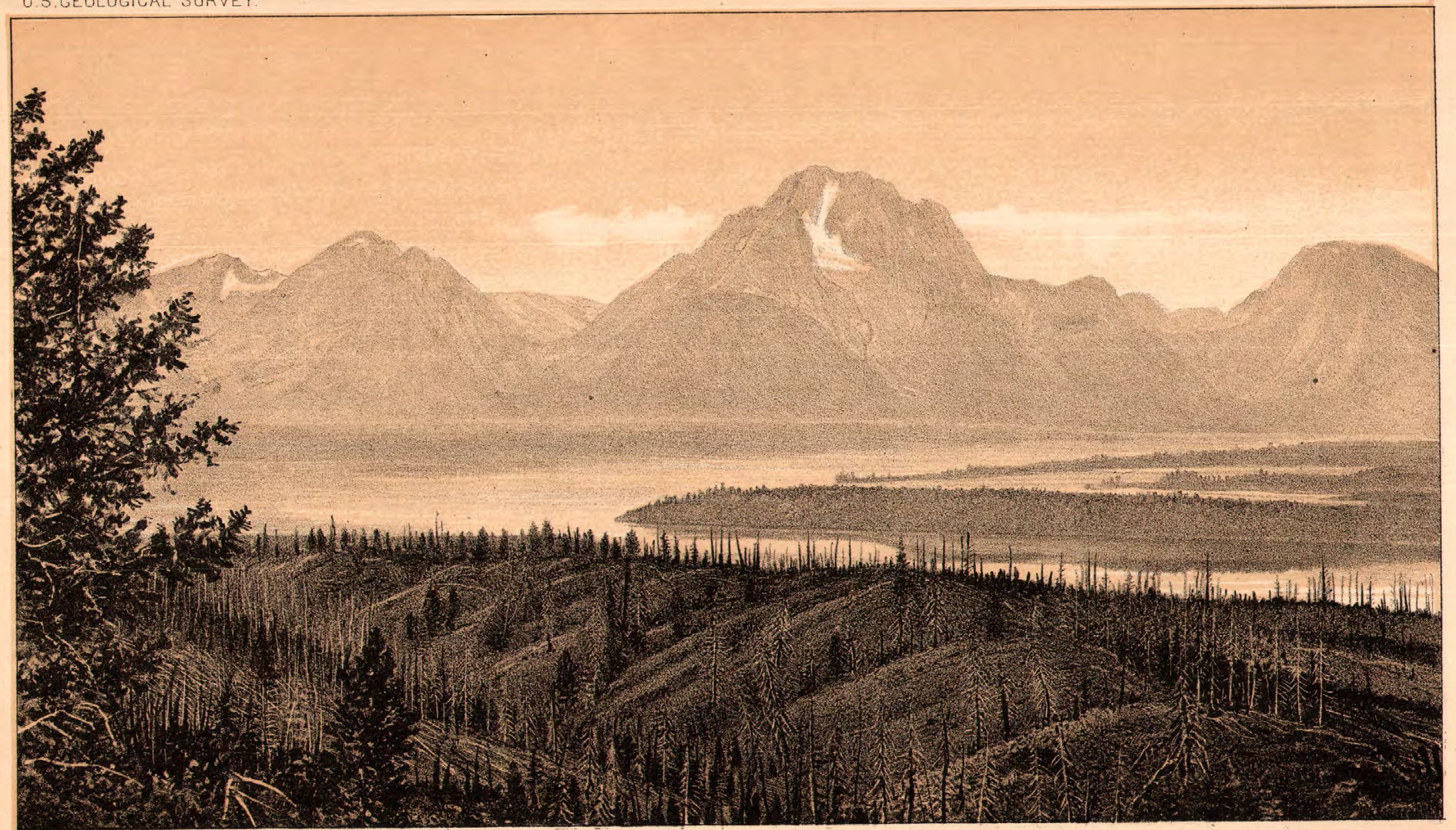




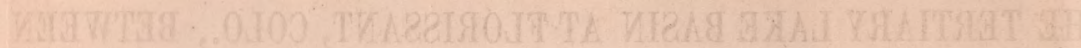

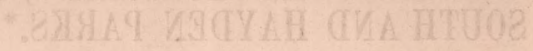

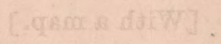

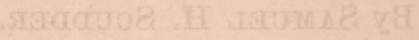

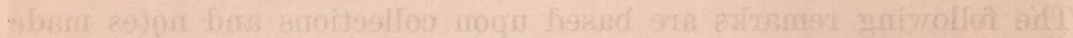

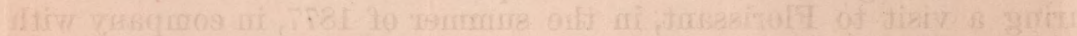

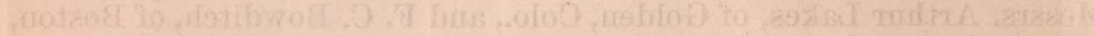

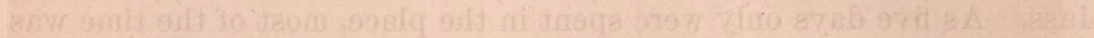

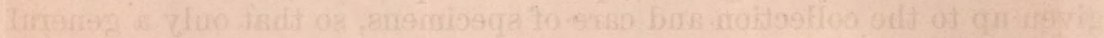

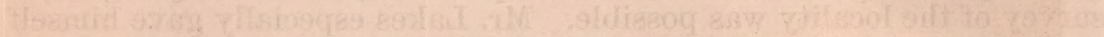

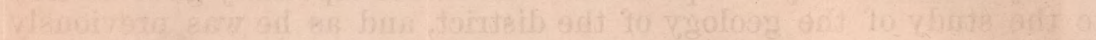

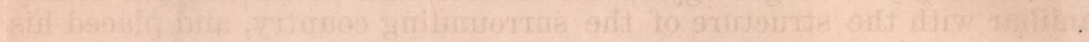

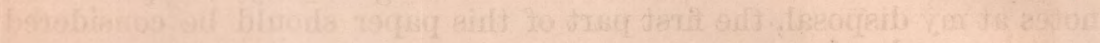

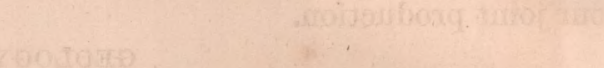

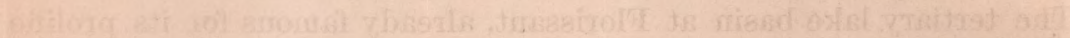

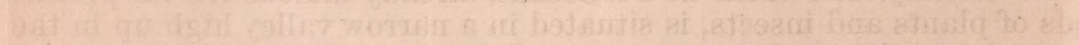

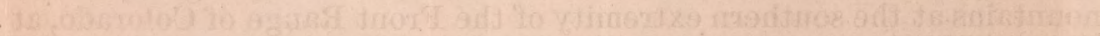

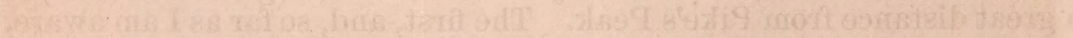

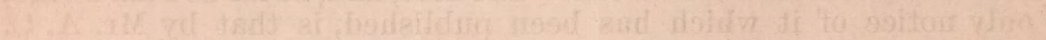

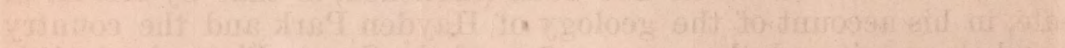

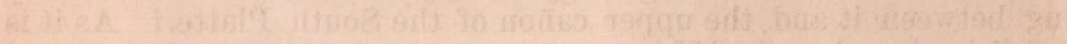

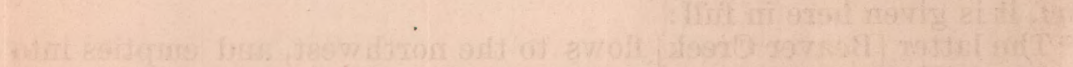

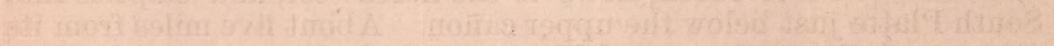

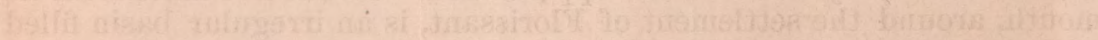

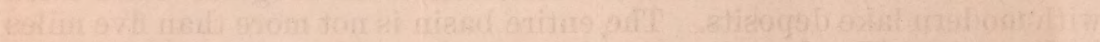

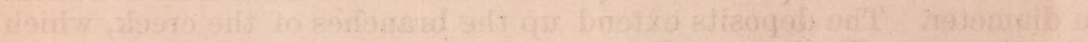

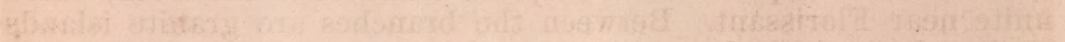

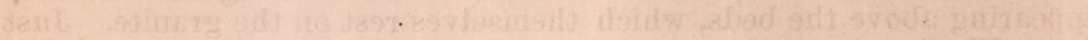

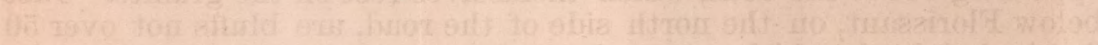

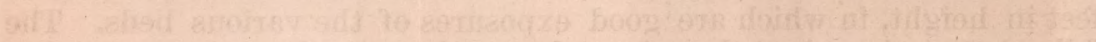

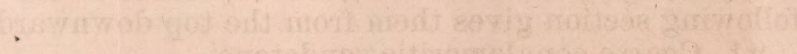

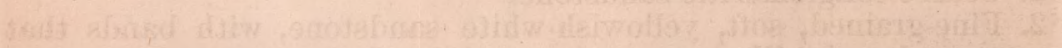

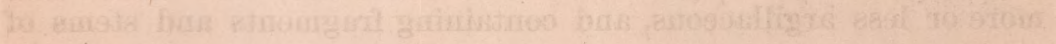

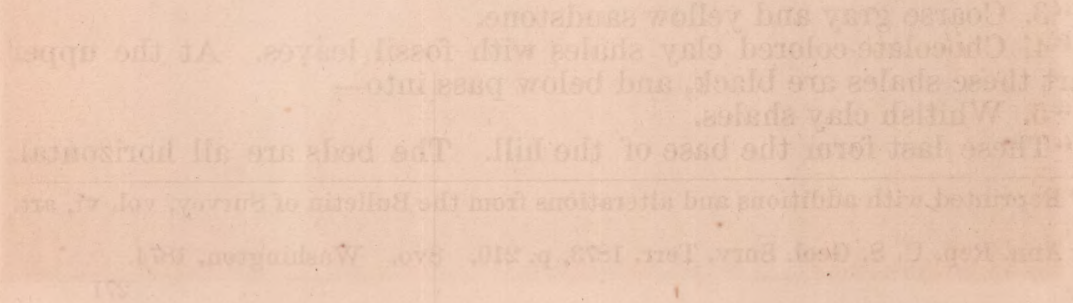




\section{THE TERTIARY LAKE BASIN AT FLORISSANT, COLO., BETWEEN SOUTH AND HAYDEN PARKS.*}

[With a map.]

By SaMuel H. Scudder.

The following remarks are based upon collections and notes made during a visit to Florissant, in the summer of 1877, in company with Messrs. Arthur Lakes, of Golden, Colo., and F. C. Bowditeh, of Boston, Mass. As five days only were spent in the place, most of the time was given up to the collection and care of specimens, so that only a general survey of the locality was possible. Mr. Lakes especially gave himself to the study of the geology of the district, and as he was previously familiar with the structure of the surrounding country, and placed his notes at my disposal, the first part of this paper should be considered our joint production.

\section{GEOLOGY.}

The tertiary lake basin at Florissant, already famous for its prolific beds of plants and insects, is situated in a narrow valley high up in the mountains at the southern extremity of the Front Range of Colorado, at no great distance from Pike's Peak. The first, and, so far as I am aware, the only notice of it which has been published, is that by Mr. A. C. Peale, in his account of the geology of Hayden Park and the country lying between it and the upper cañon of the South Platte. $\dagger$ As it is brief, it is given here in full:

"The latter [Beaver Creek] flows to the northwest, and empties into the South Platte just below the upper cañon. About five miles from its mouth, around the settlement of Florissant, is an irregular basin filled with modern lake deposits. The entire basin is not more than five miles in diameter. The deposits extend up the branches of the creek, which all unite near Florissant. Between the branches are granite islands appearing above the beds, which themselves rest on the granite. Just below Florissant, on the north side of the road, are blufts not over 50 feet in height, in which are good exposures of the various beds. The following section gives them from the top downward:

"1. Coarse conglomeritic sandstone.

"2. Fine-grained, soft, yellowish-white sandstone, with bands that are more or less argillaceous, and containing fragments and stems of leaves.

"3. Coarse gray and yellow sandstone.

"4. Chocolate-colored clay shales with fossil leaves. At the upper part these shales are black, and below pass into-

" 5 . Whitish clay shales.

"These last form the base of the hill. The beds are all horizontal.

\footnotetext{
* Reprinted with additions and alterations from the Bulletin of Survey, vol, vi, art. xi.

† Ann. Rep. U. S. Geol. Surv. Terr. 1873, p. 210. 8vo. Washington, 1874.
} 
Scattered around are fragments of a trachyte, which probably caps the beds. In one of the valleys Mr. Taggart discovered, uear an old well, pieces of trachyte, which, on looking at the excavation, was found to be the first laver penetrated. The point of overflow from which this material came is probably to the southward, in Dr. Endlich's district. The lake basin may possibly be one of a chain of lakes that extended southward. I had thought it possible that the beds were of Pliocene age. The specimens obtained from bed No. 4 , of the section above, were submitted to Professor Lesquereux, who informs me that they are 'Upper Tertiary.' 'But I do not believe, as yet, that the specimens of the Green River group, to which your species are referable, authorize the conclusion of Pliocene age. I rather consider it, as yet, as Upper Miocene. The species known of our Upper Tertiary are as yet too few and represented in poor specimens for definitive conclusion. Your specimens have a Myrica, a Cassia, fragments of Salix angusta (A. Br.), a Rluus, an Ulmus, and a fragment of Poa or Poacites.'

"6The shales were so soft and friable that it was rather difficult to obtain any specimens.

"About one mile south of Florissant, at the base of a small hill of sandstone, capped with conglomerate, are 20 or 30 stumps of silicified wood. This locality has been called 'Petrified Stumps' by the people in the vicinity. The specimens of wood are not particularly good."

This basin is shown on sheet 13 of the geological atlas of Colorado published by Dr. Hayden's survey, and its outlines are marked with considerable accuracy, although upon a comparatively small scale. The data upon which that sheet was constructed have formed the basis of the accompanying map, in which the limits of the basin are given witfi closer accuracy and in greater detail.* The point of greatest difference is in the valley of Fish Creek, where we noticed no extended prolongation of the lacustrine deposits; and as the contours of Dr. Hayden's parties themselves seem to forbid the probable extension of the deposits in this direction, we have closely limited them to what we saw.

The ancient lake lies in the valley of the present South Fork of Twin Creek, and of the upper half of the main stream of the same after the South Fork has joined it. Following the road from South Park to Colorado Springs, and leaving it just above Florissant Post Office, $\dagger$ and then taking the track-half road, half trail-which leads over the divide toward Cañou City, we shall pass between the Platte River and the Arkansas divide, through the entire length of the basin. This road crosses the South Platte a short distance, say a kilometer and a half, below the mouth of Twin Creek, climbs a long, gradual slope on the east bank of the river to an open, grassy glade, about 2,500 meters above the sea, and then descends a little more that three kilometers from the river to join the valley of Twin Creek. We scarcely begin the descent before our attention is attracted by the outcropping of drab-colored shales, which continue until almost the very summit of the divide is reached and the descent toward the Arkansas begun, a traveling distance of not far from thirteen kilometers.

By climbing a neighboring peak, thrice baptized as Crystal Mountain, Topaz Butte, and Cheops Pyramid, we obtain an admirable bird's-eye view of the ancient lake and the surrounding region. To the southeast

\footnotetext{
* The heights are given in feet.

† Florissant is merely a post-office at Castello's Ranch, which is also provided with a store, the basis of supplies for all the inhabitants within a radius of fifteen kilometers. One would have to look far to find in Colorado a more comfortable hostelry than that to which "Judge" Castello will welcome us.
} 
is Pike's Peak; to the west South Park and the cañon of the South Platte, shown by a depression; to the extreme south, the grand cañon of the Arkansas; while to the north a few sharp, ragged, granite peaks surmount the low wooded hills and ravines characteristic of the nearer region. Among these hills and ravines, and only a little broader than the rest of the latter, lies, to the south, the ancient Florissant Lake basin, marked by an irregular L-shaped grassy meadow, the southern balf broader and more rolling than the northwestern, the latter more broken and with deeper inlets.

Recalling its ancient condition, and it will appear that this elevated lake must have been a beantiful, though shallow, ${ }^{*}$ sheet of water. Topaz Butte, and a nameless lower elevation lying eight kilometers to its southwest, and which we may call Castello's Mountain, guarded the head of the lake upon one side and the other, rising three or four hundred meters above its level. It was hemmed in on all sides by nearer granitic hills, whose wooded slopes came to the water's edge; sometimes, especially on the northern and eastern sides, rising abruptly, at others gradually sloping, so that reeds and flags grew in the shallow waters by the shore. The waters of the lake penetrated in deep inlets between the hills, giving it a varied and tortuons outline; although only about sixteen and a half kilometers long and very narrow, its margin must have measured over seventy kilometers in extent. Still greater variety was gained by steep promontories, twenty meters or more in height, which projected abruptly into the lake from either side, nearly dividing it into a chain of three or four unequal and very irregular open ponds, running in a northwest-southeast direction, and a larger and less indented sheet, as large as the others combined, connected with the southwesternmost of the three by a narrow channel, and dotted with numerous long and narrow wooded islets just rising above the surface.

The ancient outlet of the whole system was probably at the southern extremity; at least the marks of the lake-deposits reach within a few meters of the ridge which now separates the waters of the Platte and Arkansas; and the nature of the basin itself, the much more rapid descent of the present surface on the southern side of this divide, with the absence of any lacustrine deposits upon its slopes, lead to this conclusion. At the last elevation of the Rocky Mountain chain, the drainage flow of this immediate region was reversed; the elevation coming from a southerly or southeasterly direction (perhaps from Pike's Peak), the lake, or series of lakes, was drained dry by emptying at the northwestern extremity. The drainage of the valley now flowed into a brook which followed the deeper part of its former floor, and the waters of the region have since emptied into the Platte and not the Arkansas, passing in their course between Topaz Butte and Castello's Mountain.

The promontories r cojecting into the lake on either side are formed of trachyte or other voleanic lavas, apparently occurring in fissures directly athwart the general course of the northwestern or upper series of lakes; aud masses of the same occur at many different points along the ancient shore, such as the western corner where the waters of the lake were finally discharged; in the neighborhood of Castello's Ranch; along the eastern wall of the lowermost of the chain of upper lakes, near where the present road divides; and at points along both eastern and western walls of the lower-southern lake. In general the trachytic flows seem to be confined to the edges of the lacustrine basin, but some, if not all, of the mesas or ancient islands of the southern lake have trachytic flows

* The shallowness of the lake is indicated by the character of the fish, the sun cracking of some of the shales, and the erect sequoia stumps. 
over them; and toward the southern extremity of the lake a larger island will be seen upon the map, now forming a rounded hill with steep northern walls, crowned by heavy beds of dark trachyte, and its slopes covered with quantities of vesicular scoriae. The rough and craggy knoll immediately overlooking Castello's Ranch, the reputed scene of Indian combats, * was witness of hotter times than those; vertical cylindrical holes, with smooth walls, in which a man could hide from sight, funnels scored by heat, mark, perhaps, the presence of former geysers; the basaltic rocks themselves are deeply fissured by the breaking up of the planes of divisious between the columns, affording the best protection to the Ute and Arapahoe warriors. But the very shales of the lake itself, in which the myriad plants and insects are entombed, are wholly composed of volcanic sand and ash; fifteen meters or more thick they lie, in alternating layers of coarser and finer material. About half of this, now lying beneath the general surface of the ground, consists of heavily bedded drab shales, with a conchoidal fracture, and totally destitute of fossils. The upper half has been eroded and carried away, leaving, however, the fragmentary remains of this great ash deposit clinging to the borders of the basin and surrounding the islands; a more convenient arrangement for the present explorer could not have been devised. That the source of the volcanic ashes must have been close at hand seems abundantly proved by the difference in the deposits at the extreme ends of the lake, as will be shown in the sections to be given. Not only does the thickness of the different beds differ at the two points, but it is difficult to bring them into anything beyond the most general concordance.

There are still other proofs of disturbance. Around one of the granitic islands in the southern lake basin the shales mentioned were capped by from one and a half to two and a half meters of sedimentary material, reaching nearly to the crown of the hill, the lowest bed of which, a little more than three decimeters thick, formed a regular horizontal stratum of small volcanic pebbles and sand (A and B of Dr. Wadsworth's note further on); while the part above is much coarser, resembling a breccia, and is very unevenly bedded, pitching at every possible angle, seamed, jointed, and weather-worn, curved and twisted, and inclosing pockets of fine laminated shales, also of volcanic ash, in which a few fossils are found (C of Dr. Wadsworth's note). These beds cap the series of regular and evenly stratified shales (D of the same note), and are perhaps synchronous with the disturbance which tilted and emptied the basin. The uppermost evenly bedded shales then formed the hard floor of the lake, and these contorted beds the softer, but hardening, and therefore more or less tenacious, deposits on that floor.

The excavation of the filled-up basin we must presume to be due to the ordinary agencies of atmospheric erosion. The islands in the lower lake take now as then the form of the granitic nucleus; nearly all are long and narrow, but their trend is in every direction, both across and along the valley in which they rest. Great masses of the shales still adhere equally on every side to the rocks against which they were deposited, proving that time alone and no rude agency has degraded the ancient floor of the lake.

The shales in the southern basin dip to the north or northwest at an angle of about two degrees, and an examination of the.map will show that the southern end of the ancient lake is now elevated nearly two hundred and fifty meters above the extreme northwestern point. The greater part of this present slope of the lake border will be found in the

*Their rude fortifications still crown the summit. 
southern half, where it cannot fail to strike the observant eye upon the spot, the southernmost margin, close to the summit of the divide, being nearly two hundred meters higher than the margin next the school-house hill.

Our examination of the deposits of this lacustrine basin was principally made in a small hill, from which perhaps the largest number of fossils have been taken, lying just south of the house of Mr. Adam Hill, and upon his ranch. Like the other ancient islets of this upland lake, it now forms a mesa or flat-topped hill about ten or a dozen meters high, perhaps a hundred meters long and twenty-five broad. Around its eastern base are the famous petrified trees, huge, upright trunks, standing as they grew, which are reported to have been five or six meters high at the advent of the present residents of the region. Piecemeal they have been destroyed by vandal tourists, until now not one of them rises more than a meter above the surface of the ground, and many of them are entirely leveled; but their huge size is attested by the relics, the largest of which can be seen to have been three or four meters in diameter. These gigantic trees appear to be sequoias, as far as can be told from thin sections of the wood submitted to Dr. George L. Goodale. As is well known, remains of more than one species of sequoia have been found in the shales at their base.

At the opposite sloping end of this mesa a trench was dug from top to bottom to determine the character of the different layers, and the section exposed was carefully measured and studied. In the work of digging this trench we received the very ready and welcome assistance of our companion, Mr. Bowditch, and of Mr. Hill, the owner of the grounds.

From what information we could gain about the wells in this neighborhood it would appear that the present bed of the ancient Florissant lake is entirely similar in composition for at least ten meters below the surface, consisting of heavily bedded non-fossiliferous shales, having a conchoidal fracture. Mr. Peale does not say whether the well seen by Mr. Taggart passed below the trachyte, which he says it first entered. Above these basal deposits, on the slope of the hill, we found the following series, from above downward, commencing with the evenly bedded strata:

Section in southern lake.

[By S. H. ScudDER and A. LAKEs.]

1. Finely laminated, evenly bedded, light-gray shale; plants andinsects scarce

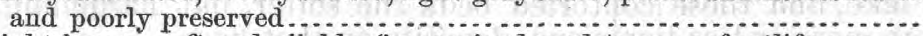

2. Light-brown, soft and pliable, fine-grained sandstone; unfossiliferous....

3. Coarser, ferruginous sandstone; unfossiliferous. . . . . . . . . . . . . . . . . . ...

5. Resembling No. 1; leaves and insect remains seamed in the middle with a narrow strip of drab shale; fragments of

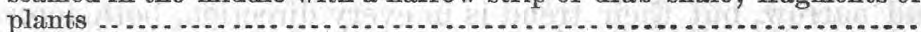

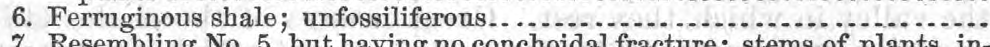

\%. Resembling No. 5, but having no conchoidal fracture; stems of plants, insects, and a small bivalve mollusk . ...............................

8. Very fine gray ochreous shale; non-fossiliferous $\ldots \ldots \ldots \ldots \ldots$

9. Drab shales, interlaminated with finely-divided paper shales of lightgray color; stems of plants, reeds, and insects......................

10. Crumbling ochreous shale; leaves abundant, insects rare.................

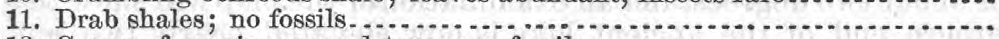

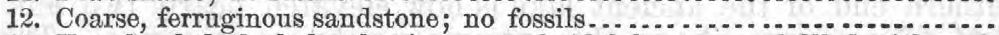

13. Very hard drab shales, having a conchoidal fracture and filled with nodules; unfossiliferous. ..........................................

14. Finely laminated yellowish or drab shales; leaves and fragments of plants, with a few insects..............................................

3.2

5

3. 8

21

28

1. 5 9 
15. Alternating layers of darker and lighter gray and brown ferruginous sand-

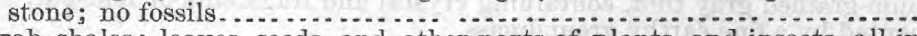

16. Drab shales; leaves, seeds, and other parts of plants, and insects, all in

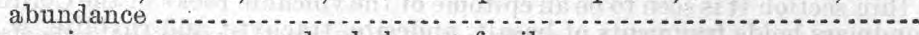

17. Ferruginous, porous, sandy shale; no fossils .

18. Dark gray and yellow shales; leaves and other parts of plants ...........

19. Interstratified shales, resembling 17 and 18 ; leaves and other parts of

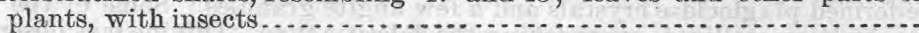

20. Thickly bedded chocolate-colored shales; no fossils.....................

21. Porous yellow shale, interstratified with seams of very thin drab-colored

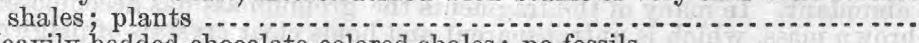

22. Heavily bedded chocolate-colored shales; no fossils ....................

23. Thinly bedded drab shales; perfect leaves, with perfect and imperfect

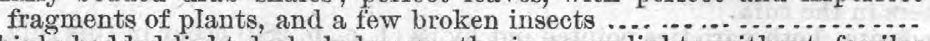

24. Thinly bedded light-drab shales, weathering very light; without fossils;

25. Thick bedded drab shales, breaking with a conchoidal fracture; also destitute of fossils . .

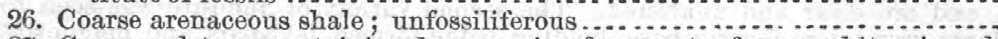

27. Gray sandstone, containing decomposing fragments of some white mineral, perhaps calcite; no fossils.

28. Coarse, ferruginous, friable sandstone, with concretions of a softer mate-

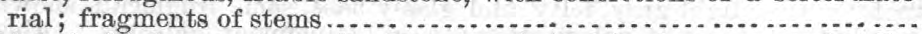

29. Thinly bedded drab shales, having a conchoidal fracture; somewhat lig-

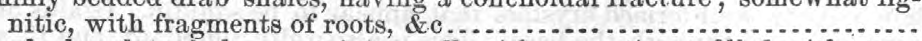

30. Dark-chocolate shales, containing yellowish concretions ; filled with stems and roots of plants .......

10

61

Total thickness of evenly bedded shales (D of Dr. Wadsworth's note) above floor deposits...................................... (meters) 6.668

The bed which has been most worked for insects and leaves, and in which they are unquestionably the most abundant and best preserved, is the thick bed, No. 16, lying half way up the hill, and composed of rapidly alternating beds of variously-colored drab shales. Below this insects were plentiful only in No. 19, and above it in Nos. 7 and 9; in other beds they occurred only rarely or in fragments. Plants were always abundant where insects were found, but also occurred in many strata where insects were either not discovered, such as beds 18 and 21 in the lower half and bed 6 in the upper half, or were rare, as in beds 10 and 14 above the middle and bed 23 below; the coarser lignites occurred. only near the base.

The thickest unfossiliferous beds, Nos. 20 and 27, were almost uniform in character throughout, and did not readily split into laminae, indicating an enormous shower of ashes or a mudflow at the time of their deposition; their character was similar to that of the floor-beds of the basin.

These beds of shale vary in color from yellow to dark brown. Above them all lay, as already stated, from fifteen to twenty-five decimeters of coarser, more granulated sediments, all but the lower bed broken up and greatly contorted. These reached almost to the summit of the mesa, which was strewn with granitic gravel and a few pebbles of lava.

Specimens of these upper irregular beds, and also of the underlying shales, were submitted to Dr. M. E. Wadsworth, of Cambridge, who caused thin seetions to be made from them, and has furnished the following account of their microscopical structure:

\section{TUFA FROM FLORISSANT.}

The method and scheme of classification employed here is that briefly sketched in the Bulletin of the Museum of Comparative Zoölogy (vol. v, pp. 275-287). By this system only do we think that the inclosed fragments could be named, for they contain so few erystals that in most cases the base is the principal thing upon which the decision must rest. 


\section{A.-THE FINER DEPOSIT JUST ABOVE THE SHALES.}

A medium-grained gray tufa, containing crystal and fragments of feldspar, augite, \&c., cemented by a fine earthy groundmass.

In the thin section it is seen to be an epitome of the volcanic rocks of the Cordilleras. The groundmass holds fragments of basalt, andesite, trachyte, and rhyolite, with detached minerals derived from them.

The basaltic fragments have in part a dense globulitic base porphyritically holding ledge-formed plagioclase crystals and a few angite granules. Some of the basalt is quite coarsely crystallized, approaching the doleritic type. Olivine was observed in some of the fragments, but it is largely altered to a reddish-brown serpentine. Magnetite is abundant. In many of the fragments the groundmass has decomposed to a reddish-brown mass, which is untransparent and holds clear crystals of plagicoclase. The basaltic fragments have suffered more from alteration and decomposition than any others in the tufa.

Of andesite, both varieties pointed out by us (1. c., p. 280) occur in this tufa. The first, which is nearest the basalt in composition, has a brown glass as its base, filled with microlites. This base holds minute rectangular and oblong crystals of feldspar. Large microlites of augite and grains of magnetite were seen. Fragments of this are common, and are clear and unaltered. The second variety of andesite was seen to have a dense gray micro-felsitic base, holding ledge-formed feldspars and magnetite grains. Some contained the reddish-brown fibers of the destroyed hornblende. Fragments of this variety of andesite are quite abundant.

The trachyte has a light gray, felty, and glassy base, some fragments showing besides this only faint traces of polarization caused by incipient feldspars. Other fragments show minute, well-formed crystals that appear to be sanidin. Grains of magnetite occur scattered through the base. This is also quite abundant, and it, as well as the basalt and andesite, surpasses the rhyolite in amount.

The rhyolite occurs in the form of a more or less clear glass, often cellular. The cells are often drawn out in the direction of the original flow, forming a fibrous structure, which when of a grayish or reddish brown color resembles woody fiber. Some of the fragments contain elliptical cells, and a few shards of water-clear glass free from inclusions were seen.

Many crystals, entire or broken, are scattered throughout the groundmass of the tufa. These crystals belong to plagioclase, sanidin, olivine, magnetite, augite, and quartz. But little quartz was observed; one crystal contained trichites and vapor cavities. The trichites are the same as those commonly seen in the quartz of granite, but this appears to have been derived from the lava. The feldspar contains inclasions of base, glass, and microlites, and through these the rock from which the feldspar was derived can often be told. The augites have the characters of andesitic augite. A little palagonite and one crystal of microline were seen.

The groundmass of the tufa is composed of comminuted and deeomposed material derived from the lavas before described. In the groundmass trachytic and rhyolitic material appears to predominate. This specimen was chosen for description, as it best represented the general characters of the tufas.

\section{B.-The COARSER DEPOSIT JUST ABOVe the ShaLes.}

This is more coarsely fragmental than any of the others, and is composed of a yellowish brown earthy groundmass, holding fragments of quartz, feldspar, basalt, \&c. Some of the fragments appear to belong to the older rocks, but none of them were seen in the section. Under the microseope the tufa is similar to the first one described, but its fragments are larger and sometimes better marked. Some kaolinized feldspars and a little biotite were seen. The hornblende in the andesite is in the usual broken forms, with blackened edges.

\section{C.-A SPECIMEN FROM FINER PORTION OF THE UPPER CONTORTED BEDS.}

A yellowish earthy groundmass holding crystals and fragments of augite and feldspar. On one side is a layer of fine detritus, composed of the same material as the groundmass of the more coarsely fragmental portion. Its microscopic characters are similar to those of A, except that its materials are more decomposed and sanidin is more abundant. One kaolinized feldspar was observed.

\section{D.-THREE SPECIMENS OF THE INSECT-SHALES.}

These are brownish and grayish brown shales, being simply the finer material of the tufas laid down in laminae of varying thickness and coarseness. One is very thinly bedded.

This volcanic material has evidently been worked over by water, but the conditions can of course best be told in the field. So far, however, as we can judge by micro- 
scopic examination, when the water commenced its work the material was in loose unconsolidated deposits. That it was thrown out as an ash, or rather deposited as a moya near its present location, is the most probable supposition. It seems, then, to have been taken up by the waves and spread ont as it is now fonnd. The reason for this opinion is that the fragments are not worn as they would naturally be if they had been derived directly from solid rock by water action, and the decomposition is not so grat as we should expect. The deposition appears to have been gentle but comparatively rapid, for there is no sign of violence or even of such decomposition as we should expect in slow deposition; and showers of ashes falling on still water or a lake acting on an unconsolidated, tufa bank answer best the conditions called for here. It is probable from the kaolinized feldspars and the macroscopic fragments of apparently older rocks that the latter are present in the tufa to some extent. This can best be explained by the supposition that it was deposited as a moya or mudflow within reach of the waters that have worked it over and deposited it in its present position. As we said before, the field evidence must be relied upon mainly in deciding such questions as these.

Cambridge, Mass., April 15, 1880.

M. E. WADSWORTH.

Another section, less carefully measured and noted with less detail than the other, was taken at or near the same place as Dr. Peale's mentioned at the beginning of this article, viz, at the extremity of one of the promontories jutting in a southwesterly direction into the middle of the upper chain of lakes, just west of the school-house* and about three kilometers west of Castello's Ranch. The top of the hill was covered with granitic gravel and loose bowlders of dark scoriaceous trachyte; below this we found, passing, as before, from above downward, the following succession:

Section in the northwestern lake.

[By S. H. Scudden and A. LAKEs.]

Decimeters (estimated).

1. Finely laminated yellow-drab shales; no fossils ......................... 12

2. Coarse decomposing yellowish shales; no fossils .......................... 12

3. Fine compact drab shales; perfect remains of plants and insects. Passing into. 15

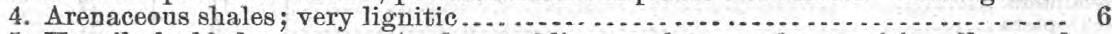

5. Heavily bedded, coarse-grained, crumbling sandstone, of a grayish yellow and whitish color, becoming ferruginous in places; partially lignitic .......... 60

6. Chocolate and drab colored shales having a conchoidal fracture, passing below into whitish paper-like shales inclosed between coarse arenaceous laminae;

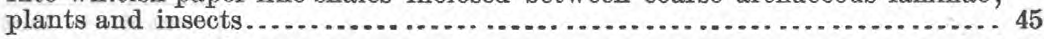

Total thickness of shales above floor deposits. (Meters, estimated) $\overline{15}$

These measurements being estimated are undoubtedly too great. The composition of this bluff is coarser in character than that of the section in the southern extension of the lake. The lignitic beds, which have been used for quarrying purposes, contain numerous fragments of reeds and roots not well preserved. The lower portions of the section correspond better with the other than do the upper beds, where it is difficult to trace any correspondence; No. 3 of the northwestern seems, however, to correspond to No. 16 of the southern series. The whitish paper shales lying at the base of this appear to be entirely absent from the southern section, and the distorted beds which crown the mesa are not apparent in the bluff, or, if present, are wholly regular. A more careful and detailed section of the bluff (for which we had not time), and particularly the tracing of the beds along the wall of the lake, would probably bring to light better correspondences. Directly in front of Judge Castello's house, at a level of a little more than 2,400 meters, is a bed of fossil fish.

Judging from the present physical condition of the basin, its age is marked as later than the movements which closed the cretaceous epoch and earlier than the last upheaval in the tertiary, which seems to have

\footnotetext{
* Not the school-house before mentioned, which lies to the south of Castello's Ranch.
} 
taken place during or after miocene times, but there are no physical data yet at hand to warrant definite conclusions on this head.

\section{PALEONTOLOGY.}

The insects preserved in the Florissant basin are wonderfully numerous, this single locality having yielded in a single summer more than double the number of specimens which the famous localities at Oeningen, in Bavaria, furnished Heer in thirty years. Having visited both places I can testify to the greater prolificness of the Florissant beds. As a rule, the Oeningen specimens are better preserved, but in the same amount of shale we still find at Florissant a much larger number of satisfactory specimens than at Oeningen, and the quarries are fifty times as extensive and far more easily worked.

The examination of the immense series of specimens found at Florissant* has not gone far enough to yield data sufficiently definite for generalization of any value, or which might not be altered or even reversed on further study. It may, nevertheless, be interesting to give a running notice of what has been observed in assorting the collection, and to make the single comparison with the Oeningen insect fauna which the number of individuals will furnish. This is indicated by the following table, based on a rough count of the Florissant specimens, but which cannot be far astray:

\begin{tabular}{|c|c|c|}
\hline Percentage of representation by- & $\underset{\text { Florissant. }}{\text { At }}$ & $\begin{array}{c}\text { At } \\
\text { Oeningen. }\end{array}$ \\
\hline 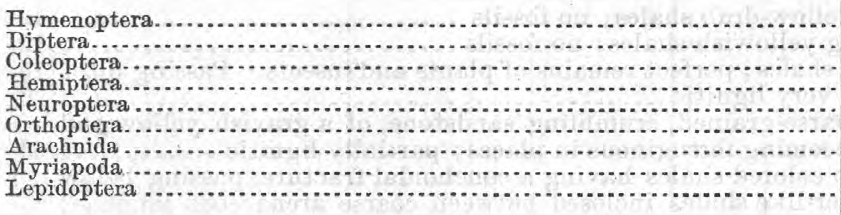 & $\begin{array}{r}40 \\
30 \\
13 \\
11 \\
5 \\
\frac{1}{1} \\
\frac{1}{1} \\
\frac{1}{23} \\
\frac{1}{25} \\
\end{array}$ & $\begin{array}{r}14 \\
7 \\
48 \\
12 \\
17 \\
3 \\
\frac{1}{2} \\
\frac{1}{10}\end{array}$ \\
\hline & 99.58 & 101. 6 \\
\hline
\end{tabular}

It will be seen that the proportion of specimens of each order is very different in all that are weil represented, with the sole exception of the Hemiptera, while the same groups (Orthoptera, Arachnida, Myriapoda, and Lepidoptera) are feebly represented in both. The greatest difference occurs in the Diptera, which are less than 7 per cent. of the whole at Ueningen and about 30 per cent. at Florissant; in the Hymenoptera, which have less than 14 per cent. at Oeningen and 40 per cent. at Florissant, due largely to the prodigious number of ants; while the case is reversed in the Coleoptera, which form nearly one-half the specimens found at Oeningen and only 13 per cent. at Florissant. We possess no count of the specimens found at Radoboj, in Croatia, which is regrettable, siuce the fauna of Florissant appears to agree much better with it than with any other, at least if one may judge from the comparatively minor part played by the Coleoptera and the great number of ants; these latter number 57 species in Radoboj, and one of them has furnished 500 specimens. Still the comparison cannot be carried very closely into other departments; for instance, only one rhynchophorous Coleopteron has been reported from Radoboj, while they are very numerous and rich

\footnotetext{
*Among these are included about 1,000 specimens submitted by the Princeton expedition.
} 
in species at Florissant, and local causes must have had much to do with the fauna of each of these localities. It is hardly worth while to institute any inquiries into the proportion of the groups represented at Florissant and in amber, siuce the nature of the entombment is entirely different.

Iet us pass, then, to a rapid sketch of the Florissant insect fauna, from which as yet only 16 species have been published; these will be enumerated in their proper place.

In Hymenoptera none have yet been described. About a dozen specimens are referred to Apidae and Andrenidae; several species are represented, but most of them are badly preserved; the largest appears to be a Bombus. Of Vespidae and other large wasp-like Hymenoptera about 70 or 80 specimens have heen found, referable to abont 30 species, one of which is a large Scolia or allied genus; several are Sphegidae, including an Ammophila; one, which seems to be a Polistes, shows traces of a blue-green metallic tint; another, apparently one of the Pompilidae, represents a species with a large subapical fuliginous spot on the wing; another, perhaps of the same family, has a circular clear spot in the center of the wing, surrounded with fuliginous. The ants are the most numerous of all insects at Florissant, comprising perhaps a fourth of all the insects; they form more than three-fourths, perhaps four-fifths, of all the Hymenoptera; I have already about 4,000 specimens of perhaps 50 species (very likely many more); they are mostly Formicidae, but there are not a few Myrmicidae and some Poneridae. I have noticed no Mutillidae. Ichneumonidae are very numerous; of minuter forms, having an expanse of wing of less than a centimeter, there are nearly 200 specimens, unusually well preserved; judging from a cursory examination they are exceedingly numerous in species, perhaps 80 all told, and many genera are represented; the larger forms, whose wings expand more than a centimeter, are even more numerous, both in species and individuals, and most of them are very fine, including a great variety, among which are especially noticeable a good assortment of species of Pimpla and allied genera. I have looked in vain for Pelecinus, or any long-tailed Rhyssae or Thalessae. The Braconidae, Chalcididae, Cynipidae, and Chrysidae, exceedingly few fossil species of which have ever been described, are very abundant, but have not been fairly separated from each other and from other small species; together they number nearly 250 specimens and probably 50 species. Among others there is a Chrysis, showing metallic green reflections on the abdomen; and also more than half a dozen species of Chalcididae, with expanded femora, represented by over 20 specimens. Finally, there are about 60 Tenthredinidae of 14 or 15 species, and several genera; besides a single species of Uroceridae.

A few Lepidoptera occur. One butterfly in a most admirable condition has already been described under the name of Prodryas Persephone, and there are two more diurnal species, each represented by a single specimen and each also generically distinct from any living forms, but yet falling in the immediate vicinity of those most nearly allied to Prodryas, namely, among the highest Praefecti. These I shall describe under the generic names of Jupiteria and Lithopsyche. Besides these there are a couple of poorly-preserved butterflies of uncertain position, and I hàve also set aside about a dozen specimens of perhaps 8 species of nocturnal Lepidoptera; but they are obscure, mostly of small size, perhaps Pyralidae or Tortricidae, and have not been critically studied.

Nearly a third of all the specimens I have seen from Florissant belong to the Diptera. Culicidae and Chironomidae are abundant, but not 
generally very perfect. Tipulidae are abundant and admirably preserved; of the larger forms alone there appear to be several hundred specimens, and apparently a considerable number of species. The smaller Tipulidae, including the Limnobina, are also abundant and well preserved. Some beautiful Mycetophilidae have been noticed, but these have not yet been selected from the mass of smaller flies. Bibionidae are the prevailing type among the Diptera; there must be 1,000 specimens belonging to this family, and on a cursory view there appears to be no great variety; probably both here and in the ants, as in some genera of plants, it will appear that there are vast numbers of a single species; a great many specimens are represented by bodies only, or these accompanied by insignificant fragments of wings; but even putting all these aside, there remain a goodly number with tolerably perfect wings, and some in which almost every part of the body is preserved; taken as a whole, however, they are perhaps less perfect than specimens of almost any other family. There are a dozen or more Stratiomyidae, of two or three species ; and several species of Midasidae or Hermoneuridae, one admirable specimen of the latter family having been described as belonging to a new genus under the name of Palembolus florigerus. There are nearly half a hundred Asilidae and Therevidae, many of them exquisitely preserved, some of great size, and among them a fair variety of forms. Bombylidae are somewhat less abundant, but show some superb specimens of great size and in wonderful preservation; there are certainly six or eight species. Syrphidae are more abundant than the last, nearly 50 specimens having been found, in which the patterns of the abdominal colors are generally well marked, and among which we find a considerable variety. There is a vast host of Muscidae and allied groups, of which no account has yet been taken, and with which, no doubt, many other forms are still commingled; but three or four species of very pretty Ortalidae may be mentioned, with ten or a dozen specimens.

About three-fifths of the Coleoptera belong to the normal series and two-fifths to the Rhyncophorous division. There are 80 to 90 specimens of Carabidae, including, perhaps, 30 species; many of them are very fine and perfect, especially in the sculpturing of the elytra. Water-beetles are not so numerous as would be anticipated; there are not more than 60 or 70 specimens, with perhaps twenty species; there are no large Dytisci, such as occur abundantly at Oeningen; the largest of our species, perhaps an Hydrophilus, not exceeding $12^{\mathrm{mm}}$ in length. The Staphylinidae are rather more numerous than the ground-beetles, with nearly 30 species, some of them tolerably large. There are half a dozen species of Nitidulidae. Some 60 or more Scarabaeidae show considerable variety, there being nearly 30 species among them. Nearly as many Buprestidae have quite as great a variety of form; a considerable number of them are large and nearly all fairly preserved, some remarkably perfect; one species, Chrysobothris Haydeni, has been described. Elateridae are more abundant, numbering more than 100 specimens, many of them in beautiful condition; they are abundantin species, over 40 having been separated, and are mostly of a medium, none of a large size. Considerably over 100 specimens are to be referred to the Meloidae, Mordellidae, and Malacodermata, but the specimens do not appear to be very well preserved, although about 40 species may be distinguished. The Cerambycidae are very beautiful, furnishing 30 or more specimens, representing more than half as many species; one fine species of a new extinct genus, Parolamia rudis, has already been described, and there are others equally fine. There are a dozen or more species of Bruchidae, one of which, 
Spermophagus vivificatus, has been published. Chrysomelidae are not uncommou; thus far I have recognized about two dozen species among the 60 or 80 specimens; one, Oryctoscirtetes protogaeus, belonging to a new genus, has already been published. Nearly twenty species of Tenebrionidae have been separated, rarely represented by more than a single specimen each, and there are also a few (from 2 to 10 species each) of Silphidae,Histeridae, Dermestidae, Ptinidae, and Coccinellidae, and a single species each of Cleridae and Telephoridae, the latter already described under the name of Chauliognathus pristinus. Two species of Rhynchophora, Anthonomus defossus and Eurhinus occultus, have been described. I have already mentioned the predominance of this type in opposition to the European tertiaries. The species are very numervus, nearly 120 having been separated, with over 500 specimens, and among them are a goodly number of large and fine species; but some of the minutest are most admirably preserved; especially is this true of the sculpturing of the thorax and elytra; no attempt, however, has yet been made to do more than rudely separate the species, so that no details can now be given. They will occupy seven plates of the forthcoming report, with one hundred and seventy figures.*

Among Hemiptera, to which eleven plates, with two hundred and eighteen figures, will be devoted in the report in preparation, Heteroptera are somewhat more numerous than Homoptera, both in individuals and species. The Heteroptera present a great variety of forms, over 100 species having been deteeted, three-fourths of which can be referred to their proper place; they will occupy seven plates, with one hundred and thirty-five figures. Lygaeidae, Reduviidae, and Pentatomidae abound. Corimalaenidae of several species are very common; but the most common of all are one or two species of Alydina (one of the groups of Coreidae), comprising perhaps a third of all the Heteroptera. There are two species of Aradidae, and half a dozen specimens of a very pretty species of Tingis, well preserved; but in general the preservation of the Heterop. tera is not so good as of the Homoptera. Very few water-bugs occur, but there are two or three species, among them a slender and very prettily marked Corixa. There are about 65 species of Homoptera, of which nearly one-half belong to the Cercopida. One genus, resembling Ptyelus, is represented by a dozen or more species, comprising together perhaps nine-tenths of all the Homoptera, some of the species being represented by 40 or 50 specimens. There are a few large Fulgoridae; one has the long recurved process of the head almost perfectly preserved. Two gigantic Aphrophorina have already been described as belonging to a new genus, and been named Petrolystra gigantea and $P$. heros; but as a whole the species are of medium size, with some minute and slender forms, the position of which is as yet undetermined. Plant-lice are common, and include probably 8 species, all A phidiinae excepting one, which is referred to Schizoneuridae; an entire plate is devoted to them, with nineteen figures. Many of the Homoptera have their markings beantifully preserved; especially is this the case in a variegated Typhlocypha or allied genus, and the venation of others is as complete as in the living form. No Stridulantia have occurred.

Sixty or seventy specimens of Orthoptera have been found, all the families being represented excepting Gryllidae and Mantides. Six specimens and nearly as many species of Locustariae are present; the finest,

*The execution of these plates, which are drawn by Mr. J. H. Blake, and engraved by Messrs. Sinclair \& Son, is far superior to that of any illustrations of tertiary insects which have yet been published. It leaves nothing to be desired, either in accuracy or finish. 
belonging to a new genus, has been described under the name of $\mathrm{Li}$ thymnetes guttatus. There are about the same number of Acridii, a single species of Phasmida, and two or three Blattariae, one of which has been described under the name of Homoeogamia ventriosus. But the mass of Orthoptera, including about 50 specimens and 8 to 10 species, belong to the Forficulariae; two of them, Labidura tertiaria and $L$. lithophila, have been described, but they are among the least interesting, several of the species exhibiting forceps of very great length; an entire plate has been devoted to them in a forthcoming report, with twenty-four figures, and theremaining Orthoptera, with nineteen figures, will occupy another.

The Neuroptera are made up in large part of Phryganidae, but no larval eases have been preserved; there ary about 100 specimens representing 15 or 20 species which are determinable, and which occupy one plate of the report and parts of others, including twenty-two figures; besides these there are several hundred which perhaps a severer study will classify; one species has wings 2 centimeters long, while others are minute; several of the subfamilies appear to be represented, true Phryganidae certainly, and probably Rhyacophilidae, Leptoceridae, and Hydropsychidae.

The collections embrace seven genera and twelve species of planipeunian Neuroptera, occupying one plate with fifteen figures. All of the species and four of the genera are new, and belong to five families. The Raphidiidae are the most numerous, embracing Raphidia with a single species and Inocellia with four; the species referred to Raphidia hardly belongs to it in a strict sense, since the costal vein is excessively short, there are no costal veinlets, and the sectors do not originate obliquely from the radius, but more indirectly by transrerse veins; all the species of Inocellia, which fall into two sections, differ from living types and also from the species found in the eocene amber of the Baltic, in having no transverse series of regular discoidal areoles below the pterostigma. A single species of Osmylus represents the Hemerobidae, and differs from living forms, as does also the amber species, in the simple character of the costal nervules, the much smaller number of sectors, and the limited supply of cross-veins in the basal half of the wing, giving this region a very different appearance from its rather close reticulation in modern types. It may here be noticed as a very general rule that the neuration of the wing is much closer in modern Planipennia than in their tertiary representatives. There are four species of Chrysopidae, referable to two genera, each of them extinct; Chrysopidae have not before been recognized in tertiary strata, the single species poorly figured by.Andrä, and never carefully studied, being much more probably one of the Hemerobidae; these two genera, called Palaeochrysa and Tribochrysa are allied to the living Nothochrysa, but differ from modern types in the zig-zag course of the upper cubital vein and in its direction, which is through the middle of the wing, as well as by the smaller number of sectors, and the entire absence of any transiverse series of gradate veinlets; Palaeochrysa is represented by a single species, Tribochrysa by three, and the genera differ from each other in the course of the upper cubital vein, which in Palaeochrysa is direct and bordered by comparatively uniform cells, while in Tribochrysa it is doubly bent in the middle, and is therefore bordered by very unequal cells. The single species of Panorpidae, referable to a new genus, has already been described under the name of Holcorpa maculosa; it differs from Panorpa in the entire absence of eross-veins, and is remarkable for the spots on the wings. No planipennian Neuroptera have been found in the Green 
River shales, but the tertiary beds of British Columbia have furnished a single species of Hemerobidae belonging to an extinct genus allied to Micromus, and which I have called Bothromicromus. The number of species of tertiary Planipennia is nearly doubled by the discoveries already made in the American tertiaries, but the families and especially the genera are very differently represented on the two continents. In the European tertiaries, the Raphidiidae have only one species of Inocellia; while on the other hand the Hemerobidae show one or more species each of Nymphes, Sisyra, and Hemerobius, besides the species of Osmylus mentioned; the Chrysopidae, as stated, are unrepresented, although two species, are indicated by Hagen from the Jura of Eichstätt; the Panorpidae have one species of Panorpa and three of Bittacus; while there are also two species of Ascalaphus and one each of Coniopteryx and Chauliodes, belonging to families not found at Florissant. To pass to other Neuroptera: Embia, too, is represented in Europe by a single amber species, and there are no less than thirteen species of four genera of Perlidae, a family unrepresented in America, and eight species of five genera of Psocidae already described, and a number more shortly to be published by Dr. Hagen; of the latter family Florissant has one highly interesting species of a new genus, Necropsocus, which seems in some measure to unite its two divisions of Atropina and Psocina, and to be curiously related to one of the interesting genera from the amber which Dr. Hagen will soon make known. Larvae and pupae of three species of Ephemeridae and an imago are also found at Florissant; immature stages of Ephemeridae have not before been found fossil, and only a single winged Ephemera has been indieated from the tertiary rocks of Europe (Oeningen), but the Prussian amber has furnished seven species. A rery interesting species of Lepisma also occurs at Florissant, the first known from any rock formation, but here again the amber discloses no less than sixteen species of Lepismatidae, besides ten other Thysanura.

The Odonata furnish the first opportunity that has been embraced of a comparison between the insect faunas of Florissant and the Green River shales; the Florissant beds have furnished six species in the perfect state besides two larvae; the Green River shales four species in the perfect state besides fragments of another, concerning which nothing more can be said than that it probably belongs to the Libellulina; two of the Florissant forms belong to Aeschna, besides one of the larvae; all the remainder, four Green River species, and four from Florissant, besides the other larva, belong to the Agrionina; the Green River shales are represented by one species of Podagrion and three species of Dysagrion, an extinct genus of the legion Podagrion allied to the genera Podagrion and Philogenia; the Florissant bed by two species of Agrion and two of Lithagrion, an extinct genus with the same alliances as Dysagrion; the species of Agrion are not sufficiently perfect to decide into what subgenus they will fall, but they are certainly closely related to each other, and appear to be most nearly allied to Amphiagrion, or else to Pyrrhosoma or Erythromma; all the Green River species then belong to the legion Podagrion, while the Florissant species are divided between the legions Podagrion and Agrion; the resemblance of the fauna of the two localities is very apparent, though the species and even the genera are wholly distinct; the facies of both faunas is decidedly subtropical. The European tertiaries have proved far more productive in Odonata than the American, nearly fifty species having been indicated, of which about fourteen are larvae or pupae; as in America, the Agrionina are the most numerous, having eighteen species and mostly representing the true Agrionina (America nine species, wholly Agrionina proper); 
Libellulina come next with sixteen species (only indicated in America), of which no less than ten are larvae or nymphs; then Gomphina with seven species (not yet detected here); and Aeschnina with six species (against three in America).

Twenty-six specimens of Termitina have been found, belonging to six species and three genera; among the specimens is a single worker, with one exception the only one that has ever been found fossil; four of the species and two genera belong to the section with branched, the others to that with unbranched, scapular vein. This is the same proportion as holds with the sixteen species of the European teritaries, where eleven belong to the first, five to the second section; of living types, on the contrary, only 35 per cent. belong to the first, 65 per cent. to the second section. Three of the species belong to a distinct genus which I call Parotermes, apparently peculiar to America, but possibly including some from the European tertiaries; another is doubtfully referred to Hodotermes, which has furnished fossil species from several localities in Europe, as well as among living forms; while the other two probably belong to Eutermes and are allied to species from Radoboj, placed with many modern types in this group. Calotermes, which has furnished species from amber and the Rhenish basin; Termopsis, which has more fossil (amber) species than recent; and Termes proper, which is represented at Oeningen and Radoboj, as well as in amber and on the Rhineall seem to be wanting at Florissant; the composition of the tertiary white-ant fauna of Florissant, therefore, differs considerably from that of any locality in Europe; but it most nearly resembles that of Radoboj in Croatia, where a like number of species has been found.

A single plate with thirty-two figures is devoted to the Arachnida, of which there are 32 species and 78 specimens; all of them are Araneides or true spiders. To show the bearing these have upon our knowledge of fossil Arachnids, it may be well to enter in this single instance into a few details.

Up to the present time a little more than 250 species of tertiary Arachnides have been described. Of these about 190 are true spiders, while the remainder are mostly Acarina, Opiliones, or Chernetidae; all but a single species are from European beds, and nine-tenths of them are preserved to us in the eocene amber. Were this means of restoring the ancient tertiary fauna unknown to us, our information at the present day would be based upon 24 species, although in addition to these half a dozen more are indicated by simple reference to genera or families. This number is exceeded by those already found at Florissant.

Whether we examine the American or European species preserved in stratified deposits $(i . e$. , excluding amber), we find an almost total absence of any but true spiders or Araneides; in each (including a tick from the beds at Green River, Wyoming), a single species of Acarina is known, though a number of others undescribed are credited to European strata. In Prussian amber, on the other hand, though Araneides are vastly in the majority, the other groups of Arachnida form twentyseven per cent. of the entire number of species.

This greater proportion of true Araneides in tertiary deposits, a proportion intensified at the present day, can scarcely be well compared to what we find in the older deposits, from the extreme pancity of their remains in the latter. Brodiê has found a single species (which he considers a true Araneid) in the secondary rocks of England; and the Euro. pean Jura has furnished merely half a dozen Arachnids (nominal species, perhaps reducible to four), of which only a single one is referable to the Araneida,-Hasseltides, considered by Weyenbergh one of the Agal- 
enidae. In the paleozoic formations, again, a dozen species are known, all but three of which have been considered scorpions,* Phrynidae and Chernetidae, or related to them; indeed, one of the other three has not been placed by its describer among the true spiders, but named Arthrolycosa only from its somewhat marked Araneid features. The remaining two seem to be the only true precursors of this group known to us from the paleozoic rocks. The proportion, therefore, of the Araneides to other Arachnides is reversed between paleozoic and cainozoic times.

The Florissant spiders are distributed among the larger groups as follows: Saltigradae (all Attides), 3; Citigradae, 0; Laterigradae (all true Thomisides), 3; Territelariae, 0; Tubitelariae (A galenides, 1; Drassides, 5; Dysderides, $2=$ =), 8; Retitelariae (all Theridides), 4; Orbitelariae (all Epeirides), $14=32$. Nearly one-half, therefore, are Epeirides, and after these the Drassides are best represented. A comparison with the European tertiary spiders shows that America is far richer in Orbitelariae, and Europe richer in Retitelariae, Laterigradae and Tubitelariae, while the Saltigradae are almost equally represented in the two countries.

If, however, we except the species found in amber, and compare only those taken from the rocks in which they have been preserved, we shall reach perhaps a more just comparison, although the data will of course be far more meager. The greater proportion of Orbitelariae in America is now found nearly the same as before, but is not so great as the now heightened proportion in Europe of Retitelariae, while the Tubitelariae become the group in which the proportion is similar in each; the Laterigradae is the only group where the proportion remains nearly the same as in the previous comparison, while the Saltigradae are nearly lost sight of in Europe, a single species being known.

Carrying the analysis a little further, we shall obtain some interesting results; as will appear from the following table, in which all the groups represented in Europe are introduced, and both the total fauna and the species from the strata tabulated.

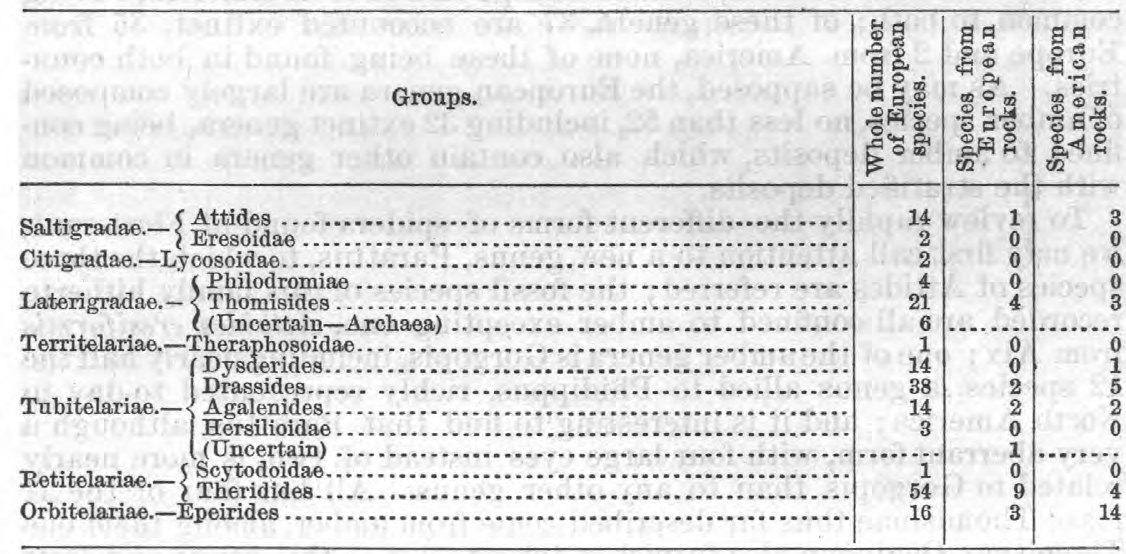

Here, it appears at a glance that exactly the same groups are represented in the stratified deposits of Europe and America in every instance, excepting the Dysderides, which is unrepresented in Europe, and has a single member in America. It also appears that just those families which are represented abundantly in amber are also represented, to

\footnotetext{
* Report has just come of a discovery of a considerable number of scorpions in the carboniferous rocks of Scotland, adding several species to those already known.
} 
some extent, in the American fauna, and (excepting, as before, the Dysderides) in the European rocks. Exception should perhaps be made for the six species of the remarkable amber genus, Archaea, the position of which in the Laterigradae is uncertain, and so marked in the table above. The relation brought out by this table is certainly striking, but it should, at the same time, be noticed that the Drassides and Theridides, and especially the latter, are enormously represented in the Baltic amber, and, in comparison with them (though not by any means to the same extent in comparison with the other groups), feebly represented in the stratified deposits of Europe and America.

A comparison of the percentage of representation of the larger groups in the different horizons of tertiary times in Europe with that of Florissant seems to indicate a greater difference between the latter deposits and those of the upper miocene of Oeningen than between the same and either the lower miocene of Rott or the upper eocene of Aix and the Baltic amber; and although the proportionate numbers of Tubitelariae and Orbitelariae of Florissant, and especially the former, are more nearly like those of Rott, the representation of the groups in general allies Florissant on the whole with the upper eocene rather than with the lower miocene of Europe.

Of extinct genera there have certainly been proposed a very large number for the European Araneidae, more than half the genera to which the species have been referred having been described as new and peculiar to tertiary times; these genera include about two-fifths of the species. Among the genera are some remarkable forms, such as Archaea and Mizalia, each of which is considered by Thorell and others as representing a distinct family. Two only of the thirteen genera into which the American species fall are new, and to them are referred 7 of the 32 species. Other genera, not before recognized in a fossil state, occurring in American strata are Titanoeca, Tetroguatha, and Nephila. To enter into brief particulars on this point, 71 genera of Araneidae are now known from the tertiaries, 66 from Europe and 13 from America, 8 being common to both; of these genera, 37 are accounted extinct, 35 from Europe and 2 from America, none of these being found in both countries. As may be supposed, the European genera are largely composed of amber species, no less than 52, including 32 extinct genera, being confined to amber deposits, which also contain other genera in common with the stratified deposits.

To review rapidly the different forms of spiders found at Florissant, we may first call attention to a new genus, Parattus, to which the three species of Attides are referred; the fossil species of this family hitherto recorded are all confined to amber excepting one, Attoides eresiformis from Aix; one of the amber genera is Gorgopis, including nearly half the 12 species, a genus allied to Phidippus, richly represented to-day in North America; and it is interesting to find that Parattus, although a very aberrant form, with four large eyes instead of two, is more nearly related to Gorgopis than to any other genus. All but four of the 21 fossil Thomisinae thus far described come from amber, among them one Thomisus; Oeningen also furnishes two species of this genus and Rott another, with a Xysticus; three species of Thomisus come from Florissant. The three families of Tubitelariae which are represented in the European and American strata are the ones most abundant at the present day. The fossil Dysderides of Europe (16 sp.) are all from amber, and include 8 species of Segestria, into which the single species from Florissant falls. The Drassides are very abundant in the European amber, and our own fauna shows four species of Clubiona and one of Anyphaena, 
both genera represented in amber, and Clubiona (which has eight amber species) also at Oeningen. Six genera of Agalenides are found in the European tertiaries, and Florissant adds another, Titanoeca (with two species) not found there, but allied to Amaurobius, which has three amber species. There is no family of spiders so abundantly represented in tertiary deposits as the Theridides, more than a fourth of the European species belonging here, with fourteen genera. America is for once poorer here than the stratified deposits of Europe, but possesses a single species of Linyphia, two of Theridium, and some egg cocoons referred for convenience to the comprehensive genus Aranea; Linyphia possesses three species from amber and two from Rott; Theridium is one of the very richest of the amber genera, having sixteen species, while three other species are described from Oeningen and Aix. The proportion of representation is very different in the Epeirides, eight per cent. of the European fossil spiders belonging in this group, while the proportion in America is forty-four per cent; Florissant possessing even more species than the amber, including seven or more species of Epeira, one each of Tetragnatha and Nephila, neither of which have before been found fossil, and four of a new genus, Tethneus, remarkable for its stout front legs. Five species of Epeira are reported from the European tertiaries, two each from amber and from Rott, and one from Oeningen. Not only, then, is Florissant peculiar for its richness in species of this family, but no other group of spiders shows so many novelties for the tertiary fauna.

The only Myriapod is a large species of Iulus, represented by half a dozen fragments, in which only the body segments are preserved.

Finally there is an odd form of animal, which although abundant and tolerably preserved is still of doubtful position. It is flattened oniseiform in shape, the body generally arched, and appears to be formed of only four nearly equal segments; each of the first three bears a pair of long swimming (?) legs, bearing a two-jointed tarsus armed with a single claw; both femur and tibia are compressed, expanded, and the latter fringed with hairs. The first segment has a median slit anteriorly, but there is no sign of a head on the 30 or 40 specimens examined, although the anterior portion of the alimentary canal appears to be extensile, being frequently preserved as protruding beyond the limits of the body and armed at the tip with a broken chitinous ring. There are no other mouth parts nor signs of eyes or antennæ. The abdomen is furnished at tip with a set of harder converging parts, which look as if they served the purpose of dragging the body backward. Larvae of any sort are exceedingly rare in the Florissant deposits, and there is no group known to me to which this seems to bear any similitude. There are sometimes faint indications of several joints to the abdomen, but when closely examined these appear to be illusory; and this would certainly exclude it from the Crustacea, unless indeed it belonged, as has been suggested to me by Prof. A. Hyatt, to a parasitic type. It is from 8 to $10^{\mathrm{mm}}$ long.

Animal remains besides those of insects are rare at Florissant. The most abundant is a species of thin-shelled Planorbis, which is not uncommon, and always occurs in a more or less crushed condition; it is the only mollusk yet found there (excepting a Physa or allied form and a single small specimen of a bivalve, referred to above in the section from the southern lake), and according to Dr. C. A. White is probably undescribed, although very similar to a species found in the Green River shales, differing from it principally in its smaller size.

Fishes rank next in numbers. Eight species have been found, belonging to four genera; of Amiidae we have Amia scutata and A. dicty- 
ocephala; of Cyprinodonts, Trichophanes foliarum and T. Copei; of Catostomidae, Amyzon pandatum, A. commune, and $A$. fusiforme; and of Siluridae, Rhineastes pectinatus. All the species have been described by Cope* excepting T. Copei, which was published by Osborn, Scott, and Speir.

Several bird's feathers have been found in these beds, and a single tolerably perfect Passerine bird, with bones and feathers, has been described by Mr. J. A. Allen under the name of Palaeospiza bella, and admirably illustrated br Blake. No other figure of a Florissant animal has yet been published. Besides these, Professor Cope has just described a plover, Charedinus sheppardianus, and writes that a finch is also found in these beds.

The plants, although less abundant than the insects, are exceedingly numerous, several thousand specimens having already passed through the hands of Mr. Leo Lesquereux. Of these he has published 37 species in his Tertiary Flora, $\dagger$ about two-fifths of which are considered identical with forms from the European Tertiaries. Of other specimens which he received after the publication of that volume, he has already given a cursory account in the annual report of Dr. Hayden's survey for 1876. He has also mentioned others in his review of Saporta's Monde des Plantes, and still others in letters. From these sources and from memoranda communicated by him, based on the plates of the Florissant species prepared for the eighth volume of Hayden's Report, the following review is drawn:

Among the exogenous plants the following polypetalous families are represented: Some flowers with long stamens are referred doubtfully to the genus Bombax, one of the Malvaceae. Of Tiliaceae, a species of Tilia has been found; of Rutaceae, one species of Ailanthus. Of Anacardiaceae, three species of Rhus are described under the names Evansi, rosaefolia, and Haydeni, and three or four others mentioned. Of Juglandeae one species, and one of Zanthoxyleae. Of Rhamnaceae, Paliurus Florissanti is the only species. A few leaves of Celastrus represent the Celastraceae. The Sapindaceae are very abundant, three genera occurring; leaves of Staphylea acuminata, numerous specimens of Sapindus stellariaefolius and $S_{\text {. angustifolius, as well as of two or three other species }}$ of the same genus, and two species of Acer, represented by flowers, leaves, and fruit. The flora has a large number of Leguminosae, of the genera Robinia, Colutea, and Cassia, besides Acacia septentrionalis and Mimosites linearifolius, described in the report mentioned. The Rosaceae show a Prunus, leaves of.Rosa, and species of Spiraea, with very finely preserved leaves of an Amelanchier, scarcely distinguishable from some of the varieties of the living species. Liquidambar europaeum Al. Br. represents the Hamamelidae; numerous leaves of Weinmannia, the Corniculeae; and, finally, there is a single species of Araliaceae, closely allied to Aralia multifida Sap. Excepting the Liquidambar none of the Polypetalae have been shown to be identical with European forms.

Among the monopetalous plants the Ericaceae are represented by Vaccinium reticulatum Al. Br., together with one or two species of Andromeda. Two species of Ilex, one described as I. subdenticulata, represent the Aquifoliaceae; one of Diospyros, the Ebenaceae; a species of Catalpa, the Bignonaceae. Oleaceae have a flowering branch of Olea and four species of Fraxinus, one referred to Heer's $F$. praedicta and another described as new under the name of $\boldsymbol{F}$. Brownelli.

The apetalous angiosperms show a great variety of forms at Floris-

* See Bull. U. S. Geol. Surv. Terr., $2 d$ ser., No. 1, pp. 3-5, 1875.

t Report U. S. Geol. Surv. Terr., vol. 7, 4to, Washington, 1878. 
sant, and among them many are referred to species from foreign tertiaries. Urticacea are the most numerous of all plants; three species of Ulmus occur, U. tenuinervis Lesq., peculiar to Florissant, U. Braunii Heer, and $U$. Fischeri Heer, both found in the European Tertiaries; of Celtis there are leaves having a close affinity to the existing $C$. occidentalis and its variety integrifolia Nutt.; they may, however, represent two species; a single species of Ficus represents a European form, $F$. lanceolata Heer; but the mass of specimens-nearly or quite one-half of all that have been brought from this locality-represent species of Planera; Lesquereux states that he has at least two thousand specimens of "leaves of Planera longifolia [Lesq.] and of its varieties, which come near Planeri Ungeri [Ettingsh.], and perhaps another species of the same genus." The Juglandaceae are represented by single specimens of Juglans thermalis* and Pterocarya americana, besides species of Palaeocarya and Engelhardtia. The six Cupuliferae recorded are all European species, viz: Quercus neriifolia Al.Br., Q. drymeja Ung., Q. salicina Sap., Q. antecedens Sap., Carpinus grannis Ung., and C. pyramidalis Heer. The Myricaceae are the next most abundant type after Planera, being represented especially by Myrica acuminata Ung., and Callicoma microphylla Ettingsh. (a true Myrica), both European species; there are, besides, no less than seven other species of Myrica, one of them referable to the European species, M. Ludviigi Schimp., another to a variety, acutiloba, of another European species, M. latiloba Heer; but the others new and either considered allied to $M$. Zacchariensis Sap. and M.arguta Sap. of the beds at Aix in Provence, or described under the names M. Copeana, M. Bolanderi, and $M$. insignis ; of the last, two specimens are mentioned; of the other two, only one. Of Betulaceae, Betula and Alnus are represented by a single species each, Betula dryadum Brongn. and Alnus Kefersteinii Göpp., both again European forms; cones of the latter are found. Salicaceae are tolerably abundant, Salix and Populus being represented by four species each; the four species of Salix are all identified as belonging to forms previously described from Europe or Alaska, viz: S. Lavateri Heer, S. integra Göpp., S. media Heer, and S. varians Göpp.; one species of Populus is referred to P. latior Al. Br., of the variety represented by Heer as denticulata; two others are considered new, one belonging to the section of $P$. glandulifera Heer; while the fourth, represented by a large number of leaves, very variable, especially in size, is considered as identical with $P$. Heerii Sap. of the gypsum beds of Aix. Finally, of undetermined plants in this group there is a species of Trilobium, and a Carpites, described as $C$. Pealei.

Among the Coniferae there is considerable variety, five species occurring, of four genera, all but one of the species represented in the European flora. There is, first, Pinus palaeostrobus? Ettingsh.; next, wellpreserved branches of Taxodium distichum miocenicum Heer; and abundant remains of Glyptostrobus Europaeus Heer; as well as two species of Sequoia, S. Langsdorffii Brongn., and S. affinis Lesq. The presence of the last-named genus is also well attested by the remains of gigantic silicified trunks in an erect position.

Finally, in the lower orders of plants, the following have been found : Of the Palms, a large specimen of a Sabal related to Sabal major Ung. of the European miocene; of the Araceae, Acorus brachystachys Heer, first described from Spitzenberg; of the Typhaceae, finely preserved leaves of a Typha; of the Naiadaceae, two species of Potamegeton; of the Iridaceae, well-preserved leaves of an Iris ; of the Gramineae, two frag-

\footnotetext{
* "Hot Springs, Middle Park," is the locality given in the text of Lesquereux's Tertiary Flora, but in the table, p. 327 , it is also credited to Florissant.
} 
ments of leaves of Phragmites; of Filices, numerous specimens of a single species; of Rhizocarpae, many specimens of Salvinia Alleni, described from Florissant and Elko, Nev.; of Musci, Hypnum Haydeni, likewise known only from this locality; and of Characeae, two specimens of a Chara.

Mr. Lesquereux has also found large numbers of leaves of a peculiar plant without any kind of neuration, which is apparently referable to the Proteeae.

We have thus from 90 to 100 species of plants already recognized from these Florissant beds, of which nearly half the species belong to the apetalous exogens. About 40 of the species are figured in the Tertiary Flora of Lesquereux.

According to this writer, such an assemblage of plants indicates a climate like that of the northern shores of the Gulf of Mexico at our epoch. "The preponderance of conifers, of shrubs, *** of trees of small size, * * * gives to the flora a general aspect which recalls that of the vegetation of uplands or valleys of mountains." Palms are almost entirely absent, only a single specimen of one species of Sabal having occurred. "Theleaves of some species are extremely numerous, none of them crumpled, folded, or rolled, as if driven by currents, but flat, as if they had been imbedded in the muddy surface of the bottom when falling from the trees or shrubs along the borders of a lake."

It is remarkable for the almost complete absence of hard fruits; and this, with the presence of flowers, of unripe carpels of elm and maple, and of well-preserved branches of Taxodium, which in the living species " are mostly detached and thrown upon the ground in winter time or early spring," led Mr. Lesquereux to believe that the deposition of the vegetable materials took place in the spring time, and that the lake gradually dried during summer.

To this we may add that the occurrence of Acorus, of Typha, and especially of Potamogeton, leads to the conclusion that the water of the lake was fresh, and not saline or brackish, equally proved by the fish, according to Cope, and by the presence of larvae of Odonata and other insects whose earlier stages are passed only in fresh water.

Neither the groups of fishes which have been found, nor the waterplants, the water-insects, nor the mollusks exclude Mr. Lesquereux's suggestion of the annual drying of the body of the lake. Moreover, certain thin layers are found overlying coarser deposits, which are suncracked through and through; but on the other hand the thickness of the paper shales, upon which most of the fossil remains are found, and which are composed of uniform layers of triturated flakes of volcanic products, being necessarily the result of the long-continued action of water, excludes this idea. The structure of the rocks rather indicates a quiet deposition of the materials in an unruffled lake through long periods, interrupted at intervals by the influx of new lava-flows or the burying of the bottom sediments beneath heavy showers of volcanic ashes.

The testimony of the few fishes to the climate of the time is not unlike that of the plants, suggesting a climate, as Professor Cope informs me, like that at present found in latitude $35^{\circ}$ in the United States; while the insects, from which, when they are completely studied, we may certainly draw more definite conclusions, appear from their general ensemble to prove the same or a somewhat warmer climate. If we inquire what testimony the fossil spiders of Florissant bear to the climate of that district in tertiary times, there is only one answer to be given; the present distribution of their allies certainly points to a considerably 
warmer climate than now-a climate which may, perhaps, best be compared to the middle zone of our Southern States. The known living species of the genera to which they belong are in general credited to regions like Georgia in this country and the two shores of the Mediterranean in Europe. The presence of species of Theridium, Linyphia, Tethneus, and Epeira, including two-fifths of the species, has no special significance; but Thomisus, Segestria, Clubiona, Anythaena, and Titanoeca, and especially Parattus, Tetragnatha, and Nephila, certainly present an ensemble, the indications of which cannot be overlooked. White ants are essentially a tropical family, only one or two out of eighty known species occurring north of latitude 40 . In North America only three have been recorded north of the border of the Gulf of Mexico, excepting on the Pacific coast, where one or two more extend as far as San Francisco. Two species, both belonging to the second section, are found in the valleys below Florissant, in $390^{\circ}$ north latitude. Florissant itself is situated 2,500 meters above the sea, and the presence of so considerable a number of white ants imbedded in its shales is indicative of a much warmer climate at the time of their entombment than the locality now enjoys. So, too, the occurrence among other Neuroptera, of Raphidia and Inocellia, of Lithagrion, and probably of the peculiar forms of Agrion, bears similar testimony; and the discovery of so many genera represented in or allied to those found in the Prussian amber is also indicative of a much warmer climate, since the amber fauna itself is held to show, for that period and place, a climate not far removed from that of the two borders of the Mediterranean. Investigation of other forms increases the weight of this evidence at every step, for nearly all the species (very few, certainly, as yet) which have been carefully studied are found to be tropical or subtropical in nature. As, however, a large proportion of those studied have been selected for some striking feature, too much weight should not be given to this evidence.

As noted above, the superabundance of specimens of single species of plants (Planera and Myrica) is repeated in the insects, where certain species of Formicidae among Hymenoptera, of Bibionidae among Diptera, of Cercopida and of Alydina among Hemiptera are to be counted by fifties and hundreds.

The only other general feature which may already be noted among the insects is an unexpected paucity of aquatic larvae or the imagos of water-insects. Hardly a dozen neuropterous larvae have come to hand, very few aquatic Hemiptera in any stage, and of Hydrophilidae and other water-beetles no great number. The paucity of neuropterous larvae is the more remarkable from the abundance of Phryganidae, while not a single larva-case has been found.

As to the age of these deposits, the opinions of Mr. Lesquereux, based on the study of tertiary plants, and of Professor Cope, drawn from his knowledge of tertiary fishes, are far more harmonious than one would expect from their known divergence of view concerning the testimony of the fossils to the age of other tertiary beds in the West. Such disparity of ideas did hold at first, Mr. Lesquereux maintaining in his earlier notices of the flora the probability of its later miocene age ; in the Tertiary Flora he placed it in the "Upper Green River" division of his "fourth group," together with the flora of Elko, Nev., the Green River beds being placed directly beneath them. In Hayden's report for 1876 he refers the Florissant deposits to the upper miocene. In his review of Saporta's Monde des Plantes,* while still considering it as miocene, he points out certain important relations which it bears to the flora of

*Am. Journ. Sc. (3), xvii, 279. (1879.) 


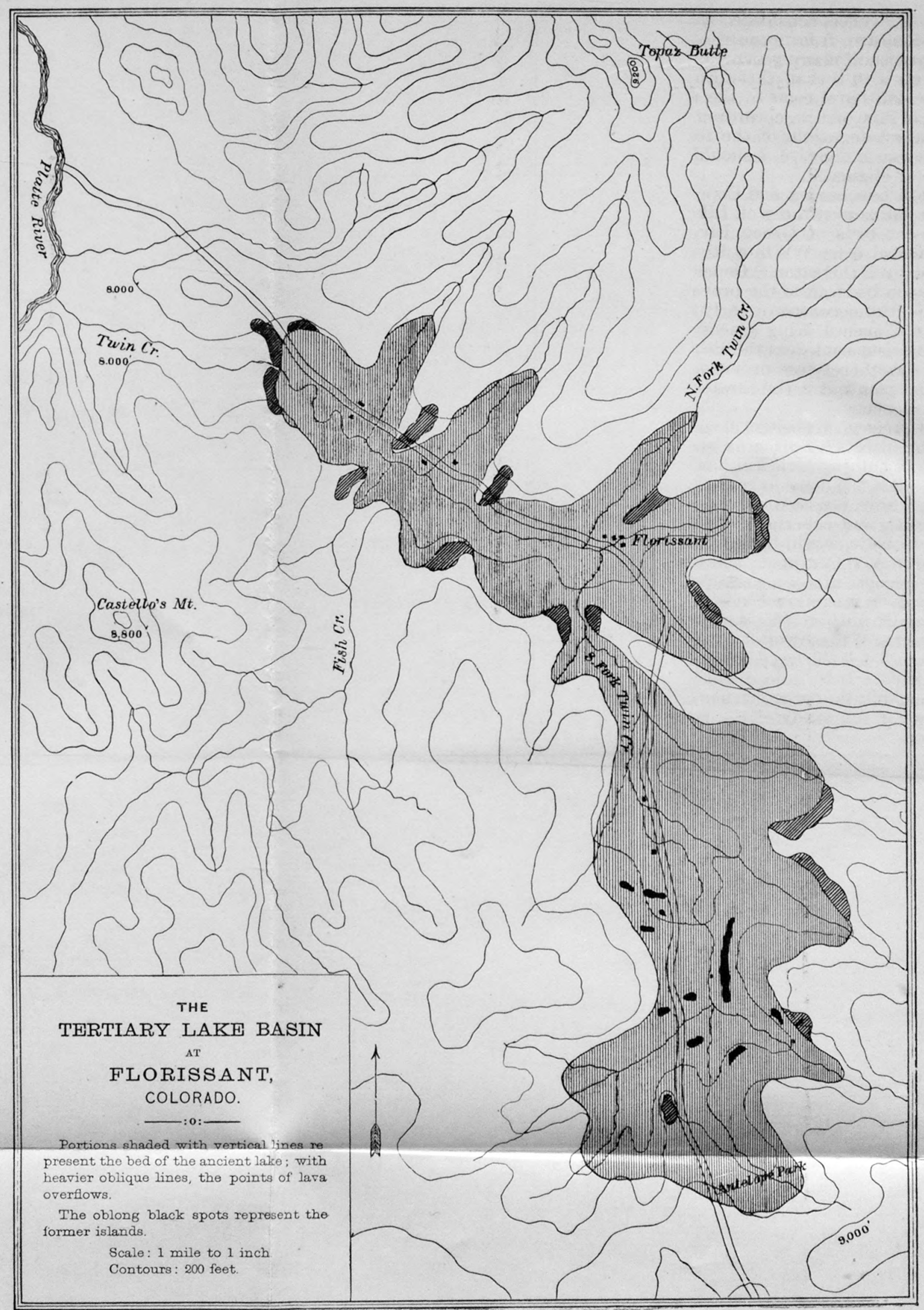


Aix, in Provence, considered as eocene. But now, after a more careful revision, drawn from more extended sources, he writes that while, by the presence of many genera, "there is an evident relation of the Florissant flora with that of the European miocene, yet by the aftinities and even identity of some of the species with those of the flora of the gypsum of Aix, which, according to Saporta, includes types related to those of the whole extent of the tertiaries from the upper cretaceous to the oligocene and above, I should rather refer this group to the lower miocene or oligocene."

Both Lesquereux and Cope agree in placing the Florissant beds at the same horizon as those of Elko, Nev., and also those directly above the Fish-cut beds at Green River, Wyoming. Lesquereux has identical species also from White River, Colorado, among specimens communicated by Mr. Denton. Cope calls the Florissant and Elko deposits the Amyzon beds, from the prevalence of that type of fish, and refers them to the "later eocene or early miocene."

Mr. Clarence King places the Green River deposits in the middle eocene, but considers the Elko deposits of the same age.

We may therefore provisionally conclude, from the evidence afforded by the plants and vertebrates, that the Florissant beds belong in or near the oligocene.

At present no geological conclusions can be drawn from what is known of the insects. So far as specific and generic determination has proceeded, nothing identical has been found in the Green River and Florissant beds," but some remarkable affinities have been noticed. To attempt, however, to draw any conclusion as to the age of either of these deposits, and especially of that of Florissant, before a closer examination is made, would be folly. The entire series of fossil insects from the beds of Aix, Oeningen, and Radoboj requires a careful generic revision, the Coleoptera alone, perhaps, excepted, and until this is done it will be difficult to make much use of the information given us in the works of European authors. This should not be considered as reflecting upon the character of these works, for it must be remembered that they were nearly all completed thirty years ago and could not be expected to meet present demands. It is, indeed, not impossible that the richer American fields, the exploitation of which has only just begun, may yet be found the best basis for the study of the relationship of the tertiary insect faunas of Europe.

\footnotetext{
* Some remains of egg cocoons of spiders are referred for convenience to the same species, but, of course, no weight whatever can be attached to obscure remains of this sort.
} 

SECTION II.

Z O ÖL O G Y. 



\title{
A MONOGRAPH OF THE PHYLLOPOD CRUSTACEA OF NORTH AMERICA, WITH REMARKS ON THE ORDER PHYLLOCARIDA.
}

\author{
BY A. S. PACKARD, JR. \\ Plates I-XXXVIII.
}

CONTENTS.

I.-Classification of living species.

II.-Geological succession.

III.-Geographical distribution.

IV.-External and internal anatomy.

V.-Development and metamorphoses.
VI.-Relation to their environment; habits.

VII.-Relatious of the Phyllocarida (Nebalia) to the Phyllopoda.

VIII.-Bibliography.

The Phyllopods constitute a division or suborder of the Branchiopoda, an order of Neocaridous Crustacea, intermediate between the Ento. mostraca (represented by the Copepoda and parasitic forms or fish-lice) and the Malacostracous Crustacea (Tetradecapoda and Decapoda). They inhabit fresh water alone, in a few cases brackish water or strong brine, but none dwell in the sea.

The Phyllopod Crustacea are especially characteristic of the western plains of our Territories, where the most striking and typical forms abound, one entire family (Apodida) not occurring east of the westeru edge of the Mississippi Valley, while the most bizarre member of the entire group, the Thamnocephalus, lives in pools on the plains of Kansas.

These Crustacea are of singular beauty and interest in themselves. The outlines of the Branchipodida are interesting, and their morements while swimming on their backs are singularly graceful. Moreover, when we consider the habits of all the Phyllopods; their singular means of adaptation to great ehanges in their environment; the great vitality of the species; when we take into account their weak and delicate individual organization, and when we note their interesting metamorphoses and many points in their structure, we are forced to conclude that the Phyllopods are the most interesting of all the Crustacea.

The materials for this monographic account of a most interesting group of Crustacea have been accumulating for over ten years.

My collection has consisted of specimens obtained by the various government surveys and sent to the Smithsonian Institution, and received from the late Dr. Stimpson, secretary of the Chicago Academy of Science, shortly before the fire which destroyed the museum of the academy. A large and very valuable collection was made for me by Dr. L. Watson, of Ellis, Kans., while a very valuable collection from Fort Wallace, Kansas, has been kindly loaned me by Prof. Joshua Lindahl, of Augustana College, Rock Island, Ill. I am also indebted to the Peabody Academy of Science, Salem; the Museum of Comparative Zoology at Cambridge, for the loan of specimens, as well as to the Museum of Yale College; and to Dr. C. F. Gissler, Mr. W. P. Seal, Mr. S. A. Forbes, 
Prof. A. E. Varrill, Mr. Edward Burgess, Dr. E. Cones; acknowledg. ments of whose valuable aid are made in their approprate places.

In the following pages I have touched upon some points in the internal anatomy of these interesting Crustacea, and only regret that want of time has prevented me from entering more into detail. For a num. ber of microseopic slides of Branchipus, Thamnocephalus, Estheria, \&c., I am much indebted to the friendly aid and skill of Norman N. Mason, esq., of Providence, R. I.

I desire also to express my thanks to Prof. F. V. Hayden, for the kind interest which he has taken in this work, and for the liberal number of plates with which the essay has been illustrated.

The chapter on the development of the young of Apus lucasanus and Streptocephalus texanus has been contributed by Dr. C. F. Gissler, of Brooklyn, N. Y., who made the drawings which illustrate the text, and also those composing Plates XXXIV and XXXV. A number of the drawings of the entire animal of the species of Apus and Lepidurus, \&c., were made by Mr. J. H. Emerton; some anatomical drawings in the plates were prepared by Mr. J. S. Kingley, while I am under obligations to Mr. Edward Burgess for the masterly manner in which he has executed the difficult sketches of the animals of Limnetis brevifrons, Estheria of several species, Eulimnadia, and Branchipus vernalis.

\section{CLASSIFICATION OF THE LIVING PHYLLOPODA.}

\section{HISTORY OF THE SUBORDER PHYLLOPODA.}

The history of this group is an interesting one. Originally mentioned in 1785 , by $O$. F. Miiller, in his "Entomostraca seu Insecta testacea," the Entomostraca were first defined in 1806, by Latreille, in his Genera Crustaceorum, \&c. Under Legio prima, Entomostraca, the Phyllopoda constituted the third order, the sole representative of this order being Apus, while the genus Branchiopoda (Branchipus of Schoeffer) forms part of a sixth order, Cephalota. The other genera of Phyllopods were not then known.

In 1820, Brongniart proposed the genus Limnadia for Hermann's Daphnia gigas (1804).

Meanwhile in 1817, in the first edition of Cuvier's Règne Animal, the order Branchiopoda was proposed by Latreille, while the classification of this order was further amended and improved in the second edition of this work (1829). In this edition the Phyllopoda constitute the second suborder of the Branchiopoda, and now the Phyllopods comprise the genera Limnadia, Branchipus, Artemia, and Apus.

In 1837, Straus-Durckheim described the genus Estheria, of which Cyzicus of Audouin (1837) and Isaura Joly (1842) are synonyms. The genus Limnetis was described by Lovén in 1845.

In 1840, Milne-Edwards, in his Histoire Naturelle des Crustaces, established the Legion Branchiopodes, equivalent to the Entomostraces. Under the Branchiopoda he regards the Phyllopoda as forming an order, and they are succeeded by the Cladocera, while the Legion of Entomostraca comprises the Ostracoda and Copepoda.

In 1853, Prof. J. D. Dana, in the Crustacea of the United States Exploring Expedition, regarded the Phyllopoda as constituting the second Legion of his first order (Gnathostomata) of Entomostraca.

In 1863, Gerstaecker regarded the Phyllopoda as forming a family of the order Branchiopoda, the Trilobita, Cladocera, and Ostracoda, forming the remaining families. Claus, in 1868 (Grundzüge der Zoologie), divided 
his order Phyllopoda into two suborders, Cladocera and Branchiopoda. Gerstaecker in Bronn's Classen und Ordnungen Arthropoden, 1866-'79, adopts the order Branchiopoda, and divides it into three suborders, Ostracodea, Branchiopoda genuina, comprising the Cladocera, Phyllopoda of other authors, and the Branchiura (Argulus, \&e.).

In 1879 the writer, in his "Zoology for Colleges," adopted the order Branchiopoda, with three suborders, viz, Ostracoda, Cladocera, and Phyllopoda.

\section{Suborder PHYLLOPODA.}

In this group the body is usually (the Branchipodidce excepted) in part covered by a large carapace (the mandibular segment greatly developed tergally), which is in the lower forms (Limnadiacea) bent down, forming two valves, connected by a true hinge, and opening and shutting by an adductor muscle, so that the shell resembles that of a bivalve molluse, such as the fresh-water Cyclas and Pisidium. They have two pairs of antennæ, a pair of mandibles, and two pairs of maxillæ, and in Apodida a pair of maxillipedes. The name of the group, Phyllopoda, is applied to them on account of the feet, which are broad and leat-like, with a series of six primary inner lobes or endites and two exites, the latter forming a gill and accessory gill or flabellum. The abdomen is not clearly differentiated from the thorax, and the abdominal feet are not different in shape from the thoracic appendages. The number of body-segments varies more than in any other group of genuine Crustacea, there being seventeen in Limnetis and sixty-nine in Apus, or over three times as many as in the lobster or Decapods in general; the segments are thus often irrelatively repeated, a sign of inferiority. The eyes are either sessile and united into a single mass, or, in the highest family (Branchipodida), they become stalked, thus anticipating the stalked eyes of the Decapoda. The telson is usually large and spiny, bearing in all the genera a pair of caudal appendages probably homologous with the limbs.

All the members of the suborder hateh from the egg in the Nauplius form, like that of the Copepod Crustacea, with some differences, all having three pairs of appendages corresponding to the two pairs of antennæ and mandibles of the adult.

The species for the most part live in pools of fresh water liable to dry up in summer; those of Artemia live in brine pools and lakes. The eggs, after being fertilized and borne about for a time under the shell or in egg-sacs, are finally suffered to drop to the bottom of the pond; here they lie after the water of the pond has evaporated, the eggs remaining in the dry mud until, the ponds having been refilled by the autumn rains, the young hatch out and the cycle of life begins anew.

\section{Family I. LIMNADIAD E Baird.}

Limnadiade Baird, Proc. Zool. Soc. London, XVII, 86, 1849; Ann. \& Mag. Nat. Hist. $2 d$ Ser. XIV, 229, 1854.

Estheriade Packard, Hayden's U. S. Geol. Surv. Ter., for 1873, 618. 1874.

Body inclosed in a bivalved shell; head usually with a large rostrum; eyes compressed, small, sessile, closely contiguous or united. 1st antennæ minute, 3.jointed or multiarticulate, the segments not being well marked; $2 \mathrm{~d}$ antennæ large, with two flagella, each consisting of from 9 to 20 joints. A pair of mandibles; one or two pairs of maxillæ; 10 to 27 pairs of swimming phyllopod feet, each with six lobular endites, and a gill and flabellum divided into two divisions, the upper in the fe- 
male keeping the eggs in place. 1st (Limnetis), or usually the 1st and $2 d$, pair of feet in the male provided with a hand; the 4th, 5th, and 6th endites modified to form a claw, finger, and thumb-like clasping organs. Posterior segments each bearing a pair of spines; the telson large, compressed, often spined, and bearing a pair of caudal appendages. Larvæ nauplius-shaped.

\section{Subfamily LIMNETIN AE Packard.}

Shell nearly spherical, with no lines of growth; rostrum very large and broad at the end, mucronate in the females, broad and truncate in the males; $10-12$ pairs of feet; in the males only the 1st pair provided with a hand; terminal segments of the body not spined; telson undeveloped. But a single genus, Limnetis.

\section{Genus LIMNETIS Lovén.}

Limnetis Lovén, Kongl. Vet. Akad. Handlingar, Tab. IV, 203, 1845; Ofversigt Vet. Akad. Förhandl. 57, 1846; Wiegmann's Archiv, II, 203, 1847.

Hedessa Lievin, Neneste Schrift. der naturf. Gesellsch. in Danzig, IV, Heft II, 4. Tab., I, II.

Hedessa Siebold, Neueste Preuss. Provincialbl. VII (XLI), Heft 3, 198, 1849.

Carapace bivalved, nearly spherical, oval, smooth; polished fine puncture-like marks in the parenchyma of the shell, giving it the appearance of being finely punctured; no beaks or umbones. Head large, the front bearing the eyes enormous, and produced into a very large rostrum, either truncated in \& and either mucronated or truncated in o in front. Eyes small, sometimes separate. First antennæ minute, slightlý elbowed, with indications of three joints; second antennæ with scape or base rather short; the flagella rather short, composed of from 15 to 21 joints, with remarkably long setæ. From 11 to 12 pairs of feet; in the males the anterior pair converted into a eomplicated hand; the end of the abdomen blunt, simple, with no spines.

The species of this genus are readily recognized by the spherical small, smooth shell, with no lines of growth, entirely inclosing the animal; by the enormous head, the large broad rostrum; the few feet, there being but one pair of hands in the males, instead of two, as in Estheria, and by the simple unarmed telson. The antennæ are shorter and thicker than in Estheria. They are sometimes mistaken by shell collectors for specimens of Cyclas or Pisidium. They swim on their backs, with the shell a little open, in a graceful but not very rapid manner compared with the Ostracoda.

\section{Synopsis of the species.}

Shell subspherical, small, front of head of male narrow; second antennæ 16 -jointed; flabellum very large......

Shell large, suboval; front of male broad and square;

L. gouldii. second antennæ 14 and 17 -jointed; flabellum remark-

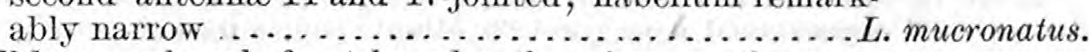

Shell large, suboval; front broader than in any other spe. cies except gracilicornis; autennæ 20 -jointed; gill very large, flabelium short and broad.................. brevifrons. Shell small, subspherical; front very broad; antennælong,

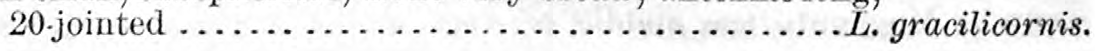




\section{LIMNETIS GOULDII Baird.}

Plates II, Figs. 1-6; XXIX, Fig. 9.

Limnetis gouldii Baird, Annals and Mag. Nat. Hist., 3d ser., vol. x, 393, 1862.

Shell smooth, spherical, quite round, not often oval as in the two succeeding species, and of a uniformly smaller size. 1st antennæ very slender, not so broad at the end as in L. brevifrons. $2 d$ antennæ with the stem longer and slenderer than in the two following species; the upper flagellum 16, the lower 16 jointed, with longer setæo than in the other species. First leg of female with a very large, long, and broad flabellum $\left(b r^{\prime}\right)$, the posterior division $\left(b r^{\prime \prime}\right)$ very long and slender, closely resembling the 6 th endite, but considerably longer; the gill rather small. The coxal lobe (1st endite) rather broad and not so long as in the two other species; the hand is much slenderer, and the claw (6th endite) is longer and slenderer than in $L$. mueronatus;

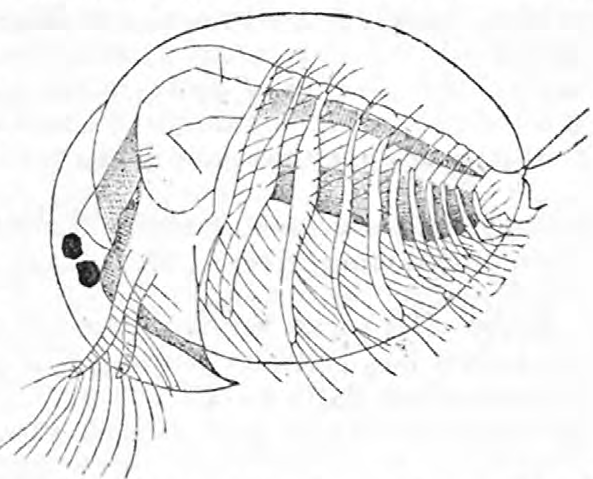

FIG. 1.-Limnetis gouldii, enlarged. Burgess del. 1st antennæ not drawn.

in the male the coxal lobe is considerably smaller and more triangular and acute than in the two other species; the comb, or 4th endite $\left(l^{4}\right)$ is armed on the edge with an inner row of small and a marginal row of much larger digitate setiferous processes; the finger $\left(l^{5}\right)$ is of moderate size, and the claw-like 6 th endite is long and slender; the flabellum $(b r)$ is about twice the size of the gill; and its posterior process $\left(b r^{\prime \prime}\right)$ is long, narrow, extending only a little beyond the base of the 6th endite. The front in the male (Fig. 3 d, in text) is truncated, but contracts below the eyes more than in the other species; while the carina on the front of the head is unusually high. In the female the rostrum ends in a sharp point, with lateral acute angles much as in sharply mucronate specimens of L. mucronatus.

Length of the shell, $3^{\mathrm{mm}}$; breadth, $2 \frac{3 \mathrm{~mm}}{5}$.

The species was first discovered in "fresh water at St. Ann's, twenty miles from Montreal, Canada." Collected by Charles Gould, esq., June, 1857 (Brit. Mus., W. Baird). The young received from Hanover, N. H. Near Boston, Mass. (Edward Burgess); near Providence, R. I., in great abundance in a pond which dried up in midsummer, occurring during May, and for at least a month after Branchipus vernalis had disappeared from the pond (A. S. Packard, jr., and H. C. Bumpus); abundant in a pond at Glendale, Long Island, in March and April (Dr. C. F. Gissler); Normal, Ill. (S. A. Forbes); Rock Island, Ill. (W. H. Pratt, Davenport Academy).

This is our most abundant species, and appears to range over New England, Canada, westward to the Mississippi River at Rock Island, IIl. It is distinguished from the two other species by the more spherical shell, its smaller size, the rather narrow, contracted front of the male, and by the differences in the antennæ and legs indicated in Plate II.

We have kept these beautiful little phyllopods in confinement from early in May until the middle of July, with few changes of water; 
they appear to be very hardy compared with the Branchipodidre. The animals are pale flesh-colored, with black eyes, and are tolerably rapid in their movements, swimming often on their backs and rapidly gathering the vegetation at the surface with their antennæ and either their coxal lobes or jaws. The eggs are carried upon the back under the shell, and are found in the spring.

We have received numbers of the east shells of the larva or nauplius from a correspondent at Hanover, N. H. The carapace bears a close resemblance to that of the nauplius of the Enropean $L$. brachyura, hav. ing the lateral front spines and two small caudal spines.

\section{Limnetis MUdronatus Packard.}

Plate I, figs. 1-6. (In fig. 1 the 1st antennæ are not represented by the artist.)

Limnetis mucronatus Pack., American Naturalist, ix, 312, 1875.

Bulletin Hayden's U. S. Geological and Geog. Survey, iii, No. 1, 172, 1877.

Male.-Carapace much flattened, oval-triangular, the dorsal edge of the valve but slightly eurved, the posterior end well rounded, while the front end is but slightly curved. Head in front truncate, much as in the males of $L$. gouldii and gracilicornis, the end being broad and square. Hand large, a little longer than broad, with the claw large, and as long as the hand is broad; the lower edge of the hand (or 4th endite) armed much as in $L$.gouldii. There are twelve pairs of limbs, the twelfth ending in a pair of large, strong, reeurved hooks. The end of the terminal segment on its ventral side is rather more produced, and with a more conspicuous spine than in the female. Two males occurred among forty-four females.

The length of carapace, $4^{\mathrm{mm}}$; breadth, $3.2^{\mathrm{mm}}$.

Female.-Carapace scarcely distinguishable from that of L.gracilicornis in outline, though it varies slightly in form, some being quite round and regular, others slightly ovate, and some quite flat and triangular. Muscular impression as in $L$. gracilicornis, but the muscular impression is much broader and proportionately shorter than in L. gracilicornis, where the front of the head is suddenly truncate, and wider at the extremity than behind in gouldii; while in gracilicornis it is also trun-

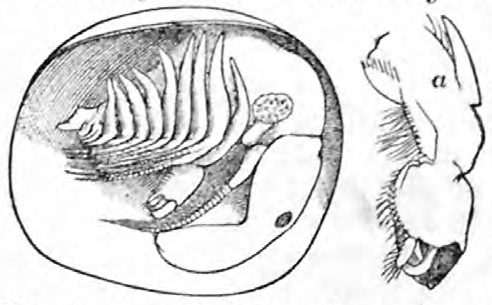
cate, but does not contract so much in front of the eyes, the narrowest point be ing between the eyes and the end of the front. In the present species, however, the front is very much produced into a long, acute, mucronate point, with two teeth on each side, the middle tooth varying much in length. The carina is very high and sharp (see $a$ in Fig. 3 in text). Fig. 2.- Iymnetis mucronatus, male; a a $2 \mathrm{~d}$ antennæ with the second joint half as
claw; both enlarged. 1st antennæ not drawn. Emerton del. joints very close, and together not as long as the succeeding seventh joint, from which arises the flagellum, the upper branch of which is 14-15-jointed, the lower one 17-jointed, with ciliated hairs about as long as in $L$. mucronatus, the longest ones as long as the entire antenna. Twelve pairs of feet.

The feet have a very long and slender flabellum, the gill being either in the first pair short and rounded at the end, or in the secondsand succeeding ones long and pyriform, being about the same shape and size 
as in L. gouldii; the filiform lower end (Pl. I, Fig. 4, br.) is much shorter than in $L$. gouldii, and endites $4-6$ are also much shorter; while the coxal lobe is large and very long.

End of the body blunt, squarely docked, the point blunter than in $L$. gouldii, and ending in a slender spine. Two dorsal terminal filaments, much as in $L$. gouldii.

Length of carapace, or shell, $4^{\mathrm{mm}}$; breadth, $3^{\mathrm{mm}}$. Forty-four females, nearly all with eggs, occurred with Lepidurus conesii, in pools on the west bank of Frenchman's River, Montana, $49^{\circ} \mathrm{N}$. (Dr. Cones.) It also occurred in large numbers associated with Limnetis brevifrons in pools at Ellis, Kans., collected by Dr. L. Watson June 29, 1874. The specimens were females with eggs, and as a rule were triangular in outline, compressed, only one or two of the Montana examples being so much compressed. The species is easily recognized by the mucronate, tridentate front, the short, thick hand and claw, by the number of antennal joints, and the long, narrow flabellum, the short endites 4-6, and by the long, stout, jaw-like coxal lobes.

\section{LIMnetis BREVIFRons Packard.}

Plate XXVII, figs. 1-3.

Limnetis brevifrons Packard. Bulletin of Hayden's U. S. Geol. and Geogr. Surv, iii, No. 1,172 , April 9, $187 \%$.

Many females. Carapace decidedly triangular in outline, more so than in $L$. gouldii, while it differs very decidedly in this respect from

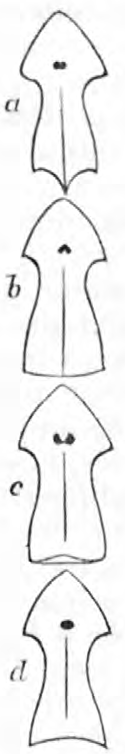

FiG. 3.-Front of head of Immnetis spp. $-a$, L. mucro. natus; $b, L$. gra cilicornis; $c, L$. brevifrons; $d, \quad$ \& L. gouldii. gracilicornis, and is considerably larger than gracilicornis or mucronatus, and is flatter than both. Front shorter and broader than usual; less contracted in width at the base of the antenne than usual. The frontal carina is high, especially a little in front of the

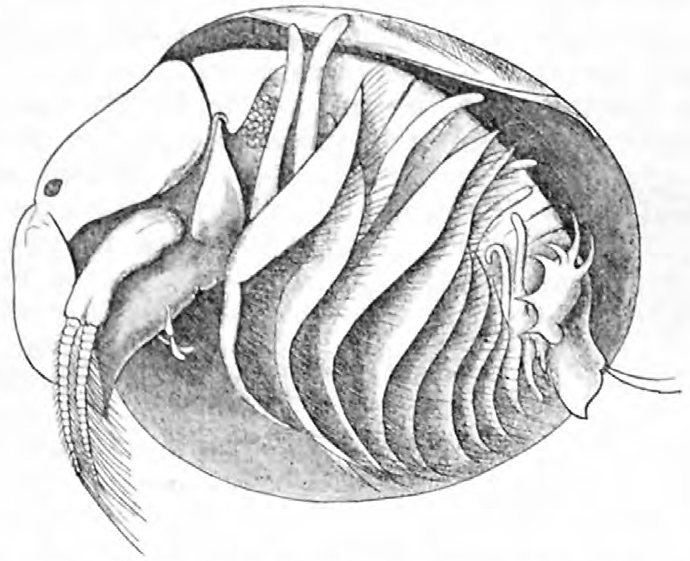

FIG, 4.-Timnetis brevifrons, female, much enlarged. Burgess del.

eyes. Compared with that of Iymnetis gracilicornis (Fig. 3, b, in text) it is much broader, shorter, the keel reaching to the end, which is squarely docked, the end boing a flattened triangle; the end of the front reaches to the middle of the antenna, while in L. gracilicornis the end reaches two-thirds of their length. It differs from $L$. gouldii (Fig. 
$3, d)$ in the front being thicker, the truncated end forming, seen from the end, a much less flattened triangle.

First antennæ much stouter than in L. gouldii. Second antennæ considerably longer than in $L$. gouldii, the terminal joint extending well beyond the end of the front, while in $L$. gouldii it does not extend beyond the front; the upper branch of the flagellum has 20 joints; the

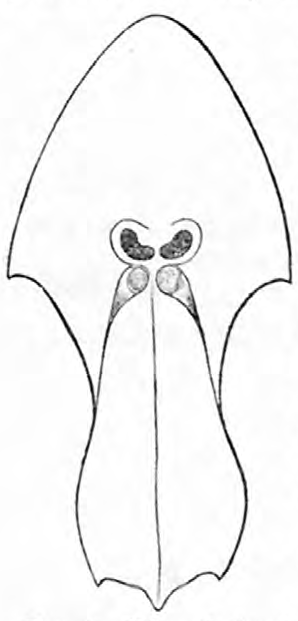

Fig. 5.-Limnetis brevifrons, frontof female, great. ly enlarged. Lindahl del. lower division of the flabellum, that next to the hand, is rather broader and larger than in $L$. gouldii. In the female the upper division of the flabellum $\left(b r^{1}\right)$ is short and broad; the gill is very long; the lower division of the flabellum (Plate XXVII, fig. 2 a) is as in L. mucronatus; the 4th endite is long and narrow, while the 5 th is longer than the 6th. Terminal segment less prominent than in L. mucronatus, while the dorsal edge is less excurved.

A verage size of most of the specimens: Length, $4^{\mathrm{mm}}$; breadth, $3 \frac{1}{2} \mathrm{~mm}$. Several larger examples were $6^{\mathrm{mm}}$ long and $5^{\mathrm{mm}}$ broad.

Ellis, Kans., June 28 and 29, Dr. L. Watson, in pools, associated with several other species of Phyllopods. A few eggs were contained in most of them. This is the largest species known, and is as a rule flatter and more triangular than any other speeies, while the truncate front of the head of the male is shorter and broader than in any other American species yet known.

\section{LIMNETIS GRACILICORNIS Packard.}

Limnetis gracilicornis Packard. Amer. Jour. Sc., 3d ser., vol, ii, Aug., 1871.

This species differs from $L$. gouldii in the longer and slenderer $2 d$ an tennæ, the flagella of which are 20-jointed; the keel on the front of the head does not reach to the front edge, while in L. gouldii it does. (Fig. $3, b$.) Shell of the same form, but much larger than in $L$. gouldii.

Length of shell, $4.2^{\mathrm{mm}}$; breadth, $4^{\mathrm{mm}}$.

Waco, Tex., with Eulimnadia texana and Streptocephalus texanus $\gamma$ G. W. Belfrage). I have unfortmately been unable within late years to obtain any specimens for dissection and study. 


\section{Subfamily ESTHERIAN E Packard.}

Carapace or shell oblong, more or less flattened or oval, sometimes subglobose, with distinct lines of growth. From 18 to 27 or 28 pairs of feet; in the males the two anterior pairs of feet with hands; the end of the abdomen with dorsal spines and two pairs of very long, large, curved, terminal spines.

\section{Synopsis of the genera.}

Shell oval, more or less globose, with 18-22 lines of growth, amber-colored; flagella of $2 \mathrm{~d}$ antennæ 11-17 jointed; 24 to 27 or 28 pairs of feet .................. Shell large, broad oval, much flattened, subtriangular, with about 18 lines of growth, a haft-organ present. Flagella of 2 d antennæ $12-13$ jointed; $18-22$ pairs of feet.....

Estheria.

\section{Limnadia.} Shell narrow-ovate, rather prominent behind the umbones, with 4-5 lines of growth. A haft-organ present. Flagella of $2 \mathrm{~d}$ antennæ $9-10$ jointed; 18 pairs of feet.... Eulimnadia.

\section{Genus ESTHERIA Rïppell.}

Plates III, IV, V, XXIV, XXV, XXVI, figs. 1, 2, XXVII.

Estheria Rüppell, Mnseum Senckenbergiannm. Bd. II, Heft. 2. Ueber Estheria dahalacensis Ruppell, von H. Strauss-Dnrckheim. 1057.

Cyzicus Audonin, Annales Soc. Ent. France, vi, 9, 183\%.

Isaura Joly, Annales des Scienc. Nat., ser. 2, XVII, 293, 1842.

Carapace valres or shell oval, more or less globose, with a prominent hinged back, Cyclas-like, with numerous lines of growth; amber colored. Body with 25-27 segments. Head with no "haft-organ;" as a whole the head is very large, being more like that of Limnetis than Limnadia, having a long narrow rostrum forming a large proportion of the head; first antennæ large and long, reaching nearly to the middle of the flagella of the second pair; the latter with a stont multiarticulate scape, the flagella extending well beyond the edge of the shell, and usually composed of about $15-20$ joints. Usually about 20 pairs of feet; in the female the coxal or maxilliform lobe is recurved, triangular, acute; the second and fourth endites are small lobes of nearly equal size, while the fifth is a long, slender, narrow process, the sixth being like it, but either wider and pointed at the end, or shorter than the fifth and scalloped along the lower edge. Of the three exites, the gill is elongate, pearshaped, while the upper division of the flabellum is very long and almost filamental at the end, nearly reaching the upper side of the body, the lower division being narrow, either pointed or rounded at the end, and scalloped along the upper edge, closely resembling in form the sixth endite. In the males the two anterior pairs are provided with hands, differing from those of the single first pair in Limnetis in the tubercle-like fourth endite, armed with stiff, sharp spines, forming the comb, while the finger-like fifth endite is somewhat bulbous at the end.

The species of this genus may be recognized by the globose ambercolored shell with numerous lines of growth. It differs from Limnadia in the large head, and long, large, acnte beak, and in the lack of a haftorgan, while it differs from Limnetis in the shell having lines of growth, a distinct beak and hinge, while the rostrum is narrow and pointed, and the number of body segments and legs is much greater, and the two anterior pairs of feet in the male are provided with hands. Moreover, the first antenme are much larger, with indications of numerous joints. 
Synopsis of the species.

Shell large, flat; beaks close to anterior end and very small ; second antennæ 13 - and 15 -jointed $\ldots \ldots \ldots \ldots \ldots \ldots \ldots \ldots \ldots$. californica.

Like californica, but with more prominent beaks, dorsal edge sloping directly down to the posterior end ................ newcombii

Shell long and narrow; beaks small, situated very near anterior end; telson armed with small fine teeth; hands of male short and thick; flagella 15 -and 14 -jointed ..................... compleximanus

Shell more swollen; beaks larger, and farther from anterior end; dorsal edge short, suddenly sloping to posterior end; flagella 17-and 16-jointed; telson with larger teeth interpolated in the smaller

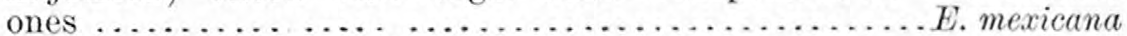

Shell still more globose than in E. mexicana; beaks more prominent in anterior third of shell; flagella 17 - and 16 -jointed........... morsei

Shell globose; beaks large and prominent, more central than in preceding species; flagella 14 - and 15 -jointed........... E. belfragei

Shell very large, thıck, globose, swollen; beaks larger and fuller, central; with more numerous lines of growth than any preceding species; flagella 17- and 16-jointed....................... jonesii

\section{ESTHERIA CALIForNicA Packard.}

Plate IV, figs. 1-5.

Estheria californica Packard, Sixth Rep. Peab. Acad. Sc., Salem, 55, 1874. Hayden's U. S. Geol. Surv. Terr. for 1873, 618, 1874. Lenz, Estheria californica, \&c., Lübeck, Ang. 5, 1876.

Shell remarkably thin, so that at first sight it might be mistaken for a Limnadia; in outline subtriangular; the umbones unusually small, very oblique, flattened, and situated much nearer than usual to the

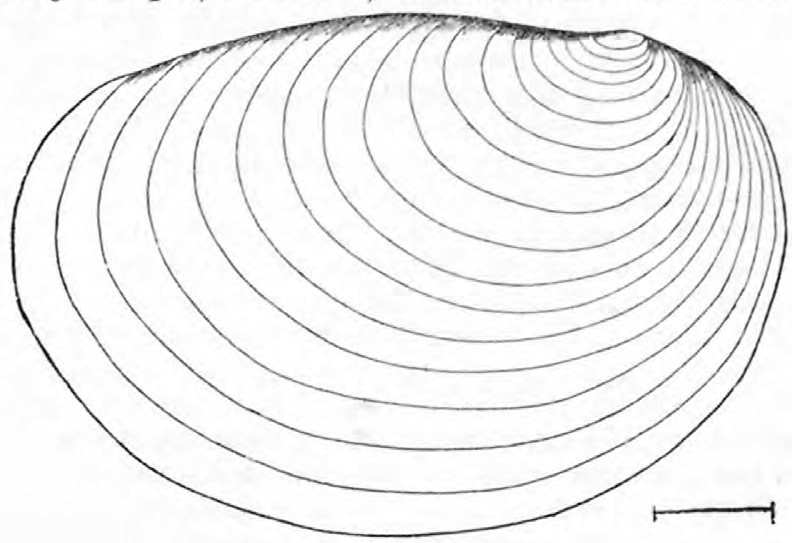

FIG. 7.-Estheria californica. anterior edge; dorsal ed ge convex, curving gradually to the rounded posterior end. Eighteen to thirty-five lines of growth. Shell very smooth, shining, with very fine granulations too numerous to be counted with a twothirds-of-an-inch trip, let; when more highly magnified they appear as in Plate XXIV, fig. 5. First der, the papillæ, however, not very well marked. Second antennæ with the upper flagellum 13-jointed, and much shorter than the lower, which is 15-jointed. Twenty-two pairs of feet. The gill is rather small and short; the upper division of the flabellum very long and slender, reaching to the back of the animal; the lower one acutely trianglar; the sixth endite is a little longer than the lower flabellum, and is broader in the third than in the first pair of limbs; the fifth endites are slender, long, and narrow, finger-shaped. The telson is armed above with numerous fine 
teeth, and about 8 much larger than the others, while the long acute caudal appendages are peculiar from having but about 4 long spines on the base of upper edge, with no fine teeth.

The hands of the males show no specifie characters of decided importance.

Length of shell, $16 \mathrm{~mm}$; breadth, $10 \mathrm{~mm}$; thickness, $4{ }^{\mathrm{mm}}$;

California (Rowell) Mus. Chicago Acad. Sc. 4 specimens; Alameda County, Cal. (James Behrens), Santa Cruz, Cal., collected by Laura F. Hicox, received through Mr. J. S. Kingsley.

It is closely allied in form to $E$. ticinensis of Lombardy, Italy, and may be said to represent that species in the Californian fauna. A detailed account of the external anatomy of this interesting species is given in "Estheria Californica Pack. Inaugural dissertation," \&c., by H. Lenz, wherein the mouth-parts and appendages, \&c., are figured. Of 25 specimens Lenz received from Mr. Behrens 11 were males and 14 were females.

From the next species, $E$. nexcombii, it appears to differ in the less prominent beaks, in the fact that the dorsal edge of the carapace does not slope directly down to the posterior extremity, which is not "nearly as broad as anterior extremity"; and there are 18 lines of growth, instead of "about sixteen," as in Baird's species, and the punctations of the shell are separate. Still it may be found that our species is synonymous with Baird's newcombii. I have been unable to see the plates, as in the copy of the Proceedings of the Zool. Soc. at hand the plates are wanting.

\section{EstheriA NeWCoMmII Baird.}

Estheria nexcombii Baird. Proc. Zool. Soc., London, 122, Pl. XII, fig. 2, 1866.

"Carapace oval in shape. Beaks prominent, placed near anterior extremity. The dorsal margin slopes directly down to the posterior extremity, which is nearly as broad as anterior extremity. Ribs of carapace, about sixteen in number, narrower at the beaks, and becoming broader as they descend towards the ventral margin. The intervals of the ribs are dotted with punctations, which are small and very numerous, and run into each other so as to produce a sort of running pattern."

"Length nearly $\frac{1}{2}$ inch; breadth about $\frac{1}{4}$ inch."

"Hab.-California (W. Newcombe, esq., Mus. Brit.)."

Estheria COMPLEXIMANUs, n. sp.

Plates V, figs. 1-7 ; XXIV, figs. 8, 10; XXV, fig. 6.

Eulimnadia compleximanus Pack., Bull. U. S. Geol. Survey III, No. 1, 174, April 9, 1s7\%, Zoology for Colleges and High Schools, 1st and 2d editions (no description) fig. on p. 302, 1879, 1880 .

Shell very long, oblong, not very thick compared with the following species; the beaks very small, situated at the anterior sixth or seventh of the dorsal edge of the shell, this edge being remarkably long and straight, more so than in any of the other species. The posterior end of the shell is narrow, not full and rounded, neither is the anterior end as full as in E. californica. About 15 lines of growth. Head with the rostrum rather long, approaching $E$. mexicana in this respect. Edge of shell with small short spines, and between the lines of growth confluent spaces arranged in oblique parallel lines. 1st antennæ long and slender, reaching beyond the lower edge of the shell, the sense papillæ very 
distinct and acute. 2d antennæ moderately slender, the scape not so thick as in E. californica; the upper flagellum 15-, the lower 14-jointed; the joints longer and slenderer than in E. mexicana. The legs of the female, especially one of the anterior pairs, have larger gills than in $E$. Mexicana. (Compare Plate XXIV, figs. 9 and 10.) The adjacent upper flabellum is moderately long, filamental in the upper half, but not reaching to the back of the animal; the lower division of the flabellum (fig. 7 br $^{\prime \prime}$ ) forms a long lobe scalloped on the upper edge, and elosely resembling in form and size the 6th endite. The 5th endite is long, finger shaped, and reaches beyond the 6th. In the male the first pair of feet have short, broad hands, with a broad 4 th endite, but the finger-like 5th endite is slenderer than that of the second pair, in which the hand is much longer and slenderer. Both pair of hands, partieularly the first, are much stouter than those of E. mexicana. The telson is armed along the upper edge with very numerous even teeth, no larger ones being interpolated among smaller ones, and the caudal appendages are finely serrated from base to tip.

Length of shell, $11^{\mathrm{mm}}$; breadth, $6^{\mathrm{mm}}$; diameter or thickness, $2.5^{\mathrm{mm}}$.

Ellis, Kansas, in pools, June 24-29, 1874 (Dr. L. Watson).

Fort Wallace, Kansas, abundant, associated with E. mexicana, Streptocephalus texanus, \&c. (Prof. Joshua Lindahl.)

This species may be readily recognized by the long, narrow shell, and

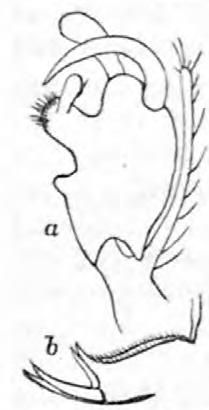

Fig. 8. - $a$. Hand of male Extheria compleximanus, mnch enlarged; $b$, telson. Emerton del.

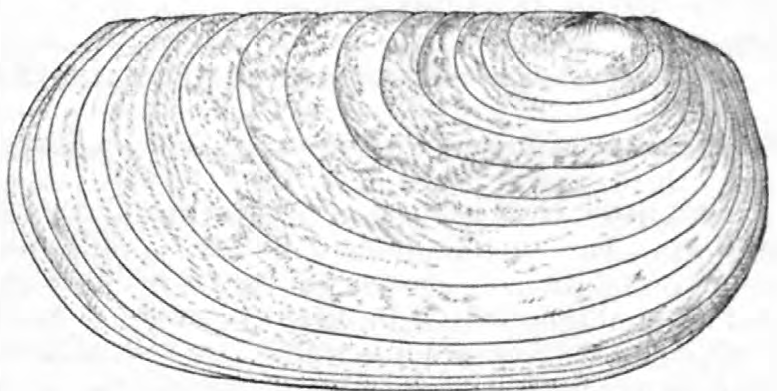

Fig. 9. Estheria compleximanus Pack, magnificd. Lindahl del.

the small beaks situated very near the anterior end of the dorsal edge; by the finely serrated edge of the telson and caudal appendages, the large gills, the short, thick hands of the male, and by the sculpturing of the shell.

By an unfortunate mistake it was referred to the genus Eulimnadia, for which it was hastily mistaken on account of its oblong-oval smooth shell.

\section{Estheria mexicana Claus.}

Plates XXIV, figs. 3, 6, 9; XXV, figs. 1-5; XXVIII, figs. 1-5.

Estheria mexicana Claus, Beiträge, zur Kennt. d Entomostraken, Marburg, Taf. III, IV, figs. 33-54, 1860.

Estheria dunkeri Baird, Proc. Zool. Soc., London. 147. Pl. XV, figs. 6, 6a, 6b, 1862 . Annals Mag. Nat. Hist., 3d ser., 391, 186\%.

Estheria caldwelli Baird, Proc. Zool. Soc., London, 148. Pl. XV., figs. 4, 4a, 4b, 1862. Ann. Mag. Nat. Hist., 3d ser., x, 393, 186\%.

Estheria clarkii Packard, Sixth Report Peabody Acad. Science, Salem, 55, June, 1874. Hayden's U. S. Geol. Surv. Terr., 1873, 619, Pl. III, fig. 7, 1874.

Shell or carapace valves thin, amber-colored, oblong oval, thin, about 
two-thirds as broad as long, with the umbones or beak rather prominent, oblique, situated on the anterior fourth of the shell, which is fuller, more globose than in the foregoing species; dorsal edge straight behind the beak, and a little beyond the posterior third of the entire shell rather suddenly sloping down, though the end is full and rounded. Shell (Fig. 10, in text) narrower than usual in the transverse diameter; about sixteen to twenty lines of growth, with fine setæ along the lines; unusually fine microscopic punctures between the lines, too numerous to be counted with a triplet. Under a higher power the dark spots in the soft tissue of the shell are seen to be either separate (Plate XXIV, fig. 3) or confluent (Plate XXIV, fig. 6), forming parallel markings, which disappear before reaching the line above. (The series of oval clear spaces in the drawing are the attachment of the setre, which are long and slender, see Plate XXIV, fig. 3.) In Baird's fig. $4 a$ and $6 b$ of E. dunkeri the punctures are separate, and probably there is a variation in this respect. Male shell narrower, and with rather more prominent beaks than in that of the female. Head, with the rostrum, loug and pointed; first antennæ rather thick, and moderately long; second antennæ with rather short joints, 17 in the upper and 16 in the lower flagellum; the upper sides of all the joints with 4-5 slender setæ; legs of the female, with the gill, rather long and large, the lower division of the flabellum quite broad; the upper or oviger (Plate XXIV, fig. 9) quite long and slender, but shorter than in E. compleximanus. First and second pair of legs of the male with rather slender hands, and both divisions of the flabel. lum are rather short and broad; the claw (sixth endite) is shorter than in E. compleximanus, as is the thumb, or fourth endite; the fifth endite is much as in E. compleximanus. The telson is shorter and higher than in E. compleximanus, with about twenty pairs of unequal spinules, the first, third, sixth, ninth, twelfth, fifteenth, seventeenth, and nineteenth much larger than in the others, while in E. compleximanus they are of uniform size; each spine is minutely spinulated; the terminal superior spine one-half as large as the inferior, but finely spinulated; the caudal appendages with fine, hair-like setæo on the upper edge.

The males have stouter spines on the telson than in the other sex. Length of shell, $10-12^{\mathrm{mm}}$; height, $7^{\mathrm{mm}}$; transverse diameter, $4^{\mathrm{mm}}$. This species differs from $E$. compleximanus in the more globose shell, the much shorter dorsal edge, which suddenly bends down, the fuller ends, the shorter hands of the male, and the unequal spines on the telson. From E. morsei it differs in the flatter, more oblong shell, and in the beak being much smaller, more oblique, and much nearer the anterior end of the dorsal edge, while the hands of the males are much slenderer than in E. morsei.

This is apparently the most abundant and widely diffused species on the continent, as will be seen by the following notes:

Lake Winnepeg, North America (W. Caldwell, esq.); (Mus. Brit.) (Baird.)

Several hundred young (figures on Plate XXVIII, figs. 1-6) about onehalf full size, collected by the late Prof. H. James Clark from a puddle in Lexington, Ky., May 21.

Cincinnati (Mus. Chicago Academy Science), Hamilton County, Ohio, in a eart rut, "so numerous that a dip of the hand would take up a dozen" (V. T. Chambers).

Ellis, Kans., "in an upland pool supplied by a spring" (Dr. L. Watson), Fort Wallace, Kansas, in company with Estheria compleximanus and streptocephalus texanus. (Prof. J. Lindahl.)

Common at the pueblo of Santa Ilsafonso, New Mexico, Angust; 
collected by Dr. Yarrow, Lieutenant Wheeler's Surrey west of the 100th Meridian.

Zimapan, Mexico, (Prof. W. Dunker coll.), Claus.

This species is exposed to eonsiderable variation, so that I was mis. led by the rather indifferent figure of Baird in considering it as distinct from $E$. caldwelli from Lake Winnepeg; and described it as $E$. clarkii. The specimens from New Mexico are large and well developed,

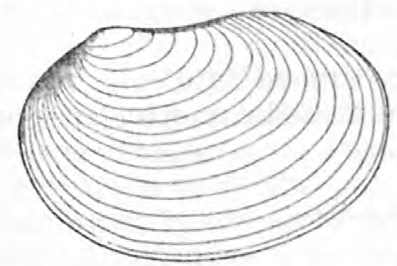

Fig. 10.-Estheria mexicana, enlarged four times. little and a larger than in the majority of the Kansas specimens. They agree well with Claus's figure of the shell, and the appendages are much as he figures them, so that as the species is abundant in New Mexico, I do not doubt but that it extends to Zimapan, Mexico, and thus the name for our most common and widely spread Estheria should be mexicana of Claus. This species is allied to the European E. dahalacensis, but the beak is fuller.

I have ventured to place $E$. dunkeri from Zimapan, Mexico, as a synonym of this species. Baird's description is almost identical with that of his E. caldwelli; but my New Mexican specimens have the same outline, the same number of lines of growth, and only differ in having less full and prominent beaks; but the artist may have exaggerated this feature in his drawing, though it is referred to in Baird's deseription, yet some smaller Kansas specimens have fuller beaks than the New Mexican ones, but, as the locality (Zimapan) and collector (Dunker) are the same as Claus's $E$. mexicana, there is little doubt but that taking into account the tendeney to variation in this species our synonymy is correct.

\section{Estheria Morsex Packard.}

Plate XXIV, fig. 7 ; XXVI, figs. 1, 2.

Estheria morsei Packard, Amer. Journ. Sc., II, Aug. 1871.

Sixth Report Peab. Acad. Sc. Salem, 56, June, 1874.

Hayden's U. S. Geol. Surv. Terr. for 1873, 619, 1874.

Morse's First Book of Zoology, 149, fig. 138, D. (No name.)

Shell much fuller, more globose than in any of the preceding species, with fuller, more prominent, less oblique, and centrally situated beaks; shell oblong oval, of a pale horn or amber color. Dorsal edge shorter than in E. mexicana, and in front of the beaks, instead of being straight and suddenly curved downward, is regularly rounder, much as in $E$. belfragei; posteriorly the dorsal edge slopes rapidly downward, without the well marked angle of E. mexicana. Coarse punctures between the lines of growth, rather coarser than in E. mexicana, there being on an average $\tilde{5}-10$ of these marking between the ribs in the center of the valve. Plate XXIV, fig. 7, also represents the markings at the edge of the shell.

Second antennæ, with a larger scape than in E. belfragei, 17 joints in the upper, 16 in the lower, flagellum. Legs of the male with a smaller lower division of the flagellum, and a smaller gill than in E. belfragei, while the upper division or oviger is much shorter and broader than in any of the foregoing species, being no longer than the gill. The hand is apparently a little thicker than in $E$. belfrage $i$.

Telson much as in E. mexicana, with about 20 pairs of teeth, coarser than in E. belfragei, about 5 pairs of which are much larger than the others.

Length, $12.2^{\mathrm{mm}}$; height, $8.2^{\mathrm{mm}}$; thickness, $6^{\mathrm{mm}}$. 
Six specimens from Dubuque, Iowa, collected by Rev. A. B. Kendig.

Six specimens from "Grindstone Creek, half way from Fort Pierre to the Bad Lands, Dakota," collected by Dr. F. V. Hayden, and received from the Chicago Academy of Science through Dr. Stimpson.

The smallest specimen from Dakota agrees exactly with the Iowa examples in being long, ovate; the others are considerably larger and with age seem to grow broader, more wedge-shaped. The following are the dimensions of the most wedge-shaped examples; length, $14^{\mathrm{mm}}$; height, $10.5^{\mathrm{mm}}$.

Differs from any of the preceding species by the full globose higher shell, with more prominent and central beaks, and the shorter oviger.

\title{
Estheria Belfragei Packard.
}

\author{
Plate III, figs. 1, 2, 4, 6; XXIV, fig. 1.
}

Estheria belfragei Packard, Amer. Journ. Sc., II, Aug., 1871.

Hayden's U. S. Geol. Surv. Terr. for 1873, 619, Pl. III, fig. 8, 1874.

Shell (Fig. 11 in text) or carapace valves with the beak situated between the anterior third and the middle of the shell; dorsal edge straight for a very short distance behind the beak. slightly serrate, bent rather suddenly downward at two-thirds of the distance from the beak to the posterior end, the end being very full and rounded; the anterior dorsal edge slopes down rapidly from the beak, and the anterior end is full and convex. Beak very full and prominent, more so than in any other species except $E$. jonesii, but they are not oblique. About twenty-four lines of growth, between which the shell is coarsely punctate; from 5-8 dots (when enlarged about four times, Emplaced in a straight line) between the lines of ertondel.

growth in central part of the shell; these punctures are reduced to a single row on the edge. In a piece taken from the edge of the shell and highly magnified (Plate XXIV, fig. 1) there are seen to be two rows of setæ, one very short and thickset, the row of larger ones very long and slender arising at some distance from the edge of the shell. The punctiform markings are seen to be large with scattered masses of denser tissue than that inclosing them. Second antennx with 14 joints in the upper, and 15 joints in the lower ramus of the flagellum. In the two anterior pairs of legs of the male, the lower division of the flabellum is rather broad and short, while the gill is moderaten in size and rather short; the hands are rather small, of the general shape of E. mexicana, but the claw is a little shorter. There are along the back seventeen pairs of dorsal spines exclusive of those on the telson, which are fifteen in number (in E. mexicana they are much more numerous), and the middile one is much larger than those near it. Caudal appendages longer and slenderer than in E. mexicana, and the terminal spine is longer and slenderer.

Length of shell, $7.5^{\mathrm{mm}}$; height, $6^{\mathrm{mm}}$; transverse diameter, $\pm 3.8^{\mathrm{mm}}$.

Six specimens, Waco, Tex., April (G. W. Belfrage).

This fine species differs from $E$. morsei, its nearest ally, in having a much shorter and higher shell with the laıger beaks nearer the anterior end. 


\section{ESTHERIA JONESII Baird.}

Plates III, figs. 3, 5, 7; XXIV, fig. 2; XXVIII, fig. 7 .

Estheria jonesi Baird, Proc. Zool. Soc. London, 147, Pl. XV, figs. 1, 1a, 1b, 1c, 1d, 1862. Packard, Hayden's U. S. Geol. Surv. Terr, for $1873,619,1874$.

Shell very large, full, globose, nearly twice as thick as any of the preceding species; the beaks very large, full, and high, situated between the middle and the anterior third of the shell; dorsal edge short; shell donaciform or wedge-shaped. It also differs from all the other species in the very numerous crowded lines of growth, with a bead-like rim of coarse punctures just above each line; along the lower edge of the shell a rim of short stiff coarse setæ. (Plate XXIV, fig. 2.) Seen from either end the shell is broad, heart-shaped.

Second antennæ stout, upper flagellum 18- the lower 17-jointed. In
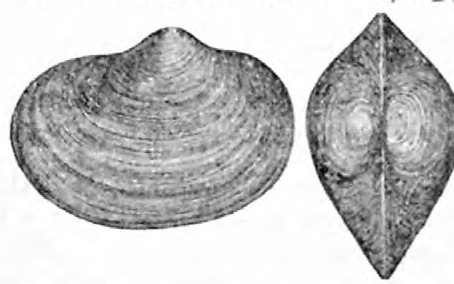

FIg. 12.-Estheria jonesii, magnified twice. After Baird. the first pair of legs of the male the gill is smaller than usual; the flabellum next to it is short and nearly twice as broad as in any of the other species, and the entire limb is short, and the hand also is short and stout, the claw being unusually short and thick.

The telson is very short and high; the upper edge with 13 pairs of coarse teeth of nearly uniform size; while a few hairs are on the basal half of the upper side of the caudal appendages.

Length of shell, $14^{\mathrm{mm}}$; height, $11^{\mathrm{mm}}$; thickness, $8^{\mathrm{mm}}$.

Cuba (Dunker).-I am indebted for specimens to Dr. E. Von Martens, of the Berlin Museum. A number of specimens, which do not differ from the Cuban examples, were loaned me by Dr. Stimpson, eurator of the Chicago Academy, and are marked "Locality lost." As no other specimens from the West Indies occur in the collection received from Dr.

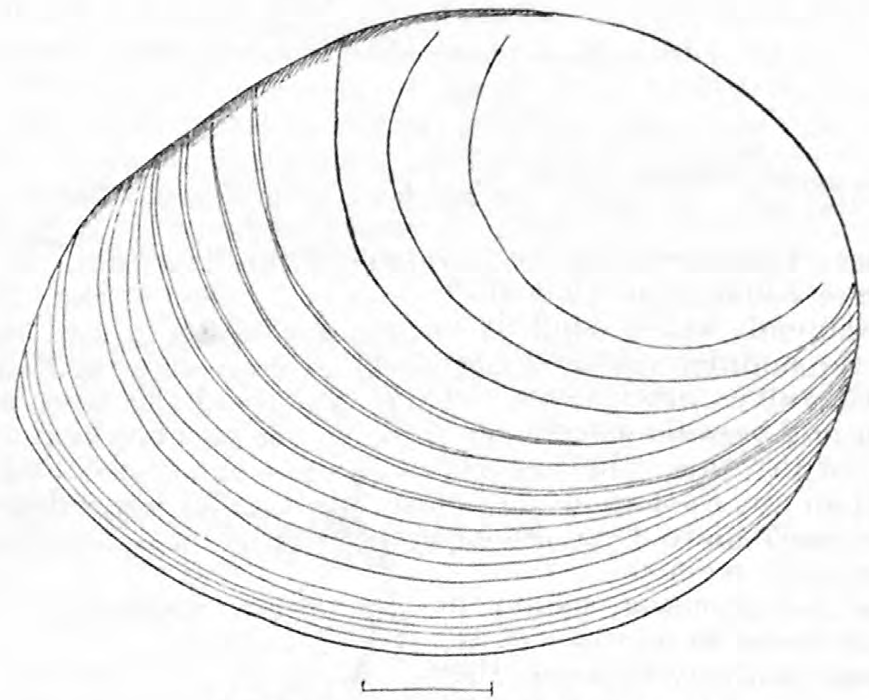

FIG. 13.-Limn̨adia americana, Packard.

Stimpson, it indicates that E. jonesii may possibly occur in the Southern States, or Central America; the only habitat as yet known being Cuba, where it is said by Baird to inhabit brackish water. 


\section{Genus IIMNADIA Brongniart.}

Limnadia Brongniart, Mémoires dn Muséum d'Hist. Nat. VI, P1. 13, 1820.

Milne-Edwards, Hist. Nat. des Crustacés III, 561, 1840.

Shell broad, flat, with about 18 lines of growth, disappearing near the very flat nearly obsolete beaks; 22 pairs of feet.

\section{Limnadia AMERICANA Morse.}

Limnadia americana Morse, Proc. Bost. Soc. Nat. Hist. XI. First Book of Zoology. Fig. 138, L., 1875.

Shell (Fig. 13 in text) large, broad, ovate, much flattened, with 18 lines of growth; smooth and shining; allied to L. gigas of Europe.

Length of shell, $12.5^{\mathrm{mm}}$; breadth, $9^{\mathrm{mm}}$.

Museum of Peabody Academy, collected by Mr. Tufts, at Lynn, Mass.

\section{Genus EOLIMNADIA Packard.}

Eulimnadia Packard, Sixth Report Peab. Acad. Sc. Salem., 55, June, 1874.

Hayden's U. S. Geol. and Geogr. Surv. Rep. for $1873 ;$ 618, 1874.

Shell narrow, oblong, oval, not nearly as wide as in Limnadia, with only 4 or 5 lines of growth; the dorsal edge straighter, less eurved than in Limnadia; 18 pairs of feet. The head and antenne do not differ essentially, but the gills are much larger than in Limnadia: while the upper or dorsal lobe of the flabellum is much smaller than in Limnadia.

The Australian Limnadia stanleyana King and L. antillarum Baird are congeneric with our $E$. agassizii and texana.

\section{Synopsis of the Species.}

Shell narrow-ovate, with 4 lines of growth ........... agassizii. Shell narrower than in preceding, more oblong, with 5 lines of growth; $2 d$ antennæ longer, more spiney and hairy than in foregoing spe-

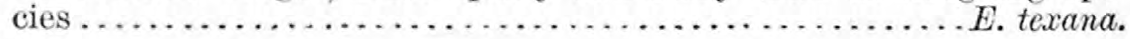

Eulminadia AGassiziI Packard.

Plate VII, figs. 5, 6.

Eulimnadia agassizii Packard, Sixth Rep. Peab. Acad. Sc., 54, 1874.

Hayden's U. S. Geol. and Geogr. Surv. for 1873. 618, 1874.

Carapace valves whitish, very transparent, quite regularly oval, narrower than usual, somewhat truncate at the end, widest slightly in front of the middle, with four lines of growth, valres much more con vex than in Limnadia americana.

Head with the "haft-organ" larger than in $E$. texana. First antemne much shorter, smaller and less distinetly segmented than in E. texana, not reaching beyond the middle of the stem or scape of the $2 d$ antennæ, while in E. texana they reach to the basal joint of the flagella. Second antemne with 9 joints

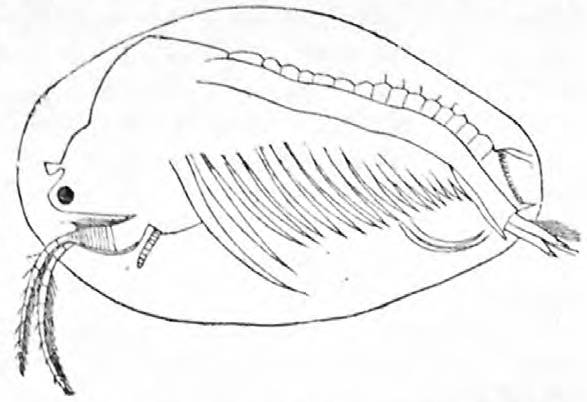

FIg. 14.-Eulimnadia agassizii Packard, enlarged about 6 times.

to each flagellum. In the upper flagellum but a single seta at the end of each joint, while there are four or five in E. texana; the setæo on the 
under side are much shorter and stouter than in E. texana; the stem is shorter and stouter than that of E. texana.

Eighteen pairs of feet.

Telson rather broad; along the dorsal edge are twelve pairs of acute spinules with the usual long forked filament between the first and second pair of spines; the large terminal spines of the telson fringed with long hair-like setre instead of spines, as in the European Limnadia gigas, but the tip is armed with minute short spines. A stout conspicuous spine on the lower angle of the telson under the terminal spines. A pair of long: abdominal cirri. The eggs are yellowish and roughly granulated.

Length of shell, $6.2^{\mathrm{mm}}$; breadth, $3.8^{\mathrm{mm}}$.

About one hundred females, mostly with eggs, occurred in a small pool of fresh water on Penikese Island, Buzzard's Bay, August 27, 1873, collected by Mr. Walter Faxon. Upon examining the pool the following July or August (1874), the young, about a line in length were found, but the pond subsequently dried up. The eggs are yellowish and with the chorion roughly granulated.

The species was dedicated to Prof. L. Agassiz.

Compared with $L$. americana Morse, which closely resembles $L$. gigas (received from Sweden through the kindness of Prof. W. Lilljeborg), it differs very decidedly in the much narrower shell and fewer lines of growth. It belongs to a different genus from the two above-named species, agreeing in the structure of the animal and the bivalved carapace with $L$. antillarum Baird, Proc. Zool. Soc., 1852, 30, from St. Domingo (Fig. 15), and L. texana Pack. From L. antillarum it differs in being more regularly oval and much more prominent behind the umbones. It also agrees with Baird's description of $L$. antillarum in its two large terminal caudal spines being hairy, it having eighteen feet and ninejointed flagella. It differs from $L$. texana in the stouter haft-organ, being less triangular in outline; in the broader telson, on the upper edge of which the teeth are less numerous; in the smaller first antennæ, and the less spiny second pair; the shell differs in being more broadly ovate than in E. texana, which is oblong, less coneave along the dorsal edge, and it differs from that of E. texana in having four instead of fivelines of growth, as in L. texana.

\title{
Eulminadia texana Packard.
}

\author{
Plates VI, VII, figs. 1-4.
}

Eulimnadia texana Packard, Amer. Jour. Sc., vol. ii, Aug. 1871.

Carapace valves rounded, oval, whitish, with 5 concentric lines of growth; shell very minutely punctured; these markings being coarser at the posterior end of the shell, where they are arranged in lines parallel to the edge of the shell; eyes double, but with the inner edges contiguous. Twenty body-segments behind the head, including the telson; 18 pairs of feet ; first antennæ extending to the first joint of the flagella of second pair; the latter each 9-jointed, each joint above with 4 or 5 stout setæ, and beneath with long spinulose setæ. First pair of legs of male with a slender hand; the claw moderately large, the fifth endite very long and slender.

Telson with sixteen fine teeth above, not including the terminal acute spine; caudal appendages long and slender, knife-shaped, the under edge fringed with long hairs; the upper edge straight. the end blunt, with the lower edge slightly curved. The eggs are yellowish and pentagonal in outline.

Length of shell, $7^{\mathrm{mm}}$; breadth, $4^{\mathrm{mm}}$.

"Quite common in many places in Western Texas in the early spring" 
(G. W. Belfrage). Very common at Ellis, Kans., collected by Dr. L. Watson, and at Fort Wallace, collected by Prof. J. Lindahl. It is associated with Streptocephalus texanus, Thamnocephalus brachyurus, Estheria compleximanus and mexicana.

The shell compared with Baird's figure of Iimnadia antillarum, which belongs to this genus, and is closely allied to the present species; is more rounded oval at each end, the shell being somewhat truncated in the St. Domingo species.

\section{Species not recognizable.}

Limnadia coriacea Haldeman. Proc. Acad. Nat. Sc., Phil. I, 184, 1842.

"Body lengthened; swimming branchiæ extending along three-fourths of the inferior surface, from the neck to the extremity of the tail; tail crested above with a row of large conical obtuse tubercles; apex of the shell elevated, and about one-fourth of the length from the anterior extremity; color, light brown; length, 5 millim.; height, 3 ; diam., $1 \frac{1}{2}$.

"Hab.-Ditches along the Susquehamna, in quiet water."

It is difficult to say whether this is a Limnadia or Estheria, as the description is too brief and inexact to enable us to determine the genus or species. It cannot be a Limnadia, and seems to approximate more closely to Estheria; though it cannot belong to that genus, as the antennæ are said to be $12-13$ jointed. Until some one collects in the localities visited by Mr. Kite, we shall be in doubt as to what this form may be.

\section{Limnadella, novum genus.}

Charles Girard: On a new entomostracan of the family Limnadidx, inhabiting the Western waters. Proceed. Academy Nat. Sciences of Philadelphia, vol. vii, 1854, 1855 , page 3 .

"Gen. character.-Eye, one. Antennæ subequal, provided upon their inferior side with long and plumose setæe, whilst on the upper side there are short, slender, and simple spines. Two elongated, tape-shaped jaws. Feet in twenty-four pairs, provided upon their extremities and sides with slender and plumose setwo or hairs. A series of spiny processes along the posterior half of the dorsal line. Post-abdominal plate very large. Nutritive system phlebenteric.

"Observations. - This genus differs from Limnadia in being provided with one eye only instead of two. Also by its antennæ, the two pairs of which are similar in structure, whilst in Limnadia one pair is smaller than the other. The post-abdominal plate and number of feet will afford other distinguishing characters between Limnadella and Limnaaia. From Cyzicus or Estheria it differs, first by the structure of the shell, which in Estheria resembles that of an Arca, whilst in Limnadella it is altogether cyproid in its general aspect. There is a marked difference between these two types in the structure of the antenna, the joints of which are provided on their upper part with numerous spines in Limnadella, whilst in Cyzicus there is but one single spine at the anterior edge. The structure of the feet is likewise dissimilar, being furnished with plumose setæ in Limnadella."

\section{Limnadella Kitei, n. spec.}

"Specif. character.-Shell: elongated, subelliptical, thickest anteriorly; twice as long as deep; anterior, inferior, and posterior margins regularly continuous; upper outline somewhat irregular on account of the 
beaks being rather prominent. Valves uniformly convex. Greatest depth, one-eighth of an inch; greatest length, one-quarter of an inch. Specimens may occasionally attain to a larger size. Color, deep or light brown, mottled with black. Animal: antennæ composed each of twelve or thirteen subequal joints. Twenty-four pairs of feet, the six posterior ones diminishing gradually away so as to render the last three rudimentary. The last of all is inserted upon the last caudal segment but one. There is a broad subtriangular plate, terminated by two pairs of very large spines, curved upwards; the inferior pair being longer and slenderer than the upper one. The concave margin of that plate is furnished with a series of quite small spines. On the uppermost part of the post-abdominal plate is inserted a pair of very delicate sword-shaped appendages, very difficult to be observed even with a good microscope. Along the posterior half of the back there exists a series of sixteen processes, provided upon their upper and posterior sides with about five or six minute-curved spines, the tip of which is bent backwards. The anterior two of these processes are but rudimentary; the most developed occupy the middle of the series; the posterior ones again diminish gradually as they approximate the post-abdominal plate.

"Specimens collected at Cincinnati were sent to the Smithsonian Institution by Thomas Kite, of that city."

Afterward Professor Haldeman makes the following statement, in Proc. Acad. Nat. Sc., Phil., vii, 34, 1854:

"I find that the Limnadella described by Mr. Girard, Proceed. Acad., vol. vii, page 3 , is my Limnadia coriacea, ib., 1, 184, for June, 1842 . At that time I doubted the propriety of placing it in Limnadia, chiefly on account of the dorsal tubercles mentioned in my deseription, but I had no means of making the necessary comparisons. It was discovered in great abundanee in a road-side puddle subject to dessication, and although I removed a number of them to a small pond, I have never met with them since."

\section{Eulminadia antmlarum (Baird).}

Limnadia antillarum Baird. Proc. Zool. Soe. London, xx, p. 30. Plate XXIII, figs. 1, $1 a, 1 b, 1 \mathrm{c} .1852$.

"Carapace valves of a rounded oval shape, and of a transparent whitish color; prominent on dorsal margin where the muscular attachment of

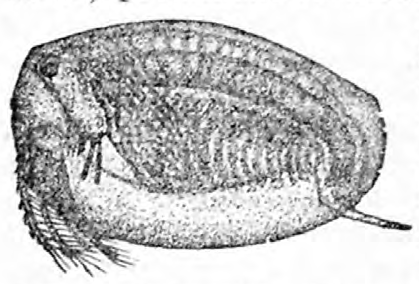

FIG. 15.-Eulimnadia antillarum. Enlarged 6 diams. After Baird. the body takes place, sloping from thence rather suddenly towards anterior extremity, where it forms a somewhat blunt point, and more gradually to posterior extremity, which, as well as ventral margin, is rounded. Antennules bluntly serrated or crenulated on their upper edge, rather shorter than peduncles of large antennæ, which are stout and not half the length of the body. They consist of nine articulations, each having one or two long plumose setæ springing from the under edge, and one short stout spine at each joint on the upper edge. Caudal lamellæ of considerable length, and beset on under edge with long plumose setæ to within a short distance of the tip, which is somewhat curved, sharp-pointed, and slightly serrated on upper edge. Feet, 18 pairs. 
"The structure of the carapace is the same as in Limnadia Hermanni, the surface being covered with minute dots or punctuations.

"This species differs from the two others in the shape of the carapace and in having the setæ of antennæ and tail plumose.

"Hab.-St. Domingo, West Indies; M. Sallé, Mus. Brit." (Baird.)

\section{Family APODIDAE Burmeister.}

Head and body in front broad and flat, shovel-shaped; carapace broad and flat; the body cylindrical, few or numerous segments extending beyond the carapace; antennæ small, $2 \mathrm{~d}$ pair minute, sometimes wanting; labrum large, broad, flat; feet numerous, usually 63 pairs; with a large coxal, maxilla-like basal lobe forming gnathites; beyond five subjointed endites; the 2-4th endites in 1 st pair of feet very long and slender, especially the 5th; gill pear-shaped or bottle-shaped; flabellum triangular, simple; the 5th endite of the 1st pair of legs is sometimes nearly as long as the body, the 11th pair bearing egg-sacs, and in the male having the genital outlet. Behind the 11 th pair two of the abdominal segments bear each six pairs of appendages, there being many more appendages than segments to the abdomen, while a variable number at the end are without appendages. Telson cylindrical, either short or ending (in Lepidurus) in a long paddle-like outgrowth. A pair of long filiform jointed caudal appendages. Larva a nauplius.

\section{Synopsis of the genera.}

Telson ending in a long paddle-shaped outgrowth.......... Lepidurus

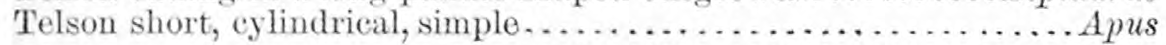

\section{Genus LEPIDURUS Leach.}

Plates XV, figs. 2, 2a, 3; XVI, figs. $1,1 a, 1 b$; XVII, XXI, figs. 1-6, 9, 11.

Lepidurus Leach. I)ict. des Sc. Nat. I, 259. 1816.

Body rather deeper, more rounded than in Apus; the carapace longer in proportion to the body than in Apus. Frontal doublure much as in Apus, but with a rather prominent tubercle at the base of the hypostoma, while the latter is much larger than in Apus. Eyes as in Apus, but the tubercle behind the eyes is oblong oval, instead of round, as in all the species of Apus I have seen. Antennæ much as in Apus. Mandibles as in Apus, with the same number of teeth; but the dorsal mandibular transverse tubercle on the carapace is larger; the maxillæ also as in Apus. The endites of the 1st pair of legs are very short, the outer ones in some species scarcely projecting beyond the edge of the carapace; there are about twelve subjoints in the 5th or longest endite, and the ends are usually (not always) rather blunt. The flabellum is very small compared with that of Apus, being narrow, triangular, the distal end acutely pointed, the gill or gill sac itself much as in Apus. In the succeeding pair of legs there are no good generic differences between Apus and Lepidurus, though endites $2-5$ are inclined to be rather the longer in Lepidurus. Gnathobases or coxal lobes much alike in the two genera.

In comparing the 10th pair of feet of Apus and Lepidurus no generic differences are to be observed, while the 11th pair, bearing the ovisacs, do not essentially differ in the two genera, but afford excellent specific characters; however, the ovisacs in Lepidurus are considerably larger and deeper than in Apus. 
The telson is produced behind, with a long, broad, often spatulate plate or expansion, in A. glacialis, twice as long as the body of the telson itself; the end subacute, or broad and rounded, or bilobed; the edge smooth or spiny. The telson itself less spiny than in Apus. The caudal stylets, or cercopoda, about as in Apus.

The principal generic differences are in the long produced telson, the shorter endites, the usually larger carapace, being larger in proportion to the body than in Apus (thongh not so in L. bilobatus), and with usually only from 5 to 12 abdominal segments, besides the telson, projecting beyond the hinder edge of the carapace.

Geographical distribution. - Western North America appears to be richer than Europe-Asia in the species of this genus, one (L.productus) occurring in the Eastern Hemisphere, ranging from Central Europe to Seandinavia and England, while two species occur in the central zoological province of the United States, and one in Greenland and Arctic America. No species of the genus have as yet occurred in the Mississippi Valley or on the Atlantic coast, and none on the Pacific coast.

\section{Synopsis of the species.}

A. Endites 2-5 very short, not projecting beyond the carapace. Carapace large; telson short, pointed, spiny on edge ...... L. glacialis. $B$. Endites 2-5 rather long and slender, projecting well besond the carapace. Carapace large, leaving only 5 abdominal segments and telson uncovered; telson long, spatulate ............ L. couesii. Carapace very short; telson long, bilobed.............. bilobatus.

\section{Lepidurus glacialis Kroyer.}

Plates XVI, figs. 1 (enlarged nearly 3 times), $1 a, 1 b$; XVII, figs. 1, 5 ; XXI, figs. 1, 2.

L. glacialis Kroyer. Naturhistorisk Tidskrift, 2d ser, vol. ii, 431. 1847.

Carapace very large, narrowing somewhat toward the eyes, being more regularly ovate than in $L$. conesii, which is more elliptical ovate. The twelve terminal abdominal segments are left nncovered by the carapace; the telson broad at the base and extended into a blunt prolongation armed with coarse teeth on the edges, and as long as the telson is broad at base; three sharp median teeth and a finely.denticulated tu. bercle on each side, at the base; the telson and its extension are smooth beneath. The cercopoda or caudal stylets are nearly as long as the body, slender and very hairy, rather than spiny.

The appendages differ decidedly from the other American species in the $2 d$ to 5 th endites being very short and broad and more equal in size; the 5th endite is much shorter than in the other species; the third and fourth of nearly the same size and length, and one-half as long as in the two other species; the second is about twice as large in proportion as in the two other species. The scale of the sixth endite is very long and slender, the tip much attenuated, with very long, hair-like setæ; the gill itself narrow, pear-shaped.

In the second pair of feet the second endite is twice as large as in the two other American species; the third and fourth of about the same size as in the other species, while the fifth is abont one half as long, the scale (6th endite) very large and ensiform, with the tip curved and ending in a spine, the inner edge with sharp spinules, the outer edge with numerous long hairs. The accessory gill is inequilaterally triangular, the proximal edge straight, not produced backwards, as in the other 
two species; the fringe of hairs is very long; the gill itself is narrower than in L. couesii or bilobatus. In the tenth pair of limbs the third and fourth endites are much longer and narrower than in $L$. couesii, the gill and flabellum very different from the other two species, the gill being small, pyriform, with a constriction near the end, while the flabellum is nearly as broad as long, rounded anteriorly, and with the posterior edge straight.

In the eleventh pair of limbs, bearing the ovisacs, the endites are also longer and narrower than in $L$. conesii.

Length of body, $14^{\mathrm{mm}}$; of carapace, $10^{\mathrm{mm}}$; breadth of carapace, $9^{\mathrm{mm}}$.

Length of cercopoda, $6^{\mathrm{mm}}$; of telson, $1 \frac{1 \mathrm{~mm}}{}$.

Locality.-Received from Southern Greenland, through Dr. C. F. Lüt. ken; Jacohshavn, North Greenland (Gerstaecker, 1064); Cape Krusenstern, Arctic Ameriea (Richardson).

\section{LePIDURus COUESII Packard.}

Plates XV, figs. 2, 2a; XVII, figs. 2, 3, 7; XXI, figs. 4, 5, 6, 9, 11.

Lepidurus conesii Pack. American Naturalist, ix, 311, 1875. Bull. U. S. Geol, and Geogr. Survey, F. V. Hayden, in charge, iii, No. 1, 177, fig. 16. April 9, 1877.

Compared with Lepidurus productus Bose of Europe, the carapace is of the same proportions, being large, broad, and leaving above five entire terminal abdominal segments exposed, ineluding the telson. The denticulations on the hinder edge of the carapace are finer than in the European species, and show a tendency to become obsolete on the lower part of the incision. The eyes are slightly fuller, more prominent than in L. productus, and the interocular tubercle is smaller. The mandib ular area of the carapace is the same as in L. productus. Labrum a little smaller than in L. productus. The teet are the same as in L. productus. The mandibles in this speeies (PI. XXI, fig. 11) have, on the cutting edge, six well marked teeth, which are rather blunter, less atienuated at the end than in Apus lucasanus (fig. 12). The maxilla (Pl. XXI, fig. 9 ) has a three-toothed lobe externally, and the inner larger lobe is setose throughout. There are usually from ten to twelve spines on the penultimate segment, as in L. productus. The chief distinction lies in the rery long spatulate telson, which is about twice as long in proportion as that of $L$. productus, and is long and narrow, varying somewhat in width, and in size. The median ridge and edge are finely spinulose, the tip is well rounded; caudal stylets nearly as long as in L. productus.

The eggs of this species, PI. XXI, are somewhat larger than those of Apus lucasanus (PI. XVIII, fig. 5; the figures of the ovisacs containing them having been drawn to the same scale by the camera lucida).

From L. glacialis Kroyer, of Greenland, it differs in the longer, larger carapace, eleven terminal segments being uncovered in $L$. glacialis. The spines on the exeavation are much smaller; telson twice as long, and not subtriangular, and excavated at tip, as in L. glacialis; exes larger; interocular tubercle decidedly smaller; labrum smaller. The first pair of legs are much longer than in L.glacialis, in which the endites are very short.

Length of an average specimen from head to end of telson, $20.2^{\mathrm{mm}}$; telson, $5^{\mathrm{mm}}$; stylets, $1 \tilde{3}-19^{\mathrm{mm}}$.

This species was collected by Dr. Elliott Coues, naturalist of the United States Northern Boundary Commission. He writes me that they "occurred in myriads in several small prairie pools, from a hundred yards to a half mile or so wide, exactly on the boundary-line, $49^{\circ} \mathrm{N}$, just 
on the west bank of Frenchman's River, Montana. You will not find this stream on the map, perhaps, by this name.

"It is one of the first of the whole series of similar streams flowing south into Milk River. The species was not observed elsewhere. The ponds were extensive shallow sheets of sweet water, of a comfortable wadingdepth, generally with a little open space in the deepest part, but mostly choked with luxuriant vegetation (Graminece, Utricularia, \&e.). Date of collection, first week in July, 1874." Thirty-two males and thirty-one females were obtained by Dr. Coues: this equality in the number of the sexes is noteworthy.

Several females with eggs were also obtained by C. Carrington, of Hay. den's U. S. Geological Survey, at Smithfield, Cache Valley, Utah. The specimens are in the Museum of the Academy of Natural Sciences, Philadelphia, to the eurator of which I am indebted for the opportunity of examining the specimens.

\section{LePIDURUS BLOBATUS Packard.}

Plates XV, fig. 3 ; XVII, figs. 4,6; XXI, fig. 3 .

Lepidurus bilobatus Pack., Bull. U. S. Geol. \& Geogr. Survey, F. V. Hayden, in charge, iii, No. 1, 178, Fig. 17, April 9, $187 \%$.

10 8, 3 ₹.-Male.-Carapace broad and short; as broad as long, measured along the median line. The eyes as in L. couesii. The excavation in the front edge of the carapace is much larger and broader than in $L$. couesii, and the teeth are more numerous, but very unequal in size, there being a few large teeth, with a number of smaller ones between them. The abdomen is longer than usual, with six (and part of another) segments beyond the last pair of feet, while in L. couesii there are only five. The spines on the edges of the abdominal segments are larger than in $L$. couv $i i$, including the five teeth on the edge of the segments as well as the spines. There are about sixteen segments beyond the posterior edge of the carapace; in $L$. couesii, eight. On the dorsal side of the abdominal segments there are eight spines on the hinder edge, while there are nine in $L$. couesii. The species differs from any other's in the remarkably short telson, which is short and broad, nearly one-half as long in proportion as in $L$. couesii. The segment is broader at base and the telson is broader than in any other species; it is truncate at the end, and divided by a slight incision into two well-marked lobes, with about seven more or less well marked median spines on the blade of the telson; this segment, including the telson, is as long as the preceding segments collectively. In the carapace, seen from beneath, the distance from the anterior edge of the hypostoma to the anterior edge of the carapace is much less than in $L$. couesii, while the hypostoma itself is much more convex. The 1st pair of legs are much longer and broader than in $L$. cousii, and the succeeding pair are rather broader than in that species.

Length of body, including caudal stylets, $48^{\mathrm{mm}}$; length of carapace (measured along median line), $18^{\mathrm{mm}}$; breadth, $18^{\mathrm{mm}}$; caudal appendages, $172^{\mathrm{mm}} ; 1$ st pair of feet, $15^{\mathrm{mm}}$.

Female.-Differs from the male in the much shorter body and shorter first pair of feet. There are five segments beyond the last pair of feet, and twelve segments beyond the edge of the carapace. It is easily distinguishable by the shorter abdomen and 1st pair of feet, but otherwise it does not differ, the telson and caudal filaments being of the same proportion. The egg-sacs were empty; they are situated on the tenth 
pair of feet. Length of body. $35^{\mathrm{mm}}$; length of carapace (measured along median line), $15^{\mathrm{mm}}$; breadth, $17^{\mathrm{mm}}$; length of caudal appendages, $14^{\mathrm{mm}}$; antennæ, $10^{\mathrm{mm}}$.

Po Cañon, Vermillion River, Colorado; collected by Dr. C. A. White, of Major Powell's Survey. Described from specimens kindly loaned by Prof. H. A. Ward, of Rochester, N. Y.

This exceedingly interesting species differs from any other known to me in the large, broad, bilobed telson, that of L. glacialis being small, subtriangular, while in $L$. productus and $L$. couesii it is long and spatulate. It differs from the two latter species in the longer, broader, 1st pair of feet, the longer body, and shorter carapace.

The differences in the appendages in $L$. bilobatus and conesii are very slight; in the $2 d$ pair of feet the accessory gill of $L$. bilobatus is longer, less rectangularly triangular than in $L$. conesii, while the pearshaped gill is of nearly the same shape in both species. In both species the four endites are long and slender, those of L. bilobatus being rather wider than in $L$. couesii. The scale (6th endite) is blunt, knife-shaped, and finely denticulate on the outside in L. bilobatus, while in L. couesii it is acute, shorter, and triangular. In the $2 d$ pair of feet the scale in L. bilobatus is very large, stout, knife shaped, and finely denticulated on the inner edge, with fine setæexternally; that of $L$. couesii is onethird smaller and acutely triangular; the four endites are much broader in $L$. bilobatus than in $L$. couesii. The accessory gill is larger and much the broader in $L$. bilobatus, the posterior end being very much produced in L.conesii. In the 10th pair of limbs the endites are longer and narrower in $L$. bilobatus than in couesii, and the scale is narrower.

The following exotic species may be referred to here:

Lepidurus viridis Baird, Proc. Zool. Soc., London, 1850. Van Diemen's Land.

Lepidurus angusii Baird, Proc. Zool. Soc, London, 122, 1866. Rain pools on the Gawler Plains, north of Adelaide, South Australia.

\section{Apus Schaeffer.}

Plates XV, figs. 1, 1a, 1b; XVI, figs. 2-5a; XVIII, XXXI, XXXV.

Apus Schaeffer, Der krebsartige Kiefenfuss, 1756. Bost, Hist. des Crust. ii, 244, PI. XVI, fig. 7 . Latreille, Hist. des Crust. Ins, iv, 195. Milne-Edwards, Hist. Nat. Crust. iii, 356, 1840 .

As in Lepidurus, but the carapace is shorter, the abdomen being longer and extending much farther beyond the hinder edge of the carapace; the 2d-5th endites of the 1st pair of legs are much longer than in Lepidurus, the 5th when stretched back sometimes reaching near the telson; the latter is short, cylindrical, without any paddle-like extension.

Synopsis of the species.

Carapace longer than in the other species; telson short, with 4 large central spines above ............................... cqualis.

Carapace shorter than in aqualis, but the telson longer...A. nevberryi.

Carapace shorter than in foregoing species; telson with only 3 central

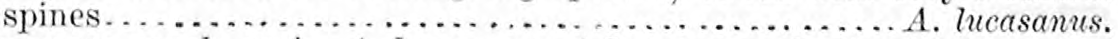

Carapace much as in A. lucasanus; telson very short, with 5 central

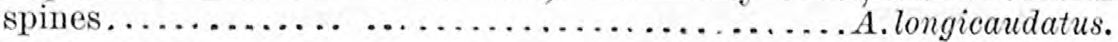


Apus AQUALIS Packard.

Plates XV, figs. $1,1 a, 1 b$; XVII, fig. 1 ; XIX, fig. 2 ; XX, fig. 2.

Apus aqualis Packard, Amer. Journ. Sc. Ang. 1871.

Two males. - This species differs from the following species in the carapace being as long as the abdominal portion beyond it. The doublure is shorter than usual; while the hypostoma is rather larger, being as long as the doublure; the front of the head beneath resembling that of $A$. longicaudatus. There are 17 teeth on each side of the sinus of the carapace. Eyes considerably larger than in A. longicaudatus ; the postocular tubercle much smaller than in the species just named. In the first pair of feet the fifth endite is rather longer than in A. newberryi, the fourth longer and slenderer, and the second also long and slender. In the second pair of feet the four endites are rather short and broad, especially the first; the "scale" (or sixth endite) is much shorter than the fifth endite, the latter being long and slender, and in one specimen reaching to the base of the telson. The fourth endite in one specimen is two-thirds as long as the fifth, in another scarcely half as long. The flabellum is smaller, but of nearly the same form as in A. newberryi, while the gill is smaller and more regular in form. In the tenth pair of feet the four endites are rather longer and narrower than in A. newberryi; the tips of the fifth endite and its scale are of equal length, the end of the latter terminating in a curved spine; the flabellum is much rounded, with a long fringe of hair-like setæ, but is not much larger than the gill itself; telson about as long as in A. longicaudatus, unusually smooth, with five median spines, three arranged in a triangle near the edge, with two moderately prominent lateral ones at the base of the caudal appendages, the latter moderately spiny, the spines being fine and numerous; beneath the telson is quite smooth, with fine spines in the middle and on the sides. Number of segments beyond hind edge of carapace, 23; beyond last pair of appendages, 11 . Total length of the body, $29^{\mathrm{mm}}$; length of carapace, $14^{\mathrm{mm}}$; breadth, $12.5^{\mathrm{mm}}$; length of earina of carapace, $9^{\mathrm{mm}}$; distance from front end of keel to front edge of head, $5.2^{\mathrm{mm}}$; length of caudal appendages, $19 \mathrm{~mm}$.

Thirteen females.-Carapace with 20 spines on each side of the hinder edge or sinus. The fifth endite of the first pair of feet reaches in all the Matamoras specimens but one to the base of the telson, in the others midway between the hind angle of the carapace and the base of the telson. Number of segments beyond the hind edge of shield, 25; number beyond last pair of appendages, 9 . Total length of the body, $29^{\mathrm{mm}}$; of carapace, $14^{\mathrm{mm}}$; breadth, $11.5^{\mathrm{mm}}$; length of keel, $8.5^{\mathrm{mm}}$; length from end of carina to front edge of head, $5.8^{\mathrm{mm}}$; length of abdomen behind the carapace, $14^{\mathrm{mm}}$; length of caudal appendages, $19^{\mathrm{mm}}$. "Matamoras, Mexico, General Couch," "Kansas, No. 5," Mus. Chicago Acad. Sc., "Plains of Rocky Mountains, No. 390," Museum of Yale College. Having been favored by Professor Baird with the opportunity of examining a colored painting by Dugés, September, 1877, of an Apus collected at Guanajuato, Mexico, I am inclined to refer it to A. aqualis, though in comparing the drawing with the specimens from Matamoras the antennæ are represented as inuch too short, and the body behind the carapace too thick; but it fairly represents the proportions of the carapace.

I have received small specimens of this species from Bosque County, Texas, through Mr. Belfrage. One of them was a young one, whose total length was $29^{\mathrm{mm}}$, the carapace along the median line measuring 
$11.5^{\mathrm{mm}}$, the abdomen beyond the middle fold of the carapace being $5^{\mathrm{mm}}$ long; the carapace was longer and the abdomen much shorter than in the adult, but in the number and arrangement of the spines on the telson and in the caudal stylets, as well as the eyes and adjacent parts, the Texan ones are the same as the type specimens from Kansas and Matamoras.

This species may at once easily be distinguished from the other American species by the greater length of the carapace, which equals that of the abdomen, also by the smooth telson with its five spines and the rather smooth, slightly spined caudal appendages. The young, one-half an inch in length, have the same proportions of the carapace and abdomen as in the largest specimens.

\section{APUS NEWBERryi Packard.}

Plates XVI, fig. $3,3 a, 3 b$; XVIII, figs. 2 , 7 ; XIX, fig. 3 ; XX, fig. 1.

Apus newberryi Pack., Amer. Journ. Sc. Aug. 1871.

Carapace rather longer than in A. longicaudatus and lucasanus, though leaving about the same number of appendages in view when seen from above. The dorsal keel of the carapace is about one-third longer than the distance between its anterior end and the front edge of the carapace. The exes are rather larger than in A. longicaudatus, and the post-ocular tubercle is of the same form, though, owing to the larger eyes, not quite so prominent as in A. longicaudatus. The transverse muscular eminence is not so long (antero-posteriorly) as in A. longicaudatus where it is much produced posteriorly. There are 14 spines on each side of the sinus of the female carapace, the posterior angle of which is a little more obtuse than in A. longicaudatus. Doublure and hypostoma as in A. longicaudatus, the tubercle at the base of the hypostoma not so strongly marked however. The fifth endite of the first pair of feet reaches only a little beyond the cephalic shield, and only as far as the basal third of the abdomen (that part not covered by the carapace), while in A. longicandatus it reaches as far as the middle of the abdomen.

The second endite unusually small and slender; third and fourth moderately short, shorter than in A. lucasanus; the flabellum is considerably prolonged and attenuated backwards, much more so than in A. lucasanus; the gill itself is rather large and twice as wide as in $A$. lucasanus; in the female there are no marginal filaments. In the second pair of feet the endites are slightly longer than in A. lucasanus, especially the first one, and they are more deeply incised or denticulated. The scale (sixth endite) is large and long, reaching to the tip of the 5th endite; it is finely spinulose, with a curved terminal spine. The tlabellum is large, as is the gill itself, which is nearly twice as broad as in A. lucasanus, and without any marginal filaments. In the tenth pair of appendages the endites are very broad, triangular; the scale longer than the 5th endite, and with a stout terminal spine; hairy externally and spiny on the inner edge. The flabellum and gill are unusually large. The endites of the eleventh or ovigerous pair are broader than in A. lucasanus.

The under side of the abdominal segments are a little more spiny than in A. longicaudatus and A. lucasanus owing to the secondary small spines developed on the base of each segment; above there is one less spine on each ring than in $A$. longicaudatus, but the same number as in $A$. lucasunus.

The telson is longer than either in A. longicaudatus or A. lucasanus; $21 \mathrm{H}$ 
the lateral spines are minute; along the middle line are five spines; the lateral group near the base are arranged more in a line than in $A$. longicaudatus, where they form a more irregular group. The under surface is nearly smooth compared with $A$. longicaudatus or A. lucasanus. The caudal appendages are two-thirds as long as the body, and gradually taper towards the tips instead of being suddenly thicker at base, as in A. longicaudatus, and are much less spiny. In A. longicaudatus there are four or five large stout, broad teeth on one side, while in the present species there are a number of minnte spinules around the basal as well as the terminal segments. Number of abdominal segments beyond hind edge of carapace, 29 ; number of segments behind the last pair of appendages, 11.

Total length of carapace, $25^{\mathrm{mm}}$; length along the middle, $192^{1 \mathrm{~mm}}$; brealth, $21^{\mathrm{mm}}$.

Length of dorsal keel of carapace, $122^{1 \mathrm{~mm}}$; from front end of keel to front edge of head, $7 t_{2}^{\mathrm{mm}}$.

Length of abdomen behind the carapace, $25^{\mathrm{mm}}$.

Length of caudal appendages, $26^{\mathrm{mm}}$.

This species differs from $A$. longicaudatus and $A$. lucasanus, to which it is nearly allied in form and in geographical range, in the longer carapace, and shorter abdomen with its longer telson. It need not be confounded with $A$. coqualis, in which the carapace is much larger and longer and the telson much shorter, while the latter species is restricted to the eastern border of the Rocky Mountain plateau and to Texas and Mexico. It differs chiefly from $A$. longicaudatus and $A$. lucasanus in the shorter endites and much longer, smoother telson, and the smooth, almost hairy, instead of spiny caudal appendages, and in the entirely different arrangement of the spines on the telson.

Locality._-"Utah, J. S. Newberry, No. 1." Two females, Mus. Chicago Acad. Sc. Ogden, Utah, collected by Mr. Henshaw, Wheeler's Survey, one female. In this individual there is one less spine on the middle of the telson than in the two others, and there are only eight instead of nine segments between the telson and the last pair of appendages. The carapace does not differ, nor do the appendages.

\section{Apus ludasanus Packard.}

Plates XVI, figs. 2, $2 a, 2 b$; XVIII, figs. 3,5 ; XIX, figs. 1,5 ; XXI, figs. $7,8,10,12,13$.

Apus lucasanus Pack., Amer. Journ. Sc. Ang., 1871. Bull. U. S. Geol. and Geogr. Survey, iii, No. i, 171, 179, April 9, $18 \% \%$.

Males.-This is the more aberrant of the two sexes. It is very near A. longicaudatus. The eyes and post-ocular tubercle as in A. longicaudatus; the musenlar eminence is not so much produced behind as in $A$. longicaudatus. Carapace a little longer than wide, with 14 teeth on each side of the posterior sinus. Doublure rather longer than in $A$. longicaudatus and the hypostoma a little smaller. Antennæ as in A. longicaudatus. The 5th endite of 1 st pair of feet are shorter than usual, often not reaching to the hind edge of the carapace, being much shorter than in any of the other American species. (It is represented as rather too long in fig. 2, Pl. XVI.) The first pair of feet and succeeding appendages are shorter and rather smaller than in A. longicaudatus. In the 1st pair of feet of male the $2 d$ endite is much larger than in $A$. longicaudatus, the three other endites being much as in the male of A. longicaudatus; the gill is narrow, regularly oval, and fringed with sparse, thick filaments, while the flabellum or accessory gill is full, 
erenly rounded in front and acute behind. In the $2 \mathrm{~d}$ pair of feet the $2 d$ endite is larger and much stouter than in A. longicazdatus; the scale of the 4th pair is large, broad, acutely ovate, the edges smooth, the end only reaching to the outer third of the 5th endite; the flabellum is large, rounded, oval, while the gill is much as in the first pair. In the 10th pair of appendages the endites are much as in $A$. longicaudatus, but slightly broader, and the scale has the same relations to the 5th endite as in $A$. longicaudatus. As regards the flabella, the two species. though so much alike externally, differ decidedly in form, those of $A$. Tucasanus being larger and more rounded externally, while the gills are narrower, and provided with scattered thick filaments on the edges, which are wanting in $A$. longicaudatus. The under side of the telson, which is longer, is also less spiny than in A. longicaudatus, and on the upper side there are three spines in the middle instead of five, as in $A$. longicaudatus, with two large spines on each side. Caudal appendages less spiny than in $A$. longicaudatus; their spines are blunt, and their arrangement into rows differs from that in $A$. longicaudatus, where the rows are arranged in twos, a row of small spines being just behind a row of large ones on the edge of the joint. Number of segments exposed behind the earapace is 33 ; number of abdominal segments beyond the last pair of appendages, 13.

Length of body, excluding the caudal appendages, $27^{\mathrm{mm}}$.

Length of carapace, $12^{\mathrm{mm}}$; breadth of the same, $10^{\mathrm{mm}}$; length along the middle, $9^{\mathrm{mm}}$.

Length of the keel, $6^{\mathrm{mm}}$; distance from front end of keel to front end of earapace, $4^{\mathrm{mm}}$.

Length of eaudal appendages, $14^{\mathrm{mm}}$.

Female.-The carapace is longer and the abdomen shorter than in the male. There are 17 spines on each side of the sinus of the carapace. Telson as in the male, while the candal appendages have smaller spines; beneath not spined, being smooth, with a row of fine teeth on the edge. The exites of the 11th ovigerous feet are decidedly shorter and broader than in A. longicaudatus. Number of segments beyond the hinder end of carapace, 29; number of segments behind the last pair of append. ages, 11. The eggs are of the same size as in LeConte's species; they are spherical, orange-yellow; the chorion thin, transparent; the yolk gramules rather large.

Total length of body, $20^{\mathrm{mm}}$; length of carapace in the middle, $10^{\mathrm{mm}}$.

Length of keel, $6^{\mathrm{mm}}$; distance from front end of keel to front edge of carapace, $4^{\mathrm{mm}}$.

Length of abdomen behind the hind edge of the carapace, 14 inches.

Several males from Museum of Chicago Academy of Sciences labeled "Cape St. Lucas, J. Xanthus, 4."

Six male specimens in a bottle received from Dr. Stimpson, and marked "Kansas? 5"; in the same bottle were 13 females of A. aqualis. These could not be distinguished from Cape Saint Lucas specimens.

This species occurred in great abundance at Ellis, Kans., associated with the other Phyllopods from this locality. It was collected in June by Dr. L. Watson. The specimens are not distinguishable from my types of A. Tucasamus from Cape Saint Lneas, Lower California.

Numerous specimens have also been received from Fort Wallace, Kansas, through Prof. Joshua Lindahl.

The occurrence of this species so abundant locally in Kansas, at Cape Saint Incas, is interesting. Fearing that some mistake had been made, I have repeatedly compared the Cape Saint Lucas specimens with numerous ones from Kausas, and have observed no differences; in com- 
paring every part of the 1st and $2 \mathrm{~d}$ pairs of feet of individuals from Cape Saint Lucas and Kansas no differences can be found.

As the species has proved to be the most abundant and accessible of all the species in this country, the specific name is not altogether appropriate, still it will serve to remind one of the interesting features in its geographical distribution.

The food of this species appears to be Crustacea, as in dissecting the month-parts of one of this species the legs of an Asellus-like Crustacean were found partly swallowed. Hence they are quite predaceous in their habits.

\section{Apus longicaudatus Leconte.}

Plates XVI figs. 4, 4a; XVIII, figs. 4, 6; XIX, fig. 4 ; XX, figs. $3,4$.

Apus longicaudatus Lec., Annals N. Y. Lyceum, iv, 155, Pl. IX, 1846.

Apus obtusus James, Long's Expedition, ii, 336. Packard, Hayden's U. S. Geol, Survey, Terr. Report for $1 \circ 73,620,1874$.

Carapace about as long as wide, being shorter than in any other known American species. This species, besides the characters given by Leconte, has the following: The frontal doublure is about one-half as long in proportion as in A. cancriformis, being sborter than the hypostoma; the latter is rather shorter and broader than in $A$. cancriformis, and with a swollen area or eminence at the base, not present in $A$, cancriformis. The antennæ are two-jointed, the $2 \mathrm{~d}$ joint slenderer, more chitinous than in $A$. cancriformis, and reaching to within a distance from the edge of the shield equal to one-fourth of their length. The 1st pair of feet are alike in both sexes. The endites are long and slender, differing only slightly from those of A. lucasanus; the specific differences are, however, best marked in the exites of all the limbs, the gills being small, rather narrow, but still wider than in A. lucasanus, but without the fringe of coarse filaments of the latter species; the ffabellum is shorter, more triangular, the anterior edge being less full and rounded. In the $2 d$ pair of feet the endites are much as in $A$. lucasanus, but the scale is long, knife-shaped, acute, and extends nearly to the tip of the 5th endite. The gill is regularly rounded, ovate, and the flabel. lum is subtriangular.

In the 10 th pair of limbs, while the endites are much as in $A$. lucasanus they are a little narrower, and while the flabellum is of nearly the same shape and size, the gill itself is much shorter and broader, being nearly round.

In the 11th pair of female limbs bearing the ovisacs, the short flabella are longer and natrower than in $A$. aqualis.

Seen from above, 32 segments may be counted in the males (in the female, 28) beyond the edge of the carapace; and seen from beneath, there are 14 segments beyond the last pair of appendages (in the female, 10).

The abdomen is unusually spiny, as also the caudal stylets, the segments of the latter being well marked by the spinules, which project unusually far out. The telson is shorter and more spiny than in $A$. lucasanus; on the upper side is a median group of three spines arranged in a triangle, with a pair lower down, with three stout lateral spines, and a group of five or six spines just within the outer edge, and near the base of the telson; the under side is more heavily spined laterally than in $A$. lucasanus, and there are more numerous, finer spines on the under side of the segment next in front of the telson. 
Total length of earapace, $19^{\mathrm{mm}}$; width of the same, $17^{\mathrm{mm}}$.

Length of keel on the carapace, $8 \frac{1 \mathrm{~mm}}{4}$; from anterior end of keel to front edge of carapace, $6^{\mathrm{mm}}$.

Length of abdomen beyond the carapace, $21 \frac{3 \mathrm{~mm}}{4}$.

Length of caudal appendages, $20^{\mathrm{mm}}$.

Diameter of the ovisacs, $2 \frac{1 \mathrm{~mm}}{2}$.

Our female differs from the males in the carapace being longer, with 28 segments, uncovered, beyond the carapace; and 10 segments bevond that bearing the last pair of appendages, while the under side of the telson is much smoother than in the males, but the upper side as in the males; the caudal appendages less spiny than in the males.

The ovisacs contained a few eggs, which were of the same size as in A. lucasanus and otherwise the same, except that the germ had commenced to develop; they were arranged in the cavity of the ovisac side by side in two rows, the lower or inner row the larger.

I have had the opportunity of examining Professor Dana's original type of Leconte's, contained in the museum of Yale College. It was, when received, broken and dried up, but with the carapace preserved, while the caudal appendages were wanting. The specimen was labeled "Rocky Mountains, near Long's Peak." This would place it within the present limits of Colorado.

Four specimens from the museum of the Chicago Academy of Sciences, received through the late Dr. William Simpson, were labeled "Texas, J. H. Clark No. 3." They only differ from Dana's type specimen in the dorsal carina of the carapace being considerably shorter than in the type, being twice as long as the distance from the front margin of the carapace to the anterior end of the keel.

In the other specimen this distance is one-third or one-fourth as great as the length of the keel. The specimens vary somewhat in the relative length of the keel, in the length of the abdomen, and the size and number of spines on the under surface of the telson, while the endites of the 1st pair of feet vary slightly in length. The size and form of the telson, and the number and arrangement of the spines afford good specific characters in this genus.

Three specimens labeled "Pools near Yellowstone River, Dr. Hayden, 6," were also received through Dr. Stimpson, of the Chicago Academy. The range of the species would seem to be from the Yellowstone River along the eastern flank of the Rocky Mountains to Texas, probably the upper part of the state.

James, in Long's "Expedition to the Rocky Mountains," says of this species: "Rain-water puddles on the Platte River, near the Rocky Mountains. . . . In rain-water puddles we remarked a new species of Branchipoda belonging to the genus Apus; small crustaceous animals, which exhibit a miniature resemblance to the King or Horse-shoe Crab (Limulus polyphemus) of our own sea coast, but which are furnished with about 60 pairs of feet, and swim mpon their back. The basins of water which contained them had been very much diminished by evaporation and infiltration, and were now crowded to excess, principally with the Apus, great numbers of which were dying upon the surrounding mud, whence the water had receded. This species is distinguished from the productus of Bose and montagui of Leach, by not having the dorsal carina prolonged in a point behind; and from cancriformis by the greater proportional width of the thorax, and more obtuse emargination behind. The length of the thorax along the middle is three-tenths of an inch, and its greatest breadth somewhat more. It may be named Apus obtusus."-Note 7, p. 336. 
We should regard A. longicaudatus as standing at the head of the genus, and the European species, A. cancriformis, lowest, the former species being on the whole more specialized, since the carapace is in $A$. longicaudatus smaller, not reaching to the middle of the whole body, while that of $A$. cancriformis is more as in the larval stages, since it reaches nearly to the telson, nearly concealing from above the limbs. The frontal doublure is also much smaller than in the European species, while in the latter species the candal appendages are considerably longer than the body, in A. longicaudatus being barely one-half as long as the whole body. On the whole, therefore, A. longicandatus seems nearer allied to Branchipodide, while A. cancriformis, by its large shield covering nearly the whole body, shows some slight approximation to the Limnadiada.

Apus Domingensis Baird.

"Apts Domingensis Baird, Proc. Zool. Soc. London, Part xx, 5 (Tab. 22, fig. 1), 18:2.

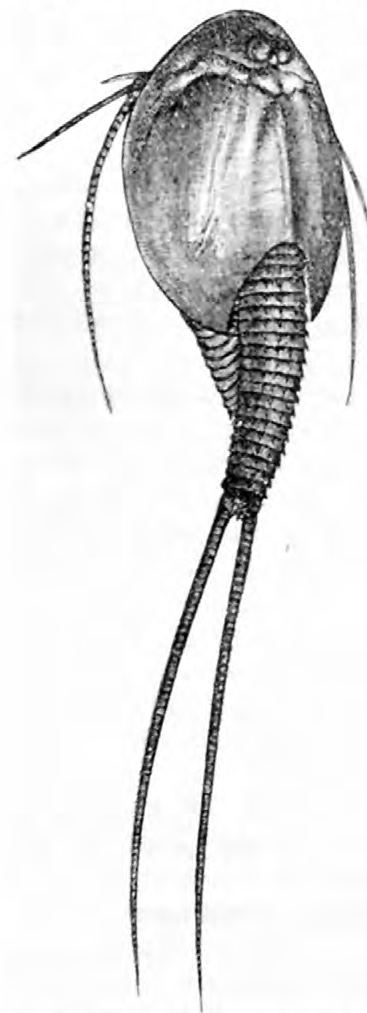

FIG. 16.-A pus domingensis, en larged. After Baird.
"Clypeo corporis dimidiam partem tegente, rotundo, tenui, corneo; ramo externo pedum primi paris corpus æquante. Long. toti corporis 1 poll; lat. clypei 3 poll.

"Hab.-In Insula St. Domingo, India Occidentali. Collegit M. Sallé. Museum Britamicum.

"Though a native of the West Indies, this species may be easily distinguished from $A$. Guildingii by its round-shaped carapace of a horny colour, covering half the boty of the animal, and its external branch of the first pair of feet only the length of the body, while in $A$. Guildingii it exceeds the whole body and caudal filament included. The carina down the center of the carapace, and the fork which it takes at the anterior extremity where the division into cephalic and thoracic portions takes place, are marked throughout their length with a deep brown color, as are also the short stout spines on the abdominal portion of the body. These are straight, not hooked, as in some of the other species. The caudal filaments are nearly the length of the body, and are covered wit very numerous, extremely short setæ. The oviparous feet are present in all the specimens I have examined, but none contain any ova."

This species (Fig. 16) is rery closely allied to A. cqualis, and represents that species in the West Indian fauna.

\section{Apus GUILDINGII Thompson.}

Apus Guildingii Thompson, Zool. Researches, Fasc., v. 108, t. 6, fig. 3; Milne-Edwards, Hist. Nat. Crust. iii, 561. Baird, Monog. Family Apodidæ, Proc. Zool. Soc. London, Pt. XX, 3, 1852. Clypeo corporis vix dimidiam partem tegente, quadrato, membranaceo, nigrescente ; ramo externo pedum primi paris longissimo, totum corpus, filamentis caudalibus inclusis, excedente.

$H a b$ - - In Insula "St. Vincents," India Occidentali; Rev. Lansdowne Guilding. 
Mr. Thompson, in his Zoological Researches, remarks: "I received this species of Apus together with the Artemia Guildingii from the West Indies, and having as yet no details must leave its history in the hands of its distinguished discoverer. It is of a light blackish color, the clypeus translucent, almost membranous, and shorter in proportion than in any of the known species, with the extreme branch of the anterior member extremely long." Unfortunately we have no further history of this species from its discoverer, the Rev. Lansdowne Guilding, but the short square-shaped carapace and the extreme length of the external branch of the first pair of feet sufficiently distinguish it.

We add the following description of an Asiatic species, briefly described by us in 1871 .

\section{Apus himalayanus Packard.}

\section{Plate XVI, figs. 5, 5a.}

Apus himalayanus Pack. Amer. Journ. Sc. $18 z 1$.

Several females.-Carapace two-thirds as long as the body, with from 14 to 16 teeth on each side of the sinus on the hind edge, the last tooth on the extreme end of the shield being more prominent than usual. Eyes and post-ocular tubercle small, as in A. cancriformis; mandibular muscular eminence behind also as in A. cancriformis ; frontal doublure, hypostoma, and appendages as in A. cancriformis. The 1st pair of feet closely resemble those of $A$. newberryi in the form of the long knife-like scale, as well as in the form of the gill and accessory gill (Habellum); the length of the 5 th endite of the first pair of feet is $19^{\mathrm{mm}}$, and it is composed of from 72 to 80 subjoints, while $A$. cancriformis has about 50 , and A. aqualis 42. Diameter of the ovisac is nearly $4^{\mathrm{mm}}(.15 \mathrm{inch})$. There are the same number of spines on the abdominal segments as in A.cancriformis, and the spines on the telson have the same arrangement, there being on the upper side four spines at the insertion of the stylets, the 4 th being minute; a single spine on the hind edge projecting over the sinus in the middle of the hind edge, which is deeper and narrower than in A. cancriformis; there is also a minute spine on each side of the sinus as in $A$. cancriformis, and two minute spines at the bottom of the sinns. Near the base of the telson, on each side, is an oval depression, with the posterior side raised and bearing three teeth, just as in $A$. cancriformis. The telson, however, is considerably longer than in A. cancriformis, being two thirds as long as wide, while in the latter it is only one-half as long. On the under side of the telson the hind edge is rather more deeply incised than in A. cancriformis, and the edge is much more spiny, there being about 7 spines on each side.

The cercopoda or caudal spines are finely spinulated, almost hairy, as in A. cancriformis, in this respect differing from all the American species.

Total length of body, $25^{\mathrm{mm}}$.

Greatest length of carapace, $16^{\mathrm{mm}}$.

Of the keel, $11^{\text {rum }}$.

Distance from anterior end of the keel to the front edge of the head, $5 \frac{1}{2} \mathrm{~mm}$.

Length of abdomen beyond the hind edge of carapace, $9^{\mathrm{rm}}$.

Length of caudal appendages, $28^{\mathrm{mm}}$.

Number of segments beyond the hind edge of the carapace, 19 (in $A$. cancriformis, 14).

Number of segments behind the last pair of limbs, 7 (in A. cancriformis, 6). 
This species belongs to the third division of the genus, of which the European cancriformis is a type, having the small eyes, and small post. ocular tubercle, while the telson is marked in the same manner, and the caudal appendages are finely spinulose, or hairy, as in no American species. The $2 \mathrm{~d}$ pair of feet are, however, very much like those of $A$. newberryi, in the form of the long cultriform scale, or 6th endite, and in the form of the gill and its flabellum, as well as the size of the carapace.

"Collected from a stagnant pool in a jungle, four days after a shower of rain had fallen. For five months previous to this rain there had been no rain upon the earth. Himalaya Mountains, North India, near where the Sutlege River debouches into the plains. A pril, 1870." Museum of Comparative Zoology, Cambridge. This is, eviclently, a high-plateau species, and a member of the Central Asiatic rather than Oriental fauna.

A pus dukianus Day (Proc. Zool. Soc. London, p. 392, 1880) differs from A. himalayam in the shorter carapace and much longer abdomen, which has 24 segments beyond the hinder end of the carapace, while in himalayanus there are 17. In the Himalayan species, also, the 5th and 6 th endites of the 1st pair of legs are much longer and the caudal appendages are much longer. A. dukianus was discovered by Dr. Duke in Afghanistan, in a pond near Kelat, in April, 1877.

\section{Family BRANCHIPODID A Baird.}

Branchipoda Leach, Dict. des Sc. Nat. xiv, 1816.

Branchipiens Milne.Edwards, Hist. Nat, des Crust. iii, 364, 1840.

Branchipuside Baird. Trans. Berwick Nat. Club, 1-45.

Branchipodida Fischer. Miıldentorf's Reise, ii, 149, 1851.

Branchipodide Baird, Proc. Zoöl. Soe. London, 1852. Ann. and Mag. Nat. His'. XIV, 216,1854 .

Branchipida Burmeister, Organiz. of Trilobites, Roy. Soc. edit. 34.

Branchipide Verrill, Proc. Amer Assoc. Ad. Se. July. 1 roro.

Branchipodide Packard. Report of Hayden's U. S. Geol. Surv. Terr. for 1873, 620. 1874. Gerstaecker, Broun's Class. u Ord. Thierreichs, v, 1034. 1866-79.

Body soft, delicate, without a carapace; head small; the eyes stalked; a distinct median ocellus; 1 st antennæ filiform; $2 \mathrm{~d}$ antenm stout in the males, forming elaspiug orgaus ; frontal appendages often present ; 11 pairs of feet (19 in Polyartemia), which are without a gnathobase or coxal lobe; the other lobes (endites), especially the 5th and 6th, broad and foliaceous, with a gill and simple rounded flabellum. First and $2 d$ uromeres with a penis in the male or an ovisac in the female. A specialized abdomen, with 8 to 9 segments not bearing appendages. Terminal segment bearing a pair of filamental not-jointed setose appendages. Larva a nauplius.

\section{Subfamily 1. BRANCHIPODINA Packard.}

Eleven pairs (in Polyartemia 19) of feet, with the outer endites moderately broad. Abdomen slender, cylindrical; terminal abdominal segment with two filamental setose caudal appendages.

\section{Synopsis of the genera.}

a. No frontal appendages.

Abdomen with eight segments; male claspers with $2 d$ joint flat, triangular; ovisac short .............................. Artemia 
Abdomen with nine segments; male claspers simple, cylindrical; ovisze

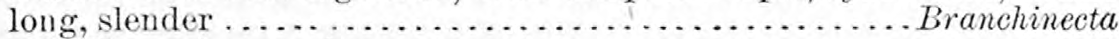
$b$. Frontal appendages present.

Frontal appendages ribbon-like, or broad triangular; $2 d$ joint of male claspers chitinous, simple, bent at tip ............... Branchipus

Second joint of male claspers long, tortuous, and forked irregularly; ovisae long and slender...................... Streptocephalus

Frontal appendages long and variously lobed or spinulose; ovisac short

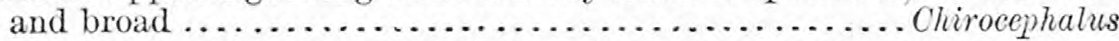

\section{Genus ARTEMIA Leach.}

Plates VIII, XXII, XXII.

Cancer Liunæus. Systema Nat. ed. 12, i, pars. ?, 1056.

Apus Schaefter, Monogr. fig. 1, 12, 1754 .

Branchiopoda Lamarck, System. des Anim. sans vert. 161. 1801.

Branchiopoda Latreille, Gen. Crust. et Insect, i, 22, 1806.

Eulimine Latreille (pre-occnpied), ${ }^{*} 181 \%$.

Artemia Leach, Dict. des Sc. Nat. xiv; 1819.

Body very slender, with eleven pairs of feet; the head rather smaller in proportion than in the other genera of the family; the male claspers (2d antennæ) very large, thin, and broad; 2 -jointed, the $2 d$ joint bent at nearly right angles upon the 1st, the latter thick, about twice as long as thick, a deep rounded sinus between the bases of the claspers exactly fitted so as during connection with the female to enclose her back. Near the middle, on the inner side of the 1st joint, a knob-like projection. The $2 d$ joint simple, broad, flat, acutely triangular, from $\frac{1}{2}$ to $\frac{2}{3}$ as broad as long. The legs beyond the 5th endite rather slenderer and more pointed than in the other genera. The gill is moderately large, abont half as wide as long; the flabellum broad and rounded, the edge serrate and setose as usual. The 1st endite divided into two lobes, the $2 d$ of which is about $\frac{1}{3}$ as long as the 1 st; endites $2-4$ are minute, conical; the 5th is moderately large and rounded on the outer angle, with large, coarse setæ, the distal edge oblique and somewhat full and rounded; the 6th is narrow, long, and more produced and acutely pointed than usual, much more so than in Branchinecta or any other genus of the family, while the setæ are much longer than in Branchinecta.

Abdomen eight jointed, very slender, ending in a pair of unusually short, small cercopods (caudal appendages) not more than twice as long as broad, being less than half as long as in Branchinecta, and less than half as long as the terminal segment. The male genital deeply cleft, each half long and slender, more so than in Branchipus, but somewhat as iu Branchinecta, though shorter and less curred. Ovisac of the female rudely bottle-shaped, shorter and broader than in any of the other genera, with a short, broad "neck" or opening.

Remarks.-This genus is in some respects simpler than Branchinecta, or any other genus of the family, and differs decidedly from any other genus, not only in the small size of the body, but also in the broad, flat, triangular 2d joint of the male claspers, as well as in the much smaller, shorter caudal appendages, and the long, narrow, acute distal or 6th endites, which render the legs rather long and slender. The ovisac is also shorter and broader than usual.

*According to Dr. Baird (Monograph of the Family Branchipodide, etc., in Annals and Mag. Nat. History, xiv, 216, 1854) the genus Eulimine Latreille, 181\%, was based on specimens of A. salina, which were badly preserved and erroneously described. That name was, however, pre-occupied among Acalephs, see Verrill, Observations, etc. 
Compared with the other genera, this upon the whole stands at the base of the family, though the male claspers are a little more complicated than in Branchinecta. Considering the fresh-water forms by themselves, Branchinecta is, without much doubt, the lowest or simplest in structure. As seems most probable from the experiments of Schmankevitch, Artemia is a modification of Branchinecta, and is a depauperated form, smaller in size, with less developed caudal appendages, due to perhaps less favorable means of obtaining food in its brine than the fresh-water forms. Hereafter, then, in diagnosing the other genera we will take Branchinecta as the simpler form, affording us a truer standard of comparison than the less normal Artemia.

The Siberman fresh-water genus Polyartemia of Dr. S. Fischer* is remarkable for possessing 19 pairs of feet; the tail is short, the ovisac quite voluminous; the male claspers are broad, flat, and consist of two branches, one covering the other; the front of the head is prolonged into a broad, very thin tentacle-like organ; in other respeets it agrees with the genus Branchipus. Polyartemia forcipata Fischer was found by Middendorf in pools on the Tumdra, near the rivers Taimyr and Boganida, and also in Lapland, near the Tri-Ostrowa.

\section{ARTEMTA GRACILIS Verrill.}

\section{Plates VIII, XXII, figs. $1,2,2 a, 2 b$; XXIII.}

Artemia gracilis Verrill, Amer. Journ. Sc. 2d Ser. xlviii, 248, Sept. 1869. Proc. Amer. Assoc. Adv. Sc. July, 1870.

Artemia monica Verrill, Amer. Journ. Se. 2d Ser. xlviii, 249, Sept. 1869. Proc. Amer. Assoc. Adv. Sc. July, 1870.

Artemia fertilis Verrill, Amer. Journ. Se. xlviii, p. 430, Nov. 1869 . Proc. Amer. Assoc. Adv. Sc. July, 1870.

Artemia utahensis Lockington, $\nmid$ Month. Micr. Journ. 137, March, 1876.

This species is characterized by the slender body, its small head and small eye-stalks and eyes. The male claspers are rather slender, the

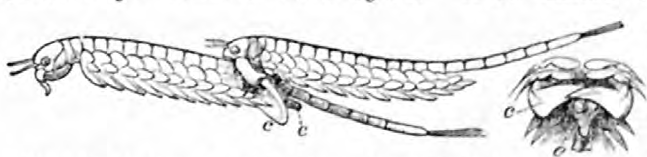
$2 d$ joint varying with age and in different individuals from the same locality; it is unusually broadly triangular and from Fis. 17. Artemia gracilis, from Great Salt Lake. A pair one-half to two-thirds as wide
wimming, the male clasping its mate with the claspers as long; at the outer angle is swimming, the male clasping its mate with the claspers as
$(c)$, in front of the ovisac $(e)$; enlarged about 3 times. Also a large angular projection, while a riew from beneath of the male claspers $(c)$ and the ovisac a large angular projection, while
(e) still more enlarged. Emerton del.

slightly excurved (Pl. VIII, fig. 1). The frontal knobs on the inside of the 1st or basal joint are small, rounded, button-like. The ocellus is black, trilobate. The legs are long and slender; the 6th endite narrow, long, and acutely triangular; the 5th endites full and rounded. The abdomen is slender, and the cercopoda very short, usually scarcely as long as one-half the width of the terminal segment of the abdomen.

In color either whitish, flesh-colored, often deep red, sometimes greenish, with black eyes.

Length of male, $8-10^{\mathrm{mm}}$; female, $10-12^{\mathrm{mm}}$.

For the reasons stated beyond I am disposed to unite Verrill's A. monica and A. fertilis with his first described form, A. gracilis, as I do not regard the difference he points out as more than individual; probably 
they are not varietal. It appears, then, that we have but one North American species of Artemia so far as vet known.

Upon comparing our species with the European it is difficult to find good differential characters, as the portions of the body where specific differences would be expected to occur are liable to considerable rariation. Upon comparing a number of females from Great Salt Lake with a number of females of the maleless generation from Trieste, Austria, received from Professor Siebold, there are really no differences of importance; our A. gracilis (Verrill's fertilis) is slighter, with a smaller head, and perhaps the $2 d$ antennie are a little slighter in build; I see no essential difference in the form of the ovisac, while the shape of the legs, especially the 6 th endites, is essentially the same. The length of females (as weil as males) is the same in both species.

Upon comparing a good many males from Great Salt Lake with several, both stained with carmine and unstained, received from Cagliari, Sardinia, through Prof.J. McLeod, of Ghent, the European A. salina is seen to be considerably stouter, the head wider, the eve-stalks longer and larger, and the eyes larger; the frontal button-like processes of the first joint of the claspers are nearly twice as large as in the American species, and a little more pointed, while the claspers themselves are larger and stouter. The legs and sixth endites are of about the same form. The most apparent difference is in the caudal appendages or cercopods, which in $A$. salina are several times larger than in $A$. gracilis, being in

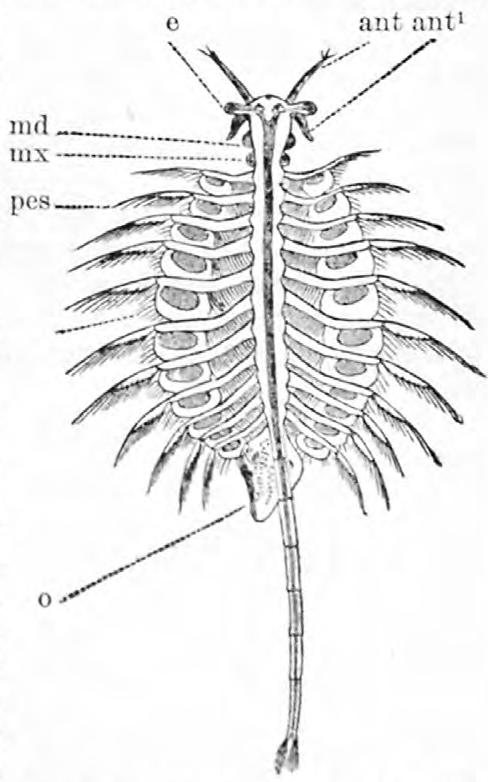

Fig. 18.-Artemia gracilis, from New Haven, seen from beneath, much enlarged. After Verrill. e, eve; ant, 1st antenna; ant $t^{1}, 2 d$ anternos; md, mandibles; $m x$, maxilla ; pes, foot; $o$, ovisac.

the Sardinian specimens nearly three times as long and much larger than in our species. In this respect the genus shows a.close affinity to Branchinecta. However, in a lot of A. salina \& from Trieste, the cercopods are very much shorter than in the Sardinian females, and only a little longer than in our American specimens. These appendages do not differ in the two sexes.

As regards the genus in Europe, several nominal species have been described, but it seems probable that but one occurs there. As stated by Verrill in his "Observations on Phyllopod Crustacea," in a foot-note, owing to differences in the development of the caudal lobes and setre, "several nominal European species, established mainly on differences in the caudal lobes and setw, are probably only the young of others, or all perhaps of A. salina, especially since those with small, caudal lobes and few or no setx, are described as small; as for example A.milhausenii, A. arietina, and A. köppeniana (Fischer species)."

Verrill's types of A. monica I have not examined, but have certainly found specimens at Great Salt Lake which agree with his description, and especially his figures of the head and male claspers.

Variations in Artemia fertilis from Salt Lake.-With specimens of the sexually mature males from Great Salt Lake the description of Verrill agrees well, the claspers being very broad, the second joint being as 
wide as two-thirds its length. The outer angle or elbow varies greatly, in some individuals not being noticeably produced, and with the onter edge nearly straight, while in others the angle is remarkably produced and the outer edge is much excavated. In one specimen, $7^{\mathrm{mm}}$ in length, the claspers are one-half as wide as in another, but with the elbow still produced. In another male, $7^{\mathrm{mm}}$ in length, selected from fifty more or less normal individuals, the elbow is enormously produced, and the claspers are small, long, narrow, and acute. In sixty other males the elbow is a good deal produced, while the elaspers are broad and triangnlar. These specimens were collected at Lake Point from the wharf, July 26,1875 , the temperature of the water under the wharf in the shade being $730 \mathrm{~F}$. The females bore about $23-24$ eggs in their ovisacs.

Sixty red-colored males from a hot, shallow brine pool at Farming. ton, late in July, the temperature of the water probably not less than $80^{\circ}$ Fabr., were examined. Of these, one male, 5.5m in length, had claspers which were even smaller and narrower than in a smaller individual, $4.5^{\mathrm{mm}}$ in length, showing an unequal degree of growth, being perhaps an example of retarded development of a secondary sexual character. A stronger example is seen $m$ two individuals of the same length $\left(5.5^{\mathrm{mm}}\right)$; one was very immature, the head being smaller than in the other, the claspers unusually small and narrow, the genital appendages smaller, and the caudal appendages one-half as long as in the other; in the second example the head is large and the elaspers fully three times as broad as those of the first individual, being three quarters as broad as the space between the ejes, while the caudal appendages were twice as long as thick, longer than those of A. gracilis, as figured by Verrill. This difference in two specimens so nearly of a size shows that the sexual characters are suddenly acquired. No young were observed less than $3^{\mathrm{mm}} \operatorname{long}$.

Identity of A. fertilis, A. gracilis, and A. monica.-On comparing 30 males of $A$. gracilis from New Haven the claspers in small specimens look like Verrill's figure of those of A. gracilis; in large specimens like that of his figure of $A$. monica, the claspers increase in width with bye. In two specimens of the same size and probably age, one has very narrow claspers, as in Verrill's figure of gracilis, in another the elaspers are broader than in his figure of $A$. fertilis. In half-grown males the claspers are narrow, as in Verrill's figure of A. gracilis. The forms of the caudal appendages vary with age.

On comparing a few days after, to be sure that I had made no mistake, 200 males of $A$.fertilis with males of $A$.gracilis, I could find absolutely no essential specific or varietal differences between these so-called species.

On examining 45 females of $A$. gracilis from New Haven, and comparing them with a number of Salt Lake females, no differences could be observed. Comparing with care a large female from Utah (Great Salt Lake) with one from New Haven of the same size, there was also the same proportion of parts. The eyes were of the same size, the eye stalks of the same length; the first and second, the latter especially, had the same proportion. The feet and endites were the same, and the length of abdomen the same, though this region varies, as it irregularly contracts in alcohol. The egg-sacs in the New Haven ex. ample are a little longer and with a more acute lateral angle than in Utah examples, but this depends on age, and these differences disappear in those which are of the same size and degree of sexual maturity, and in which the eggs are similarly developed. The caudal appendages in the Salt Lake example (which was $12.5^{\mathrm{nm}}$ in length) are nearly but 
not quite so long as in New Haven ones, but there are not even varietal differences in the two examples. From these comparisons it may be inferred that the two species should be united.

On comparing a number of Salt Lake females with individuals of the same sex of the European Artemia salina, our species was found to be undoubtedly specifically distinct; the Utah specimens are slenderer, smaller, and the sixth endite of all the feet considerably slenderer and longer in proportion than in A. salina. The ovisacs were of the same proportion but slenderer, and the head is slighter and smaller in our American species.

Habits of Artemia fertilis at Great Salt Latie, Utah.-The food of the Artemia appears to be the smaller fragments of brownish algæ which abound in the water, especially Polycistis Packardii of Farlow.* The cells of this alga are filled with molecules of protoplasm. The contents of the alimentary canal of alcoholic specimens of Artemia is a darkish mass, which, on being examined under a $\frac{1}{5}$ Tolles objective, shows the same granulated protoplasmic mass as that to be found in the lobules of the alga, leaving little doubt in my mind that the partly digested substance in the digestive canal of the Artemia is the alga.

At Farmington, on the shores of the lake, where there are old brine pools, filled with strong brine, the shallow water was crowded with Artemia. The water was very warm, and the Artemice were deep red in color, though some red ones were collected in the lake itself. They were afterwards observed at Lake Point July 26, 1875. The temperature of the water in the shade at the end of the wharf was $73^{\circ} \mathrm{F}$. at the surface, and also at the bottom at a depth of eight feet; the temperature of the air was $80^{\circ} \mathrm{F}$. at $11 \mathrm{a} . \mathrm{m}$.

Out of a large number observed, from 500 to 800 individnals, but very few were half grown, some being from $\frac{1}{5}$ to $\frac{1}{4}$ inch long. Few solitary males were seen, as the large majority were attached by their claspers to the females in the attitude shown in fig. 17. The females far outnumbered the males, as certainly over half of them had no males attached.

The egg sacs and eggs were in different stages of development. I conld see no attempts at copulation, unless in one instance, where a male violently jerked his body; but that was perhaps simply to obtain a stronger hold with his claspers around the body of the female, the claspers being placed just in front of the orisac.

The eggs are light, floating on the surface of the water. They are dull, dirty, yellowish white.

The nauplius (Pl. XXII, fig. 1) is blood-red, with a single sapphire-red eye, and it is very active.

Four sets of Artemice were observed:

A. Some, both males and females, entirely green.

B. Nost of the females were red in front of the abdomen, the red being caused by scattered pigment cells. The males attached to them were greenish.

C. Some red males attached to green females.

D. The largest females entirely deep blood-red, with distended ovisacs, but containing no eggs.

There must be numerons sterile or parthenogenous females. There is a great disproportion in the numbers of the sexes. The males are stronger swimmers than the females, darting at certain individuals and then leaving them to go after others, as if exercising some choice. 
Some males were attached to females much larger than themselves. I was told that the Artemia appears in the spring, from the middle of April to May 1, and disappears during very cold weather in autumn.

\section{Artemia Guildingit Thompson.}

Artemia Guildingii Thompson. Species haec, reperta in India Occidentali, delineata est a Domino Thompson in 'Zoological researches' sed non descripta, necnon satis accurata delineata est.

Artemi Guildingi, Thompson Zool. Researeh, Fasc, 5, t. p. 11.

Hab.-In insula "St. Vincents," in India Occidentali; Rev. L. Guilding.

"This species is figured by Mr. Thompson, but not sufficiently described to enable me to give a good diagnosis of it. It was found at St. Vincents, in the West Indies, by the Rev. Lansdowne Guilding, by whoin its natural history was intended to have been more fully detailed. The body seems to be thick and the abdomen shorter than the body and stout; the caudal segment does not appear to be lobed nor setigerous. The cephalic segment is conical in shape, and the smperior antenne, according to Mr. Thompson's figure, consist each of four joints. The ovarian sac consists, aceording to the same authority, of two articulations." (Baird's Monograph of the Family Branchipodida. Anuals and Mag. Nat. Hist. 2 d ser. xiv, 1854, p. 226).

\section{Genus BRANCHINECTA Verrill.}

\section{Plates IX, X.}

Branchipus Milne.Edwards, etc. (in part).

Branchinecta Verrill, Amer, Jonrn. Sei. 2d ser. xlviii, 250. Sept. 1869. Proc. Amer. Assoc. Adv. Sc. July, 1870.

Body rather long and slender, but stouter than in Artemia; head rather small, but larger than in Artemia ; $2 d$ antennæ of male (claspers) with a knob on the basal joint as in Artemia; the elaspers simple, quite persistent in form in the different species, not elbowed, 2 -jointed, with joints eylindrieal; 1st joint slightly bent; the $2 d$ joint not bent on the first, round, and about one-half as thick as the basal joint. The $2 \mathrm{~d}$ antennæ of the female are rather long and slender. Labrum large and long, extended beyond the closed mandibles; the end is square, with a nipple-like projection in the middle. Eleven pairs of legs, which are shorter and broader than in Artemia. The gills are usually larger, the flabella moderately large, and quite regularly oval externally; the 1st endite and the three following are much as in Artemia, but the first is not so distinctly divided distally into a secondary lobe. The 5th is decidedly rectangular in outline, the distal edge being straight, sometimes hollowed out, with rather shorter setæ than in Artemia; the 6th endite in all the legs is much shorter than in Artemia, being short and broad and well rounded at the end, with rather short setæ.

The abdomen has nine segments, and is as long or a little longer than the head and thorax together; the cercopoda are much longer than in Artemia, and equal in length to the terminal segment, which is much shorter than in Artemia; compared with Branchipus and succeeding genera they are small, short, and conical. The penis is deeply divided into two long slender curved branches. The ovisac is cylindrical and remarkably long and slender; in B. coloradensis nearly half as long as the abdomen, and deeply cleft at the end. 
This genus stands in simplicity of structure next above Artemia, being related to it by its short cercopoda or caudal appendages, and the simple male claspers, with the knob-like projection at the base of each. It is less complicated than in Branchipus, and in his valuable paper on this group I hardly understand why Professor Verrill should have interposed Branchipus, his Eubranchipus, streptocephalus, and Chirocephalus between Artemia and the present genus, as the genera in the order we place them in this essay present successive degrees of complexity from Artemia to Chirocephalus and Thamnocephalus. The Southern Enropean Branchipus spinosus Nordman, from a salt lake at Odessa, appears to us, on examination of a number of specimens receired from Professor Siebold, to belong to this genus, contrary to Verrill's opinion, who referred it to his genus Eubranchipus. In this species the knob-like processes of the male claspers are present; the male claspers also are much as in $B$. coloradensis, but mnch slenderer; the caudal appendages are short and small, as in our American speeies of Branchinecta, but the orisacs are rather shorter than in any American and Arctic species, though still longer than in Branchipus. The genus is certainly a good one, and easily distinguishable. It is especially interesting to indicate the close affinities of this genus to Artemia, for it is Branchinecta ferox (Fischer sp.) which Schmankeviteh found to transform by artificial means into Artemia, and the characters of Brauchinecta are such as we might believe a well-fed Artemia subjected also to water of suitable temperature and freshness might suddenly acquire. The fact, however, that the two genera may be artificially produced does not militate against the naturalness of the two genera, Artemia and Branchinectes, since we can point to three American and Arctic species of Branchinecta which preserve their generic identity.

As suggested by Verrill, Milne-Edwards' Branchipus ferox (Edwards' Crustaces, iii, 369), from fresh water near Odessa, most probably belongs to this genus. Milne-Edwards thus characterizes it: "Cornes cephaliques sans appendice près du côte interne de leur base, pointnes au bout et sans dent sur le bord externe. Abdomen lisse, nageoires candales longues et étroites." It has been rediscovered in 1572 in salt pools near Odessa by Schmankevitch. Verrill also states that Branchipus middendorffiana Fischer, of Siberia and Lapland, may be a Branchinecta, and, judging by Fischer's figures of the mal. clasper, the ovisac, and the cercopoda, it is without much donbt a genuine Branchinecta. By Grube and Dybowski it is regarded as a synonym of $B$. paludosa. It inhabits Siberia, having been collected by Middendorf near the rivers Taimyr and Boganida, as also in Lapland near Tri-Ostrowa, while it was also collected by the Ural Expedition. Hence the species of the genus Branchinecta range from the Arctic regions to Southern Russia in Europe, and to the higher portions of the Rocky Mountain plateau of Colorado in North America, as well as the plains of Kansas, the genus, with the exception of the two species living at Odessa, and $B$. lindahli, of Kansas, being inhabitants of Arctic and Alpine regions.

\section{Synopsis of the species.}

Male claspers pointed, not turned in, serrated inside of 2 d joint; no

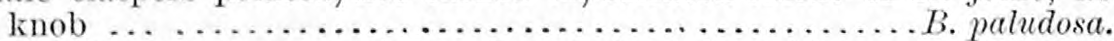
Male claspers large, end broad and bent in, with no teeth; knob

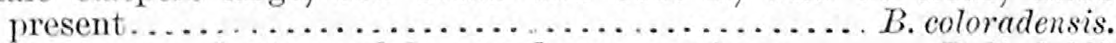
Male claspers short; caudal appendages very long........ B. lindahli. 


\title{
Branchinecta paludosa (Müller).
}

\author{
Plate IX, figs. 1-6; Pl. X, figs. 1-5.
}

Cancer stagnalis O. Fabr., Fauna Groen. (non Linn. et Miill. Prodr.), 247, 1780. Cancer paludosus Herbst, Naturgeschichte der Krabben. Bd. II, p. 118.

Branchipus paludosus, Miiller, Zool. Danica, ii, 10, Pl. 48, figs. 1-8, 1782-1806.

Branchipus paludosus Reinhardt, Bidrag til en Beskrivelse af Groenland, 1057; Packard, Glacial Phenomena of Maine and Labrador, ete. Memoirs Boston Soc. Nat. Hist. i, 295, 1867.

Branchipus (Branchinecta) groenlandicus Verrill, Amer. Jour. Sc. 2d ser. xlviii, 253, Sept. 1869.

Branchinecta groenlandica Verrill, Proc. Amer. Assoc. Adv. Se., July, 1870.

Branchinecta paludosus Verrill in part (B. arctica regarded as distinct).

Branchipus middendorfianus Fischer," Middendorft's Sibirische Reisen. Bd. II, p. 153.

Body moderately large. Male claspers much shorter and slighter than in $B$. coloradensis, not reaching far beyond the middle of the thorax, basal joint more bent than in the other species, but of the same proportionate length, though withont any knobs (also absent in immature males of B. coloradensis); the distal half of the inner edge with a row of fine teeth, the points ending in fine setæ. 2d joint very slender, narrowing gradually to the tip, which is one-half as wide and not bent in or slightly expanded as in B. coloradensis; $2 d$ antennæ of the female narrow and slight, at the tip suddeuly contracting and ending in a mucronate tip.

The feet are short and broad; the 5th endites, straight on the onter edge, with the onter angle rectangnlar, while the 6 th endites are short and broad; the setæ, especially at the distal angle, are rather coarser and shorter than in $B$. coloradensis.

Caudal appendages small, narrow, scarcely longer than the terminal joint. The ovisac is oval-cylindrical, rather long, the lobes pointed at the end; only one-half as long as the abdomen.

Length of body of male, $15^{\mathrm{mm}}$; length of clasper, $4^{\mathrm{mm}} ; 2 \mathrm{~d}$ joint, 1.5 ; cercopoda, $1^{\mathrm{mm}}$.

Length of body of female, $12^{\mathrm{mm}}$; of ovisac, $4^{\mathrm{mm}}$.

The foregoing description was drawn up from an individnal selected from a collection of abont 80 made by Dr. Emil Bessels, at Polaris Bay, Northern Greenland, Angust 1, 1872.*

On carefully re-examining, after the lapse of over fifteen years, a portion of the material originally collected at Labrador, and comparing a male and three females (labeled $B r$. arctica by Verrill) with the abundant material collected by Dr. Bessels, in Northern Greenland, I am unable to find any specific differences between them. The Greenland examples are smaller and less matire than the Labrador ones. I find that they possess the same characters as those which separate the species from $B$. coloradensis, and which occur in the Greenland B. paludosus. There are the same proportions in the male elaspers, the knob-like processes on the basal joints are also wanting, the row of teeth on the distal balf of the joint are of the same size. Owing to the greater size of the specimens the male claspers are a little larger, but the $2 d$ joint has the same proportions, being narrow, not widening at the tips, which also is not incurved. The ovisac is of the same length and form. The penis is of the same form, and with a similar prong-like process projecting

*Considered by Grube and also Dybowski as a synonym of B. palndosus. See Archiv für Naturgeschichte, XXVI, i, p. 201.

* I have been kindly permitted by Dr. Bessels to use this material in this connection, and also the excellent drawings by Mr. Emerton, which were made originally for a report on the Natural History of the Polaris Expedition. 
inward near the base of each branch or fork. The candal stylets are a little longer than in the Greenland examples, but this is probably due to the more mature development of the specimens.

Length of male, $19^{\mathrm{mm}}$; length of elaspers, $5^{\mathrm{mm}}$; length of $2 \mathrm{~d}$ joint, $2^{\mathrm{mm}}$.

Length of cercopoda or eaudal appendages, $1.5^{\mathrm{mm}}$.

Length of female, $18^{\mathrm{mm}}$; length of ovisac, $5^{\mathrm{mm}}$.

Although predisposed to think that Professor Verrill* had found good reasons for separating the Labrador from the Greenland individuals under a distinct specific name, though I originally had examples of the Greenland B.paludosus from Dr. Lütken, of the Copenhagen Museum, for comparison, I have carefully re examined them for any specific characters that I might have overlooked. I see no differences in the appendages, the 5th and 6th endites especially not differing in any essential point, as will be seen by the numerous figures on Plates IX and X, the apparent discrepancies in the drawings being due to different stages of preservation. There is a slight difference in the tips of the male claspers, which are a little blunter in the Labrador than in the Greenland examples, but this may be on account of the smaller size and less degree of maturity of the Greenland examples. I have not at hand the larger Greenland examples originally received from Greenland through Mr. Liitken. The Labrador examples were taken August 7, 1864 , in a small pool of water in a depression in the rocks on a point of land projecting into the water at "Indian Tickle," on the north side of Hamilton or Invuctoke Inlet, Northern Greenland; and others were seen at Tub Island, on the south side of the entrance of the bay, August 10.

We add the following account by Baird of what seems to be without much doubt B. paludosus, and which shows that it inbabits Aretic America in latitude $68 \circ 15^{\prime} \mathrm{N}$., longitude $1133^{\circ} 50^{\prime}$, of Greenwich :

"Some fragments of a species of Branchipoda were brought by Sir John Richardson from Cape Krusenstern, in North America, collected there by Mr. John Rae in August, 1849, along with the Apus glacialis. They consist of portions of two males and two females. The male antemnæ are two-jointed; the basal joint is thick, and has at its lower part, near its junction with the second, a row of small teeth; the second joint is cylindrical and pointed. The female horns or antennæ are flat, apparently, and have a short hooked spine at the extremity. The caudal fins are rather long, and fringed with long eilia. In some respects this species resembles the figure of the Cancer paludosus of Miuller, but the fragments are too much decayed in the spirits to enable me further to describe it. It does not appear to have either antenniform appendages or any apparatus attached to the antennæ of the male.

Should these three species prove to be distinct they may form another genus of this family, characterized by the want of these appendages and the toothed or serrated basal joint of the male cephalic horns."

Under the name of Branchipus (Branchinecta) arcticus, Mr. E. J. Miers notices this species in the Annals and Mag. Nat. Hist., ser. 4, vol. xx, p. 105 , Pl. IV, fig. 1. His figmre is a very indifferent one, and he erroneously represents the ovisac as double. Discovery Bay is in latitude $81^{\circ}$ $41^{\prime} \mathrm{N}$., longitude $64^{\circ} 45^{\prime} \mathrm{W}$. We reproduce his description and remarks:

"Coll. Hart: Discovery Bay, in a small fresh-water lake and in a stream under ice. Several specimens were collected, including males and females, of a species of Phyllopoda, which I refer to the B. arcticus of Verrill. Of these species I have only seen the descriptions in the journals above quoted, not having been able to meet with Verrill's full re-

" Prof. Verrill writes me that he has since (Amer. Jour. Sc.) decided that his $B$. groenlandica is identical with $B$, paludosa. 
port on the American Phyllopoda in the volume for 1869 of the Ameriean Association for the Advancement of Sciences and Arts. These specimens possess the elongated claspers, with serrated basal joints, and elongated egg pouches of the species of Branchinecta, and are distinguished from the Branchipus paludosus of Mïller, also from Greenland, (if his figure in the Zoöl. Danicá, Pl. 48, be correct) by the much shorter lanceolate caudal appendages. In $B$. paludosa these are represented as very slender, acuminate, and half as long as the abdomen.

"These specimens differ slightly from the descriptions of B. arcticus and groenlandicus, as will appear from the following description. If distinct (which may be possible, althongh I think it more probable that the three forms are varieties of one and the same species), the species may be designated $B$. Verrilli. The antennæ are slender, linear, and nearly as long as the basal joint of the claspers. The large prehensile antennæ, or 'claspers', as they are called by Verrill, are nearly half as long as the body, two-jointed, the basal joint as long as the second, nearly straight, and of the same thickness throughout, with a not very prominent rounded lobe at the distal extremity on the inner side. This, and the distal half of the inner margin, armed with a series of ten or a dozen small teeth or spines. The second joint is smooth, slightly tapering to its distal extremity and concave on its inner surface. The branchial feet are eleven in number, and the lobes on the inner margin are beautifully fringed with long, close, flexible hairs; the fifth and sixth pairs are the longest, and the others decrease regularly in size. The vesicular body is narrow, oblong-oval; the terminal lobe of the second joint is regularly oval in shape. The caudal appendages lanceolate, small; margins with slender setæ, which become longer as they approach the distal extremity. The specimens are smaller than that collected by Dr. Packard, averaging only 12 millimeters in length.

"Verrill's specimens of this species were from Labrador, and if, as is thought possible both by Packard and Verrill, this species be not dis. tinct from the B. groenlandicus and B. coloradensis, it must have a very extended geographical range. Specimens of B. groenlandicus are mentioned by Packard as having been obtained during the late American expedition of the Polaris at Polaris Bay, between latitudes $81{ }^{\circ} 20^{\prime}$ and $811^{\circ} 50^{\prime} . "$

\section{Branchinecta coloradensis Packard.}

Plate X, figs. 6, $\tau$.

Branchinecta coloradensis Packard, U. S. Geographical and Geol. Survey, Report for 1873, 621, fig. 12.1074 .
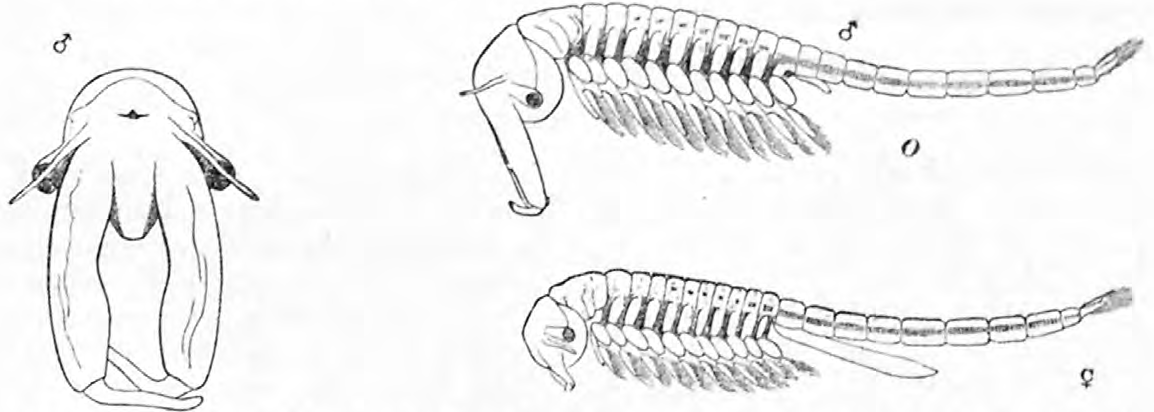

Fig. 19.-Branchinecta coloradensis, male and female, with a view of front of the head of the male, showing the claspers; all enlarged, Emerton del.

Body considerably larger than in $B$. paludosa; moderately stout; head rather large; ocellus larger than in $B$. paludosa, and the eyes also 
rather larger. The claspers of the male are large, thick, and long, extending to the base of the last pair of feet. The basal joint is provided with stout prominent tubercles at the base; the joint itself is nearly one-fourth longer than the distance between the outstretched eyes. The second joint is one-half as thick as the first, and as long as the first beyond the basal internal knobs; it is slightly bent near the base, the tips broad, rounded, and suddenly bent inwards a little. The forks of the penis are long, slender, suddenly curving outwards, and nearly meeting at the tips over the median line of the body. The caudal appendages are rather long and slender, nearly twice as long as the terminal segment, though shorter than in B. paludosa, and not slightly contracting near the base as in B. paludosa. Female larger and stouter than in $B$. paludosa; the ovisac very long and slender, reaching to a point beyond the middle of the penultimate abdominal segment, and with the lobes acutely pointed. The $2 \mathrm{~d}$ antennæ are much broader than in B. paludosa, being more triangular and coming more gradually to a mucronate point than in B. paludosa. In life this species is of different shades, from deep salmon or flesh color to pale whitish.

Length of body of male, $18^{\mathrm{mm}}$; length of male claspers, $7^{\mathrm{mm}}$; of $2 \mathrm{~d}$ joint, $3^{\mathrm{mm}}$; of eandal appendages, $1^{\mathrm{mm}}$.

Length of female, $17^{\mathrm{mm}}$; length of ovisac, $8^{\mathrm{mm}}$.

Deseribed from several hundred specimens collected by myself from a small pond or pool forming the head of a brook above timber line and near the snow line, abont 12,000 feet elevation, near the trail leading to the summit of Gray's Peak; it is donbtful if this pond erer dries up, as I have seen it full in the summers (Angust) of 1875 and 1878. They were observed in great abundance August 21, associated with a species of Daphnia, and swam as usual on their backs; a number were seen copulating. They thus live under almost exactly the same meteorological conditions as B. paludosa in Northern Labrador and Greenland, the temperature near the snow line in Colorado in Angust being about the same as that of Northern Labrador and Greenland in August.

My first published brief description was drawn up from a female specimen from a "pond on a mountain near Twin Lake Creek, Colorado, elevation 12,500 feet" (Hayden's Survey of Colorado, 1873, collected by Lieut. W. L. Carpenter, U. S. A.); also from about 100 males and females with eggs, Colorado, Dr. Viele (Museum Comp. Zoology, Cambridge, no date).

From Mr. V. T. Chambers we have received the following note regarding the occurrence of this form in Colorado:

Beauchinecta Coloradensis occurs in conntless thonsands in a pond fed by melted suow on top of Weston's Pass, altitude 11,676 feet elevation (Hayden), and a Caddis larva feeds voraciously upon it.

\section{BRANCHINECTA LINDAHLI n. sp.}

Plate XI, figs. 1, 7 .

One male.-Body robust; $2 \mathrm{~d}$ antennæ or claspers short and stout; 1 st joint of the usual thickness and much as in B. coloradensis, but much shorter, at least a third; $2 \mathrm{~d}$ joint as long as the basal, curved, distinctly triquetal, with the angles prominent; much thicker than in B. coloradensis, rather blunter at the end than in B. coloradensis, and with the inner side of the tips larger and more turned in than in B. coloradensis, giving an entirely different appearance to the joint. Male genital organs much as in the Colorado species, but the caudal appendages somewhat longer, otherwise of the same form.

Twelve females.-Eyes rather large; 2d antennæ slightly shorter, less blunt than in $B$. coloradensis. Oviduct with the lower lip acutely pro- 
duced. The caudal appendages are nearly twice as long as in B.coloradensis. The egge are more numerous (about 50 contained in the ovisac) and much smaller than those of B.coloradensis, being abont one-half as large. The feet are well developed; the 5th endite square and hollowed out a little on the outer edge; the 6 th is long and more pointed than in the other species of Branchinecta; the gill is large, as is also the oval broad flabellum.

Male, length of body, $8^{\mathrm{mm}} ; 2 \mathrm{~d}$ antennæ, $3^{\mathrm{mm}}$; length of $2 \mathrm{~d}$ joint, $1 \frac{1}{2}{ }^{\mathrm{mm}}$; caudal appendages, $1^{\mathrm{mm}}$. $2^{\mathrm{mm}}$.

Female, length of body, $15^{\mathrm{mm}}$; ovisac, $4-5^{\mathrm{mm}}$; caudal appendages,

This species differs remarkably, especially in the long caudal appendages, and in the large pointed 6th endites of the feet. It may at once be distinguished from Branchinecta coloradensis by the shorter $2 \mathrm{~d}$ antennæ, the basal joint being one half shorter, and the $2 d$ joint very short, while the inner projection or spur is much larger and more pointed than in B. coloradensis, and the caudal appendages are much larger, while the ovisac is much shorter than in that species. The eggs are of the same size as those of $B$. paludosus.

The specimens occurred in a pool at Wallace, Kansas, in company with the other Phyllopods from that place.

This species is named in honor of Prof. Joshua Lindahl, of Augustana College, Rock Island, Ill., who collected the specimens examined, with many other Phyllopods which he kindly lent me for study.

\section{Genus BRANCHIPUS Schaeffer (in part).}

Branchipus Schaeffer (in part), Elementa Entomologica, 1766 (type B. pisciformis $=?$ B. stagnalis Ex. Verrill). Latreille, Regne Animal; Leach. Milne-Edwards, Crustacés, iii, 364 (in part), 1840.

Chirocephalus Dana (in part), non Bénédict-Prévost, 1803; Jurine, Thompson, Baird. Branchipus Verrill, Amer. Journ. Science, xlviii, 250, Sept. 1869.

Branchipus (and Eubranchipus) Verrill (in part), Proc. Aner. Assoc. Adv. S3., July, $18 \% 0$.

Body large and very stout; head large; male claspers elbowed, large and thick, complex, varying much in form; 1st joint very stout and thick, nearly stranght, with a stont inward-pointing spine at base; $2 \mathrm{~d}$ joint varying in form, usually simple and straight, chitinous, bent a little at the tip. Head of male with a pair of frontal appendages hanging down between the male claspers and varying much in form, being long, slender, filiform, and simple (in B. stagnalis), ferming two broad, flat triangular lobes with crenulated edges (in B. vernalis), or very large and deeply and finely lobulated (B. grubei). The 11 pairs of feet are much as in Branchinecta, but usually the 5th endites are larger and the edge less square than in Branchinecta, and the 6th endites are larger and more pointed. The penis is large and broad, in B. stagnalis quite deeply cleft, or (B. vernalis) only slightly so, the cirrus long and slender. Caudal appendages long and slender, nearly twice as long as is usually the case in Branchinecta (B. lindahli excepted).

Female with the body long, the head large, caudal appendages as in the male, the ovisac broad and short, bottle-shaped, the opening transverse, at the end of a short neck.

The type of this genus is Branchipus stagnalis (Linn.), of Europe, and in this country it is represented by $B$. vernalis.

As limited by Milne-Edwards, the genus was too comprehensive, being composed of three generic forms, since he included in it B. spinosus 
and B. ferox, which, as we have previously explained, are true Branchi necte, and also Chirocephalus diaphanus. In 1870 Verrill eliminated his Branchipus vernalis, described in 1869 under the name Eubranchipus vernalis, and also remarked that "this genus appears to include Braizchipus spinosus Edwards, from a salt lake near Odessa, but the latter appears to have no tooth at the base of the second joint of the claspers." Had Professor Verrill had specimens for examination he would undoubtedly have seen that this species was a Branchinecta.

I do not see good reasons for separating our common American species generically from the common European B. stagnalis and the less known more recently described species B. grubei. Comparing B. vernalis with B. stagnalis, the frontal lobes of stagnalis are in position homologous with the much more complicated ones of B. vernalis and the lobulated, highly complicated ones of B. grubei. In both species the $2 \mathrm{~d}$ joint of the claspers is thick, in section triangular, but much slenderer than the very thick 1 st or basal joint.*

The ovisac and penis, as well as the caudal appendages and the general form of the body, are the same. B. grubei Dybowsky, which I have received from Breslau through Professor Siebold, is a genuine Branchipus; the large, deeply lobulated frontal appendages, a sexual character peculiar to the males, are only exaggerations of those of $B$. vernalis. It has similar stout claspers; the ovisac of the female differs from the two other species examined, in being a little longer and slender, but still it retains the short, broad, bottle-shaped form so characteristic of the genus, while the caudal stylets are the same.

To this genus also undonbtedly belongs Fischer's Branchipus birostratus (see Middendorf's Reise, p. 152, Pl. VII, figs. 12-16, from Charkow, Russia). As regards the frontal appendages, this species is intermediate between B. vernalis and B. grubei, as those organs are short, triangular, but little longer than in B. vernalis, but deeply, acutely lobed at the end.

The frontal appendages in this genus and in Chirocephalus are possibly the homologues of the knob-like projections near the base of the $2 \mathrm{~d}$ antennæ of Artemia and Branchinecta, but the frontal appendages are situated nearer the base of the 1st joint, and are more dorsal. On the outer side of each appendage there are transverse lines reaching to the edge between the tubercles, giving a segmented appearance to the outer half of the appendage. Under a Tolles' $\frac{1}{5} \mathrm{~B}$ eyepiece the tubereles are seen to be filled with nucleated oval cells like those scattered through the meshes of the fine muscles which ramify throughout the middle region of the appendage. The cells are not nerve-cells, and I do not regard these organs as sensory, but probably auxiliary to the elaspers, and possibly of use in holding the female.

\section{Synopsis of the species.}

Frontal appendages short, finely lobed; $2 d$ joint long and

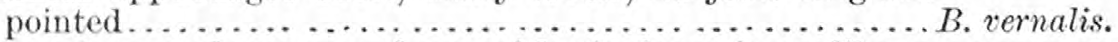
Frontal appendages very long, with six long finger-like processes on each side; $2 \mathrm{~d}$ joint of male clasper half as long as in B. vernalis, and

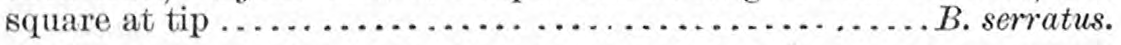

* Gerstaecker makes a singular blunder in copying Dybowski's figure in Bronn's Classen und Ordnungen der Thierreich, Bd. v, abd. 1, Taf. xxix, figs. 2, 4, from Dybowski in Archiv. fiir Naturgeschichte xxvi, 1. The male and magnified head of the male of Branchinecta paludosa from Greenland, correctly figured by Dybowski as such, are by Gerstaecker in his explanation of Tat: xxix called the female of Branchipus grubci. 
Brancmipus verialis Verrill.

Plates XI, figs. 2-6; XXII, figs. 3-6.

Branchipus stagnalis Gould, Invertebrata of Massachusetts, 339, 1841. Branchipus vernalis Verrill, Amer. Journ. Sc., XLVIII, 251, Sept., 1869. Eubranchipus vernalis Verrill, Proc. Amer, Assoc. Adv. Sc., July, 1870.

Body stout, pale flesh-colored with reddish tints, head large; claspers with the basal joint very stout, slightly curved, nearly one-half as thick as long; retractile, drawing in with it the base of the $2 d$ joint; $2 d$ joint chitinous, rigid, with a long obtuse spur on the inner side at the base, which is directed inwards at right angles; beyond this spur the joint in transverse section triangular, the edges very prominent; the inner edge of the joint is hollowed out at the base, while the extremity is bent outward somewhat like the foot of a sock before it is worn. The interantennal or frontal appendages are broad, triangular, flat (from above downward), nearly twice as long as broad, acutely pointed; with the edge finely serrated, the teeth, when highly magnified, being separate at base, and bottle-shaped, with one, and sometimes two, rarely three, "necks" or "points" (Pl. XXI1, fig. 5, 5a). The external organ of reproduction (penis) is stout, massive, not deeply cleft in the middle, while the cirrus (Pl. XXII, fig. 3, c) is minute, long, and tiliform.

The body of the female is as stout and of the same size as in the male; the ovisac is not so long as broad, pink, with a prominent, full " neck." with a transverse narrow opening for the exit of the eggs; the lower lip of the opening is smaller than the upper lip.

Male.-Totallength of body, $23^{\mathrm{mm}}$; of 2 d antennæ, $8^{\mathrm{mm}} ; 2$ joint of same, $4.5^{\mathrm{mm}}$; of penis, $3.5^{\mathrm{mm}}$; caudal appendages, $4^{\mathrm{mm}}$.

Female.-Total length, $23^{\mathrm{mm}}$; length of ovisac, $3-4^{\mathrm{mm}}$; of caudal appendages, $4^{\mathrm{mm}}$.

This species ranges from Salem, Mass., through Rhode Island to New Haven, and southward to Philadelphia (March 27, Mr. W. P. Seal) and westward to Southern Ohio (Wapakoneta, Ohio, Wm. Kayser), and Indiana, (received from Irvington, Ind., Mr. O. P. Hay, Amer. Nat. 1882, 242). In Southern New England it is found from the last of November until the first week in May, but has not yet been found during the summer from the middle of May until the middle of November, as will be seen by the following record of localities and dates of capture: Salem, Mass., April 19, 1859 (R. H. Wheatland, Essex Institute; A pril 12, 1876 , a few halt-grown ones (Packard); Danvers, Mass., Nov. 25, 1878, December and Jan. 10 (John Sears); Brookline, Mass., March 30, 1878 (M. T. Henshaw); Pawtucket, R. I, March 1S, 1850 (H. H. Davison); Newport, K. I., Feb 15, 1877 (Mr. Powell, Mus. Comp. Zool.); New Haven (Dana, Eaton \& Verrill); At Seekonk, Mass., they occurred abundantly May 2, in a large pond which completely dried up in summer (H. C. Bumpus); when I visited the pond in company with Mr. Bumpus, May 13, none were to be found. It seems from this quite evident that the animal probably dies off at the approach of warm weather and does not reappear until after cool weather sets in late in the antumn, being represented in the summer by the eggs alone; and thus the appearance and disappearance of this Phyllopod is apparently determined mainly by the temperature.

In life the body is of a pale flesh color, the tips of the penis deep reddish-brown, from thence a narrow line widening to the posterior half of the abdomen. The white setæo on the caudal appendages and the white tips of the endites contrast with the deep reddish-brown of the rest of 
the posterior half of the abdomen. The tips of the 5 th endites are edged with reddish. Observed in very large specimens, from Dorchester, Mass. Jan. 4 to $9,1882 . *$

\section{BRANCHIPUS SERRATUS (Forbes).}

Eubranchipus serratus Forbes, Bull. Illinois Mus. Nat. Hist. I. 13, Dec. 1876.

This interesting species is of the size and general appearance of $B$. vernalis, but the frontal appendages are twice as large and long, reach. ing to the end of the first joint of the male claspers. They are broad and flat; on the middle of the inner and outer edge is an expansion from which arise six digitiform processes, those on the inner edge being shorter and smaller; the appendages each end in a rolled-up slender tip. Male claspers with the 1st joint short and thick; the $2 \mathrm{~L}$ joint much shorter and thicker than in B. vernalis, being one-half as long, thicker in proportion, with the end squarely cut off, and triquetal seen from the end. At the base of the joint is a broad-based stout spur which points inwards. The caudal appendages are a little shorter and less coarsely setose along the edge than in B. vernalis. The genitals are as in $\dot{B}$. vernalis; the ovisac of the female is similar, the opening being the same, while the eggs are of the same size as in that species.

Total length of male, $15-20^{\mathrm{mm}}$; length of claspers, $4^{\mathrm{mm}}$; length of $2 \mathrm{~d}$ joint, $2^{\mathrm{mm}}$; of caudal appendages in both sexes, $2.5-3^{\mathrm{mm}}$; total length of remale, $20^{\mathrm{mm}}$.

"Collected in temporary pools of water at Normal, Illinois, in April, 1876 ; about a fortnight afterwards it entirely disappeared." "Another species [specimen] has been sent me by Professor Bundy, by whom it was taken in Wisconsin." I am indebted to Prof. S. A. Forbes for a pair of type specimens of this interesting species, which bears a close resemblance to, and thus represents in the United States, Branchipus grubei of Europe; it differs, however, from that species in the rather smaller frontal appendages, which are not so continuously and deeply fringed

*The following observations by Dr. Gissler, made on the appearance of Branchipus vernalis and Chirocephalus holmani may prove of interest:

Brookuyn, November 14, 1881.

I recorded the following in my memorandum last year: Ponds near Maspeth dried up in October, 1800 , until October 30 , filled up; heavy rain again November 5 ; heary rain again and $68^{\circ} \mathrm{F}$. on November 11; November 18, a thin coat of ice formed in the evening; November 19, little rain in afternoon, again cold in evening; November 20, cold; November 21, freezing; ditto November 22, 23, and 24, a little suow at 9 p. m.; 25 th, snow, cold; 26 th, very cold, and 27 th and 28 th, thawing after $10 \mathrm{a} . \mathrm{m}$.; same day rain frotn $10 \mathrm{a}$. m. till 11 p. m.; 29th, clear and mild; 30th, frozen ; December 1, rain; 2d, mild and clear; 3d, cool and clear; 4th, mild; 5th and 6 th, warm; 7 th, cold ; 8th, 9 th, 10 th, and 11 th, very cold: 12 th, mild; 13 th warmer, and 14th, ditto with rain; Deeember 15,16 , and 17 , all ponds solidly frozen; 18 th, thawed; 19 th, frozen; ditto 20 and 21 , with snow; frozen, 22,23 , and 24 ; thawing on 25 th; frozen, $26,2 \%, 28$, and 29; December $30,5^{\circ}$ below zero; 31st, cold, frozen; ditto January $1,2,3,4$, and 5 , 1841; milder and muddy on $6 \mathrm{th}, 7 \mathrm{th}$, and 8 th ; colder on $9 \mathrm{th}$, rain in the evening; ditto all day on 10 th; 11 th, went to Maspeth, ico 1 inch thick on isolated pond, water running into it from neighboring elevated fields, nothing found; 12 th and 13th cold; warm rain in A. M. of $14 \mathrm{th}$, cold after 3 p. m., went to Maspeth and obtained one larva, the smallest I ever saw, from pale race; $15 \mathrm{th}, 17 \circ \mathrm{F}$ at 9 a. m.; cold 16 th, obtained 3 red Eubranchipus larva a few days old; 16 th, cold; 17th mild; ditto 18, 19, and 20, eight inches ice at Maspeth; 21st, warm rain ; 22d, snowed over night, cold; 23d, cool; 24 th, 25 th, and 26 th, cold; 27 th, 28 th, 29 th, 30th, and 31 st, very cold; a larger larva was found February 10, age about 5 days; heavy rains February 18 and 19; March 3, obtained from Maspeth 4 larve $3 \frac{1}{2} \mathrm{~mm}$ long, red Eubranchipus, ice 3 inches; March 6, obtained 17 larva of the red Eubranchipus between $3-5 \mathrm{~mm}$ long, no pale ones seen; March 11, obtained 40 or 42 half-grown red Eubranchipus; March 23, a great number of adult Chirocephalus found near Glendale.

C. F. GISSLER. 
with the digitate processes as in the European form. Its occurrence, however, in this country and its being an intermediate form between $B$. vernalis and B. grubei shows that the genus Eubranchipus is not sufficiently distinct to be regarded as a valid genus. As our description is brief and gives only the salient points observed in alcoholie specimens, we reproduce Mr. Eorbes's original descriptions, drawn up from living examples:

"An important character, constant in the large number of both sexes which I have examined, is found in the abdominal segments, which are narrowed in front, with rounded anterior angles, while the posterior angles are produced backward, giving a decidedly serrate appearance to the abdominal margin. The last two abdominal segments are closely nnited and broader than the preceding.

"The antennce extend a little beyond the exes, and terminate in a cluster of about five slender olfactory clubs. The frontal appendages of the male are considerably longer than the claspers, to the front inner base of which they are attached, the line of attachment being parallel to the length of the basal joint. Their form is irregularly oval, the inner edge being regularly convex on its distal three-fourths, and the outer sinuate-convex on basal two-thirds, and slightly. concave on terminal third. Both margins are pectinate, except near base, with thick blunt teeth, which are longest on the basal half of the outer margin, where they are as long as the undivided part of the appendage is wide. At the middle of this margin the teeth become suddenly shorter. On the inner margin they are longest near the middle, regularly lessening towards each end. The under (posterior) surface of the appendage, as well as the teeth, is set with short spines, each springing from an inflated base. The claspers of the male are shorter and stouter than in E. vernalis. The basal joint is soft and inflated and bears a corneons rounded tuberele at its inner base (wanting in vernalis). The second joint is stout and regularly incurved, strongly angulated at its base in front where it is received into the first joint. A long strong tooth, ahout half as long as the joint, extends backward and a little inward from near its base. The rounded tip of this tooth is thickly set with minute, low, circular elevations, each with a central depression, within which is a disk-like elevation, the whole having the appearance of a minute sucking disk. The tip of the clasper is expanded and flattened within so that the inner (anterior) part has a spatulate form, while the opposite surface rises into a thick prominent ridge, giving to a transverse section of the tip the form of the letter $\mathrm{T}$. The anal appendages are linear-lanceolate, as long as the last four segments of the abdomen, and plumosely haired to the base. The ovisac of the female is as broad as long, three lobed behind, with the middle lobe the largest.

"Length of a full grown male, including anal stylets, $20^{\mathrm{mm}}$; width, $6^{\mathrm{mm}}$; across eyes, $4^{\mathrm{mm}}$; elasper, $4.5^{\mathrm{mm}}$; frontal appendage, $5^{\mathrm{mm}}$ by $3^{\mathrm{mm}}$. The largest females were a little more slender than the males."

\section{Genus STREPTOCEPHALUS Baird.}

Plate XII; figs. 1-7.

Streptocephalus Baird, Annals and Mag. Nat. Hist. 2d Ser. XIV, 219. 1854.

Heterobranchipus Verrill, Amer. Journ. Sc. xlviii, p. 250. 1869.

Streptocephalus Verrill, Proc. Amer. Assoc. Adv. Sc. July, $18 \pi 0$.

Body rather slender, much more so than in Branchipus. $2 d$ antennæ of male 3-jointed, remarkably long and large, tortuous and twisted, 
the basal joint stout, armed externally at the end with a very long, slender spur, about as long as the joint itself; the $2 d$ joint thick, very long and bent upward and inward; near the end on the inside is a row of small papillæ; at the extremity it enlarges into a short, thick handlike portion, the $3 d$ joint, which divides into two long unequally forked chitinous appendages. 2d antennæ of the female as usual, broad and suddenly mucronate at tip. Eleven pairs of feet; much as in Branchinecta and Branchipus: the first endite as usual, but the fringe is rather long, as also that of the other endites; the 5th endite square, the outer edge hollowed out, the spines on the lower edge few and un. usually blunt; the 6th endites more acute than in Branchipus; the flabellum large and rounded, fuller than in Branchipus; the gills rather large. The penis consists of two separate very long curved filiform processes. Uvisac of the female long and slender, much as in Branchinecta. Caudal appendages longer and broader than in Branchipus.

This genus differs from Branchipus in the want of frontal appendages, and may be easily identified by the long 3-jointed twisted and elbowed claspers, and by the two long slender filamental processes forming the male genital armature. Judging by the form of the $2 d$ antennæ, particularly the 1st joint, and by the absence of any frontal appendages, and especially the form of the ovisac, Streptocephalus appears to be a modified Branchinecta, and to have been differentiated from that genus rather than from Branchipus; in fact we may, I think, regard Branchinecta as the more generalized, ancestral type of the family.

\title{
Synopsis of the species.
}

Male claspers larger and slenderer at tip than in S. similis... S. texanus. Male claspers shorter than in S. texanus................ sealii. Male claspers shorter and broader at base than in S. tex-

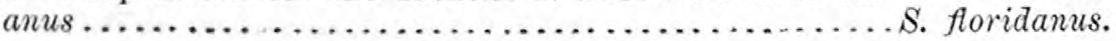

\section{Streptocephalus texanús Packard.}

\author{
Plate XII, figs. 1-7.
}

Streptocephalus texanus Pack., Amer. Journ. Sc, August, 1871.

Streptocephalus watsonii Packard, Hayden's Annual Report of the U. S. Geol. \& Geogr. Survey of the Territories for $18 \pi 3$, p. 622. Pl. IV, fig. 13 .

Male-Front of the head with a small median lobe which projects downward between the bases of the second antennæ, and is flattened,

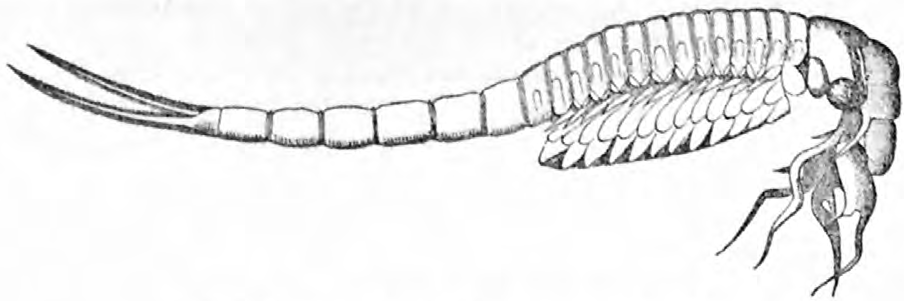

FiG. 20. Streptocephalus texanus, enlarged.

broad at the end, but not lobed, there being but a rery faint median sinus. The subconical upper surface of the head bearing the oblong ocellus near the front edge is truncated conical, being a little longer than broad. 1st antennæ long and slender, twice as long as the eyestalk, 
2 -jointed, 2 d joint about two-thirds longer than the 1st, tapering towards the end; basal joint curved a little at the base. 2d antenno or clasplers large and tortuous; the basal joint extends outward and downward; the $2 \mathrm{~d}$ joint extends backward parallel to the body, and is bent at right angles to itself, and the $2 . t$ is directed forwards and inwards, the ends nearly meeting over the median line of the body; $3 d$ joint siort, swollen, and subdividing into three branches, the longest of which reaches in its natural position to the 8th segment behind the 1st antennary seg. ment. An antenniform appendage springs from the end of the basal joint and reaches to the end of the 5th ring behind the eyes; it is slender, flattened, and much as described in s. similis Baird. At the end on the outside of the 21 joint is an acute, short, flat, conical appendage. Of the two terminal large appendages, the longer and sleuderer one is sinuate and sends off a slender spur from the base, reaching nearly to the bend in the appendage, where there is a slight projection, beyond which it is long and slender, flattened, cylindrical. The other appendage is irregularly flattened, very sinuate, and about two-thirds as long as the other. Near the base on the outer edge are two flat lamellate teeth, the inner much the smaller and slenderer; the outer broad and suddenly ending in a finger-like point, the appendage ending abruptly in an acute point. For want of material it is difficult to draw up a good comparative description of the appendages of this species as compared with $A$. floridanus and $A$. sealii.

By reference to the figures on Plate XII a good idea of the form of the appendages and their endites and exites can be obtained; but which characters are generie and which specifie would be difficult to say. The 1st endite is broad and large. with long, fine, hair-like setæ; in the $8 \mathrm{th}$ pair the base of the edge of the 5th endite has six stont, truncated, short spines (see Pl. XII, fig. $5 l^{5}$ ). The gills are oval, lanceolate in form; the flabellum rather broad and well rounded on the outer edge, which is serrate, the teeth giving rise to small, fine setæ.

The male reproductive organs arise from the 8 th segment counting forward from the telson, or the 15th from the head, and are slender, simple, unarmed, eylindrical, of the same thickness thronghout, with the end blunt, and are curved around so as to touch at their origin.

Telson very short; eandal appendages but slightly separated at base, long and rather stout, gradually tapering to the end and well fringed on both edges.

Length of the whole animal, $16.2^{\mathrm{mm}}$; length of longer appendage of $2 \mathrm{~d}$ antennæ, $4.2^{\mathrm{mm}}$; length of caudal stylets, $3.2^{\mathrm{mm}}$; length of penis, $3.2^{\mathrm{mm}}$.

Female.-Differs from the male in the $2 d$ antennæ, which scarcely reach beyond the 1st antennæ, and which are flat, conical, ending in a fingershaped point. Ovisac attached to the 13th and 14th segments behind the bead; it reaches backwards to the segment in front of the telson, forming a long cylindrical sac ending in two valves, the upper one triangular, hollowed beneath, the under one short, forming the end of the ovisae. The external opening of the oviduets are situated on the basal segment of the abdomen. The eggs are a little the larger at the end of the ovisac. The caudal appendages are rather shorter and considerably stouter than in the male.

Total length, $14^{\mathrm{mm}}$; of eaudal appendages, $3^{\mathrm{mm}}$; of ovisac, $5^{\mathrm{mm}}$.

This description is mainly based on the few examples received from Waco, Tex., through Mr. G. W. Belfrage, who found it in 1871, and again February 17,1872, with Limnetis and Estheria. Afterwards a large number, mostly immature, were received from Dr. Watson, at Ellis, Kans., and 
these were supposed to represent a different species and described in the Bulletin of Hayden's U. S. Geological Survey of the Territories in 1877. Since then I have received a number of specimens from Wallace, Kans., through Professor Lindahl, some of which were of the same size and state of preservation as the Texan specimens, and which showed no specific differences, and finally, on carefully examining and drawing the feet of specimens from the two States, I found that they could not be separated specifically.

I append the description of the Kansas specimens from Hayden's Bulletin, which may show how the individuals vary, especially in the male claspers :

"Male.-The claspers (2d antennæ) are much longer than in S. texamus, reaching, when extended, to the middle of the body, while in S. texamus they only reach a third of the length of the body. The median lobe of the head, which is very large and long in S. texanus, reaching nearly as far as the insertion of the basal filamentary appendage of the tinird joint of the claspers, is, in $S$. watsoni, not half as large. The two basal joints of the claspers are twice as long and much slenderer than in $S$. texanus; the third joint is nearly as long, while the branches and spines of the 4th joint, though of the same number, are much longer and slenderer. Of the longer branch the supplementary spine is much longer, and without the small inner spine, while the main branch beyond is bent at right angles, the elbow being much bent, the inside, howerer, regularly curved. At the base of the broader and shorter branch are four unequal teeth; one attached to the third joint, the other to the fourth, the two terminal ones very unequal, and the fourth square and three times as large as the third, while the correspondning tooth in S. texamus is long: and narrow, and smaller than the one behind it. The genital appendages are long and slender, much as in S. texanus, being as long as the three segments following the one to which they are inserted. The caudal appendages are much shorter and broader than in $S$. texanus, each blade being broader, and tapering regularly from base to tip, not contracted in the middle, nor curved, as in the male of $S$. texanus; on the other hand, they are of much the same form as in those of the female $S$. texanus.

"Female.-Very closely allied to the female S. texanus, though as a rule somewhat smaller, the eyes being decidedly smaller. The second antennæ are a little, sometimes much, longer in proportion, and are mucronate, as in the other species. The ovisacs are as in S. texanus, but the eggs are much smaller in proportion. The caudal appendages do not differ materially from those of the males, nor from those of the females of S. texanus.

"Length of males, $16^{\mathrm{mm}}$; females, $12-18^{\mathrm{mm}}$. About fifty of each sex examined, althongh several hundred were casually looked over, without finding any that approached $s$. texanus any nearer than has been indicated.

"Ellis, Kans., in pools on the prairie, June 28, 29, September 27, and October 10-22, Dr. L. Watson. A large number of hilf-grown males and females occurred in June. The largest females, those measuring 18 millimeters in length, occurred October 22 , the ovisacs filled with eggs in some cases; in others, partially or entirely empty. The body was soft and in such a state of preservation as to indicate that they were at the point of dissolution. They were found associated with Thamnocephalus, Limnetis, Estheria, Eulimnadia, and Apus lucasanus. The tails were red, says Dr. Watson, and in some the bodies were blue. This refers to those which were collected in June and early in Juls, "Those 
found in October and early in November (the 6th) were pure white, and the appendages to the tail seemed to me to be more divaricate than those of summer, in which those appendages were of a red color.' While the males are easily distinguishable from those of $S$. texanus by the much greater length and different style of branching of the second antennæ, as well as in the smaller frontal tubercle and the slenderer caudal appendages, the females differ but slightly, but may still be distinguished by the smaller eyes and longer second antennæ. This species is dedieated to Dr. L. Watson, who has been indefatigable in securing me specimens for examination of this and other Phyllopods. The male differs from S. similis Baird from St. Domingo in the second antennæ or claspers being much longer and slenderer at tip of the longer branch, while the shorter branch is much narrower. In the female the ovisac reaches to the penultimate segment of the abdomen, while, according to Baird's figure, in S. similis it scarcely reaches to the end of the fourth segment from the end, and the second antennæ are represented as being much larger than in our species. The figures do not exactly correspond with Baird's description, for it is nearly impossible to make a characteristic drawing of the members of this family, and particularly of this genus."

\section{Streptocephalus seali Ryder.}

Streptocephalus sealii Ryder, Proc. Acad. Nat. Sc. Phil., p. 200, 1879.

"In form and size this speeies resembles S. torvicornis Waga, but the third joint of the second antennæ differs from that species in the details of its structure, and the ovigerous sacs of the female are

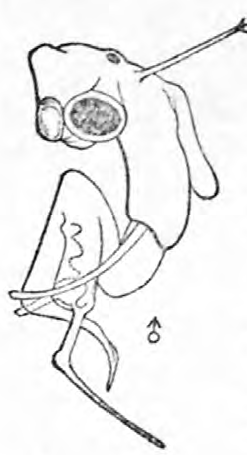
not blue, as in Waga's animal. The inner branch of the terminal joint of the male claspers is the shortest instead of the longest, as in S. torvicornis; at the internoanterior margin of the short branch there are two unequal lobes extending forwards and lying flat against the laminar posterior border of the anterior branch; at the lower posterior angle of this lamina, or blade of the forward branch, there is a well-marked, somewhat falcate process, which fits between the lower lobular process of the posterior branch and its scythe-slaped lower extremity. The anterior branch crosses the posterior at nearly right angles, and for abont a third of its length maintains a pretty uniform thickness, and is straight, when it suddenly swells and bends forwards, 21.- Headof Streptoce and as suddenly contracts and tapers for its remaining after Ryder extremity. The first joint is long and robust, and from its apex externally the cylindrical, curved, antemniform organ arises, which is about as long as the filiform first antennæ. The second joint is very tortuous, and is strongly bent and twisted upon itself. The third joint, which bears the complex terminal appendages, is wide; the appendages close against each other like the blades of scissors, whilst the processes of their opposing margins interlock as has been already described, and as can be fully understood by reference to the accompanying cut of the head of the male. The front of the head is prolonged into a straight beak, which hangs down nearly vertically between the first joints of the claspers, and is flattened antero-posteriorly, and emarginate at its tip. The antenniform appendage is much longer than in S. texunus Packard, whilst the terminal branches of the claspers are widely different from those of that species in their shape and relative proportions. The male 
organs are very feebly armed with a few short spines and are nearly straight. The cephalic horns of the female are twisted upon themselves, slightly bent and flattened at their extremities, which are fringed with short hairs. The large lateral, ovoid, pedunculate, apparently glandular organs behind the eyes are the same in size and shape in both sexes. The ovigerous sacs are large, nearly half as long as the abdomen, conical in form, and contain a great number of ochraceous eggs, more numerous and much smaller than those of Chirocephalus holmanii from the same locality. The male is of a beautiful green, deeper about the head, as though saturated with acetate of copper; the female, on the other hand, is yellow, with a tinge of green, verging to brownish in parts, and is very nearly of the same size as the male, if not a little larger. This similarity in the size of the sexes, with a tendency in the females to be largest, is observed only in S. torvicornis, as far as I am aware. The two rather long, plumose, tapering branches of the tail are red in both sexes, but of a much brighter red in the female; more slender in the male. Length, $27 \mathrm{~mm} "$ (Lyder).

The main difference between S. seatii and texamus is that in the former the claspers are considerably shorter, the $2 \mathrm{~d}$ joint being much shorter and the $3 d$ joint at base much broader, while the $2 d$ spine on the shorter fork is nearly three times as large as in S. texanus, and the longer fork is much slenderer. There are no differences in the feet, as I find after careful microscopic examination. C. sealii also appears to be rather larger.

Regarding the mode of occurrence of this species we quote from a letter of Mr. W. P. Seals, dated Woodbury, N. J., Norember 7, 1879:

"I have delayed auswering your letter until I could assure myself positively as to the present existence of Streptocephalus sealii. Unfortunately I did not save any specimens, and the swales in which I found them are now dry with one exception, and in that I cannot find a single specimen. Perhaps the following notes which I have made will interest you. I find them in two places separated by about a mile. One of these is never dry. In this one they disappeared about the beginning of June, and have not yet reappeared. In the other swale they disappeared about June 6th by reason of its drying up. In abont two weeks after the heavy rains in the latter part of August they had again made their appearance. By Otober 20th they had again disappeared by reason of the drying up of the swale. Chirocephalus holmanii also exists in this swale, but has not made its appearance since disappearing last June."

We have also received numerous specimens from Dr. C. F. Gissler, who sends us the following notes:

"I send you now a bottle with Chirocephalus of both sexes. A few specimens of Eubranchipus vernalis might have slipped in also, as they oceur together in a rery large and deep pond (no fishes seen so far) near Glendale, L. I. With one Eubranchipus about twenty Chirocephalus holmani oceur. The males are in average about $1 \frac{1}{2} \mathrm{~mm}$ shorter than the females. Color yellowish or reddish or greenish, last 3 abdominal segments with red pigment, the latter confluent, not granular. The \& has the same second inner lobe as Ryder figures it. Ovary (observed in many 9 ) extends upward to the 4th pair of branchipods from the end; no anastomosis in the post-abdomen. The water of the pond is perfectly clear, colorless, numberous Entomostraca occurring in it. I have seen them in copulation many a time, and can assure you that the tentacles do not come into use as an auxilliary."

On March 23, 1881, Dr. Gissler visit d the same pond at Glendale and found $C$. holmani in great abundance, getting two or three dozen at every dip of the net. 


\section{Streptocephalus Floridanus Packard.}

Streptocephalus floridanus Packard, American Naturalist, p. 53, Jan. 1880.

The two basal filaments are as in S.texanus; of the forceps at the end of the claspers, the filaments are much shorter and smaller than in S. texanus, so much so that there is no need of confounding the two species, and, besides, in the Floridian species the processes are less broad and flat, and the inner of the two blades of the forceps have but one instead of two teeth. It approaches S. texamus in the robustness of the body, in the form and size of the caudal appendages, which equal, in length, the three last abdominal segments. It seems to approach S. similis Baird, which inhabits St. Domingo, but that speeies is not described with sufficient exactness to enable us to compare it properly, and indeed without good specimens for comparison it is difficult to say whether this species is different or not from $S$. sealii Ryder.

Total length of male, $10^{\mathrm{mm}}$; length of $2 \mathrm{~d}$ antennx when stretched out, $5-6^{\mathrm{mm}}$; length of caudal appendage, $2^{\mathrm{mm}}$; total length of female, $10^{\mathrm{mm}}$.

A pair, $\delta$ and , found in the Saint John's River, Florida, May 23, 1879, by Alex. P. Fries; received from Dr. Carl F. Gissler. It appears to differ from S. similis in the shorter filiform appendage of $3 d$ joint of $2 d$ antennæ, which is also very much shorter than in S. texanus.

\section{Streptocepmalus smmLis Baird.}

Streptocephalus similis Baird, Annals and Mag. Nat. Hist. 2d ser. xiv, 220, 1854.

"This species, which was found by M. Salle in the island of St. Domingo in the West Indies, is of a slender and cylindrical form. The male is about five-eighths of an inch in length, and the female half an ineh. The inferior antennæ or cephalic horns in the male are large and tortuous; they are composed of three joints; the first or basal joint is the largest, is cylindrical, and extends for some distance straight forwards; the second, smaller than the basal, is also cylindrical, curves slightly at first, then bends suddenly backwards upon itself; the third or terminal joint bends as suddenly forwards and terminates in a club-shaped extremity, which divides into two branches, one longer than the other, terminating in a long filiform process; the other flatter, shorter, and dividing into two shorter filiform processes of unequal length. The antenniform appendage is long and eylindrical, rather stout, and springs from close to the extremity of basal joint. The basal joint is destitute of the lanceolate-toothed appendage on internal edge, which we see in the preceding species (S. cafer, Lovén). The superior antennæe are long and slender, and consist of two joints, the basal one much shorter than the 2d. The male organs are rather long, cylindrical, and of a horny texture. The front of the head is prolonged into a beak, which is flat, rather broad and slightly lobed at the extremity. Feet short. Abdomen slender. Candal appendages of moderate length, and beset on each side with numerous short and plumose setæ.

"The cephalic horns in the female are short, thick, and terminate in a short spine at the extremity. The ovarian bag is conical, acute, and the ova are of an ochreous color.

"The chief differences between this species and $S$. cafer consist, in the male, in the shape of the front of the head, the organs of generation, and in the inferior antennæ having no lamina with teeth on the basal joint; in the female, in the shape of the external ovary." 


\title{
Genus CHIROCEPHALUS Prevost.
}

\author{
Plate XIII.
}

Chirocephatus Prevost, Journal de Physique, 1rii, 37, 1803; Thompson, Zoological Researches, 1834.

Branchipus, Milne-Edwards, Fischer, Latreille, Desmarest, Guerin, Lamarek.

Chirocephalus Baird (in part), British Entomostraca, 38, 1850; Annals and Mag. Nat. Hist. $2 d$ ser. xiv, 221, 1854; Verrill, Proc. Amer. Assoc. Adv. Sc., July, 1870.

Body slender, head of moderate size, $2 d$ antennæ or male claspers with the basal joint very large and thick and somewhat curved; 2 d joint very long and slender, curved inward, with a basal sharp spur. Two remarkably long and large frontal appendages arising between the base of the $2 d$ antennx, about twice as long as the $2 d$ antemne, much twisted and coiled and variously lobed and spinulated. Eleven pairs of swimming feet; the basal lobe or endite long and with the edge regularly curved, the $2 d$ with an outer subdivision about $\frac{1}{d}$ as broad as the 1st; each paler, with rather long fringe of delicate hair-like setæ; the 2-4th endites, as in the foregoing genera, small, each with three or four long minutely spinulated setie. The 5th endite of the usual size, but rather square, much as in Branchipus, but with a tendency in the lower outer angle to be somewhat produced so as to be subtriangular in outline. (Pl. XIII, fig. 1.) The bth endite is unusually long and narrow, almost lanceolate, and with long setæ in the $3 d$ pair of feet, or small, narrow, and abruptly rounded in the 1st pair; in the 10 th pair they are narrow and rounded at tip. Flabellum and gills much as in Branchipus.

Male genital apparatus short and small, deeply cleft, forming two slender curved portions, each with its eirrus. Caudal appendages long and broad, much more so than in Branchipus.

In the female the $2 d$ antemn have the mueronate spur or tip larger and longer than usual. Ovisac short and broad, with the end produced likê the neck of a bottle, much as in Branchipus. The eggs are few in number (about a dozen), and the eggs are larger than in streptocephalus and Branchipus.

This genus differs from Branchipus in the slenderer body, the very long, coiled, twisted, lobulated, and spinulose frontal appendages, and in the differences in the endites already noted. In the form of the external male organs and of the ovisac the genus approximates closely to Branchipus, and in the frontal appendages, as seen in the European $C$. diaphanus, is only an exaggeration of those of Branchipus. It seems reasonable to infer that Chirocephalus is a more recent group than Branchipus, and has probably originated from that genus, as Sireptocephalus has in all probability arisen from individuals. The singular frontal appendages are supplied with two large museles, and as no nerves have as yet been detected in them it is probable that the organs are simply prehensile and perhaps of use during the union of the sexes.

Chmocephalus holmani Ryder.

Plate XIII, figs. 1-5.

Chirocephalus holmani Ryder, Proc. Acad. Nat. Sc., Philadelphia, 148, 1879.

Body rather slender; $2 d$ antennæ or claspers of the male with the the 2 d joint considerably shorter than the 1st; it is forked, spur large and pointed; the longer branch slender (its tip crossing that of 
its fellow of the opposite side when in repose). The two frontal appendages (Pl. XIII, figs. 4, 5) very long, coiled, and twisted, with the appearance of being jointed, and gradually diminishing to a long, curved point, which is minutely spinulated, the spinules short, stout at base, and acute at tip; variously and finely lobed with about seren finger-like spinulated processes, best marked in old males (Fig. 22); near

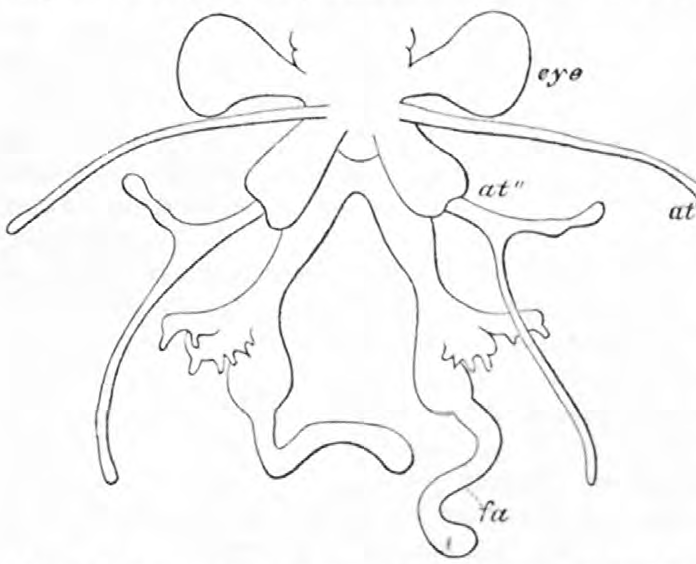
the middle a group of four or five setæ. These organs, when stretched out, are about three times as long as the male claspers. As a rule the 6 th endites of all the feet are narrow and obtuse at the end, much as in Branchipus, the gill varying much in size. The head of the female is simple, without any frontal appendages; the ovisac is short and small, containing abont a dozen very large eggs, showing that the number of individuals

Fic. 22. - Chirocephalus holmani; male. Front view of head in this species is far less of male, much enlarged, the fromal appendages somewhat re than in the other species of
tracted; $a t^{\prime}$, tirst anterna; at", secomi antema or male clasper, than with the spur and filiforn $2 d$ joint; $f a$, frontal appendage. Giss- the family except, perhaps,
ler del. Artemia.

Total length of body of male, $15^{\mathrm{mm}}$; of $2 \mathrm{~d}$ antenuæ, $3^{\mathrm{mm}}$; of frontal appendages when outstretched, $5-6^{\mathrm{mm}}$; of genital organs, $2^{\mathrm{min}}$; caudal appendages, 2-2, $3^{\mathrm{mm}}$.

Total length of female, $16^{\mathrm{mm}}$; of ovisac, $2^{\mathrm{mm}}$.

I have received the $\delta$ and $q$ from Mr. Ryder, the types of his description, and also a number of both sexes, the females with eggs, from Woodbury, N. J., near Philadelphia, collected in company with Branchipus vernalis, March 27, by Mr. William P. Seal; also from Glendale, Long Island, from Dr. C. F. Gissler, who kindly sent me a drawing of the head of an old male, although the sketches of the head of the male by Mr. Ryder in the Proceedings of the Philadelphia Academy of Sciences are truthful to nature.

This Branchipod is certainly, only excepting the next genus, the most interesting and bizarre of all our fresh-water Phyllopods. The sketches in Plate XIII will convey a better idea of the form of the feet than any verbal description.

\section{Subfamily THAMNOCEPHALIN Æ Packard.}

Body large, very stout and thick; eleven pairs of feet; 2 d male antennx with the 2 d joint simple, curved; nine abdominal segments; ab. domen broad and flat, ending in a single broad, spatulate, fin-like lobe; endites of feet much broader and more rounded than in Branchipodina; frontal appendage of male tree-like; of female, long and clavate, simple.

\section{Thamnocephalus* Packard.}

Thamnocephalus Pack., Bull. Hayden's U. S. Geol. and Geogr. Survey Territories, iii, 175. April 9, 1877.

Male.-Claspers (second antennæ) with the basal joint short, the upper 
lobe forming a long, up-curved, chitinous, slender appendage, extending, when outstretched, to the first third of the body; the lower lobe fleshy and short, straight. A distinguishing and remarkable character is the frontal, interantennal, shrub-like, branched, biramous appendage extending out in front, the brush more than half the length of the body, and sending off branches anteriorly, which are provided with minute spinules. The male genitals united at base as usual; they are small and deeply cleft.

Female. - The frontal shrub is replaced by a pair of long, slender appendages, acute, lanceolate-ovate at the end, and contracted somewhat in the middle. Labrum rather long and large. The second antennx are remarkably long and broad, oar-like, acute at the tip. The egg-sac is long, subconical, rather thick and broad at the base, which is concealed by the leaf-like feet; it ends in two valves.

In both sexes the body is unusually short and thick, though the head is of the usual size. There are 11 pairs of feet, with the lobes broad and short, much more orbicular than usual. The gill is larger and broader than usual, the flabellum being somewhat ovate in outline the relation of the gill to the rest of the appendage is best seen in the transverse view of the body, Plate XIV, fig. $4 \mathrm{br}$.). The 1 st endite or lobe is much shorter than in the other genera, and with coarser, hair-like setæ; the $2 d$ endite is large, being from one-third to one-half the size of the 1st endite; the setie are rather coarse; the $3 d$ and 4 th endites small as usual, each with three or four setulose seta; the 5th endite is broad and large, bluntly and quite regularly pointed, not so rectangularly bent as in most of the other genera of the family. The 6 th endite is usually short and broad, quite different from the long subacute-ovate form prevailing in the other genera of the family. The abdomen consists of nine segments, dilates into a remarkably largo, broad, fin-like expansion, beginning at the sixth segment from the end, and expanding at the last segment until it becomes wider than the body, and extending a little way beyond the last segment. It is fringed with delicate hair like setæ, and canals from the body ramify in it; at the end it is deeply notched, forming two br. ad, rounded lobes.

This remarkable genus differs from any other known to me by the short and broad, spatulate, fin-like expansion of the abdomen, while the male claspers are curved and simple. In both sexes the body is stout, broad, and the egg-sac of the female is subconical, spreading out at the base. It is quite unlike any European gemus, and in the frontal appendage, the end of the abdomen, and the broad, short gills and endites stands alone in the family.

\section{ThaMnocephalus platyuRus Packard.}

Plate XIV, figs. $1-\%$.

Thamnocephalus platyurus Packard, Bull. U. S. Geol. and Geogr. Surver Territories, iii, No. 1, 175. April 9, 1879.

Male.-Frontal shrub over half as long as the body, the two branches subdividing into about seven subbranches, all directed forward. First antennæ long and slender, extending to the end of the basal joint of the second or male claspers. The latter with the basal joint rather short, the claspers long, slender, and recurved, simple, saber-like, chitinous, the lower lobe soft, acute, subconical. Genital appendages in the usual position, short, not so long as the segment to which they are attached, 
and bilobed, there being two short terminal tubes, with distinct, large openings, directed downward.

Female.-Second antennæe large and long, extending back a little beyond the base of the ovisac, oar-like, expanding broadly on the onter two-thirds, especially on the upper edge. The ovisac is subconical, the base broad and concealed by the limbs; it terminates at the posterior edge of the fourth segment from the end, ending in two unequal flaps, the upper four times larger than the under flap, and triangular in outline.

Length of male, $23^{\mathrm{mm}}$; female, $265^{\mathrm{mm}}$. Ellis, Kans., Dr. L. Watson, collected June 26, 28, and 29, and again September 27, Octo-

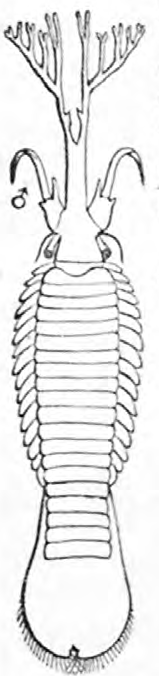

ber 1,10 , and 22,1874 , in pools of water on the plains, in company with Estheria and Limnetis. A fully-grown male oceurred September 27th. October 1-22 females of full size were collected, in company with Apus lucasanus, Estheria compleximamus, and Estheria mexicana.* The ovisacs still contained eggs, though empty at the ends.

No striking rariation was observed among several hundred specimens of different ages. Dr. Watson writes that the gen-

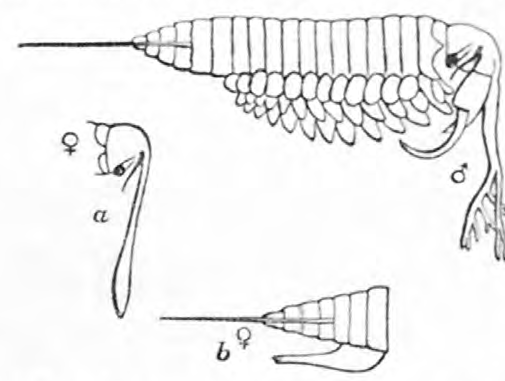

FIG. 23.-Thamnocephalus platyurus PACK., male, natural size, "dorsal and side view; $a$ head, and $b$ end of body of female, showing ovisac.

ing Kansas of this interesting genus, and of Apus lucasanus, Streptocephalus texanus, Estheria mexicana, and Limnetis I extract from a letter of Dr. Watson, dated Ellis, Kans., October 12, 1874:

The Apus moves about on the bottom of the pools, rarely rising enough to allow the slipping of the net under him, and is not easily captured unless in close quarters. The Estheria and Limnetis swim about, go. ing to the bottom and coming to the surface, and are easily eaptured by slipping a net under them when up. The Thamnocephalus are always in medio, and by gentle action are easily taken. The forked-tail ones (Streptocephalus) at the edge of the pool, and the larger emarginatedtailed ones always in the middle, or in circumscribed clear places having 6 or 12 inches of water. The heavy rain of June 14 washed out the ravines by torrents. The dates 1 have before given for former collections indicate the development of those specimens after that date. Those now sent (October 14) have developed, certainly since September 2; probably since September 8 ; possibly since September 13 .

"In relation to the localities where I have found the Crustaceans :

"There are "divides" upon these plains, between streams; just here,

* From Mr. R. P. Whitfield we have received specimens of Estheria mexicana collected by Dr. C. A. White, on the Vernilion River, Colorado, in company with Lepidurus bilobatus Pack. See American Naturalist, xiv, 53, 1880, where this species is referred to under the name of Estheria watsoni Pack. (no description), which is synonymons with E. mexicana. 
three hundred miles west of the Missouri River, the Smoky Hill River is twelve miles south. 'The 'divide' between it and Big. Creek, one of its tributaries (upon which Ellis is situated), is about one-third of the distance, or four miles. Six miles north is a tributary of the Saline River, with a "divide" about midway between it and Big Creek. From these "uivides," at varied intervals, are rarines, those upon the north side often deep enough to be called cañons, and in some of which are small springs, sufficient to maintain pools containing fishes (and Amphipods). 'The ravines from the south of these 'divides' are more gentle or less abrupt, and though, upon heavy rains, torreuts of 8,10 , or more feet of depth, rush down them, they are ordinarily dry pools of water remaining only two or three weeks at the angles where are bluff banks, or in other excavated places. In such pools, well up the ravines beyond where fishes from the creek run up during the flood, these Crustaceans are found. They are not found in 'buffalo wallows' or in any upland pools. Under the circumstances of this year or last only three or four weeks of life can they have. Millions of them perish by the drying up of the pools in July. A less number hatch out after the fall rains, and they can have hardly more than a month to live.'

\section{II.-THE GEOLOGICAL SUCCESSION OF THE PHYLLOPODA.}

\section{FOSSIL FORMS.}

Up to this date but four species of fossil Phyllopoda are known from North America; these are:

Estheria pulex Clarke; ${ }^{*}$ from the base of the Hamilton shale in New York.

Estheria ovata T. R. Jones; from the Triassic beds of North Carolina, Virginia, and Pennsylvania.

Estheria dausoni Packard; from the Quaternary Clays of Canada.

Leata leidyi, T. R. Jones; from the Lower Carboniferous of Pennsylvania.

We reproduce the descriptions of the forms deseribed by Prof. T. R. Jones from his nonograph of the fossil Estheriæ. London Palæontological Society, 1862.

* Estheria pulex Clarke, Amer. Journ. Sc. Jume, 1882, 476.

"In examining some fragments of soft, olive-colored shale from near the base of the Hamilton proper, in Miles' Gully, Hopewell, Ontario County [N. Y.], I have detected the above representative of this extremely interesting genus. The hittle carapaces are never more than $\frac{2}{\mathrm{~mm}}$ in width and $\frac{1}{2} \mathrm{~mm}$ in length, and may be described as having the ventral margin nearly semi-circular, the beak central or very slightly anterior, hinge line sloping laterally. The surface is marked by six, or in the largest seven, concentric ridges, which are very broad, with narrow intervening furrows. There appears to be no more elaborate sculpturing of the carapaces than Jones has figured for his species, E. membranacea, which is the simplest of any as yet noticed.

"It is interesting to notice that this Estheria, the first ever found below the Trias in America, and nowhere at so low a horizon as this, resembles in its subcentral heak, its outline and surface markings, this species just referred to, E. membranacea Jones, from the Old Red of Caithness, while all others figured by that author (Mon. Esth. Palæontogr. Society, vol. xviii) all from higher horizons, have the beak anterior and the ontline of the carapace more nearly subtrigonal."

This is a very remarkable species of Estheria, and may yet be found to represent an undescribed genus. It differs from any species of the genus figured by Jones, including $E$. membranacea, in wanting a straight hinge-margin. Its small size, few lines of grow th, and lack of a hinge-margin, indicate that it is very young, and for that reason may yet prove to be a true Estheria. 


\section{Estheria ovata Jones.}

Posidenomya mimuta (Bronn.) W. B. Rogers, Proc. Acad. Nat, Sci. Philad., 1843, vol. 1, p. 249; Posidonia, sp.? Proc. Boston Soc. Nat. Hist., 1854, vol. 5, p. 14. ? Lyell, Quart. Journ. Geol. Soc., 1847, vol. iii, p. 274, fig. 6.

Posidonia orata Lea, Proc. Acad. Nat. Sc. Philad., 1856, vol. 8, p. 77. parva, Lea, ibid.

P. ovalis Emmons Geol. Rep. North Carolina, 1856, p. 323, fig. W, 1 and 2 ; Amer. Geol., part 9, 1857, p. 40, fig. 12; Manual Geol., 2 d edit., 1860, p. 191, 166, 3.

P. multicostata Emmons, Geol. Rep. N Carolina, 1856, p. 337, fig. X; Amer. Geol., part 6, 1857, p. 134, fig. 103; Manual of Geol., 2d edit., 1860, p. 191, fig. 166, 4.

P. triangularis, Emmons, Geol. Rep. N. Carolina, p. 338, fig. 5; Amer. Geol. part 6, p.

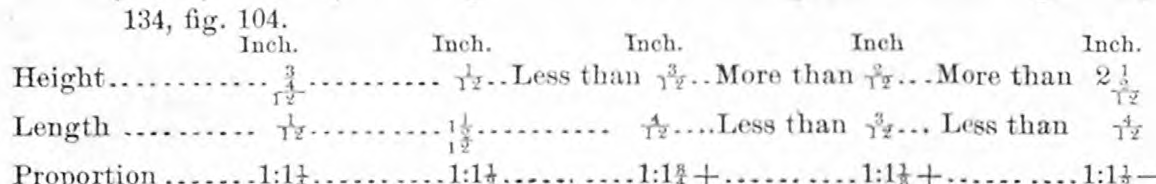

"Carapace valves broadly subovate, almost semicircular; the straight dorsal line reaches across the valve, the extremities enrving suddenly downwards; the postero-dorsal angle being the sharper of the two. The front and posterior margins are nearly equally rounded, but the valve is usually deepest at the anterior third, in a line with the umbo; the well-curved ventral border being rather more oblique posteriorly than anteriorly. The concentric ridges are about fifteen in fig. 26, about twenty-eight in fig. 27, and much more numerous in fig. 28. In fig. 27 we see the gradual crowding of minor concentric ridges towards the ventral border in an adult specimen, and in fig. 28 we have an individual in which, owing to some peculiarity of growth, the ridges are too numerous to be very distinet, and are unaccompanied with any orna ment of the interspaces (figs. 29,30). In other specimens we find, besides blank surfaces (fig. 37), modifications of a reticulate ornament on the interspaces (figs. 32, 36), with occasionally a barred or transversely wrinkled pattern (figs. 37, 38). Fig. 31 is a set of narrow interspaces, smooth and without ornament. Fig. 32 shows how a smooth surface may mask the reticulate structure. Figs. 33, 34, 35, and 36 are reticulate interspaces, the meshes being of various sizes and arranged either longitudinally, diagonally, or vertically. In the first case the walls of the meshes would strengthen if not give rise to minor concentric striæ; in the last case they may give rise to the bar.ornament, such as is seen in fig. 37. The obliquity of the meshes in fig. 35 may be due to pressure. Fig. 38 seems to show narrow interspaces bonneted by thick ridges and crossed by short thick bars.

"For most of these illustrations we have had recourse to specimens from Pennsylvania, Richmond, and Dan River (from Prof. W. B. Rogers' collection), which evidentiy belong to the species. These specimens are-

1. From Pennsylvania. Black shale. Estheriæ excessively crowded in horizontal layers.

2. From Prince Edward, near Richmond, Va. Black shale, with conchoidal fracture, fine-grained. Estheriæ tolerably well preserved, but crumpled.

3. From Dan River, North Carolina. Black, laminated shale, obliquely crushed. Estheriæ very thin."

LEAIA, gen. nov.

"I have proposed the above name as a generc denomination for certain peculiar, quadrate, bivalved carapaces, occurring in the Coal- 
measures of Britain and the lower Carboniferous red sandstone of Pennsylvania. I know nothing of their nature, except that they are small, thin, horny, brown, stiffly quadrate, symmetrical bodies, unlike Molluscan shells, but possibly Crustacean and Phyllopodous.

"I have some specimens from the upper Coal-measures of Ardwick, near Manchester collected by Professor Williamson, F. R. S., several years since), and some from the lower coal-measures of Fifeshre, collected by Mr. Salter, F. G. S., of the geological survey. Dr. Isaac Lea described and figured, a few years ago, a similar fossil from the red sandstone of Pennsylvania, and named it Cypricardia leidyi. All these three are very much alike; but, on account of the obscurity of their relationship, and the distant places, geological and topographical, of their occurrence, and making the most of their slight differences of contour, I propose to keep them nominally distinct as Leaia leidyi (Plate 5, figs. 11, 12), L. leidyi, var. williamsoniana (Plate 1, figs. 19, 20), and L. leidyi var. salteriana (Plate 1, fig. 21) Dr. I. Lea, of Phila. delphia, being the first to notice and figure a specimen of this proposed genus, I have distinguished it by a name commemorative of that well known conchologist. The carapace-valves are oblong; truncate behind, with a slight curvature of outline; boldly rounded in front; either straight or somewhat curved on the ventral border; straight on the dorsal edge; a slight umbo takes the place of the antero-dorsal angle, from whence two conspicuous ridges (hollow within) pass along the surface of the valve; one directly across the valve to the anteroventral angle; the other, and longer one, passes diagonally to the postero-ventral angle; these ridges divide the convexity of the valves into three, nnequal, triangular, smooth, sloping areas; the anterior space is the smallest, and nearly semicircular; the middle one has its apex at the umbo, and its base along the ventral margin; and the posterior space is based on the hinder margin, and reaches along the dorsal region to the umbo. The surface of the valve is marked with $10-13$ (?) delicate ridges (hollow within), concentric, beginning at the umbo, conformable to the outline of the valve, and sharply bent at the divergent ridges; they are curved and closely set on the anterior area; more open, horizontal, and straight, or nearly so, on the middle area, and vertically straight or slightly curved, and wider apart, on the posterior part of the valve. These symmetrical markings of eoncentric angular lines and transverse divergent ridges give this fossil, at first sight, a striking likeness to some fish-scales, when the two valves lie open, in contact by their dorsal edges (as in Plate 1, fig. 19), and produce a bilaterally symmetrical, subquadrate, concentrically lined figure, with triangular sloping areas. Dr. Lea points out some Cypricardix and other shells of Palæozoic age to which this little fossil has some resemblance in shape; and some Urthonotx have a general resemblance to it; but some of the small Astartes of the Chalk and Oolite, small as the A. Roemeri, Miiller's Petref: Aachen, Kreideform, Plate 6, fig. 12, and A. interlineata, Morris and Lyeett, Mollusea of the great Oolite (Palaentog. Soc. Monograph), Plate 9, figs. 14, 15, have even a greater resemblance in size and shape, without being at all allied to the form before us.

The horny tissue of Leaia-its long dorsal edge destitute of hingeits stiff and simple style of ornament-and its two diagonal, raised hollow ridges or folds, remove it from the Mollusca. It has been suggested (by Phillips and Williamson) that these fossils may be Trigonellites (of Goniatites?); but there is little or nothing to support the hypothesis. 
LEAIA LEIDYI T. R. Jones.

Cypricardia leidyi Lea, sp. Proceed. Acad. Nat. Sc. Philadelphia, 1855, 7, p. 341, pl. 4.

Height of ralre, nearly $\frac{3}{24}$ inch. Proportion 7 to 12 , or $1: 13$ -
Length of valve, nearly $\frac{5}{24}$ inch.

In the "Proceedings Acad. Nat. Science of Philadelphia," Mas, 1855 , vol. 7, p. 341, Dr. I. Lea has described a small fossil found by Dr. Leidy in red sandstone at Tumbling Run Dam, about a mile southeast of Pottsville, in Pennsylvania. The specimen consists of the impression of the outside of the two valres. It is figured carefully, of natural size, and enlarged, in plate 4 (op. (eit. ${ }^{1}$ ), and is named Cypricurdia Leidyi by Dr. Lea, who thus describes it:

"Shell oblong, ronnd before and truncate behind, very inequilateral, striate; dorsal and basal margins parallel; umbonal slope shortly carinate; anterior slope with an elevated line from the back to the basal margin; strix about twelve, very regular, and nearly equid stant bent at an angle of $90^{\circ}$ at the umbonal slope). Length, two-twentieths, breadth, nearly four twentieths, of an inch." "The shell is accompanied on the specimen with some obscure impressed linear marks of a dlant.

The figures are reproduced here (Plate 5, figs. 11, 12). The sandstone is referred to the formation called No. 11 by Prof. H. D. Rogers in the Srate Geological Survey of Pennsylvania, and referred by him to the base of the Car. boniferous system, but regarded by some geologists as the uppermost part of the Devonian or Old Red Sandstone. In this formation of sandstone (which, with its associated shales, is 3,000 feet thick), foottracks of reptiles, rain-prints, wave marks, and trails of annelids or molluses are not uncommon at two or inore horizons.

Jones then describes as rarieties of the foregoing,

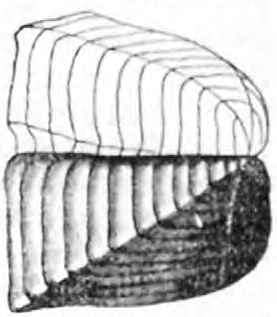

Fig. 24.-Leaia leidyi enlarged. After Lea. Leaia villiamsoniana, from the uppermost coal-measures of Lancashire, England, and L. salteriana, from the lower Carboniferous rocks of Fifeshire, Scotland.

Estheria DAWsoni Packard.

(Plate XXIV, figs. 4, 4 a, 4 b.)

Estheria dacsoni Packard, American Naturalist, xv, June, 1881, p. 496.

We have received through the kindness of Principal J. W. Dawson, LL. D., of Montreal, a valve, in partial preservation, of an Estheria quite unlike any existing American form. The following account of its discovery is from Principal Dawson:

"It was found at Green's Creek, on the Ottawa River, in nodules in the Post-pliocene clay, holding skeletons of Mallotus villosus and other northern fishes, and shells of Leda (Portlandia) arctica, Saxicava rugosa, \&e.; also leaves of Populus, Potanogeton, \&c. 'The deposit is of the age of the Leda clay of the Saint Lawrence (middle glacial) and belongs to a period of submergence where, in the bay or estuary then representing the Ottawa River, northern marine animals were embedded in deposits into which was also washed the débris of neighboring land, and of fresh-water streams. The climate at the time was colder than at present, and the area of land less, so that, if this Estheria still lives, it is most likely to be found in the vicinity of the Aretic coast."

This Estheria is entirely unlike any northern American or European 
species, differing decidedly from Estheria morsei or Estheria mexicana. It rather approaches $E$. jonesii from Cuba in the form of the shell and style of marking of the valves. It does not resemble closely any of the fossil forms figured in Jones' Monograph of fossil Estherix." The markings, however, present some resemblances to $E$. middendorfii Jones, but differs in the want of anastomosing cross-wrinkles between the ridges.

One valve and portions of others were preserved; but none of them show the breaks (umbones), though the form of the remainder of the shell indicates that they were situated nearer the middle of the valve than usual, i. e., between the middle and the anterior third of the shell. The shell is deep, probably more so than in E.jonesii, though the valres have evidently been flattened and somewhat distorted by pressure, but apparently the head-end was more truncated than in $E$. jonesii, as the edge of the shell and the parallel lines (or ridges) of growth along the head-end are below bent at right angles te the lower edge of the shell. The raised lines of growth are very numerous and near together; they are of nearly the same distance apart above near the beaks as on the lower edge. The very numerous lises of growth are thrown up into high sharp ridges, the edges of which are often rough, finely granulated, and often the valleys between are rugose on the surface. In one or two places a row of papillæ for the insertion of spinules may be seen where the shell has been well preserved, aud between many of the lines of growth there are irregular superficial ridges. Length $10^{\mathrm{mm}}$; depth $7.5^{\mathrm{mm}}$.

The valve is evidently that of an Estheria, much truncated anteriorly, and with the lines of growth much thicker, higher, and closer together than in any North American species known to us, and may prove, when better specimens are found, to be allied to the Tertiary Siberian $E$. middendorfii.

The species is named in honor of the discoverer, J. W. Dawson, LL. D., who has so persistently and ably investigated the Leda clays of Canada.

It should be observed that fig. 4 is not a particularly good representa. tion of the fossil.

A point of a good deal of interest in connection with this Quaternary species is that at present no species of Estheria is known to be peculiar to the Atlantic province. Estheria mexicana, however, ranges as far east as Ohio, but this is not at all related to $E$. dawsoni. 'The question arises where did the latter Quaternary species come from. It is not an Arctic form, for no species of the genus is known to inhabit the circumpolar region. It would seem as if it had been a Quaternary survivor through the glacial period of a southern or Tertiary species.

Geological Succession.-The following table gives a view of the geologieal succession of the fossil Phyllopoda; it is compiled from the works of T. R. Jones and Gerstaecker, with the additions made, (1878-'81,) since the publication of those works.

\begin{tabular}{|c|c|c|}
\hline Quaternary ............ & 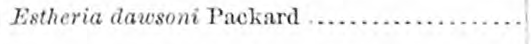 & Leda clay, Canada. \\
\hline $\begin{array}{l}\text { Tertiary? ............ } \\
\text { Eocene Tertiary ...... }\end{array}$ & 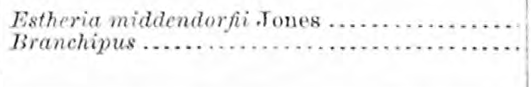 & $\begin{array}{l}\text { Siberia. } \\
\text { Fresh-water limestone, Isle of } \\
\text { Wight. }\end{array}$ \\
\hline $\begin{array}{l}\text { Mesozoic?............. } \\
\text { Wealden.............. } \\
\text { Oolite............... }\end{array}$ & 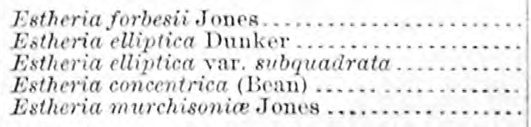 & $\begin{array}{l}\text { South America. } \\
\text { Germany. } \\
\text { Sussex, England. } \\
\text { Yorkshire, England. } \\
\text { Skye, Scotland. }\end{array}$ \\
\hline
\end{tabular}

*Proceedings Geological Society of London, 1878. Abstract in Anuals and Mag. Nat. Hist., 5th ser., i, p. 99,1878 . 


\begin{tabular}{|c|c|c|}
\hline Triassic ............ & $\begin{array}{l}\text { Estheria ovata (Lea) ...................... } \\
\text { Estheria mangaliensis Jones ............... }\end{array}$ & $\begin{array}{l}\text { United States, Pennsylvania, } \\
\text { Virginia, North Carolina. } \\
\text { India. }\end{array}$ \\
\hline Rhætic ............. & Estheria minuta (Alberti) var. brodieana..... & England. \\
\hline Rhatic or Jurassic.... & 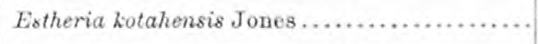 & India. \\
\hline Keuper.............. & 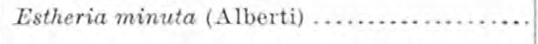 & Hanover, Germany, England. \\
\hline $\begin{array}{l}\text { Keuper ............ } \\
\text { Lettenkwhle........... } \\
\text { Bunter .......... }\end{array}$ & Estheria minuta and "Apus" .............. & France, Germany. \\
\hline Permian .............. & 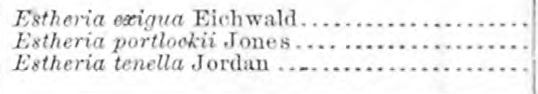 & $\begin{array}{l}\text { Russia. } \\
\text { Ireland. } \\
\text { Saxony. }\end{array}$ \\
\hline $\begin{array}{l}\text { Upper Carboniferous.. } \\
\text { Middle Carboniferous.. } \\
\text { Lower Carboniferous... }\end{array}$ & 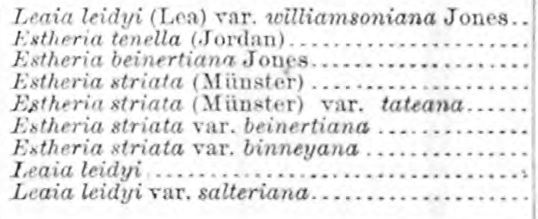 & $\begin{array}{l}\text { England. } \\
\text { France, England, Germany. } \\
\text { England. } \\
\text { Bavaria, Belgium. } \\
\text { England. } \\
\text { Silesia, England, Scotland. } \\
\text { England. } \\
\text { Pennsylvania. } \\
\text { Scotland. }\end{array}$ \\
\hline Deronian ............. & 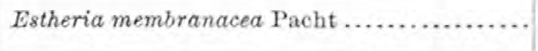 & Livonia and Scotland. \\
\hline
\end{tabular}

It appears from the foregoing table that the oldest Phyllopod crustacean is a genuine Estheria, ${ }^{*}$ judging, of course, from the carapace valves alone; the more or less problematical form, Leaia, being carboniferous. Thus Estheria dates from the Devonian.

As to the ancestral forms of Phyllopods in general, they may have been derived from forms like the Cladocera. Limnetis indicates in its resemblance to Daphnia, that from this Branchiopod with its cladocerons allies the Phyllopods may have sprung. Next below the Branchiopods stand the Copepoda from which all the other Neocarida have sprung; the Copepodia all originating from a nauplius ancestor. The Ostracoda, the lowest suborder of Branchiopoda, flourished in the Lower Silurian seas, hence the Branchiopoda must have originated in the Laurentian period and the Phyllopod suborder at least as early as the Upper Silurian period.

The accompanying table may serve to give a rude idea of the rela. tions of the principal groups of the Crustacea, and their appearance in geological history, so far as the extremely scanty data we possess will allow, while the diagram may also serve as a genealogical tree, showing the probable origin of the main divisions of the Crustacea.

As is well known, the Trilobites are met with in comparative abundance in the lowest fossiliferous beds of the Silurian period, and they are the most ancient of Crustaceans, so far as their remains give evidence. The genera Conocephalites, Dicellocephalus, Paradoxides, and Agnostus, besides other forms, appear in the Potsdam sandstone or equivalent primordial rocks of this and other countries. The type disappeared during the Carboniferous period, the genera Phillipsia (one

*As there exists some doubts in my mind as to the Estherian nature of E. palex Clark, I have left this out of present consideration. 
species is Permian), Griffithides, and Brachymetopus being the sole representatives of the type which prevailed so extensively during the Silurian.

\section{Geological succession of the Crustacea.}

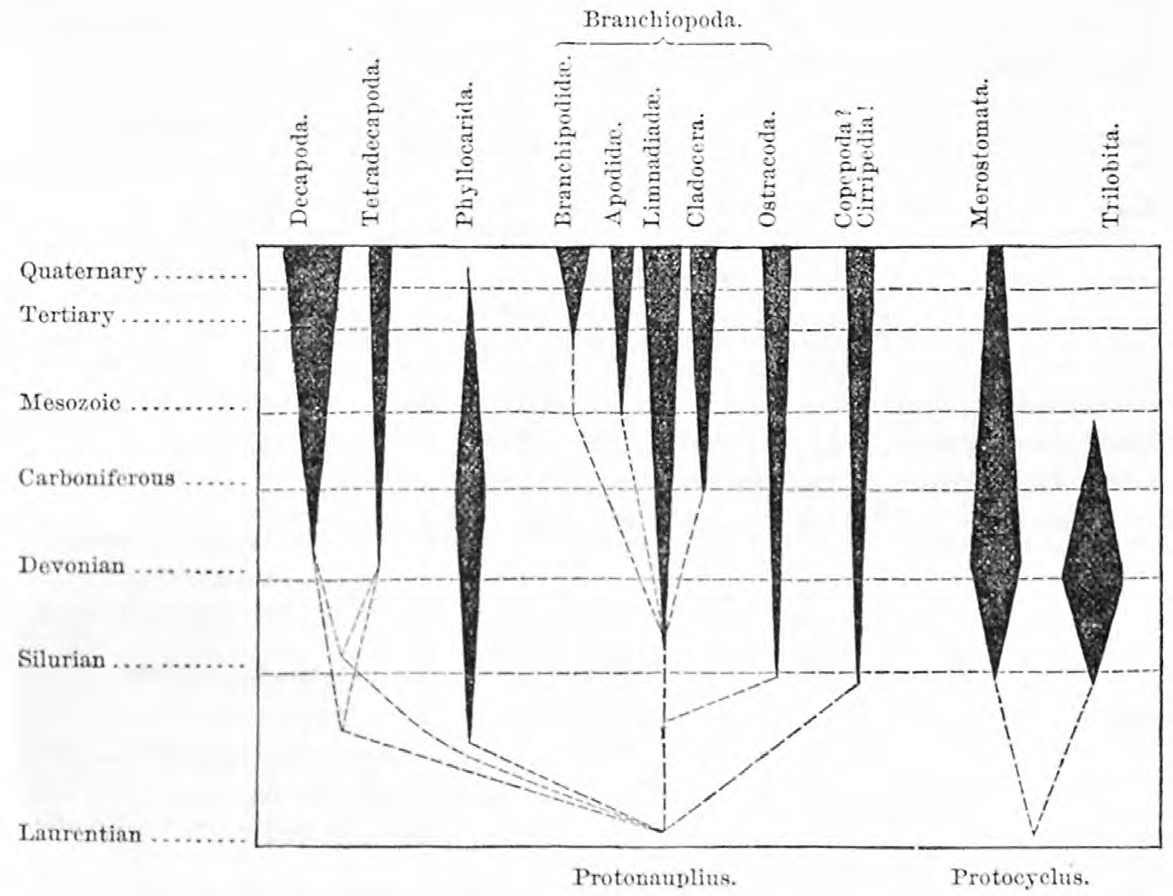

Simultaneously with the appearance of the larva-like Agnostus, and the more highly organized Paradoxides, sc., we find in the Lingula flags the remains of a species of Phyllocarida, the Hymenocaris vermicauda. Mr. J. W. Salter, who was the first author to draw attention to the close relation of the fossil-genera Hymenocaris, Ceratiocaris, Peltocaris, Dictyocaris, \&c., to Nebalia, has given us a series of sketches showing graphically the geological succession of this group and the Estheriadr. Hymenocaris, which Salter regards as "the more generalized" type, lived during the primordial period; Peltocaris and Discinocaris (Woodward) characterize the Lower Silurian period; Ceratiocaris the upper; Dyctyocaris the Upper Silurian and lowest Devonian; Dithyrocaris and Argus the Carboniferous. No Mesozoie member of the family has yet been discovered, but as there are sereral species of Nebalia now living in our seas, it is reasonable to suppose that the type has existed in an unbroken succession from primordial times until now. The Palæozoic species were gigantic in size, some being about a foot or more (the carapace of Dithyrocaris pholadomya Salter being seven inches long) in length, while our recent Nebalia is less than an inch in length.

The Potsdam sandstone also contains the remains of a third grand division of Entomostraca, the Ostracoda; remains of Leperditia having been found in Canada, as well as the Lower Silurian of Europe.

No fossil Copepoda have yet been discovered, but we should scarcely wonder at this, owing to their soft bodies. Gerstaecker (Brom's 
"Classen und Ordnungen der Thierreichs") suggests that the Lernæans might have infested Palæozoic fish, and on general grounds we should think that they probably extended as far back as the primordial zone, inasmuch as highly developed Trilobites and Ostracodes appear there. Ano'her argument is the interestmg discovery made in 1865, by Mr. Woodward, of the Cirripede Tarrilepas Wrightii from the Wenlock limestone and Dudley shale of the Upper Silurian formation. Previous to this, according to IVoodward, "the oldest known Cirripede was the Pollicipes rhoticus from the Rhotic beds of Somersetshire"; while the type is not uncommon in the Cretaceous, and has flourished from that period to the present.

Of the Merostomata the oldest group is the Eurypterida, the Xiphosura not dating beyond the Lower Carboniferous. The Eurypterids have not been found below the Upper Silurian (Lower Helderberg in America), and the aberrant forms Hemiaspis, Bunoödes, Psendoniscus, and Exapinurus are Upper Silurian forms. Among the Xiphosura, Cyclus, the lowest form, is found in the Carboniferous, and ranges, according to Woodward, as far up as the Permian. In the same period occur Bellinurus, Prestwichia, and Euproöps, being in this country found in the lower part of the true Coal-measures, and associated in the same beds with Ceratiocaris, Eurypterus (Anthraconectes and certain Isopoda and Macrurous Decapoda (Anthrapalæmon). The genus Limulus first appears in the Jurassic, and the species differ but slightly from those now living.

The more typical Phyllopoda made their appearance during the Triassic period. The lowest group, however, the Estheriadæ, appeared duriug the Devonian, a species referred to Estheria being found in that formation in Europe. The Cladocera are not known to have existed previous to the Tertiary period, and it was not until recently (1862) that Von Hayden discovered the ephippium of a Daphnia in the Rheinish brown coal (Gerstaecker, in Bronn's Klassen und Ordnungen, \&c.), said by Lyell to be of Eocene age. It should be noticed, however, that the fossil belongs next to Sida, the most highly organized genus of the group, and as it is not unlikely that such pelagic forms as Evadne may have existed in the Mesozoic seas, if not earlier, I have ventured to run the point of the wedge into the Carboniferous period.

The Apodidx date back to the early part of the Mesozoic, a Triassic species of Apus having been found in Europe, according to Mr. Salter.

\section{III.-GEOGRAPHICAL DISTRIBUTION.}

(With a map.)

The materials for the thorough study of the geographical distribution of the Phyllopod Crustacea of North Ameriea, as indeed of any other of the continents, perhaps not excepting Europeo-Asia, are quite scanty. The exceptional habits of the members of this suborder, their usual iarity or periodical occurrence, and their very local distribution, have caused them to escape the observation of most collectors, and to be found more by accident than as the result of well-matured plans of search.

The salient points in the distribution over the globe of the Phyllopods are as follows; although the conclusions here presented are, of course, provisional, and much yet remains to be discovered as to the distribution of these interesting forms.

It will be seen by reference to the lists presented in the following pages that a large proportion of our North America Phyllopoda, includ. ing nearly all the species of Estheria, are restricted to the elevated dry central zoögeographical province of the United States, and adjacent 
portions of Aretic America, and of Northern Mexico, a region exposed to great summer heats, winter cold, to long droughts, sudden rainbursts, and other meteorological extremes. And it is interesting to notice that the larger proportion of the Old-world forms are likewise restricted to Eastern and Southern Europe, to the Nediterranean region, and to Central and Northern Asia, $i$. e, to Mr. Sclater's "Pale-arctic Region." The Western European species are few in number, as in the Eastern United States. In Africa the Phyllopods are restricted to the northern portions of the continent, which are more or less elevated, dry, and arid, as Algeria, Egypt, and Abyssinia, or to the Cape of Good Hope (Capeland), while but a few, and those species of Estheria, have been brought from the "Oriental Region" in Asia, and few from the AEthiopian Region" in Africa. Apus himalayanus, described by us from the Himalaya Mountains, is evidently a member of the Central Asiatic or Manchurian province, and not of the Indian region, while A. dukianus is reported from Afohanistan.

Of purely tropical forms there are two species of Apus, one living in St. Domingo, another in the island of St. Vincent, while a species of Eulimnadia exists in St. Domingo, and a species of Estheria flourishes in Cuba. The Mexican forms are plateau species, while none have yet been described from Central America. Two species of Estheria have been described from South America.

The map accompanying this memoirl represents the principal faunal divisions of North America, with the isothermal lines of $32^{\circ}, 40^{\circ}, 60^{\circ}$, and 720. The American continent is divided into-

1. The Arctic Realm and its Alpine outliers.

2. Boreal province and its Alleghanian outliers.

3. The Atlantic or Eastern province.

4. The Central province.

5. The Western or Californian province.

6. The Antillean region.

There are no species from the Central American province.

\section{THE AMERICAN ARCTIC PROVINCE.}

This is a more or less natural subdivision of the Arctic or Circumpolar Realm, which includes the coast of Labrador, the northern shores of Hudson's Bay, and the Aretic coast of North America, north of the sothermal of $32^{\circ}$ around to Bering's Strait and Greenland. We reject the term "Nearctic" proposed by Mr. P. L. Sclater, and adopted by Mr. A. R. Wallace, for America north of Central America, for the reason that it seems to us an unnatural and artificial term. The fauna is essentially American north temperate, while the Arctic regions of America and Europe-Asia form a realm by itself, of much less importance, it is true, than thenorth temperate realm (American and EuropæoAsiatic regions), when we consider the land plants and animals, but of nearly as much importance as regards marine life. To apply the term Nearctic to so vast a region as the American involves the idea that the region covers an area essentially aretic in its features. It is to be hoped that the term will not be adopted by American writers, as it is not by German asd French writers, and we heartily indorse Mr. J. A. Allen's protest against the use of the term by American writers on this subject. The circumpolar or Arctic realm is a realm by itself, limited by the low degree of temperature and mainly bounded by the isothermal of $32 \circ$, and the adoption of this term will conduce, it appears to us, to 
clearer and more concise ideas of the geographical distribution of life on our continent.*

The following two species of Phyllopods characterize this realm: Lepidurus glacialis, Arctic America, Lapland, Nova Zembla, Spitzbergen, Beeren Island; and Branchinecta paludosa. Neither of these are confined to the American continent (being found at Cape Krusenstein) and Green . land, as they occur in Aretic Europe and Asia. These two species occur not only in Greenland and Aretic America, but also in Swedish Lapland at an elevation of 2,000 feet; Branchinecta paludosa occurs in Finmark near the North Cape and in Russian Lapland, and Middendorf found it (var. middenāorfianus) in Asiatic Siberia.

\section{THE ATLANTIC OR EASTERN PROVINCE.}

This region includes the area bounded on the north by the isothermal of 400 , including the northern shore of the Saint Lawrence west of Quebec, the Great Lake region, except the northern shores of Lake Superior, and the United States east of the ninety seventh meridian.

The following species inhabit this province:
Limnetis gouldii.
(Limnadella coriacea.)
Limnadia americana.
Streptocephalus sealii.
Estheria mexicana.
Eulimnadia agassizii.
Branchipus vernalis.
serratus.
floridanus.
Chirocephalus holmani.

\section{THE CENTRAL PROVINCE.}

This prorince lies between the Atlantic and the Californian, extending northward into British America to the limits of trees near latitude $55^{\circ}$; and southward along the Mexican plateau as indicated on the map. The Rocky Mountains oppose no continuous barrier to the distribution of the species; and it includes the southern extremity of the Californian peninsula. We reproduce from the American Naturalist for August, 1878 , the leading characteristics of this Central prorince.

The first attempt to divide the United States as a whole into zoölog. ical provinces was in 1859, by Dr. Le Conte, in his "Coleoptera of Kansas and Eastern New Mexico (Smithsonian Contributions, 1859)." He divided the Coleopterous fauna of the United States into three great zoölogical districts, distinguished each by numerous peculiar genera and species, which, with but few exceptions, do not extend into the contiguous districts. He named them the Eastern, Central, and Western divisions;

*In our "Observations on the Glacial Phenomena of Labrador and Maine," etc., Mem. Bost. Soc. Nat. Hist., 18t6, p. 254, we thus referred to this fauna, speaking especially of the marine animals:

"The arctic or circumpolar fauna is restricted to a district north of the yearly isothermal line of $32^{\circ}$, which thus includes the Arctic American archipelago, Northern Greenland, Spitzbergen, Nova Zembla, and the coast of Siberia. This is a true circumpolar fauna, and can scarcely be said to be Asiatic, European, or American, though members of the group extend in diminished numbers and size down on the Asiatic coast to Japan, as we are informed by Dr. W. Stimpson, and by P. P. Carpenter in the Report of the British Association for 1856; on the European coast as far as the Mediterranean Sea, and on the eastern American coast as far as New Jersey, where the polar currents give, at great depths, the necessary amount of cold for their existence."

Compare also onr monograph of Geometrid Moths, or Phalænidæ, of the United States, pp. 567, 586, 1876. Our classification of the American fanna is adopted with slight modifications from Mr. J. A. Allen's writings on the Mammals and Winter Birds of Florida, etc., Bull. Mus. Comp. Zoöl. ii, 3, 1871, Bull. Hayden's U. S. Geol. Surrey, 1878 , p. 529. 
so that to him is due the credit of first distinguishing the Central prov. ince.

In 1866, Professor Baird, ${ }^{1}$ from a study of the avifauna of the United States, concluded that "the ornithological provinces of North America consist of two great divisions of nearly equal size in the United States, meeting in the vicinity of the one hundredth meridian, the western half divisible again into two, more closely related to each other than to the eastern, though each has special characters. These three sections form three great provinces to be known as the western, middle, and eastern; or those of the Pacific slope; of the great basin, the Rocky Mountains and the adjacent plains; and of the fertile plains and region generally, east of the Missouri."

In 1871, Mr. J. A. Allen ${ }^{2}$ divided the avifauna of the United States into two provinces, the eastern and western, the latter embracing the Pacific coast. Mr. Allen afterwards adopted Professor Baird's division into three provinces. (The geographical distribution of the mammalia, etc. Bulletin of Hayden's U. S. Geographical and Geological Survey of the Territories, May 3, 1878.)

In $1873,{ }^{3} \mathrm{Mr} . \mathrm{W}$. G. Binney published a map of the distribution of our land shells, dividing the molluscan fauna into the Eastern, Central, and Pacific provinces.

In 1875, Prof. E. D. Cope, in his check-list of North American Batrachia and Reptilia, ${ }^{4}$ divided the Nearetic realm of Sclater into the Aus. troriparian, Eastern, Central, Pacific, Sonoran, and Lower Californian regions. He remarks that "the Pacific region is nearly related to the Central, and, as it consists of only the narrow district west of the Sierra Nevada, might be regarded as a subdivision of it. It, howerer, lacks the mammalian genera Bos and Antilocapra, and possesses certain peculiar genera of birds, as Geococcyx, Chamaca, and Oreortyx. . . . There are some genera of reptiles, e. g. Charina, related to the Boas, Lodia, Aniella, Gerrhonotus, and Xantusia, which do not oceur in the central subregion. There are three characteristic genera of Batrachia, all Salamanders, viz: Anaides, Batrachoseps, and Dicamptodon; while the eastern genera Plethodon and Diemyctylus reappear after skipping the entire central district." Cope adds that "the fresh-water fish fauna is much like that of the central district in being poor in types." Cope's Sonoran region is evidently a northward extension of the Central American fauna, which sends its outliers into Southern Arizona, Utah, and New Mexico, and is not to be taken into account in discussing the faunal provinees of the United States alone.

In 1876, Wallace, in his "Geographical Distribution of Animals," divided the Nearetic region into four subregions, viz: the Californian. Central or Rocky Mountain, Alleghanian, and Canadian. His Central subregion extended to lat. $25^{\circ} \mathrm{N}$.

It will be seen from this review that by general consent the fauna of the Pacific slope is on the whole regarded as belonging to a separate province from that of the Rocky Mountain plateau, whether we regard the mammals, birds, reptiles, amphibians, Coleoptera, or land shells.

Botanically, as observed by those who have traveled across the plains to California, the flora of the great plains is quite different from that of the Eastern States, and the Pacifie flora is as distinct from the central flora. This has been clearly shown by Sir J. D. Hooker and Prof. Asa

${ }^{1}$ American Journal of Science and Arts, January and March, 1866.

2 Bulletin of the Museum of Comp. Zoology, April, 18 r.

${ }^{3}$ Catalogue of the Terrestrial Molluses of North America. Bull. Mus. Comp. Zool, 1873.

1 Bulletin U. S. Nat. Mus., Washington, 1875. 
Gray in their preliminary notices of the results of their botanical researches in connection with Dr. Hayden's U. S. Geological Survey of the Territories.

In traveling in the summer of 1877 , in pursuance of the work of the United States Entomological Commission, I passed rapidly over a large area of the Central province lying north of the fort ieth parallel, including Colorado, Wyoming, Northern Utah, Western Idaho, Central and Northern Montana, and was thus enabled to observe in a superficial way the general features of the flora and fauna nearly up to the British line. I was impressed with the resemblance of Central and Northern Montana to Northern Utah, the insect-fauna being apparently nearly identical. Doubtless this insect-fauna extends northwards into the Upper Saskatchewan valley as far as the southern limit of trees, there being much less intermixture with Canadian forms than might be expected. Then crossing the Sierra Nevada, and going overland to Oregon, I was able to trace the gradual passage of the Californian insect fauna into the Oregonian, with some Canadian forms; and by passing up the Columbia River to Wallula, here as well as at Reno in Nevada, to perceive the great differences between the fauna of the Pacifie slope and that of the plains and deserts of the Central province.

In briefly reviewing the different orders of insects, other than Coleoptera, which have been so fully elaborated by Dr. Le Conte, and certain groups of Crustacea, we will begin with the Hymenoptera, and point out a few eharacteristics distinguishing the Central from the Pacific provinces. In 1865 and 1866 a large number of Coloradian fossorial Hymenoptera passed under the writer's hands, Mr. Cresson having previously described from this material a large number of Coloradian Hymenoptera of all families. The richness of the hymenopterons fauna of Colorado struck me, and I was impressed with its distinctness from that of the Eastern States. I have seen few of these from California. Among the family of ants (Formicida), there was one form characteristic of the plains which does not occur on the Pacifie slope. This is the Pogonomyrmex occidentalis (Cress.). I have seen its large hills at,Brookville, Kans., and observed them in Colorado and Utah, and in Reno, at the base of the Sierra Nevada, but not west of that point. It ranges, according to Mayer, south into New Mexico, and San Luis Valley, Colorado. Its nest, forming large elevations in cleared spaces sometimes six or eight feet in diameter, is one of the characteristic sights on the plains.

Among the Lepidoptera, family Bombycidce, there are several forms peculiar to the central district, notably the genus Dirphia (Coloradia), Euleucophous, Gloveria (Mesistesoma), Hemileuca, Juno, and Hera, and Platysamia gloverii. The family is feebly represented in the Central province, but richly so by numerous species on the Pacific slope, which do not appear east of the Sierra Nevada.

The Phalanida, or geometric moths, are richly developed in the Pacific province, and but poorly in the Central province, owing to the absence of deciduous trees; of those found in the latter some occur west of the Sierra Nevada, and some are peculiar to the plains and Rocky Mountains.

Of the Orthoptera there is a large number of species peculiar to the plains which I did not observe in the Pacific States; of these, Caloptenus spretus is thoroughly characteristic of the Central province. It does not oceur in the Pacific and only breeds temporarily in the Eastern province, and its natural limits define well those of the province itself. It ranges up to latitude $53^{\circ} \mathrm{N}$. on the North Saskatchewan and south 
to Southern Utah and Colorado. The exact limits of its distribution are given in the First Annual Report of the United States Entomological Commission.

While we are still quite ignorant of the distribution of insect life between the hundredth meridian and the Pacific Ocean, there seems good reason, from what little we do know, and from the great differences in the Hora, and the soil and climate, especially the rainfall east and west of the Sierra Nevada, to regard this lofty range as the general point of separation defining two grand zoological provinces. Nany groups of insects abounding west of the mountains do not occur east, except in isolated cases. Of a number of Mrriopods found on the Pacific coast none occur east, and so of the Arachnida so far as known, and Dr. Thorell, who has worked up some of the spiders of Colorado, was struck by the general similarity of some forms to those occurring in the plateau of Northeastern Asia. Among the insects there are a few Pacific forms which closely resemble European species, and which are not represented east of the Sierra Nevada. It should be borne in mind, however, that the Sierra Nevada does not present an absolute barrier, as a considerable number of species occur on each side of it, and it is well known that the Rocky Mountains are but a slight barrier to the distribution of the animals on either side, the fauna of Colorado, Northern Utah, Wyoming, Montana, and Idaho being quite homogeneous, and the fauna of these Territories the same on each side of the high mountain ranges traversing them.

Among the fresh-water Crustacea the Astaci of the Pacific slope, as is well known, belong to the European genus Astacus, those east of the Sierra Nevada to the genus Cambarus, which is so richly developed in the eastern provinces, especially in the Mississippi Valley.

The distribution of the fresh-water Phyllopoda is of peculiar interest. The family Apodida is restricted to the Central province; none are found in the Mississippi Valley, and none in California. Of the four species of Apus all inhabit the Central province; Apus aqualis lives on the plains of the Rocky Mountains, and also at Matamoras, in Mexico. It is a curious fact that Apus lucasanus Pack. not only occurs at Cape Saint Lucas, Lower California, but is also an abundant species at Ellis, Kansas. This is a parallel case to the presence of certain birds at Cape Saint Lucas which, as observed by Professor Baird, belong to the Central rather than to the Pacific province. Of the genus Lepidurus there are two forms (L. conesii and $L$. bilobatus) characterizing the plains. $I$. couesii occurs in Northern Montana and in Utah, and is allied to the recently described Lepidurus macrourus from Archangel, Russia, according to Lilljeborg.

The eastern limits of the Central province extend to near the 97th meridian in Kansas and Nebraska, according to the writer's observations.

The following species inhabit this province:

Limnetis mucronata. brevifrons. gracilicornis.

Estheria compleximanus mexicana. belfragei. morsei.

Eulimnadia texana.

Lepidurus conesii.
Lepidurus bilobatus. Apus newberryi. aqualis. Tucasanus. longicaudatus. Branchinecta coloradensis. lindahli.

Streptocephalus texanus. Thamnocephalus platyurus. 


\section{THE CALIFORNIAN OR PACIFIC PROVINCE.}

But one species, Estheria californica, (unless E. newcombii be regarded as distinct) inhabits this area, which is separated by the Cascade Mountains and the Sierra Nevada from the Central province, and extends from $52^{\circ}$ north southward to San Diego.

No species is as yet known from Central America; and the two Mexican forms occur in elevated regions in Northern Mexico, and are not peculiar to Mexico, being characteristic of the Central province of the United States.

THE ANTILLEAN PROVINCE.

The species inhabiting the West Indies are comprised in the following brief list :

Estheria jonesii.

Eulimnadia antillarum.

Apus domingensis.

Apus guildingii.

Artemia guildingii.

Streptocephalus simitis.

SPECIES COMMON TO THE ATLANTIC AND CENTRAL PROVINCES.

Estheria mexicana ranges from Ohio to Lake Wimnepeg, northward, and westward to Western Colorado, and into Northern Mexico.

Artemia gracilis ranges from Salem, Mass, to Mono Lake, in Oalifornia, but the life-conditions of this brine-inhabiting genus are so exceptional that we have not mentioned it in the foregoing lists. Our only truly Al. pine form is Branchinecta coloradensis, found at an elevation of 12,000 feet in Colorado.

\section{SPECIES INHABITING SOUTH AMERICA (Brazilian Region).}

Estheria brasiliensis Baird. Brazil.

Estheria dallasii Baird? Brazil.

SPECIES INHABITING THE EUROPAO-ASIATIC REGION.

$$
\text { a.-The European Province. }
$$

1. Western Europe.

Limnetis brachyurus. Germany.

Estheria cycladoides. Toulouse.

Limnadia hermanni. France and Germany.

gigas. Central and Northern Europe.

tetracera. Germany.

Branchipus stagnalis.* England and Central Europe. grubei. Central Europe.

Artemia salina. England and Europe.

Chirocephalus diaphanus. England, France, Switzerland.

Lepidurus productus. England and Central Europe.

Apus cancriformis. Central Europe.

grubei. Germany.

lubbockii. Germany.

* Branchipus lacunce Guérin, Baird, Grube; and B. braueri Frauenfeld, are regarded by Lilljeborg (Nov. Acta Upsala (3), ix, A, p. 3) as synonyms of B. stagnalis. 
2. Eastern Europe (Russia, \&c.).

Limnetis brachyura.

Limnadia tetracera. Charkow.

Estheria pestensis. Pesth.

Branchinecta ferox. Odessa.

claviger Nordmann. Odessa.

Branchipus birostratus. Charkow.

braueri Frauenfeld. Parndorper Heide.

Chirocephalus carnuntanus Brauer. " " "

Streptocephalus torvicornis. Warsaw.

A.temia salina, vars, mülhausenii.

arietina.

köppeniana.

b. The Mediterranean Province (including Northern Africa).

Estheria dahalacensis. Abyssinia.

donaciformis. Korkofan.

gubernator. Cairo.

hierosolymitana. Jerusalem.

gihoni. Jerusalem.

lofti. Bagdad.

+ cycladoides. Algeria.

melitensis Baird.

ticinensis. Italy (Lombardy).

Apus numidicus. Algeria.

cancriformis. Italy, Algeria, and Constantinople.

Branchipus eximius. Jerusalem.

Chirocephalus recticornis Brauer. Tunis. rubricaudatus Kosseir.

oudneyi. Fezzan.

Branchinecta ferus Brauer. Jerusalem.

Artemia sp. Egypt.

Chirocephalus bairdii Brauer. Jerusalem.

\section{c. Siberian.}

Limnetis brachyura. Archangel.

Polyartemia forcipata. Northern Sweden, Lapland, Taimyr, and Siberia.

Branchinecta paludosa (Middendorfianus). Siberia and Lapland.

Chirocephalus claviger (Fischer). Taimyr, Siberia.

Lepidurus macrourus Lilljeborg. Archangel.

\section{d. Manchurian.}

Apus dukii Day. Afghanistan.

Apus himalayanus. (North India.)

Apus numidicus Dauria. Baikal Sea.

Apus sp.**

* Apus sp. in Tibetan Salt Lakes. Schlagintweit, Reisen in Hochasien ii, 218, 1872 . 
SPECIES INHABITING THE INDO-AFRICAN REALII.

a. African Region. (Central Africa, White Nile; South Africa, Cape
of Good Hope.)

Limnetis wahlbergi. Port Natal.

Limnadia africana Brauer. White Nile.

Estheria rubidgei. Cape of Good Hope.

macgillivrayi. Cape of Good Hope.

australis. Caffer-land.

Apus dispar Brauer. White Nile.

sudanious Brauer. Chartum.

Branchipus abiadi Brauer. White Nile.

Streptocephalus cafer. Port Natal.

vitreus Brauer. White Nile.

proboscidens Framenfeld. Chartum.

b. Indian Region.

Estheria compressa. India.

hislopi. India.

potita. India.

boysii. India.

similis. India.

Branchipus dichotomus. India.

Apus granarius. Peking.

SPECIES INHABITING THE AUSTRALIAN REALM.

Limnetis maclayana. Australia.

Limnadia stanleyana. Australia.

Apus viridis. Tasmania.

angasii. Australia.

Apus sp. New Zealand.

Lepidurus kirli Thompson. New Zealand.

compressus Thompson. New Zealand.

From these data it appears that but a single genus is peculiar to North America, i. e., Thamnocephalus; while Polyartemia is peculiar to the Europæo-Asiatic Region; all the other genera occur in nearly all of the continental masses of the globe, though no Branchipodida occur in Australia, and no Limnadia has yet been found in Asia. This cosmopolitan distribution of the Phyllopoda (the Branchipodida, the highest family, being excepted) points towards the high antiquity of this group of fresh-water crustacea. The distribution through zones across oontinents, noticed by Cierstaecker, appears not to be exceptional to that of other classes. We have noticed it in Geometrid moths, and also in mammals, the central portion of Asia repeating the characteristics of Central North America.

\section{IV.-MORPHOLOGY AND ANATOMY.}

A transverse section of the anterior part of the body of any genus of Phyllopods will convey an excellent idea of the leading features in their organization, especially those by which they differ from the members of other Crustacean orders. The leading topographical features in the body, particularly of Arthropods, are the form of the elemental segments with their appendages, and the relations of the principal anatomical systems to the body walls.

General relations of the systems of organs to the body-walls.-We will first look at sections of representatives of the three families of Phyllopods; i.e., an Estheria (Plate XXIV, figs. 9, 10), Apus, Plate XXXII, fig. 2 (see also fig. 25 in text), and a Branchiopod, such as Thamnocephalus (Plate 
XIV, fig.4). The body-walls are rather thick and the muscles are well dereloped, particularly the dorsal extensor muscles, and the motor or extensor muscles of the limbs, which arise in part from the dorsal re. gion, and in part from the sides and sternal region. The body cavity is rathersmall. The heart is large, either cylindrical as in Estheria, or flattened as in Thamnocephalus. The digestive tract is large, capacious, aud the car. ity of the head is mainly filled with the two liver masses; the brain being remarkably small, while the nerrous cord, especially the brain and succeeding ganglia, are remarkably small and weak, compared with other Crustacea, either the malacostracous or the entomostracous orders; this peculiarity is well brought

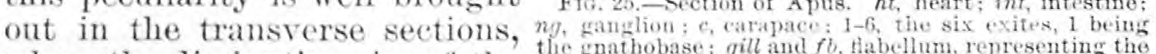
where the diminutive size of the exites.

thoracie ganglia, partieularly in Estheria (Plate XXIV, figs. 9n, 9), is noteworthy. The apparent bulk of the body is largely due to the large size and nature of the leaf like or foliaceous appendages, with their broad attachments; the latter peculiarity is characteristic of the Branchiopods in general and the Phyllopods especially, and is quite different from the definite, small coxal articulations of the legs of Malacostraca or Copepola. The ovaries or testes, according to the sex, form a large lobulated mass extending along each side of the digestive canal, as far forward as the base of the head. Their relations in Apus are seen in Plate XXXII, fig. 2, and in Thamnocephalus in Plate XIV, fig. 4.

Nomenclature of the body-regions and appendages.-As the terms "head," "thorax," and "abdomen" are more or less inexact when used for Arthropoda as compared with the worms and molluscs, as well as vertebrates, there should be suitable designations for these regions.

In 1869, in our Guide to the Study of Insects, we proposed the term arthromere for the segment or ring forming the primary element in the composition of the body of any jointed or articulated animal. The terms "zoönule," "zoönite," "zonite," and "somite," have been used by various anthors, but these terms have been used rather indiscriminately, and we therefore suggested the term arthromere for the body segments of articulated animals (worms and arthropoda). While the term "somite" or "zonite" may be properly applied to the rings of worms and other animals as the Chitons, we would suggest that the term arthromere be restricted to the segments, or body-elements of Arthropoda.

For the three primary regions of the head the only scientific terms as ret in use are those proposed by Prof. J. O. Westwood in Bate and Westwood's History of British Sessile eyed Crustacea (vol. 1, p. 3). These are cephalon for the head, pereion for the thorax, and pleon for the abdomen; while the thoracic feet are termed pereiopoda anc the abdominal legs pleopoda ; the three terminal pairs being called uropoda.

As the names applied to the thorax and abdomen have no especial morphological significance, the Greek $\pi \varepsilon \rho a t o \nu$, simply meaning ulterior, and $\pi \lambda_{s o \nu}$, more, we would suggest that the head of Arthropoda be termed the Cephalosome, the cephalic segments cephalomeres, and the cephalic 
appendages in general protopoda, the term "cephalopoda" being otherwise in use. The thorax of insects and of most of the crustacea might be designated the Banosome ( $\beta a c \%$, to walk, locomotion), and the thoracic appendages Bcenopoda, the segments being called banomeres; while Urosome might be applied to the abdomen, the abdominal segments being called uromeres. Westwood's term uropoda might be extended so as to include all the abdominal appendages. The term gonopoda we have suggested for the external organs of the Decapods concerned in reproduction, which are simply modified uropoda. The long, slender, antenna-like anal appendages of the cockroach, mantis, \&c., corresponding to the anal cerci of Acrydii, may be designated as cercopoda, and this term might be applied to the terminal pair of uropoda of the Phyllopods, $i$. e., the jointed, slender, spinulose appendages of Apodida, or the unjointed appendages of the Branchipodida.

The segments of the body.-The Phyllopoda are exceptional to other Crustacea in having an indefinite number of segments composing the body, and in having in one family (Apodida) more than one pair of appendages to an arthomere. While the normal number in the Decapoda is 20, in the Phyllopods it varies from 14 in Limnetis to 47 in Apus. The following table shows the number in different genera of American species :

\begin{tabular}{|c|c|c|c|c|c|c|c|c|}
\hline • & 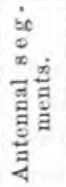 & $\frac{\frac{d}{3}}{\frac{\stackrel{d}{3}}{3}}$ & 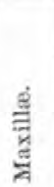 & 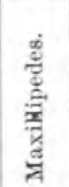 & 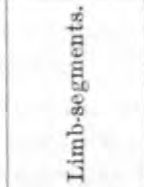 & 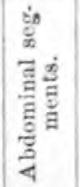 & $\underset{f}{\stackrel{g}{8}}$ & 莺 \\
\hline 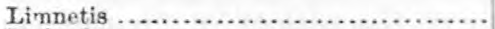 & 2 & 1 & 1 & $\ldots \ldots$ & $12(-14)$ & 0 & 1 & $17-19$ \\
\hline 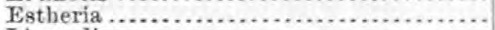 & $\overline{2}$ & 1 & 2 & $\ldots \ldots$ & $23-27$ & 0 & 1 & $29-33$ \\
\hline 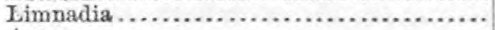 & 2 & 1 & 2 & ....... & $\begin{array}{lll}1 & 22\end{array}$ & 0 & 1 & 28 \\
\hline 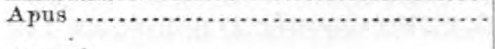 & $\star^{*}$ & 1 & 1 & $\dagger 1$ & $\begin{array}{l}27 \text { (60 pairs } \\
\text { limbs). }\end{array}$ & 32 (14) & 1 & 47 \\
\hline 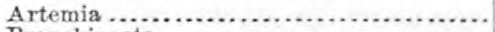 & 2 & 1 & 2 & 0 & 11 & 8 & 1 & 25 \\
\hline 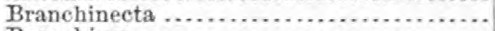 & 2 & 1 & 2 & 0 & 11 & 9 & 1 & 26 \\
\hline 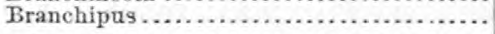 & 2 & 1 & 2 & 0 & 11 & 9 & 1 & 26 \\
\hline
\end{tabular}

* Second antennæ sometimes wanting. †The endite wanting in the American species of Apus.

In an Apus lucasanus 42 millimeters in length there are 60 pairs of legs behind the maxillipedes. There are 42 segments behind the maxillipedal segment, including the telson, and 27 limb-bearing segments, or 60 pairs of legs to 27 segments, the average being $2 \frac{6}{2}$ appendages to each leg-bearing segment. On the first eleven leg bearing arthromeres, or the 10 thoracic (bænomeres) together with the first abdominal arthromere there is but a single pair of appendages to a segment, so that there are 49 pairs of abdominal appendages to 16 arthromeres, or $3 \frac{1}{16}$ pairs of limbs on the average to each abdominal arthromere. The fourteenth, fifteenth, and sixteenth pairs are situated on two arthromeres, and so on with the succeeding until the limbs become more numerous. On the two arthromeres before the last leg-bearing one there are 12 pairs of appendages, or 6 to each arthromere.

This irrelative repetition of arthromeres is only paralleled in one other Branchiate group, the Trilobita. In this group the new segments are interpolated between the head and abdomen at successive moults, as shown by Barrande.

The grouping of the body segments into a cephalothorax and abdomen, comparable with those two regions in the Decapoda is but slightly, if at all, indicated in the Phyllopoda. In Limnetis there is no such distinction of regions, in Apus the cephalothorax merges insensibly into the 
abdomen, and it is not until we ascend to the Branchipodidæ that we meet with a well-marked abdomen separated by tolerably clear indications from the thorax.

\section{THE APPENDAGES IN GENERAL.}

The appendages of Crustacea may be divided into four groups: First, the sensory appendages, or antennæ, which are in the adult preoral; second, the organs of prehension of food and of mastication, $i . e$., the mandibles and accessory jaws, or maxillæ and maxillipeds, which are postoral; third, organs of locomotion, whether natatorial or ambulatory, which are appended to the thoracic portion of the body; and, fourth, the appendages of the abdomen, which are both natatorial and concerned in reproduction; of the latter are the two pairs of gonopoda* in the Decapoda, while the eleventh pair of appendages in Apus may be regarded as gonopods.

Spangenberg has described the mode of origin of the intromittent organs, and has shown that they arise as two independent outgrowths from the under side of the twelfth and thirteenth segments in Branchipus stagnalis, but from his drawings they appear essentially to arise from the twelfth. Each process or finger-shaped lobe contains a cirrus or intromittent organ. These two appendages appear from Spangenberg's illustrations to be three-jointed. If so, we do not see why they should not be properly regarded as homologous with the eleventh pair of legs of male Apodidæ, in which, as stated by Gerstaecker, were found the male openings for the passage of the semen. We hence regard these ergans as in general homologous with the gonopods of Decapoda, although the latter are solid and do not act as direct intromittent organs.

It is perhaps as probable, however, that the gonopods or double intromittent organ of the Branchipodide is homologons with the male organ of the Copeporla, which is a double eminence, on each of which is a genital pore. The female genital outlet is in the Copepoda also situated on the first segment of the abdomen, according to Claus.

Lankester has suggested, and it seems to us with good reason, that in order to arrive at true conclusions with regard to the homologies of the limbs of the Arthropoda we should "abandon altogether the use of such terms as 'autenna,' 'mandible,' and 'maxillipede' as homological categories, and to apply them merely as descriptive terms proper to the particular case under examination. In the consideration of homologies, the appendages should be regarded simply as first, second, third, and so forth, without the introduction of terms calculated by their reference to function to prejudice the argument as to homology. The first appendage of an Arthropod, A, may be homologons with (or homogenous with) the first appendage, or with the second or third of another Arthropod, B, and so on; but ambiguity is inevitably introduced if we attempt to indicate this homology by the use of such terms as antennule and antenna, to be applied in both cases alike, for in such cases as the parasitic Copepoda, the various Arachnida, and the living and fossil branchiate scorpions (Merostomata), these descriptive terms, and others like them, are found to be absolutely contrary to fact in their implications, and involve also debatable assumptions in reference to ancestral primitive forms."

\footnotetext{
* I have (American Naturalist, xv, p. 881, 1881) applied the term gonopoda (Gr. Yovin, generation; $\pi \circ v 5, \pi \circ \delta \circ 5$, foot) to the first and second abdominal limbs of the Decapoda, which are, as is well known, modified into accessory generative organs., The term is suggested as a convenient one to use in descriptive carcinology when speaking of either or both pairs of the basal abdominal limbs of the male Decapod. In the femule they are not modified.
} 
With this view, with some restrictions, we would agree, and while believing that the use of the terms antenna, mandible, maxilla or maxillipede wonld be authorized within the limits of the same subclass, as the normal, neoearidan crustacea, or the Merostomata (which we certainly would not consider as branchiate scorpions), with the Trilobita (Palaocarida), or either of the three subclasses Tracheata or Insecta, i.e., Hexapoda, Arachnida, and Myriopoda; the different pairs of appendages must receive different names in different subclasses. The following table will give our idea as to the nomenclature of the appendages in the three subclasses of Tracheata and the two subclasses of Branchiate Arthropods.

TABLR A.

\begin{tabular}{|c|c|c|c|c|c|}
\hline 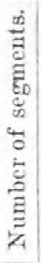 & Hexapoda. & Arachnida. & Myriopoda. & $\begin{array}{l}\text { Crustacea (neoca- } \\
\text { rida decapoda). }\end{array}$ & $\begin{array}{l}\text { Merostomata. } \\
\text { (Limulus.) }\end{array}$ \\
\hline 1 & Antennæ.... & Mandible......... & Antenna ......... & First antenna ... & First (preoral) \\
\hline 2 & Mandibles. & Maxilla (chela)... & "Maxilla"......... & Second antennæe.. & Second (post. \\
\hline 3 & First maxillæ..... & First thoracic leg. & "Mandible"...... & Mandibles ........ & $\begin{array}{l}\text { oral) leg. } \\
\text { Third pair legs. }\end{array}$ \\
\hline 4 & $\begin{array}{l}\text { Second } \mathrm{m} \text { axilla } \\
\text { (labinm). }\end{array}$ & $\begin{array}{l}\text { Second thoracic } \\
\text { leg. }\end{array}$ & "Labium"... & First maxillæ .... & Fourth pair lege. \\
\hline 5 & $\begin{array}{l}\text { First thoracie } \\
\text { legs (bænopods). }\end{array}$ & Thira thoracic leg. & First pair of legs.. & Second maxilla... & Fifth pair legs. \\
\hline 6 & $\begin{array}{l}\text { Second thoracic } \\
\text { legs (banopods). }\end{array}$ & $\begin{array}{l}\text { Fourth thoracio } \\
\text { leg. }\end{array}$ & Second pair of legs. & First maxillipedes & Sixth pair legs. \\
\hline 7 & $\begin{array}{l}\text { Third thoracie } \\
\text { legs (bænoporls). }\end{array}$ & $\begin{array}{l}\text { Embryonic, decid- } \\
\text { uous. }\end{array}$ & Third pair of legs. & $\begin{array}{l}\text { Second maxilli. } \\
\text { pecles. }\end{array}$ & First abdominal \\
\hline 8 & $\begin{array}{l}\text { First embryonic } \\
\text { deciduouslegs:. }\end{array}$ & $\ldots$ do $\ldots . . . . . . . . .$. & Fourth pair of $\operatorname{leg} A$ & Third maxillipedes & $\begin{array}{l}\text { Second abdomi. } \\
\text { nal legs. }\end{array}$ \\
\hline 10 & $\begin{array}{l}\text { Second embryonic } \\
\text { deciduous legs. }\end{array}$ & ....do ..... & Fifth pair of legs & $\begin{array}{l}\text { First pair of legs } \\
\text { (banopods). }\end{array}$ & Thind aidominal \\
\hline 10 & $\begin{array}{l}\text { Third embryonic } \\
\text { deciduons lege. }\end{array}$ & Wint ra & Sixth pair of legs.. & $\begin{array}{l}\text { Second pair of legs } \\
\text { (bonopods). }\end{array}$ & $\begin{array}{l}\text { Fourth abdomi- } \\
\text { nel legs. }\end{array}$ \\
\hline 12 & $\begin{array}{l}\text { Fourth embryonic } \\
\text { deciduous legs. }\end{array}$ & $\begin{array}{l}\text { First pair spin- } \\
\text { nerets. }\end{array}$ & $\begin{array}{l}\text { Seventh pair of } \\
\text { legs. }\end{array}$ & $\begin{array}{l}\text { Third pair of legs } \\
\text { (baenopois). }\end{array}$ & $\begin{array}{l}\text { Fifth abdominal } \\
\text { legs. }\end{array}$ \\
\hline 13 & $\begin{array}{l}\text { Fifth embryonic } \\
\text { deciduous legs. }\end{array}$ & $\begin{array}{l}\text { Second pair spin. } \\
\text { nerets. }\end{array}$ & Eighth pair of legs & $\begin{array}{l}\text { Fourthpair oflegs } \\
\text { (bonopods). }\end{array}$ & $\begin{array}{l}\text { Sixtb pair abdom. } \\
\text { inal legs. }\end{array}$ \\
\hline 14 & $\begin{array}{l}\text { Sixth embryonic } \\
\text { deciduons legs. } \\
\text { First pair of rhab. }\end{array}$ & $\begin{array}{l}\text { Third pair spin- } \\
\text { nerets. } \\
\text { Telson of scor. }\end{array}$ & $\begin{array}{l}\text { Ninth pair of legs } \\
\text { Tenth pair of legs. }\end{array}$ & $\begin{array}{l}\text { Fifth pair of legs } \\
\text { (bouopods). }\end{array}$ & \\
\hline 15 & $\begin{array}{l}\text { dites. } t \\
\text { Second pair of }\end{array}$ & & Eleventh pair of & $\begin{array}{l}\text { First abdominal } \\
\text { legs (uropods). } \\
\text { Second abtontinal }\end{array}$ & Telson (spine). \\
\hline 16 & $\begin{array}{l}\text { rhabdites. } \\
\text { Third pair of rhab. } \\
\text { dites. }\end{array}$ & & $\begin{array}{l}\text { legs. } \\
\text { Twelfth pair of } \\
\text { legs. }\end{array}$ & $\begin{array}{l}\text { legs (nropods). } \\
\text { Third abdominal } \\
\text { legs (nropods). }\end{array}$ & \\
\hline 17 & $\begin{array}{l}\text { C ercopoda of } \\
\text { someorthoptera } \\
\text { and Neuroptera, } \\
\text { and anal legs of } \\
\text { caterpillars. }\end{array}$ & & $\begin{array}{l}\text { Thirteenth pair } \\
\text { of legs. }\end{array}$ & $\begin{array}{l}\text { Fourth ablominal } \\
\text { legs (uropods). }\end{array}$ & \\
\hline 18 & $\begin{array}{l}\text { Eleventh ab- } \\
\text { dominal seg- } \\
\text { ment in some } \\
\text { Orthoptera a nd } \\
\text { Pseudoneurop- } \\
\text { tera. }\end{array}$ & & Fourteenth ........ & $\begin{array}{l}\text { Fifth abdominal } \\
\text { legs (uropods). }\end{array}$ & \\
\hline 20 & & & Fifteenth...... & $\begin{array}{l}\text { Sixth abdorsinal } \\
\text { legs (uropods). }\end{array}$ & \\
\hline & & & in Geophilus.† & & \\
\hline
\end{tabular}

* See Kowalevsky, Embry., Stndien an Würmern nnd Arthropoden, 1871, Plate XII, fig. 10. Embryo of Sphinx populi, in which the first ten abdominal segments have temporary rudimentary appendages, some of which persist in the caterpillar, serving as prop-legs.

t'The ovinositor of insects, as we originally pointer out in 1868 (Proc. Boston Soc. Nat. Hist., xi, 393), is primarily composed of three pairs of appendages (called by Lacaze-Duthiers "rbabdites"), which ariso in the same way as the legs; this view has been confirmed by Ganin, Kraepelin, and Dewitz.

+ The number of movable segments in the Geophilidæ, according to Newport, varies from about 35 to more than 200 . 
This view as to the homologies of the limbs is directly opposed to what we have previously held, and to the views of Claparede* and Zenker; but progress in the embryology of Arthropods and of worms has now given us a basis for better grounded views as to the homology of the limbs of the leading groups of Arthropods. It now appears that in the higher worms the mouth is, as a rule, situated in the first segment, the invagination of the ectoderm forming the stomodæum or primitive gullet. This is seen in the Nemateiminthes (Cucullanus $)^{1}$ in Nephelis ${ }^{2}$ and in Lumbricus, and is probably common to all worms; and in the Annelida the mouth does not shift; it is a fixed point, and the first pair of tentacles arise from the first segment. So also is the vent or anus (proctodæum), which is the result of an invagination of a portion of what becomes the terminal segment of the body. In Arthropods the anus remains invariably, in all proctuchous forms, a fixed point. On the other hand the mouth shifts from a position originally in the embryo in front of all the appendages in the head to a point posterior to the antennæ of both pairs, when two pairs are present, as in the Crustacea; i. e., to a position in adult life between the mandibles. So far as we are aware we were the first to call attention to this fact of the change from an anterior to a posterior position of the mouth in relation to the antennæ in our account of the embryology of Limulus polyphemus, ${ }^{3}$ where the mouth at the time of the appearance of the limbs is anterior to the first pair of appendages. This was probably the case with all the extinct Merostomata and Trilobita. In the normal Crustacea Bobretsky ${ }^{4}$ has shown that in Oniscus the mouth opening is at the extreme end of the body, in the antennal segment, the middle of the procephalic lobes or antennal segment forming the front wall or roof of the stomodæum. In the nauplian stage in embryo of Astacus, Reichenbach ${ }^{5}$ has shown that the mouth is placed directly between the first antennæ; and in the active freshly-hatched nauplius of the Copepoda, as well as of all the Phyllopoda, the mouth opens between the first pair of limbs, which become finally the first pair of antennæ of the adult. In Peripatus Moseley has shown that the mouth opens in the autennal segment, which really forms the procephalic lobes. In the Arachuida, according to Claparede, all the appendages are in the embryo postoral.

In the Hexapodous insects Kowalersky has clearly shown that the mouth is at first situated between the antennæ, which arise from the procephalic lobes; before hatching it retires to an intermandibular position.

The embryology of all the Arthropodan subelasses (the Myriopods probably not excepted, this point not being shown in Metschnilioff's plates) shows, then, that the mouth is not a permanent fixed point, since in the embryo it is pre-appendicular, while towards or at adult life it assumes a position behind the antemne, when functional antennæ are present, or in Arachnida and in Merostomata behind the first pair of appendages.

An examination of the structure and homologies of the Arthropodan brain or supra-asophageal ganglia shows that in the Phyllopods the

* Claparède, Recherches sur l'Evolution des Araignées, 1862, pp. 77-87.

"Bitschli. "Entwicklungsgeschichte der Cucullanus elegans," Zeit. f. wiss. Zool. xxvi, 1876.

2 C. O. Whitman, Embryology of Clepsine, Quart. Journ. Micros. Se. xviii, 1878.

${ }^{3}$ The Development of Limulus polyphemus. Mem. Bost. Soc. Nat. Hist. i, March, 1872.

4 N. Bobretsky. Zur Embryologie des Oniscus murarius. Zeit. für wissen. Zoologie xxiv, 1874. See Taf. xxii, figs. $20,23$.

${ }_{5}^{5}$. II. Reichenbach. Die Embryoanlage und erste Entwicklung der Fluskrebses. Zeit. für wissen. Zoologie, xxix, 18i7. See Taf. x, fig. 8. 
brain only innervates the ocelli and eyes, the two pairs of antennæ arising in Apus from the commissures connecting the supra and infra œsophageal ganglia. In Limulus, the living representative of the Merostomata, the first pair of limbs are innervated from the ganglionie subcesophageal ring, and not the brain; while in most other Crustacea the brain supplies the antennæ of both pairs, as well as the eyes. Thus, apparently, the only sure basis for exact comparison is to begin with the first pair of appendages and to regard them, whatever name be applied, as homologous throughout the Arthropodan series, the parasitic Isopods and Copepods perhaps being counted out by reason of the degradational changes, which render it difficult to determine in adult life the exact homologies of their appendages.

The general relations of the segments of the bodies of Arthropods being similar to what exists in Annelids is to our mind a strong argument for the derivation of Tracheate and Branchiate Arthropods, each independently, from the worms, the first pair of appendages of the Arthropods being perhaps homologous with the first pair of tentacles of Annelids.

Homologies of the labrum.-This brings us to consider in passing the probable origin and homologies of the labrum* of Arthropods. We are inclined to regard the labrum as possibly the homologue of the median frontal tentacle of certain larval Annelids, for instance. If the reader will compare Metschnikoff's figure of the temporary long, large, slender, tentacle-like labrum of Chelifer, the general resemblance to the frontal unpaired tentacle of certain Annelids is suggested. We have always regarder the clypeus and labrum as a median development, merely forming the front wall of the mouth; embryology certainly bears out that view. In the embryos of most insects the clypeus and labrum project out remarkably, and may then, perhaps, be compared to the unpaired, median tentacle of certain young Annelids.

The history of this organ is interesting. While in the larval Estheria and Limnadia the labrum is enormous, and nearly as long as the body, thus resembling the larval Cirripedia; in the adult it becomes a small fleshy process under the base of the second antennæ, and partly resting on the base of the mandibles. In Limnetis (Plate XXXI, fig. 6, lab.) it is rather large. In the Apodida it forms a comparatively large, square, horizontal plate (Plate XXXI, fig. 1) on the under side of the head, behind the frontal doublure. In the Branchipodide it is again reduced to a small fleshy inconspicuous lobe.

The carapace.-This is greatly developed in the Limnadiacea, where it forms two large valves, usually with definite "lines of growth," and connected over the region of the mandibles by a definite specialized hinge, and completely encloses the body, only the second pair of antennæ and perhaps the telson projecting beyond the edges while the animal is swimining. Plate XXIV, fig. 9, shows the relation of the bivalvedcarapace in Estheria to the body and its appendages. The hinge has a large central median tooth projecting inwards, each valve having a sharp denticle which strikes against the central much larger tooth. (See also Pl. XXXIII, fig. 1.

The histology of the carapace has been described briefly by Grube in 1865 , but his figure (Taf. $\mathrm{X}$, fig. 11) does not express satisfactorily the nature of the soft cellular portion or layer. The cuticular layer is struetureless but laminated, and it has been claimed by Prof. E. S. Morse that the carapace valves in Estheria are due to the fact that the shell, instead of being cast free from the body when molted, remains attached 
to the new shell underneath, and thus the "lines of growth" correspond to the successive molts of the animal. In his First Book of Zoology, p. 149, he remarks: "The concentric lines on the shell appear like lines of growth, and such they really are; but they are not made like the lines of growth on the mussel. When the creature molts the delicate skin covering the antennæ and swimming legs is discarded. The molting process also takes place with the bivalve shell; but, instead of its being discarded, the molt is held or cemented to the new shell, which forms underneath. Molt after molt of the shell is thus retained, the increasing size of each molt showing as separate concentric lines of growth. If the shell is cut into and the cut edge is examined with a microscope, the successive molts will be seen resting one upon the other, like the leares of a book." This view would seem, at first sight, to be borne out by the relation of the marginal row of spinules, which are present in most species of Estheria, as seen in our figures of the edge of the carapace of Estheria jonesii (Plate XXIV, fig. 2), where there are four marginal rows of round sockets, which must originally have borne spinules like the marginal ones. But our sections of the shells of Estheria mexicana show that Morse's view is not tenable, as the shell, if anything, is thicker at the edge than near the hinge, and there are no overlapping lines of growth.* An inspection of the broken shell of E. jonesii (Plate XXIV, fig. 2) shows that the ridges or so called lines of growth are superficial, and, like the rows of beads and tubercles on the shells of the other species, together with the spines themselves, are merely external ornamentation; for when the shell is broken and split, as in our fig. 2 of this plate, they are seen not to extend throngh the shell, there being irregular, not parallel, structural, lines in the substance of the shell. That the entire shell is molted with the integument or cnticula of the head and appendages is also shown by the fact that the carapace-valves of Limnetis show no such lines of growth, nor the carapace of Apus. So that, in respect to the casting of the carapace, the process in the Limnaniadæ is not an exception to that in other erustacea where the cuticula of the entire body-wall is cast at once. Hence it would appear that the so-called "lines of growth" may be simply a superficial ornamentation, the ridges differing in different species.

That the shell of Estheria mexicana is cast at each molt is shown by a number of sections where the new chitinous shell is seen lying next to the hypodermis and the shell about to be cast is split off; also near the hinge, and especially over it, the shell is absorbed, so that the hinge margin is not cast. The old shell was also in our sections divided into three layers. Claus also states that Estheria mexicana casts its shell.

It is probable that each species of Estheria has a row of spinules along the edge of the carapace-valves; we have found these spinules very long and slender in Estheria belfragei and E. mexicana, very short in E. jonesii and E. lindahli. We have not observed any in E. californica, nor has Lenz.

\footnotetext{
*According to Joly and Klunzinger in Estheria and Limnadia during the moulting as seen in repeated precise periods, only the delicate layer lining the inside of the sbell is east off with the skin of the telson, the hardened lamellated outer layer not only remains, but forms each time a new marginal zone. Since the inner layer is a direct continuation of the delicate body-skin, so is a periodical renovation of the same through a process of formation arising from the underlying matrix evidently found at each moulting of the telson; at the same time, however, this matrix, while it adds to the extent of the surface, also externally produces a new layer which, on the other hand, lies under that last formed and projects from the edge. In this way with the general growth of the shell, not only the lanellw overlying one another, but also the concentric lines, each one of which corresponds to a line of growth, find their simple explanation, and hence the view of Claus, who considered that the whole shell was cast at each moulting and was newly formed, cannot be the true one.
} 
The structure of the hypodermis is seen in fig. 7, Plate XXXIII. The sets of curved fibers $(f)$ are arranged in upright bundles, with some transverse fibers, the ends of the former radiating at the surface and forming the stellated appearance so characteristic of the surface of the integument in these Phyllopods. The spaces between the bundles are not hollow, as represented by Grube; but in the specimens we examined besides numerous smaller cells there is a very large central cell $(l . c$.$) ,$ which is perhaps actively concerned in secreting the shell.

The shell-gland (Plate XXIV, fig. 9, shg) is seen to be a specialized portion of the cellular layer of the carapace; the cells glandular in their nature and secreting the material for the shell or cutiele, which is distributed by the three primary ducts represented by the six openings seen in the drawing. The structure of the shell-gland in the Phyllopoda has been fully described by authors, particularly by Leydig, Claus, ete.

While the carapace is well developed in the Limnadiada, with the Apodide it is very much smaller, eovering only the cephalothoracic portions, leaving the abdomen exposed, so far as cephalothorax and abdomen may be said to exist in the Phyllopoda. The carapace is largest in the lower species and smaller in what we regard the higher species in the genera Lepidurus and Apus, respectively. In this family, therefore, its small size in adult life is a sign of superiority; as when it is large and covers most of the abdomen, it approaehes nearly the larval condition of the species, and also the Limnadiad nature of the carapace, and in this respect, as well as in regard to the head, the Apodide are but one step removed from the Limnadiades.

It also appears that the carapace is, as in Decapods, dne to the hypertrophy of the tergum of the mandibular segment, the adductor musele being situated immediately over the mandibular adductor museles.

In the adult Branchipodidæ the carapace is entirely wanting. In adult life the shell-glands persist (Pl. XXIII, figs. 1, 2, gl.). Thus the Branchipodida are the extreme in the Phyllopod series, and stand at the head of the snborder, and hence as regards the carapace the development of the individual Branchiopod is in a degree an epitome of that of the suborder; and we have already seen that this succession or relative standing of the three families of Phyllopods accords with the geological succession of the genera Estheria, Apus, and Branchipus.

Morphology of the head.-The relative size and form of the head varies greatly in the three families of the Phyllopoda. In Limnetis the head is enormous in size and about equals in bulk the rest of the body; this is due to the great development of the sternal side, but especially of the tergal portion in front of the eyes. In respect to the great bulk of the head the Limnadiadæ, and especially Limnetis, are connecting links between the Cladocera and Phyllopoda. In the Cladocerous genera Daphnia, and especially Acroderus as figured by Leydig, the head and particularly the frontal region is greatly developed, though much less specialized than in the Limnadiada. For example, the front is produced into a large, broad, solid preocular subregion, forming the rostrum, which is acutely mucronate at the tip in the females, broad and truncate in the males; behind this is a broad, solid region in which the eyes are situated. The head, in fact, may be divided into a distinct, specialized preoral antenniferous and oculiferous, or sensory; and into a postoral region; the preoral region in Limnetis and Estheria may be subdivided into two, namely, a preocular and an ocular subregion. In Limnetis the preoral region is separated from the rest of the liead by a deep suture, and in Estheria there is a deep dorsal incision, allowing a cousiderable play of this region upon the postoral region. In Limnadia 
the whole preocular subregion is wanting, the head under the eyes rapidly retreating backward and downward. This great development of the preocular region is probably connected with the burrowing habits of these crustacea, which take refuge in the soft mud at the bottom of ponds.

In Apus and Lepidurus (Apodider) the head is shovel-shaped, being also adapted for burrowing like a Limulus in soft mud; in this family the preoral region is very large, but instead of being compressed, it is flattened vertically, or shovel-shaped.

In the more highly differentiated Branchipodides the head is small in proportion to the rest of the body, and more completely differentiated or separate from the thoracic portion of the trunk, and the bulk of the head is composed of the preoral region; the postoral, as seen in fig. 2, Plate XI, carrying the mandibles and the nearly obsolete maxillæ, and forming what appears as a single segment, a little smaller than the first limb-bearing segment next behind it. In this family the preocular region of Limnetis and Estheria is reduced to a minimum and is represented by the small triangular frontal, inter-antennal lobe, which in Branchipus and Chirocephalus is subdivided into two appendages of various complicated shapes. There is, thus, as we ascend from Limnetis to Branchipus a more or less gradual differentiation and condensation of the head; and the head of A pus approximates in form the Estherian type.

The postoral region bears the mandibles and maxillæ, and maxillipedes when present, and merges insensibly into the limb-bearing or thoracic region (bænosome), so that there is in the Plivllopoda only a slightly marked cephalothoracic region, the urosome also being but slightly differentiated from the bænosome.

The urosome or abdomen.-This region, so well marked in the Decapoda, is in the lower Phyllopods not differentiated from the cephalothoracie, no arthromeres being in the Limnadiada interposed between the last limb-bearing or appendigerous arthromere and the telson. The external genital organs, which may serve to roughly indicate the limits between the cephalothorax and the abdomen are wanting in the Limnadiada.

In Apus and Lepidurus the eleventh pair of feet (first pair of uropods) are modified to form ovisaes, but there are numerous pairs of uropodit beyond, and there is no regional distinction of even the slightest description between the limb-bearing segments and the telson. In the Branchipodida, however, a differentiation into a head, thorax, and abdomen is tolerably marked. As may be seen by reference to figs. 1 and 2 of Plate IX, and Plate XXII, fig. 3 , the last pair of limbs are, in the male, modified to form a penis-like organ, which is double at base and is dereloped from a single segment. In the female Apodida the oviducts open externally into the same segment as that which bears the ovisac, and we are disposed to regard the ovisac as an extreme modifieation of the gonopods; as in Branchipus and Artemia, Plate XXII, fig. 2, this organ is at base bilaterally symmetrical. The abdomen, then, of Branchinecta and Branchipus, for example, consists of nine segments, including the last, which corresponds to the telson of the lower Phyllopods.

In the Decapoda the first pair of gonopods (there being two pairs corresponding to the first and second abdominal feet of the females) is situated on the first abdominal segment, and thus the Branchipodide somewhat approach the Decapods in this respect. It will also be remembered that in Limulus the genital outlets of both sexes are in the first abdominal segments. Whether, however, the eleventh pair of feet 
in Apus should be regarded as the first abdominal pair or not must, it seems to us, remain an open question; there seems, however, to be no other line of demarkation in the family which this genus represents.

The telson.-This portion of the abdomen, sometimes called "postabdomen," is large and well differentiated in the two lower families, especially in Estheria - where it is compressed, high, armed above with numerous spines, and bearing below a pair of modified candal ap pendages which we shall consider under the head of the appendages.

We will rapidly recall the salient points in the form of the telson in the three families of Phyllopods. In Limnetis the telson is much as in some Cladocera, being small, without teeth along the upper edge, though still bearing the pair of dorsal filaments (see f.r. 4 , in text, and Plate I, fig. 6). These are also present in certain Cladocera, Daphnia, Bosmina, \&c., and in several genera allied to Daphnia, Alona, Pleuroxus, \&c., the upper edge is dentate or spined; this with other features in Limnetis shows that the Phyllopods have probably descended from Cladocera-like ancestors. In Estheria and Limnadia the telson is large and densely spined along the upper edge. The large spiny telson is probably of use to aid the animal in pushing itself through submerged dense vegetation, for all that portion of the body which can be thrust out between the valves is armed with stout spines, whereas in Limnetis, only the telson can project beyond the edge of the carapace valves.

In Apus the telson is nearly cylindrical, short and small, and flattened from above downwards, and is without much functional value, though the cercopods are of use in swimming; but in Lepidurus it is produced into a long spatulate portion like a beaver's tail, and which must give it an advantage over Apus in extricating itself from muddy places.

In the Branchipodide the telson assumes the form of a simple segment, cylindrical, soft, unarmed, but in Thamnocephalus becoming very broad and flattened into a lateral fin-like expansion and without any candal appendages, which are always present in the other genera of the family.

What we call the telson, and which is simply the last abdominal segment, is called by Gerstaecker, and we suppose earlier authors, the "postabdomen." Some authors, the most recent, Gerstaecker in Bronn's Classen und Ordnungen, \&c., speak of the "abdomen" and "postabdomen" in the Branchipodida, but they do not state where the abdomen begins. The term "postabdomen" is applied to the last eight (Artemia) or nine (Branchipus, \&c.) segments of the body (uromeres), but we see no good reason for not regarding these segments as forming a true abdomen (urosome), the first segment, or ninth from the end, in Branchipus bearing the external reproductive organs. We really see no need of employing the term "postabdomen" in speaking of any Branchipod, nor in fact, so far as we are aware, does it have any special significance in othér groups. We here consider the so-called "postabdomen" of the Limnadiada and Apodida as the telson, and the homologue of the telson in the macrurous Decapoda.

The eyes.-There are in the lower Phyllopoda but a single pair of compound or facetted eyes, but in the Branchipodida the simple, unpaired eye of the larva is retained. In the Limnadiada these are sessile; in the Branchipodidce they are stalked. The structure of the eye of Apus cancriformis and Branchipus (species not named) has been described and in part figured by Grenacher in his great work "Untersuchungen iiber das Sehorgan der Arthropoden" (1879). The eye of Branchipus stagnalis has previously been investigated by Leydig in 1851; and that of Estheria californica by Lenz in 1876. The eye of Limnetis has apparently not been investigated, and our own observations on it are but 
fragmentary and superficial. The eyes are closely approximate, apjearing as a single eye. Unlike that of Estheria the number of lenses is small. Plate II, fig. 6, represents the eye of Limnetis gouldii, a circle of crystalline lenses surrounding the central pigment mass or retina. The lenses are contiguous, the pigment not extending between them as in Artemia, Plate XXIII, fig. 6. Plate II, fig. 5, represents the two optic nerves and optic ganglia, the cornea with the crystalline lenses and pigment layer having been torn off with the needle. The optic nerves are very thick, and instead of, as usual, being composed solely of nerve fibers, appear to be largely made up of nerve cells; fig. 5 a represents an enlarged view from near themiddle of the optic nerve, which is made up almost wholly of strings of nerve cells. Toward the distal 'nds of each optic nerve converge delicate fibers which connect the cells of the optic ganglion with the optic nerves. An enlarged view of the optic ganglion is seen in Plate XXIX, fig.9. The ganglion cells are not very numerous nor crowded; they are nucleated and nucleolated, and a nerve-fiber broad, triangular next to the cell, rapiolly diminishes in size towards the middle of the fiber. It is interesting to notice the intercommunication in the median line of the hearl between the two eyes; a small number of cells on the opposing edges of each eye are seen to send transverse nerve-fibers (fig. $9, t r . n$.) across to the opposite optic ganglion; though externally the system of crystalline lenses do not quite touch each other. We have not examined the crystalline lenses of Limnetis.

The eve of Estheria is nearly on the same general plan as in Limnetis. Lenz has discovered that the lenses are composed of five segments, instead of two, the usual number in Crustacea, particularly Apus and Branchipus.

The inner structure of the eye of Artemia was studied on the living specimens, Plate XXIII, figs. 1 and 6 . Fig. 1 shows the general relation of the sessile square simple eye and of the stalked compound eyes to the head and also to the brain. Fig. 6 represents the relations of the eye and its optic lobe to the eye-stalk of the living animal. The optic nerve is in the center; the large rectus muscle of the eye is situated on the hinder or outer side of the stalk, arising near the brain and being inserted on the cornea at the base of the eye near the first crystalline lens; the exact mode of insertion was not observed. The blood cireulates freely, flowing from the head along the anterior side of the outstretched eje, the corpuscles, of different sizes and not very numerous, passing between the optic nervules (op. n.) and returning, as the arrows indicate, along each side of the rectus muscle back to the head.

The general structure of the eye of Artemia gracilis is much as represented by Leydig in Branchipus stagnalis; the ganglion opticum, however, is in our specimen of Artemia composed of but a single mass, not of two distinct masses connected by coarse nerve-fibers. From the ganglion opticum about a dozen optic nervules penetrate the retina, which is larger in proportion to the exe than represented in Leydig's figure; the superticial circle of erystalline lenses or cones showing very plainly.

The question as to whether the eyes of Crustacea, particularly the stalked eyes, are homologous with the other appendages, and thus represent distinct segments of the head, and which is still held by some uaturalists, may, it seems to us, be set at rest by examining the eyes of Phyllopod Crustacea. In the Limnadiada and Apodida, where the eyes are sessile, it is easy to see, particularly in Limnetis and Limnadia, that the eyes are modified epidermal cells covering the ends of the optic nerves. They are situated on the front or upper walls or tergum of the 
first antennal segment; and, as it is a general law that but a single pair of appendages are borne by a single segment, we should not expect to find the law broken in this case, at least as regards the cephalic segments.

When we come to the Branchipodida, where the eye is mounted on a long moveable stalk, they are still plainly tergal outgrowths of an an. tenual segment. The embryological history of the eyes would also prove that the eyes in all stalked Crustacea first begin as a specialized group of epidermal cells, dereloping on the anterior segment of the head; even in the zoëa of Decapods, the eyes remain sessile until just before the hatching of the larva; the growth of the stalk is one of the latest changes in embryonic life. It the eve-stalk were homologous in its history and structure with the limbs, then why should not the stalk in the stalk-eyed species bud out from an independent primitive segment, as do the appendages of the cephalothorax and abdomen? Instead of that, the stalks on which the eyes are situated are developed very late in embryonic life, and are evidently not derived from ancestral forms; while in all stalk-eyed forms, whether Phyllopoda, Phyllocarida, or Decapoda, the stalk is preeminently an adaptive feature of the head, and is developed on the first antennal segment.

The first antenne.- The Phyllopoda have, with the exception of individual A podidæ, invariably two pairs of antennæ. They are, however, very unequally dereloped, the first pair being minute and smaller than the second pair, except in Apodida, where the second pair are minute and sometimes wanting. In Limnetis they are minute and difficult to find. Their position and size in relation to the first pair are well shown by Mr. Burgess in Fig. 4 (in text). They are there seen to be inserted quite in advance of the second pair, and to be slender and two-jointed. Those of $L$. gouldii are much slenderer than in $L$. brevifrons.

In Estheria and Limnadia they are much larger and longer, multiar. ticulate, the joints, however, not well defined on the inner edge; they appear to be inserted behind the second pair, but careful examination shows that they originate anteriorly. In the Apodida the first antennæ are much larger than the second pair, but small as they are, and apparently almost functionless, they are yet invariably present. The relative size and form of the two pairs are shown on Plate XXXII, figs. $2 a, 2 b$. The first pair are inserted on the vertical inner wall of the frontal doublure. They are slender, two-jointed, and by their position and diminutive size must be nearly useless to the animal, and only the survival of larval organs. In the Branchipodide the first antennæ resume somewhat of their normal size and importance, being rather long, slender, filamental appendages, but not jointed. The histology of the first antennæ in Limnetis has not been previously noticed. Under a high power, those of Limnetis gouldii (Plate XXVI. figs. 4, $4 a^{*}$ ) are seen to be provided along the outer edge with long, slender sense-filaments, rather more closely crowded and better developed at the end than along the side. The substance of the joint is rich in cells which are not closely crowded, and are arranged in series ending at the base of the sense-filaments, where the cells become more closely crowded. These cells occur at the base of the sense-filaments, but elsewhere in the filament there are only minute scattered corpuscles of the size of the nuclei of the sense-cell. In L. brevifrons (figs. 5, $5 a$ ) the histological structure is nearly the same, but the

* In Fig. 4, which represents the second joint of the antenna, the left side has been omitted by the artist. The line which should have been drawn here has wrongly been added to the right side of fig. $4 a$. 
sense-filaments, or what we may call the olfactory filaments, are smaller and less numerous than in $L$. gouldii.

In Estheria mexicana, Plate XXIX, fig. 1, $1 a, 1 b$, the segments on the anterior side are produced into what may be called the olfactory tubercles, which give a bluntly serrate outline to this side of the antenna in contrast to the even opposite or inner side. In fig. 1, the antennal nerve (at. $n$.), where the sense cells and tubercles do not occur, is seen passing through the middle of the antenna, and the ends of the fibers disappear among the nerve cells, which crowd the olfactory tubercles (fig. $1 b, o l$.). In this species no olfactory filaments were observed to be present. In Estheria compleximanus however, Plate V, figs. 3, 4, they are well developed, two or three, and scmetimes more, short filaments arising from the tubercles, which are more acute than in E. mexicana (from Kansas). The structure of the olfactory papillæ (ol. pap.) is nearly identical with those of Limnetis. The ultimate fibers of the olfactory nerves are here plainly seen to enter the mass of nerve cells.

In Limnadia texana, Plate XXVI, fig. 3, the joints of the antenna are more richly charged with nerve cells, which are rather smaller than in Estheria compleximams, thongh those of the latter species are larger than in E. mexicana. The histological structure of the first antennæ in the present family is quite unlike that of the same appendages in the Apodide and Branchipodide; ; and reasoning by exclusion, and taking into account the fact that this pair of antenne do not project much beyond the edges of the valves, and that they are placed very near the jaws and mouthopening, and also bearing in mind the great abundance of the sensecells, we are inclined to believe them to be either olfactory or gustatory in function, and that in this family at least the first antennæ are mainly organs of smell or taste. We have often observed Limnetis gouldii, swimming quite rapidly on its back at the surface of the water, apparently feeding upon the vegetable matter floating on the surface; during its movements it would stop and feed upon some object, as if arrested by its smell. The sense lodged in these organs are therefore restricted either to the sense of smell or taste, probably the former.

The finer structure of the antennæ of Apus has not been examined, and it is probable in an indifferent state. That of the first antennæ of Branchipodida is quite simple. Plate XXIX, fig. 6 , represents the first antenna of Branchipus vernalis greatly enlarged. It is simpler in strueture than in the Luropean B. stagnalis as figured by Leydig (Sieb. u. Köll. Zeits. Wiss. Zool., iii, Pl. VIII, fig. 8), since it lacks the series of seven sense filaments ending in knobs of the European species, though the three terminal setæ are much longer. In our species the antennæ are seen to be unjointed throughout its whole length. Two nerves, one on each side (fig. $6 n$ ), and composed of several fibers with here and there a ganglion cell, approach each other in the middle of the appendage, where they are reinforced by a ganglion cell or two. At $n^{\prime}$ two nerves are seen passing along the center of the appendage; at $g c$ are situated several ganglion cells in the nerves, which finally lose themselves in a terminal mass of small compac ganglion cells, situated at the base of the three setæ. Leydig only figures five cells, where in $B$. vernalis they are smaller and much more numerous. It seems obvious that in this family the first antenna only possess the sense of touch.

On Plate XXXंIV, fig. 4, Dr. Gissler has figured the first antenna of the larva of Streptocephalus texamus, from Kansas, and it will be seen that the histological structure is rather different from that of the adult Branchipus. The ganglion cells are more abundant at the base of the antennæ; the nerve passes along the center, is reinforced by a few large 
spindle-shaped ganglion-cells before terminating in the spherical ganglion-cells at the insertion of the three setæ. The same general arrangement of the nerve-fibers and cells is seen in the same organs earlier in life at fig. 3 .

In Chirocephalus holmani, according to Dr. Gissler's figure, the first antennæ each bear not only three terminal setæ, but also a series of about five sense-setæ like a teu-pin (Fig. 8). These are apparently homologous with the olfactory cylinders of Leydig* on the smaller antennæ of Asellus aquaticus.

The second antenno.-These are not apparently organs of any special sense. In the Limnadiadce they are evidently derived from the "ruderarme " of the Cladocera, being large, long, biramons appendages of constant use as oars in swimming, the long setæassisting in the oar-like movements. The form is very persistent in this family, the use of the appendages being the same in each genus.

In the Branchipodida, the second antennæ of the males are modified in a striking way, which afford apparently good specific characters us'ful in such a difficult genus as Streptocephalus. As clasping organs their use is seen in the engraving of Artemia (fig. 17 in text). The rounded sinus between their bases just fit over so as to inclose the back of the female, and the two knob-like processes further seem to hold her fast; in Branchinecta the structure of the base of the claspers is the same, while the simple unarmed second joint is not particularly well fitted for prehension. In Branchipus each second joint has a stout spine pointing inward which acts as a prehensile apparatus, as has Streptocephalus, in which also the second joint is variously divided into prehensile parts.

In Chirocephalus and Thamnocephalus the second joint is incurved, and thus rendered sufficiently prehensile.

It appears, then, that the highly specialized male second antennæ have lost perhaps altogether their sensory functions, or their use as swimming organs, like those of the Limnadiada, and are simply of use as clasping organs and minister solely to the reproductive function.

In the Apodida, as stated by Lankester (Quart. Jour. Micr. Sc., A pril 1881 , p. 346), the existence of the second pair of antennæ has recently been denied. "Zaddach states that they were generally absent in $A$. cancriformis, but were found by him in two cases; Huxley states that he was unable to find them in Apus glacialis examined by him, whilst Claus, whose statements have the very greatest weight, both on account of his extended investigation of the morphology of the Crustacea and of his special observations on the development of Apus and Branchipus, brings forward the total absence of the second pair of præoral appendages in Apus, as a special characteristic of the family Apusidæ." Gerstaecker simply, in reference to this point, quotes Zaddach's statement. Lankester adds "In the adult Apus cancriformis and Apus duliii, from Affghanistan (?A. himalayanus), this second pair of præoral appendages, although reduced to a rudimentary condition, is always present,

${ }^{*}$ Leydig, F. Ueber Geruchs- und Gehörorgan der Krebse und Insecten. Reichert $\mathrm{n}$. du Bois-Raymond's Archiv. 1860, Tab. 7 , fig. 4.

Spangenberg (on Limnadia hermanni, Zeits, für W. Zoologie Suppl. 18i8) thus describes the taste-organs. On the 1st antennæ "they are situated-usually six in number-as small, clear points on the hinder much-swollen surface of the base of the antennæ, and may be traced back, as all these taste-filaments, to the spines on the nanplius-antenne. The structures on the base of the known pale taste-cylinder, described by Claus as 'highly characteristic shaped nerve-pins,' are the young taste-cylinders reaching out in the succeeding moult, and are not of a nervous nature, but cuticular early grow ths." 
so far as my observations go. I have found them always present in full-grown specimens of Apus cancriformis from Munich, from Prag, and from Padua."

In specimens of Apus cancriformis kindly sent us by Professor Siebold, of Munich, we have found the second antennæ to be inserted on the inner declivity of the frontal doublure forming the front of the head, and inserted behind the first antennæ, and farther out from the labrum than the first antennæ. They are in form as described and figured by Lankester. I also found them in my examples of Apushimalayanus, and, as in $A$. cancriformis, they are larger and more easily found than in the American species.

On looking for the second antennæ in our American species I was at first unable to find them, they were so minute and so closely appressed to the body. In specimens of Lepidurus couesii which were well preserved the antennæ were found, but none in $L$. bilobatus, of which I had but two indifferently preserved specimens. Figs. $2 b, 2 c$, of Plate XXXI, show their relative size in Apus lucasanus, both being drawn to the same scale. In order to find them the mandibles have to be forcibly moved backward. They were also found in Apus newberryi, A. wqualis, and in A. longicaudatus, but in all these American species they are much smaller and more difficult to find than in the European and Asiatic species; a point of some interest, which coupled with the greater obsolescence $0^{e}$ the maxillipedes and the smaller carapace shows that the American species have reached a stage farther removed from the larval condition than the Old World forms.

Histology.-The histological structure of the 2 d antennæ of the Limnadiada is shown at fig. 2, Plate XXIX, which represents the three terminal joints of one of the flagella of the second antennæ of Estheria. The joints are seen to be crowded with nerves of special sense, and the antennal nerve is seen to terminate in fibers, one of which passes into each seta; so that these organs must be highly sensitive, perhaps only tactile, however, while they are also rowing or swimming organs.

The mandibles.-All Phyllopoda have well-developed mandibles, except in the highest or most specialized family, the Branchipodida, in which they are weak and feeble in function, though with primarily the form common to the group.

In the Limnadiada (according to Lilljeborg), in Limnadia gigas, and as we have observed in the A podida, the mandibles are without a palpus in the adult, and are solid chitinous appendages with the biting edge either smooth, as in Limnadiada, or provided with strong acute teeth as in Lepidurus and Apus. (Plate XXI, figs. 11, 12.)

When we look at the larval mandibles of $A$ pus, which are represented by Dr. Gissler (Plate XXXV, fig. 1, md), it is not only plain that they are the third and last pair of the limbs of the Nauplius, but it is also plain that the mandible originally consists of two portions, the basal joint with its masticating edge and the two-jointed palpus; this palpiform appendage becomes absorbed or at any rate disappears in the two families under consideration, and it is easy to see that the mandible proper represents or is the homologue of the basal joint of the axis of the limb, together with the first endite, coxal lobe, or gnathobase of the adult Limnadiad or Apodid leg (e.g., Plate V, figs. $5 l^{1}, 7 a$; Plate XXI, fig. $4 c l$ ).

In the Apodidx the cutting edge of the mandible is provided with eight or nine teeth, which are naturally less blunt in the adult than in the larva (see Plate XXXV, fig. 4, $4 a$ palpus).

In the Branchipodida the mandibles, as shown by Spangenberg (suppl. 
Taf. I, Fig. $6, m d)$, retain the palpus, which is represented by a single setose bristle, the remnants of the large part of the Nauplian third leg. The teeth on the cutting edge in Branchipus stagnalis are finer and more numerous than in the two other families.

The first maxilla.-Sueceeding the mandibles are two pairs of maxillæ in the Limnadiade and Branchipodida, while in the A podida thereappears to be but a single pair of maxillæ, which are succeeded by a rudimentary gill-bearing appendage, the maxillipede. The first pair of maxillæ in Limnadia gigas are described and figured by Lilljeborg; those of Estheria mexicana by Claus. According to Lilljeborg the first maxilla of Limnadia consists of but a single lobe with very numerous uniformly dense, fine, slender, and very long setose setæ.

In the Apodidee the first maxillæ consist of two parts, the basal (Plate XXI, figs. 9, 10), which censists of a single large chitinous piece, with the free cutting edge provided with two kinds of teeth, an inner submerginal row of stout, acutely triangular teeth, while there is a marginal row of hair-like setx. In Lepidurus the external portion of the cutting edge is somewhat differentiated, there being here, as seen in Plate XXI, fig. 9, a specialized portion with three stout teeth; this becomes obliterated in Apus lucasanus, but in the larva of the same species, as Dr. Gissler's drawing (Plate XXXV, fig. 5) shows, this portion is at first separate from the rest of the cutting edge, and in Lepidurus this feature is retained in adult life. Situated close behind the large chitinous portion and loosely connected with it at base is what I should regard as the palpus (Plate XXI, figs. $7,8,13$ ); that this should be regarded as a portion of the first maxilla is, I think, proved by reference to the condition of the maxilla in the larva. By reference to Dr. Gissler's figure of the maxilla of the larval Apus 7ucasanus this palpuslike portion is clearly seen to be a large flat bilobed portion lying behind but next to the outer part of the cutting edge of the maxilla.

The maxilla proper, $i$. e., the cutting or main portion of the appendage, is with good reason homologized by Lankester with the first endite or coxal lobe (his gnathobase) of the feet of Apus. The piece which we regard as the palpus, Lankester is apparently disposed to regard as a part of the maxilla, and not, as Zaddach thought, the second maxilla.

In the Branchipodida the first maxillæ have been best described and figured by Spangenberg (Taf. I, fig. 5). It consists of a broad, flat maxilla, the inner edge, $i$. $e$, that corresponding to the cutting toothed edge of the maxilla of Apus, but which is smooth, with fine, delicate, hair-like setæ; while appended to it on the hinder side is a large palpus with long, slender, stiff setæ. The same parts are representell by Dr. Gissler in the first maxilla of the larval Streptocephalus texanus (Plate XXXIV, fig. 6), where the maxilla without setæ and its stout palpus with two sets of setæ are represented. When the larva is 5 millimetres in length a considerable change has taken place in the palpus; one of the outer set of bristles has become barbed; while the inner set, originally composed of three setose bristles, is now composed of eleven setæ.

The second maxilla.-In Limnadia gigas, according to Lilljeborg, the second pair of maxillæ are very much smaller than the first pair, and are rounded on the free edge, which is provided with long setiferons bristles and short stout ones.

In the advanced larva of Estheria according to Clans's "Untersuchnngen," ete, Taf. xix, fig. 1, the second maxillæ are very small, slender, twojointed appendages, consisting of two portions, apparently the maxilla proper and an outer, slender palpus. 
In the Apodida no traces have yet been discovered of the second maxillæ.

In the Branchipodida they are present. Spangenberg figures them in Branchipus stagnalis as a pair of single elongated oval appendages, very minute, and ending in a long setose bristle, with a group of smaller setæ on the inside near the middle, next to the first maxillæ.

Gissler has figured them in Streptocephalus texanus (Plate XXXIV, fig. $6 \mathrm{~m}^{2}$ ), where they are represented as oval bodies, with two setæ, having nearly the same form as in the adult Branchipus stagnalis, but less setose.

The maxillipedes.-These organs, which are here called maxillipedes because they bear a gill, are characteristic of the A podida alone. No such appendages have been found in the Limnadiada or Branchipodida, and thus those of the Apodida may yet be proved to be homologues of the second maxillæ of those two families, true second maxillæ not existing in the Apodida, though it should be borne in mind that they constitute in the Apodide the second pair of appendages behind the mandibles, and thus occupy the place of the second maxillæ of the two other Phyllopodous families.

The maxillipedes of Apus cancriformis have been described and well figured by Lankester; we have found them as he describes in our specimens of this species, and also in Apus himalayanus.

We have also found them in Lepidur us couesii and $L$. bilobatus, the spiny inner appendage or first endite corresponding to the maxilliform coxal lobe (gnathobase of Lankester) of the succeeding feet.

Lankester says of this endital portion of the appendage, after speaking of the gill, or what he calls the "bract," "The other process is an oval chitinous plate, with long marginal setæ $\left(e n^{\prime}\right)$; it may possibly represent the flabellum, but more probably one of the endites, perhaps endite 1 (the gnathobase). There is no means of deciding this point, for Claus gives but a very slight allusion to the early condition of this appendage in his account of the derelopment of Apus."

On carefully examining our four American species of Apus, none were found to have the endite of the maxillipedes present, only the gill or exite being developed. It thus appears that in the absence of the endite of the maxillipedes, and in the nearly obsolete second antennie, the American species of A pus have advanced, so to speak, a step farther than the Old World species of the genus, which have retained the Lepidurus condition; and in this respect as well as in the smaller carapace and the longer abdomen, the genus Apus stands abore Lepidurus. The history of the maxillipede in the development of the early stages needs special research, as it will be most interesting to learn the date of its appearance, its structural changes during the metamorphosis of the individual, and the final disappearance of the endite in the American species.

The thoracic feet or banopods.-Although the differences between the first eleven pairs of feet and those succeeding in the Apodida, or the thoracic feet and so-called abdominal feet in the Limnadiada, are but very slight, and they mainly differ as regards the abdominal members, in having genital openings situated upon one (the anterior) pair, so that on the whole the distinction seems artificial, yet when we ascend to the Branchipodida, where the abdomen is differentiated from the thorax, and has but a single pair of appendages (the gonopoda), it is easy to see that all the members in front of the external reproductive appendages may be properly designated as thoracie (bænosomal). We will, then, in this paper consider the external opening of the oriauct in the female, and 
the genital pore of the male Limnadiada and the Apodida, together with the gonopoda of the male Branchipodida, as indicating the line dividing the thorax (bænosome) from the abdomen (urosome).

In the Limnadiada the female bænopods are remarkably uniform in appearance; in the males, however, the first pair (Limnetis) and in Estheria and Limnadia the first two pairs have the fourth to sixth endites transformed into a grasping or hand-like extremity, whose structure is very interesting.

We will first describe the thoracic foot of the female, as it is simpler in structure than in the male. As seen on Plate I, figs. 3 and 4, Plate II, fig. 1, in Limnetis the axis or trunk of the limb is quite indefinite in outline, and is entirely subordinate in size and differentiation to the lobular outgrowths, the endites and exites.* In this respect the Limnadiad leg closely resembles the Cladocerous appendage, and in this characteristic the appendages seem clearly enough a direct bequest of the lower Branchiopods (Cladocera and Ostracoda). Considering first the inner or sternal series of lobes, $i$. e., the endites, we can easily make out six endites, the normal number for all Phyllopoda. (See fig. 26 in text.) The first endite (fig. $1 l^{\prime}$, in other figures $c l$ ) we have called the coxal lobe $(c l)$; it is the "maxillarfortsatz" of Grube, and corresponds, or is homologous with, the first foot-lobe of A pus of Gerstaecker, or the gnathobase of Lankester (Q.J. M.S., p.348, 1881). It would be difficult, and a straining of homologies, to compare this with the coxopodite of a Decapod, as these endites are characteristic of the Branchiopoda, and do not exist in a completely jointed appendage, such as those of the Malacostracous or Copepodous Crustacea.

The gnathobase is large, long, and well developed in Limnetis; its long, sharp, stout spines nearly meeting those of its fellow opposite, over the sternal groove of the under side of the body, and serving admirably as maxilla-like organs for the retention of the food, and for passing it forwards to be crushed between the mandibular teeth guarding the mouth.

The second and third endites are broad, short, unequal lobes, the second the longer, and provided with long, delicate setulose setæ. The fourth endite assimilates in form to the fifth and sixth, being long and slender, though the setiferous edge is as extended as in the second endite. The fifth and sixth endites $\left(l^{5}, l^{6}\right)$ are each very long and slender, and semi-jointed, a seta arising from each pseudo-joint.

The exite in this family is much more differentiated than in the Apodida or the Branchipodida, and the flabellum performs a variety of work besides respiration. In Limnetis the exite is divided into three portions; the gill, which is oval, pear-shaped, and moderately large, while the flabellum is differentiated into a dorsal or upper very large and broad (Plate II, fig. 1; Plate XXVII, fig. 3), or rather narrow (L. mucronatus) portion $\left(b r^{\prime}\right)$, and a lower slender part $\left(b r^{\prime \prime}\right)$ which assimilates in form, and probably in function to the fifth and sixth endites of the same appendage.

In Estheria and also in Eulimnadia the relations of the dorsal division of the flabellum (which is narrow and slender) to the gill is seen in Plate V, fig. 1, and also in Plate XXIV, figs. 9 and 10. Some of those at the middle of the body serve to hold the eggs in place, for which function they are well qualified by reason of their great length, since they nearly meet over the back of the animal, and their long setæ seem to hold the

* The terms endite and exite were first proposed by Professor Lankester in his memoir on Apus, Q. J. M. S., 1 1 81 . We have extended the term to the outer lobes of the feet of Phyllopods in general. 
eggs in place in the different genera of the family. On account of its holding or keeping the eggs in place, this portion of the flabellum may be called the oviger. These ovigers are best developed functionally near the end of the body, the eggs being grouped near the end of the dorsal edge of the shell.

In Estheria the gnathobase (Plate V, figs. 6, $7 c l^{1}, 7 a$ ) of the anterior bænopods is rather more complicated than in Limnetis. Fig. $7 a$ represents one highly magnified. The inner edge is beset with rather stiff simple setæ, while those on the outer edge are thick at base, beyond slender and setulose. Similar hairs are seen on the gills (flabella) of the Ostracoda (Cypris, \&c.) and in the endopodal as well as the exopodal portion of the feet of the Cladocera (Daphnia, \&c.).

In Estheria the second, third, and fourth endites are equal in size, while the fifth is long and narrow, and the sixth shorter and broader, scalloped on the inner edge ; the gill is large, the oviger long and narrow, while the lower lobe of the flabellum $\left(b r^{\prime \prime}\right)$ exactly repeats in form the sixth endite.

In Eulimnadia (Plate VI) the female endites $2-5$ are quite equal in size and appearance while the sixth is finger-shaped in outline, like the ent of the flabellum, and the gill $(b r)$ is very large. The hand of the male differs from that of Estheria in lacking the thumb-like growth on the fourth endite $\left(e n^{4}\right)$; while the diminutive flabellum $\left(b r^{\prime \prime}\right)$ does not reach to the base of the fourth endite, and the dorsal end of the flabellum is rudimentary.

Turning now to the first male bænopod of Limnetis, while the exite and their basal endites have undergone no modification, the three outer endites are curiously changed into a hand-like organ. The fourth endite is a long and broad lobe, with two rows of short, basally stout setæ. This lobe we call the comb or pecten (Plate 1I, fig. 2; Plate I, fig.5). From the distal end arises a thumb-like moveable process provided externally with setæ. The fifth endite is modified into a curved forefinger-like process with a few terminal setæopposing the thumb; while the sixth endite forms a still longer and much larger finger, which is bent upon the entire hand and is not setose. These lobes arise from a distal chitinous specialized portion, which may be called the hand or manus, with its two "fingers" opposing the "thumb."

The second pair of bænopods are in Estheria and Eulimnadia modified in the same manner (Plate V, fig. 6); the chief difference being the narrower fourth endite, whose setæ are broad, stout, lancet-like (Plate XXV, fig. 3b). In the second pair of feet of Estheria the fifth endite differs from that of the first pair, and also the single pair of Limnetis, in being two-jointed (Plate XXV, fig. $3 a, l^{5}$ ); the end of the distal joint being slightly bulbous.

Claus represents the sixth endite or "claw" of Limnadia stanleyana from Australia as bearing a sucking dise; a similar dise oceupies the same position in Limnadia africana Brauer and L.mauritiana Guerin. It thus seems to oceur in certain species of Limnadia, but not in the American genus Eulimnadia.

Turning now to the appendages of the Apodida, we find it comparatively easy to homologize the different parts with those of the Limna. diada, though, as a whole, the apodid foot is the most peculiar, sui generis, of any phyllopods. The limbs of the European Apus have been studied with care by Professor Lankester in his paper on the appendages and on the nervous system of Apus cancriformis; and he has briefly compared them with the published drawings of other phyllopods, as well as of the Decapods. He regards the axial portion of the limb of 
Apus as the axis or corm; and finds that the first and second pairs only are divided into joints-the first pair into four joints, and the second into two joints; the remaining pairs not being jointed. The figures in our Plates XVII-XX were drawn chiefly to exhibit the zoological differences of the appendages in our American Apodida without reference to the morphology of the axis, but since reading Professor Lankester's suggestive paper we havereexamined the appendages; and our observations teach us that, as he states, only the first and second pair of feet show traces of joints, and even these are such as to be easily overlooked, and should rather be styled psendojoints (or pseudarthra). Plate XXXI, fig. 4 , shows the pseudosegmentation of the axis of the first pair of feet in Apus lucasa. nus.

As our figure indicates, the basal pseudo-joint $\left(a x^{1}\right)$ bears the first endite or gnathobase; the second pseudo-joint $\left(a x^{2}\right)$ is in our species reduced to a minimum, but the second endite rises from it; this joint is represented by

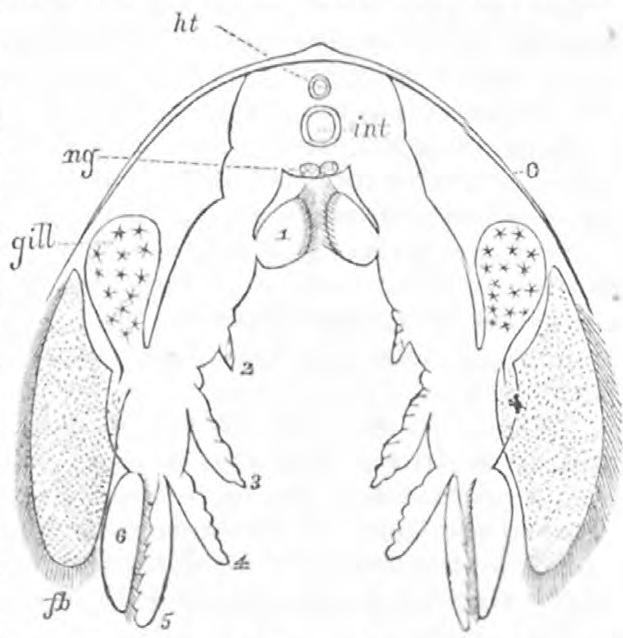

Fig. 26.-Section of A pus. ht. heart : int, intestine: $n g$. ganglion; $c$. carapace; 1-6, the six exites, 1 boing the gnathobase; gill and $f$. flabellum, representing the exites. Partly diagramatic.

Lankester as being much larger in the European species. The third joint is tolerably well marked, but its basal limits are not differentiated well from the outer part of the first joint. The third endite is thrown off by the third joint $\left(a x^{3}\right)$ plainly enough. The fourth joint $\left(a x^{4}\right)$ is a definite segment, and from it originate the fourth, fifth, and sixth endites. In A. lucasanus, however, the gill and flagellum plainly arise from the fourth joint; but according to Lankester's drawing of the same limb in A. cancriformis, these exites arise from the third joint. Taking into acconnt, then, the incomplete nature of the two basal joints, and the fact that the succeeding pairs of feet are not jointed, we see that they share the nature of the feet in other Phyllopods, and that it is one of the characteristies of the Branchiopods in general, including the Phyllopoda, not to have truly jointed feet comparable with those of Copepods on the one hand or Malacostracous Crustacea on the other hand. On this account, while it may be safe to regard the basal joint of the anterior foot of Apus as perhaps the homologue of the coxopodite of Decapoda, we should not venture to go farther and homologize the succeeding more or less perfected joints with those of the adult Decapodous toot.**

But the jointed nature of the first foot of A pus and Lepidurus is valu. able from a morphological point of view, as indicating that the endites are processes from the subjoints, as we may call the imperfectly differentiated joints, and do not in any Phyllopod form the joints themselves.

* Huxley's (Manual of the Anatomy of Invertebrated Animals, 1977) account of the nature and homologies of the foot of Lepidurus glacialis is somewhat inaccurate and misleading. He has torn away the feet represented in his fig. $63 \mathrm{E}, \mathrm{F}$, from the body, leaving the gnathobase attached to the body; and this important and easily recognized part is not drawn; he figures five endites but counts them backwards, beginning with the sixth one. The gnathobase he briefly describes under the name of coxopodite. "Each appendage," he says, "consists of three divisions-an endopodite, exo- 
The axis of the second pair of bænopods is composed of two joints, but we should not agree with Lankester's notation of the joints; the joint marked 1 includes what corresponds to $a x^{1}$ and $a x^{2}$ of the first leg; and his joint $2\left(a x^{2}\right)$ corresponds to $a x^{3}$ and $a x^{4}$ of the first leg; in other words, of the two divisions of the axis of the second leg the first represents the two basal joints of the first leg and the second the third and fourth. So it seems to us the "joints" are more or less arbitrary sui. divisions of the axis, and are not, properly speaking, true joints, hence we would call them pseudo-joints or subjoints.

Beginning with the endites, the first is transformed into a large, broad, thick, squarish lobe, whose inner edge is beset with dense fine, stiff setæ. This is the gnathobase of Lankester, and what we have called the coxal lobe (Plate XIX, fig. 3, elsewhere $c l$, or $l^{1}$ ). The gnathobase of each limb is diverted outward and backward, and thus, with those of the other limbs, forms a long series bordering the median sternal line of the body behind the mouth-parts, and which, as in the Limnadiada, serves to retain the food and to push it toward the month and jaws.

We should not, as Professor Lankester appears to do, say that "a similar feature is characteristic of Limulus." The set of stiff spines in the Merostomata are developed directly upon the coxopodite or basal joint of the limb, which is directly homologous with the coxopodite of a crab, the resemblance to that of Apus is one only of analogy, though a very interesting one; the function, of course, being the same in each.

The succeeding five endites of the first pair of limbs are similar in form, being subjointed, the joints not, however, being complete and not movable upon each other, the sutures marking them only extending part way towards the middle of the process. The third, fourth, and fifth endites, particularly the fifth, are remarkably long and antenniform. The sixth forms a minute pointed scale, whose base is confluent with that of the fifth.

The gill in the Apodide is rather small and pyriform; while the fla. bellum is very simple in form compared with the Limnadiada, but still well provided with muscles, and, as in the latter family, forming the principal swimming as well as respiratory organs. They are triangular, the outer end rounded, the inner pointed and somewhat produced, but there is no such interesting differentiation in form and function as occurs in the Limnadiad flabellum.

Both exites and endites are remarkably persistent in form in the different species and are not of mnch use in taxonomy.

In the larva, $22^{\mathrm{mm}}$ long, of Apus lucasanus, as drawn by Gissler (Plate XXXV, fig. 7), which corresponds well with Claus's drawing of the same stage in Apus cancriformis I have added the references to the pseudo-joints $\left(a x^{1}-a x^{4}\right)$. The gnathobase has two series of spines, the inner short; the sixth endopodite is seen to be very long and slender, while it is minute, short, and broad in the adult. The two spines at the end are noticeable, as there are four small ones in Claus's drawing. The flabellum is very much smaller than in the adult, while the gill is but little larger.

podite, and epipodite, supported on a protopodite or basal division (fig. $63 \mathrm{D}, \mathrm{E}, \mathrm{F}$ ). The latter consists of three joints-a coxopodite produced internally into a strongly setose prominence (not represented in the figures), a basipodite, and an ischiopodite, the latter elongated internally into a lanceolate process, and bearing on its outer side two appendages, of which the proximal-the epipodite or branchia is pyriform and vesicular in specimens preserved in spirits. The distal appendage which appears to represent the exopodite (6) is a large flat plate, provided with long setæo on its margin." Huxley did not find the maxillipedes and second antennæ in Lepidurus glacialis. 
In the second and succeeding thoracic pair of limbs the second to fifth endites are short and nearly equal in size, while the sixth is much larger than in the first pair, being nearly as long as the fifth endite and varying somewhat in the different species. In Lepidurus glacialis it is noticeably slender, as are the exites.

In the male of Apus dispar from the White Nile, the second pair of feet are curiously modified to serve as grasping organs, the notches along the edge of endites $2-5$ being much enlarged so as to aid the animal in retaining its hold of the female.

A more generalized form of the leg is seen in the tenth and several succeeding pairs (Plate XVIII, figs. 1-4; XXI, figs. 1, 3, 4, 5), there being no difference in form between the last thoracic (tenth) and first abdominal (eleventh) legs; except the female eleventh pair and the fact that the eleventh male foot has the genital pore.

The tenth leg of Apus lucasanus, for example (Plate XVIII, fig. 3), or of Lepidurus glacialis (Plate XXI, fig. 1), has a portion or lobe of the axis, which Lankester calls the subapical lobe, which does not even exist in a rudimentary state in the first pair of limbs in A. lucasams; nor does it exist in $A$. cancriformis, and is not to be seen in the larval limbs of A. lucasanus figured by Gissler, nor is it figured by Clans. Lankester regards this lobe as present in the secoud pair of thoracie feet of A. cancriformis and figures it, but states that it "is relatively small." We have not noticed it in the second pair of feet of any species of A pus, but have seen it in the second feet of Lepidurus bilobatus (Plate XVII, fig. 6), where it forms a lobe at the base of the exites.

In the tenth pair of feet of the different species of Apus this lobe becomes a large and prominent expansion situated between the base of the sixth endite and the flabellum. (Plate XVIII, figs. 2, 3, 4, x, and Plate XXI, figs. 1, 4, 5, no lettering.) The importance of this exital lobe becomes apparent when we examine the modified legs of the eleventh pair of the female. The history of this lobe in Apus cancriformis has been well related by Professor Lankester, and an examination of our American species shows that it is developed in all our species of Apus and of Lepidurus, much as he describes in the European Apus.

In the posterior feet this lobe finally becomes obsolete.

Under the rather ponderous name oostegopod, Professor Lankester describes the singular ovisacs or brooding-legs of the female and their mode of origin, with which our own observations on the American Apodides agree. On Plate XVIII, figs. 5, 6, 7; XXI, figs. 2, 6, are shown the forms of the eleventh pair of legs in the female of Apus and Lepidurus. The ovisac as originally shown by Zaddach, and more recently by Lankester, is formed by the great derelopment of the subapical lobe, over which, as Lankester says, "the flabellum fits as a lid." Our lettering on Plate XVIII, fig. 7 , was put on two years ago when making the drawings for the plate, and from hasty examination and overlooking the minute gill, which, however, is figured in this drawing, we supposed, with Gerstaecker, that the sac was formed by the flabellum and gill; but since the plate was figured Lankester's description has been published, and upon re-examination we have found the mouth of the egg-sac* (Plate XXXI, fig. 5, os).

\footnotetext{
* Braver, in 18\%2, in his Beitrage znr Kenntniss der Phyllopoden, gives an account of the mode of copulation in Apus. In the spring of 1871 , a male was discovered among twenty $q$. The male swimming towards a $\rho$ turned under the $q$, placed itself firmly on the dorsal shield of the same, so that the whole body assumed a curved, almost humpbacked, position, and made repeated convulsive eontractions. It then attempted, ly feeling around with the end of its body over the hinder edge of the carapace of the $q$, to reach to it, and then threw several times and very rapidly the
} 
Except the dimmished size of the gill, the only other important modification in the foot is the large triangular sixth endite, which shares in part the enlargement of the subapical lobe.

In the Branchipodida, where the head, thorax, and abdomen are clearly differentiated, all the legs are thoracic, there being no abdominal appendages except the gonopoda and the cercopoda. The legs also differ much more from the two lower Phyllopodous families than those of the members of these two families from each other. The axial relations of the Branchipod limb are much as in the Limnadiade, the axis being not only entirely without any traces of joints, but not differentrated in any such way as in the Apodida from the endites or exites; in this respect the limb corresponds to those of the Limnadiada. The chief difference, however, from the two lower families is the absence of a functional gnathobase. The basal or first endite, as seen in the figures on Plates VIII-XIV, forms a very short and broad unitormly curved lobe with no armature at the base, the edge being uniformly fringed with rery long, delicately setulose setæ; the lobe is weak and only adapted for swimming. By reference to Plate XIV, fig. 4 , it will be seen, as in the genus Thamnocephalus, that the sternal groove along the under side of the body is broad, that the endites on either side are quite remote from each other, so as to be of little use in retaining the food or prey. This figure also shows the relations of the endites to the leg or axis, and of the leg as a whole to the body. The second endite is in general about one-third as wide as the first, while the third and fourth are minute, more or less pointed, and provided with three or four long setulose or ciliated setæ.

The great size and breadth of the fifth and sixth endites constitute a characteristic and diagnostic feature of the family. The fifth is very large and squarish or rounded, and armed on the edge with short remote spines. The sixth is more or less paddle shaped, subtriangular, and provided with a fringe of very long and rather stiff setæ, being well adapted for use in swimming; this lobe, with the fifth, is mainly concerned in locomotion. The two exites, the flabellum and gill, are in this family mnch more alike than in the other two groups. The gill (br) in Artemia, Branchinecta, Branchipus is small, oral in outline, and much as in the Apodida, but in Chirocephalus, and especially in Streptocephalus, it becomes much larger, while in Thamnocephalus it is much like the flabellum $\left(b r^{\prime}\right)$ in size and form as well as in strueture.

It is interesting to observe, from the drawings of Claus and of Gissler, that in the development of the legs in the early larral stages the endites are the first to be developed, the exites not appearing until some time after the six inner lobes are indicated.

The abdomen and the abdominal legs (Uropoda).-These are not present in the Branchipodida, and in the Limnadiade and Apodida they do not

whole of the abdomen not covered by the shield over the edge of the carapace of the female to her ventral side. These motions were wholly similar to those made by the male Branchipus with its body during sexual congress, so that I have no doubt that the smaller individual was the male, and that the whole performance was none other than the fertilization of the gill-foot. The male repeated this act upon all the other females present through a period of several days. Then a pause ensued, whereupon the exhibition began anew.

During the act of copulation the egg-sae of the $q$ came in contact with the 11th feet of the 3 ; but the whole occurrence was so short, the animals going under and turning themselves several times, that it was difficult to give a clear idea of the relation of the body parts to one another.

Throegh a later anatomical examination of the male I found my view completely confirmed. It was filled abundantly with testes-tubes, finger-shaped, the branches filled with seminal cells, as were described by Kozubowski. He then quotes Kozubowski's similar observations on the mode of copulation, from which Brauer's observations differ somewhat. 
differ in any important respect from the thoracic limbs, since the abdomen in these families is not differentiated from the anterior part of the body. Indeed, if an abdominal leg were exhibited to us separately and placed side by side with a thoracic leg, it would be mere guess-work to distinguish them. The only distinction between the two regions, or the so-called abdominal and thoracic legs, is the fact that in the Apodidce the eleventh pair contains the end of the oviduct of the female or vas deferens of the male. In the Apodide the gonopods or ovisac-bearing legs have been described.

Kozubowski has discovered and described the male outlet for the seminal fluid on the eleventh pair of feet of Apus cancriformis. The short vas deferens ends in a minute cup-shaped opening on the gnathobase or coxal lobe of the eleventh pair of feet. (Gerstaecker's Arthropoden.)

The abdominal legs succeeding the eleventh pair lose somewhat of their characteristic features, until the terminal pairs assumea generalized form; the endites, including the gnathobase, being equal in size and appearance except the last (sixth), which differs mainly only in being larger; the gill is small, while the flabellum is in proportion large and orbicular with a few large setulose setæ, instead of the fringe of fine, short, cilia-like setæ edging the exite.

As to Limnetis, Grube states that the narrow opening covered by a rather long lamella in the last three limb-bearing segments of the body may prove to be the male porus genitalis. The eggs are held in place by the ovigers of the last three segments in the female. The upper lobe of the flabellum of the last pair of feet appears, as seen in fig. 4 (in text), to be enlarged and modified to hold the eggs, and I have found the freshly extruded eggs heid by the ovigers of the last three pairs of appendages, so that we may conclude that in Limnetis the last three segments of the body form what we may regard as corresponding to the abdomen, although the distinction is a somewhat arbitrary one.

In reference to the male opening in Estheria nothing is known, as Grube states. He thinks he found the opening of the oviduct of the female at the base of the ninth and tenth pairs of feet. Should the hole he discovered be proved to be the genital pore, then the part posterior to the eighth pair of legs should be regarded as abdominal; and thus, in this respect, the abdomen in its general relations would compare with the abdomen of the Apodida.

Spangenberg has discovered the genital opening in Limnadia. "The position of the [oviger] on the 11th pair of feet, as well as the general agreement in the structure of the Phyllopods, have enabled me to discover the hitherto hopelessly-sought-for sexual opening. It lies, certainly as in Apus, on the basal joint of the 11th pair of feet; but it is very difficult to find if the oviduct is not very full of the shell-forming secretion. Except the lengthening of its gill-appendages (oviger), which it shares with the two feet in front, the 11th foot undergoes no change with the reproductive function."

The last joint of the abdomen (urosome), viz, the telson, is only in one genus produced into a median spine-like process. This is seen in Lepidurus. This spine-like process is seen in the fossil Phyllocarida, and in common in the Malacostracan Crustacea.

The telson itself, particularly the tergal or spinous portion, in Lepidurus, as in Decapods (shrimps, lobsters, etc.), forms the roof or upper wall of the rectum, and may thus be functionally compared with the labrum of the head, which, like the spinous portion of the telson, is a median unpaired process. The cercopoda, on the other hand, may be 
homologized with the antennæ, being true appendages. This is especially seen in the cockroach and in Mantis tessellata (Guide to Study of Insects, p. 17, fig. 23).

The cercopoda.-We would suggest the name cercopoda* for the caudal appendages of the Phyllopoda, which are outgrowths from the telson. There seems to be no such appendages of the telson or anal arthromere in the Malacostracous Crustacea, as the uropoda are developed on the segments anterior to the telson. But when we tarn to the Entomostraca, we see that they occur, as a rule, in all Copepoda, where, in some genera (Pontellina, Zaus, Thalestris), they are two-jointed. These appendages then, in Copepoda, are true jointed appendages, arising from the end of the terminal segment of the urosome, and thus forming the last pair of abdominal appendages. In the order Branchiopoda the cercopods of the Copepoda are represented by the moveable, curved, slender, terminal claw of the telson; and this form persists in the higher Limnadiadce (Plate III, fig. 7; Estheria, Plate XXV, figs. 5, 6), being absent in Limnetis. The long, jointed, strle-like caudal appendages of Apus are also the homologues of the Copepodous cercopoda, as well as of the Limnadiad claw-like appendage. In the larva, as seen by Dr. Gissler's drawings, fig. 8, Plate XXXV, they are short and broad, and their cavity is continuous with the body-cavity. Late in larral life, as seen in fig. 9 of the same plate, a joint appears, and later on in adult life the cercopoda of the Apodida, as seen in Plate XVI, are nearly perfectly jointed, with short, stout setæ arising from the edge of each joint.

In the cercopoda of the Branchiopods we have reprodnced quite exactly those of the Copepoda. So it appears that these appendages are restricted to the Entomostracons Crustacea, although they are also a characteristic feature of the Phyllocarida.

Histology of the postoral appendages. - The male hands of the first pair in Estheria and Limnadia present some peculiarities of interest. The finger-like two-jointed fifth endite of Estheria mexicana (Plate XXV, fig. $\left.3 a, l^{5}\right)$ is traversed by a thick nerve, which appears to originate from a multitude of nerve-cells, almost completely filling the distal joint. The latter when magnified by a Tolles $\frac{1}{5} \mathrm{~A}$ eye-piece (fig. 3 c) is seen to be filled with rather large nerve-cells $(g c)$, which are arranged serially. Between the rows of cells are apparently fine nerve-fibers, which have not been so distinctly indicated by the artist as in my original drawing. These fine fibers appear to arise near the terminal cells $(g c)$ and probably originate in the seven setæe at the end of the joint. It is plain that this endite is the sensitive portion of the hand, though whether it is of any special sense and other than tactile may seem doubtful.

In Estheria compleximanus (Plate XXIX, fig. 5) and in the same joint of the fifth endite of the first pair of hands, when magnified by the same power $\left(\frac{1}{5}\right.$ Tolles $\left.A\right)$, the main nerve is seen to traverse the joint, passing through a great number of very large nerve or ganglion cells (gc), which are not, however, arranged serially as in E. mexicana. The nerve appears to break up into a number of fibers which probably innervate the numerous fine cilia-like setr at the end of the finger-like appendage.

In the first pair of legs of Estheria compleximanus (Plate V,fig. 7) the six th endite is provided with nerve-cells and nerves which supply the setæ, as seen in Plate XXIX, fig. 3. Here the ganglion-cells are contained

* We should also apply this name to the jointed anal stylets of insects such as the cockroach, Mantis, and other Orthoptera and Pseudonouroptera, as well as the dipterous Chrysopila, and numerous other forms. 
in the nerves, $i$. e., forming ganglionic enlargements, while there is a marginal fine nerve which connects the ends of the setal nerves. The structure and arrangement of the nerves in the sixth endite of Estheria appears to be nearly the same as in the Branchipodida, described farther on, and the ganglion-cells are seen to be of the same size, the parts being magnitied with $\frac{1}{5}$ Tolles A eye-piece. Plate XXIX, fig. 4 , represents the end of the oviger of the same leg as fig. 7, Plate V. A ganglion and setal nerve supply each seta, while the main nerre passes through the middle, at $t n$, being reinforced by ganglion-cells ; while at the end are several cells from which a nerve passes into each seta.

In Eulimnadia texana (Plate VII, fig. 2, 2a, 2b) where the fifth endite of the first leg of the male is provided with a minute palpus-like process, which was not observed in Estheria, the histological structure of the second joint is the same, though the nerve-fibers were not so distinct in the specimen examined; Eulimnadia differs, however, in the terminal setæ being coarser and much more numerous.

In the Apodida, from the nature of the dense opaque integument of the appendages, it is probable that no special sense-apparatus is present.

In the delicate swimming thoracic appendages of the Branchipodidee some interesting histological features were observed, especially in legs stained with carmine.

In Branchipus vernalis the edges of the endites are provided with clusters of two or three ganglion-cells which are situated in the margin near the insertion of the setæ. These are noticeable in the fifth endites, but especially so in the paddle-like sixth endite. (Plate XXX, fig. 1.) This tigure is drawn with the camera lncida and shows the relation of the muscles supplying it, and also of the peculiar system of ganglionie nerve-cells and nerves supplying the marginal tactile setæe. The striated muscular fibers are situated in the central portion of the foot (muscle); they suddenly terminate in the manner indicated in the figure, and originate from a median muscle passing out of the axis of the limb; associated with them are irregular groups of ganglion-cells.

The marginal ganglion-cells are arranged in two series: a submarginal set $\left(n c^{1}\right)$ and a marginal set $\left(n c^{2}\right)$. Whether the masses of parenchymatous matter filling the spaces between the two sets is truly nervous matter, or undifferentiated protoplasm, I cannot say, but, judging by fig. 3 , it is probably nervous. At the base of the anterior margin of the endite where the setæ are reduced in size the submarginal series of cells disappear. Toward the posterior margin the setal nerves are seen to enter the setæ from a group of submarginal ganglion-cells. The connection of the submarginal and marginal series of cells and nerves with a main axial nerve of the leg was not observed, though several specimens were examined and search made for it, and hence I am inclined to think that the system of setal nerves and their cells is independent of the central nerve system.

In fig. 2 of the same plate is represented the sixth endite of one of the anterior legs of Streptocephalus texanus, in which there is nearly the same relation of parts as in Branchipus. The axial branches of the two muscles (mus) are seen to be in one case connected with the series of striated mus les in the central area of the endite. No main endital nerve was detected, and here, as in Branchipus, we see the same system of submarginal and marginal nerve-cells, and of setal nerves. The cells, however, are less numerous as seen in fig. 3 , which represents the end of a bundle of striated muscular fibers; also their mode of termination, the space between the ends of the muscular fibers, and the submarginal 
nerre-cells $\left(n c^{1}\right)$. There is in each set but a single submarginal and a marginal nerve-cell $\left(n c^{2}\right)$. The two cells are connected by a broad nervous tract, and beyond the marginal cell the setal nerve continues into the base of the setæ.

In the sixth endite of the first pair of feet of Thamnocephalus platyurus the arrangement of the ganglion-cells differs somewhat from the other Branchipods described. As seen in Plate XXIX, fig. 8, there seems to be no marginal ganglion-cells, but a much larger number of submarginal cells, which are arranged serially, the outer row of the separate nerves forming a quite regular series parallel to the edge of the endite. The tactile nerves $(t n)$ containing these ganglion cells pass into the setæ. There is also to be seen a submarginal row of minute setæ. The same histological nervous structure is seen in one of the smaller endital lobes, $i$. e., the fourth (Plate XXIX, fig. 7). A nerve here evidently leads from the axis of the leg, and enlarges before reaching the large mass of ganglion-cells $(g c)$ from which the setal nerves arise. It will be seen that the ganglion-cells are of the same size and appearance as in the end of the finger of the male of Estheria compleximanus (fig. 5).

The base of the flabellum of Thamnocephelus, as of all the genera in the family, are filled with large cells, rich in fat granules, as seen in Plate XXIX, fig. $8 b$; while the polygonal cuticular cells of the flabellum are represented at fig. 8 a.

\section{NOTES ON THE INTERNAL ANATOMY OF THE PHYLLOPODA.}

It was not the author's design to make a special investigation of the internal anatomy of the Phyllopods, and the following notes on American species should only be regarded as supplementing what has been already published by Zaddach, Grube, and Spangenberg, which we have consulted and of which a résumé will be found in Gerstaecker's Arthropoden.

The general anatomy of Limnetis observed in $L$. gouldii while alive does not differ in any important respect from that of Limnetis brachyura, well figured by Grube, whose figure I have reproduced on Plate XXXI, figs. 6-8. The form and topographical relations of the digestive canal with the liver, and of the heart are the same in our species as Grube represents.

Uur fig. 6 on Plate XXVI represents the structure of an ovarian lobe of Limnetis gouldii. The mass is filled with ovarian nucleated cells.

The digestive system.-An undeviating characteristic of the Phyllopods is the relation of the liver to the stomach and the peculiar way in which it is packed away in the head-cavity, enreloping the brain and filling the frontal cavity of the Limnadiada and of Apodida. The only other Crustacean except the Branchipods which have this characteristic is Limulus, and in this respect this animal closely resembles the Phyllopods.

In Limnetis the mouth (Plate XXXI, figs. 6,8 ) is situated between the mandibles, as seen in our copy of Grube's figure, and the duct of the liver (Fig. 8, liv.) is seen to enter the digestive tract very near the short œsophagus.

In Estheria mexicana Plate XXXIII, fig. 2, shows the relation of the lobes of the liver to the common duct, and the connection of the latter with the rather large stomach. The cavity of the head is capacious, and filled with the convoluted lobules of the liver, of which transverse and longitudinal sections are shown in the figure. Fig. $2 a$ is a still 
more enlarged view of one of the lobules, there being a single layer of secreting nucleated cells.

The relations and cellular structure of the œsophagus of the same species are seen in figs. 1, 4, oes, and $4 a$. A section of the œsophagus where the microtome passes throngh the brain and larval ocellus shows that the walls of the œsophagus are formed above of two layers of epithelium and beneath of three or four, the serial arrangement of the cells below not being so marked as above.

In Fig. 1 we see that the razor passed throngh the œsophagus and the intestine, the section being oblique, and the digestive canal curving considerably in the front part of the body, so that it is cut through twice. The comparative size and general relations of the intestine to the other viscera are seen in figs. 9 and 10 of Plate XXIV.

In the Apodida, as seen in Plate XXXII, figs. 1 and 2 , the mouth is situated between the mandibles. The csophagus is narrow and very oblique, while the rest of the digestive canal is large and of quite uniform thickness. The cavity in fig. 1 is the body cavity, after the digestive canal has been removed; but that its body-cavity is completely filled by the digestive canal is seen in fig. 2 int. The intestine gradually contracts towards the narrow rectum, the anus $($ an $)$ being small and situated rather dorsally than ventrally, as in most, if not all, Anthropoda, and opening between the bases of the cercopods.

In living examples of Artemia gracilis (Plate XXIII, figs. 1, 2), the œsophagus is very short, while the stomach is situated in the head. The stomach is apparently divided by a medio-longitudinal constriction into two large sacks or pouches, these being the ducts to the liver, which has a few short lobules, the liver being much less voluminous in the Branchipodida than in the two lower families.

The intestine we regard as that portion lying behind the liver. It is divided into two portions, one in the head and thorax (bænosome), and the other in the urosome. The anterior or cephalothoracic portion is a large, straight tube with thin walls, and is of nearly the same thickness throughout its length (fig. 2 int). It contracts at the base of the urosome and forms a slender tube one-half the diameter of the anterior portion (fig. 3 , int), ending in a well marked rectum (rec), which is provided with constricting eirenlar museles, and held in place by three sets of slight muscular threads $(m)$. It does not contraet at the vent.

The ovaries. - The relation of the genital glands, particularly the ovaries, are seen in Plate XXXI, fig. 7 (Limnetis after Grube); those of Estheria mexicana in Plate XXXIII, figs. 1 and 6. The ovary in Limnadiada forms a rather large mass, situated in the body behind the head. Fig. 6, Plate XXXIII, represents a portion of the ovary of Estheria mexicana, showing the epithelial or ovarian cells $(e p)$ and the developing egg. It forms a compact mass, situated on each side and below the intestine. The ovary in Apus lucasanus (Plate XXXII, fig. 1 ov and $2 o v$ ) forms a loose mass, extending from the region over the mouth to the last pair of uropoda. Its general appearance and histology is well shown in the figures of Siebold in his work on parthenogenesis in Arthropoda (Taf. II).

When we ascend to the more specialized Branchipodidee we see that the genital glands are restricted to a special sac, which grows from the under side of the basal uromere. We have nothing new to add to the descriptions already given by European authors. Plate XXII, figs. 2, $2 a, 2 b, 3,4,4 a$, from drawings by Dr. Gissler and myself, give the general relations of parts in Artemia gracilis and Branchipus vernalis, and for particulars regarding certain points the reader is referred to Dr. Gissler's 
remarks further on, and to the explanation of the plate. In fig. 2 (Artemia, drawn from living specimens) the ovaries are without any ovarian eggs, the cells representing simply the epithelium. The ovary sends two slender attachments into the last bænomere, and two larger tubular prolongations into the second and third uromere. The oviducts (e) are just large enough to contain a single egg (Fig. $2 b$, egg) at one time. The glandular cells secreting the chorion are represented at $2 a$ and $2 b, e c$. They are about $\frac{1}{5}-\frac{1}{6}$ the diameter of the mature egg, and have a very distinct nucleus.

The heart.-In the Limnadiade the heart of Limnetis is a short, thick tube, as represented by Grube (see our Plate XXXI, fig. $6, h t$ ), and does not extend far back in the body. In the section of Estheria mexicana (Plate XXIV, fig. 9), which passes through the antennæ, the heart is seen to be present, but in E. compleximanus, fig. 10, it does not appear to reach far behind the anterior pairs of bænopods.

In Apus the heart has been figured and described by Zaddach, our fig. 6, Plate XXXII, being copied from his work, and in our fig. 1 the heart is represented diagrammatically, the drawing not being strictly accurate in some respects. The size of the heart of Apus lucasanus in reIation to that of the intestine is seen in fig. 2, which is a camera drawing. The walls are thick and muscular.

In the Branchipodida the heart is much larger than in the Apodida, as seen in Plate XXIII, figs. 2, 3, 3a, and 4, drawn with the camera from living specimens of Artemia gracilis. The heart extends from a point just below the mandibles, and extends as a long, slender tube to the middle of the terminal uromere. In fig. 2 the anterior end of the heart is represented conjecturally, as we conld not see the exact mode of termination or the origin of the arteries; $*$ but the valve at the pos. terior end was readily made out as at $3, h t$, and $3 a$, where a treble valvular arrangement allows the blood to enter, and is closed at the time of contraction of the heart. Two lateral arteries are sent off to the shell-gland, and there is a median notch or ostium in front. The lateral valvular openings are more numerous in front than at the end, as the last pair of valvular openings is situated a long distance from the end of the heart, as seen in fig. 3. As seen in fig. 4, the heart is loosely held in place by slight muscular bands $(m)$, and along the onter walls of the heart are scattered rounded epithelial cells (ep. $c$ ). The valvular openings, indicated in the figures by the arrows, are arranged alternately. The size of the blood-corpuscles, which are colorless, is shown in the figure. The blood flows into the heart through the valvular openings, and is pumped out of the anterior end and passes into the head by two currents, while a current on each side passes backward, thus indicating the existence of two anterior arteries and a pair extending downward and backward. The circulation in the eye is readily observed, and is indicated by the bloodcorpuscles and arrows in fig. 6 . The mode of circulation in one of the feet is illustrated by the blood-corpuscles and arrows in fig. 7 (Pl. XXIII). The blood flows directly toward the end of the sixth endite, while a portion passes around the edge of the gill; the circulation is more active in the gill proper than in the flabellum. The blood passing into the sixth endite along the upper side, returns by the lower edge: a current, entering the fifth endite, passes along the upper and returns by the lower edge; a current also enters the basal endites. Each

* The anterior end of the heart in the young Apus is well shown by Claus in fig. 6 , Taf. VIII, of his elaborate memoir. 
endite has its distinct blood passage, and thus respiration takes place all th rough the appendage.

The nervous system.- The nervous system is quite uniform in the Phyllopods, and that of Limnetis has been described by Grube, that of Limnadia by Klunzinger,* and more lately by Spangenberg, and that of Apus by Zaddach, while the brain and nervous cord of the young Branchipus stagnalis has been figured and described by Claus.

Our Plate XXXI, fig. 8, copied from Grube's drawings, illustrates the nature of the brain and nervous cord of the European Limnetis brachyura. The brain is very small, forming a single flattened mass from which the large optic nerves arise. The first antennal nerves arise from the beginning of the commissure, which forms an œsophageal ring, and the second antennal nerve arises opposite the transverse commissure, which com pletes the œsophageal riug behind. Then succeed the peculiar ladder-like ganglionated ventral cord; from the two anterior ganglia arise respectively the mandibular and maxillary nerves, the third pair of ganglia supplying the first bænopods.

The anatomy of the nervous system of Limnadia hermanni has been fully described by Spangenberg, $\dagger$ but unfortunately he has given no illustrations. The following account is translated from his paper:

"The nervous system of Limnadia shows the greatest agreement with that of Apus. It has a primitive, embryonal character, as that of Apus. This is seen in the ganglions of the second antennæ. These are in most Crustacea united in a common mass with the brain. In Limnadia not only the ganglion-swelling, but also the two trausverse commissures uniting them preserve their original form, and the ganglion pair of the second segment differ here in no important point from that of the other segments, except in the lip-commissure springing from it. There also remain the ganglia of the ventral cord in the last body segment, both longitudinally and transversely well separated from each other, while in Branchipus and Artemia they are not more perfected, lut in Apus suffer a widespread consolidation.

"The central nervous system of Limnadia consists, as that of all Phyl. lopods, of a two-lobed supraœsophageal ganglion before the csophagusscarcely properly called a brain-and right behind the oesoplagus, between the digestive canal and floor of the body a ladder-like ventral chain of 26 ganglia, the tail segment being without a ganglion.

"Brain.-The supraœesophageal ganglion consists of two spindleshaped lateral lobes and one unpaired median section. All these possess their own centers and send ont the nerves originating from them. Such centers are five in all, fonr arranged in pairs in the lateral lobes, the fifth unpaired in the middle lobe.

"Of the two paired centers the foremost is by far the largest; it serves as the central organ for the optic nerve, the eye-muscle nerves, and furnishes the nervous tract reaching to the so-called larval eye. The smaller, situated somewhat farther behind, lying under and external, sends fibers to the first antennal nerve. What significance the beanshaped central body of the middle lobe, met with in all Phyllopods, has is not elear to me. It lies perpendicular to the longer axis of the animal in the hinder third of the middle lobe between the commissural threads passing from one lateral lobe to the other. From all sides pass curved nerve-fibers into it, which are variously covered and intertangled with one another. It consists quite unlike the paired centers of large ganglion-cells, but solely of the so-called Leydig's punctsubstanz, a confused mass of the finest fibers variously matted together. Whether,

\footnotetext{
* See his figure in Sieb. u. Köll. Zeits. w. Zool. XIV, Taf, XIX, fig. 26.
}

$\nmid$ Zeitschrift für wissensch. Zoologie. Supp. 1878. 
however, nucleus.like bodies occur on the points of intersection, I have not yet been able to discover. In the profile view of the animal the central body appears exactly as in the Daphnida, in the form of a clear ronnd vesicle in the feeble (matten) brain-substance, and can thus give ready opportunity for illusion. An independent vesicle, such as Claus describes in Daphnia magna, I have not seen here.

"From the lateral lobes of the supracsophageal ganglion arise the following 5 nerve-pairs:

"1. The large optic nerve.

"2. Several nerve-twigs to the eye-muscles.

"3. A slender fiber on each side to the frontal organ.

"4. First antennal nerve.

"5. The 'hirnschenkel.'

"From the middle division arise only 3 paired and an unpaired nerve, viz:

"6. An at least externally unpaired nerve, and

"7. A paired nerve-stem, both to the so-called larval eye.

"8. An outermost fine fiber on each side, which arises laterally from the seventh pair, and goes above and outside of it.

"9. A slenter pair of nerves to the osophageal museulature.

"Of these nerves Zaddach (Apus) knew only those mentioned under 1, $4,5,7$, and 9, but as they occur also in Branchipus as well as in several Cladocera investigated by me, there can be no doubt that they are present also in Apus, and were overlooked by him."

Spangenberg then describes the ganglion opticum and eye.

Ventral ganglion chain.-The second cephalic or first ventral pair of ganglia, which lie on the side of the osophagus, are the second antennal ganglia. This ganglion, and the $2 d$ antennal nerve which arises from it, is figured by Klunzinger.

Then follows the mandibular and then the maxillary ganglia. These are succeeded by 22 pairs of ganglia.

There is probably no essential difference between the nerrous system of Estheria and Limnadia. From a number of sections of Estheria mexicana kindly made for us by Mr. N. N. Mason, we have drawn figures $1,2,4$, and 5 , Pl. XXXIII, which partly illustrate some points in the structure of the nervous system. Fig. 2 represents a section which evidently passed through the brain $(b r)$. It is seen to be a donble ganglion, with the hemispheres more distinctly marked than in Grube's representation of that of Limnetis. Fig. 1 and the enlarged view, Fig. 4, passes through a ganglion, which we take to be the brain. The section must have been very oblique, as the œsophagus is seen to appear as if situated above the brain. The section passes throngh the larval ocellus, whose cones and pigment mass have still survived, though sunk out of sight under the integument.

Fig. 5 represents a ganglion posterior to the maxillary ganglion, and probably supplying the nerres to the first pair of feet, and situated directly under the intestine, the epithelium of which is shown in the figure. The histological structure is seen to be very simple. The ganglion consists of scattered ganglion-cells and fine granules, which may be the ends of fibers, but no distinct fibrous structure was to be detected. The brain, fig. $4 \mathrm{br}$, and fig. $2 \mathrm{br}$, is apparently no more complex in its histological structure than the ventral ganglia.

A good deal of time was given to attempts to work out the nature of the brain, but though Mr. Mason very kindly made sections of a nnmber of specimens of Estheria, Apus, and different fresh Branchipodida, yet owing to the inherent difficulties in the nature of the investigation very 
poor success attended our efforts. The brain lies, as seen in fig. 2 , in the midst of the liver, and in the process of cutting through the head the brain slips aside from or crumbles before the edge of the razor. Of course the only proper way is to remove the brain from the living animal and properly prepare it for the mierotome; but this is next to impossible owing to its small size. Indeed, the difficulties in the way of making a good dissection of the brain of these creatures, particularly Apus, are very great. After working for some time at the brain of well-preserved Apus lucasanus, we were able to satisfy ourself that the drawings and descriptions of Zaddach in his elassical work on Apus cancriformis are correct, although his drawing of the entire ventral chain (his Tab. III, fig. 1) might be improved; his representations of the brain are undoubtedly correct enough for all practical purposes, and we have copied in Plate XXXII three of his excellent figures. The figure of the entire nervons system of Apus lucasanus (Plate XXXII, fig. 1) was drawn by Mr. Kingsley, and adopted with some important corrections in the position and form of the brain. The sketch is necessarily in part diagrammatic, and no nerres te the appendages are represented. As seen in the copies of Zaddach's figures the brain is small, situated right under the compound eyes, and it innervates only the simple eye or ocellus and the compound eyes. The nerves to the two pairs of antennæ, fig. 5 $\left(a n t^{1}, a n t^{2}\right)$, arise from the commissures, and not from the supracsophageal ganglion. The rest of the nervous cord is ladder-like.

In the Branchipodidee the nervous system shares with the other systems of organs in a general advance to a higher plane of organization. According to Clans excellent figures of the brain, especially of the very young Branchipus stagnalis, the nerves to the first and second antennio arise from groups of ganglion-cells situated on the outside of the commissures, the ocellus and two stalked eyes being innervated from the brain as in all other Phyllopods, and it will probably be found that in the early stages the commissures are provided with ganglionic enlargements from which the appendages of the head are innervated; thus there may be a slight resemblance in this respect to the ganglionic cesophageal ring of Limulus.

We have, then, in the subøsophageal ganglion of all the Phyllopods a simple, small ganglion, no more differentiated than those forming a part of the ventral cord. Plate XXIII, fig. 1, gives a vertical view of the brain of the adult Artemia, which is nearly continnous with the optic ganglion. On Plate XXXIII, fig. 8, is represented a section of the small brain of Branchipus vernalis. It is very simple in structure, the ganglion cells small, scattered, and indistinct. Fig. $8 a$ shows the ganglion cells enlarged. No fibers appear, though more careful observations than I was able to make are needed before we can have a complete knowledge of the brain of the supracesophageal ganglion in the Phyllopods.

For the structure of the abdominal portion of the nervous cord the reader is referred to Leydig's account and his figure in Tafeln zur Verg. Anatomie, Taf. V, fig. $\tilde{5}$.

It is apparent, however, that in the Phyllopoda the brain is a very simple affair, and not much higher in complication of strncture than the brain of worms, and when we compare it with the brain of the Decapods, or at least that of the crayfish and lobster, these alone having been studied, we are comparing two very different organs. The brain of the Decapoda is an aggregate of at least two pairs of ganglia besides the primitive pair innervating the eyes. The extreme degree of cephalization. by which the head becomes more compact and homogeneous, has had its resultant effect upon the primitive brain and the ganglia behind 
it, and thus the brain of the shrimp or crab represents the brain of the Phyllopod plus the osophageal ring of the latter. We have seen that in the larval Branchipus the two pairs of antennal nerves actually do arise from masses of ganglion cells. These two masses may form the two pairs of antennal lobes in the Decapodous brain, which is therefore probably an aggregate of three pairs of ganglia.

The brain of the Phyllopods is more primitive than in the Cladocera. Clans"* figures of the brain of Daphnia magna show that the first antennal nerves arise from the brain, while the second antennal nerves arise some distance back from the succeeding pair of ganglia.

In the Calanida there is a distinct brain from which arises the first antennal nerves, while in the Corycceida the ventral cord is fused with the brain.

It will thus be seen that the Phyllopods possess the simplest, most primitive form of brain, characterized by the lack of antennal nerves. If we were to confine ourselves simply to the Apodida and Branchi. podides, in which the body is much elongated, we should attribute the want of concentration of the brain peculiar to the Phyllopods as due to the elongation of the body and to the exceptional number of arthromeres composing the body, but we see the same structure and form of the brain in Limnetis, the most generalized form in the suborder, where the body in lack of differentiation approaches the Cladocera. Hence the nerrous system of the Phyllopods does not seem to have been borrowed from the Crustacea standing below them.

The brain of the Apodide is called by Lankester, in his paper on Apus, an archicerebrum, while the composite brain of "all Crustacea, excepting Apus, and possibly some other Phyllopods," he denominates a syncerebrum. As to the nature of the brain of Limulus, Professor Lankester states that "the only other case amongst adult Arthropods, in which it appears with certainty that the so-called cerebral ganglion is a pure archi-cerebrum, is that of Limulus," although he adds (p. 375), "I should wish, however, to guard against the inference that I consider any close affinity to obtain between Apus and Limulus."

We are disposed to agree with the view that the brain of Limulus is a genuine archi-cerebrum, comparable with that of the Phyllopods, and regard this as corroborative proof that Limulus is a Crustacean rather than an Arachnidan, no true arehi-cerebrum being known to exist in adult Arachnida. Furthermore, in the esophageal ring of Limulus, which is fundamentally made up of ganglia with cross-commissures, it appears to us that we have a parallel to the ladder-like arrangement of the postoral head-ganglia of the Phyllopods.

The histological structure of the arehi-cerebrum of Limulus is more complicated than in that of the Phyllopods, which, so far as we have been able to see, is slightly more complicated than the brain of the Chætoporls, judging by Leydig's excellent figures (Taf. IV).

The following provisional grouping of Crustacean brains appears to be justified by known facts, although, except the brain of Decapoda and Limulus, no special histological work has been accomplished:

$$
\text { Syncerebrum }\left\{\begin{array}{l}
\text { Decapoda. } \\
\text { Tetradecapoda. } \\
\text { Phyllocarida. } \\
\text { Cladocera. } \\
\text { Entomostraca. } \\
\text { Cirripedia. }
\end{array}\right.
$$

*Zur Kenntniss der Organization und des feinern Baues der Daphniden und verwandter Cladoceren. Von C. Claus. Zeit. wissen. Zool. XXVII, 1876, 36\%, Taf. XXVI, figs. $8-10$. 
Archicerebrum $\left\{\begin{array}{l}\text { Phyllopoda. } \\ \text { Merostomata (Limulus). }\end{array}\right.$

The syncerebrum of the Tetradecapoda (Amphipoda and Isopoda), judging by Leydig's figures ${ }^{1}$ and our own observations (from dissections made by Mr. J. S. Kingsley) on that of Idotæa and Serolis ${ }^{2}$, is built on a different plan from that of the Decapoda. The syncerebrum of the Phyllocarida is somewhat like that of the Cladocera and Copepoda (Calanidx); being essentially different from that of the majority of the Malacostracous Crustacea.

The Copepodous sfncerebrum is an unstable, highly variable organ, but on the whole belongs to a different category from the syncerebrum of other Neocarida.

We have then, probably, three types of syncerebra and two types of archicerebra among existing Crustacea.

\section{HOMOLOGIES OF THE CRUSTACEAN LIMB.}

Comparison with limbs of Cladocera.-We should naturally first compare the appendages of ihe Phyllopodis with the members of their own

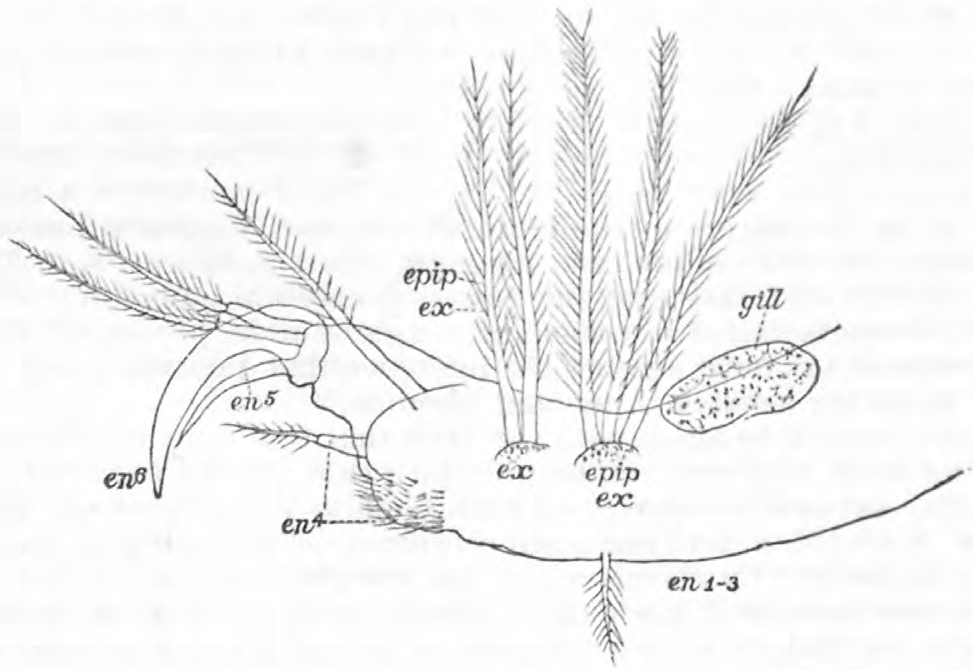

Fig, 27.-First leg of male of Moina (for comparison with that of male Limnetis) : ex, exite; epip, epipodal portion of limb; en $4-e n^{6}$, endites 4-6, to compare with the endites forming the hand of the male Limuetis. The base of the endopodal region (en 1-3) not differentiated as in the rhyllopod limb.

order, and especially the Cladocera; and here, whether we consider the carapace-valves, the eyes single and compound, the two pairs of antennæ, or the telson, we find a very close connection in form between Limnetis and Daphnia or Moina. In the accompanying figure from Grube's and Weismann's excellent paper on the Daphnidæ3 (which we have slightly modified, introducing dots in the branchial portion) may be seen how nearly the first leg of the male of Moina rectirostris agrees with that of the male Limnetis, as seen in the sixth endite forming a claw like that of Limnetis, although the flabellum is not clearly dif-

${ }^{1}$ Tafeln zur Vergleichenden Anatomie. Von F. Leydig. Tubingen, 1864.

${ }^{2}$ Zoology for High Schools and Colleges, figs. 255, 256 .

${ }^{3}$ Ueber einiger neue oder unvollkommen gekannte Daphniden. 1877. 
ferentiated from the endopodal portion of the limb. But when we look at the third pair of limbs of the female of the same Cladoceran (fig. 28), we find an epipodal portion (flabellum [ex.] and gill) differentiated from the endopodal portion of the limbs. The endopodal

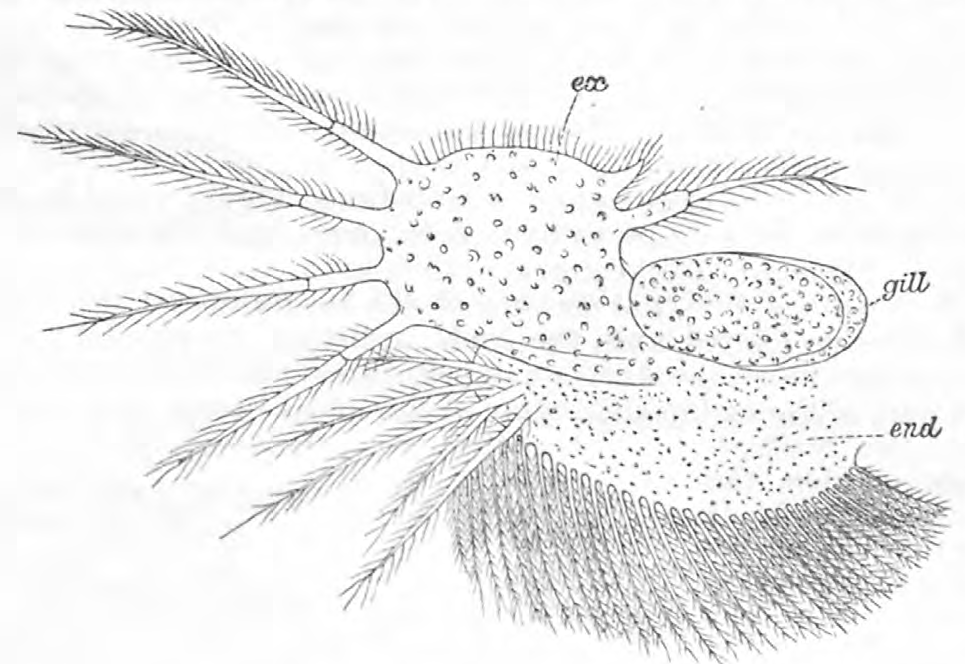

FIG. 28. - One of the third pair of limbs of Moina: end, the endopodal portion; ex, the exopodal (epipodal) portion of the limb.

portion in the Cladocera is not differentiated, not forming a number of well-marked lobes or endites, as in the Phyllopoda, this differentiation into six endopodal lobes being peculiar to the Phyllopoda.

The Cladocerous limb is intermediate in form and complication between the Phyllopodous and Ostracodous limbs, and the latter are evidently derived from the Copepods, so that there is a continuous ascending series from the Copepoda through the Ostracoda to the Cladocera, and thence to the Phyllopoda. Hence, as the young of the Copepoda are all Nauplii, and also those of the Phyllopoda, it follows that the ancestral form of all the Entomostracous Crustacea, as originally insisted on by Fritz Müller (Für Darwin), was a nauplius like animal.

Comparison with the Decapodous limbs.*-Having studied the homologies of the Phyllopodous limbs among themselves, and also compared them with those of the Cladocera and Ostracodes, it remains now to compare the thoracic appendages of the Phyllopods with those of the adult Decapoda. At the outset, however, it seems nearly impossible to compare the swimming legs of the Phyllopods with the abdominal and thoracic appendages of Decapods. The thoracic Decapodous legs are axially jointed, consisting of an axis or protopodite, which is wanting in the Phyllopoda and all lower Crustacea, with no endital lobes as in Phyllopods, though the gill and flabellum of the Phyllopods are homologous with the gills and flabellum of the Decapod. There is no such relation or close resemblance as to lead us to infer that as regards the nature of the thoracic and abdominal feet the Decapods have descended from the Phyllopods. The Decapods have probably come down to us by a different branch of the Crustacean ancestral tree, and have arisen entirely independently of the Phyllopodous branch, by a line leading

* In comparison with those of the Nebalia, the reader is referred to the last chapter on Phyllocarida. 
back directly to the ancestral Nauplius, the common ancestor of all the Neocarida.

Nor does it seem to us that this statement or hypothesis is weakened when we consider the resemblances between the thoracic feet of the Phyllopods and the maxillæ and maxillipedes of the Decapoda. When we compare the leg of a Phyllopod with the second maxillæ* of the lobster or cray-fish, we can detect a close homology, the chief difference being in the fact that the lobes of the endopodite are less numerous in the Decapod than in the Phyllopod. This close resemblance is based on the fact, which appears to have been over-

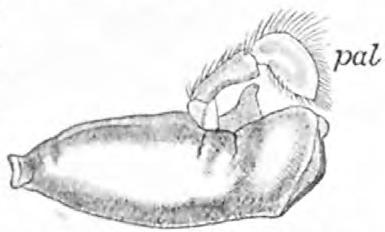
looked by Claus and Lankester, i. e., that, as in Frs. 29.-Mandible of the lobster, the Phyllopodous limb, the maxillæ of the De-Homarus americanus: pal, palpus. capods have no jointed axis, the limb consisting of epipodal and endopodal portions alone, the stem or axis being wanting. In the maxillipedes, where part of the endopodal region of the limbs becomes, as Lankester claims, two multiarticulate endites, the tifth and sixth; or, as in the thoracic leg, becomes a single serenjointed endite, the homologies cannot with certainty be traced. The lobster's thoracic leg consists of the jointed axis which is the homofab, flabellum. B. second maxilla of lobstur: bp, basipodite (epigna. logue of perhaps the thus): cxp, coxopodite. (This appendage, with its five endopodal lobes, fifth endite of the approsimates nearest to the Phyllopod limb.)

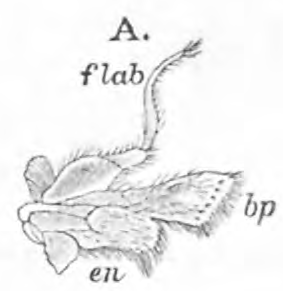

B.

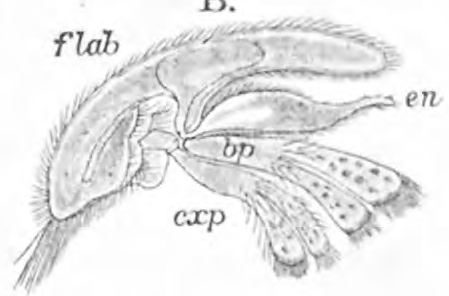

Phyllopodous foot, and the complicated gills and gill-fan (seaphogna. thite) correspond to the gill and flabellum of the Phyllopodous leg or flabellum.

In brief the maxillæ of the Deeapoda most closely resemble the leg of Phyllopods. The maxillipedes, for example those of the third pair, are much more differentiated than the

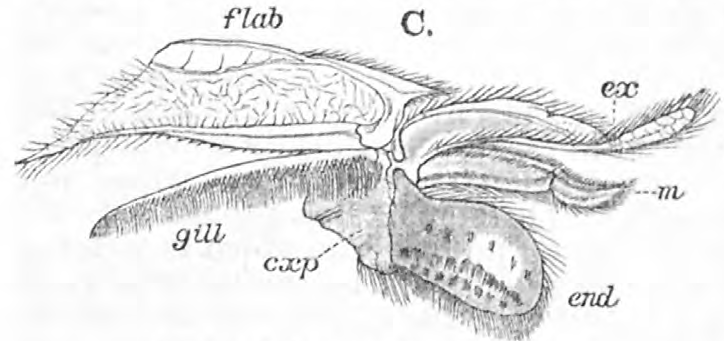

FIG. 31.-C, first maxillipede of louster.

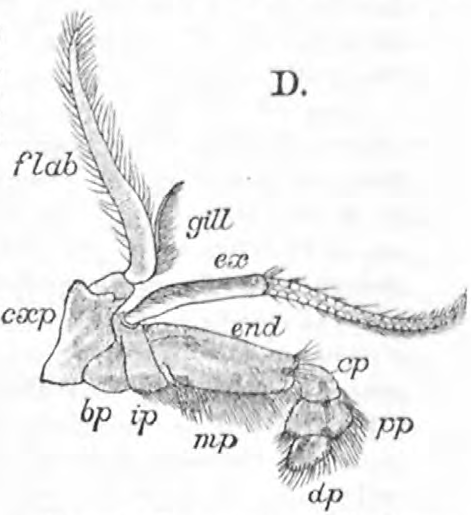

FIG. 32.-D, second maxillipede: $e x$, exopodite; end, endopodite; flab, epipodite or flabellum, or seaptogathite.

limbs of the Phyllocarida or Phyllopoda. In the Decapoda the gill and flabellum are homologous with those of the groups just enumerated;

* The resemblance to the second maxillo of the young lobster in its first stage when freshly hatched is still more striking. See Smith's Early Stages of the American Lobster, Pl. XVI, fig. 4. 
while the endopodite and exopodite of the Decapoda represent the endopodal portion of the limb of the lower groups. There is in the Phyllopoda no division into a coxopodite and hasipodite or stalk, from which two axially jointed divisions branch off, homologous with the exopodite and endopodite of the Decapoda. In the latter the max.

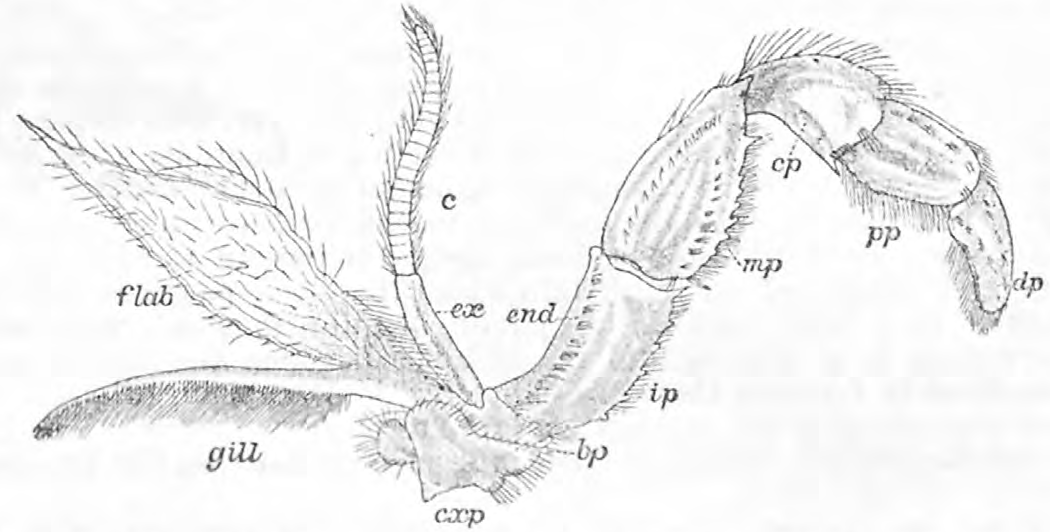

FIG, 23.-B, third maxillipede; cxp, coxopodite; $b p$, basipodite; ip, ischiopodite; mp, meropodite; $c p$. carpopodite; $p p$, propodite; $d p$, dactylopodite; $c$, multiarticulate extremity of exopodite or palpus; Nab, epipodite.

Nojk. - The maxille and maxillipedes of the lobster are drawn in their natural position; so fur as possible the exopodal portion (gill and flabellum) dorsal, and the endopodal portion ventral to compare with the Phyllopod limbs. (Compare Plates xxiv and xxxil and Fig. 34. Apus.)

illipede is highly differentiated; in the thoracie limbs of the Phyllocarida and Merostomata it is miaxial and jointed, but in the Phyllopoda not truly jointed. In the simplest Decapod limb, that of the abdomen, we have a stem succeeded by two divisions, the exopodite and endopodite; in the thoracic feet we have but one of these branches, the endopodite, while in the maxillipedes, the most differentiated, we again have a stem and two branches (endopodite and exopodite), together with the gill and flabellum. Thus the entire leg of the Phyllopod (without the gill and flabellum) is homologous with the endopodite of the Decapod maxillipede, and the gill and flabellum with those of the Decapoda.

Comparison with the thoracie limbs of Nebalia (Phyllocarida). - Not to enter into detail, by a glance at the accompanying figure (36) and the figures in Plate XXXVII, as well as the wood-cuts in section VII, it will be seen that the thoracic appendages of Nebalia consist of an inner axial, jointed portion (the endopodite), which may perhaps be regarded as homologous with the endopodite of the Decapod maxillipede, and also with the thoracie legs of the lobster. This also corresponds to the endopodal unjointed portion of the Phyllopod thoracic limb. In the exopodal or respiratory portion $(e x)$ the upper part corresponds to the Phyllopod gill, and the double lower portion to the flabellum.

Comparison with the feet of Limulus (Merostomata). - The resemblance between the abdominal legs of Limulus and the thoracic ones of Nebalia is apparent on inspection of figs. 36 and 37 (p.409). In Limulus the shell flares out widely and the appendages are mited in the middle, although separate in embryonic life, so that this is a feature of secondary import. ance. The point of special interest is that the abdominal feet of Limulus may, as in the thoracic appendages of the Phyllopoda and of the Phyllocarida, or the maxillæ, maxillipedes, and thoracic feet of the Decapoda, be divided into an inner endopodal portion (whether ambulatory or natatory), 
and an outer or respiratory portion, as in Nebalia and Decapoda. The endopodite of Limulus (en) is axially jointed, there being three wellmarked joints to this part of the limb. The branchiate portion of the limb $(e x)$ is homologous with that of Nebalia, and the epipodital or branchiate portion of the Decapod thoracic limb. At the same time that of Limulus presents some remarkable peculiarities, $i$. e., the exopodal (or epipodital) portion is jointed; and the gill, instead of being a simple fan-like extension, as in the Phyllopoda and Phyllocarida, is replaced by a number of flat, thin gill-plates, arranged parallel to each other, in an antero-posterior sense. When, however, we compare the gill, or rather the epipodital portion of the leg of Limulus, with that of the lobster we have the various fundamental elements, i. e., an artery and a vein passing into the foot and in connection with a number of gill-plates. In the lobster we have along the base of the gill (fig. 33) collective veins and an artery into which the blood passes after being aerated in a large number of cylindrical gill-filaments. Morphologically there is a fundamental resemblance between the two types of branchiæ; in Limulus there are gill-plates, in Decapods gill-filaments, each presenting in the aggregate a large respiratory surface. The gills of the Isopoda are in some degree intermediate between the Decapods and the Merostomata.

When we compare the anterior or cephalic appendages with the thoracie appendages of the lobster, there is a close resemblance in the axially-jointed endoporlite (fig. 38, end) of Limulus with its large terminal claw to the foot of the Decapod. The absence of the gill or branchiate (epipodital) portion in Limulus is correlated with the ambulatory nature of its anterior or cephalic appendages.

In the trilobites, however, as may be seen by Mr. Walcott's able restoration (fig. 40), we have attached to the thoracic ambulatory feet a respiratory epipodital portion. In some respects, then, in the trilobites we have a style of structure intermediate between the Merosto. mata and the Decapoda.

In the trilobite we apparently have, besides a true-jointed locomotive endopodite (fig. 40,en), an inner jointed appendage $\left(e n^{\prime}\right)$, which may be homologized with the exopodite of the Decapod maxillipede (fig. 33). From near its base arises the two singular spiral gills, which are nnique. It is to be observed that the two jointed appendages and the stem of the gills arise from what appears to be a true coxopodite, and that this coxopodite is apparently homologous with that of Limulus (fig. 38). It thus appears that a study of the general internal anatomy and of the appendages of the normal, recent Crustacea (Neocarida) throws light upon the structure of the archaic Crustacea (Palcocarides), and that the most archaic Neocarida, the Phyllocarida (Nebalia), as regards their thoracic limbs, do not remotely resemble the abdominal limbs of Limulus. In this connection we would draw attention to fig. 39 , which is designed to show the possible relations between Limulus and Calymene or the Merostomata and the Trilobita. The essential difference is in the nature of the limbs; the thoracic limbs of the trilobite, while having a jointed endopodite as in Limulus, also having an exopodite and a forked spiral gill. Now, if we append to the coxopodite of Limulus an exopodite, and instead of having the gills arranged anteroposteriorly, like the leaves of a book, have them arranged on one side (the outer) of a more or less cylindrical epipodite, as we have drawn them in fig. 39, we shall hardly be doing greater violence to nature than we see to occur in any Decapod, where, as may be seen in fig. 35 of the lobster, the maxillø have no specialized exopodite, such 


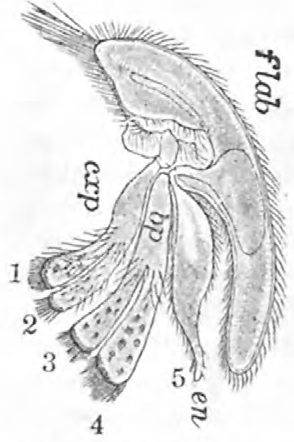

FIg. 35.-Maxilla of lobster, with its five lobes (1-5) corresponding to the endites of the Phyllopod thoracic limb.

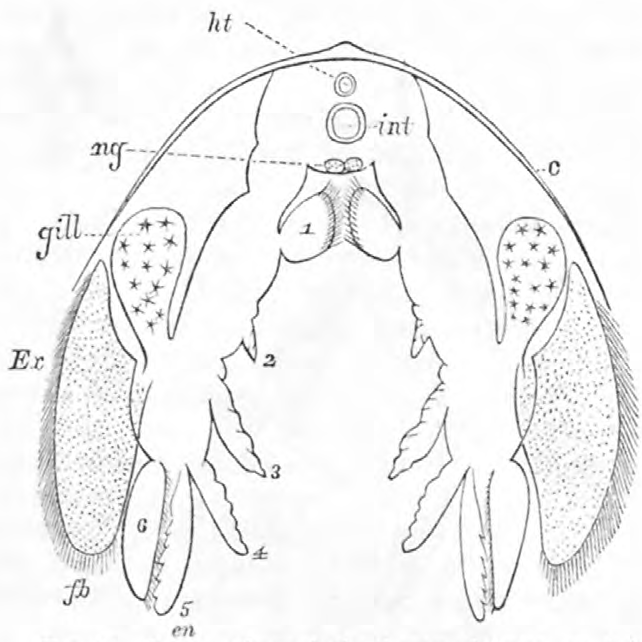

Fyc. 34,-Section through the thorax of Apus: en, 1-6. the six endites; ex, exopodal or respiratory portion of the limb; $c$, carapace.

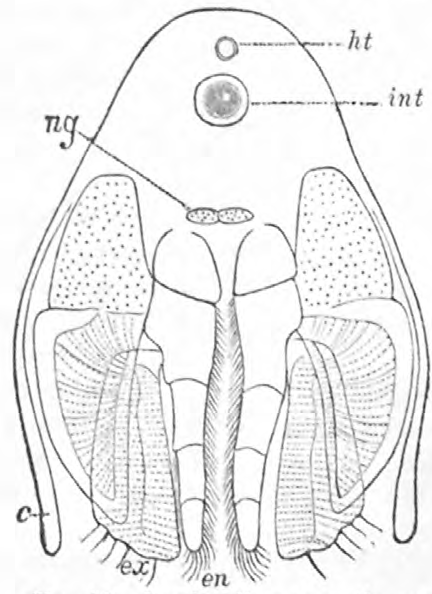

Fig. 36.-Partly diagrammatic section through the thorax of Nebalia: en, the axial-jointed endopodite; ex, exital portion or gill (above irregularly dot. ted) and flabellum below with rows of dots; $c$, carapace.

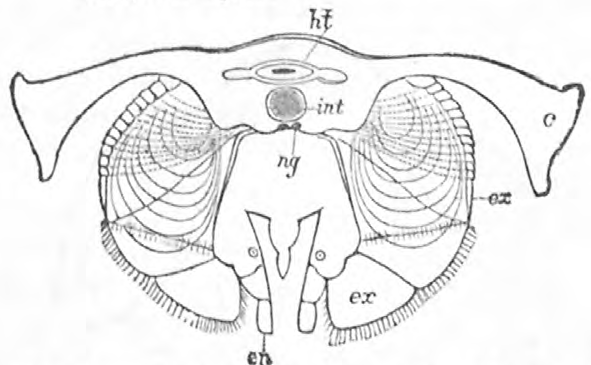

Frg. 37.-Actual section through the abdomen of Limulus: c carapace; $h$, leart; int. intestine; $n g$, fanglia (lettering being the same $\mathrm{s}$ in Fig. 36); en, exial, jointed endopodite; ex. exitul or respiratory portion bearing the gill-lamella: the outer division (ex) homologous with the exopodal portion of the Phyllopod and Phyllocaridan appendago. 


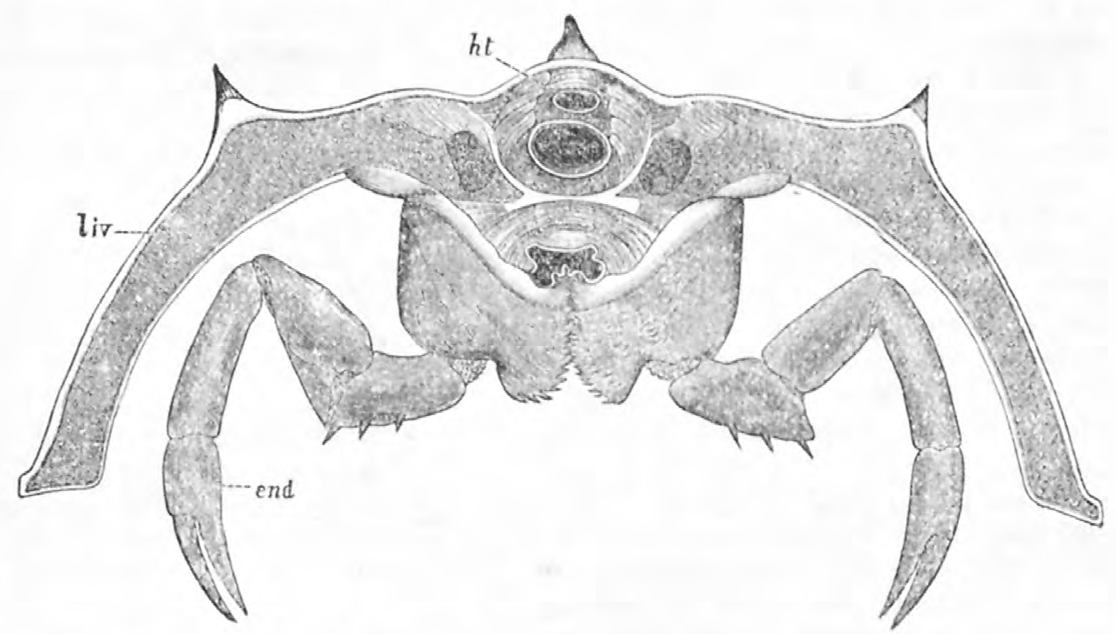

Fig. 38.-Actual section through the head of Limulus, showing the second pair of appendages and their relations to the shell or carapace: ht, heart; liv, liver; end, appendage homologous with the en. dopodite of Decapoda.

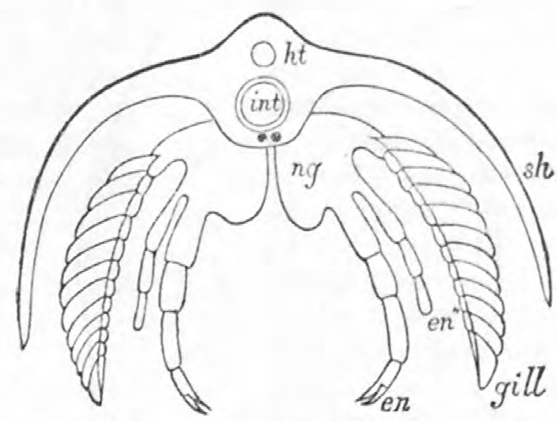

FIG. 39.-Diacrammatic section through body of a hrpothetical form to show the possible homologies between the appendages of Limulus and a trilobite; the lettering as in Fig. 40.

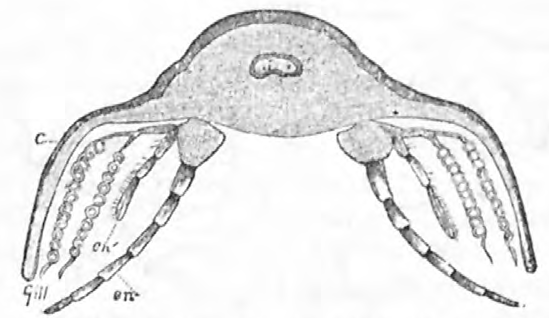

FIG. 40.-Restored section of the thorax of a trilobite (Calyment) after Walcott: c, carapace; en, endopodite; en', exopodite, with the gills on the exopodal or respiratory part of the appendage. 
as is so well marked in the maxillipedes, and the thoracic legs possess not even the rudiments. Change of function and radical changes of structure are most extreme in the Malacostracous Crustacea, from the Brachyura to the Isopoda and Amphipoda. If so startling in these comparatively recent forms, it is not to be wondered at that still greater and more fundamental modifications of the Crustacean type obtain in the archaic forms, the Palwocarides, of which Limulus is the sole survivor. To those who insist on the Arachnidan affinities of the Merostomata, we would suggest that the same shifting and change of function and structure is to be observed among the Tracheate Arthropoda, and that Limulus is not less a genuine Branchiate Ar- h thropod for presenting some features analogous to the Arachnida.

A study of the Phyllopoda and Phyllocarida must tend to confirm the view we have expressed as to the synthetic, or generalized nature of Limulus, while we have in another place endeavored to show in the light of A. Milne-Edwards' anatomical studies on Limulus, that it is an abnormal Crustacean and far re. moved from the Branchiopoda; there are nevertheless some points in which it comes in contact with the Phyllopoda, and which have been noticed ever since the time when O. F. Muller comprised Apus in his genus "Limu. lus." If the reader will compare the accompanying longitudinal section of Limulus with our section of Apus in Pl. XXXVII, some striking resemblances will be seen; externally the front edge of the carapace, $i$. e., the frontal doublure, so well adapted for burrowing in the mul; the relations of the hypostoma or labrum, and the retention of the ocelli, as well as the mode of moulting the shell, are external points of resemblance, while

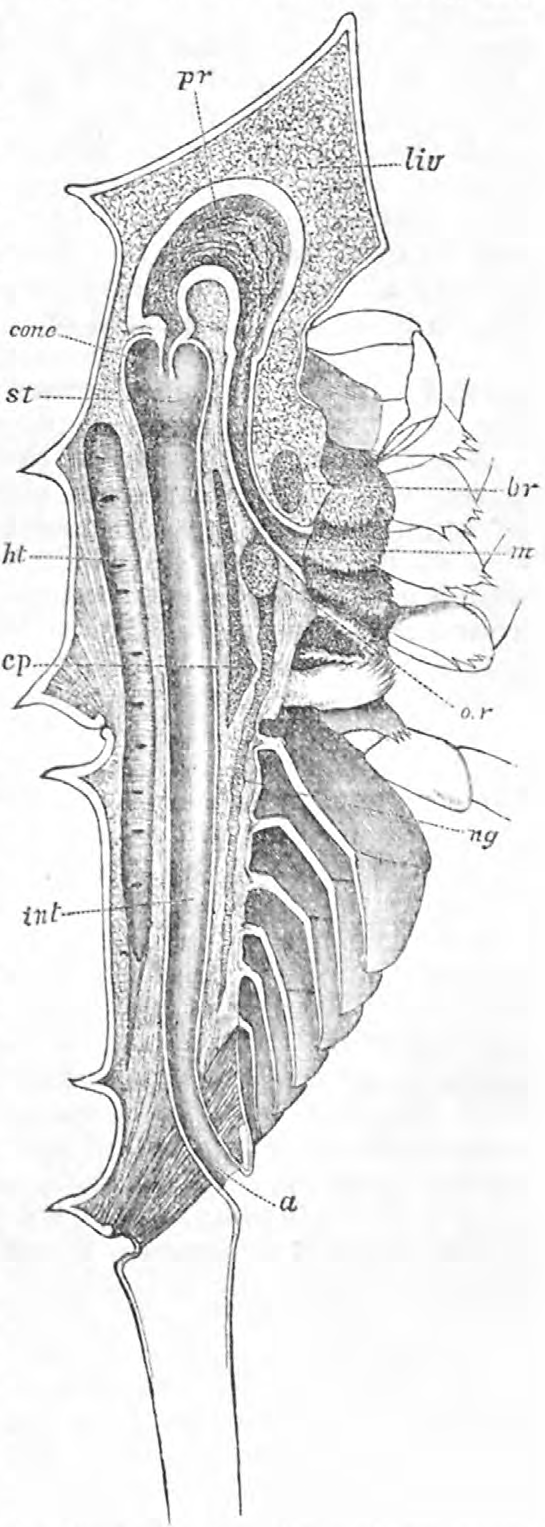

Fig. 41.-Section through a small Limuhus poly. phemus (much enlarged), to compare with a neocaridous Crustacean such as Apus: liv. liver; $p r$. filled with the lobules of the liver, Paginous plato over the nervous system; int, filled with the lobules of the liver, Paginous plato over the nervous system; int, the oblique, long, narrow, cesopha-intestine; $a$, anus; br, brain; m, month; or, gus, the position of the stomach under wsophageal ring; ng, abdominal ganglia.

the eyes so far in front in the head, the simple archi-cerebrum, the general form of the heart, and the guathobases near the mouth are additional points of resemblance. 
In his little tract on Worms and Crustacea, ${ }^{1}$ Professor Hyatt refers to the simple eyes of Limulus, as if they were the primitive eyes, retained from larval life. The structure of the two simple eyes of Limulus appears to be in some important respects quite different from that of Apus, Estheria, and other Phyllopods, in which there is a circle of cones, while in Limulus there is a single large corneal lens on the same plan as the facets of the composed eye of the same animal. If, however, these simple eyes, be regarded as survivors of the primitive larval eye, it would suggest that Limulus and all Merostomata which have similar eyes, have like the Neocarida, deseended from a Nauplius ancestor; although the development of Limulus polyphemus has been shown to be an abbreviated one, the young hatching in the form of the adult. The presence of the single eyes would of course be an argument for its Crustacean affinities; while on the other hand the possession of compound eyes is a still more important Crustacean character.

Another point of interest is the mode of moulting in Limulus as compared with Apus. From our childhood we have found the cast shells of Limulus, with the carapace split around the edge of the doablure, and we have a partially moulted specimen in alcohol. We have not seen a cast skin of Apus, but on asking Dr. Gissler, who has raised the young Apus from the egg, as to the mode of exuviation in this Crustacean, he writes me as follows: "I am certain that the larvæ of Apus (from skins examined) split across or just in front of the eyes, and with two or three jerks the animal rids itself of the underlying skin." It would appear then that Apus, which is shaped in front so much like Limulus moults in a nearly similar manner.

In a general way we accept the homologies pointed out by Professor Lankester between the Phyllopodous leg and the maxillæ and maxillipedes of the cray-fish, but think that he, in common with Professor Huxley, pushes the homologies too far when he proceeds (on p. 365) to compare minutely the first leg of Apus with the third maxillipedes of Astacus. We do not, as we have stated on p. 391, regard the axis of Apus as truly jointed, and he stretches his homologies entirely too far when he attempts to homologize the first and second endites of Apus with the coxopodite of Astacus; and the third and fourth exites of Apus with the basipodite of Astacus. We would suggest that here, as among the orders of Arachnida, or Hexapoda, or Myriopoda, if we do not stop at a certain point, we are led into erroneous and misleading attempts at too close homologies. We should, it seems to us, bear in mind the fact that there are ordinal and class homologies; or, in other words, there are different degrees of blood relationship, i.e., different and more or less parallel branches of the Crustacean genealogical tree.

The Decapods did not descend directly from the Phyllopods, but by a longer line, independent on the one hand from the Phyllocaridous ancestral line, and on the other from the Brancbiopodous stem or branch. But a comparison between the Phyllopodous leg and Decapod maxillæ and maxillipedes shows that the Decapod exopodite is but a modified endopodital lobe, and is not homologous with the exites of the Phyllopods, the latter corresponding to the epipodite (or gills and flabellum, of the Decapods. We have seen that in all Phyllopods the gill and flabellum are differentiated parts of the epipodal portion of the leg (epipodite). Huxley's view, that the base of the corm or "protopodite" of the first thoracic foot is the endopodite, and the endites are merely second-

${ }^{1}$ Boston Society of Natural History. Guides for Science Teaching, No. VII, Worms and Crustacea. By Alpheus Hyatt, Boston, 1882. 
ary processes, is apparently not correct. We regard the Phyllopodous limb as not differentiated into an axially-jointed portion, but that it is divided into a dorsal and ventral portion, the outer side of the limb being epipodal and the inner side endopodal, the endites of Lankester being processes of the endopodal portion.

Returning now to the general homologies of the Crustacean limb, in the light of Professor Lankester's suggestions as to the nomenclature of the limbs of Apus, and from our knowledge of the limbs of Crustacea from the Copepoda and Ostracoda upward, and more especially the Cladocera, Phyllopoda, and Phyllocarida compared with the Decapoda (the Tetradecapoda being considered as a side branch of the Malacostraca and not affecting the general homologies here given), we would suggest the following views:

Looking at the generalized legs of the Cladocera as exemplified in Moina (fig. 28, third pair), we see that there is no specialized axis or stem, and that the limb may be divided into an outer, partly dorsal or respiratory epipodal moiety (the dotted portion in the figures), and an inner, ventral locomotive moiety, which may be called the endopodal portion of the limb.

Now, if we look at the figures in the plates we shall see that the larger part of the epipodal or respiratory portion of the limb is thrown up over the back, as seen in the side view of Limnetis, Estheria, Limnadia (Plates I, III-V), or in the sections of Estheria (Plate XXIV), Apus (Plate XXXII, fig 2), or Thamnocephalus (Plate XIV, fig. 4). This relation is also seen in the lobster or cray-fish upon removing the side of the carapace; the branchiæ and flabellum are thrown up dorsally, while the locomotive portions of the limb hang down or are usually directed forward. The importance of the epipodal or branchial portions of the limb has been underestimated by writers on the homologies of the Crustacea, because they have viewed the subject from the standpoint of the Decapodous structure, where the epipodites are comparatively unimportant. But in the order Branchiopoda these parts are often quite as well developed as the endopodal, and are not on!y respiratory, but, as in the large flabellum of the Phyllopods, are largely locomotive, while in the Limnadiade and Apodidae they are variously modified to carry the eggs.

The epipodal portion is differentiated into the flabellum and branchia or gill, the simple gill of the Phyllopods being the homologue of the highly differentiated complex decapod gill; and the fan-like flabellum of Apus, for example, is the homologue of the scaptognathite of the Decapoda. The gill and flabellum might be properly called branchites, but we have adopted Lankester's term, exites, for these parts.

The endopodal or locomotive portion of the limb of the Phyllopod is differentiated into six lobes or endites (Lankester); there being no parts corresponding to the stem or protopodite (the coxopodite and basipodite together) of Decapods. These are to be found only in the Decapoda. In Apus there is a slight approach to the Decapodous protopodite, but we differ from Huxley or Lankester in regarding the base of the apodid leg as truly axial and jointed, as the supposed joints are shifting and with incomplete articulations. Lankester considers "that the endopodite of the Astacus maxillipede is the homologue of the endite 5 of the Apus limb; its exopodite is homologous with endite 6 of the Apus limb, and its epipodite is homologous with the flabellum of the Apus limb." (Quart. Jour. Micr. Sc., 1881, p. 365.) 
The nomenclature and synonymy of the parts of the Crustacean limb in general may, then, be tabulated as follows:

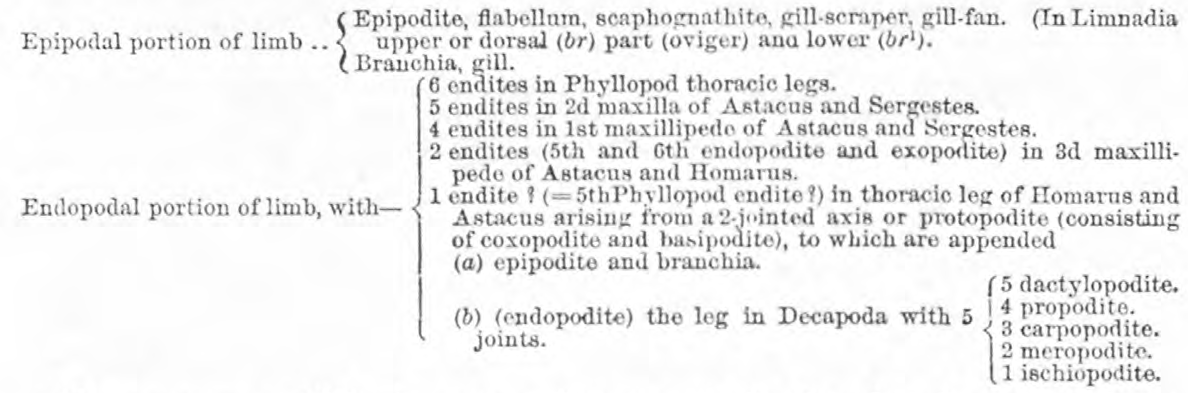

The carapace.-This is seen, when we study the development of the Phyllopods, to originate in the Nauplius as the undifferentiated covering or tergal portions of the first and second and mandibular segments of the Nauplius. which become enlarged during the successive monlts of the animal until, as in Estheria or Limnadia ${ }^{1}$, it may cover the entire body. In adult life it becomes bivalvular and is attached to the body by the adductor muscle, which is situated in the mandibular segment, the præ-oral part of the head in the Limnadiada and Apodida being more or less differentiated from the carapace proper.

As long ago pointed out by Professor Dana, the carapace of the Decapoda (the lobster for example) is a development of the tergal portion of the second antennal and mandibular segments. The development of Pencers and Euphausia from the nauplius to the adult confirms the view that the carapace is originally the antennal and mandibular tergites which form a single carapace and finally covers the cephalothorax of Decapoda. That no part of the carapace represents the thorax is seen in the zoëal carapace which covers the front part of the body before the thoracie segments are developed.

\section{HOMOLOGY OF THE EYES.}

When we consider the nature of the compound eye of the Cladocera and Phyllopoda and study the mode of development of the cornea from epidermal cells, we see that the eye-stalk of the Branchipod eye is simply an unjomted protuberance of the first antennal segment, and can in no way be regarded as the homologue of a jointed appendage. Moreover, the embryology of these Crustacea shows that the compound eyes are developed upon the tergal part of the first segment of the head, and that there are no traces of a præ-antennal segment.

In the Decapoda our unpublished observations on various zoeæ (Lupa, Pulamon and Tozeuma carolinensis), as well as the data given by those who have written on the embryology and metamorphosis of Decapods, all show that the faceted stalked eyes of Decapods shonld not be regarded as homologues of the legs, although eminent anthorities, such as Hnxley, Claus and others, regard them as being the morphological equivalent of the succeeding jointed members. In Tetradecapods the compound eyes are invariably sessile. In the Merostomata, Limulus, as

In Limnadia, as shown by Lereboullet (see Fig. 43), and in Estheria, as stated by Clans, the carapace valves apparently arise from a post-mandibular segment, but this is exceptional anong the Phyllopods. 
well as its fossil allies, and the Eurypterida, the compound eyes are sessile and situated on the third segment of the head, and, as we have endeavored to show in our essay on the development of Limulus polyphemus, ${ }^{1}$ the stalked eyes of Decapods do not represent a pair of appendages.

\section{V.-THE DEVELOPMENT, METAMORPHOSES, AND GENE- ALOGY OF PHYLLOPODS.}

\section{I.-The Nauplius form in the Phyllopods.}

As introductory to the notes furnished by Dr. Gissler on the development of Apus and Streptocephalus, we will preface his remarks with some account of the early phases of different Phyllopods, beginning with Limnetis, as worked out by Grube. ${ }^{2}$

The young of this genus is a Nauplius of peculiar form, with three pairs of appendages, a very large carapace which covers the entire body, and the edges of which are serrated. The carapace is larger than in any other Phyllopod larva known, and there are two large lateral hornlike projections from each side of the head in front of the first pair of appendages. The labrum is not especially developed, while in the other genera it forms a characteristic feature of Phyllopod nauplii.

Limnetis gouldii has a nauplius of the same general shape as the European species, as we have received specimens of a similar carapace from Hanover, N. H.

A quite full account of the development of Limnadia hermanni has been given by Lereboullet. Fig. 42 represents the freshly-hatched Nauplins, which is of very primitive form. The first pair of antennæ are in the Nauplius wanting, not budding out until near adult life.

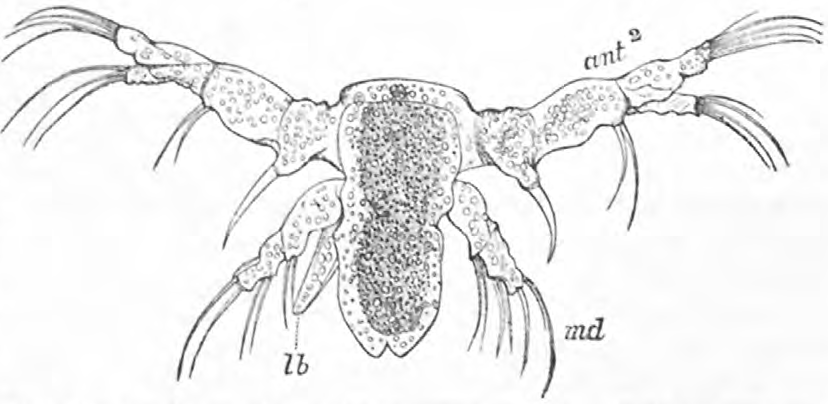

The labrum (lb) Frg.42.-Nauplius of Limnadia hermanni. ant $t^{2}$. second antenna; md, man. is enormous and dible; $b$, labrum. Much enlarged. Atter Lereboullet.

very long. The carapace arises in this genus, as also in Estheria, from a point in the head just behind the mandibular segment. Fig. 43 represents the larva before the first antenne have begun to grow out. The ocellus is still large and performs its functions, while the abdomen ends in a pair of uropoda. The development of Estheria, as given in a fragmentary way by Joly, shows that the Nauplius differs mainly from that of Limnadia in the iabrum being three-toothed at the end.

Fig. 44 represents the freshly hatched larva of Apus cancriformis; the usual three pairs of nauplius-appendages representing the first and second antenne, and the mandibles of the adult are present; while the orate body is segmented behind the mandibular segment.

The first larval stage of Lepidurus, as worked out by Brauer (Figs. 45, 46), is rather different from that of Apus. The limbs are slenderer, and a rudimentary carapace arises on the antennal segments, while the body behind is not segmented. 
Plate XXII, fig. 1, provisionally represents the freshly hatehed larva

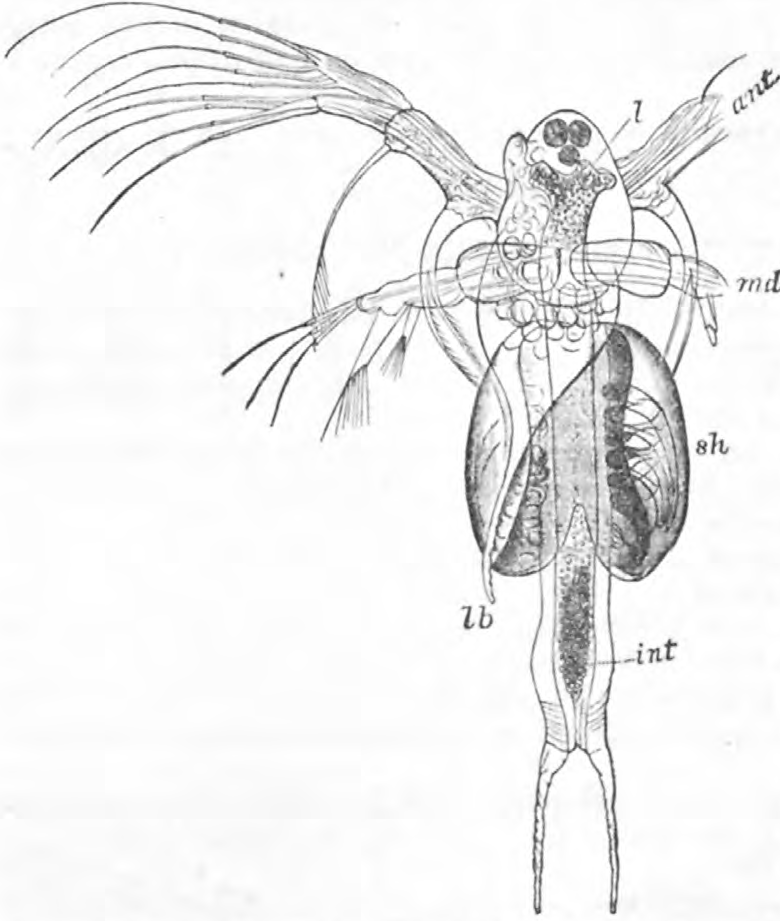

Fig. 43.-Advanced larva of Limnadia hermanni lettering as in fig. $42.8 h$, carapace valves; int, intestine; $l$, liver, mnch enlarged. After Lereboullet. of Artemia gracilis, which we observed at Great Salt Lake, Utah, the drawing having been made from an al. coholic specimen. On comparing it with Claus' figure of the freshly hatched larva or Nauplius of the European Branchipus stagnalis (Fig. 47) the first antennæ are seen to be much shorter; the second pair with much shorter and smaller setæ; while the mandibles are nearly destitute of setæ. Moreover the body is segmented be. hind the mandibles.

Our Salt Lake Artemia differs from the figures of the European Artemia salina in the shorter first anten. næ; in the shorter and smaller setre of the second antennæ. But a single larva was, however, observed, and our figure is, though a camera drawing, subject to future correction.

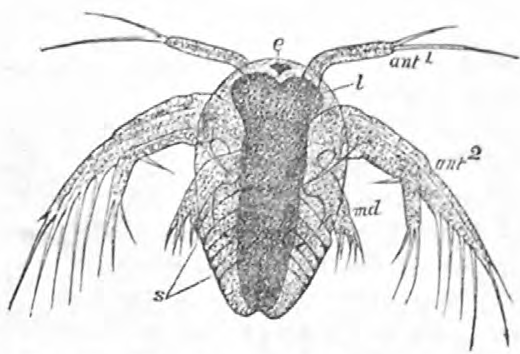

FIg. 44,-Nauplius freshly hatched, of Apus cancriformis. 8 , segments behind the mandib. ular segment; $l$, liver; $e$, simple eye. After Claus.

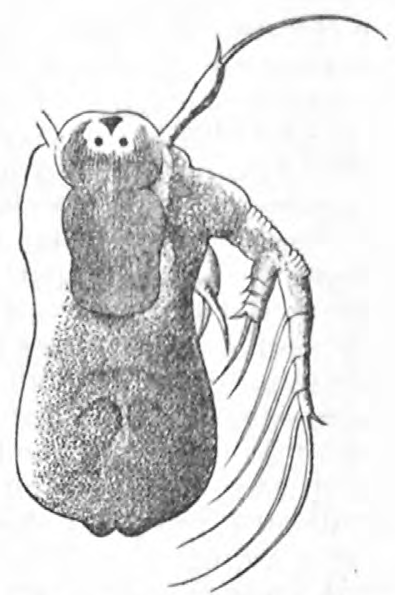

Fig. 45.-Nauplins of Lepidurns much enlarged. After Brauer.

THE GENEALOGY OF THE PHYLLOPODA.

In considering the question of the genealogy of the Phyllopods, we have two sets of considerations to guide us. First the embryologs, anatomy, affinities, and systematic position of the group, and second 
their palæontological histors, the latter being an important check upon any errors arising in the former.

It has seemed to us the more natural view that the systematic position and relations of the Phyllopods, as compared with the Cladocera, is that the Phyllopods are simply a highly developed and extremely specialized branch of a Cladocerous stem; that the Cladocera are a step higher than the Ostracoda, which connect the Branchiopoda with the Copepoda. There is a tolerably com. plete ascending series of forms, beginning with the

Copepoda and culminating Fig. 47.-Nauplins of Branchiin the Phyllopods. Here

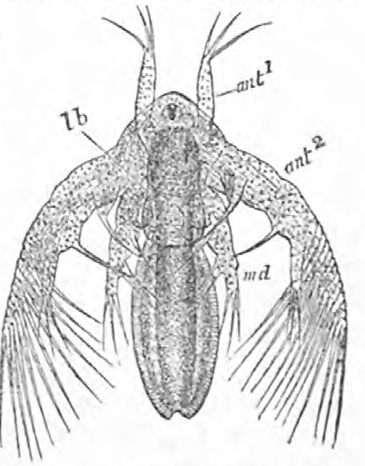
we should stop, and in endeavoring to account for the origin of the Decapoda, we do not see what facts there are to sustain the view that the highly specialized Decapoda, much less the Tetradecapoda, originated from the Phyllopods or forms like them. The more natural view is that the Malacostraca originated by a direct line of ancestral forms, resembling the zoëa, protozoëa, \&c., beginning with a Nauplius condition; the development of Pencus and Leucifer giving us data for such a hypothesis.

Hence the Phyllopods and Decapods, for example, for a time probably followed the same developmental path or rather parallel paths. The Phyllopods, culminating in the highly specialized peculiar type of Apodide and especially the Branchipodide, were the flowering out or consumation of, so to speak, the Branchipodous branch of the Neocaridan crustacean tree. On the other hand the Decapods, beginning with the Nauplius form, perhaps more rapidly and by an accelerated course of development comparatively late in palæontological history, assumed the primitive Decapodous characteristics perhaps before the Phyllopodous type had been perfected, but in the Tertiary Period culminated in a great profusion and luxuriance of forms, remarkable for the number of species and variety of shapes of macrourous and especially brachyurous types.

The palaontological history of the Neocarida, as we have endeavored to show by the diagram on p. 361, shows that the shrimps existed during the Devonian, ${ }^{1}$ that the crabs were already in existence during the Carboniferous Period, before the Apodida and Branchipodide had, judging by their fossil remains, appeared; while the Limnadiada, genuine Phyllopods, appeared before any Decapods in the Deronian, the Ostracodes being abundant in the Lower Silurian strata. It seems to us therefore most probable from a geological standpoint that the Decapods could not have originated from the Phyllopods, as the two types were developed during the Palæozoic era.

That the Phyllocarida were developed independently either of the Phyllopods or of the Decapods seems probable from the fact that the Phyllocaridan type became established as early as the Lower Silmrian. We shall see that the Phyllocarida are not related to the zoëa of Decapods, and that the Decapods probably did not originate from them.

${ }^{1}$ Palcopalcmon newberryii has been described by Whitfield from the Devonian of Ohio. 
Hence the three orders of Branchiopoda, the Phyllocarida, and the Decapoda (with the Tetradecapoda) must, it appears to us, have independently of each other originated from some Laurentian Nauplius-like form.

The views of Clans and some important criticisms upon them are given at length by Mr. Balfour in his valuable Comparative Embryology, while we wotild observe that neither Claus, Dohrn, nor Balfour appear to refer to the palæontological history of the Crustacea.

Professor Claus, in his suggestive work on the genealogy of Crustacea, according to Balfour, claims that the later Nauplius stages of the different Entomostracan groups and the Malacostraca (Penceus larva) exhibit undoubted Phyllopod affinities. He therefore postulates the earlier existence of a Protophyllopod form, from which he believes all the Crustacean groups to have diverged. This ancestral form, Balfour thinks, had three anterior pairs of appendages similar to those of existing Nauplii. It may have had a segmented body behind the third pair of appendages provided with simple biramous appendages. A heart and cephalothoracie shield may also have been present, though the existence of the latter is perhaps doubtful. There was no doubt a median simple eye, but, adds Balfour, it is difficult to decide whether or no paired compound eyes were also present. The tail ended in a fork, between the prongs of which the anus opened, and the mouth was protected by a large upper lip. "In fact, it may very probably turn out that the most primitive Crustacea more resembled an Apus larva at the moult imme. diately before the appendages lose their Nauplius characters (fig. 208 B), or a Cyclops larva just before the Cyclops stage (fig. 229), than the earliest Nauplius of either of these forms" (Balfour, p. 418).

That the Decapods and Phyllopods may lave originated from such a form as Balfour thus depicts seems to us to be quite probable

Mr. Balfour, on page 380 , states that " the Branchiopoda, comprising under that term the Phyllopoda and Cladocera, contain the Crustacea with the maximum number of segments and the least differentiation of the separate appendages. This and other considerations render it probable that they are to be regarded as the most central group of the Crustaceans, and as in many respects least modified from the ancestral type from which all the groups have originated."

Against this view may be, however, offered two criticisms. The excessive number of segments in the Apodidee is paralleled among the Tracheata by the Chilopods, in which the numerous segments appear to have each two pairs of feet, and these Myriopoda are probably not the more ancestral, generalized Myriopodous forms, the Pauropus and Eurypauropus being much more so, these forms having few segments, each with no more than one pair of feet. The excessive number of seg. ments in Apus and the irrelative repetition of abdominal feet appear to us to be signs of a vegetative repetition of parts in a type which has culminated, and is subject to decline and extinction.

Again, in Polyartemia, with its 19 pair of feet, where Artemia has the normal number of eleven (within its family limits) appears to us like Apus to be a highly specialized and extreme form; Artemia being the more generalized, though, as compared with Branchipus, a degradational form.

The view that the Phyllopods "are members of a group which was previously much larger and the most central of all the Crustacean groups," is not fully sustained by zoögeography or palæontology. At present all Phyllopods are fresh-water forms, and they are exceptionally rare forms, occurring only locally, though every continent has its quota 
of these Crustacea. There are no marine allies of the Phyllopods. Moreover all the fossil forms appear to have been fresh-water forms, their remains occuring in fresh-water strata. No fossil Phyllopods have occurred as yet previous to the Devonian Period.

The difficulty is (and this is a point apparently overlooked by Fritz Muiller, Dohrn, Claus, and Balfour) to account for the origination of the Phyllopods at all from any marine forms. The only explanation we can suggest is that the Phyllopods have arisen through Limnetis directly from some originally marine Cladocerous type like the marine forms now existing, such as Evadne. We imagine that when a permanent body of fresh water became established, as, for example, in perhaps early silurian times, the mariue forms carried into it in the egg-condition, possibly by birds or by high winds, hatched young, which, under favorable conditions, changed into Sida, Moina, and Daphnia-like forms. The Cladocera are, then, probably the more generalized forms, from which the Phyllopods, at this time and probably ever since Devonian times, par excellence a fresh-water assemblage of forms, took their origin. This view, it seems to us, accords with the well known facts in the biology and palæontology of these forms.

The view which we believe Dohrn entertains, and to which Mr. Balfour gives some support (though Claus opposes it), that the Ostracoda may have decended from ancestors with a larger number of appendages than they have at present, appears to us to be negatived by the fact that their valves are so abundant in the lowest palæozoic rocks. The type appears to have persisted and to have remained unchanged from the Potsdam Period to the present day, and is more marine than fresh water. So close do the lower Cladocera approximate to Cypris that the transformation of an Ostracode ${ }^{1}$ into a Cladoceran, and a Cladoceran into a Phyllopod, is much more easily imaginable than a hypothetical Protophyllopod ancestor for the Phyllopods.

All this clears the way for the view that the Malacostraca had an independent origin from some Nauplius, through, we will admit, some an. cestral Protophyllopod form which was succeeded by a protozoëa, and finally a zoëa, the ancestor of the existing Decapods as a whole; and it also leaves open a field for the independent evolution of the Phyllocaridan type, composed of gigantic Nebalia-like Silurian forms, which also have originated at a much earlier date than the Decapods, and have held somewhat the same relations to the Decapods as the Eurypterida did to the Limuli.

In conclusion, therefore, we consider the Phyllopods as a whole, especially the Apodides and Branchipodidex, to be a comparatively recent, highly specialized group, which were developed under exceptional biological conditions in bodies of fresh water, and which, as in Apus, show that this branch of the Crustacean genealogical tree has culminated. The irrelative repetition of the segments and appendages (in Apus) gives evidence that the type, so far from being ancestral, is one comparatively modern, specialized, and fully worked out.

${ }^{1}$ Balfour remarks that "the independent origin of the Ostracoda from the main Crustacean stem seems probable." Page 424. 


\title{
VI. MISCELLANEOUS NOTES ON THE REPRODUCTIVL HAB- ITS OF BRANCHIOPODW A. ${ }^{1}$
}

\author{
By Carl F. Gissler, Ph. D.
}

\section{EUBRANCHIPUS VERNALIS Verrill.?}

Among the very large individuals gathered during the past winter (1879-80), I found a male and female, each with but one right clasper. Several experiments on Eubranchipus showed that the least artificially applied lesion of the claspers proved to be fatal to them, and so I am inclined to see in the above mentioned two specimens simply a malformation acquired through some unknown cause at an early larval stage. Where the other claspers ought to be the integument is perfectly smooth and rounded. During eleven days I could never see the malformed male in copulation, although I always noticed him pursuing the females. He was frequently seen to be touched by other normal males, especially when they approached his left side from behind, on account of the missing left clasper, and also probably on account of the excessively swollen genital segment, taking it for a female bag. This singular individual presented altogether much oddity in its behavior. Unlike the others, it often swam suddenly through the aquarium in a beeline, frequently resting on its back at the bottom of the jar for 10 or 12 minutes, slowly moring its branchipeds. Perfect sammersaults and other curious motions were often noticed.

The malformed female did not present any odd movements; I kept it for several days alive and could see no other anomaly about it. The largest females usually preferred the bottom of the aquarium as a protection against the erer-attacking males. In old females I often noticed a laceration of the furca ${ }^{3}$ (sometimes entirely gnawed off), caused by insect-larvæ crawling about the bottom. They bear a lacerated furca well for a long time, as the furca merely consists of chitin and bristled integument.

The larger ponds were found already in January to swarm with Lymnetis gouldii Baird, a great number of a species of Daphnia, many Cy. pridinæ, Csclopidæ, and Calanidæ.

If the months of November and December are mild, as has been the case during the past three years, there occur in January adults $1 \frac{1}{2}$ inches long, as well as larvæ of only a few millimeters in length. Three years ago they disappeared in the beginning of May, year before last in April, last year in March, and this year (1881) in the middle of April. A sudden change in temperature, warm or cold, will cause them to disappear for two or three days, when, atter another change, they suddenly reappear diminished in number and in company with another young generation.

The female sexual organs of the red Eubranchipus vernalis are less complicated than those of its pale races, and I have occasionally alluded to them in describing those of the latter.

Copulation in the red Eubranchipus lasts but a moment, and on this account I was unable to closely observe the same.

\section{SEXUAL ORGANS. (Plate XXII.)}

(1.) Male organs.- The posterior (lower) tapering end of the testicle is fastened by a very fine hyaline thread to the wall near the eighth post-

${ }^{1}$ This is in part a continuation of a paper entitled "Evidences of the effect of chemico-physical influences in the evolution of Branchiopod Crustaceans," read before the 29th meeting of the Amer. Assoc. Adv. Se. held at Boston, Aug. 1880.

2 Observations on Phyllopod Crustacea, ete., by Prof. A. E. Verrill, 1869.

${ }^{3}$ The red Eubranchipus has a white furca, the pale races have a red furca. 
abdominal segment; it broadens rather suddenly, and reaches up in the form of a whitish tape to near the middle of the united genital segments, where it expands and suddenly contracts again into a more cylindrical, narrow string, the vas deferens, for but a short distance, after which follows a second larger expansion, representing the seminal vesicle, bending knee-shaped down and outward, and after again narrowing to a tubular duct, the ductus ejaculatorius, is interrupted several times with what I take to be accessory glands, just before entering the terminal extensile portion, the complicated muscular apparatus. The cirri are non-perforated, and supplied with minute hooklets (as in Branch. ipus grubei and B. stagnalis). At its base several powerful muscles insert themselves, the musculi retrahentes.

The anterior (upper) end of the testicle is in younger individuals of the red Eubranchipus and pale race $\mathrm{A}$ an obliquely cut-off tip, as Spangenberg ${ }^{1}$ figures it in Branchipus stagnalis, but in set B no trace of this prolongation, either in younger or older individuals, can be seen, thus resembling Dr. F. Leydig's figure. ${ }^{2}$

The complicated muscle-apparatus, described and figured by Dr. H. Nietsche $^{3}$ (Branch. grubei), occurs also in Eubranchipus and its pale races, the cirrus being likewise non-perforated and hooked. Chitinou papilli (Branchipus grubei) and spines (Branchipus stagnalis) I could not observe.

(2.) Female organs (pale).-The spirally-wound ovary extends in set B (and $\mathrm{A}$ ?) not only with its posterior end into the penultimate post-ab. dominal segment (as in red Eubranchipus, Branchipus grubei and B. stagnalis), but also with the anterior (upper) end up to the limit of the fourth last pair of branchipeds. ${ }^{4}$

I have often observed in living specimens from 5 to 6 plasmatic eggs of a turbid white color in the upper ovarial string, but then the postabdominal section on the same side was empty, or the reverse. I also occasionally observed both sections, the anterior and posterior, full of plasmatic eggs, and at the moment of entering the oviduct by jerks from the posterior section, the anterior portion of the ovary remained filled for some time until also emptied into the oviduct. The emptying of the anterior section usually took place also on putting live specimens into alcohol, and in this instance the posterior portion remained filled. The eggs of the anterior section have the same form and appearance as those of the posterior.

Another notable fact is a very short, transverse, tubular anastomosis within the sixth and near the seventh post-abdominal segment. This I have not seen to occur in the females of red Eubranchipus, neither have I found it in all females of the pale races. The anastomosis ${ }^{5}$ passes under (ventrally) the intestinal tract, and is sometimes filled with 2 or 3 plasmatic eggs. It is about $1,{ }^{1 \mathrm{~mm}}$ long, narrower than the lateral ovaries; its skin apparently muscular, since the eggs are squeezed sideways out into the lateral strings when live specimens are placed in alcohol, or when, by a jerk, the eggs enter the oviduct.

${ }^{1}$ Zur Kenntniss von Branchipus stagnalis von Dr. Friedrich Spangenberg, mit Tafel I-III. Zeitsch. f. wiss. Zoologie, xxv; Supplementheft, 18i5, Fig. 28, t.

"Dr. Franz Leydig, "Ueber Artemia salina und Branchipus stagnalis." Zeit. f. wiss. Zool. iii, 1851, Taf. VIII.

${ }^{3}$ Dr. Heinrich Nitsche, "Ueber die Geischlechtsorgane von Branch. Grubei von Dybowsky" in Zeit. f. wiss. Zool., xxv, page 281, Taf. XXII.

${ }^{4}$ Schmankewitsch doubts whether or not some of the branchiped-bearing body-segments belong to the post-abdomen. The peculiar arrangement of the ovary here seems to give support to this assumption. See Zeit. f. wiss. Zool. 1875, pages 114 and 115 ; also Spangenberg, in op. eit. pages 8 and 9 ; and Nietsche in op. cit.

${ }^{5}$ This anastomosis indicates a sexual relationship with certain Schizopod and Copepoda. 
A little abore the middle of the genital segment the two oraries are rather loosely attached to a yellowisl: and somewhat trilobed body, ${ }^{1}$ the median (unpaired) funnel of the two oviduets. I said "loosely," because on macer. atmo a female in dilute acetic acid this funnel as well as the two orarial strings separate, the funnel usually remaining loosely-apparently only attached by connective tissue - to one of the strings, and sometimes it is entirely separated. The two oviducts resemble inflated pig-bladders; their skin is very muscular and elastic. The lower (outer) terminus of each oviduct appears to be closed by a sort of a sphincter, since the eggs contained therein (often crammed together) will be retained until the chorion is formed. The time occupied is very variable, but I have neglected to record the same. After copulation the eggs are emptied from the oviducts into the outer "uterine" bag, where they appear in the shape of a small eluster at each outer side of the two oviducts, where they undergo the process of segmentation. This outer bag consists of a very thin but tough chitinous skin inclosing the two ovidnets and the cement-glands, and is fastened with a broad base to the upper (anterior) part of the external genital bag. Its exit is a very short tip in the median line and connects with the outer valve. The eggs are now still plas. matic, not quite spherical in shape, and remain in their present place, surrounded by the brown cement-glands, during continual rhythmic motions produced by a ramified muscle-net, ${ }^{2}$ for from 14 to 20 hours. At the end of this time they are perfectly spherical, having received by the liquid brown secretion of the gland (the gland-lobules are now perfectly colorless, the brown secretion surrounding the eggs), a chitinous, lightbrown, finely granulated egg-shell.

The cement-gland consists of three nearly equal, long, parallel, and longitudinal sections; there are two lateral and a median section. The median section (between the two oviducts) has now acquired a darkblue hue. The newly-formed ovarial eggs have meanwhile also entered the oviduct, and, after copulation, are again emptied from the oviduct into the outer "uterine" bag, simultaneously expelling the already present light-brown eggs around the oviducts toward the median line, where they cluster in the median dark-blue cement gland. After two hours the blue glands become colorless, and ayain, after some three or four hours, they turn from a slight pink into brown. There the eggs remain until they become dark brown and very hard, afterwards to be deposited through the median apex of the inner uterine bag and thence through the valvule into the water, where they sink down.

Remarks.-In a paper read before the American Association Adv. Science, 1881, I have referred the evolutionary changes seen in the pale races to direct chemico-physical influences; ${ }^{3}$ morphological differences were explained through Wagner's migration theory, ${ }^{4}$ as well as through Darwin's selection theory. ${ }^{5}$

Morphological changes, such as seen in set B, C, and (?) D, may be regarded as a sort of Hypertelie, ${ }^{6}$ (specimens, not showing similarity in form without purpose, originate after certain laws, slumbering in them until the phenomenon, Hypertelie, is animated by external influences.)

\footnotetext{
${ }^{1}$ Probably what Spangenberg (page 46, op. cit.) took for a receptacnlum seminis.

${ }^{2}$ See R. Buchholz, "Ueber Branchipus Grubei" in Sehriften der phys.-œcon. Gesell. zu Königsberg, v, page 100, 'Taf. III, and also F. Leydig in op. cit.

"See Schmankewitsch, loe. cit., and same author in Zeit. f. wiss. Zool. 1877, XXIX: "Ueber den Einfluss äusserer Lebensbedingungen anf die Organisation der Thiere."

" "Die Darwin'sche Theorie und das Migrationsgesetz der Organismen" von Dr. Moritz Wagner, 1868. See, also, "Kosmos," iv, April, 1880; "Ueber die Entstehung der Arten durch Absonderung" von Dr. M. Wagner.

5 "On the origin of species by means of natural selection," 1859.

6 "Ueber Hypertelie in der Natur" in Verhandlungen der k. k. zool.-bot. Gesellsch. zu Wien, 1873, xxiii, page 133.
} 
The indirect factor of the red color (or green, of others) of Eubranchipus I assume to be microscopic organisms contained in the soil of the ponds, primarily and gradually acted upon by quercitannic acid or tannates and humus.

I have grave doubts whether to regard the pale races, set $B$, as partially starved individuals, since their nourishment consists of organic matter contained in the mud. The latter is taken up in precisely the same manner as known in the European Branchipus stagnalis, i. e., by striking with the occipital part of the head against the mud, thus filling through the agitated mud the ventral median canal between the branchipeds, and thence by gradual paddling, the mud will pass therefrom toward the head and mouth. The contents of the alimentary system, as examined, also correspond with this manner of feeding. They will never partake of any kind of food thrown into the water. (The pale races had not reached sexual maturity had they not had food enough.) Sesquichloride of iron did not indicate even a perceptible trace of quereitannic acid in the clay-water of the isolated pool, but such was the case with the brownish elear water of the surrounding ponds inhabited by the normal large and red Eubranchipus.

The slightly milky water of the isolated pool owes its color to finely suspended clay-particles, and, I should judge, although I have neglected to microscopically examme the same, contains comparatively more organic matter, adhering to the inorganic particles, than the clear water of the other pools. This is eontrary to the assumption that the pale races were partly starved individuals.

I rather draw the inference, that we here have both, a difference in quantity, and quality of nourishment, the former preponderating, the latter indifferent as to color. The contents of the alimentary system of Branchiopods are for the greater part a fine soft magma of mud intermixed with oil-globules, the latter being the secretion of the wall-glands of the canal.

Very likely specimens living in water with finely dispersed mud or clay, have less trouble in getting their food, the nourishment being more uniform and already so fine that it needs not to be masticated or sepa. rated from coarser particles. ${ }^{2}$

Remarks on the cephalic scute or Kopfschild.-Is not the larval cephalic scute $^{3}$. (in our form $\delta$ of set B, preserved in the adult) a rudiment of the two valves of the Estheridæ? In that family two or three thoracic segments serve for the insertion of the bivalvular duplicature.

Mode of copulation of pale race of Eubranchipus vernalis.-The copulation between males of set B with females exhibiting the two forms of claspers illustrated by figures $61, \mathrm{~A}, \mathrm{~B}$, lasts from 3 to 4 minutes, but many unsuccessful attempts to accomplish the same are usually made, often ending with the escape of the females, owing to the check caused by the crossed claspers. In both the red and white race the attempts were never made

\footnotetext{
${ }^{1}$ An interesting note on chlorophyll and protection of colorless cells as an absorbent of certain light-rays is to be found in Amer. Nat. March, 1880 .

${ }^{2}$ Mr. E. P. Austin-Amer. Nat. X (Aug. 8, 1876), page 508-mentions that in March he obtained 28 different species of Dytiscida from a small clay-pit which had been filled with water. Some of the species occurred in immense numbers.

Hermaphroditism, Amer. Nat. March, 1880, page 200.--Hermaphroditism seems to be a thraldom necessary at the outset, but from which all living things are seeking to escape. (Sexual differentiation in Epiga repens, by Lester F. Ward, A. M.)

${ }^{3}$ Spangenberg, loc. cit., page 14, Taf. I, Fig. 1, and also Dr. Carl Claus, "Zur Kenntniss des Baues nnd der Entwioklung von Branchipus stagnalis und Apus cancriformis." Göttingen, 1873, Taf. II, Fig. 5, D. P.; also same author in "Beitrüge zur Kenntniss der Entomostraken." Marburg, 1860, I. Heft ; also Dr. A. S. Packard in "Phyllopod Crustacea," and same author in "Cave Fauna of Utah and deser. of new spec. of Crust."
} 
on already copulated females, with filled uterine bags, which fact agrees with what has been observed in Branchipus stagnalis. (In the latter the claspers do not cross.) Slipping off of the female after having once been clasped by the male, I could never observe in the normal red Eubranchipus. Therefore comparatively more muscular power is required to open the crossed claspers, and owing to this fact only has the copulation a longer duration in the pale races; the same difficulty was noticed on releasing the copulated female. Immediately after the clasping the post. abdomen turns around to the rentral side of the female, the two normally crossed cirri-points enter the valvule simultaneously, spreading. open the same.

The protruting trifold muscular apparatus, first observed and figured by Dr. Heinrich Nitsche, in Branchipus Grubei von Dybowsky (op. cit.), is closely brought to the valvule, emptying through it (apparatus) and not through the two cirri, the spermatic fluid evidently into the inner uterine bag, where it meets with the revolving eggs. The claspers of the male tightly pressing upon the anterior (upper) portion of the female sack thus produce a gaping of the valvule. All this taking place in an instant, the entering of the two eirri, however, is repeated several times during the three or four minutes. A few jerks of the male postabdomen, apparently coincident with strained jerks of the male claspers (and following right after) are necessary to free the two sexes. The male slowly sinks to the bottom for several seconds, lays curved on its back and repeats the post-abdominal jerks with protruded cirri and apparatus. In this condition, and more so in clay-water, the seminal fluid ean be observed with an ordinary magnifying glass to ooze out of the extensile apparatus and slowly flow over the sides of the curved abdomen.

\section{II.-Larval stages of Chirocephalus holmani Ryder.}

The single specimen of Chirocephalus found in January, 1880, proved to be Chir. holmani Ryder, being considerably larger, but agreeing in general with the latter. On March 22, 1881, I found a very large and deep pond between Glendale and Ridgwood, L. I., about three miles from Maspeth, populated with Chirocephalus holmani. So abundant

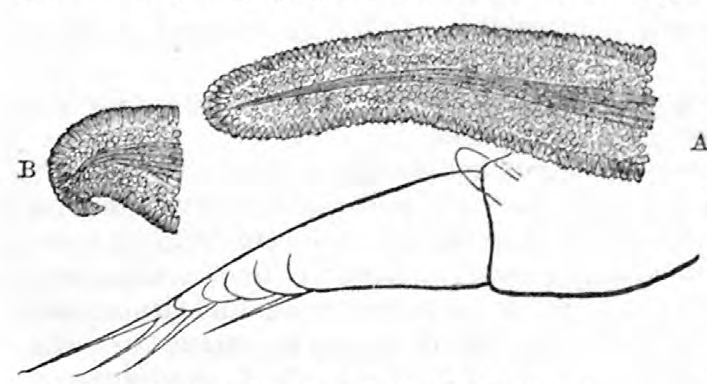

Fis. 48.-A, male frontal tentacle of Oh. holmani

B, the same in male of Eubranchipus vernalis. were they that with every dip I brought up some 30 to 50 specimens of both sexes. They were of a greenish A transparent hue with their furca reddish pigmented. The pigment of the furca was confluent and not granular.

The males averaged $20^{\mathrm{mm}}$ in length and the females about $18^{\mathrm{mm}}$. The stalked eyes were of a beautiful dark-red color. Eubranchipus occurred sparingly together with them, and now (in May, 1881), also a great number of a variety of Diaptomus sanguineus Forbes ${ }^{1}$ and Lymnetis Gouldii Baird.

Having observed them often in copulation in the aquarium, I can state that the latter is of very brief duration, and details relate to those of the normal red Eubranchipas, and principally the frontal tentacles do not come into play as auxiliary organs.

The internal genital organs of the male are the same as those figured 
and described by Dr. R. Buchholz, in his "Branchipus Grubii von Dybowsky," Tafel III, fig. 6 , with the exception that the blind appendage of the descending testis is missing.

The smallest larval stage I obtained from the Glendale pond measured $3^{\mathrm{mm}}$ in length, but when mounted in glycerine jelly I could not tell whether it was a Chirocephalus or an Eubranchipus larva, as the frontal tentacles were not exposed. The same thing occurred in three other larger larvæ. One larva of $42_{2}^{1 \mathrm{~mm}}$ in length showed the appendage as illus. trated by Fig. 48. The inner basal elasper-hook just budded, is turned downward, the anterior, upper surface of the second antennæ and the frontal tentacle is seen. Another larva scarcely larger, second antennæ in about the same stage of develop-

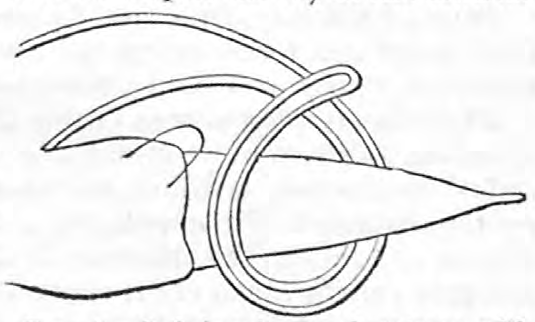

Fig. 49-C. holmani, second antenna with frontal tentacle, from above. ment, exhibits the frontal tentacle as illustrated by fig. 49. It appears, and $I$ judge from twenty-six mounted heads (in glycerine jelly) that the growth of the frontal tentacles of our Chirocephalus is very rapid, its entire length being probably attained between two exuviations.

\section{II.-Larval stages of Apus ludasanus Packard estheria com- plextmanus Pack. and Streptocephalus texanus Packard (Plates XXXIV, XXXV).}

From dry mud received from Dr. L. Watson, of Ellis, Kans., I hatched numerous specimens of larva of both Streptocephalus texanus Pack. and Estheria compleximanus Pack. but only three specimens of Apus lucasanus Pack. The mixture of mud and fresh water was kept at a temperature of about $75^{\circ}$ to $80^{\circ} \mathrm{F}$. during the summer months, and in nearly every instance, after the third or fourth day, I could, with the naked eye, observe some small larvæ actively swimming about in the aquarium. The larve of Streptocephalus, as well as those of E. compleximanus, look at first like little white birds, and Prevost, in Jurine's "Histoire des Monocles," in 1820, has compared the larvæ of Chirocephalus in a similar manner.

I have often obtained from one arid the same lump of mud both the very small Nauplii of Estheria compleximanus and the Streptocephalus texanus but, strange as it appears, when the larvæ of the two genera were thus together, only those of the former (Estheria) survived, but those of the latter rapidly died off. In the single instance, when three Apus larva of several millimeters length were found at the bottom, they were also the only occupants of the jar. F. Spangenberg has drawn attention to this fact on page 61 of his paper on Branchipus stagnalis. $\mathrm{He}$ says that a single larva of Apus cancriformis kills in a few days a number of Branchipus larvæ. How one kills the other I could not observe, but have either raised Streptocephalus alone or Estheria or Apus alone. It is very likely that the secretion of the antennal gland, which is present in all members of this family, whose outlet is under the base of the second antennæ, is antagonistic to other species. The principal function of the gland is believed to be for lubrication, to assist the constantly-moving second antennæ. Its early appearance in the larva, its comparatively large development, together with its distinct orifice, may give support to my opinion.

F. Brauer, C. Claus, and F. Spangenberg agree that the new-born Apus sinks to the bottom, and gradually, with sluggish motions, rises 
again. I did not observe this, but fonnd that older larvæ keep constantly ereeping over the mud, and do not so actively swim about as other Branchipodidee do.

I received about a pound and a half of dried clay-mud of a greyish color from Kansas, of which from five to ten grammes were used at the time for each experiment.

Plate XXXV (except figs. 3 and $4 a$ ) refers to A pus lucasanus, of which I obtained but three advanced stages. A very high and uniform temperature appears to be necessary to keep them alive.

Estheria compleximanus (Plate XXXV, figs. 3 and $4 a$ ) was frequently hatched, even at a temperature of $45^{\circ}$ to $50^{\circ} \mathrm{F}$., but I have unfortunately neglected to follow up its stages of development. It is a limnicolous, ostracod-like crustacean. The older larvæ, as well as the adult, like to dig and make furrows in the clay. I have seen them also swimming in copula for several seconds. The Nauplius is extremely minute, and has on either side two long, broad, juxtaposed spines (one a little higher up than the other) at the posterior side of its carapace. In the adult the shell-duplicature is of an elliptic form and of milk-white color. It is frequently cast off, but no notes were taken as to the number or manner of castings. They seem to take up their food while making furrows in the clay; the carapace protects the branchipeds which paddle continuously while the animal feeds.

With every moult a new addition of limbs is effected, an advanced specialized structure attained, until after the sixth or seventh moult of Streptocephalus, when of about $3^{\mathrm{mm}}$ in length, the inner genital glands make their appearance, followed by the outer, and shortly afterwards a change of the second pair of antennæ is noticed, simnltaneonsly with the full development of the eleven pair of feet. To avoid repetitions as to the gradual development of the latter, as well as of the inner and outer genital organs and the furca, I must refer to C. Claus and F. Span' genberg's papers.

I presume that the chorion proper in all Branchiopodidæ, situated between the exochorion or outer shell and the amnion or inner eggmembrane, has the same structure as that of Argulus and is similarly acted upon by water (under conditions peculiar to each species), described and figured by C. Clans.

The egg of Streptocephalus texarus is rather small, when dry, partly transparent, brownish, and measures three-tenths of a millimeter in diameter. It is of spherical shape and finely granulated.

The egg of Apus lucasanus is larger, brown, and measures one-half millimeter. Its exochorion is of the same structure as that of Apus cancriformis, showing large, thick.walled polygonal markings.

The Nauplius-stage of Streptocephalus texanus does not in the least differ from that of Branchipus stagnalis of Europe, perhaps the whitish instead of yellow color excepting. The first acinaciform or saber-shaped hook-bristle is on the inner side of the first or basal segment of the second antennæ. It is naked and becomes beset with two rows of fine ciliæe after the first moult, and after another moult it is split into two unequal flat termini, which are also ciliated. The second segment also bears a long flat and bent-inward hook-bristle, which is first naked and ciliate after the first moult. The second antenna terminates likewise with two branches, the shorter inner one bearing three long bristles, the outer longer having five long bristles arising from four segments. The second antennæ are the principal parts of locomotion, and give the larvæ the appearance of little white pigeons. The second antennæ remain in their previously described shape until a time when sexual differentiation takes place. 
The further growth of the larva brings about an elongation and segmentation of the body. The latter begins from the base of the body, finally extending to its tip.

A nearly perfect eircular dise is seen on the anterior part of its dorsal side; this is the cephalic scute (carapace).

With the subsequent gradual development this scute retreats, confining itself in the adult to the occipital part of the head. In the base of the second pair of antennæ a rather large meandering gland is seen whose outlet is right below the first sabershaped flat bristle. This is the so-called antennal gland, whose presence has been ascertained in most members of this family of Crustaceans. Below the middle of the Fig. 50-Streptocephalus texanns. Left clasper of male front of the larval head hangs larva with main branch budding; the greater part of brisdown a short broad fleshy

lobe, which in live specimens under the microscope is seen occasionally to lift and lower again. This is the labrum, which we also find in the adult in a somewhat reduced state. The median pigmented eye on the front of the larva is sessile, very simple, having but one pair of "corpora vitrea" placed laterally. The Nauplius can distinguish light from dark, but cannot discern the exact outlines of objects with it.

The mandibular basal process of the third larval leg is transformed into a mandible with a curry-comb-like dentation, and makes its appearance at the time when the fourth or fifth pair of branchipeds begin to bud.

A ? of Streptocephalus texanus had 22 flat acinaciform, long maxillary teeth, and a very minute curved spine at the lower end. The first of the teeth at the upper end has 14 spines, all the rest have 8 or 9 ; the uppermost of them in each case being about twice as long and much stouter.

Transverse segmentation of the body always preceeds the lateral budding of the branchipeds.

The furca or terminal fork of the abdomen very early begins to bud in the shape of two latero-terminal protuberances with two short minute spines, and a little later another smaller lateral spine is formed. In larvæ of about $3.5^{\mathrm{mm}}$ in length, five such spines have made their appearance on each of the two protuberances. The number of spines, with the middle one the longest, gradually after each moult, multiplies until the typical furca of the adult is attained. Between the first pair of branchipeds and the mandibulary palpus at an early age the two pair of maxillæ are formed, the first pair of which has in the adult Streptocephalus the characteristic form as illustrated by Plate XXXIV, fig. 7. In none of the numerous specimens examined by me could I ever find a mandibulary palpus in the adult.

When of about 3 or $4^{\mathrm{mm}}$ in length, the second pair of antennæ are replaced by another form, the old one gradually dogenerating. First the posterior, together with the two curved basal hooks, then the middle, and finally also the terminal long bristles and inner branch drop off from the inner side of the second antennæ. In the interior of the second antenna, near its base, an exuberant growth of cells takes place at this time (Fig. 50). On the outer side, near the base, three protuberances are seen, from each of which groups of hyaline, rather stout and short spinelike bristles arise. Their bases can be seen to originate from the deeper 
underlying cells, in fact they are prolongations of the latter. This change takes place in our Streptocephalus at a time when the eleventh

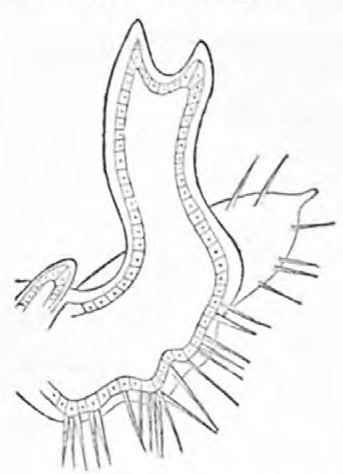

Fig. 51.-Streptocephalus texanus - right clasper of larva $4^{\operatorname{ma}}$ in lemgth. pair of branchipeds has made its appearance and the stalked eyes which laterally bud out of the head are already contracted behind and provided with

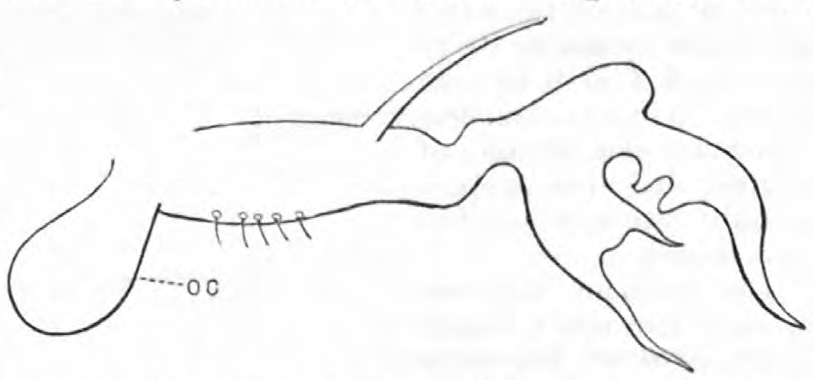

Fig. 52.-Right clasper \& Streptocephalus texanus Pack. oc. eye.

a stalk, while in Branchipus stagnalis the change in the second antennæ takes place earlier.

The three protuberances do not appear before the accumulated cell. masses have pushed out on the inner side of the antennæ in a downward direction part of the main branch of the male forked clasper. At the time when the latter just begins to fork at its tip a second inner branch is budding near its inner base (Fig. 51).

The remainder of the former second antennæ grows out into the outer long flat branch of the clasper, but, as in the aquarium the full grown form is seldom reached, I could not closely follow the development of this outer branch in detail. The new clasper shows in its entire length polygonal cells in the integument, which, after another moult, have partly disappeared, being then permanently confined to but a few spots on the inner rounded corrugate sides of the same.

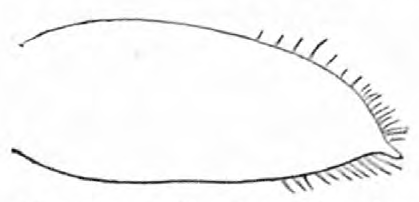

Fig. 53.- - S Streptocephalus texanus, right clasper.

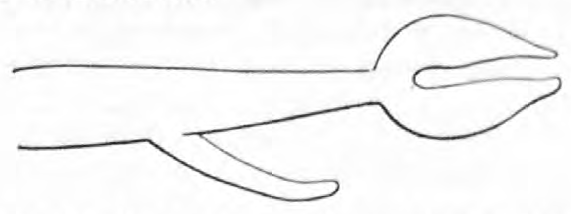

Fig. 54.-Cast-off skin of snbimago-stage Streptocephalus texanus left male clasper from above.

\section{III.-Larval stages of Eubranchipus vernalis Verrill.}

During the whole summer of 1880 I experimented with dry mud from ponds inhabited by either the normal or pale race of this Branchiopod, but all in vain. Neither jars kept on ice in a large refrigerator, nor frozen, dampened mud, gradually or suddenly thawed, developed any

- larvæ. The mycelium of a fungus, a few Daphnidæ, and microscopic organisms were the usual result.

However, I obtained a few early stages of the pale race and many specimens of the later stages of the normal form from the ponds themselves. The latter are reddish and already pigmented when but $4^{\mathrm{mm}}$ in length, while those of the pale race were dull white.

Eubranchipus larvæ are comparatively much stonter and larger in their first stages than their allies. Larva of $0.8^{\mathrm{mm}}$ in length with the first three branchipeds budded out and (osmic acid prep.) nine more 
segments indicated show a diameter of $0 . \tilde{5} 5^{\mathrm{mm}}$ on the broadest part of the body, at the first pair of branchipeds.

Streptocephalus texamus in the same stage of development (in an aquarium) of branchipeds and segments measures $0.8^{\mathrm{mm}}$ in length and $0.43^{\mathrm{mm}}$ in width. The first and second pairs of antennæ, of course, are also proportionally stouter in Eu. branchipus.

The anterior antennæ have (in the above stage) three lyyaline flagellate bristles of $0.75 \mathrm{~mm} !$ in a length, which, after the third moult, are reduced

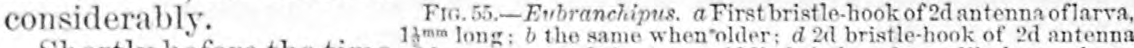
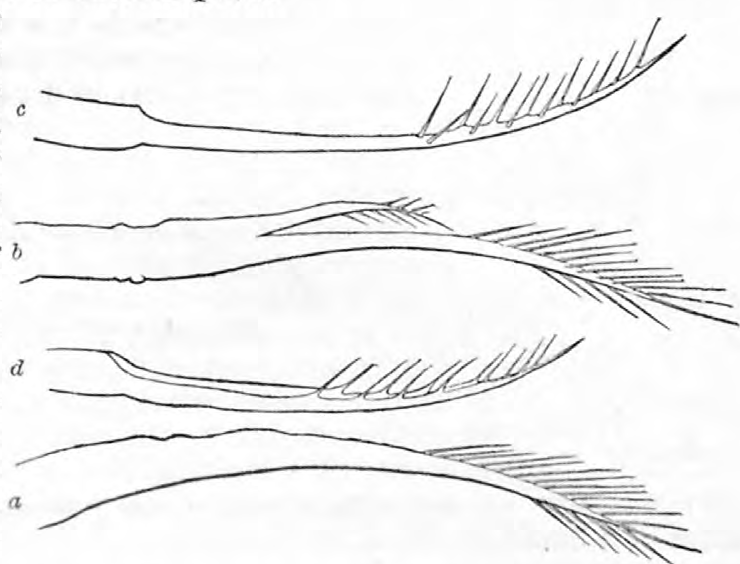
Shortly before the time of larva; $c$ one of the two middle bristles of mandibulary palpus. when the second antennæ Pale var.

drop their long bristles the first four olfactory bacilli make their appearance at the side of the tip of the anterior antennæ.

The second pair of antenne agree in general with those of Branchi. pus or Streptocephalus. There is a basal hook bristle, first plain

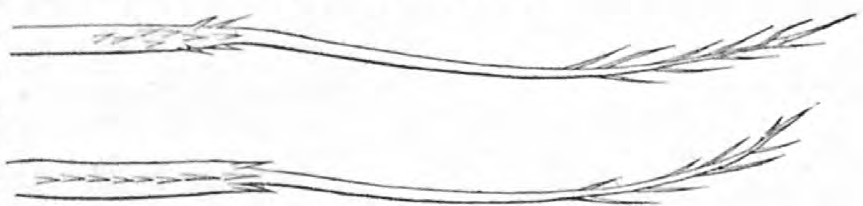

Fig. 56.- Setre of first maxilla of Eubranchipus. then ciliate (Fig. $55 a$ ) and then split. Second bristle-hook appears (Fig. $55 d$ ) to be triangular or rounded exteriorly, and two-edged and ciliate

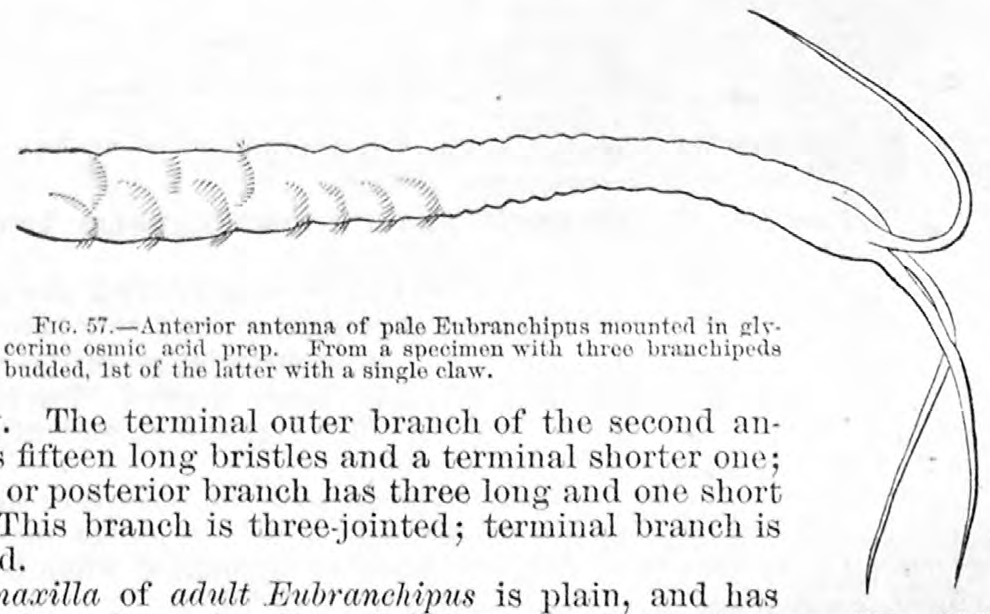

interiorly. The terminal outer branch of the second antenna has fifteen long bristles and a terminal shorter one; the inner or posterior branch has three long and one short bristle. This branch is three-jointed; terminal branch is subjointed.

First maxilla of adult Eubranchipus is plain, and has thirty-one long, flat, acinaciform bristles or teeth, equally long (Fig. 56.)

The second maxilla is composed of a narrow, small, basal piece, with two strong, thick spines, each finely ciliate. 
Mandibutary palpus is four-jointed, bearing seven ciliate bristles, the two basal and the three terminal ones being nearly straight (more so the

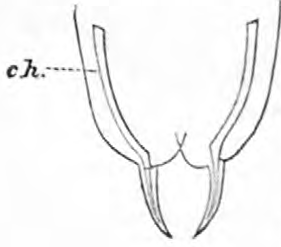
former); the two middle bristles have a stout base, and are curved inwardly (Fig. 55 c).

The first (anterior) (Fig. 57) and second antennæ hare their basal half, in very young forms, at least, peculiarly ciliate. This is mentioned also by F. Spangenberg, but not figured.

Second antenna.-At the time of sexual differentiation the greater part of the bristles and the inner Frc. 58.-a. Same larva branch drop, the basal piece sprouts a few single ciliæ (with 3 branchipeds bud- (not in groups), and from the under side at its base
ded, 1 at of the latter with a singleclaw): Lower part the future first elasper-hook begins to bud, which of abdomen with a chitin- then becomes corrugate at its tip. An exuberant the furca. Plasmatic mat cell-complex in the basal piece, formation of transter and remainder of yolk verse and longitudinal muscles, subdivision of the fect of osmic acid. the of vinal piece of the antenna near its base, and bud. ding of a small roundish protuberance at the inner side of the middle piece takes place, and the male clasper is nearly developed. If a female specimen, the entire antenna remains but with muscnlar differentiation; and at its inner base, on

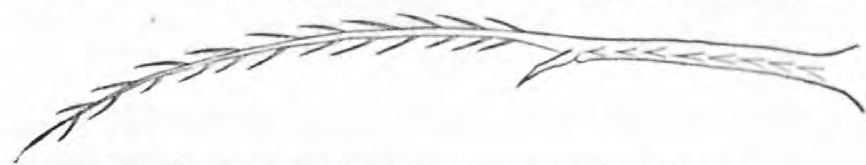

Fig. 59.-Seta of first maxilla of Streptocephalus texanus. a broad frontal protuberance, a number of hyaline ciliæ appear. Some. what later the form of the female clasper slightly changes into one

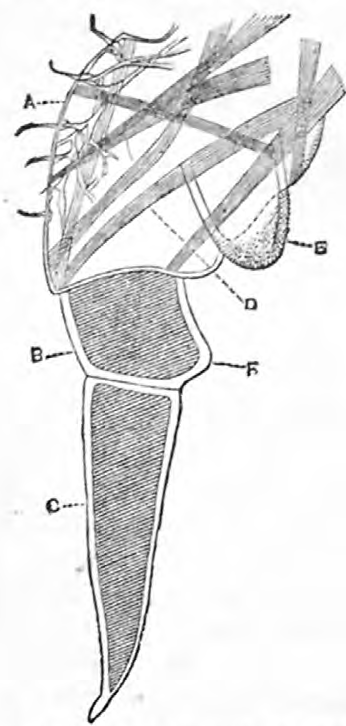
peculiar to this genus (Fig. 61), which is very variable in form.

At the time when in the male clasper the first hook is budding, the frontal tentacles are already present, but owing to their tendency to coil ventrally and their small size I did not succeed in closely following their mode of origin (Fig. $60 \mathrm{~B}$ ). In its early stage the margin is entire, with a continuous row of large marginal cells; plasmatic contents in general intermingled with oil globules, and longitudinal muscles transversely striate. I think at a later time the latter will branch lat. erally, since the developed tentacle shows also transverse muscles. The peculiar mammiform excrescences along the margin are attained after several moults.

Larvæ with three branchipeds budded, the first of which, with a single claw, show the develop. ment of the post-abdominal furca, as illustrated by Fig. 58. I am of the opinion that the narrow piece running along the end of the body is a supFIG. 60-Right male clasper port for the embryonic furca, and is not a muscle, Eubranchipus, from life. A, but a chitinous stick or bacillus, which, after one basal joint, B, $2 \mathrm{~d}$ joint, $\mathrm{C}$, 3d
joint, old antenna: D, longitudi- or more moults (Fig. 63) is pushed out, and its nal muscles; E, first hook, cor-integument becomes ciliated. But the latter, after rugated, budding from below; more moults, does not become the permanent
$\mathrm{F}$, future inner angle wherefrom more the terminus will twist. furca, as we should expect, for it is cast off with the other integument, and the typical development of the furca begins (Fig. 62). 
No internal chitinous support is found until in the adult state, when we again meet with a flat chitinous plate, confined to the furca alone. It is
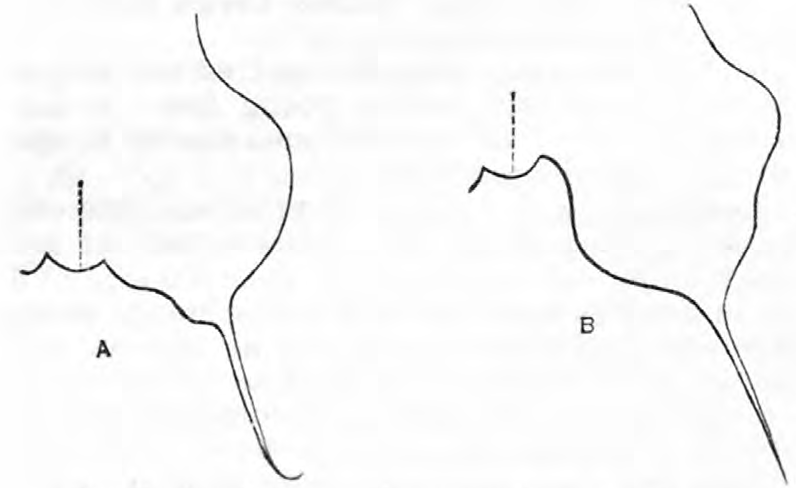

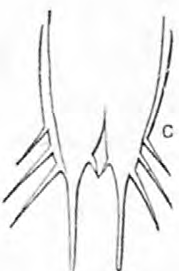

Fig. 62.

Fig. 61.-Female claspers; $b$ more peculiar to the pale race.

an interesting phenomenon to see that the red normal Eubranchipus has a white and the ale prace a red furca. The transparent, greenish, Chirocephalus holmani and the whitish Streptocephalus

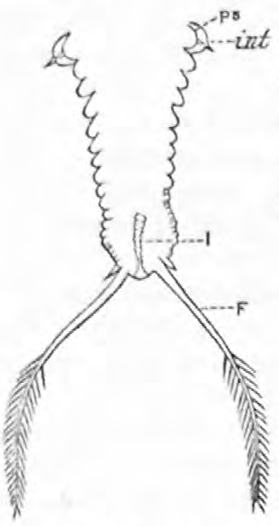

Fig, 63.-Last few seg. ments of an Eubranchipus larva of 1 inm length. Cammounted osmic acid pre- of Branchipus are homologues of the leg, and I venparation. $\mathrm{P}^{5}$, fifth pair of ture to compare the frontal tentacles in a similar intenchipeds; int cast of thanner. The following points support this theory : acid); I, intestine; F, First, they are lateral appendages; second, their furca, ciliate. Gissler del. marginal appendages, more developed exteriorly, closely agree with the embryonic development of the branchipeds, from a single mammiform process up to two and three of the latter. The frontal appendages are different in nearly every species of branchiopod crustaceans; they are sometimes on the basal portions of the claspers in the adult, or they are reduced to minute papillæ. Dybowsky ${ }^{1}$ calls them basal appendages, referring to the base of claspers, while Grube calls them more properly frontal appendages; Fischer calls them cephalic tentacles (Middendorf's Reisen nach Sibirien, Band II); Verrill callis them lanceolate, ligulate, fleshy processes.

\footnotetext{
${ }^{1}$ Archiv, fiir Naturgeschichte, 1860, Vols. 1 and 2, 26th Jahrgang: Beitrag zur Phyllopoden. Fanna der Umgebung Berlins nebst Kurzen Bemerkungen ïber Cancer paludosus Mïller von B. von Dybowsky, M. D., page 195, Taf. X.
} 


\section{VII.-THE ORDER PHYLLOCARIDA AND ITS SYSTEMATIC POSITION.}

Having studied the Phyllopoda, we may now discuss the relationships of Nebalia and the group which it represents.

Fistory of the Phyllocarida.-The genus Nebalia was first established by Leach ${ }^{1}$ in his Zoological Miscellany, vol. 1, p. 99, 1814. Nebalia geoffroyi Edwards, was described and the external appendages figured by Milne-Edwards in the Annales des Sciences Naturelles, tome 13, p. 297,1828 , and in the 2 d series, tome 3, p. 309 . Our Nebalia bipes was originally described under the name of Cancer bipes by Otho Fabricius in his Fauna Groenlandica, 1780.

In his Histoire naturelle des Crustacés (1840) Milne-Edwards places Nebalia in the family Apusidæ among the Phyllopoda; at the same time he remarks: "Les Nébalies sont de petits crustacés très-curieux qui, à raison de leurs yeux pélonculés et de leur carapace, se rapprochent des Podophthalmes, mais qui ne possèdent par de branchées proprement dites, et respirent à l'aide des membres thoraciques devenus membraneux et foliacés. Elles semblent, à plusieurs égards, établir le passage entre les Mrsis et les Apus."

In 1850 Baird, in his British Entomostraca, founded the family Nebaliada, regarding Nebalia as a Phyllopod.

In 1853, in his great work on Crustacea, Prof. J. D. Dana gave the name Nebaliada to the family, with a diagnosis. He placed the group in his tribe Artemioidea in the Legio Phyllopoda.

Nebalia remained, by the general consent of earcinologists, in the Phyllopoda until Metschnikoff, in 1865, published an abstract of his essay on the development of Nebalia geoffroyi, which appeared in full in 1s68. Unfortunately, his work was published in Russian, but Fritz Müller, in his "Fiir Darwin," quotes as follows from Metschnikoff, "that Nebalia, during its embryonal life, passes through the Nauplius and zoea stages, which in the Decapoda occur partly (in Penëus) in the free state." "Therefore, I regard Nebalia as a Phyllopodiform Decapod."

In 1872, Claus gave an account, with excellent figures, of the external anatomy of Nebalia geoffroyi; and in 1876, in his valuable work on the genealogy of Crustacea, he described the internal anatomy of the same species.

In 1875, in his "Atlantic Crustacea from the Challenger Expedition," Willemoes-Suhm placed the Nebaliada among the Schizopoda. While, however, the thoracic appendages of his Nebalia longipes have very narrow respiratory lobes (exites), yet they can be directly homologized with those of the other species of Nebalia, and in all other characters N. longipes does not differ essentially from the other species of the genus.

In 1879, in the American Naturalist for February, 1879, and in our "Zoology" (1879) we proposed the name Phyllocarida for Nebalia and

1 "Dr. Leach, in his 'Naturalist's Miscellany,' vol. 1, p. 99, published in 1814, describes it [Nebalia bipes] more fully than Montagu, and says the species he describes is not uncommon on the southwestern and western coasts of England. As he saw that it constituted a very distinct genus from any previonsly given by modern writers, he formed the genus Nobalia to receive it, and adds, "in a systematic work this genus would hold a very conspicuons and important place, as it is not referable to any family hitherto established.' In a paper published soon afterwards by him, in vol. xi of the Limnean Transactions, on the Arrangement of the Crustacea, he assigns its place amongst the Malacostraca, in the order Macroura; in which he is followed by Lamarck, Bose, and Desmarest, Latreille, Olivier, and Risso; the three latter authors, however, referring the species described to the genus Mysis." Baird's British Entomostraca, p. 3\%. 1850 . 
its fossil allies (see Bibliography), and gave a description of the order and mentioned the types composing it.

Nearly a year later, in 1880, Claus, in the last edition of his Zoology, according to Carus' Yahresbericht, 1880, also suggested that Nebalia represented a distinct order, which he calls Leptostraca. We have not seen the last (fourth) edition of Claus' Zoology (1882), in which the order is noticed.

Habits. - The species of Nebalia inhabit the sea at moderate depths. We have dredged $N$. bipes on the coast of Labrador in from four to eight fathoms, and on the coast of Puget Sound we collected a similar species, just below low-water mark, among fucoids. The following is taken from Baird's British Entomostraca: "Otho Fabricius tells us that it earries its eggs under the thorax during the whole winter; that they begin to hatch in the month of April, and that the young are born in May. They are very lively, he adds, and adhere to the mother, who appears then to be half dead. The adult swims in a prone state, using its hinder feet to propel it throngh the water. They are not very active. Montagu informs us that when moving in the water the superior antennæe are in constant motion as well as the abdominal feet, but that the inferior antennæ are usually motionless and brought under the body. They are found, according to Leach, on the southwestern and western coasts of England, under stones that lie in the mud, amongst the hollows of the rocks; and Mr. McAndrew dredged it from a considerable depth amongst the Shetland Isles."

\section{1.-The anatomy and development of Nebalia.}

The first published description of the present species was by Kröyer, in his Naturhistorisk Tidskrift (Ser. 2, Bd. 2). It is written in Danish, and not accompanied by any figures.

In Nebalia bipes the body is rather slender and somewhat compressed, the anterior half protected by a carapace, beyond the lower edge of which the broad thin phyllopodiform feet do not project.

The carapace.-The head and anterior half of the body, including the thorax and four anterior abdominal segments, are covered by the carapace, which on the lower edge extends below the ends of the thoracic feet, covers the basal joints of the antennæ, and entirely covers the mouth parts. The sides are compressed, and are drawn together over the body by a large but rather weak adductor muscle (Pl. XXXVII, fig. 6), situated a little in front of the middle of the thorax. There is no large highly specialized adductor muscle connecting the two sides of the carapace, nor any well-marked round muscular impression in the carapace, such as is characteristic in the Estheriada ; nor is there any hinge, a still more characteristic feature in the bivalved Phyllopods. On the contrary, as seen in Pl. XXXVI, fig. 3, representing the carapace removed from the body and flattened out, there are no signs of a median hinge-joint.

The nature of the rostrum is one of the diagnostic features of this order. In Nebalia, the rostrum is long and narrow, oval, seen from above, terminating in an obtuse point quite far in advance of the head. It is loosely attached to the sinus in the front of the carapace, and thus forms a long, narrow, tongue-like flap, with a free movement up and down. It is thus seen to be rather a movable appendage of the carapace than a solid, immorable continuation of it, as in the Decapoda. Upon removing the carapace and flattening it out, it is seen to be readily comparable with the carapace of Ceratiocaris. 
The eyes.-The eyes are mounted upon a stalk, and thus Nebalia may be said to be essentially stalk-eyed. In this respect it is similar to the eye of the Branchipodidce on the one hand, or to the eye of the Decapoda on the other. They are inserted just above and slightly in front of the 1st pair of antennæ. The cornea is considerably less in extent than the end of the eyestalk itself, and in this respect differs from the eye of Decapods.

The antennce.-The two pairs of antennæ are large, well dereloped, and of nearly equal size in the female, but in the male the second pair extend backward beyond the bases of the candal appendages. In the 1st pair the stem (scape or protopodite) is seen to be composed of fine joints, the 1st, $2 \mathrm{~d}$, and 4 th the longest, the $3 \mathrm{~d}$ and 5 th short. From the scape arises the flagellum or endopodite, which has 16 well-marked joints, each joint provided externally with numerous setæ; and besides, there arises from the 5th joint of the scape or stem a scale-like unjointed appendage, which may be regarded as an exopodite; if so, then the 1st instead of the $2 d$ antennæ in the Phyllocarida bear a scale-like exopodite; the $2 \mathrm{~d}$ antennæ in Decapoda bearing the exopodite. The outer edge of this exopodite, is thickly fringed with numerous long, delicate setæ. It thus appears that what corresponds to the setæ or protopodite of the 1st antennæ of Decapods consists of 5 instead of 3 joints.

The 1st antenna of Nebalia may be compared with that of the first stage of the larval lobster (Smith, Pl. XV, fig. 8) at the period when the exopodite is short, seale-like, and single-jointed.

The $2 d$ antennæ have a 2 -jointed stem or scape (protopodite), and a single long many-jointed flagellum or endopodite, the basal joint a large one; no exopodite being present, even in a rudimentary form.

The 1st and $2 d$ antennæ are thus seen to be quite unlike those of the Malacostraca, and to resemble the Copepods, in that the anterior pair are rather the stouter of the two; but in those Copepods with very long antennæ it should be remembered that they are the 1st and not the $2 d$ pair, as in the male Nebalia. It will thus be seen that while the antennæ of the Phyllocarida are entirely unlike those of the Plyllopoda, they are neither closely homologous with those of the Decapoda (Mysis or Cuma) or the Copepoda.

The $2 d$ antennæ of the male is said by Clans to be very long, and to resemble those of male Cumacea, but upon a comparison the stem of the antenna is in Cuma quite different in the relative length of the three joints. So also, while, as Clans observes, they are like the antennæ of the Amphipoda, this resemblance is quite general; on the whole, how. ever, the antennæ of both pair bear a general resemblance to the Malacostracous type; also, on the other hand, they may also be compared with the more primitive Copepodous type.

The mandibles (Pl. XXXVI, fig. 4; fig. $2, m d$ ).-These are remarkable from the small size and weak development of the biting edge or mandible itself compared with the palpus. The oval or biting end of the protopodite is small, and armed with comparatively few and weak setre, which shows that the Phyllocarida probably feed on decaying animal and vegetable food, which is easily brushed into the mouth by their slight stiff bristles. The palpus, however, is enormously developed, extending out quite to, if not a little beyond, the edge of the carapace (Fig. 1). It is 3-jointed; the $2 \mathrm{~d}$ a little longer than the basal, and swollen at the-base, while the $3 \mathrm{~d}$ is somewhat longer but slenderer, and edged with a fringe of close-set, rather stiff setæ. Though so immensely developed as to the palpus, and entirely unlike the mandible of the Phyllopoda, in which only the protopodite is developed, it may be com- 
pared with the mandibles of the Decapoda, especially of Mrsis and other Schizopods, ${ }^{1}$ in which a very long three-jointed palpus is developed. But the very long and large mandibular palpus and very weak protopodite may be set down as a diagnostic feature of the Phyllocarida.

The 1st maxille (Pl. XXXVI, fig. 2, $m x^{1}$; fig. 5, $m x^{1} ; 5$ a).-These are likewise singular and diagnostic features of this order, as represented by their structure in the Nebaliada. They consist of a small lobe (Fig. $\left.5 a, c x^{1}\right)$ with about 8 stout setæ, and a larger lobe $\left(c x^{2}\right)$ with the outer edge fringed with long coarse setæ, one of which is a large ciliated seta; from this arises, after bending on itself at its base an extremely long and slender multiarticulate process (or endopodite?) which, in the female, is directed upward and backward (Fig. 5 a, en), reaching to the tergum of the basal abdominal segment, and ending in two very long slender setæ, while a few other similar setæ arise, one from each joint. ${ }^{2}$ In the male of $N$. geoffroyi, according to Claus, the long setose process is directed forwards and downwards.

The 2 d maxilla (Pl. XXXVI, figs. 2, 5, $m x^{2}$ ).-These are entirely unlike those of the first pair, and unlike the Decapodons or Phyllopod type. They consist of a basal portion composed of four thin, delicate, unequal lobes (Fig. 5, 1,2,3,4), edged with long setæ, with two setæ twice as long as the others arising from the 4th lobe; from this 4-lobed basal joint or coxopodite arise two appendages, the anterior (exopodite, ex), small, 1-jointed; the posterior (endopodite, en), 2-jointed, the end of the second joint carrying above 5 long, spreading, stout, slender setæ. This twojointed appendage Claus considers as representing the stock of a palpus.

This pair of maxillæ are quite unlike those of Decapods (Mysis, ete.), as well as those of the Phyllopods, and appear to be another diagnostic feature of the order.

The absence of any maxillipedes, or of any rudiments of them, either in the adult or in the embryo, is a negative character of a good deal of importance when we regard the affinities of the group to the Decapods, or the zoëa-form of the same order, where two (Macrura) and three (Brachyzra) pairs of maxillipedes are present, there being three pairs in the adult Decapod.

The eight pairs of Phyllopodiform thoracic feet (Plate XXXVII, fig.3).The maxillæ are directly succeeded by eight pairs of leaf-like thoracie feet, the maxillipedes not being present. The feet all repeat each other in form, and a description of the 3d or 4th pair will answer for the 1st as well as the last. The leg (Fig. 3, 3d or 4 th pair) consists of a broad, thin, six-jointed appendage, the endopodite $(e n)$, which is fringed with very long delicate setæ, those arising from the terminal joint being ciliated; while a second series of fine stiff setæ axise obliquely from the edge. To the second joint of the endopodite are appended a distal or lower very broad thin gill, not quite twice as long as broad, and which reaches to the end of the endopodite, while situated more externally is a double broad large lobe which corresponds to the exite or flabellum of the Phyllopod foot, this flabellum being as long as the entire endopodite, but not quite so broad as the gill. The distal portion of the flabellum is more pointed than the proximal, and, as will be seen by referring to the figure, is more actively engaged in the process of respiration. The figure shows by the dotted lines of parenchymatous matter

${ }^{1}$ Compare G. O. Sars. Monographi over Mysider, 1870 ; Pl. I, fig. 8. Clans states that the large palpus is very similar to that of many Amphipoda, but apparently overlooks the still closer resemblance to that of Mysis.

"Claus draws attention to the position of this foot as compared with the $2 \mathrm{~d}$ maxille (putzfuss) of the Ostracoda. 
the course taken by the blood in passing through the gill and accessory gill or flabellum, and that it must also be partly aerated by the jointed endopodite; the entire appendage, therefore, as in those of the Branchi. podida, is concerned in respiration. It will thus be seen that the limb is lamellated, but differs essentially from the Phyllopodous limb in that the endopodite is simple, the axis multiarticulate, but sending off no endopodal lobes from the axites, such as form the characteristic feature of the Phyllopodous foot. From overlooking this important and radical difference from the Phyllopodous foot the earlier observers were led to place Nebalia among the Phyllopods.

In comparing the thin, lamellar thoracic foot of Nebalia with the thoracie foot of any Decapod from Cuma to Mysis, and up through the Macrura to the crabs, it will be found impossible to homologize the parts closely, though a general homology is indicated, the endopodite of the Nebalia and the gills corresponding in a general sense to those of the Decapods, and it is this lack of elose homology more than any other which forbids us from regarding the Nebalida as entitled to take rank under the order of Decapoda, or with any of the Malacostraca. But when we compare the thoracie legs of the adult Nebalia with the maxillipedes of the zoëa of the Decapods, then we can detect a slight and interesting resemblance, but the resemblance and homology is not so close as between the thoracic legs of the Phyllopods and the maxillæ of the early zoëa.

On comparing the broad lamellate thoracic feet of the adnlt Nebalia with the rudimentary thoracic feet of the later stages of the zoëa the resemblance is but slight. Just before the zoëa passes into the adult condition the five pairs of thoracic feet of the adult bend ont as two-lobed processes; but the resemblance to the leaf-like foot of Nebalia is too remote to be of any taxonomic value; and this remote resemblance shows that Nebalia does not belong to the Deeapod type.

The six pairs of abdominal feet (Plate XXXVII, figs. 4, 5).-Turning to the abdominal feet, we find that they are simple, without gills, and entirely different from the leaf-like thoracic appendages, and we have in this differentiation of true abdominal from the thoracic feet a Malacostracan character, one quite unlike the differentiation or blending of the two regions in the Phyllopods.

The abdomen is nine-jointed, the segments cylindrical and edged with obtuse spines (Pl. XXXVI, fig. 8.) much as in Copepoda.

The segment succeeding the 8th thoracic is much larger and extends farther down sternally than the 8th thoracic, and bears a large, stout pair of feet, to which the three following pairs are closely related in form. For example, the $2 d$ pair (Pl. XXXVII, fig. 4) consists of a large, thick, long stem (protopodite) which sends off three appendages, an outer (exopodal) stout, blunt appendage, $(e x)$; edged with stout setæ externally and more densely on the inner edge with ciliated, delicate setæ the middle two-jointed appendage (endopodite, en) is longer and slenderer than the outer, and edged externally with finer setæ; a third minute bract-like appendage, Claus says, acts as a retinaculum (Fig. 4, ret.) to connect the two legs of the same pair while the creature is in the act of swimming. In their general form the abdominal legs appear to resemble the simple biramous legs of the Copepoda, but still more closely those of the Amphipoda, in which, as Claus observes, there is a similar retinaculum. (See also Milne-Edwards's Crustaces, Pl. 30, fig. $3^{\text {a }}$.)

The 5th and 6th segments of the abdomen bear much smaller, more rudimentary legs. The first pair (Pl. XXXVII, fig. 5) are seen to be two-jointed, the $2 d$ joint long and slender, bearing near the end stout raptorial setæ, and on the inner edge slender setæ. The 6th pair are 
still more rudimentary, one-jointed, and with but few setæ, which are stiff and coarse. These resemble the simple, unbranched 5th and last pair of abdominal feet in Copepoda (Calanus $\uparrow$ ).

The long, slender terminal segment bears two very long, narrow cercopods (PI. XXXVI, fig. 7) ending in one large and several small setæ, but there is no telson; the cercopods are simple, the integument entirely smooth, with no striæ or any other markings, and they are edged externally with short and internally with long ciliated setæ. In the absence of a telson Nebalia differs from Cuma or any other Decapod, and in this respect, and the simple cercopods, shows a close resemblance to the terminal segment with its two setiferous cercopods of the Copepoda. According to Claus the males differ from the female in $N$. geoffroyi in the rather narrower carapace and slighter body, but chiefly in the very long $2 \mathrm{~d}$ antennæ, the flagellum of which reaches nearly to the end of the caudal appendages. The male sexual glands open on the last of the eight thoracie segments, which fact Claus regards as a proof of the agreement of Nebalia with the Malacostracous type.

Internal anatomy.-Claus remarks in his "Untersuchungen zur Erforschung der genealogischen Grundlage des Crustaceen-Systems" (1876) that in all the internal systems of organs Nebalia is considerably re. moved from the Phyllopoda, and shows an immediate relationship to the Malacostraca, sometimes approaching near the Amphipoda, sometimes near the Mysidax. The nervous system consists of a large two-lobed brain and of a ventral cord extending through all the limb-bearing segments, there being, as shown in Metschnikoff's Fig. 25 of the embryo, 17 ganglia, corresponding to the 17 limb-bearing segments of the body behind the head. A transverse section of a rentral ganglion of $N$. bipes (Pl. XXXVI, fig. 9, or Fig. 66, in text, $n g$ ) shows a form of ganglion quite unlike that of the Estheria and other Phyllopods (Pl. XXIV, fig. $9, n g$; XXXI, fig. $8, \mathrm{G}^{3}, \mathrm{G}^{4}$; XXXII, fig. $2, n g$; XIV, fig. $4, n g$; XXXIII, fig. 5 , gang.), in which the ganglia are separate, connected by rather long transverse commissures, whereas in Nebalia the pair of ganglion are consolidated and of the form of the Decapod ganglion, as also pointed out by Claus, who says that there is a very close resemblance in the form of the nervous centers to the ventral ganglionic chain of the Mysida.

We have endeavored to obtain good sections of the brain of Nebalia bipes, and Fig. 65 (in the text) will serve to illustrate tolerably well the form and intimate structure of the supra-osophageal ganglion. The brain is very small, and the section represented was the third from the front of the head. The ovaries $(o v)$ pass into the head, the end of each ovary overlying the brain. The brain itself is composed of two lobes closely united, and seen in section the brain is as deep as broad, with a constriction passing around the outside in the middle. The histological structure is very simple, with nothing approaching the complex nature of the Decapodous brain. Each division or ganglion of the brain is composed of nucleated ganglion-cells, the nuclei large and distinct, as seen in Fig. $66 a$, and imbedded in a fine granular substance (puntzsub. stance). At the lower part of each ganglion the fibers forming the commissures are quite distinct. Whether the 1st antennæ or both pairs are innervated from the brain Claus does not state, and we have been unable to observe. It is probable, however, that at last the 1st antennal nerves arise from the brain, judging from Metschnikoff's Fig. 25, wherein he shows a nerve descending from the under side of the ganglion, while the osophageal commissures are directed backward; and we feel uncertain whether the descending nerves in our figure are the 1st antennal 
nerves or the csophageal commissure. Claus also likens the stalked eyes to those of Mysida. In Nebalia no ears have been found.

In the digestive canal, says Claus, we have a quite specific peculiarity, together with approximations sometimes to the Amphipoda and

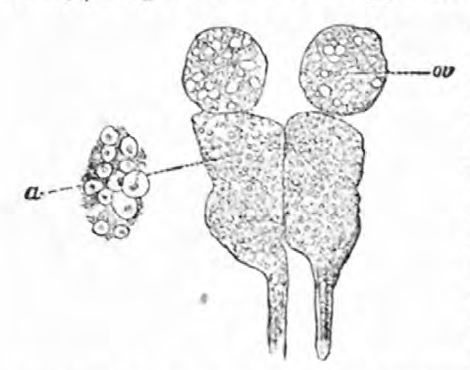

FIG. 65.-1. Section of brain of Nebalia bipes: ox ovary: $a$, portion of broin atill more enlarged to show tho ganglion cells Author del. Isopoda, and sometimes to the Mysidee and Podophthalmata. The short up curved œsophagus leads into a stomach with a complicated chitinous armature, in which an anterior and a posterior division can be distinguished. While in form and rel. ative size of both parts there is a resem. blance to the stomach of Amphipoda, so we may also observe in the position and number of the chitinous plates of the apparatus for triturating the food a true resemblance to the Isopoda, but also to the pyloric division of the stomach of the $\mathrm{My}$. sidæ, whose capacions and sack-like expanded cardiac division seems to correspond to the differently-formed esophageal portion of Nebalia. The slender intestinal canal along its whole eourse is surrounded with a uniform layer of eircular muscles, and on the inner side of the tunica propria is surrounded with a thick, fatty layer of epithelium; it reaches to the beginning of the last seg. ment, which is nearly filled by the muscular rectum (afterdarm). At the origin of the intestine (chylusdarm) arise two anteriorly and four (two larger than the others) posteriorly-directed liver-tubes; these forr latter-named tubes or eœea are attached by a richly-developed fatty tissue of the serous membrane to the intestinal walls, and reach far into the abdomen. The two anteriorly-directed cœea reach to the antennal segment, and are frequently wholly enveloped by the fat corpuscles of their serous coat. (Compare our figure of $N$. bipes, Pl. XXXVII, fig. 6.)

"The two anterior biliary cœea manifestly correspond to those which we so often, though not always, meet with in Podophthalmatous larvæ (Phyllosoma, Sergestes-larvæ, \&c.), but which, however, exist only in a rudimentary state in many Edriophthalma. The histological structure of the liver-tubes agrees closely with that of the intestine; the circular muscles still remain, though scattered and absent at intervals. The epithelium consists of smaller and larger cells filled mostly with large, fat cells, whose secretions, like a fluid tinged yellowish, fills the often widely distentled cavity of the canals. Now, arising in a remarkable way on the under (or lower, unterer) side of the intestine are two long ascending appendicular tubes, for the most part embedded in the fat body, which is enveloped by fat cells. The hinder intestinal appendages of Nebalia, in which we could not detect the colored secretion of the livertubes, remind one of the so-called malpighian tubes of the Gammaridæ, which arise at the beginning of the much longer rectum which passes through the three terminal segments of the abdomen. In Nebalia the relatively short rectum, by means of the numerous muscular bands suspending it from the intestine, performs the movements so generally observed in Phyllopods, by which the water is drawn in in an almost rythmical manner and then expelled. The anus, concealed by two triangular chitinous plates of the terminal segment, opens between two small lateral flaps, which closely resemble those in the inner side of the furcal appendages of the Protozoëa larva of Penæus.

"Of the pair of tubular glands which serve in the body of Phyllopod 
larvæ as antennal and shell glands, but which in the Malacostraca undergo a substantial reduction, we find in Nebalia the anterior pair as slender glandular tubes in the basal joint of the $2 d$ antennæ. This relation of this gland, which is absorbed in the course of the metamorphosis, but in the Malacostraca, however, is generally present as a simple or winding glandular passage, affirms further the near affinity of Nebalia to the Malacostraca stem. Of the complicated shell-gland no remains survice in the Malacostraca. What we are accustomed to regard in the Decapoda as shell-glands is nothing more than the anterior gland which belongs to the maxillary region, but opens externally on the basal joint of the $2 d$ antennæ. But we can surely prove, after careful researches on living Malacostracan larvæ, that the rudiments or survivors of this gland are situated on the sides of the maxillæ (kiefer). In the Stomapod larvæ I think I have found such a survival in the shape of a simple, somewhat curved glandular tube; and also in this place the residuum of the shell-muscles are preserved. The shell or adductor muscles of Nebalia appear to be well developed, quite as in the shelled Phyllopods. On each side of the shell we observe, under the mandibles, somewhat dorsally, a large round impression with an upper and under somewhat curved row of muscle-facets. On the upper end of the group of muscles, however, on the inner side of the shell, is to be found a small gland. ular tube, which with a contracted neck extends to the region of the maxillæ, and is surely nothing else than the survivor of the true shellgland of the Entomostraca."

Our sections of the body of Nebalia bipes show that in their general features the digestive eanal and appendages are much as Claus describes for the Mediterranean species. We were unable to get good sections of the proventriculus or kaumagen. Plate XXXVII, fig. 6, evidently passes through the stomach in front of the heart, which is much

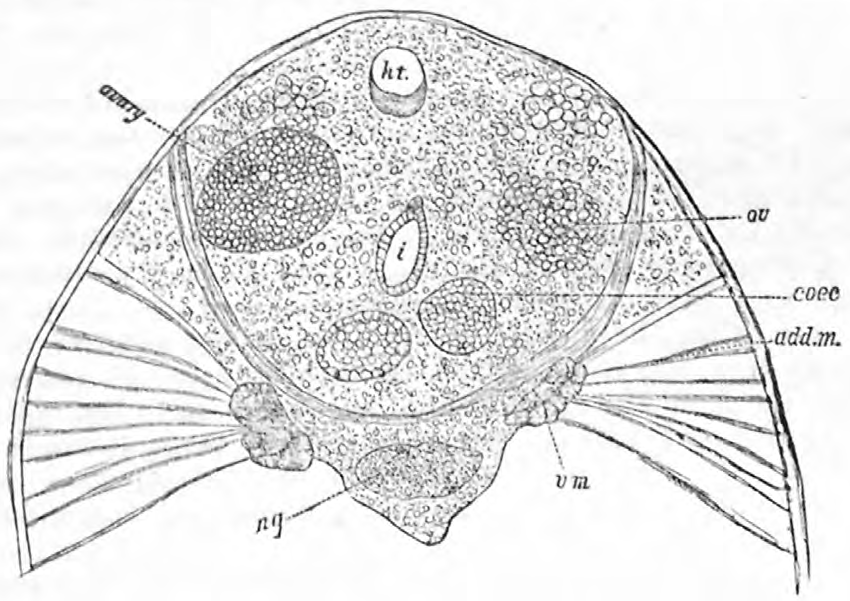

Fig. 66.-Section through the front end of the thorax of Nebalia bipes; ht. heart; $i$, intestine; $n g$, ganglion; vm, ventral muscle; add $m$, adductor muscle. Author del.

larger than the intestine (fig. $i$, in text). Fig. 66 (in text) is a section (No. 9) through the anterior part of the thorax, in the region of the adductor muscle $(a d d . m$.$) ; the heart (ht) is quite remote from the small$ intestine, which is smaller than the two anterior cœca. In Fig. 67 (in text) of section 14, through the same specimen at the end of the thorax, the heart $(h t)$ is of its maximum size, and now we see sections of six 
cœeal tubes, the series of four lower ones being the four posterior tubes described by Claus as passing back into the abdomen. In this section

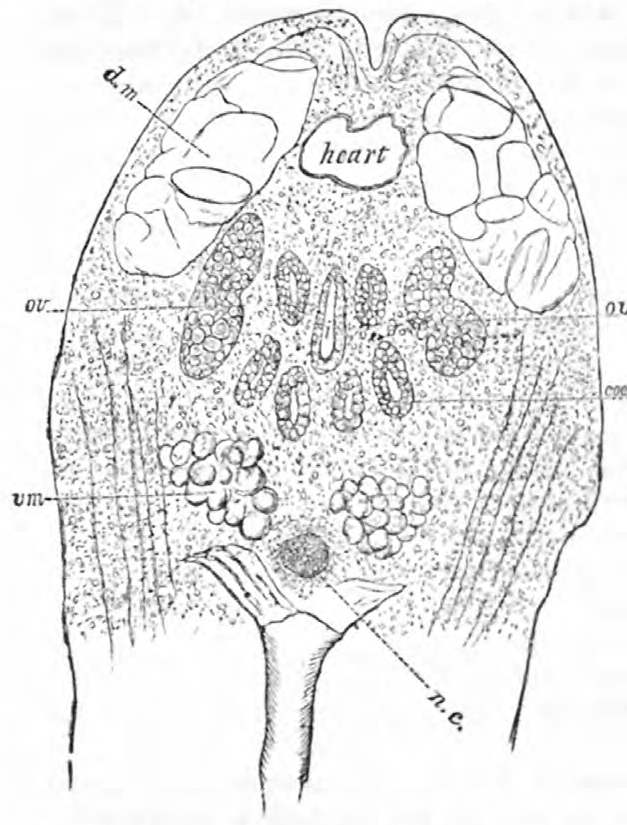

FIG. 67.-Section throngh the end of thorax of Nebalia bipes, showing the six coea (ccec), the heart (ht), the ovaries $(o v)$, and the sets of muscles; $d m$, dorsal mus. cles; vm, ventral muscles; nc, nervous cord; ov, ovary; $i$, intestine. Author del. the dorsal muscles $(d m)$ of the posterior part of the body appear, and the ventral muscles $(\mathrm{vm})$ are larger than in section 9 , while the ovarian tubes (ov) are smaller.

Without translating in full Claus' description of the heart and circulation we will only give his conclusions. The heart of Nebalia is a long straight tube a little thicker just in front of the middle, beginning over the maxillæ just in front of the 1 st thoracic segment (tergite) and extending to the middle of the 4 th abdominal segment. It has two pairs of lateral large ostia for the entrance of the venous blood, and four pairs of dorsal arterial openings in the anterior part of the heart. Says Claus: "The heart combines the characters of Phyllopods and Malacostraca, while the tubular dorsal vessel passing through twelve segments, in its form and in the greater number of ostia resembles the many-chambered dorsal ressel of the Phyllopods, so on the other hand the relation of the two ends with the head and abdominal aortæ, together with the hinder pair of arteries, reminds us of the swift, regular, and in general complicated and vascular circulation of the Malacostraca. Of especial interest is the similarity of the shell, or carapace-circulation of the Stomapods and Mysidæ with Nebalia."

Of especial interest, says Claus, is the sexual apparatus, which combines in a surprising way in structure and form the peculiarities of Phyllopods and Malacostraca (Amphipoda), and also in position and topography retains the primitive relation of the ovaries and testes. Both are slender, long tubes, which lie right and left on the dorsal side of the intestine from the sixth abdominal segment to the region of the stomach (kaumagen), and by means of a short cross passage open out on the thorax. In the male sex this efferent duct opens in the basal segment of the 8th pair of thoracic limbs, namely, in the same place as in the Malacostraca.

Claus includes Nebalia among the Malacostraca, but when we consider the composite nature of the internal organs as described by him, we wonder that he failed to appreciate the independent, synthetic nature of the Phyllocaridan type, which, when we take into account the external as well as internal organization, forbids our regarding Nebalia as a true Malacostracan, though the type of a group standing outside of, but nearer to the Malacostraca than are the Phyllopods.

The development of Nebalia.-Our knowledge of the development of Nebalia is due to the distinguished Russian embryologist, who in 1868 published an elaborate account of the developmental history of Nebalia 
geoffroyi. Unfortunately the pamphlet is in Russian, and only brief abstracts of it have appeared in German. But as ample and well-drawn figures illustrate the work we can state the salient points in the ontogeny of this interesting Crustacean. The yolk does not undergo total division, but by the subdivision of a large polar eell the yolk becomes surrounded by a layer of blastodermic cells. Soon after the rudiments of the two pairs of antenwæ and of the mandibles bud ont, the abdomen also being differentiated from the rest of the body (Pl. XXXVIII, fig. 1). This is regarded as representing the free nauplius condition of other Crustacea. At a succeeding stage (Fig. 2) the two pairs of maxillæ and two pairs of thoracic feet bud out; and in a stage immediately succeeding (Fig. 3) the palpus of the mandibles elongates, the maxillæ are twobranched, and seven (or eight) pairs of thoracic feet are indicated. In a succeeding stage (Fig. 4) Nebalian characters assert themselves; such are the carapace and large rostrum, the biramous anterior pair of antennæ, the unbranched $2 \mathrm{~d}$ pair, the long mandibular palpus, the ab. sence of any rudiments of maxillipedes, and the eight pairs of thoracic feet (bænopoda) and three pairs of abdominal feet (uropoda), all of which are now well developed. At this stage it may be seen that, as in spiders, the 1st pair of thoracic feet may represent the $2 d$ maxillæ of insects transferred from the head to the thorax; so in Nebalia, the three first of the eight pairs of thoracic feet may correspond to the three pairs of maxillipedes of Decapods, which in early life, before the thorax is differentiated from the head, may have remained afterwards as a part of the thorax. An intermediate step is the retention in the Myside of the last pair of maxillipedes or the 1st pair of thoracie feet, so that these Crustacea have six pairs of feet. Moreover Nebalia at this time, in the absence of differentiation of thorax from the abdomen, and of thoracic and abdominal feet, the two sets being similar in form and development to each other, may also represent the Phyllopod stage. In the next stage, at the the time Nebalia leaves the brood sac of the mother, it is but one step removed, so to speak, from the adult form.

Metschuikoff's observations were made on Nebalia geoffroyi of the Mediterranean Sea. We have in the sections of Nebalia bipes observed stages of development in the young similar to the stages represented by Metschnikoft's figure 13 or 14, and have found in the bottom of the vial in which the specimens were sent several young which had fallen out of the brood sac of the parent. Upon comparing these with Metschnikoff's Fig. 19, or Fig. 68, in text, they are of the same form; the rostrum being large, the procephalic lobes large, the eyes small, the stalks not yet developed, while the maxillary palpus stretches back to the 1st abdominal feet; the thoracic feet are covered by the large carapace; and a 4th pair of abdominal feet have developed, while the caudal appendages are as in the adult. In ali these features we see only a general resemblance to the Schizopods of any value, the similar earliest phases of development proving of no special importance.

Comparison between the early stages of Nebalia and the Decapod (Schizopod) Mysis.-It would appear that if Nebalia were a Decapod that in its larval stage it should present a close homology with the Schizopods at a similar stage of existence. In Euphausia the young leaves the egg and becomes a free swimming nauplius, and then a protozoëa, and at length a zoëa larva before assuming the adult condition. It is evident that since Nebalia passes its early stages in the incubatory pouch of the mother, that it should be rather compared with the young, when about ready to leave the mother, of some Mysis-like form.

Happily Prof. G. O. Sars has afïorded us the material for such a com- 
parison. The early stages of Mysis, as worked out by Van Beneden and Claparède, and of Nebalia, are much alike; the formation of the blasto. derm is much the same. The nauplius stage in the egg is nearly identical in both, but beyond this the parallelism ceases to be an exact one; Nebalia turns off and follows quite a different developmental path from Mysis or any Decapod. If we compare the young of Nebalia, taken from the brood-sac, with that of Mysis, as figurea by Claparède (Plate XVII,

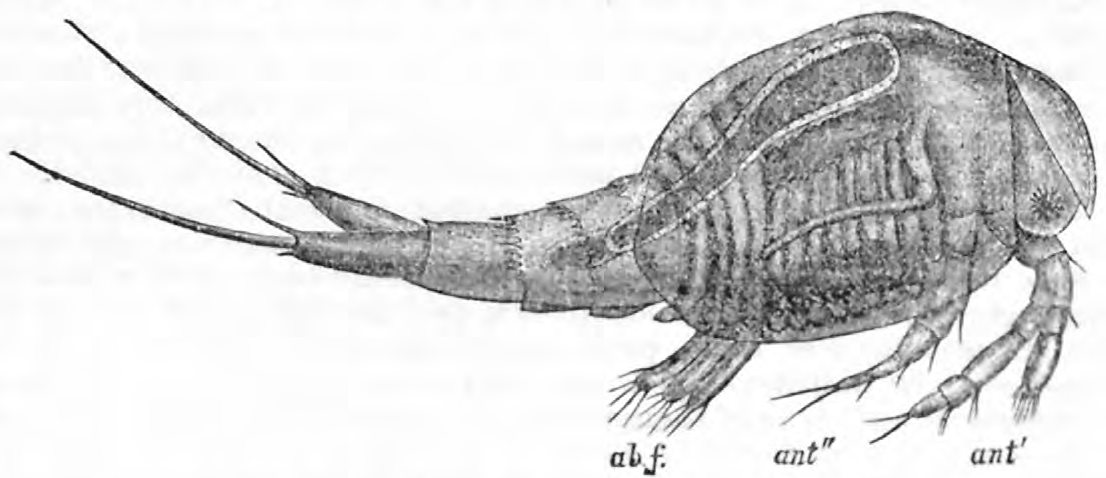

Fig. 68.-Fmbryo of Nebalia ready to hatch, enlarged; ant', 1st antennæ; ant", $2 \mathrm{~d}$ antennæ; $a b, f$. abdominal feet or uropoda. The first maxilla crosses the thoracic feet. After Metschnikoff.

fig. 6), or a more advanced stage, particularly that of Pseudomma roseum, as figured by Sars, ${ }^{1}$ we shall find that many of the difierential characters which, in the adult, separate the Phyllocarida from the Decapoda, are to be found in the young. In Mysis and allies at the same stage as Metschnikoff's, fig. 18 of Nebalia, (our Plate XXXII, fig. 4, ) the $2 \mathrm{~d}$ antennæe are simple instead of being bifid as in Nebalia; there are no maxillipedes, and the maxillæ are, as in the adult, immediately succeeded by the eight pairs of thoracic feet; moreover there are no abdominal feet in Mysis or Pseudomma, while three pairs are present in the young Nebalia. But with the exception of the lack of abdominal feet in the Mysida at this stage, it may be thought upon the whole, as has already been stated by Balfour, that "the development of Nebalia is abbreviated, but from Metschnikoff's figures may be seen to resemble closely that of Mysis. . . . There is in the egg a nauplius stage with three [pairs of] appendages, and subsequently a stage with the zoëa appendages." It seems to us that the comparison ${ }^{2}$ here made is, as regards any resemblance to a zoëa, loose and inexact, whether applied to the Mysida or to the Phyllocarida. The stage of the Mysida succeeding the nauplius is characterized by the presence of the rudiments of eight pairs of appendages, the two pairs of maxillæ, and the six pairs of thoracic feet of the Schizopodous type, while the zoëa has no thoracic feet at all, so that it would appear that the Schizopods do not pass through a genuine zoëa state like that of the higher Decapods. Nor on the other hand is the Nebalia stage represented by Metschnikoft's fig. 18 (our fig. 4), a zoëa stage, for the embryo has the rudiments of eight pairs of thoracic feet, and besides those of three pairs of ab. dominal feet, while there is a well-marked carapace and rostrum, as well

${ }^{1}$ G. O. Sars, Monog. over Mysider, Heft 1. Taf. IV, fig. 23.

${ }^{2}$ Claus (Genealog. Gundlage des Crust. Systems, p. 31), as we find since writing the above, does not accept Metsc!nikott's comparison of the young Nebalia with the zoëa, although he does not give the reasons for his dissent. 
as procephalie lobes with eyes, all these parts not being developed in the embryo Mysidæ.

But whatever may be said of the resemblances between Nebalia and the Mysida at an early period after the nauplius stage has been discarded, when we compare the later stage represented by Metschnikoff's fig. 19 (our fig. 68, in text) with the latest larval stage of Pseudomma (see Sars's figure, our Plate XXXVIII, fig. 5), then we see that the diagnostic ordinal characters of the Phyllocarida have declared themselves. There are to be seen in Nebalia the large movable rostrum, the compressed pseudobivalvular carapace, the lack of maxillipedes, the eight pseudophyllopod thoracic feet, four pairs of abdominal feet, out of the six of the adult. On the other hand, in Mysis of the same stage, the two pairs of maxillipedes are well developed, and the six pairs of remarkably long thoracic feet (the first pair modified maxillipedes) are present. There is little to indicate that the Schizopods have descended from a Nebalia-like form, but rather from some accelerated zoëa form; while, as we attempt in this essay to show, the Phyllocarida have had no Decapod blood in them, so to speak, but have descended by a separate line from Copepod-like ancestors, and culminated and even began to disappear before any Malacostraca, at least in any number, appeared.

\section{II.-The Paleozoic allies of Nebalia.}

Having studied the anatomy and development of Nebalia we are prepared to compare it with a group of fossil forms which are scattered through the older Paleozoic rocks from the lowest Silurian to the Carboniferous. In a brief article ${ }^{1}$ Mr. Salter, nearly twenty years since, sketched out the characters and showed the relationship of Ceratiocaris and a number of allied forms to Nebalia in the following paragraph:

"Before the structure of Ceratiocaris was known, of which genus a reduced figure is here given, the rostral portion of Peltocaris could not have been understood. But a reference to the accompanying series of wood-cuts will show that a tolerably broad rostrum, placed in the same relative position, occurs in Ceratiocaris. In the recent Nebalia it is fixed, and in Dithyrocaris and other genera it is perhaps yet to be discovered. Again, Ceratiocaris, together with its movable rostrum, has a bivalved shell, yet habitually keeps its valves half closed, as I learn from perfect specimens."

Salter then enumerates the characteristics of the fossil genera, beginning with Hymenocaris, which he considers the more generalized type, and in the wood-cuts which we partly here produce shows the geologi. cal succession of these genera, which also serves as a genealogical tableHe regards them as Phyllopods, associating Estheria and Apus, regard. ing the latter as "the most complete and decided form, and it is one of the latest of the group, as it commences in the Trias." He also says: "The links between these coal-measure forms and those of recent times are many of them wanting; but in Nebalia we have a good representative of the compact, shield-shaped form of Ceratiocaris, the two valves soldered into one, and the rostrum attached, the eyes being still beneath the carapace." It is evident from this that Mr. Salter regarded the fossil genera he enumerates as allied to and as the ancestors of Nebalia, and as representatives of it in Palæozoic times. He evidently adopted the views of Milne-Edwards and others as to the Phyllopodous nature of Nebalia.

${ }^{1}$ On Peltocaris, a new genus of Silurian Crustacea, by J. W. Salter, Quarterly Journal of the Geological Society of London, vol. xix, 1863, p. 8\%. 
Discarding the Phyllopod forms, we here reproduce Salter's figures and geological succession, which has been confirmed by the discoveries of Barrande and $\mathrm{H}$. Woodward. Salter's figure of Nebalia is, however, replaced by an original one.

In his article on the structure and systematic position of Nebalia, ${ }^{1}$ Claus thus refers to the paleozoic forms:

"It is generally considered that the oldest paleozoic crustacean remains whose shells and form of the body partly resemble

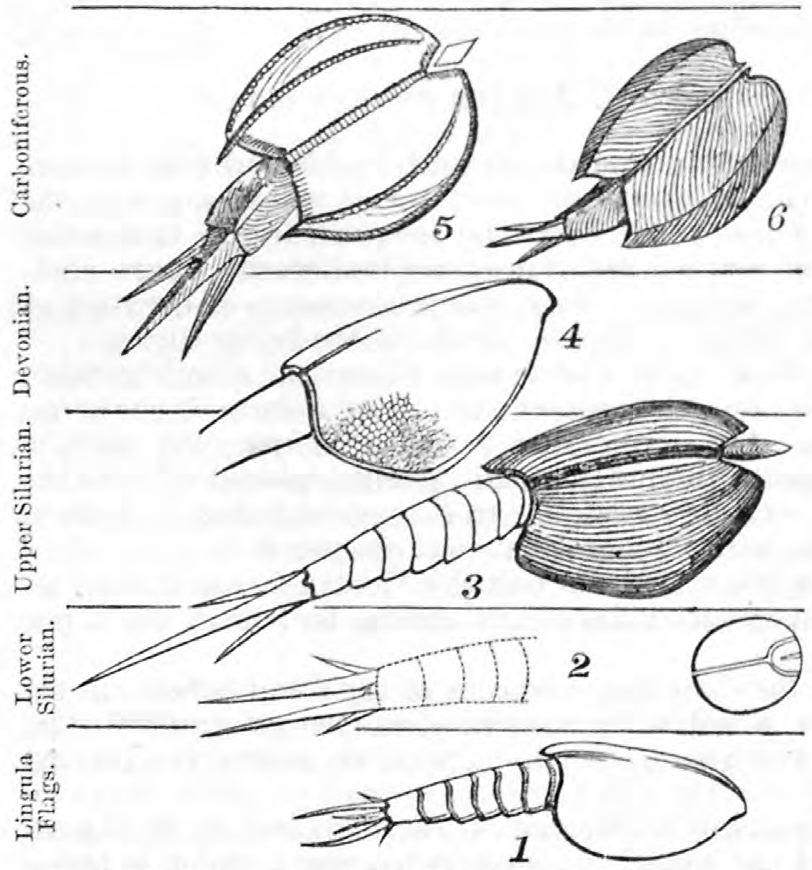

Fig. 69.-1. Hymenocaris (Lingula Flags) ; 2. Peltocaris (Lower Silurian); 3. Ceratiocaris (Upper Silurian); 4. Dictyocaris (Devonian); 5. Dithyrocaris (Carboniferous); (6. Argus); 7. Nebalia (Recent).
Apus, and partly show a great simi. larity to Nebalia, for this reason are considered to be Phyllopods, though we are without any information as to the nature of the limbs. But now the instruc. tive error, to which the consideration of Nebalia gave occasion, will lead us to exercise greater caution in the interpretation of such incom. pleteand imperfectly known remains.

"In Ceratiocaris Salter we have a great Nebalia-like carapace by which a series of free segments were covered, and moreover a long well-separated lancet-formed rostrum. On the other hand, the form of the abdomen, with the powerfully developed telson beset with lateral spines, indicates a different form, which also finds expression in the appendages of C. papilio Salt. figured as antennæ or thoracic limbs. If these representations indicate true limbs, then they remind us most of the larval limbs of Decapods. So also the position of Dictyocaris Salt. and Dithyrocaris of Scouler to the other silurian fossils regarded as Phyllopods (Hymenocaris, Peltocaris) will remain problematical until 
we have obtained more precise explanations as to the nature of their limbs.

"It is in the highest degree probable, however, that all these forms are not true Phyllopods, but have belonged to a type of Crustacea, of which now there are no living representatives, but which, taking their origin from forms allied to the lower types of Entomostraca, have prepared the way for the Malacostracan type. Such a connecting link, which has served to the present day, we evidently find in the genus Nebalia."

In $1879,{ }^{1}$ without knowing the views of Claus, just quoted, we published the following brief notice of the leading characteristies of the group, and proposed that the paleozoic fossil forms, Ceratiocaris, etc., be united with the Nebaliadæ to form a separate order of Crustacea under the name of Phyllocarida.

"The Nebaliada, represented by the existing genus Nebalia, have generally been considered to form a family of Phrllopod Crustacea. Metschnikuff; who studied the embryology of Nebalia, considered it to be a 'Phyllopodiform Decapod.' Besides the resemblance to the Decapods, there is also a combination of Copepod and Phyllopod characteristics. The type is an instance of a generalized one, and is of high antiquity, having been ushered in during the earliest Silurian Period, when there were, when we regard the relative size of most Crustacea, and especially of living Nebalia, gigantic forms. Such was Dithyrocaris, which must have been over a foot long, the carapace being 7 inches long. The modern Nebalia is small, about half an inch in length, with the body compressed, the carapace bivalved as in Limnadia, one of the genuine Phyllopods. There is a large rostrum overhanging the head; stalked eyes; and, besides two pairs of antennæ and mouth parts, eight pairs of leaf-like, short, respiratory feet, which are succeeded by swimming feet. There is no metamorphosis, development being direct.

"Of the fossil forms, Hymenocaris was regarded by Salter as "the more generalized type.' The genera Peltocaris and Discinocaris characterize the Lower Silurian Period, Ceratiocaris the Upper, Dictyocaris the Up. per Silurian and the lowest Devonian strata, Dithyrocaris and Argus the Carboniferous Period. Our existing northeastern species is Nebalia lipes (Fabricius), which occurs from Maine to Greenland.

"The Nebaliads were the forerunners of the Decapoda, and form, we believe, the type of a distinct order of Crustacea, for which the name Phyllocarida is proposed."

A slightly fuller account of the order was also published in the writer's Zoology, ${ }^{2}$ and the order Phyllocarida was placed (pp. 325, 326) below Tetradecapods and Decapods, the scheme then presented being on the following page:

On examining the figures of Salter and of Barrande, for we have been unable to study any of the fossils themselves owing to their extreme rarity, the relationship to Nebalia is very marked, as seen in the form of the carapace, the nearly free or detached rostrum, unless the separation took place after the death of the animal, and also of the rather long, slender abdomen. Upon examining the appendages at the end of the abdomen there is to be seen an important distinction from Nebalia; a long, slender telson is usually present, with a single pair of large caudal stylets, or cercopoda, in form like those of Nebalia. But in Hymenocaris and Peltocaris the telson appears to be represented by a pair of small

${ }^{1}$ The Nebaliad Crustacea as types of a new order. By A. S. Packard, jr. American Naturalist, February, 1879, vol. XIII, p. 128.

${ }^{2}$ American Science Series. Zoology for High Schools and Colleges, 1st edition, 1879. $12^{\circ}$. H. Holt \& Co., New York. 
(in Peltocaris minute) spines. In the presence of the telson in the typical fossil genus Ceratiocaris we certainly have an important character separating the type with its allies from Nebalia, and allying them to the Decapods; and thus in the provisional synopsis of the order presented farther on, we have placed the fossil forms in a separate suborder from the Nebaliadce.

CLASSIFICATION OF THE SUBCLASSES AND ORDERS OF CRUSTACEA.

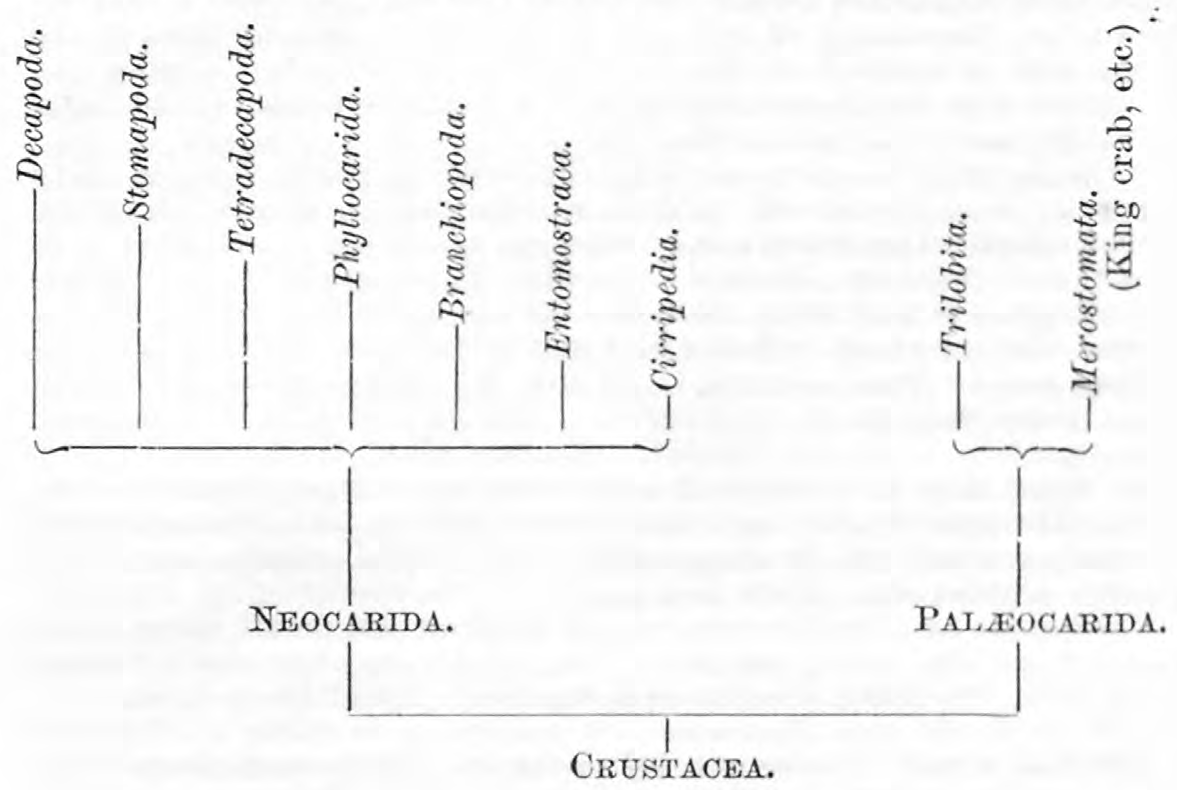

While the posterior edges of the abdominal segments in Hymenocaris appear to be spined as in Nebalia, there are some characteristies of importance in the fossil forms which deserve mention; these are the seulptured carapace, especially of Dictyocaris, in which the surface is reticnlated. ${ }^{1}$ Moreover the size of these genera was enormous, but if we, as we seem to be warranted in doing, regard Nebalia as a survivor and decrepit or old-age type of the order, which has lost the ornamentation of the integument, the size, and the telson even, being dwarfed, smoothskinned, and in general very simple compared with the forms which existed at the time when the type culminated and before it began to die out, we may have an explanation of the greater simplicity of the carapace and abdomen of Nebalia, as compared with its paleozoic ancestors.

From our total lack of any knowledge of the nature of the limbs of

${ }^{1}$ It should here be remarked that while the carapace of Nebalia is smooth, upon making a section of it a reticulated structure is plainly seen in the parenchyma or soft parts of the shell, but it is entirely too minute to be perceptible in the shell even under high powers. This structure may be comparable with that of Dictyocaris, especially as Salter remarks (Ann. and Mag. Nat. Hist., 1866, p. 161): "The entire surface of the carapace is marked with hexagonal reticnlations one-thirtieth of a line in diameter, of which the area are convex and the bonnding lines sunk on the exterior aspect. This would, I think, indicate the ornament to be connected with the structure of the carapace rather than to be a mere external sculpturing. As no films can be obtained thick enough to furnish a section for microscopic examination, the point cannot be ascertained." 
the fossil Phyllocarida, we have to be guided solely by analogy, often an uncertain and delusive guide. But, in the absence of any evidence to the contrary, ${ }^{1}$ there is every reason to suppose that the appendages of the head, thorax, and abdomen were on the type of Nebalia, since there is such a close correspondence in the form of the carapace, rostrum, and abdomen.

But whatever may be the differences between the fossil forms represented by Ceratiocaris, etc., they certainly seem to approach Nebalia much nearer than any other known type of Crustacea; they do not belong to the Decapods; they present a vague and general resemblance to the zoëa or larva of the Decapods, but no zoëa has a telson, though one is developed in a postzoëal stage; they do not belong to any other Malacostracous type, nor do they belong to any existing Entomostracous type, using those terms in the old sense. No naturalist or paleontolo. gist has referred them with certainty to the Decapods, or to any Crustacean type than the Phyllopods. To this type (in the opinion of Metschnikoff and Claus, who have studied them most closely) they certainly do not belong; and thus, reasoning by exclusion, they either belong to the group of which Nebalia is a type, or they are members of a lost, extinct group. The natural conclusion, in the light of our present knowledge, is that they are members of the group represented by the existing Nebalia.

In order, then, to summarize our present knowledge of the living $\mathrm{Ne}$ balia and its fossil allies, we will give what we regard as the characters of the group and subdivisions, which may be regarded as provisional, though perhaps of some present use.

\section{Order PHYLLOCARIDA Packard.}

External diagnostic characters of the order.-Body compressed; consisting of 21 segments, 5 cephalic, 8 thoracic, and 8 abdominal. Carapace compressed, with no regular hinge, loosely attached to the body by an adductor muscle; with a movable rostrum inserted in a depression in the front edge, the carapace covering the basal joints of the abdomen. One pair of stalked eyes; no simple eyes. Two pairs of well-developed, many-jointed, long, large antennæ, the first pair biramous, the $2 \mathrm{~d}$ pair with a very long flagellum in the male. Mandibles weak, with a remarkably long 3-jointed palpus. Two pairs of maxillæ; the first with a remarkably long, slender multiarticulate exopodite; $2 \mathrm{~d}$ pair well developed, biramous; no maxillipedes; 8 pairs of biramous, broad, thin, respiratory, thoracic feet, not adapted for walking; the exopodites divided into a gill and flabellum; 4 pairs of large and 2 pairs of small abdominal swimming feet; no appendages on the 7th segment, the terminal one bearing two long caudal appendages (cercopoda). No telson present in the living species; well developed in the Ceratiocarida. Young developed in a brood sac; development direct; no marked metamorphosis; the young but slightly differing from the adult.

Remarks.-By the sum of the foregoing characters the Phyllocaridæ appear to be excluded from any other group of Neocaridan Crustacea.

${ }^{1}$ Close scrutiny of specimens in existence may yet show indications as to the nature of the limbs; for example, Saltor figures, in the Annals and Magazine of Natural History, 3d series, vol. 5, 1860, p. 154, fig. 3e, what he calls the jaws of Ceratiocaris papilio, but the figure appears to us rather to represent a 4-jointed piece of an antenna. In fig. 2 there are represented the tergal portion of seven segments lying under the carapace. If fresh attention were directed to the discovery of the nature of the limbs success might result. 
The differential characters separating them from the Decapods or any other Malacostracous type are:

1. The loosely-attached carapace, the two halves connected by an adductor muscle.

2. The movable rostrum, loosely attached to the carapace.

3 . The very long and large mandibular palpus; the long, slender appendage of the first maxillæ, and the very long biramous maxillæ.

4. The absence of any maxillipedes.

5 . The 8 pairs of pseudophyllopod thoracic feet, not adapted for walking; the animal swimming on its back.

7. No zoëa-formed larva.

The differential characters from the Phyllopods are the following:

1. Carapace not hinged; a rostrum present.

2. Two pairs of well-developed long and large multiarticulate antennæ; the hinder pair in the male longer than the 1st pair.

3. The thorax and its appendages clearly differentiated from an ab. domen.

Internal organs-no functional shell gland; no highly developed liver tubes like those of all Phyllopods; stomach and cœeal appendages (liver) entirely unlike those of Phyllopods.

The nervous system is entirely unlike the Phyllopod type, and approaches more the Decapod and Tetradecapod type.

The resemblance to the Copepoda is in some points quite striking; this is seen in the equal size of the two pairs of antennæ, in the form of the abdomen, and the two caudal appendages, as well as the spines on the hind edge of the segment, in the well-developed palpus of the mandibles, in the absence of maxillipedes, as well as the simple reproductive glands.

In short, we regard the Phyllocarida as an accelerated, prematurative type of Crustacea which became well established in the lowest Pri-

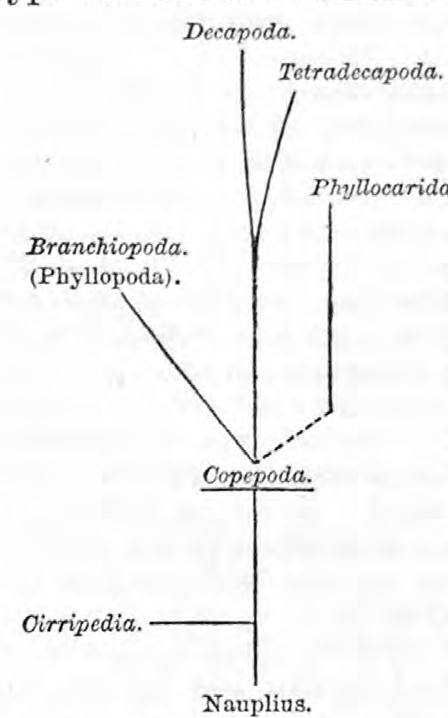

rida to other Neocaridan Crustacea. mordial Period, flourishing at a time when there was no Malacostracous forms, and which eulminater in the Upper Silurian Period, and became nearly extinct at the close of the Carboniferous. Judging the group by the structure of Nebalia alone, whether we consider the external or the internal structure, it is a highly composite or synthetic type, combining Copepod, Phyllopod, and Decapod-like features with more fundamental characteristic ones of its own. The group existed at a time when, save in the Carboniferous Period, no Mala. costraca, or at least very few, existed, and they thus anticipated the incoming of the more specialized Decapods. Like many other synthetic types, the fossil representatives were of colossal size compared with the living survivors.

The accompanying diagram will express our views as to the relation of the Phylloca- 


\section{Family NEBALIAD $A$ B Baird, 1850.}

With the characters of the order; the telson wanting.

\section{Genus Nebalia Leach, 1815.}

With the characters of the family. Paranebalia has narrow gills.

Nebalia bipes Kroyer, Grönlands Amfipoder, 91; Kroyer's Naturh. Tidskrift. 436, 1847. Cancer bipes O. Fabricius, Fauna Groenlandica, 246, fig. 2, 1870.

Nebalia bipes Baird, Brit. Entomost. 1850.

Monoculus rostratus Montagu, Linn. Trans. 1807.

N. herbstii Leach, Zool. Mise. i, 100, Pl. 44, 1814.

N. glabra Lamarck, An. S. Vert. v, 345 , Bosc.

N. ciliata Lamarck.

N. montagui Thompson.

Nebalia geoffroyi Edwards, Ann. Sc. Nat. 1828. (N. strausii Risso.)

Nebalia longipes Willemœs-Suhm, Trans. Linn. Soc. London, 2d ser, vol. 1, 1875. Bermuda.

Paranebalia longipes Clans. (See Carus' Yahresbericht, 1880).

Nebalia longicornis Thompson, Ann. \& Mag. Nat. Hist., 1879, 418. New Zealand.

We found in August, 1877, what is probably a fifth species, closely allied to $N$. bipes, between tide-marks at Victoria, Vancouver's Island, Brit. Columbia. The specimen was unfortunately lost.

\section{Family CERATIOCARID E Salter, 1860.}

Often gigantic forms, like Nebalia, but with a long, spine-like telson, which is sometimes represented by a pair of spines.

It is possible that the Nebaliadre and Ceratiocaridx should rather stand as suborders; and that under the Ceratiocaridæ there are two families, one represented by Ceratiocaris and allies, and the other by Peltocaris.

Salter states that the carapace of Dictyocaris slimoni from the upper and lower Lndlow Rock "frequently measured from 9 inches to a foot in length!" If so, then the entire length of the animal must have approximated 2 feet; and he says the length of the largest Ceratiocaris yet known could not have been less than 15 inches.

The following imperfect synopsis of the fossil genera is taken, with some modifications, mainly from Salter; it begins with Hymenocaris, which Salter regarded as the oldest as well as most generalized type. (Compare Barrande's account, Syst. Sil. vol. 1, 1872, p. 436.)

\section{Genus Hymenocaris.}

The shield neither flat nor bivalved, but simply bent; and without any rostrum. A median number (6-7) of free abdominal segments; the body ending in 3 pairs of spines. Lingula flags or Primordial zone.

\section{Genus Peltocaris Salter, 1863.}

Only the carapace known, which is orbicular, with a median suture, and a deep, rounded rostrum? or piece whose front edge is continuous with the rounded front edge of the carapace.

$P$. harknessi Salter, Journ. Geol. Soc. 1863. Llandeilo flags.

P. aptychoides Salter, 1. c. p. 87. 
Genus Ceratiocaris MeCoy, 1850.

Leptocheles McCoy, 1850.

Carapace bivalved, united by a hinge-like suture, the valves orate, semiovate, or subquadrate, with a long, narrow rostrum. Head (or thorax?) with jointed appendages. Body many (fourteen or more)

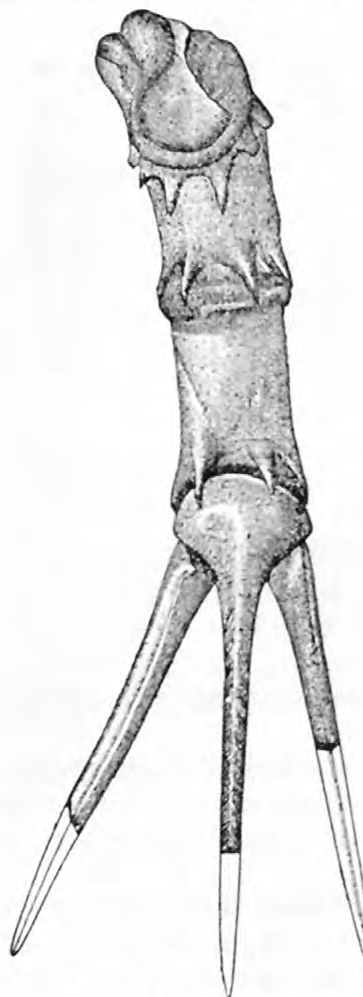
jointed, of which 5 or 6 segments extend beyond the carapace; the last one longest, and support. ing a strong, bulbous telson and two shorter appendages. Surface generally lineate, often finely so.

C. papilio Salter, Siluria, 262, figs. 1,2, vol. 5. Great Britain.

C. stygius Salter, Ann. Mag. Nat. Hist. 1860; Quart. Am. $1860,156$. Great Britain.

C. inornatus MeCoy, 1. c, 156 . Great Britain.

C. murchisoni McCoy, 1. c. 157. Great Britain.

C. leptodactylus Mcioy, 1. c. 157. Great Britain.

C. robustus Salter, l. c. 157 . Great Britain.

C. decornes Phillips, Mem. Geol. Surv, ii, Pl. 30, fig. 5. Great Britain.

C.? ensis Salter, 1. c. 159. Great Britain.

C. vesica Salter, 1. c. 159 . Great Britain.

C. cassia Salter, 1. c. 159. Great Britain

C. aptychoides Salter, Quart. Geol. Journ. viii, Pl. 21, fig. 10. Great Britain.

C. Tudensis Woodw., Geol. Mag. viii, 3, 1871. (Over two feet in length.)

C. oretonensis Woodw., 1 c.

C. truncatus Woodw., l. e.

C.? brevicauda Salter; Bigsby, J. J. Thesaurus 3ilur. 73, 1868.

C. 7 gigas Salter; Bigsby, J. J. Thesaurus silu $\therefore$ 73, 1868.

C. 9 legumen Salter; Bigsby. J. J. Thesaurus silur. 73, 1868.

C. $?$ perornatus Salter; Bigsby, J. J. Thesaurus silur, 73, 1868.

C. bohemicus Barrande, Syst. Sil. 447, Pl. 19. Bohemia.

C. debilis Barr., 1. c. Pls. 18, 19, 26, 31. Bchemia.

C. decipiens Barr., 1. c. Pl. 21. Bohemia.

C. docens Barr., l. c. PI. 21. Bohemia.

Fig. 70-Echinocaris punctatus; C. inaqualis Barr., l. c. Pl. 19, var, decurtata. Bohemia. abdomen, dorsal view, natural size. From Hall.

\section{C. tardus Barr., 1. c. Pl. 18. Bohemia.}

C. primulus Barr., 1. c. Pl. 18. Bohemia.

C. zcharyi Barr., 1. c. Pl. 32. Bohemia.

C. longicaudus Hall, 16th Rep. State Cab. N. York, Pl. 1, figs. 4-7, 1863. Genesee.

C. (Onchus) dewii Hall, ${ }^{1}$ Pal. N. York, ii, 320, P1. 71, 1852. New York.

C. maccoyanus Hall, Pal. N. York, iii, 420, 1859. New York State. Devonian. New York.

C. acuminatus Hall, 1. c. 1859 . New York.

C. aculeatus Hall, l. c. 1859 . New York.

\section{Genus Echinocaris Whitfield, 1880.}

Carapace bivalve, valves subovate. Abdomen compnsed of several segments, each bearing spines on the posterior margin. Type, $E$. $s u b$ levis Whitfield.

E. subleris Whitfield, Amer. Journ. Sc. 36, 1880.

E. punctatus (Hall), 16th Rep. State Cab. N. Y. 74, P1. 8, fig. 1.

${ }^{1}$ The following species are of doubtful position (see, also, Whitfield, l. c.):

Ceratiocaris (Colpocaris) bradleyi Meek, Ohio Geol. Surv. Palæontology, Pl. 18, figs. $6 a-e, 318,1875$.

Ceratiocaris (Colpocaris) elytroides Meek, l. c. Pl. 18, figs. 5a, $b, c, 319$.

Ceratiocaris (Solenocaris) striata Meek, l. c. Pl. 1๙, figs. 4a, b, c, 321. 
E. armatus $($ Hall $)=E$. punctatus $($ Hall $)$, Hamilton group, Devonian, New York.

E. pustulosus Whittield, 1. c. 38, Erie shales, Devonian. Ohio.

E. multinodosus Whittield, 1. c. 3๖, Erie shales, Devonian. Ohio.

Genus Discriocaris Woodward, 1866.

Like the upper valve of a Discina, but with a wedge-shaped opening which cuts the disk nearly to its center.

D. browniana Woodward, Proc. Geol. Soc. 502, 1866.

\section{Genus Spathiocaris Clarke, 1882.}

Differs from Discinocaris in the presence of the "rostrum" or plate acting as another valve to cover the cleft, and also in its more nearly circular outline (Clarke).

S. emersonii Clarke, Amer. Jour. Sc. xxiii, 477, June, 1882.

\section{Genus Lisgocaris Clarke.}

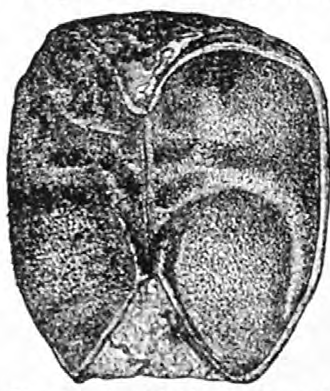

Fig. 71 A.-Echinocaris multi. nodosus. After Whitfield.

Carapace in one piece, without evidence of dorsal suture. Periphery subpentagonal, lateral edges parallel, making sharp angles with the two anterior edges, which are re-entrantly curved, and meet in the axis of the carapace. As in Spathiocaris, there is a cleft beginning centrally After Whitifieldinocaris sublevis. at the highest point of the carapace.

L. lutheri Clarke, 1. c. 478,1882 .

\section{Aptychopsis Barrande, 1872.}

Differs from Peltocaris in the rostrum being triangular instead of parabolical; and from Discinocaris in having no suture indicating the
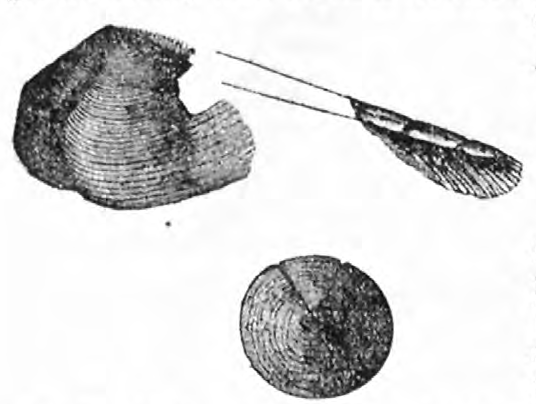

Fig. 72.-Discinocaris browniana, natural size, side view and disk, with the wedge-shaped rostrum in situ. After Woodward. furrow. separation of the two principal valves.

A. primus Barr. 1. c. 457 , Pl. 33,1872 . Bohemia.

\section{Genus Dictyocaris Salter (1860).}

Carapace ample, bent along the dorsal line, but not two-ralved, largely reticulate, the area of the reticulations being convex. The shape of the carapace is rudely triangular, pointed or rounded in front, truncate and produced behind, and margined along the

D. slimoni Salter, Ann. Mag. Nat. Hist. vol. 5, 1860, 162.

D. ramsayi Salter, l. c. 162 .

\section{Genus Dithyrochris Scouler.}

Carapace large, apparently covering all but the last abdominal segment; "the rostrum minute or possibiy (but not probably) absent" (Salter). 
Lower Carboniferous Rocks. The genus Argus seems to be the same as Dithyrocaris, although Salter does not express that opinion. Fig. $69^{6}$ represents Argus testudineus; the surface of the body is striated. Dithy. rocaris pholadomyia Salter had a earapace 7 inches long. The genus Argus of Scouler is apparently the same as Dithyrocaris.

D. tentistriatus McCoy, Woodward, Geol. Mag. viii. Great Britain.

D. belli Woodw. 1. c. Devonian, Gaspé, Canada.

D. Neptuni Hall (Fig. 73), 16th Ann. Rep. State Cabinet, N. York. 75, Pl. I, fig. 9, 1863. Hamilton group, Devonian of New York.

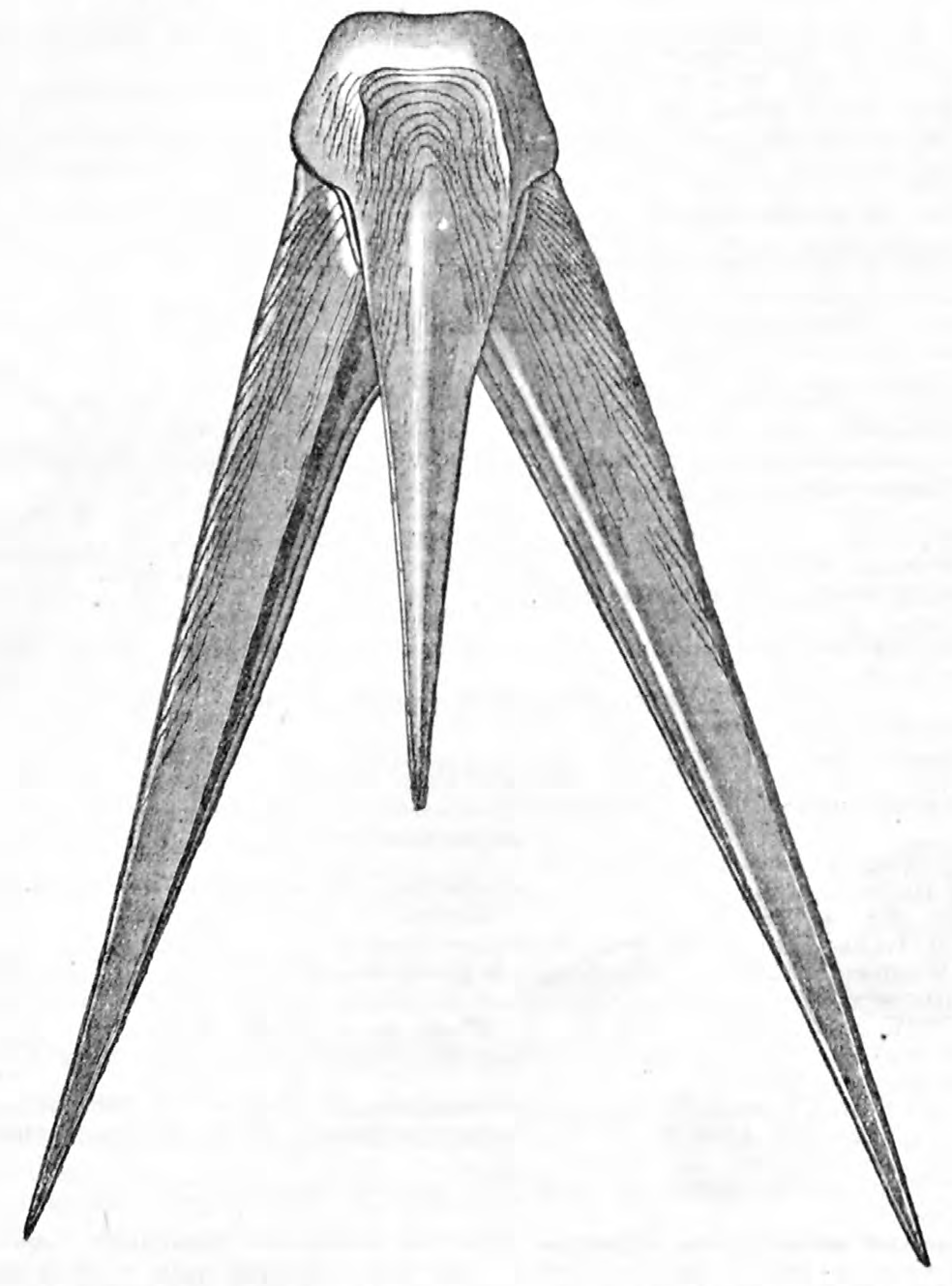

Fig. 73.-Dithyrocaris neptuni Hall; telson atd cercopoda, natural size. From Hall.

Hall's figure was made from a cast, no restoration having been attempted. From the size of the telson and the cercopods, it is evident that the animal must have been enormous, perhaps between two and three feet in length.

\section{Genus RHAchura Scudder, 1878.}

R. venosa Scudd., Proc. Bost. Soc. Nat. Hist. XtX, 296. Pl. 9, fig. 3, 3a. March, 1878. Coal measures, Dauville, Ohio. 


\title{
VIII.-BIBLIOGRAPHY.
}

\section{PHYLLOPODA.}

\author{
a. LIVING SPECIES.
}

1. J. L. Frisch, Vom flossfüissigen seewurm mit dem Schild (Beschreibung von allerley Insecta in Tentschland, $\mathrm{x}$, i, Taf. i). 1732.

2. R. Richardson, Part of a letter concerning the Squilla aquæ dulcis (Philos. Trans. Royal Soe. London, vol. 38, No. 433, 331, f.). 1734.

3. J. Th. Kiein, Insectum aquaticum antea non descriptum, eujus iconem et descriptionem misit (Philos. Trans. Royal Soc. London, vol. xl, No. 447, 150-152). 1737 .

4. J. CHR. SCḦ̈FFER, Apus pisciformis, insecti aquatici species noviter detecta. Cum tabula ænea picta. i. Norimbergæ, 1752. 4०. Editio ii, Ratisbonæ, 1757. 4\%.

5. J. Chr. Schäfrer, Der fischförmige Kiefenfuss in stehenden Wassern um Regensburg, Anfangs in der lateinischer und itzo in der deutchen Mundart heschrieben. Mit 1 illum. Kupfertafel. Regensburg, 1754. 4․ (Also in "Abhandlungen von Insecten," ii. Band, 39-64, 1 Taf.

6. J. Chr. Schäffer, Der Krebsförmige Kiefenfuss mit der kurzen und langen Schwanzklappe beschrieben. Mit 7illum. Kupfertafeln. Regensburg, 1756. $4^{\circ}$. (Also in "Abhandlungen von Insecten," ii, 6 $\tau$-200, 7 Tateln).

7. J. A. Schlosser, Auszug aus einem Brief wegen einer neuen Art von Insecten (Hamburger Magazin, xvii, 108-112). 1756.

8. EDWARD KING, A description of a very remarkable aquatick insect (Philos. Trans. Royal Soc. London, vol. 57, 72-74). 1767. Transl. in German in Hamburger Magazin, $477-480$.

9. Chr. F. Schulze, Der Krebsartige Kiefenfuss in den Dresdener Gegende. Neene Hamb. Magazin, No. 68, 99-132). 1772.

10. J. BeckmanN, Beitrag zur Naturgeschichte des Kiefenfusses (Naturforscher No. $6,35-40) . \quad 1775$.

11. F. H. Loschge, Beobachtungen an dem Monoculus apus (Naturforscher No. 19, 60-69). 1783.

12. G. SнAw, Description of the Cancer stagnalis of Linnæus (Transactions of the Linnean Soc. of London, i, 103-110). 1391.

13. Benedict Prevost. Histoire d'un Insecte (ou d'un Crustacé) que l'auteur a cru devoir appeler Chirocéphale, et de la suite remarquable des métamorphoses qu'il subit (Journal de physique, lvii, 37-54 and 89-106, pl. i). 1803.

14. Th. Racketт, Observations on Cancer salinus, (Trans. Linnean Soc. London, xi, 205, f.). 1815 .

15. H. M. GAEDE, Monoculns apus, Schäffer's Kiefenfuss mit der Schwanzklappe in (Wiedemann's zoologisehes Magazin, i, 87-91). 1817.

16. A. Brongniart, Mémoire sur le Limuadia, nonvean genre des crustacés (Mémoires du muséum d'histoire naturelle, vi, 83-92, pl. 13). 1820.

17. J. KRYNICKI, Des Limnadies (Bulletin des naturalistes de Moscou, ii, 173-182). 1830.

18. A. Berthold, Beiträge zur Anatomie des Apus cancriformis (Isis, 685-694). 1830.

19. Fischer von Waldheim, Sur une nouvelle espèce de Branchipus (Bulletin d. natur, de Moscon, vii, 452-461). 1834.

20. J. V. Thompson, Zoological researches and illustrations, vol. 1, part 6. Cork, 1834.

21. Hermann Burmerster, Ueber den Bau der Augen bei Branchipus paludosus, Chirocephalus Prevost (Archiv fuir Anatomie und Physiologie. Jahrgang 1835, $529-534$, plate 13$)$.

22. Payen, Note sur les causes de la coloration en rouge des marais salans (Comptes rend. de l'Inst. de France, iii, 541-546). 1836.

23. PAyen, Lettre sur les crustacés colorés en rouge, qu'on rencontre dans les marais salans (Annales de sciences naturelles, 2. sér., Zoologie, x, 315-318). 1838.

24. HernRICH Rathke, Ueber Thiere welche in fast gesättigter Salzauflösung leben (Froriep's Neue Notizen, ii, No. 27, 68-i1). 1837.

25. H. Rathke, Zur Fanna der Krim (Petersburg, 1836), 105-111, Tab. 6. 
26. F. E. Gứrin-Méneville, Note monographiqne sur le genre Limnadia et description d'une espèce nouvelle (Magasin de Zool., vii), 7, plate 21. 1837.

27. Herc. Straus-Dürkhem, Ueber Estheria datalacensis Rỉppell (Museum Senkenbergianum, ii, 117-128, Tab. vii). 1837.

28. Audours, Genre Cyzicus (Bulletin de la soc. entomolog. de France, 9-11). 1<37.

29. N. Joly, Histoire d'un petit crustacé, anquel on a faussement attribué la colo. ration en rouge des marais salans méditerranéens, suivie de recherches sur la cause réelle de cette coloration (Annal. d. sc. nat., 2. sér., xiii, 225-290, illustr.). 1840.

30. G. ZADDACH, De apodis cancriformis anatome et historia evolutionis. 4 plates. Bonnæ, 1841.

31. N. JoLy, Recherches zoologiques, anatomiques et physiologiqnes sur l'Isanra cycladoides. (Annales des sciences naturelles, 2. sér., xvii, Zool., 293-349.) 1842.

32. N. Joly, Note sur les genres Limnadia, Estheria, Cyzicus et Isanra, faisant suite au mémoire sur l'Isaura cyclad. (Annal. sc. nat., 2. sér., xvii, Zool., 349-361). 1842.

33. S. Haldeman, Limnadia coriacea n. sp. (Proceed. Academy of Nat. Sciences of Philad., i, 184). 1842.

34. WAga, Nouvelle espèce des crustacés du genre de Branchipes (Annal. soc. ent. de France xi, 261-263, pl. xi). 1×42.

35. J. Leconte, On a new species of Apus (Annals of the Lycenm of nat. hist. N. Y. iv, 155-156, plate -). Ameriean Jonrn. Science, 2d ser., 1i, 274). 1846.

36. J. BuDGE, Bemerkungen iber Branchipus palndosus (Verhandlungen des naturh. Vereins der prenss. Rheinlande, iii, 66-95, illustr.) 1846.

37. C. Mayer, Ueber Branchipus stagnalis (Froriep's Nene Notizen, xxxviii, No. 832, $273-275) . \quad 1846$.

38. H. KroYer, Apus glacialis (Naturhistor. Tidsskrift, 2 Raek, ii, 431-435), 1847.

39. W. BAIRD, mouograph of the fam. Limnadiadæ a family of entomostracons crustacea (Proceed. Zool. Soc. London, xvii, 84-90, pl. xi). 1849.

40. C. 'Th. vox Srenold, Ueber die rothen Beutel des Apus cancriformis Latr. (Isis, $429-434) .1831$.

41. C. Th. von Sinbord, Ueber Isaura cycladoides Joly als Beitrag zur Schlesischen Fauna (28ter Jahresb. d. Schles. Ges. f. vat. Cultur, 89). 1850.

42. C. Th. E. v. Snebold, Beiträge zur Parthenogenesis der Arthropoden. Leipzig, $1 \times 71$.

43. C. Th. E. v. Srebold, Ueber Parthenogenesis der Artemia 8alina. Sitzung der math. phys. Classe der k. b. Akademie der Wissenschaften in München, Heft ii, 168. 1873 .

44. C. TH. E. V. Sinbold, Ueber die in München gezichtete Artemia fertilis aus dem grossen Salzsee von Utah. Separat Druck aus den Verhandlungen der 59 ten Jahresversammlung der Schweiz. naturf. Gesellschaft, in Basel 18.6, 16.

45. Franz Lfydig, Ueber Artemia salina und Branchipus stagnalis; Beitrag zur anatomischen Kenntniss dieser Thiere (Zeitschritt für wiss. Zoologie, iii, 280307, Tab. viii). 1851.

46. W. BAIrd, Monograph of the family Branchiopodiæ with a description of a new genus and a species of the family and two Limnadiadw (Proceed. Zool. Society of London, xx, 18-31, plates). 1852.

47. W. BAIKD, monograph of the family Apodidæ, a family of crustaceans belonging to the entomostraca with a description of a new species and two Ostracoda. (Proc. Zoogloical Soc. Lond., xx., 1-8, plates). 1852.

48. ED. Grube, Bemerkungen über die Phyllopoden, nebst Uebersicht ihrer Gattungen (Wiegmann's Archiv tiir Nat., xix, 71-17\%, 3 plates and appendix 247). 1853.

49. ED. Grube, Ueber die Gattungen Estheria nnd Limnadia und einen neuen Apus (Wiegmann's Archiv. f. Nat., xxxi, 203-282, plates). 1865.

50. Charles Girard, On a new Entomostracan of the family Limnadide inhabiting the western waters (Proceed. Academy Natural Sciences Plitiad., vii, 3). 1854.

51. Lrèvrn, Branchipus Ondneyi, der Fezzar-Wurm (Neueste Schriften der uat. Ges. Danzig, v, 4tes Heft, pp. 10, plate). 1856.

52. A. Kozubowskx, Ueber den männlichen Apus cancriformis (Wiegmann's Archiv. f. Naturg., xxiii, 312-318, Tab. xiii). 1857.

53. C. Chyzer and A. Toth, Beitrag zur Kenntniss des Branchipus ferox Edw. (Naturfreund Ungarns, ii, 1). 18.58 .

54. G. B. Criver.li, Di un nuovo Crostaceo della famiglia dei Branchiopodi Fillopodi, riscontrato nella provincia di Pavia (Memorie dell' Instituto Lombardo di Scienze, vii, 113-120, Tav. 1). $\mathbf{3} 859$.

55. Carl Claus, Ueber die Estherien, insbesondere über Estheria mexicana (Beiträge zur Kenntniss der Entomostr., 12-25, Tab. iii and iv). $1 \lessdot 60$.

56. C. Claus, Ein Australischer Limnadia. Nachrichten von der k. Gesellschaft der Wissenschaften, 6. M̈̈rz 1872. 
57. C. Claus, Ueber den Körperbau einer australischen Limnadia und iiber das Männehen derselben. Zeit. f. wissen. Zool. xxii, 355. Taf. xxix, xxx, 1872.

58. B. voN DyBowski, Beitrag. zur Phyllopoden-Fauna der Umgegend Berlins (Wiegmann's Archiv f. Nat., xxvi, 195-204, plate). 1860.

59. J. LuBbock, Notes on some new or little known species of freshwater Entomostraca (Transact. Linnean Soc. Lond., xxiv, 197-209). 1863.

60. Klunzincer, Beiträge zur Kenntniss der Limnadiden (Zeitschr. f. wiss. Zool. xiv, 139-164, plates). 1864.

61. Lerebocllet, Observations sur la génération et le dévelopement de la Limnadia Hermanni Brongn. (Annales d. scieuc. natur., 5. sér. Zoolog., v, 283-308, plate). 1866.

62. A. Friesch, Ueber das Vorkommen von Apus und Branchipus in Boehmen (Verhandl. d. zool. bot. Ges. Wien, xvi, 557-562). 1866.

63. R. Bucrinolz, Branchipus Grubei Dybowsky (Schriften der phys. ök. Gesellschaft zu Königsberg, v, 93-107, plate). 1866.

64. Klunzrnger, Ueher Branchipus rubricaudatus n. sp. (Zeitschr. f. wissensch. Zool., xvii, 23-33, plate). 1867.

65. E. S. Morse. Proc. Boston Society Nat. Hist., xi, 404. 1866-'68.

66. E. S. Monse. First Book of Zoology. New York, 1875, 120 (Estheria and Limnadia figured).

67. A. E. Verril., Descriptions of some new American Phyllopod Crustacea. Contr. to Zool. Mus. Yale College, No. iii. Amer. Journ. Sc., 244, xlviii. 1869. Ann. and Mag. Nat. Hist. London, 1869.

68. A. E. Verrit.. Observations on Phyllopod Crustacea of the family Branchipidæ, with descriptions of some new genera and species from America. Proc. Amer. Assoc. Adv. Se. for 1869 . July, 1870.

69. W. Lintseborg, Limnadia gigas (J. F. Hermann) förekommande i Sverige in

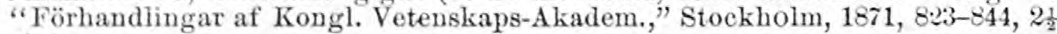
plates.

70. W. LIL IJEBorg, Synopsis Crustaceorum Svecicorum ordinis Branchiopodorum et subordinis Phyllopodorum. pp. 20. (Reg. Soc. Sc. Tpsaliensi tradita die viI, Apr. 1877.

71. A. S. PACKard, JR. Preliminary notice of new North American Phyllopoda. Amer, Jonm, Sc. and Arts, ser. 3, ii. August, 1871.

72. A. S. PACKARD, JR. Descriptions of new North Ameriean Phyllopoda. Sixth Report Peabody Acad. Sc. Salem, Mass., 54. 1874.

73. A. S. PACKARD, JR. Syuopsis of the fresh-water Phyllopoda of North America. Rep. U. s. Geol. Survey Terr. (F. V. Hayden in charge) for 1873. Zoology, 613. 1874 .

74. A S. PAckard, JR. New Phyllopod Crustaceans. American Naturalist, ix, 311. May, 1875 .

75. A. S. PACKARD, JR. Explorations of the Polaris Expedition. Amer. Nat. January, $18 \pi 7$.

76. A. S. PACKARD, JR. Descriptions of new Phyllopod Crustacea from the West. Bulletin U. S. Geol, and Geogr. Survey (F. V. Hayden in charge), iii, No. 1, 171. April 9, 1877 .

77. A. S. PACKARD, JR. Occnrrence of the Phyllopod Eubranchipus in winter. Amer. Nat., xii, 186. March, 1878.

78. A. S. PACKard, Jr. Notes on Phyllopod Crustacea. Amer. Nat., xiv, 53. January, 1880.

79. A. S. PACKARD, JR., A new Distomnm parasite in the egg-sacks of Apus. (Distomum apodis) American Naturalist, 142 . Feb. 1882.

80. Friedrich Braver, Beitrïge zur Kenntniss der Phyilopoden in Sitzungsberichte der k. Akad. d. Wissensch., lxr. Band, 1te Abth., 1 plate, 1-13. Wien, 1872.

81. Frmerich Brauer, Vorlänfige Mittheilungen über die Entwicklung und Lebensweise des Lepidnrus productus Bosc. In Sitzungsb. d. k. Akad. d. Wiss. Wien, Band lxix, 1te Abth. 1-12, 2 plates. $18 j 4$.

82. Friedricir Brauer, Beiträge zur Kenntniss der Phyllopoden. Sitzungsberichte der k. Akad, d. Wissen. Wien., Math-Naturw., Classe, lxxv. Band, v. Heft, 583, 8 Tuf. 1878 .

83. G. O. SArs, Bemmrkninger om de til Norges Fauna horende Phyllopoder in Vidensk. Selsk. Forhandlinger, 3-7. 1873.

84. F. Spangenberg, Zur Kemntniss von Branchipus stagnalis. Zeits. für wissen. Zool., xxv. Supp. Heft, 1, Taf. i-iii. 1875.

85. F. Spangenberg, Bemerkungen zur Anatomie der Limnadia Hermanni Brongn. Zeits. f. wissen. Zool., ¿xx. Supp. Band, 476. Mai, 1878.

86. Hennich Lenz, Estheria californica Packard. Inaug. dissertation, 24-40, 2 plates. Rostock, 1876.

87. H. Nitscne, Ueber die Geschlechtsorgane von Branchipus Grubii. Zeits. f. wissen. Zool., xxv. Suppl. Band, 281. Taf. xxii, Dec. 22. 1875. 
88. J. A. Ryder, Description of a new species of Chirocephalus (Ch. Holmani). Proceed. of the Academy of Natural Sciences, Philadelphia, 3 wood-cuts, 148149.1879.

89. J. A. RYDer, Description of a new Branchipod. Proceed. of the Acad. of Nat. Sciences Philad., 200-202 (Streptocephalus Sealii), 1 wooG-cut. 1879.

90. J. Whadimir Schmankewitsch. On Branchipus. Schriften deriii, Versammlung Russisch. Naturforschen, Zoolog. Theil.

91. J. Whadmir Schmankewitsch. Sitzung der neurussischen Gesellschaft der Naturforscher in Odessa, Sept. 20, 1874, ii, Th. ii.

92. W. J. Schmaxkewrtsch, Ueber das Verhältniss der Artemia salina Miln.-Edw. zur Artemia Muhlhausenii Miln. Edw. und dem Genus Branchipus Schaef. Zeits. f. wissen. Zoologie, xxv. Supp. Heft, 103, Taf. ii. 1875.

93. J. WhadimR SchmankEWITsch, Zur Kenntniss des Einflusses der äusseren Lebensbedingungen auf die Organisation der Thiere. Zeitsch. für wissensch. Zoologie, xxix, 429-494. 1877 .

94. Carr F. Gissler. Deseription of a hermaphroditic Phyllopod Crustacean (Eubranchipus vernalis), American Nntn"alist, 136, xv. February, 1881.

95. Carl F. Gissler. Evidences of the elieet of chemico-physical influences in the evolution of Branchiopod Crustaceans. American Naturalist, 280, xv. April, 1881.

\section{b. Fossil Phyllopoda.}

96. T. Rupert Joxes, A monograph of the fossil Estheriæ. Lond. Palæont. Society, 134,5 plates, 4 . 1862 .

97. T. RUPERT JoNEs, On fossil Estheria and their distribution (Quarterly Journ. Geol. Soe. Lond., xix, 140-157.- Natural Hist. Review, 262-276. 1863.

98. T. Rupert Jones, Note on Estheria Middendorfii (Quart. Journ. Geol. Soc. Lond. $\mathrm{xix}, 73), 1863$.

99. H. Laspeyres, Das fossile Phyllopoden-Genus Leaia Jones (Zeitschrift der dentschen geolog. Gesellschaft, 733-746, 1 plate). 1870.

100. A. S. PACKARD, Jr., A fossil Phyllopod Crustacean from the Quaternary clays of Canada. American Naturalist, 496, xv. June, 1881.

101. Jomn M. Clarke, New Phyllopod Crustaceans from the Devonian of Western New York. Amer. Journ Sc., 476, xxiii. June, 1882.

\section{PHYLLOCARID'A.}

\section{a. LIVING SPECIES.}

1. Henri Munne-Edwards, Annales des Sciences Naturelles, tome xiii, 1828.

2. Henri Milne-Edwards, Annales des Sciences Naturelles, 2. sér., tome iii, 1835.

3. Henri Milne-Edwards, Histoire Naturelles des Crustacés, tome iii, Paris, 1840.

4. Henrik Kroyer. Karcinologiske Bidrag. Naturhistorisk Tidskrift, ser, 2, ii, 436, 1847 .

5. Elias Metschnikoff (Abstract of Embryology of Nebalia). Sitzungsberichte der Naturforscherversammlung zu Hanover, 1865, 218. Also Keferstein's Jahresbericht, 1867.

6. Elias Metschntkof f, Development of Nebalia (in Russian). 1868. $8^{\circ}, 48,2$ plates.

7. Fritz MÜller, Für Darwin. Leipzig, 1864. $8^{\circ}$. (Facts and Arguments for Darwin. By Fritz Miiller, with additions by the author. Translated by W. S. Dallas. London, 1869), 12, 144.

8. C. Craus, Ueber den Bau und die systematische Stellung von Nebalia, nebst Bemerkungen über das seither unbekannte mannchen dieser Gattung. (Zeits. f. w. Zoologie, xxii, 323, Taf. xxv). 1872

9. C. Claus, Nachrichten von den königl. Gesellschaten und der G. A. Universtät, zu Göttingen, No. 10, 1871.

10. C. Claus, Untersuchungen zur Erforschung der genealogischen Grundlage des Crustaceen-Systems. Ein Beitrag zur Descendenzlehre. Wien, 1876.

11. R. von Willemoes-SuHm, On some Atlantic Crustacea from the Challenger Expedition. III. On a Nebalia from the Bermudas, pl. vi. Trans. Linn. Soc., 2d ser.. i, $26,18 \pi 5$.

12. A. S. PACKARD, jr., The Nebaliad Crustacea as types of a new order (Phyllocarida) American Naturalist, xiv, 28, Febs, 1879. Annals and Mag. Nat. Hist. London, 1880.

13. A. S. PaCKard, jr., Zoology for High Schools and Colleges. New York, Dec., 1879. (Order Phyllocarida described.) 


\section{b. FOSSIL SPECIES.}

14. MCCox, Annals and Magazine of Natural History, ser. 2, vol. iv, 412, 1850.

15. MCCoy, Synopsis of Britısh Palæozoic Fossils Cambridge Museum, fasc. i, 136, Pl. I, E. 1851 .

16. McCoy, Quart. Journal of the Geological Society of London, Feb., 1853, 13, 1853.

17. James HaLL, Palæontology of New York, ii, 320, pl. 71, 1852 .

18. James Hall, Palieontology of New York, iii, 420, 1859. 16th Ann. Rep. Stat. Cabinet of Nat. Hist, New York, App. D. Albany, 1863.

19. R. Murchison, Siluria, 236, 1854.

20. J. SAltri, On some new Crustacea from the uppermost Silurian Rocks. Proc. Geol. Soc. London. xii, 26, 1856. Quart. Journ. Geol. Soc. London, 33, xii, Fel., 1856.

21. J. Salter, On new fossil Crustacea from the Silurian Rocks, Annals of Natural Hist., 3d ser., v, 153-162. March, 1860.

22. J. SAlter, On Peltocaris, a new genus of Silurian Crust. (Quart. Journ, Geol, Soc. Lond., xix, 87-92), illustr., 186.3.

23. J. Salter, On some tracks of Lower Silurian Crust. (Quart. Journ. Geol. Soc. Lond., xix, 32-95, illustr ), 1863.

24. J. Salter, Memoirs of the Geological Survey of Great Britain, iii, 294, 1866.

25. Axgelin, Pal. Scandin, Suppl. Pl. B, 1860.

26. Hevry Woodward, On the oldest known British Crab; notes on the species of the genus Eryon Desm., and on a new genus of Phyllopodous Crustacea (Quart. Journ Geol. Soc. Lond., vol. xxii, 493-505, 2 plates). 1866.

27. Henry Woonward, On some new Phyllopodous Crnstaceans from the Palæozoic rocks (Geolog. Magazin London, vol. viii, No. 3, 3-6, plate iii, 1-5). 1871.

28. Hzxry Woodward, On Fossil Crustacea (Geological Magazin Lond., vol. viii, No. $11,1-4), 1871$.

30. J. J. BigsBy, Thesaurns Silur., 73, 1868.

31. Joachim Barraxde, Systéme Silurien du Centre de la Bohême, vol. i, suppl. Pragne 1072, 435-459. (Also Jahrbuch, von Leonhard und Bronn, Heft iii, 322, 1853.)

32. Henry Wondward, Geological Magazine, ii, 401, pl. xi, 1865.

34. J. Salter and Henry WoOd Ward, Chart of Fossil Crustacea, 1865.

29. Hexry WoODWARd, Geological Magazine, iii, 203, pl. x, 1866 ,

33. R. P. Whitfiedd, Notice of new forms of Fossil Crustaceans from the Upper Devonian Rocks of Ohio, with descriptions of new Genera and Species. Amer. Journ. Se., 3d ser., xix, 33. Jan., 1880.

35. R. P. Whitrield, Geol. Surv. Ohio, Palæontology, iii.

36. S. II. SCCDdke, Rhachura, A new Genus of fossil Crustacea (Rhachura venosa. Scndder. Danville, IIl., Bed, No. 14, Coal Measures). Proc. Boston Soc. Nat. Hist., xix, 296, P1. 9, fig. 3, 3. March, 1878.

37. John M. Crarke, New Phyllopod Crustaceans from the Devonian of Western New York. With a plate. Amer. Journ. Sc., 476-8, xxiii. June, 1882. 



\title{
A.-ON ARTEMIA FERTILIS VERRILL, FROM GREAT SALT LAKE, UTAH TERRITORY. ${ }^{1}$
}

\author{
By Prof. C. Th. von Srebold, of Munich.
}

[Translated by Dr. Phil. Carl F. Gissler, of Providence, R. I.]

Having positively convinced myself several years ago that Artemia salina, which is known to inhabit in countless numbers shallow brackish water ponds along the shores of Europe, in those localities propagates parthenogenetically without males, ${ }^{2}$ I put to myself the question whether this was also the case with other species of the genus Artemia. To solve this problem I conceived the idea of procuring live specimens of the brineshrimp from the Great Salt Lake of Utah, which I knew to occur there in both sexes and in great numbers. The middle of March this year (1876) I obtained, through the kindness of Dr. Hermann A. Hagen, of Cambridge, Mass., a considerable quantity of dried mud from the Great Salt Lake, with which I experimented in the following manner: Toward the end of March, of the same year, I divided some of the dried mud into several shallow glass jars, pouring over it on the 6th of April artiticially prepared sea-water, using common hydrantwater and Reichenhaller brine. On the Sth day of April already the water in one of these jars swarmed with Nauplii, the hatching of which I eagerly watched, as I observed many brown Artemia eggs on stirring up the mud infusions. The brood prospered excellently, the mud being evidently impregnated with organic matter, the latter serving as food during their different moults and stages of development; and already on April 16, abont eleven days after hatching, indications of sexual characters could be perceived, in the male sex perceptible by a stouter swelling of the claspers. This sexual character, after which the differentiation of the organs of reproduction appear, refers to the organs of copulation only, and not to the true fructification organs, and was for my experiments of great importance. This early differentiation of the male and female individuals of Artemia fertilis gave me occasion to distinguish the males from the females, and to keep them separate already at a time before the internal sexual organs, the testicles of the males and the ovaries of the females, began to develop. The second pair of legs of the six-footed Nauplius is, after the first moult, promi-

${ }^{1}$ Ueber die in München gezüchtete Artemia fertilis aus dem grossen Salzsee von Utah. Von Prof, C. v. Siebold in München. Separatabdruck aus den Verhandlungen der 59ten Jahresversammlung der Schweiz. naturf. Gesellschaft in Basel, 18శ6. Basel, 1877. $8^{\circ}$. p). 16.

So much that is of great interest in connection with the doctrine of evolution and of parthenogenesis has been published regarding the Pbyllopods, that we avail ourself of the kind permission to insert, as an appendix, the most important papers which have appeared. I am indebted to Dr. C. F. Gissler for this and the following translations and abtracts.

"See my lecture on "Parthenogenesis of Artemia salina," in the Sitzungsberichte der mathematisch-physikalischen Classe der K. Akademie der Wissenschaften, of June 7, 1873, p. 168 . 
nently developed, serving as a rudder organ; after the subsequent moults this organ becomes graduálly shorter, less movable, bent down, loses its bristled margin, and in the females is transformed into two small, scarcely movable, tongue-like bent processes, while in the males the same develops itself into disproportionately large claspers with broad lobes, functionating as a eatching and clasping apparatus. These robust clasper's, bent downwards and backwards, betray the male sex, as above stated, in the earlier stages by an incipient swelling of the said rudder organs, while the same, after their hystolytic degeneration, remain small in the females. In this way it was easy for me early to distinguish the males from the females and, significant for my experiments, to keep them apart.

The growth and prosperity of the carefully-separated sexes proceeded well in various jars with artificial sea water, and pains were also taken to add only boiled Utah mud to prevent any Artemia eggs from hatching. Without this precaution I would eventually have received younger broods of different sexes together with the older ones, already kept apart, which would have interfered with my experiments, in which latter the utmost certainty was required to prevent the meeting of the two sexes before the setting in of concupiscense. Having raised a large number of carefully-watched virgin individuals in the above mentioned manner, I waited the period of coneupiscence in one-half of their number without giving thein occasion to come in contact with any males, while the other half of virgins I placed together with a number of ma. tured male individuals for the purpose of getting fertilized by them. I sncceeded in this, since the males very early, as already stated, betrayed their future sex and were vigorously grown up, and gave repeated indications of sexual desires. They manifested the latter in their pugnacious behavior, embracing themselves with their powerful claspers in such a manner as if they would perform copulation; many of them clasped other males, no matter how they struggled against it, and with such a violent fervor that they, as may be assumed, applied the claspers on almost every part of their body. Such couples remained entangled for several days, swimming around in the most umnatural positions.

The testicles, filled with whitish zoösperms, presented themselves to the naked eje through the translucent body. I selected the most vigorous individuals, placing them in a jar together with boiled-up Utah mud and a number of virgin Artemiæ, and had then very soon the pleasure to see that they did not refuse the ardent embraces of the males, the females making no efforts to free themselves of their burden. The male with its claspers embraces the postabdomen of the female from the back, which region appears swollen by the ovisac. In this way both individuals, bearing their abdomens parallel above each other, swim about as if animated with but one will. From time to time such a couple swims along the surface of the mud, turns around its longitudinal axis. dorsal side up, thus whirling up the loose mud for the purpose of obtaining food. Occasionally the male, utilizing the embrace of the female, bends its postabdomen around for the purpose of inserting its two protrusile cylindrical copulative organs into the female genital orifice, whereby the closest contact with the female, as well as an afflux of spermatic particles, was effected.

The actual process of copulation, as closely observed by me, was interrupted after shorter or longer intervals, but in incessantly longcontinued embraces it was often repeated. One of these couples hung together for three dass. After copulation ensued, I transferred those females which were abandoned by their males and which females I re- 
garded as fecundated into a new jar, into which they could eventually deposit their eggs. But to be sure that no new brood of Artemia was developed out of the Utah mud added as food, I again took the precaution to use only well-boiled mud in which any possible eggs would then be destroyed. The fecundated Artemia females, howerer, continued to prosper in their new jar, and I soon perceived the activity of their inner generative organs. This activity manifested itself very soon in the two blind ovarial strings situated in their postabdomens; in the interior of those strings white, uniseriately-placed ovarial germs came into view, which latter grew more and more, their places of contact becoming flattened. All these eggs in their complete form possessed neither a germinal resicle nor a yolk-skin. The latter is not formed until the uncovered eggs have entered the upper bent-inward-and-backward end of the ovarial strings, and then it represents a very tender translucent and homogeneous egg-membrane. I should call these bent terminal portions of the ovarial tubes oviducts, since they enter after a short course a capacious cavity, the latter certainly functionating as an uterus.

The uterus possesses in its walls a very complicated muscular apparatus, which, through its active contractions, mores the contents of the uterus in rarious ways. One can now also observe six cell complexes in three pair of groups on the right and left behind each other, divided and fastened to the uterus walls, which in their organization and meaning fully correspond with the egg-shell glands, as observed and described ${ }^{1}$ by me in Artemia salina, only with the difference that.in Artemia fertilis three pairs, in A. salina only two pairs of such shellglands occur. These glands at first appear perfectly colorless, becoming gradually amber-yellow, finally assuming a rust-brown color, with which coloration the secreting function of these glands begins. It was now interesting and striking to me in these investigations that the first lot of eggs that entered the uterus through the oviduct, which eggs were surrounded by but a delicate yolk-membrane, did not yet receive any hard egg-shells, although they were incessantly moved to and fro by the muscular walls of the uterus. They remained without shells, because the shell-glands had not yet discharged their contents into the uterine eavity. Un the other hand, to my greatest astonishment, a perfect segmentation process was going on in the uncovered eggs, which could be closely followed through the tender and transparent yolk-skin. Finally, I perceived the red eye-dot of the now developed Nauplins through the yolk-skin, soon afterwards the entire brood of Nauplii escaping and rowing about in the water. Curiously enough, this parturitive act did not repeat itself in all those females of Artemia which gave birth once, although their uterus was repeatedly filled with tender-skinned eggs; in short, all fertilized females of Artemia fertilis became, after first giving birth to live young ones, from this time oriparous." ${ }^{2}$ Whether now all females of Artemia fertilis show the peculiarity of always producing live young ones at the first process of propagation and then become oviparous, I can give no decisive answer. The observation seems to me important, which I here, though already mentioned, again repeat, that in raising Nauplii from the "Daner-

${ }^{1}$ Opus citatum, p. 191.

${ }^{2}$ I had already occasion to make similar observations on A. salina, and refer to $p$. 190 of op. citat., and there I attempted to express presumptions as to the causes which induce the females of Artemia at one time to be viviparous and at other times oviparous; the correctness of those conjectures I cannot warrant, since I have not yet acquired the necessary amount of experience on these striking phenomena. 
eggs" contained in dried Utah mud, male as well as female Artemiæ, and both in about the same number were obtained. To these observations I have to annex the following, which, as regards the questions what sex issues in the different manners of propagation in the Nauplii, in future will turn out to be important. Namely, I refer to the fact that also those Nauplii, which the fecundated, primiparous females of $A r$. temia fertilis, raised from "Dauer-eggs," yielded in exactly the same manner, like those Nauplii hatched from "Dauer-eggs" contained in Utah mud, male and female individuals of Artemia fertilis.

Concerning the manner of propagation going on after (einmalig) viviparturition and oviposition of the fecundated females, I have to say that this process of oviposition oecurs in the same manner and with the same repetition as observed by me in non-fertilized females, and which I shall describe later. As the second part of my report on the domestication (Zeuchtung) of Artemia fertilis I have to mention experiments through which I tried to force this Branchiopod to produce parthenogenetic generations. In how far I did or did not sueceed in these experiments I cannot yet eall to aecount, since I till now could realize only preparations and introductions for the same. I only want to state how I succeeded in obtaining the material with which I could convince myself whether Artemia fertilis, like A. salina, possesses the peculiarity under certain circumstances to propagate parthenogenetically. It was easy for me to procure the necessary material, since I kept separate, as already stated, a jar with Artemiæ, which showed in their earlier developing stages indications of yielding female individuals. From this jar I selected such females in which the first traces of concupiscence were noticed, and those I raised separately in a jar with brine water and boiled Utah mud, watching them earefully to prevent any access of males, and to let them, as genuine virgins, become concupiscent. ${ }^{2}$ At the time when in these isolated virgins the generative organs attained maturity, which showed itself in the ovaries distended with germs, my particular attention was directed to the jar containing them. There I noticed that in these virgins the eggs entered from the ovaries into the oviduct, whence they accumulated in the uterine cavity, during which time the six above-mentioned shell-glands assumed a brown color. Later on the amber-colored secretion of the glands discharged into the uterus, flowing around the tender-skinned unfecundated eggs, which latter, kept in rhythmic motion by the contractions of the muscular walls

"Above I make use of the word "Daner-eggs" (or permanent eggs) avoiling the hitherto customary specification "winter-eggs" as not quite prop-r. Of course (allerdings) most Phyllopods deposit two different kinds of eggs, one kind of which develops soon after being deposited, while the other kind hatches after a very long time, and in our climate, in most cases, after hibernation. But those latter eggs can also endure two or more winters under casual external conditions, if the necessary impulse from outside for the batching of the eggs continues; I mean to say when the suitable moisture, giving action and completion for the development of those Phyllopods, does not come into effect. In this way it is accounted for that in such pools serving as a habitation for Phyllopods, but which remain dry for several years and which afterwards again become filled with water, the long disappeared Phyllopods suddenly reappear, as the there buried winter eggs (or better) "Daner-eggs," under the influence of the water become animated to live activity out of the latent condition.

${ }^{2}$ To demonstrate during my lecture I prepared three jars with mud and salt water, into which I divided three different objects concerning Artemia in the following manner: One jar contained several full-grown males, the second jar contained fertilized egg-bearing females, together with two entangled copulating couples, while the third jar, contained virgin females, bearing non-fertilized eggs. These Artemiæ arrived in goode condition, after being conveyed in their jars from Munchen to Basel, and thero could be exhibited alive during the lecture. 
of the uterus, became darker and darker and surrounded with a hard brown shell, so that the non-fecundated, differed neither in form nor color or structure from the fecundated ones. The virgin Artemiæ depos. ited their eggs some time afterwards, dropping them into the mud at the bottom of the jar. The uterus of such unfertilized females appeared to be empty after the eggs were dropped; their shell-glands were pale, but their ovaries again contained new germs, which gradually developed, while the pale shell-glands, after some time, again assumed their brown color, and I surmised that they prepared themselves once more for ovipositing non-fecundated eggs. The same process reoccurred several times in virgins, the latter not differing therefore in this respect from fecundated ones. In this manner I succeeded in accumulating a large number of non-fecundated eggs in the mud of the jar prepared for the concupiscent, non-fertilized females. I must now draw your attention to the fact that such oviparous virgins were never viviparous before depositing eggs. For the suecess of my experiment on parthenogenesis this was a bad omen. It is evident, however, that the primiparturition of live young ones is not realized in virgin females of Artemia fertilis; but it is, nevertheless, possible that the "Daner eggs" dropped by the virgins possess the peculiarity of developing themselves without fertilization, and do yield females, and therein we would have again a con. tribution to our knowledge on the distribution of parthenogenesis. I shall preserve during the coming winter (1876-'77) the different kinds of dried mud which are partly impregnated with fertilized, partly with non-fertilized "Dauer-eggs" of Artemia fertilis, for the purpose of examining next spring whether the mud with fertilized eggs alone, or besides it, also the mud with non-fertilized eggs, will yield Nauplii, when it will be of importance to learn from what set the parthenogenetic Nauplii develop themselves.

\section{B.-PROF. CARL THEODOR VON SIEBOLD ON PARTHENO- GENESIS IN ARTEMIA SALINA. ${ }^{1}$}

\section{ABSTRACT.}

\section{By Dr. C. F. Gissler.}

Owing to the remarks expressed two years ago in my paper "Beiträge zur Parthenogenesis der Arthropoden" (Leipzig, 1871, p. 197), I am indebted to Prof. Carl Vogt, of Geneva (Switzerland), for a lot of live individuals of Artemia salina, which arrived at München August 27, 1872. I was very pleased to have received seventy live and five dead specimens, together with a number of larvæ, in a jar of salt water. All the full-grown individuals were females, which was also the case with a number of Artemiæ Dr. Vogt receired from Professor Martins at Cette. I observed that in all the seventy specimens thus obtained the egg-sac was filled with embryos. The various behavior of this brood attracted my special attention. Having dissected the egg-sac of a dead individual, I noticed several live embryos escaping from the same, together with a few pear-shaped bodies of orange color sinking to the bottom. The latter proved to be also embryos inclosed in a homogeneous thin egg skin. The outlines of the inclosed embryos could be distinctly seen through the egg skin, as well as the motions of the embryo. Such viviparous

"'Sitzungsberichte der mathematisch-physicalischen Classe zu München, 1873, Heft. II." 
Artemiæ I also observed amongst the other live specimens. After the escape of the brood the egg skins remained in the egg-sacs. But many Artemiæ proved to be also oviparous. The egg-sae in such oviparous specimens then contained brownish spherical, hard-shelled eggs. In breaking this brittle shell between two glass slides the homogeneous inner egg skin could be noticed. Joly, who also observed this mode of multiplication, supposed the season of the year had something to do with it. Vogt noticed that they became oviparous when kept in a more capacious ressel, and viviparous when kept in small jars. I, myself, did not succeed in raising more than two generations. Not a single male individual was obtained from the young Artemiæ received as viviparous generation; only 35 females attained sexual maturity. Of these 35 females, on the 20th of October the largest ones had soft, white eggs in the egg-sac, which became gradually brown in a few days; some had their eggs deposited on November 5, involving at the same time a certain mortality among my specimens, all having died by November 21 , 1872. The deposited egg did not hatch.

After this unsuccessful attempt I concluded to get some more fresh material, which was forwarded to me through the kind intermediation of Duke Carl Theodor of Bavaria, of whose active interest in natural science I was aware. On the $3 \mathrm{~d}$ of December I received two bottles with 50 live Artemiæ, which were eollected near Capodistria by Dr. Syrski, of Triest, also a large bottle of marine mud and fresh sea water. The Artemiæ were, though dead, still of a fresh appearance. They were all females, and their egg-sacs were crammed with brown eggs. After removing the eggs I placed them in a shallow vessel with marine mud and sea water. Already four days afterwards I observed new-born embryos swimming about, and mauy more toward evening. I divided them on December 12 in two jars, marked with $a$ and $b$. Owing to the marine mud containing much organic matter (which was probably not the case in the former experiment) they prospered well, shed their skins often, and developed into females. The jar destined for the specimens originally received from Capodistria I marked with $e$. The embryos hatched therein from the eggs of the killed original specimens and those embryos I divided into the two jars $a$ and $b$.

That the embryos thus hatched did not all come from the eggs taken from the egg-sacs of the original dead but still fresh specimens is quite obvious, as the marine mud very likely also contained eggs of Artemia, which were thus brought to development. Finally I got fully convinced of this view, as in the larger jars $a$ and $b$ gradually an immense number of young Artemix grew up, whose number by far exceeded the sums of those embryos which I took from jar $e$, and which I placed into the jars $a$ and $b$. In no case could this superfluous brood have originated from the older, fully-raised embryos, as the latter were not yet sexually mature when I noticed the bulky throng of continually fortheoming embryos. On examining a quantity of the remaining mud from Triest I found many Artemia eggs. The hatching of embryos in jar $e$ kept on from December 7, 1872, till March 23, 1s73.

Some marine mud I placed also into jars $a$ and $b$, and care was taken to replace the evaporated salt water, a water of 10 Beaumé having been used for this purpose. On January 12, 1873, I counted 31 full grown and 136 younger individuals, not counting the very youngest ones. In the ovaries of seven adult females I noticed on January 19 the first traces of egg-formation; on the 24th I saw the yellowish eggs in the ovaries in 18 adult ones; 4 of them had yellowish eggs in the egg-sacs, and 3 had brown ones; on January 26th 3 more had also brown eggs in the egg-sacs. 
To verify whether those eggs were really unfertitized, I arranged another large jar with artificial sea water and marked it with $f$. Into this jar I placed some Triest marine mud which had been previously boiled to destroy any eggs possibly contained therein. The aduit females placed in this jar prospered well. The number of adult females in jars $a$ and $b$ continually increased, counting, on February 1,24 females, all with brown eggs in their egg-sacs. Six of these females dropped their eggs on February 5, their ovaries again showing activity. I again arranged another jar, bearing the letter $h$, placing previousiy boiled mud into it and those 6 females, whose egor-sacs, on February 16 , contained for the second time brown eggs, and again the same day I placed 8 more specimens into it, taken from jar $f$, which afterwards prepared themselves for a third oviposition, so that I was urged to take for those 14 females another moderately large jar, bearing the letter $i$, to allow them to deposit for a third time. On March 2 this jar $i$ was arranged with the 14 females, the latter depositing their eggs during March; on A pril 15 a jar marked $m$ was prepared with boiled mud, placing 2 females into it from jar $i$, which were about to deposit for the fourth time. Un May 4 one of the two deposited for the fourth time, and although a fifth series began to form, I did not prepare another jar; the specimen showed great weakness, and died subsequently.

As a matter of course the females taken from jars $a$ and $b$ multiplied in the jars $f, h, i, m$. In jar $f$, out of which I took, up to February 28, 14 females and placed them into jar $h$, I counted, on A pril 6, 39 females. It would be too tiresome to put down here all the notes as I wrote them down seriatim in reference to further development of Artemia, and I shall here briefly state the result of my experiments. The eggs were for the greater part on the suface of the muddy bottom. On March 16, being the 40th day after my first raised virgin Artemiæ deposited their eggs, I noticed two embryos of the Nauplius-stage, as figured by Joly. For the sake of maintaining stricter control of the embryos, of whose parthenogenetic origin I had to be fully convinced, I placed these, as well as all those later hatched in jar $f$, into a smaller jar, $g$, with some previously boiled Triest mud. On March 24 I had eight such embryos in jar $g$; counting on March 30, 2\%; and up to May 10 I had transferred 71 embryos from jar $f$ into jar $g$. Hencefurth the development in jar $f$ increased rapidly (May 11, hatehed 25 , and May 12, 49 embryos), so that np to May 23 I obtained from jar $f 40 \%$ embryos. In this manner I verified that from eggs deposited by virgin females of Ar. temia salina, which were not fertilized by any male sperm, a brood can develope. The empty egg-shells were found to be partly floating on the surface or hidden in the mud at the bottom. The fresh unhatched egg never swam on the surface, and the empty egro-shells on the bottom all showed a erack.

Seventeen embryos were removed from jar $g$ and placed in a jar marked $k$, with a quantity of prepared (boiled) Triest mud. This was done for better observing the sexual derelopment. Of these 17 individuals 5 were nearly full grown on April 30, with no indication of ovaries, though with beginning egg-sac formation; two other individuals of those 17 Artemix did not yet show, though full grown, any sexual differentiation.

On May 10 I transferred from jar $k$ those specimers which approached sexual maturity into a jar marked o, together with some unprepared fresh-water clay-mud. These 14, in jar o transferred Artemix dereloping into egg-bearing females, prospered well in the salt water of the new jar, and filled, as usual, their intestine with mud as if they had had ma- 
rine mud. I had to take fresh-water mud because the marine mud began to show sigus of decomposition.

On May 22 the four oldest individuals in jar o had brown eggs; also all the others attained maturity by Mas 29, so that I was sure that these 15 females would soon deposit for the first time their eggs.

How many successive generations of Artemia salina retain the fac. ulty to reproduce parthenogenetically without males remains to be examined. Joly made his observations with Artemiæ from Southern France in 1840, and supposed that these Artemix must be either hermaphroditic, or, if really males existed, that a single fertilization was sufficient for many generations.

It would be of interest to re-examine the specimens of Artemiæ of the localities eited in literature of the years 1840, 1755 (Schlosser), 1830 (Thompson), 1851 (Leydig). Very likely the result would be that par. thenogenesis in Artemia often occurs.

The examination of the ovaries and the occurrence of viviparous and oviparous individuals led mo to the conclusion that oviposition appears in Artemia only when the egg-shell glands have so fully dereloped that the necessary quantity of congealing matter can be recreated, as only by this can the eggs obtain a solid, durable shell. Surrounded with such a shell the eggs obtain the power, hidden away in mud or even perfectly dried up, to endure the most unfavorable external conditions and preserve the faculty of development after long periods of time. But if the development of the egg-shell glands has not been fully attained the conditions for the formation of a solid and durable shell are wanting. The eggs of such Artemiæ then only receive a very thin egg skin, in consequence of which the favorable influences for the de. velopment of the embryo will act upon the egg contents from ontside, thus accelerating the.embryo formation.

\section{C.-ON THE RELATION OF ARTEMIA SALINA MILNE-ED. WARDS TO ARTEMIA MUEHLHAUSENII MILNE-ED. WARDS AND TO THE GENUS BRANCHIPUS SOHAF. FER.}

$$
\text { By W. J. Scmunkewitsch. }{ }^{1}
$$

[Translated by Dr. C. F. Gissler. With Plate XXXIX.]

In the session of the Neorussian Society of Naturalists at Odessa, held September 20,1874, I made an addition concerning this matter to the observations made in former years, and now I have again to com. municate the following later results. I shall here briefly state that Artemia salina M. Edw., Joly (Branchipus arietimus Grube var. Schmankewitsch. Artemia arietina Fischer var. Schm.), a very variable form, yields not only by domestication but also in a state of nature even at a gradually increased concentration of the water, a form similar to Arte. mia muehthausenii Milne-Edw., Fischer, which I had occasion to observe in the closed Kajalniker Salt Lake (Andreewsky-Liman) near Odessa during the years 1871 to 1874 , inclusive.

In 1871, on the occasion of a great spring flood, the embankment which separated the lesser saline water of the upper portion of the Kajalniker Lake from the more saline portion of the lower part of the same lake broke, whereby the water of the latter became diluted to $8^{\circ}$ Beaumé. At the same time Artemia salina appeared in great numbers, probably

\footnotetext{
'Zeitschrift für wissensch. Zoologie, xxv, 1tes Supplementheft, 1875.
} 
brought along with the flood from the upper portion as well as from the surrounding brine ditches near the same.

After restoration of the embankment the density of the water of the lower part rapidly increased, showing already in the summer of 1872 $14^{\circ}$, in $187318^{\circ}$, at the beginning of August 1874, 23.5 , and after a continued drought in September of the same year $25^{\circ}$ of Beaumés areometer, at the latter time the lower part of the lake beginning to deposit salt.

Simultaneously Artemia salina gradually degraded from generation to generation, so that toward the end of the summer of $187 . t$ the majority of individuals were without furcal lobes, showing then all the specific characters of Artemia muehlhausenii (Fig. 6). In 1871 Artemia salina, or better, one of its rarieties, had moderately large furcal lobes, and on each of them eight to ten, seldom 15, setæ, distributed orer both sides and the tips (Fig. 1).

In the successive generations in the beginning of the summer of 1872 , these fureal lobes were already smaller, with but 3 to 5 or 3 to 4 setæ, the salt water then showing $14^{\circ}$ Beaumé (Plate XXXIX, Figs. 2 and 3 ).

In the same season of 1873 and at $18^{\circ} \mathrm{B}$. the furcal lobes were still smaller, representing short conical knobs with but one, two, seldom three, setæ (Fig. 4). Toward the end of the summer of 1874, many individnals still possessed conical knobs or protuberances instead of furcal lobes, without or with but one seta on tip, but the majority of them were entirely destitute of furcal lobes and setæ, as is the case in Artemia muehthausenii with which these degraded examples were identical in their smaller size as well as in other characters (Figs. 5 and 6 ).

I also obtained the same results by domesticating Artemia salina in salt water of gradually increased density or concentration, the examples obtained being identical with those from the Kujalinker Lake at the end of the summer of 1874 (Artemia muchlhauscrii), yielding also the same transitory forms.

By a reverse treatment, $i$. e., by gradually diluting the salt water, I succeeded with Artomia muehthausenii in producing already, after several weeks, a furca in the form of conical knobs, with one terminal bristle, by which treatment also the development of other parts of the body assumed a direction toward the higher specialized varieties of Artemia salina, this being at rariance with the retrograde development taking place in condensing the salt water.

It is remarkable that the gills of these animals enlarge in proportion or in ratio with the density of the water, so that in the form without furcal knobs (Artemia muehthausenii) the surface of the gills is much larger in proportion to the size of the body than in Artemia salina. The gills of the former especially enlarge in width. I draw the inference that as the water of higher density contains less oxygen these Crustaceans adapt themselves by gradually enlarging the surface of the breathing apparatus.

Concerning the gills, I have to state that they are olongate in Artemia salina and oval in A. mehlhausenii (Figs. 7 and 8). The width of the gills in A. salina average searcely half of their length, in A. muehlhausenii two-thirds of their length.

As regards the length of the body, I may mention the following: measurements, showing the proportionate sizes of the gills; In Artemia salina the average length of the gills at a density of $10^{\circ} \mathrm{B}$. is the onetwenty-first part of the body length, the width being the one-thirty-ninth part of the same. In Artemia muehthausenii the average length of the 
gills at a density of $24^{\circ} \mathrm{B}$. is one-eighteenth part; their width is the one twenty-eighth part of the body length.

In measuring the Artemia salina the furcal lobes were not counted in, which would have made the difference still greater, considering the larger bulk of the body of Artemia salina compared with A. muehl. hausenii.

It appears that the species (Arten) of the genus Artemia are liable to undergo, also, progressive developments at a gradually lessened density of the salt water. The nature of those salt-water pools yields the conditions necessary for their progressive growth, which pools, after a number of years by continued washing of the briny soil, may turn into fresh-water pools. Indeed, Artemia salina inhabits, also, such salt-water pools in the neighborhood of the lake in which oceurs, at a low density of the water, also Branchipus spinosus Grube; at a still lower density, Branchipus ferox Grube, and another species of Branchipus with hooklike bent furcal lobes, which latter species I described as Branchipus medius in the "Schriften der dritten Versammlung russischer Natur. forscher."

In artificially domesticating Artemia salina in gradually diluted salt water I obtained a form with the characters of the genus Branchipus, (B. Schaefferi) which might be regarded as a new species of Branchipus.

I had already occasion to disenss this point in the "Schriften" of the Russian Naturalists, third session, and in the "Schriften" of the Neo. russian Society of Naturalists (Vol. II, part 2), and again have to state as follows:

The only two characters separating the genus Branchipus from the genus Artemia are the following: Firstly; that Artemia, inclusive of the genital segment (two segments together), possesses eight apodous postabdominal segments, with the last of these eight segments nearly twice as long as the penultimate (Fig. 9c), while Branchipus has nine such segments, of which the neighboring segments, by twos, show but a small difference in length; and, secondly, the existence of a physiologi. cal difference, parthenogenesis occurring in Artemia, which phenomenon has not yet been observed in Branchipus. This is a negative and ill. defined character.

The first mark of distinetion seems to be more important, but nndergoes ehanges in Artemia nuder the influences of the surroundings, where the character of the genus Branchipus appears especially, than when several generations of Artemia are domesticated in gradually diluted salt water.

I have convinced myself, that the last long eighth segment of the postabdomen of Artemia is homologous with the two last segments of the post. abdomen in Branchipus, namely the eighth and ninth.

In the progressive growth of sereral generations of Artemia in gradually diluted salt water the last apodous eighth postabdominal segment of Artemia subdivides itself into two segments, whereby nine apodous segments are formed (Figs. $10 \mathrm{c}$ and $d$ ), as in Branchipus. Branchipus, however, in its youth and towards the end of its last larval state, has but eight abdominal segments, of which the last is also as long as in Artemia. Also without artificial domestication we can convince ourselves of the homology of the last eighth apodous segment of Artemia with the same two last apodous segments of Branchipus.

In the species of Branchipus occurring in this region we find fine bristles distributed around the posterior end of each postabdominal segment, excent in the last ninth segment. Every bristle arises from the middle of a complex of small tooth-like spines which are of extraordinary 
size in the male of Branchipus spinosus. Such bristles we also find in Artemia in the same places and similarly distributed (Fig. 9d), only that they do not arise out of a complex of dentate spines, but out of the middle of a complex of cuticular cells, which can searcely be distintinguished from the surrounding tissue (Fig. 11).

It is of some importance that in Artemia not only near the end of each segment do we find such circularly placed bristles, but also in or a little above the midale of the last long eighth postabdominal segment, $i . e$., on that spot where the articulation ought to be, and where it is actually found in Branchipus, between the eighth and ninth segment, and where in Artemia this articulation after domestication of several generations in salt water of successive lower density, i. e., under such conditions, is formed, which may be serviceable to progressive development. ${ }^{1}$

Under the same conditions the complexes of cuticular cells just mentioned transform; out of their midst bristles develop by degrees in both sexes of the domesticated Artemiæ, into complexes of denticular spines, as they are found in both sexes of Branchipus. (Fig. 12.)

These denticular spines are small and of equal size in both sexes of Branchipus ferox; in the female of B. spinosus they are also smat, but in the males of extraordinary size; in Branchipus medius (described elsewhere) they are large in both sexes, somewhat larger however in females than in males.

At the same time, in domesticating Artemia, all other characters change progressively toward Branchipus; as, for instance, the length of the furcal lobes, the number of their bristles, and so forth.

After such results we unwillingly arrive at the conclusion that the Artemia usually occurring in salt water of great density is nothing else than a degraded form of Branchipus under the influence of its surroundings, which latter form usually inhabits fresh water or salt water of low density.

On the other hand we have in Branchipus a higher developed form of Artemia, which has transformed in a progressive direction.

The cause of this may not only be the different concentration of the water, but also its temperature. In nature Artemice mostly inhabiting salt lakes represent the summer forms, while Branchipus, often populating dried-up pools, represents the spring or fall form.

in domesticating, I observed that a high density of the water retains the growth and the development of specific characters of these animals, while a simultaneous higher temperature evokes sexual maturity earlier than the complete development of limbs; higher temperature together with higher density of the salt water also contribute to retrogradation of forms and their degeneration.

()f course, as I conrinced myself, a gradually increased density of the salt water, even at a lower temperature, tends to degradation of forms; for such a water, besides its mechanical influences upon the organism, contains less oxygeu than less saline water and much less than fresh water, which plainly shows itself in artificially domestieating these animals, and which joint I have already referred to.

The following are the principal results of my investigations:

1. In artificial domestication of sereral successive generations of $A r$. temia salina Milne Edw. in salt water of gradually increased density we obtain a form identical with Artemia muehthausenii M. Edw.

2. Artemia salina M. Edw. is also apt in a state of nature after a

${ }^{1}$ See Plate II of the "Schriften" of the third meeting of Russian Naturalists, Zoological Part. 
small number of years, and a comparatively shout series of generations, in a salt lake with increased density to transform itself into a form identical with Artemia muehlhausenii M. Edw., whereby this form is enabled to remain constant, as long as the surroundings are not changed.

3. Artemia is apt, in artificially domesticating several generations in salt water of gradually decreased density, to progressively develop towards the genus Branchipus, obtaining thereby its generic characters, nine apodous segments.

4. In a state of nature salt-water ditches of different-density, inhab. ited also by the higher specialized forms of Artemia, yield the conditions for progressive development of Artemia into Branchipus.

5. The size of the furcal lobes in Artemia, the number of bristles and their distribution on the tips and sides of the lobes, are, together with the other generic characters, depende.t on the concentration of the salt water inhabited by Artemia.

6. At a lower density of the salt water occur also in certain brine ditches Artemia with pretty long furcal lobes, with a considerable number of bristles (up to 22 distributed over each lobe), similar to Branchipus.

7. The only characteristic features distinguishing the genus Branclipus from the genus Artemia are:

Firstly, the presence of eight apodous postabdominal segments, whereby the last eighth segment is nearly twice as long as the preceding, while in Branchipus there are nine such apodons segments, of which neighboring segments, by twos, show but a trifling longitudinal diflerence.

Secondly, parthenogenesis occurs in Artemia, while in Branchipus it is not yet known to occur.

8. The last long eighth postabdominal segment of Artemia is homologous with the last two postabdominal segments of Branchipus.

I have now to append a few words on the parthenogenetic propagation of our Artemia.

I had already observed parthenogenesis in Artemia in 1871, while artificially domesticating several isolated generations. It being something new to me at that time, I devoted more attention to investigations on the influence of surroundings on Artemia relative to morphology.

Of three isolated generations of \& Artemia salina I obtained, while artificially domesticating them, by parthenogenetical propagation, in every density of the salt water that sustained their life, oniy fomates. . . . I mentioned in the "Schriften" of the third meeting of liussian naturalists at Kiew, . . . that the males appear in the lake in great numbers at a moderate density of the salt water.

For such moderate density I took the density of the Hadschibe: Lake in the summer of 1870 , it having been literally filled with Artemia, whence they were thrown on the shores in piles by the waves, where they decayed.

However, I committed a mistake, overlooking an error in the protocol of the third meeting at Kiew, having said in my printed report that only at a mean (moderate?) density of the water, similar to the density of the preceding year (1870), by domestication as well as during the summer in the lake males appear, instead of having said, only at a moderate density of the water, similar to that of the preceding year, by domestication as well as during the summer in the lake the males ought to appear. As I noticed at the time, that the males of Artemia appear in the lake at a certain density of the water, I assumed, after I could not obtain them either at a higher or lower density, that they still ought to make their appearance at the density for which I took the salt water in the 
summer of 1870, then not yet being a ware that, according to Professor Siebold's investigations, no males conld be dereloped. ${ }^{1}$ The same error crept into an extract of the protocol, sessions of the zoological part of the third meeting of Russian naturalists at Kiew contained in this journal (Zeitsch. f. w. Zoologie), and this gare Professor von Siebold occasion for a timely remark. ${ }^{2}$ Taking advantage of the present occasion to correct the mistake, observing that it was not printed in my paper, although the latter, together with the report, was prepared in the same session, I have yet to add that Artemia salina becomes accustomed to gradual changes in the concentration of salt water in the lake, as well as in domesticating them, and then becomes fitted to stand a very high or very low density of the water, so that either of them form a suitable enviroument. In rapidly changing the concentration of the salt water the same is rendered unfit to sustain life, changing the manner of obtaining food, and produces, at the same time, in a state of nature, the appearauce of males in forms to which parthenogenesis is peculiar.

I had already observed this in Artemia in the lake, but saw this especially in Daphnia with artificial domestication of non-isolated females, that the males of the domesticated species first appear on the most extreme life-sustainable limits of the surrounding elements, $i$. e., as well at a too low as at a too high temperature.

If we domesticate the fresh-water species, Daphnia magna Leydig, in weak salt water, which they stand well, there appear, at this comparatively rapid heightening of density of the salt water, males and fertilized eggs at such a moderate temperature, at which ordinarily the same species in fresh water propagates parthenogenetically.

In the Hadschibei Lake occurs Daphnia rectirostris Leydig, at a density of the salt water of $5^{\circ}$ to $8^{\circ} \mathrm{B}$., especially in spring and fall; the same disappearing in summer at a higher density of the salt lake, while before the females often in the middle of the summer cease to propagate parthenogenetically, bearing as in fall fecundated eggs in ephippia.

Altogether I produced during the artificial domestication of Daphuia the appearance of males and fecundated eggs through rapid angmentation of the density of the salt water as well as throngh rapid increase of temperature. However it is difficult to say which will be the mean of concentration for a known species of Artemia, because a slightly lessened density, though favorable for the growth of the individual, weakens its jower of propagation, while a heightened density augments (or supports) propagation, on the other hand this being a hindrance for the derelopment of the individuals. The undiscovered mean of density, it seems to me, must be between these two points, the most extreme limits of the favorable condition of the surrounding elements being then outside of those two points.

On these limits we must find a density at which the males appear in the lake in great multitudes, as severel observations and analogous investigations on Daphuia have demonstrated.

I therefore recede from my opinion that the males of Artemia appear at a mean density of the salt water, if the mean density is determined between that of favoring the development and that of assisting the propagation.

Until now I have found the greatest number of males of Artemia salina in the Hadschibei Lake in the middle of the summer of 1870 , at a

${ }^{1}$ C. von Siebold, Beiträge zur Parthenogenesis der Arthropoden. 1871, p. 224.

(C. von Siebold, Ueber Parthenogenesis der Art. salina. Extract of the sessions of the Royal Academy of Sciences at Niinchen, 1873, p. 190. 
strong evaporation after continued drought, the salt water then rapidly reaching a high concentration.

I have yet to add a few words on the geographical position of the lake and the salt-water ditehes inhabited by Artemia salina.

Two great salt lakes, the Hadschibei and the Kujalnitzky, are situated about 7 or 9 rersts from Odessa towards Nikolajeffi. These two lakes (Russian, limane) were formerly two broad river entrances and ocean bavs, into which two rivers formerly poured.

At present these two small draining rivers no more deserve their names. The "limanes" were subsequently cut off" from the sea by broad stretches of sand, the Peresippe, and were transformed into salt lakes.

Only in the lower part of the Kujalniker-Limane, separated by an artificial embankment from the upper part for the purpose of obtaining salt, is the salt deposited.

The Hadschibei-Limane showed with $m y$ areometer $5^{\circ} \mathrm{B}$. as the low. est and $12^{\circ} \mathrm{B}$. as the highest concentration.

The salt-water ditehes are distributed over the saline soil in the neigh. borhood of the lake, situated between the lakes and the seashore along the Peresippe to near the city of Odessa.

In the various ditches occurs salt water of varions densities from nearly fresh water up to water of $5 \circ$ Beaumé.

Only the more salty ditches of $4^{\circ}$ to $5^{\circ} \mathrm{B}$. are inhabited by a (ziemlich ansgebildet) developed form of Artemia salina, often associated with Branchipus spinosus. In less saline ditches occurs Branchipus ferox and Branchipus medius.

Similar results, as regaräs the evolution of the form, I have also obtained from Daphnia, Cyclops, and Canthocamptus, and I promise to soon publish these investigations.

REMarks.-1. I have especially endeavored in the above writings to draw attention to the fact that in domesticating Artemia salina in gradually diluted salt water, after several generations and at a pro. gressive development, I obtained a form presenting the most important morphological characters of the genus Branchipus, so that such a form was at one time regarded by me as a new species of Branchipus.

The principal generic characters of Branchipus I regard as the nine apodous postabdominal segments.

Although we obtain in progressively domesticating Artemia the characters of the genus Branchipus, and although, also, the other char. acters change in the direction toward Branchipus, such an artificially domesticated Artemia, for many reasons and marks of distinetion, can only be considered as a lower form of a Branchipus, representing, consequently, a transitory form from Artemia toward Branchipus, and an intermediate form between these two genera. Such a form can also be looked at as a prototype or radical type of these two genera.

2. An important circumstance is that in those Branchipus observed by me, a few bristles are distributed in a circle around each postabdominal segment just before the articulation, and that in Artemia such bristles occur also in a circle at a little above the middle of the last postabdominal segment. I mentioned above that in Branchipus each such bristle arises out of the middle of a complex of dentate spines, which are of very large size in the male of Branchipus spinosus.

I find it necessary to add that I found such dentate spines in both sexes of the species of Branchipus examined by me only on the ventral side of the postabdominal segment just before the articulation, at which location they could be plainly seen. It is well known that in the male 
of Branchipus spinosus groups of dentate spines occur only on the ventral side of the postabdomen just before the articulation.

In the same places fine bristles arise out of groups of circulatory cells in Artemice living in salt water of high density, which cells, by domestication of several generations of Artemia in gradually diluted salt water, transform into groups of small dentate spines.

3. Under the name of postabdomen I mean the last nine segments of the posterior section of the body, or all apodous segments which are frequently called postabdomen. Artemia has eight such segments.

After all, it seems to me that not all apodous segments deserve either the term abdomen or postabdomen, since the first two segments, bearing the external genital organs, are more sharply defined or insected from the following segments, being also somewhat shorter and broader than the latter, having therefore more resemblance with the preceding limb-bearing segments.

It appears to be more proper to add the two connate gemital seaments to the præabdomen, calling postabdomen all the other apodous segments; this view concurring also with the developmental history. According to the latter view we have seven apodous segments in Branchipus and six in Artemia.

\section{D.-OONTRIBUTION TO A KNOWLEDGE OF THE INFLUENOE OF EXTERNAL CONDITIONS OF LIFE UPON THE OR- GANIZATION OF ANINALS.}

\section{By Whadmir SCHMaNKEWITSCH. ${ }^{1}$}

[Translated by Dr. C. F. Gissler.]

I published in 1875 in the Russian language, in the Transactions of the Neo-Russian Society of Naturalists (Vol. III, $2 \mathrm{~d}$ part), a paper under the title "Some Crustaceans of the salt and fresh waters, and their relation to the surrounding elements." 2

After the further elaboration of the material, I shall publish the entire contents of my labors, at present submitting only the part which I regard as the more complete.

I.-Some instances illustrating the influence of salt-lake surroundings upon the life and development of several crustaceans.

${ }^{1}$ Zeitschrift fuir Wissenschaftliche Zoologie, XXIX, 429-494, 1877.

2'The contents of the paper are the following: Chapter I. The genns Cyclops (C. bicuspidatus Cls. and C. odessanus n. sp.. C. brevicaudatus Cls., C. brericornis Cls., C. serrulatus Fischer. C. tenuiformis Cls., C. minutus Cls.). Enumeration of the species and races of this genus from the neighborhood of Odessa. Diagnosis of the undescribed forms of Cyclops. The indication of forms necessary to compare the characters of the known species of this genus. General remarks on Cyclops brevicornis and C. brevicaudatus. Effect of the surronuding element upon the forms of Cyclops under artificial domestication. Chapter II. Cletocamptus genus novum (family of Harpactida), Cl. strömii and $C$. retrogressus, and domestication of the latter in changed surroundings. Chapter III. Transfuga gen. novum (fam. Harpactida), Tr. salimus n. sp., and Tr. lacustris n. sp. Chapter IV. The relations between marine forms and freal-water forms in the family of Harpactide. Chapter V. The genus Daphnia. D. magna Leyd. varietas, D. rectirostris Leydig (Moina rectirostris Baird) of salt and fresh waters. Daphnia degenerata n. sp. and D. rudis n. sp., both marine forms. Chapter VI. The genera Artemia and Branchipus. Artemia salina Milne-Edwards. The generations of Artemia salina receiving the characters of Art. Mithausenii. Branchipus ferox Chyzer varietas. Branchipus spinosus Milne-Edw. Branchipus medius mihi. The characters of the genera Artemia and Branchipns. The transformations of the branchial sacs and posterior gill-lobes in Artemia and Branchipus under the infuence of the surroundings. 
For the purpose of illustrating this, I have chosen Daphnia rectirostris Leydig (Moina rectirostris Baird) and Branchipus ferox Ohyzer.

Daphnia rectirostris occurs here in large numbers in fresh-water basins, brine ditehes, and also in the Chadschibaisky Salt Lake. In the latter they occurred at a concentration of from five to eight degrees of Beaume's areometer. Two characters are seen in the Dapknia rectiros. tris living in so diversified elements, the former depending on the latter. It appears firstly, that in salt water, and especially in the more saline Chadschibai Lake the middle temperature is lower, $i . e$. the temperature more favorable for the life of I aphnia rectirostris than the temperature favoring the life of the same Daphnia in fresh water, so that the Daph. nia, being in reality a summer form of the fresh waters, changes in salt water into a fall form, occurring till the beginning of winter in the salt lake at a concentration of $7 \circ$ to $8 \circ$ Beaumé in immense quantities, even remaining viviparous at a temperature at which the individuals of the fresh-water generations of the same species could live no longer. Secondly, the individuals of the salt-iake generations of Daphnia rectirostris represent a degraded or retrograde form of the fresh-water generations of the same species, differing from the latter the more the higher the concentration of the salt-water basins in which they occur increases, so that the individuals of the salt lake difter more from the fresh-water forms than the individuals living in salt ditches.

So much do the forms of Daphnia rectirostris from the salt lake differ from those of the fresh waters that they could be regarded as a separate variety of Daphnia rectirostris, although it is but a transformed generation retarded in its development, and changed under the influence of the surroundings of Daphnia rectirostris inhabiting the fresh waters. On account of various observations and experiments, I presume that the peculiarities of the salt-lake form of Daphnia rectirostris are entirely. dependent on the properties of the salt water which they inhabit.

Daphnia rectirostris cannot stand in summer a density of the water of the salt lake of $6 \circ \mathrm{B}$., while it lives in great quantities in the same salt lake at a density of $8 \circ \mathrm{B}$. in the fall, toward the end of October and in November, being than viviparous, that is, at such a season in which the fresh-water form of our Daphnia has already ceased to live. This is not an extraordinary phenomenon, considering that a certain aeration of the water is unconditionally necessary to sustain the life of Daphnia rectirostris, and that it is unimportant by which means the aeration of the water is regulated. Agreeing with the physical law the less the aeration of the salt water, the higher its density becomes, which results that fresh water must contain more air than any salt water of the same temperature. It consequently follows that also in a salt water of certain concentration at a corresponding lower tem. perature the same quantity of air as in fresh water could be contained. It is obvious that the quantity of air in the water of the Chadschibai Lake toward the end of October and at a density of $8 \circ \mathrm{B}$. could approximately be the same as that in fresh water during the summer, and therefore the processes of nutrition in the organism of Daphnia rectiros. tris could in reality be as favorable in both the fresh and salt water. Though analogous in general, they differ singly from each other, as, for iustance, by the higher pressure of the more dense water, which density again depends on the quantity of salt and the lower temperature of the water. Dependant on such differences between salt and fresh water are also partly some differences in the organization of the salt and fresh water forms of Daphnia rectirostris.

In the females of the Chadschibai Lake, the penicilii or fascicles of 
knobbed setæ (Tast-borsten) are but little dereloped, being scarcely fifty times shorter than the antennæ themselves, while in the females of the fresh water the same sensitive penicilli are moderately long, and only six times shorter than the entire antenna. In the males, the sensitive bacilli are also shorter than in those males inhabiting fresh water. The small hooks situated near the sensitive bacilli on the tips of the male antennæ of fresh water are strongly curved with pointed tips, while in the males of the Chadschibai Lake those hooks are shorter, less curved, and with blunt tips. Uf the two pointed pale sensory threads situated on geniculated protuberances of the first posterior third section of the male antemmæ, the posterior one is a little shorter than the anterior thread, the latter coming out a little more in front. These threads are in the males of Daphnia rectirostris of the Chadschibai Lake, not in a straight, but in a screw-like line. The distance between one thread and the other is considerable, which character in the fresh-water males is much less prominent. The fresh-uater individ. uals of this species have in their earlier stages a period during which they resemble in this, as well as in other respects, the mature forms of the salt lake.

Besides the differences observed in the antennæ of the salt-water generations of Daphnia rectirostris, our attention is called to the number of slender "gefiederten," or, better, finely toothed spines, which occur on the lateral surface of the postabdomen of Daphnia rectirostris, running laterally seriatim and nearly parallel with the direction of the rectum. Leydig ${ }^{1}$ called them finely feathered spines, which I would have called triangular, laterally finely dentate plates. However this may be, we observe in our fresh-water forms of $D$. rectirostris on each side 11 to 13 of these spines or plates, only 7 to 9 in the salt-lake form, meaning here, as a matter of course, mature individuals only. In younger specimens there are less spines than in the adults of the same surroundings, and therefore the young fresh-uater forms have the same number of spines at a certain age as the alult forms of the Chadschibai Lake, which demonstrates the retarded development of the latter. Furthermore, our fresh-water Daphniæ (D. rectirostris) are nearly colorless, or of a slight yellowish color, while the same species in the salt lake are of a reddish color. The so-called winter eges of the former have an ochreous or orange-colored yolk. Those of the latter are red throughout. The bristles in general are less numerons in the salt-lake form of the Daphnia than in the fresh-water form, and the average size of body in the latter is also less than in the former, although the difference is but slight.

The generations of $D$. rectirostris inhabiting our salt ditches represent in every respect a transitory form between the fresh-water form and the salt-lake form, which lake has a higher density of the salt water than the water in the salt ditches, where it fluctuates between $1^{\circ}$ and $5 \circ$ Beaumé.

In domesticating Daphnia rectirostris I also convinced mrself that the salt-lake form can also live at a lower concentration of the salt water, only requiring herein a higher temperature, than that fit for them in the very saline lake; that is, it wants a summer but no fall temperature. In this less concentrated salt water the degradation of individuals is considerably diminished with the generations, so that they finally resemble the individuals of this species from salt ditches, $i$. e., they approximate the fresh-water form. In so domesticating,

\footnotetext{
${ }^{1}$ Naturgeschichte der Daphniden, Leipzig, 1860, p. 175, Tab. X, 76.
} 
during a rather brief duration the sensory threads on the tips of the antenme become nearly three times longer than before the begiuning of domestication.

We now find in comparing the fresh-water generations with the saltwater generations of Daphnia rectirostris that the latter generations not only changed in consequence of the immediate effect of the surrounding elements, but also in consequence of retarded development under their intluence; and, furthermore, that the sexual maturity shows itself earlier in the salt-water generations than the complete typical development of the body parts. The termination of the sensory antemmæ, the color of the body, the lesser pinnulation of the bristles in the salt-water genera. tions are principally dependent upon the immediate effect of the sur. rounding elements. The smaller number of the above-mentioned spimes on the postabdomen principally depends upon the retarded develop. ment under the influence of changed surroundings. In the latter case the individuals commence, without awaiting the development of their body parts, to augment, and are in that state a complete animal form.

Branchipus ferox affords a still more characteristic example of the in. fluence of the salt-lake element. Milne-Edwards, ${ }^{1}$ whose words Grube repeated in his diagnosis of this species, gives a brief description of Branchipus ferox from the neighborhood of Odessa. Ohyzer ${ }^{3}$ completed his deseription from Hungarian specimens. The diagnosis by Chyzer of this species differs so much from that of Milne-Edwards that both authors could not possibly have had one and the same form of Brauchi. pus, as we shall see later on. It is difficult to understand why MilneEdwards does not mention the two so important characters of this species, which ought to rank with the principal characters which Chyzer enumerates. This is the conspicuous length of the egg-sac, and especially the fact that the abdominal appendages or furcal lobes are bristled ouly on their inner edge. To this latter peculiarity Chyzer especially points out the characteristics of Branchipus ferox. It is evident that Milne-Edwards had a very elosely allied form to that of Chyzer's, since in the neighborhood of Odessa, wherefrom Milne-Edwards's form came, generations of this species occur in salt, brackish, and fresh water, which, owing to their dependence of the density of the water basms, considerably differ in their characters. The generations inhabiting salt-water ditches of about $5^{\circ}$ Beaumé differ as much from the individuals inluab. iting fresh water, especially the Hungarian forms described by Chyzer, as any species will differ from another one. Had I not found all pos. sible transitory forms between fresh-water and salt-diteh forms, had I not convinced myself of the variability by domestication of this form, I should have regarded the salt-lake specimens as a new form. For some time I really took them for a variety of Branchipus ferox Chyzer. At present, and after so many convincing results, I can only conditionally regard this form as a variety.

To demonstrate how much the salt-lake generations of Branchipus ferox (from the salt-water ditches) differ from the Hungarian freshwater specimens, compare the following characters: The egg-sac of the salt-lake Branchipus ferox reaches in its length only to the beginning, or to the middle, of the fifth apodous segments, but as the following sixth, seventh and eighth segments are longer than the auterior seg. ments, the egg-sac reaches scarcely to the middle of the postabdomen,

\footnotetext{
${ }^{1} \mathrm{H}$ :stoire naturelle des Crustacées, III p. 369.

2 Bemerkungen iiber die Phyllopoden, Archiv f. Naturg p. 142, 1853.

${ }^{3}$ Eauna Ungarns Crustaceen. Verhandl. der zoologisch-botanischen Gesellschaft in Wien, 1858, p. 516.
} 
counting in all apodous segments, while in the Hungarian forms the length of the egg-sac equals the whole postabdomen, excluding the ab. dominal appendages. Besides, in Branchipus ferox of the salt-water ditches the egg-sac is not spindle-shaped, only elongate, often entirely oval, i. e., not only shorter, but also broader, as in the form diagnosed by Chyzer. In our salt water ditch forms the furcal lobes average in length the eighth part of the body length, inclusive of the furcal lobes; in Uhyzer's Hungarian form, as shown by the measurements, the furcal lobes average the fourth and a half part of the whole body length including them, that is, they are much longer in the Hungarian form. The most important difference consists in that while in Branchipus fero $x$ of our salt ditches the furcal lobes have both edges bristled, in the form described by Chyzer only the inner edges of the lobes are bristled. Lastly, our salt-water ditch form measures, inclusive of the abdominal lobes, seventeen to twenty-two millimeters, the Hungarian form twentynine to thirty four millimeters. Our salt-water form approaches in all other respects the diagnosis of Chyzer, and does not disagree with the determinations of Milne-Edwards and Grube.

Besides the difference between the specimens of our salt-lake-water and the Hungarian fresh-water forms of Branchipus ferox, we find, after strict examination of the matter, that the bristles of the furcal lobes in our silt-water-ditch forms, only in young animals shortly before becoming sexually mature, commence at the base of the lobes in one height, and that on getting older the number of bristles is lessened along the exterior edge, and that in the adult, and especially in old individuals, the bristles on the exterior edge of the furcal lobes will be seen to commence more than twice lower than on the inner edge of the same. At a length of the furcal lobes of $2.5^{\mathrm{mm}}$, in the adult form, the bristles begin on the inner edge at a distance of $0.24^{\mathrm{mm}}$ from the base of each lobe, but on the exterior edge they begin at a distance of $0.52^{\mathrm{mm}}$ from the base of each lobe. The bristles on the exterior edge of the lobes are in adults of this form more than twice shorter than those on the opposite inner edge, especially on the first half of the furcal lobes. The younger the individuals are the more trifling is the difference betwoen the bristles of the inner and outer edge of the lobes. Furthermore, in the salt-water ditches of low density such generations of Branchipus ferox live, whose individuals have an average size of about $22^{\mathrm{mm}}$. In these larger specimens the exterior edge of this or that abdominal appendage in the adult state has no bristles from base to the middle of the lobes. The bristles of the exterior edge are also shorter and more sparsely distributed than in the preceding form. Their egg-sac usually reaches down to the middle of the fifth apodous segment, and is a little longer than the eggsac of the preceding form. The ditches with nearly fresh, searcely saline-tasting, water harbor also still larger specimens of Branchipus ferox, measuring some $25^{\mathrm{mm}}$ in average length. In these large individnals in mature age the exterior edge of either furcal lobe is without bristles from base down to over the middle of each lobe. The remaining bristles are again still more sparsely placed, and also shorter than in the preceding form; the egg-sae is also a little longer.

Specimens of Branchipus ferox, collected by me in ditches on Taman Island, in the neighborhood of the city of Kertsch, represent another link in the series of transitory forms between the extreme generations of the salt-lake and Hungarian fresh-water specimens. In the Taman specimens, which have a length of $30^{\mathrm{mm}}$, the egg-sac reaches to the middle or to the end of the fifth apodous segment of the abdomen, the furcal lobes having nearly the same length as those of the Hungarian 
specimens; but in the adult state, on their exterior terminus of the lobes, remain more or less short, sparsely placed bristles, the less the older the specimens are. As the smallest number of bristles, I found seven; so that at $6.9^{\mathrm{mm}}$ length of a lobe its exterior margin was bristled only up to a distance of $1.5^{\mathrm{mm}}$. As the highest number of bristles in mature specimens, I counted fifteen; so that at $6.8^{\mathrm{mm}}$ length of a lobe its exterior margin was bristled up to a distance of $3.4^{\mathrm{mm}}$ from the tip of the lobe.

To explain the formation of such a remarkable character as the miss. ing of bristles on the exterior margin of the furcal lobes in generations of Branchipus ferox inhabiting fresh-water ditches, we need only be reminder that these lobes are the longer the less dense the water is in which they live, and that in the real fresh-water generations of this species the furcal lobes are the largest. I have also observed that these lobes distend at a wide angle in swimming; the wider they distend the longer they are. In addition, the exterior margin of these lobes continually cut the water, being therefore in a higher degree, subject to the mechanical influence of the water. Even if the pressure of the saltwater be higher then are the furcal lobes of the salt-water forms of this species much shorter, and, besides, we may say that the salt-lake generations do not fully grow up; therefore, remaining provided with the principal eharacters of the young fresh-water forms. The fresh-water generations of Branchipus ferox have, amongst all European species of Branchipus, the longest furcal lobes.

The domestication of several generations of this species in sait water of various concentration verifies also the effect of the surroundings.

I therefore can see no necessity of admitting here an intluence of nat. ural selection and to add new unknown factors to solve this problem.

One of the most remarkable phenomena is the fact that in our shallow marine district so rich in salt-water basins (closed lakes and salt-water ditches), even in pure fresh water the typical fresh-water form of Branchipus ferox Chyzer does not occur, but only a form approximating in a certain degree those of the lowest generations of this species, inhabiting our salt-water ditches, connecting it with the Artemia; above all with the extreme race of Artemia salina (varietas a), which also lives in our salt-water ditches. This is not the only example of such an abberration of form. In the fresh waters of the neighborhood of Udessa we do not find the real Daphnia magna Leydig; however, one of its races occurs, representing an abberration toward Daphnia pulex Leydig ${ }^{1}$ of a lower grade. The generations of our fresh-water Daphnia magna variety, distribute themselves also in a few salt ditches, where ther form a still greater deviation from the typical form. In more saline ditches (of about 30 Beaumé) occur such forms of Daphnia, bearing the characters of another, simultaneously reminding one of Daphnia magna varietas, D. pulex, and partly also of Daphnia reticulata and D. quadrangulata Leydig. I described this form under the name of Daphnia degenerata ${ }^{2}$

Regarding it as a degraded form of those ancestors, which gave origin to the existence of Daphnia magna and $D$. pulex, I actually convinced myself in examining generations of Daphnia degenerata at different seasons of the year and at various densities of the salt water, and also, by domesticating them, that it is a changed and degraded form of our

${ }^{1}$ See my reports in the "Schriften" of the Neorussian Society of Naturalists, Vol. III, Part 2, pp. 196-216.

2 Opns citatum, pp. 228-232. I have to add the following: The sensory antenna of the female of $D$. degenerata is provirled on its npper surface with the same bristle as occurs in D. magna. 
variety of Daphnia magna, the latter variety being itself again an inter mediate form between the typical Daphnia magna and $D$. pulex. If we would restore the middle radical form, which gave origin to Daphnia magna and D. pulex, we would receive a form most similar to our Daphnia magna varietas, in the production of a still farther allied, a prototype for the largest number of Daphniæ, we would arrive at a form most similar to Daphnia degenerata from the salt-water ditehes. Such examples show that, owing to the neighborhood of salt waters in which the generations of the fresh-water species distribute themselves and in which they change under retardation of development, the species themselves in fresh waters of such districts deviate to a certain degree jrom the typical form, i. e., they change toward the direction of the next lowest species of their genus. In consequence of the existence of such an ele. ment in these districts the area of distribution of the species changes; but as the center of this area will be found somewhere between the fresh-water and the salt-lake e'ement, the aberration of the fresh-water generations in the neighborhood of salt-lake waters, in which the generations of the fresh-waters pecies already considerably changed themselves and become retarded in their derelopment, is easily understood.

The salt ditches, which distribute themselves on saline soil near Odessa between the sea and the two salt lakes, the Chadschibaisky and the Kujalnitzky, become fresh-water ditches after gradual elevation, and simultaneously begin to become populated with fresh-water generations, whereby these generations form, to a certain degree, changeable transitions toward the more changed salt-lake forms. Some of the ditches six years ago containing salt water of about $3^{\circ}$ to $4^{\circ}$ Beaumé, and inhabited by the salt-water species, Branchipus spinosus Milne Edw., now contain nearly fresh water, and are populated this year (1876) with the freshwater forms Daphnia magna Lesdig varietas and Cyclops brevicaudatus Claus, slightly ehanged in the direction toward the lower forms. In relation to the latter, a transitory form of Cyclops brevicaudatus varietas $b^{1}$ and Cyclops brevicaudatus Claus, was to me of great interest. In the real fresh-water Cyclops brevicaudatus the extreme inner one of the four furcal bristles is twice as long as the extreme outer, or actually the twentyfifth part shorter than the double length of the last outer bristle; in generations inhabiting less saline ditches the extreme inner bristle is, on an average, the sixth part shorter than the double length of the extreme outer. In Cyclops brevicaudatus varietas b. the extreme inner furcal bristle is but little (one-quarter) longer than the extreme outer. The adult forms of the changed generations of Cyclops brevicandatus in the less salty ditches exhibit nearly the same relation of body parts, as seen in the young, immature, pure fresh-water forms of the same species; but the mature individunls of said variety correspond in this point with the younger individuals of the species.

To this I have to refer also the interesting influence of the surroundings upon the development of specimens of Artemia. The growth of the specimens of Artemia salina in salt water of high density and at the same temperature proceeds at least twice as slow as the growth of speci. mens of Branchipus ferox in less saline water. Abstractedly from the fact that the growth of specimens of Artemia salina requires much time, sexual maturity appears much earlier in proportion to the full development of body-parts, than in Branchipus. At a high concentration

"Consult my paper in the "Schritten" of the Neoruss. Soc. of Naturalists, vol. iii. part 2 , pl. 32 to 36 , and 74 to 77 . Also on the domestication of Cyclopidae, ibidem, Pp. 84 to 95 . 
of the salt water, only inhabitable by Artemia, and especially at suffi cient warmth, the mature sexual products show themselves already at a time when the provisional parts of the second, lower antennæ were scarcely dropped, i. e., when they have not yet left the last larval stage. Artemia lives a much longer time in the larval state than Branchipus, indeed the longer, the higher the concentration of the water for Artemia and the lower for Branchipus. Between the fresh-water Branchipida and those Artemice which can still live in a salt-lake self-depositing salt, there is a relative great difference. Accordingly we must allow that we can produce, by corresponding domestication of generations of Artemice, already in their larval stage, but in any case in the last per iod of the latter, before the second antennæ have dropped their provisional parts, sexual maturity. Carl Vogt's observations have shown that the eyes appear much later in Artemia than in Branchipus, ${ }^{1}$ and I presume that this is applicable to those Artemia which are in relation to Branehipides, degraded forms of the latter.

I have to mention the circumstance that the concentration of the salt water vigorously stimulates the multiplication of Artemia. The highest increase of a given species of Artemia is brought about by a density of the salt water which is a little higher than that generally assumed as the mean for this species; therefore under such conditions which hinder, to a certain degree, the growth of the individuals and the development of their body-parts. On the other hand the most rapid growth and the progressive development of body-parts happen to appear at such a concentration of the salt water, which is a little below the mean for a given species, and at which density the propagation of the individuals decreases. In Artemia salina I observed the highest multipli. cation in a state of nature at a density of the salt water of $10^{\circ}$ to $12^{\circ}$ Beaumé's areometer and with summer temperature; the highest developments of body-parts I noted at $5^{\circ}$ to $7 \circ$ Beaumé, and at the same t'm. perature. Between these limits must be the mean density of the salt water for our Artemia saina; I have also to remark, that the density of the salt water, together with the temperature, and independently of the same, influences the growth and the propagation of these animals. It appears that the parthenogenetic reproduction in Artemia does not only depend upon the temperature, as in Daphnia, but also upon the density of the salt water. I observed at least viviparous reproduction in $\mathrm{Ar}$. temia salina in stronger saline water at such a low temperature at which viviparturition in the same species does not oceur in less saline water, although it does not hinder viviparturition at a comparatively higher temperature. In all such cases the quantity of air contained in the water and dependent upon temperature, as well as upon concentration of the salt water, plays an important rôle, regulating many of the funetions of life. Perbaps the variability of the concentration of the salt water yields, in Artemia, one of the main causes of parthenogenesis, the latter not being yet known to occur in Branchipodida, inhabiting principally fresh water. Density and temperature of the salt water in their influence upon Artemia are combined in such a manner that, when the existence of an Artemia-like form in fresh water is possible, the same can only exist at a nearly summer and possibly high temperature. The lower the density of the salt water che higher a temperature is re. quired, if Artemia shall preserve its form at least in its principal characters. In this sense, Branchipus stagnalis, which, according to the

1 "Revue scientifique de la France et de l'étrang.," 2. series, 1873, No. 27, pp. 632 to 633. Also in "Meeting of Swiss Naturalists" in Freiburg i. s., 1872. 
statements of the authors (Leydig, Claus, Spangenberg) has eight apodous segments of the abdomen, represents in its principal characters an Artemia-like form; however, it remains to be determined whether this species is peculiar to summer temperature, of which we have a few intimations. It seems that the dependence of the quantity of air in the salt water upon its density, beside the mechanical effect of such a water, forms one of the main factors of the sexual and specifie characters of Artemia, whose forms are distributed according to the various densities of the salt water, as the species of a known genus are dispersed according to geographical latitudes, or also after their appearance at different seasons (annual species). Moreover, a certain concentration of the salt water is, probably again in consequence of a certain quantity of air, in accordance with the physiological processes in Artemia. I here omit the respiration and the changing of the gill-sacs of Artemia with the changing of the concentration of the salt water, simply mentioning the circumstance, that we most rarely find males with those lowest degraded forms of onr Artemia, bearing the characters of Artemia Mithausenii, living at the highest density for Artemia, and that, as we will see, the males of that race of Artemia salina (varietas $b$.) in salt ditches occur, which are most progressively developed and which live, in comparison with our other forms, at the lowest density of the salt water, as will be explained later on.

\section{II.-ON the GLl-SACs AND the Posterior Branchial Lobes in ARTEMTA AND BRANCHIPUS.}

I shall speak in this section of the relation of these appendages in Artemia and Branchipus to their external life conditions. First we have to agree as to the determination of these parts. The gill-sac in these forms is ealled by $\mathbf{C}$. Claus (in his paper on Branchipus stagnalis and Apus cancriformis) "Kiemensäckchen" (gill-sacklet).

Grube calls it "unterer Branchialanhang" (lower branchial appendage).

S. Fischer called it " nnterer Branchialsack" (lower branchial sac).

The posterior branchial lobes are called by Claus (ibidem) "hinteres Branchialblatt" (posterior branchial leaf); by Grube, "oberer Branchialanhang" (upper branchial appendage); by S. Fischer, "oberer Branchialsack" (npper branchial sac).

The first which demands our attention is that the gill-sacs and poste. rior branchial lobes in Artemia and the salt-lake Branchipus enlarge in length and more so in width during the domestication of specimens, or still more of generations of these forms in salt water of increased density.

Specimens of Artemia salina taken from the Chadschibai Lake, showing a density of $9 \circ$ Beaumé, I divided into two equal vessels, gradually diluting the salt water in one of them, but increasing the density of the salt water in the other. I kept the water in both vessels at equal height. In both vessels were old and young growing specimens. Both jars stood near to each other and were, with the exception of differentlyconcentrated water, as regards temperature and all other influences, under the same circumstances. The experiment lasted for four weeks, during which time I daily measured the length and width of the gill-

1 "Abhandlungen der königlichen Gesellschaft der Wissenschaften zu Göttingen," vol. xviii, 1873 .

${ }_{2}$ "Bemerkungen ïber die Phyllopoden" in "Archiv für Naturgeschichte," 1853, p. 141 .

${ }^{3}$ Middendorf's Sibirische Reise, St. Petersburg, 1851, vol. ii, part 1, p. 151.

$31 \mathrm{H}$ 
sacs and the posterior branchial lobes of the domesticated mature speci. mens of both vessels, measuring also the length of the body, finding also the ratio between the length and width of these appendages to the length of the body, inclusive of the furca. The resulting figures gradually in. creased with the strength of concentration of the salt water in one or the other ressel in two different directions, the animals showing in the fourth week of domestication a very considerable difference, which plainly illustrated the increase of the length, and more so of the width, of said appendages at a heightened density of the salt water, and also the deerease of those parts at a reduction of density of the water. Toward the end of the fourth week the salt water in both jars attained a difference of $10^{\circ}$ Beaumé, the gradually-diluted salt water showing then $3^{\circ}$ Beaumé; the salt water of gradually-increased density indicated $13 \circ$ Beaumé. To compare the size of the gill-sacs and posterior branchial lobes of $\mathrm{Ar}$. temia salina at decreasing and increasing density of the salt water, in measuring I searched for figures which indicated which part of the body. length the length and width of these or those appendages in these or those specimens formed. During the fourth week of the above-men. tioned period of domestication I obtained the following figures as aver. age results in two diverging directions:

At a decreased density

in length the 24, 3, in width the 46,5

part of the entire boty-length; of the salt water the gill-sacs yielded

At an increased density

in length the 22,4 , in width the 40,6 in length the 17,6 , the posterior branchial lobes yielded

\section{part of the entire body-length.}

in length the 16,8 , in width the 34,9

I have to remark that toward the end of the period of domestication the resulting figures in the measurements showed considerable oscillations. The cause of it is that in salt water of extremely decreased or extremely increased density the animals soon became so short-lived that the older individuals, as well as the younger just before or soon after becoming sexually mature, died. The relation of the body-parts in such young, though sexually mature individuals, resembles in some degree the relation of the body-parts in young immature individuals in another surrounding element, then normal for the species; for we observe also a slight retardation of growth in a suddenly produced extreme decrease of the density of the salt water the same as in the increase of the density of the salt water. In insufficiently gradually diluting the salt water the individuals of Artemia salina die, as it were, of debility, which cause lies probably in the heightened oxidation in the organism dependent on the increased quantity of air in diluted salt water. The highest development of the furca and the greatest number of its bristles are not incongruous with the lowest density of the salt water which this species can endure for a longer or shorter time, but it is congruous with a concentration not much lower than that peculiar to the species. The more gradual the concentration of the salt water in the domestication of successive generations of Artemia salina is changed the more deviates the mean (for this species) favorable concentration from that concentration which is the mean for it in free nature.

In comparing Artemia salina with those degraded forms and genera of this species exhibiting the characters of Artemia milhausenii, living 
at a rery great density of the salt water, approaching the natural deposition of salt, or having attained the latter already, we find a great difference in the size of the gill-sacs and the posterior branchial lobes, since the appendages mentioned are considerably larger in the latter than in Artemia salina. To see this, we compare specimens of Artemia salina from the Chadschibai Lake at $9 \circ$ Beaumé in the first half of September with the degraded genera of this species ${ }^{1}$ taken from the Kujalnetzki salt lake at $24^{\circ}$ Beaumé, also in the first half of September of the same year, that is, at very different density of the salt water and at nearly the same temperature. Hereby we receive in middle average, and omitting fractions, the following figures:

In Artemia salina in Septem-

ber at $9 \circ$ Beaumé-

In degraded specimens of $A r$. temia salina with the character of Art. milhausenii at $24^{\circ}$ Beaumé-

in length the 23 , the gill-sacs yielded

in width the 44

part of their body-length;

the posterior branchial lobes yielded

in length the 17,

in width the 36 ,

in length the 18, in width the 28

in length the 15 , in width the 24

part of their body-length.

The length of the body of Artemia salina was here taken together with the furcal lobes, exclusive of their terminal bristles, in the same manner as in the above stated experiment; the body-length of the specimens with the characters of $A$. milhausenii to the end of the abdomen, as they have no abdominal furca. Since the furcal lobes form a part of the body of Artemia salina and partake of the nutrition like the other body-parts, I have not excluded them in my calculations, although, too, the relations without this furca, which is of inconsiderable length, in comparing the specimens of this or that species, scarcely vary. I also add that I took here, as well as in the above stated experiment, the gillsacs and posterior branchial lobes of the eighth pair of legs, thoush they are not the largest in this leg. These appendages in mature specimens increase in size from the first to the sixth pair of legs, on the following legs becoming somewhat smaller, without, however, there being much difference between the sixth and eighth pair of legs. The comparison in any case loses nothing, as the specimens have been compared after one and the same pair of legs. I took these appendages from the eighth pair of legs, coming nearer the mean figure, which would express their size in all pairs of legs.

Not less different is also the form of the gill-sacs in the degraded generations with the character of Artemia milhausenii and in Artemia salina. For comparison it is better to take the gill-sacs from the middle pair of legs, as they are of smaller size on the first two or three pairs of legs, and as if not fully developed, having a somewhat deviating form in the last pair of legs, gradually broadening towards the end, becoming in Artemia salina, as well as in specimens with the characters of $A$. milhausenii, nearly uniformly rounded. In comparing the gill-sacs of the middle pairs of legs of Artemia salina and Art. milhausenii we see that these sacs in Artemia salina are of an elongated form and that

${ }^{1}$ Compare my report in the Zeitschrift f. wiss. Zoologie, 1875, vol. xxv, 1st supplemental part. 
the width of the sac nearly amounts to the half of its length, while ther have an oval form in Art. mithausenii, the width of the bag nearly amount. ing to two-thirds of its length. ${ }^{1}$ In long continued domestication in salt water of gradually increased density I obtained, after several successive generations of Artemia salina, specimens in which the gill-sacs and posterior branchial lobes had the same form and size as those of the specimens with the characters of A. milhausenii, ont of the Kujalniker Lake at $24^{\circ}$. Beaumé, and in which still other characters appeared peeuliar to them in free nature.

It is important that in young individuals of $A$. salina in a certain age the gill-sacs and posterior branchial lobes have nearly the same size and form as in the mature individuals, with the characters of Artemia milhausenii, with the difference that in young individnals directly after quitting their larval state, and even, also, until they liberate themselves from the provisional parts of the second antennæ, the largest of these appendages are not on the sixth pair of legs as in the matare forms, but on the fourth pair. Under the same circumstances under which in mature specimens of Artemia salina the gill-sacs on the fourth pair of legs amount in their length to the twenty-eighth and in their width the fifty-sixth part of the whole body-length, the gill-sacs in the young specimens (in the above-mentioned age) of the same pair of legs measure the seventeenth part of the body-length in length and the twenty. seventh part in their width; but at the time at which in mature specimens (at low temperature) of $A$. salina each gill-sac measured, on the sixth pair of legs, in its length the twenty-fourth, in its width the forty. eighth part of the body-length, in young specimens of the above-mentioned age each gill-sac of the same pair of legs measured in its length the nineteenth and in its width the thirtieth part of the entire body. length. In young individuals of Artemia salina of this age the gill-sacs of the eighth pair of legs corresponded, together with the posterior branchial lobes, in form and size with the same appendages of the same pair of legs in the mature individuals, which have the characters of $A$. milhausenii, inhabiting most saline water (about $24^{\circ}$ Beanmé). In any case, on the whole, these appendages are, in the young specimens of A. salina of the stated age, considerably larger than in mature specimens of the same species, being, also, as it must be in the course of development, larger on the anterior pair of legs to the sixth than on the following pairs. In the young individuals of the age stated the gill-sacs measure on the third, fourth, and six th pairs of legs in their mean length together the eighteenth and in their middle width the twenty-ninth part of the whole body-length, but in mature specimens of this species and under the same conditions the gill-sacs of the third, fourth, and sixth pairs of legs measure in their middle length together only the twenty. eighth and in their middle width the fifty-sixth part of the body-length-

From the fact that the gill-sacs and posterior branchial lobes of the young individuals of Artemia salina of the stated age correspond in form and size with the same appendages in the matnre individuals bearing the characters of $A$. milhausenii, we can infer that the latter is a generation of A. salina retarded in its development in consequence of the appearance of sexual maturity before the full development of the parts of the body. However, such an inference would be but partially true. The individuals with the characters of $A$. milhausenii not only exhibit retarded development under the influence of their surroundings, but they are also the result of the demand of the same element-the result

${ }^{1}$ Consult my report in Zeitschrift f. w. Zoologie, 1875, vol. xxv, 1st suppl. part, Tab. VI, figs. 7 and 8. 
of the influence of the organism upon the surrounding element. The hightening of the density of the salt water is naturally accompanied by a decrease of aeration in such a water, but this decrease again must produce in Artemia an enlargement of the breathing surface, $i . e$., the surface of the gill-saes. Concerning the posterior branchial lobes, they (partly also the gill-sacs) have to enlarge themselves in water of high density as auxilliary organs of locomotion, perhaps they also serve as auxilliary organs in respiration, especially in Artemia, wherein the posterior branchial lobes are marked out for their greater tenderness, than generally in Branchipus, in which they often are margined with toothlike spines or little-developed bristles, being, as it were, the beginning of bristles and spines developed on the other branchipeds.

According to Leydig's view the gill-saes of Artemia and Branchipus do not serve as special respiration organs; but the investigation of Claus $^{1}$ and Spangenberg ${ }^{2}$ make it in the highest degree probable that the inference that the gill-saes, but not the posterior branchial lobes, are not special respiration organs, is a proper one. Such a conclusion will also be made by the consideration of these appendages in their relation to the surrounding element, under which latter I not only mean the density of the salt water, but also the temperature; toward the latter the gill-sacs are especially sensitive in a high degree, as we shall see further on.

From such a great sensibility of these appendages toward the surrounding element, we must assume that they have a considerable size in specimens with the characters of Artemia milhausenii, not only owing to retained growth of $A$. salina, whose younger specimens have larger appendages, but also in consequence of their accession, owing to augmentation of their mass, due to the surrounding element, owing to the high density of the salt water. The fact serves as a proof that, in comparing young individuals of Art. milhausenii with individuals of Art. salina of the same age, we find the appendages in the former of considerably larger size. Only a much earlier state of growth of Art. salina relatively agrees with the later state of age of those individuals, bearing the characters of Art. milhausenii, inhabiting salt water of much higher density than Artemia salina. Beside the interesting changes occurring during the course of development of generations influenced in a known manner by the surrounding element, we here observe an accession and, as it were, an accumulation of mass in the known parts reacting upon the element and developing according to the demands of this element. I call this a direct influence of the surrounding element, and moreover such an influence, toward which the organism keeps active, and I distinguish it from another likewise direct influence of the same element, toward which the organism, so to speak, passively submits. As an example of this latter intluence, I mention the retrograde development of the abdominal furca of Art.salina in salt water of high density, whereby the furca becomes as if atrophied, and, indeed, independently of the sexual maturity in specimens, appearing earlier than the full development of the body-parts. That influence of the element upon which depends the change of form, owing to the changed point of appearance of sexual maturity, I call the immediate influence of the surrounding element upon the organism. In Artemia, and also to some degree in

1 "Zur Kenntniss des Baues und der Entwicklung von Branchipus stagnalis und Apus cancriformis." In the "Abhandlungen K. Ges. der Wissensch. zu Göttingen." Vol. XVIII, 1873, p. 19.

2 "Zur Kenntniss von Branchipus stagnalis." Zeitschrift f. w. Z., vol. xxv, 1st supplemental part, pp. 23 and 37 . 
other species of crustaceans examined by me, we can observe all these modifications of the influence of the surroundings upon the organism.

The formation and full development of the gill-sacs and posterior branchial lobes depend in Artemia and Branchipus not only on the salt-quantity of the water, but also on its temperature; since by a lox. ering of temperature the size of the gill-sacs decreases, by a heightening of the temperature they enlarge. 1 do not possess sufficient measure. ments concerning the posterior branchial lobes by which I could attest with correct figures the change of these appendages by temperature, althongh I obtained unmistakeable results, according to which ther, contrary to the gill-sacs, but in a less degree, enlarge by lozering the temperature. Putting temporarily the posterior branchial lobes aside, I shall treat of the gill-saes only.

In measuring the gill-sacs in specimens of Artemia salina, gathered in the first half of September ont of the Chadschibai Lake, I was sur. prised at the figures obtained by the relation of their size to the length of the body, deviating far from the figures received in measuring the summer-forms, although the density of the salt water in the lake was but little lessened. Later in the fail, the speeimens of Art. salina collected out of the Kujalniker Lake, at a density of the salt water of $13 \circ$ Beaumé, had even a little smaller gill-saes than the specimens collected in summer at $9 \circ$ Beaumé, from the Cladschibai Lake. Subsequently, I di. vided the young and old specimens taken from the Kujalniker Lake at a density of $13^{\circ}$ Beaumué into two sections and domesticated one section at an average temperature of $14^{\circ}$ [Réaumur?] the other section at an average of temperature of $70+$ Réaumur. A considerable differ. ence showed itself after two weeks, those individuals living at a lower temperature, but kept by me at a uniform concentration in both jars, had their gill-sacs; especially in width, considerably smaller. In indi. viduals living in higher temperature, each gill-sac on the eighth pair of legs on the average amounted to the twenty-second part in length ani the forty-second part in width of the whole body-length; in individuals living at a lower temperature the gill-sac of the same pair of legs gave the twenty-fifth in length and the fiftieth part in width of the body-length.

It seems that temperature has upon the gill-sacs a more vigorous effect than the concentration of the salt water; on the other hand, the density of the salt water has a stronger influence on the posterior branchial lobes. The circumstance is hereby illustrated, that in the first, red variety of $A$. salina (varietas $a$, deseription farther on), the gill-sacs are smaller, but the posterior branchial lobes are larger than in A. salina. Not to mention so many figures, I point to the width of these appendages, since in these forms they differ in length little from each other. In measuring the specimens of A. salina at a density of $13^{\circ}$ Beaumé, and the specimens of the first, red rariety at a density of $16^{\circ}$ Beaumé, at one and the same (molerately low) temperature, I found that the width of the gill-sacs of the eighth pair of legs in A. salina was the thirteenth, but in the stated variety it was the forty-ninth part of the body length, and that in $A$. salina the width of the posterior branchial lobes was the thirty-fifth, but in the red variety it amounted to the thirty-second part of the whole body-length. In this manner, besides the fact that the specimens of this variety were collected at a higher deusity of salt water than the specimens of A. salina, their gill-sacs are neverthcless smaller than in the latter; but the posterior branchial lobes are larger in the variety than in its species, this corresponding already with the larger quantity of salt contained in the water. Such 
a phenomenon is only explicable by the fact, that in a state of nature, on the average, a lower temperature is, together with a higher density of the salt water than with A. salina, peculiar to the first variety of A. salina (varietas $a$ ). The gill-sacs, as special organs of respiration, must become smaller by a lower temperature, whilst the posterior branchial lobes, as the auxiliary organs of locomotion, must enlarge by the greater density of the water dependant on the lower temperature and the higher concentration. But since the density of the salt water depends more on its concentration than on temperature, it is obvious why, by domestication of Artemia, we observe more changes in the posterior branchial lobes by the concentration of the salt water than by temperature.

The first of these varieties of $A$. salina (varietas $a$.) corresponds amongst our forms of Branchipus mostly with the species Branchipus spinosus: Milne-Edw., according to the relation of the gill-sac and posterior branchial lobes and some other characters, together with the element which it inhabits. Brunchipus spinosus is characterized among our forms of Branchipus in a similar manner as the first variety of A. salina, and A. salina by small gill-sacs and large posterior branchial lobes, only here in Branchipus spinosus is the difference in size of these append. ages considerably larger. Such a phenomenon also fully corresponds with that element which Branchipus spinosus among our salt-water torms of Branchipus principally inhabits. It lives, in comparison with our other Branchipus forms, in a lower temperature, but at a higher concentration of the water. Especially in younger age and at a certain time the gill-sacs and posterior branchial lobes much resemble the appendages of the mature specimens of the stated variety of $A$. salina (varietas a.), and altogether in younger age of the specimens of Branchipus there is a certain period when their leg-appendages in measurements more approach the appendages of the mature forms of Artemia than the appendages of mature forms of the same species of Branchipus. For comparison we take mature individuals of Branchipus spinosus and young individuals of this species, some time after they quitted their larval state, when the section between the eighth and ninth apodous segments of the abdomen has scarcely just been formed, and the furca is still two or two and a half times shorter than the section consisting of the two last segments of the abdomen, and which is homologous with the last (eighth apodous) segment of the abdomen in Artemia. In the mature Branchipus spinosus the furca equals the section consisting of the last two apodous segments. We obtain the following proportions:

In the old specimens of Branch. spinosus-

in length the 40 , in width the 118 in length the 19 , part of the whole body-length; the posterior branchial lobes amounted
In the young specimens of Branch. spinosus-

\section{the gill-sacs amounted}

in length the 24, in width the 61 st in width the 37

in length the 16 , in width the 28 th

part of the whole body-length.

The first rariety of $A$. salina (varietas a.) is in relation to this, especially concerning the gill-sacs, between the species $A$. salina and the young specimens of Branchipus spinosus. I only kept the figure of the measurement of varietas $a$. of A. salina at such a salt capacity 
of the water, at which it (the variety $a$.) forms the transition to the corresponding variety of $A$. milhausenii, that is, at $15^{\circ}, 16^{\circ}$, and $18^{\circ} \mathrm{con}$. centration after Beaumé's instrument. In concluding, it results that at such a concentration of the salt water, at which the above stated meas. urements of A. salina showed themselves, $i$. e., at $9^{\circ}$ Beaumé, and the temperature of the month of September, we must obtain the following figures for this race:

The gill-sacs

the 25th,

the $52 \mathrm{~d}$

The posterior branchial lobes must amount in their length

the 16,5 th, in their width

part of the whole body-length.

the 34 th

The variety Branchipus ferox, hereabouts living in salt water ditches, and to which is peculiar a lesser concentration of the salt water, however at a higher temperature than that peculiar to the species Branchipus spinosus, yields the following figures, in relation to the gill-sacs and posterior branchial lobes:

The gill-sacs

the 24 th, amount in length to

The posterior branchial lobes

the 56 th

in width

the 20 th, the $43 d$

part of the whole body-length.

The variety Branchipus ferox (from salt-water ditches) is, in its leg. appendages and according to the element which it inhabits, in proportion to Artemia salina as Branchipus spinosus is to varietas a. of A. salina. Especially those generations of A. salina which live in salt-water ditches of about $4 \circ$ Beamme, or the generations of the second variety of $A . s a$. lina (variotas b.) are in relation to gill-saes and posterior branchial lobes and some other characters, also in the element in which they live nearer the salt-lake generations (from salt-water ditches) of Branchipus fero $x$ (varietas). I must add here that the legs themselves are longer in Branchipus ferox var. and in A. salina than in Branchipus spinosus and in A. salina varietas $a$, and that only on this account the posterior branchial lobes of the forms of the one or the other category relative to length have no great differences. But the length of the legs corresponds with that temperature and with that concentration of the salt water which is peculiar to each of these forms. ${ }^{1}$

Concerning Branchipus medius mihi, we can nevertheless recognize abstractedly from the point that it forms a too isolated species in its characters and in the relation-figures of its gill-sacs and posterior branchial lobes, the result of the effect of the element in which it is distributed, as I have mentioned in the description of this species. ${ }^{2}$

The knowledge of the effect of the surrounding element upon the gillsacs and the posterior branchial lobes in these animals is important because the differences of size between these appendages, according to authors (Milne-Edwards, S. Fischer, Grube), represent no important species-characters.

It is here the place to add a few remarks which show how far the life of A. salina depends on the air-capacity (actually the oxygen of the

\footnotetext{
${ }^{1}$ Consult any paper in the "Schriften der Neurussischen Gesellschaft der Naturforscher," 1875 , vol. iii, $2 d$ part, pp. 297 to 200 .

${ }^{2}$ Ibidem, pp. 305 to 313
} 
air) of the salt water. By changing the air-capacity of the salt water by a changed concentration of the water, we can at least explain a number of interesting phenomena in the life of Artemia.

1. If we in certain limits dilute the salt water too much in domesticating Artemia, then the animals become, by the too much reduced concentration of the salt water, transparent, attenuated, their intestinal canal empties and becomes translucent, the gill-sacs often blacken, and the animals will die at the bottom of the jar, as it were, of debility. But if we in time notice at the excessive dilution of the salt water the sickness of the animals, and if we, instead of augmenting the concentration of the salt water, heighten its temperature a few degrees, the diseased animals will become animated, the intestinal canal fills itself, the motions become more rapid, the animals leave the bottom of the jar, doing well in such diluted salt water at a corresponding higher temperature. It seems to me that such a temperature supplants the superfluous air of the diluted salt water, which in the organism of the animals produced a too great oxidation, leading to weakness, during which the nutritive substances could not replace the consumption. If by too strongly diluting the salt water the Artemia is consumptive, on account of want of nourishment, owing to the dying off of those microscopic organisms on which Artemia lives, these animals would not have revived so soon after a corresponding increase of temperature. Moreover, microscopic organisms appear in the diluted salt water in great number, even Infusoria, while Joly ${ }^{1}$ observed that Artemiæ are omnivorous, and that they principally live on the lowest organisms of the vegetable kingdom peculiar to the salt lakes, such as various forms of Chlamidomonas, zoospores of Cladophora, \&e.

2. If we, in domesticating Artemia, excessively increase the concentration of the salt water and not sufficiently gradually, its alimentary canat becomes solidly constipated, the animals keep nearer the surface of the water and die there, especially during exuviation, which is hereby just as difficult to overcome as in too much diluted salt water. However, if we in time in this case lower the temperature, instead of diluting the salt water, the animals, even at a too high concentration of the salt water, revive, doing well in such a water with, to a certain degree, lowered temperature. It seems to me that in this case such a combiuation of high concentration and temperature is formed, bearing to the equilibrium of aëration in the water, i.e., the quantity of air in the salt water is lessened by the increase of its concentration for just so much, as it is, according to physical laws, heightened by lowering the temperature. A want of nourishment in very saline water is here out of question, since such a water is inhabited by immense numbers of simple organisms, and even at a concentration, allowing self-deposit of salt, great quantities of a red Monad occur, which is known under the name of Monas dunalii Joly (Diselmis dunalii Dujardin=Chlamidomonas dunalii Rabenliorst).

3. If we gather out of a salt lake the adult Artemiæ, together with their larvæ, and dilute the salt water to excess, then the larvæ will soon expire, while the adult individuals long after resist the dilution of the salt water. It appears that the larve of Artemia die faster in too strongly diluted salt water, because the small stock of material in the organism is not sufficient toward the intense oxydation in consequence of an excess of oxygen in such a water.

4. In a broad jar and at a low surface of water these animals also

${ }^{1}$ Joly, Sur l'Artemia salina. Annales des sciences naturelles, vol. xiii, Zoologie, pp. 246 and 255 . 
prosper in such non-diluted salt water, which was taken from the salt lake at a middle concentration peculiar for this species (Artemia salina), but they do not prosper so well in a narrower jar with higher water-surface, as they soon die in such a water. In the same narrow vessel and at the same high water-level these animals will still prosper if the salt water is proportionally diluted. In this latter case the animals are so circumstanced, as in more saline water in the broader jar with lower water-level. The diluted water contains more air, it being more penetrable and better adapted for gas exchanges.

5. Accepting the fact that the water in a salt lake at a given time shows $10^{\circ}$ Beaumé, and that it is populated with crustaceans of the genus Artemia, if we now take two equal vessels, placing in one of them water of this salt lake and a certain number of specimens of one genus of these crustaceans, and placing in the other jar specimens of the same animals out of the same salt lake, diluting the salt water to $7^{\circ}$ or $6 \circ$ Beaumé, a large number of animals will die in the first vessel under the same conditions, while keeping up the initial concentration of the water, but in the second vessel the majority of the animals will remain alive. In the second case, that quantity of air is as if restored, which is wanting in the first, apparently by the influence of the vessel itself, as the water in the vessel is under different conditions from that in the salt lake. This is all the more so the case with a summer-like temperature.

6. The animals prosper also in a non-diluted salt water better at a temperature lowered to a certain degree than at a higher temperature, jet they do much better in dilnted salt water, when the concentration of the salt water has not been reduced above a certain degree.

7. Finally, the enlargemeut of the surface of the gill-sacs in Artemia with the increase of concentration of the salt water proves, as mentioned already above, apparently the dependence of Artemia in this relation principally on the reduction of air-capacity of such a water, even if the gill-sacs, according to their location and formation, as it were, in these animals represent modified organs of locomotion. It remains for the physicists to determine how considerable is the solubility (the coefficient of assumption or of capacity) of the oxygen of the air in salt water when the variation of its concentration varies. In relation to this $I$ can find no accurate data.

\section{III.-THE GENERA ARTEMIA AND BRANCHIPUS, AND THE RELATION OF SOME OF THEIR SPECLES TO THE SURROUNDING ELEMENTS.}

In the whole order of Phyllopoda the species of the genera Artemia and Branchipus are apparently those which are most sensitive to the influence of the surrounding element, in such a sense that a modification of the surrounding element is capable of producing in their generations in a pretty short time visible mutations in their forms. A change of the surrounding element can even in one and the same generation produce such a variation of some parts of the body that it is difficult, in a state of nature, to immediately distinguish those forms which are most closely allied to each other. The species of these genera have been found by me mostly in salt lakes and salt ditches (Artemia exclusively), whereby they distribute themselves in such a manner that each species is peculiar to a certain concentration, and the change of this concentration in artificially domesticating their generations produces a ehange of form in the direction towards the next species or race which lives in another concentration of salt water, toward which side the 
change of concentration in the artificial domestication yielded. The temperature hereby co-operates with the concentration of the water. Relating to this, the forms of the genus Artemia deserve special attention.

\section{1.-Artemia salina Milne-Edwards.}

This species occurs here in the closed Chadschibai and Kujalnitzki Lake and in the salt-water ditches. It sustains a fluctuation easily noted in the variation of body-parts, and in its growth at a fluctuation of the concentration of the salt water from $5^{\circ}$ to $12^{\circ}$ Beanmé, in which limits it was found by me in the water basins. At a concentration of the salt water which is higher than $12^{\circ}$ (and still more than $15^{\circ}$ ) Beaumé, onr Artemia salina commences in its generations to exhibit trausitory forms towards Artemia milhausenii Milne-Edw., the latter living by a far greater concentration of the salt water than Artemia salina, that is, at self-deposition of salt or not far from it, i. e., at $24^{\circ}$ and $25^{\circ}$ Beaumé,

To the description of Artemia salina given by the authors we have to say, that the representation of characters of this species, as altogether of the whole genus Artemia in the present time, is very inexact and vague. Firstly, we find mentioned that Artemia possesses but six terminal segments, while there are eight, since we have to count also these two first apodons segments of the posterior part of the body, on which, in the species of Artemia-genera, the external genitals occur. Grube, ${ }^{1}$ in making of Artemia a section or a sub-genus of the genus Branchipus, repeats the mistake of his predecessors, saying, in the diagnosis of the group Artemia "segmentis apodibus sex." Only in Artemia milhausenii, which lives at a very high concentration of the salt water, are the articulations between the segments, especially between the more posterior ones, some what less distinct; but we can nevertheless, at least in specimens bearing the characters of this species from our districts (also from the Krimea), always distinguish them, especially in fresh material which has not been preserved in weak alcohol for a long time. In the latter case, even in Artemia salina, only with difficulty can we see the articnlations of the abdomen. If in any region Artemia mithausenii occurs with connate, apodous segments, be it in some or all specimens, then it is very likely that we, even in such an Artemia, camnot count six apodous segments. Secondly, it has been considered hitherto as the principal characters of the genus Artemia, that in the species of this genus the abdomen ends with a short furca, whose branches are bristles only on the end, and such a diagnosis of the genus Artemia we discover even in the very latest zoological hand-book. Grube ${ }^{2}$ repeats in the diagnosis of his group Artemia in the genus Branchipus the characteristics of the genus Artemia of his predecessors, in saying: Apperdicibus caudalibus brevibus, apice tantum setosis aut mullis. Our Artemia and two of its varieties, which I shall mention later on, have the bristles not only on the end but also on the sides of the furcal lobes, just as in the species of Branchipus, which usually only have more bristles. Besides the Artemia salina from the district of Odessa I have the same distribution of bristles on the furea in specimens of this species brought from the neighborhood of Astrachan and the Krimea. We have here dry years with a hot summer where the concentration of the salt water in the Chadschibai Lake is too high for Artemia salina. Then many specimens of this species have, especially in summer, bristles only on the end of the

1"Bemerkungen über die Phyllopoden" in "Archiv für Naturgeschichte," 1853, p. 139.

2 Opus citatum, ibidem. 
furca, the furca being at the same time shorter and less bristled, as under opposite physical conditions. If we compare the descriptions and illustrations of Artemia salina of the various authors, we find that they agree less among themselves than they do compiled from specimens of Artemia salina, or taken from the descriptions of specimens gathered under various physical conditions, that is, at various concentrations in combination with temperature. Milne-Edwards ${ }^{1}$ says: That on each furcal lobe in Artemia salina oceur three or four bristles, while Grube ${ }^{2}$ states, in his diagnosis, that 5 to 8 bristles occur on each furcal lobe. We find in Artemia salina from our district, under various behavior of the surroundings, on each lobe of the furca 4 to 12 bristles, seldom more. In the third form, living in salt ditches in the neighborhood of Odessa and the Krimea, we find 12 to 22 bristles on each lobe of the prettywell developed furca. I take the latter form to be another variety or race of Artemia salina, though it obviously originated from generations of this species with progressive development under the influence of saltwater ditches, having a lower saline capacity than the salt lakes, populated with Artemia salina. In those cases, where in our Artemia are more than five or six bristles on each lobe of the furca, the bristles are distributed not only near the end but also on the sides of the furcal lobes. The specimens of Artemia from the very saline Kujalnitzki Lake, having but three, two, one bristles on the end of the furcal lobes, or lacking them altogether, in the latter case having a very slightly developed furca, with the other parts modified; those I take to be transitory forms between Art. milliausenii and Art. salina; altogether the distribution of bristles on the furca, the number of bristles, and the shortness of the furea itself ean not serre as an important distinctive character between the genera Artemia and Branchipus, and much less so as a point of distinction between the species of Artemiæ.

In Artemia salina, as one of the most constant points of distinction, we observe the termination of the superior antennæ or antennæ of the first pair. The upper antenna here terminates with two protuberances or papillæ of the form of a truncated cone, one of which is somewhat stouter than the other. At the terminus of the stouter, broader cone, we notice three moderately short spines, only one of which can be seen on the terminus of the thinner cone. Each spine is a li tle curved, having at its base a quadrate, yellowish, light-refracting body. These four spines are the olfactory bristles of these animals. Immediately under the terminus of the upper antenna, near the end of its upper surface, arise three moderately long and usually curved bristles.

Beside the mentioned terminatious of the upper antennæ we have to complete the description of Artemia salina by the following characters. In Artemia the posterior part of the body consists of eight apodous segments, the first two of which bear the external genital organs, but the last eighth segment is twice as long as the preceding, being homologous to the two last apodous segments of the Branchipodes. The furca in Artemia salina is of very variable length. In our Odessa $A$. salina the furca is on the average six times shorter than the prolonged last abdominal segment. The bristles of the furca are also of very variable number. We notice in our Artemia salina on each lobe of the furca from four to twelve bristles, which are not only near the end of the lobes, but for the greater part distributed along their sides, at least if there are more than four or six bristles on each lobe. Toward autumn at a lowering of temperature and dilution of the salt water of the Chad-

${ }^{1}$ Histoire naturelle des crustacées, Vol. III, p. 370.

s "Bemerkunken über die Phyllopoden," Arch. f. Nat. 1853, p. 144. 
schibai Lake by rain, the furca becomes in the late generations longer and the number of bristles greater, since under these conditions the growth of Artemia salina is less retained and the sexual maturity appears not so early, that is, not earlier than the complete development of the body-parts, which, however, is not so well defined in this species, being, as it were, but a relative matter. Also the termination of the npper antennæ, being the most constant character of this species, modifies to a certain degree. For instance, $I$ found in the autamn of one year, at low temperature and diluted salt water of the Chadschibai Lake, in many individuals of A. salina near the end of the apper antennx five olfactory bristles, instead of the normal number of fonr. In domesticated generations of this species in gradually diluted salt water we perceive also five olfactory bristles on the npper antennæ. With the distinctive characters of $A$. salina we have also to include the form of the gill-sacs. They are in $A$. salina of an elongate form, their width being on the average twice less than their length. This character distinguishes $A$. salina from $A$. milhausenii, in which the gill-saes are of oral or more rounded form, being on the average two-thirds as wide as long.

As another important point of distinction of $A$. salina from the nearest allied races, I mention the proportional size of the posterior part of the body constituting the apodous segments; the anterior part from the beginning of the head to the end of the last leg-bearing segment, i. e., to the beginning of the first apodons segment and the posterior part of the body, from the beginning of the first apodons segment to the end of the last segment before the beginning of the furca. The furca does not come into account, as its length is variable, being for instance in A. milhausenii, with which the other forms must relatively also be compared, entirely missing. We find that in A. salina the anterior part of the body is somewhat shorter than the posterior; proportionate to it as five to six or as five to seven. This relation of the parts also depends upon the concentration of the salt water in which these generations live. In reduced concentration the posterior part has an inferior size than in the higher concentration. Altogether the postabdomen of $A$. salina becomes longer and more slender with increased concentration. In many of our specimens with the character of A. milhausenii, which live at self-deposition of salt or nearly so, the anterior part of the body is twice shorter then the posterior part.

To the most variable characters of $A$. salina we must reckon that reddish layer which lines the anterior part of the alimentary canal in the shape of a tube, which layer Joly ${ }^{2}$ calls the liver, and Leydig ${ }^{2}$ the stomach, as he separates it from the following part, the alimentary canal to the anal orifice. For better distinction I shall call the anterior part the stomach part of the tract, the second, the posterior part. ${ }^{3}$ The stomach part of the tract terminates in Artemia abont in the middle of the seventh apodous segment, but the length of this part depends upon the concentration of the salt water inhabited by the generations of this species, and partly also from the growth (age) of the specimens. 'At high salt capacity of the water this part of the tract does not reach to the end of the sixth apodous segment of the abdomen; at lower salt

" "Snr l'Artemia salina" in Annales des Sciences nat. 1840, pp. 238 to 239.

${ }^{2}$ F. Leydig, "Ueber Artemia salina and Branchipus stagnalis," Zeitschrift f. w. Z. 1851 , p. 283 to 264.

3 The first part of the tract Clans calls "Magendarm," the second part, the "EndDarm" in his "Zur Kenntniss des Baues und der Entwicklung von Branchipus stagnalis und Apus cancriformis," l. c., as above. 
capacity of the water, but especially in autumn, it exceeds by far the beginning of the erghth abdominal segment. Likewise this part is longer in old individuals than in young, otherwise sexually mature specimens. If we examine, relative to this, specimens on the extreme concentration-limits of the salt water, we find a great difference amongst them. In $A$. milhausenii the stomach part of the tract searcely reaches to the beginning of the sixth apodous segment, but in our species of Branchipus this part terminates not far from the anal orifice.

Finally, we must mention as a character of our A. salina the following: The claspers, or the lower antemnx in the males, are mnch broadened on their second joint, having such a form as the male claspers of $A$. arietina, according to a drawing of $\mathrm{S}$. Fischer. ${ }^{1}$

On the anterior part of the male claspers, between the head and the protuberances, serving to clasp the female with, near the bent-down margin, there are two groups of ten-pin-shaped teeth or spines, in one group on each side. It appears that these denticulate groups correspond as rudiments of the well-known appendages, occurring on the claspers of many species of Branchipus, as for instance in Branchipus spinosus. Such bundles of teeth or spines oceur also in that form of Artemia examined by Ulianin from Sebastopolis, and which was re. garded by him as a race of Branchipus arietinus Grube (= variety of Ast. arietina Fischer).

Artemia salina Milne-Edw. varietas a.-This form, called by me Artemia salina var. a., approaches the species Artemia salina so inuch that, beside its larger size, no other distinct eharacters exist by which we, with the general variability of so many characteristic points of the Artemiæ of this species, could distinguish the same. However, if we have specimens before our eyes of this or that form, we must confess that we have to do with forms differing so much that we even could regard them as different species of the genus Artemia.

A view of profound truth has been expressed already in 1871 , by Professor C. Th. von Siebold, on the comparison of descriptions of Artemia salina of various authors. Siebold says:" "In comparing the various descriptions and illustrations given of Artemia salina, we become convinced that probably with this species-name entirely different species or races were marked out, and therefore a revision of the species of the genus Artemia by carcinologists would be recommendable, though this, bowever, would necessitate a comparison of vast material, especially as the hitherto insufficient diagnoses of the species of Artemiæ, without reference to the characteristic formation of the male heads, have been compiled." Further on Professor Siebold, in perusing the descriptions of the second antennæ of the males in Artemia salina and that of the postabdomen of this species, foresaw what is now actually corroborated. I find two principal races of Artemia salina, one of which is of smaller size, the Artemia salina, but the other is Artemia salina rarietas a., and there are, besides, still other changes of its generations depending on various concentrations of the salt water, inclnding also those degraded and modifled generations of the troo races of Artemia salina, which are, as I suppose, recorded in zoological literature under the name of the species of Artemia milhausenii.

The main distinctions of the variety $a$. of the species Art. salina forms another mean length of it. Accepting as the mean length of Artemia salina six lines, we must accept eight lines of French foot for

${ }^{1}$ Middendorf's sibirische Reise. St. Petersburg, 1851, Vol. II, 1st part. Table VII, fig. 32 .

" "Beiträge zur Parthenogenesis der Arthropoden." Leipzig, 1871, p. 203. 
the mean length of Artemia salina var. a. As a rule the specimens of this variety are two lines or nearly so larger than the specimens of the species. ${ }^{1}$

With the mean size as a point of distinction, the fact may serve to show that the posterior part of the body in this variety from the beginning of the first apodous segment to the end is somewhat longer than in the normal species. The anterior part of the body in Artemia salina is in proportion to the posterior part in most cases as 5 to 6 (or 5 to 7 in higher concentration of the water), but in this variety usually as 5 to 8 , slightly fluctuating to this or that side in different salt capacity of the water. The postabdomen in this variety is not only longer, but also slenderer than in the normal species.

The furca is longer in the variety than in the species, and the number of bristles on the furca is also greater in the variety. If the furca in the species is six times shorter than the last prolonged segment of the abdomen, then it is but four times shorter than that segment in the race. But we also meet with specimens of the species with such a proportion of the furca to the last segment, as in this variety, and again we see furcal lobes in specimens of the variety with the same proportion to the last segment as in the normal species. In Artemia salina occur from 4 to 12 bristles on each lobe of the furca, rarely more; in the variety $a$. of Artemia salina there are from 8 to 15 , but seldom more. In this race, as well as in the species, we find however also less than four bristles on each furcal lobe; there occur three, two, and one bristle on each lobe, especially in more concentrated water; but such specimens and generations must, by modifications of other structures, be regarded as transitory forms between Art. salina and A. milhausenii.

The claspers or second antennæ of the males of the variety are less broad than in the males of the normal species. The groups of spines or teeth on the anterior part of the claspers, near their base, are somewhat better developed in the males of the variety than in the males of the species $A$, salina. The second antennæ of the females of this race are a little smaller and narrower than in the normal species, just as the male claspers are narrower than in the species.

The specimens of the variety $a$. of Artemia salina are of a far darker red color than the specimens of the species, althongh there occur also specimens with the same color amongst the latter. The rariety $a$ of A. salina is usually of a red color, and is found here in the Kujalnitzki salt lake, but Art. salina is usually of a grayish or reddish-gray color, occurring principally in the Chadschibai salt lake, in which occur also specimens of red color ${ }^{2}$ which represent, as it were, the points of aberration of the species toward its race (var. a.).

In the variety $a$. of Artemia salina the gill-sacs are a little smaller; the posterior branchial lobes, on the other hand, a little larger than in the normal species. According to the other structures, it does not differ from the species Artemia salina; and all that was said relative to the influence of the surrounding element about the species refers also to the rariety $a$. of $A$. salina.

All the characters of this variety correspond with the circumstance that specimens of them, in comparison with the specimens of the species, prosper better at a higher concentration of salt water, but at a lower temperature.

1 The specimens of the species are about $14 \mathrm{~mm}$ length, the specimens of this variety 17 or $18 \mathrm{~mm}$. The summer generations are in one, as well as in the other form, a little smaller than the fall generations.

${ }^{2}$ The Kujalnitzki Lake has more saline water than the Chadschibai Lake. 
Important for my purposes is the following remark of Dr. Nitsche concerning Branchipus Grubii (von Dybowski) from the neighborhood of Leipzig: "Further on it exhibited the remarkable circumstance that two races of this species occurred: a larger one abont 20 to $22^{\mathrm{mm}}$ long, and a smaller one about $15^{\mathrm{mm}}$ long. These lived in various ditches, and those inhabited by the larger race contained far less specimens than those inhabited by the smaller race." 1 The existence of two races of different sizes of Branchipus Grubii and the cireumstance that the specimens of these races lived in different ditches is of importance. It would be interesting to learn ${ }^{2}$ whether this "ratio quantitatis" between two races occurs at any time of the year (which I do not accept). Information about this latter point would especially be of value, whether the specimens of these two races occurred together in one and the same ditch.

Artemia salina Milne.Edw. varietas $b$., like variety $a$., in reference to the species, represents, so to speak, another branch of the middle radical form, from which it, together with the normal species, originated in the distribution of generations in a modified element; this second variety (var. b.) represents in its distribution in an element of lesser concentration of the salt water the progressively developed generations of the species itself.

Variety $b$. occurs in salt ditches near Odessa and Sebastopolis. In salt ditches near Odessa $I$ found it at a concentration of $4^{\circ}$ Beanmé, while at the same time in the other salt ditches of higher concentration specimens of A. salina occurred.

The length of the specimens of variety $b$. scarcely differs from the length of specimens of the normal species; its postabdomen, however, is shorter and stouter than in the species; the furca is by farlonger and more bristled than in the normal species. The postabdomen (exclusive of the furca) is in this race also a little shorter than the anterior part of the body, at least in the young, thongh sexually mature specimens, while the same somewhat elongates with age. As the posterior part of the body elongates with the growth of the specimens to mature and old age, and likewise in heightening the concentration of the salt water, we can presume that it is in $A$. salina var. $b$. either shorter than the anterior part, or equals it, or is scarcely longer than the same, while in the species $A$. salina the posterior part of the body is considerably longer than the anterior. ${ }^{3}$ Only in the young specimens of the species itself, some time before becoming sexually mature, the posterior part of the body is still shorter than the anterior. In any case, such a character cannot sharply demarcate this variety from the normal species. There are other characters by which we can distingnish them. The furca of the variety $b$. does not show any simple conical protuberances at the end of the abdomen like two prolongations of the same, bat real-even if not segmented from the end of the abdomen, but only by a transverse, easily noticed ring, separated at the sides from its base-divided furcal lobes. They are rather large and more developed than in other forms of Artemiæ. They have the shape of lancet-like plates, tapering

${ }^{1}$ H. Nitsche: "Ueber die Geschlechtsorgane von Branchipus Grubii (von Dyb.)." Zeitschrift, f. w. Z., vol. xxv, p. 281.

' From Dr. Nitsche we cannot expect to hear all the singularities referred to the race of Branchipus Grubei. Especially inquiring into the structnres of the sexual organs of Branch. Grubii, which formed the topic of his dissertation, Nitsche sufficiently pointed out the existence of two races of $\mathrm{Br}$. Grubii, calling it a remarkable circumstance.

${ }^{3}$ The postabdomen is on the average longer and slenderer in the species of Artemia than in those of Branchipus. 
toward the tip, with sides and ends bristled, whose number fiuctuates on each lobe between 12 and 22 . The furcal lobes are in length only two and a half times shorter than the last abdominal segment.

This last (eighth apodous) prolonged segment of the abdomen differs here in the important peculiarity that it possesses, a little above its middle, often a more or less distinct transverse ring, like an articulation, as existing between the eighth and ninth apodous segments of the abdomen in the species of Branchipus, in which the furcal lobes are in the majority strongly developed, as it were, on account of the ninth apodous segment, which is rather short with them. This transverse ring. is just below the last sensitive bristles, occurring in A. salina a little above the middle of the eighth apodous segment of the abdomen, ${ }^{1}$ as also at the end of each of the anterior apodous segments just before the segmentations. If this transverse ring on the eighth prolonged apodous segment was more conspicuous in variety $b$. of $A$. salina, and if it was of constant occurrence, then we would have a form with nine apodous abdominal segments, which is one of the principal characters of the genus Branchipus. But since there is no actual segmentation on the eighth apodous abdominal segment of variety $b$. of $A$. salina, this race forms, remaining with the genus Artemia, a transitory link between this genus and the genus Branchipus. With the latter genns the examined race possesses by far more harmony than the other hitherto known forms of Artemix. The prolonged, laterally and terminally, bristled furcal lobes, the transwerse ring between these lobes and the abdominal eurl, the shortness of the postabdomen, the lesser length in proportion to these parts in other Artemia forms, the greater thickness of the segments of the postabdomen, the more or less distinct traces of segmentation on the last (eighth) apodous, homologous with the two last (eighth and ninth apodous) segments of Branchipus, likewise also yet other less conspicuous characters of Artemia salina varietas b., demonstrate this.

Amongst the characters in which the examined Artemia-form incline to the genus Branchipus I will note two more. One of them consists in the presence of groups of spines on the ventral and lateral surface of the postabdomen, on the end of the third, fourth, fifth, sixth, and seventh apodous segments, anteriorly of each segmentation, and a little before the middle of the eighth apodous segment before the more or less noticeable transverse ring on this segment. On some segments occur two aggregations, one on each side, but on others oceur four aggregations arranged circularly around the segment. From the middle of each aggregation arises a sensory bristle, which, together with the groujs of spines sitnated near their base, ean easily be seen under a magnifying power of 350 . In A. salina and its variety $a$. oceur, instead of groups of spines, on the same spot groups of enticular cells, which do not rise above the surface of the integument (from which they are somewhat differentiated), and which give rise to one bristlearising from their mirlst. These complexes of cuticular cells in $A$. salina and in its variety $a$. are homologous with the mentioned complexes of spines in race $b$. of $\dot{A}$. salina and the species of Branchipus. In domesticating several successive generations of the species A. salina in gradually diluted salt water, I obtained, together with the other corresponding characters on the post-

${ }^{1}$ On this spot of the last segment of the abdomen we obtain the segmentation in the species A. salina by domesticating several of its generations in gradanally diluted salt water. Compare my paper in the "Schriften" of the third meeting of Russian natnralists at Kiew, Zoological section, pp. 71 and 87 ; also, my paper in Z.f. w. Z., xxv, 1871. 
abdomen, the development of groups of spines from the above-mentioned groups of cuticular cells. However, these cuticular cells also commence in free nature in fall generations of the species $A$. salina to point themselves on their tips and to elevate themselves above the integument. To be sure under such external conditions the enlargment of the furca and the number of their bristles testify in these specimens to a lesser retention of growth than in summer at higher salt capacity of the water and at higher temperature. These cuticular groups of cells, or, in known cases, these denticular groups of spines occurring near the base of the sensory bristle on the abdomen of A. salina and its varieties, are homologous with the minute denticular spines occurring near the base of the sensory bristles on the lateral surface of the postabdomen in both sexes of Branchipus ferox and $B$. spinosus. Concerning the large spines on the ventral surface of many apodous segments (from the third to the eighth) of the abdomen of the males of B. spinosus, they apparently represent a phenomenon independent of the sensory bristles and their basal denticular groups of spines, or both structures are so connected with each other that the substituted sexual characters can be connected with the sensory organs, for which we have to take the large rentral spines of certain abCominal segments of the male B. spinosus. Beside these large spines, occur, exteriorly of them, at the side of the segments, in the males as well as in the females of this species, groups of minute denticular spines, each with a sensory bristle.

The last of such conspicuous characters of the variety $b$. of A. salina, approximating this form to the genus Branchipus, consists in the fact that the male claspers on the anterior ventrally-directed side near the margin between the rugose protuberances and the middle have not only at the sides a complex of teeth, but also that they have on these spots several protuberances or integumental duplicatures. It seems to me that those teeth ocenr on that spot where certain appendages on the male claspers of many species of Branchipus occur. The claspers themselves are considerably smaller in the males of this race than in the species A. salina.

Still further on a cireumstance in the biology of $A$. salina var. $b$. points to the inclination of this form towards the species Branchipus. It is that the males of this variety evidently occur comparatively more frequently than in the other forms of Artemia. Of sixteen specimens brought to me indiscriminately from the Krimea, six of them proved to be males. ${ }^{1}$ Such a percentage of males I never met with in other species of Artemia, among which the males are generally rare. Near Odessa I had succeded hitherto in finding but one female of this varietr, together with B. spinosus in a salt-water ditch of $4^{\circ}$ Beaumé, none of the other forms of Artemia occurring there. Variety $b$. of A. salina, however, lives among all forms of Artemia known to me at the lowest concentration of salt water in salt ditches, in which live also several species of Branchipus, some at higher, others at lower concentration of the salt water. This circumstance is of importance, inasmuch as in suecies of Branchipus, which do not indicate such a difference in figures as the species of Artemia, parthenogenesis is unknown, while it without doubt exists in Artemia, and in this number probably also in variety $b$. of $A$. salina, being yet solely on the limits of the genus Artemia. Very rarely

\footnotetext{
${ }^{1}$ In the summer of $1876 \mathrm{I}$ found in the neighborhood of Sebastopolis, in several salt-water ditches and smaller salt lakes of lesser salt capacity of the water, progressively developed generations of $A$. salina; nearly half of their number were males.
} 
do we find males in the degrauled generations of A. salina alrealy bearing the characters of Artemia milhausenii, and which live in the most saline water. However, we can plainly notice that in the salt ditches and in very small salt lakes drying up in summer, that the males of Artemia appear in immense numbers at a certain time of the rear, and at a certain concentration of the salt water, as $I$ observed it at a compara. tively rapid evaporation of the water of the salt-water basins at the time of continued drought. Here we have to give ourselves the solution of the question about the change of this physiological function in consequence of the distribution of generations of a species in another element, together with a certain rariation of other functions, and of the animal organism. Referring to this I mention but one of the sides, to which variety $b$. of $A$. salina inclines to the genus Branchipus.

This rariety has with the species the other structures in common, with the exception of those less noticable aberrations depending upon the element, i.e., principally from the lower concentration of the salt water, together with their own organization. So, for instance, are the gillsacs in the variety a little smaller, but especially narrower than in the species; likewise in the body more of a gray than a reddish color, and more transparent. This form most closely approaches the rariety of Branchipus ferox of our salt ditches, but perhaps it is the radical form of B. ferox and B. spinosus.

Consequently we have, therefore, here three closely allied forms of Artemia: A. salina, A. salina var. a., and A. salina var. $b$. The species A. salina must justly be regarded as a double form, consisting of $A$. salina and its first variety (var. a.), as these two forms in long past times must have oxiginated by division and formation of races of their generations from one for both middle forms. Regarding the second variety (var. b.), it represents a form originated from $A$. salina, and became distributed in salt ditches of lesser salt capacity, and it is likely that also a similar offspring of the second variety exists.

These three forms, howerer, have so many different characters that they in any case can be recognized as varieties amongst themselves. We find such cases also in other widely-distributed species of Crustaceans, ${ }^{1}$ for instance, in Cyclops bicuspidatus Clans, and especially in Cyclops odessanus n. sp., where two (Cyclops bicuspidatus) or still more (C. odessanus) near, but still differing forms under certain external conditions, each living in either its peculiar pond in one and the same, or also in different water basins, and where each under certain exterual conditions or at another season of the year obtains preponderance at least in the number of specimens. But the forms of Artemix have the preference before other Crustaceans, inasmuch as the surrounding element includes less complicated conditions, which by the observer can be kept under better control.

Among the forms of Artemix we may regard $A$. milhausenii as one of the most retrogressively developed ones; but as one of the most progressively developed forms we have that which I provisionally call variety $b$. of $A$. salina. Parallel to this $A$. milhausenii lives in very saline water, near the self-deposition of salt, or near the same (about $23 \circ$ to $25^{\circ}$ Beatumé), but variety b. of $A$. salina lives in comparatively less saline water $(4 \circ$ B.).

Onr A. salina does not fully agree with that examined by Joly, ${ }^{2}$

1 Consult my paper in the "Schriften" of the neorussian Society of Nat. 1875, vol. III, 2 i part.

¿Joly, Sur l'Artemia salina, Annales des Sc. Nat. 1840. 
occurring in the south of France. Our A. salina is rather a middle form between A. salina Joly and our large race of A. salina (var. a.). The considerably prolonged furea and the rather thin female claspers (males were unknown to Joly) of A. salina Joly recall these parts in the mentioned variety, but the body-length and the proportional length of the abdomen agree with the same characters of our A. salina. The mean concentration of the salt water Joly mentioned for his species corresponds better with the mean concentration for our variety $a$. of $A$. salina. Besides, according to the drawing of Joly, in his Artemia salina the sixth apodous (Joly's fourth) segment of the abdomen is a little longer than the seventh, but in our $A$. salina the sixth apodous abdominal segment is usually a little shorter than the seventh; still it becomes longer only at too high concentration of the salt water and also in younger stages of the specimens. In mature specimens of our $A$. salina is the sixth segment especially longer when the concentration of the salt water does not change from year to year, but in a shorter time, as, for instance, from spring toward summer. The relative length of the sixth and seventh apodons abdominal segments in our A. salina may also serve as a measure for determining the age of already mature specimens at a given concentration of the salt water, since the seventh apodons abdominal segment prolongs with the age, and when this segment in heightened concentration of the salt water, also in mature specimens, remains equal with the sixth or shorter, it indicates that sexual ma. turity appears under such conditions a little earlier than the full development of the body-parts. In variety $a$. of our $A$. salina is the sixth apodous abdominal segment generally somewhat longer than the seventh, which corresponds with the illustration of Joly and the usually not sexually mature specimens of our $A$. salina.

The male claspers of onr A. salina are. as alluded to abore, of the same form as figured by S. Fischer for his A. arietina (Middendorf's sibir. Reise, vol. II, part i, Pl. VII, fig. 32), but the termination of the upper antenna separates, according to the description and illustration of $\mathrm{S}$. Fischer, this form from Artemia salina.

Concerning the diagnosis of $A$. salina Grube (Branchipus salinus Grb.) it remains unknown wherefrom Grube took the statement, that in this species there are eleven bristles on the edges of the terminal plates (lobus tarsalis Grb.) of the legs. The lobus tarsalis Grb. is the palette of Joly, as expressed by Grube, but Joly points out 30 to 38 bristles on each such plate. I believe that this is a mistake in Grube's diagnosis, and that Grube connted eleven bristles from Joly's illustration on another foot-plate of Art. salina, that is, on one of those plates which Grube $^{1}$ calls himself lobi tibiales. This mistake in Grube's diagnosis can be sufficiently cleared up by the comparison of the description and illustration of Joly with Grube's diagnosis and synonyms, which Grube mentions for the terminology of these lobes in these animals after various authors.

I wonder that I have not hitherto succeeded in finding that species which S. Fischer described from the neighborhood of Odessa ${ }^{2}$ under the name of Artemia arietina. The principal and very great difference of A. arietina consists, according to Fischer, in that the terminations of the first pair of antennæ in this species are divided into two branches, whereby the end of one branch bears two olfactory bristles, but the end of the other bears two prolonged bristles, while in all Artemia collected 
by me here and in the Krimea an entirely different type of structure of the first antennæ predominates, there being on the searcely biramous eud of the antennæ of the first pair four olfactory bristles and three rather long bristles. Also at my visiting the Krimea last year (1876) I found the same Artemiæ as near Odessa. It is the same Artemia salina with its two forms (a smaller, the Artemia salina, and a larger, the variety $a$. of A. salina), and moreover with its different variations, as they depend upon the different concentrations of the water in a known salt lake (the specimens with the characters of variety $b$. of A. salina and those with the characters of $A$. millhausenii). Beside the lake near Eupatoria I also visited tive other small lakes near Sebastopolis. Out of one of these lakes, the second on the Chersonesis and at the same season of the year, Ulanin ${ }^{1}$ obtained Artemia and, as communicated to me by the author himself, alcoholic preparations already rather injured, which he described as a variety of $A$. arietina Fischer $(B r$. arietinus Grb.). S. Fischer described his A. arictina also from alcoholic specimens, but we ought from all Crustaceans, Artemidæ the least, not to describe them after alcoholic specimens, as in them especially the number and the relation of the postabdominal segments remain concealed from any observer who does not succeed in obtaining lise material. Unhappily also the systematic description of the Artemia and Branchipus has hitherto remained still the same, as founded in literature by descriptions from alcoholic specimens. Such misrepresentations arise from this, that, for instance, in one species, Artemia salina, the secoud antennæ of the male, while in another species, Artemia milhausenii, under the same name, the second antemas of the female have been described (cornes céphaliques, Milne Edw. Hist. nat. des crustacées), as the males of this species were not yet known, ${ }^{2}$ about which I shall speak further below. For those uninitiated in Artemia and the singularities of its literature, such diagnosis may form a source of many errors, which I have elsewhere endeavored to clear up. ${ }^{3}$

\section{2.-Generations of Artemia salina Milne Edac. receiving the characters of Artemia Milhausenii Milne Edw.}

Artemia mithausenii has been described by authors ander various names (Branchipus milhausenii Fischer von Waldhein, Art. salina Rathke, Art. milhansenii S. Fischer) from alcoholic specimens, and therefore we find various contradictions and inacurate acconnts in the descriptions of this species. Other authors (Milne Edw., Grube) borrowed accounts from the former for the diamnosis of this species. If the forms occurring in nature and those obtained by a certain domestication from $A$. salina and its first variety (varietas $a$.) agree with those which have been deseribed by the authors under the name of A. mithausenii and synonyms, or, better expressed, if there is in a state of nature no other A. milhausenii than the degraded and modified form of A. salina, which receives with the generations after a certain time and by heightening the salt capacity of the salt lake the characters of $A$. milhausenii, then A.milhausenii, owing to the manner of its origin and the

1 "Schriften der kaiserlichen Ges. der Liebhaber der Nat. Anthrop. and Völkerbeschr. Moskau. Vol. V, part i, page 96.

2 C. von Sicbold, Beitriige zar Parthenogenesis der Arthropoden, 1871, p. 209.

:Consnlt my yraper: Explications relatives anx difiérences qui existent entre l'Artemia salina et l'Art. milhatanenii et entre les genres Artemia et Branchipus. Biblioth. Universelle et Revne Suisse. "Archive des sciences phys. et natur. Geneve." Vol. 57 , No. 224,1876, pp .358 to 365. 
infirmity of its characters, in which, however, it differs from the nearest forms, as one species differs fiom another species, does not represent an independent or original species. At constant high or little changed concentration of the salt water, this form is able to produce entire series of generations with the characters of $A$. milhausenii, like an original species. Even if the generations of our form with the characters of $A$. milkausenii are qualified at a certain behavior of the surrounding element to preserve their distinctive specific characters, then these generations only represent a degraded and modified torm of $A$. salina, or, indeed, two closely allied forms of $A$. salina, of which one represents the changed generations of $A$. salina, the other the changed generation, of the first variety (varietas a.) of this species.

In a short treatise in Zeitschrift f. w. Zoologie, Vol. XXV, first sup. plementary part, I have spoken of the changes of the generations of $A$. salina produced by heightening the salt-capacity of the water in nature and by artificial domestication, whereby they received the species characters of $A$. milhausenii. Without repeating the same, I will only point out that, together with the moditications of the postabdomen of $A$. salina, the other parts also gradually changed in the direction toward Artemia milhausenii, $i$. e., the postabdomen became more slender and longer, the female claspers narrower; the leg-parts also changed themselves, whereby the number of bristles and fimbriate spines of the leglobes lessened, and the gill-saes (Clans) changed from elongate to oval, thus comparatively increasing their size. We obtained finally all the peculiar characters of $A$. mistausenii, as they were described by the authors.

The specimens with the characters of A. milhausenii in the Kujalnitzki salt lake justly represent a degraded aud changed form of $A$. salina and its first large variety (a.), for that we also distinguish two different forms of individnals with the characters of A. milhausenii. Some correspond with the specimens of the species, others with the mentioned variety of A. salina. Even if the characters of the species and this variety of $A$. salina, through degradation of their individuals, become somewhat obliterated, it is nevertheless still possible to distinguish individuals originating from this or from that form. Those corresponding with $A$. salina have about $10^{\mathrm{mm}}$ length, those of the mentioned variety are about $12 \mathrm{~mm}$ in length. In the former the postabdomen is a little shorter, and the posterior or apodous segments is shorter than the double length of the anterior part of the body, and is in proportion to it on the average as 8 to 5 , but in the latter the posterior part of the body is equal to twice the length of the anterior part, or a little shorter, in the proportion in the latter case of 9 to 5 . In both species this relation moreover depends upon the age of the already sexually mature individuals, since in already older ones the posterior part of the body is longer. Moreover, the former have a less dark red color, and their rounded abdominal end is somewhat broadened and as if flattened in the direction from above downward, but the latter have a more dark red color and the abdominal end is less broadened, only rounded. In this way the specimens of $A$. mithausenii have two forms, but the difference of their characters is scarcely sufficient to regard one of them as a true race in relation to the o her, and the less so, as the deviation of the individuals of the one or the other category on one or the other side, according to age, even at the time of sexual maturity, allows some transitory stages to be recognized between them. It is only apparent that some represent a degraded form of $A$. salina, but that others represent a degraded form of variety $a$. of $A$. salina. It is necessary to remark, that 
the former already at $20^{\circ}$ Beaumé represent a just as far degraded or retrograded form as do the latter at $23^{\circ}$ or $24^{\circ}$ Beaumé, and that the former occur principally in one, but the latter in another, now cut-ofi part of the Kujalnitzki salt lake. For better distinction I shall call the former the smaller, the latter the larger form with the characters of $A$. millhausenii.

Did this Artemia, with the characters of A. milhausenii, one form of A. salina, change by the influence of the surroundings, or one by the influence of the same in the development-retarded form? To this ques. tion the characters themselves, and the course of postembryonal development of this modified and also in development retarded form, answer. Not only characters show themselves in this form peculiar to the younger age of A. salina, and originated from retarded development, but also newly acquired to the surrounding adapted characters. The young individuals of $A$. salina and its variety have, as is known, in the beginning no furca, but it develops much later. This circumstance testifies that in adults with the characters of A. milhausenii no furea has been formed, owing to retarded growth. But we must consider that in those transitory forms between $A$. salina and $A$. milh., which in mature and old age have a little-developed furea, with a very small number of bristles, have, in still young age, just before the appearance of sexual maturity, and shortly after the same, a still more developed furea, with a larger number of bristles preserved, than in old age, during which this part at one and the same salt capacity of the water more degrades. This phenom. enon can still be better noticed in the domestication of successive gen. erations of $A$. salina in salt water of gradually increased concentration, wherein that period, during which the furea mostly develops, shortens with each following generation, the development of the furea becoming a weaker one, appearing in shorter time-spaces. It is important that this period includes the space of time immediately before and partly also after the appearance of sexual maturity, in the beginning of mature age; also in those specimens in nature in which in later, mature, and old age altogether no furca exists, a little dereloped appears in said period, partly with bristles, or only in later generations, by the influence of the surroundings in the same direction, this phenomenon of characters of higher original form is more and more obliterated. All these phenomena prove that the absence of the furca in the forms with the characters of $A$. milhausenii depends upon retarded development of the organization of the generations, not only from the appearance of sexual maturity still before the full development of the body parts, but also from the immediate influence of the salt water of higher concentration, at which the appendages just beginning to develop became as if atrophied. There are many similar examples of retrograde derelopment of the form and of the individual.

The greater length and slenderness of the postabdomen in the specimens with the characters of $A$. milhausenii compared with the part in mature and still more in younger $A$. salina, proves with certainty that the organization of such specimens in this relation depends almost entirely upon the immediate influence of the element, but not upon an indirect influence, $i . e$. , from the mechanical pressure of the salt water, and the later appearance of sexual maturity, and not from the retained growth and the appearance of sexual maturity before the complete development of the body parts. Had the postabdomen of the specimens with the characters of A. milhausenii formed as a consequence of retarded growth aud in comparison to A. salina earlier and before the full development of the body-parts ensuing appearance of sexual maturity, this postabdo- 
men would have remained comparatively short and stout in the conduct of these parts in the young $A$. salina, in which the furea is not yet de. veloped, or it would be in any case shorter and stouter than in the mature A. salina. I almit that in further degradation of the generations with the characteristies of $A$. millausenii the postabdomen could have become even, if not shorter, yet less shorter, than in the mature A. salina, but I only speak of what has really been the case in these specimens. The circumstance that at a higher salt capacity of the water, the growth of the degraded specimens of $A$. salina is going on slow, and the sexual waturity appears in time late, gives its postabdomen the chance, as if in contrast with the degrading influence of the element to prolong, and the latter perhaps also retains the prolongation of the abdomen, especially in combination with the heightened temperature, which also, according to the time, awakens the sexual maturity earlier. In $A$. milhausenii, lescribed by Rathke ${ }^{1}$ under the name of $A$. salina, is the posterior part of the body, consisting of apodous segments, also shorter than the anterior part, although the description, illustration, and figures of this author stand in great contradiction to each other. From the description of this author it follows that this Artemia in summer lives in a concentration of the salt lake reaching self-deposition. Even if the postabdomen in our specimens with the characters of A. milhausenii is larger than in $A$. salina, there is nevertheless in transitory forms, in which the degradation dic not yet reach the extreme limits, a postabdomen somewhat longer than in the specimens which in the further generations live at a higher concentration, lacking the furca already, as is especially noticed in the summer generations. The length and sienderness of the postabdomen prove in any case, especially in our specimens with the characters of $A$. milh., the dependence of the organization of these specimens upon the immediate influence of the surrounding, dependent upon the retarded development and sexual maturity appears earlier than the full development of body-parts, since on the whole the postabdomen of these forms is longer and slenderer than in the young, and also even in the mature forms of Art. salina.

Contrarily the gill-sacs also prove the retarded developmen: of $A$. milhausenii if they are also in their development simultaneously adapted to the demands of the surroundings. That is, in young specimens of A. salina exists a period in which their gill-sacs have nearly the same form as in the mature individuals with the characters of A. milhausenii. Likewise the gill-sacs are in the mature individuals with the eharacters of Art. milh. larger than in mature individuals of $A$. salina, especially in relation to width and in the comparison with the length of the body in these or those individuals.

But the young individuals of A. salina now have larger gill-sacs than the full-grown ones, there being a period in their development in which the gill-sacs are in length and width so in proportion, as is the case in mature specimens with the characters of $A$.milhausenii. This apparently points to the exclusive dependence of the gill-sics upon retarded development of the form in the latter specimens, but this only seems to be so. If we domesticate generations of $A$. salina in gradually diluted salt water this period appears, during which the gill-saes of the young Artemia have the measure of the gill-sacs of the mature specimens with the characters of $A$. milhausenii, always earlier, $i$. e., it approaches the beginning of development; in the domestication of these generations in an opposite direction, this period always appears later; $i$. $e$, it ap- 
proaches the end of the development, so that the young specimens of one and the same age, but, from a different element, do not correspond in this relation, and the younger age of the former concurs with the later age of the latter. Since the whole development of these or those specimens proceeds similarly, so must the development itself depend upon the immediate influence of the surroundings, after which the organism of these or those forms develops, whereby that in the generations sums up what the external conditions in them produces; and what they as a consequeuce of the influence of the surroundings acquire. Here we must imagine the trausfer of the course of development of a single individual upon the course of development of particular animal forms. From all this it results that the gill sacs of the young individuals of $A$. salina are in a certain age similar to the gill-sacs of the mature individuals of A. milhausenii, but the gill-sacs of the young individuals of this latter species are at the same period still larger, and obviously represent an addition in the organization of this form in comparison with A. salina, and a result of the influence of some force. This force was the surrounding element of a certain composition, that is, the large salt capacity of the water alone, or in combination with hoightened temperature. Hence, we see that the gill-sacs in $A$. milhausenii, together with some other parts of the body, testify to the retrograde development of this form under the influence of the surronulings as well as of the immediate influence of this element. It is worthy of remark that the fact that the adaptation to the element is accompanied by a retarded development of the generations, as in other cases the adaptation to the element in these animals is accompanied by a progressive development of the generations; in another element by the, as regards this species, typical derelopment of the body parts and sexual maturity. In the one and the other case the element effectuates a change of form in a direst and indirect manner. Of course, nature effects this in a great neasure, not so much by the change of the element as by distributing generations of a species in a highly varied element.

Touching now the question, whether the specimens with the characters of $A$. milhausenii, which in the course of several years and a comparatively small number of generations issued from $A$. salina in the Kujaluitzki Lake, at a gradual heightening of the salt capacity, do represent a species, or at least a variety, I must answer in the negative. If it turns out that the actual Artemia milhausenii of the authors, according to its structure and origin, is equal to the degraded specimens of $A$. salina, then it has no right to be regarded as a species jroper, yea, not even to be a variety of $A$. salina, or of any other species, since the manner of its origin under the mentioned conditions contradicts the prevailing conception of species and race. Species and race possess a comparatively great endurance of characters, and must originate in consequence of more or less widely spread distribution of generations of their preceding or contemporary forms in a differentiated element (without natural selection or with it), but not owing to the modification of the surrounding element in a given locality, and moreover in a brief space of time, in the course of perhaps four years. ${ }^{1}$

Even if the change of the element at a certain rate of slowness can faror the change of form, the main cause of their origin must, neverthe-

${ }^{1}$ The lowest organisms appear, by certain changes of the surroundings, in an inconsiderable space of time to represent definite series of forms, which we are aceustomed to hold as species. The beginuing of my papers in this direction relative to the lowest organisms, forms my artiele in the "Schriften" of the Neorussian Society of Nat. uralists, $18 \% 6$, vol. iv. 
less, lie in the disposition of the generations to distribute themselves in much raried elements, that is, to distribute themselves beyond the limits of that element, at which, in the generations, the typical characters of the species preserve, regardless as to the causation of such distribution, by increased augmentation of the individuals, or of such external influences, like modification of the element in a given locality. Our individuals with the characters of $A$. milhausenii actually represent the degraded and modified generations of $A$. salina, by the itself rapidly changing element which also influences the Artemix living in it. Similarly, like certain annual species, which with their generations are much distributed, according to the seasons of the year; represent rather great differences in spring and summer forms. As the most extreme generations of the seasonably distributed species deviate from their species-type toward the nearest allied forms, as is seen, for instance, in Cyclops brevicaudatus Claus, and Daphnia magna, Leydig, var., ${ }^{1}$ so likewise deviates Artemia salina with its generations at the most extreme limits of endurable concentration of the salt water toward the forms allied to them. But there is a great difference between these phenomena. Artemia salina changes during the course of several years in the direction toward A. milhausenii, passing through a comparatively large series of generations, and whereby we, in comparison, finally obtain a far greater modification than any hitherto known deviation in the generations distributed seasonally. If there actually exists in nature a self-sustaining species, $A$. mitharsenii, like an A. koeppeniana Fischer, besides the degraded yenerations of $A$. salina and similar forms, then such degraded generations of the highest speeies of Artemiæ represent transitory forms toward the lower species of this genus, and indicate the element under whose influence the latter originated. This element must be a salt water of great concentration, together with heightened temperature. It is possible that in long-continued duration of the salt-lake element peculiar to the lowest Artemiæ, the degraded generations of the higher species of this genus still more degenerate, rendering their characters more permanent, but the forms themselves more independent, even if the principal condition of the origin of independent forms consists in the distribution of generations of these forms producing species in a heterogeneous element, but not (or less) in the modifications of the element of a known district or of a certain water-basin. It seems to me that, with a very gradnal increase of the concentration of the salt lake, the species populating it will rather die off in this location, than producing a new self, sustaining itself with the element modifying species.

In view of such phenomena a strict serutiny of such lowest Artemiæ as $A$. mithausenii is unconditionally necessary; all the more, since these species were described by the authors for the greater part from alcoholic specimens, and moreover at a time in which the modifying effect of the salt water upon the Artemiæ was yet entirely unknown.

To solve the question, whether $A$. milhausenii exists as a self-sustaining species, I visited during the middle of July, 1876, the Krimea and examined specimens of Artemiæ from that salt lake, which is located near the Tatare village Sakki on the way between Eupatoria (Koslov) and. Simpherpolis, from which the authors (Fisher von Waldheim, H. Rathke, S. Fischer), who described the Artemia milhausenii obtained their Artemix. I saw that in this lake occurred already at the self-deposition of salt specimens fully answering the descriptions of Artemia

${ }^{1}$ Consult my paper in the "Schriften" of the Neoruss. Soc. of Naturalists. 1875. Vol. iii., Pp. 18 to 44 and 206 to 214. 
milhausenii of the authors (exclusive of their mistakes), and likewise occurred in it at the same time specimens of the transitory form toward A. salina Milne-Edw., whose specimens here were in various degrees of degeneration in the direction of Artemia milhausenii. They were all such specimens as those found by me at the end of summer, 1873, and middle of summer, 1874, in the Kujalnitzki Lake, near Odessa, that is to say, partly complete, partly not fully changed, specimens in form, known under the name of Artemia milhausenii. 'The circumstance that in the very saline Sakki Lake, there still occurred also in the middle of July many specimens of the transitional form between $A$. salina and $A$. mil. hausenii, is explained by the fact that the preceding winter in the Krimea was very snowy, that the water in the salt lake in spring became very diluted, and that the specimens and generations of Artemia salina had to change rapidly in one summer, therefore many specimens did not succeed in fully transforming in this one summer. (Only at very gradual increase of the concentration of the salt water have the following generations of Artemia salina in all their specimens the form of Artemia milhausenii, as observed by me in the course of several years in the Kujalnitzki salt lake near Odessa.) After several days of great drought and increase in the amount of the deposited salt in the Sakki Lake, 1 could not find a single individual of Artemia. I have to state that the specimens of Artemia in this lake belong to those two races of Artemia salina, which live in the neighborhood of Odessa in the Knjalnitzki salt lake. The smaller individuals of this much distributed species answer to Artemia salina, changed in the known manner, but the larger individuals answer to variety $a$. of Artemia salina changed in the same direction.

It would here be important to know what is really wanting in the degraded generations of Artemia salina, in order to possess all the char. acters of Artemia milhausenii Autorum.

Contrary to the diagnosis of this species (A. mitharsenii of Milne. Edwards), we in our generations notice but the one difrerence, that on the female claspers of our individuals toward the middle is found a small protuberance or broadening, Milne-Edwards not mentioning this (of course in the females, as the males were yet unknown at that time). These words of Milne-Edwards do not correspond wirh Rathke's statements, who described this species under the name of his Artemia salina. We see from Rathke's drawing and deseription that the second antenne of the female of this species has two broadenings divided by a transverse ring, which the author regards as the two tirst joints, whereby a broadening occurs near the base, another one in the middle of the antenna, which answers the same as similar broadenings in our female specimens with the characters of this species. In comparing Artemia milhausenii with A. salina we must observe that in Milne-Edwards's diagnoses (Histoire naturelle des crustacées, Vol. III) the second antennse of the males of $A$. salina, and the second antenna of the females of A. milhansenii, of which latter the males were yet naknown, have been described, as already stated above. For these determinations in both diagnoses (cornes céphaliques) Milne-Edwards omitted to give the necessary explanation.

Opposed to this the description of Rathke gives the following difference: He says that in this species the upper antennæe are four-jointed, which is very doubtful, since in the forms of this genus and in Branchipus the upper antennæ are not jointed, but we only observe after a number of subsections similar to faint transverse rings, which should not be

${ }^{1}$ Midderdorf's Sibirische Reise, Vol. II, part i, pp. 155 to 156. 
taken for articulations. Furthermore, according to Rathke, this species has, besides the upper lip, no other oral parts, while S. Fischer, ${ }^{1}$ in completing the description of this species, describes beside the upper lips, also other oral parts (upper and lower jaws), which differ in nothing from the same parts in other Artemia. In our specimens with the character's of A. milhausenii, these parts fully correspoud with the description given by S. Fischer. Such a great contradiction between the authors awakes a doubt whether they had to do with the same forms, thus rendering the determination of this species difficult. Likewise Rathke does not mention in this species the existence of the posterior branchial lobes, while he dwells at length upon the gill-sacs, as if the former were not existing at all. But in reality Rathke probably did not see them at all on aceomnt of their transparency. These branchial lobes exist in our specimens (and those from the Krimea) with the characters of Artemia milhausenit, and $\mathrm{S}$. Fischer gives an illustration of them with his description of Artemia köppeniana. On the contrary, in Rathke's description there is yet a difference in the length of the abdomen. In our individuals with the characters of Artemia milhausenii, the posterior part of the body, consisting of apodous segments, is longer than the whole anterior part, being to it in proportion at least as eight to five; but in the specimen described by Rathke the posterior part of the body is shorter than the anterior. However, we can with certainty say of Rathke's description, what length the posterior part of the body had in the specimens described by him. From his words it is to be assumed that Rathke calls the whole posterior part of these animals (without the first two apodous segments of the abdomen?) a tail. The comparative length of this tail he compares with the tail (postabdomen) of the scorpions, and shows by the illustration that the posterior part of the body is nearly $\frac{1}{7}$ shorter than the an verior part, while in the stated measurements he has such figures as surprise me by their disproportion, and according to which the tail would be two and a half times shorter than the anterior part of the body. The latter can only be called a misprint; it remains unknown, however, how the omission of oral parts (excepting the upper lips) and the posterior branchial lobes can be explained in Rathke's descriptions. If the degradation of this form had proceeded so far, that with them these parts were not developed at all, it would have been different from the form examined and more completely described by S. Fischer. S. Fischer, however, calls the tail of the form examined by him, long, which expression ${ }^{1} H$. Rathke does not use, but the termination of the postabdomen, according to Fischer's drawings, differs from the termination of this part in Rathke's drawing, not showing any broadening. It is possible that Rathke and Fischer had different forms in possession, whereby Rathke's form is identical with the very degraded generations of Artemia salina, or corresponds with them, while Fischer's form is a degraded form of the larger variety $a$. of Artemia salina.

Finally, on the other hand, Grube's ${ }^{2}$ diagnosis of this species aiffers from our generations with the characters of Artemia milhausenii, in having on the terminal lobe (lobus tarsalis Grb.) not about 17, but about 25, marginal bristles; it is possible that here Grube borrowed the number of bristles from Rathke's drawing, who drew on his small illustra. tion about such a number of bristles, only saying in the description

\footnotetext{
${ }^{1}$ Milne-Edwards calls in his diagnosis the postabdomen of Artemia milhausenii also long, but does not take this expression in his diagnosis of Artemia salina.

${ }_{2}$ "Bemerkungen iiber die Phyllopoden" in Archiv fïr Naturgesch. 1853, p. 145. He correctly remarks, amongst other things, that Rathke could not have observed the very tender and transparent posterior branchial lobes in so old alcoholic specimens.
} 
that there were many bristles. On Rathke's drawing are 18 such bristles, and even if there had not been more this makes no great difference, especially in view of the fact that the specimens obtained by Rathke, from a salt lake in comparison with ours, could have been more degraded. I must here add that in our Artemia salina there are some thirty bristles on the terminal lobe of the leg (?); in variety $a$. of Arte. mia salina there are some thirty-three marginal bristles. Had we not had in the Kujalniker Lake in 1874 a second inundation, the generations with the characters of Art. milhausenii would certainly have proved more degraded in relation to this, as there strouger concentrated salt water would have remained in the lake.

I therefore cannot, without excluding the possibilty of the existence of a self-sustaining species of Artemia milhausenii, regard the degraded generations of Artemia salina obtained as a species proper, aud even not then, if such degraded generations exhibited all the characters of Artemia milhausenii: the characters of $A$. milh. at a certain modifica. tion of the element in the course of several years or also by domestication of several successive generations of Artemia salina in a correspondingly changed element.

After all I hope nobody will think that I endeavor, with the aid of modifying the element in the domestication of animals, to produce from one species one or more new species. Everywhere I have sought to obtain the intermediate transitional forms between the nearest-allied species, and I approached myself in a moderate degree the characters of the actual species, but we cannot regard such forms as independent ones which have by domestication received characters of unknown constance (in nature), and which we obtain by changing the element during domestication of several generations. It is possible that in earlier times and even also at present in different other localities, as species and ancestors of our present species such middle transitional forms among the closest allied forms live; nevertheless these forms, resulting from domestication, will neither represent independent species nor varieties, as incipient species, but they only show the way in which the characters of a given species combined and which way man, with his zoological experiments, especially with the present means of science, cannot fully follow. Should we sneceed in producing, with the aid of domestication, a form possessing all the characters of a species existing in a state of nature, then this form will differ from the real in nearly the same way as the best picture will differ from the original. This would be like making concessions to the present conception of species. Owing to the stated facts it seems to me that our present species can be artifically produced by man, only this does not happen with the aid of artificial domestication, but by adaptation of physico-chemical factors. We shoult? never forget that in nature the characters of a species have a relative stability.

\section{3.-The characters of the genera Artemia and Branchipus.}

The characteristics of the genera Artemia and Branchipus are demonstrated by many authors, owing to an insufficient knowledge of the characters of the genus Artemia, in a confused and even wrong manner. Already in 1853 had Grube made' his protest against the stability of the genns Artemia, seeing that Artemia differs only from Branchipus by quasi-negative characters; he also saw the necessity of forming

\footnotetext{
${ }^{1}$ Grube, Bemerk, iuber die Phyllopoden in Arch. f. Nat. 1853, pp. 132 to 134.
} 
from Artemia a proper group or a subgenus of the genus Branchipus, like Branchipus proper and Polyartemia. Dr. Grube, nevertheless, gave in reference to the then known facts of Artemia a mistaken char. acteristic of his subgenus Artemia, saying, amongst other things, that it possessed six apodous segments and that the short furca was only bristled at the ends (appendicibus caudalibus brevibus, apice tantum setosis .... . . Relatire to the number of apodons segments of the abdomen, Grube repeated the statement of those authors (Joly) who in Artemia did not take into consideration the first two apodous segments of the abdomen, bearing the external sexual parts. Without these two first apodous segments of the abdomen Artemia has really six apodous abdominal segments, but since the external sexual organs answer morphologically to modified limbs, we only in this sense can count in Artemia six segments of the abdomen; like Branchipus in this case it would have but seren and not nine segments. But Grube in this sense does not count six apodous segments in Artemia, as he demonstrates nine apodous segments for his subgenus Branchipus, and we can see from the general diagnosis of the genus Branchipus (1. c., p. 136), that those segments, bearing the external genitals, were taken in with the apodous segments of the abdomen of his genus Branchipus, i. e., inclusive of Artemia and Polyartemia. But, in fact (as mentioned above in the completed description of Artemia salina) the speeies of Artemia have eight apodous abdominal segments, the first two of which bearing the external genitals, and of which the last is nearly twice as long as the preceding and is homologous with the two last apodous segments of the species Branchipus, but the Branchipoda have nine apodous abdominal segments, of which the first two also bear the genitals, and of which the last, located before the furca, is not longer, but usually shorter than the preceding. ${ }^{1}$

In regard to the position of the furcal bristles in Artemice I have already stated above that in our forms of Artemiu the bristles are not only at the end but also often on the margins of the furca, and that these bristles often occur also in great numbers, the furca assuming, as in variety $b$. of Artemia salina, a plate form.

If we ask now whether all species of Branchipus really possess nine apodous segments, of which the two last ones are homologous with the prolonged last segment of Artemia, then it seems indeed to be the case. Only Branchipus stagnalis could form an exception. At least from the statements of the authors ${ }^{2}$ the number of apodous abdominal segments (whether eight or nine) cannot be inferred with certainty, and I myself had not hitherto occasion to examine Branchipus stagnalis.

Concerning the question whether all the species of the genus Artemia have eight apodous abdominal segments, and whether in all the last segment is prolonged and homologous with the last two abdominal

${ }^{1}$ In my paper in Zoitschrift $f$. w. Zool., vol. $x x v$, supplenent part, appearing nuder the title "Ueber das Verhälniss der Artemia salina M. Edw. zu Art. milhansenii M. Edw. und dem genus Branchipus," I must add a correction relative to the proportional length of the last abdominal segments in Branchipus. There it says: "Branchi- " pus has nine last apodous segments, of which the two neighboring segments show only a small difference in length among themselves" (1. cit., pp. 106 and 110). I ought to have said: "Branchipus has nine apodons aldominal segments, of which the last, situated before the furca, is not longer but usually shorter than the preceding seg. ment."

${ }^{2}$ Leidig, "Ueber Art. salina und Branch. stagnalis." Zeit. für w. Zool. 1851, p. 281. Spangenberg, "Zur Kenntniss von Branch. stagnalis" in Zeit. f. wiss. Zool. 1876. pp. 8 to 9. Simplement part. Claus, "Zur Kenntniss des Banes und der Entwicklnng von Branch. stagnalis und Apus cancrif." Göettingen, 1873, p. 14, Tab. V, fig. 10 . 
segments of Branchipus; of this no indicatious occur in literature. That Artemia salina observed by Joly has eight apodous abdominal segments with a very prolonged last segment can be seen from Joly's illustrations, and also from this, that he counts six apodous ablominal segments without including the two first apodous abdominal segments which bear the external sexual organs. Accorling to Rathke, who observed alcoholic specimens of Ariemia milhausenii (Art. salina Rathke), the postabdomen is indistinetly divided into segments; he did not indicate how many segments there are. Our degraded generations of Artemia salina with the character of Artemia milhausenii have just as many apodous abdominal segnents as Artemin salina, only the articulation is more distinct. In the description of Artemia arietina S. Fischer and Artemia köppeniana S. Fischer nothing was said about the number of apodous abdominal segments. Grube very incorrectly states the number of apodous segments in Artemia as being six, incorrect, for because right after in another diagnosis he correctly mentions in his subgenus Branchipus nine apodous segments, thus showing which segments of the abdomen he considers as apodous. Joly gave occasion for this conclusion in omitting the two first apodous segments of the abdomen, which in Artemia, as well as in Branchipus, bear the external sexual organs. In the other mostly examined alcoholic specimens of Artemia, the articulation is not very plain to see. In this regard Branchipus oudneyi Lie. vin (Artemia oudneyi Baird's) deserves attention, under which name an Artemia from a salt lake in Africa was described by Dr. Lievin. This African form has in the illustrations eight apodons abdominal segments, of which the first only bears the external genitals, the last being short, at least shorter than the preceding. Although this form, as in Artemia, has eight apodous abdominal segments, it can nevertheless in this pro. portion be included neither with the genus Artemia nor with the genus Branchipus. But the illustration now does not correspond at all with the description of the posterior part of the body of this Artemia. It is said in the description ${ }^{2}$ that the specimens examined had laid a long time in alcohol, and that therefore the number of abdominal segments could not exactly be determined; that the abdomen of some specimens ansiered as if to one segment only, while in others four could be distin. guished, again, in others five segments; but from the fifth in the others ther could not be distinctly seen. Dr. Lievin considers the presence of eight abdominal segments as probable. Here the author understands as abdomen only the whole of the apodous abdominal segments. Accordingly, the number of apodons abdominal segments of this Artemiaform, and also their proportion to each other, is considered as unknown.

It appears to me that with the absence of certain characters in Artemia for listinction from Branchipus, we mnst assume eight apodous abdominal segments. Of these the first two bear the external genitals, but the last, terminating with a furca, is nearly twice as long as the preceding, and is homologous with the two last apodous abdominal segments in Branchipus. The latter possess at the end of the abdomen, besides these segments, also abdominal appendages, mostly separated from the last segment by an articulation. In Ariemia the last abdomi. nal segment is only somewhat shorter than the doable length of the penultimate segment, sometimes eren a little longer. Here I have to remark that in young, though fully dereloped specimens, the relative length of this segment is more considerable than in old ones, as the

"Lievin, "Branchipus ouhney, the Tezzanworm," in "Feneste Schriften der Natur. forschanden Geselesch. zu Danzig." Vol. V.

2 Loc. cit., Pp. 8 to 9. 
preceding segments in old specimens are more prolonged than in young ones. With the furca is the last abdominal segment usually a little longer than the double length of the penultimate segment, however sometimes also a little shorter, which probably depends upon the age as well as upon the surroundings. I have yet to add that the longer the abdominal furca in the form Artemia is, the shorter appears the last abdominal segment; it is as if the furca develops on account of this segment, especially on account of the second half behind the sensory bristles (which are nearly in the middle of its length). This answers the circumstance, that in the species Branchipus, with usually great length of the abdominal appendages, the last abdominal segment is considerably shortened, as the abdominal segment, which corresponds to that part of the last abdominal segment in Artemia, which part is behind the last sensory bristles, $i$. e., behind that part where Artemia lacks the articulation, which exists in Branchipus (excepting Branchipus stagnalis?).

Regarding the circumstance that the last apodous abdominal segment of Artemia is homologons with the two last, $i$. $c$., the 8 th and 9 th apodous segments of Branchipus, we mast firstly realize the disposition of the sensory bristles on the abdomen of the species Artemia and Branchipus, and secondly the origin of the articnlation in the middle of the last prolonged segment of Artemia, immediately behind the sensory bristles, in the domestication of the entire generations of these animals in continually diluted salt water. On each apolous abdominal segment of the Branchipide the sensory bristles are at the end of the segment before the articulation; the last segment makes an exception, which has no sensory bristles before the abdominal appendages. The Artemice show an equal disposition of sensory bristles on the postablomen, with the sole exception that such bristles arealso on the last (eighth apodous) prolonged segment, about in the middle or above it. As into the sensory bristles, located about in the middle of the last prolonged (eighth apodous) segment in Artemia, enter likewise nerve-branches, as is the ease with those at the end of the preceding segments, and the sensory bristles at the end of the segment in Branchipus (therefore also into those at the end of the penultimate segment), it follows that the first half of the last segment (eighth apodous) in Artemia corresponds with the whole penultimate (eighth apodus) segment of Branchipus, while the second half of this segment (eighth apodous) in Artemia is homologous with the last (ninth apodous) segment in Branchipus. As I do not write a monograph of a species, and as for me only the disposition of the sensory bristles was of importance, I cannot give the number of bristles on each apodons abdominal segment. Sometimes I found only two bristles on the seg. ments, sometimes fonr, circularly distribnted around the segment). I only know that these sensory bristles also exist at the end of the two first apodous segments opposite the external sexual organs, and also at the end of the last limb-bearing segment, likewise also on the other segments of this body-part. Spangenberg found in Branchipus stagnalis ${ }^{1}$ sensory bristles by twos on the abdominal segments, and only on the eighteenth, being the seventh apodous segment, he fond four bristles. It is withont doubt, that in Branchipus stagnalis, in case it has only eight aporlous segments, the sensory bristles are not at the end of the eighth apodous segment, but before the faint articulation of this segment, which is figured by Clans, ${ }^{2}$ or if Branchipus stagnalis should, like the other species possess nine segments on the end of the eighth segment.

${ }^{1}$ Zeitschr. f. wiss. Zool., vol. $\mathrm{xxv}$, supplem. p. 28.

${ }^{2}$ Loc. cit., Plate V, fig. 16. 
This location corresponds to that, where in Artemia on the long segmentan articulation is formed, if we domesticate entire generations in gradually diluted salt water (especially at not too high temperature), and also to that location where in the Branchipida this articulation exists between the eighth and ninth apodous segment. It would look too forced, on account of a single character, to include the one assemblage in the genus Artemia, the other in the genus Branchipus. By this rather unnatural systematic treatment Branchipus stagnalis would come into the genus Artemia, though this species according to its characters, with the exception of the eighth apodous segment, belongs to the genus Branchipus. I note that in regard to apodous segments Branch. stagnalis has not the full characters of Artemia, as with it the last (eighth) apodous segment is not so long as compared with the preceding, as in Artemia. There are other structures, according to which the species of Branchipus can be distinguished from Artemia. Such a character is that in the males of Artemia the claspers toward the end, that is, in the second half (last joint) become broader, so that the second half is tabulate, which does not occur in Branchipus, since their male claspers are not tabulate; moreover, their first half is broader and thicker than the second. ${ }^{1}$

The circumstance that there are often certain appendages on the claspers or on the front of various Branchipida, and that the furca generally is tabulate and better developed, can be but partly regarded as a character of Branchipus. On the male claspers of Artemia, we see also certain appendages in the shape of little tuberosities for holding the female; we even see whole groups of denticular spines, while in certain species of Branchipus (Branchipus ferox Grb. and B. medius mihi) no appendages at all occur on the claspers of the males. Although the branches of the furca in Artemia have mostly the shape of a stylet, or are conical in shape, there are, nevertheless, also Artemice with tabuliform branches of the abdominal furca, like the second variety of Artemia salina (var. b.), Artemia salina itself has even often a large development of the furca under the influence of certain external conditions. Otherwise, the furca of the above-mentioned Branchipus medius resembles this part in Artemia, only it is somewhat obliquely cut off or shoe-sole-shaped, curved. ${ }^{2}$ Concerning the statement that the furea in Artemia was only terminally bristled, this is incorrect, as even in one and the same species the furca can be more or less developed, being bristled either terminally, or both terminally and laterally, according to conditions in life. But there is a physiological feature, which can be added to the characters distinguishing the species of Artemia from those of Branchipus; in the genus Artemia the phenomenon parthenogenesis is known to occur, which is unknown with Branchipus. After all this is a negative character for Branchipus, but is important together with other structures in Artemia. Consequently, according to my view, the distinguishing characters of the genera Artemia and Branchipus are the following:

\section{Genus Artemia.}

Eight apodous abdominal segments, of which the first two bear the external sexual organs, but the last about twice as long as the preceding, being homologous to the last two abdominal segments, the apodous eighth and ninth, in Branchipus. The segments of the abdomen have a considerable

${ }^{1}$ In some species of Branchipus, like B. rubricaudatus Klunzinger, the male claspers are divided at the end into several branches.

"Consult my paper in the "Schriften" of the third meeting of Russ. Naturalists at Kiow, 1871, Zoological section, Plate III, figs. 1 to 3 and 5. 
greater length than width. The antennæ of the second pair (claspers) are more or less broadened in the males, and have principally on their second interiorly directed part a flattened form. These antennæ are either without appendages, or only with a few little developed append. ages, in the form of rounded or knob-like protuberances on the interior margin of their anterior, outwardly directed, or finally with small ap. pendages in the shape of denticular spines near their base. For the most represents the little developed, terminally and often laterally, bristled abdominal furca, a simple prolongation of the last segment of the abdomen; the furcal branches are conical or stylet-shaped, seldom tabulate. Parthenogenesis is known to occur in this genus.

\section{Genus BRANCHIPUS.}

Nine apodous abdominal segments (Branch. stagnalis excluded?), of which the first two bear the external sexual organs, the last segment located before the furca being not larger, but mosky smaller than its preceding. The antennæ of the second pair (claspers) in the males have their first joint stout, often with much developed appendages on their sides or at their base, in the shape of digitate processes or denticular tuberosities, the second part being more slender and narrower than the first; in the opposite case the antenna is terminally divided into several branches. The generally much developed, laterally and terminally, bristled furca has its branches nearly always of a tabulate form, which are separated from the last segment by an articulation. Parthenogenesis is unknown in this genus.

Eleven pair of legs are the common character for these two genera, distinguishing them from the genus Polyartemia Fischer, which has nineteen pair of legs and a lesser number of apodous segments of the abdomen.

Odessa, May $5,1877$. 



\section{EXPLANATION OF PLATE I.}

\section{Limnetis MUCronatus Packard.}

Frc. 1. The male, enlarged; the first antenne unfortunately omitted by the artist.

FIG. 2. Second antenna of female, $\times \frac{1}{2}$ Tolles objective $A$ eye-piece.

Fig. 3. Either the first or second foot of female; $l$, first endite or gnathobase; $l^{2}-l^{6}$, second to sixth endites; $b r$, gill (gill-sack; $b r^{\prime}$, upper, $b r^{\prime \prime}$, lower end of flabellum, $x \frac{1}{2} \mathrm{~A}$.

Fig. 4. One of the anterior feet of female, $\times \frac{1}{2} \mathrm{~A}$.

FIG. 5. Hand or fourth endite of the first foot of male; $p$, palpiform appendage of the fourth endite; $l^{5}$, the fifth exopodite, and $l^{6}$, the sixth, modified to form a curved, finger-like, grasping spine; comb, the comb-like inner edge of fourth endite of the hand.

Fig. 5a. Branchia (br) of the same leg.

Fig. 6. Telson or end of the body of the female.

Fig. 1 drawn by J. H. Emerton; Figs. 2 to 6 drawn, and details filled in with camera lucida, by the author. 


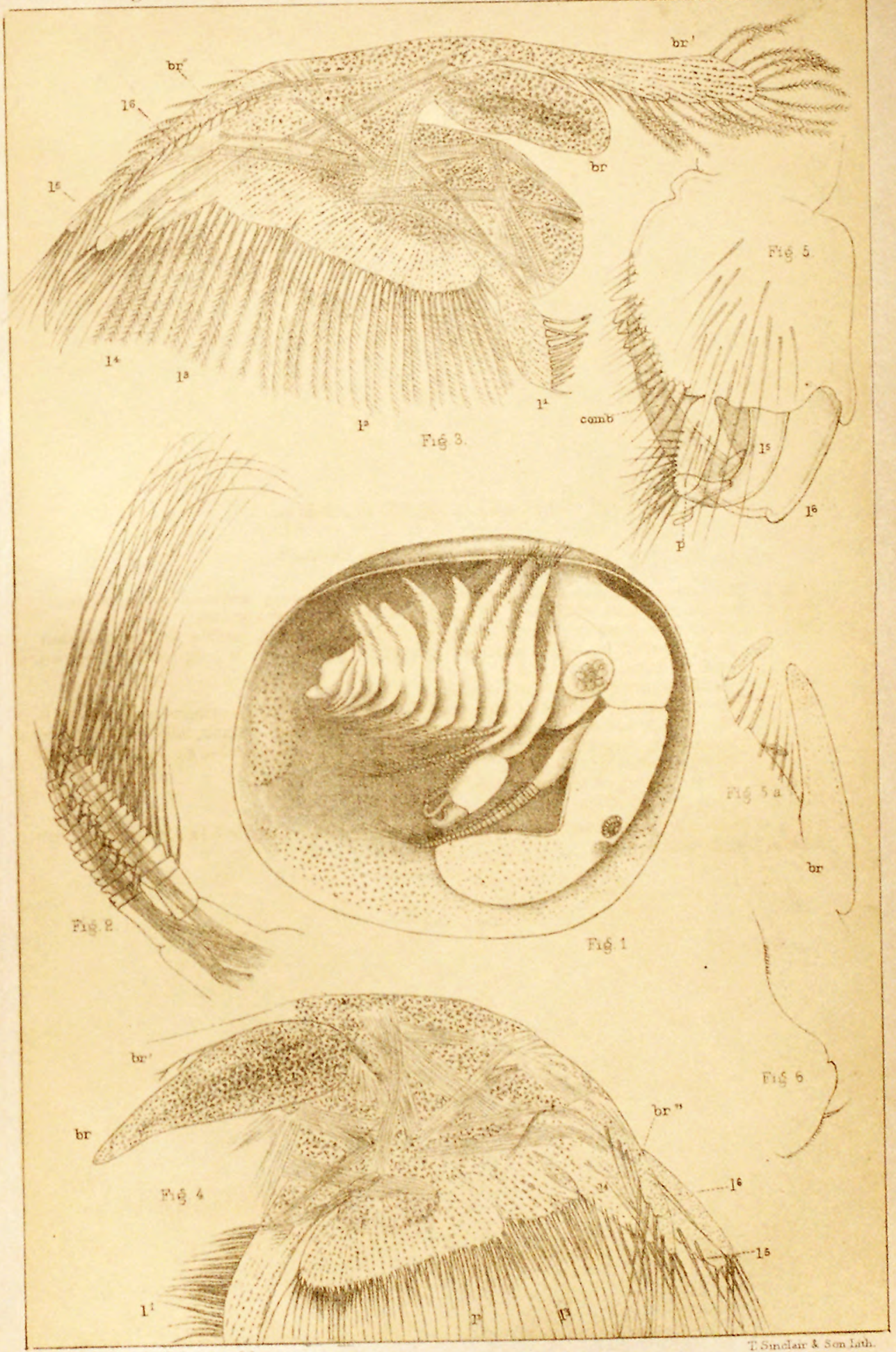




EXPLANATION OF PLATE II.

Details of Limnetis gouldir Baird. (For figure of the entire animal, female, see Fig. 1 in text.)

FIG. 1. First leg of female, $\times \frac{1}{2} \mathrm{~A}$. Lettering as in Plate $I$. The lower branchial lobe $\left(b r^{\prime \prime}\right)$ very slender, and subjointed, as in the fifth and sixth endites $\left(l^{5}, l^{\circ}\right)$.

Fig. 2. First leg of male.

Fig. 3. Second antenna, $\times \frac{1}{2}$.

Fig. 4. First antenna, from the same specimen as Fig. 3.

FIG. 5. Eyes (double), with the optic nerves; the cornea and retina removed.

Frg. $5 a$. A portion of the optic nerve situated half-way between the brain and eye, magnified \& $\mathrm{B}$ Tolles, to show the ganglion cells, constituting the greater portion of the optic nerves.

Fig. 6. Cornea, with the peripheral circle of crystalline cones, and the retina in the middle of one of the double compound eyes.

Drawn, with the details filled in with the camera lucida, by the author. 


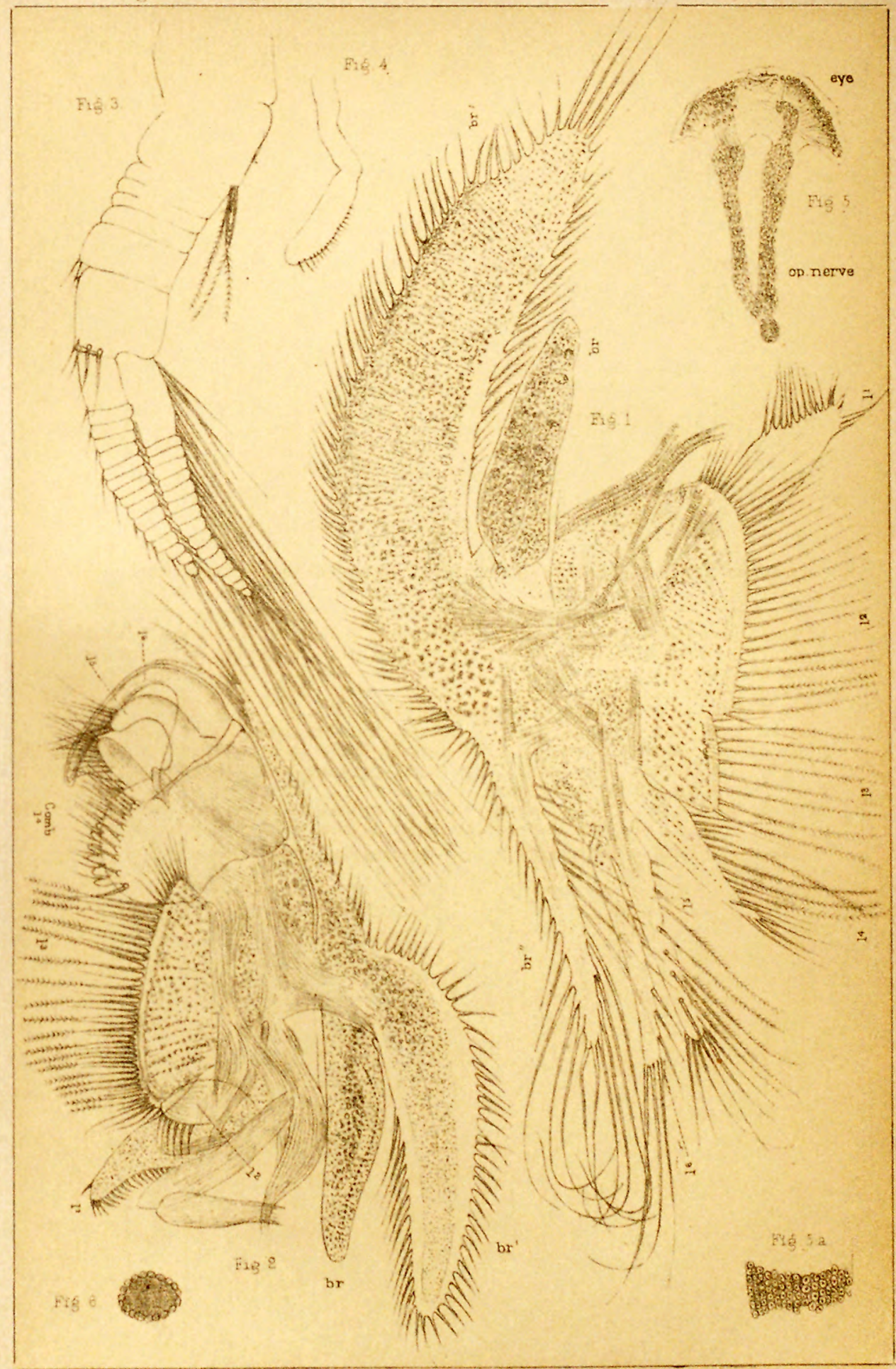




Estheria Belfragei Packard, and dotails, with details of E. Jone8Ir Baird.

Frg. 1. The male of $E$. belfragei, much enlarged, in its shell.

Fig. 2. Second antelna of male of $E$. belfragei.

FIG. 3. First antenna of Estheria jonesii.

Fig. 4. First leg of male E. belfragei.

Frg. 5. First leg of male of $E$. jonesii. The process extending beyond the gill is probably a muscle.

Fig. 6. Second leg of male of $E$. belfragei.

Fig. 7. End of body, with telson, of E. jonesii.

Fig. 1 drawn by Mr. E. Burgess; details drawn, and filled in with the camera lucida, by the author. 


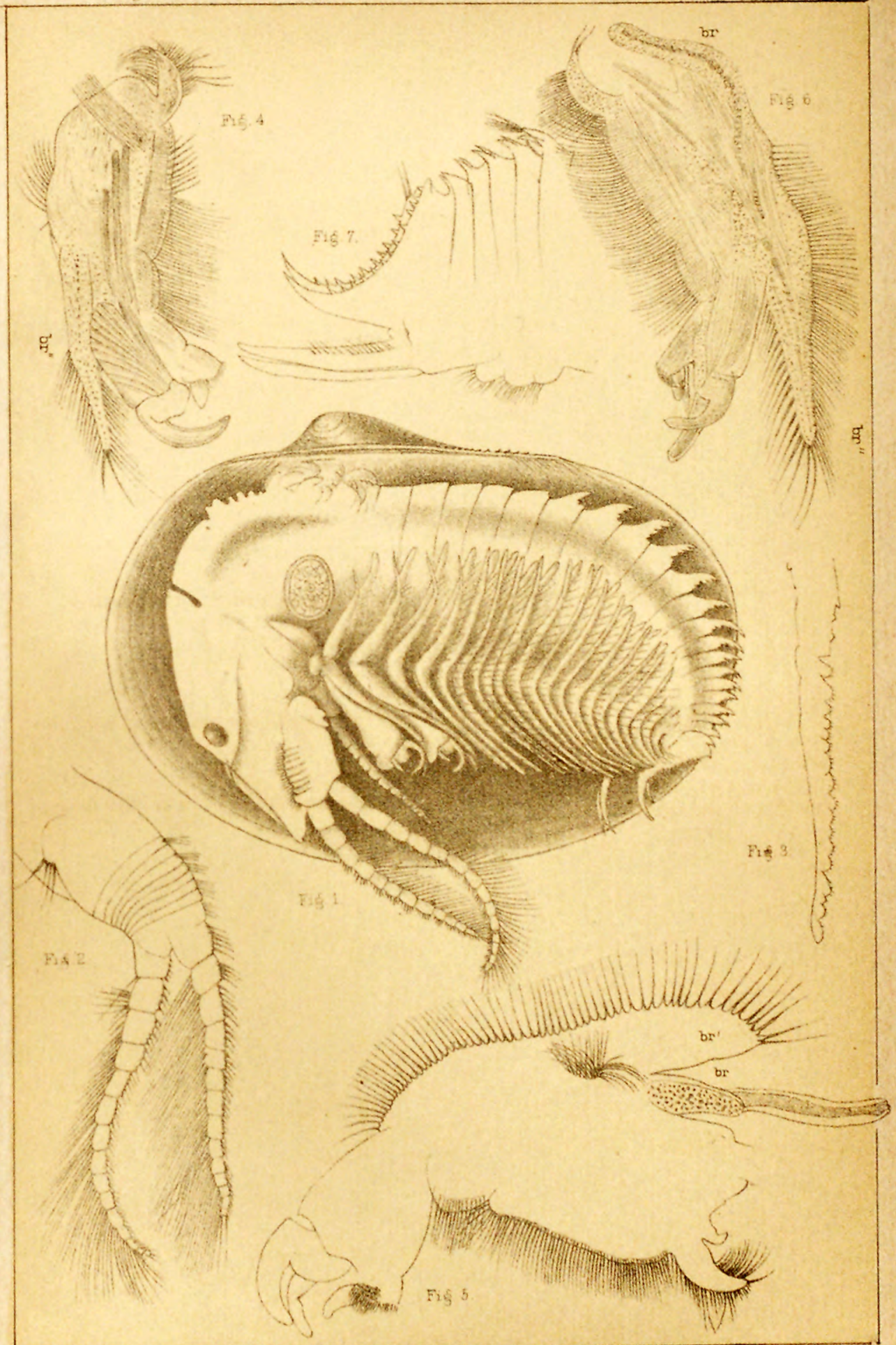






\section{EXPLANATION OF PLATE IV.}

Estheria Californica Packard, and details.

Fig. 1. The male, much enlarged.

Fig. 2. Second antenna of female, $\times$ about 30 diameters.

FIG. 3. First antenna of female, $\times$ about 30 diameters.

Fig. 4. First leg of female, $\times$ about 30 diameters.

Fig. 5. Leg of third pair of female; $b r^{\prime}$, the extremely long and slender upper branchial lobe forming the oviger.

Fig. 1 drawn by Mr. E. Burgess, the details by the author, with the camera lucida. 


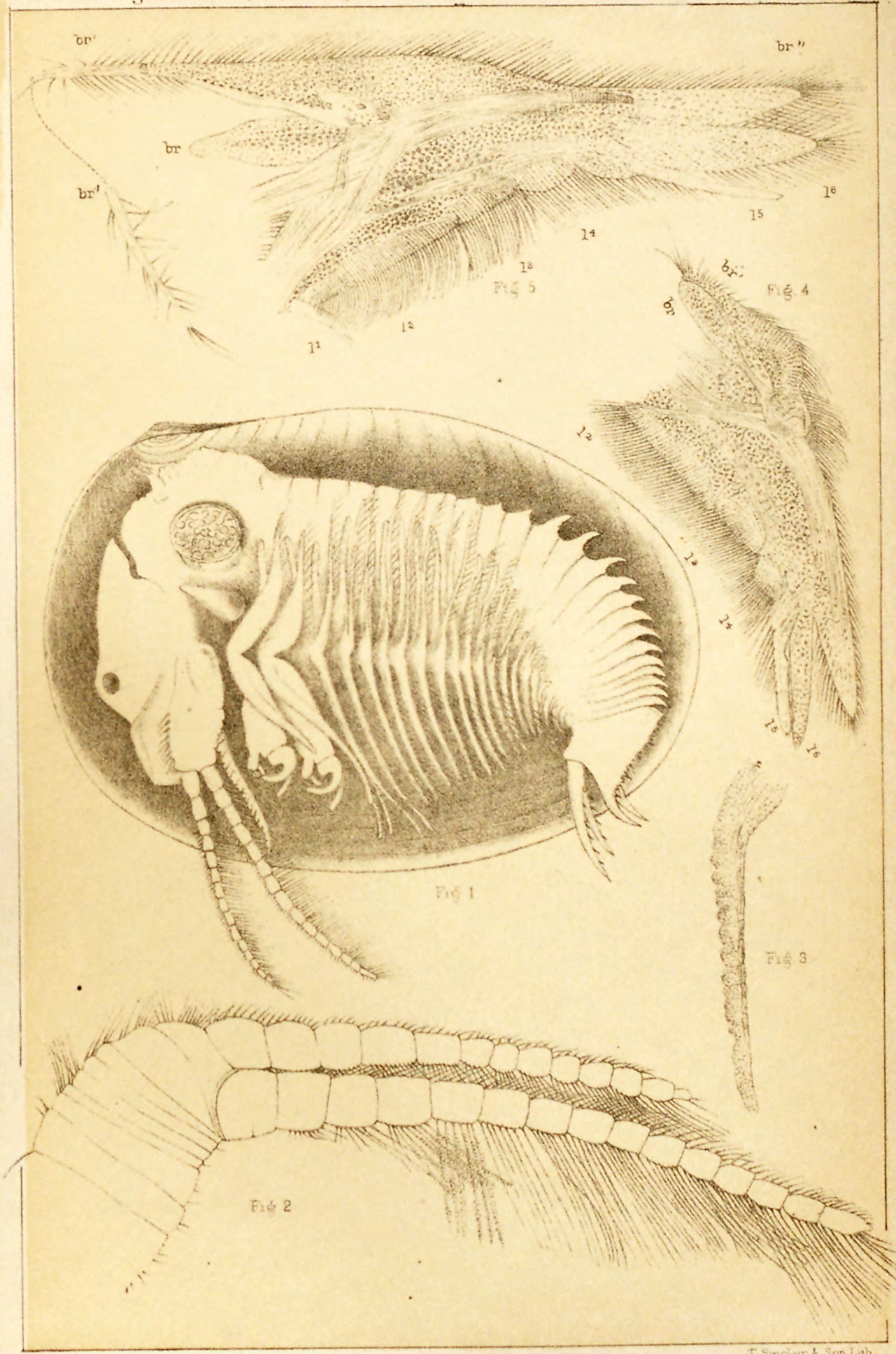




EXPLANATION OF PLATE V.

Estheria compleximanus Pack., and details.

Fig. 1. Male; much enlarged, ant $t^{1}$ 1st antennæ; ant $t^{2}$, second antennæ; md, mandible; mus, adductor muscle; $b r$, gill; $b r^{\prime}$, npper, and $b r^{\prime \prime}$, lower end of flabellum.

FIg. 2. Second antenna of male.

Fig. 3. First antenna of male; atn, antennal nerve; ol, olfactory procese.

FIG, 4. Five terminal joints of 1st male antenna, showing the terminal fibers of the antennal nerve imbedded in the sense-cells; ol. pap, olfactory papillw.

Fig. 5. First leg of male.

Fig. 6. Second leg of male.

FIG. 7. One of the foremost legs of the female; $b^{\prime \prime}$, broad, flat lower end of flabellum, closely resembling in form the sixth endite $\left(l^{6}\right)$.

FIG. 7a. First endite, or gnathobase of Fig. 7, forming the maxilla-like lobe situated on each side of the median ventral line of the body, just behind the mouth; $c$ s, setæ, $\times \frac{1}{2} \mathrm{~A}$.

FIG. $7 b$. Five setæ of the gnathobase still further enlarged, to show the musoular tissue (not nerves) entering base of the jointed setw; the outer joint fringed.

Fig. 1 drawn by Mr. E. Burgess; the others by the anthor, with the camera lacida 


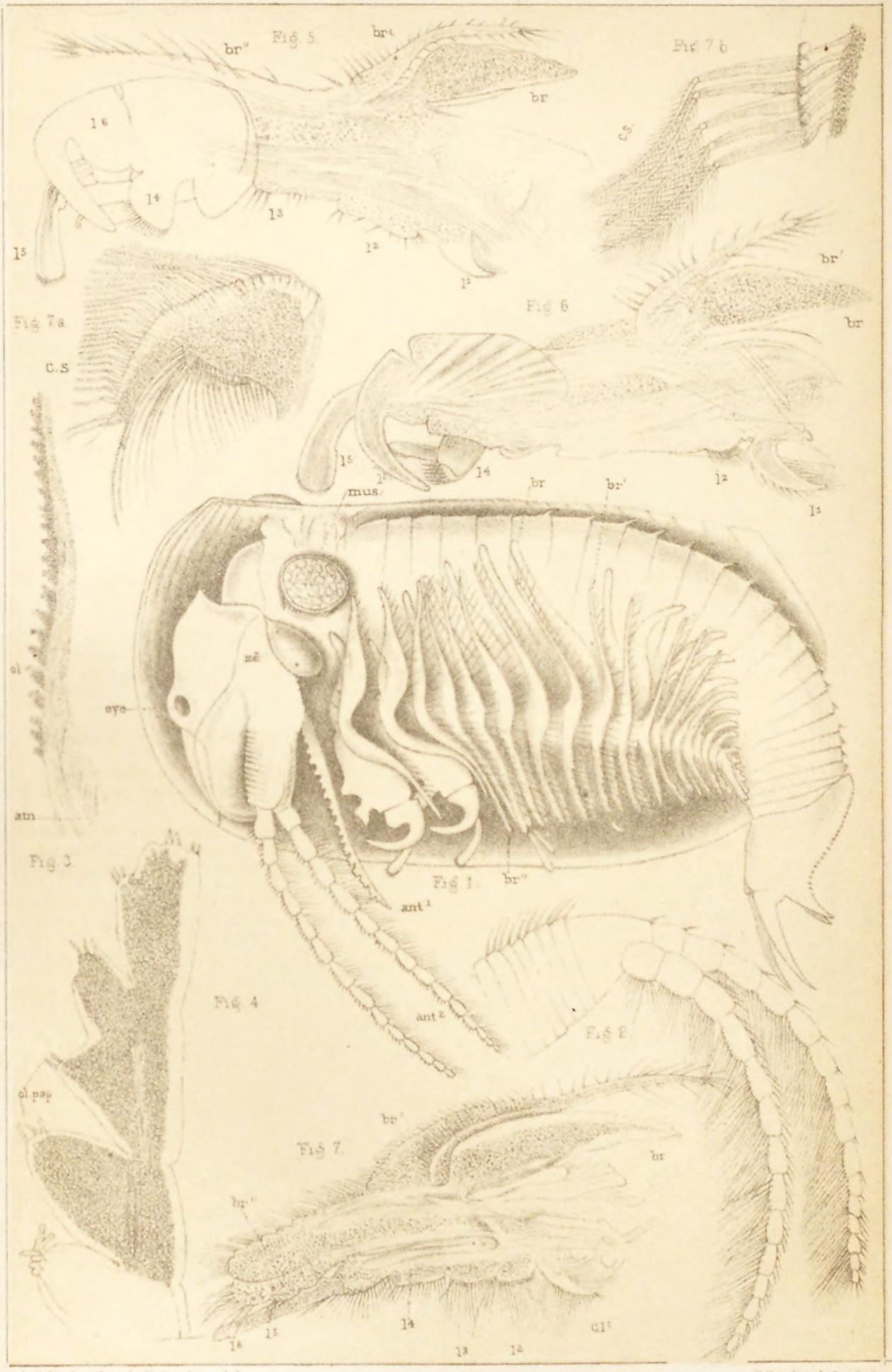




EXPLANATION OF PLATE VI.

Eulimiadia texana Pack.

Fig. 1. Eulimnadia texana; female, much enlarged.

Frg. 2. One of the first pair of feet; $e n^{1}-e n^{6}$, endites $1-6 ; f$, flabellum. Frg. 3. Second foot of the male; (ext should read ent).

Fig. I was draxn by Mr. Burgess; the others by the author. 

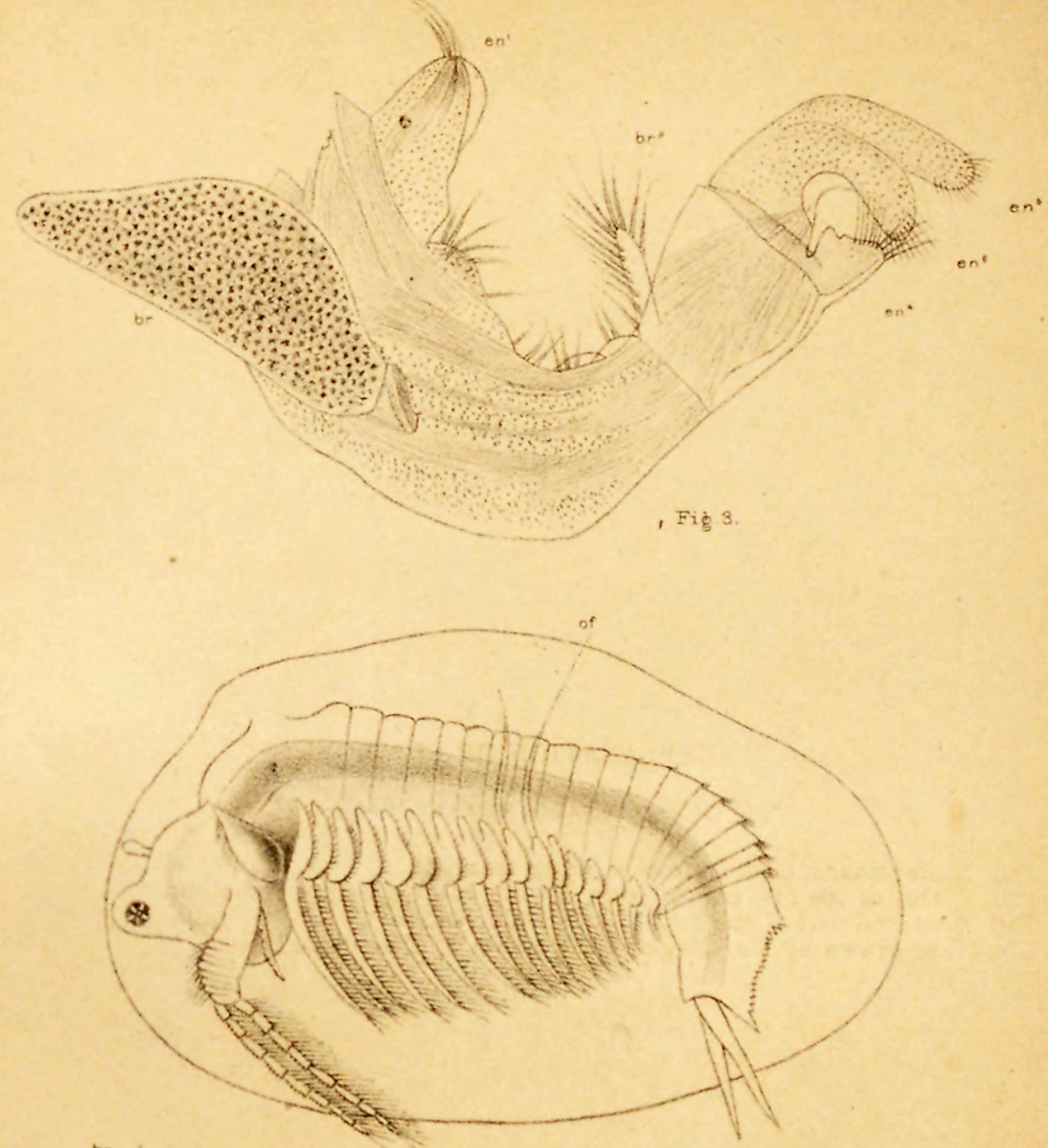

Fig.1.

$\times 236+2+x$

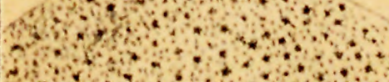

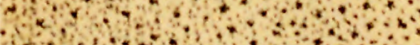

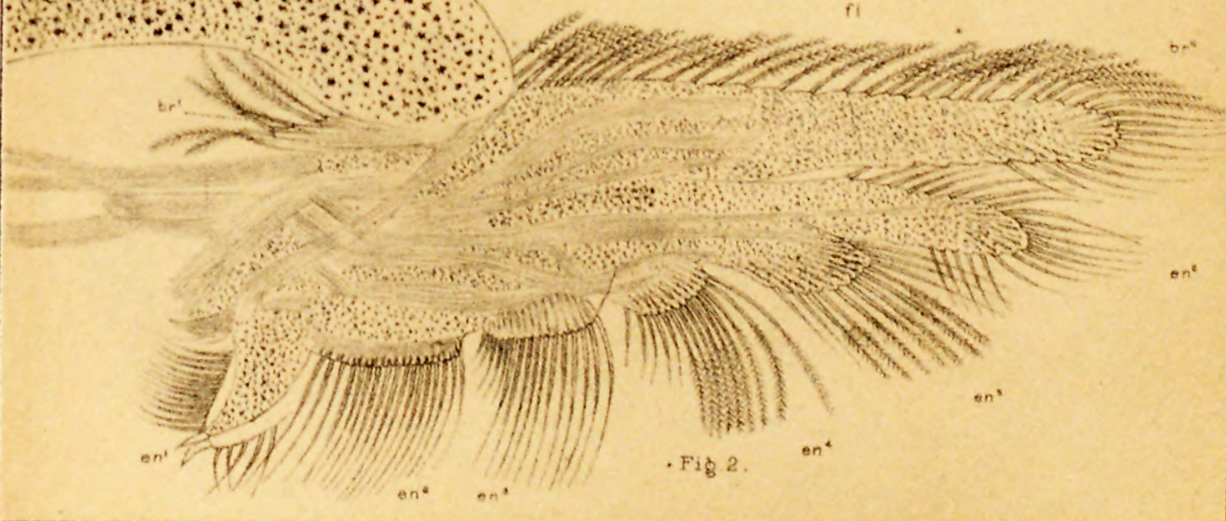

Turỹuss and Packared dol 






\section{EXPLANATION OF PLATE VII.}

Eulimnadia texana and E. Agassizir.

Fig. 1. Eulimnadia texana, hand of second foot of male, enlarged.

Fig. 2. First foot of male.

FIG: $2 a$. Hand of extremity of fifth endite, much enlarged, showing the broad, flat setæ at tip, and the accumulation of sense-cells.

Fig. 3. Front of head, showing the eye and frontal process, or "haft organ."

Fig. 3 bis. First and second antennæ.

Fig. 4. Telson, $4 a$, end of caudal appendage, a little more enlarged.

FIG. 5. Eulimnadia agassizii, head, with frontal process $(f p)$, eye, and first and second antennæ.

FIG. 6. Eulimnadia agassizii, telson. 


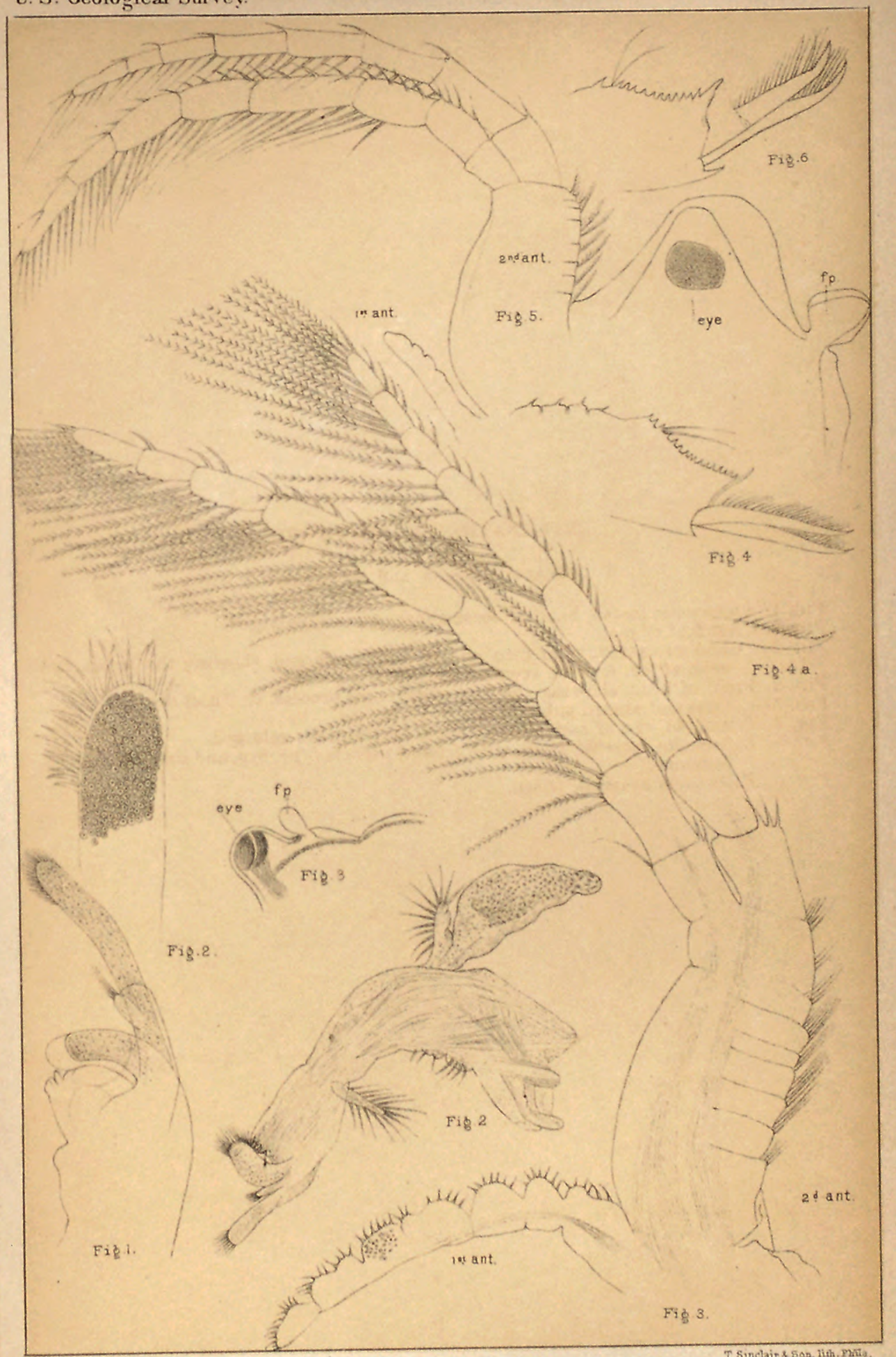



$34 \mathrm{H}$ 


\section{EXPLANATION OF PLATE VIII.}

\section{Artemia gracilis Verriil, (From Utah.)}

Fig. 1. A dorsal view of male head and claspers; oc, ocellus; at, 1st antennæ; at , $2 d$ antennæ or claspers.

Frg. 2. An anterior leg.

FrG. 3. A middle leg.

Fig. 4. A last leg.

Fig. 5. End of abdomen.

Drawn and details filled in with camera iucida by the author. 

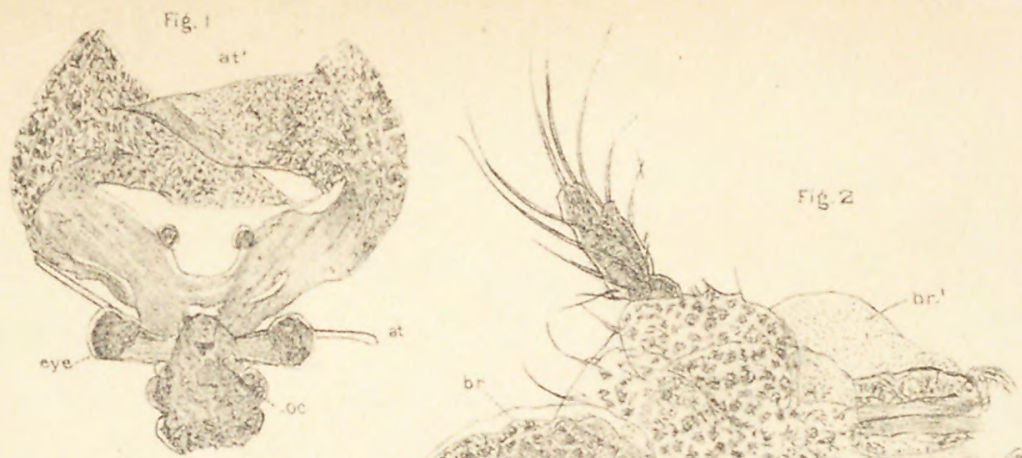

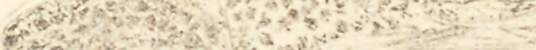
Fise

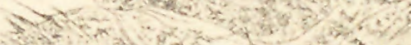
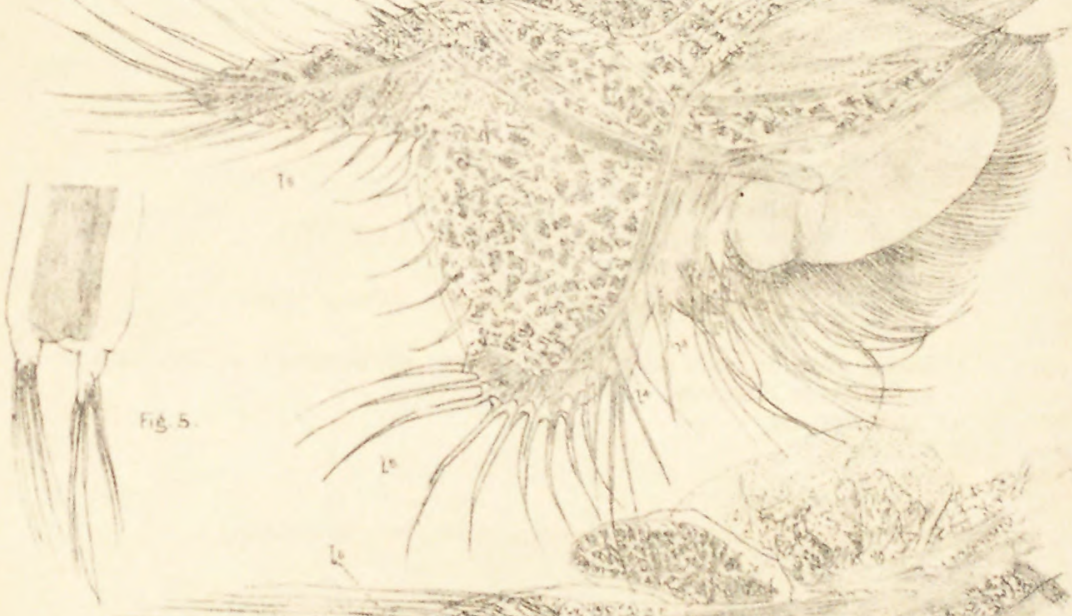

to. a

6. 1 के

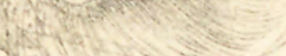
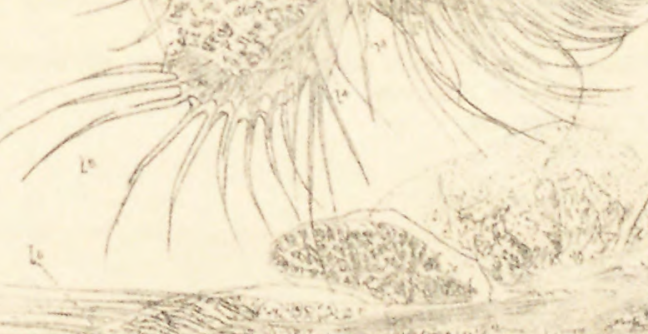

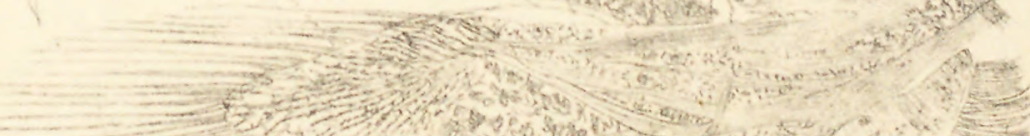
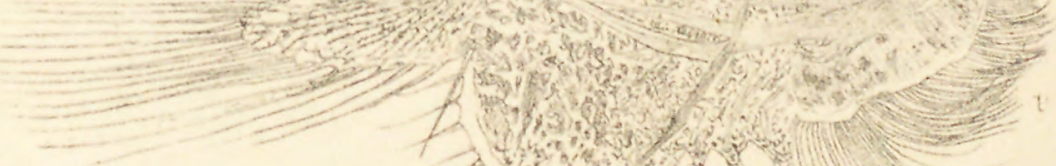

La

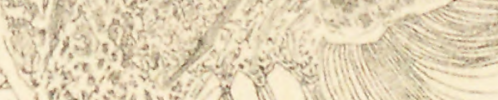
(1)

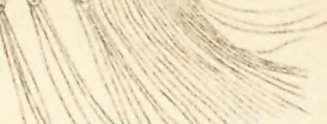

Fig. 4 .
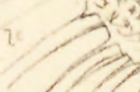
DIPMPI)

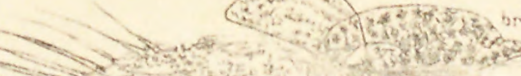

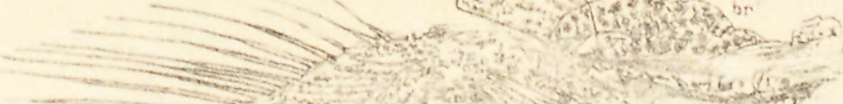
न

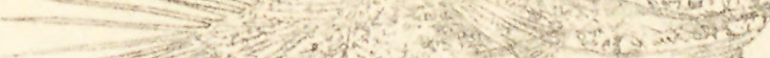

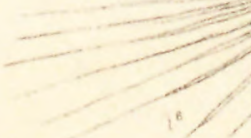
ind

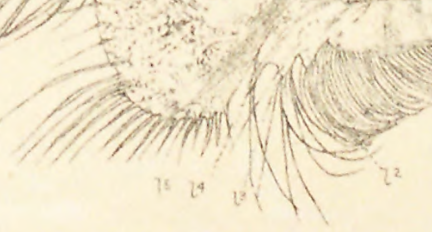






\section{EXPLANATION OF PLATE IX.}

\section{BranchINecta Paludosa with details.}

Fig. 1. Male, at, first antennæ; at', elaspers, or second antennæ : p. penis (gonopola . Fig. 2. Female. This and Fig. 1 enlarged several times.

Fig. 3. First foot of male, $\times 50$ diameters.

Fig. 4. Second foot of male, $\times 50$ diameters.

Fig. 5. Tenth foot of male, $\times 50$ diameters.

FIG, 6. End of abdomen, with the candal appendages.

Figs. 1 and 2 drawn by J. H. Emerton for Bessels report on the Voyage of the Polaris; kindly loaned by Dr. Emil Bessels. Figs. 3-6 drawn and filled in with the camera lucida by the anthor. 


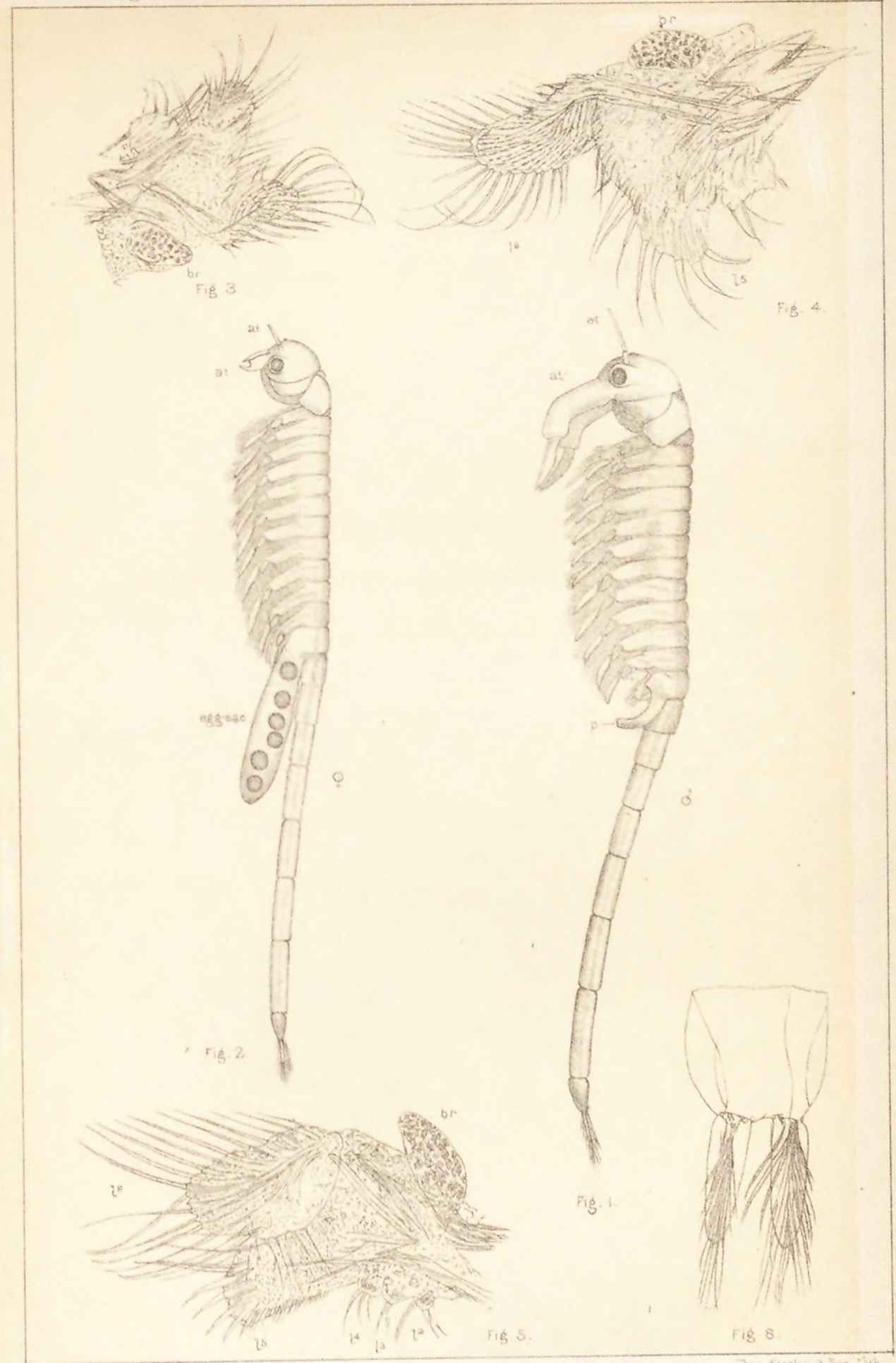






\section{EXPLANATION OF PLATE $\mathbf{X}$.}

Branchinecta paludosa and B. coloradenels.

Fig. 1. Branohinecta paludosa Müll. (arctica Verrill.), first foot of male.

FIG. 2. Branchinecta paludosa Müll. (arctica Verrill.), second foot of male FIG. 3. Branchinecta paludosa Müll. (arctica Verrill.), tenth foot of malo.

FIG. 4. Branchinecta paludosa Müll. (arctica Verrill.), eleventh foot of malz

FIg. 5. Branchinecta paludosa Müll. (arctica Verrill.), cercopoda.

FIG. 6. Branchinecta coloradensis Packard, first foot of male.

FIG. 7. Branchinecta coloradensis Packard, eleventh foot of male. Anthor, del. 


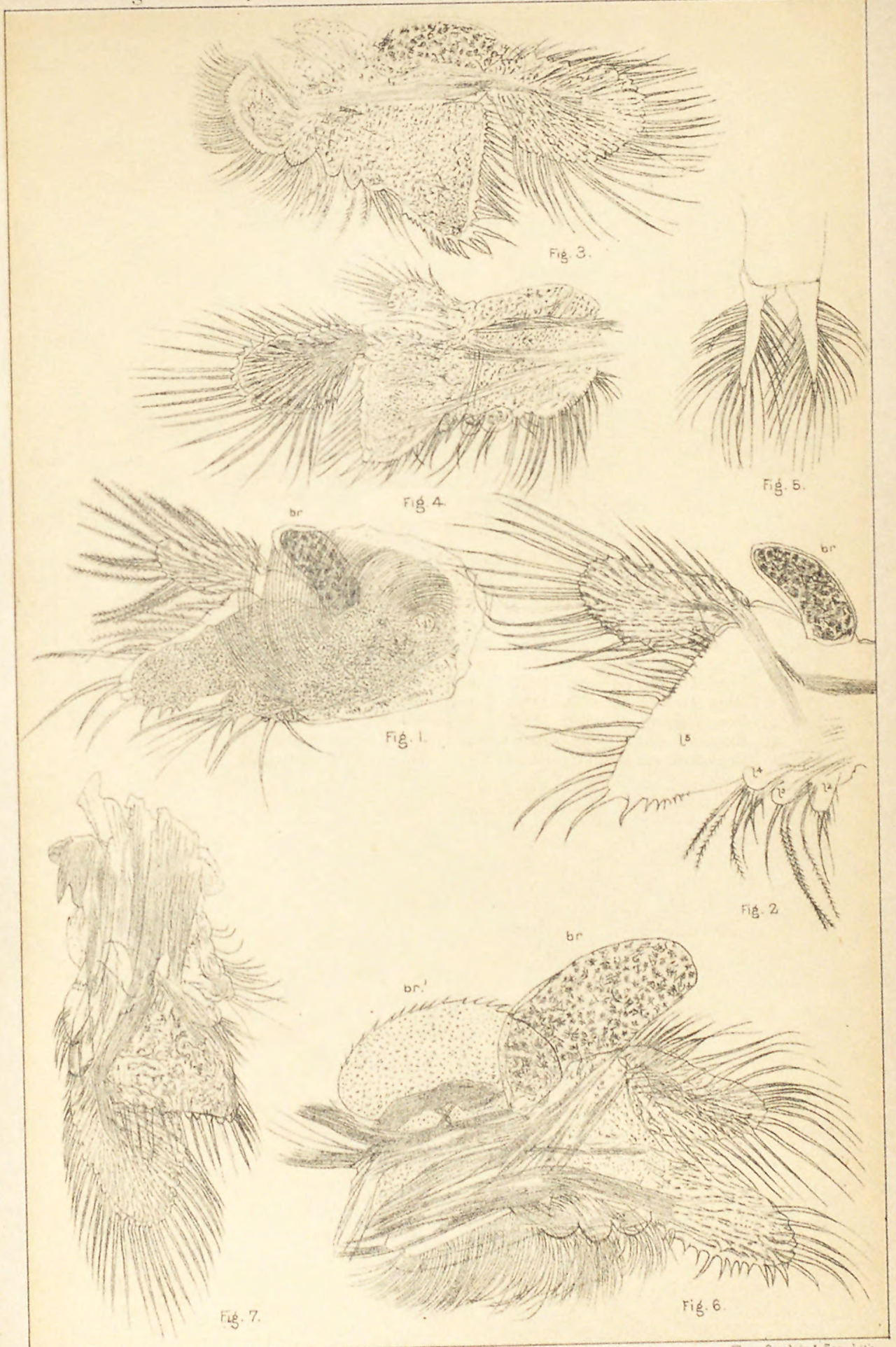

A.S Packard del 


EXPLANATION OF PLATE XI.

Branchinecta lindahli and Branchipus vernalis Vertill, and details.

Frg. 1. Branchinecta lindahli, 10 th foot, $\times 1 \frac{1}{2} \mathrm{~B}$.

Frg. 2. Branchipus vernalis Verrill. Enlarged $3+$ times; $f g$, frontal process ; int, intestine; $p$, penis (gonopoda).

ExG. 3. Branchipus vernalis, first foot of male, $\times 30$ diameters.

Frg. 4. Branchipus vernalis, first foot of female, $\times 30$ diameters.

FrG. 5. Branchipus vernalis, eleventh or last foot, male, $\times 30$ diameters.

FIG. 6. Branchipus vernalis, end of body (cercopoda) of male.

Frg. 7. Branchinecta lindahli, end of body of female, $\times 30$ diameters.

Fig. 2 drawn by Mr. E. Burgess; the other figure by the sathor, with the eamera incida. 


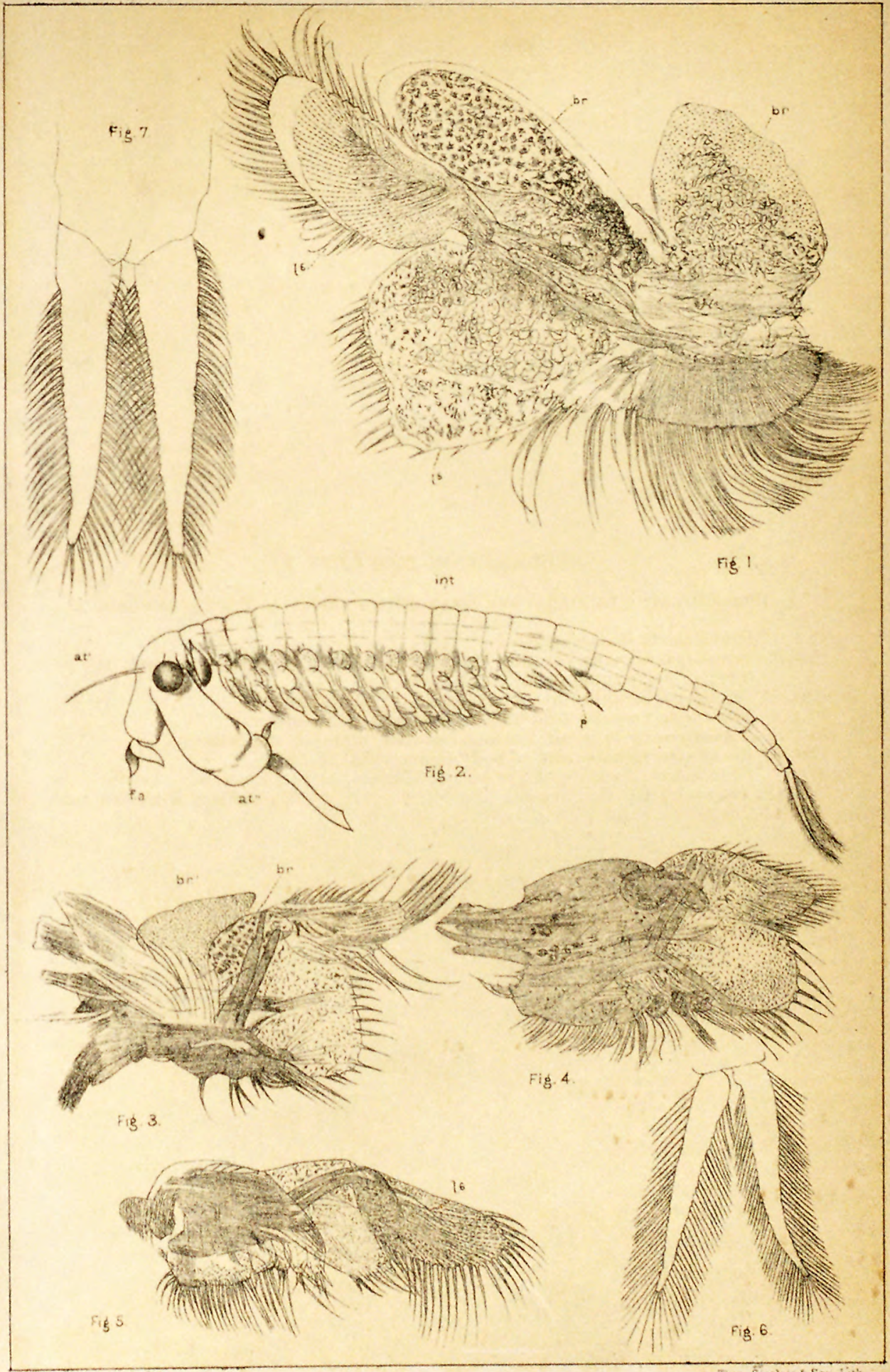




Fig. 1. First foot, male from Kansas, $\times \frac{1}{2} \mathrm{~A}$.

Fig. 2. First foot, male from Texas, $\times 50$ diameters.

Fig. 3. Sixth endite of $2 d$ foot, from Texas, $\times 50$.

Frg. 4. Sixth endite of 9 th foot, from Texas, $\times 50$.

Fig. 5. Tenth foot of specimen from Kansas, $\times 50$.

FIG, 6. Eleventh foot of specimen from Kansas, $\times 50$.

Fig. 7. End of body of specimen from Kansas, $\times 30$.

Drawn by the anthor, with the aid of the camera lucida. 


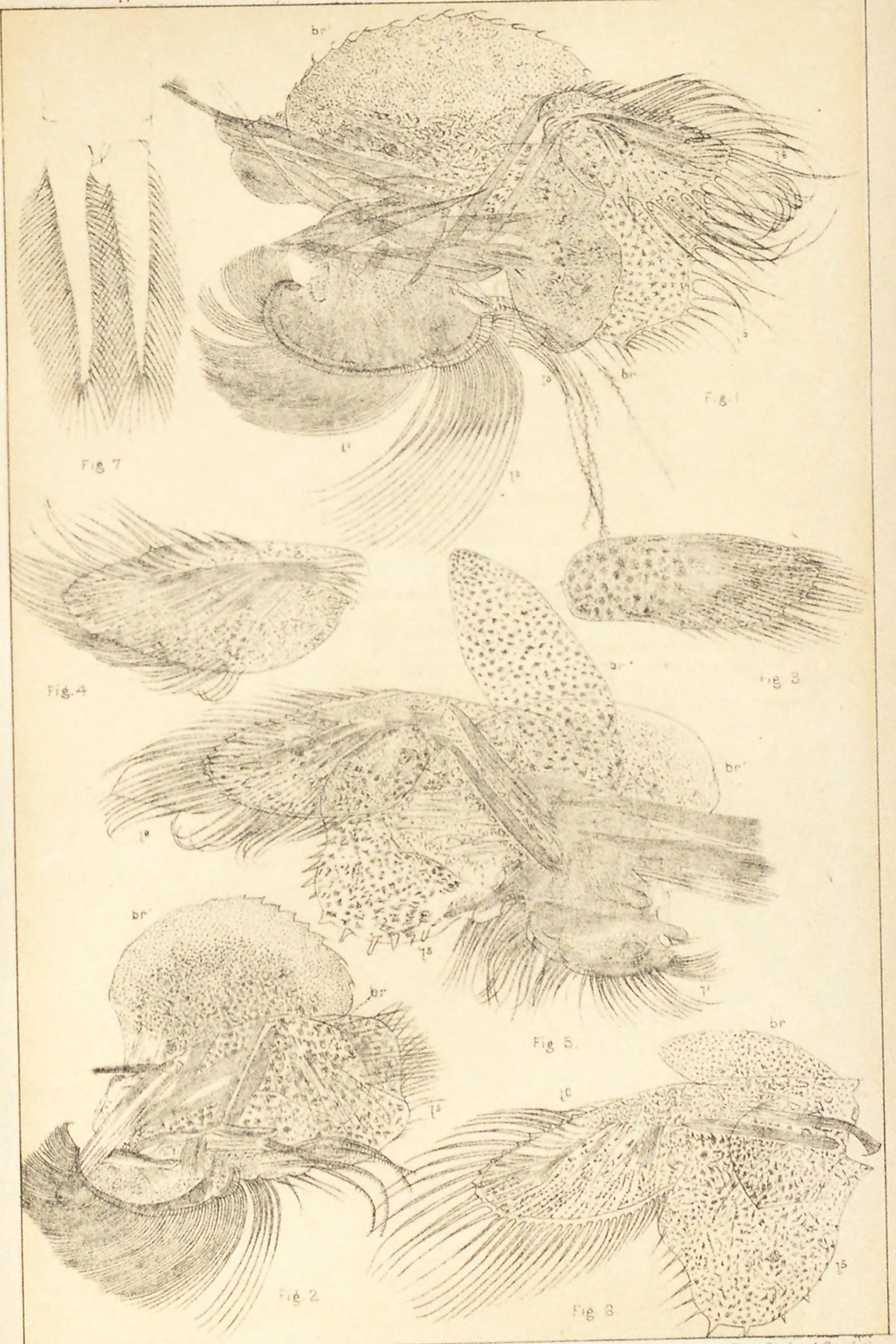




Chirocephalus holmani Ryder, details.

FIG. 1. Foot of the first pair, with the following one, from a femsle; the 1st slightly overlapping the $2 \mathrm{~d}$ foot, $\times \frac{1}{2} \mathrm{~A}$.

FIg. 2. Tenth foot of a female; the sixth endite is turned down and the fifth tarned up, $\times \frac{1}{2} \mathrm{~A}$., the third and fourth endites not seen.

FIG. 3. Third foot, showing the third and fourth endites, between the 1at and 2d, and the 5th, only the latter designated by the sign $l^{5}$.

FIG. $3 a$. Sixth endite from the third foot.

Frg. 4. Frontal process of an old, large male.

FIG. 5. Frontal process of younger, smaller male.

Drawn by the anthor, with the aid of the camera lucida. 


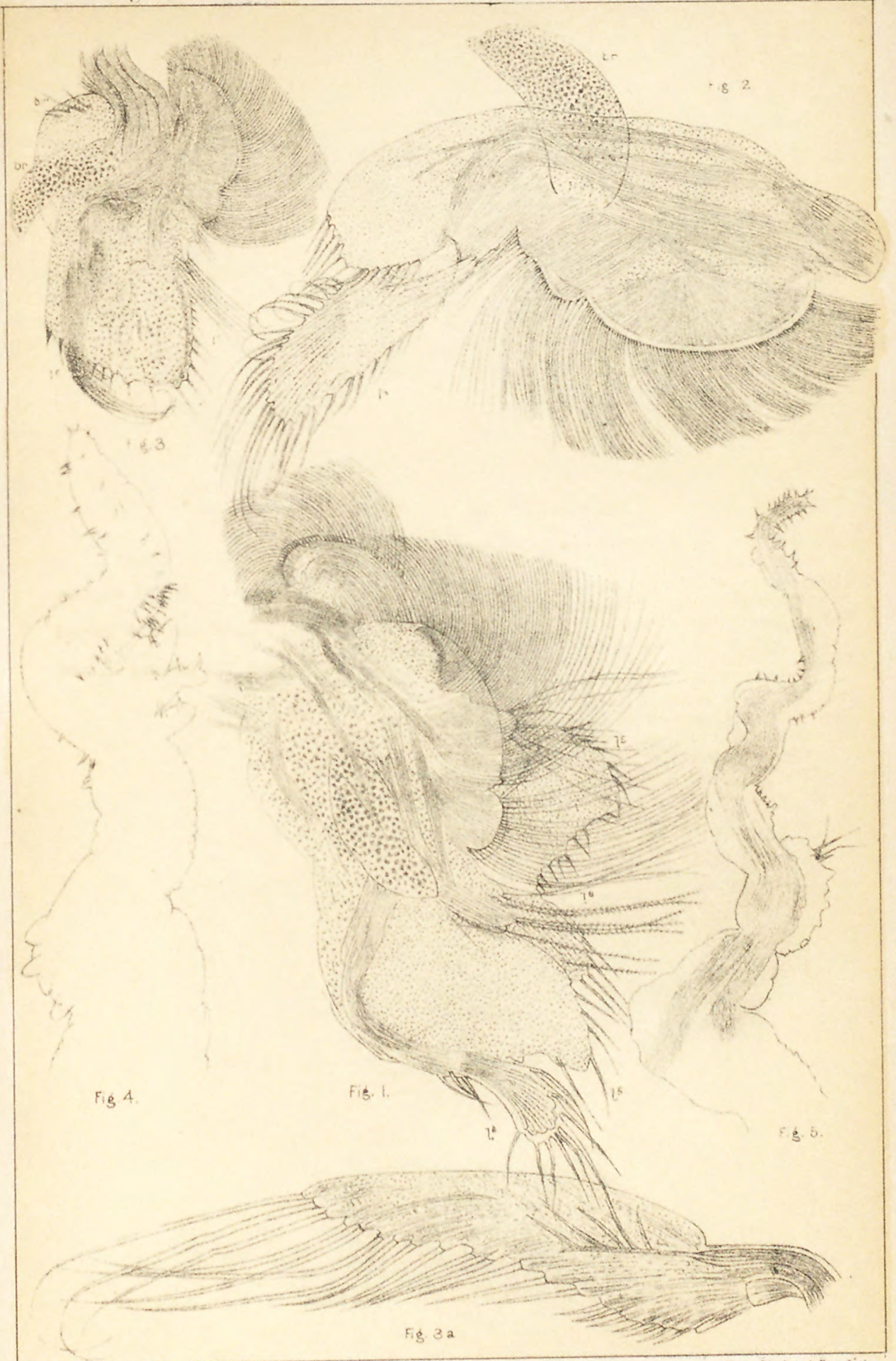

A.S Paekard del

Whan Sincleire Son, Lith 


EXPLANATION OF PLATE XIV.

Thamnockphalus platyurus Packard, details.

Fig. 1. An anterior leg.

Fig. 2. A middle leg.

FIG. 3. A posterior leg.

Frg. 4. Section through the body, showing the relation of the heart, intestine (int), and nervous cord ( $n g$, a pair of nervous ganglia cut through) to the body walls and the appendages, $l^{5}, l^{6}$, the two last pair of endites, $b r$, the gill.

FIG. 5. The male frontal appendage; $5 a$, end of a branch showing the twigs, and the wrinkles and spinules with which the appendage is armed.

Fig. 6. The female frontal appendage.

Frg. 7. Side view of the head of the female without the frontal appendage, at, first antenna; $a t^{1}$, claspers or $2 d$ antennæ; eye,-the eye and eye stalk. 


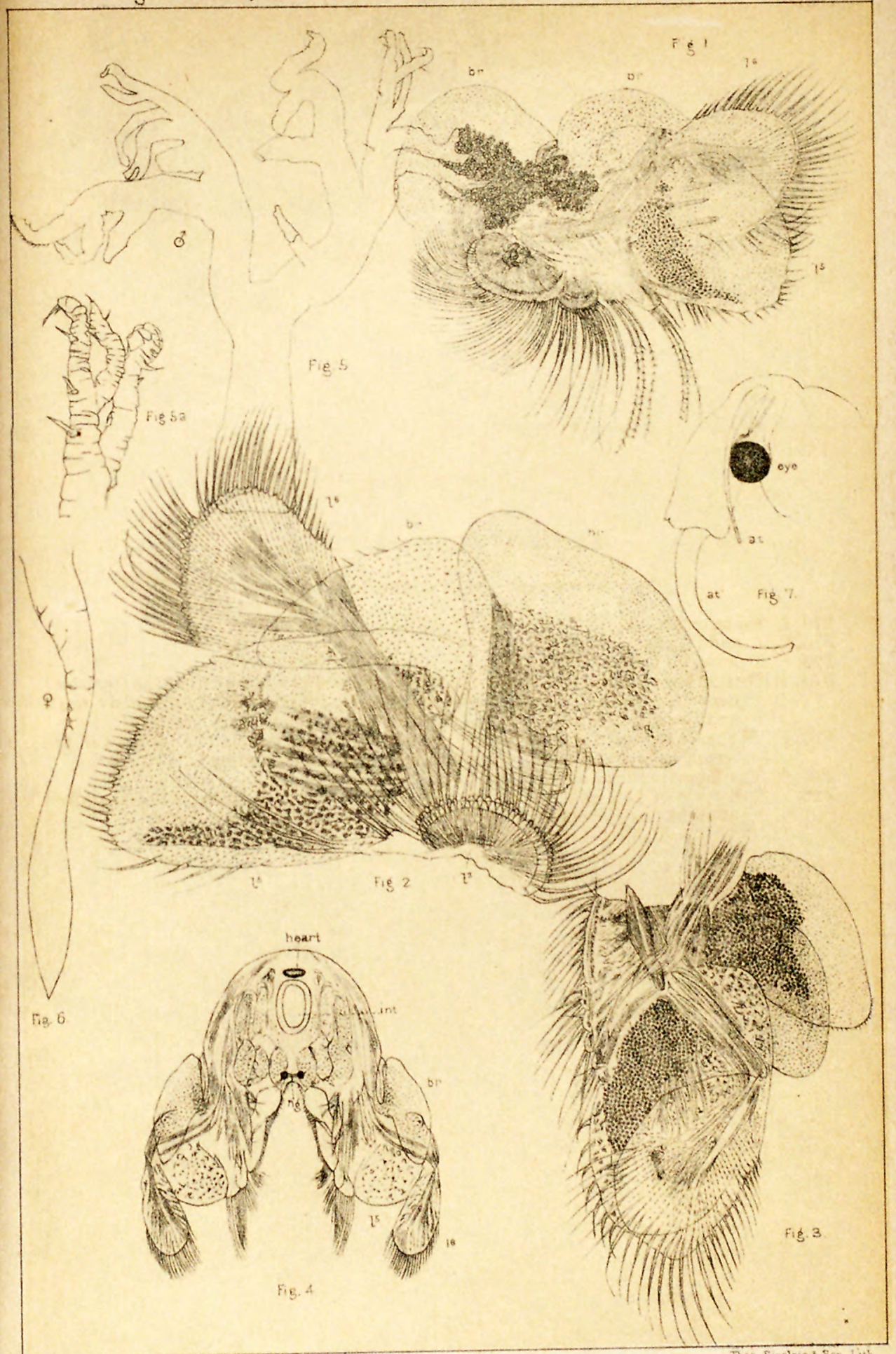






\section{EXPLANATION OF PLATE XV.}

Fig. 1. Apus aqualis Packard, $q$ enlarged twice. 1a, upper; $1 b$, under side of the telson enlarged.

Frg. 2. Lepidurus conesii Packard, nat. size. 2a, side view of the same.

Fig. 3. Lepidurus bilobatus Packard, nat. size.

Drawn by J. H. Emerton. 


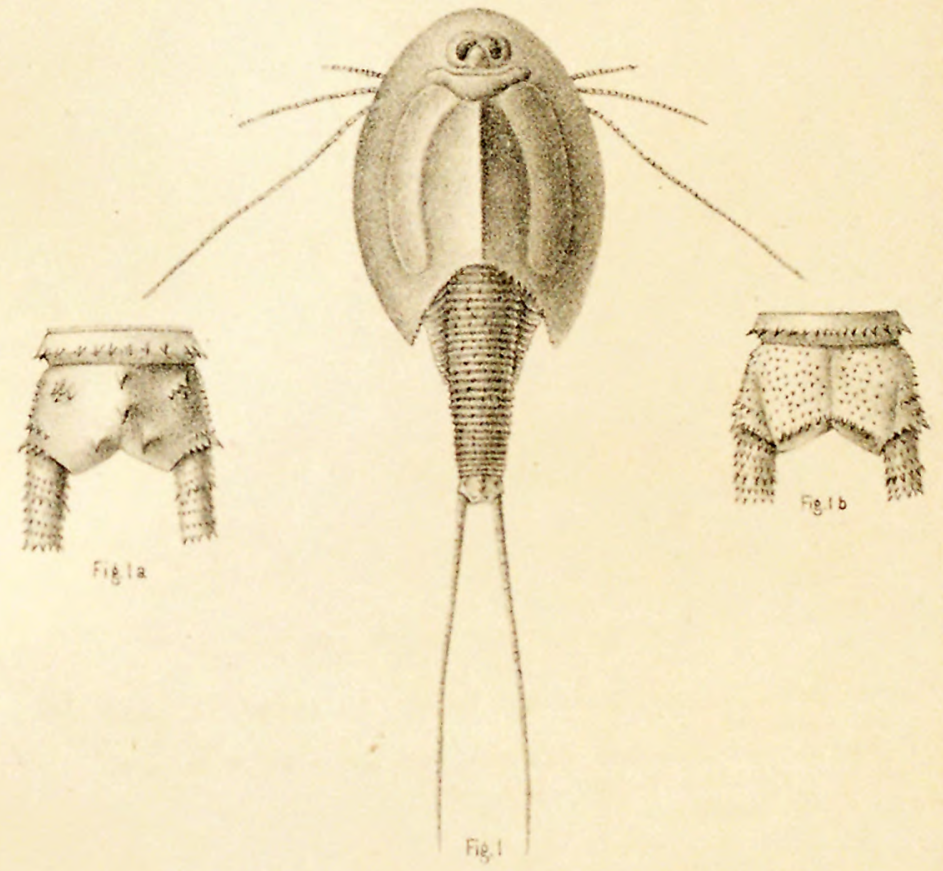

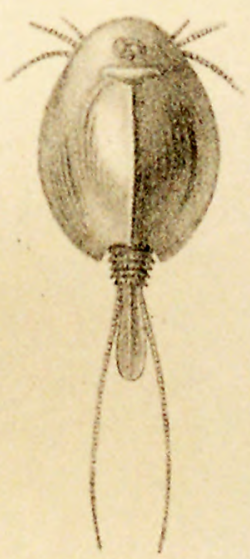

Fig 2

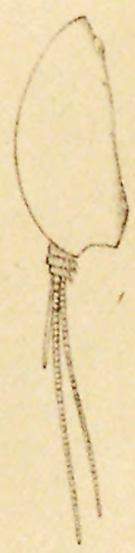

Fig, 2a

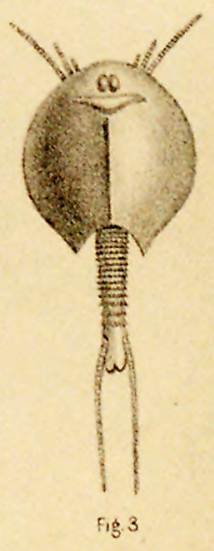

Fig. 3 



\section{EXPLANATION OF PLATE XVI.}

Fig. 1. Lepidurus glacialis, enlarged nearly 3 times. 1a, upper, $1 b$, under side of the telson enlarged.

Fig. 2. Apus lucasanus Packard, nat. size. 2a, upper; $2 b$, under side of telson, enlarged.

Fig. 3, Apus newberryi Packard, nat. size. 3a, upper; $3 b$ (on right-hand side), under side of telson, enlarged.

Fig. 4. Apus longicaudatus Le Conte, upper, $4 a$, under side of telson.

Fig. 5. Apus himalayanus Packard, telson. $5 a$, under side of telson, enlarged. Drawn by J. H. Emerton. 


EXPLANATION OF PLATE XVII.

Fig. 1. Lepidurus glacialis, first foot; $c l$, gnathobase or coxal lobe; $c l^{1}$, the same of the succeeding limb.

Fig. 2. Lepidurus couesii, first foot.

Fig. 3. Lepidurus couesii, first foot of another (malformed?) individual.

Fig. 4. Lepidurus bilobatus, $q$, first foot.

FIG. 5. Lepidurus glacialis 9 , second foot.

Fig. 6. Lepidurus bilobatus, o, second foot.

Fig. 7. Lepidurus couesii, second foot.

All enlarged; drawn by the author, with the aid of the camera lucida. 


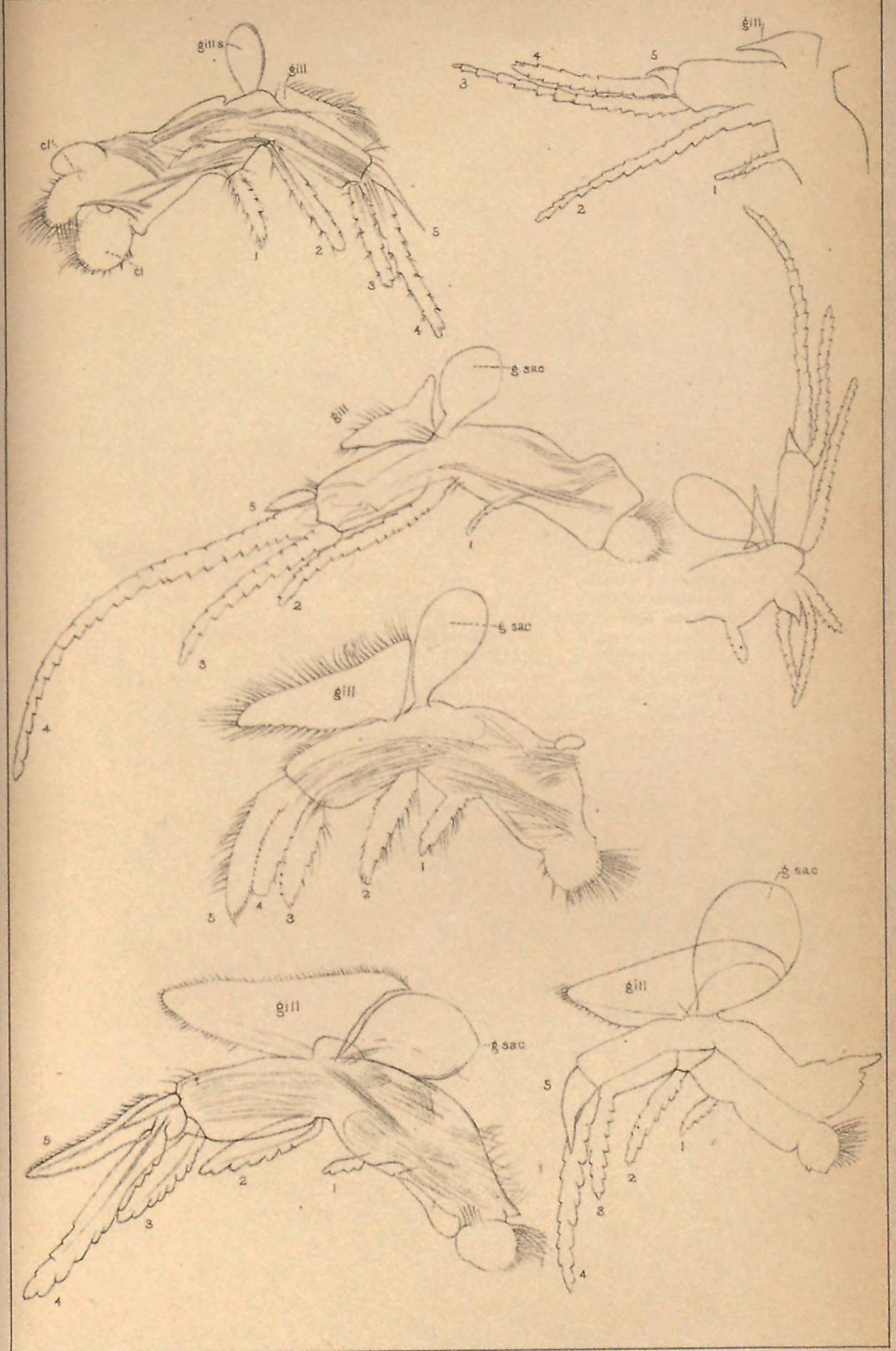






\section{EXPLANATION OF PLATE XVIII.}

Fig. 1. Apus aqualis, $q$, tenth foot.

Fig. 2. Apus newberryi,, , tenth foot, $x$, "subapical lobe."

FIG. 3. Apus lucasanus, tenth foot, $x$, as in Fig. 2.

FIG. 4. Apus longicaudatus, tenth foot.

Fig. 5. Apus lucasanus, eleventh foot of the female, with the ovisac, containing a few eggs.

Fig. 6. Apus longicaudatus, eleventh foot of female.

FIG. 7. Apus newberryi, eleventh foot of female.

All the figures on this and Plates XIX-XXI much enlarged, and drawn by the author with the camera lucida. 


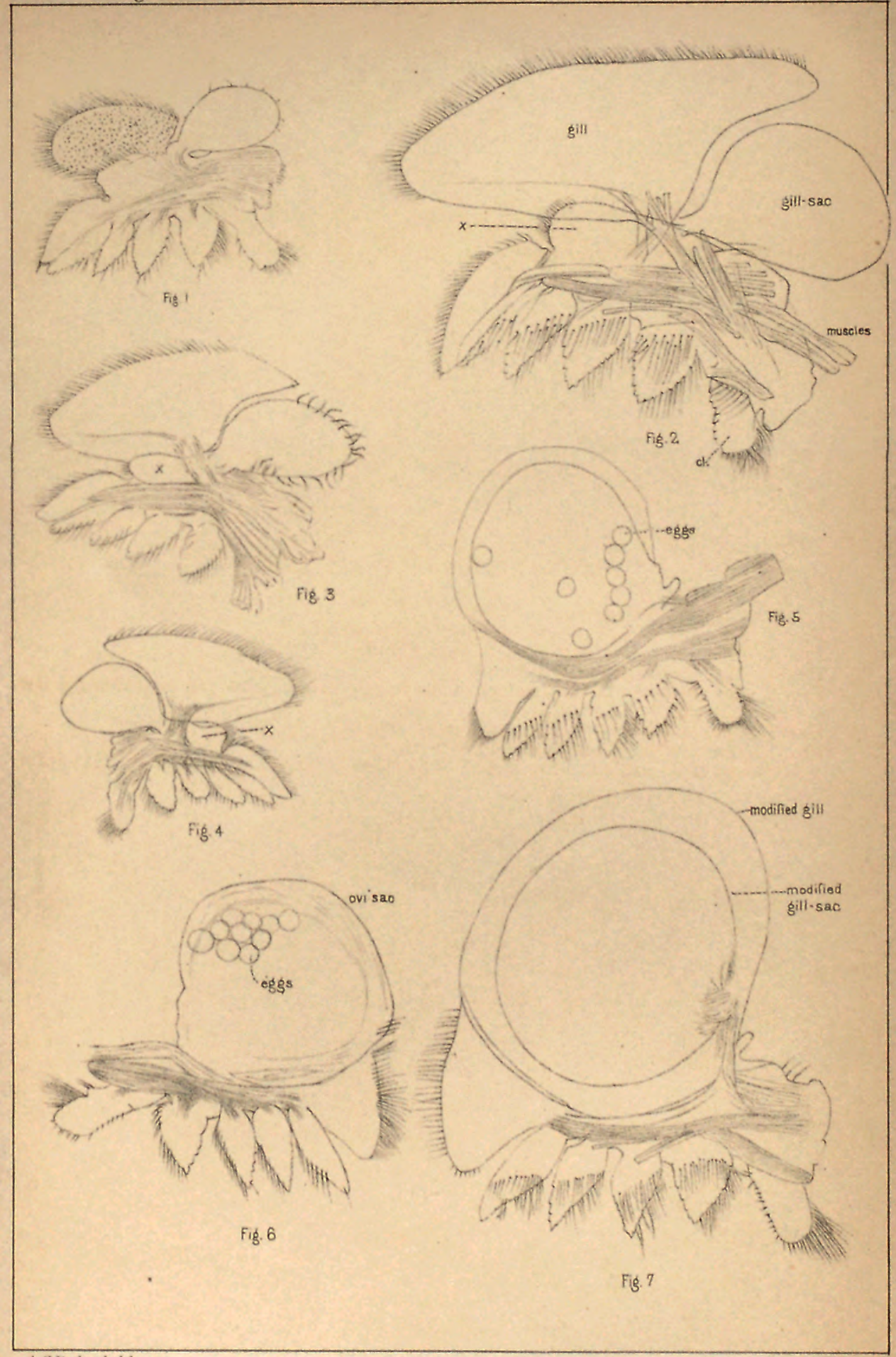

A.S. Fackand, del

Thos Singleir \& Son. Lith. 


EXPLANATION OF PLATE XIX.

Fig. 1. Apus lucasanus, first foot; $c l$, gnathobase; $c l$, that of the following appendage. FrG. 2. Apus aqualis, second pair of feet.

FIG. 3. Apus newberryi, $\&$, second pair of feet.

FIG. 4. Apus longicaudatus, second pair of feet.

FIG. 5. Apus lucasanus, $\jmath$; second pair of feet; differs from the female in having the filaments on the gill. 


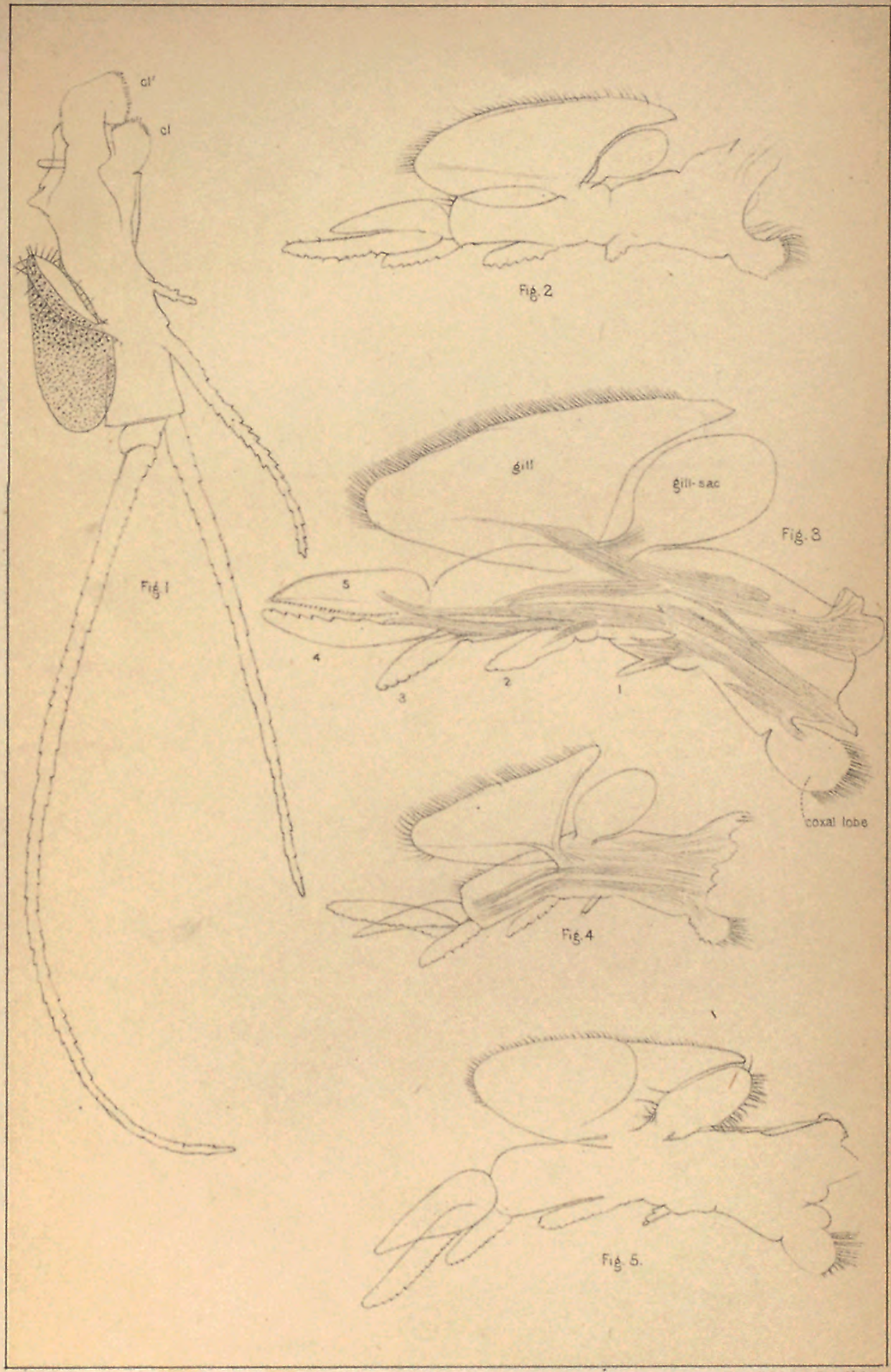




EXPLANATION OF PLATE XX.

FIG. 1. Apus newberryi, $q$, first foot.

FIG. 2. Apus aqualis, $q$, first foot.

FIG. 3. Apus longicaudatus, $\subsetneq$, first foot.

FIG. 4. Apus longicaudatus, 8 , first foot. 


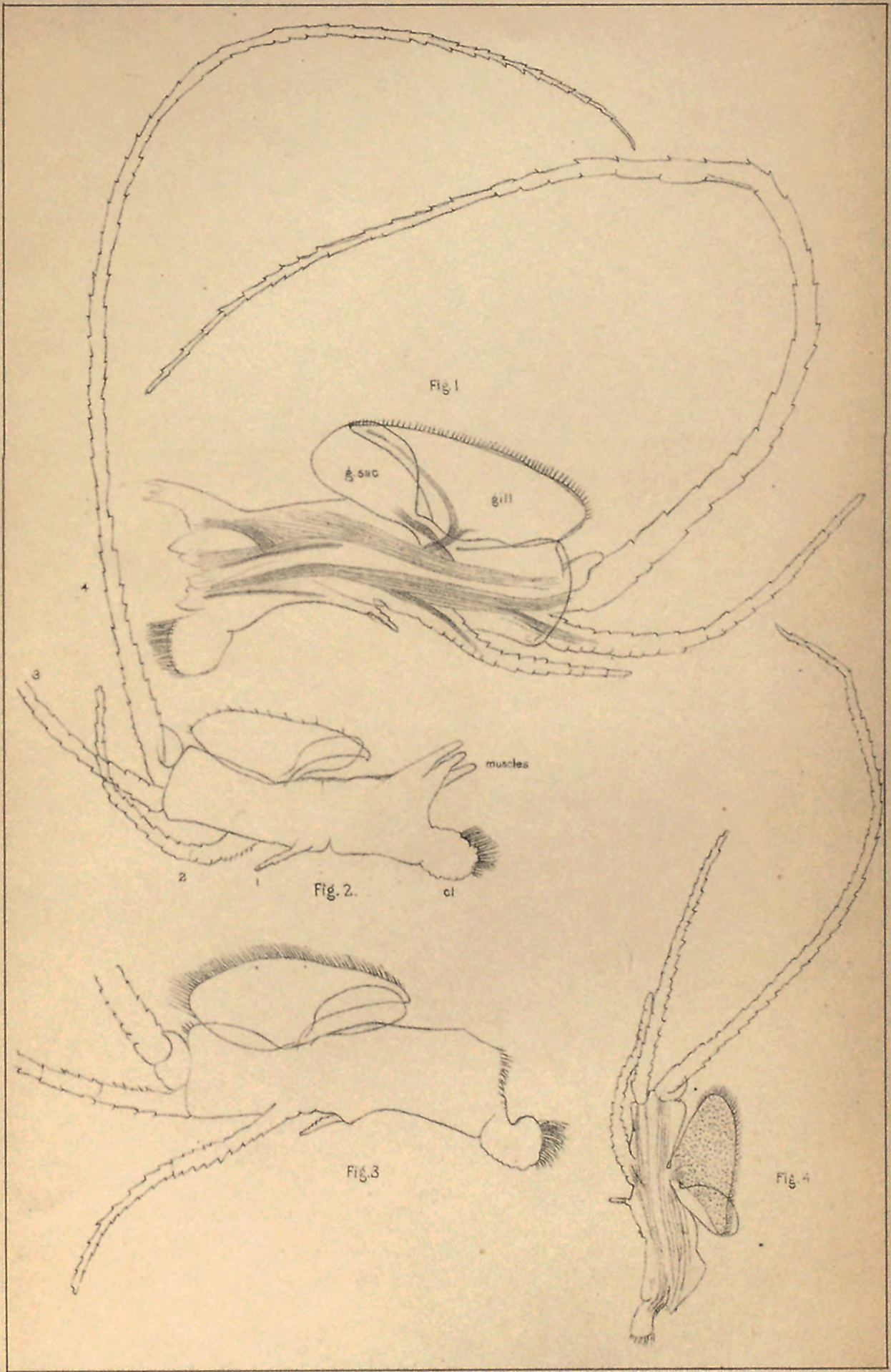






\section{EXPLANATION OF PLATE XXI.}

Fig. 1. Lepidurus glacialis, female; tenth appendage.

Fig. 2. Lepidurus glacialis, female; eleventh appendage, with orisac.

FIG. 3. Lepidurus bilobatus, female; tenth appendage.

Fig. 4. Lepidurus conesii, male; tenth appendage.

Fig. 5. Lepidurus couesii, female; tenth appendage.

Fig. 6. Lepidurus couesii, female; eleventh appendage.

Fig. 7. Apus lucasanus, maxilla.

Fig. 8. Apus lucasanus, maxilla, seen from the inside.

Fig. 9. Lepidurus couesii, maxilla.

Fig. 10. Apus lucasanus, maxilla.

FIG. 11. Lepidurus conesii, mandible.

Fig. 12. Apus lucasanus, mandible.

Fig. 13. Apus lucasanus, outside view of the same specimen as Fig. 8 represente. 


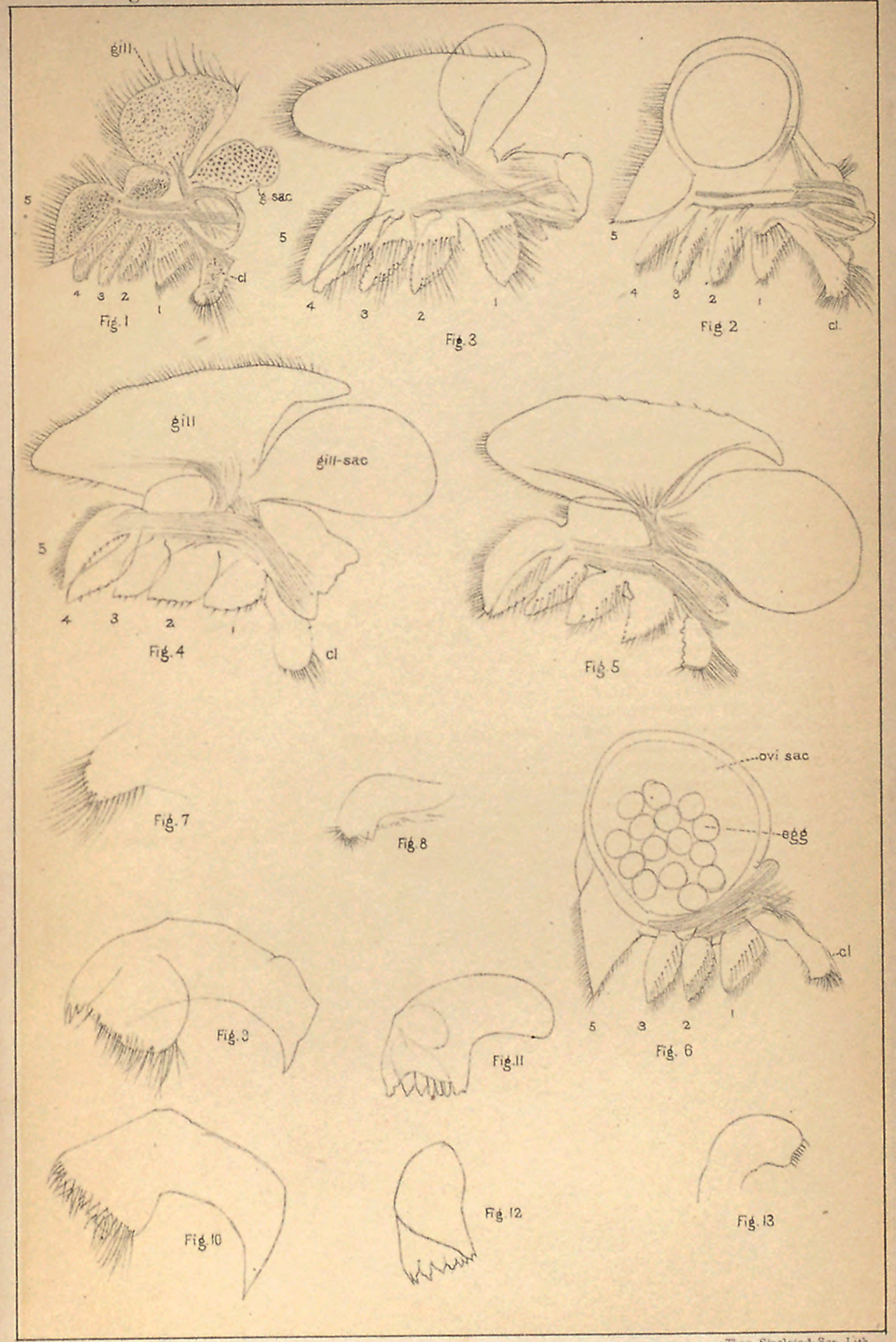






\section{EXPLANATION OF PLATE XXII.}

\section{Axatomy of Artemia and Braxchipls vernalis.}

FIG. 1. Nauplius or first larval state of Artemia gracilis from Great Salt Lake. I, first antennæ; II, second antennæ, III, nandibles.

Fig. 2. Artemia gracilis, from New Haven, ovisac and ovary; $c$, ovary; $d$, anterior points of attachment of the ovary, the intestine passing between them; $e$, $e$, oviducts.

Fig. 2a. Artemia gracilis, from New Haven, cells of the cement-gland.

Fig. 2b. The same; end of the long middle lobe, with the cement-gland cells (ec) and the fully developed eggs $(e g g)$.

FIG. 3. Branchipus cernalis. Male generative organs; $t$, testis; $t^{\prime}$, first dilated portion of the testis; $t^{\prime \prime}$, contracted portion or vas deferens; $\mathrm{t}^{\prime \prime}$, second dilated portion, performing the function of seminal vesicle; $d t$, ductus ejaculatorius; $g$, glandular and accessory apparatus; $c$, cirrus; $b r$, gill of last left foot ; int, intestine; $h t$, heart or dorsal vessel; $h h$, ostium, or valvular opening of heart.

FIG. 4. Branchipus vernalis, pale variety, ovisac; $a$, external wall of the ovisac; $b$, internal wall of the same; $c$, the two ovarian tubes (somewhat twisted and stretched in living specimens); $d$, anterior continuation of the same; $e$, the two muscular oviducts; $f$, lateral portion of the cement-gland; $g$, median portion of the same; $h$, female valvular orifice ; $a b^{3}$, third abdominal segment.

Fig. 4a. Ovaries (ovt) and oviducts $(o v)$ of pale variety.

Fig. $4 b$. Side view of a contracted oviduct.

FIG. 4c. Branchipus vernalis, oviduct filled with eggs, of au old red female; $a$, valvule, below which is the orifice; $c$, transverse ridge; $d$, lateral protuberances; $e$, margin of the following segment.

Fig. 5. Branchipus vernalis, frontal process of a red male, the right side being the outer edge, with double-headed papillæ.

FIg. 5a. One side of same in a pale male.

Fig. 6. $r, s, t$, different forms of ocelli or median eye in pale races, $\delta$ and $s$.

Figs. 1,2, $2 a, 2 b$, drawn by the author; the others by C. F. Gissler, Ph. D. 


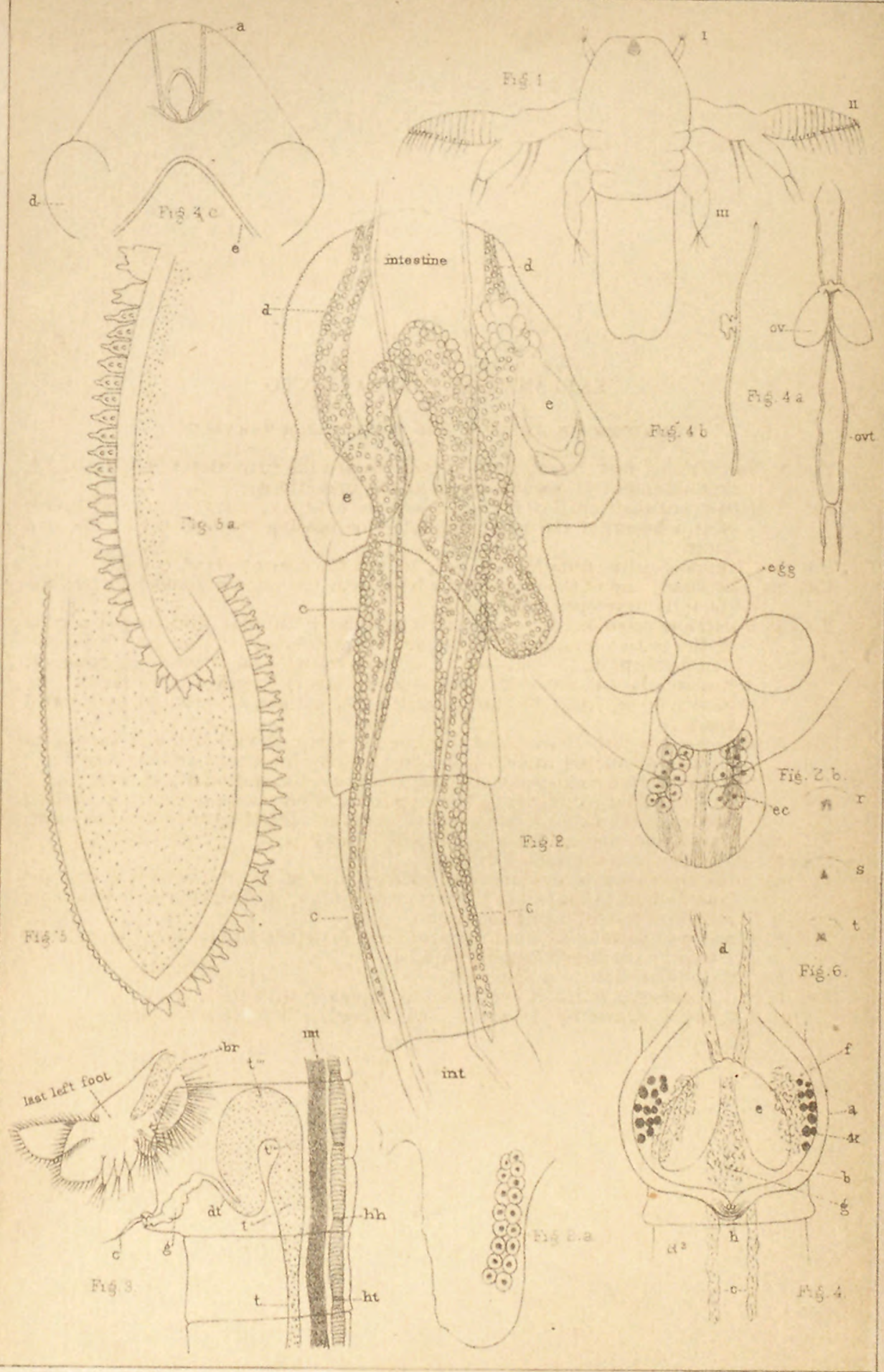




EXPLANATION OF PLATE XXIII.

Artemia gracilis Verrill (from New Haven), details.

FIG. 1. Artemia gracilis Verrill. Head, showing the relation of the brain to the eyes, optic nerves, and ocellus (ocel), with the stomach and liver; $m d$, mandible; $g l$, rudimentary shell-gland.

Fig. 2. Front of the body, showing the circulation of the blood; $h t$, heart; the dots and arrows indicate the course of the blood-currents; int, intestine.

Fig. 3. End of the same individual represented by Fig. 2; $h t$, end of the heart, with the two valves (seen at Fig. $3 a$ ); rec, rectum; $m$, three pairs of muscular bands which hold the rectum in place.

FIG. 4. Portion of the heart during action; the arrows on each side point towards the ostia or valvular openings; the blood dises are represented within the heart itself; ep. c, epithelial cells in the walls of the heart; $m$, muscles which hold the heart in place.

FIG. 5. End of the body ; rec, rectum; $m$, muscles; anus, vent.

FIG. 6 . One of the compound eyes; cone, one of the crystalline cones; retina, the black retina; op. $n$, the optic nervules; opn, the main optic nerve; $r$. $m$, retractor muscle of the eye; $g . o p$, ganglion opticum, consisting of ganglionic cells, $\times \frac{1}{2} B$.

FIG. 7. Circulation of the blood in a foot, the dots representing the blood dises; the arrows indicating the course of the blood.

Drawn from the living specimens, with the camera lucida. by the author. 


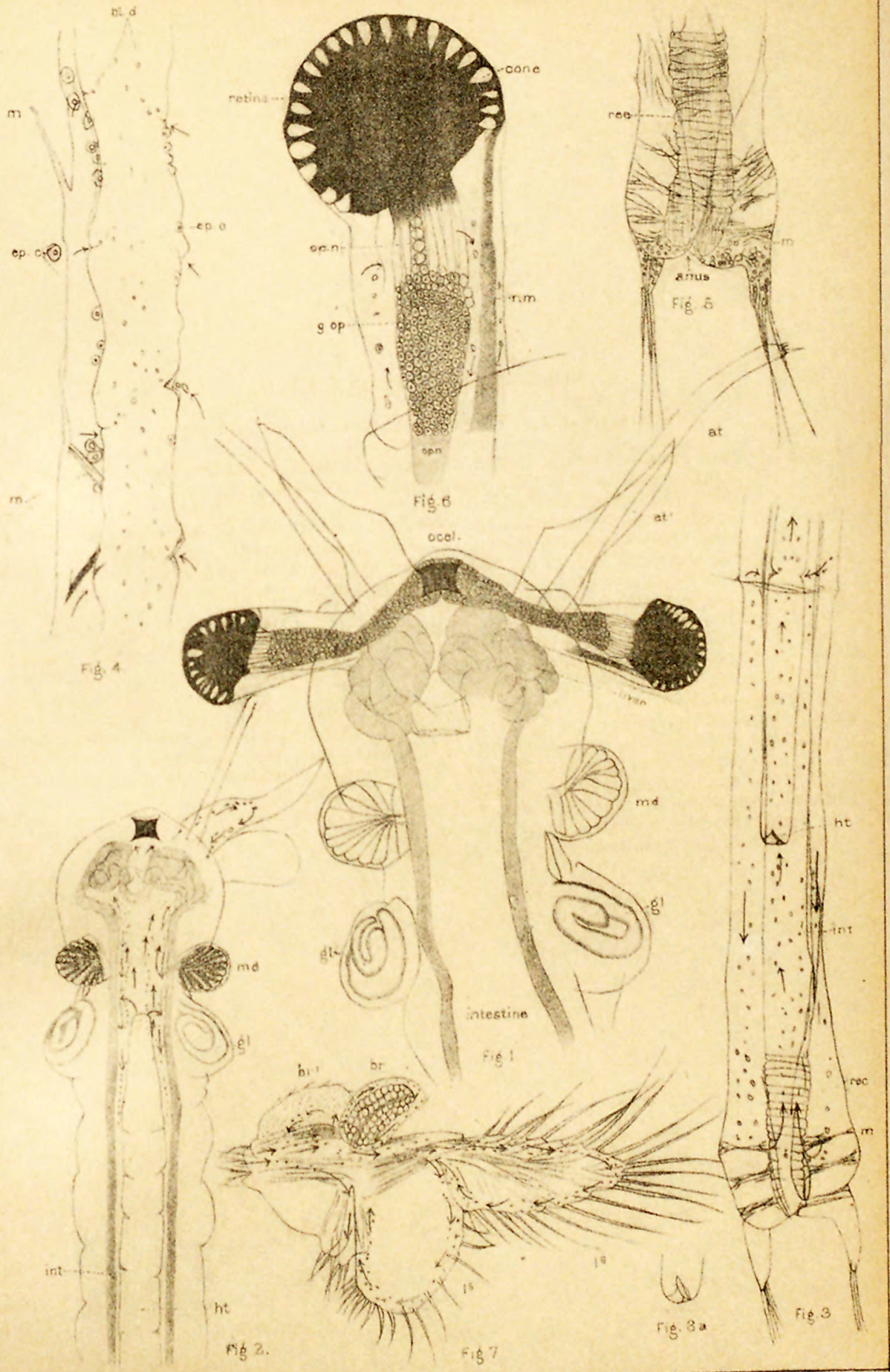

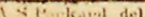



Fig. 1. Estheria belfragei, edge of carapace, greatly enlarged, $\times \frac{1}{8}$ Tolles, A. ocular FIG. 2. Estheria jonesii, edge of shell, with a portion chipped off, $\times+\mathbf{A}$.

Fig. 3. Estheria mexicana, Ohio, $\times \frac{1}{8} \mathrm{~A}$.

Fig. 4. Estheria dawosoni (fossil). Drawn by L. Trouvelot.

Fig. 4a. Estheria dawsoni, showing the granulated ridges, $\times \frac{1}{4} \mathrm{~A}$.

Fig. 4b. Estheria dawsoni, showing the pits between the ridges.

Fig. 5. Estheria californica, $\times \frac{1}{2}$ A.

Fig. 6. Estheria mexicana, Kansas, $\times \frac{1}{2} \mathrm{~A}$.

Fig. 7. Estheria morsei, Iowa; edge of the shell.

FIG. 8. Estheria compleximanus, Kansas; edge of shell, $\times 225$ diameter.

Fig. 9. Estheria mexicana, section through the entire animal, through the front part of thorax; ant $t^{1}$, antennæ; ant $t^{2}$, base of second antennæ; shg, section through the shell-gland; $b r^{\prime}$, upper, $b r^{\prime \prime}$, lower division of the flabellum; int, intestine; $n g$, nerve-ganglion; 1-6, first to sixth endites.

Fig. 10. Estheria compleximanus. Section through the posterior part of the thorax, the shell having been removed; lettering as in Fig. 9 ; mus, dorsal muscles.

All the figures, except Fig. 4 drawn by the author. 


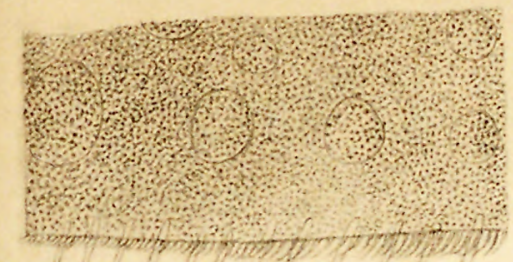

Fig. 1

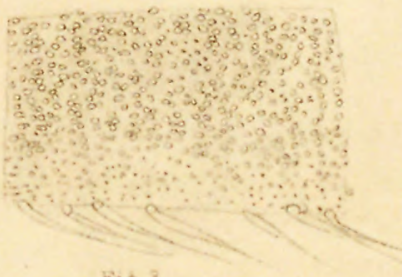

$$
\text { Fis } 3 .
$$

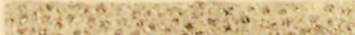

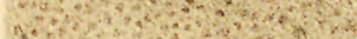

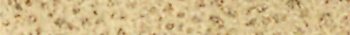

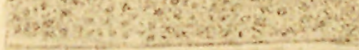

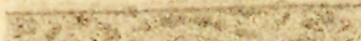
W $\beta^{2}+2, y=g^{2}$ is ate

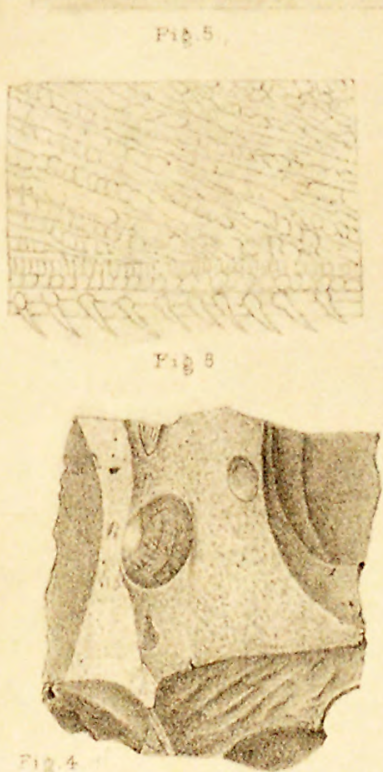

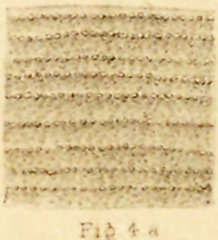

$\mathrm{Fin} 4 \mathrm{a}$

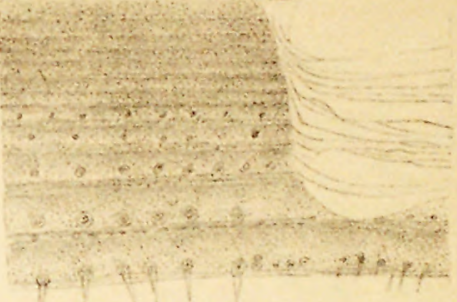

Fis 2 .

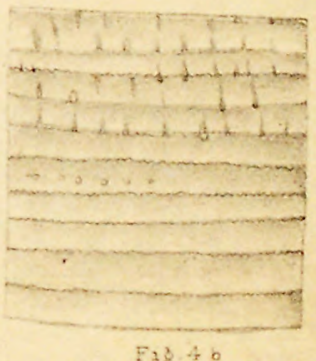

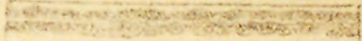

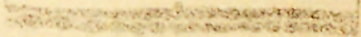

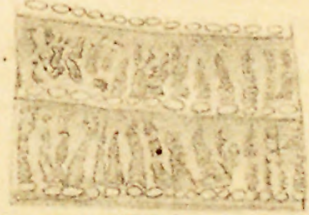
$F_{2} \cdot 6$

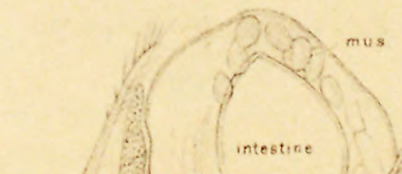

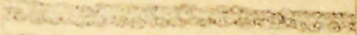

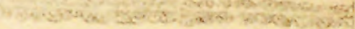

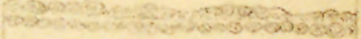

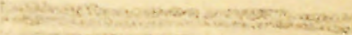

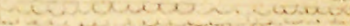
Fig 7

heart

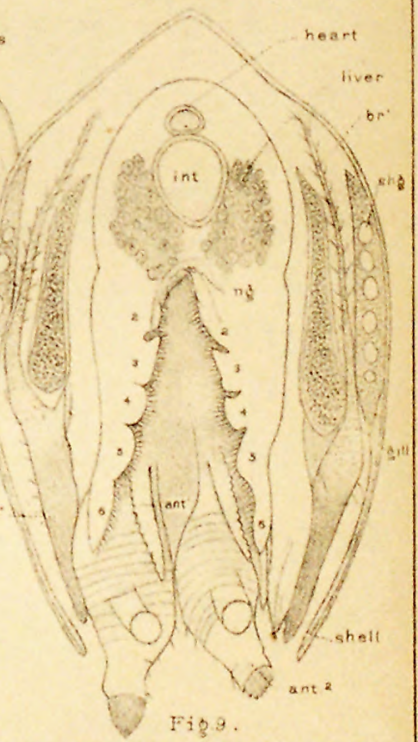




Estheria mexicana aNd E. COMpleximancs, details.

Fic. 1. Estheria mexicana. Second antenna.

Fig. 2. Leg of first pair; male; $c l$, 1st endite.

Frg. $2 a$. Hand, including the fourth endite with the palpiform thumb $(p)$, and comb. like edge of the endite.

Fig. 3. Leg of second pair, male.

Fig. $3 a$. Hand of second pair of male, leg; musc, muscles of hand.

FiG. $3 b$. Comb, or spiney edge of the fourth endite.

Fig. 3o. Palpus-like terminal joint of the fifth endite, showing the sense-cells with which it is filled, and the tactile hairs at the extremity, $x+\frac{1}{\mathrm{~A}}$ Tolles.

Frg. 4. View of the head with the double-eye, from above.

Fig. 4a. The same, seen from the side.

Fig. $4 b$. Another lateral view of the head and rostrum.

Fig. 5. End of the abdomen, including the telson of the male (female the same).

FIg. 6. Estheria compleximanus Packard. End of abdomen.

Drawn, and details filled in with the camera lucida, by the anthor. 


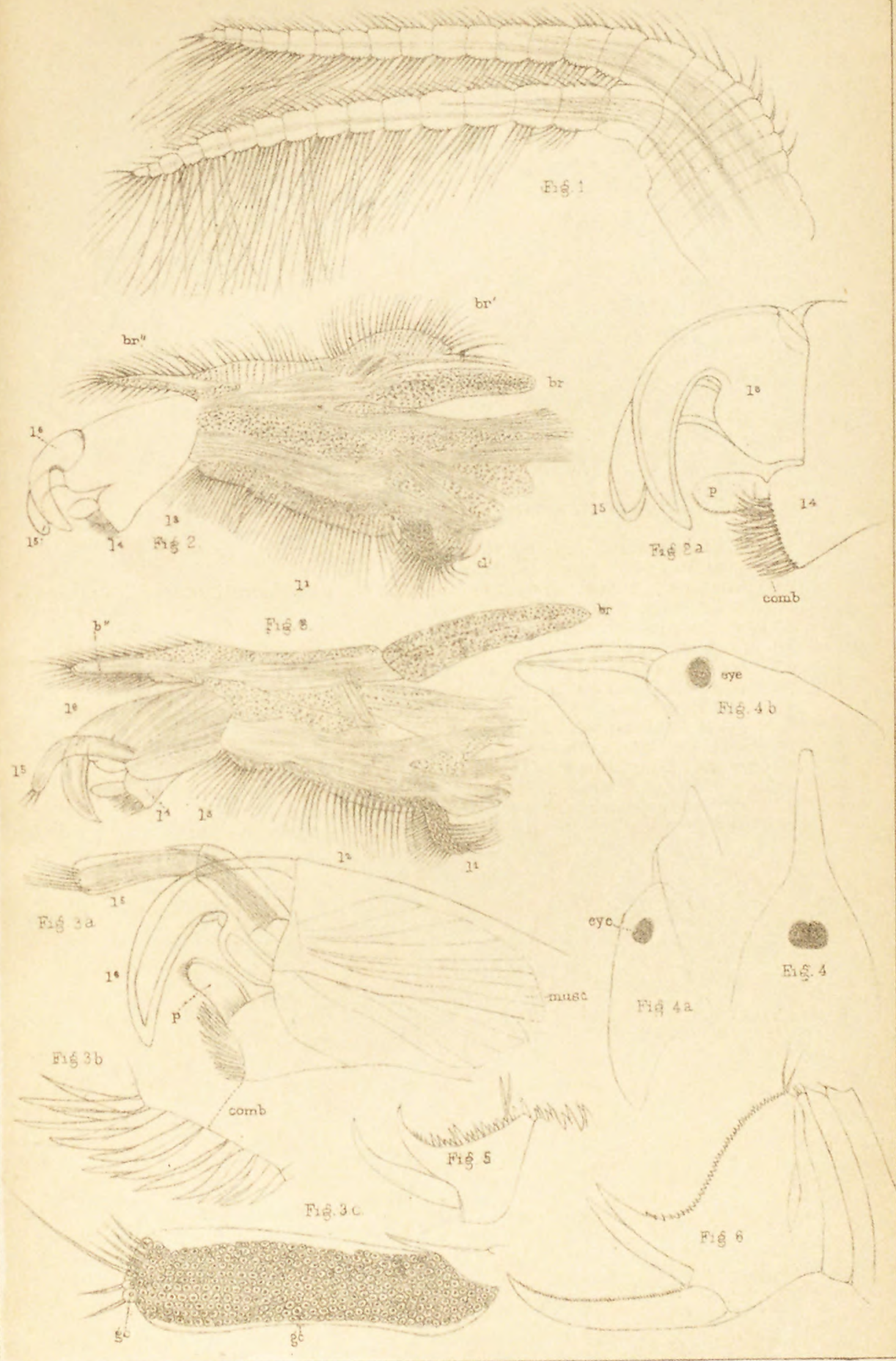

A.S Parkand del 




\section{EXPLANATION OF PLATE XXVI.}

FIG. 1. Estheria morsei Pack; male, much enlarged.

FIG. 2. Estheria morsei; male, first foot.

FIG. 3. Eulimnadia texana Pack.; end of first antennæ, showing the olfactory papillæ, and crowded nerve sense-cells.

FIG. 4. Limnetis gouldii Baird; end of first antennæ, showing the nerve-endings, the large nerve-cells, and the long, finger-like olfactory papillæ, $\times \frac{1}{6} \mathrm{~A}$.

Fig. $4 a$. Portion of end of the same, $\times \frac{1}{8} \mathrm{~B}$ ocular, showing the nuclei in the papillw and the series of nucleated sense-cells. (The line on the right side was drawn by mistake; it should form the left side of Fig. 4.)

Fig. 5. Limnetis brevifrons Pack. ; first antenna.

Fig. 5a. End of the same (Fig. 5), much enlarged.

Fig. 6. Limnetis gouldii; portion of the ovary, $\times \frac{1}{8} \mathrm{~A}$.

Fig. 1 was drawn by Mr. E. Burgess; the other figures by the author. 


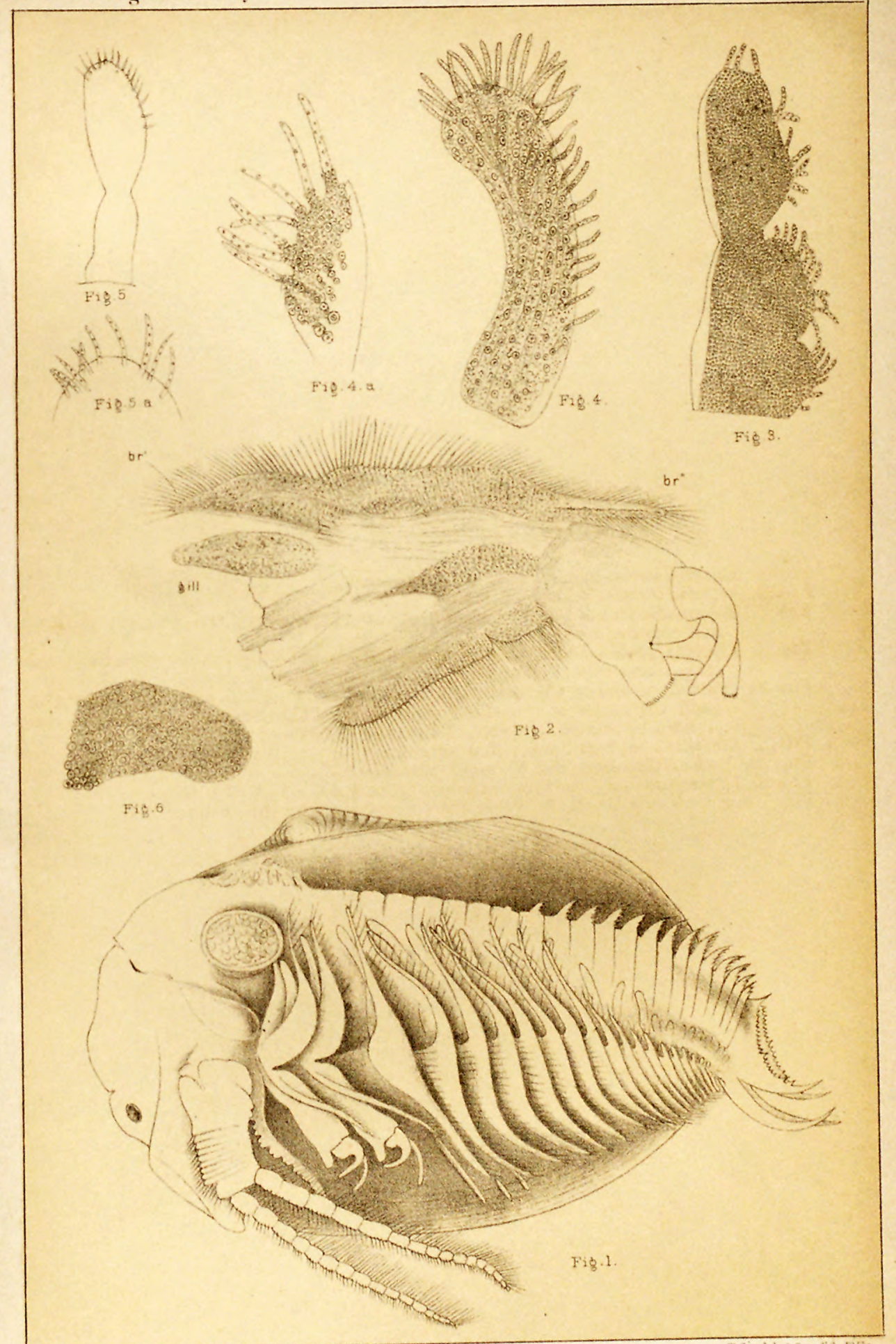




Frg. 1. Limnetis brevifrons Packard; second antenna of female.

Fig. 2. Limnetis brevifrons Packard; first leg of female.

Fug. 2a. Limnetis brevifrons Packard; end of first leg of Fig. 2, showing endites 4-6 and the lower division of flabellum $\left(b r^{\prime \prime}\right)$.

Frg. 3. Limnetis brevifrons Packard; male, first leg (en above en should be en $\left.n^{5}\right)$. All the figures drawn by the author. 


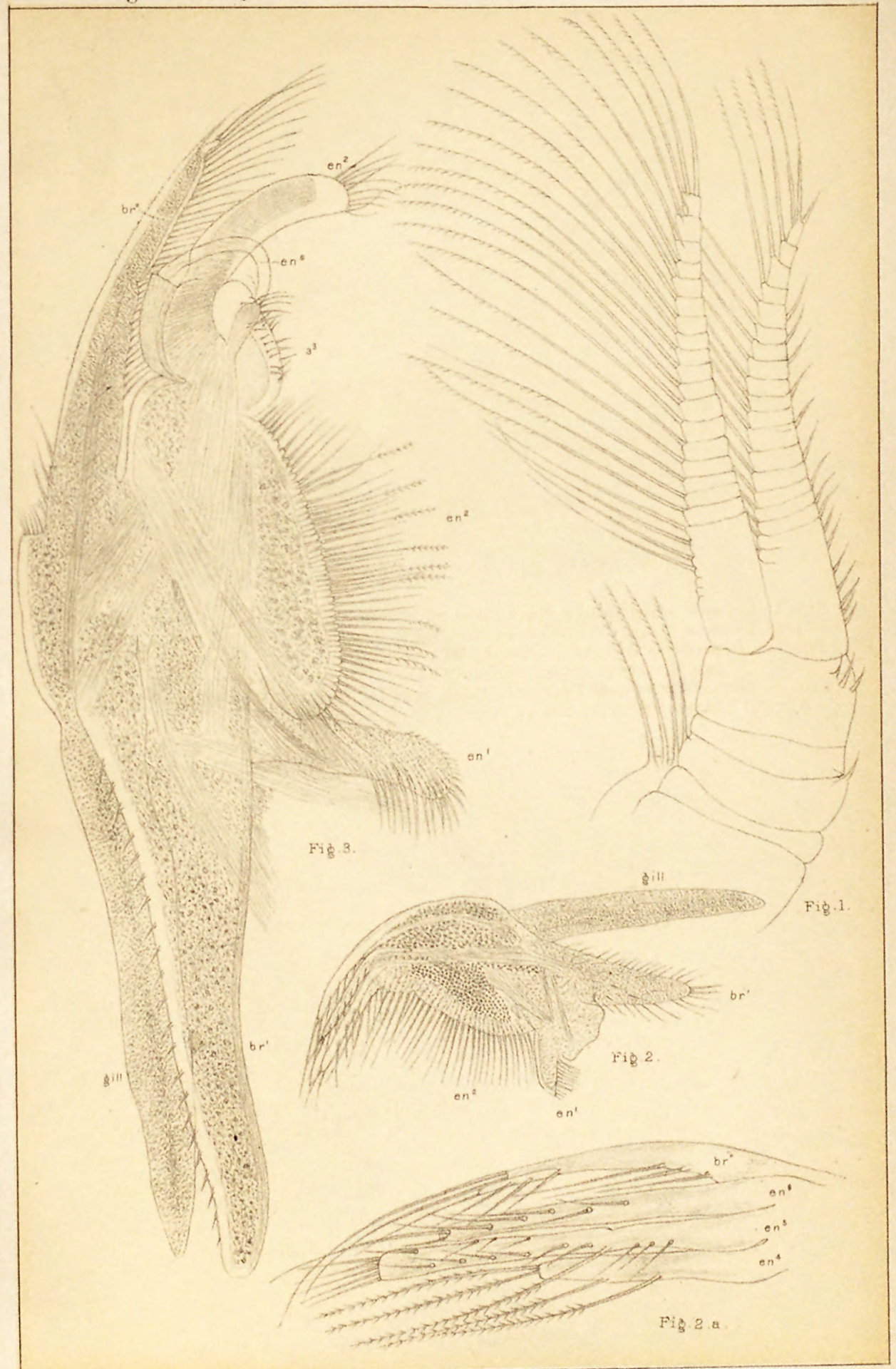






\section{EXPLANATION OF PLATE XXVIII.}

Figs. 1-5. Estheria mexicana Clans, immature specimens from Kentucky (E. clarkii Pack.).

Fig. 1. Thoracic leg, female.

FIG. 2. Fifth leg from the last.

Fig. 3. First antenna.

Fig. 4. Second antenna.

Fig. 5. Telson.

Fig. 6. Estheria jonesii Baird; second antenna. 


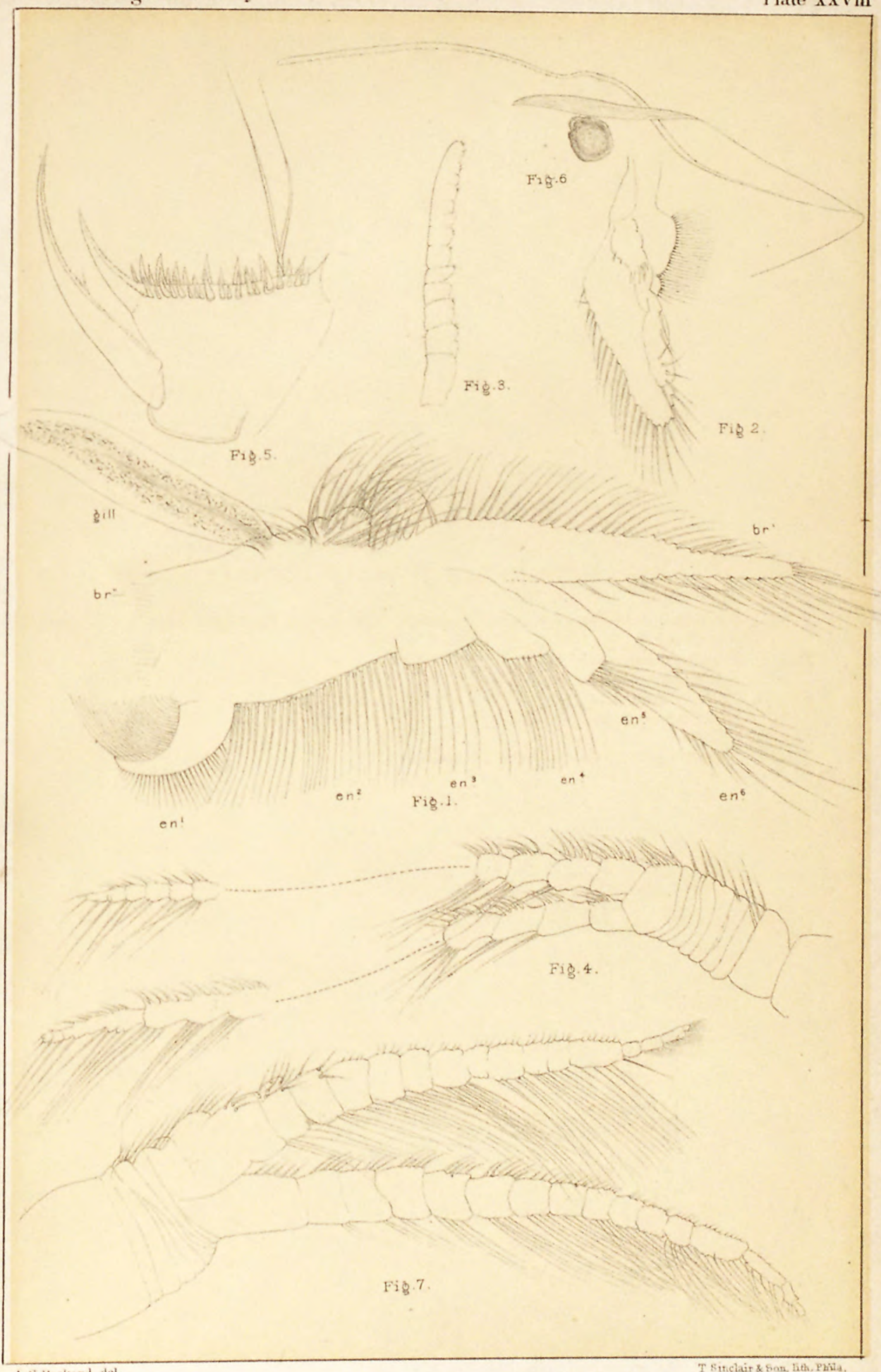

A.s lackard del 


EXPLANATION OF PLATE XXIX.

Fic. 1. Estheria mexicana Clans, from Kansas (E. caldwelli); first antenua ; ol, olfactory lobes; at, $n$, antennal nerve.

Fig. 1a. Terminal joints of the same, filled with olfactory cells; no papillæ present.

FIG. 1b. Olfactory lobes from near the middle of the antenna.

FIG. 2. Estheria mexicana (caldwelli); three terminal joints of the second antennw, showing the nerve-endings and the sense-cells at the base of the setre.

FIG. 3. Estheria compleximanus, edge of sixth endite (of Pl. V, fig. 7), showing the ends of the tactile nerves leading to base of tactile setæ and connecting with the marginal nerve; with the two series of independent nerve or ganglion cells, $\times 225$ diameters.

FIG. 4. Estheria compleximanus Pack.; end of the dorsal lobe or oviger of one of the anterior legs (figured on P1. V, fig. 7), showing the tactile nerve (tn) with its ganglionic enlargement near and at the end of the lobe: with the ganglion cells at the base of the setæ.

Frg. 5. Estheria compleximanus, end of 5th endite of 1st leg (Pl. V, fig. 5), showing the very large crowded ganglionic tactile cells $(g c)$.

Fig. 6. Branchipus vernalis Verrill. End of 1st antenna, with the three tactile setro at the tip; $n$, antennal nerve; $g c$, ganglion cells, $\times \frac{1}{6} \mathrm{~A}$.

Fig. 7. Thamnocephalus platyurus Pack. The 3d or 4th endite of the 1 st foot, with $n$ the nerve to the endite, the large ganglion cells arranged in quite regular series, and $t n$ the origin of a tactile nerve passing into the seta (s); each seta is about to moult, as the new setæ with the fine setulæ are present.

FIg. 8. Thamnocephalus platyurus Pack. Portion of the edge of 1st or innermost endite of 1st pair of feet; $n$, nerve-fibres; $g c$, ganglion cells; $t n$, tactile nerves pass. ing into the long, slender setre ( 8$)$, near $t n$, the marginal row of fine sete.

Frg. 8a. Thamnocepholus platyurus Pack. Cuticle of flabellum with nuclei $(u)$ and fine tubercles.

Fig. 8 b. Thamnocephalus platyurus Pack. Cells at base of 5 th endite containing fat granules.

NIG. 9. Limnetis gouldii. One eye with the cornea removed, the same specimen as represented on Pl. II, fig. 5. Op. $n$, optic nerve; the upper op. n. should be op. $g$, optic ganglion. From the peripheral nucleolated cells the nerves with the rods (if the latter are present) converge towards the optic ganglion; $t r . n$, transverse nerves arising from peripheral cells and connecting the two eyes.

All the figures drawn with the camera lucida by the author. 


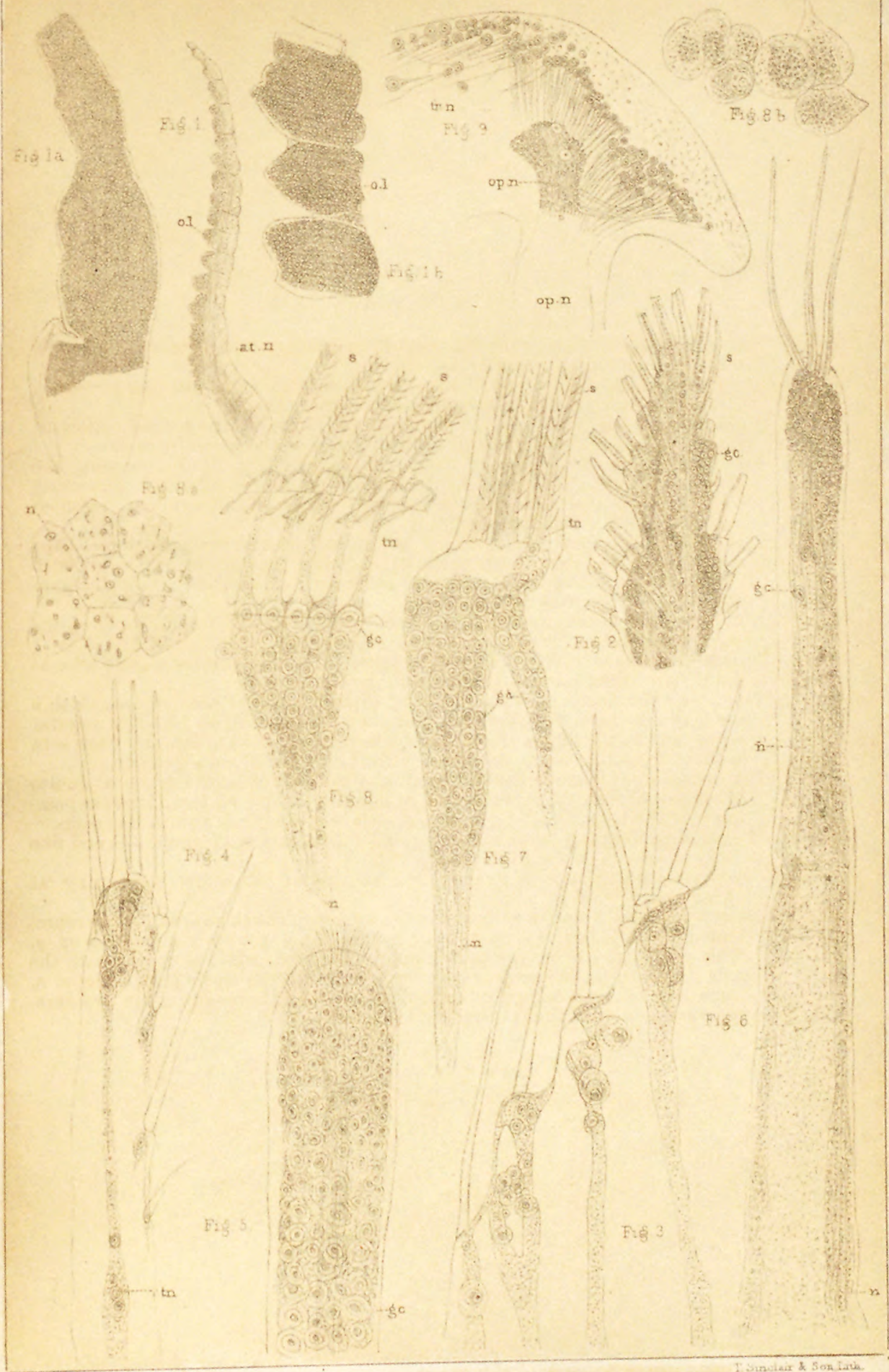




Fig. 1. Branchipus rernalis Verrill. Sixth endite of an anterior leg, showing the muscles and tactile nerves, which arise independently of the central nervous system near the margin of the lobe; $n c^{1}$, inner series; $n c^{2}$, marginal series of ganglion cells; on the left side the origin of the setal nerves are seen.

Fig. 2. Streptocephalus texanus Pack. The 6th endite of an anterior foot.

FIG. 3. Streptocephalus texanus Pack. A portion of fig. $2 \times \frac{1}{5} \mathrm{~A}$, showing the mode of termination of the muscle in the middle of the lobe; the origin of the setal nerves from the inner series of ganglion cells $(n o) ; 8$, seta. 


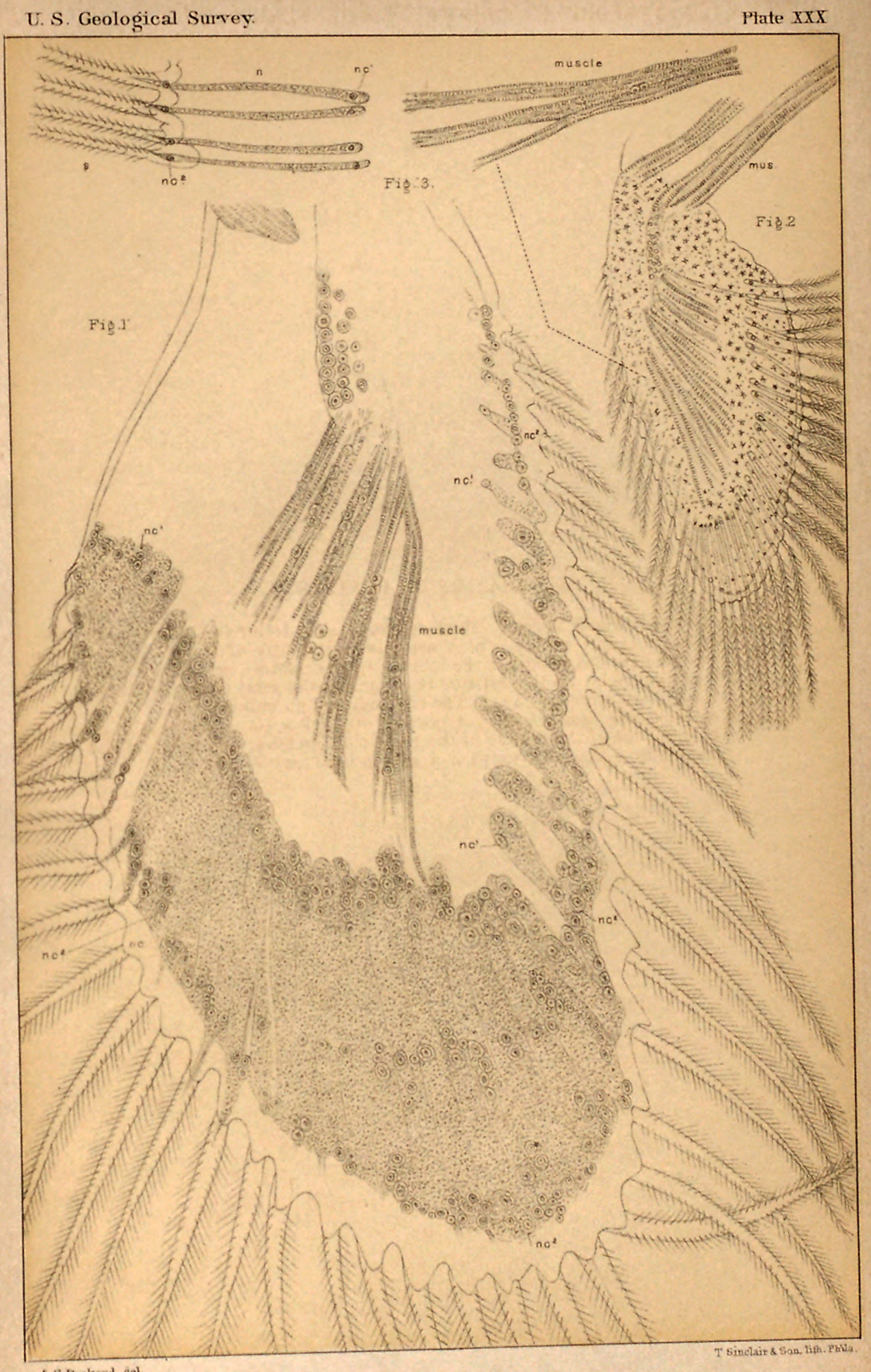






\section{EXPLANATION OF PLATE XXXI.}

Fig. 1. Apus lucasanus Pack. Seen from beneath. Enlarged $3 \frac{1}{2}$ times. md, mandibles. Fig. 2. Apus lucasanus Pack. First antennæ.

Fig. 2a. Apus lucasanus Pack. End of the same magnified. The antennæ of both pairs drawn to the same scale.

FIg. 3. Apus lucasanus Pack. Maxilla, showing the $(a)$ anterior and $(b)$ posterior divisions of the free edge; max, the gill of the maxillipede.

FIG. 3a. Apus lucasanus Paok. Maxillipede, represented by the gill only.

Frg. 4. Apus lucasanus Pack. First leg giving (with some changes) Lankester's nomenclature of the parts; $a x^{1}-a x^{4}$, the pseudojoints; $e n^{1}-e n^{6}$, the six endites, with the gill and flabellum.

FIG. 5. Apus lucasanus. The oostegite, or part of the 11th pair of legs of the female containing the eggs; 08 , aperture of the sack; $f$, modified flabellum; $x$, the greatly enlarged subapical lobe (compare Plate XVIII, figs. $2,3,4 x$, and Plate XXXII, fig. $2 x)$; $b r$; the gill.

Fig. 6. Limnetis brachyura (Europe). Ant 1 1st antennæ; ant 2 2d antennæ; lab, labrnm; sh. g, shell gland; int, intestine; $h t$, heart; add. $m s$, adductor muscle; oc, ocellus; md, mandible; liv, liver.

FIG. 7. Limnetis brachyura. Section through the body and shell $(8 h) ; h t$, heart; int, intestine; ov, evary; $1-6$, the six endites.

FIG. 8. Limnetis brachyura. Brain (br) and nervous cord; $n$. ant $t^{1}$, origin of 1 st antennal nerve; $n . a n t^{2}, 2 \mathrm{~d}$ antennal nerve; $m d . g$, mandibular ganglion; $m x . g$, maxillary ganglion; $G^{1}, G^{2}$, succeeding thoracic ganglia. Other letters as in Fig, 7 .

Fig. 9. Distomum apodis Pack. Amer. Naturalist, vol. xvi, p. 142, Feb., 1882. Side view, greatly enlarged. A parasite in oostegite of Apus lucasanus.

Fig. 9 bis. The same; ventral view.

Fig. 1 drawn from nature by J. S. Kingsles: Figs. 6-8 copied from Grube; the others drawn witl the camera by the anthor. 


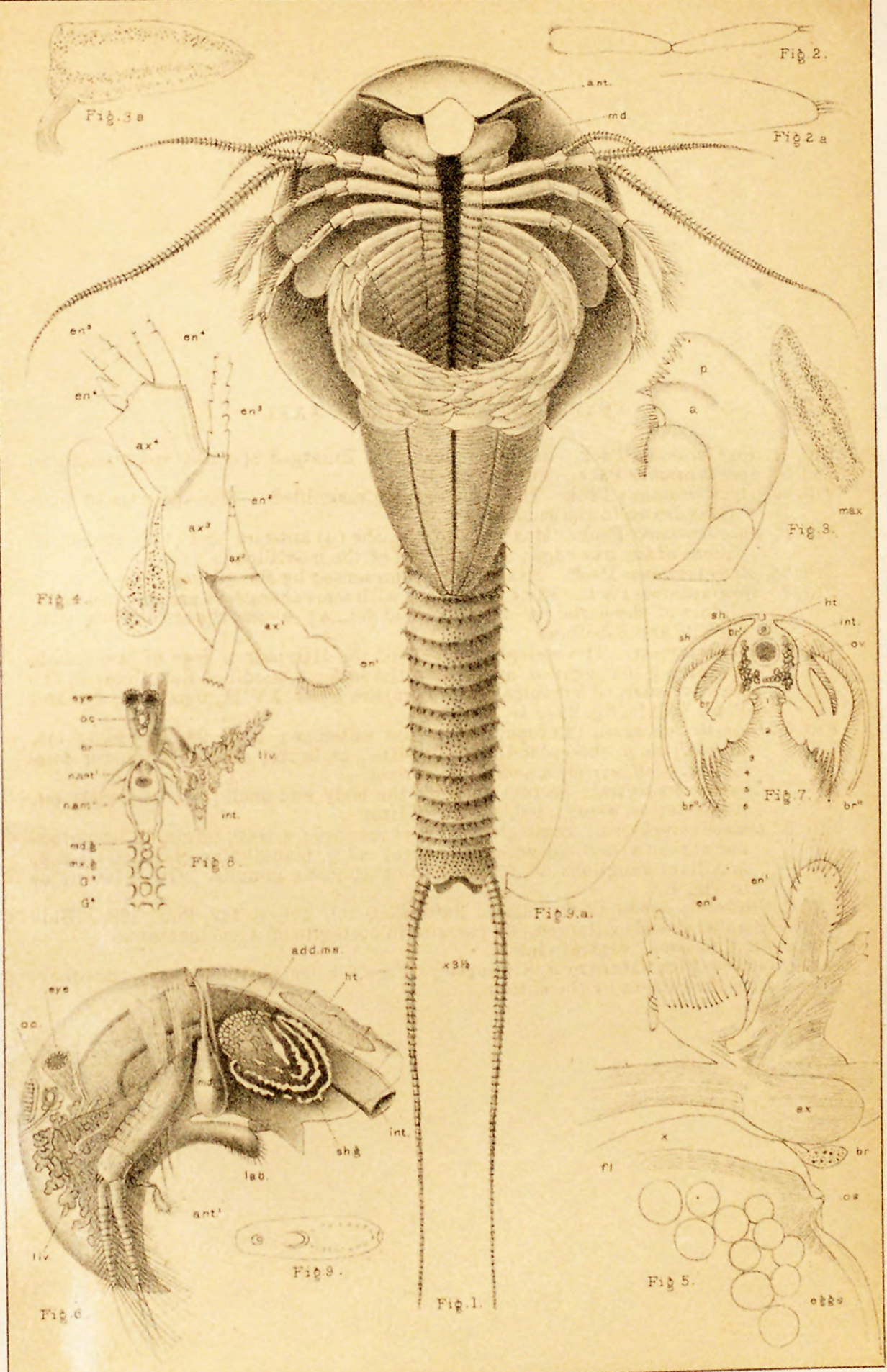






\section{EXPLANATION OF PLATE XXXII.}

Fig. 1. Apus lucasanus Pack. Section throngh the body, with the intestine removed $m d$, mandible; $a n t^{1}, a n t^{2}$, 1st and $2 d$ antennæ; $l e g^{1}$, first pair of legs; $b r$. flabellum; ov, ovary; $n g$, ganglionic chain.

FIG. 2. Transverse section through the body at the 7 th or 8 th pair of feet, the shell removed, mus, dorso-ventral adductors of the feet, crossed by the adductors of the exites; $h t$, heart; int, intestine; ov, ovary; $n . g$, ventral ganglion; $e n^{1}-e n^{6}$, endites; $b r$, gill; $f l$, flabellum; $x$, subapical lobe.

FIG. $2 a, 1$ st antenna; $2 b, 2 d$ antenna; $2 c$, the extremity of $2 d$ antenna, with 4 beadlike joints, showing the three imperfect joints, the third ending in a moniliform portion.

FIG. 3. Maxillipede with the gill $(b r)$ and single endite.

FIG. 4, $4 a$, dorsal and lateral view of the brain of the European Apus cancriformis; $b r$, brain; com, commissure to subœsophageal ganglion; $g$ op, optic ganglion; $o c$, ocellus; oes, end of œsophagus.

FrG. 5. Brain and part of ventral cord of Apus cancriformis; oc, nerve ocelli; ant $t^{1}$, $a^{2} t^{2}$, first and second antennal nerves; $\mathrm{G}^{1}$, œsophageal ; $\mathrm{G}^{2}$, mandibular gavglion, sending off three mandibular nerves $(n m d) ; d$, descending œsophageal nerve; $h$, unpaired or lower osophageal ganglion; oes, nerve passing to the muscles of the cesophagus.

Frg. 6. Heart of Apus cancriformis.

Fig. 7. Apus longicaudatus, portion of embryonic membrane lying next to the chorion, and supposed to represent the amnion in Limulus; the nuclei in many of the cells have become absorbed.

FIG. 8. An egg of the same, showing the cellular nature of the amnion.

Fig. $8 a$. A portion of the same amnion seen sideways of the egg.

Fig. 1 drawn under the anthor's direction by J. S. Kingsley; Figs. 4, 4a, 5, and 6, copied from Zaddach; the reminder drawn with the camera by the author. 


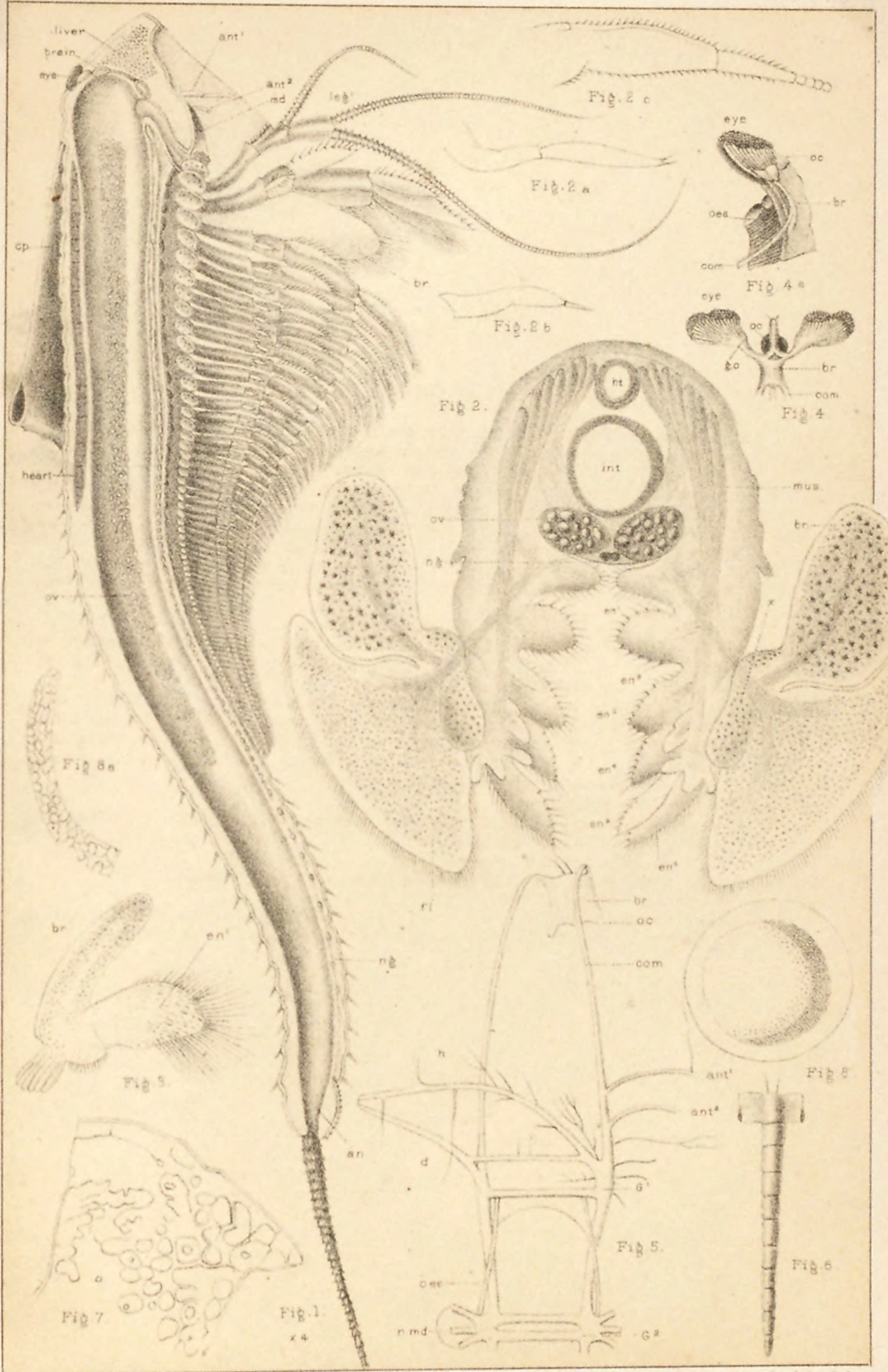

Kisestey Znddach Packard.. del. 


EXPLANATION OF PLATE XXXIII.

Fig. 1. Estheria mexicana Claus (Caldwelli, from Kansas). Section through the shell, hinge, and body ; oes, cesophagus; oc, larval eye or ocellus ; add, $m$, adductor muscle of the valves; $m d$, mandibles; $o v$, ovary; $g l$, liver

Fra. 2. The same, section through the stomach, showing the biliary ducts leading into the stomach from the convoluted liver lobules; $b r$, brain.

Fig. 2a. Section through a biliary tube.

Fig. 3. Eye of $E$. mexicana; $c$, cones; $r$, rods.

FIG. 4. Oblique section through head of $E$. mexicana; $c$, cones; ret, retina.

Fig. 4a. Section of the cesophagus in Fig. 4, enlarged. .

FrG. 5. Section through ganglia (gang) near but posterior to the maxillæ, and through the intestine (int).

Fig. 6. E. mexicana, ovary; ep, epithelium.

FIG. 7. E. mexicana, section through the shell and hypodermis; sh, shell; $l c$, large secreting cells; $f$, fibers.

FIG. 8. Branchipus vernalis Verr. Section through the brain and eye, $\times \frac{1}{2} \mathrm{~A} ; 8 a$, a portion from the middle of the brain, $\times \frac{1}{5} \mathrm{~A}$.

Fig. 9. Branchipus vernalis Verr. Section through the eye; $c$, cones; ret ${ }^{1}$, retina; ret ${ }^{2}$, second retinal streak; $r$, rods; $g$. opt, optic ganglion; $n . o p$, optic nerve.

Drawn by the author from sections made by Mr. N. N. Mason. 


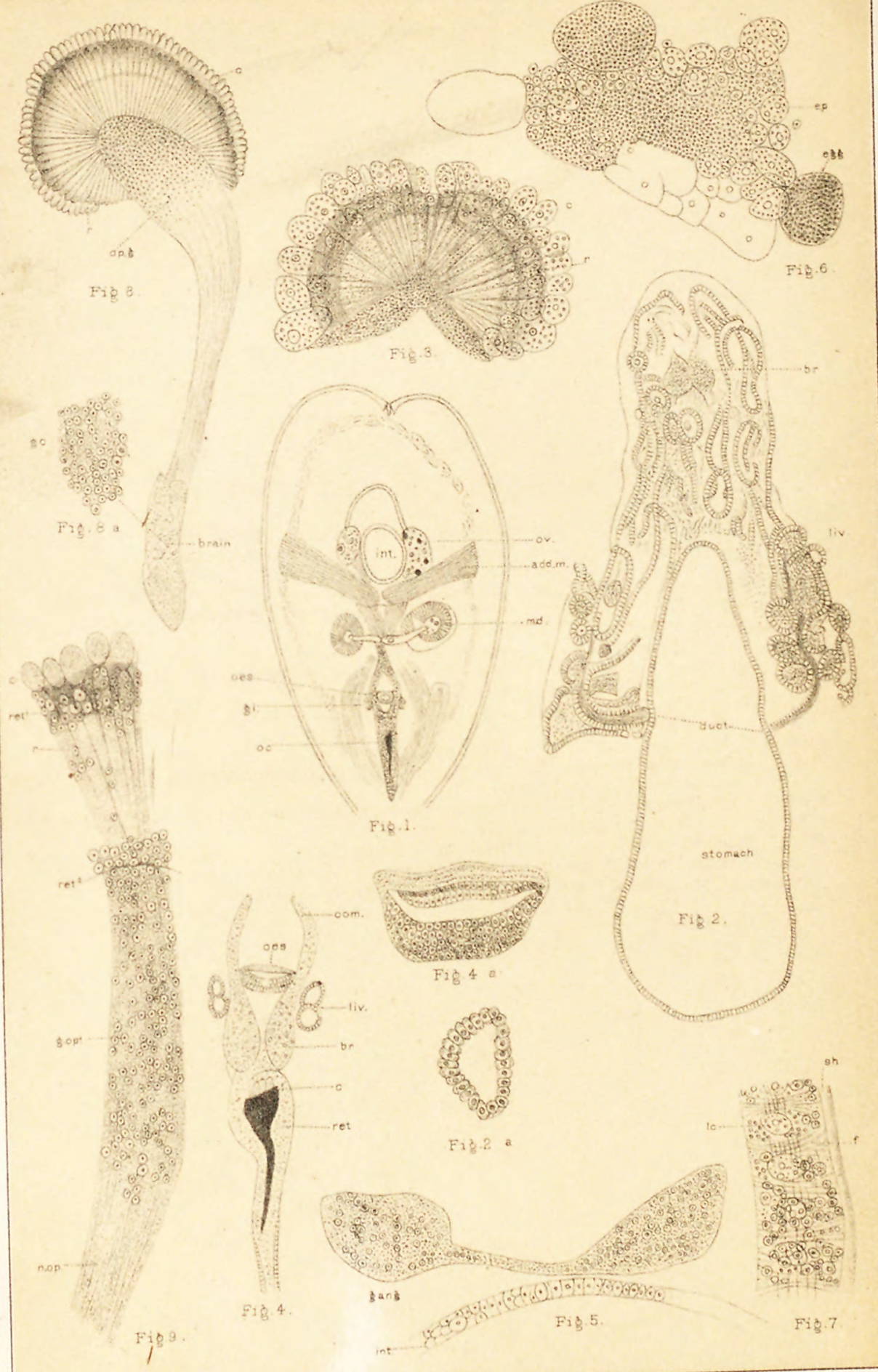

T. Sinctair \& Son Lrtì 




\section{EXPLANATION OF PLATE XXXIV.}

FIg. 1. Streptocephalus texanus Pack. Third developmental stage, dorsal view. Length $0.2^{\mathrm{mm}}, o c$, ocellus; $m d$, mandibles; $m d p$, mandibular palpus; $8 g$, shell gland; $m$, transverse muscle of the $2 d$ antennæ; $m^{1}$, levator muscle of the labrum; $m^{2}$, rectal muscles; int, intestines; $8^{1}$, forked spine on $2 d$ joint of $2 d$ antennæ.

Fig. 1a. Union of the two muscles $m^{1}$ in Fig. 1.

FIG. 2. 2d antennæ seen from below. Larva $4.2^{\mathrm{mm}}$ in length.

Fig. 3. 1st antennæ, $3 d$ larval stage; $n$, antennal nerve; mne, marginal nerve-cells; sp. $c$, bipolar spindle-shaped cells; s, setæ.

FIG. 4. 1st antennæ of larva when $3^{\mathrm{mm}}$ in length; lettering as in Fig. 3 ; gc, terminal ganglion cells.

Frg. 5. 2d antennæ of larva $4^{\mathrm{mm}}$ in length; $8^{\mathrm{l}}, 8^{2}$, spines of basal joints.

FrG. 6. Mouthparts of same larva as Fig. 5, and drawn to the same proportions; $m d$, mandible; $m p$, mandibular palpus; $m x^{1}$, 1st maxilla; $m^{1} p$, 1st maxillary palpus; $m x^{2}, 2 d$ maxilla.

FIG. 7 . The maxillæ (1st and $2 \mathrm{~d}$ ) of larva when $5 \mathrm{~mm}$ in length.

FIG. 8. Chirocephalus holmani Ryder (Glendale, L. I.), tip of 1st antennæ and olfactory seta.

Fig. 9. Mouth of larva of $S$. texanus when $5^{\mathrm{mm}}$ in length.

FIG. 10. Branchipus vernalis Verrill. Olfactory seta.

Fig. 11. Chirocephalus holmani Ryder. Dorsal bristle of 3d segment, a little way from the articulation; Fig. 11a, the same on the 2d (genital) segment.

Note.-All the figures in this plate were drawn by C. F. Gissler, Ph. D. 


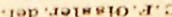

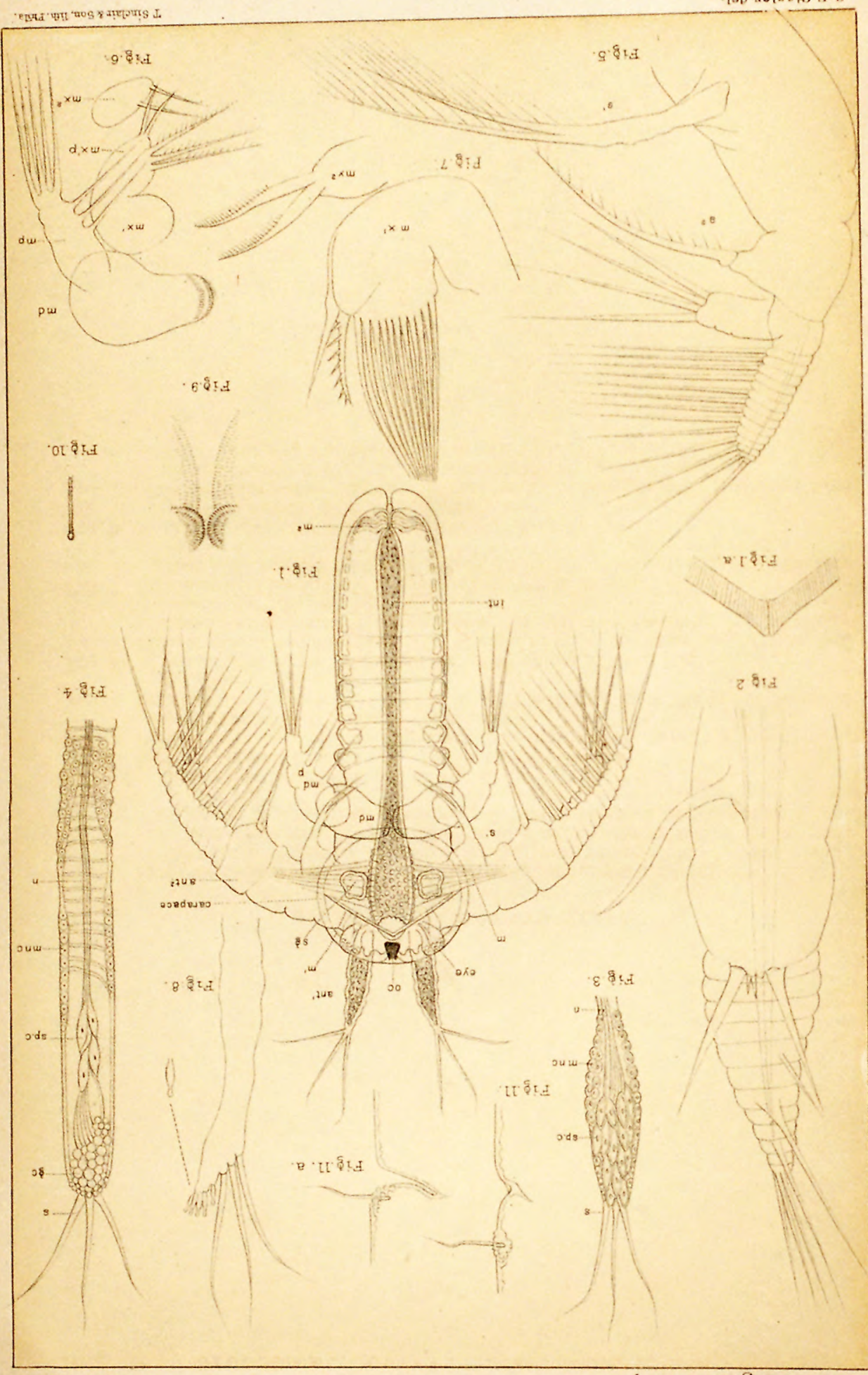






\section{EXPLANATION OF PLATE XXXV.}

Fig. 1. Apus lucasanus Pack, raised from mud from Kansas. Larva about $7^{\mathrm{mm}}$ long.

Fig. 2. 1st antenna of larva $5 \mathrm{~mm}$ long,

FIG. 3. 2d antenna of Eulimnadia texana Pack.

Fig. 4. Mandible (left) of Apus lucasanus Pack.

Fig. 4a. Mandibular palpus of Eulimnadia texana Pack.

Frg. $4 b$. The last smallest tooth on the cutting edge of the mandible, enlarged.

Fig. 5. Apus lucasarus; 1 st maxilla of larva $5^{\mathrm{mm}}$ in length, with the maxillary lobes and the spinose portion.

Fig. 6. 2d maxilla of Fig. 5, drawn to the same scale.

Fig. 7. Apus lucasanus; 1st leg of male larva when $5^{\mathrm{mm}}$ in length. en $n^{1}-n^{6}$, endites 1-6. $a x^{2}-a x^{4}$, pseudo-joints of the axis of the limb; $e n^{1}$, the gnathobase.

Frg. 8. Apus lucasanus; End of abdomen of larva $3-5^{\mathrm{mm}}$ long.

Frg. 9. Apus lucasanus; End of abdomen of larva $1^{\mathrm{mm}}$ in length. rec, rectum; $m$, sphincter muscles of anus; $c r$, chitinous rod.

Frg. 10. Apus lucasanus; Lower margin of shield of $85^{\mathrm{mm}}$ in length; lat, latersl line becoming gradually obliterated; $i p$, inner posterior line.

No ce.-All the figures on this plate were drawn by C. F. Gissler, Ph. D. 


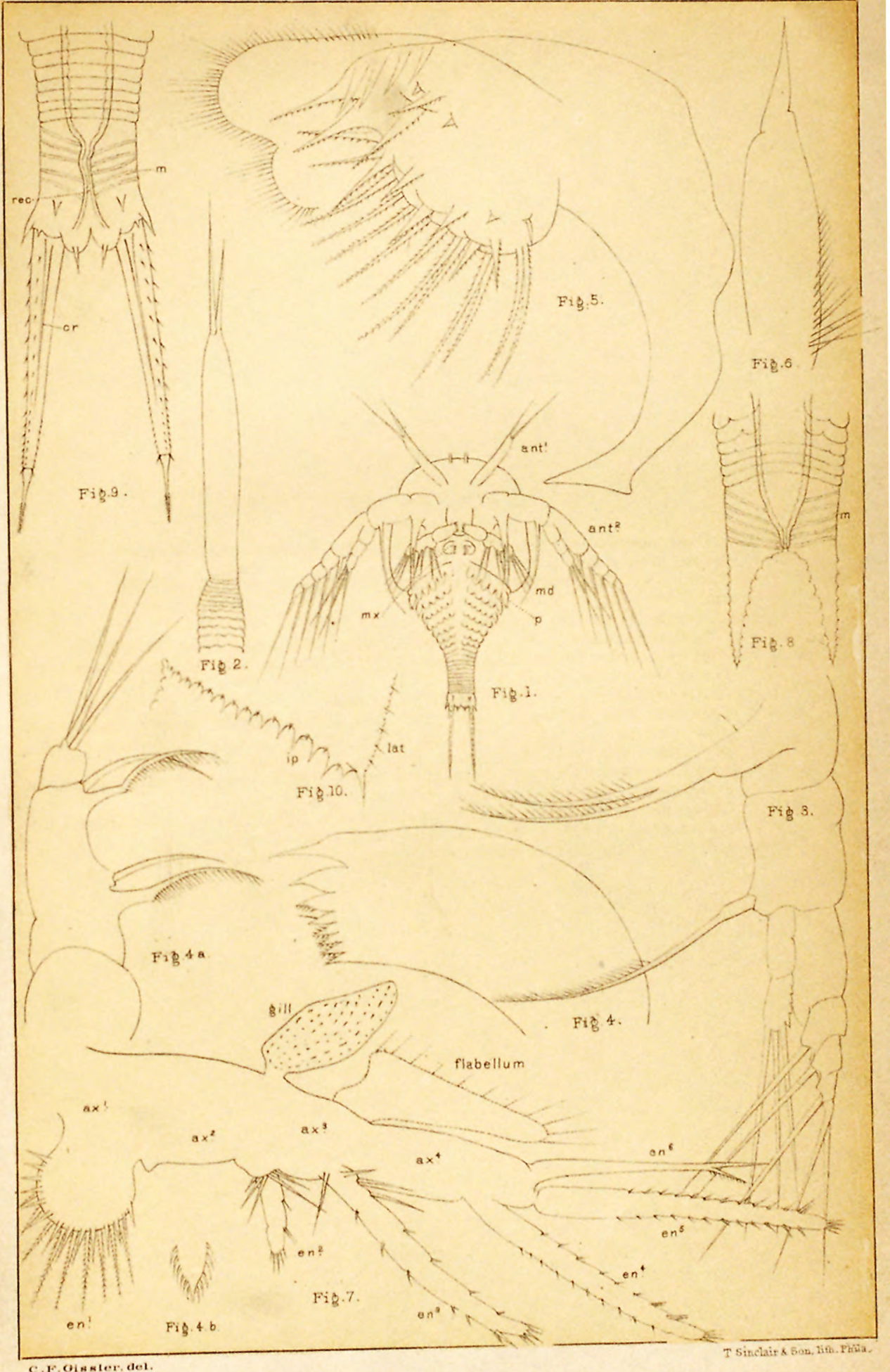






\section{EXPLANATION OF PLATE XXXVI.}

FIG. 1. Nebalia bipes Kroyer; female, much enlarged.

Fig. 2. Nebalia bipes Kroyer; female, head; ros, rostrum; car, carapace; ant $t^{2}$, 1st antenna, (1-5) five basal joints; ex, exopodite; ed, endopodite; ant ${ }^{2}, 2 d$ antenna, with 1-3, three basal joints; pes ${ }^{1}$, part of first pair of feet; md, mandible; $m x^{1}$, first maxilla; $m x^{2}$, second maxilla; st, stomach.

Fig. 3. The carapace flattened out to show relations of rostrum.

Frg. 4. Mandible, $m d$, cutting edge; $p$, palpus.

Fig. 5. The two maxillæ; 1-4, the four lobes of the coxopodite.

FIG. 5a. 1st maxilla; $c x^{1}, c x^{2}$, coxopodite; en, endopodite.

Frg. 6. (Omitted.)

FIG. 7. Cercopoda or caudal stylets.

FIG. 8. Portion of dentate edge of an abdominal segment.

Fig. 9. Section through a ventral ganglion. Author del. 


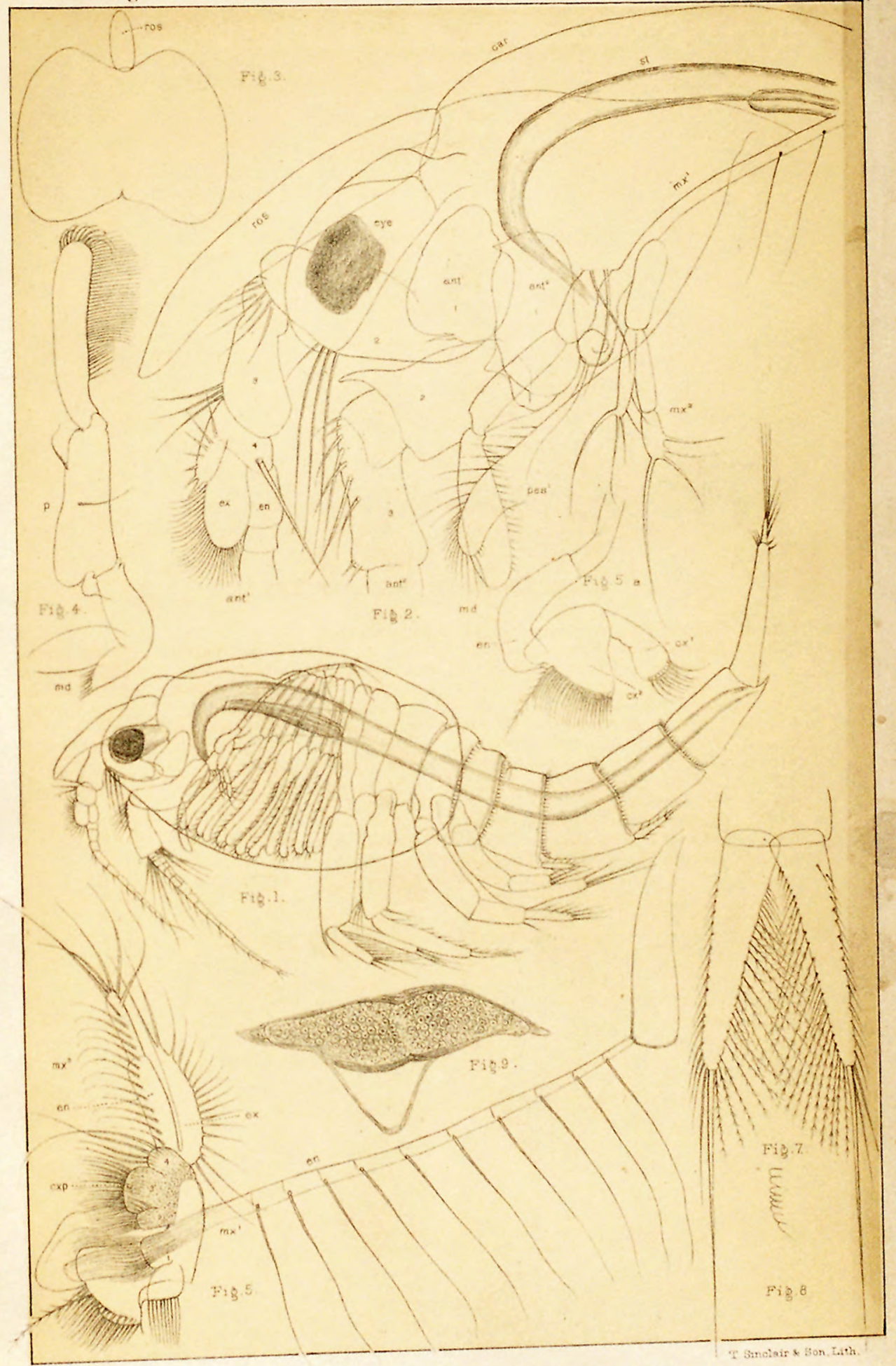




Fig. 1. Nebalia bipes Kr. $\$$; 1st antenna; lettering as in Pl. 36; k, lobe from 4th joint. Fig. 2. 2d antenna.

Fig. 3. One of the $3 d$ or 4 th pair of thoracic feet; $f l$, flabellum; ex, exopodite; $e n$, endopodite.

Fig. 4. One of $2 d$ pair of abdominal legs; ret, retinaculum; $e n$, endopodite; ex, exopodite.

FiG. 5. One of the fifth pair of abdominal feet.

Frg. 6. Section through the body just behind the first pair of thoracic feot, through the stomach (st), and the two anterior cœes (CoO); add. mus, adduotor muscle; $8 h$, shell.

Fig. 7. Section throngh one of the coer. 


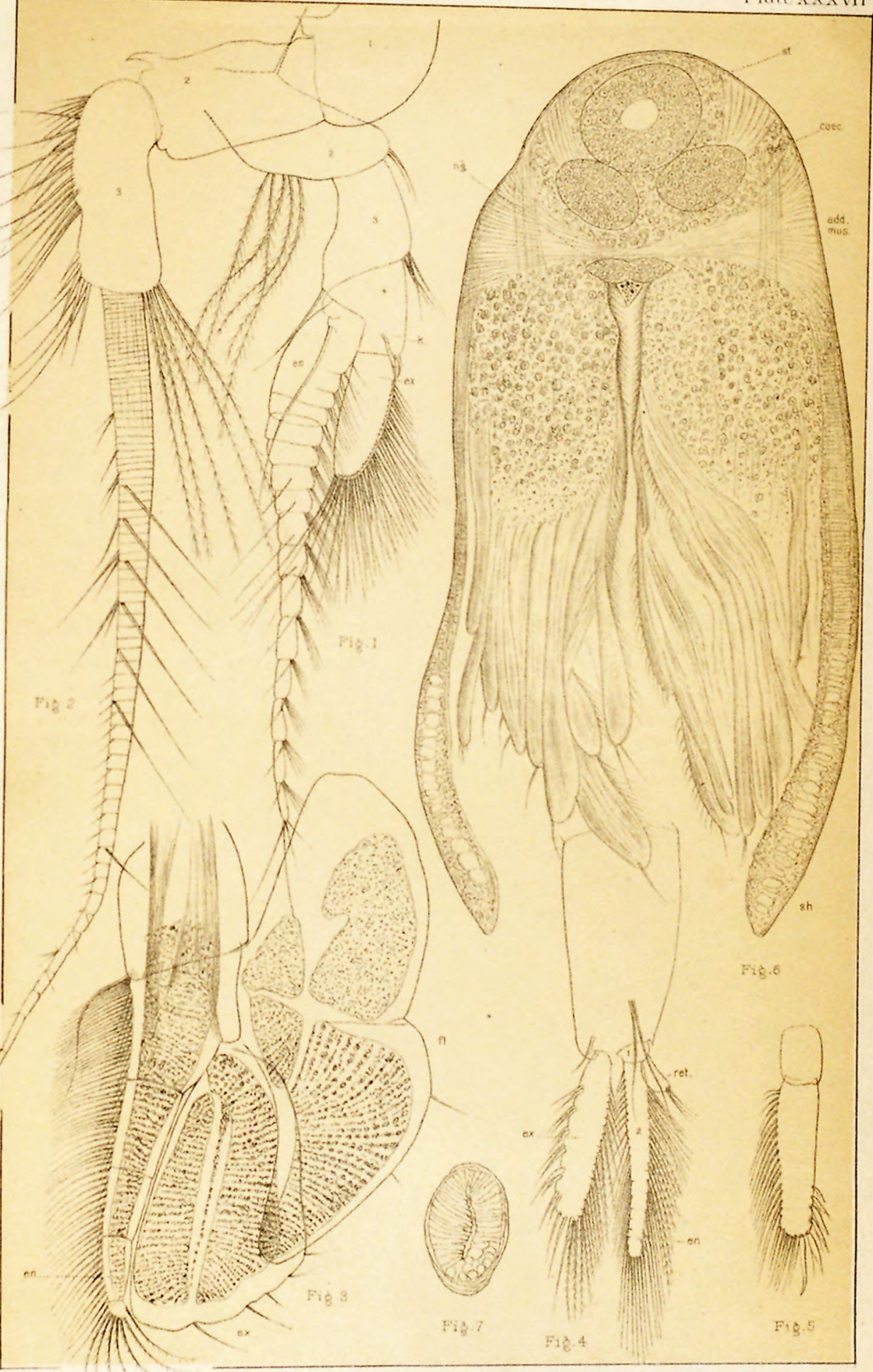






\section{EXPLANATION OF PLATE XXXVIII.}

$a^{1}$, first pair of antennæ.

Lettering .

$a^{2}$, second pair of antennæ.

$m d$, mandibles.

$m x^{1}$, first pair of maxillæ.

$m x^{2}$, second pair of maxillæ.

$p b^{\prime}$, first pair of thoracic feet.

$p b^{\prime \prime}$, second pair of thoracic feet.

th. $l$, thoracic feet.

$a b . f$, abdominal feet.

$\propto$, œsophagns.

$e p$, epithelium of stomach.

$p$. $d$, procephalic or antennal lobe.

$s t$, stomach.

Fig. 1. Embryo of Nebalia geoffroyi in the Nauplius stage.

FIG. 2. The same, farther advanced, with the rudiments of the cephalic and first two thoracic appendages and the hind gut.

FIG. 3. The same, still more advanced, the biramous thoracic feet developed.

FIG. 4. Embryo of the same nearly ready to hatch.

FIG. 5. Embryo at the time of hatching.

Figs. 1-5 copied from Metschnikoff.

FIG. 6. Embryo of Schizopod Pseudomma roseum. Copied from Sars. 


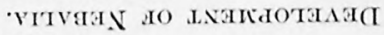

T PIA
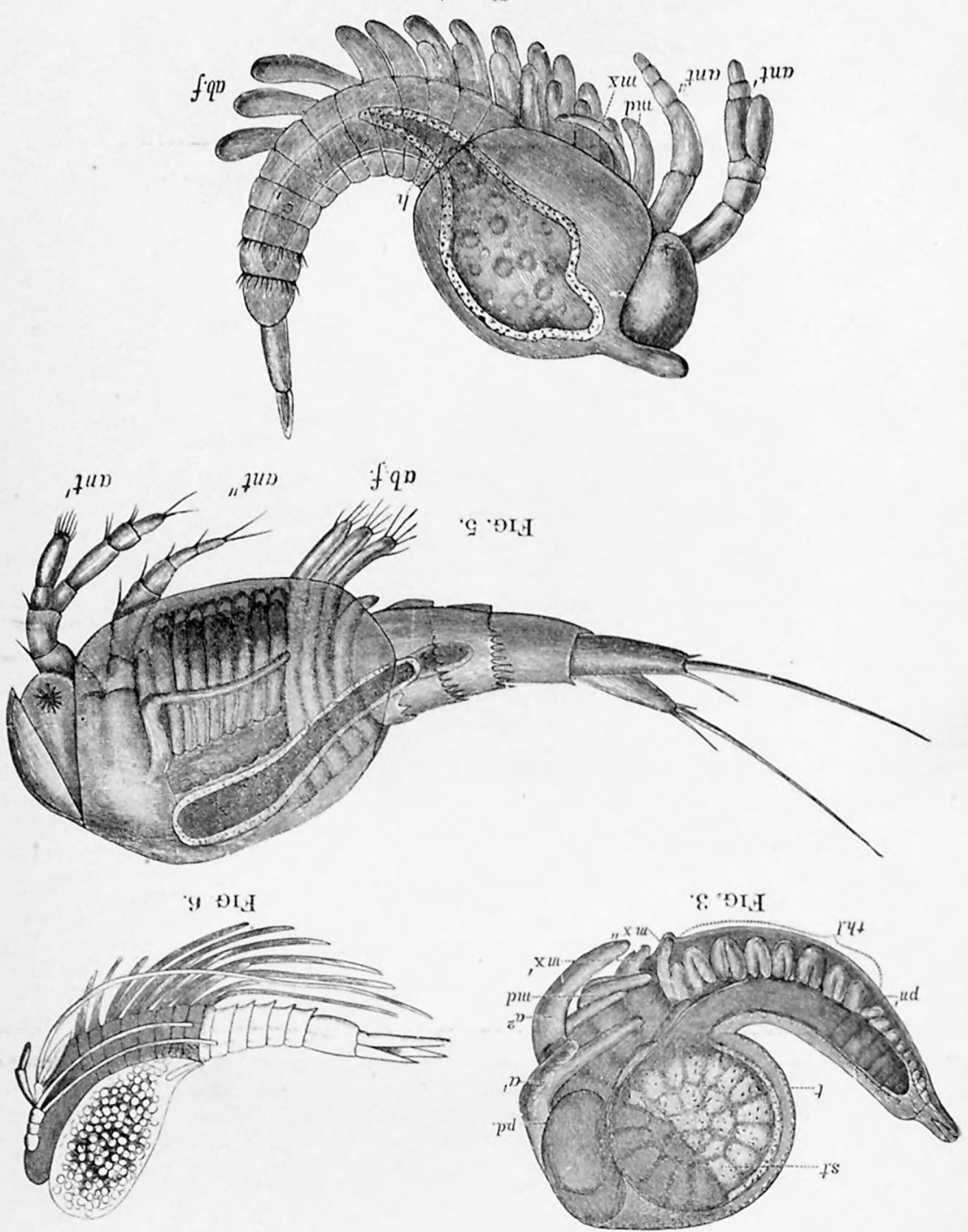

$\% \cdot \vartheta I_{H}$
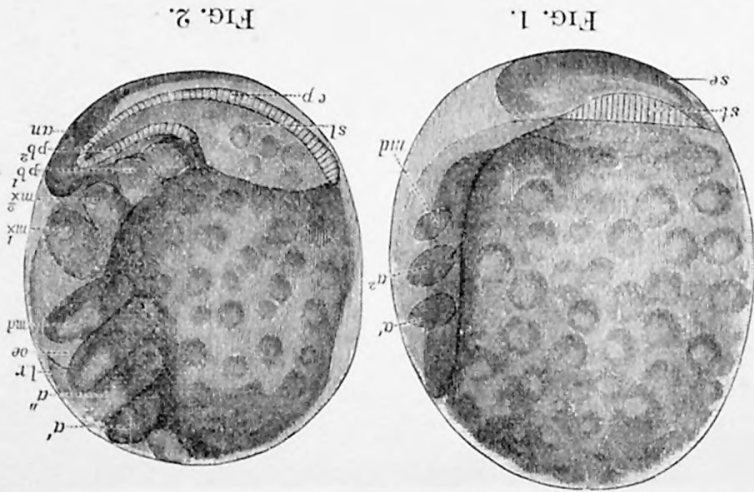

is. 




\section{EXPLANATION OF PLATE XXXIX.}

FiG. 1. End of postabdomen with the furca of Artemia salina taken from the Kujalniker salt lake in spring, 1871 , at $8^{\circ}$ Beaume, after an inundation.

Fig. 2. The same part of an Artemia salina taken in summer, 1872 , at $14^{\circ}$ Beaume, from the Kujalniker salt lake.

Figs. 3 and 4. The same parts of the already more changed Art. salina, taken from the same lake in summer, 1873 , at $18^{\circ}$ concentration.

Frg. 5. The same part of an Artemia forming a transition between Art. salina and Art. mithausenii. Taken from the same lake in the first half of Angust, 1874, at $23 \frac{1}{2}$ concentration.

Frg. 6. End of the postabdomen of an Artemia which I take for Art. milhausenii. Taken from the same lake in beginning of September, 1874 , at $25^{\circ}$ concentration, when salt began to deposit itself.

Fig. 7. One of the middle gills of Art. salina.

FrG. 8. One of the middle gills of Art. milhausenii.

FIG. 9. The lower part of the postabdomen of an Art. salina taken from the Hadschibei Lake at $10^{\circ}$ concentration.

$a$, end of the sixth segment; $b$, seventh segment; $c$, long eighth segment with the furcal lobes; $d$. bristles occurring at the end of each segment before the articulation (but two have been drawn of each ring); $e$, the same bristles nearly in the middle of the eighth segment.

Fig. 10. The lower part of the postabdomen of a young specimen of the third generation of Art. salina, which was domesticated in gradually diluted salt water for the purpose of yielding progressive growth.

$a$, end of the sixth segment; $b$, seventh segment; $c$, eighth segment; $d$, ninth segment; $e$, two of the bristles from the bristle-ring oceurring at the end of each segment before the articulation; $f$, spot where the long eighth segment divided into two segments, the eighth and ninth.

Fig. 11. A group of cuticular cells found near the base of the above-mentioned bristles of the postabdomen of Art. salina, whose lower part is illustrated by Fig. 9.

Fig. 12. A group of denticular spines found near the base of the bristles of the post abdomen of progressively changed individuals of Art. salina, whose lower part of the postabdomen is illustrated by Fig. 10.

Figs. 1 to 10 are 65 times, 11 and 12 are 330 times magnified. Copied from Schmankewitch. 



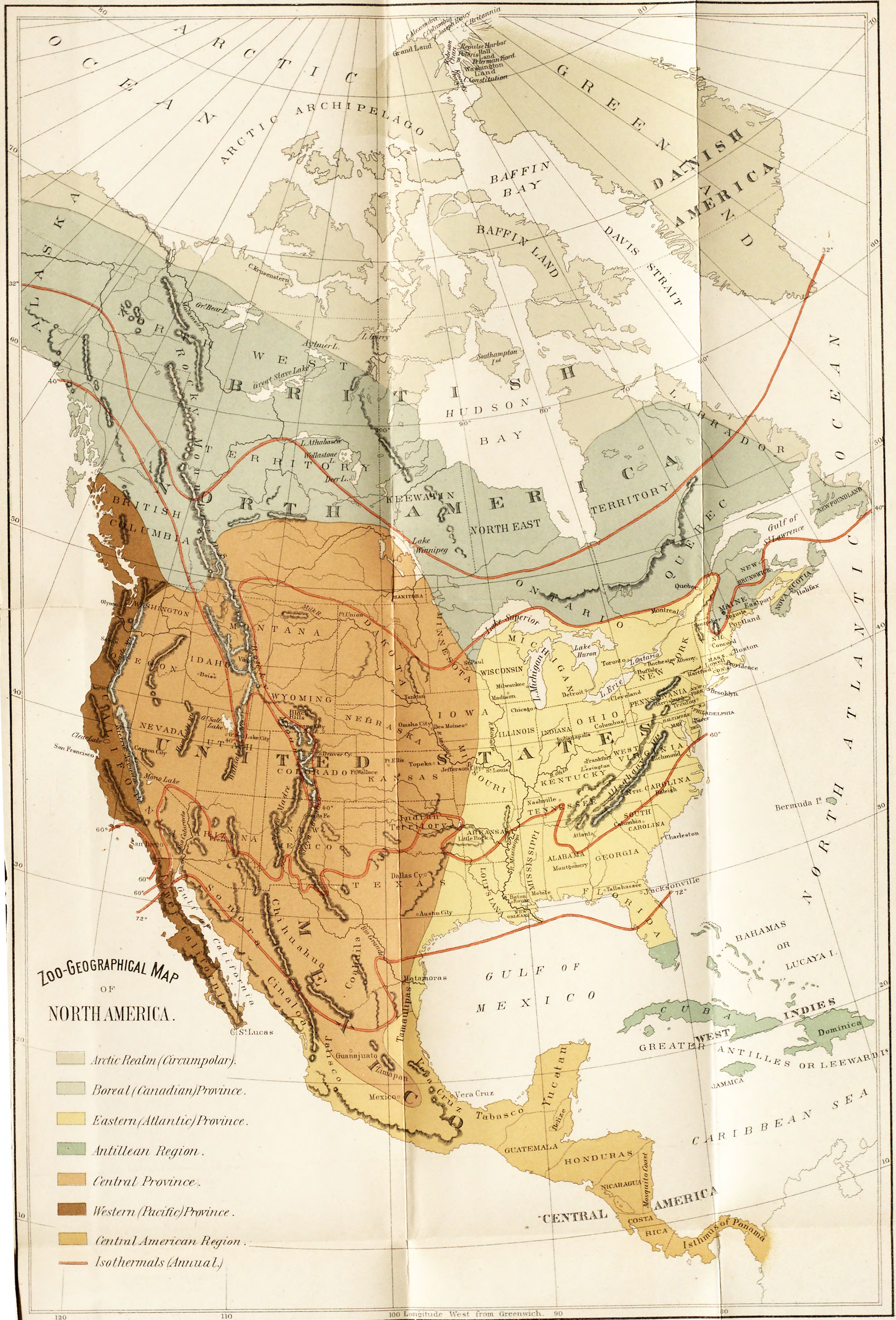





\title{
OSTEOLOGY OF SPEOTYTO CUNICULARIA HYPOGEA.
}

\author{
By R. W. Shufeldt, M. D., \\ Captain, Medical Depar/ment, Cniled Stales Army.
}

At the present writing we know of but one species of the so-called Burrowing $\mathrm{O}$ wls inhabiting America, and this is represented by three existing races, the typical and largest of these being the Athene cunicularia, a species confined to South America, while its two varleties occur within the limits of the United States. Little difference seems to exist between these latter, S. cunicularia foridana being of nearly the same size as the subject of this paper, but darker in plumage, with fewer feathers upon the tarsi, so that, with the ex. ception of certain measurements, the description of the skeleton of any one

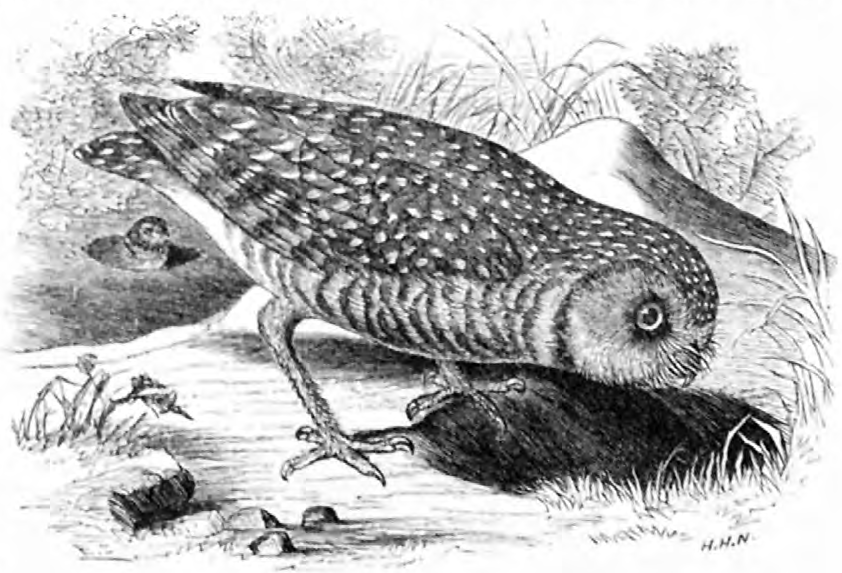

Speotyto cunicularia hypogara.

of them will answer pretty well for them all. To those unacquainted with the habits of these owls, both the English and technical names might be misleading, giving one to suppose that the birds actually burroxed; such, we believe, is never the case, they all having the like habit of resorting to the villages of many of the species of marmot squirrels, and occupying their deserted burrows for the purpose of nidification; sev. erál families of these owls often being found in the same village. $S$. cunicularia hypogcea occurs upon the open and treeless prairies 'est of the Mississippi River, where the writer has had abundant opportunity to study its very unique and interesting habits as well as to secure unlimited material for the purposes of dissection.

We are well aware, however, that other naturalists have believed, to a greater or less extent, that speotyto really, under certain circum. stances, burrows for itself, but owing to the fact that it has never actually been known to construct an entire burrow, or what I must believe any part of one, and in face of the apparent inadaptability of its small feet and not overpowerful beak to accomplish such a task, we can hardly 
accredit the statement. This idea has no doubt been brought about by the fact that sometimes a few families of prairie dogs (Cynomys), for instance, will start an independent village, which, from some cause or the other, they are afterwards led to desert; whereupon the owls are only too glad to avail themselves of the empty burrows, and the traveller is very likely to find one or two such peaceful colonies in the course of his rambles, as the writer has, where the owls are present, but all signs of the rodents obliterated, in some cases even the grass and flowers having grown again to the very entrances of the burrows.

Speotyto, unlike the majority of the members of the great family to which it belongs, is not strictly nocturnal in its habits, but on the contrary one may find them wide awake and active, in the villages where they are found, at almost any hour of the day ; indeed, as a rule they are quite wary, and one may often resort to all of the stratagems his experience has taught him before he succeeds in securing a specimen. In powers of flight they are weaker than most owls, a fact largely due no doubt to the lack of exereise of this privilege.

As we pass to the study of the skeleton of this interesting species, we shall, no doubt, find several instances wherein it has been modified and received certain impressions due to the mode of life and habits of the owner, that we have so briefly called the reader's attention to. We add here also a cut showing some of the external characters of this bird.

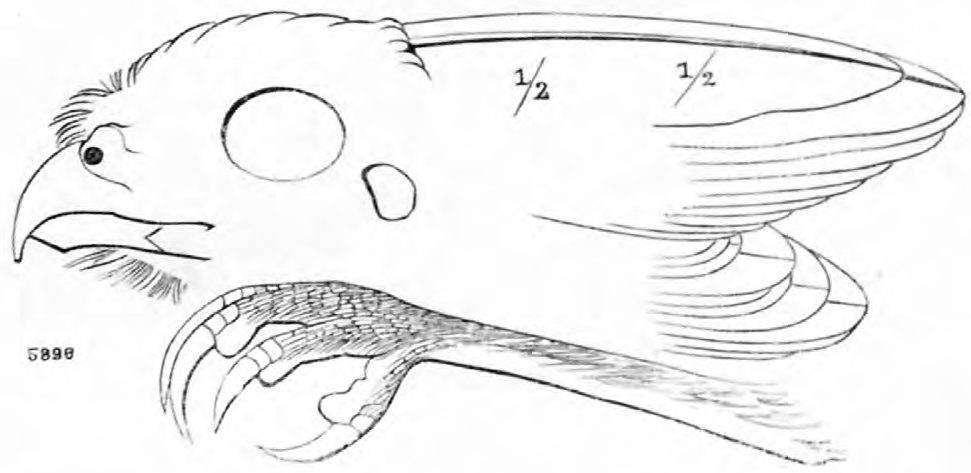

In enumerating and describing the separate bones of our subject, the smaller ones of the ear have not been taken into consideration, as they more properly come to be treated in the study of the organ of hearing; certain very small sesamoids may also, with propriety, be overlooked.

The skull.-As a general rule, it is only in the young of the Class Aves that the many bones of the skull can be separated from one another; the majority of the primitive segments of ossification of the four vertebræ ${ }^{1}$ that go to form this, the superior expansion of the vertebral col-

\footnotetext{
${ }^{1}$ My reader will no doubr remember that this monograph, accompanied by another of about equal size, upon the Osteology of Eremophila alpestris, appeared in the Bulletin of the United States Geological and Geographical Survey of the Territories, vol. vi, No. 1, Washington, February 11, 1881, being followed in the same year, September 19 , in No. 2 of the same volume, by my monographs upon the Osteology of the North American Tetraonida and Lanius ludovicianus excubitorides. In one and all of these paper I considered the cranium as composed of four vertebra, as many of the old school comparative anatomists had clone before me, and in adopting this theory I likewise adopted the nomenclature of the elements as given by Professor Owen, in his Anatomy and Physiology of Vertebrates. When I was first privileged to enter upon my anatomical studies, comparative and otherwise, this theory was the then prevailing one, and my nind became imbued with its fascinating precepts, its plansibility and appa-
} 
umn, being firmly anchylosed together, with their sutures completely obliterated when the bird has attained maturity. This is eminently the case in the adult skull of the species we have before us, so much so, in fact, that, with the exception of certain bones that remain permanently free during life, we will undertake to describe the skull only as it presents itself to us in the adult as a whole. In referring to certain points for examination, then, in this part of the skeleton, we will have to rely largely upon the reader's familiarity with general anatomy, and the extent and position of the bones as they occur in the variously shaped heads of immature birds. The major part of the occipital lies in the horizontal plane, only that portion which originally constituted the superoccipital segment and the posterior third of the exoccipital segments curving rather abruptly upwards to meet the mastoids and parietals. All its primary parts are thoroughly coalesced, and its articulations with the surrounding bones obliterated, save a fine ridge, running transversely, just anterior to the condyle, separated from it by a depression which seems to indicate the remains of the occipitobasi-sphenoidal suture. Posterior to the foramen magnum the bone rises and displays a well-marked "cerebellar prominence," with a depression on either side of it. On the summit of this prominence, in the median line, just before we arrive at the foramen magnum, we find the superoccipital foramen. This foramen varies in size and shape in different individuals-in size, from one to two millimetres; in shape, from a circle to a transverse ellipse, though it is usually small and circular. It is said to be formed by a thinning of the bone due to muscular pressure from without and the pressure of the cerebellum from within; in the fresh specimen it is covered by a thin membrane. Lring in the horizontal plane, anterior to the cerebellar prominence, is the foramen magnum. In shape it resembles a square with the four angies rounded off. Its average measurement is five millimetres transversely and four millimetres antero-posteriorly, the latter diameter being encroached upon by the occipital condyle in the median line. The occipital condyle is sessile, though raised above the level of the basis cranii, hemispheroidal in form, with a minute notch marking it posteriorly in the middle. Immediately beyond the condyle appears a depression, on either side of which are seen the precondyloid foramina for the transmission of the hypoglossal nerves; they are extremely small, and open anteriorly. External to these, lying in the same line transversely, is seen a group of usually three foramina for the passage of the glossopharyngeal and vagus

rent universal alaptability; in fact, its truth became one of the treasured results of my university education. Several years elapsed before I was again allowed to renew my favorite study, during which time the vicissitudes of my life allowed but little opportunity to follow the many advances in this important science, and when the day finally came, and the above monographs were written, and I drew the plates illustrating them, I was many hundreds of miles, and for several years, removed from all that one has access to in large cities and scientific circles. From this standpoint they must be judged, then, and for this reason did errors and theories creep into them that are " so dangerous to the credit of comparative anatomy." It is believed that the Osteology of the Cathartida will be largely exempt from sucb errors. The author deems it entirely unnecessary to enter upon the merits or demerits of any theory here, simply announcing in connection with what has already been said above, that he believes the vertebral theory of the cranium to be untenable in the light of modern science, and incompatible with modern thought. Aside from the theory involved, it is hoped that the purely anatomical facts will be found to be correct as given, and as any attempt to eradicate the theory from these memoirs would simply result in a rewriting of the whole, the author has allowed them to stand substantially as they first appeared, simply offering his reader the above explanation and making such changes as ho deems best through the medium of foot-notes; introducing into the body of the paper only such material and facts as he has been able to gather since, bringing the whole up to the standard of a revised edition. 
nerves and the internal jugular vein. The lateral terminations of the occipital, the paroccipital processes, are large, thin, pointed forwards, and on a lower level than the rest of the bone, forming a large part of the floor of the tympanic eavity. The semi-elliptical contour of the cranium, regarding it from a basal view, is well carried out laterally by the wing-light and attenuated mastoids. They contribute largely to the formation of the walls of the tympanic cavity internally, and externally assist in some degree towards com pleting the temporal fossæ. These fossæ are deep; commencing posteriorly on either side at the external borders of the depressions already mentioned that bound the cerebellar prominence laterally, they take a course upwards and outwards, terminating at a foramen that lies just within the posterior periphery or the orbit, which foramen allows the passage of the tendon of the temporal muscle. From the upper boundary of the temporal fossæ to where the frontals sudienly abut against and even overhang, to some extent, the nasals, the external and superior surface of the skull is of a pearly whiteness and very smooth in the dry skeleton, presenting not a trace of the sutures between the bones that go to form it, the frontals and parietals. This surface is divided by a well-marked furrow, that extends in the median line between the cerebellar prominence and the upper mandible. It is deepest in the parietal region. Close inspection of this area reveals minute ramifying grooves for the lodgment of vessels, one set running in the direction of the temporal fossæ and another toward the orbits. In the "bird of the year" the skull cap is very thin and brittle in the dry condition; but a very different state of affairs presents itself when we remove a section of the cranial vault from above, in the adult, where the skeleton is full. grown, such as we have before us. We find exposed to our view one of the common characteristies of the family ; the two tables are light, thin, but compact, with a goodly supply of diploic tissue between them, attaining a thickuess in some localities, notably above the exit of the olfactories, of two millimetres or more. Owing to the large orbital cavities, the brain-case is crowded to the rear to such an extent that the fossæ for the cerebral hemispheres are situated immediately over the cavities intended for the other encephalic lobes. We find the internal opening of the foramina, already described, at the base of the brain. The petrosals have the appearance of two white leaves, harder than the surrounding bone, slightly turned upon themselves, with their stems leading towards the fossa for the hypophysis. They present for examination the openings for the portio dura and portio mollis, the former foramen being ou a lower level and anterior to the latter. In the median line running from the cerebellar fossa to the exit of the first pair of nerves aloug the roof is a raised crest, grooved on its summit for the longitudinal sinus. It sinks for a little distance, in the fresh specimen, into the cerebral in terspace. The "sella turcica" is deep, its long axis being perpendicular to a plane passing through the foramen magnum. It has at its base the openings for the carotids. Immediately beyond its anterior superior border is seen the optic groove, with its foramen at either end, for the passage of the optic nerves and lodgment for the optic chiasma. Above the optic foramina, situated stiil more anteriorly, is a conical pocket, pointing forwards and a little upwards, with the olfactory foramina at its apex, two in number, giving passage for the nerves to the orbits. The basi-sphenoid is thoroughly united with all the bones it comes in contact with, except the pterygoids, palatines, and tympanics. Its anterior process-the basipresphenoid-losts itself in the interorbital septem, not a trace remaining of the original margins of the two bones. Its wings, the orbito- 
sphenoids and the ali-sphenoids share the same fate with tine bones that surround them. They form the larger part of the posterior wall of the orbital cavities. With the body of the bone the ali-sphenoids assist in closing in the tympanic cavities. We cannot positively state that this owl possesses a true boney vomer. The "pterapophysial" processes of the basi-sphenoid are present; they are short, thick, and elliptical on section, crowned by facets of the same figure at their distal extremities, which look downwards, forwards, and outwards, articulating with a similar facet at the middle third and posterior border of each pterrgoid. The bone also presents for examination the usual nervous and arterial foramina and grooves for the Eustachian tubes, the foramina being particnlarly worthy of notice on account of their marked individuality, all of them being distinct and nearly eircular. The tympanics are free bones, and carry out all the usual functions assigned to them. The mastoid condyle is long, affording by its extension an additional margin at the under side at the end of the bone for attachment of the ear-drum; the neck between it and the orbital process is somewhat constricted, and presents a large pneumatic foramen on the inner surface. The pointed orbital processes extend upwards, forwards, and in wards, slightly clubbed at their extremities; they project into the space half way between the pterygoid and wing-like post-frontal. The mandibular condyle is double; the inner one is a semi-ellipsoid, placed transversely; the outer an irreg. ular figure, and separated from the inner by a shallow pit. The oval, cup-shaped cavity for the reception of the tympanic extremity of the squamosal looks directly forward. Between the orbital process and inner mandibular condyle, on the free edge of the bone, is seen a small articnlar surface for the tympanic extremity of the pterygoid. The pterygoids diverge from each other towards the trmpanics by a very open obtuse angle. They are slender and scale-like, being compressed from above downwards, twisted on themselves at their tympanic extremities, causing the long axis of the articular facets for the articulation with these bones to be vertical. As already described, they have a mid-posterior facet, which meets the pterapophysial process of the basi-sphenoid. Anteriorly they do not touch each other, but articulate with the extremities of the palatines, and the combined four bones touch, and in the living bird glide over for a limited distance the lower border of the rostrum of the basi presphenoid. The anterior ends of the palatines articulate by an anchylosed schindylesial articulation between the lower surfaces of the maxillaries and the thin upper surface of a bony process extending backwards from the intermaxillary. From this point they slightly diverge from each other and become broader, being broadest about their middles; they then rather abruptly approach each other posteriorly, where they form the joint with the pterygoids already described. Their posterior ends are kept slightly apart by the lower border of the presphe. noid. They are flattened from above downwards throughout their entire extent. Their outer borders are sharp, and form from one end to the other a long convexity. As the inner and concave borders approach each other posteriorly they develop a raised rim on their under sides, thereby affording a greater surface for muscular attachment. Above, near their middles, they aid the maxillaries (and in large part developed from them) in supporting on either side an irregular spongy bone, that serves the double purpose of narrowing the apertures of the posterior nares and adding bony surface to the roof of the mouth by constriction of the palatine fissure. ${ }^{1}$ As is the rule in nearly all birds, the tym-

These are the maxillo-palatines of Huxley, and the reader is referred to that anthor's invaluable paper upon the Classification of Birds, etc. Proc. Zool. Soc. Lond, 1867, p 441, where these bones are shown in Otus vulgaris, fig. 26. 
panic end of the infraorbital bar is on a lower level than the maxillary extremity; it is received into the cup-like articulating cavity on that bone. The two oblique sutures, persistent in many birds, and denoting the original division of this bony style into three separate bones, the maxillary, malar, and squamosal, are here entirely effaced. As a whole, it is compressed from side to side, and of ample size in comparison with other bones of the head. At about the locality of the malo-zymotic suture the bone throws upwards a thin expansion that meets the descending postfrontal, thus completing the orbital cireumference at that point. Its anterior and fixed extremity is made up by the maxillary. Here it forms externally a portion of the posterior surface of the bill, while internally it assists in forming the roof of the mouth and floor of the nasal cavities, and otherwise behaves as already described. The lacrymals are extremely spongy in texture, covered by an outside delicate, compact bony casing. They articulate above by a ginglymoid joint with the posterior border of the nasals, resting below on the spongy bones de veloped from the superior surfaces of the maxillaries. They are limited to a slight movement inwards and outwards, and aid in separating the orbital cavities from the rhinal chamber. Externally they present for examination a shallow groove traversing the bone obliquely downwards and forwards and a.little inwards for the lacrymal duct. The orbital carities are very large, and remarkable for the completeness of their bony walls and the near approach their peripheries make to the circle, any diameter of which measures the merest trifle above or below two centimetres. The septum in the adult bird has rarely more than one small deficiency of bone in it. This usually occurs in about the position shown in Pl. i. The sutures among the various bones have entirely disappeared, nothing being left to define the exact outline of the vomer especially. The groove for the passage of the olfactory nerves forward is well marked, the cranial foramina for them being distinct, one in each orbital cavity. This also applies to the openings for the optic nerves. The extent of the roof is increased on either side by a superorbital process (shown in Pl. II, Fig. 1) that points downwards, backwards, and outwards, and serves for membranous attachment. The posterior walls are marked by ramifying grooves for vessels. They have a direct forward aspect, which is enhanced by the low descent of the broad and thin postfrontals. Anteriorly, the aperture between these and the rhinal vacuities is diminished by the lacrymals externally and by a wing-like plate thrown off from the prefrontal internally. This latter bone here terminates in a sharp concave border, with a descending ridge on either side just within it. The floors of the orbits are more complete than is usually seen in the class, due to the flatness and position held by the pterygoids and palatines, the wing-like process of the ethmoid just referred to, and the pterapophysial processes of the basi-sphenoid. The sclerotals number from fifteen to sixteen, all of them being about the same length, but varying as to their width; in figure they are trapezoidal and universally oblong, with the short parallel side in the circumference of the cornea and the opposite one resting in the periphery of the posterior hemisphere. We have never observed one that was wide enough to appear square. They are rather thin, concave outwards, very slightly movable at their opposed edges, and carry out their usual function of maintaining the form of the optical apparatus. The upper mandible of this bird is made the more conspicuous and distinct from the remainder of the skull by the abrupt way in which it is attached and the much firmer texture of the bone. The mandibular culmen is perfectly convex from the tip of the sharp-pointed extremity to where it suddenly terminates under the 
slightly overhanging frontals, or, more correctly, the minute surface appearance of the prefrontal, for although it is not evident in the adult that that bone makes itself visible at this point, yet it may be demonstrated in skulls of younger specimens. The culmen, as in other birds, is formed by the intermaxillary, which is here firmly united with the nasals, and the two in conjunction form the peripheries of the truly elliptical external nasal apertures or nostrils, the first bone bounding them anteriorly, while the latter completes their ares in the rear. These in the dry skull measure through their major axes seven millimetres, and through their minor ones barely five millimetres. They have a distinct ring raised around their circumference, which is wanting, however, where they nearest approach each other anteriorly at the culmen. The plane of the nostril faces upwards, outwards, and forwards; the nostrils are comletely separated from one another by a vertical bony septum, developed from the intermaxillary, not a common occurrence in birds. They have, in addition, a concave bony floor, that rises behind into a posterior wall leaving really two semicircular openings just beneath the culmen, separated from each other by the vertical septum. The osseous mandibular tomium, also a part of the intermaxillary, is as sharp as when the bill is sheathed in its horny integument. The arc is concave, and falls off rapidly as it approaches the tip of the beak. Occasionally, in very old birds, the ethmo-turbinal bones in the nasal passages may ossify. The nasals form here the sides of the bill, and are firmly anchylosed to the bones they meet, except the lacrymals. The movability of the frontomandibular articulation is limited. The dry skull is extremely light and brittle, giving one the sensation in handling it that he might experience while examining an egg from which the contents had been removed. A line drawn from the tip of the upper mandible to the ontermost point of one tympanic, around the are of the cranium to a similar point on the opposite side, and back to the point of departure, describes nearly the sector of a circle. The longest radius, which is in the median line, measures four and one-half centimetres, the cord between the tympanics about three centimetres.

The hyoid arch.-The hyoid arch is suspended from the base of the skull by its usual attachments. In this Owl it consists of but six very delicate little bones, involving five articulations. The tips of the upturned posterior extremities are about opposite the lower borders of the temporal fossæ, its two limbs diverging from each other at an angle equal to that made by the lower mandible. The cerato-hyals are rathir large in comparison with the other bones. They are joined both anteriorly and posteriorly by bony bridges, forming a fenestra between them, to be filled in by a thin membrane. The amount of divergence they make from each other is less than that made by the hypo-branchial elements of the thyro-hyals. Anteriorly, the bone connecting them supports a cartilaginous glosso-hyal, while the posterior connection presents for examination the usual smooth articulating surface that enters into the arthrodial joint it makes with the basi-hyal. The basi-hyal and urohyal are confluent, not a sign of the point of union remaining. The latter bone is continued a short distance posteriorly by a tip of cartilage. The anterior end of the basi-hyal is devoted to the articular surface for the bone connecting the cerato-hyals, forming the joint mentioned above. It is concave from above downwards, convex from side to side, the lower lip being the longer. It will be plainly seen that this combination grants to the tongue a morement in the rertical and horizontal planes. The anterior articulating heads of the hypo-branchial elements of the throhyals are opposite each other, each being received into the diminutive 
acetabulum intended for it at the side of the united basi- and uro hyals, and most probably at the junction of the two latter bones. These two elements are long bones having a cylindrical shaft, terminating at either end in an articulating head. They are the longest bones in the hyoid arch, and have gentle curvature upwards throughout their extent. Their inner heads form an arthrodial joint on either side with the outer heads of the cerato-branchial elements of the thyro-hyals. These, the last bones of the arch, are joined in the manner already shown above. Their inner ends are quite pointed, even as far as the bone goes, the extreme points being finished off with eartilage. They curve upwards from about their middle thirds, and, like the first elements of the thyro-hyals, they are long bones, but with curved cylindrical shafts, the outer end, however, being the only true articulating one.

The lower mandible-(Pls. I and II, Fig. 3).-That portion of the bone which originally was separate as the dentary element, and as far back as to include the interangular vacuity, is firm and compact, while the remainder has much the same character as the bones of the cranium, being cellular and light, having only a very thin outside layer of the harder tissue. All of the primary segments are firmly knitted together, the only sutural trace to mark the margins of any one of them being the posterior border of the dentary elements as they bound the fenestra before and slope away beneath it. The articular extremities are some little distance below the upper outline of the bone. Their superior surfaces are indented so as to accurately receive the condyles of the tympanics on either side, forming the joint that allows the opening and closing of the mandibles. Their under surfaces are smooth and rounded, having a fine ridge running across them transversely. Internally they are drawn ont gradually into subcylindrical processes that point upwards, in wards, and a little forwards, exhibiting superiorly on each, about the middle, an oval pneumatic foramen. The upper edge rises rather ab ruptly from the articular ends, presenting as it arrives near the general level a rudimentary coronoid for the insertion of the tendon of the tem. yoral. With the exception of a little elevation where the dentary ele ment meets the surangular, the superior outline is unbroken; it falls away rapidly as it approaches the symphysis, where, with the opposite border, it completes a little notch at the extremity. The tomium is not as sharp as in the upper bill, and the mandibles do not fit nicely to each other until covered with their horny sheaths. The inferior border is rounded throughout its extent, and on a level at its posterior com. mencement with the under surfaces of the articular ends and running nearly parallel with the superior. The curve described by the rami before they meet at the symphysis inferiorly approaches the parabolain outline. 'The sides of the jaw are nearly smooth internally and externally. The vacuity that occurs in so many birds at the junction of the middle and inner thirds is rather large, long, and spindle-shaped, and filled in, in the fresh state, by an attenuated membrane.

Professor Huxley, in his Classification of Birds (Proc. Zool. Soc. Lond., 1867, p. 46:, 5 Etomorpha), presents us with some of the most important cranial characters of the Strigida; and we find through the literature of the subject not a few authors who have touched upon the osteology of this interesting group of birds. The attention of ornithologists and others has been directed on several occasions to the asymmetry occurring in the skull of certain species of Owls, notably in Nyctale. In 1870, Dr. T. H. Streets, of the United States Navy, noticed this point and published his observations. (Proc. Acad. Nat. Sci. Phil, 1870, p. 28.) In the next year, Robert Collett, esq., of Norway, noted 
the same thing in N. tengmalmi. (P. Z. S., 1871, pp. 739-743.) Figures showing this condition are given by Mr. Collett in an interesting paper of his that he kindly sent me upon the Craniets og Oreaabningernes Bygning hos de nordeuropæiske Arcer af Familien Strigidæ. Mr. Ridgway has likewise figured the skull of Nyctale richardsoni in the North American Birds. In Ulula cinerea we have another variety of era. nial asymmetry; in the specimen before me the post-frontal wing is thrown farther outward on the right side; this is not the case in Strix nebulosa, a species that has a perfectly symmetrical skull. This characteristic occurs in other Owls. In Surnia funerea we find the osseous nasal septum well perforated at its upper and inner part, very much as it is in Circus. The Hawk Owl has likewise superorbital processes of the same form as those we have described abov: for Speotyto. The periphery of the orbit above in Surnia is slightly rounded, not nearly as much though as it is in Strix nebulosa, much less than in Asio. These borders are very sharp in Scops, while in Aluco they nearly merge into the orbit. This latter $O$ wl has a skull that is at once strikingly different from other forms of the family, being long and narrow, the orbits being separated by a great, thick, spongy septum, the wings of the ethmoid are likewise spongy cylindrical masses, and the lacrymals are very large, being composed of the same material. For a family where the skulls of the various forms vary so much, differ so much from each other, we note quite an exception in the crania of Nyctea and Bubo, owls that have skulls strikingly alike, except in point of size, and a few minor differences.

The spinal column; cervical portion.-There are fourteen cervical vertebra, each one having a more or less free movement with the one beyond and behind it, maintaining in all positions some variation of the usual sigmoid curve observable in the division of the vertebral column throughout the class. The arrangement, as well as the direction, of the planes of the zygapophysial articular surfaces allow considerable rotary movement and bending in the vertical plane, with combinations of the two. It is a common habit of this bird, among other of his anties, to duck his head smartly downwards and again upwards, several times in succession, upon being approached. The relative position of the cervi cals has been figured in Plate I from the dead bird, placed in the act of this particular manœuvre, in a specimen after careful dissection. The ealibre, as well as shape, of the neural canal in this portion of the spinal column varies at different points. It originates at the atlas as a transverse ellipse, with a major axis of four millimetres and a minor axis of a little less than three millimetres; this is about the maximum capacity throughout the entire canal. From the atlas to the sixth or seventi vertebra the ellipse gradually approaches the circle, with a marked diminution in size, its diameters being at the seventh about two millimetres in any direction. From this point to the twelfth, inclusive, it rises as it fell from the atlas, and in the same manner, when we again discover a transverse ellipse, perhaps a jot smaller than the one described in speaking of the atlas. In the thirteenth the canal is smaller than, though in all other respects resembles, the twelfth, but an abrupt change takes place in shape as we pass to the fourteenth or last cervical, where the form of the neural tube suddenly approximates the circularity of the dorsal vertebre. The vertebral canal begins, eireular, on either side at the third cervical vertebra, most of its length being immediately beneath the prezygapophyses of each segment. It is formed in the usual manner by the di-and par-apophysial processes uniting laterally with the pleurapophysial elements. Small at the cephalie 
extremity of the column, its calibre gradually increases in each vertebra as we proceed toward the thoracic extremity, until it attains its maximum capacity at the eleventh vertebra. In the twelfth the integrity of its walls is lost by a parting of the par-and pleur-apophysial elements, with a disappearance of the former, leaving it no floor, so that in this vertebra it ceases to be a closed canal. The most prominent object presenting itself for examination in the atlas, superiorly, is the deep reniform cavity for articulation with the occipital condyle of the basi-cranii. It makes up to the entire superior articulating surface of what would first appear to be the centrum of this vertebra, unless we should not consider such to be the ease until the odontoid process of the vertebra next below, the true centrum of the atlas, lends its assistance, in which event the surface of this artienlation is only complete when made so by the extremity of the process just alluded to. A membrane sometimes stretches across this interspace, separating the extremity of the odontoid from the condyle of the occiput; this is not invariably the case, however, as in many of the individuals we have examined a minute vacuity exists, allowing the process to come in immediate contact with the condyle at one point. Below and posteriorly there is another articulating surface, convex for the centrum of the axis and concave for its odontoid process, accurately meeting the opposed surface of this vertebra and forming the atlo-axoid articulation. A lip of bone, a portion of the hypapophysis of the vertebra we are now describing, projects downwards and shields this joint in front, overlapping, indeed, a good part of the axis. The neurapophyses of the atlas are slight in structure. The concave postzygapophyses articulate with the convex prezygapophyses of the axis. The bone is devoid of a neural spine. In the axis we find both an hypapophysis and neural spine developed, the former being produced from the ridge on the anterior aspect of the centrum of the bone. The odontoid process arises vertically from the posterior margin of the upper surface of the centrum. Its summit and anterior face are convex and articulating, while behind it is flat and continuous with the spinal canal. The facet for articulation with the centrum of the third vertebra looks downwards and inwards, is convex from side to side and concave in the opposite direction. The postzygapophyses are concave, look downwards and outwards, the conditions in the prezygapophyses being exactly the opposite; this is the rule throughout the cervical portion of the column. After we pass the atlas and axis, we find in the third cervical vertebra, here, as in most vertebrates, parts that are common to the series of this portion of the column, deviating but slightly from each other as we examine them in seriatim; but gradually as this deviation proceeds, some requisite condition is brought about when the climax is attained. The fact of the presence of a neural spine on the axis is conveyed, though in a less inarked degree, to the third or next vertebra below, where it occupies a position about in the middle of the bone. As we descend, this process becomes less and less prominent, being found set further back on each successive vertebra; it disappears about entirely at the tenth, after which it rapidly begins to make its appearance again, assuming its former position in the middle of the vertebra, being quite evident in the twelfth in the shape of a pointed spine, while in the fourteenth it bears the quadrate form, with extended crest, being the first step towards an assumption of that notorious feature found further on in the dorsals. In the third vertebra the space between the pre-and post-zygapophyses is almost entirely filled in, a minute foramen on either side alone remaining, by a lamina of bone extending from one process to the other, giving to this 
vertebra a much more solid appearance, which in reality it possesses above that attained by any of its fellows. This bony lamina is reduced in the fourth vertebra to a mere "interzygapophysial bar" connecting the processes, while in the next succeeding one or two vertebræ it occurs only on the prezygapophyses more as a tubercle, being directed backwards, then disappearing entirely, is to be found again only on a few of the last cervicals as an ill defined knob, still retaining its original positionThe diapophyses at first project nearly at right angles from their re. spective centra, then approach the median line by being directed more backward near the centre of the cervical division of the column, and on nearing the dorsals again gradually protrude more and more directly outward. The prezygapophyses of the ninth cervical support wellmarked anapophysial tubercles, which are feebly developed also on a vertebra or two both above and below the ninth. The joints between the bodies of the cervicals of this $\mathrm{Owl}$ are upon the same plan as those found throughout the class; the anterior facet being concave from side to side, convex from above downwards, the reverse being the case with the posterior facets, and when articulated fitting accurately into each other. The pleurapophysial elements, well marked in all the cervicals after passing the axis, become in the thirteenth rertebra a free cervical rib, about three millimetres in length, without neck or true head, being merely suspended on either side from the diapophysis of the vertebra, and freely movable on its exceedingly minute articulating facet.

Attached to the last cervical we find the second pair of free pleura pophyses, about two-thirds as long as the first pair of dorsals or true ribs of the thorax, terminating in pointed extremities and artieulating with the vertebra by both capitula and tubercula, the former on elliptical facets, placed vertically on either side of the centrum at the anterior margin of the neural canal, and the latter on rounded facets beneath the diapophyses. The tubercle on one of these ribs is nearly as long as the neck; at the junction on the posterior side is found a pneumatic foramen of considerable size. These ribs are more or less flattened above from before backwards, being convex anteriorly, concave posteriorly, becoming rounded below. From the third to the ninth vertebra, inclusive, appear beneath the vertical canal anteriorly well-developed styliform parapophysial processes, directed backwards and downwards. They are best marked on the segments of the middle of the neck. There is no instance in this bird of these processes being produced so far backwards as to touch the next vertebra below ; their tips, as a rule, about overhanging the middle of the centrum of the vertebra to which they belong. We have found in specimens of Bubo virginianus the parapophyses of the fourth vertebra overlapping and touching the fifth for a millimetre or more. The third and fourth cervicals have, beneath in the median line posteriorly, strongly developed hypapophyses, quadrate in form, a process that exhibits itself on the fifth vertebra, anteriorly, merely as a small tubercle. On the sixth this tubercle has disappeared, and has been supplanted by two others that are now found just within the periphery of the anterior facet of the centrum on the parapophysis of each side, beneath and inclined toward each other. These processes, now a double hy papophysis apparently developed from the parapophyses, continue to increase in size and inclination towards each other on the next three vertebræ, so that on the ninth, where they last appear, they nearly form a closed canal. The passage between them is intended for the carotids, to which they afford protection. The hypapophysis of the tenth, eleventh, and twelfth vertebræ is single, large, quadrate, and 
directed forwards and downwards. There are three on each of the last two vertebræ, each having an independent root, the two lateral ones directed down wards, forwards, and ontwards, with characteristies similar to the one in the median line. Several pneumatic and nutrient foramina perforate each cervical vertebræ at various points, except in the axis and atlas, where, after diligent search, aided by the lens, we have sig. nally failed to discover them.

Dorsal vertebre; vertebral and sternal ribs; sternum.-The dorsal vertebræ number five; the anterior one articulates with the last cervical and the last dorsal with the first sacral. Althongh the dorsals of this bind fit very snugly to each other, it requires no further maceration to separate them from one another than it does to remove the ribs from their attachments. This close interlocking, however, greatly diminishes the movement of this division of the spinal column, bestowing upon it a rigidity only exceeded by the anchylosed vertebræ of the sacrum; yet, it must be understood, they do enjoy, in this $\mathrm{Owl}$, a considerable degree of movement, especially laterally. The neural spines have here attained their maximum development, forming, when taken together, an elevated and compressed median erest, with a thickened summit, and having a firm hold upon the remainder of the vertebræ below. Taken separately, the last is the smallest, the fourth next, the first next, and the second and third the largest. Their anterior and posterior borders are concave, allowing, when articulated, spindle-shaped apertures to exist among them, while their summits are produced backwards and forwards, thick. ened, and wedged into each other. This wedging is performed in the following manner: The posterior extremity of the crest forming the sum. mit of the neural spine of the first dorsal divides and receives the anterior extremity of the crest of the second. This same arrangement $\mathrm{ex}$. ists between the second and third, and at the summit between the third and fourth, but the fourth immediately below the junction also divides for a little distance and receives the edge of the posterior rim of the third, just beneath the union of the crests. This latter method of join. ing is feebly attempted between the fourth and last. (See Pl. I.) The neural canal is neariy cylindrical in the dorsal region, its calibre being less at the sacral extremity, and rather compressed from side to side, as are the centra as we approach that end, each one being a little more so than its neighbor beyond. Viewing these five vertebræ from above in the articulated skeleton, we observe the spinous crest already described; we are struck with the regularity with which the postzygapophyses overlap and adjust themselves to the prezygapophyses from before backwards, like the scales in some fishes, the facets of the former facing downwards and outwards, the opposed surfaces of the latter facing upwards and inwards. The neurapophyses are horizontally compressed and rather broad; the diapophyses jut from them at right angles from points about their middles. There is an inclination for the latter to be directed slightly backwards as we near the sacrum. The diapophy sis of the first dorsal is the shortest and stoutest, that of the last the most delicately constructed. Superiorly, these processes support metapophysial ridges at their extreme outer borders. These ridges on the diapophyses of the first dorsal are the largest, rounded at both ends, extending a little both backwards and forwards, but far from touching the ridge either in front or behind them. The metapophysials of the last dorsal are smaller, sharp, styliform, and project only forwards, though they do not by any means touch the diapophyses in front of them. On the intermediate vertebra they change gradually between these two extremes, but in no instance meet the diapophyses of the vertebra be- 
fore or behind them, and thus constitute an additional aid to the rigid. ity of the bark, as it does in other species of this family and in many other birds. The centra increase in depth beneath the neural canal the nearer they are to the sacrum. In the first dorsal the body measures about one millimetre, the vertical diameter of the canal being three; in the last dorsal it equals the diameter of the canal. The interarticular facets are in the vertical plane, with their concavities and convexities opposed to each other, as they were described when speaking of the last cervical vertebræ. The bodies aré about of a length, constricted at their mid. dles and expanding towards their extremities. The first two dorsals each bear in the median line, beneath, an hypapophysial process of consider. able size, affording abundant surface for attachment of some of the muscles of the neck. The process of the first dorsal has one common trunk, with a compressed midprong and two lateral and pointed subprocesses. (See Pl. II, Fig. 5.) The second dorsal possesses a single long hypapophysis, quadrate in form, dipping into the chest further than the first. There is not a trace on the remaining dorsals of this appendix. Parapophysial processes, so prominent in nearly all the cervicals, afford in the dorsal vertebræ simply articulating facets for the capitula of the pleurapophyses situated just within the anterior margin of the neural canal of each centrum, never extending to the rertebræ beyond, forming the demi-facet of andranatomia. Immediately above these facets, on either side, may be noticed a group of pneumatic foramina of various sizes and shapes, and again, anterior to these foramina, the rim of the body of the vertebra for a limited distance becomes sharply concave, being opposite to a like coneavity in the next vertebra, the two, when opposed and articulated, forming the oval foramen for the exit of the dorsal nerves. Elliptical artic. ulating facets for the tubercula of the pleurapophyses, looking down wards and outwards, are seen on the inferior ends of the diapophyses with a midridge running from each facet to the base of the process, to be expanded and lost on the sides of the centra. As there are five dor. sal vertebræ, so are there five pleurapophyses articulating with them anct with the hæmapophyses below. Each rib is attached to a single vertebra, as shown while speaking of the dorsals. The necks of these ribs become more elongated the nearer they are to the pelvic extremity of the body, the first possessing the shortest. This is exactly reversed in regard to the pedicles bearing the tubereula, being the longest in the first pleurapóphysis and shortest in the last. This contraction of the pedicles is progressively compensated for by the lengthening of the corresponding and respective diapophyses of the rertebra to which they belong. Viewing the ribs from the front, in the skeleton, the curve they present resembles the quadrant of a shortened ellipse, the vertex of the major axis being situated at the base of the neural spines; viewed lat erally, the curve is sigmoidal, though a much elongated and shallow one, with the hæmapophysial extremity looking forwards and the facet of the tubercle backwards. The first rib is the shortest and generally, though not always, the broadest; the last being the longest and most slender, the intermediate ones regularly increasing in length and diminishing in breadth from the first to the last. In form, the ribs of this Owl are flattened from side to side, widest in the upper thirds, narrowest at their middles, and club-shaped at their lower extremities, where they articulate with the sternal ribs by shallow facets. On theinner surfaces we find the necks produced upon the bodies as ridges, running near their anterior margins and becoming lost at about the junction of the upper and middle thirds in the body of the rib. Pneumatic foramina, from two to three in number and of considerable size, are found just within 
the commissure between neck and tubercle, posteriorly. All the vertebral ribs bear a movably articulated epipleural appendage, each resting in a shallow cavity designed for it upon the posterior borders. They leave the rib at right angles, but soon turn upward with a varying abruptness. The appendage of the first rib is situated lowest of any on its rib, that of the last the highest; the facets of the others are found in the line joining those of the first and last. They all make acute augles with the bodies of the ribs to which each belong, above their points of insertion. The angle made by the last is the least, and it increases to the last. The epipleurals of the leading pleurapophyses are the widest and generally the longest (the one on the second rib in a skeleton of this bird now before me is as wide as the rib at the point from where it starts), the one on the last rib being always the smallest.

Clubbed at their superior extremities, each one overlaps the rib behind it, and in this manner add stability to the thoracic parietes, which is undoubtedly one of the functions these little scale-like bones were intended to fulfill. The hamapophyses connect the vertebral ribs with the sternum. There are six of them, one articulating with each vertebral rib and hav. ing a concave facet to receive it, while the last meets the sacral rib above and articulates with the posterior border of the fifth below. The first one is the shortest the most slender of all; the fifth is the long. est. With the exception of the last, their superior ends are enlarged and compressed from side to side, while below their middles they become smaller; then turning upon themselves, suddenly enlarge again, so as to be flattened from before backwards, when each terminates by a transverse articular facet for articulation with the hæmal spine. Quite an interspace exists between their points of contact with the sternum. They all make a gentle curve upwards just before meeting their respective ribs. The hæmapophysis that articulates with the sacral rib is inserted in a long, shallow groove on the posterior border of the sternal rib that articulates with the last dorsal pleurapophysis, but does not meet the sternum-simply terminating in a fine point on the posterior border of the sternal rib mentioned. From before backwards the sternal ribs make a gradually decreasing obtuse angle with the vertebral ribs, while the angle they make with the sternum is a gradually increasing acute from the fifth to the first. On the anterior surfaces of their expanded sternal ends are to be found on each a minute pneumatic foramen or two. The anterior third of the lateral borders of the sternum is the space allotted for the insertion of these bones.

The Burrowing Owl being a bird not possessed of any considerable power of flight, a circumstance arising from the life it was destined to lead, or the necessity of having that flight ever long sustained, we wouid naturaliy expect to find, in the course of a study of its anatomy, those characteristic modifications of the various systems which pertain to species of the class in which that gift has always been a secondary consideration. Nor are we disappointed in this expectation, for a single glance at the size of the sternum of this $\mathrm{Owl}$, when compared with the remainder of its skeleton with regard to areas for muscular attachments, reveals to us the disproportion of the surface supplied by that bone for the attachment of the pectorals. That its dimensions are relatively coutracted is proved by actual, comparative, and proportional measurements of the bones with other species of its family, individuals of which, at the best, are not noted for their powers of flight, and consequentiy the sternum does not present so prominent a feature of the skeleton as it does in other species of the Class Aves where vigorous flight is habitual. Life-size figures of this bone, viewed from the 
three principal positions for the purpose of study and measurement, are offered to the reader in Pl. I and Pl. II, Figs. 5 and 6. The concave dorsal aspect of the body is smooth, being traversed in the median line by a very shallow groove that lies immediately over the base of the keel. This groove terminates, within five millimetres of the anterior border, in a little depression, at the bottom of which are discovered pneumatic foramina, two or more in number, leading to the anterior thickened vertical ridge of the carina beneath. Other minute openings for the admission of air into the interior of this bone are seen among some shallow depressions just within the costal borders. The bone does not seem to be as well supplied in this respect as it is in some other Owls. The costal borders supporting the transverse articular facets for articulation with the hæmapophyses occupy about one-third of the entire lateral border on either side anteriorly. At the bases of the majority of the depressions that occur between these facets are found other pneumatic foramina. The anterior border is smooth and rounded, with a median shallow concavity occupying its middle third. At its extremities, laterally, the costal processes arise with a general forward tendency at first, but with their superior moieties directed backwards. The costal borders terminate at the posterior borders of the processes, at a higher level than the anterior sternal margin does at their anterior borders. The coracoid grooves are just below the anterior border. They are deep, continuous with each other, having a greater depth behind the manubrium in the median line than observed at any other point. Their general surface is smooth and polished, looking upwards and forwards, and lying principally in the horizontal plane. They melt away into the body of the bone laterally, at points opposite and not far distant from the posterior articulations on the costal borders. The margin that bounds them below is sharp, travels at right angles from the median line at first to a point posterior to the costal processes, then making a little dip downwards, then again curving upwards, disappears gradually with the groove it bounds. That portion of it from the point where it changes its direction to its termination is deseribed by authors as the subcostal ridge. The manubrium, ocenpying its usual position in the middle line, is comparatively small, quadrate in form, compressed below, slightly notched and flattened above, its posterior surface forming the inner anterior surface of the coracoidal groove. All the borders bounding the posterior parts of the bone are sharp; the lateral one, taken from the apices of the costal processes to their other and lower terminations, are concave. As is the arrangement generally among $\mathrm{O}$ wls, the xiphoidal extremity of the sternum is four-notched, two on either side, the outer notches being the deeper. Both have rounded bases, and the processes that separate them are ample and possess rounded extremities. The border upon which the keel ends posteriorly is square, though we have met with specimens in which it was slightly notched in the median line. The body is oblong, and, if we include the xiphoidal processes on either side, has a length half as long again as its width. The ventral and convex surface, like the dorsal, is smooth and presents but two points for examination. The pectoral ridge, faintly marked throughont its extent, originates on each side at a point near the outer borders of the coracoid grooves, running inwards and backwards, and dies away at the base of the keel near its middle. This little ridge denotes the line between the pectoralis major and minor. The keel is moderately well developed, the distance from the base of the manubrium to the carinal angle being equal to the distance from the same point at the base of the manubrium to the base of either costal process or outer 
anterior sternal angle. It is compressed, smooth, and thin, but its sta. bility is greatly aided by the carinal ridge on either side, which commences strong and well marked at the base of the manubrium, just within the anterior border running parallel with the latter, and disappears as it approaches the carinal angle. The anterior border of the keel is sharp and concave; the inferior border is convex, with the edge slightly thickened. The point of intersection of these two borders anteriorly is rounded and forms the carinal angle. The inferior border expands posteriorly, and the keel terminating a short distance before arriving at the posterior sterual border, the two become blended with the surface of the body of the bone.

Sacral vertebra; pelvis; and coccygeal vertebra.-In the sacrum of the Owl now under consideration, with the exception of a few faint lines indicating the original individuality of the vertebræ, these vones are thoroughly anchylosed together and to the ossa innominata. From in. spection of this compound bone in immature birds, we find the usual number of sacral vertebræ composing the sacrum to be thirteen. The anterior face of the first possesses all the necessary elements for articulation with the last dorsal. The neural spine has a thickened crest that soon meets the ilia on either side; its anterior edge is thin, and gives attachment below to the interspinous ligament. The nenral canal is circular, and the prezygapophyses well marked. The articular facet of the centrum is in the vertical plane, with its curvatures similar to those ascribed to the anterior facet on the centra of the dorsals. The neurapophyses are broad and the diapophyses are strong and raised, with their enlarged extremities expanded upon and firmly united with the iliac bones. There is but one pair of tree sacral pleurapophyses; these are long and slender, articulating with the first vertebra in the usual manner, but the relation is much more intimate, as they touch the diapophyses for some little distance beyond the tubercula towards the capitula. The lower extremities of these ribs are terminated by little roundish knobs, which articulate with the hæmapophysis on either side, described as being inserted in the posterior border of the fifth sternal rib. Viewing the bone dorsal-wise, it is to be seen that the thickened crest of the neural spine of the first vertebra protrudes from the angle made by the ilia meeting it anteriorly to a greater or less distance. This broad and compressed crest, then continued backwards, is firmly wedged between the ilia until we pass the third vertebra; at this point the ilia diverge from each other to another point just anterior to the acetabula, then converge, terminating in the posterior sacro-iliac border within five or six millimetres of each other. The sacrum completely fills in the lozenge-shaped space thus formed from the third vertebra-first, by continued broadening and compression of the neural spine, that soon becomes one with the neurapophyses; and, secondly, by the expanded extremities of the di-and par-apophyses, the processes themselves also taking due part. The integrity of the surface is unbroken, save posteriorly, where a few pairs of foramina exist among the expanded transverse processes, increasing in size from before backwards. Anterior to a line joining the acetabula this surface is in the horizontal plane; posterior to this line there is a decline, which declination is accepted also by the innominate bones; this gives the entire pelvis a shape that seems to be characteristic of the majority of both the diurnal and nocturnal Raptores. The "ilio-neural" canals, here present, open by small apertures posteriorly, at about the point where the ilia commence to diverge, passing obliquely downwards and forwards; their anterior openings are large enough to allow a view of their internal walls. The neural spine that divides them throughout is com- 
pressed from side to side; the ilia which form their outer boundaries are convex; the neuro-spinal crest forms the roof, the basal surface being deficient, formed merely by the spine-like di- and par-apophyses of the vertebræ and the confluent neural arches. This tirst vertebra occupies the lowest level, the bird supposed to be standing as in Pl. I. Now, a line drawn mesial on the centra below, from the first centrum to the last gradually rises until opposite the anterior borders of the ischiadic foramina, then curves rather abruptly downwards to its termination. The centra of the first two or three vertebræ are compressed from side to side to such an extent as to cause them to appear wedge-shaped, the common apex or edge being below; after that, however, they rapidly broaden, become compressed vertically and more cellular in structure; they are very broad from the fourth to the ninth, inclusive-then as rapidly become contracted as they approach the coccyx. Minute but numerous pneumatic foramina are seen at or near the usual localities. The largest foramina for the exit of the roots of any pair of sacral nerves is generally in the fifth vertebra; they decrease in size as they leave them either way. In the young, only the last few of these foramina are double; they are all double in the adult and placed one above another, a pair on the side of each centrum at their posterior borders, for the exit of the roots of the sacral nerves. The diapophyses of the anterior five sacral vertebre are thrown out against the internal surfaces of the ilia, to which they are firmly attached, and act as braces to hold the engaged bones together. The parapophyses of the first, form facets for articulation with the sacral ribs; the second and third have none; in the fourth and fifth they also act as braces in the manner above described, joining the ilia just before their divergence commences. Reliance seems to have been placed entirely in the completeness of the sacro-iliac union in the last vertebræ, for the apophysial struts terminate in that portion of the pelvic vault formed by the sacrum itself, except in the last two vertebræ, where the parapophyses abut against the iliae borders. The parapophyses of that vertebra which is opposite the acetabula are prominent, they being long and ample, reaching to the border and re-enforcing that part of the pelvis that requires it the most, the vicinity of the leverage for the pelvic limbs. In other Strigida several apophyses are thrown out at this point. The posterior opening of the neural canal in the last sacral vertebra is subcircular, its diameters being about a millimetre in length. This vertebra also possesses small postzygapophyses, looking upwards and outwards for articulation with the prezygapophyses of the first coccygeal vertebra; the articulating facet of the centrum is also small, long transversely, notched in the median line, the surface on either side being convex. At every point where the sacrum meets the iliac bones union is firm and complete, though both upon the internal and external surfaces the sutural traces are permanently apparent. The anterior iliac margins, as they diverge from the sacral spine, form an acute angle, concave forwards; they have a well-narked rim or border, nearly a millimetre in width, raised above the general surface of the bone, which disappears on the outer borders as we follow them backwards. The two anterior and outer angles overhang the sacral and fifth or last dorsal pleurapophyses. From these last the marginal boundaries, which necessarily give the bones their form, are produced backwards and outwards to a point opposite the centrum of the third sacral vertebra, then backwards and inwards, forming at the above points two lateral angles. From the apices of the two lateral angles to where the borders terminate on either side in front of the acetabula with the pubic bones, the direction is such as to form a concavity on each side; the line joining 
the bases of these concavities, points opposite the posterior openings of the ilio-neural canals, being the narrowest part of the pelvis. The upper and at the same time the inner margins of the bones in question, from the anterior and median angle, at first approach, soon to diverge from each other, and form the gluteal ridges and borders of those scale-like pro. jections of the posterior portion of the ilia that overhang the acetabula. Produced now as the "gluteal ridges," they tend almost directly back. wards, though very slightly inwards, to terminate in the ischial margins. The preacetabular dorsal iliac surfaces are generally concave, while the postacetabular, and at the same time that surface which occupies the higher plane, is flat, having a slope downwards and backwards, with a ventral reduplication after forming the rounded and concave posterior boundary of the pelvis. The preacetabular superficial iliac area is nearly double the extent of the postacetabular. The antitrochanterian facets that surmount the cotyloid eavities have the usual backward direction, though their surfaces look downwards, outwards, and a little forwards. The external surfaces of the ischia look upwards and outwards, having just the reverse direction ventrally. Posteriorly, these bones are produced beyond the ilia into finely pointed extremities, tending to approach each other. The slender pubic bones, after closing in the obdurator foramen on either side, touch and unite with the inferior borders of the ischia as far as the pointed ends of the latter, beyond which they are produced nearly to meet behind. The interval between the free extremities of the pubic bones in some individ. uals, notably "birds of the year," is very slight, less than a millimetre sometimes, approaching a closed pelvis. The cireular and thoroughly perforated acetabula are formed in the usual manner by the three pelvic bones. They have a diameter of about three millimetres, and their eircumferences are in the vertical plane. The ischiadic foramina are ellip. tical and large; they are, as usual, posterior to the acetabula and above the obdurator foramina. These last are also elliptical, and about onethird the size of the others. Should the major axes of these two ellipses be produced backwards, they would intersect and form an acute angle just within the posterior pelvic border. Viewing the pelvis ventralwise, we observe, in addition to points mentioned when speaking of the sacrum, the reduplication of the ilia, forming pockets behind and internally, that open outwards through the ischiadic foramina and inwards into the general pelvic cavity. The pelvic passage is subcircular, unclosed, with an average diameter of 1.7 centimetres vertically, and a little less transversely. The narrowest part of the pelvis measures 1.2 centimetres, the widest 2 centimetres, being taken between the iliac projections over the acetabula; the average length, including anterior neural spine, is 3 centımetres. Pneumatic foramina occur in the shallow anfractuosities, between the antitrochanters and gluteal ridges in the ilia. None of the caudal vertebra are grasped by the pelvis, the posterior extremity of the sacrum always assisting to form the curve of the pelvic passage. The usual number of these vertebræ is seven, though occa. sionally an additional one is found, making eight in some individuals. This enumeration does not include the modified and ultimate coccygeal vertebra, the pygostyle. They are all freely movable upon one another, and the first upon the last sacral vertebra. The articular facets upon the centra vary in shape throughout the series; that upon the first is long transversely, with a double convexity so arranged as to accommodate itself to the one on the extremity of the sacrum; they soon become uniform, to pass to the subcircular one existing between the last vertebra and the pygostyle, on which it is concave. 
The pleurapophyses and parapophyses are very rudimentary or entirely suppressed. Each vertebra bears a prominent neural spine, which, from the first to the sixth, inclusive, is bifurcated; in the last two it appears as a mere primitive knobule. The transverse processes are all deflected downwards and outwards, very small in the first and still more so in the last; are largest in the fifth and sixth. Prezygapophyses are well marked; they reach forwards and articulate with the feebly developed postzygapophyses. In a few of the posterior segments there appears to be an effort on the part of the neurapophyses to overlap the vertebra next beyond them. The neural canal is pervious throughout, commencing in the first with a calibre equal to that in the end of the sacrum; it gradually diminishes, and terminates in a minute, blind, conical socket in the pygostyle. Hypapophyses are produced downwards in a few of the ultimate vertebræ. They hook forwards and articulate with the centrum of the vertebra next beyond them. Sometimes they are observed to be free, or rather resting upon a facette on the anterior margin of one centrum and extending over to the anterior margin of the centrum of the vertebra anterior to it, to meet a similar facette, as a tiny styliform process. The spinal column is completed posteriorly by the pygostyle-that ploughshare-shaped segment that articulates with the last coceygeal vertebra. Above its cup-shaped facet this bone arises as a laterally compressed plate, extending backwards and bifurcated at its extremity, as if to imitate the neural spines of the vertebræ of the series of which it is an ultimate appendage. Below the facet it projects forwards and completes the median sequence of hypapophyses of the centra, being rather larger than any of them. The posterior curve is simply inflected downwards and forwards from its apex.

The scapular arch-(See Pl. I). ${ }^{1}$-The three elements that constitute this arch are all represented, and all independent or free bones; the coracoids articulate with the sternum and scapulæ; coracoids and clavicle, connected by ligaments, lend their share to form or strengthen the shoulder-joints. The coracoid, comparatively large and strong, forms in the usual manner an arthrodial joint of restricted movement with the sternum, its lower end being in the coracoid groove on the anterior part of that bone. The inner angle of its base is about 2 millimetres from the mesial line, and 4 millimetres intervening between it and its fellow of the opposite side in the groove. This extremity is broad, its outer angle being beneath the third sternal rib at its point of meeting the costal border; it is compressed from before backwards. The articular facet, looking downwards, backwards, and a little inwards, is transversely concave, with a slight dividing ridge, ruming antero-posteriorly, converting the general concavity into two smaller ones. The coracoid when in position is produced upwards, forwards, and outwards, making, with the vertical line through its base, rather an acute angle. A limited portion of the middle third of the bone only is subelliptical on section and at all shaft-like, due to the fact that the coracoid in this bird being: perhaps less than the average length as compared with the size of the bird, and, secondly, to the unusually enlarged extremities, features observable, more or less, in Raptores generally. The anterior groove of the upper extremity, that is arched over by the head of the clavicle above, is deep, and occupies fully the upper third of the bone. The coraco-clavicular process springs, thin and compressed, from the inner

${ }^{1}$ It will be seen that in this figure, corresponding limbs, and other parts that are alike on either side of the body, have not been reproduced, it being thought the better way, as the bones on the side towards the observer would necessarily obseure the more remote ones, complicate the figure, and show nothing additional. 
side of the shaft of the bone, at junction of upper and middle thirds, to turn upon itself, so as to be projected upwards, forwards, and a little outwards, terminating with an elliptical facet for articulation with the clavicle. The upper border of this process is concave lengthwise and articulates throughout its extent with the inferior margin of the acromial process of the scapula. The lower and thin edge of the coracoclavicular process tends obliquely downwards, to be lost on the inner surface of the shaft of the bone near its middle. The outer wall of the anterior groove is formed by the coracoid itself, the process just described being really nothing more than a wing-like extension forming the inner boundary of the groove in this bird; it terminates above both clavicle and scapula in a rounded, tuberous head. Below this head, anteriorly and still more inwardly, the coracoid affords a vertical, elongated facet for the claricle, while behind, looking a little outward, is the concave elliptical facet that constitutes about one-third of the glenoid cavity for the humerus, internal to which, and running first directly upwards, then making a right angle and continuing forwards, a little upwards, and outwards, the last direction being the upper margin of the coraco-clavicular process, is another facet, for the scapula. Behind and below, this bone displays one or two lines and depressions, boundaries of muscular attachments. In the middle of the anterior groove, opposite the base of the coraco-clavicular process, the shaft of the bone is perforated; this perforation is elliptical lengthwise with the shaft, and passes directly through to make its appearance on the posterior convex surface just below the scapula. This foramen transmits a branch of that cervical nerve coming from between the twelfth and thirteenth cervical vertebræ. This nerve branch, after passing through the bone, is distributed to the under surface of the pectoralis minor muscle, and its filaments ascend among its fibres. This foramen is observable also in other Owls, as Bubo virginianus, and in some of the diurnal Raptores, as in Accipiter cooperi; in very many birds it is absent. The scapula presents little that is unusual in that bone among the class generally. It lends the additional two-thirds of articular surface to form the glenoid cavity with the coracoid; internal to this the acromion process extends forwards, touching the coracoid as described, and having a limited bearing on the clavicle. Posteriorly its blade-like length is produced, expanding, turning slightly outwards to terminate in an obliquely truncate extremity, with its point over the second dorso-pleurapophysial interspace.

What the scapula lacks in interest is amply made up by the changes observed in the last bone of the group, the claviele. This element is broad above, much compressed from side to side throughout; it spans the anterior groove of the coracoid and touches the scapula as described above, rapidly diminishing in size as it is produced downwards and inwards by a gentle curve towards the fellow of the opposite side. The upper extremities in adult birds are separated by an average distance of 2.3 centimetres. If the sternum pointed to feebleness of flight in this little $\mathbf{O w l}$, it is still further carried out by the ill-developed clavicles, which constitute that arch in birds, where they are thoroughly and firmly united below, that assists to resist the pressure of the humeri when the wings are depressed in flight, and send them back to their former position after the completion of the action. In examining again Pl. I, which represents the skeleton of an old male, we find this bone to be simply a pointed styliform process; in other individuals, and adults too, it does not even attain the length here shown; but, as if to bid defiance to all law or invariable rule governing it, we again find in very young 
birds cases where it becomes confluent with its fellow, forming a broad U-shaped arch, though never a very strong one. In a case of this kind the bone was finely cancellous throughout, with an extremely attenuated layer of compact tissue outside, scarcely covering it. In Pl. I, and other individuals like it, the clavicles were pneumatic. Again, in both young and old, it may have any of its lower parts completed by cartilage; it never displays a mesial expansion of bone at the point of confluence. We believe in the Barn $\mathrm{Owl}_{\mathrm{wl}}$ (Aluco) it anchyloses with the sternum at the carinal angle, by its bending backwards and meet. ing it at its lowest and median point. As already shown, the superior entrance of the anterior groove on the coracoid is a complete circuit, formed by the three bones of the group. The head of the coracoid overhangs it above; next below is the clavicle, closing it in anteriorly; lowest of all the scapula behind. A plane passed through the superior margins of this aperture would look upwards, inwards, and backwards. All the bones of the scapular arch are pneumatic, with the exception sometimes seen in the clavicle, and the foramina, to allow the air to enter their interiors, look into the inclosed groove of the coracoid just described. In the scapula the foramen is usually single and in the acromion process; single again in the clavicle, it is seen in the broadest part of the head, while in the coracoid there is generally a group of these little apertures, situated in the depression on the surface that overhangs this entrance to the coracoidal groove.

As in many others of the family, in common, too, with not a few of the diurnal Raptores, this $\mathrm{Owl}$ possesses, particularly the older individuals, an os humero scapulare, of the usual form, that increases the articular surface of the shoulder-joint for the humerns.

Of the upper extremity.-The upper extremity consists of ten distinct bones in the full-grown bird, omitting minute sesamoids that might exist. These are the humerus of the arm, the radius and ulna of the forearm, two free carpals, the metacarpal, and four phalanges. (See Pl. I.) The humerus is a long, extremely light and smooth bone, and when viewed from above in its position of rest, with the wing closed, it reminds one of the curve in the small italic letter $f$, being concave above towards the scapula; and this bone is so twisted that this same curve is exhibited, though not quite as well marked, when viewing it laterally. The humerus is 5.5 centimetres long, subcylindrical on section at midshaft, at which point a minute aperture exists for the passage of the nutrient vessels that are distributed to the osseous tissue and its internal lining. This foramen enters the bone very obliquely, its external orifice being nearest the proximal extremity. This end is well expanded and surmounted above by a strongly developed radial crest that overhangs the shaft slightly towards the palmar aspect. It occupies a line on the bone from the articular facet for the shoulder.joint to an extent shown in Pl. I. The ulnar crest, or lesser tuberosity, incloses quite an extensive fossa below, which acts also as a partial screen to the pneumatic foramina, for the humerus is highly pneumatic. They usually consist of one circular opening, surrounded by a group of many smaller ones. In young birds a very large foramen is generally present; this closes in as age advances. Between the two tuberosities is the vertical and elliptical convex facet for articulation with the glenoid cavity of the shoulder-joint, constituting the "head of the humerus." The radial crest displays palmad, a ridge for the insertion of the tendon of the pectoralis major. The distal end of the humerus is also expanderl in the vertical plane and gently convex anconad, the reverse 
condition of the proximal extremity. It presents, for examination, the articular facets for the ginglymoid joint it forms with radius and ulna, and the superior and inferior condyles. The larger, and at the same time the superior, of these two facets is intended for the cup-shaped depression in the head of the radius, as well as a portion of the articular surface on the ulna. It is oroid in form and placed obliquely on the bone, the inferior end of the long axis of the oval being situated the nearer the proximal extremity of the shaft. This facet is separated from the trochlea surface for the ulna by a well-marked depression; this latter is a knob-like tubercle when compared with the radial facet. The condyles and the entire articular surface are about in the same plane posteriorly; that is, neither increases the length of the bone, one more than another. Passing from the trochlear surface for the ulna towards the inner aspect of the shaft, there is to be observed a shallow depression, which corresponds to the olecranon fossa of human osteology, and in full extension of the limb allows room for that process of the ulna in this bird. The radius has an average length of 6.6 centimetres, and the ulna a corresponding length of 6.8 centimetres, so that their distal extremities, when articulated, as we examine them in the closed wing, extend beyond the head of the humerus. In this position also the radius occupies a higher level than the ulna, and is the innermost bone of the two. The radius is slender, the transverse diameters of its subcylindrical shaft varying but little throughout its extent, thongh its extremities are expanded. From the elbow-joint, when the two bones are in position, it at first diverges from the ulna at a moderate curve, to approach that bone again by a more gentle inclination to nearly absolute contact at the junction of middle and distal thirds; from this latter point it lies parallel with the ulna to the wrist. The head of the radius is elliptical, being crowned by a depression for articulation with the oblique facet on the distal end of the humerus. Beyond, below, and to the outer aspect of this facet is another of similar form, thongh convex for articulation with the ulna, while still more advanced toward the distal end we find the bicipital tuberosity, and still more distally, the minute nutrient foramen; all of the bones beyond the humerus being non-pneumatic. The distal extremity of the bone in question is terminated by a little fan-like expansion that caps the ulna and articulates by its anterior convex margin with the scapho-lunar of the wrist. It is marked above by the longitudinal groove for the tendon of the extensor metacarpi radialis longus. The shaft of the ulna is nearly three times as large as that of the radius. Its outer half is straight, its inner curved towards the humerus, thereby increasing, at the proximal moiety, the interosseous space, by the assistance of the opposite curve made by the radius. The stronger end is the one involved in the formation of the elbow-joint; here is to be observed the depression for the head of the radius, or the lesser sigmoid cavity, while the articular surface beyond that occupies the entire end of the bone, directed downwards, inwards, and backwards, presents for examination the greater sigmoid cavity, the olecranon and coranoid proeesses, and the cavity for articulation with the oblique facet of the humerus. The greater sigmoid cavity is subcircular and of some depth; its lower and produced lip represents the coranoid process, as does its upper, better marked, and more tuberous prolongation represent the olecranon of andranatomia. Extending radiad is another concave, quadrate, articular facet for the oblique tubercle of the humerus, as the first-mentioned concavity articulates with the ulnar tubercle or trochlea. A little beyond this articular surface are various small tuberosities and 
depressions for the origin and insertion of muscles. Approaching the wrist, the shaft is seen to be generally smooth, and diminishes in calibre at junction of middle and proximal thirds, in the locality of the nutrient foramen, while along its entire length, at certain intervals, are the slight elevations for the apices of the quills of the secondaries. The distal extremity of the ulna enters into the formation of the wristjoint; it is not nearly as large as the proximal end. The articulating surface has a deep mesial cleft in the vertical direction, limited externally by an elliptical curve, internally by a double, tuberous knob for articulation with the irregularly formed cuneiform of the carpus, while above is a roughened surface that is covered by the expanded end of the radius. ${ }^{1}$

The carpus is composed of the scapho-lunar, os magnum, and cuneiform. The scapho-lunar articulates with radius, os magnum, and ulna. The radial articulation is a rather deep and elliptical concare facet, its lower border gliding over the ulna, while the distal end of the radius plays in the concavity. The opposite face of this six-sided little bone is also smooth, and is a nearly flattened surface that articulates with os magnum. The upper and lower surfaces, as well as the ends, are simply roughened and fashioned to give the proper form to that part of the joint into which it enters, and for the attachment of ligaments. Os magnum has become confluent with the mid-metacarpal, forming its trochlear surface for articulation with scapho-lunar, cuneiform, and ulna. The cuneiform is an extremely irregularly shaped bone; it appears to be rather the larger of the two free carpals, and is the lower in regard to position. It articulates with ulna and os magnum, simply. Its outer ulnar facet is elliptical and shallow, monopolizing the entire face of the bone; its inner facet is very irregular, being formed so as to accommodate itself to the ulnar tubercles, with which it articulates. Projecting towards the metacarpus, this little bone has two prongs or limbs, the inner aspect of the extremities of each possessing a subcircular facette that articulates, the outer and shorter limb with the internal trochlear margin of os magnum, on the same side; the inner and longer limb straddles the metacarpal and glides over the surface, during movements of the joint, at a point about where magnum becomes confluent with mid-metacarpal. The cuneiform has also attached to it ligaments that enclose the wrist-joint beneath-capsular ligaments of the carpus.

The metacarpus is formed in the usual manner, by the amalgamation of the index, medius, and annularis metacarpals, the first, second, and third, respectively. It is 3.3 centimetres long, articulating with scapholunar, ulna, and cuneiform at its proximal extremity by means of os magnum, that has become anchylosed with mid-metacarpal and the pha-

\footnotetext{
${ }^{1}$ In the October nnmber of the Bulletin of the Nuttall Ornithological Club, for 1881, Cambridge, Mass., I published an article entitled "On the ossicle of the Antibrachium as found in some of the North American Falconidæ"; wherein I described a very interesting sesamoid that was found above the carpal articulation, on the radius, in a specimen of Circus hudsonius. This sesamoid I named the os prominens, but subsequently ascertained that it had been noticed by Milne-Edwards, and after this naturalist, by Mivart (Lessous in Elem. Anat., p. 320, Lond., 1877). My attention was afterwards called to its occurrence in the Owls, by Mr. Forbes, prosector to the Zoological Society of Lonilon, and again by Mr. F. A. Lucas, of Rochester, New York, the latter observer finding it in Bubo and Nyctea. Subsequently I found it in other American Owls, and have no reason to doubt but that it will be found in Speotyto, though I have not material at hand, now, to confirm it. Additional literature and remarks upon this sesamoid will be found in following numbers of the Bulletin quoted above; one in the January number, 1882, by Mr. J.A. Jeffries. It does not show in the carpus of Bubo virginianus (Plate III, Fig. 11), accompanying this article, because at the time I drew the figure I was not aware of its occurrence in that Owl, or the joint represented would have been placed so as to exhibit it.
} 
langes at its distal end. The first metacarpal is short, and fused with the second just anterior to the boundary of the trochlear surface of os magnum; it makes an angle with the shaft of the second metacarpal. its extremity being directed upwards. At its base, close to the shaft of mid-metacarpal, it bears a uniform facette for articulation with the index phalanx, a free, three-sided, pointed little bone, about 9 millimetres in length. The second metacarpal is straight; its enlarged proximal extremity is formed chiefly by the confluent os magnum; its shaft is inclined to be subtrihedral, with its broadest face looking forwards; its distal extremity is terminated by a knot-shaped enlargement, that is still further enhanced by the confluence with the third metacarpal. It bears a digit composed of two phalanges, the proximal one bearing on its posterior border, for nearly its entire length, a quadrangular expansion, that has a raised margin, leaving a single concavity radiad; a similar concavity oceurs on the ulnar side, but is there divided by a ridge, sloping downward into two shallow depressions. This little bone somewhat reminds one of a cleaver, with the end of its handle attached to the metacarpus. It supports at its distal extremity the second phalanx of this digit, a bone having very much the same appearance and shape as the index digit, ${ }^{1}$ only being longer and more pointed. The proximal ends of all the phalangeal segments are more or less expanded, in order to support the ample facets of articulation that oceur among them, and the metacarpus. The third metacarpal is expanded transversely above, slender below, where it falls a little beyond the medius after its confluence with it. It also has a small, pointed phalanx, freely attached to its distal extremity, and lying in that recess formed by the shaft and posterior expansion of the first phalanx of the second digit. At a very early date, comparatively, in the life of this $\mathrm{Owl}$, ossification is normally extended to many of the tendons of important muscles of the antibrachium and pinion.

Of the pelvic limb.-The lower extremity is composed of twenty distinct segments, including the patella, or just double the number found in the pectoral limb. This inerease will not surprise us when we recollect the greater number of small bones devoted to the foot above those fornd in the hand. Its most striking feature, next to those osteological characteristics common to the family, is its extreme length, dne principally to the tibia and tarso-metatarsus. All the bones of the lower limb in this species are non-pneumatic. The femur is comparatively of good size and strong; articulated in the usual manner, it measures 4 centimetres in length and 7 millimetres across the condyles at their widest part. At the proximal extremity, externally, above the shaft, there is a flat and roughened surface, bounded above by the curved trochanterian ridge. This surface forms the major part of the great trochanter. There is no trochanter minor present. The trochanterian ridge is the highest part of the bone, when it is held vertically ; it lies in the antero-posterior plane, with the femur in its natural position, the bird standing erect ; from it, sloping directly inwards and occupying the remainder of the summit between it and the head, is a smooth articular facet, broadest externally, merging into the globular head internally.

\footnotetext{
${ }^{1} \mathrm{Mr}$. J.A. Jeffries, in a very interesting article entitled "On the Fingers of Birds" (Bull. Nutt. Ornith. Club, January, 1881, p.6), endeavors to settle the argument upon the homology of this joint. This author says: "Whether the metacarpus are the I-III or the II-IV has been a mooted question, Rolleston, Huxley, and Gegenbaur holding the first view, and Owen, Wyman, Morse, and Coues holding the second view." I have always maintained the view expressed by the latter gentlemen men tioned; the fact, however, that the first phalanx of manus in Aves is the homologue of pollex of the pentadactyle limb seems to be gaining ground.
} 
With the head it constitutes the articular surface for the pelvis-it being opposed to the antitrochanterian facet of the ilium, while the caput femoris plays in the cotyloid ring. The excavation for the ligamentum teres on the latter is conical and deep, consuming a good part of the bone; it is situated on its upper and inner aspect. In looking into the relation existing among head, neck, and shaft of the femur of this bird, we must observe that if the straight line lying in the middle of the surface of the internal aspect of the shaft were produced upwards, it would pass through the centre of the facet at the summit-if anything, nearer the trochanterian ridge than it does to the head. This facet also is notably narrower just before arriving at the head than at any other point. Again, the plane passing through the external and circular boundary of the head makes an angle of a good $45^{\circ}$ with this line, so that with these facts in view we can hardly assert in the case of the species before us, as do some authors on comparative anatomy in describing this bone in general, that the head of the femur is either nearly at right angles with or is sessile with the shaft. It would appear, though, that jt has quite as much of a neck to boast of as the anatomical neck of humerus or the neck of the scapula in works on human anatomy. The shaft throughout its length, until it begins to approach the distal condyles, where it is subcompressed and expanded antero-posteriorly, is nearly cylindrical, bent slightly backwards at its lower end, and offers for examination merely the intermuscular ridges, with the linea aspera, feebly marked, and the nutrient foramen, all of which maintain their usual positions on the bone. At the distal extremity the rotular canal, the intercondyloid notch, and the popliteal fossa are all strongly produced, giving due prominence to the condyles, internal and external, between which they form the dividing tract. The external and lower condyle is dirided in two by a vertical excaration, deepest above. Of the two facets thus formed, the inner articulates with the tibia, the outer with the head of the fibula. The external surface of this condyle is flat and continuous with the shaft. The inner condyle, broad posteriorly, has a slight depression in the surface that bounds it on the tibial side, and as a rule the usual sites for ligamentous attachments about this extremity are at best but feebly represented. The patella, encased in the tendon of the quadriceps femoris, is situated about 3 millimetres above the rotular erest of the tibia, anteriorly, having the form of an oblate hemispheroid with its base directed upwards, the long diameter of which measures 3.5 millimetres. The tibia is the longest bone in this bird's skeleton, and at the same time, taking this length in to consideration, the least curved or bent along the shaft; it has, however, a slight and just appreciable gradual currature forwards that is most apparent about the junction of middle and upper thirds. Its average length, measured on the inside, is 6.7 centimetres; its extremities being expanded for articulation, above with the femur, below with the tarsometatarsus. These expansions are of about equal dimensions, though differing vastly in form, in this respect being unlike some of the diurnal Raptores, in which the distal condyles constitute the smaller end of the bone.

Among the most important points presented for examination about the head is the articular surface that crowns it above for the condyles of the femur. This is subquadrate in form, uneven, highest at the inner and anterior angle, sloping gradually to the opposite one, bounded almost entirely around by a raised margin, that is most feebly developed posteriorly, and at a point anterior to the head of the fibula, where it is absent. In front this border may be nominated the rotular or epi- 
cnemial ridge, though it is no more prominent there than at any other point, but in many birds it is so produced as to form a process of some size, to which these terms are applied. Externally and posteriorly the margin is roughened for the attachment of ligaments that bind the head of the diminutive fibula to this bone. In the middle of this articular surface is to be seen a tuberosity, on either side of which are the depressions for the femoral condyles. Produced downwards, anteriorly from the rotular ridge are the cnemial ridges; these have their crests bent slightly outwards, and they merge into the shaft below, abreast the superior point of the fibular ridge. Of the two, the outer or ecto-enemial is the shorter; that is, it does not extend so far down the shaft as the inner or pro-enemial. They have between them an orate concavity, with the larger end above, the lower end subsiding upon the shaft with the ridges themselves. The vertical elevation on the external aspect of the shaft for articulation with the fibula runs down the side but a short distance; a little below its abrupt termination may be observed in a line with it, the nutrient foramen, entering very obliquely from above downwards. After leaving the fibular ridge as far as the point where the bone begins to expand transversely at the distal extremity, the shaft is remarkably smooth and nearly cylindrical. This transverse and distal expansion is cheeked, both anteriorly and posteriorly, by abruptly meeting the distal condyles, the point of meeting perhaps being rather the higher behind. The condyles, differing but little in size, are singularly uniform as to shape, with their curved surfaces downwards, being flat on their outer aspects, with a raised rim bounding them in each case. They stand out prominent and apart. Anteriorly their convex surfaces are the widest, behind they slightly approach each other, and the articular convex surface is narrowest on the onter condyle. The intercondyloid notch is deep, and appears equally well marked thronghout its extent. Immediately abore it, anteriorly, there is a deep triangular depression; another, and more shallow one, is found behind in the corresponding locality. Up the shaft a short distance on the inner side, anteriorly, is a little tuberele, to which is attached the ligament that binds down some of the strong tendons of the extensors. This ligament crosses the anterior triangular depression mentioned above, obliquely, to be inserted near the external condyle superiorly. This is the arrangement also in Bubo virginianus, but in some of the Hawks this ligamentous bridge has become thoroughly ossified, forming a strong bony band across the concavity in question. It is interesting to remark here, however general the rule may be as applying to the diurnal and nocturnal Raptores, that whereas this band is ligamentous in the tibia in some of the Owls, a bony one fulfilling the same function is found in them just below the head of the tarso metatarsus; these conditions are just reversed among some of the Hawks. In fact, we know of no exception to the arrangement just mentioned for the Owls; even Surnia funerea has this bony bridge on the tarso-metatarsus very prominent, and on the inner side of the upper third it being much in the same position as we find it in the well-known exception to the Hawks, that is, in Pandion. In short, among the Raptores it seems to be found among those birds that possess the reversible toe. Usually, in old birds of this species, the fibula is firmly anchylosed to the entire length of the fibular ridge of the tibia; arching outwards, its head, surmounted by an antero-posteriorly elongated facet, rises a little above that bone at the point where it is attached to it by ligament. This is the larger part of the shaft in regard to size. Below the ridge this bone becomes simply a delicate little spine, that emerges into the shaft of the 
tibia at about the junction of middle and distal thirds, though it may be traced after this as far as the middle of the outer condyle, where it terminates by a minute tubercle. The head is notched externally, near the centre, and has lodged at that point a small sesamoid that is in the lateral ligament of the knee-joint. Posteriorly on the shaft, about midway down the superior tibio-fibular anchylosis, we observe a small tubercle for the insertion of the tendon of the biceps. The long segment that exists between the tibia and the phalanges of the pelvic limb is the bone tarso-metatarsus, or the confluent metatarsals of the second, third, and fourth toes with certain tarsal bones at its proximal extremity. It meastures down the anterior aspect, mesially, 4.6 centimetres, and has its extremities enlarged for articular purposes, in common with other long bones of the skeleton. At its proximal end the bone presents superiorly two concave articular surfaces for the condyles of the tibia. They appear nearly on a level with each other, the bone being held vertically. The inner and larger of the two is elliptical in outline, antero-posteriorly; the outer and smaller is fashioned off behind by a tuberous process, directed upwards and outwards. Between these two surfaces arises a prominent tuberosity, that in the articulated limb enters the intercondyloid notch of the tibia quite accurately, and is intended for a ligamentous attachment. Anteriorly and internally a groove exists that runs down the shaft, to disappear a little above its middle. This canal is deepest immediately below the articular expansion, and is here bridged orer by a little arch of bone, a millimetre in width, that serves to bind down and hold in its proper place the teudon of the long extensor of the toes. Posteriorly there is a much deeper and longer tendinal canal, that extends the entire length of the shaft, being 'shallowest at the middle and most capacious at the proximal extremity; this is bounded above and internally for a short distance below the head of the bone by the calcaneal process, a thin lamina of bone that has a foramen near its base; this process is surmounted by an elliptical and compressed tuberosity, placed vertically. The opposite wall, above, of this groove is also thin, and extends, in common with the calcaneal process, directly backwards. There are two other foramina seen at this end of the tarso-matatarsus; one just at the external termination of the bony bridge mentioned above, and the other outside and a little above it. Their posterior openings are immediately behind the anterior ones, or, in other words, they do not pierce the shaft in any way obliquely. The shaft of this bone is nearly square on section for the major part of its extent, being encroached upon, however, both before and behind, by the aforesaid tendinal grooves. The tendons, especially those that occupy the posterior canal, are vers prone to ossification, forming quite sizable bones in the adult, the largest of these being equal to the fibula in bulk, exclusive of course of the head of that bone, and not being as long. Returning to the tarso-metatarsus, we find at its distal extremity, for examination, the trochlex that articulate with the rear segment of all the toes except hallux. Viewing this end with the bases of these trochleæ towards one, we find the general outline made by them to be crescentic, with the horns having a tendency to approach each other behind. The outer trochlea is the highest and longest from before backwards; the other two are anout on the same level, the inner one having a posterior and internal process, while the middle one is possessed of a median cleft traversing its face anteroposteriorly. They are sharply divided from each other by narrow slits, that extend up as far as the articulating part, and are continued on the anterior aspect of the shaft for a short way as delicate groovelets. A foramen is situated in the outer of these, that gives passage to the ante- 
rior tibial artery, and is comparatively larger than usually seen in the Owls. Behind, the tendinal groove expands, and is bounded distally by the concave border formed by the trochlex. Upon its internal margin, just above the extremity of the bone, it shows an elongated but feebly marked depression of about 3 millimetres in length. This facet articulates with the os metatarsale accessorium, which is joined to the bone by ligament. This little bone in this bird has an average length of 4 millimetres. It is twisted upon itself, and bears upon one border a convex, smooth surface for the tarso-metatarsus, while distally it has an articulating surface, resembling more the mid-trochlea than any other, for the proximal segment of the hallux. Above it is sharply grooved for the tendon that goes to that toe. The toes are four in number, and their bony segments follow the rule that governs the greater part of the Class Aves; that is, first, second, third, and fourth toes have 2, 3, 4, and 5 phalanges allotted to them, respectively. The first phalanx of the hind toe is more compressed from side to side than in the other toes, possessing more of the characteristics of the second joints. Its posterior facet, that articulates with the accessory metatarsal, fits accurately into the cleft surface seen on that little bone. Anteriorly the facet has a median groove, forming two vertical convexities for the double concave facet on the claw, with its dividing ridge. The claws are all a good deal alike, varying in size, the rear one being the most compressed laterally. They are pointed, arched, and nearly conical, the horny thecæ that cover them during life only being grooved on the under side. Their proximal ends have an articulating facet for the next phalanx behind them; this is so arranged that they can be more smartly flexed than any of the other joints of the foot, due to the convex articulating surface extending well beneath on the phalanx they meet. On the under sides of their proximal extremities is a tuberosity for the attachment of the flexor tendons; it has on either side, below, an oval foramen to allow vessels and a nervelet to pass to the extremities of these ungual phalanges. The first joint of the second toe, and the first and second of the third, are thickest and short, articulating internally with the tarso-metatarsus, and having their facets so arranged as to allow of motion only in the one plane. These bones may almost be said to interlock with each other, with their superior projecting processes behind fitting closely into the deep groove intended to receive them on the anterior faces of the joints to their immediate rear. The other underscribed phalanges of these two toes resemble the proximal segment of hallux. The fourth or outside toe possesses five phalanges, but the three innermost segments are very short, and are really nothing more than one of the middle type of phalangealbones, such as the third on the mid-toe, divided into three nearly equal parts, the proximal and distal pieces retaining all the characteristies of that bone, while the middle segment is simply a mid-section of the shaft. This arrangement, however, together with the manner in which the proximal phalanx, if it may be termed so in this bird, articulates with the long and elevated trochlea on the tarso-metatarsus, gives this toe a versatility and a power to be thrown outward and, to a limited extent, to the rear, not enjoyed by any of the other toes, constituting one of the most interesting anatomical features that we find in the family Strigida. 



\section{PLATE I.}

The skeleton of Speotyto cunicularia hypogar.

Note.-The drawings from which the lithographic plates and the woodcuts of the bones in these monographs were made were executed by the author; all the cuts of external characters and illastrations of the birds are from Baird, Brewer and Ridgway's North American Birds, and kindly lent me by Professor Baird. 


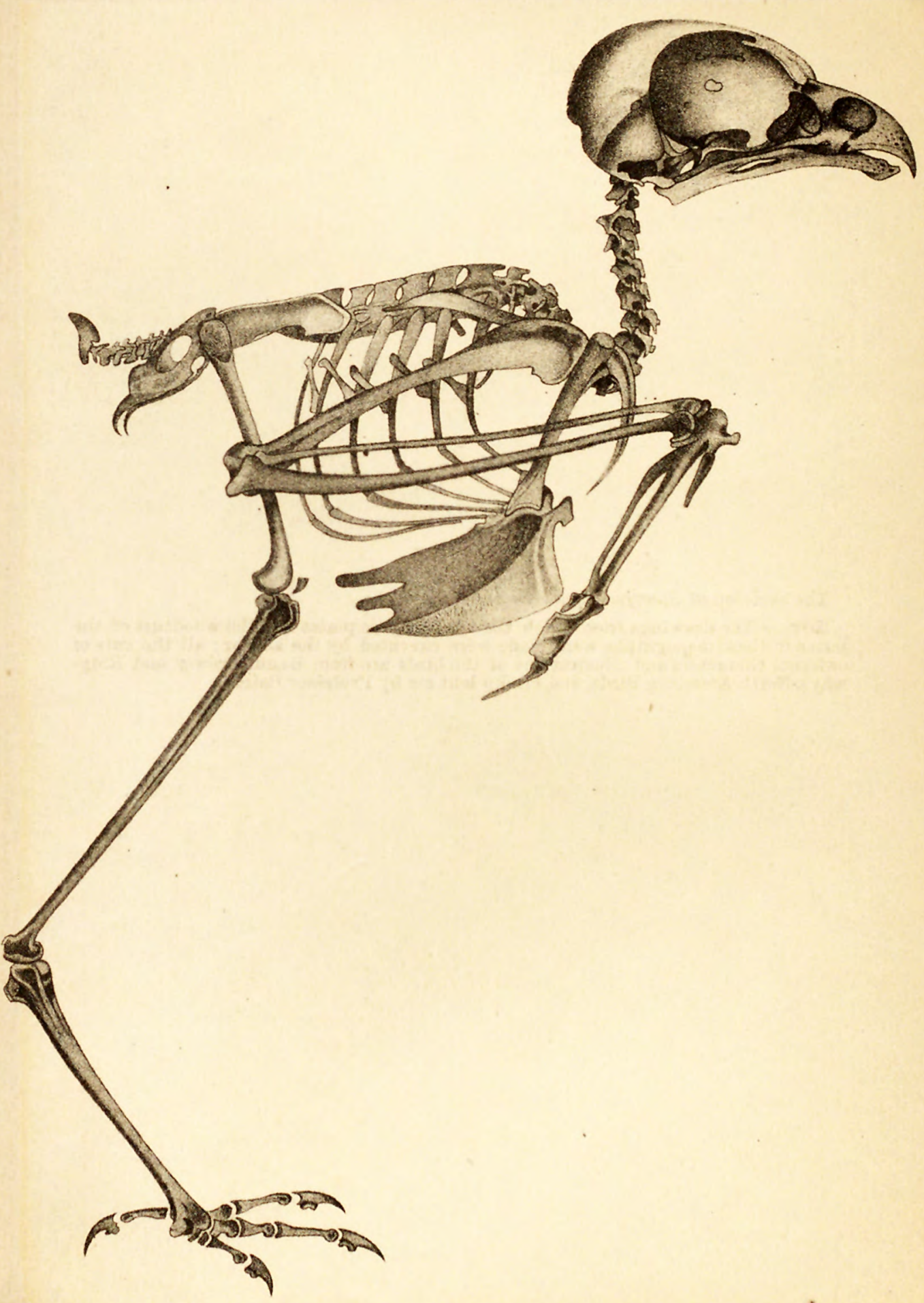






\section{PLATE II.}

The skull, sternum, pelvis, ete., natural sıe.

Fig. 1. The skull from above.

Fig. 2. The skull from below.

FIG. 3. The mandible from above.

FIG. 4. 'The pelvis from below.

Fig. 5. Anterior view of sternum and first dorsal vertebra, with its corresponding vertebral and sternal ribs.

Fig. 6. The sternum from below. 

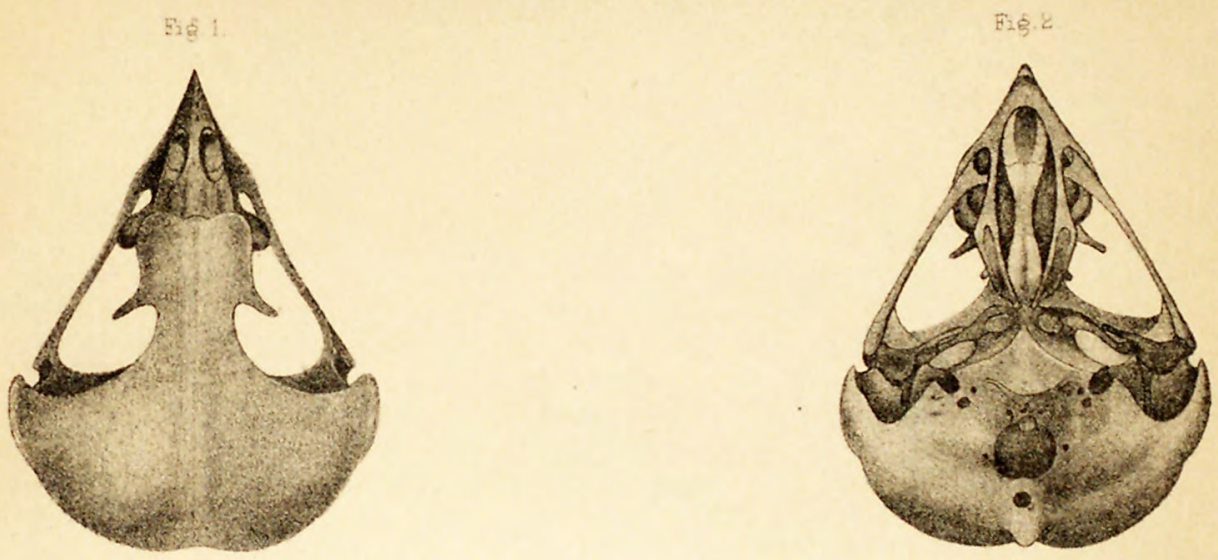

Figु 3

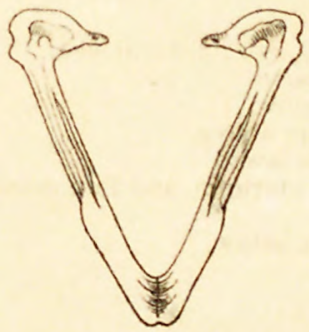

Fis 4

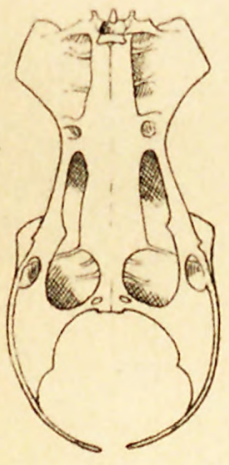

Fis 6

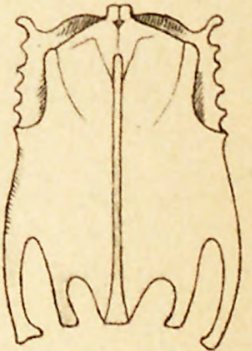

OSTEOLOGY OF SPEOTYTO CUNICULARIA VAR. HYPOGEA. 

$40 \mathrm{H}$ 
PLATE III.

Various bones of the skeleton.

Fig. 7. Anterior view of skull, the lower mandible having been removed.

Fig. 8. $H$, humerus; $i$, nlnar tubercle; $i$, oblique tubercle for radius and ulna; $h$, radial crest; $S A$ and $S^{\prime} A^{\prime}$, scapular arch ; $S$ and $S^{\prime}$, scapula ; $C$ and $C^{\prime}$, clavicle ; $C r$ and $C r^{\prime}$, coracoid ; $f$, perforating foramen.

Fig. 9. $H^{\prime}$, humerus; $h^{\prime \prime}$, radial crest; $p f$, pneumatic foramina; $S A^{\prime \prime}$ and $S A^{\prime \prime \prime}$, scapular arch; $S^{\prime \prime \prime}$ and $S^{\prime \prime \prime}$, scapula; $C^{\prime \prime}$ and $C^{\prime \prime \prime}$, clavicle; $\mathrm{Cr}^{\prime \prime}$ and $\mathrm{Cr}^{\prime \prime \prime}$, coracoid; $f^{\prime}$, perforating foramen.

FrG. 10. $H A$, hyoid arch; $a$, superior view of atlas; $a^{\prime}$, the same viewed laterally; $b$, the axis; $o$, its odontoid process.

Frg. 11. Right carpus of Bubo virginianus, outer aspect, with the bones composing it moved partly from their normal positions to show articulating surfaces; $r d$, radius; $u l$, nlna; $s$, scaphoid ; $c$, cuneiform ; $m$, metacarpus; $d$, index digit.

Fig, 12. Right radius and ulna, Speotyto, inner aspect; $u$, ulna ; $r$, radius ; $y$, articular facet for oblique tubercle of humerus ; $y^{\prime}$ for ulnar tubercle of humerus.

FIG. 13. The same bones, inferior surface, when in position and the wing closed; $r^{\prime}$, radius; $u^{\prime}$, ulna.

FIG. 14. Posterior surface, right metacarpus. The differences in form and position of such portion of the articular surface in the metacarpus as is shown by $z$ and $z^{\prime}$, in Figs 11 and 14, between Bubo and Speotyto, are here seen; flat and rounded below in the first, prominent and pointed in the second.

FrG. 15. Anterior surfaces, right tibia and fibula; $F$, fibula; $T$, tibia.

Fig. 16. Posterior surfaces, same bones; $F^{\prime}$, fibula; $T^{\prime}$, tibia.

FIG. 17. Right femur; $v$, posterior surface; $v^{\prime}$, anterior surface.

Fig. 18. Anterior surface, right tarso-metatarsus; $m$, bony bridge over tendons; $j$, foramen for anterior tibial artery ; $e$, facet for outer toe, $l$, for midale, and $t$ for inuer toe.

FIG. 19. Posterior surface same bone: $j^{\prime}$, the foramen for the anterior tibial artery ; $e^{\prime \prime}$ facet for outer toe, $l^{\prime \prime}$ for middle, and $t^{\prime \prime}$ for inner toe ; $k$, facet for os metatarsale accessorium.

Fig. 20. $A$, right os metatarsale accessorium, superior surface; $B$, base or inferior surface of right tarso-metatarsus; $e^{\prime}$, facet for outer toe, $i$, for middle, and $t^{\prime}$ for inner toe. The section of the shaft shows just above the middle facet, on the posterior aspect, ranging near the middle third of the bone. 
BULL. U.S. GEOL. SURV VOL. VI.

PLATE III.

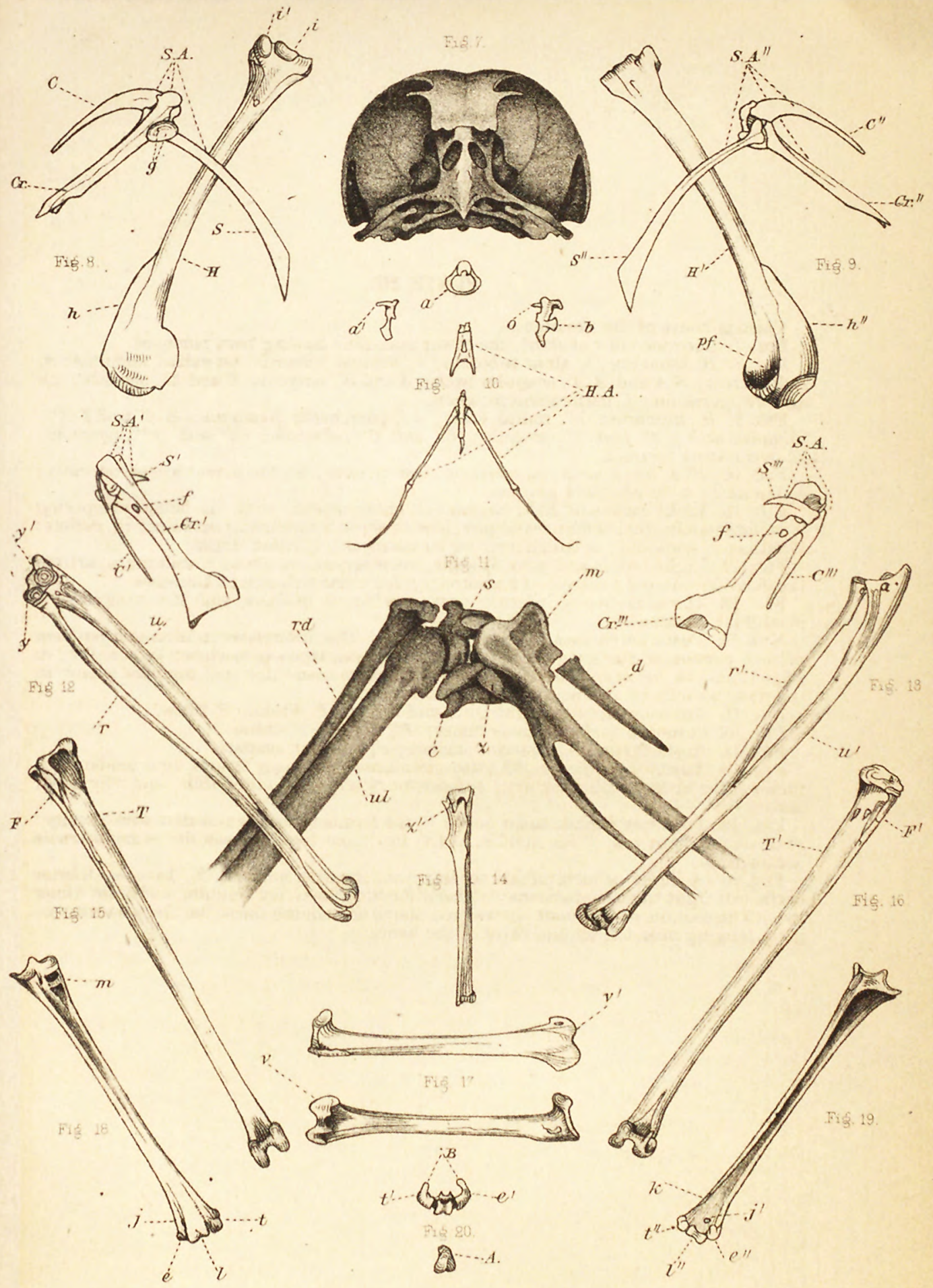

OSTEQLOGY OF SPEOTYTO CUNICULARIA VAR. HYPOGEA. 



\title{
OSTEOLOGY OF EREMOPHILA ALPESTRIS.
}

\author{
By R. W. Shufeldt, M. D. \\ Captain, Medical Department, Enited States Army.
}

The 11th of March, 1880, was a particularly severe day at Fort Fetterman $^{1}$ A violent wind and snow storm prevailed during the entire twenty-four hours. In the creek bottom, below the fort, where the wind had exposet the ground of some land that had been used for gardening purposes the year before, thousands of Horned Larks congregated. They seemed disinclined to vacate their partially sheltered position, preferring to face the few death-dealing fires $I$ delivered them rather than be tossed over the prairie by the freezing storm. At each shot, the flocks arose, skimmed low over the ground, soon to alight again. These simple manœuvres afforded me abundant opportunity to secure many specimens, and several hundred were taken. As they afterwards lay upon the table in my study, one would almost have said, before submitting them to careful scrutiny and examination, that not only was true alpestris represented, but both the varieties, leucolama and chrysolama, described by modern writers. Certainly it was that there were many shades of their normal eoloring among them, accompanied by differences in size that were not due to sex. I have never seen the black pectoral crescent of this bird in the low position in which Audubon represents it in his work (B. Am., Vol. VIII, pl. 497), where he figures his Alauda rufa, the Western Shore Lark.

Before proceeding to the study of the skeleton of this interesting species, we will remind the reader that of all the genera that go to make up the family Alaudida, or Larks, but few species have fallen to the lot of our North American avi-fama. We have the Sky Lark, Alauda arvensis, ${ }^{2}$ and the subject of the present monograph, with its two varieties, E. alpestris leucoloma and chrysolama, mentioned above.

The Skull-(Pl.IV, Figs.22, 25, and 26).-It is a striking characteristic in the skulls of nearly all adult birds that certain bones become firmly united, their sutures entirely disappearing; perhaps in no species of the highly organized suborder Oscines has this almost universal avian feature been so thoroughly carried out as in our present subject, the Horned Lark. Occasionally we do find, however, a trace to guide us in locating: the original boundaries of the primitive elements, even among the $O s$ cines, as the sutures, amidst the parietals and frontals in the cranium of Lanius, when maceration is carried to a high degree, but in Eremophila,

${ }^{1}$ W yoming Territory, United States, lat. $42^{\circ} 23^{\prime} 35^{\prime \prime}$ N., long. $105^{\circ} 21^{\prime} 4^{\prime \prime} \mathrm{W}$.

${ }^{2}$ Alauda arvensis, Limn.-Cf. Dresser \& Sharpe, Birds Enr., pt.-, and B. B. \& R. Hist. N. Am. B., ii. 1874, 136 (Greenland and Bermuda), and Bull. U. S. Nat. Mus., No. 21, p. 293, and Coues' Check-list of N. A. B., 2nd ed., 1882, p. 33, No. 85. 
as already stated, there is a total absence of any such indicaticn. If we remove the lower mandible from the skull in any of the Class Aves, and place the remainder on the horizontal plane, with the basi-cranii downwards, we observe that in different skulls there exists in this position differences in equilıbrium, and differences in, what we will call, the an terior and posterior bearing points, or the points upon which this part of the skull rests upon the horizontal plane. To illustrate this in the skull we are studying, we find, when placed as directed above, that its equilibrium is quite stable, and that it rests posteriorly upon the tympanics, anteriorly upon the tip of the superior mandible, which constitute, respectively, its posterior and anterior bearing points. In this case there is but one anterior bearing point, with two posterior ones. This is a very common result, but there are at the same time many exceptions to it, as in Numenius, and many species of the family Anatide.

Again, if we erect a perpendicular from one of the posterior bearing points, or the posterior bearing point, for sometimes it is the condyle, we find that the planes passing through the circumference of the foramen maguum and the occipital vertebra, and the point where the foot of this perpendicular and the posterior bearing points coincide, make certain angles with the horizontal plane (the ordinary born protractor is the best instrument to take these angles with), which we will call, respectively, the angle of the foramen and the angle of the base. These two angles, in many instances, practically coincide, as in our Lark, where they make an angle of $40^{\circ}$ with the horizontal plane. In the cut, $\mathrm{H} \mathrm{H}^{\prime}$ is the horizontal plane; $a$ the anterior and $p$ the posterior bearing points.

These angles also difier in many birds; $e . g$., the anterior bearing point in Ardea herodias is the tip of the upper mandible, the posterior ones being the inner of the three facets on each tympanic; the angles of the planes of the base and foramen about coincide, and is $50^{\circ}$. In many of the Owls and diurnal birds of prey, the bearing points being the same as in the last example (it being, however, the inner facet of two on the tympanies, as a rule), the comtined angles, or either of them separately, is very small, or the base and foramen may be found to lie nearly in a plane parallel to the plane upon which the skull rests, or the

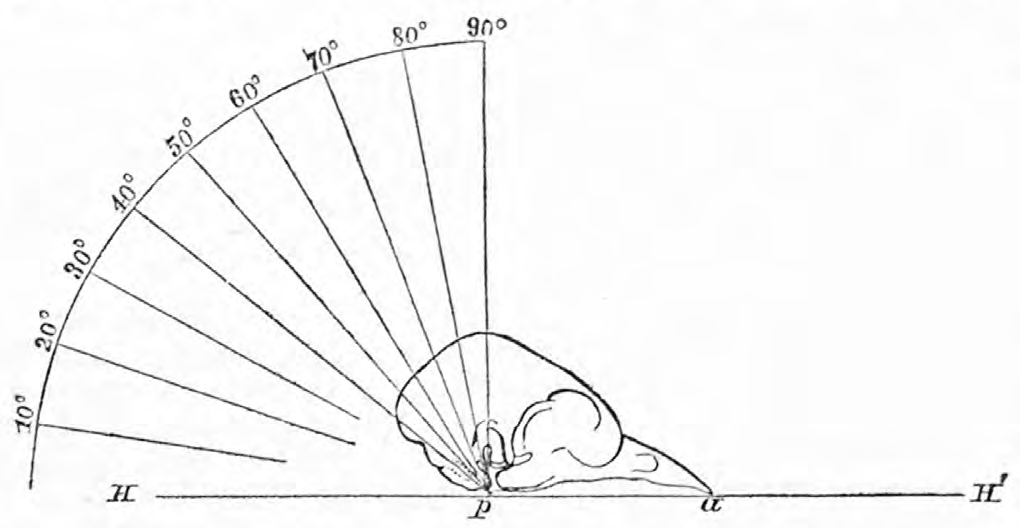

angles are $0^{\circ}$. We see then that in the present case, the bearing points being given, the angle of the combined planes is $40^{\circ}$, which fact, even without actually taking the angles in question, conveys to our minds about the "pitch" or relation of the basi cranii to the other salient features of the skull. Taken accurately, these angles, it is obvious, would 
have a certain value when we come to compare the various skulls of the Class.

The primary elements of the occipital, or first cranial vertebra, have become completely fused together, and with such other bony elements of the vertebra beyond, of the mesencephalic arch, with which they usually articulate. The well-marked superior eurved line that limits muscular attachment above would seem to be, and in all probability is, about the position of the lambdoid suture, and the superior boundary of the bone we are describing. This curved line descends and is gradually lost along the boundaries of the mastoids and occipitals on either side. Externally and inferiorly we find the occipital pierced by the usual foramina of the basi-cranii. The group for the exit of the eighth pair of nerves, being the most anterior of all, are situated on either side, in well-marked depressions or pits, some 7 millimetres apart. Back of these and nearer together are the minute precondyloids, looking forwards and outwards for the passage of the hypoglossal nerves. These last foramina are just anterior to the border of foramen magnum; this latter aperture is of good size, comparatively, having antero-posterior and transverse diameters of 3 millimetres each, with an additional millimetre for the oblique diameters, making the latter 4 millimetres each. It is subcircular in outline, its anterior rim passing around a depression that lies just in front of the condrle, giving the latter the appearance of jutting out into the foraminal space. The condyle is nearly sessile, having the merest trace of a neck, hemispheroidal in form, with an horizontal and average diameter of .5 of a millimetre. Above and midway, laterally, the borders of the foramen are encroached upon by the petrosal on either side, giving it rather a constricted appearance; from these points, as we follow the posterior moiety of the foraminal periphery, we find it to be grooved, each groove ending posteriorly within a millimetre of each other, in a minute foramen that traverses the internal table of the cranium upwards, outwards, and forwards for a short distance, thence to arch around, as a sinus, the epencephalic fossa, to meet in the longitudinal sinus coming from above. This arrangement obtains in the Corvida, and some other families, where it is more strongly marked. The diapophyses of the occipital vertebra are in a plane but a little lower than the basi-sphenoid; they form, as is quite common, the horizontal floor of the cavity of the otocrane, and blend with the surrounding bones. A moderately well-marked "cerebellar prominence" occupies its usual site in the middle line; no openings or foramina are ever to be discovered either at its summit or laterally, as seen in some other birds (Anatida, Strigid(e). It divides the shallow temporal fosse that slope away from it on either side, and varies somewhat in size in different inclividuals. From the upper region of the ear and the superior boundaries of the temporal fossæ to the line of that psuedo-articulation, the fronto-mandibular, this bird's cranium is remarkably smooth, and of a clear white, and, owing to the extraordinary amount of diplöic tissue, possessing a peculiar translucency. The median furrow is only well marked as it passes between the orbits; the superior peripheries of these cavities, as constituting one of the boundaries of the surface under consideration, are sharp at first, rounding as they include the lacrymals, and entirely devoid of any notches or indentations. As is usual, all sutural traces are absent (Pl. IV, Fig. 25). The transverse line of the fronto-mandil, ular juncture is slightly concave backwards along its midclle third, the extremities sloping a little downwards and backwards. The joint mo. tion is only moderately free. No well-marked suture defines its exact locality, as in Harporhynch us and others. The bones that go to form 
the superior mandible, both above and below, are mutually confluent at all their usual points of contact and articulations, with complete obliteration of their original borders. The nearly perpendicular nasals on either side form the anterior boundary of a triangular opening, of which the lacrymals and maxillaries form, respectively, the posterior boundary and base. These triangles are not complete, insomuch as the lacrymals do not meet the infraorbital bars at the inferior and inner angles. They lead into the rhinal vacuity on either side. It must be borne well in mind by the reader that in describing the upper mandible in the skulls of all birds, it invariably presupposes the removal of its horny integumental sheath that it wears during life, and gives to this portion of the cranium a vastly different shape. Either tomial edge is curved and quite sharp; their anterior mergence, or point of the beak, is decidedly rounded, and fully a millimetre in width.

The superior mandible is rather broad at its base; the culmen, originating in a flattened space just anterior to the fronto-mandibular articulation, is ronnded throughout its extent and gently curved downwards, while below, the line joining the middle points of the bases of the triangles above mentioned, averages 7 millimetres in length. The sides of the inter-maxillary are smooth, presenting only occasionally a row of very minute foramina for examination; sometimes a faint suture shows itself on either side, extending almost down to the nostril, between this bone and each nasal. Beneath, the palatine fissure is broad and rounded anteriorly, the roof of the mouth beyond being gently concave and grooved mesially for its entire length, and marked by a few foramina. The external apertures of the nostrils are quite large, nearly elliptical in ontline, approaching each other within less than .5 of a millimetre above. Their borders, formed by the nasals behind, are sharp; anterior, more rounded. The major axes of these openings average 4 millimetres, the corresponding minor axes 3 millimetres. The planes passed through their peripheries look upward, outward, and forward. The nasals are fan-shaped, both above and below, the expansion being slightly twisted, in order to accommodate themselves to the form of the bill. The broad lacrymals, assisted by the prefrontal, effectually separate the orbital vacuities from the rhinal chambers. The latter are more than usually open, owing to the size in the skull of the various apertures leading into them from without, already described, and devoid of all septa or bony offishoots, although the prefrontal, intermaxillary, and palatines together occasionally develop irregularly formed ethmo-turbinals, that extend into this space from behind and afford the necessary surface for the pituitary membrane. But there is nothing that has the slightest semblance to an osseous septum narium. The anterior olfactory foramina, narrow slits one millimetre long, are found between the lacrymals and prefrontal, close to the vertical septum of the latter; their outer extremities being the superior, they are seen to look downward and forward as they open into the nasal cavities from the bases of the concavities formed by the bones above mentioned.

The orbital cavities are capacious, having rather a forward look; at the same time they look a little downward. Their limiting borders are ovate in outline, with the greater end backward, being incomplete below. Anteriorily the septum that divides them is remarkably entire and of considerable thickness; posteriorly and above there exists quite a deficiency, of a shape shown in Pl. IV, Fig. 22; this is situated just in front of the large quadrilateral rhinencephalic foramen, and allows a good passage from either orbit into the brain-case. The same condition obtains below with the opening for the exit of the optic nerves, only the 
latter is much smaller and quite circular; to its outer side there are several minute foramina that lead directly into the brain-case. The groove for the first pair is distinct anteriorly on either side, and opens into slits between the prefrontal and lacrymals, similar to those described when speaking of them in connection with the nasal cavities. These, the anterior rhinal foramina, together seem to be the homologue of the "cribriform plate" of anthropotomy. The anterior wall of an orbit is formed by a lacrymal; this bone is larger than usually found in avian crania of this size. It is quadrilateral in form, concave posteriorly, thoroughly confluent with the frontal, nasal, and ethmoid, but not coming in eontact either with the palatines or suborbital style. About the middle of its outer border it presents a rounded notch for the lacrymal duct. Its anterior surface, forming the posterior wall for the rhinal vacuity, is undulating, though generally convex.

The superior wall of the orbit is narrow, gently concave, and formed as usual by the frontal. It looks downwards and outwards and merges into the orbito-cranial septum behind, conformably with the shape of the cavity under consideration. The posterior wall of the orbit presents quite a number of interesting points for examination. Internally and above we find the posterior rhinal foramen, and below it the foramen opticus, already described. In addition to other minute openings mentioned above, we have the foramen ovale, occupying a lower plane than any of the others, and situated more external to them, being almost directly behind the orbital process of the tympanic. Above it we observe a thin circular convexity, indicating the locality of the mesencephalic fossa; this sometimes develops at its outer border a sharp, vertical, osseous spine or plate, that points downwards, forwards, and inwards into the orbital cavity. Still beyond this, outwardly, we find another process, or rather two processes combined, with an elliptical foramen between them, placed vertically. The inner portion consists of a square lamina of bone, looking upwards and forwards; the other smaller and outer portion is a trihedral spine that descends, apparently from the frontal, to meet its external margin. The arrangement gives to the entire posterior wall a certain facing, directly forward, forcing upon the cranium of this little bird an aspect peculiar to another family, fróm which it is far removed-the Strigida.

The osseous floor of the orbital cavity is always more or less imperfect throughout the class, and is here formed by the customary bones, the tympanic, pterygoid, slightly by the lacrymal, and limited externally by the malo-maxillary squamosal bar.

The palatines nowhere come in contact with each other, and the palatine fissure is very wide, broadly rounded at both ends. The anterior extremity of each of these bones articulates in the usual manner, with the maxilliary and intermaxillary, the joints being immovable ones. Back from this point as far as the under surface of the lacrymals, on either side, they are but very slender, straight, and horizontally flat. tened little bones, without plate or process; at this latter point they suddenly expand into quadrate posterior ends, each slightly inclined downwards towards the median plane, throwing out a thin, nearly vertical plate for articulation with the fan-like and anterior ends of the pterygoids, while mesially they develop two other slender horizontal plates, the superior one being prolonged forward as a fine spicula of bone to meet the ethmo-turbinal mass, as above described.

They lightly touch the rostrum of the sphenoid, in company with the pterygoids, forming the usual arthrodial joint at this point in avian structure. Above they are smooth, look upwards and outwards, and 
the superior mandible, both above and below, are mutually confluent at all their usual points of contact and articulations, with complete obliteration of their original borders. The nearly perpendicular nasals on either side form the anterior boundary of a triangular opening, of which the lacrymals and maxillaries form, respectively, the posterior boundary and base. These triangles are not complete, insomuch as the lacrymals do not meet the infraorbital bars at the inferior and inner angles. They lead into the rhinal vacnity on either side. It must be borne well in mind by the reader that in describing the upper mandible in the skulls of all birds, it invariably presupposes the removal of its horny integumental sheath that it wears during life, and gives to this portion of the cranium a vastly different shape. Either tomial edge is curved and quite sharp; their anterior mergence, or point of the beak, is decidedly rounded, and fully a millimetre in width.

The superior mandible is rather broad at its base; the culmen, originating in a flattened space just anterior to the fronto-mandibular articulation, is ronnded throughout its extent and gently curved downwards, while below, the line joining the middle points of the bases of the triangles above mentioned, averages 7 millimetres in length. The sides of the inter-maxillary are smooth, presenting only occasionally a row of very minute foramina for examination; sometimes a faint suture shows itself on either side, extending almost down to the nostril, between this bone and each nasal. Beneath, the palatine fissure is broad and rounded anteriorly, the roof of the mouth beyond being gently concave and grooved mesially for its entire length, and marked by a few foramina. The external apertures of the nostrils are quite large, nearly elliptical in ontline, approaching each other within less than .5 of a millimetre above. Their borders, formed by the nasals behind, are sharp; anterior, more rounded. The major axes of these openings average 4 millimetres, the corresponding minor axes 3 millimetres. The planes passed through their peripheries look upward, outward, and forward. The nasals are fan-shaped, both above and below, the expansion being slightly twisted, in order to accommodate themselves to the form of the bill. The broad lacrymals, assisted by the prefrontal, effectually separate the orbital racuities from the rhinal chambers. The latter are more than usually open, owing to the size in the skull of the various apertures leading into them from without, already described, and devoid of all septa or bony offshoots, although the prefrontal, intermaxillary, and palatines together occasionally develop irregularly formed ethmo-turbinals, that extend into this space from behind and afford the necessary surface for the pituitary membrane. But there is nothing that has the slightest semblance to an osseous septum narium. The anterior olfactory foramina, narrow slits one millimetre long, are found between the lacrymals and prefrontal, close to the vertical septum of the latter; their outer extremities being the superior, they are seen to look downward and forward as they open into the nasal cavities from the bases of the concavities formed by the bones above mentioned.

The orbital cavities are capacious, having rather a forward look; at the same time they look a little downward. Their limiting borders are ovate in outline, with the greater end backward, being incomplete below. Anteriorily the septum that divides them is remarkably entire and of considerable thickness; posteriorly and above there exists quite a deficiency, of a shape shown in Pl. IV, Fig. 22; this is situated just in front of the large quadrilateral rhinencephalic foramen, and allows a good passage from either orbit into the brain-case. The same condition obtains below with the opening for the exit of the optic nerves, only the 
latter is much smaller and quite circular; to its outer side there are several minute foramina that lead directly into the brain-case. The groove for the first pair is distinct anteriorly on either side, and opens into slits between the prefrontal and lacrymals, similar to those described when speaking of them in connection with the nasal cavities. These, the anterior rhinal foramina, together seem to be the homologue of the "cribriform plate" of anthropotomy. The anterior wall of an orbit is formed by a lacrymal; this bone is larger than usually found in avian crania of this size. It is quadrilateral in form, concave posteriorly, thoroughly confluent with the frontal, nasal, and ethmoid, but not coming in contact either with the palatines or suborbital style. About the middle of its outer border it presents a rounded notch for the lacrymal duct. Its anterior surface, forming the posterior wall for the rhinal vacuity, is undulating, though generally convex.

The superior wall of the orbit is narrow, gently concave, and formed as usual by the frontal. It looks downwards and outwards and merges into the orbito-cranial septum behind, conformably with the shape of the cavity under consideration. The posterior wall of the orbit presents quite a number of interesting points for examination. Internally and above we find the posterior rhinal foramen, and below it the foramen opticus, already described. In addition to other minute openings mentioned above, we have the foramen ovale, occupying a lower plane than any of the others, and situated more external to them, being almost directly behind the orbital process of the tympanic. Above it we observe a thin circular convexity, indicating the locality of the mesencephalic fossa; this sometimes develops at its outer border a sharp, vertical, osseous spine or plate, that points downwards, forwards, and inwards into the orbital cavity. Still beyond this, outwardly, we find another process, or rather two processes combined, with an elliptical foramen between them, placed vertically. The inner portion consists of a square lamina of bone, looking upwards and forwards; the other smaller and outer portion is a trihedral spine that descends, apparently from the frontal, to meet its external margin. The arrangement gives to the entire posterior wall a certain facing, directly forward, foreing upon the cranium of this little bird an aspect peculiar to another family, fróm which it is far removed-the Strigida.

The osseous floor of the orbital cavity is always more or less imperfect throughout the class, and is here formed by the customary bones, the tympanic, pterygoid, slightly by the lacrymal, and limited externally by the malo-maxillary squamosal bar.

The palatines nowhere come in contact with each other, and the palatine fissure is very wide, broadly rounded at both ends. The anterior extremity of each of these bones articulates in the usual manner, with the maxilliary and intermaxillary, the joints being immovable ones. Back from this point as far as the under surface of the lacrymals, on either side, they are but very slender, straight, and horizontally flat. tened little bones, without plate or process; at this latter point they suddenly expand into quadrate posterior ends, each slightly inclined downwards towards the median plane, throwing out a thin, nearly vertical plate for articulation with the fan-like and anterior ends of the pterygoids, while mesially they develop two other slender horizontal plates, the superior one being prolonged forward as a fine spicula of bone to meet the ethmo-turbinal mass, as above described.

They lightly touch the rostrum of the sphenoid, in company with the pterygoids, forming the usual arthrodial joint at this point in avian structure. Above they are smooth, look upwards and outwards, and 
form a portion of the floor of the orbit on either side. The union among the basi-presphenoidal process and prefrontal plates is complete, all sutural traces having disappeared, and the included bones form the interorbital septum as already described. The zygomatic style, very slender, straight, and throughout its continuity nearly of uniform calibre, descends from before backwards from its maxilliary articulation to the tympanic, about 4 millimetres, the skull being horizontal.

The coalescence among its three original elements is unusually perfect. The anterior horizontal expansion is very slight, being crowded towards the intermaxillary osseous tomium on either side by the widely separated palatines. Its posterior extremity is elub-shaped and turned upwards, bearing on its inner aspeet a hemispheroidal articular facette for the cotyloid cavity of the tympanic.

In no single articulation found in the skeleton throughout the class does there seem to be more variation in plan, to meet the same end and carry out the same function, than we find in the pterygo-palatine with the rostrum of the basi-sphenoid. In our present subject, as in Pica and Corvus and many others, this extremity bears a thin expansion that articulates by its anterior edge with the palatine plate and neatly grasps the rounded and inferior side of the ros. trum, the two bones not usually coming in contact. The shaft of the pterygoid also slightly expands horizontally just before this articular surface is developed, more particularly in the angle between the two, adding greatly to the strength of the bone, and somewhat to the floor of the cavity of the orbit. The angle of divergence of the pterygoids in the present instance is exactly $45^{\circ}$; the intertympanic chord, 7 millimetres. The shaft of this bone is comparatively slender, prismoidal in form, somewhat twisted, and develops among the older birds sharp projecting edges. The enlarged tympanic extremity bears a subelliptical articulating facette, that glides upon a similarly formed surface surmounting the ptyergoidal process at the base of the orbital process of the corresponding tympanic element. These two little bones are well separated from the basi-sphenoid, and never any evidence of the development of pterapophysial processes is to be observed. As is generally, though by no means universally, the case among birds, the mastoid process of the tympanic in this Lark is distinctly bifid, each limb presenting for examination at its extremity an elliptical convex facette for articulation in a cup-shaped cavity intended for its reception in the roof of the aural vacuity. Of the two surfaces, the outer and at the same time the anterior looks outwards, forwards, and upwards, while the inner and posterior one, surmounting the shorter limb or bifureation, looks backwards and upwards. These two projections of the mastoid process are further separated posteriorly by a deep non-articular depression. The orbital process is well developed, long and slender, terminating in a knobbed extremity, the whole extending well within the orbital space. It has at its base, internally, the facette for the pterygoid already alluded to. This process is subcompressed from before backwards, and has throughout a gentle curvature upwards, having much the form of the thorn of the common rose, without its sharp point.

There are two articular facettes on the inferior side of the mandibular end, divided by rather a deep depression. Of the two, the inner is the larger and more symmetrical in form, being transversely elliptical. The outer one seems to be borne on rather a constricted neck, having on its outer aspect the acetabulum for the hemispheroidal facette on the squamosal. The anterior surface of the body is smooth and triangular in outline; the opposite and inner surface, somewhat similar in appearance, 
presents for examination, just below the mastoid process, a large, oval, jneumatic foramen; other of these openings may exist in the depression on the posterior surface of the body of the bone already described.

The inferior surface of the basi-sphenoid is convex outward, and slopes away gradually into the rostrum, anteriorly. The external orifices of the Eustachian tubes are extremely minute, as are the foramina for the entrance of the branches of the common carotid to the cranium. As already intimated when speaking of the pterygoids, there are no pterapophysial processes.

The external aperture to the cavity of the otocrane is an elliptical slit, 1.5 millimetres wide at its widest part, looking almost directly forwards, its lower end being the innermost or nearest the median plane. The mastoid, however, does not extend so far forwards but that in a direct lateral view we may see, through the opening, the funnel-shaped internal orifice of the Eustachian tube. The stability of the ear cavity is here, as in many birds, highly enhanced by the presence of numerous osseous trabeculæ, acting as struts and braces to its walls.

An examination of the interior of the brain-case shows the fossæ for the several cephalic lobes to be large-indicating a brain of good size for the bird. As already defined, the forafnina for the first and second pairs of nerves are in each case single, and as a whole more or less oval. A constriction, however, takes place in their outlines at the middles, formed by the encroaching interorbital septum, so that, looking out of the eavity, the foramen in either case appears double, whereas a view from an orbit reveals the fact of there being but one opening in either case. The olfactory foramen is very large-in the dry cranium-the defieiency being made up by firm membrane in the living Lark. The minute openings for the carotids at the base of the pituitary depression are placed, as usual, side by side transversely. The posterior wall of the sella turcica is deeply notched.

The longitudinal sinus is best seen along the superior and median crest, just before it arrives at the olfactory foramen. The middle fossa for the accommodation of the cerebellum is distinctly marked by long transverse concavities, admitting the rugæ upon the lobe in question when the brain is in situ. With regard to the structure of this bird's cranium, we may say that it is largely cancellated, the intermaxillary and petrosal approaching nearest the compact variety of bone; this fact lends to this part of the skeleton a great lightness, and well-prepared skulls of this Lark are very pretty objects.

The most remarkable feature to be observed, however, is the great amount of separation between the tables of the vault of the brain cavity, being fully a millimetre, and in some localities more, the interspace being filled in by quite an open diplöic tissue. This condition we well know to be a striking feature in the anatomy of the Strigida, but here is a bird that has the same arrangement as well marked, we believe, for its size, as any Owl in the North American fauna. The outline of the base of the cranium in Eremophila approaches the sector of a circle, a figure more or less true in all birds, and here, as in most others, the greatest departure from that figure being a too great convexity of the subtending arc. The length of the radius represented by the middle line is 3.2 centimetres, the intertympanic chord, including the bones, being 1.4 centimetres. We will only mention here, in regard to the free osseous elements of the sense capsules, that the sclerotals retain their usual form and arrangement, numbering in each eye from thirteen to fifteen. The attachment among them is rather firm, remaining as shown in Pl. IV, Fig.41, after a considerable amount of maceration. The ossicula auditus 
are also present, but a lens of some power is required to study their form and arrangement.

The hyoid arch-(Pl. IV, Fig. 37, seen from below).-This, the hæmal arch of the parietal vertebra, in no way deviates in this little Lark from the usual ornithic characters possessed by it among living birds, in being freely suspended beneath the cranium and acted upon by certain muscles. The glosso- and cerato-hyals seem to be confluent, and the bone thus formed consists in two narrow little affairs, that for their anterior two-thirds run alongside of each other with a greater or less intimacy, to have their tips slightly diverge anteriorly. Posteriorly the ends have a still greater amount of divergence, and at the junction of the middle and posterior thirds there is a transverse bony bridge, that bears the facette for articulation with the basi-hyal behind. Scarcely any anteroposterior curvature exists. The posterior tips overhang the artieulation of the thyro-hyals with the confluent basi- and uro-hyal. As we have never examined the tongue of the young of Eremophila, we may be in error in saying that the glosso- and cerato-hyals are confluent, as the bones we hare just described may be the cerato-hyals alone, the glosso-hyal being entirely in cartilage. The posterior tips of the ceratohyals have an expansion to accommodate the articulation referred to, bearing on either side small, elliptical, articular surfaces, looking backwards and ontwards for the heads of the hypo-branchial elements of the thyro-hyals.

The bone is subcompressed from above downwards, the nro-hyal being produced behind by cartilage, or rather tipped by that material, while the articulation at the anterior extremity of these confluent bones is hidden from view in the superior aspect of the arch by the glosso- and cerato-hyals; and, as is common, the inferior lip that the basi-hyal lends to this joint is the longer, and protrudes forward.

The hypo- and cerato-branchial elements of the thyro-hyals are very long, slender, up-curved little bones, produced posteriorly, as is the urohyal, by cartilaginous tips.

The shaftlets of these delicate elements are slightly flattened from above downwards, as are their articular heads. The free extremities have a tendency to curve inwards a little, or towards the median plane, as well as upwards.

The lower mandible-(Plate IV, Figs. 22 and 29).-Eremophila is another example exhibiting the non-approximation of the tomial edges of the mandibles in the dry skull, this feature being more often absent among Grallatores and many of the Natatores, where these edges come in contact with almost an equal amount of exactness as where the bill is armed with its horny theca.

The lower mandible of the Horned Lark seems to be, in point of structure, composed almost entirely of compact tissue, and, owing in addition to the thorough coalescence of its primary elements, a very firm and strong bone. Sutural traces, the indicators of the boundaries of pristine segments, have entirely disappeared, and no one would ever suspect, in examining it, the presence of nine original parts, were he not familiar with avian osteology or had the opportunity of dissecting the young. The inferior surfaces of the articular ends are on a level with the major part of the under rim of the rami, but they are well below the coronoidal elevations on either side. They present superiorly the usual undulatory surface to meet and articulate with the condyles of the tympanics. Below appears a longitudinal ridge, due to the extension upon that side of the ramal edges. A knob-like process projects behind, and the true articular processes are sharp and rather long. They are directed in- 
wards, upwards, and then forwards, having the usual pneumatic foramen above and near their pointed extremities. The superior margin of the inferior maxilla starts at once from each articular surface, to rise by a inoderate angle to the representative coronoids, a distance of 4 millimetres; it then falls gradually to the rounded and anterior termination of the bone. It exhibits about its middle, on each side, a long but very low convexity, the corresponding shallow concavities being between them and the coronoidal elevations. The "coronoids" are marked by deep groovelets with raised borders that extend forwards and downwards as far as the interangular vacuity.

The inferior boundary of the bone, as already stated, rises on each side in the inferior articular surfaces, to ascend first for two-thirds of its extent on each ramus, then to fall at about an equal angle, to sweep round and form the anterior and curved termination in the dentary element. The median line on the dentary segment averages 5 centimetres, this portion of the bone being quite thick and concave above, convex below. The general surface, both inside and out, between the boundaries just defined, is in each case depressed, smooth, and translucent until we arrive at the solid dentary portion, where we find it marked by a row of minute pits. Of some dozen or more lower maxillæ before me, one of the most striking differences existing among them seems to be the variation in size of the interangular vacuity or foramen. This is elliptical in outline with the major axis of the ellipse in the long axis of the bone, and in some specimens squarely meet the raised ramal borders within, while in other individuals, even though the bone be larger, this foramen is markedly smaller. A large concavo-convex sesamoid is found between the tympanic and articular end on each side. The long axes of these bones are placed vertically, and their concave surfaces look forwards. They are attached to the middle of the pointed articular processes behind by a delicate ligament, and above by the same means; by a somewhat broader attachment to the squamosals and tympanies, posteriorly.

Spinal column, cervical portion-(Pl. IV, Figs. 22 and 35).-In making a study of the vertebral column of this Lark, the student will find that he will be materially assisted if he make use of an engraver's eye-lens, or, better still, one of the low-power objectives of a good microscope, as some of the points for examination are rather minute, and are not so easily or satisfactorily demonstrated by the unarmed eye. The cervical portion of the column is composed of thirteen vertebræ; these enjoy, from the atlantal throughout the entire series, a perfectly free movement among cach other by their several articular surfaces; and some form of the sigmoidal curve, characteristic of the bird-neck, is invariably preserved during life and action. We find, too, the majority of the salient points pertaining to these segments described by ornithotomists, present, and strongly marked, and the chief functions of this jointed and bony isthmus well carried out-as affording protection for the myelon in its passage from the brain to the body below, and the vessels from their centre to the brain above. The neural canal, beginning in the atlas as a transverse ellipse, rapidly becomes circular, retaining this form throughout the tube, only to resume the elliptical again in the last two or three segments, where in the thirteenth it seems to be of a larger calibre than at the cranial extremity, the ellipse still being placed transversely.

The usual processes of ten of these vertebræ, the third to the twelfth, inclusive, afford protection to the vertebral artery and sympathetic nerve. By an apparent contraction of the parapophyses in the twelfth, 
the canal is open laterally in this segment. It is confined to the anterior third on each side of the vertebræ enumerated, and is exceedingly small throughout its extent; its largest calibre being at its commencement, its finest in the tenth or eleventh. Among the long vertebræ in the middle of the neck the anterior entrances of the vertebral canal are ellipses placed vertically. They become more circular as we approach the thoracic end of the chain. On the eighth vertebra, mesially, and beneath anteriorly, we find, bounded on either side by the parapophysial processes, the commencement of the interhyapophysial groove or camal for the carotid artery. It extends through the fourth vertebra with about an equal amount of distinctness and depth.

A neural spine is feebly developed upon the axis posteriorly, this process becoming more strongly marked on the summits of the next three succeeding vertebræ, the remainder of the cervical segments being devoid of this feature, though we have occasionally found an evident attempt at its reproduction in the ultimate cervical. The nethermost portion of the psendo-centrum of the first vertebra has been considered to be the atlantal hypapophysis. Be this as it may, the hypapoplyysis of the axis certainly has a much greater claim to be termed a process, while on the third and fourth segments this spine constitutes one of the most marked features of the vertebra, being a longitudinal and quadrate lamina of bone, equally well developed on the two vertebræ in question, directed immediately forward. In the case of the fifth cervical the hypapophysis has again degenerated to a minute median point, to be entirely obliterated in the sixth. At the ninth it again makes its ap. pearance as a delicate and flattened plate at the anterior margin of the vertebra beneath, at the point at which in the carotid canal it is first seen in the eighth. In the remaining ones it is prominently developed and directed forwards from the median plane in each vertebra as a quadrate lamina. It is usually triplicate in the last, but does not arise from a common stem, as in other birds.

Parapophysial processes appear as lateral spines first on the third cerrical; in the middle of the series they are very long and delicate, being parallel with the centrum of the vertebra to which they belong. They become markedly suppressed near the termination of this division of the spinal column.

Anterior and posterior zygapophyses retain throughout the cervieal vertebræ their most common ornithic features; in the middle of the neck the postzygapophysial processes are long and bent slightly towards the neural canal, leaving quite an extensive lozenge-shaped space between them in this region where the chord is unprotected by bone; the interarticular facets among the centra likewise retain their most common avian characteristics. The bodies for the most part seem to be slightly compressed from side to side, with a faint inferior median crest. The fourth vertebra has a delicate and outwardly-arched interzygapophysial bar, that includes within it an elliptical foramen on each side of some size. This bony connection in the third vertebra nearly fills in the interzygapophysial space, a very minute vacuity alone remaining.

All the cervical vertebræ appear to be pneumatic, but the foramina in some of them are excessively small and difficult of detection.

The bony cup of the atlas is not usually pierced by the odontoid process of the axis, but one cannot but wonder, this cup being less than half a millimetre across, that the skull, so very large as compared with its tiny occipital condyle, should not be subject to frequent dislocations; this undoubtedly would be the case were not the occipito- 
atloid articulation so thoroughly re-enforced by the thick muscles that surround it.

A square bony plate projects from below in the atlas, more anterior than any other part of the bone, that covers the atlo-axoid articulation in front.

The arch that connects the neurapophyses is broad and smooth, and assists greatly in the protection of the myelon between the two bones.

The odontoid process on the axis is concave in front, flat behind, with a roundish summit. It averages one millimetre in length, and is directed slightly backwards. The articular surface at its base is reniform in outline, the centium that supports it being contracted below. The postzygapophyses show faint traces of anapophysial tubercles; these are better marked in the latter cervicals. The last or thirteenth verte. bra has freely suspended from beneath each diapophysial articular sur face a rudimentary pleurapophysis that averages about two millimetres in length. These little bones represent the only true cervical ribs, though we must admit here that in several individuals we found the first pair of dorsal pleurapophyses unconnected with the sternum by the usual hæmapophyses, and ending in pointed extremities. Should such a specimen alone be examined, we would have to recognize fourteen cervical vertebræ, the last two bearing free pleurapophyses, but the common rule must dictate here as elsewhere, and the condition just mentioned be reckoned as the exception.

Dorsal vertebra, vertebral and sternal ribs, sternum-(PI. IV, Figs. 22, 24,27 , and 38).-The number of vertebræ devoted to the dorsal portion of the spinal column in Eremophila seems to be invariably five. They are easily detached one from another, and after ordinary maceration of the skeleton drop apart almost as readily as the cervical vertebræ, so that during life there is at least quite a little amount of free movement among these bones.

The neural canal, as it passes through this series, starts with the transverse ellipse as we left it in the last cervical, in the vicinity of the dorsal expansion of the myelon, to terminate nearly circular, and much diminished in calibre, in the ultimate segment of the sacral extremity.

The neural spines form by their interlocking a continuous ridge above. The thickened crest of this ridge is produced by what we will call the arrow-head joint, a true schindylesial articulation to be found in many of the class. The superior margin of each spine becomes pointed anteriorly, extends forward, and is received into a fissure of the posteriorly produced superior margin of the neural spine of the vertebra next beyond it. This arrangement has the appearance of so many little arrowheads placed in similar juxtaposition, and constitutes one of the elements of stability of the dorsal vertebræ in this bird. The open spaces remaining among the bodies of the spines below, between their produced crests and the sereral neural arches, are filled up by connecting ligament and membrane.

The diapophyses of the dorsals are a very much horizontally flattened series. They are all slightly tilted upwards, the anterior ones being the broadest and shortest, and the ultimate one, by a gradual departure in this regard from the first, the narrowest and longest. In the middie of the series, moderately well developed and antero-posteriorly produced metapophysial ridges are found limiting the diapophyses externally; they do not reach from one vertebra to another. The pneumatic foramina at the bases of these processes are very minute and scarcely discernible by the naked eye.

The inferior diapophysial facettes for the pleurapophysial tubercula 
are concave-elliptical surfaces, with their major axes parallel to the median line. The anterior ones are the more circular.

The zygapophysial processes, to assist in the intimate proximity of these vertebra, are short and thick. The anterior ones look upwards and inwards, the reverse being the case with the posterior series, which latter develop pointed spines that overlap above, each in its turn, on either side, the vertebra next behind, at the base of the common neural spine. The longest of these processes are found anteriorly; they gradually disappear as we near the sacrum.

The first dorsal hypapophysis consists of three plates, arising from the centrum of the vertebra separately, and arranged as shown in Fig. 38. On the second dorsal we find only a single quadrate plate in the median plane, directed forwards. It occupies a position at the anterior margin of the vertebra, but is produced posteriorly as a low, thin lamina of bone, along the remainder of the centrum mesial to the raised and posterior margin. The third vertebra takes it up in this form, and it is thus passed along the series, constituting a continuous hypapophysial ridge, intersected by the expanded anterior and posterior borders of the centra.

The articular surfaces among the bodies retain their usual characters. They extend into the ridge just described. The centra of the dorsal vertebra are somewhat compressed in a slightly increasing degree from before backwards; each lateral and anterior margin supplies a nearly circular parapophysis for the pleurapophysial capitula, while at points on the posterior margins in the same plane we fiud the major share of the notch, which in coaptation of the segments constitutes the subcircular foramina for the exit of the dorsal nerves.

There is a free pleurapophysis for each dorsal vertebra, but the first is not always connected with the sternum by a sternal rib, as already defined; it sometimes has all the characteristics of a movable cervical rib; again, when it conneots with the sternum, its hæmapophysis articulates rather high on the costal border (Pl. IV, Fig. 22). It may or may not bear an epipleural appendage.

The vertebral ribs of this Lark articulate, as usnal, by tuberenla and capitula, with the dorsals, meeting par-and di-apophyses in the ordinary manner. The necks of the ribs in the middle of the series are the longest, and often we find among the ultimate ones a slight projection beyond the tubercle, that is received in a corresponding notch at the outer border of the diapophysis it meets. There is but little difference in the width of these flat bones; perhaps the auterior ones have rather the advantage in this respect. Minute apertures, to allow the air to enter their bodies, are observed in the usual localities.

The laterally viewed curve of a dorsal rib is barely sigmoidal; viewed from in front it approaches a portion of the curve of an arc of an ellipse.

A ridge continuous with the neck is carried down the inner aspect of each bone, to gradually disappear near its middle. The lower extremities of these ribs are slightly enlarged, to afford space for articulation with the sternal ribs; the surface is convex.

The epipleural appendages of the dorsal pleurapophyses are confluent with the posterior elges of the bones, and situated below their middles. Occasionally the one in the middle of the series has sufficient length to overlap two ribs; in young birds of this species they are much shorter, and the best-developed ones show an angle on their inferior borders just after leaving the rib, as if they had left that bone with the original intention of proceeding downwards and backwards at a gentle 
angle, but suddenly changing mind, proceeded directly upwards and backwards at an equal angle; hence the condition alluded to.

When the first dorsal rib articulates with the hæmal spine below by the intervention of a sternal rib, this latter bone is quite small and delicate, averaging about 3 millimetres in length, and but slightly curved. The remaining dorsal hæmapophyses become longer and more curved as we follow them backwards. They are all flattened from side to side, their lower extremities being abruptly twisted at right angles with their shafts, enlarged, and terminating in a flattened articular surface for the costal border of the sternum. These articular surfaces are dumb-bell shaped, $i . e .$, contracted in their middles. The upper ends of these sternal ribs are also enlarged and laterally flattened for articulation with the vertebral ribs. These latter enlarged ends are sometimes larger, sometimes smaller, than the extremity of the pleurapophysis they meet.

If we accept as true the old vertebral theory of Oken, Goethe, and Owen, a theory that holds that the skull of all vertebrates is composed of three, four, or more modified vertebræ, that these vertebræ in evoluting from the very earliest forms in which a bony segmented column appeared, that during this evolution many metamorphoses took place in the skull, such as the restriction of the notochord to the first or occi. pital vertebra, the mode of development of the elements themselves, whether by cartilage or membrane, and the appropriation by these "cranial vertebræ" of bones that did not originally belong to them, that we cannot positively say what may become of the cranial extremity of the spinal column of Amphioxus, or some of the hæmal arches in the hag and others, then we must recognize in the sternum of birds, developed as it may be, the confluent hæmal spines of the dorsal series of ribs; and in it, in its maturity, see one of the most interesting bones to contemplate, it being one of the most diversified in form in the bird skeleton. Owen styled the type of this bone, as found in the Lark now under consideration, "cantorial" (Anat. and Phys. of Vert., Vol. II, p. 20). It is certainly typical of the suborder Oscines, as far as American ornithology is concerned; good examples as testifying to this I have now before me, in the hrmal spines of Turdus migratorius, Ampelis garrulus, Mimus polyglottus, Lanius, and many others.

In Eremophila the sternum is very light and delicate in structure; so thin is it in some individuals that we find deficiencies occurring, usually in the body, as foramina of no mean size (1.8 millimetres). Its outer surface, indeed the entire surface of the bone, has the appearance as if it were venated, the solid bony veins being thicker and more opaque than the general surface of the bone, and branching from the various borders.

The carina is moderately well developed, measuring in the vertical line below the coracoidal groove 9 millimetres. Its inferior border, expanded behind, is ronnded and somewhat thickened; this thickening disappears on the anterior border, which is sharper and continuous with a couspicuous crest on the front of the manubrium.

The carinal angle, with an aperture of $70^{\circ}$, is quite prominent and produced anteriorly. Just within the anterior margin of the keel we find a rather prominent carinal ridge, its lower extremity branching backwards, and by its ramifications taking part in the superficial venation referred to above. The keel arises abruptly from the inferior and median angles formed by the sides of the body where they meet mesiad.

The xiphoidal prolongation is profoundly notched once on each side. These notches have the outlines of isoceles triangles, with their angles rounded, and apices but a short distance from the costal borders. These 
deep indentations of the xiphoid give rise on either lateral sternal border to a long, stout process, extending backwards and outwards, with dilated extremity.

The outer surface of the body of the sternum presents for examination well-marked pectoral ridges, and, running from the bases of the xiphoidal processes to the outer angles of the coracoidal depression, clearly defined subcostal ridges.

The manubrium is a prominent, superiorly bifureated, trihedral process, jutting out from a substantial base in the median plane, forwards and upwards, from the angle formed by the coracoid groove and the front border of the carina. At its base internally there is an extensive oval pneumatic foramen. Its bifurcations are rounded, and give attachment at their extremities to firm ligaments, that pass directly to the coracoidal capitula above.

The groove for the coracoids is strongly marked and continuous in front, extending from costal process to costal process; its boundaries form the thickest and stoutest part of the bone we are describing.

The costal processes, possessed of broad bases, arise as thin but prominent lamina, upwards, forwards, and outwards, terminated by flattened summits. Their posterior margins bear the costal facets for the articu. lating ends of the sternal hæmapophyses.

The sides of the body of the sternum on its ventral aspect make an obtuse angle with each other. The line of meeting in the mesial plane is quite evident; its anterior half is the seat of a row of various-sized pneumatic foramina. There are upon each costal border five, sometimes six, transverse facettes for the sternal ribs; the shallow depressions among them are scantily supplied with pneumatic foramina.

The mid-xiphoidal border, in which the keel terminates posteriorly, is thickened; its other boundaries are sharp, with raised ridges below, just within their edges. The greatest length of the sternal body is a little more than two centimetres, and its greatest width a little more than one centimetre, the last measurement taken to the rear of the costal processes.

Sacral vertebra and ribs, pelvis, cocoygeal vertebra-(PI. IV, Figs. 22, 23, and 28).-The first sacral vertebra has become thoroughly confluent with the ossa innominata on either side and with the vertebra behind it. Its diapophyses seem to have spread out upon the under surface of the ilia, combining with them, for we observe that the first sacral pleurapophyses articulate in the ordinary manner with the transverse processes and the parapophyses, the tubercula being situated just near the outer iliac borders. This rib may become, as a rare event, confluent with the pelvis, but is usually free. Its hæmapophysis is the longest of the series, and the articular facette on its lower extremity meets the last facette upon the sternal costal border. This sacral pleurapophysis may possess an epipleural appendage, though it seems to be the exception.

The second sacral rib is a delicate hair-like bone of uniform thickness, that does not show any decided tubercle, merely, after leaving the vertebra, coming in contact with the under surface of the ilium, on each side, for the entire interspace between the tubercle and head. It, too, may become confluent with the pelvis on its lower surface.

Extending downwards and forwards by a gentle curve, it meets its hæmapophysis through a miniature articulation. This latter style articulates along the posterior border of the sternal rib of the first sacral pleurapophysis, never reaching the costal border, and the second sacral rib never bears an epipleural spine on its posterior border. 
The sacral vertebræ are invariably confluent throughout the chain in the pelvis of the Horned Lark; indeed, it is only by a process of staining this compound bone, and the aid of a strong light, that they can with any satisfaction be counted. There are eleven of them; exceptionally, twelve.

The neural canal, circular at the outstart, shows the usual pelvic sucell, chiefly anterior to the acetabula, conformable with the ventricular dilatation of the myelon in that locality. The exit of this tube distally is likewise nearly circular. The foramina along the bodies of the centra, in the vicinity of the dilatation referred to, are double and placed one above another, for the separate egress of the roots of the pelvic plexus.

The anterior aspect of the first sacral vertebra presents every element and process requisite for articulation with the ultimate dorsal segment. It is largely overshadowed by the ossa innominata. Opposite the iliac contraction, in the neighborhood of the fourth and fifth sacrals, these vertebræ throw out their par-and di-apophysial processes far enough to meet and brace the iliac bones. We do not meet with such braces again until arriving opposite the acetabula and beyond, where the parapophyses project upwards and unite with the outer margins of the transverse processes, the ilia articulating with the free and united borders.

Foraminal deficiencies not unusually occur among these processes, more particularly between the last two sacrals, where they seem to be constant, though of varying size and shape in different individuals.

The last sacral vertebra is compressed from above downwards, retain. ing, however, all the elements required in articulation with the first and much-modified coccygeal vertebra.

Viewing the confluent sacral vertebræ, or the "sacrum", from above, we find the united neural spines, as a vertical lamina, dividing the anterior interiliac space into two capacious ilio-neural grooves at that moiety of the bone.

This common neural spine and the ilio-neural grooves proceed backwards until the gluteal ridge of the ilium curves outward to the antitrochanter on either side. At this point the spine disappears with the grooves, the sacrum becomes nearly flat and spreads out, to gradually contract again before its ultimate dilatation in the diapophyses of the last vertebra.

It is a well-known fact to the ornithotomist that the pelves of birds differ with respect to the ilio-neural grooves in one of two ways. As seen in this bird they are grooves, as the ilia do not meet the united spines of the vertebræ; they are very frequently, however, converted into canals in other orders, by meeting of the interested bones above. The condition as defined though, in the previous paragraph, as relating to Eremophila, seems to be characteristic of American Oscines. The sacrum is slightly convex from before backwards on its upper surface. moderately concave along the confluent centra below.

The pelvis of this bird is uncommonly wide and short, and the ischiadic and pubie posterior extremities remarkably flared outwards. The anterior and inner angle of each ilium, apparently assisted by the diapophysis of the first sacral vertebra from beneath, is pointed; the anterior border slopes backwards gradually, for a distance of 3 or 4 millimetres, to the rounded anterior external angle of the ilium. Between this point and the acetabulum the iliac border is strongly concave inwards, as is the surface of the bone above it, the preacetabular being included between this border and a well-defined gluteal ridge. The superior postacetabular iliac surface is nearly square in outline, convex. and equal to a little more than one-third of the bone. It is thin and 
translucent, its outer and posterior borders receiving the greater share of osseous reënforcement, particularly in the vicinity of the antitro. chanter.

Posteriorly, the ilium, slightly aided by the ischium, is carried out from an ilio-ischiadic, overhanging erest, as bony processes, with their points turned slightly inwards.

These processes are strongly marked in another of our Oscines, Harporhynchus rufus, a bird that has a strikingly angular and rather unique pelvis.

The antitrochanter is subelliptical in outline, and faces downwards, forwards, and outwards. The articular surface is produced downwards as far as the cotyloid cavity, upwards slightly above the general surface of the ilium, and is bounded posteriorly by the ischiadic noteh.

The foramen at the base of the hemispherical cotyloid cavity has so far absorbed the bone that really scarcely anything remains of it beyond a cylindraceous acetabular vacuity, the internal and external apertures being circles of equal diameter, and the femur consequently relying almost exclusively upon its fleshy and ligamentous attachments to retain its head in the ring.

Sutural traces of the margins of the pelvic bones as the components of this osseous ring have entirely disappeared, having been obliterated during the pelvic consolidation.

The ischium, for its major part, is like the ilium-very thin, more particularly so at its free posterior borders; joining with the ilium behind, it shuts off a large aud elliptical ischiadic foramen, the superior are of which is situated just beneath the ilio-ischiadic erest described above. The major axis of this ellipse is directed downwards and backwards.

The posterior extremity of the ischium has an odd-appearing, foot-like termination, that is bent down to meet the pubis.

This latter bone is an extremely slender style, that, immediately after assisting in the formation of the cotyloid ring, closes in a small, in fact the smallest of the group, subcircular obturator foramen behind; then running parallel with the ischium, by touching its further end, inclose, another long spindle-shaped vacuity; it is finally produced beyond that bone by a pointed extremity, that curves backwards and inwards.

It only remains now to say of the pelvis, as far as its internal aspect is concerned-after what we have said in regard to its extreme lightness, its translucency, its sacrum, and its borders-that, in general, superior convexities cause or create internal concavities, and vice versa. It is capacious, and the various bones that compose it thoroughly anchylosed together.

There are seven coccygeal or caudal vertebra, rarely only six, and the pygostyle; they are in the skeleton so arranged and articulated that they have, as a whole, a gentle curve upwards, terminated by the quadrate "coccygeal vomer."

These segments are all free, being easily individualized, even before maceration, by simple section of the ligaments that bind them together.

The subcircular neural canal, that passes through them, almost capillary in its dimensions, terminates without passing into the pygostyle.

There is no hæmal canal developed, and indeed hypapophyses are found as stunted tubercles only on the last two or three vertebræ.

A neural spine is developed on each, as a prominent and curved process, pointing forwards; this spine is wanting, however, on the last caudal.

Of the lateral apophyses the transverse processes seem to be the only ones entitled to any consideration; these, as broad, flattened lamina, 
extend from each vertebra, downwards and outwards, decreasing in width from before backwards; in fact, each vertebra in the coccygeal series becomes more and more rudimentary as we proceed in that direction.

The articular facettes upon the centra start reniform, to terminate almost circular in the last vertebra; and the zygapophysial processes are exceedingly elementary in character.

The pygostyle is parallelogramic in outline, articulating with the ultimate coccygeal vertebra by an unperforated cup-shaped depression, at the middle of its long anterior side. The edge of the bone above this point rests on the posterior border of the neural spine of the last caudal; below it is free.

The superior angle is more or less produced, and the posterior corner of the parallelogram is expanded laterally; this expansion is highly developed in many birds, as in Colaptes mexicanus and other members of the family Picide. The caudal vertebræ are non-pneumatic in our present subject, whereas in the pelvis we find these foramina in their usual localities.

The scapular arch-(Pl. IV, Figs. 22, 30, 32, 33, and 34).-This arch is very strong and perfect in this bird, as it is among the Oscines generally.

The bones can be easily separated from each other by maceration, though during life they are remarkably well strapped together and to the sternum by their numerous ligaments.

The scapula lies along the dorsum in its usual position over the dorsal pleurapophyses, parallel with the vertebræ, with its posterior point touching the fifth one in the vast majority of the specimens.

Certain bones in all skeletons force upon us their resemblance to familiar objects, and we know many of them have received their distinctive appellations through such likeness; more particularly is this the case in the skeleton of man, where the bone we are describing is frequently termed the shoulder-blade, but how much more blade-like is the scapula in this Lark and many other birds, as far as shape is concerned. It is truly a miniature bony cimeter in Eremophila. This is not true for scapulæ of all birds, however, for no one would ever be struck by such a resemblance while regarding the $J$-shaped scapula of Colaptes mexicanus, or the straight, almost square-cut bone in some of our natatoriai birds.

In the Horned Lark the scapula is pointed and obliquely truncate behind for more than a third of its slightly dilated posterior portion, on the side towards the vertebræ.

The outer border is reënforced by a rounded ridge for nearly its entire length, while the inner is quite sharp.

The blade becomes stouter and subcompressed as we near the glenoidal process; this broad tuberosity extends downwards, forwards, and outwards, and is crowned on its entire summit by a curved, subcircular, articular facet, that supplies rather more than one-third of the glenoid cavity for the head of the os humeri.

The acromial process is bifurcated, and the clavicular head rests in the fork. The larger bifurcation is the lower, and both rest against the coracoid, on the inside and just below the head, creating the usual scapulo-coracoid foramen, which in this case is not very extensive.

The scapula is pneumatic, and the foramina are to be found at the extremity of the larger bifurcation of the acromial process, and in the notch between the two.

The coracoid can boast of a very fair subcylindrical shaft between its 
head and inferior expansion. This flared extremity is quite thin ontwardly, stouter within, where it appears to be more of an extension and spreading of the shaft in its course downwards. Below there is a narrow crescentic facet for the sternum, and at the upper edge of the exterior and thin side of the dilated end we find a notch, sometimes a foramen, that appears to be constant.

The upper extremity of the coracoid is an irregular tuberosity, con. sisting of a lower, inner, and smaller process for articulation with the clavicle, and an upper, superiorly convex head, that curls over mesiad to create a fossa, at the base of which we discover a group of various sized pneumatic foramina. Anteriorly the head shows rather a well marked process, into which the ligament coming from the horn of the sterual manubrium, of the same side, is inserted.

To the outer aspect, and below the head, is the reniform and vertical facet that, with the scapula and os humero-scapulare, goes to complete the glenoid cavity.

The os humero-scapulare is a free bone, rather larger than the patella, found at the upper and posterior angle of the glenoidal process of the scapula. It is an elliptical dise, with a peg-like process extending from it from behind. The outer surface is concave and articular for the completion of the glenoid cavity. This ossicle is held in position by various fibrous ligaments stretching from its borders to the scapular arch and the humerus. ${ }^{1}$

The clavicles are thoroughly fused together, forming one deeply U. shaped bone; their cylindrical and curved lengths support at the union, mesially and below, a long lamina of bone, in the median plane, that is directed upwards and backwards, parallel to the anterior carinal crest, to which it is united by ligament in the living bird. Their upper ends are expanded and placer in the skeleton flat-wise against the acromial process of the scapula and the head and the lower or clavicular process of the coracoid. The acromial process, through its bifurcation, partially grasps the hind border of this expanded end of the furculum, on either side.

This bone seems to be non-pneumatic, while the coracoids are hollow almost throughout their entire extent, having in their composition very little cancellous tissue and a thin though firm, compact layer. The scapulæ are hollow for some little distance into their blades, to be terminated by a cancellous structure, with an external and attenuated outer compact coat.

With the scapula arch in situ, we observe that the coracoids do not meet below in the coracoidal groove of the sternum, but approach only, on each side, as far as the periphery of the pneumatic foramen at the base and behind the manubrium.

They are directed upwards, forwards, and outwards, at an angle of about $45^{\circ}$ with the horizontal plane, the skeleton being erect; and, as a consequence, we find their upper ends further apart than any other part of the bone.

The aperture between scapula and coracoid is in nearly a right angle, and the straight part of the inner scapular borders are parallel, their obliquely cut ends alone slightly turning outwards.

A scapula is 2.5 centimetres jong, a coracoid 3 centimetres, the interclavicular space above being 1 centimetre.

In Turdus migratorius we find the scapula shorter in proportion when

${ }^{1}$ This little bone should be considered as a sesamoidal auxiliary to the shoulder girdle, as it increases the articular surface of the glenoid cavity, and never be enumerated as one of the bones of the pectoral limb. 
compared with the other bones of the arch; the coracoids more depressed, i. e., more in line with the sternum; and the furculum in its direction backwards showing a gentler curve.

The upper extremity - (Pl. IV, Figs. 22, 31, 36, and 43).-The pectoral limb in Eremophila maintains the usual ornithic characters of a great number of the class, both in arrangement and number of the bones comprising it. The skeleton arm has ten distinct segments; of these, we find one devoted to the brachium, two to the antibrachium, two to the carpus, one to the metacarpus, and four to the phalangeal portion of the manus.

The bone humerus in this bird is more remarkable for its lack of curv. ature than anything else, being short and straight, as in others of the suborder among which our subject is classed and belongs.

The head of the bone is broad and moderately flexed anconad, developing only a very narrow and thin radial crest, which is bent for its entire extent toward the palmar aspect. This erest, answering to the "greater tuberosity" of anthropotomy, and giving attachment to the usual muscles, extends along on a straight line on the upper aspect of the shaft longitudinally for only about half a centimetre.

The nlnar tubercle, or lesser tuberosity, makes up the thickened and proximal border of the confines of the pneumatic foramen; a deep little pit on its palmar side or margin lodges the extremity of a strong ligament coming from the head of the coracoid of the same side, and materially assists in keeping the head of the humerus in its socket.

The elliptical and convex articulating facet of the head eurls over anconad, and from its middle a line runs down the bone for a short dis. tance, being one of the angular boundaries of this the trihedral extrem. ity of the bone. Quite a notch exists between the facet just described and the wall of the pneumatic foramen. This latter is on the under side of the head of the bone, snrrounded on its upper, proximal, and lower aspects by a firm bony wall, the lower and proximal parts of which are continuous with the smooth and otherwise unbroken surface of the expanded and palmar side of the head.

The pneumatic fossa thus formed is deep, having at its bottom the foramen alluded to. Quite often the aperture is multiple, and vast differences in size exist, being very large in some individuals, nearly consuming the base of the fossa where it is found. From the lower boundary of the pneumatic enclosure another longitudinal line is seen on the proximal end of the shaft, limiting the anconal face of the trihedral end of the humerus in this direction. The palmar aspect of the head, broad and smooth, arches gradually inwards and towards the articular facet; it is also slightly convex from above downwards, supposing the bone to be in situ and in its position of rest, as we do during the course of our description.

The shaft of the humerus is subcompressed from within outwards, smooth, and, viewing it laterally, it is barely convex above, by virtue of the ends being bent slightly down; viewing it from above, we may say that it is almost straight.

It retains its form until close under the expanded distal extremity, which is curved palmad. On the radial side of this end of the bone we find the transverse and convex elliptical trochlea below, for the sigmoid articulating depression of the ulna. This has inferiorly the quadrilateral internal condyle.

The ulnar convexity is separated from the oblique tubercle for the radius most effectually by a deep, well-marked, though narrow, notch.

The oblique tubercle maintains its usual position as found on this bone in birds generally. 
The trochlea surface does not extend inwards very far; i.e., does not pass over the end of the bone. Above it, and towards the proximal end, appears a distinct and prominent external condyle.

Anconad, this extremity of the humerus presents for examination the upturned internal condyle and a longitudinal tendinal groove, situated opposite the radial convexity, with intervening indentations. This ar. rangement lends to this aspect of the bone rather an uneven and tuber. ous look. The nutrient foramen, almost too minute to be observed by the naked eye, is found at the middle and inner aspect of the shaft.

The radius is a long, delicate bone, with a bent and compressed shaft. A moderately well-expanded and circular head presents the usual concavity for the oblique tubercle of the humeral trochlea, while below is a feebly marked ulnar facet and bicipital tuberosity; beyond this, again, the shaft develops a sharp, protruding edge, that extends nearly to midshaft and into the interosseous space.

The distal extremity of this bone is spread transversely and curved downwards. It articulates with the upper surface and distal end of the ulna, and is lined above by very minute tendinal grooves. The outer border of this extremity presents a transverse lamina of bone that seems to be superadded to the dilated end.

In articulation, the radius at first curves away from its companion, the ulna, to approach it again towards the carpal end, for about the outer third of the shaft, to remain with it until both arrive at the wrist. The distal border of the radius is transversely convex for an articular facette on the scapho-lunar. The ulna is the main bony support of the forearm, and, indeed, its shaft is nearly equal in size and strength to that of the humerus itself, having the appearance of being the true continuation of the pectoral limb, so diminutive and slender is the accompanying radius.

Its proximal extremity is the larger, and is gently curved anconad, to meet the corresponding flexure of the brachium to form the elbowjoint, the articular surface engaged being quite extensive and vertically expanded. The lower, circular, and concave trochlea is the greater sigmoid cavity, and is intended for the ulnar tubercle of the humerus. Its proximal margin is so produced as to form a strongly defined "ole. cranon process", the lower lip of the cavity being the homologue of the "coronoid process", and is so teebly developed as to scarcely deserve the distinction. In close proximity to the greater sigmoid cavity, above, there is another articular surface, quadrilateral in outline, decidedly concave from above downwards, much more shallow in the opposite direction, for the oblique tubercle. Immediately beyond its distal margin is a weak and shallow facette for the side of the head of the radius, so that the oblique tubercle articulates in a cavity furnished by the cupped head of the radius and the larger quadrilateral trochlea of the cubitus, the two being almost continuous.

The outer aspect of this extremity presents simply certain feeble elevations and depressions for muscles and the ligaments surrounding the joint.

From the proximal extremity, the nearly cylindrical shaft curves gently palmad from its inner third only; after that it takes a comparatively straight course for the wrist. The anconal aspect of the shaft presents at the junction of the inner and middle thirds an eliptical nutrient foramen, that enters the bone almost perpendicularly to its long axis. The tubercles for the insertion of the bases of the quills of the secondaries, so prominent on this bone in some birds, as in Colaptes, seem to be entirely absent. We find them barely present in Harporhynchus, quite strongly marked in Lanius. The carpal extremity of the 
ulna is likewise articular, being vertically cleft and curved downwards. Anconad it develops a rough eminence, and above a depression for the fan-like expansion of the radius. This end, as in the majority of the class, articulates with the three carpal bones and the radius above.

The humerus measures 2.4 centimetres, the ulna 3 centimetres, and the radius 2.7 centimetres; so that when the bones are placed in situ and the wing closed, the anti-brachium projects beyond the brachium about 5 millimetres. The bones of the forearm, though hollow, are apparently non-pneumatic, as is the case with the earpals and long bones of the manus.

As in the great majority of the class, the bird-wrist is composed of the two free carpals and the os magnum, which is confluent with the proximal extremity of the second metacarpal.

The superior and smaller carpal is the scaphoid, here an irregularly shaped bonelet, introduced among the cubitus, the radius, and the confluent os magnum, with a distal articular face for the latter and two proximal ones for the trochleæ of the anti-brachium. Between the scaphoid and the cuneiform, the other free and inferior carpal, there exists an interspace, where the ulna meets the os magnum.

The cuneiform has an elongated facet on its outer aspect for the ulna, and two articular processes that grasp the metacarpal below-an arrangement that admirably meets the action required of the avian wrist.

The last carpal merely constitutes the trochlear head of the confluent metacarpals; by a gentle and backward sweep its general surface is di. rected inwards.

The composition of the metacarpal bone of this bird does not deviate from the general rule, as applied to the class, in any imi)ortant particular. The three long bones comprising it are firmly anchylosed together and bear the fingers. The shortest and first metacarpal, obliquely fused with the anterior and upper end of the second, supports a free and pointed index digit. The second, or medius, supports, first in order below, a phalanx peculiar to birds, that is at once recognized by its expanded posterior border. It is here deeply concave on its inner surface, which concavity is partially divided by a feeble transverse line.

The blade of this bone is quite thin in some birds, even the general surface is sometimes absorbed, leaving nothing but the rounded and limital borders, as in Larus delawarensis and others.

The neck of this bone is but moderately constricted between the blade and articular facet for the metacarpal to which it belongs. It bears below another, and the smallest, phalanx of the hand, a little, free, sharppointed and compressed finger, that completes the skeletal bird-arm distally, being the ultimate segment.

The third metacarpal, termed annularis, a slender, ribbon-like bone, fast above and below to medius, and extending slightly beyond it, also articulates distally with another free phalanx, of the general character as the index digit and the ultimate jont of the mid-metacarpal, although it is longer than either of them. Measuring along the anterior aspect, from the summit of mid-metacarpal to the point of the last phalanx, we find the manus in Eremophila to average 2.6 centimetres.

This, the pectoral limb, as we have endeavored to picture it in this Lark, with its brachium, anti-brachium, and pinion in proportionate equipoise as to length of segments, with its various bones smooth, straight, and devoid of those evidences of being acted upon by powerful muscles, would require but a glance from the student of avian skeletology to pronounce it as belonging to a bird possessed of a flight barely mediocral in rapidity and power. 
Of the pelvic limb-(Pl. IV, Figs. 22, 39, 40, 42, 44, and 46).-The inner aspect of the upper extremity of the femur presents the usual globular head for articulation with the cotyloid ring of the pelvis. It is nearly sessile with the shaft, the neck amounting to almost nil. A shallow and inconspicuous excavation occurs on the head for the insertion of the ligamentum teres. The articular surface that originates with this hemispherical protuberance extends outwards over the summit of the bone, constantly spreading, until limited by the trochanterian ridge, in a plane with the outer aspect of the shaft; it occupies a slightly higher level than the head, and it is opposed to the anti-trochanter in the articulated skeleton.

Anteriorly the trochanterian ridge and line are quite prominent, extending a short distance down the shaft, to be lost on the general surface ; posteriorly it projects outwards horizontally from the articular surface, over a shallow concavity that is found immediately below, that presents at its base a circular foramen that leads to the hollow shaft, and is probably the pneumatic foramen, though the femur of this bird does not have the appearance of a bone possessed of pneumaticity ; the ori fice, if nutrient, is certainly situated in an unusual place, though we must confess that a careful search over the entire shaft with a powerful lens has failed to reveal any other opening. The trochanter minor is not represented.

The shaft, for the greater part of its extent, is cylindrical, and decidedly convex forwards, with a clean superficies, undivided by any intermuscular ridges or lines, or if so, they are very faintly marked.

The distal extremity of the femur enters largely into the knee-joint, and is more bulky than the proximal extremity of the bone. It is directed backwards, and, as usual, is divided by an antero-posterior shallow intercondyloid notch, which is continued up the shaft anteriorly, as the "rotular channel," soon to disappear into internal and external condyles. The larger and lower external condyle is longitudinally eleft posteriorly, so as to afford an additional and outer condyloid surface for the head of the fibula, with which it articulates.

A tuberosity is found behind, just above this cleft, and a few others, less prominent and situated more internally, are seen on this aspect of the bone, in the popliteal fossa.

The limiting margin of the internal condyle is sharp and distinct. The ordinary features, as tuberosities and muscular lines and markings, usually sought for at this end of the bone in nearly all birds, are very feebly reproduced in our present subject.

The proximal extremity of the tibia has a very interesting form, due to the prominence of the cnemial ridges. These are attached to the head of the bone, well above the horizontal articular surface for the condyles of the femur. Their superior border is continuous and convex upwards; their inferior borders meet the shaft abruptly, and there terminate. Both of these wing-like processes are turned towards the fibular side of the bone, the procnemial process being the larger in every respect; and the ectocnemial sometimes is produced downwards into a very sharp and needle-like spine, a characteristic of other Oscines. They include between them a triangular concave and rather deep recess. The expansion supporting the superior articular surface projects over the shaft of the bone in all directions, being quadrilateral in outline, and having an articular facet for the fibula on the outer side, while in the middle of the surface above a tuberous spine of the tibia exists, with concavities on either side for the condyles of the thigh-bone.

The shaft is remarkably straight, light, and hollow, though apparently 
non-pneumatic, no apertures having been discovered to allow the air access to the interior.

A fibular ridge, 4 millimetres long and 1 millimetre deep, is developed in the upper third of the shaft, perpendicular to its outer aspect, for the lower articulation of that bone.

Huxley and Gegenbaur maintain that the distal extremity of the tibia represents the astragalus among the Class Aves, and there certainly seems to be some foundation for this assertion, for if we examine this bone in the young of any of the Gallina, as in Centrocercus, we find the segment that eventually ossifies with this end of the tibia to be rather too extensive for a mere epiphysis, and may represent that tarsal bone. This joint is more thoroughly discussed in the osteology of the Tetra. onida, further on. Without further remark, then, upon this important and still unsettled question here, we will observe that in Eremophila, and in all birds, the leg-bone terminates distally by two anteriorly placed condyles, separated by a well-defined intercondyloid notch. These condyles, approaching each other behind, diverging in front, are reniform in outline and shape, with their convex surfaces downwards. They are higher on the shaft anteriorly, and the articular portion is more extensive. Likewise, anteriorly the shaft is grooved below, to be bridged over just above the notch by a narrow bony span, arched outwardly, that holds the tendons of the deep extensors in position

The inner end of this arch is the higher on the bone, and just above it, on the shaft, we find a minute tubercle, that gives attachment to a lig. ament that is extended to another tubercle lower down on the shaft, and on the opposite side.

The fibula is the merest apology for a bone, represented only by a slender spine on the outer side of the tibia. It has a superior and knoblike head, that articulates with the horizontally expanded head of its sizable companion; lower down it meets the fibular ridge, and is firmly attached to it by a strong, fibrous, and close-fitting connection.

Below the ridge the fibula is continued, hair-like in dimensions, to meet the tibia below the middle of the shaft, to become thoroughly and indistinguishably confluent with it.

The patella (Pl. IV, Fig. 22) is a free bone, and is found in the tendon of the quadriceps extensor. It is compressed antero-posteriorly, with an elliptical base above. From the points representing the vertices of the major axis of this ellipse, bounding lines pass, to meet broadly concave below. The anterior surface, limited by these boundaries, is convex outwards; the posterior surface, slightly concave, is divided by a vertical ridge into two unequal parts, the outer of which is the greater.

The femur averages 2 centimetres in length, the tibia 3.2 centimetres, and the bone now to be described as the tarso-metatarsus nearly 2.3 centimetres.

The metatarsals of the second, third, and fourth toes, and certain tarsals at the upper extremity of the bone, coalescing, form the segment, tarso-metatarsus, next in order below the tibia, with which it articulates.

The articular surface of its summit is so arranged as to accommodate itself to the condyles of the tibia, consisting essentially of an inner and outer antero-posterior facet, and a prominent spine on the anterior margin, that accurately fits in the intercondyloid notch of the bone above.

On the posterior aspect of the bone above we find the "calcaneal" process, here approaching a right parallelopiped in form, being vertically pierced by four minute cylindrical canals, two next the shaft and two parallel with them and above. They are for flexor tendons, which pass through them. The shaft is straight, subcylindrical, and hollow, ex- 
panding below for the trochlex for the phalanges. For its upper half and posteriorly, ranging below the calcaneal process, it develops a sharp vertical crest, that gradually subsides below.

The anterior aspect of the shaft is faintly grooved longitudinally, and where it dies out below, just above the notch between the third and fourth terminal trochleæ, we observe a minute perforating foramen for the anterior tibial artery. Upon the inner margin of the shaft below there is the well-marked though shallow facet for the os metatarsale accessorium. This diminutive bone is, as usual, slung to the tarso-metatarsus by a ligament, articulating beyond with the hallux. It represents the first metatarsal, and has all the appearances of one of the larger-sized phalangeal segments, divided obliquely through the shaft, with the cut surface closed in and forming the articular surface for the tarso-metatarsus. Its position, in situ, is figured in Pl. IV, Fig. 44. The lower and expanded end of the tarso-metatarsus, bearing the trochleæ of the remaining phalanges, is further conspicuous for the marked manner in which the bone is compressed antero-posteriorly, causing the trochlear ends to be placed side by side, transversely. The middle one is the largest and grooved entirely round, the one for the second toe being slightly the higher and bent a little outwards; finally, the fourth is the smallest. Slit-like spaces among these "processes" completely divide them.

The joints of the toes are arranged upon the most common plan, and, we believe, upon the general rule for all Oscines; $i . e$. , the hallux possesses two phalanges, second toe three, third toe four, and the outer and last toe five.

These joints are not impressed with any thing particularly remarkable, beyond what is found in them among the class generally. Their vertically cleft and anterior extremities articulate with the joint beyond, which is diminished in size and articulates in like manner with the next anterior segment.

The claws are grooved laterally, and show a process at their proximal and lower aspects.

A glance at Pl. IV, Fig. 22, will be sufficient to satisfy ourselves that the great length of the claw of the hind toe sometimes seen in Eremophila, and always characteristic, is due almost entirely to the growth of the horny theca that encases it, and not to the length of the osseous claw.

In the figure just referred to, the hallux, with the first metatarsal, has been drawn backwards in the skeleton, not only to show the os metatarsale accessorium, but also a sesamoid, of no mean size, that is found on its outer side, an ossicle that betrays its possessor and declares the habit he has of spending a good share of his time upon the ground. 



\section{PLATE IV.*}

Fig. 22. Skeleton of Eremophila alpestris.

Fig. 23. Sacrum and pelvis from above.

Fig. 24. The sternum from below.

Fig. 25. The skull from above.

Fig. 26. The skull from below.

FIG. 27. The sternum from above.

Fig. 28. Sacrum and pelvis from below.

Fig. 29. Lower mandible from above.

Fig. 30. The clavicular furculum from in front.

FIG. 31. Left humerus, anconal aspect.

FIG. 32. Left scapula and coracoid, internal aspect.

Fig. 33. Scapular extremity of clavicle.

Fig. 34. Left scapula and coracoid, external aspect, showing extent of glenoid cavity.

Fig. 35. The thirteenth cervical vetebra, showing first pair of free pleurapophyses.

Fig. 36. Left humerus, palmar aspect.

FIG. 37. Hyoid arch from below.

Fig. 38. Anterior view of sternum, first dorsal vertebra, with its movable pleurapophyses and hæmapophyses, in situ.

FıG. 39. Right tarso-metatarsus, anterior aspect.

FIG. 40. Right femur, anterior aspect.

Fig. 41. Sclerotals, right eye.

Frg. 42. Right tibia and fibula, anterior aspect.

FIG. 43. Right ulna, anconal aspect.

Fig. 44. Right foot, with a portion of the podotheca removed to show the os metatarsale accessorium, in situ.

Fig. 46. Right femur, posterior aspect.

* The figures on this plate are numbered in continuation with the author's plates and figures to his Memoir on the Osteology of Speotyto cunicularia hypogoea. 


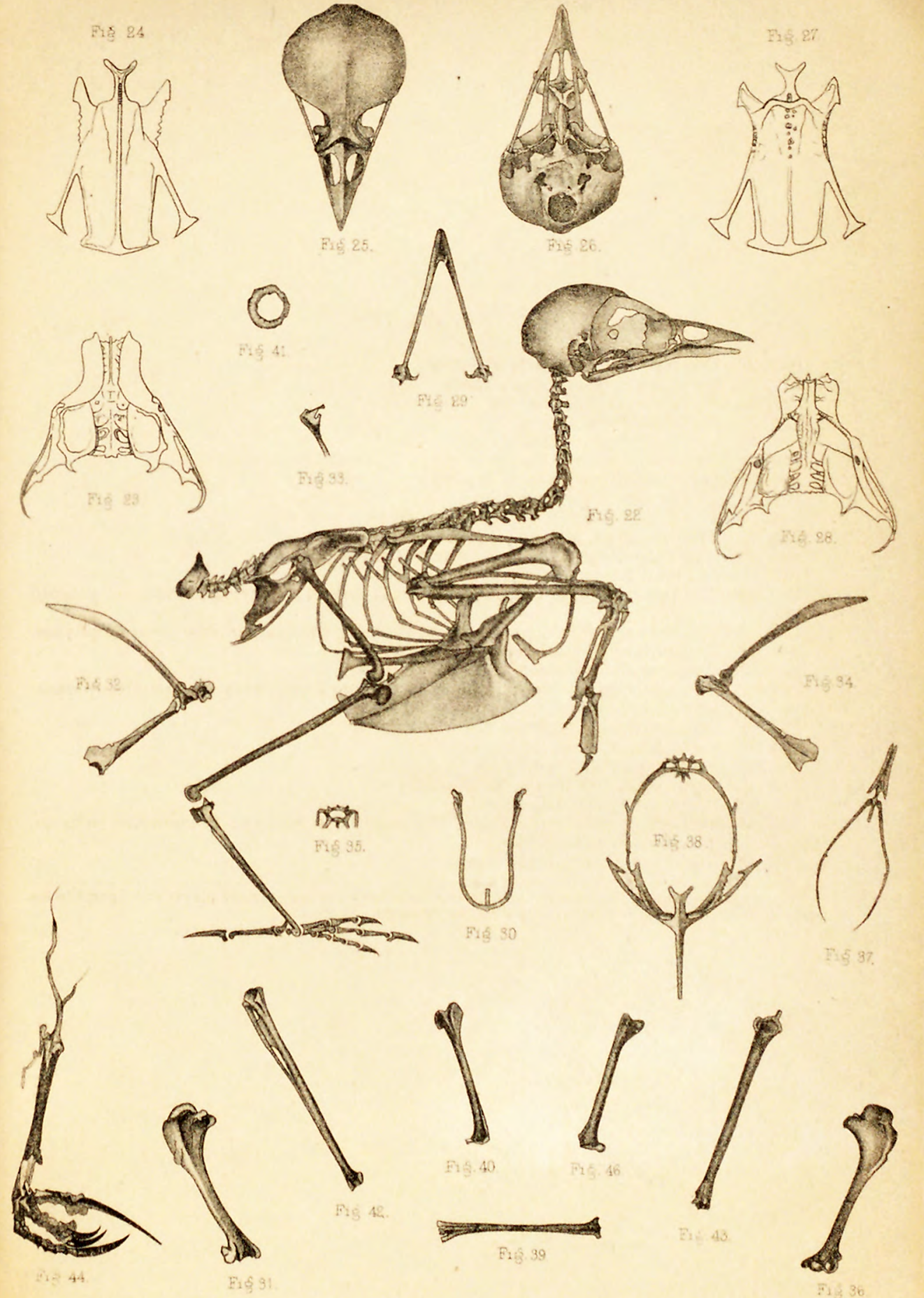





\title{
OSTEOLOGY OF THE NORTH AMERICAN TETRAONIDE.
}

\author{
By R. W. Shufeldt, M. D., \\ Captain, Medical Department, United States Army.
}

The representatives of the Gallinaceous order of birds in the North American fauna are referred to four families, the Cracida, the Meleagrida, the Tetraonidae, and the Perdicida. Members of the family Cracidee or the Curassows, are all Ameriean birds, being distributed over the continent from the Rio Grande southward.

The latter group has been divided by Messrs. Sclater and Salvin into three subfamilies, the Cracince, the Penelopine, and the Oreophasince. Of the fifty or more species making up these subfamilies, at the present writing, but one form has been taken within the limits of the United States, this being the Ortalis vetula maccalli, the Chachalaca of the Texans and Mexicans. The subfamily Penelopince, referred to above, has been divided into seven genera, of which Ortalis is the last, and the one to which our only North American species belongs. Every attempt of the author to secure the skeleton of this interesting bird has thus far failed, and as he has had no personal experience with Ortalis in its native haunts, the reader is referred to the standard works upon ornithology for descriptions of this species. In Meleagrida, the second family enumerated above, we have but one genus, Meleagris, containing the Turkeys, well-known fowls peculiar to North America, and of which there are two species, or rather a species, the western form, Meleagris gallopavo, and the eastern variety, or subspecies, Meleagris gallopavo americana. ${ }^{1}$

Although the writer has had the opportunity of comparing several skeletons and parts of skeletons of both of these forms with the Tetraonida, it must be understood that in recording his observations it has only been with the view of calling the reader's attention to the osteological similarities and differences, en passant. Professor Huxley, in his studies of this group, has left but little to be desired in the way of osteological descriptions, clearly pointing out differential characteristics existing between the Turkeys and the Numidida, or the Guinea Hens. It is the third family, the Tetraonida, in our enumeration that has claimed the greatest share of our labor, and to which the title of this paper has been awarded in consequence. We have before us a complete collection of the skeletons of the members of this group, which is unfortunately more than we can say for the partridges, although of the latter family we have, we believe, a sufficient number to observe their general characteristics.

The family Tetraonide includes the Grouse, of which there are six genera in North America, containing sixteen species, embracing ten varieties. Of these we shall give a synopsis further on, showing their principal external characters, as set forth by American ornithologists,

\footnotetext{
${ }^{1}$ A second species, $M$. ocellata, is found in portions of Yucatan, Honduras, and Guatemala. 
and also from the author's observations, both in the field and from specimens in his own collection.

Among gallinaceous fowls the Grouse are known by certain char-

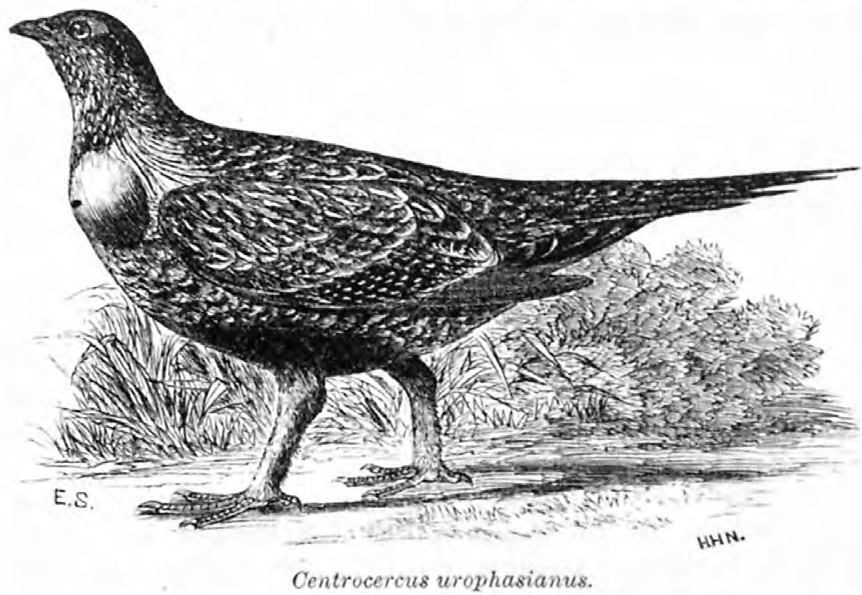
acters, such as the narrow and naked supra-palpetral processes; by the feathers filing the exter. nal nasal fossæ; by the cervical and intlatable airsacs of Cupidonia and others; and finally by the feathered tarsi, the naked toes, with the peculiar horny processes, fringing their edges In Lagopus the feathers of the tarsi are dense, and earried to the very claws, this genus thus forming an exception to the last observation.

In the arrangement of the genera we adopt the high authority of the authors of the History of North American Birds (A Hist. N. A. Birds, Boston, 1874, Baird, Brewer, and Ridgway). In this work we find the following divisions given us, with some few modifications, which the reader will readily recognize:

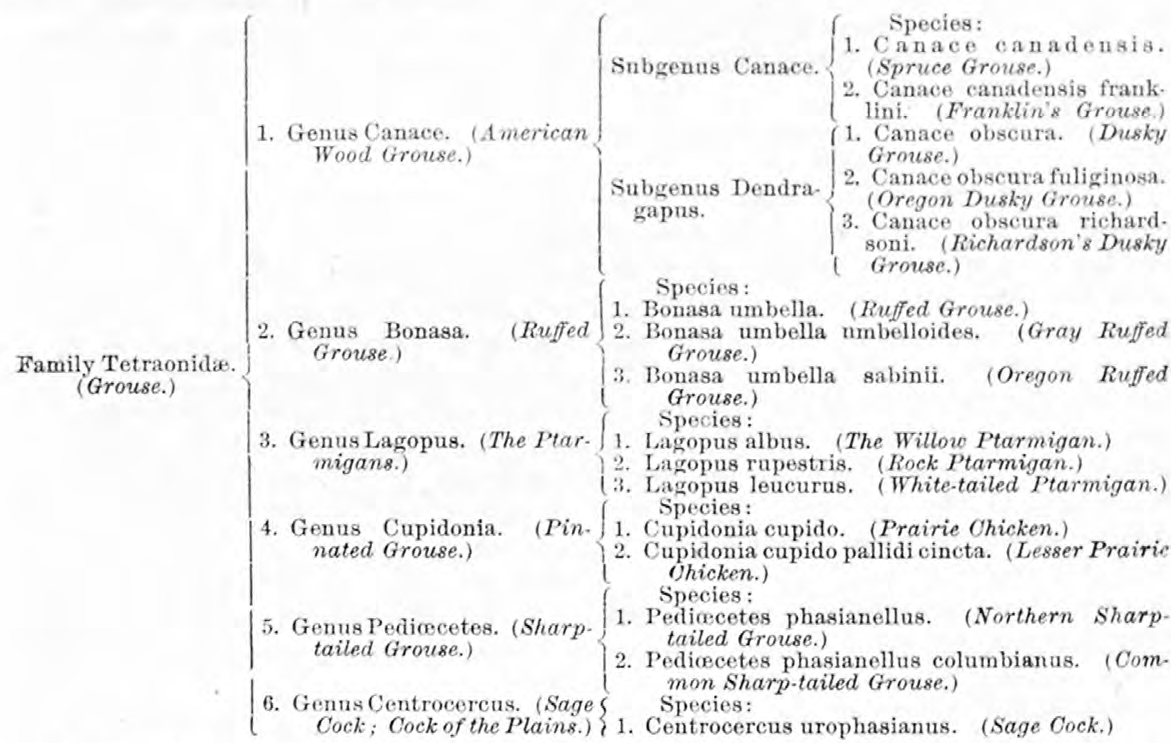

For the two subgenera of Canace, the principal differences seem to be, that the first, Canace, differs from the second, Dendragapus, in that it is of smaller size; has sixteen tail-feathers to twenty of the latter, and also Canace has no inflatable air-sac at the side of the neck, which the subgenus Dendragapus has. Otherwise the varieties of each subgenus 
seem to have arisen mainly, as so many varieties doubtless have, from climatic influences, due to their inhabiting various geographical areas.

Canace canadensis is found ranging from northern United States to the Arctic seas; west nearly to the Rocky Mountains. C. canadensis franklini from northern Rocky Mountains, near United States boundary, and west to the Coast Range. Canace obscura ranges in the Rocky Mountains to the south of South Pass and Sierra Nevada, north to Oregon and south to San Francisco Mountains, New Mexico, and finallyCanace obscura fuliginosa, northwest coast region, from Oregon to Sitka. The latter two varieties intergrade at their limits. (Habitat. from Hist. N. A. Birds, Baird, Brewer, and Ridgway, 1874.)

The writer has had the pleasure of hunting the Dusky Grouse at various times and localities in the mountainous districts of the Territory of Wyoming. On one occasion, in the early autumn of 1877, I found myself heading a file of several Sioux Indians, winding my way over a well-beaten game-path, along the side of one of the highest peaks of the Big Horn Mountains. My companions were armed with the well-known car. bine, and I had my double fowlingpiece, a weapon that none of them had ever seen before and were evi-

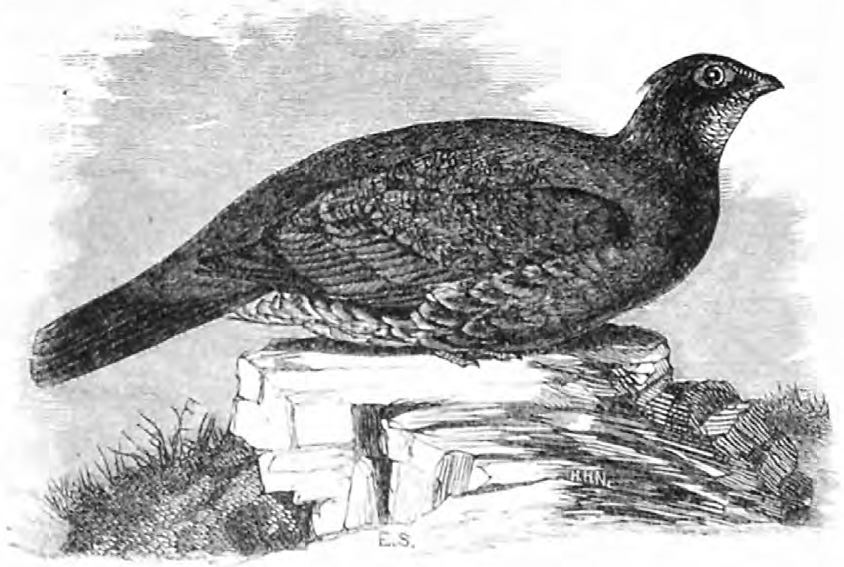

Canace obscura. dently quite curious to see the use and effect of. Suddenly we emerged into one of those delightful little open spaces that we occasionally find occurring even on the sides of the most rugged ascents. It was devoid of trees and carpeted with the greenest of verdure. Hardly had we entered this area when away went a magnificent "Blue Grouse" from his hiding place and cover. It was the first bird of the kind that I had ever seen alive, and the effect could hardly have been less demoralizing than the impression produced upon the renowned Wallace, when the first Bird of Paradise dazzled his vision in the jungles of New Guinea. Suffice it to say, that, in a twinkling, this vigorous old Grouse was entirely out of my reach, and was whirling up the mountain-side through the darkpine woods that covered it.

But my game was not alone in a spot so inviting, for a step or two more started two other fine old males of the same bevy. By this time self-possession had been entirely recovered, and before this pair could reach the confines of the open space in which we were, each had been overtaken by the contents of one of the barrels of my breech-loader with fatal effect. Before the echoes of the double report had died away among the rocky cañons, my Indians had these beautiful birds in their hands and were closely examining them, apparently looking for some immense wound that the bore of my gun certainly seemed capable of inflicting. The Indian has, we know, an aggravating way of not showing his wonderment even on the most startling occasions, and it has 
always been a source of intense gratification to me if I could by any means whatever so surprise one of these stolid sons of the forest as to induce him to elevate his eyebrows, be it ever so little. On this particular occasion the position was mine. I simply shrugged my shoulders, giving them to understand that it was an extremely simple matter, and left them to make what they could out of it.

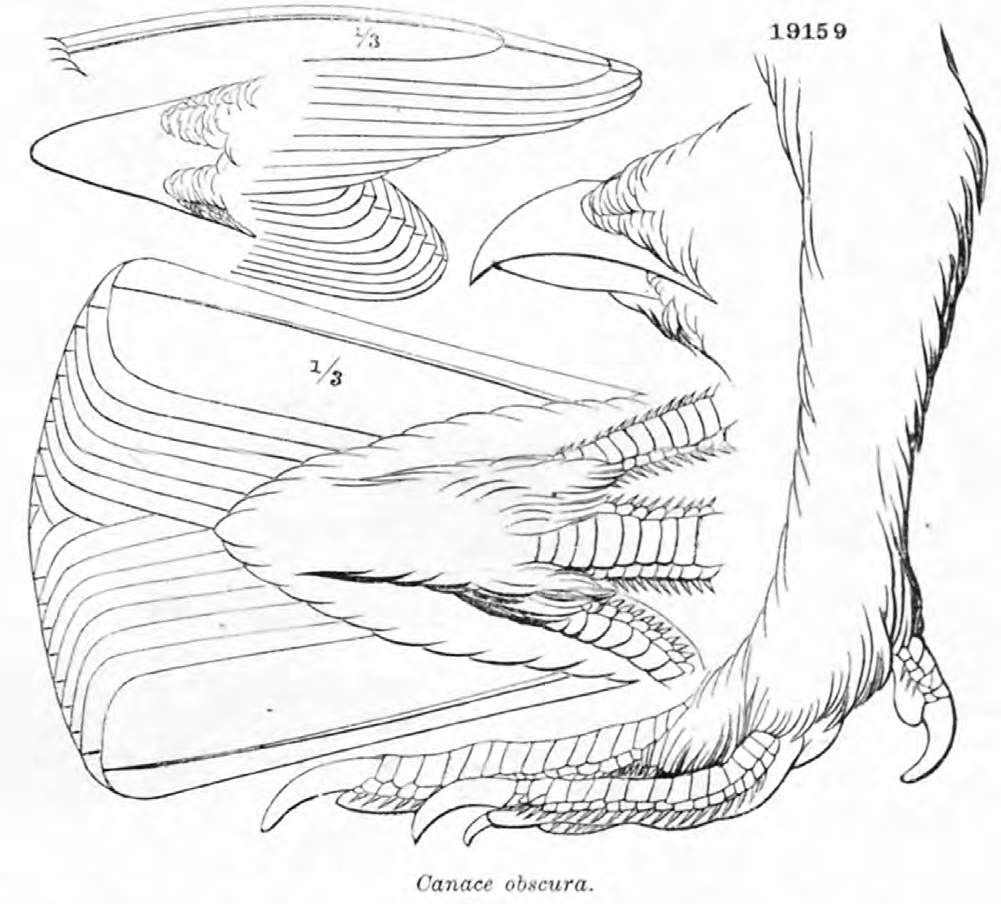

All of the birds of this species taken in the Big Horn Mountains were, to the best of my recollection, the form recognized as $C$. obscura richardsoni I do not remember an exception. This is not the case, however, when we come to the Laramie foot-hills about the country and less elevated peaks lying to the southward and westward of Fort Fetterman. It was in this vicinity and near the top of one of the highest hills to the eastward of Casper Mountain that the writer, in the depth of winter, with the thermometer many degrees below zero and the snow knee-deep, found small bevies of the type bird $C$. obscura, and succeeded in taking several specimens. They seemed to occur more frequently in those hills where the immense herds of elk resorted, and perhaps this was due to the fact that these animals bared the ground of snow in many places, and thus exposed winter berries and other foods that might not otherwise have been added to the bill of fare of these Gronse. Centrocercus urophasianus occurs throughout the Northwest, frequenting, almost with out exception, the arid plains wherever the sage-brush thrives, the buds and leaves of which form its principal food.

Thus far this genus has contained but the one species just alluded to, and although this Grouse occurs over an immense area of country, there is not an ornithologist that we are aware of, that has ever detected sufficient differences in specimens taken in widely-separated districts that would guarantee the establishment of varieties. The author for 
several seasons had the opportunity to study these birds in the very heart of their native haunts ; observed them under all manner of circumstances, both young and old; but the bird and its habits are so well known at the present writing that personal experiences will be almost superfluous here.

For the species and varieties of Bonasa, we find that the type, B. um. bella, is found throughout the eastern districts, it being the Partridge of New England and the Pheasant of the South. This form intergrades with the first variety that we find as we proceed westward; that is, $B$. umbella umbelloides, a geographical race found in the Rocky Mountains and British America. The last variety, B. umbella sabinii, the Oregon Grouse, is the Pacific coast form. The best authorities allow that the varieties of the type of this Grouse owe their differences in coloration to geographical modifications.

The extent of this intergradation is well described in the History of North American Birds, already cited. After presenting a synopsis of the varieties, it reads as follows:

The above synopsis is intended to present in the simplest form the characteristic features of the three definite races of this exceedingly variable species, as exhibited in a light-rusty rufons-tailed form of the Atlantic States, a pale, gray, ashy-tailed form of the Rocky Mountains of the United States and British America, and a darkrusty rufous-tailed form of the Northwest coast region. These three, when based on specimens from the regions where their characters are most exaggerated and uniform, appear sufficiently distinct; but when we find that specimens from the New England States bave the rufous bodies of umbellus, and gray tails of umbelloides, and continue to see that the transition between any two of the three forms is gradual with the locality, we are unavoidably led to the conclu-

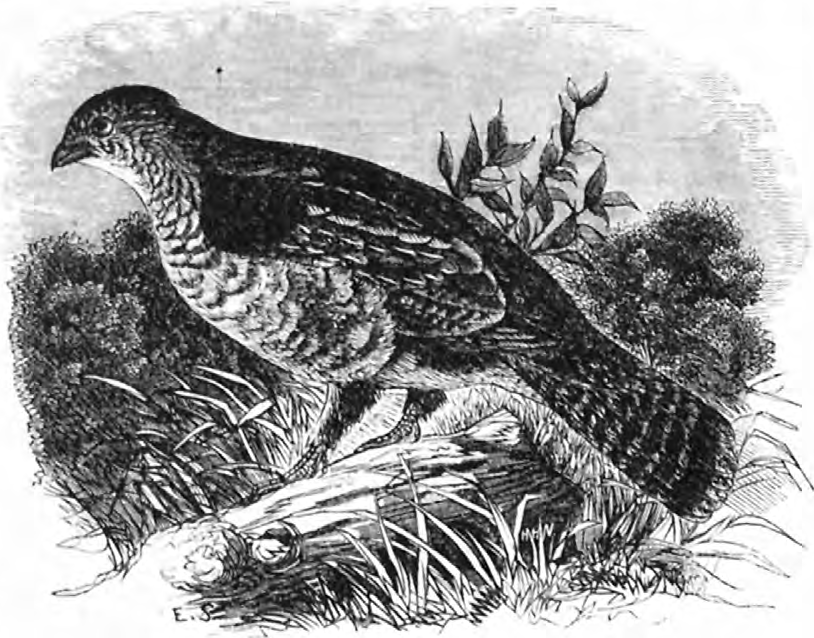

Bonasa umbella. sion that they are merely geographical modifications of one species.

Pediceetes presents us with two forms, already given in our enumeration of species and varieties; the first, $P$. phasianellus is found pretty generally throughout British America and to the northward of our boundary. It also occurs in Alaska. P. phasianellus columbianus supplants this species, being a variety of it, and is found in the prairie regions west of the Mississippi River, and has even been taken as far east as Chicago.

In Wyoming, I found them during the spring and winter months in large numbers along the banks of the Platte River and the streams and creeks that empty into it. During the summer months, however, they desert these localities and resort to the hills and mountains, where many of them breed.

As in the genus just alluded to, Cupidonia has its type and a variety. 
Cupidonia cupido being found in the more central portions of the United States, and at one time, we are well aware, was plentiful all along the Atlantic Coast, particularly to the northward. C. cupido pallidicincta is a variety occurring from Texas to Nebraska, generally lighter in color, and decidedly smaller. This is one of the most interesting members of the family Tetraonida, and descriptive ornithologists have delighted in repsenting us in their works with the engaging history of the famed prairie hen.

There are three species of ptarmigan found in North America, as already shown in our table given above. Lagopus albus is confined to sub-Arctic and Aretic America, occurring more or less abundantly across the continent. L. rupestris is also an Aretic bird, while our last species, $L$. leucurus, is not only found in these sub-polar regions but inhabits the mountainous districts of the West as far south as New Mexico.

I have not had the pleasure of hunting this beautiful Grouse, never having been in sections where it was found, so that in the following partial synopsis of external characters and appearances of the Tetraonida, I am, as far as this species is concerned, indebted entirely to the authors of A History of North American Birds, from which valuable work I have borrowed the necessary data differentiating this genus from others of the group.

\section{GENERA OF THE TETRAONIDE.}

CANACE.-Nasal fossæ occupying barely half the culmen. An extensible bare space on either side of neck. No cervical ruffs. Tail broad and rounded at outer angles. Toes without feathers, which occur on the basal membranes between them and the entire tarsi. The varieties $C$. canadensis and $C$. franklini are distinguishable in that the former has a rounded tail that terminates with a lightish brown band, and the upper tail coverts have light ash emarginations, whereas the latter bird has nearly a square tail, entirely black, only occasionally showing a light colored tipping, and the superior tail-coverts have extensive white margins.

BoNAsA.-Crested, cervical ruffs of black and particularly soft and glossy feathers. Tail broad and nearly square. Tarsi bare below. Anterior scutellæ arranged in two rows, approaching the Partridges in this as in many osteological characters.

B. umbella umbelloides.-Pale; slaty-gray the prevailing shade. (Coues.)

B. umbella sabinii.-Dark; chestnut-brown the prevailing shade. (Coues.)

LAGOPUs.-No cervical ruffs. Tail but slightly rounded. Tarsi and toes thickly feathered to the very claws. Species become white during winter season.

$L$, albus.-Bill very stout. "Bill as high as the distance from the nasal groove to its tip. Tail always black, narrowly tipped with white; wing (except upper coverts) pure white."

L. rupestris. - "Bill slender; distance from the nasal grove to tip (.35) greater than height at base (.27). In summer the feathers of back black, banded distinctly with yellowish-brown and tipped with white. In winter white, the tail black; the male with a black bar from bill through the eye. Size considerably less than that of L. albus."

L. leucurus._-"Entirely pure white, including the tail."

Cupidonia.-Nasal fossæ less than one-third thelength of the culmen. Sides of neck ornamented with long and sharp outstanding tufts, composed of thick black feathers. Tail shorter in comparison than any other Grouse. Feathers extend to lower end of tarsi. Head slightly crested. Inflatable air-sacs below cervical tufts. Osteologically Cupidonia and Pediocetes are nearly related and opposed to all the other forms or genera of the Tetraonido. As in the following genus, Cupidonia has one well-defined variety, C. cupido pallidicincta; this form is alluded to in the History of North American Birds, above cited, in these words: "In its relations with the $C$. cupido this race bears a direct analogy to Pediocetes columbianus, as compared with $P$. phasianellus, and to Ortyx texana, as distinguished from O. virginiana. Thus in a much less development of the tarsal feathers it agrees with the southern Pediocetes, while in paler, grayer colors, and smaller size, it is like the southwestern Ortyx."

Pedracentes.-Nasal fossæ less than half the length of the culmen. Cannot be said to be crested, but has the habit of raising the feathers of the crown under the same circumstances that the crested forms elevate their crests. Have seen specimens that certainly seemed to possess rudimentary cervical tufts. The mid-pair of tail-feathers produced beyond the short and graduated tail proper, their ends being truncate. Tarsi feathered 
to the toes. In $P$. phasianellus the toes are hidden by the feathers and the coloration of the two forms differs materially.

Centrocercus urophasianus. - Nasal fossæ nearly two-thirds the culmen. Large, inflatable air-sacs. Not crested. Feathers of throat with spiny shafts, and those of the body with large after shafts. Tail long, graduated, and of twenty acuminate feathers. Tarsi covered with feathers, which extend over the basal webs.

As we do not enter especially into the subject of the osteology of the family Perdicida, we will merely present the reader here with a synopsis of the North American forms and their habitats.

GENLS.

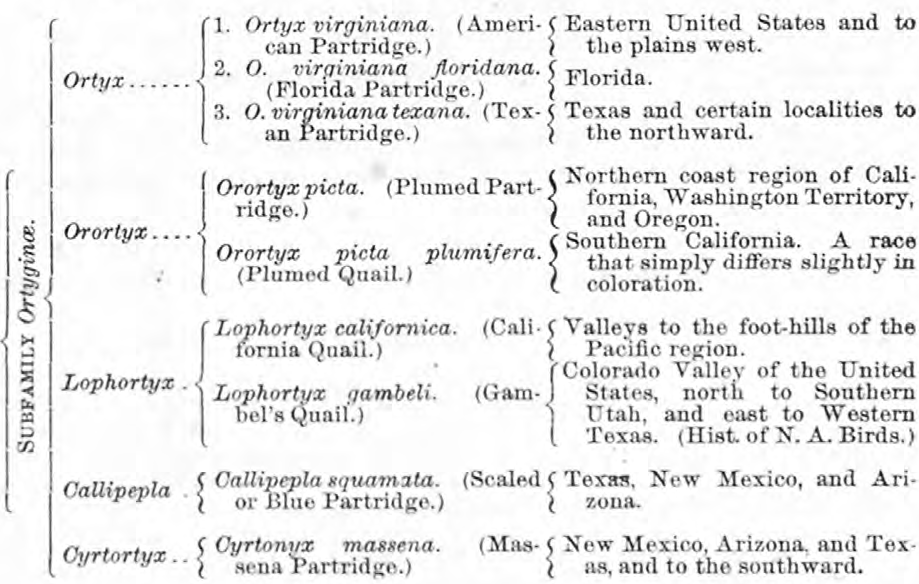

To this list, my friend Dr. Coues has added Coturnix dactylisonans, the common Migratory Quail of Europe, a bird that at different times has been imported and set at liberty in various parts of the Union-in New England for one locality-and it is at present supposed that this Quail will become a bird of the country, as Passer domesticus has.

I learn also from Mr. Lucien M. Turner, lately returned from Alaska, that he has been so fortunate as to find a new race of Lagopus that will be duly described in his report.

The anatomical peculiarities of the order Gallince has been the favorite theme of many an able writer, and we find Huxley, Owen, Gegenbaur. Parker, Coues, and others, in their several works, dwelling largely upon the osteology of these birds, ably exposing the observed characteristics of structure both by pen and pencil; but, as far as our knowledge extends, no one has as yet devoted himself to the production of a paper devoted exclusively to the osteology of the North American Grouse, such as the writer here proposes to undertake with every hope of success, aided as he has been by the kind assistance of many friends in different parts of the Union, in sending him valuable material in the way of representatives of the Family.

In this monograph we will omit, as we have in former ones now published, any detailed description of the osseous elements of the ear, or the respiratory tube, small sesamoids, or such tendons as may ossify in the extremities. The hyoid as an arch of one of the cranial vertebræ evidently is not included in this category, and will in consequence receive the attention it undoubtedly deserves in its proper place.

The study of the bones entering into the cranial vertebræ has been initiated at a stage in the chick's life a few days after birth. and their 
relation to each other and their development carried up to the adult bird. It will be observed after a glance at the writer's drawings in Plate $\mathrm{V}$ that he has chosen the young of that grand old prairie-loving: Grouse, Centrocercus urophasianus, as an example of the growth of the skull from the time above referred to in the Tetraonina.

In this plate the first three figures show respectively the skull of the young of the Sage Cock a few days after the parent has led it from the nest: 47 from above, 48 lateral view, with mandible, and 49 from below, the mandible removed.

Fig. 50 shows the bird in August of the same year, and Fig. 51 the disarticulated skull of the same, whereas in the next plate we observe the skull of an old cock of the same species, that has, no doubt, trod the prairie for many a season. (Fig. 52.)

In these birds the greatest amount of difference exists in point of size

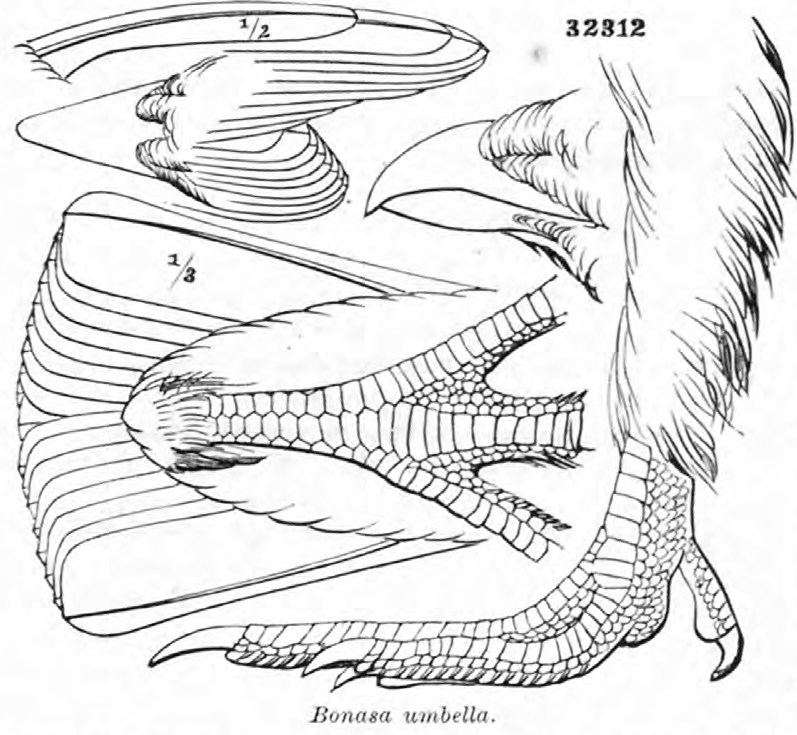

among the sexes and in individuals of various ages of the same sex; so we naturally find a corresponding amount of difference in the sizes of their crania.

Fig. 52 is the skull of an exceptionally large adult, z , chosen from a bevy of several hundred others, with a view of affording the reader the opportunity of seeing the proportions this Grouse may attain, as far as this part of its skeleton is concerned. This peculiarity seems to be confined to Centrocercus, and does not obtain with the other varieties, they seemingly arriving at maturity of growth at a much earlier period of their existence. Canace obscura may form an exception to these re-. marks, but it is certain that it is not by any means so striking a characteristic in this bird. Another interesting point to be observed here, that no doubt has forced itself upon the reader since his inspection of the plates already introduced, is the unusual length of time that the original bony segments of this Grouse's head retain their individuality over others of the class. This is indeed so, and in birds of one or two years of age, if we exclude the epencephalic arch of the occipital vertebra, it is not an unusual occurrence to be able to distinguish all the sutural boundaries among the remaining elements, and these appear to be persistent when applied to the nasals and the premaxillary bone of very old birds. We are all well aware that this rule holds good in the common barn-yard fowl.

Students of the works of that eminent anatomist and observer, Owen, will remember that in his Comparative Anatomy and Physiology of Vertebrates he seems to accuse the Struthionide alone of this singular feature, or at least "those birds in which the power of flight is abrogated." Now, such of my readers as have had the opportunity of ob- 
serving the flight of the "Cock of the Plains," after he has once been induced to take wing, will agree that there is anything save an abrogation of that avian privilege.

Crania of the North American Tetraonince being placed on the horizontal plane, as described in my monograph on the osteology of Eremophila alpestris (Bull. U. S. Geol. and Geogr. Surv. of the Ters., vol. vi., No. 1), we observe that their equilibrium is moderately stable, the anterior bearing point being the tip of the superior mandible, and the two posterior bearing points being the external facets upon the tympanics. The angles of the foramina magna average $70^{\circ}$ while the centrum of the parietal vertebra is the chief bone of what here must be the basicranii, and is found to be nearly in the horizontal plane; the neural arch of the occipital vertebra being, as a whole, gently convex outwards and lying in nearly the same plane with the foramina magna.

The Skull. ${ }^{-}$-So distinct do we find the hæmal arch of the first cranial or occipital vertebra, and fulfilling such a diverse end, with its appendage the pectoral limb, in birds generally, that its description will be undertaken further on under the subject of the "scapular arch," and our attention be engaged at this point only with the neural or epencephalic arch of this segment of the cranium.

The primoidal elements of this, the superior arch of the vertebra in question are seen to a greater or less extent in situ in the young and "bird of the year" of Centrocercus in Plate V, Figs. 47-50, and in the disarticulated skull of the same, Fig. 51, as $8 o, e o, b o$, and po, lettering respectively the essential elements "superoccipital," "exoccipital" (the parial bone and counterpart of this segment being intentionally omitted, as are the duplicates of other segments), "basioccipital," ${ }^{2}$ and the connately developed process, "paroccipital" of the neurapophyses.

In Sage Cocks the size of those figured in Plate V, Figs. 50 and 51, we find the neutral spine of the first vertebra, so, to be a light, spongy bone, one and a half centimeters wide by about one-half of a centimeter deep-covered with a thin layer of compact substance. Its upper border displays in the median line a demi-lozenged shaped notch that when the bone meets the parietals, which latter have their posterior and inner corners deficient, forms in many birds of this age a fontanelle. In younger individuals this diamond-shaped vacuity is always present, the

'The anthor's plates and figures illustrating this paper are numbéred in continuation with others of his published monographs.*

The reader is kindly referred to the foot-note under "Skull" on page 594 of this volume, in my monograph upon the osteology of Speotyto cunicularia hypogaa, where he will find the author's remarks upon the theory of the four cranial vertebræ, and the reasons why they were adopted in certain of his papers. These remarks apply with equal force to the present article.

${ }^{2}$ The terms here used for the elements superoccipital, exoccipital, and basıocipital, seem to be more or less universally adopted and applied by anatomical writers. Professor Parker and Gegenbaur term the first-mentioned element the supraoccipital rather than the superoccipial, as here given. The former of these comparative anatomists says, in his Morphology of the Skull (Lond., 1877, p. 241) in regard to these segments as they are found in the chick of the common fowl the second day after hatching: "The extensive occipital plane, swelling backwards above, is largely ossified, although there are considerable chondrous tracts remaining. The basioccipital extends into the occipital condyle, and it is considerably underfloored by the basitemporal plate in front. (Fig. 63.) The exoccipitals ossify the lower half of the sides of the foramen magnum. They are very irregular in shape, extending considerably into the ear-cartilage. They are perforated by the vagus and hypoglossal nerves. The supraoccipital centers have coalesced almost completely to form a large bone bounding the upper half of the foramen magnum, which is pointed above. Superiorly, the margin of the bone is curved like a fan, and abuts on the parietals." The supraoceipital centers, according to Professor Parker, are two in number, developing side by side. (Op. cit., page 235.) 
anterior fontanelle being formed in them in a similar manner, though narrower and longer, between the frontals and parietals. The lower border of the superoccipital presents a smooth, angular depression, that in the articulated vertebra goes to complete the superior third of the foramen magnum.

The lateral bodies of this bone are cellular masses with several apertures opening forwards and outwards, the mastoids closing them in, in the completed cranium. On its outer surface near the inferior angles we observe two, one on either side, grooved foramina, leading upwards and inwards, to open into the lateral sinuses on the inner surface of the segment, nearer together. As age advances these canals contract, but still exist throughout life.

The basioccipital segment, $b o$, also is largely cancellous in structure, wedge-shaped, having at its apex a long, rounded tubercle curving outwards and backwards, overhanging a slight depression beneath it. This tubercle in the complete vertebra forms the middle two-thirds of the occipital condyle, which, in the adult, is found below the foramen magnum, sessile, uniform in outline, with the rounded border below, and all indications of its original division into three parts obliterated.

The neurapophyses of this vertebra, termed the "exoceipitals" (Plate $\mathrm{V}$, Fig. 51, eo), are each nearly as large as the neural spine; on their inner borders they present for examination the deeply-rounded margins to complete the foramen magnum, and immediately beneath, the minute tubercle jutting out that lends its assistance on either side to form the condyle of the occiput.

The outer angles, quadrate in outline, deflected slightly downwards, are the transverse processes of the vertebra, the "paroccipitals." The precondyloid foramina are also to be observed here, with one still more external, belonging to the group from which the eighth nerve makes its way from the cranium. The internal aspect of an exoccipital is a mass of open, irregular cells, that are closed in when this segment is approximated with the mastoid, superoccipital, and the "petrosal", ${ }^{1}$ (Fig. 51,1), that odd-shaped and spongy bonelet which constitutes the capsule of the organ of hearing-and which has a foramen on its inner and smooth surface for the passage of the auditory nerve-forming, also, by a bending forwards of a part of this surface, and aided by the basi-sphenoid, the floor of the mesencephalic fossa on either side, while externally it shares in forming the entrance from without to the otocrane.

With the exception of the petrosal, the elements thus far described, when duly articulated, form the neural arch of the occipital vertebra, as already intimated above. The basioccipital, the centrum of this vertebra, by its larger extremity and the exoccipitals with the connate diapophyses articulate with the basi-sphenoid in the basi cranii below; the latter, with the superoccipital, meet the parietals and mastoids above and laterally. In old birds every trace, both sutural and otherwise, becomes completely obliterated as the osseous amalgamation progresses, though throughout the group a well-defined "superior line" limiting muscular attachment, indicates very nearly the terminating borders above, and sometimes, as in Centrocercus, a fainter indication exists in the ricinity of the union among the interested bones below. On either side of the condyle to its outer aspect we observe in a slight depression a group of usually four foramina-two external opening into

\footnotetext{
${ }^{1}$ Quite recently Dr. Coues has, in an admirable paper, presented us with a review of the literature bearing upon the so-called "temporal bone" of human anatomy, and as in this paper the true relations and composition of the "petrossal" are so clearly set forth, and they express the views now generally accepted, that it gives me pleasure
} 
the otocrane, one into the cranial eavity, and one leading through the basi-sphenoid to the base of the "sella turcica" at the carotid opening; they transmit principally the eighth nerve and the internal jugular and branches.

In some of the very old individuals of the Tetraonina quite a striking characteristic presents itself in the capaciousness of the opening to the otocrane, produced by a thin, wing-like expansion, recurved forwards, formed by the outgrowing and union of the centrum of the second vertebra and the diapophysis of the first. This feature is not particularly noticeable in the Ortygina, nor in Lagopus, Oupidonia, and Bonasa, still less so in the Sharp-tailed Grouse, among the Tetraonince, but quite marked in old males, especially in Canace and Centrocercus (Figs. 52, 74,88 , and 89). No very decided differences exist among the Grouse with regard to the foramen magnum and the occipital condyle; the former is universally of good size for its owner, subcircular, and without any encroachments upon its margins beyond the condyle. This latter, always sessile, reniform in contour, accupies its usual position below the foramen, with its long axis placed horizontally. In all the Grouse, save Canace and Centrocercus, it slightly invades the marginal periphery of the great foramen of the occiput, and in all the excepted genera is more or less shortened transversely.

The second cranial segment constitutes the parietal vertebra, and its elements are shown in the same plate, Fig. 51, where indicators pass through its neural and hæmal arches, $\mathrm{P} . \mathrm{V}$. and $\mathrm{P} . \mathrm{V}^{\prime}: \mathrm{P}$. $\mathrm{V}$ is the mesencephalic arch, constituted in the complete cranium by the bones $\mathrm{P}$, the parietal or neural spine, when linked with its fellow; $a . s$. , the alisphenoids, the neurapophyses ; m. s., the mastoids, the diapophyses ; and

to quote the following from him. In summing up the various parts of the temporal bone, he says:

The following is a list of these morphological elements :

1. Squamosal. A membrane bone with which in mammals the maxilla is connected by the malar and the mandible is directly articulated. The "squamous portion" of the temporal.

2. Tympanic. Accessory to the organ of hearing, forming the meatus auditorius externus. The "auditory process."

3. Pro-otic.

4. Epi-otic.

5. Opisth-otic

Primitive otic elements together forming the periotic or petro-mastoid; the otocrane or bony capsule of the organ of hearing, inclosing the bony labyrinth, developing the mastoid cells, and practically constituting the "petrous" and "mastoid" parts of the temporal,

6. Mallens.

7. Incas.

8. Stapes.

Ossicula aditus or phonophori in man devoted to audition,
but

6. Malleus, the proximal end of the mandibular arch

7. Incas, the proximal end of the hyoidean arch. 8. Stapes, connecting fenestra ovalis with the hyoidean arch.

9. Tympano-hyal. $\{$ Elements of the hyoidean arch. $\{$ Tympano-hyal not recognized in human anat10. Stylo-hyal. $\quad\left\{\right.$ Elements of the hyoidean arch. $\left\{\begin{array}{c}\text { omy. } \\ \text { Stylo-hyal, the "styloid process." }\end{array}\right.$

This does not include the os orbiculare, a minute ossification occurring at the junction of the incus with the stapes, and in man for a short time separate.

Still further on this author states: "The periotic develops from a mass of cartilage situated in the basis cranii between the occipital and sphenoid from three centers of ossification, which, however speedily and completely they may coalesce, as they do in man before birth, represent as many distinct bones, one or more of which may remain separate in many animals. These are the prootic, the epiotic, and the opisthotic. The first of these is anterior and in special relation with the corresponding vertical semi-circular canal. The second is superior and external. The third is posterior and inferior in relation with the posterior vertical semi-circular canal. Their confluence completes a bony periotic capsule, inclosing the labyrinth or cavity of the inner ear. This is the triune periotic bone; with its mastoid developments the still only triune petro-mastoid bone; with its tympanic annex the otocrane, or skull of the ear, containing the essential parts of the organ of hearing. The periotic proper corresponds closely enough with the "petrous portion of the temporal" of human anatomy-the "petrosal bone," as it is sometimes called. (The Nature of the Human Temporal Bone, Am. Jour. Otology, vol. iv, Jan., 1882, pp. 25-29.) 
$b . s$., the basi-sphenoid, the centrum of the vertebra. The hæmal arch we see in the "hyoid," which here shares the same fate of its neighbor in the occipital vertebra, insomuch as it is ununited to the superior arch by either osseous connection or by articulation, for in all living birds the hyoid, the well-known bony support of the tongue, depends entirely upon its muscular and ligamentous connections to retain its rela. tions with the cranium. The manner in which the disjoined neural spine of the parietal vertebra goes to form the posterior fontanelle in the halfgrown bird has already been sufficiently dwelt upon. The bone P, as detached in an individual of this age, is quadrilateral in outline, excessively spongy and light, owing to the paucity of compact substance over quite a large share of diploic tissue, which is chiefly deposited in a protuberance on its inner table, which protuberance, in union with the fellow of the opposite side of the complete cranial vault, forms two concave surfaces out of the remainder of the superficies, essential portions of the ep- and prosencephalic fossæ.

Superficially, these elements are smooth and convex, and in the adult, after consolidation, exhibit some faint evidence of a parietal eminence on either side-more marked elevations, however, occurring in the spine of the vertebra beyond, immediately anterior to the suture termed in Anthropotomy the "coronal." With the exceptions of the tympanomastoidal articulation and the connections between the mastoids and petrosals, the majority of the articulations of this vertebra in the mid. aged bird may be classed among the variety known and described in works upon human anatomy as the "squamosal"-the parietals being beveled above to accommodate themselves to the frontals.

The alisphenoids are separated from each other mesially by nearly half a centimeter; above they meet the frontals, below the basi-sphenoid, and laterally the mastoids - the lower and outer angles almost reaching the cup-shaped articulation for the tympanics. This segment seems to ossify from its borders towards the center, leaving a foramen that is eventually closed in. Touching this point, Professor Parker says, when treating of the development of the skull of the Common Fowl, "From the hinder half of the basisphenoidal region a considerable elongated alisphenoidal lamina arises (a. s. Fig. 59), passing outwards and backwards on either side in the cranial floor, and ascending a little into the side wall; coalescing at its extremity with the periotic mass, but leaving an elongated space unfilled by cartilage between the two tracts. The cranial surface of the alisphenoid conforms closely with the concave curvature of the hinder part of the cranium (see Fig. 62)." (Morphology of the Skull, Lond. 1877, p. 230). And further on, "A membranous fontanelle $(a . s . f$.) arises in its center; and both in front and behind this distinct ossific centers appear in the cartilage; these afterwards unite to form one alisphenoid bone." (Ibid p. 236).

Professor Huxley, in treating of the development of the cranium, says of this bone-

"In front of the auditory capsules and of the exit of the third divis. ion of the fifth nerve, a center of ossification may appear on each side and give rise to the alisphenoid, which normally becomes united below with the basisphenoid." (The Anat. of Vert. Animals, p. 24.)

This bone, on its mid and lower border, presents for examination the half of the "foramen ovale," which is completed by meeting the centrum of the vertebra. It is for the transmission of the trigeminal nerve into the orbital cavity. Laterally there is developed a quadrate apophysis (the parapophysis of the vertebra?), which joins with a similar, subsequently scale-like process coming from the mastoid, resulting in a fora- 
men, cordate in outline above, elliptical below, between them, giving passage to the fibres of the temporal muscle that is markedly characteristic of the Tetraonida. Below the point of union this sphenotic process, as this latter apophysis has been termed by authors, is triangular, with its apex pointing forwards and downwards, flat, with its inner surface looking forwards, upwards, and inwards. Internally, the alisphenoid is deeply concave. (Plate VI, Fig. 52, and other skulls illustrating this paper.)

The external appearance of the mastcid ${ }^{1}$ is well shown in Plate V, Fig. 50 , and as $m . s$., Fig. 51. Internally the half-cells observed close in by the aid of similar excavations in the segments of the occipital vertebra, the acoustic capsule; and a double-concave surface assists in forming cranial fossi.

We now come to examine the ornithic characters of one of the most interesting segments of the bird-skull, the centrum of the parietal vertebra, well termed by most ornithotomists and general anatomists as the basi-sphenoid. At an early date in the life of the chick (Centrocercus and others) this bone becomes confluent with the centrum of the frontal vertebra be-

vond; this confluence takes place, if we may be allowed to differ with such high authority as Owen, who makes the rather sweeping assertion "that the pit for the pituitary body marks the boundary" (Comp. Anat. and Phys. of the Vert., vol. ii. p.

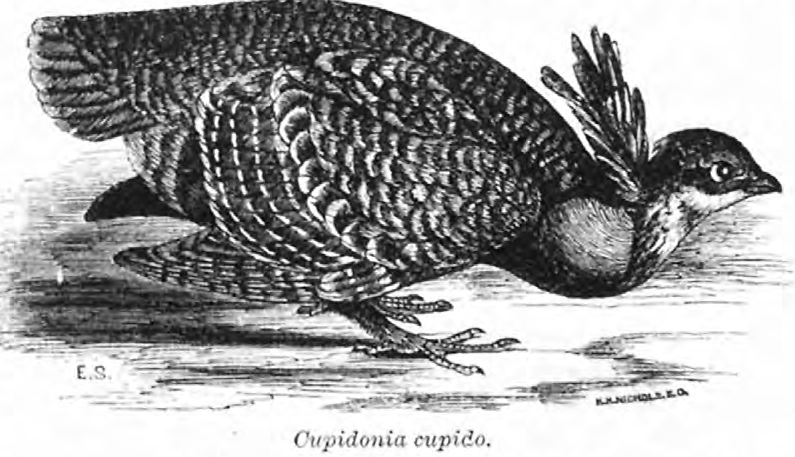
45 ) in the following manner, and the sutural trace is yet discernible in young birds of the Family under discussion (Plate V, Fig. 51). The pre-sphenoid lies beneath a tuberous process projecting anteriorly from the latter bone, reaching nearly as far back as the carotid foramina. The combined bones, the centra of the two mid-cranial vertebræ, thus constitute the compound bone basi-pre-sphenoid of comparative anatomists.

Viewed from above, we discover, proceeding from before backwards, in the median line, 1. The upper aspect of the apophysis just mentioned, and immediately to its rear the deep "sella turcica" with the osseous canals of the carotids opening into one foramen at its base; 2. Two smooth surfaces, one on either side and a little laterally, for the optic chiasma to rest upon; 3 . Another surface still more posteriorly for the mesencephalic fossa, being perforated by diminutive parial foramina; 4. A roughened open space for the articulation, with the head of the wedge-like basi-occipital. Auteriorly, and at the same time laterally, broad and uneven borders for the alisphenoids, with their smooth groovelets of the foramen ovale, while back of these again, on either posterior angle, a concave wing-like expansion, the terminations of the Eustachian

'The bone here called mastoid is the squamosal of the majority of authors, as Huxley, Parker, and others. It corresponds with the bone that bears the same name in the works of Professor Owen. The bone squamosal of this latter author, and used in the same commection by myself in this monograph, is the quadrato-jugal of Huxley and others. 
tubes, that add to the parietes of the entrance of the otocrane. Below and superiorly, at the base of the junction of the two bones, we find the carotid foramina, with a depression between them mesially, and still lower down, slightly protected by an attenuated offshoot from beneath, the separate apertures of the anterior and buccal entrances of the Eus. tachian tubes.

The remaining surface, unbroken in character, extending posteriorly, goes to complete the basi cranii. The coaptation of the elements form. ing the neural arch of the parietal vertebra is shown in Plate V, Figs. 47-50, their amalgamation in the adult in Plate VI, Fig. 52.

The chief importance of the hæmal arch of this vertebra depends upon the bony support it affords the tongue. In a fine specimen of an adult Lagopus leucurus, kindly presented me by Mr. Robert B. MeLeod, then residing in Leadville, Colo., we find the following characteristics presented to us for examination, and they extend with little deviation to all the members of the family. The hyoid arch ${ }^{1}$ consists of, in the specimen under consideration, seven bones. The confluent ceratohyals and glossohyal, which latter is largely completed anteriorly by cartilage, form one segment; the ceratohyals diverge from each other smartly behind, and at their point of meeting afford the facette for the trans. verse trochlea surface on the basi-hyal. This last bone, the second in order, measures half a centimeter in length, being enlarged at both extremities, flattened from above downwards, the anterior end being fashioned to fulfill the purpose already mentioned, while the posterior and larger extremity presents two facettes, looking backwards and outwards, to articulate with the hypobranchial elements of the thyro-hyals. The third segment also meets this compound articulation at this point, a short urohyal, it, too, being completed at its posterior extremity by cartilage. The hypo- and cerato-branchial elements of the thyro-hyals make angles with each other and curve upwards in conformity with the basi. cranii.

The sub-cylindrical hypo-branchials are one and a half centimeters long, and connected with the posterior elements by quite along and intervening piece of cartilage of the same caliber; the smaller ceratobranchials also taper off behind with the same material.

This arch in the Tetraonida long remains almost entirely cartilaginous, the hypo-branchial elements alone being composed of bone, and a bird must be of quite an advanced age before he can boast of a complete osseous framework as forming a component part of his lingual apparatus.

The neural arch of the third cranial vertebra now to be defined is the prosencephalic-its hæmal arch the "mandibular," as its hæmapophy. sis constitutes the lower jaw, termed "mandible," in avian skeletology.

The fusing of the centrum of this segment with the basi-sphenoid has already been elucidated; the rostrum thus formed is gently inclined upwards and forwards, grooved along its entire superior aspect, tapering to a sharp point anteriorly to receive the connate prefrontals in the bony gutter at its distal third. Beneath it displays towards its base the

\footnotetext{
${ }^{1}$ In speaking of this compound bone, Professor Gegenbaur tells us: "Two pairs of arches can be made out in birds. The rudimentary first arch fuses to form the socalled entoglossal bone (Fig. 259, 2), posteriorly to which lies the true body of the hyoid. The second arch, however, is well developed, and gives rise to the coruna $(\dot{4}, 5)$, which are formed of two large pieces, which generally curve backwards behind the skull, without being directly connected with it. Behind the copula there is the remnant of a second one, which forms the hyoid process (3)." (Elements of Comp. Anat., Lond., 1878, p. 472.) In the description of the hyoil in this paper the ceratohyals correspond to the entoglossal bone, as referred to in the above quotation from Gegenbaur, and the copula of that author to the basi-hyal, his hyoid process being the urohyal.
} 
parial facets for the pterygoids and beyond the rounded surface for the palatine articulation.

It will be remembered that in the first edition of this monograph the writer announced the fact that he had failed to discover the orbito-sphenoids (considered as the neurapophyses of the arch) $i . e$., they were not found as bones that were produced from separate points of ossification. Since that time, more than a year ago, I have not had the opportunity to look more thoroughly into the mattter, but the series of my skulls of the common fowl and those of Centrocercus show the spaces these bones occupy in the mature birds to be completely filled in, the posterior orbital walls being more or less complete, a fact familiar to all of us, but in birds of the year and still younger specimens large vacuities exist where these bones should be; moreover, I have in my possession a skull of the common fowl in which the basi-sphenoid sends up on either side two delicate bony sprouts that subsequently complete the periphery of the circular foramen for the oculomotorial nerve and the optic. Professor Owen seems to think that these are the centres of ossification for the orbito-sphenoids, for this anatomist tells us that "the bones, 10 (orbitosphenoids), of the third neural arch coalesce with each other, and the centrum below, protect a smaller proportion of the prosencephalon than in the Orocodile, but maintain their neurapophysial relation to it and to the optic nerves, below the exit of which they begin to ossify." (Anat. of Verts. Vol. II, p. 46.) Huxley, in his Anatomy of Vertebrated Animals, page 22, says, "In front of, or above, the exits of the optic nerves the orbitosphenoidal ossifications may appear and unite below with the pre-sphenoid." Professor Parker is even more decided, for this writer informs us that "Above the optic foramen, wedged in between the alisphenoid and the interorbital septum, a four-sided bone has arisen in membrane on each side, and there is a smaller pair in front of and above the larger, helping to fill in the fenestræ left unoccupied by the orbital plates of the frontals. These are the anterior and posterior orbitosphenoids (o.s. Fig. 66.) The anterior half of the interorbital septum is ossified, the mesethmoid encroaching on the anterior margin of the interorbital fenestra." (Morph. of the Skull, young fowls up to nine months old, page 249.)

This is very clear, and as Professor Parker is a very careful observer and devoted himself particularly to the subject in question, no doubt his observation is correct, and some more fortunate observer than myself will some day detect these ossifications for the orbito-sphenoids in our Tetraonida; for since they occur in the common fowl, it seems only natural that we should look for them in the Galline generally. This accounts for the fact that in my drawing in Plate V., Fig. 51, the position of an orbito-sphenoid was simply shown by dotted lines, and marked os.; in this same figure Fr. is the "frontal," ps. the prefrontal or centrum of the vertebra, and $x$ the usual site for the postfrontal-this exogenous element, the diapophysis of the vertebra is not here found, its position being occupied by a depressed roughened surface for the squamous articulation of the mastoid. We have never personally ex. amined any bird in our avi-fauna where this bone is seen independent. Descriptive ornithotomists, in their studies upon the skulls of Rheida and Struthionida, give the presence of this process as occurring free.

The neural spine of the frontal vertebra follows the example of the parietal in being completely bifidated in the younger specimens: As a whole it is perhaps the largest segment in the bird-skull-certainly as far as our Grouse and Partridges are concerned. Either half of its spine presents, projecting anteriorly from the middle, a flattened process, directed gently forwards, downwards, and outwards; that at its extrem- 
ity is marked above by quite an extensive surface for one of the nasals, and below by another, against which the head of the ethmoid abuts. The concave surface below this process and the remaining hinder moiety form the vault of the orbit. Another scale-like projection is thrown out posteriorly, deeply concave within, correspondingly convex without, to shield the prosencephalic lobes-the bones being joined. Huxley terms the pleurapophysis of the hæmal arch of this segment the "quad. rate"-the "os quadratum" of the older anatomists. Owen defined it as the tympanic, ${ }^{1}$ it being the homologue of a bone of the vertebral skull generally -it was the os carré, in birds, in the writings of the eminent Cuvier. The tympanic bones here, as in all sauropsida, are free ossicles, connecting the articular ends of the lower jaw with the skull. They are in the Tetraonida, symmetrical and well proportioned, not exhibiting any marked peculiarities or deviations from a common type. The mastoidal and orbital arms are about of a length and calibre, the first being rather the larger, and is surmounted by a hemispherical articulating head for the cup on the lower border of the mastoid. The neck below the processes is moderately constricted before it expands to become the "mandibular" end, that has beneath its tranverse elliptical facet outwardly the intervening notch, and then the inner and smaller one, all for artic ulation with the mandible. The bone has likewise a surface to articu. late with the pterygoid below the orbital process, and is always pneu. matic. From the outer aspect of the mandibular extremity it sup. ports its two appendages, the bony styles, termed "squamosal" and malar-the first by a diminutive ball-and-socket joint articulated in the usual manner. The malar, as we know, is the mid-style of the infraorbital bar-the maxillary completing the connection anteriorly. and although upon superficial inspection of this striking ornithic feature of the lateral aspect of the skull, it seems to be firmly united in its schin. dylesial articulation, it simply requires ordinary maceration in the adult of any of the Grouse or Quails to have the three styles separate from each other and from their tympanic and intermaxillary connections.

The lower jaws of the Tetraonince are singularly alike in all their characteristies throughout the sub-family. The single bone is developed in the usual way by confluency of the "articular," "surangular," "angular," and "splenial" elements posteriorly, and the outer moiety by the "dentary" element, the hæmal spine. (Plate V. See explanation of plates for the above-described bones.)

The mandible in the adult has a gentle and increasing curvature downwards from the interangular vacuity forwards. The curvatures

${ }^{1}$ There can scarcely be a reasonable doubt left in the minds of comparative anato. mists that the question is now settled and the fact generally accepted that the bone termed tympanic and so used by Professor Owen in his writings, is the representative of the malleus of the mammalı. It is the "quadrate bone" of all modern writers, I believe without exception, and articulates with the skull, the quadrato-jugal and the pterygoid and the lower jaw on either side. Professor Huxley alludes to its development in the following words: "In the sauropsidan embryo a rod of cartilage occupies the first viseral arch on each side and meets its fellow in the middle line. The rod becomes jointed, and the part on the distal side of the joint is converted into Meckel's cartilage, while that on the proximal side of the joint is modeled into the rudiment of the quadrate bone, which is invariably in its earliest state cartilaginous. Soon, however, the quadrate cartilage ossifies, and a centre of ossification appears in that part of Meckel's cartilage which articulates with the quadratum. This gives rise to the articular element of the mandible. All the other constituents of the lower jaw are developed in the fibrous tissue which surrounds the rest of Meckel's cartilage, which structure either persists throughout life or disappears." (On the Representatives of the Malleus and the Incus of the Mammalian and other Vertebrata, Proc. Zool. Soc. Lond., 1869, page 401.) 
at the extremities of the symphysisial suture are both parabolic, the inner being the more open of the two. The interangular fenestra is a flattened ellipse, whieh has distinct sutural traces leading from it, indicating the borders of some of the original bits of bone of which it is composed.

The "coranoids" are but feebly developed and the articular ends not far below them; these latter have the usual pneumatic foramen at the ends of their in. pointed and blunt extremities, and sharp recurved processes behind, in a line with the rami of the jaw, which apo. physes long remain in cartilage in immature birds. (Plate X, Fig. 71.)

On the lateral aspeet of the bone, two muscular lines lead away from the coronoidal elevations. These last two mentioned features are universally charac. teristic of the Tetraonide; they are strongly marked in Lagopus. (Plate

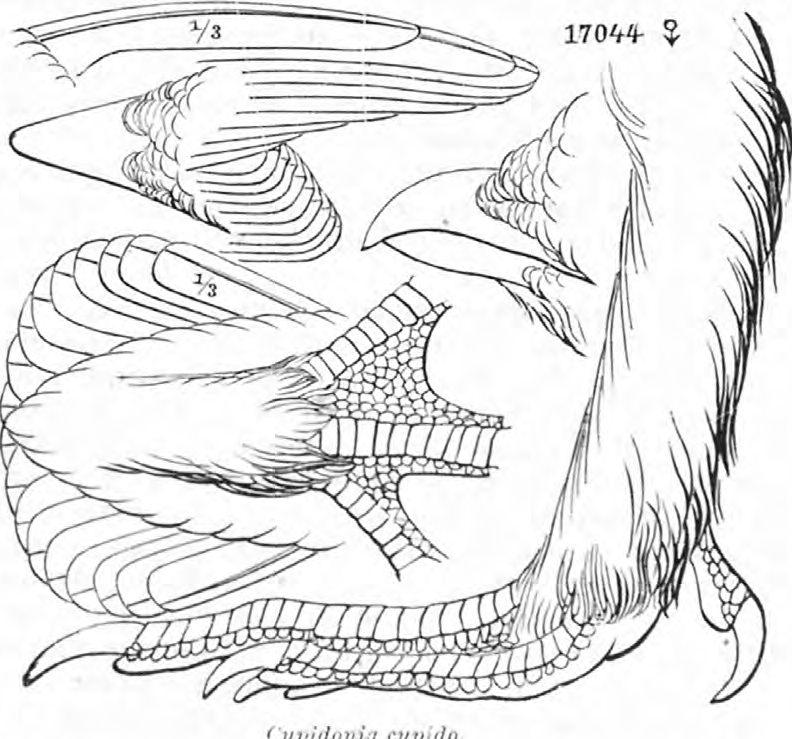

XIII, Fig. 88.). Minute foramina are found above and below near the dentary margins, and two quite prominent, one beyond the ramal fenestra on the inner surface of the jaw; still another just anterior to a small tubercle below the coronoids on the same aspect. The inferior ramal borders are smooth and rounded, as are the under surfaces of the articular ends where they originate in nearly the same plane.

The divergence of the ramal limbs of the mandible in Ortygince is greater, owing to the greater width of the skull when compared with its length.

In some fine specimens of Lophortyx californica, generously furnished us by Mr. Charles A. Allen, of Nicasio, Marin County, California, we note the striking departure from the mandible in the Grouse in the absence of the interangular vacuity - this feature obtains, however, in the common Virginia Partridge and others. The deflection of the rami anteriorly is greater in these birds also, or at least more sudden, and so prominent are these ramal borders that the inner sides, towards the posterior ends, are converted into true fossæ.

Those interesting osseous and diminutive oblong plates, the sclerotals, present in all of the class, we believe without exception, are found here occupying their usual position. (Plate V, Fig. 51, 2, and Plate X, Fig. 75 , in Cupidonia.) They number from thirteen to eighteen or twenty, and their function is so well known that it will not be dwelt upon here. They differ principally in the amount of tenacity with which they retain their normal relation after prolonged maceration. Cupidonia holds a high place here, and the fact seems to be due to the greater overlapping of the edges of these little affairs and the toughness, or 
perchance the thickness, of the internal and external sclerotic coats that cover them. Lately we saw in the case of Sayornis nigricans where these platelets were apparently confluent; no such condition ever occurs in the Grouse or Partridges.

The "lacrymal" (Plate V, Fig. 51, 3 and other figured skulls), is found on the anterior margin of the frontal, enjoying a free harmonial articulation that encroaches slightly on the nasal border. Each is a squamous, cordate lamella, with its larger end nearer the orbital cavity; this completes the bone in young birds, but in mature individuals it sends down a curved and delicate style with its point directed outwards, that encircles and gives support to the lacrymal duct on its passage to the rhinal cavity (Centrocercus).

We now come to examine into the last of the cranial vertebræ, and, in the family under consideration, the one most modified. It is the "nasal," and its neural arch the "rhinencephalic," the hæmal, the "maxillary."

In the Tetraonida its centrum, the "vomer," is missing. ${ }^{1}$ Whether this be due to the foreshortened skull of the Grouse, with its long sphe. noidal rostrum rendering any further extension superfluous, we cannot say. In the lengthened skull of any of the Anatido, where such a bone is imperatively called for, as a sub-interspinal partition, it is invariably present and unusually prominent (Plate V, Fig. 51, vr. vomer, is merely outlined to indicate its position in other birds).

The neurapophyses of the arch are found in the connate prefrontals, the bone called "ethmoid" in androtomy. It here, in the young bird, is lodged in the outer third of the groove on the pre-sphenoid, rises columnar, sub-compressed laterally, leaning forwards at a gentle angle to expand above in a trikedral summit for the support of the frontals, nasals, and intermaxillary, a short process being projected backwards for the former. The posterior aspect of the column develops as the bird grows, the interorbital septum, reaching to, and perhaps aiding in, the formation of the exogenous orbito-sphenoids.

The nasals, or the divided neural spine of the arch, are squamous

${ }^{1}$ Since making the above statement I have been able to examine a large mass of material from all imaginable sources, and have come to the final conclusion that the vomer occurs in the entire group of gallinaceous birds of America. Many things may have led me to believe at the time that this bone was missing, as stated in the text: In the first place, it is an extremely delicate and freely articulated one in the Tetraon$i d \propto$, and in the second place the doubt still harasses my mind as to whether there may not be instances where this vomer does not ossify until very late in the life of the bird, and all of the fresh specimens I examined may have been of this character. The foundation for this assertion lies in the fact, that quite recently I examined, with great care, numbers of market specimens of Bonasa and Cupidonia, in which I failed to discover this bonelet, while in others it was easily found. The specimens examined were all apparently birds that had attained maturity, and displayed no external characters by which they could be separated from each other.

The plates accompanying this edition were not submitted to me in time to add this bone to such figures in which it would show, so that the vomer does not appear in any of them. In Plate V, fig. 51, where it is shown in dotted outline as vr., it should be beyond the ethmoid. Pf. and shaded like the other bones indicating its presence. A good figure, giving its proper position, is presented to us by Huxley in his Anatomy of the Vertebrated Animals, page 283 (figure 82 of the common fowl). This writer tells us "the vomers vary more than almost any other bones of the skull. They underlie and embrace the inferior edge of the ethmo-presphenoidal region of the basis cranii, and, in all birds in which they are distinctly developed, except the Ostrich, they are connected behind with the palatine bones. In most birds they early unite into a single bone; but thes long remain distinct in some Coracomorphe, and seem to be always separate in the Woodpeckers."

I have found it in numerous adult specimens of the common fowl, but it is a rare coincidence to ever find it in the crania of museum collections. I have in my section at the United States National Museum, the "Darwin types" of the skulls of the wild 
lamella, twisted upon themselves in a manner to conform with the superior base of the beak, overlap the frontals, as already defined, are separated from each other by the intermaxillary, throwing out below to meet this bone a sharp process, thus forming a broad elliptical boundary limiting the capacious osseous nares. In all adults of this family they are easily detached by maceration. These bones are well shown in Plate X, Figs. 71 and 73 , in the cranium of Cupidonia, from an unusually fine bird sent with a number of others, for which our thanks are graciously tendered to Captain Richards Barnett, Medical Department, United States Army. It will be observed that the bone becomes so at. tenuated in some specimens as to give rise to a foramen, as seen in the latter figure. The hæmal arch of this vertebra is called the maxillary as its lower rib and spine constitute the major share of the superior mandible or maxilla. The pleurapophyses seen in the palatines are long, riblike bones with their anterior ends much flattened from above downwards, to fit into a fissure on either side made for them in the intermaxillary below the maxillaries. Near their middles they curve moderately outwards to develop compressed heads at their posterior extremities, fitting into a notch in either pterygoid, and concave mesially for the rostrum of the basi-sphenoid.

At their inner thirds they send off thin sheets of bone that curve upwards, barely to touch the ramphosial process of the sphenoid, accompanying it as far as it extends distad, then sloping away on the ribs of the bones themselves. The hæmapophysial maxillaries are elements that seldom change their ornithic characters, and in the Tetraonida seem to be reduced to their simple typical form-in completing the delicate infraorbital bar on the one hand-and just previous to becoming wedged into the premaxillary above the palatines, dispatching a bony offshoot on either side nearly to meet each other in the palatine fissure on the other.

The remaining pair of bones found at the interior aspect of the bird's skull are the pterygoids. In the Grouse they are stumpy, subcompressed concerns, with half-twisted shafts, having broad concave surfaces for the facets on the rostrum, which are notched distally for the reception of the palatines. The articulation with the tympanies is equally extensive, monopolizing long, narrow facets beneath the orbital processes 'on those bones.

We have arrived finally at the point in our descriptive skeletology of the avian skull, where we have to deal with the anterior and ultimate

Gallas baukiva and the Horned Fowl of the Azores. They were presented to the Smithsonian Institution by Mr. Tegetmeier. The vomer is present in neither of these crania, although no doubt it may have been originally, and in the drawings made from these very crania the vomer has likewise been omitted. (Darwin's Animals and Plants under Domestication. Vol. 1, pp. 275, 279, figs. 34, 36.)

Other eminent writers describe its development in the following language: "The pre-maxillaries and the rest of the bones of the upper jaw are further advanced in development, becoming more solidified, and perfecting the various relations already described. A new bone has arisen in the palate, viz, the vomer (v. fig. 65, p. 246), which is however but a very small style, lying under the nasal septum, behind the points of the maxillo-palatine processes of the maxillaries." (Parker and Bettany, Morph. of the Skull. Section 549. Common Fowl, fourth stage.) And again: "The slender maxillary (figs. 64,65) now rises in front into the angle between the descending crus of the nasal bone and the hinder edge of the dentary process of the premaxillary. The maxillo-palatine plates ( $M x$. p. Fig. 65$)$ are broader and reach nearly to the mid-line, being separated partly by the nasal septum and partly by the small vomer, which is rounded in front and split for a short distance behind. The forks of the vomer $(v$.$) articulate with the inner and anterior points of the inner plates of the$ palatine bones, which lie side by side mesially, nearly concealing the rostrum." (Ibid. sect. 563. Fifth stage. The chick second day after hatching.) 
hæmal spine, here fulfilling most important functions as the superior mandible, as it does throughout the class at large. In the Tetraonida, as in the vast majority of birds, the intermaxillary or the "premaxillary" of some authors is of much stouter material than most other bones of the head, its use being a very obvious reason for this. (Plate V, Fig. 51 , N. Pf. $m x, i . m x$.)

From the moderately free fronto-maxillary and pseudo hinge-joint, between the out-turned frontals, the culmen of this bone slopes by a gently increasing are to the tip of the beak. This surface is rounded and split in two from the enlarged inner extremity to a point over the distal border of the nostril; this division lasts during life. The external nasal orifices are unusually large and sub-elliptical in outline. The head of the ethmoid shows in very young chicks, but is eventually cov. ered by this bone, which also fills in snugly the internasal space (Plate X, Fig. 73).

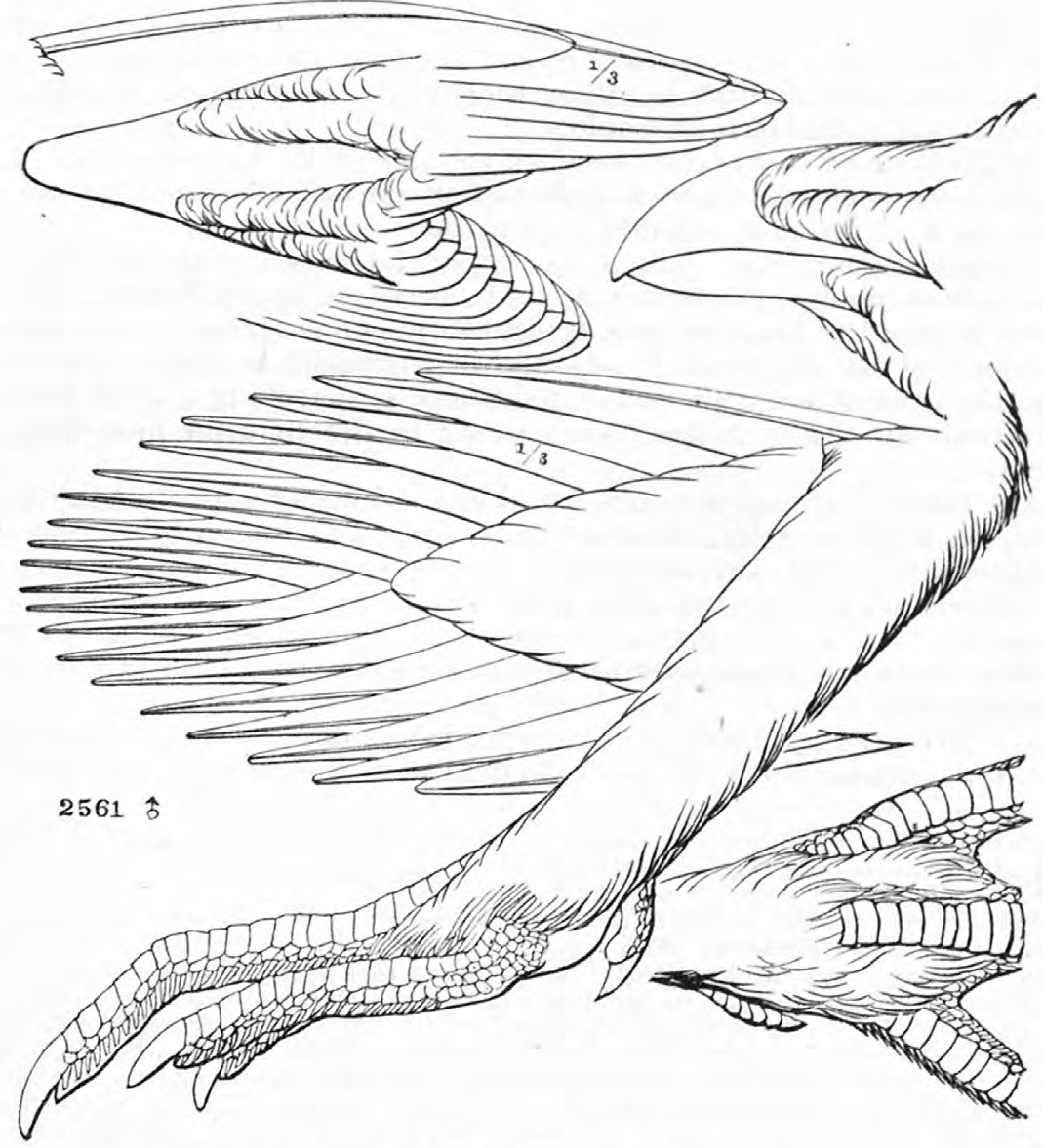

Centrocercus urophasianus.

The osseous maxillary tomia are even sharper than when they were capped with the horny integumental sheath that the entire bill wears during life; they are produced backwards on a triangular process of the bone below the shaft of the maxillaries, touching them in the Quails. 
A row of minute foramina encircle the beak anteriorly, where it is the thickest, though the segment is non-pneumatic. The general surface beneath is depressed below the tomial margins, though it is not very extensive, as the wide palatine fissure occupies a good part of the space, that terminates anteriorly in a $\mathbf{U}$-shaped curve, opposite the outer nasal border. In the Ortigynce the curve of the culmen is more abrupt, and the frontals rise above, in some cases even jut over, the premaxil. lary. The nasal apertures are also very large and of a shorter elliptical outline; the palatine fissure is likewise narrower in comparison, a few of which differences are such as one would naturally look for in a bird of so near kin, and whose beak has been more than proportionately curtailed.

On removing the vault of the cranium in an adult female of Centrocercus, so as to obtain a free view of the brain-case, we discover the usual nervous and vascular foramina present at their most common sites, but beyond this we are more struck with the feebleness with which many of the salient points are developed, as compared with some of the other avian groups; we might sum it up by describing it as a lack of angularity and depth. It is true the various fossæ are well, though not strongly divided, the superior median crest is present, but not very prominently developed, and the rhinencephalic fossa is barely conical. The section shows the greatest amount of deplöic tissue to be in the basi-sphenoid, and bones of the occiput, where for potent reasons such material is most urgently in demand.

In the study of the crania of the adult Tetraonidas as an entirety we find among the most conspicuons features enlisting our interest the unusual number of bones that remain free in them. The skull can be so stripped of its outstanding segments that nothing remains save the cephalic casket with the interorbital septum. The rhinal chamber is strikingly open, due to the great external nasal passages, and all its internal structures, as the ethmo-turbinals, internasal septum, and floor being formed only in cartilage. A pocket existing in the extremity of the premaxillary, that fills in with a spongy osseous tissue during life, is observed in Centrocercus, which is solid in the Ortygince and Lagopusparial, subcircular pits placed side by side in like locality in Canace obscura.

The orbits are more fortunate in the completeness of their bony inclosures - the heavy plate generously extended by the ethmoid to divide these cavities very rarely shows any deficiencies. Of all the crania before us Canace obscura is the only delinquent in this respect, though no doubt this may occur in others. In it quite a vacuity exists near the middle of the septum. Anteriorly the prefrontal and frontal throw out laterally squamous septa of greater or less completeness, that divide these cavities from the common rhinal space. These plates may coalesce with the processes of the lacrymal, as a rare coincidence, and perchance meet the infraorbital style. The foramina for the passage of the optic nerves and the first pair are, as a rule, singularly circular and distinct, the minor apertures about them enjoying a like individuality. They are noted for their greater size among the Partridges.

A separate canal is devoted to each olfactory nerve immediately below the orbital vaults, that usually at its outstart from the cranial end has a small opening between it and the one of the opposite side. About the entrance to the otocrane we notice principally a rounded, squamous plate thrown down from above by the mastoid, that is present in all the Grouse. sust below and within, this segment also develops a sharp spicula of bone, posterior to the tympanic articulation, that evidently 
serves the purpose of keeping this free ossicle in its socket in certain movements of the jaw.

Peculiarities of the floor of this cavity have already been described above; in specimens of Canace canadensis, carefully selected for me by Mr. William Brewster, of Cambridge, Mass., and forwarded to me by Prof. J. A. Allen, of the Museum of Comparative Zoology, also of Cambridge, to whom my grateful acknowledgments are due for so many like favors, we find, upon viewing the skull from below, the elevations or convexities due to these ellipsoidal and wing-like formations, reminding one of their marked resemblance to the acoustic bullæ of the tympanic found among the crania of Felide.

The author in his various plates and figures believes he has given sufficient life size, as they all are, views of basal and superior aspects of the skulls of these birds, will not enter here into any needless details of measurements. The variation in size in this respect in Centrocercus has already been dwelt upon; it is not nearly so marked in other genera. The surfaces of the skulls above have a rough look caused by many minute depressions and groovelets, these running out to the margins of the orbits cause them in some to be finely serrated.

The sharp-tailed Gronse is a unique exception to this, it being a bird of rather a delicate skull with smooth eranial superficies. All save Cen. trocercus possess rather depressed foreheads, apparently due more to a slight tilting upwards of the superior orbital peripheries. The lateral temporal fossæ are shallow and scarcely noticeable, the muscles they afford lodgment-not being remarkable either for their size or strength.

Did the writer feel that he had sufficient material before him he would gladly devote a few of these pages to the description of some of the exceedingly interesting osteological differences existing between the domestic and the wild Turkey; but as such facts can only be considered reliable, and such differences constant, after the examination of a large series of each, such as we have not at present at our hand, we will simply speak of a few of the cranial peculiarities as seen in a set of skulls of Meleagris gallopavo and M. gallopavo americana from the collection of the Army Medical Museum of Washington. As we might expect, the skull of Meleagris has in it all of the leading points that we have attributed to the Tetraonida generally. The occiput and the foramen magnum are found to be nearly or quite in the vertical plane, the skull resting on its bearing points in the horizontal plane; the surface above is more or less rough and venated, as in Cupidonia. The parietals rise above the general surface as rounded domes, constituting quite a prominent feature in the skull of this bird. A depression occurs in the frontal region between the margins of the orbit and posterior to the nasals; this is more decided in my specimens of Pavo cristatus, a bird that possesses a cranium not at all unlike the Turkey. In Meleagris we find the lacrymals to be strong and pointed bones directed backwards, articulating principally with the nasals, though the frontals usually extend down to meet their posterior borders; below, their descending processes are flattened and turned towards the median plane. Taken as a whole the lacrymals of the Wild Turkey are quite different bones as compared with the same bones as we found them in the Grouse and Quails. A very interesting change is seen to take place in these bones in Numida meleagris, as this bird attains maturity. We have just said that the frontals in the Turkey extended down so as to meet and articulate with the posterior borders of these bones on either side; now, the older the bird the more extensive is the meeting of these bones; this is carried to its maximum condition in Numida, for in the young of 
this fowl the lacrymals are found to be freely articulated to the outer borders of the nasals, the frontals barely making any encroachment upon them, but in a very old bird we find the lacrymals actually wedged in between the frontals and nasals on either side, and the superior periphery of each orbit formed by the continuous outer margins of a frontal and a lacrymal. The prominent bony crest seen in the median line of the skull of the Guinea Hen is formed entirely by an uprising of the frontals and increases as this fowl becomes older.

In the Wild Turkey, the external nasal apertures are large and elliptical, and the various sutures among the bones of the superior mandible, long remain clear and distinct as we found it to be the case in the Grouse. On a lateral view of the skull we find the arrangement of the sphenotic process the same as in all of the Tetraonida; it differs in Numida by being single and very stout; there seems to be no rule governing the condition of the orbital septum, for in skulls of Wild Turkeys of apparently the same age-in one, large deficiencies will be found in this plate while in the other the partition will be entire and quite thick.

The pterygoids are large and stumpy bones, articulated in precisely the same manner as we described them for the Grouse. The vomer is short and the spinal chamber in the dry skull capacions and undivided by an osseous septum narium.

The lower jaw is stout and may or may not have the fenestra present in its side; behind it has the sharp, upturned processes so characteristic of Gallinaceous birds. The ramal apertures is absent in all of my specimens of Pavo and Numida, otherwise the birds have inferior maxillæ typical of the family to which they belong.

We have examined skulls of all of the forms of Lagopus occurring in America, and discover but trifling differences existing; in a specimen of $L$. albus the orbital septum is complete and the cranium of the bird is broad across the fronto-maxillary region; a deep median pit exists in this region among many of the Quails, less marked in Ortyx, but very decided in Cyrtonyx massena, still more in Orortyx picta, the beautiful plumed Partridge of the Pacific States. In this latter bird we find a deep and longitudinal cleft occurring in the median line on the superior aspect of the skull, between the orbital margins, that is characteristic and not found among the other American Quails.

The skull of the young of Pediocetes, a few days after it has left the nest, differs in no great degree from the skull of the young of Centrocercus-i.e., in points of ossification and the relation of the bones.

of the Vertebral Column.-In discussing the development and peculiarities of the vertebral column, we will still continue to adhere to Centro. cercus as our model, explicitly stating names of other species when occasion requires a departure therefrom.

In examining the atlas and axis as they occur together in the chick a few days old, we find that the neurapophyses of the first have as yet failed to fairly meet above in the median line; though they may in some instances, as they undoubtedly do, soon touch each other. No ossific centre exists for an atlantal neural spine, as that process is not found upon this boue in any of the Tetraonida. Below the arch the interesting procedure is progressing in the appropriation of the centrum of this segment by the axis. The inferior extremeties of the atlantal neurapophyses have inserted between them a circular ossicle whose plane is in the horizontal plane and on a level with the floor of the neural canal of the axis. This bonelet eventually becomes the "odontoid process" of the second vertebra. At this stage it is a little less than a millimeter in diameter, and in the adult occupying the same position remains a sub. 
sessile, and in comparison with the bulk of the bone it is attached to, an insignificant tubercle, though unquestionably fulfilling all the impor. tant functions required of it. In less than six weeks the odontoidal larceny is complete, and no trace remains to lead one to suspect how matters stood at the earlier date.

Immediately beneath and a little posterior to the primoidal and distinct centrum of the atlas, there is another, and still larger, free ossific centre, uniform in outline, concave above, surrounding the primitive odontoid apophysis with its long axis lying transversely; behind, and in contact with it, are two more very minute and elliptical ones placed side by side. The first of these unite with the atlas and latterly form the bony ring for the occipital condyle to revolve in, and the surface for the odontoid to move upon, and a notched lip of bone that projects from it behind, that subsequently develops; the remaining two, behind the first ossicle mentioned, form the anterior part of the body of the axis that bears the articulating surface for the first vertebra. In the fullgrown bird the postzygapophyses of the first vertebra projecting well to the rear look almost directly inward. They meet the prezygapophyses of the axis that face in a contrary direction and a little backwards. The articulating facet for the centrum of the axis is subelliptical, convex, of some size, and has in the segmented column the inferior and convex surface of the odontoid playing just above it, the superior and flat surface of the latter being confined by intervening and delicate ligament forming a part of the floor of the neural canal of this bone. In the axis of the adult the anterior part of the bone with the odontoid process, that was separately added, projects conspicuously forwards beyond the neural arch, and in birds of several months of age it can be distinctly discerned where the union was established between neurapophyses and centrum.

In the mature vertebra the neural canal is nearly circular. In the center of the bone, above, a knob-like tubercle acts as the neural spine, which has mesially and behind a deep pitlet for the insertion of the interspinous ligament. Anapophysial tubercles are found above the postzygapophyses, which latter are of considerable size, concave, and faced downwards. The centrum of the axis is subcompressed from side to side and supports mesially, just anterior to the second vertebral articulation, the first hypapophysis of the series. The first two segments of the vertebral column are non pneumatic.

Vertebræ throughout the chain in the young chick invariably show the line of union between the centra and neurapophyses, but it is lost as soon as the birds come to be two or three months old. At this age, however, still very interesting points of development are strikingly visible in the third vertebra, which otherwise varies but slightly from the same bone in appearance as seen in the column of an old male, such as we have before us.

The neural spine, more compressed than in the axis, is nearer the middle of the vertebra, still deeply pitted for the interspinous ligament behind, and slightly so on its anterior margin. This characteristic becomes very faint among the long vertebræ in the middle of the neck, to be more strongly reproduced as we approach the dorsals, the posterior depres. sion always being by far the best defined. We find anapophysial tubercles still present in the third vertebra. These also exist throughout the cervical series, with more or less clearness; they form ridge-like lines upon the elongated segments of the mid-neck. The zygapophysial processes in general look upwards and inwards anteriorly, and vice versa be. hind-the fourth vertebra having in common with the one we are now 
describing an interzygapophysial bar, lending to these two segments that broad and solid appearance well known to ornithotomists, not possessed by any other of the cervicals. The neural canal in the third vertebra is nearly circular, which is also its form in the adult, becoming only moderately compressed from above downwards in the last three or four cervicals. Regarding the third vertebra from below, we observe that the articulating surface of the centrum for the axis to be quite concave and turned a little downwards. The processes that fall beneath the prezygapophyses form what would be a canal with its lateral margins; this groove, however, in the "bird of the year" is converted into the vertebral canal by an independent ossicle being placed over it on either side, and, being below the rest, it causes a broad shallow concavity to appear mesially and anteriorly.

These small bones have at the very outstart stumpy apophyses projecting backwards, which are the parapophyses of the vertebra-the projections they meet from above being the pleurapophyses, the groove they form mesially being the broad termination of the carotid canal.

The fourth vertebra has the same general appearance of the third, that we have just been describing; it is a little longer, however, and in both large pneumatic foramina are found laterally and beneath the diapophyses. These apertures are found in the vertebral canal in the remainder of the cervicals. Again, in both, the bodies are rather compressed from side to side, and it is not until the bird has arrived at maturity that the hypapophyses are well seen in these two segments.

Now, taking up the cervicals from the fifth vertebra, we find certain characteristies holding good throughout the series, with certain gradual modifications. In the adult the neural spine in the fifth is prominent and placed anteriorly ; it slowly subsides to the tenth, where it is more tuberons, nearer the middle of the bone, and bears evidence of having a posterior projection overhanging the depression for the interspinous ligament. This is the type to include the thirteenth, the projection being more and more prominent and slightly cleft behind; in the fourteenth and fifteenth it suddenly assumes the broad quadrate spine of the dorsal type. Returning to the fifth vertebra, we note another change in the lengthening of the postzygapophyses; the acme of this modification is seen to be in the sixth and seventh vertebræ. From these they gradually shorten again, while the anterior ones spread ont with the diapophyses to assume the form of the consolidated ones in mid-dorsal column. This arrangement allows lozenge-shaped apertures to exist between the segments above, and subelliptical ones laterally, that become smaller and more circular above as the postzygapophyses shorten, and quite large laterally as they approach the point opposite where the brachial plexus is thrown off from the myelon.

In the adult Cock of the Plains we detect beneath, in the fifth vertebra, well anteriorly, a strongly-developed quadrate hypapophysis. This process entirely disappears in the sixth, for in this segment the centrum of the bone, anteriorly on either side, just where the parapophyses meet the body mesiad, a tubercle commences to make its appearance, the apices slightly inclined towards each other. From the sixth to the tenth inclusive these apophyses become longer, approach each other below, but never meet so long as they have the "carotid canal," which they form between them. In the eleventh they seem to have met throughout their extent to form a hypapophysis on the exact site they occupy in the tenth, the tenth vertebra being the last cervical where there is any evidence of the carotid canal; hence from this method of formation Professor Owen is made to say (Comp. Anat. and Phys. of Vertebrates, 
vol. $11, ? .190)$, "In the common Fowl each carotid * * * enters (ing) the canal formed by the hypapophyses."

In the completed twelfth vertebra of mature birds we find this hypapophysis very large, with expanded extremity, and the parapophy. sis, on either side, sending down long subsquamous processes. In the thirteenth segment of the "bird of the year" the parapophyses begin to take on a change. This change develops in the adult still a perfect hypapophysis, but in the younger individual the parapophysial element begins to be notched anteriorly, a part favoring the pleurapophysis, a part the centrum, so that in the fourteenth vertebra of the adult the hypapophysis is still present anteriorly with a tubercle developing on either side of it, with the parietes of the vertebral canal very much slenderer. In examining this segment in the younger bird we ascertain that the original ossicle is now a descending pleurapophysis meeting the parapophysis, a delicate and independent process, which, in the fifteenth and last cervical vertebra, constitutes a free rib, while the hypapophysis consists of a mid-process and a smaller nodule on either side. This beautiful metamorphosis can be thoroughly studied and easily comprehended in the cervical portion of the vertebral column in our Cathartes aura.

So that, as a partial recapitulation of the first fifteen segments, we find that they make up the "cervical portion" of the column. Their centra are universally subcompressed at their middles, they develop in the young bird parapophysial projections that eventually produce free ribs by the aid of the descending pleurapophyses, and their interarticula. tions, as far as their bodies are concerned, bear out the general ornithic law of being apparently procelous on vertieal section and opisthocelous on horizontal section.

Backwards from the fifteenth the vertebral segments or the links of the chain take on a metamorphosis that is charaeteristic of the Tetraonidce. It consists in, in all the adults of the genera, a consolidation of the ensuing four vertebræ. The confluent bone thus formed constitutes the major part of the dorsal division of the spinal column and invariably supports free pleurapophyses (Plate VI, Fig. 55, Centrocercus, ad. ô).

In Centrocercus these four vertebræ can easily be distinguished from each other until the bird is over a year old, but very soon after this all sutural traces are entirely obliterated and we have the segment as represented in the plate.

The neural spines become one long parallelogrammic plate, occasion-

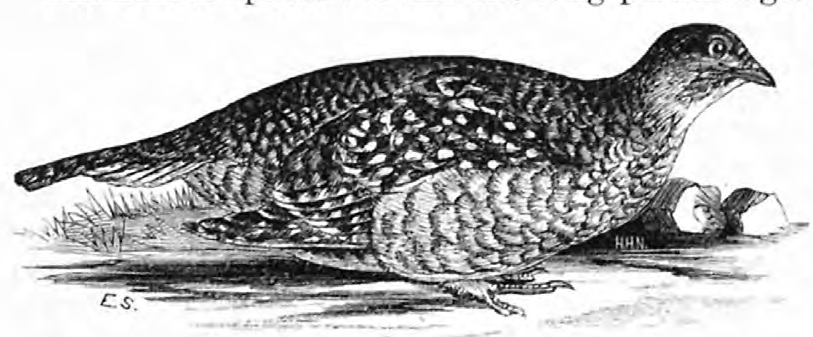

Pedicecetes phasianellus. ally exhibiting a foramen or so at the site of the original interspinous spaces.

Its erest is rounded, but has no independent rim. Muscular fascia attached to it posteriorly often ossifies, leaving in the prepared skele-

ton flattened spiculæ, on either side, directed backwards. The anterior aspect of this bone has all the necessary elements to meet the last free vertebra beyond it. The first pair of diapophyses are the shortest, the last pair the longest and most raised; these processes are more or less bound together by metapophysial offshoots of variously defined serrate margins, that allow interdiapophysial vacuities to exist. Below, and 
just anterior to the bases of the diapophyses, are the four subelliptical and concave facets of the capitula of the dorsal pleurapophyses. From their upper and posterior points sharp crests run beneath the transverse processes to meet the out-turned and cordate facets at their extremities for the tubercula of the ribs. At regular intervals, and nearly in a right line among the diapophyses, are the elliptical orifices for the transmission of the dorsal nerves.

Pneumatic foramina are found about the bases of the transverse processes, the most anterior one being of some size.

The centra of these amalgamated vertebræ are very much compressed from side to side. This compression has its due influence upon the form of the neural tube within, while the bone below is produced downwards into an excessively thin and sharp crest, which is still further extended into four inverted $T$-shaped hypapophyses of large size. They join each other beneath to a greater or less degree in many of the genera. This union more frequently takes place between the first and second, and the first is always upturned and flanged out laterally, a feature prominently reproduced in Lagopus and Bonasa. These winglike side extensions of the lower margins of the hypapophyses not infrequently are continued on two or three consecutive ones, and are sometimes the widest on the second.-Canace.

Both in the Grouse and Partridges we find a free vertebra inserted between the compound bone we have just been discussing and the first sacral vertebra. This segment we must consider as belonging to the dorsal series, although in Cupidonia and Pediocetes the upper and distal aspects of its diapophyses are more or less moulded to conform with the ilia. This bone is also figured in Plate VI, Fig. 55, in conjunction with the other dorsals, with which it has all its characteristics in common, and such ones superadded as we might expect to find in a vertebra naturally disjointed in the middle of the column. It has the longest diapophyses of any of the series to which it belongs; facets for the tubercula and capitula of its own free pleurapophyses; a hypapophysis of no mean length that may or may not be expanded below.

Metapophysial spiculø on its transverse processes sometimes are so far produced as to reach vertebræ before and behind it.

This segment is likewise pneumatic.

There is a wonderful vein of regularity running through the dorsal pleurapophyses, hæmapophyses, and hæmal spine or sternum. As to the first pleurapophysis, or rather the first pair of these bones, we have already described them as they are found in the ultimate cervical. There we are aware it never reaches the sternum by the intervention of a sternal rib; that they are usually found to possess thoroughly developed heads and tubercles for the vertebra, their shafts being less Hattened than the dorsal ribs, and only in Lagopus did we discover any epipleural appendages.

As far as our observations extend, the consolidated portion of the column of the dorsum has always consisted of four vertebræ, and consequently we find in this portion four pairs of movable dorsal pleurapophyses and one pair for the free dorsal vertebra, reckoning five altogether for this region. The first pair of dorsal vertebral ribs terminate in free extremities, which are usually in line with the inter-hæma-pleurapophysial articulations in old specimens, and as a rule support epipleural appendages, characteristic of the species to which the rib belongs.

In the Tetraonida, following the general aphorism of the class, we observe a gradual dilatation of the skeleton from the inter-coracoidal aper- 
ture towards the pelvic extremity of the body. To compensate, or rather what really gives rise to to this, as far as the bird's osseous structure is concerned, among other things, is a lengthening of the diapophyses as we proceed in that direction. The ribs also become longer; the xiphoidal forks of the sternum flange outwards. So, too, we find a corresponding shrinking of the tubercula on the dorso-vertebral pleurapophyses, and a stretching of the correlative necks, so that the capitula may reach the facet intended for them on the vertebræ.

The vertebral ribs as seen in the Grouse are pneumatic, the foramina being found on the posterior aspect of these bones immediately below the tubercles, sheltered by the flattened bodies as they dilate in that region.

As in nearly all birds, these ribs are compressed from within outwards, and in Centrocercus are wider below the uncinate processes, contracting as they meet their sternal ribs. In these birds, too, the epi-pleural appendages are firmly knit to the body of the rib-though iн Bonasa, Lagopus, and Canace they may be easily detached, leaving behind them in each case a shallow concave facet. In the last dorsal rib this append. age is the smallest, and is directed upwards nearly parallel with the body of the rib, and sometimes (Centrocereus) the edge of its rib swells out to meet its apex above; and this may have been the method by which the unique and remarkably striking uncinate appendages were formed in Cupidonia, a bird that constitutes itself an exception among the North American Grouse in this respect (Pl. XI, Figs. 79, 80), where not only the vertebral ribs are unusually broad, but their processes much more so, being great, odd, quadrate and compressed plates confluent with the body of the rib, and only rarely condescending to be weakened by the merest apology for a foramen to exist in them, as in Fig. 80. The Sharp. tailed Grouse appears to come next in approaching this state of affairs; it, coo, invariably developing more or less expanded ribs. The only sacral pair of pleurapophyses conform to the general shape of the series to which they belong, and never support epi-pleural processes.

These bony protectors of the thoracic parietes were found to be exceedingly delicate in specimens of Bonasa kindly sent me by Leslie A. Lee, Esq., of Brunswick, Me.

Four hæmal ribs ascend from the costal borders of the sternum to meet the dorsal pleurapophyses in arthrodial articulations above the mid-horizontal plane of the bird's body. As is usual, their sternal ends are twisted so that the facets are situated transversely, while the upper extremities are broad and flat, particularly in Cupidonia and Pediocetes.

The first pair are generally in advance of the others, and insert themselves higher up on the costal processes: The pneumatic foramina for these bones are to be found just abore their transverse facets anteriorly. The extremities of the hæmapophyses of the sacral ribs meet the pos. terior borders of the hæmal ribs of the last dorsal pair usually about the junction of their middle and lower thirds of the bodies of these bones.

The distal or upper extremities of these, the last pair of hæmapophyses, are sometimes very much expanded, and in a specimen of Centrocercus, $q$, a small bit of bone has been superadded, simulating an additional hæmal spine on either side, as if anticipating the descent of another pair of sacral ribs to protect this otherwise feebly guarded region of its owner's anatomy.

The short pair of xiphoidal processes overlap the ultimate sternal ribs of all the Grouse and Quails, on either side, as do the ilia the sacral pleurapophyses above. 
The Sternum, in the North American Tertraonido, is dereloped from five points of ossification, and to these it seems to have added, later in life, or before the bone becomes one entire piece, an ossific centre at the extremity of each of the four lateral xiphoidal prolongations from which their subsequently dilated ends are produced. These later are easily to be demonstrated in the hæmal spine of Centrocercus, in the "bird of the year" (Plate VI, Figs. 53 and 56).

Fig. 53 represents the young of this last-named Grouse a day or so old, at which time all five of the primoidal points of development are eminently distinct. The "body" of the bone is nearly circular. The "keel," of which only the anterior part has as yet ossified, dips well down between the tender pectorals; the manubrium, now only in cartilage, has at this date no evidence of the foramen that later joins the coracoidal grooves. As to the rest, bands of delicate membranous tissue bind them loosely together. The sternum in a bird of several months' growth is shown in Fig. 56. Here the bone is rapidly assuming the shape it is destined to retain during life. The body and with it the keel is extending by generous deposition of bone tissue at its margins, principally at the mid-xiphoidal prolongation. The manubrium, still in cartilage, we find pierced at its base by the foramen just alluded to, and a rim of the same material runs about the anterior border of the lophosteon, Fig. 56, 4, while a rapidly diminishing band also connects the elements known at this stage as the pleurosteon, $i b ., 6$, and the metosteon, $i b$., 5. In cases where severe maceration is resorted to with this bone, in still older specimens, in which the sutures are not suspected, these parts will still separate about the original points of ultimate union.

On the reverse side of the bone shown in Fig. 56 we find that even at this stage it is deeply perforated by the pneumatic foramen at a point immediately over the carinal ridge.

In the adult the sternum is highly pneumatic, air having access to it through such apertures not only at this point but also in the costal borders between the sternal ribs, and by a single foramen in the groove, posterior to the manubrial process mesiad.

In P'late VI, Figs. 52, 54, and 55 are all parts of the skeleton of the same bird-an old adult Sage Cock, Centrocercus-of which Fig. 54 is a view from below of the sternum.

It will be seen that it has a length of 14 centimetres, and other measurements can be easily obtained from it. We have never seen this bone any larger, and, as it is, it represents the maximum size the hæmal spine attains among North American Grouse. The bone is shown in other plates also, and the.. owners ean be ascertained if the reader will kindly refer to the description given opposite each plate.

The unique outline of the sternum of the Gallina has long been known, many authors having both figured and described it, and we will say here that in the Tetraonide of our country no marked deviations are to be noted from the more common type.

Anteriorly the manubrium juts out as a quadrate process with rounded angles; its inferior margin is continuous with a line that runs down between the slightly prominent carinal ridges, to become continuous below with the anterior earinal margin.

Above, the general surface of the sternal body extends over it. A subcircular foramen, connecting the coracoidal grooves, pierces it at its base. The coracoidal furrow, thus becoming one groove, is biconvex, being depressed mesiad behind the manubrium, in which depression arother vneumatic foramen usually occurs. Their upper and lower 
margins are produced slightly outwards, the inferior being the sharper of the two.

The "costal processes" are exceedingly prominent, being bent over anteriorly at their apices, which are rounded. Behind them are observed the limited "costal borders," exhibiting the four transverse facets for the sternal ribs, and pneumatic foramina. The "carina" or keel affords the greatest amount of osseous surface of the entire bone, greatly exceeding the body. Its lower margin is a long convex curve outwards, and the "carinal angle" protrudes forwards nearly as far as the manubrium, causing the anterior margin of the keel to be decidedly concave.

The "carinal ridge" is thickened and heary superiorly, where it limits or rather c nstitutes the boundary of the bone in that direction. Below it spreads out and is gradually lost, within the boundary of the carinal border proper.

"Subcostal" and " pectoral ridges" are nearly always well defined.

The superior and inferior xiphoidal processes are very characteristic of the Tetraonida. They terminate by dilated extremities of nearly similar shapes, Cupidonia being an exception; the ends of the apophyses of the superior pair in this bird being rounded posteriorly (Plate XI, Fig. 82; see Plate XIII, Fig. 91, Lagopus, for the common pattern.) These processes arise from a common stem, and their shafts are flat internally, with a raised ridge extending the entire length externally. The "body" of the sternum is, as a rule, very narrow, and notably concave anteriorly, becoming nearly flat behind, where it is produced beyond the keel for a greater or less distance.

The manner in which this part terminates varies in the different Grouse.

In Centrocercus it is nearly square across; in Lagopus roundly notched in the middle line, as it is in Bonasa ; in Tetrao canadensis it is broadly cordate; while in Canace obscura, Cupidonia, and Pediocetes it is listinctly cuneiform. The body is very narrow in Bonasa, approaching the Ortygince, where it seems really to be nothing more than a good ribbon-like finish to the superior border of the keel. In these birds, too, we are struck with the double carinal margins anteriorly formed by the projecting ridges, and the long spicula-form costal processes that extend nearly half-way up the shafts of the coracoids.

So much do the sterna of the Grouse resemble one another in species of average size that it would puzzle one not a little to tell them apart if they were separated from the skeleton, and we were not allowed to examine them in connection with other diagnostic features of the osseous parts of the species to which they might belong.

In the Ortygince dilatations at the outer extremities of the xiphoidal prolongations are sometimes but moderately developed, as in our specimen of Cyrtonyx massena, and the Plumed Partridge. The dilatations of the anterior or shorter pair of these processes are very broad in Meleagris, as are the stems that support them; the expanded part may have a foramen in it, or it may become bifurcated and the same specimen may show both varieties of termination. The longer or posterior pair in this species become very narrow behind, but stouter, and scarcely support any terminal expansions at all. The anterior half of the keel of the sternum of the Wild Turkey is very thick and strong, and all its anterior parts are prolonged upwards and forwards, being massive and lofty in very old birds. In other respects the sternum is stamped with the leading features of the bone as found among gallinaceous fowls generally, and this remark applies also to the sterna of Pavo cristatus and Numida.

Cupidonia and Pediocetes are particularly alike, but the former could 
be recognuz ad by its superior xiphoidal processes, Bonasa by the narrow body, Centrocercus by its size in the larger specimens, and so on.

We will still continue to consider such of the vertebral column as is confluent in the old bird, or rather such vertebræ as become confluent and are more or less embraced by the ossa innominata, as the sacrum, and composed of sacral vertebræ, attempting to make no such divisions as Professor Huxley did, in his Anatomy of Vertebrated Animals, of this compound bone, though we must believe that this anthor is emi. nently correct in the view that he takes of this bone.

There are sixteen of these segments that are to be so reckoned in Centrocercus, but it is only in the "bird of the year" that they can be counted with anything like accuracy, and even then great care must be exercised, and various pelves examined and compared with the younger birds at different stages and ages.

The first sacral vertebra possesses free pleurapophyses, whose hæmapophyses do not reach the costal borders of the sternum, but articulate in a manner to be described further on. Regarding the pelvis from be. low in Centrocercus, we note that the anterior four sacral vertebræ have their combined par-and diapophysial processes thrown out as braces against the expanded anterior iliac wings. After this the ilia change their form to accommodate themselves to the basin of the pelvis. which they assist in inclosing, and with this change the succeeding vertebræ have their diapophyses much elevated to meet the internal iliac margins.

This section consumes four additional vertebræ, the centra of which go to make up the latter moiety of the cavity for the "ventricular dilatation" of the myelon, and they show the double foramina on either side, one above another, for the separate exit of the motor and sensory roots of the sacral plexus.

A double row, $i . e$., one on either side of subcircular vacuities, exists here also among the transverse processes (Plate XIII, Fig. 90, Canace canadensis, 8 ). It is through this portion of the sacrum that we observe in the chick the greatest amount of tardiness in sealing up of the neural tube above by the superior union of the engaged neurapophyses.

The remaining eight vertebræ become much compressed with expanded processes that rarely allow apertures to remain among them, forming an excellent mid-section to the broad and capacious pelvic cavity, with nearly all sigus of its original formation obliterated on the outer and superior aspect.

The neural canal is distinctly circular as it enters the sacrum anteriorly, becoming only slightly flattened as it nears the coccyx. Above we find the neural spine confluent with the ilia anteriorly along its summit, and some additional bone deposited posteriorly in the way of their lateral plates, to bridge over the ample "ilio-neural" canals. Opposite the "gluteal ridges" the bones are yet firmly knit, but for the remaining part of the sacro-iliac suture the interested bones can be said only to snugly meet each other. Cupidonia alone has quite an interspace present (Plate XII, Figs. 83 and 84).

The sacral wedge is quite thoroughly permeated by air, which enters through foramina in the vertebræ in localities similarly situated to those described in speaking of the anterior part of the column.

In Centrocercus sometimes the first sacral vertebra bears a well-developed hypapophysis, and there may even be some evidence of this process on the second segment. The expanded extremities of these median processes are connected along their inferior margins by a delicate ligament of a firmer consistence than that membrane, which fills in the racuities between the processes to which it is a limiting border. 
Now, it depends how far this ligament is conducted backwards as to how many of the anterior sacral vertebræ bear hypapophyses, as from its attachment to the hypapophysis (we have never seen it commence on the cervicals, though the directions assumed by their processes bear it out) of the first dorsal it completes a long shallow are of an ellipse, in which the lower margins of the hypapophyses are found and assist to complete. This semi-osseous, semi-membranous, attenuated median plate dips down into the thoracic eavity in the living bird for some little distance, as an interpneumonic septum.

The number of free caudal vertebræ in the adult Sage Cock is five,

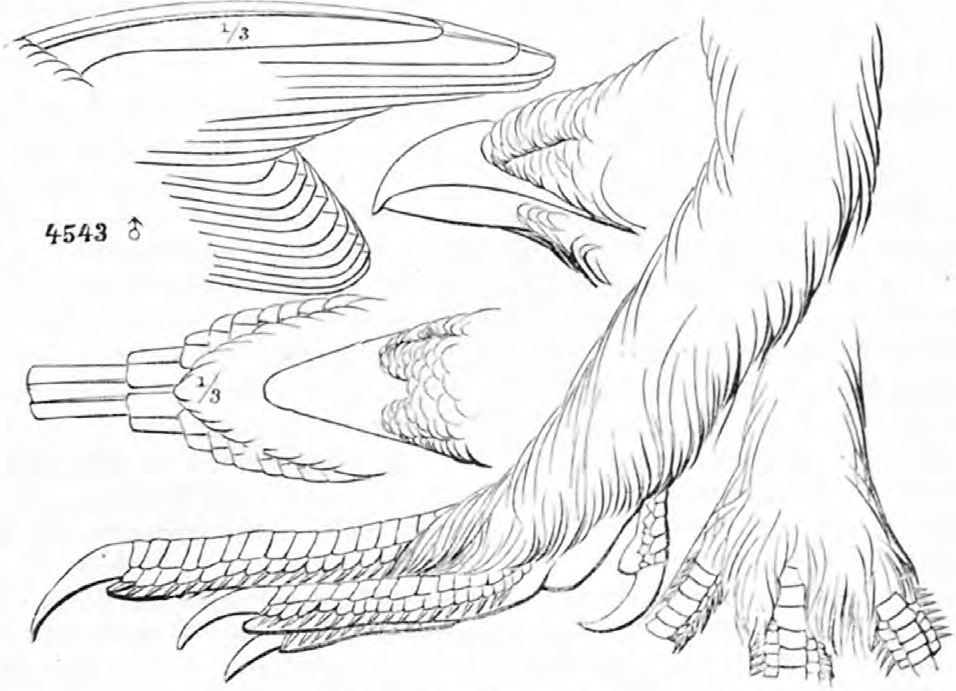

Pediacetes phasianellus.

and to these is to be added the pygostyle. They all have pretty much the same general appearance, differing principally in the length of their outstanding transverse processes. In this respect the first and second are about equal; in the third and fourth two or three millimetres are added on either side, with a roughened tuberosity above; while the fifth and last is in appearance and size very much like the first. These diapophyses are rounded at their extremities, and all slightly deflected. The centra are transversely elliptical and of good size. The neurapophyses arise from them to inclose a subcircular neural eanal, which is roofed over by the bifid and clubbed terminations of the elements, that hook or lean forward (Plate IX, Fig. 66; Plate XIII, Fig. 91). We have never observed an hypapophsis upon any of them; and all the elements and processes, as always occurs in the cocygeal series, are more or less imperfectly developed.

The pygostyle is an acute subcompressed triangle with tuberous base. Anteriorly and above it exhibts a bifureated process that simulates the crests of the series; below this a shallow facet, for articulation with the last caudal, and a feeble subconical depression to protect the termina. tion of the myelon between the two. Behind it has, at its lower angle, a deep groove, with a heavy bony rim or margin that shows a constriction near its middle (Plate IX, Fig. 65). This formation is easily explained when we come to examine the development of this compound appendage in the chick of a day or so old. This will reveal the fact 
that the pygostyle is composed of three vertebræ, which are fused together, distorted and modified as the bird grows, so as to eventually result in the bone we have before us.

We will now offer a few remarks upon the vertebral column, as applied to others of the North American Tetraonida.

Of all the specimens examined, representing all the genera, the number of distinctly free vertebræ between the skull and the anchylosed dorsals has been found to be invariably fifteen, the last one supporting movably-articulated plenrapophyses, that in Lagopus, at least, possess small epi-pleural appendages. This portion of the spinal column, then, will constitute the cervical division, and in it we note that the third and fourth segments have interzygopophysial bars present, becoming so broad in the quails that the foramina they give rise to are sometimes very minute.

The pleurapophyses become long and sharp in some and more conspicuous than in others; this applies particularly to Cupidonia and Pedicecetes. The last cervical in the former has osseous spiculæ leading backwards from its neural spine and postzy gapopbyses, as in the anterior dorsals. In the same vertebræ the hypapophyses become confluent to form one broad process placed traversely with a mesial keel in frout as the only indication of its original device.

The normal number of cervical vertebræ in any of the species of Wild Turkey of this country is likewise fifteen, and this number holds good also, in the Guinea Hen and the Peacock.

The carotid canal seems to commence and terminate in the same vertebræ both in Tetraonida and Ortygina.

Of the eminently characteristic dorsal bone little has to be said in addition to what has already been noted above. The number of vertebræ included in the anchylosis is never more nor less than four, and the first vertebral ribs have no hæmapophyses; so they never connect with the sternum, though they invariably bear uncinate processes, and in many species contribute a good share toward the stability of the thoracic parietes. The metapophysial processes vary principally in their extent: in Bonasa, Cupidonia, and Pediceetes. In several specimens they nearly cover the tops of the diapophysial arms. In Lagopus a narrow bar defines them, connecting the extremities of the transverse processes with comparatively few offshoots. In Canace canadensis the bone is very long and delicate. In C. obscura it has the same general appearance as in Centrocercus. The hypapophyses develop after the common type, but often irregularly; they are found to be missing on the ultimate segment or rather the pelvic end of the bone in the Quails.

The free and last dorsal may or may not have a hypapophysis; we believe it never does in the Ortygina. It is overlapped by the ilia in Cupidonia and the Sharp-tailed Grouse. We find this to be a very marked feature in the last, and well marked among some of these birds sent me by Capt. James C. Merrill, Medical Department United States Army, from Fort Custer, Mont., at a time they were particularly acceptable, and when this erratic fowl became suddenly and unusually rare in many localities, so that the gift was reckoned at the time as more than valuable desiderata. As far as the sacral vertebræ are concerned, the same general plan seems to be carried out: sixteen seems to be the allotted number among the Grouse and, as a rule, among the Partridges. In these birds the sacrum, $i$. e., the anchylosed sacral vertebræ, is much narrower, as is the entire pelvis, and much fewer perforations are to be seen among the dilated processes that go to meet the ossa innominata.

In Cupidonia and Pediocetes the sacrum is very broad, conforming to 
a pelvis in these birds that will be described further on. We find in a specimen of Canace canadensis, for which we are greatly indebted to $\mathrm{Mr}$. Manly Hardy, of Brewer, Me., where the sacro-iliac anchylosis is so per. fect, and original land-marks so obscure, that one might easily imagine the pelvis in this individual as being developed from a very much fewer number of ossific centres. The caudal vertebræ number five in all the Grouse except Cupidonia and Pediccetes, these birds each having dis. tinctly six apiece. We would especially call the reader's attention to this fact, because when we come to discuss the pelves of these two birds, and recapitulate general skeletal data, it will be found that, as far as osteo. logical similarities are concerned, they come very near to each other. The coccygeal vertebræ, otherwise, in common with the pygostyle, show very few differences worthy of record. ${ }^{1}$ In Ortyx and Lophortyx there are but four caudal vertebræ and the pygostyle is markedly acute and long. Occasionally the last segment is but feebly developed, as in Lagopus, where it may be a mere nodule; and in Bonasa, too, sometimes a sixth vertebra can be be found, but usually requires force to detach it from the pygostyle, and in our specimens seems to be one of those that originally formed that bone-though we do not deny in the face of such evi. dence that specimens of the Ruffed Grouse may be found that possess six of these vertebræ.

Of the Scapular Arch and the pectoral limb.-This arch, with its con. comitant, could have, with all propriety, been described in comnection with its vertebra, but so distinct has it become, and so far removed in order to assist in carrying out such a notorious function as the bird's flight, that the author prefers to follow the general ruling of others by discussing it separately. Nothing could be more entertaining in the whole range of osteological research and study than the contemplation of the various avian shoulder girdles, with their attached wing bones, particularly the former, as exemplifying the law of equilibrium between a bird's habits, the never-varying part it is to play in nature, and its skeleton or the framework that has been given it to carry that part out. This thought invariably enforces itself upon me in every instance after an examination of a collection of clavicles of different species of birds. It seems that there could not be an equipoise established anywhere in living nature more thoroughly compensatory than that 'twixt a bird's power and mode of flight, and its scapular arch and other bones about the chest-to meet it, more essentially the clavicles. See the broad, ex. cessively pneumatic, yet robust, clavicular arch in any of the genus $\mathrm{Ca}$. thartes, birds that sail aloft for hours apparently without fatigue, or the very similarly shaped arch in the Canada Goose, but in the Jatter for a very opposite style of sustained flight is non-pneumatic; the feeble and often ununited arch in Speotyto, a bird with scarcely any pretensions to being a good flyer at all; in short one would, having a thorough knowledge of a bird's habits, be, in the vast majority of instances, able to guess very near as to the pattern of the furculum he would expect to find.

Now we have seen, in reviewing the skeletons of the Grouse, that in many points some of the species, if we disregard size, similate each other very elosely, as for instance in the various sterna and vertebræ. The clavicles of these birds form no exception to this rule, as far as

${ }^{1}$ The number of caudal vertebræ present or absent in any species must not be overrated as a character, as the segments are liable to vary. I once heard it said that the number of true caudal vertebræ, including those that went to form the pygostyle, ought to equal the number of pairs of feathers in the bird's tail, judging from the arrangement as found in Archeopteryx. 
general appearance goes. The common model is seen in Plate XII, Fig. 87, Cupidonia; but observe even here in these closely-related fowls how habit still tells upon skeletal characteristics. The broad, and not deep, pneumatic $U$-arch of Cathartes becomes the long non-pneumatic, almost acute, $\mathbf{V}$-arch of the birds we are describing; so, in view of being familiar with the habits of the Sharp-tailed Grouse aud Sage Cock, need one be surprised to find in the fourchette of the first a depth of 4 centimeters (omitting the inferior clavicular expansion), with an interspace of 2.5 centimeters separating the superior articulating extremities, as compared with the bone in the second, where the depth is 6.2 centimeters, and the interspace above only 1.7 centimetres.

The bones of this arch are easily taken apart by maceration, and as has already been hinted they resemble each other very closely among the genera. The posterior angle between scapula and coracoid averages for the species about $60^{\circ}$, and among the Grouse the distal end of the shoulder-blade is usually found to orerhang the fourth dorsal pleurapophysis on either side; but in the California Quail these bones actually extend so far back as to overshadow the ilia for nearly a centimetre, they being proportionately narrow for their unusual length. This bone with the Grouse is only semi-pneumatic, its pneumaticity being confined to its coracoidal extremity, where the foramen is found in its usual site.

The blade is thin behind, becoming stouter as it nears the glenoid cavity, sharp along its inner border, rounded without, clubbed at its pelvic end, and turned gently outwards along its entire length. Anteriorly it contributes about one-third of the surface for the humeral joint, the coracoid the remaining two-thirds, while the acromial process within reaches forward barely to tonch the clavicle, forming, as it does so, the usual interscapulo-coracoidal canal.

These bones are narrow in Bonasa and in $C$. canadensis, more curved in Lagopus, and very stont in Centrocercus, a good medium being seen in the Pinnated Grouse (Plate XII, Fig. 85).

In Meleagris, they have their distal extremities cut square across, and reach back slightly beyond the pelvis. These bones in this species are also very stout and strong, and present the interesting variation in having a long pneumatic foramen on the superior aspect of each just beyond their glenoidal ends; this feature is not present in Pavo. They are exceedingly narrow and long in the Massena Partridge.

The Coracoids are quite stout bones, but devoid of any marked peculiarities; after leaving their sternal beds they extend upwards, forwards, and outwards, the furculum governing their distance apart at their upper ends. The glenoidal procss is extensive, and rises nearly as high as the head of the bone; the clavicular process is faintly bifurcated, and curls over slightly towards the fellow of the opposite side. The shafts are compressed from before backwards, and soon dilate into broad expansions below; anteriorly one longitudinal muscular ridge marks the surface of the bone, while on the sternal aspect two or three very distinct ones occur. The inner angle of the dilated base nearly meets its fellow of the opposite side through the foramen, at the root of the manubrial process; from this corner outwards, for about two-thirds of the distance the surface is devoted to a curved articulating facet for the coracoidal groove, while the outer angle is tilted upwards and finished off by a distinctive little tubercle. On its posterior aspect, about the middle of the dilated part, a large, irregular pneumatic foramen is found in all the Grouse, but seems to be absent in the Partridges. They are very large in Meleagris, at the same time being elliptical and 
so open as to give a pretty fair view of the interior of the bone in some cases.

The position of the united clavicles, or the free acromial extensions of the scapulæ, is shown for Lagopus in my drawing in Fig. 91. Something has been said about this bone already; we will add, however, that the superior ends always terminate by rather tuberous enlargements, smooth internally, but even as applied to the clavicular processes of the coracoids. The shafts are gently curved, of even calibre, and fall nearly directly downwards in some species, to be slightly expanded beneath in order to give better support for the large median dilatation below; this is triangular in outline, thickened in front, sharpened behind. In Ortyx this process is sometimes produced backwards, so as to nearly touch the sternum; this feature obtains, also, among some of the other Quails.

The furculum of Meleagris is very different from that bone, as just described in general terms for the Grouse. It is V-shaped, to be sure, but for the size of the bird is extremely slender, the medium plate is smaller than we find it in many of the Quails; the superior halves of the limbs are dilated and exhibit excavations on their inner aspects, at the bases of which we find irregular groups of pneumatic foramen; these limbs terminated above in truncate and thickened ends for artic. ulation with the remaining bones of the shoulder girdle.

The furcula of Paxo and Numida are much more like the general type of the bone as found in the Tetraonidae than the same bone in the Wild Turkey is.

The bones of the shoulder girdle are all well advanced in ossification

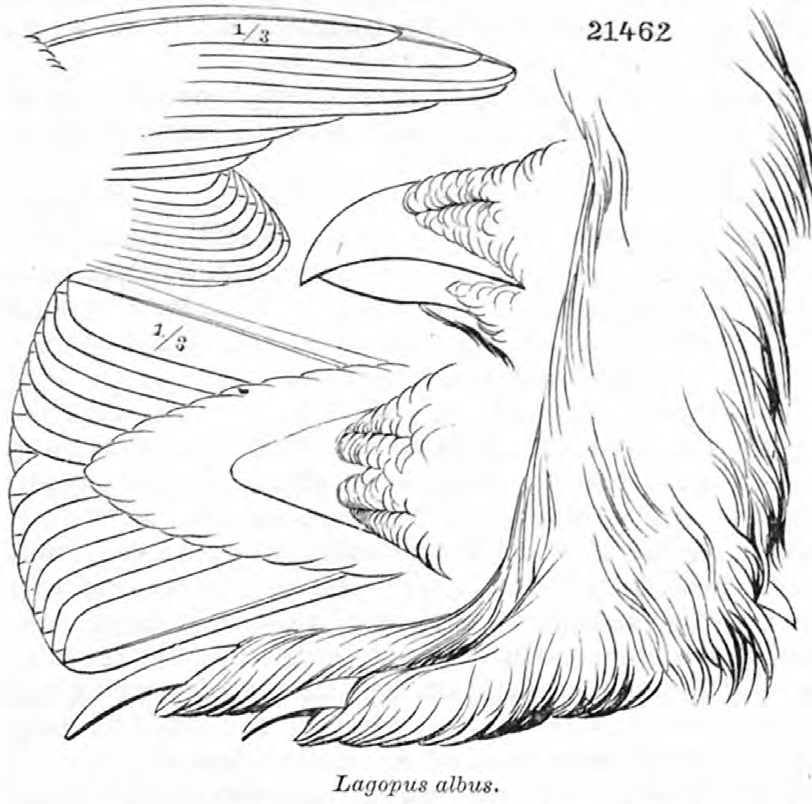
in the young ehick, but do not develop their distinctive markings until a bird is pretty well along in age; this applies more particularly to muscular lines on the shafts, the base of the coracoids, and the clubbed extrem. ities of the scapulæ. In Bonasa, where we noticed how the body of the sternum was narrow like the Quails, we find also the median process of the united clavi. cles produced back. wards towards that bone. This Grouse's skeleton, in fact, seems to have the greatest tendency Partridge-ward over any other of the North American Tetraonida.

The free ossicle of the shoulder-joint, the os humero scapulare, is not present in any of these birds; a firm piece of inelastic cartilage seems to supersede it and fulfill a like function.

The humerus (Plate VII, Fig. 57, H-Figs. 60, 61; also Plate X, Figs. 
76,77 of Cupidonia) of Centrocercus is so exceedingly regular that it could be well chosen as the type of that bone in all birds in which it is pneumatic. It is due proportion for the size of the bird to which it belongs, possessing the usual sigmoidal curves from lateral and superior aspects (we describe the bone in situ in the closed wing) in graceful, though not decided prominence. The head or proximal extremity, slightly bent anconad, displays the most usual points for examination about it; an extensive convex, smooth surface is seen for the glenoidal cavity, below it a deep notch, then the well-defined "ulnar crest" or lesser tuberosity curling over a large sub-elliptical pneumatic foramen, that is so patulous that the osseous trabeculæ and net-work are plainly seen at its base. The radial crest encroaches but very little upon the shaft, is quite stout, and only at its summit shows any disposition to curve over palmad.

The shaft is smooth, elliptical on section throughont its extent, and almost entirely devoid of any muscular markings or lines; it swells gently in the vertical plane as it approaches the distal end of the bone, upon which is placed the ordinary tubercles for articulation with radius and ulna. The inferior condyle, the internal of human anatomy, is the better developed of the two, and the ulnar tubercle is produced a little beyond the bone distally, while the oblique tubercle is brought down on the shaft. The olecranon fossa is rather shallow in the Grouse, being decidedly better shown among the Quails. There are no prominent points of difference in this bone among the Tetraonida, except in regard to size; Cupidonia, which has rather a heavy skeleton any way, the humerus is moderately robust in accordance.

In the Ortygina the same characteristics are to be seen; but we discover in addition at the proximal extremity of the bone, on its anconal aspect between the greater and lesser tuberosities, a deep fossa that has a great resemblance to the pneumatic orifice externally, and of about the same dimensions, being only separated from that depression by a thin bony wall ; it seems to be designed simply for muscular insertion, and has no communication with the general cavity of the hollow humeral shaft.

The radius and ulna are also singularly typical in their avian characteristics, as might have been looked for after our remarks upon the bone of the brachium; their principal difference lies in their being nonpineumatic, although they are hollow like all long bones.

In the right arm of Lagopus leucurus, which we have before us, carefully dried, in its position of rest, with all the ligaments still attached, in situ, we find the radius to be unusually straight, in fact almost in line between the oblique tubercle of the humerus and the bone it meets in the carpus. Its shaft is nearly cylindrical, and shows a muscular line, upon an otherwise smooth surface, that travels along its proximal twothirds beneath. Distally it overlaps the cubit by a transversely dilated extremity to articulate with its carpal bone. The head of the ulna is large, and betrays the fact that it belongs to a bird of considerable power of flight; the olecranon process is a blunt, tuberous apophysis, slightly bent anconad; the greater and lesser sigmoidal cavities are distinct and fairly marked, particularly the former.

The shaft of the bone is more than twice the bulk of that of its companion, decidedly convex outwards, the curve being greatest at the junction of the proximal and middle thirds; it is elliptical on section, the major axis of the ellipse being vertical. The muscular lines of the ulna are but faintly developed, as are the row of minute tubercles for the bases of the quills of the secondaries.

Anteriorly the bone displays its usual trochlea head for its own carpal segment; this surface is bounded palmad by a sharp and even curve,

$44-\mathrm{H}$ 
convex distally, while the inner articulating surface beneath the ex. panded end of the radius is uneven and applied to the concavities and convexities of the free pair of carpal elements.

These bones among the Partridges and other Grouse, except in size, present to us no extraordinary departures from the description just given of Lagopus. This remark applies also to the Wild Turkey, but the wing-bones in this bird seem to be shorter in comparison with its general size.

We do not believe there is a bird in our country that can offer us better facilities for the study of the bones of the carpus than the young of Centrocercus urophasianus. Anchylosis of the various segments involved is exceedingly tardy, and it is not at all necessary for the student of this joint, that has puzzled so many comparative anatomists and orni. thotomists, to seek the primoidal ossicles in the very young chick, unless he desires to ascertain the points as regards priority of ossification of the carpal bones, a question we will evade here entirely, for these bones are quite distinct and easily detached in the bird at six weeks or more of age, such as we offer our reader in the plates.

In the adult Sage Cock, the carpus has the appearance of this joint, as it is seen in nearly all of the class where there are two free carpal bones, and the os magnum confluent with the proximal extremity of the metacarpus, and the mode of articulation is the same. This we know to be, first, a free, six-sided, uneven bone, the scaphoid, articulating chiefly with the distal extremity of the radius and the metacarpus. This is the scapho-lunar of my former papers, and we retain the same name for it here; it is also the rawiale of Prof. Edward S. Morse, who has made such positive advances in the elucidation of the tarsus and carpus in birds.

The second bone is the cuneiform, larger than the first, and engaged principally by the cubit, but having also a process and an articulating surface for the confluent carpal and metacarpals; this is the ulnare of Morse.

These are the two carpals that remain free during life.

We will now devote ourselves to the joint as observed in the bird at six weeks of age. We have no trouble in finding scapho-lunar and cunei. form whatever. At the summit of the second metacarpal there is found a concavo-convex segment, that is universally taken to be the os magnum, termed also carpale by Morse (Plate VII, Fig. 59, om). It articulates anteriorly with the upper end of the index metacarpal, covers the entire proximal extremity of the second, and nearly or quite meets another bone behind that is grasped by cuneiform; this is the unciform (Plate VII, Figs. 57 and 59, $z$ ). It has the appearance of being a detached and bulbous extension of the third metacarpal, and is about the size and shape of an ordinary grain of rice, having a shallow concavity on its anconal aspect.

There is yet one perfectly free and distinct bone to be observed; it is found on the inner aspect, very near the extremity of second metacar. pal, just below os magnum; it nearly meets unciform, and articulates with the process of cuneiform behind. This little segment is flat and very nearly circular, being applied by one of its surfaces against the shaft of the metacarpal, and held in position by ligaments. This segment we do not find described by any author known to us, and here call it the pentosteon. ${ }^{1}$ The manner in which it eventually joins the metacarpus and

${ }^{1}$ This little bone of the earpus, which I still believe was originally described by myself, was called in the first edition of this Monograph the pisiform. This name might lead the student into the belief that I considered it either the analogue or even 
the conformation it gives to that bone in the adult are shown in Plate VII, Fig. 58, and it is marked 8 in Fig. 59 of the young Sage Cock. The metacarpal for the index digit is likewise detached, although even at this early date it begins to assume a likeness to the bone as found in the adult.

Medius and annularis metacarpals are also distinctly free, and their size and position faithfully portrayed in the figure alluded to above. The prominent process on the rear and upper third of the shaft of medius of the adult is now found only in cartilage in the younger individual. The rest of the bony part of the pinion is familiar to all of us; it consists, in the adult "Cock of the Plains," as in all Grouse and the Ortygina, of a trihedral phalanx for the first metacarpal, constituting the index. We have found this phalanx in Meleagris and Ortyx bearing a well developed claw, covered with horn as in the ungual phalanges of of the feet; this is also the case in Numida and Pavo, and there is hardly a doubt but that this is the case with all of the American Gallince, and in this respect they agree with this class of birds of the Old World. Two more phalanges are devoted to the medius metacarpal, the superior joint or phalanx having the usual expanded blade, with the long sree and pointed finger-bone below; and finally the smallest phalanx of all, freely attached to the distal end of the third metacarpal or annularis.

These bones are non-pneumatic, as are all the bones beyond the brachium in the Tetraonida.

Of the Pelvis and the Pelvic Limb.-After what we have said and seen in regard to the dilatory manner in which originally primitive elements in these birds anchylose, and only after the lapse of weeks condescend to amalgamate and form the confluent bones and eavities that occur in the major division of the Class, we must not be surprised to find the same routine and a like tardiness exhibited in the pelvic hæmal arch, or the pelvis, and its appendage the lower extremity.

A glance at the figures illustrating the condition of the bones in question, of birds from one to two months old, will convince us at once hat the rule still obtains; in them we find the sutures among the ossa in. nominata still ununited, and the three bones of either side of the pelvis independent, and easily detached from each other about the cotyloid ring.

In the young chick of Centrocercus (Plate VIII, Fig. 62), the ilium is a scale-like bone that rests against the sacral vertebræ. The preacetabular portion is excessively thin and delicate, and at this period constitutes the longest and widest part of the bone; its border mesiad bears no vertebral impressions, but is sharp and brittle; the outer margin is slightly rounded; this condition increasing as we near the diminutive acetabulum, where it is the stoutest. The distal margin, imperceptibly continuous with the inner, presents a convex curve anteriorly; the included surface viewed from above has a general concave aspect, especially near its central portion. As we proceed backwards, however, it gradually becomes convex, to rise over the region opposite the cotyloid ring to form the general convex surface of the post-acetabular portion.

The distal margin of the bone is nearly square across, and does not extend as far back as the ischium, the two being bound together at this age by cartilage, which has been removed in the plate. The outer and exterior margin of this division of the bone is rounded and fashioned

the homologue of the pisiform as found in the Mammalia; such at present being by no means the case, and all things considered, I have taken the liberty to change its name to the pentosteon, it being the fifth bonelet in the avian wrist. 'The samo argument might be urged against the unciform, but I had nothing to do with the christening of that bone. 
to the cotyle, the anterior half of which it eventually forms. From this point it arches backwards over the future ischiatic foramen. The inner margin of the post-acetabular portion is rather more rounded than its anterior extension, and directly opposite the "ring" presents for examination the depressions of the tranverse processes of the ninth and tenth sacral vertebræ in elongated and concare facettes. The ninth vertebra seems to be the first to come in contact with the ilia, and the pelvis is so inclined that the remaining vertebræ soon, by their outgrow. ing apophyses, come in contact with it, ultimately fusing to develop the compound bone, usually termed sacrum. A good idea may be gained of the form of the ischium and os pubis by an inspection of Fig. 62 , Plate VIII, at this stage of the bird's existence. For very obvious reasons the stoutest part of the ischiatic element surrounds the acetab. ulum; an inferior process, extending towards a similar one directed backwards by the ilium, grasps the head of the os pubis between them. From this point the ischium sends backwards a triangular thin plate, rounded behind, that is intermediate in length between ilium and pubis. This latter is satisfied to follow suit and direction by contribut. ing a simple and diminutive spine. This crosses soon after the pubis has given its share to the cotylis, the obduratic notch of the ischium, converting it, as the bones fuse, into the obdurator foramen.

We give an additional figure in the Plate, Fig. 63, that exhibits the further advances of these elements towards maturity. The bird is now nearly two months old, and it will be seen that one after another the vertebræ impinge upon the iliac margins within. The ilia and ischia extend behind, including vertebra after vertebra, from a series that at this age might be easily taken for an extraordinary number of coccygeal segments. The head of the pubis at this time is entirely out of proportion with its rib-like extension, it having so spread and insinuated itself into the formation of the cotyloid ring as to form about one-fifth of its circumference. At this stage, too, the necessary cartilage begins to be thrown out to form the future anti-trochanter on the ilium.

So much for pelvic development; now let us examine this bony basin as it is seen in the full-grown representatives of the genera.

The manner in which the confluent sacral vertebræ meet the ossa in. nominata forming the ilio-neural canals and sacral sutures has already been defined above, so that here nothing more need be said of the mid. section of the pelvis taken as a whole. We give among the plates figures of the pelves of Centrocercus, Canace canadensis, Lagopus, and Cupidonia from the skeletons of the adult birds, and if the reader will compare the lateral views given of the Ptarmigan and the Sage Cock he will see how few the differences are that exist between the two birds, and the same may be said, we assure you, for its superior and inferior views; in fact in the case of Logapus it may be stated that its pelvis in most instances is the perfect miniature of this bone found in Centrocer. cus in all resp,ects. This applies, also, though not quite as strictly, to Canace and Bonasa. Of course certain minor differences are easily to be picked ont, such as a greater fullness there, as slightly deeper depression here, and so on; still our plate of Tetrao canadensis represents the general pattern of the pelvis among all the North American Grouse, save Pediacetes and Cupidonia. In the superior aspect of this confluent bone in a fine specimen of Canace obscura, we find the pre-acetabular portions of the ilia very much depressed below the general surface of the bone, and quite concave. The convex anterior borders are embellished with a flattened rim that bounds them, often produced forwards as two median sharp-pointed processes. The post-acetabular surface is raised, 
and including the sacrum forms a gently convex surface; the "gluteal ridges" dividing these two regions commence with the anterior iliac borders and are conveyed clear round to form the posterior ones of the same bones, describing two great Ss, the lower and outer curves of which pass by the acetabular projections, points where in some birds they terminate.

Among the principal features to be noted in a lateral view is that the shaft of the pubis is in nearly all instances free from the ischium after quitting the cotylis and forming the elliptical obdurator foramen. If it anchyloses with this bone at all it usually occurs just behind that orifice.

The ischium overlaps the pubis at two points-one quite broadly near its middle, and, again, by a process at its outer and inferior angle.

The "ischiaric foramen" is the largest vacuity of the group of three that here present themselves; its boundary is sub-elliptical, with its major axis depressed posteriorly if it were produced.

Both the internal and external margins of the cotyloid eavity, or ring rather, are circular, the former of which is not a little smaller, thus affording a very good and quite extensive surface for the head of the femur; the anti-trochanterian process or facet directed backwards is likewise ample, so that the femora are well supplied with articulating surfaces.

There seems to be among the Grouse a predisposition for the ilia to overhang the region of the ischiadic foramina; it is most successfully carried out in Cupidonia. Viewed from below, we are struck with the amount of room and space these combined bones inclose; the profundity of the pelvic basin. This is very much enhanced by broad reduplicatures of the ilia and ischia behind, and a general though even constriction of a prominent rounded border or rather ridge that extends from the fourth diapophysial abutment of the rertebra against the ilia on either side to the outer angles of the ischia. Within, too, we often find about and at the base of these iliac fossæ apertures for the entrance of air into these bones; such pneumatic foramina are also seen beyond the os pubis and below the cotylis on either aspect.

The pubic extremities never meet behind, though in many species they are very long and usually take the curve given them by the ischia just before leaving these bones. Their distal extremities are flattened in

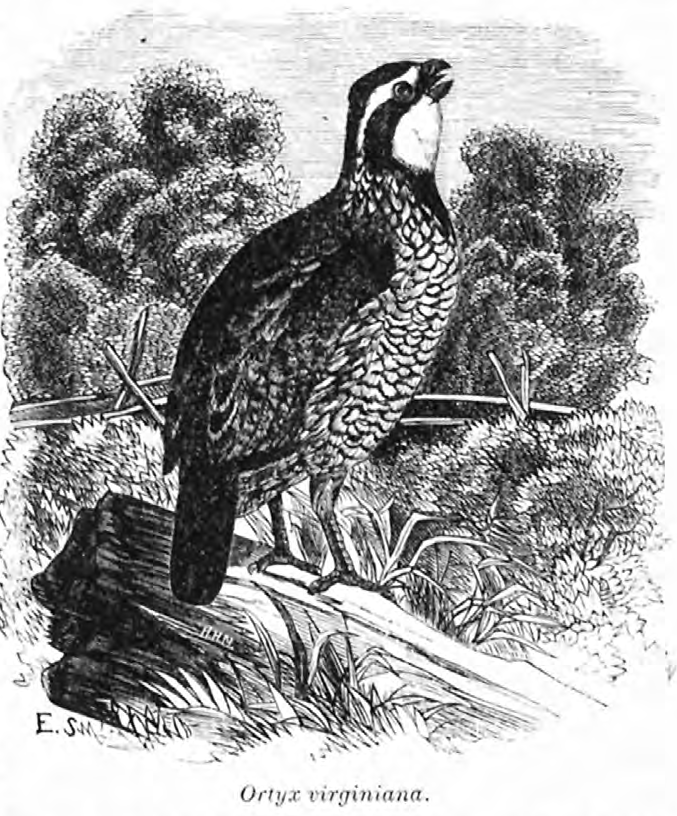

Centrocercus and generally more expanded than among the other varieties.

The pelvis of Cupidonia is so different from the general description we have just given, that the author feels justified in giving his reader 
two addittonal figures, that present superior and lateral vieys of the bone in this bird; in comparing it with other figures given one cannot avoid being struck with these marked departures from the common type. There is one other Grouse that affects this style of pelvis, and that is Pediccetes, and the attempt is not a bad one. The principal points wherein the Sharp-tailed Grouse has failed to make a perfect imitation of the unique pelvis of his ideal are, the ilia have failed to produce such ponderous overhanging lateral flaps, that nearly shut out from view the ischiadic foramen on either side. Again, these bones in Pediocetes meet the sacral vertebræ for their entire length internally; and in this bird, too, the pubic elements often unite all along the inferior borders of the ischia. This does not occur in the Pinnated Grouse; otherwise the bones are very similar and marked exceptions to the general pattern of the other members of this subfamily.

After examining a large number of the pelves of our Grouse, and noting their capacious cavities and great width from side to side, one cannot help but be surprised at the complete change in outline, on turn. ing to these bones as they are found among the Partridges.

As a rule in these birds, the pelvis is elongated and unusually narrow, though the drooping ischia behind give it additional depth in its more posterior parts; the pubic bones are turned up behind after they extend beyond the elements above them, and the lateral walls formed by the ilia are, just beyond the acetabula, almost vertical; in fact, one would almost suspect the pelvis of the common Virginia Partridge as belonging to the skeleton of some variety of Curlew, had he not been sure of the owner. This apparent departure from the more general model of this bone in gallinaceons fowis, however, is not nearly so decided in other varieties of the Ortygince, as for instance in Lophortyx californica, and a very good drawing of the pelvis of this bird can be seen and studied, in Mr. T. C. Eyton's Osteologia Avium, London, 1867, Plate 22 , figs. 1, 1, 1, 1; three of the figures here cited, however, are for the palatine bones, inferior view of sternum, and anterior and posterior views of the tarso-metatarsus. We have carefully compared the diam. eters of these representations with the skeletons of the species in ques. tion, and find them quite accurate.

The pelvis in the Wild Turkey has the general resemblance of this bone as found among the gallinaceous birds at large. The sides of the ilia, in the preacetabular portion are nearly vertical, spreading out only anteriorly into the horizontal plane. We are struck with the unusual size of the ilio-neural canals. These passages are over three centimeters long, having a complete bony septum dividing them, composed as usual of the neural spine of the leading sacral vertebræ. The major part of the common roof above is formed by the meeting of the ilia. The postacetabular region is quadrilateral in outline, rather extensive and very flat. In this locality the iliac borders meet the vertebræ, but only partially to anchylose with them. The sides of the pelvis are broad and deep, and the pubic bones never join with their lower margins. Just beyond the cotyloid ring, on either side, we find a stumpy spine, very much the same thing as we see in the common fowl. Between the ischiatic and obdurator foramen a deep triangular pit occurs, that usually has a few pneumatic foramina at its base. Five caudal vertebræ are found in the Wild Turkey, and the pygostyle is very long and sharp, being produced backwards. In the Peacock we find the pelvis shorter than in Meleagris and generally arched above, as if the bone in this locality had gradually been distorted by the burden of feathers it bears above which pull upon the muscles overlying it. To afford additional support for 
this beautiful appendage in this fowl, we find the four coccygeal vertebræ very broad and spreading, while the pygostyle is equally extensive, being composed of two horizontal plates connected by a vertical one, lying longitudinally in the middle plane. The pelvis and the caudal vertebræ, including the pygostyle in the Guinea Hen, are very much the same pattern as we find them among the Grouse generally, and both this bird and Pavo have the characteristic spine protruding anteriorly beyond the acetabulum on either side.

The femur in the young chick of Centrocercus is but partially developed; above, the head is almost entirely cartilage, while below the condyles are very indistinct and the bone bears no signs of pneumaticity. In a few weeks, however, these points rapidly exhibit themselves: a rounded trochanterian ridge is thrown out; the head essays to assume its sphericity; the condyles become evident; the fibular groove appearing last of all and about the same time with the vascular foramen or medullary orifice at junction of upper and middle thirds. In our examination of this bone in a fine old cock Cupidonia, and comparing it with others, we find that it is remarkably well balanced in point of length and general development.

The trochanterian ridge is prominent and arches over the articular facet for the ilium; the neck is distinct and makes an angle of $45^{\circ} \mathrm{with}$ the shaft; the head is well formed, spherical, and in all Grouse seems to bear a double depression for the ligamentum teres. Anteriorly below the trochanterian eminence there is an extensive collection of pneumatic foramina. The "trochanter minor" never develops.

The shaft is smooth, bent slightly forwards; displays the usual mus. cular lines and the medullary orifice; it is nearly cylindrical on section about its middle, and before terminal expansion takes place. Below, the rotular channel is deeply grooved, separating the prominent condyles; of these the external and lower one presents the usual fibular fissure; behind, the popliteal depression is well sunken, one of the muscular lines running into it, and often a foramen is found at its base. Shallow fossa are found laterally at the onter surfaces of the condylar enlargements, and sometimes a notch where shaft meets the internal one anteriorly. The bone is usually slenderer in Bonasa, Pedi. acetes, and Canace canadensis.

Among the Ortygina the femur has the same general characteristics; it is, how. ever, non-pneumatic, the double pit for the ligamentum teres is better marked, and the muscular lines are scarcely perceptible.

The patella is never absent in the Tetraonida, and occupies its usual position as a

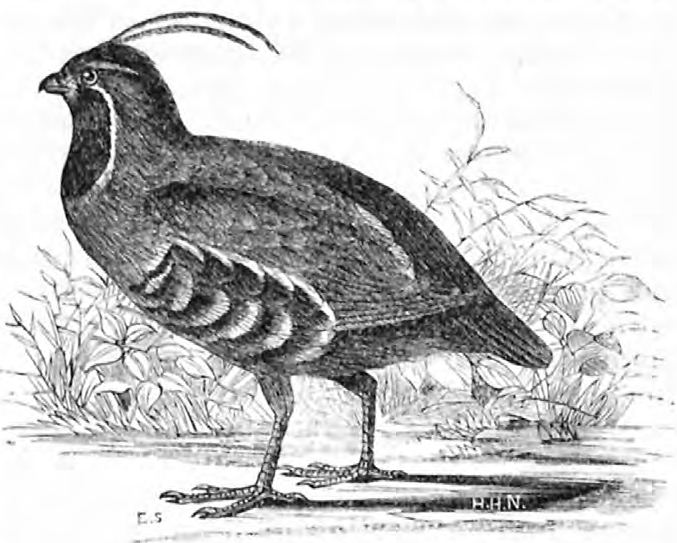

Orwartyr picte.

free bonelet protecting the anterior aspect of the knee-joint. It accommodates itself to the conformation of the rotular channel, having a flattened surface superiorly, a rounded border below, and a double surface behind, the most extensive aspect of which is applied to the side towards the internal condyle. 
The proximal extremity of tibia in the young chick of Centrocercus has advanced so little towards assuming any of the definite characteristics of the full-grown bird, that, almost in self defense, we take up for exam. ination the bone from a skeleton of a bird of the same species several weeks older; here we discover the superior general condylar surface still capped with cartilage, and the borders confining it, as yet, but feebly produced. The most interesting point, by far, is the appearance of an unusually large epiphysis, if it may be so termed, fashioned to and resting upon the future location of the "rotular crest."

Why this bone should be here added we cannot, as far as our knowl. edge extends, exactly comprehend, for in the old and mature birds of any of the Grouse the epi-enemial crest is never very prominently produced, nor is it in any of their near kin. As age advances this seg. ment becomes thoroughly confluent with the tibia, and leaves no trace of its early existence.

The head of the bone in the adult Sage Cock is a very substantial affair, with pro- and ecto-cnemial ridges, well produced, that soon merge into the shaft; the latter ridge is usually dilated on its anterior as. pect, and the rather extensive concavity between them is directly con. tinuous with the shaft below.

The tibia never becomes pneumatic either in the Grouse or Quails, and in the former, sections of its shaft are universally transversely oval; the fibular ridge of the upper and outer third of this portion of the bone in Centrocercus is about 2 centimetres long, and appears to be little more than a raised and ronghened line. Below the fibular ridge we find the nutrient foramen, but otherwise the tibial shaft is very straight and almost entirely devoid of any markings, at least to that point anteriorly, where the ascending groove coming from between the condyles impresses it, and that, with an increasing intensity to its termi. nation over the intereondyloid noteh; at this point a bony bridge is thrown across obliquely, the outer abutment of which is the lower. (Plate IX, Fig. 69.)

The most engaging points of interest, so far as the tibia is concerned, center about the distal extremity of the bone. After careful examinations of the recently-killed subjects, dried skeletons, and carmine-stained specimens, the following result seemed to be presented with greater or less distinctness in every case, and these results correspond very nearly with Professor Morse's invaluable investigations and studies: In the young of Centrocercus, several days after leaving the nest, we observe at the future site of the tibial condyles, encased in the then articular cartilage, on either side, a free reniform ossicle. These ossify to the surface in time, and the outer becomes the fibulare, the inner the tibiale; both are tarsal bones. It will take time and further research to decide definitely as to which is the os calcis, and which the astragalus. Above the former, and a little towards a mid-shaft position, there is yet another free ossicle; it is the intermedium of Morse. That it is another tarsal bone, there can be no doubt, we believe, at this date; but before we decide upon its special homology we must satisfy ourselves by further research and dissection of the young at various stages of development in birds and other vertebrates where this bone constitutes a feature of the skeleton.

It soon fuses with the tibiale, and the latter with the fibulare, so that the faintest traces are alone discernible in the bird at two months of age. (Plate IX, Fig. 67, $\mathrm{E}^{\prime}$ ). At this period the subsequent bony span for tendinous confinement above them has not commenced to ossify.

In the adult the apex of the intermedium affords attachment to the 
oblique ligament that is attached higher up on the inner aspect of the shaft, that also holds some of the extensor tendons in position. The condyles in mature birds have an antero-posterior position at the extremity of the tibia; these are of a uniform outline, and the inter-condyloid notch that separates them is of no particular depth until it arrives on the anterior aspect of the bone. Externally and laterally almost within the limits of the outline of the outer condyle we find two tubercles, one above another; the lower is for ligamentous attachment, the upper is the remnant and only existing evidence of the lower extremity of the fibula. A similar tuberele is found on the opposite, side corresponding to the lower one just described on the outer aspect.

The fibula is freely detached and never completely anchyloses with the tibia. Its proximal extremity is clubbed, enlarging very much as it rises above the condylar surface of its companion from the fibular ridge; it is laterally compressed and convex above at the summit. In many Grouse the attenuated remains of its extension below can be traced on the shaft of the tibia, which bone has nearly absorbed this third of its weaker associate.

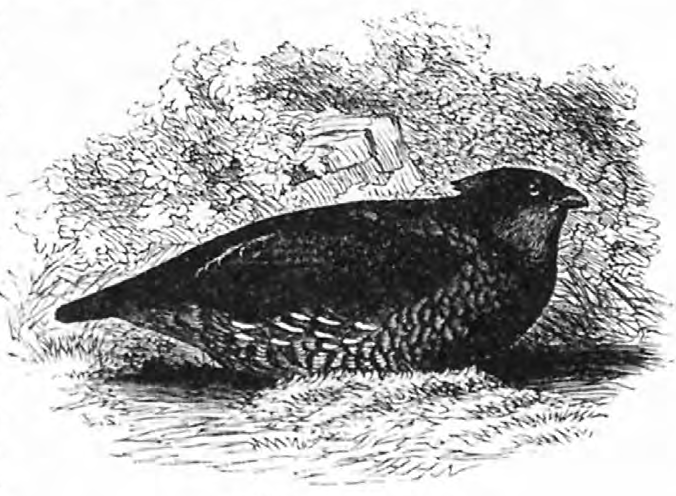

Callipepla squamata.

In the early life of the chick of the Grouse we have been discussing, the combined tarsals are surmounted by a third plate of cartilage, that subsequently ossifies, apparently by one center. The bone thus formed, the centrale, we believe undoubtedly to represent either a single tarsal element or the connate bones of the second row.

At this age the metatarsals that combine to form the shaft of the tarso-metatarsus are still easily individualized, though well on the road toward permanent fusion. It will be observed that we still retain the term tarso-metatarsus, and we think justly so, as the compound bone of the mature bird has combined with it at least one of the tarsal bones. The tibia could with equal reason be termed the tibio-tarsus, and again the compound bone in manus, the carpo-metacarpus, but for obvious reasons such innovations are not always advisable.

We discover in Centrocercus and Canace canadensis-in that strong inelastic cartilage that is found at the back of the tarsal joint in all the Grouse, on the inner side-a concavo-convex free bone, nearly a centimeter long in the Sage Cock, and two or three millimeters wide; this ossicle must be regarded only as a sesamoid, though it is nearly as large as the patella, and in no way as constituting one of the tarsal bones.

It will be remembered that in the first edition of my monographs upon the osteology of Speotyto and Eremophida, the old term of the "calcaneal" process was retained for that prominent projection found at the superior and hinder end of the bone tarso-metatarsus. It having anything to do with the calcaneum or the os calcis in the homologies of the avian tarsus, was stoutly denounced in the first appearance of my monograph upon the osteology of the North American Tetraonida. In these papers, as well as in my osteology of Lanius ludovicianus excubitorides, it was given the name of the tendinous process, from the well-known fact that by one means or another it transmitted the flexor tendons at the 
back of the tarsus. At the present writing we know of no author who has very recently added any thing to the literature of this subject, bear. ing upon this particular point, and the writer was quite confident that all he had said in his Grouse paper could be sustained; for if this process did not separately ossify in the Tetraonida, and thus weaken its claim as being a homolonge of one of the tarsal bones, why should this not be the case among all birds? A few months ago we made a discovery

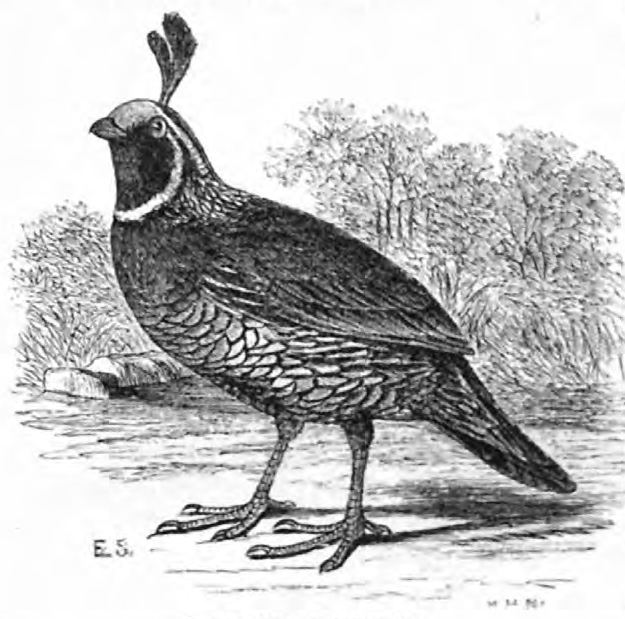

Lophortyx californica.

that again shook our faith in this matter, and led us to believe that perhaps this process was more entitled to the appellation of the calcaneal than we had previously supposed. The facts in the case are these, and we must leave our reader to draw his own conclu. sions. We have before us the tarso-metatarsus taken from the young of two widely-separated genera and families. The first is that of the chick of Pedicecetes. one of our present genera; the second is from the young of $\mathrm{Cin}$. clus mexicanus, the American Water Ousel. In the first we observe all those characteristics that we have already ascribed to this family in general, and elncidated above; but in the tarsal joint of the Dipper, our second example, we find that the centrale and the so-called calcaneal process are connately developed; the latter element being of good size already shows the grooves for the flexor tendons. Of the number of points of ossification in this development in Cinclus the author can say but little, as his material has been chosen from a few of these birds, furnished by the Smithsonian Institution. The subject is an extremely interesting and important one, and will well repay further investigation and research, and the author only regrets that at this date he can make but such slight additions to what we already know of it through the exertions and examinations of others. In any of our adult Grouse, this process is vertically grooved and perforated for the passage of tendons; from its inner and posterior angle in many of the Tetraonida it sends down a thin plate of bone that usually meets the shaft at junction of upper and middle thirds, occasionally running further down to become confluent with it in every instance; this feature is rarely present in the Quails. In Centrocercus and others the hinder aspect of the tarso-metatarsus is sharply marked by museular ridges. The superior and articulating surface of this bone displays eminencies and depressions fashioned to aceommodate themselves to the condyles of the tibia ; a tuberosity on the anterior margin in the articulated skeleton fits into the intercondyloid notch of the bone. Below this the shaft in front is scooped out, having at the base of the depression two small elliptical foramina, side by side, and to the inner side of its boundaries one or two pointed muscular tubercles. The distal and transversely expanded end of the bone presents the foramen for the anterior tibial artery, occupying its usual place, and the three trochlear apophyses for the toes, the middle one being the largest and on the lowest level. The two lateral ones, separated by wide notches from the former, are thrown but a limited distance to the rear, so that the concavity behind them is not peculiar for any great amount of depth. 
The os metatarsale accessorium is situated rather high upon the shaft, and bears more than an ordinary semblance to a demi-phalanx, with its distal articular trochlea. As usual it is freely attached by ligaments.

The internodes are based upon the more common plan as applied to the avian foot; $i . e$. , in the order of the phalanges, from the first to the fourth, 2, 3, 4, 5 joints. They are in proportionate sizes for their sev. eral owners, and possess nothing peculiar about them, having all the usual characters as found in the gallinaceous foot generally.

They possess the usual enlarged and biconcave proximal extremities, with the distal and convex bitrochlear ends, with a more or less subcylindrical shaft; the ungual joints being but moderately curved downwards.

There are but few or no striking differences to be noted as existing among the lower extremities of our Tetraonidas.

The bones are very delicately fashioned in Canace canadensis and the Sharp-tailed Grouse; that is, the calibres of their shafts seem to be less as compared with their general lengths, but they belong, we must remember, to very trim little game birds, as contrasted with our heavy and ponderous old Sage Grouse of the western prairies. Our specimens of Lagopus and Canace obscura do not show the bony extension from the tendinous process at the back of the tarso-metatarsus, apparently present in all the others and alluded to above-Centrocercus sometimes proving an exception-and this bone never normally develops a spur in any of our North American Grouse, as seen in birds of near kin.

Tendons of the anti-brachium and pinion are very prone to ossify, and one is quite constant on the anterior aspect of the metacarpus. This applies with still greater force to the lower limb, where it seems that every tendinous extension of the museles of thigh and leg become bone for their entire lengths, then forking sometimes over the fore part of tarso-metatarsus as they branch to be distributed to the podium.

It may be found that Bonasa can claim normally six segments as rep. resenting the caudal vertebræ, and we have in our possession a pelvis of this bird where a rudimentary second sacral rib is evident, but this can only be regarded in the light of an anomaly.

The pelvie limb of the Wild Turkey has nothing about it of peculiar interest, $i . e$., in the adult fowl, and we have never been so fortunate as to examine the young of this bird. The entire extremity is non-pneumatic, and composed of quite powerful bones. From the lower and outer angles of the tendinous process of the tarso-metatarsus, a thin plate of bone is thrown down that gradually approaches but does not touch the shaft until it arrives opposite its middle, when it merges into it. The lower portion of this lamina bears the short spur in Pavo, but of my three specimens of Meleagris, no such appendage is seen; they are no doubt all females or perhaps young males before the development of the spur, as we believe old male Turkeys, always possess it.

Interesting osseous malformations are occasionally to be seen, but they are beyond the jurisdiction of this monograph to treat; nor will it be practicable to enter into the engaging subject of the differences between the pelves in the male and female birds, but that such differences do exist there can be no reasonable doubt.

Our Grouse and Quails all belong to the Alectoromorpho of Professor Huxley's elassification, sharing in common with the representatives of that group many of their osteological characters; some of these characters, such as the general form of sternum, certain cranial peculiarities and others, are positively distinctive and differ from all other groups. Our Tetraonida, with the exception of Pedicecetes, and Cupidonia, have certain similarities or osteological resemblances found 
among the more prominent bones of the skeleton, as the pelvis, sternum, and scapular apparatus, that bind the remaining genera very closely together. The same may be said in a general way of the Quails,

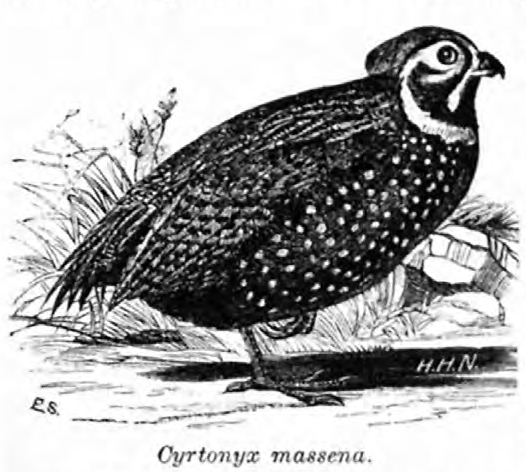
or Ortygince, taken as a subfamily, have many such characters in common, as compared among themselves.

Cupidonia and Pedicecetes although they possess the usual tetraonial oste. ological characters referred to above, have in addition quite a number of mu. tual external characters, that compel us to regard these two forms as being of very near kin, and our osteological studies of the sub-family have certainly demonstrated the fact that this relation. ship is by no means weakened by the latter investigation. In short, although ornithologists will no doubt always retain these two forms in separate genera as the classification of birds goes, still it may be well to bear in mind that nearly or quite all of the anatomical characters of Cupidozin and Pedicecetes when compared together bring these two Grouse nearer to each other than any other two forms of the group in our fauna; so near, in fact, that but little violence would be perpetrated by restricting them both to one and the same genus, and no doubt there are not a few instances in our present classification of birds where forms not so nearly related as these two Grouse are that have been retained in one genus.

Washington, D. C., May 1. 1882. 

PLATE V.

Fig. 47.-Cranium of young Centrocercus, three or four days old, viewed from above.

Fig. 48.-The same; lateral view, with lower jaw added, showing articular element detached.

Frg. 49.-The same, viewed from below.

Fig. 50. - Centrocercus. Lateral view of skull of "bird of the year" four months old; the hyoid arch has been detached.

Fig. 51.-The same aged bird as in Fig. 50, showing the disarticulated segments of the four eranial vertebræ: OV, neural arch of the occipital vertebra (epencephalic arch), first of the skull; $\mathrm{OV}^{\prime}$, its hæmal arch in outline (scapular arch); 80, superoccipital ; eo, exoccipital ; po, the connate paroccipital; bo, basioceipital; PV, neural arch of the parietal vertebra (mesencephalic arch), second of the skull; P. V.', its hæmal arch (the hyoidean); $\mathrm{P}$, the parietal; $m s$, the mastoid; $a s$, the alisphenoid; $b s$, the basi-sphenoid; $g h$, the glossohyal; $c h$, the ceratohyal; $b h$, the basi-hyal; $u h$, the urohyal; $h b$ and $c b$, the hypo-branchial and cerato-branchial elements of the thyro-hyals, respectively; F. V., neural arch of the frontal vertebra (proencephalic arch), third of the skull; F. V.', its hæmal arch (the mandibular); Fr, the frontal; $x$, the site of the postfrontal in some of the class; $o s$, the orbito-sphenoid in outline; $p 8$, the basi-presphenoid; Tp, the tympanic; ar, the articular; S. an, the surangular; an, the angular; se, the splenial element; and de, the dentary element; N. V., the neural arch of the nasal vertebra (rhinencephalic arch), the fourth and last in the skull; N. V.', its hæmal arch (the maxillary); $\mathrm{N}$, the nasal; $P f$, the prefrontal (ethmoid); $V r$, vomer in outline, as it does not occur in this bird, (see description in text); $P l$, palatine; $m x$, max. illary; $i . m x$, intermaxillary (or premaxillary); 1 , the petrosal; 2 , the sclerotals; 3 , the lacrymal; Pty, the pterygoid, the diverging appendage of $P l$, the palatine; $s q$ and $m a$, the squamosal and malar, respectively, are diverging appeudages of $T p$, the tympanic. 

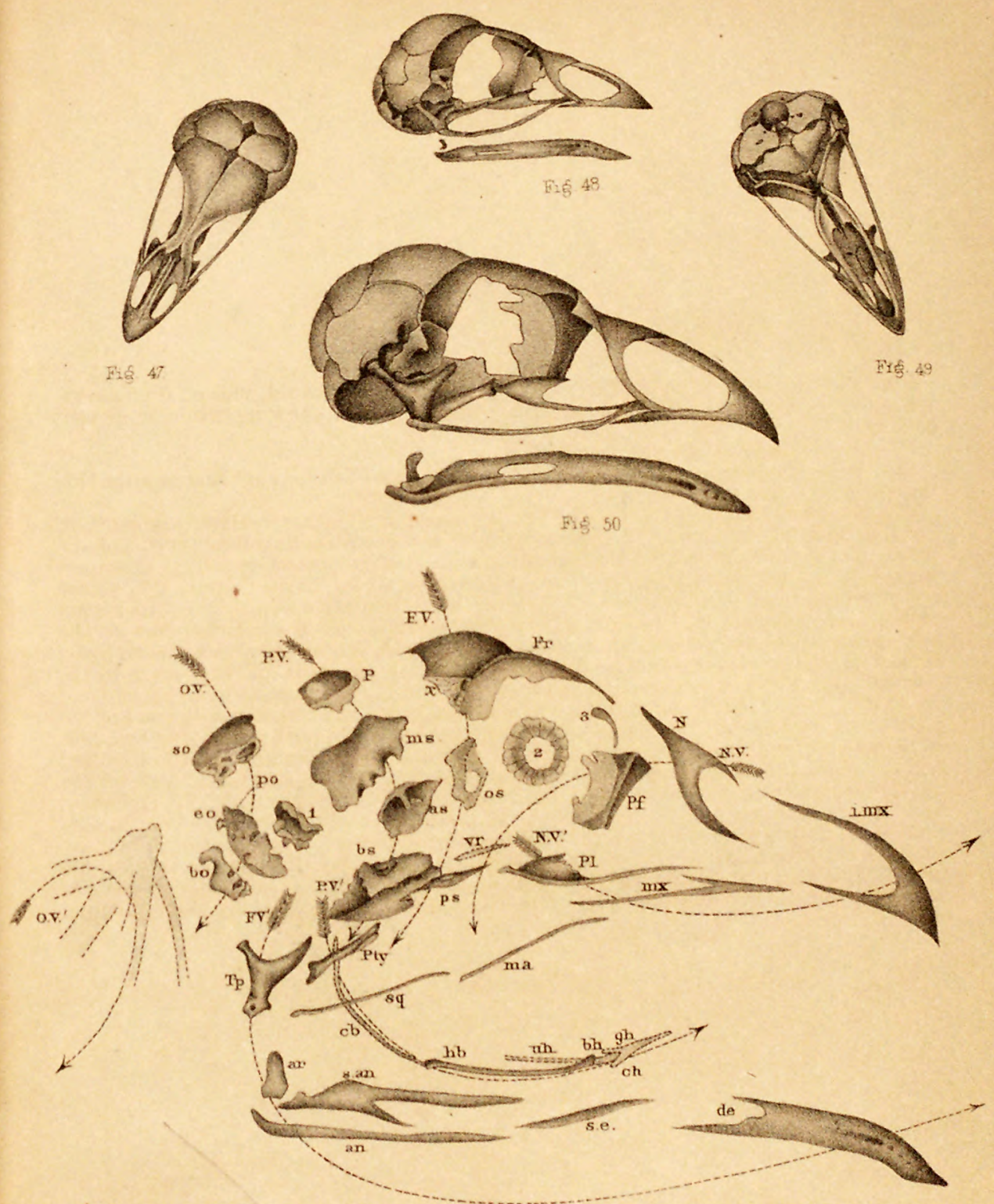

Fif 5 :

T. Sinclair \& Son, Lith

SHUFELDT ON THE OSTEOLOGY OF AMERICAN TETRAONIDAE. 




\section{PLATE VI.}

FIG. 52.-Lateral view of skull of Centrocercus, adult $\delta$, hyoid arch removed. Figs. $54,55,58,61,64,65,66,68,69$, and 70 are from the skeleton of the same specimen.

Fig. 53.-Sternum of the chick, three or four days old; Centrocercus.

FIg. 54.-Sternum of Centrocercus, viewed from below; adult 8 .

Fig. 55.-Dorsal vertebra, lateral view, left side, from the same.

Fig. 56.-Sternum of Centrocercus, "bird of the year" (two months old), showing development of this bone: 4, lophosteon; 5 , metosteon; 6 , pleurosteon. 

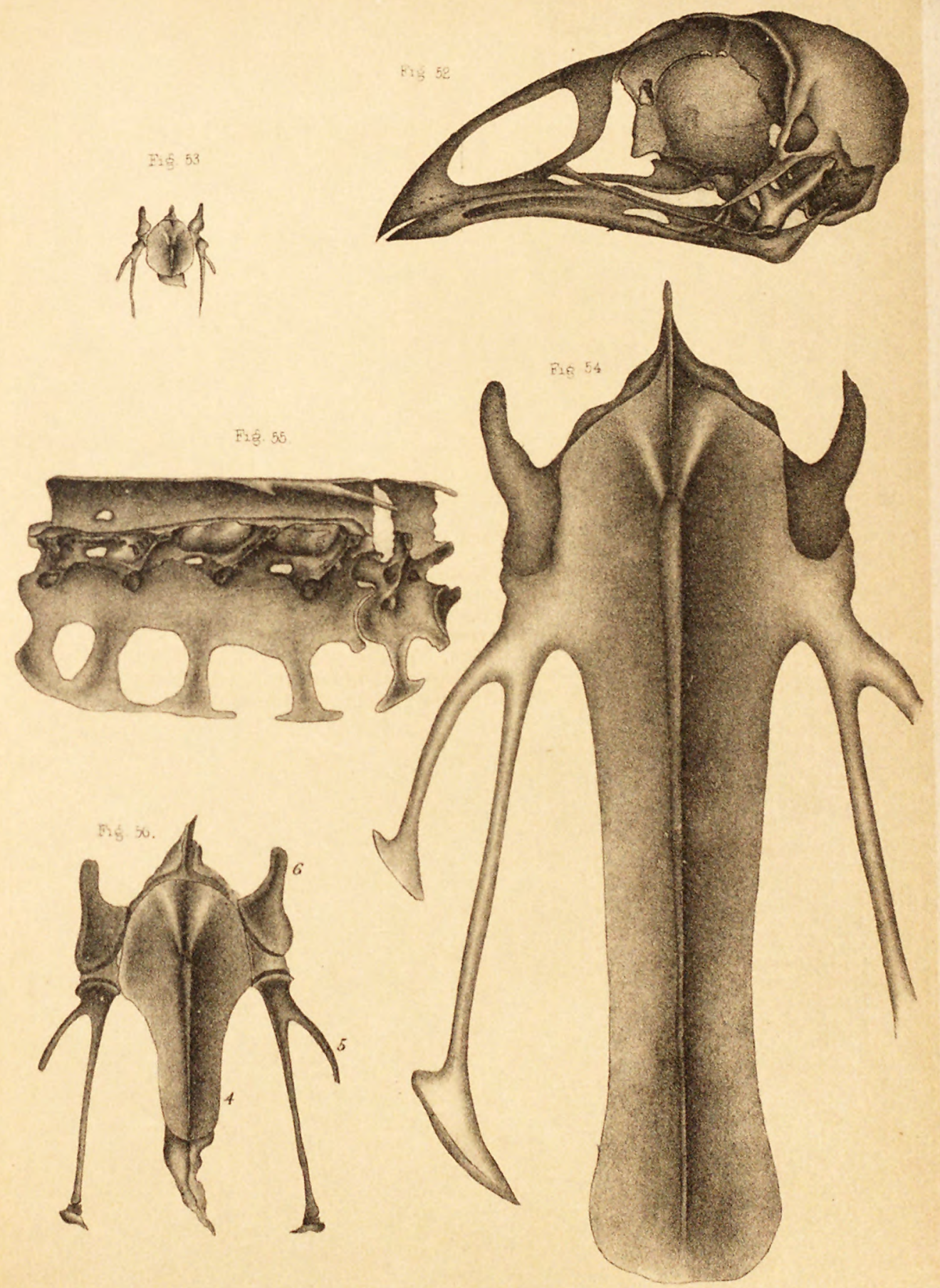

S 3 on tat

SHUFELDT ON THE OSTEOLOGY OF AMERICAN TETRAONIDA. 



\section{PLATE VII.}

Fia. 57.-Right pectoral limb of Centrocercus, same bird as the stennum in Fig. 6 if was taken from. $\mathrm{H}$, humerus, palmar aspect ; $r$, radius; $u$, ulna ; 8 , scaphoid (таdiale); $c$, euneiform (ulnare); $z$, unciform ; $d$, index digit ; 9, third metacarpal (annularis); $9^{\prime}$, second metacarpal (medius); $d^{\prime}, d^{\prime \prime}$, phalanges of the second metacarpal; $d^{\prime \prime}$, phalanx of the third metacarpal.

Fig. 58.-Left metacarpus of an adult Controcercus.

Fig. 59.-Left metacarpus of the same bird as figured in $5 \%$, showing all the sed. ments that go to make up the bone in Fig. 58: om, carpale or os magnum; $z$, unc. form ; 7, index or first metacarpal ; 8, pentosteon ; $9^{\prime}$, second metacarpal ; 9, third metacarpal (annularis).

FIG. 60.-Left humerus (Centrocercus), taken from the same bird as in Fig. 57 .

FIG. 61.-Left humerus, anconal aspect, Centrocercus; adult. 

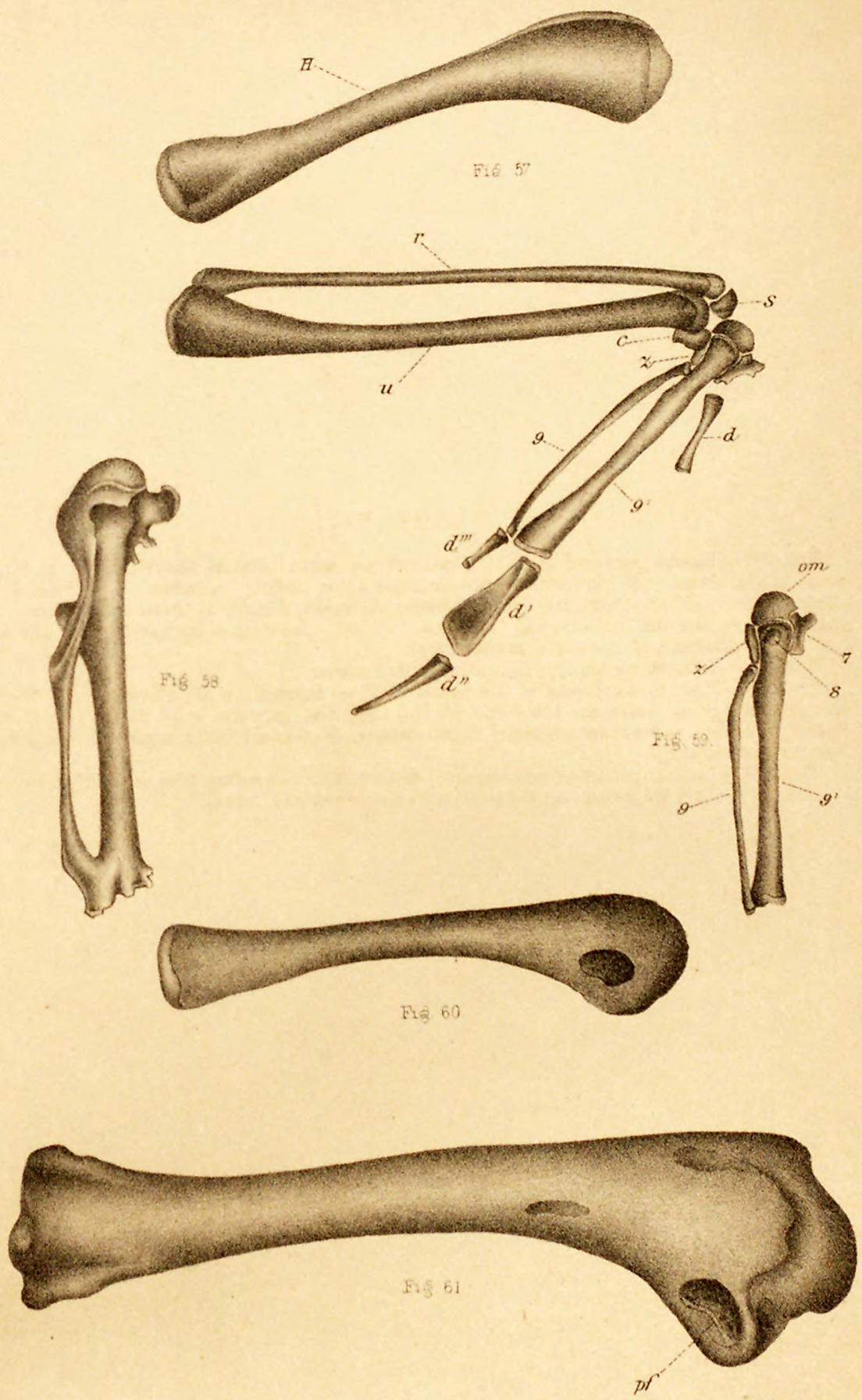




\section{PLATE VIII.}

Fig. 62.-Ossa innominata, Centrocercus, three or foar days old, showing how the pelvic bones form the acetabulum: $X$, ilium ; $Y$, ischium ; $Z$, os pubis.

Frg. 63.-Pelvis, same bird as in Fig. 57; Centrocercus; $X$, ilium; $Y$, ischium; $Z$, os pubis.

FrG. 64.-The perfect pelvis, lateral view, as in 62 and 63 , of Centrocercus; adult 8 


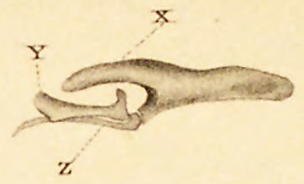

Fis 62
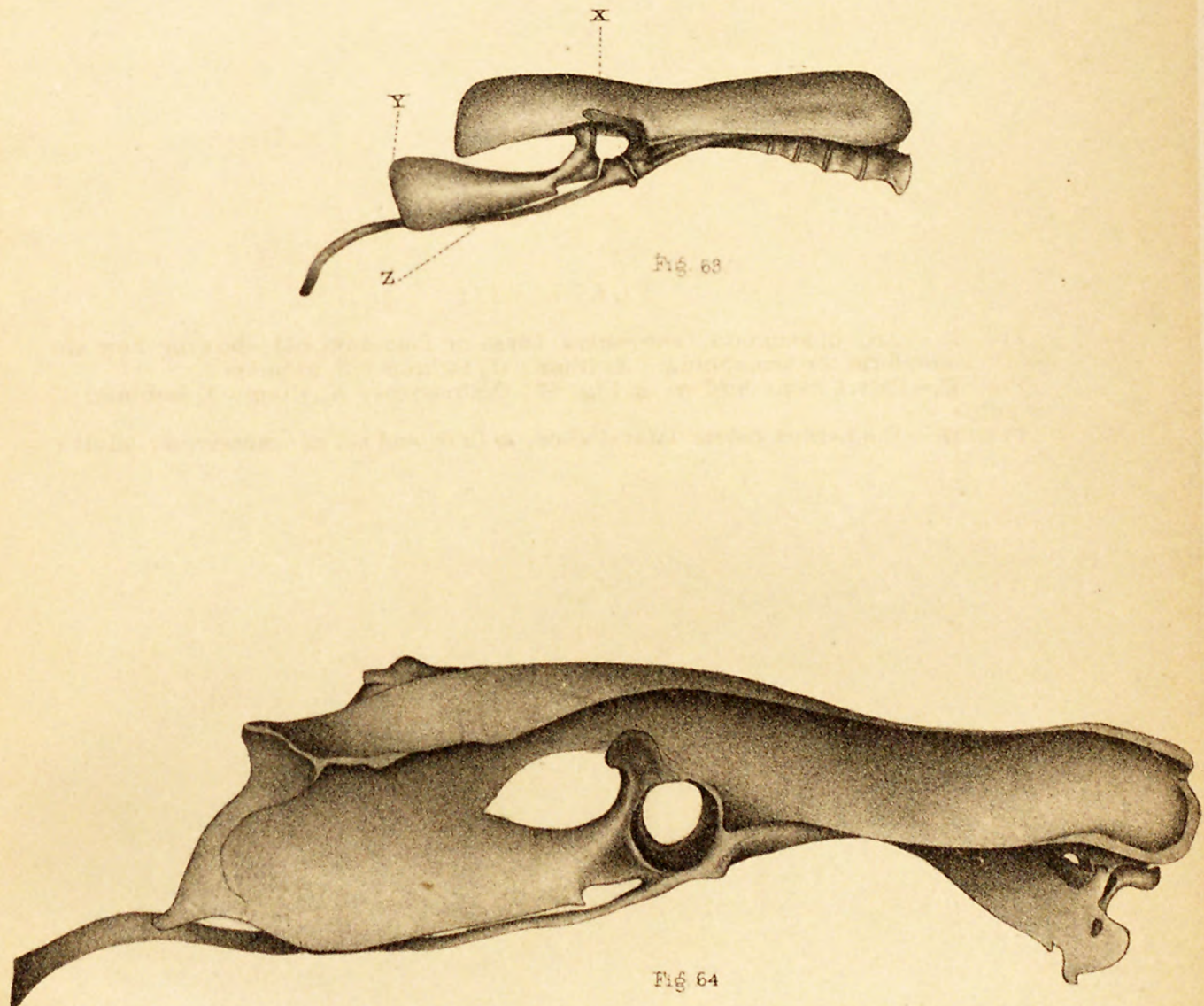

SHUFELDT ON THE OSTEOLOGY OF AMERICAN TETRAONIDE. 


PLATE IX.

Frg. 65.-Posterior view of pygostyle, adult Centrocercas.

Fig. 66. - The same, left lateral view.

Frg. 67.-Pelvic limb, anterior view, Centrocercus, taken from same bird as in Fig, $5 \tau$ : E, Epicnemial epiphysis of the tibia; $E^{\prime}$, the conflnent tarsal bones fond at the distal extremity of the tibia at this age, tibiale (astralagus), and fibulare (os ealcis): $E^{\prime \prime}$, the centrale.

Fig. 68.-Leit tarso-metatarsus, inside view, adult of, Centrocercus.

FrG. 69.-Anterior view of right tibia and fibula, from the same skeleton as 68 .

Fig. 70.-Anterior view of right femur, same bird as shown in Figg. 68, 69. 

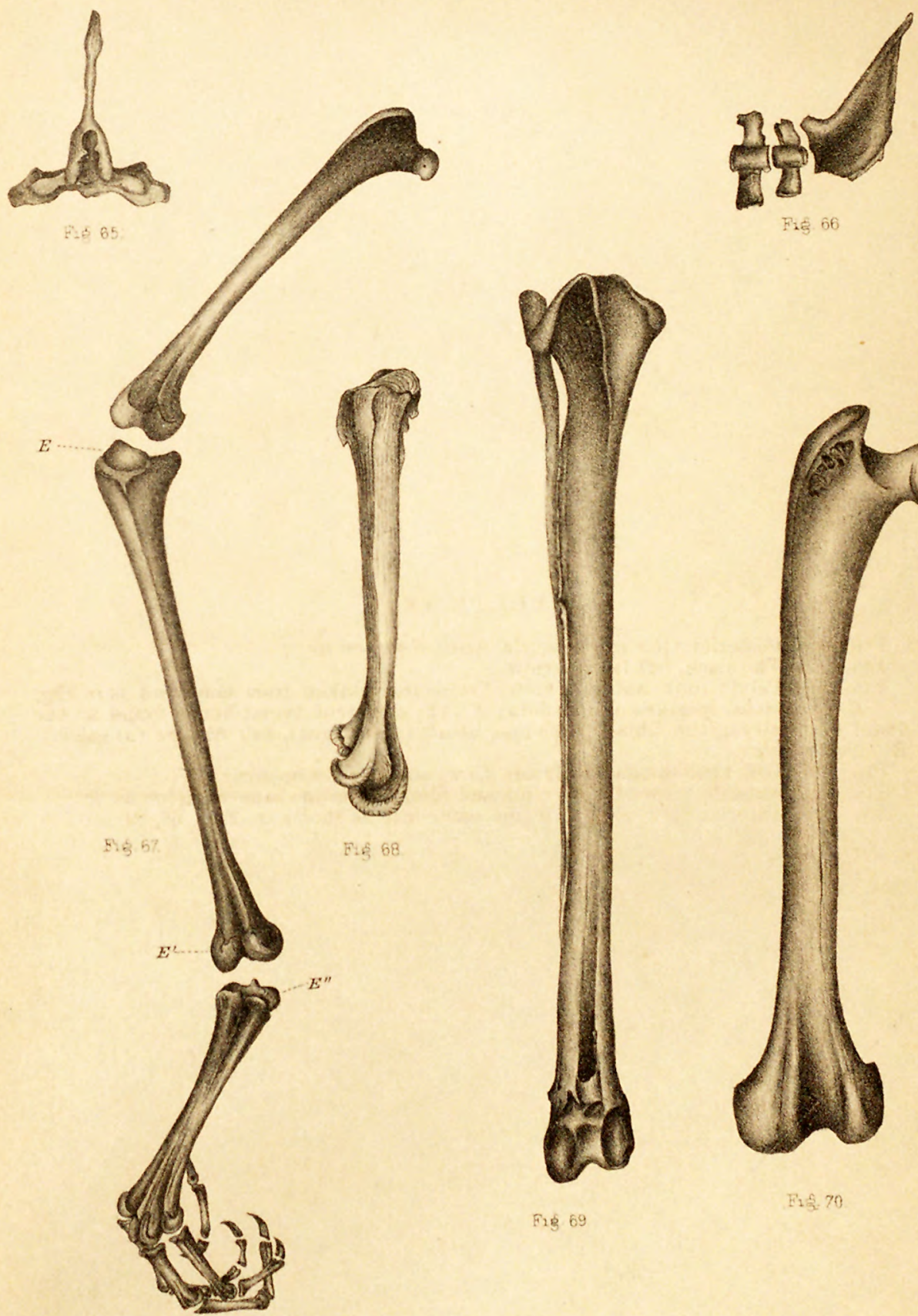

Fis 69
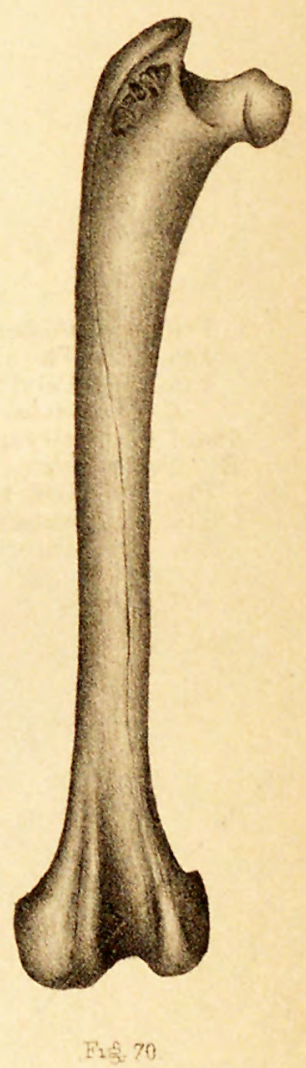

SHUFELDT ON THE OSTEOLOGY OF AMERICAN TETRAONIDAE. 


FIG. 71.-Right lateral view of skull of adult z Cupidomia eupiria.

FIG. 72.-Lower mandible from the same, viewed from above.

Fig. 73.-Skull from the same, lower jaw removed; seen from aboro.

Fug. 74.-The same from below.

Fig. 75.-Sclerotals, right eye from the same.

F1G. 76.-Right humerus, from the same, palmar aspect.

Fig. 77.-The same, anconal aspect. 

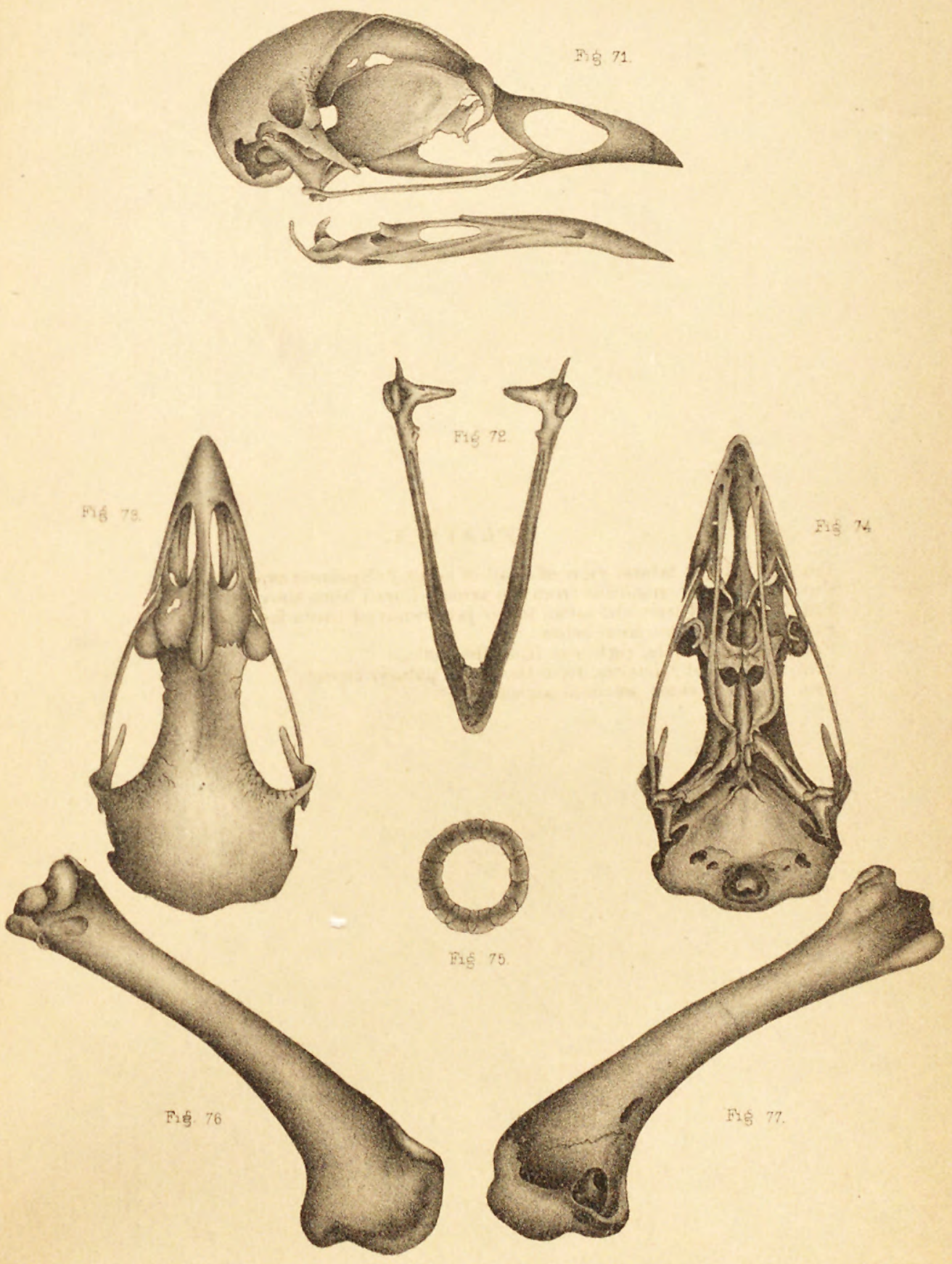

T Sinclair \& S on Lith

SHUFELDT ON THE OSTEOLOGY OF AMERICAN TETRAONIDAE. 




\section{PLATE XI.}

Fig. 78.-Sacral vertebral rib with its hæmapophysis, left side; $w^{\prime}$, the pleurapophy. sis, posterior view; $w$, the corresponding hæmapophysis.

FIG. 79.-Fifth pleurapophysis with its corresponding hæmapophysis attached; from the same bird, dorsal vertebræ, inside view.

Fig. 80.-Fourth plenrapophysis with its corresponding hæmapophysis attached; from the same bird, (Cupidonia), dorsal vertebræ, outside view.

FIG. 81.-Sternum from below; same bird.

FIG. 82.-Sternum, left lateral view; same bird (Cupidonia cupido). 


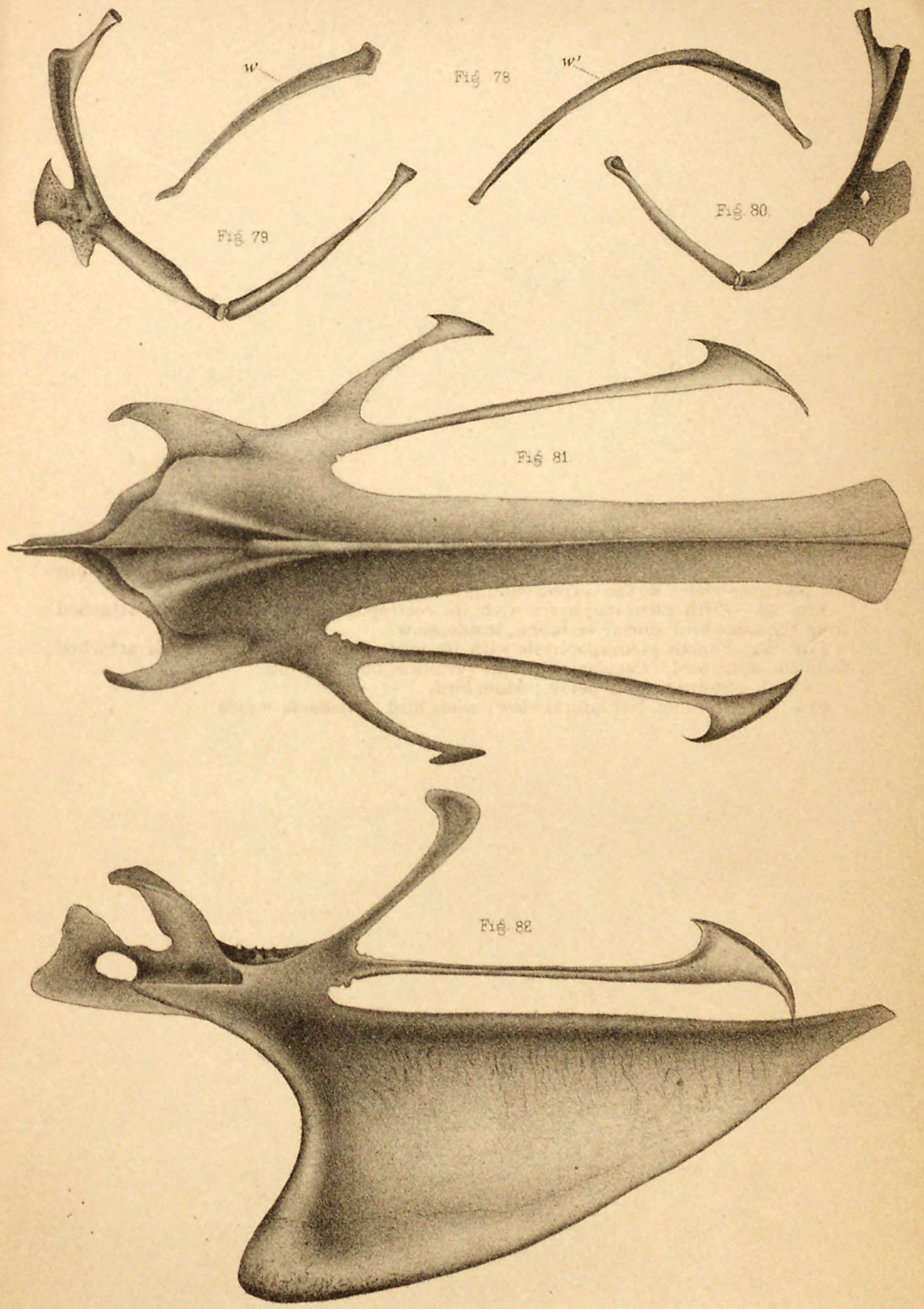

T. Sinctaix \& Son Lith.

SHUFELDT ON THE OSTEOLOGY OF AMERICAN TETRAONIDE. 


Fig. 83.-Pelvis from above; Cupidonia cupido.

FIG. 84.-Pelvis, right lateral aspect; same bird.

Fig. 85.-Right scapula and coracoid, in situ; same bird.

Fig. 86.--Left coracoid, posterior view, from the scapular arch of the same bird.

Fig. 87.-Right lateral view of clavicles, from the scapular arch of the same bird; dotted lines show the outline viewing it from behind. 

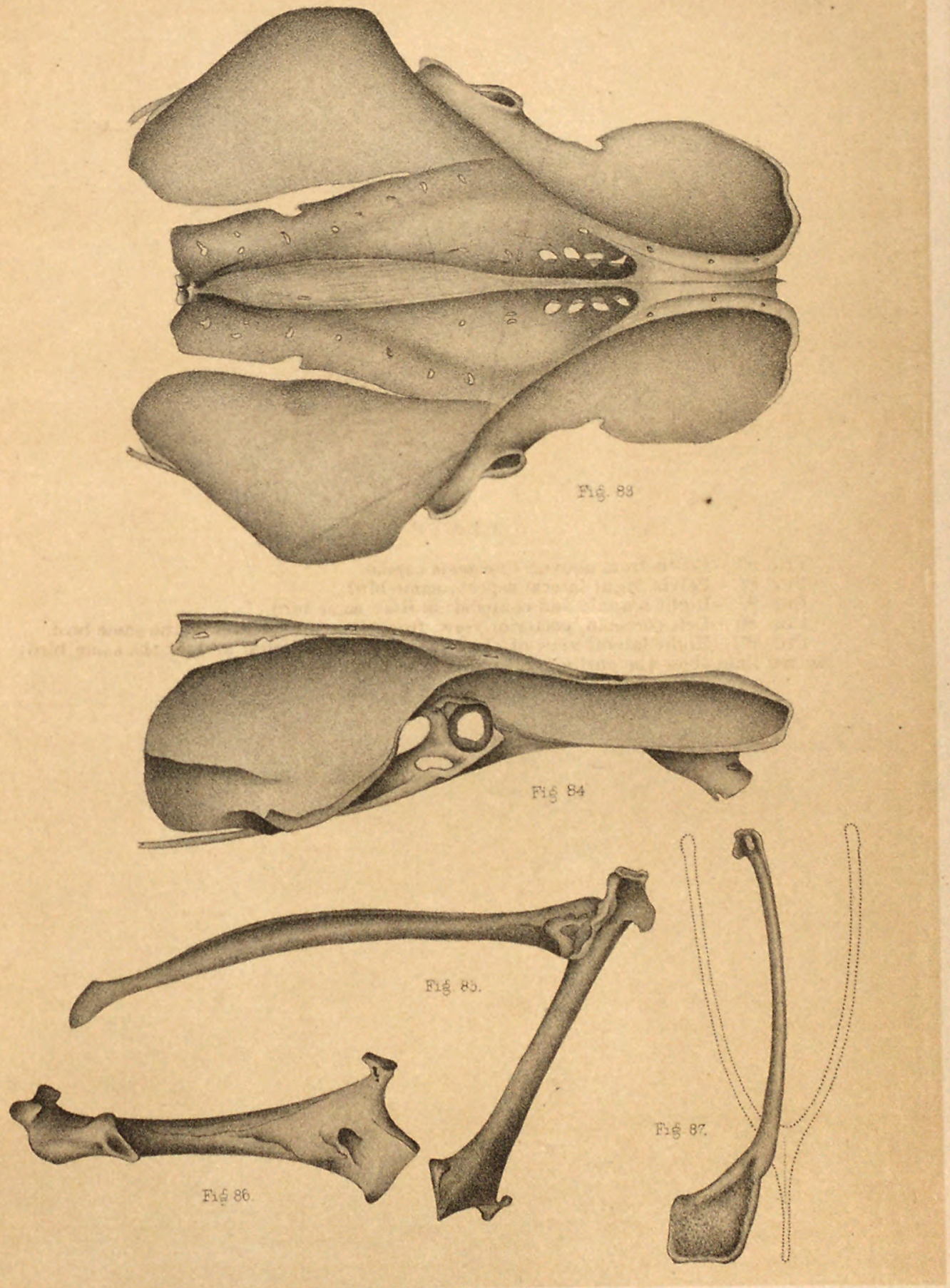

I. Sinclair \& Son, larh 


PLATE XIII.

Fra. 88.-Right lateral view of skull of aduit \& Lagopus lenourus; hyoid arch has been removed.

Fig. 89.-Cranium of Pedicecetes phasianellus; lacrymal, nasal, and intermaxillary still attached.

FiG. 90.-Pelvis, adult $\delta$ Canace canadensis, viewed from above.

FIG. 91.-Portion of skeleton of Ptarmigan, Lagopus leucurus, showing thoracic and pelvic bones in situ, with the scapular arch and caudal vertebræ. The last cervical vertebra still remains attached in order to show its free pleurapophysis. 

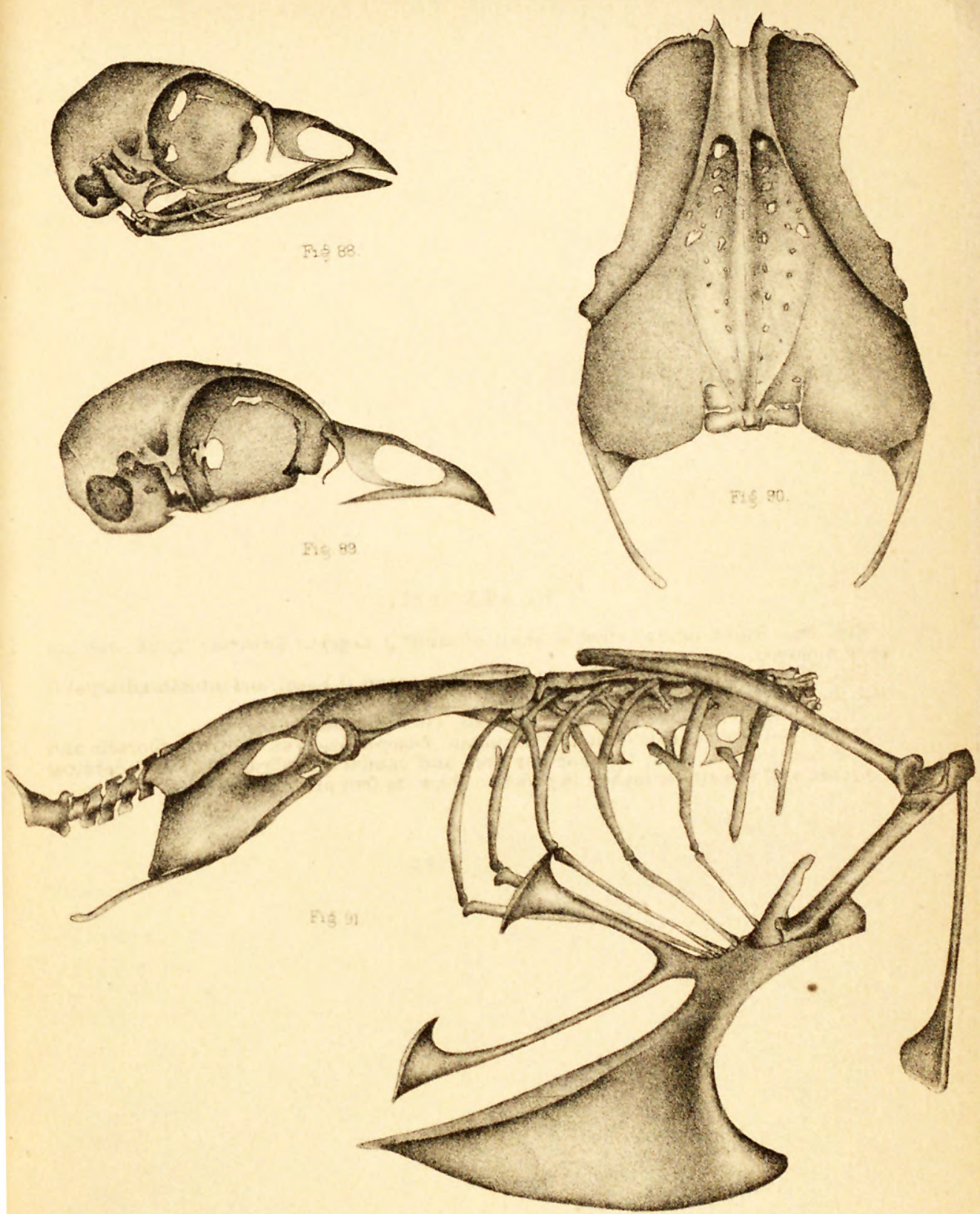



\title{
OSTEOLOGY OF LANIUS LUDOVICIANUS EXCUBITORIDES.
}

\author{
By R. W. Shufeldt, M. D., \\ Captain, Medical Department, United States Army.
}

Mr. Robert Ridgway, in his carefully prepared check-list of North American Birds (Bull. No. 21, Nomenclature of N. American Birds, chiefly contained in the U. S. Nat. Mus., Washington, D. C.), gives us the representatives of Laniida, the species borealis and ludovicianus, with the two western varieties of the last, robustus and excubitorides, which latter form we have chosen as the subject of this paper to demonstrate the peculiarities of the skeleton of these interesting birds. The habits of the Shrikes are well knowi to all ornithologists, so one will not be surprised, after a view of Fig. 100, in the plate (where our subject has been made, by the aid of the dissecting knife and maceration, to exhibit one of the truest indices of his character), to find the large, semi-hawk like skull surmounting the remainder of a bony frame-work, that might easily be mistaken as belonging to a Thrush or any other Oscine; but it is this very characteristic that individualizes these truly passerineraptorial birds.

In the skull, divested of the lower jaw and hyoid areh in the adnlt, we find that anchylosis of the primoidal segments has been very thorough; outside of the bony parts of the sense capsules- the ossa quadrata and the pterygoids are the sole escapers of this notorious feature in avian eraniology-indeed, we discover in the skull of this species, before it has left the nest, that the primitive segments that go to make up the group of bones that we described as the occipital vertebra in former papers are well advanced towards permanent union, especially about the condyle, traces of its formation being extremely difficult of discernment, and in the mature bird this hemispherical facet for the atlas is exceedingly diminutive, measuring only .5 of a millimeter in diameter. About the basi-cranii we find the usual foramina for the exit and entrance of vessels and nerves, and note in our examination that the anterior apertures of the Eustachian tubes are double, very small, and protected by an osseous lip from the basi-sphenoid. The foramen magnum is sub-circular and of medium size; together with the basi-cranii, it makes an angle with the horizontal plane of $25^{\circ}$, the anterior bearing point being the tip of the beak, and the two posterior bearing points being the internal facettes upon the ossa quadrata. That part of the cranium above, formed by the frontals and parietals is rery broad and smooth, and quite often the sutural traces are easily made out, and in cases where maceration is persisted in, the coronal suture may gape; beyond, the interorbital region becomes slightly depressed. The pseudo fronto-maxillary articulation is denoted by a transverse line nearly a centimeter long, and is moderately flexible; the superior tips of the lacrymals form its lateral boundaries. The superior mandible is made up of the usual bones, it 
is very broad at its base, and gently deflected throughout; the nasal bones bound posteriorly on either side vacuities that lead into the rhinal chambers, but the true nostrils are found beyond these, as distinct elliptical apertures. It is, however, the horny integumental sheath that really gives to this bird's beak its peculiar raptorial aspect, for when stripped of this, the osseous tomia show no sign of tooth or noteh beyond. Below, the palatine fissure is quite wide, and through its opening we discover that the ethmo-turbinals are more or less developed, together with a partial septum narium, and the space is further intruded upon by a sub-compressed and originally distinct vomer, that is bifurcated behind to receive the rostrum of the basi-pre-sphenoid, lodging a portion of the prefrontal in its fissure above.

The palatines have become amalgamated with the inter-maxillary anteriorly, and form, with the pterygoids, the usual joint on the rostrum of the sphenoid behind; they throw out sharp lateral apophyses that are directed backwards. The pterygoids are very much expanded at their mesial ends, their shafts being straight and delicate; and there are no pterapophysial processes; they meet the tympanics in sub. eircular heads, of no great size, just below the orbital processes. These latter elements possess very broad and twisted mastoid prolongatious, with the usual double facet and intervening depression below; and the orbital apophyses are pointed at their extremities, sometimes slightly clubbed, being turned gently upwards. The segments composing the infraorbital bar have long since become one single bone, a slender strle fulfilling its ordinary functions. A sub-elliptical sesamoid is found at its proximal end, between it and the tympanic. The orbital cavities are capacious, and well divided from the rhinal chambers by the broad, quadrate lacrymals on either side; their vaults are concavely arched, and their posterior walls quite extensive, looking almost directly forwards. The foramen for the exit of the first pair from the brain-case has run into one irregular aperture; but rarely joins, in the adult, with the elliptical foramina for the optic nerves below them. The orbital septum is never complete, a vacuity of greater or less extent occurring near the center of the plate. Laterally we observe shallow temporal fossæ above elongated openings to the otocrane, that look downwards, forwards, and outwards, standing out quite prominently from the side of the skull. The squamosals throw forwards and downwards horizontally flattened apophyses, which by the aid of smaller ones from the alisphenoids, help it to guide the temporal muscles to their points of insertion. A moderately marked "cerebellar prominence" is found at its usual site, above the foramen magnum behind; but we have nerer observed the foramina, caused by bone thinning, to occur on either side of it. In removing the cranial vault, we find the various fossæ unusually well defined, anc bounded by sharp borders; the carotids enter by separate openings at the base of the "sella turcica," which latter has it deep noteh, mesiad, in its posterior wall.

In the recent cranium, the internal and external tables are separated by an interspace of a millimeter or more, that is sparsely filled in by diplöic tissue; but upon examining skulls that have been kept for a long time, and consequently become thoroughly dried, we cannot distinguish between the two tablets; the diplöic tissue has entirely disappeared, and the whole roof is extremely attenuated and flexible. We are not prepared to explain how this remarkable change comes about.

The hyoid arch bears out its usual ornithic and oscine characteristics, and does not require any special description here, as the author intends 
to furnish a more elaborate description of the skull when he comes to touch upon the Vireonida; a faithfal outline of this arch is giren, however, from a superior view in Fig. 101 of the plate.

Before the young of this Shrike has left the nest the numerous elements of the lower jaw have become fused together, so that during maceration the two rami rarely separate at any other point except the symphysis between the dentary elements. In the old bird it is a stout and strong bone, with sharp-pointed extremity beyond, and deeply scooped-ont articular ends posteriorly, with blunted processes behind, and up-turned ones looking towards each other, mesiad. Externally the "sides of the jaw" are concave for their posterior two-thirds, and exhibit the usual elliptical foramen (Fig. 102); while the superior ramal borders are rounded and rise into slight prominences at the junction of the outer and middle thirds. As to the sense capsules, we find that the sclerotals are well developed and very accurately matehed together; the usual ossicles of the organ of hearing likewise ossify.

There are thirteen vertebræ devoted to the cervical portion of the spine, and, although they make a faint attempt towards a raptorial appearance, they are more oscine in their character than any thing else, and are not noted for the prominence of any of their outstanding processes ; d'sregarding the atlas, the first four bear neural spines, this feature not showing itself again until we find it in the last two, the thirteenth posessing it as well developed as any of the dorsals. The post- and prezyga. pophyses are markedly short, thus bringing all the segments quite near together, giving considerable stability to this division of the column. The parapophyses are very delicate where they are produced anteriorly at mid-neck, and quite inconspicuous above; the first four and the last six vertebra bear hypapophyses, they being three-pronged on the last two; this limits the carotid canal to the fifth, sixth, and seventh cervicals, unusually slight protection for this important arterial branch. The vertebral canal commences in the tenth-i. e., in this segment it is completely surrounded by bone, and continues its course through the axis; the last two or three vertebrie are very broad from side to side, the ultimate one bearing a free pair of vertebral ribs that have in their turn distinct uncinate processes.

The neural tube as fonnd in this section of the spine commences and terminates broadly and transversely elliptical, merging into the sub. circular as it nears its mid-portion at the middle of the neck; it is of considerable caliber thronghout. The dorsal division of the spine has allotted to it five vertebræ, closely locked together, yet easily detached by ordinary maceration; their combined neural spines form one continnous quadrate crest. These are fastened together above by the "arrow-head" joint that we have described in other papers. There is very little difference in the lengths of the transverse processes, from first to last, so we do not find much change in the processes of the ribs they sustain, as to length of pedicles and tubereula. Short metapophysial ridges are found above the transverse processes; they never seem to attain sufficient length to connect the vertebral segments, however.

The neural canal commences transversely elliptical, to terminate, much diminished in caliber, in the subcircular form. In the first dorsal we find a thin quadrate lamina of bone, projecting downwards and forwards in the mesial plane, as a well-developed hypapophysis; the second supports the merest apology for this process, and the remaining dorsals have none at all, though by compression of the centra a low ridge jresents itself along their middles, which is only faintly perceptible in the last, There is a free pair of ribs for each dorsal rertebra, and these are mov. 
ably connected with the sternum by corresponding pairs of costal ribs, the whole structure and appearance being distinctly oscine in char. acter. The vertebral ribs are very slender below and not so much ex. panded above as they are in some other birds. Commencing with the last cervical rib, and continuing entirely through the dorsals, we find the series of epi-pleural appendages complete on either side, and freely artic. ulated with the posterior borders of the ribs, with which they make an angle of about $45^{\circ}$, and attain sufficient length to overlap the rib in their immeciiate rear, though often in younger birds, and even some old ones, the last uncinate process does not reach the free sacral rib. The sternal ribs are quite delicately fashioned, and support, as usual, anteriorly the trans. verse heads for articulation with the costal border of the sternmm, while posteriorly we discern the moderately upturned and clubbed extremities with shallow facettes for the inferior ends of the vertebral ribs.

The sternum of the Loggerhead Shrike is almost or quite typically "cantorial" in its outlines, but only feebly pre-eminent in those features that stamp it as belonging to a bird of any great power of flight. The manubrium, directed upwards and forwards, springs from a solid base to become bifurcate at its anterior extremity and throw down a sharp border below, that becomes continnons with the carinal margin in front; the coracoidal grooves pass round laterally well beneath the costal processes, and merge into each other, mesiad, their point of meet. ing being denoted by an elliptical depression, at the base of which we occasionally find a single pneumatic foramen. The costal processes rear themselves upwards, forwards, and outwards, being broad but thin laminæ of bone, impressed upon their posterior margins by the five trans. verse facettes for the sternal ribs. The "body" is concave above, sloping to a shallow, osseous gutter, lying in the mesial plane direetly over the keel; beyond, in this groove we observe a few scattered foramina for the admission of air to the more solid structures of this confluent hæmal spine. Behind, the bone is one-notched on either side, cutting out lat. eral processes with expanded posterior ends and a broad mid-xiphoidal portion-the direct continuation of the sternal body-(Fig. 92). The "carina" below averages about 7 millimeters at its deepest part; anteriorly it protrudes as a rounded earinal angle, from which point its inferior boundary sweeps backwards by a gentle convex curve to terminate in a diminutive triangular space at the middle of the xiphoidal process beneath.

The sides of the keel present for examination well-defined subcostal, pectoral, and earinal ridges; the latter falls on either side from the base of the manubrial process to near the carinal angle, just within the bor. der, and sometimes has a thickened backward branch starting from its lower end. The confluent pelvis, in common with the majority of pas. serine birds, has that strikingly angular outline, due largely to sharpened borders and outstanding spiny processes. There are ten vertebræ in its "sacrum," all unusually firmly fused together, vacuities only oceasionally occurring among the diapophyses of the ultimate few, three or four at most. The pre-acetabular region of the ilia on either side is deeply concave, this concavity being carried up over the anti-trochanters to terminate in shallow grooves over the ischiatic foramina. The greater share of this surface looks almost directly outwards and only slightly upwards. The ilio-neural canals are divided by the confluent spines of the first four or five vertebræ, they vary in width in different individuals, and terminate at points opposite the cotyloid cavities, at which point the neural spine suddenly becomes compressed, or rather annihilated, and the sacrum sustains a flattened surface to the ultimate boundary of the 
bone. The post-acetabular regions are of about one-third the extent of the surfaces anterior to the cotyloid rings; they are produced behind in strong and clubbed processes, the outer margins of which are the terminations of the gluteal ridges or lines continuous with these ridges; these surfaces are convex and narrowed by the encroachment of the broad sacrum (Fig. 103).

Laterally the ilium overhangs the extensive and elliptical ischiatic foramen, which is bounded in front by the anti-trochanter, directed backwards and slightly outwards ; the cotyloid ring is circular and but lit tle difference exists between the diameters of its inner and outer peripheries. The obdurator foramen is very small and varies in the figure of its outline, though generally assuming more or less the form of the ellipse ; the broad and thin hinder blade of the ischium again dips down to meet the slender pubic shaft, just before its termination, to shut in an elongated spindle-shaped tendinal vacuity. (Fig. 100.)

Upon the ventral aspect of the pelvis, we note that the bone affords no shelter whatever for the important organs it incloses until we pass the fourth sacral segment and the very decided vertebral swelling to form the sinus rhomboidalis; it then drops into a deep depression on either side, whose concavities and convexities correspond with those described and attributed to the dorsal surface. The apophysial braces thrown out by the vertebræ are extremely slender, except in the cases of the first and fourth : the former segment bears a free pair of slender pleurapophyses, whose hæmapophyses articulate along the posterior border of the ultimate sternal ribs, as do some of the inferior so-called "costal cartilages" in anthropotomy, lacking the necessary length to arrive at the costal borders of the great ventral hæmal spine, constituting a common ornithic character. These sacral ribs rarely or never support uncinate processes.

Six segments are deroted, in this Shrike, to the coccygeal division of the column, exclusive of the pygostyle; they share the same fate, with their fellows and representatives in nearly all of the class Aves, in having many of their original rertebral components either rudimentary or entirely suppressed; the neural spines, hooking over each other, anteriorly, become more and more feebly developed as we proceed backwards ; this order of things is just reversed when we come to examine the hypapophyses on the nether aspects. The neural canal that passes through them dwindles to mere capillary dimensions before reaching the pygostyle, into which bone it enters but a very short distance.

The transverse processes of the caudal vertebræ are bent downwards, compressed horizontally, broad, and show but slight differences in length, before reaching the last one, in which they are shorter. The lamina of the pygostyle has the outline of an isosceles triangle, being truncate at its apex; the "body" below is of a substantial structure, barely dilated behind, and otherwise presenting the usual characteristics as found among the oscines.

The bones of the scapular arch are all free and independent of each other, the stability of their relative position depending upon strong ligaments in the living bird. The blade of the scapula is quite narrow, and, in the vast majority of cases, extends across the dorsal pleurapophyses, or vertebral ribs, its distal end being obliquely truncate, from within, outwards; the blade-like portion is brought up in close juxtaposition with that portion of the bone that affords the scapular moiety of the glenoid fossa. Its acromial process is very short, owing to the fact that it has to proceed but a short way before it abuts agaiust the much-expanded head of clavicle, on either side; it forms with the coracoid the usual ten- 
dinal canal between the two bones. The head of the coracoid rears well above the glenoid cavity, in order to afford the required-surface upon its mesial aspect for the broad clavicular extremity that rests against it; upon its opposite side it offers the usual surface to assist in completing the eavity for head of humerus. The shaft of the bone is very slender and cylindrical for its major part, and the wing-like extension, so broad in many birds, is here but a meager osseous scale attached to the side of the shaft, for its outer and lower half, becoming continuous with the formal dilatation of the bone below; for the sternal articulation. this is transversely concave and very narrow.

The minute pneumatic perforations of the scapulæ and coracoids oc. cupy their usual sites back of the glenoid eavity, under the protection of the tendinal canal, at the heads of the bones. The united clavicles, or the furculum, inclines decidedly to the $\mathbf{U}$-shaped variety (Figs. 94. 95); we have already alluded to the fact as how broad, yet compressed. their scapular ends are found to be; from these heads the shaft-like portions fall downward, with a gentle curve backward to meet and sup. port the mesial and usual clavieular lamina, which here lies in that re. cess formed by the anterior and concave border of the carina of the steruno (Fig. 100).

Directing our attention again to the shoulder-joint we discover that this Shrike is another example of those birds in which that little peg. like ossicle, the os humero-scapulare is found, here attached by its usual ligaments to the upper and back part of the articulation and fulfilling its ordinary function. The humerus of Lanius bears the closest resemblance to that bone as found in many of the family Turdida-particularly does this apply to Mimus polyglottus, a bird the Shrike not un. successfully apes in point of external coloration.

The head, in most individuals, is well bent, anconal, and supports a short radial and not lofty crest, with the usual ulnar tuberosity overhanging an ample pneumatic fossa. The shaft is quite straight and nearly eylindrical, its distal and expanded extremity presenting quite a unique appearance (Figs. 96 and 97). The internal and external condyles are distinct processes, the former projecting almost directly back. wards, the latter forwards and upwards; the olecranon fossa is likewise clearly defined, and on the palmar aspect we observe the oblique and ulnar facets unusually prominent. The humerus is the only bone of the pectoral limb that has air admitted to its interior, the bones of the antibrachium and pinion lacking this rather rare prerogative.

The ulna is more than four times the bulk of the radius, being, as in most vertebrates, the main support of the forearm; there is scarcely any perceptible curvature along its well-balanced and cylindrical shaft, which presents a row of distinct little tubercles for the bases of the quills of the secondaries. Its proximal end presents for examination a prominent olecranon process, directed backwards, and the greater and lesser sig. moid cavities on its anconal aspect; the distal extremity is rather under the average in point of eminence, but shows all the usual indentations and surfaces to accommodate this end of the bone to the wrist and radins. The radius differs principally in having a general curvature distributed along its subtrihedral shaft, rather than having it confined to its proximal third, as in many birds; otherwise it presents its ordinary ornithic characteristics.

Among the mature birds representing the Laniide, as in so many other families, the carpus is composed of the two free ossicles, the cuneiform and the scapho-lunar, which are here impressed by their usual articulating facettes, for the radial and ulna trochleæ and the metacarpus, 
and although we have the young of this Shrike before us, the limits of this paper will not allow a critical description of this interesting and important region of the skeleton, that can only be obtained by careful study of the youngling.

The manus contains its customary complement of bonelets, as seen in the pinions of the major part of the class in general (Fig. 100); medius and annularis metacarpals are firmly united together, and with the short first metacarpal that bears the index; the broad phalanx of the second is concave upon its anconal aspect and supports below the distal joint of the hand; the smallest phalanx of all is freely attached to annularis, which latter metacarpal extends some little distance below its stouter fellow, the medius. The pelvic limb is non-pneumatic, and consists in the adults of the usual number of bones, the patella being present. The femur, less than 2.5 centimeters long, has no trochanter minor, and the larger process of this name is but feebly produced; the head, with its single depression for the ligamentum teres may justly be said to be at right angles with the cylindrical shaft, which latter is slightly convex forwards; the condyles are well developed and the outer one presents the usual fibular groove. The tibia presents nothing that differs in any marked extent from the oscines in general; it has no rotular process, but the pro-and ecto-cnemial apophyses are well produced and turned slightly outwards; at its distal end we observe, anteriorly, the usual tendinal bony bridge for extensor tendons. The fibula can be detached from the tibia by maceration, but its lower extremity spins out into a mere thread at the junction of mid and lower thirds of the latter bone. There are no free tarsal segments, and the same remarks apply here as we used in speaking of the wrist-joint above. The tarso-metatarsus (Fig. 99) is very delicately constructed below, while above it is stouter and presents immediately back of its head the process we have called tendinous, pierced by two pairs of foramina. A thin lamina of bone extends along its shaft behind. We observe that the os metatarsale accessorium is unusually large, as is the toe it supports; but otherwise the internodes are arranged upon the general plan of the oscine foot, which brings to our mind nothing of a raptorial type, except, perhaps, as we know the bird, the decided curvature of the hind claw, which is still further ncreased and lengthened when armed with its horny theca. 


\section{PLATE XIV.}

FIG. 92.-The sternnm, from below. Lanius ludovicianus excubitorides.

FIG. 93.-Right scapula and coracoid, onter aspect.

Fig. 94.-Clavicular arch, from in front.

Fig. 95.-Head of clavicle, right limb, outer aspect.

FiG. 96.-Right humerus, palmar aspect.

FIG. 97.-The same, anconal aspect.

FiG. 98.- Right femur, posterior aspect.

Fig. 99.-Left tarso-metatarsus, anterior aspect.

FIG. 100.-Skeleton of adult 8, Lanius ludovicianus excubitorides; the left free ves tebral and costal ribs and the peetoral limb have been removed.

Fig. 101.-The hyoid arch, from above.

FIG. 102.-The lower mandible, from above.

Fig. 103.-The pelvis, from above

FrG. 104.-Superior aspect of skull, the lower mandible having been removed. 

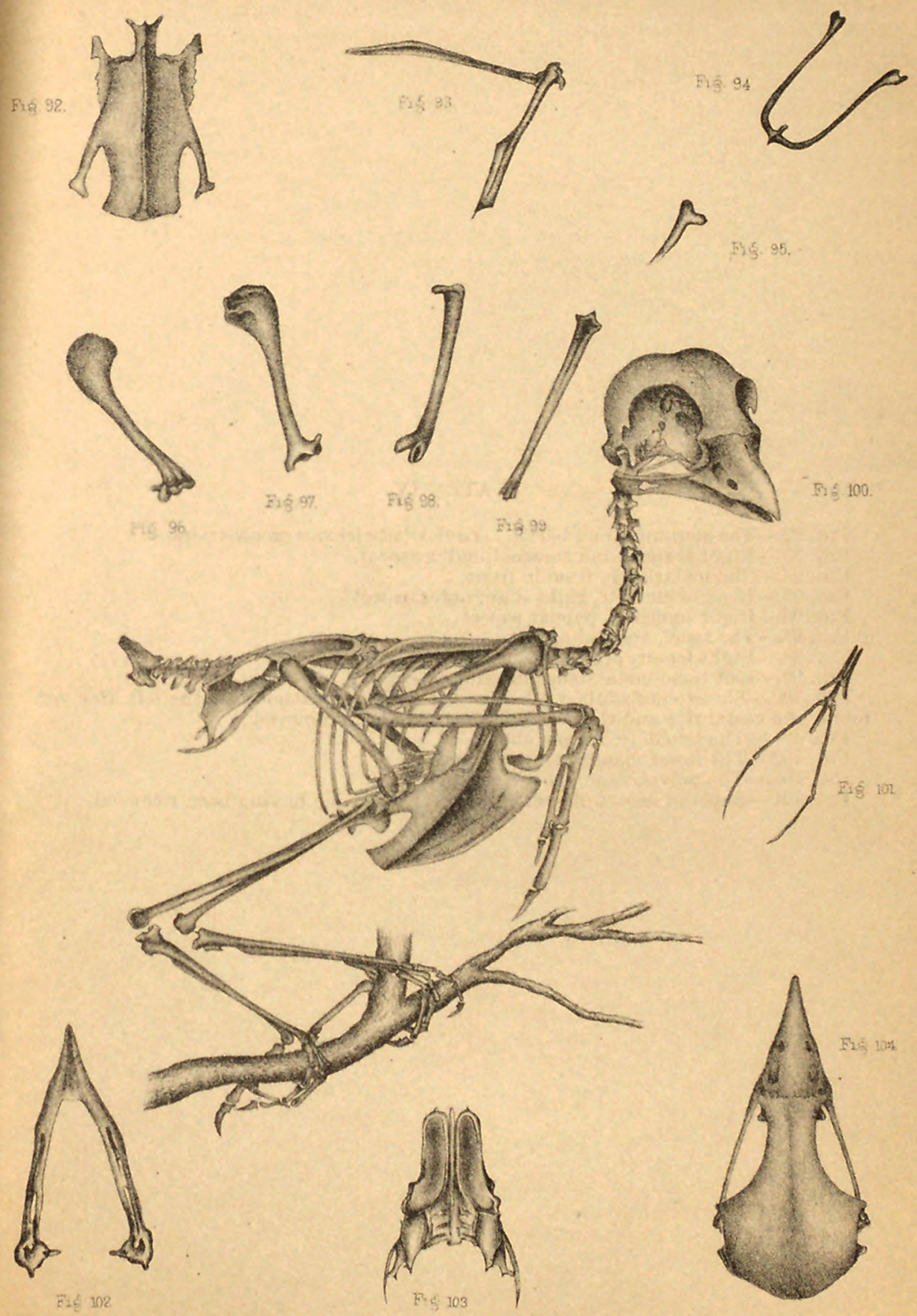

SHUFELDT ON THE OSTEOLOGY OF LANIUS LUDOVICIANUS EXCUBITORIDES. 




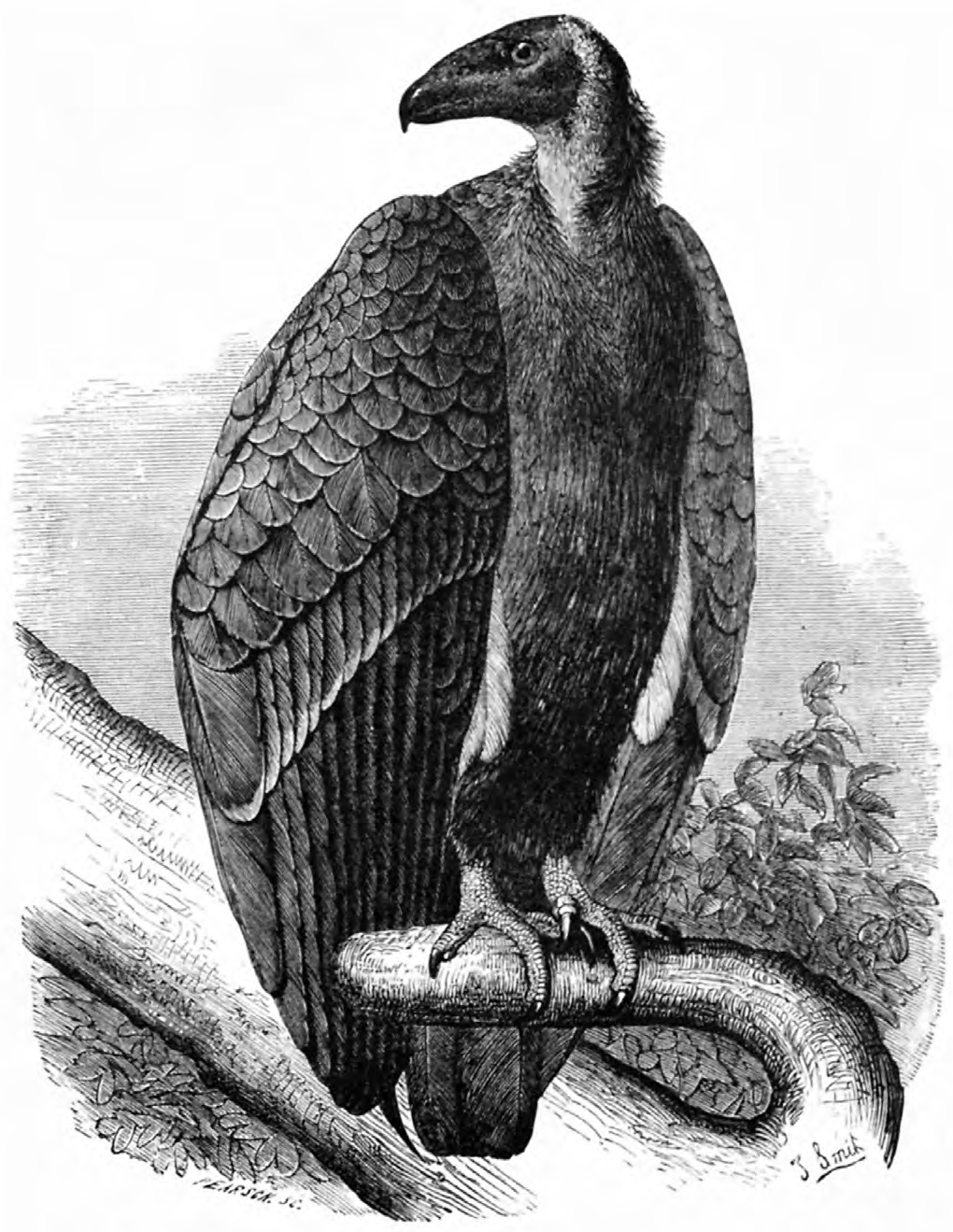

[Face p. 727, Hayden's 12th Annual.] 


\title{
OSTEOLOGY OF THE CATHARTIDE.
}

\author{
By R. W. Shuteldi, M. D. \\ Captain, Medical Department, U. S. Army.
}

Nowithstanding the fact that living birds, taken as a class, form one of the best isolated groups we have in uature, their arrangement into families and the division of these families into genera is still on a very unsatisfactory basis. This, no doubt, has been largely due to the fact that all of the variously proposed classifications have rested almost exclusively upon external characters; only an author here and there pointing out in lis writings differences in internal structure. Of recent years, however, this imperfect system and highly uncertain course has been very much modified and improved by the attention given to avian anatomy by quite a number of earnest and painstakmg zootomsts. The published labors of these gentlemen and the facts they have succeeded in elucidating have already made their impression upon the problem to be solved, and in many cases the family lines are now more sharply defined.

We must all agree, though, that this good work is yet in its infancr, and that the question of the classification of birds can only be definitely se tled when we are thoroughly familiar with the habits, external structure, and charactersstics of each species, and these are combined with a complete knowledge of their internal anatomy in all of its minutest details. The classification resting upon the digested and compared facts of such a knowledge as this ean be the only perfect one, and the only one that will not be subject to sudden surprises and consequent changes, rendered necessary by periodical discoveries in structure and the derelopment of new anatomical facts. In short, as distant as the day may seem, we will only be able to devise a perfect classification of living objects in nature when we have mastered their anatomy, using the word in its broadest sense. So that well-estrblished and recorded anatomical data become particularly valuable to descriptive zoologists, and we feel sure that it is the aim of every one interested in this im. portant subject to further the efiorts of those now engaged in this particular branch of the science, in anyway in their power, in order to meet the end in view. Probably there is no better illustration afforded us anywhere in the recent literature of the science of ornithology, in which anatomy has played a more prominent part in deciding classificatory division, than in the separation of the Cathartida from the Old World Vultures, nor in none, if it had continued to be relied upon, where simple external characteristies could have been more misleading. In this particular instance the osseous system was the one that finally ren. dered the principal assistance in determining the dividing line.

Accepting as we must, then, these prerequisites to a sound classification, how idle it is for any one to attempt to define permanent family lines that will stand the test of time and research by any singl: set of 
characters; as, for instance, cranial peculiarities, or such forms as the sternum may assume. It seems to me that this latter bone would be particularly unreliable to adopt for any such purpose, for we will soon see in the Cathartide that its shape appears to vary with the age of the individual, and a description of the bone in one bird, apparently an adult, would not answer for another of the same species, and per. haps of the same, or nearly the same, age.

At the present writing it is well agreed among ornithologists, and, no doubt, very correctly so; that the Cathartida, or American Vultures, form a family of themselves quite distinct from the vulturine Falconida of the old World. This rather recent step, taken as it was through the aid of modern researches in the matter, will, in all probability, be a final one, and the Vultures of our continent will, we think, always be considered as forming a well-defined family to which we can now hardly look for any new additions. The writer trusts that in the present paper he will be able to demonstrate to his readers, by the study of the skeletons of these birds, that the osteological characters of the group, some of which are new, go still further towards sustaining the division made and referred to above. The question as to how the Cathartide should be divided generically is quite another thing, and its discussion will be postponed until we have examined the various skeletons of the members of the family and compared our data with onr present knowledge of the other systems of these birds' economy.

Vultures, as a rule, are found in the warmer climates, where they pursue their useful avocation as scavengers, feeding upon all carrion that chance may throw in their way. To carry on this mode of living we find certain marked features presenting themselves to us in their superficial anatomy or external topography that are common to all of them. 'The most important of these points we will hastily review here, so that the reader may have them at hand as external landmarks or references to compare, where comparison becomes possible, with points upon the skeleton within. In the first place, we find that their upper mandibles terminate anteriorly in a well developed hook, which is much better defined when encased in its horny covering; in fact, it requires the addition of this integumental sheath to approximate the mandibular margins in any of the Cathartida. The head and a greater or less extent of the upper third of the neck is devoid of feathers, a fine down being found only in the young birds. There is no osseous septum narium present, and the external bony nasal apertures or nostrils are made to assume different degrees of perviousness by the surrounding cere. They have an external claw covered with horn, as in the ungual joints of the feet, that articulates by its base with the apex of the first digit in manus. A web is found between the inner and middle and middle and outer toes occupying more or less of the basal thirds. Claws of the feet large, strong and curved, though these members are not fashioned for grasping purposes, as we believe Vultures never carry their plunder away by means of their feet, they being given these curred claws rather to hold down firmly the portion of the carcass upon which they may be feeding while they tear it in shreds by their powerful hooked beaks. It will be recognized at once that some of the characters just enumerated have nothing whatever to do with the present mode of living of these birds, but may have done so in their ancient ancestors; we refer particularly to the external claw exhibited on the manus, a character they possess in common with some, if not all, of the Old World Vultures.

The family Cathartida, as defined by its most recent describers, con- 
sists of the following genera and species: First. Sarcorhamphus, containing $S$. gryphus, the Condor of the Andes, a bird whose range is so well known as not to require any definition from me here. Gyparchus papa, the King Vulture, a species which, until recently, was supposed never to enter the confines of the United States, but inhabited the subtropical countries to our southward. Its presence at the ṕresent writing, however, is strongly suspected in the Territory of Arizona, as referred to by Dr. Coues in the Bulletin of the Nuttall Ornithological Club for October, 1881, under General Notes. Third. Psendogryphus, containing the single species P. californianus, the Californian Condor, a huge Vulture that is confined to our western coasts and principally to the State from which it derives its name. Fourth. Cathartes, containing $C$. aura, $C$. burrovianus and $C$. pernigra. The range of the first of these, the common Turkey Buzzard, is thus defined by Mr. Ridgway:

"Probably none of the birds of America have so extended a distribution as this Vulture, occurring as it does in greater or less abundance from high northern latitudes at the Saskatchewan, throughout North America, from the Atlantic to the Pacific, and in all portions of South America, even to the Straits of Magellan. (Hist. of N. A. Birds; Bd., Brewer \& Ridw., pp. 345.)"

From my own experience it can be said that this Vulture was found to be quite common during the years 1877-80 throughout the northern territorial districts of the United States.

In April, 1880, Ridgway calls our attention to $C$. burroviamus and $C$. pernigra in the following words (Nutt. Ornith. Bull., Apr., 1880, p. 83):

Cathartes burrorianns, Cass.-Recent anthorities" having almost uniformly ignored the claims of this bird to specific rank, I have, in the absence of any opportmity to examine the type specimen in the museum of the Philadelphia Acadeny, carefully read Mr. Cassin's description in order to satisfy myself whether we are justified in the suspicion that Mr. Cassin's supposed species was based on a small specimen of $C$. aura. Upon reading Mr. Cassin's description I was surprised to find how well and unmistakably it applied to the bird usually called $C$. urubitinga Pelz. in every particular. In the description, as quoted below, I have italicized the phrases which are strictly. and peculiarly diagnostic of $C$. urubitinga, in order to show at a glance how certain it is that Cassin's C. burrovianus is the same bird. The only question, it appears to me, can be as to the locality, which may be erroneons, since $C$. urubitinga is not known to occur anywhere out of Eastern South America, though the evidence to this effect, it should be remembered, is purely negative.

The earliest notice of this species is that of Brisson (1760), the Vultur brasiliensis of this author being unquestionably the same species, as his full and very accurate deseription clearly shows. Therefore, it is quite possible that some author may have applied the name brasiliensis to the species under consideration before Mr. Cassin's name burrovianus was bestowed upon it, in which event the proper specific term would be brasiliensis, and not burroviamus. I cannot find, however, that such use of Brisson's name has been made. It is altogether probable that burrovianus will stand.

Mr. Cassin's description (Pr. Philad. Acad., March, 1845, p. 212) is as follows:

"Head naked, smooth, with the nostrils large and oval; plumage of the body entirely black, with a greenish-blne gloss, paler beneath; the feathers extend upwards on the back of the neck; a small bare space on the breast. Wings long, the quills and tailfeathers black, with the shafts of the primaries white and conspicuous; third primary largest. The smallest American Vulture known.

"Total length (of skin) 22 inches, bill $2 \frac{1}{2}$, wing 18 , tail $8 \frac{1}{3}$.

\section{Hab.-Near Vera Cruz.}

"This species resembles $C$. aur $a$, Linn., in the shape of the bill and the nostrils, and in having the tail rounded, but differs from it not only in size, but the feathers extend upuards on the back of the neck and lie flat instead of forming a ruff; the plumage of the specimen now described is black, none of the feathers having pale margins, as is commonly the case in specimens of $C$. aura; the shafts of the primaries are clear white, and the head is more entirely destitute of downy feathers. The tarsi are longer and more siender.

* Conf. Elliot, Illustr. Am. B., II, 1866; Allen, Bull. Mus. Comp. Zö̈l., ii, 1871, p. 311; Sharpe, Cat. Acc. Brit. Mus., i, 1874, p. 28 ; Gurney, The Ibis, 1875, p. 94. 
"The head of $C$. burrovianus is quite smooth, in which, as in other respects, it is very different from $C$. atratus, Wilson.

"This new species was obtained in the vicinity of Vera Cruz, by the late M. Bur. rough, M. D., in honor of whom I have named it, as a slight acknowlergment for his very valuable services to natural history and to this academy."

Cathartes pernigra, Sharpe.-A specimen of this species is in the Maximilian collec. tion, at the American Musenm, New York. It appears quite distinct from both $C$. aura and $C$. burrovianus, being, in fact, somewhat intermediate between the two. In size it is nearly, if not quite, equal to $C$. aura, and, like the latter, has the nape entirely bare of feathers, the plumage commeneing abruptly about half way down the neck. The shafts of the primaries are a lighter brown than in $C$. aura, but not so white as in burroviauus. In regard to the plumage, however, there is a much closer resemblance to $C$. burrovianus, the back and wings being wholly black, like the lower parts, withont a trace of the light-brownish borders to the feathers, so conspicuous in aura. The black is also much less glossy than in the latter.

The specimen (male) is, unfortunately, not quite adult, the bill being partly blackish, and the nape covered with a soft dusky down. The mearurements areas follows: Wing, 20.00; tail, 12.00; culmen (chord of the arch), .85; tarsus, 2.50; middle toe, 240 .

The bill and feet appear more slender than those of $C$. aura.

In conversation with Mr. Ridgway at the present date November 12,1881 ) we find him still adhering to the views he so clearly set forth in the Bulletin the year before, still declaring that $C$. burrovianus and O. pornigra are both "good species."

We had the opportunity to examine a mounter specimen of the former in the cabinet of Vultures at the Smithsonian Institution on the same day, and must agree with Mr. Ridgway, that as far as external charav. ters are concerned, as compared with aura, the birds certainly appear distinct. We observed the additional fact that the nostrils in burroxi. anus were far more pervious than those in aura even

A specimen of $C$. pernigra we never have had the good fortune to examine; in fact, both of these Vultures are uncommonly rare in col. lections, and the writer has thus intentionally taken the pains to bring out all of the data that he has at his command bearing upon these two birds, as he must here confess to his reader that it has been found im.

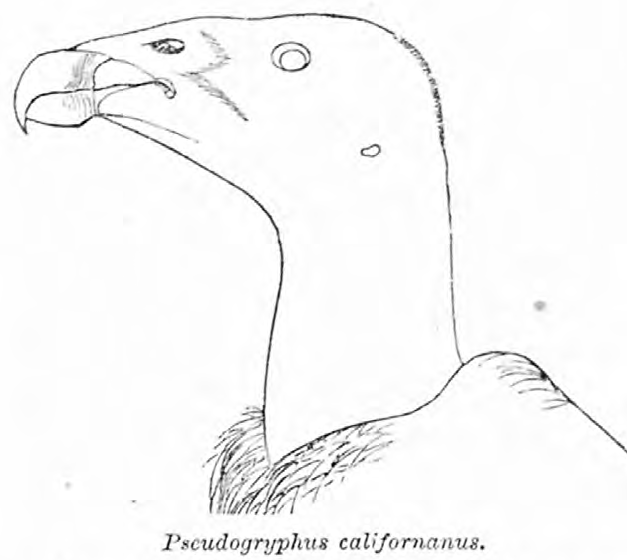
possible to secure a skeleton of either burrovianus or pernigra, so that the characteristies of the genus Cathartes must be drawu from its common representative, aura. We do not know of a skeleton of either burrovianus or pernigra being in any of the osteological cabinets in the United States, and it must be left to some more fortunate ornithotomist to compare the osteological characters of these two birds, with what the author hopes to bring out in regard to the genus in which have been placed, from their northern representative.

Fourth, and lastly, we have the genus Catharista, containing the single species C. atrata, the Carrion Crow, or Black Vulture. This bird is confined more or less to our Southern States, inhabiting particularly the maritime districts, and to various localities in Sonth America, its habits and tastes always being those of a true Vulture, which it is. It will be remembered that for a loug time many authors placed all of our North American Vultures in the one genus Cathartes; the gromp containing, 
according to Coues' Key of North American Birds (1872), Cathartes cali. fornianus, C. aura, and C. atratus. They appear in Mr. Ridgway's Nomenclature of North American Birds (Bull. U. S. Nat. Museum, No. $21,1881)$ as we have given them above $(G$. papa not being included), viz, Pseudogryphus californianus, Cathartes aura, and Catharista atrata.* We shall soon see, when the skeletology of these have been compared, how far the osteological characters will support this generic division.

Before passing, however, to the examination of the skeletons of these birds, the author proposes to present his reader with a short table showing additional points in external structure that have been gleaned from various sources and authorities as well as from his own memoranda. We feel sure that although in a paper proposing, as its title indicates, to be purely osteological in character, such a diversion will hardly be considered amiss.

* Dr. Coues, in his Check List and Ornithological Dictionary of 1882, also adopits this arrangement. 
Many of the characters noted in the above table are from those observed by John Henry Gurney (Descrip. Cat. of Rap. Birds in Norfolk and Norwich Mus., Lond., 1864), others are from Mr. Ridgway's Falconida and Cathartidce (Hist. of N. A. B. by B., Br., and Ridgw.). This latter ornithologist describes still one other Vulture found in South America (Nutt. Ornith. Bull., Apr., 1880), but it seems to us that it is not yet sufficiently proven that this bird is not S. gryphus in immature plumage. Particularly may this be the case, as we do not positively know how long the Condor requires to attain the adult plumage, and, furthermore, we can hardly believe that a bird of the size of the one described

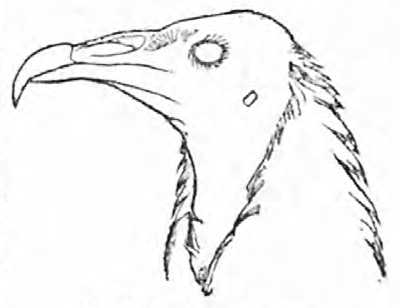

Cathartes burrovianus. could have so long escaped observation. However, in case we may be wrong in the matter, and future developments prove this to be a new Condor, we will here insert Mr. Ridgway's notes upon this Vulture, taken from the bulletin above quoted.

Sarcorhamphus aquatorialis, Sharpe?-In the vivarinm at Central Park, New York City, I aaw in December, 1878, a Condor of uniform brown plumage, which Mr. Conklin, the director of the menagerie, informed me had been received July $23,18 \% 5$, and that it was three months old when captured. It was obtained on Monnt Conquences, Chili, and was presented by Rear-Admiral Collins, U. S. N. The fact that this example had not yet, when

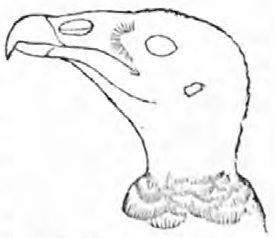

Cathartes aura. nearly four years old, begun to assume the plumage of $S$. gryphus, proves conclnsively either that the latter species retains the livery of the young until four or more years of age, or that there really is, as has been asserted by anthors, a species of Condor among the Andes which has permanently a uniform brown plumage, something like that of Gyps fulvus.* The locality of this specimen would extend considerably the range of $S$. eqquatorialis, Mr. Sharpe giving only Eeuador, and dombtfully Colombia, as the habitat of his species.

I will also remark here, and I have noted it in birds of various species, more especially in a living specimen of Haliaëtus leucocephalus that I had in my possession for a long time, that birds do not seem to acquire their adult plumage nearly so soon when they are kept in a state of confinement as when leading their natural life. Other authors have likewise noted this fact. With so many curious cases on record among other species, it is hard telling exactly what effect such an entire change would have upon S.gryphus, having been taken young, removed to an entirely different climate, kept confined, and no doubt has-

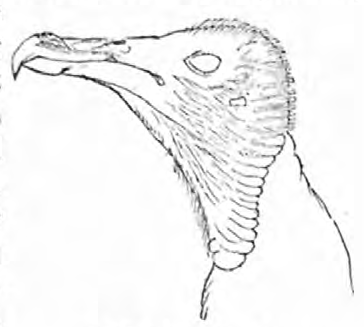

Catharista atrata. ing a radical change made in its diet.

Before closing what we have to say upon the external characters of

* Since the above was written, Mr. Conklin has favored me with the following particulars, under date of February 10,1880, in response to my inquiry as to the present condition of this specimen: "The plumage remains still unchanged, except that the ruff about the neck is somewhat fuller, and has a little sprinkle of white through the down . . It has not increased much since then (July 23, 1875, the time when received at the menagerie), either in size or weight. The bill is black at the base, the apical half ivory-white; head bare, no wattles; iris dark brown." Mr. Lawrence has also favored me with the following transcript from his note-book, April 1, 1ez6: "Condor, said to be nine months old. Bill black; cere and naked sides of head grayish-black; head sparsely covered with short downy feathers of a smoky black; plumage, in general, of a dark snuff-brown." Angust, 1877: "No change except the development of the ruff, which is colored like the back." "The ruff is now (February 23, 1880) more full, but no appearance of becoming white ; underneath the feathers are whitish." 
these birds, the writer inserts the following valuable quotations from Nitzsch, an author who paid no little attention to the external charac. teristics of birds, more particularly the feather tracts.

The chief pterylographic character of these, as of the Old World Vultures, is to be found in the formation of the pectoral portion of the inferior tract. This is not separated by a space from the jugular portion, but the two sections of the tract are perfectly continuous. Just as the inferior tract, gradually enlarging, has arrived over the pectoral muscles, it receives the axillary tract, and thus acquires a very remark. able breadth. It then divides into two branches, which, however, are generally weak, and are rendered indistinct by the circumstance that the feathers of the tract are more scattered. The two branches are at first of equal width, and run parallel; towards the extremity of the great pectoral muscles they curve in towards each other; and whilst the inner one is continued unchanged as the ventral portion, the onter one is narrowed, and returns by a narrow process, rumning along the margin of the musculus pectoralis major to the ventral part again.

In this way the two branches inclose a pretty large insular space, the whole tract thus presenting very close resemblance to that of Centropus (refers to plate). This, however, does not conclude the list of the pterylographic peculiarities of the American Vultures; but we must add: 1. The amalgamation of the jugular part of the inferior tract with the cervical portion of the spinal tract, which would convert the plumage of the lower part of the neck into a continuous one, if the space did not entirely or partially penetrate it. 2. The remarkable narrowing of the dorsal portion of the spinal tract, which frequently consists only of two rows of feathers, gradually diverging anteriorly, and connected with the branches of the fork of the cervical part. 3. The presence of a large lumbar tract. 4. The constant and invariable presence of twelve feathers of the tail. 5. The absence of a circlet of feathers at the apex of the oil-gland. The broad, obtuse form of this organ seems to stand in relation to this. At its extremity there are two distinct orifices. 6. The covering of the feet may also be cited as a characteristic element; it consists of small scales upon the tarsus, but of scutes upon the whole of the toes; moreover, besides the outer and middle toes, the middle and inner toes are united by a membrane.

The elongated nostrils, parallel to the longitndinal axis of the beak, certainly remind one of Neophron; but the absence of a bony septum between them is one of the most characteristic external distinctions of the American Vultures; the tongue, moreover, has a series of teeth on its margin, at least in $C$. papa and $C$. aura.

I have examined $C$. gryphus, papa, aura, and uruber (fotens Illig.), and fonnd in all some little differences in the form of the tract, but no characters from which I conld justify their division into the genera Sarcorrhamphus and Cathartes.-(Pteryl. Trans., from German Ed., by P. L. Sclater, Lond., 1867, p. 50.)

From this point the author goes on to give, under "Cathartes," descriptions of the feather tracts of the birds that he mentions as having examined in the above list, in detail.

The writer has to present to his reader the following material for examination, of the skeletons of the Cathartide, upon which to base the results of his monograph. At the outstart we must deplore the fact that we do not possess the skeletous of the young of any of the family under consideration. To be sure, specimens of the young of Psendo. griphus have been obtained on sereral occasions, but at the present writing there are none in the Smithsonian Institution, and should such be obtained at a later date they can be discussed in some future paper. Of Sarcorhamphus gryphus we have in our study one very good skeleton, the property of the Smithsonian Institution, and kindly lent us for the purpose in hand; it however lacks the osseous part of the claw of the tirst digit of the hand. This is also the case in our skeleton of Gyparchus papa, an unusually fine skeleton belonging to the Army Medical Museum, prepared by Prof. H. A. Ward, of Rochester, and obtained in Ecuador, probably by some of his collectors. Of Pseudogryphus californiamus, also from the osteological cabinets of the Smithsonian Institution, we have two imperfect skeletons; they, however, show the cranium and the majority of the principal bones. We may consider ourselves fortunate, however, in having even this much, for this Vulture is becoming rarer and rarer each year that slips by, a fact that is to be accounted for 
through many causes, chief among which is its destruction by poisoned flesh and carcasses thrown out by the cattle-owners of the countries it inhabits, to destroy the wolves and bears. Then, too, it no doubt, being a bird not difficult to approach, forms a good target for many a hunter who chances to meet it with rifle in hand, and happens to be ambitious to add to his record the fact of having slain the largest bird in North America. For Cathartes aura we have numerous skeletons and parts of skeletons obtained from various sources, some from the Smithsonian collection, others from the Army Medical Museum, and one or two from my own cabinet, obtained by myself while in the territorial districts of the interior. We have already stated that we lack any osseous material from the two remaining species of this genus, C. burrovianus and $C$. pernigra, and are of the opinion that the skeletons of these birds are not to be found in any of the collections in this country.

Lastly, Catharista atrata is represented by several good skeletons and many crania and separate bones, placed at our disposal by the institutions above mentioned, being amply sufficient for the purposes of description and comparison with the other members of the family. In addition, we have before us a good skeleton of Gypogeranus serpentarius, one very complete mounted skeleton of Neophron percnopterus, from Abyssinia, from the collection of the Army Medical Museum, and finally a mass of odds and ends of skeletons of Hawks, Eagles, and Falcons, that bear more or less upon the discussion of such a subject as we have undertaken, the majority of which latter material we are deeply indebted to the kindness of Professor Baird, and the exertions of Mr. Ridgway, in the way of selection.

In the matter of plates, we trust we have laid a sufficient number before our reader to thoroughly illustrate all we have to say in the text, and the author assures you that he has not spared his pains in choosing subjects such as he deemed would best fulfill the end in view. Perhaps Pseudogryphus in this choice has taken the lion's share, but we must remember that in extenuation of this claim our Californian Vulture will soon be reckoned among the birds that were, and life-size portraits of the bones of his skeleton will be ranked among those of the famed Dodo, and the great Auk. His cranium and the outline sketch of the metacarpus are from my own pencil, but the remainder of the bones of his skeleton are from photographs taken at the Army Medical Museum, under my own supervision, and are all life-size. The skull of $S$. gryphus was kindly drawn for me by Dr. J. C. MeConnell, of the Army Medical Museum, to whom science is so much indebted for illustrations in so many of its branches. In another plate we present an entire skeleton of $G$. papa from a photograph and reduced to one-third of its size; this figure shows well the tout ensemble of the bones of the skeleton in one of our typical Vultures, as well as the relations of size and position of these bones as compared with each other. It is the Equador specimen referred to above. The two plates, figuring three views of the cranium of $C$. aura, with two views of its sternum and its furculum and remainder of scapular arch, are India ink productions of the writer's, being drawn from a fine specimen of this bird, secured by him in the Laramie range of hills in Wyoming. The remainder of the figures are life-size views of the subjects they represent, from photographs taken at the Army Medical Museum, and are very accurate conceptions of the bones they depict. Their detailed descriptions must, howerer, be deferred until we come to describe the parts of the various skeletons from which they were taken.

Upon viewing the skeleton of one of these birds for the first time, 
such as we offer in Plate XV, fig. 105, G. papa, we are struck with the vul. turine appearance of the skull, with its more or less open, capacious external nasal orifices, its hooked beak, its rather large orbital cavities and the good size of the bones at the bases of these orbits. The seg. ments of the vertebral column, or the vertebræ, are all free, from occiput to sacrum, with their processes and arches well developed. We observe, too, the great length and size of the bones of the extremities; particularly those of the brachium and anti-brachium of the upper, and the robust femora of the latter. To support these great limbs, we find these birds possess correspondingly well developed arches of the axial skeleton. Nor are the bones of the feet backward in indicating to us the arocation of their owners, attached as they are, too, to powerful leg bones. In short, the Cathartide must be regarded as possessing skeletons composed of bones above the average, for the size of the bird, in point of volume and length. These characteristics, howerer, do not bring with them a correspondingly heary skeleton, but quite the contrary, for if we pick up the bony framework of any of our Vultures we cannot help but being struck by its unusual lightness; this is due to almost a universal pneumaticity of the bones composing it, and so marked a feature is this of the birds we are describing that it will not be considered out of place to give a general description of this condition here, so as to aroid, as much as possible, what would have to be a constant reference to the many pneumatic foramina that occur in nearly all of the bones that we shall come to describe further on.

Let us choose a specimen of Catharista atrata that we have before us for this purpose, simply reminding the reader that at least some of these openings will necessarily have to be referred to again, while with others their description will cease here. In the skull of this Vulture, as in all others of the family, the only elements that seem to possess this property are the quadrate bones (the tympanies of my former papers), the posterior thirds of the limbs of the lower mandible, and the lacrymals. In the quadrate bones we usually find a single, rather large, sub-elliptical opening at the bases of the mastoid ends or pro. cesses with a large one at their summit in Pscudogryphus-while several such foramina occur on the superior aspects of the articular extremities of the lower jaw; two of these latter seem to be constant and are found towards the points of their in-pointing prolongations. On the inner aspect of the lacrymals we find either one such pneumatic orifice or a group of several of them, and the air seems to attain complete access to these bones, and perhaps enters to a limited extent the wings of the ethmoid that they anchylose with on either side. It is very apparent that the walls of the brain-case or the bones that go to form the beak could not afford to make any such sacrifice of stability for the little additional lightness that would be gained thereby-the functions of these parts would evidently be weakened by it, affording as it would insufficient protection for the brain, and rendering the beak constantly liable to fracture.

The author is free to confess that at the present writing he knows not of a single instance among the class where to look for a bird possessing an atlas endowed with this property, and we find here in the Cathartidee again, this bone apparently solid, or at least absolutely nonpneumatic, while the following vertebra, the axis, is quite so. Constituting, as its occurrence does in this bone, rather an uncommon eondition for it, knowing as we do that in many birds where every vertebra will be found to be pneumatic, the atlantal and axial segments remain ex. empt. 
In the cervial portion of the column one or more of these little apertures are found to pierce the centrum of each vertebra, within the vertebral canal or just outside of it, anteriorly. This is not a circumstance, however, we will find when we come to examine the dorsal segments, for here about the bases of the diapophyses or transverse processes great circular openings occur that allow one a view directly through the vertebra, and the center of these segments are in some cases riddled with similar though smaller foramina.' Such openings, likewise, are found to exist at the inferior aspects at the extremities of the diapophyses, and sometimes a few minute ones in the metapophysial off-shoots beneath.

The position of these foramina are but little changed, much less their number or size materially decreased or diminished in those vertebræ constituting the sacrum. After we pass the first three or four segments of this division in $C$. aura, however, we seem to lose sight of them in the diapophyses, which is not the case among the species of the other genera, though they are very sparsely distributed in $C$, atrata. Arriv. ing at the coccygeal vertebræ, we find that pnemmatic foramina have disappeared entirely, and this holds good for all the Vultures and applies equally well to the ultimate segment of this division, the pygostyle. We present two or three figures in which the extensive preumatic openings that occur on the outer aspects of the expanded heads of the elavicles may be seen. In C. atrata, as in the others, these consist essentially, one each side, of a large cloaca that extends immediately into the bone, rendering it one of the lightest for its size of any of the skeleton. About the entrance of this general opening we observe many smaller and circular or variously shaped ones irregularly arranged in groups, with sometimes only a single one beyond, isolated from the rest (Pseudogryphus), or another separate little collection in this situation (C. aura). In the scapula the openings occur near the glenoid cavity, and again a grouplet beneath the ridge found at the crest of the acromial process, on its outer aspect, but the number or size of these foramina in this bone is never very great.

In any member of the family, a careful search about the head of either coracoid is usually rewarded by the discovery of a few scattered openings of this sort, but these bones seem to depend almost entirely for the admission of air into their shafts and extremities upon a cluster of these foramina that are met in the recess of the dilated ends below, on their posterior aspects.

Passing next to the sternum, we find in all the Vultures, less marked in $C$. atrata than any, a rounded and prominent ridge, extending backwards from the anterior margin immediately posterior to the manubrial eminence, to the middle line of the concave and superior aspect of the body below. It is on either side of this ridge that we find pneumatic perforations that lead into the heavier portions of the bone, more particularly the promintory of the manubrium, and downwards into the thickened carinal ridge. Again, in the recesses above the subcostal ridges we discover irregular groups of these pneumatic foramina, that pass into the lateral portions of this bone; while lastly, the apertures through which additional rerification of the sternum takes place occur in the pits along the upper side of the costal borders, that we find among the facets of articulation for the sternal ribs. In these localities they have a tendency to gather around the bases of the eminences that support these facets, rather than be generally distributed throughout the depressions in question. (Plate XVII. fig. 107, Pseudogryphus.)

In the free ribs, both those of the cervical division of the column, as well as the dorsal ones, we find these pneumatic foramina entering the 
bone as one large opening (C. aura) or by a group of several smaller ones (C. atrata) at the outer extremities of their necks, just below the tubercula, anteriorly. We have just said that they occur in the free ribs of the cervical portion of the spine; this is indeed the case, but of very rare occurrence, and we may almost add in perfect safety the ribs of the sacral vertebræ to the list of non-pneumatic bones of the Cathartida.

The sternal ribs, at their inferior extremities, show like perforations, more commonly on their anterior aspects, though by no means do we always find them wanting on the posterior faces; more likely would we be disappointed in our search for them in the last sternal ribs; and we doubt of their ever occurring in the set that articulate with the first pair of sacral ribs.

The osseous portion of the basin, completed by the parial pelvic bones, is not usually permeated by air as thoroughly as it might be; indeed, in all those parts of the pelvis where the component bones become platelike in character or flatten out, this property is denied them, and it is only where ridges become thickened from any cause whatever or other prominences take place that we find pneumatic foramina present. Notably these localities are three in number: Externally, in the recess on either side, just below the angle formed by the deflection of the gluteal ridge, and above the antetrochanter. Internally, in two places about the cotyloid ring at the extremities of its horizontal diameter slightly produced, at a greater or less distance from its periphery, and again at the base of the posterior concavity formed by the ilium and ischium, immediately within the rounded margin of the ischiatic foramen.

Uf the Vultures, $O$.atrata seems to possess the most pneumatic sacrum, while that of $C$. aura is the least so. In Pseudogryphus the foramina are particularly well supplied, forming good-sized groups at all the localities just specified. They are absent in the last situation mentioned, in C. aura, Sarcorthamphus, and $C$. atrata, but in the last species quite a cluster oceurs in the ilium on its internal surface, well within the upper margin of the ischiatic foramen.

The pectoral limb of the Cathartida is highly pneumatic from humerus to the last joint in manus, with the sole exception of the osseous core of the claw on the first digit.

In the humerus the large pneumatic fossa, with the collection of smaller openings at its base on the anconal aspect of the head, is never absent; in all but aura a few additional ones are found at this extremity of the bone, on the opposite side, just beyond the articular surface. At the distal end of humerus other" openings occur of no mean size, especially in G. papa and C. atrata. These are generally situated on the anconal aspect of the bone, in a shallow but circumscribed depression that is found there, beyond the tubercles for articulation; sometimes a large one is found quite near the ulnar tubercle.

The cubit and radius both have these little perforations well supplied them, especially about their proximal extremities, anconad; the number not being nearly so great at the other end of the bones. The two free earpal bones possess at least two or three of these foramina apiece, and we note on the anterior face of scapho-lunar in C. atrata two very sizable ones, that seem quite constant for this species.

In metacarpus, the bone is pierced by a single foramen just beyond os magnum, at the point where index and medius metacarpals joined in the growing bird. Other perforations are found about both extremities of this segment in the angles and recesses formed by the conformation given it by the amalgamation of second and third metacarpals. 
The palmar aspect of all the long digits show one or more such aerial penetrations, while the blade-like expansion of the first phalanx of second metacarpal seems to be absolutely riddled by these foramina, lending to it a decidedly honeycomb appearance.

The femur is the only bone of the pelvic limb that enjoys the condition we are discussing. In it air gains aceess to its interior through a single opening (C. aura), or, as in most cases, several of them, on the anterior aspect of the bone, below the great trochanter, close to the prolongation of its curling crest. In Pseudogryphus we discover a few additional ones on the upper face of the trochanter major, beyond the usual group.

We may say, then, that as a rule for the Cathartide, the only bones in their skeletons that do not receive air into their interiors through pneumatic foramina are certain portions of the cranium, lower maxilla and pelvis, the hyoid arch, the atlas, the coccygeal vertebræ, including the pygostyle, the bones of the pelvic limb below the femur, and all sesamoids and ossifications pertaining to the sense organs.

Passing to the Falconides and the Old World Vultures, we observe in the latter that although they have the greater share of their skeletons pneumatic, it is not nearly so perfect a condition as it has just been shown to be in our Cathartida. In Neophron percnopterus the axis is non-pneumatic, as are all the segments of the pectoral limb save the humerus. To these must be added the bones that we have just passed over and enumerated in the family in hand, as being so.

We find the furcnlum in the Vulturince a bone not nearly so well ærated as we have described it for the New World Vultures, it is still less so in Gypogeranus, and the same remarks will apply here in gen. eral for the remainder of the skeleton of this bird that we have this moment made in regard to the Vulturinc. In general they are equally applicable to the remainder of the family Falconida. We believe that we will not go far astray in laying it down as a rule for the entire order Raptores, that this attribute of the skeleton seems to have arrived at its acme in Catharista atrata, exists to a greater or less degree in all of the American Vultures, then becomes less marked as we pass to the vulturine Raptores of the Old World, among which we believe that the clavicles will be found to be far less pneumatic throughout, though the femora still remain so, down among the diurnal and nocturnal Raptores of both continents, until we arrive at such forms as Speotyto, where we know the entire pelvic limb to be exempt from this condition, and that air is excluded from more than half the bones of the skeleton of this ground-abiding $\mathrm{Owl}$.

Having dwelt now, and we trust with sufficient thcroughness, upon the present classification of the Cathartida, their leading and more important external similarities and differences, and then touched upon some of the more general characteristics of their skeletons, we will proceed to investigate these latter more in detail, beginning, as we have done in former memoirs, with the skulls of the species to be treated. It is the object of the author during this investigation to keep these two things prominently before his reader, the first being the prime object of the work we have to do, viz, an accurate description of the skeleton of each species of the family as far as our material will allow us to give it; and, secondly, from time to time, to compare the principal bones of these birds with those of members of their own family, and then with those of other families of near kin; our second aim being, so far as osteology will justify it, to test the all-important question as to whether the Cathartida have been wisely arranged and distributed in the genera 
created for them, and, if such prove to be the case, to present the re. sults of our labor, and so apply it as to settle these birds in the places they now occupy upon a still firmer basis, to the end that we may have it said that classification has been assisted and furthered.

of the skull.-It will be remembered that when we treated of the osteology of the North American Tetraonidae (Bull. U. S. Geol. and Geogr. Surv. Terr. Vol. VI, No. 2, pp. 311, and Plate V, fig. 51) we made a careful dissection of the skull in the young bird before the seg. mental anchylosis commenced, and figured and named all the various bones that enter into the cranium of the majority of the class. At this date, however, the author does not advise the student to implicitly follow the nomenclature there given, nor accept all of the deductions set forth. We have already informed our reader of the fact that it will be impos. sible to carry this interesting part of the subject out in the case of the Cathartida as we do not possess the necessary material. Still, the figure above referred to, and the description given for the young of Centro. cercus, will no doubt assist us in approximating very closely the boundaries and limits of many of the cranial bones, not that there is the slightest relationship among the species of the two families, $i$. e., the Tetraonida and the Cathartida, but that certain rules hold good in each. The outward appearances, though, in one case is quite striking, and led Dr. Coues to say in his Key:

"In a certain sense, they represent the gallinaceous type of structure; our species of Cathartes, for instance, bear a curious superficial resemblance to a turkey."-(Key to N. A. B., pp. 221, ed. 1872.)

It is hardly necessary to say here that osteologically the species are quite distinct, as Meleagris has its skeleton nnmistakably stamped with all the characteristics of the Gallina, as Cathartes aura has all those of the Vultures, the two being very different.

In the crania of the Cathartidae we find that, after the different species have arrived at maturity, a union has taken place among the various segments of the so-called vertebral arches that is quite above the average result or condition in birds generally, for upon examination we find that we have only as free bones the ossa quadrata, the pterygoids, bones of the sense capsules (except the ethmo-turbinals), the hyoidal segments of the tongue, and the inferior maxilla, all the others having firmly united together, very few sutural traces of original separation being left.

Plates XXII and XXIV, figures 119 and 127, respectively, give good representations of the superior aspects of the skulls of $C$. aura and $C$. atrata. Many of the peculiarities we discern in these figures are common also to the other members of the family. We are struck at once with the great breadth of the pseudo-articulation that goes generally by the name of the "fronto-maxilliary." This is due principally to the fact that the nasal bones are unusually broad, in order to encircle the great sub-elliptical nostrils of these birds. This articulation, notwithstanding its width, is very mobile, and offers several departures from the usual mechanism of the system to which it belongs to interest $u$ s. We find that from the anterior border of the united lacrymal, on either side, a niche exists that gives rise to a process, below which process, in turn, has its superior border grooved lengthwise and converted into au articular surface for a quadrate apophysis thrown out by the outer and posterior angle of either nasal. In a position of rest a foramen re. mains at the base of this niche in the lacrymal formed by the two bones in question, allowing in action or movement the process of the nasal to glide into it. (Pl. XXII, fig.118.) This is the state of things in C. aura.

In Pseudogryphus the nasal process is much longer, curved upwards, 
and glides over a greater surface on the lacrymal. The quadrate form of the nasal process becomes peg-like in atrata, really articulating in a socket on the interior aspect of the lacrymal. In the remaining species we find this joint more or less persistent, perhaps less so in the South American Condor. This mobility produces rather a confusing condition at the pterygo-basi-sphenoidal articulation, for we have observed in all of the dry skulls of the Cathartide that the pterapophysial processes of the basi-sphenoid never meet the facets on the ptery goids that are evidently intended for their articulation. This seems to be due to a warping upwards of the superior mandible during the process of drying, drawing both the palatines and with them the pterygoids away from these pterapophyses. If we take the pains, however, to dissect the head of a recently-killed Vulture, as the author has done, we will at once appreciate the normal state of affairs, and find that by the slightest pressure downwards of the upper bill the facets upon the pterygoids glide over the pterapophyses. We will find many of the illustrations representing them with the interspace between. Our own plates do so, and Professor Huxley has done so before us, as we find about 2 millimeters of space between the pterygoids and the processes from the sphenoid in his view of the base of the cranium in C.aura, although he remarks in the text, "The basipterygoid processes are large and articulate with the pterygoids." (Class. of B., Proc. Zoöl. Soc. Lond., 1867, pp. 440, fig. 22.) The reader will remember that in our figure of the base of the skull of Speotyto they remain in situ even in the dry condition.

To return to the fronto-maxillary joint we find in all of our Vultures the sutural traces of about the upper third of the intermaxillary, persisting, with a line between them, indicating to us that the process of the bone is bifid, as we found it in the Tetraonida. There are no good evidences that the ethmoid has not been completely hid beneath the frontals and the other segments that surround the point where it is sometimes superficially observed in other birds. In this position we find a more or less marked depression occurring in all of the Cathartida, caused by prominence of the froutals behind and alike elevation of the culmen in front, and the lacrymals and nasals on either side. This depression is shallow and broad in Pseudogryphus and Cathartes; deeper and more decided in Sarcorhamphus and Catharista, where a slight median elevation in the latter, better shown in G. papa than any, gives it the appearance of being double. From this point the upper and convex surface of the nasals, and the wide intermaxillary, cause the osseous culmen to start broad and spreading - to rapidly contract again between the capacious nostrils, then suddenly fall roundly convex to the tip of the beak, after first passing over a rise that occurs with greater or less abruptness just in front of the anterior margins of the peripheries of the nasal apertures. This is best seen in Sarcorhamphus, and less deeided in Pseudogryphus than any of the others. It is really the upper culmenal depression that persists down the sides of the bill to cause the "swell" at its extremity in the Condor and Carrion Crow. (Fig. 118, Pl. XX.) The osseous tomia of the superior maxillary are sharp from a point taken below the center of the nostril, until they terminate at the point of the beak. This much of this margin at first presents a long convexity, then a corresponding concavity, to drop suddenly to the tip of the bill where the two meet anteriorly. A row of nutrient foramina are found at a greater or less distance above this margin in all the Cathartida, with numerous other smaller ones scattered about above them, without any apparent attempt at order or regularity. Venations caused by the vessels running into them are permanently impressed 
upon the bone in many instances; they are less perceptible in S. gryphus than in any other member of the family. The remainder and undescribed half of each tomium running backwards is flat or slightly rounded, and includes on either side about the anterior fourth ( $C$. aura) to the seventh of the maxillary (Pseudogryphus). Owing to the deep sides, the inferior aspect of the upper mandible is very much scooped out, and strongly reminds one of a well-shaped canoe; two sharp little ridges, one on either side, start from the tip of the beak here, and run backward as far as the palatine articulation, being nearly parallel with the tomial edges at the middle of their course. The maxillo-palatine fissure is wide and sub-elliptical in outline, terminating posteriorly by an opening in its are that leads into the true inter-palatine cleft. (Fig. $120, \mathrm{Pl}$. XX.)

In all of the Cathartida we find just within the lower vorder of each nostril a diminutive bony shelf, formed partly by the palatine, partly by the lateral processes of the intermaxillary; following this along

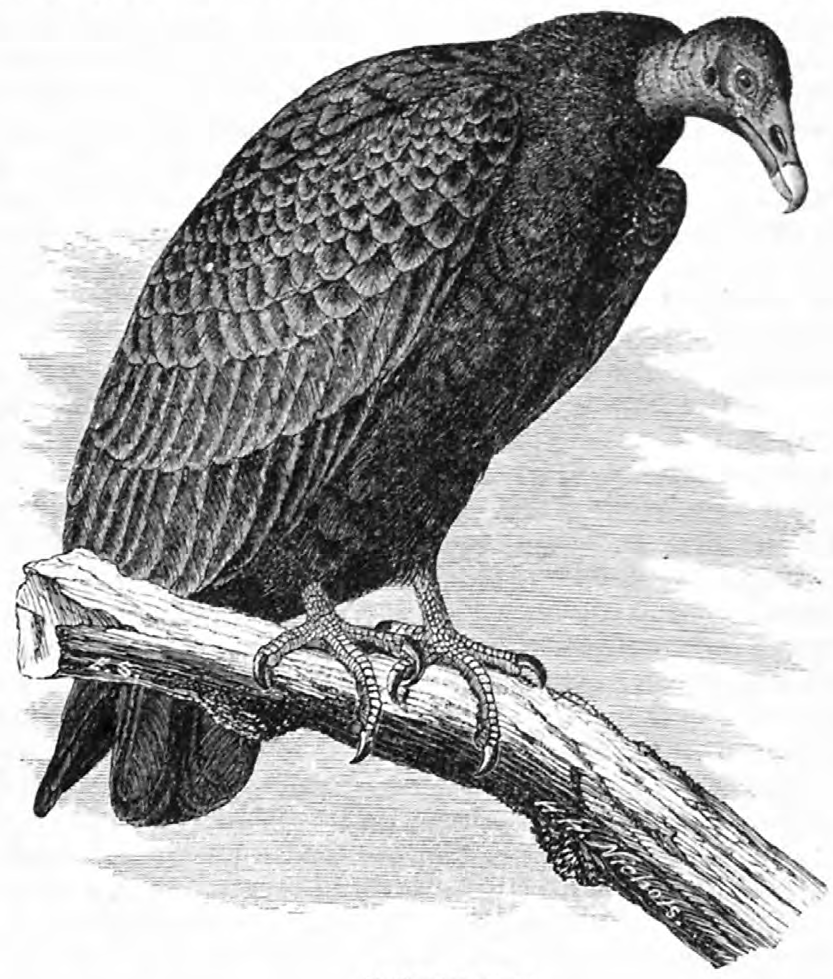

Cathartes aura.

towards the tip of the beak we find it to terminate in a conical socket on either side. In $C$. atrata they can be seen just within the anterior margin of each nostril, while in Pseudogryphus they are a full centimetre beyond.

The bony nostrils in these birds are placed upon the sides of the superior mandible and very nearly in their same planes. In form they assume more or less of an oval outline, being long and narrow in atrata, high and broad in the Californian Condor and the Turkey Buzzard.

In Pseudogryphus and Sarcorhamphus, less so in Cathartes, their inferior and posterior margins blend with the transverse plate of the ethmo-tur- 
binal coming from within; this can hardly be said of $C$. atrata, as the latter bone in this Vulture is so far removed backwards into the rhinal cavity. The forms of the nostrils among the Cathartida can be better studied from the various figures in the plates than from any detailed description we might give, however elaborate it might be. Thus far we have spoken of the irregular wing-like bone found in the rhinal chamber of any of the Cathartide as the ethmo-turbinal, and it certainly fulfills the functions of that bone as found in others of the class, where it occurs. Not having the young of any of the Vultures at hand, howerer, we cannot say that its representative here ossifies as a separate segment, though to all appearances it does.

Huxley seems to refer to it when he says: "In the genera Cathartes and Sarcorhamphus the cleft between the thin and scroll-like maxillopalatines is very deep and wide, and the ossification of the septum is small in extent, and only forms a sort of bridge over the deep and wide valley between the maxillo palatines."-(Classification of Birds, Proc. Zoöl. Soc. Lond., 1867, pp. 441.)

It consists essentially of a horizontal plate of bone extending across the nasal cavity to the rear of the nostrils, and about half way between the roof of the rhinal chamber and the palatine plates beneath. Mesially it throws out a sharp process in front $(C$. aura $)$, which curls up in Pseudogryphus (Plate XVI, fig. 106), and another plate, that reaches to the roof of the cavity, where it extends backwards to meet the ethmoid in $C$. aura and $C$. atrata, and in all of the species spreads ont more or less laterally, thus forming a strong abutment above, while it divides the space into two, that by the curling edges of the plates appear like true nostrils within.

The horizontal plate blends with the inferior borders of the external nasal orifices, and at their posterior peripheries throws up another brace, forming a foramen at these points in Pseudogryphus (fig. 106), and in the other species, but not so well marked (figs. 116, 118). On either side below the horizontal plate, lateral wings are developed, that curl inwards and backwards, reaching forward to be inserted with the palatines, showing an elliptical foramen in their sides just before arriving at the articulation. No doubt but this irregular ossification that we have been describing affords additional surface, wben it is covered with the nasal mucus membrane, for the ramification of the nasal nerves. We have in our possession a specimen of a skull from Catharista atrata that shows extenstve and distinctive necrosis of this region, the infraorbital bars being destroyed for their anterior thirds, with a terrible loss of structure to the ethmoid and lacrymals and the palatine plates beneath. Can we account for this state of affairs by saying that it is due to the entrance of putrid matters while feeding upon carrion through the apertures in these ethmo-turbinals? We believe that the disease in this Vulture before us must have eventually resulted in its death. It may be the cause of death among many of its kind, and, if so, would be another cause for the decrease in birds, and constitute an item to be taken in connection with Henshaw's interesting treatment of this subject. (Nutt. ()rnith. Bull., Oct. 1881, pp. 189.) We would add that on the under side of the horizontal plate of the ethmo-turbinal we always find little pits existing, the only exception to the rule being, in the material we havethe cranium of Pseudogryphus. They are grouped without any particular regard to any special arrangement, varying in specimens of the same species.

The elevation existing immediately to the rear of the fronto-maxillary articulation has already been alluded to as a feature of the superior 
aspect in the skulls of our Cathartida from this locality as far back as the well-defined line limiting muscular attachment on the posterior aspect of the cranium and between the upper boundaries of the orbits. The surface of the skull presents a very evenly distributed convexity, it being most decided as it slopes away over the auricular entrances on either side. The median groove, present in so many of the clas, is absent. The surface exhibits many osseous venatious, the majority of which run to the foramina that exist in an irregular double row, removed by a few millimeters from the orbital peripheries. These foramina lay along in a shallow groove in these localities. From them the bony and sharp-edged brows overhang the orbital cavities below to a greater or less degree; we say for a greater or less degree because this is one of the characteristies of the skulls of these birds that seem to vary in every individual and in every species. As a prominent instance, look at the two crania of Pseudogryphus that we have before us; in one the superior orbital peripheries are jagged and thin, coming very close to the row of foramina described above, being only a little over 2 centimeters apart, measuring between points in the two lines that are the nearest together, while in the other they are rounded and arched over the orbital cavities, thick and heavy, the edges being nearly 5 centimeters apart, lending to the general aspect of the skull a far more raptorial look, as the osseous brows are thus made to be permanently arched and overhanging. This variance in the integrity or completeness of the vaults of the orbit may be due to the age of the specimenthe older the individual the more complete the roof of his orbit may be; but we have nothing to offer to sustain any such theory.

Ridgway in his "Outlines of a Natural Arrangement of the Falcon$i d a "$ [read before the Philosophical Society of Washington, April, 1875] gives us some very interesting and valuable studies upon the lacrymal and its superciliary process as found among these genera, illustrating his remarks with very good outline drawings of the species treated. We find that the lacrymal is subject to a great many changes as to its form, its method of articulation, the bones it comes in contact with, and so on. As these changes are quite constant for the species where they occur, they become valuable as points of distinctive differences tor diagnostic purposes. Among the majority of the Hawks and Eagles the superciliary process stands out from the head, at a varying angle for different species, and may have articulating with its extremity an "accessory piece" (Harpagus bidentatus).

In Micrastur brachypterus so long and prominent has this superciliary process become, that, aided by the intervening membrane, it makes up the major part of the orbital vault.

In Polyborus auduboni we find the body of the bone, freely articulating with the entire border of the wing of the ethmoid and threefourths of the inner margin of the supercilary process, freely, though very intimately, meeting the frontal and nasal; the membranous interspace being limited.

The next interesting step we observe in the cranium of Gypogeranus serpentarius, where the superciliary process forms much the larger share of the entire bone, while the body becomes a mere inbent osseous bar that touches the ethmoidal wing at the angle. Here the inner border of the superciliary process meets the nasal and frontal segments for its whole length; the union being very close, but the suture plainly visible.

In Neophron percnopterus the arrangement leans more towards the Falconide than towards the Cathartidce, though there is a positive step 
vulture-wards. In this bird the supereiliary process has shrunk up in size, articulates principally with the margin of the nasal, while the body of the bone below engages the entire border of the ethmoid, all the natural traces being evident. The roof of the orbit is formed by the frontal. A very decided change takes place among the Cathartida; here complete anchylosis with the surrounding bones has taken place, obliterating all traces of original individuality on the part of the lacry mal. By its aid the great width is attained across the fronto-maxillary articulation. (Pl. XXIV, fig. 127.) Its body below knits with the ethmoidal wing, and is produced downwards, backwards, and outwards so as to almost touch the infraorbital bar, as a club-like process in Sarcorhamphus gryphus and $P$. californianus. Its outer side shows the groove for the lacrymal duct. By the assistance of the lateral extensions of the ethmoid, these bones make a very substantial partition between the orbital cavities and the rhinal chamber; above and between the two there is an opening for the passage of the nasal nerve and vessels.

It is difficult to say, from an examination of the skulls of the adult birds, whether the vomer exists in them as a separate ossification or not; we are of the opinion, however, that it does not; at any rate, there is no such bone present as we find among many of the Ducks and Geese (it must be remembered, however, in this connection that this delicate little wone is often lost in the maceration and preparation of avian crania).

The ethmoid (the mesethmoid of Parker) meets the vault of the rhinal space above in a spreading abutment; from this point it takes a direction

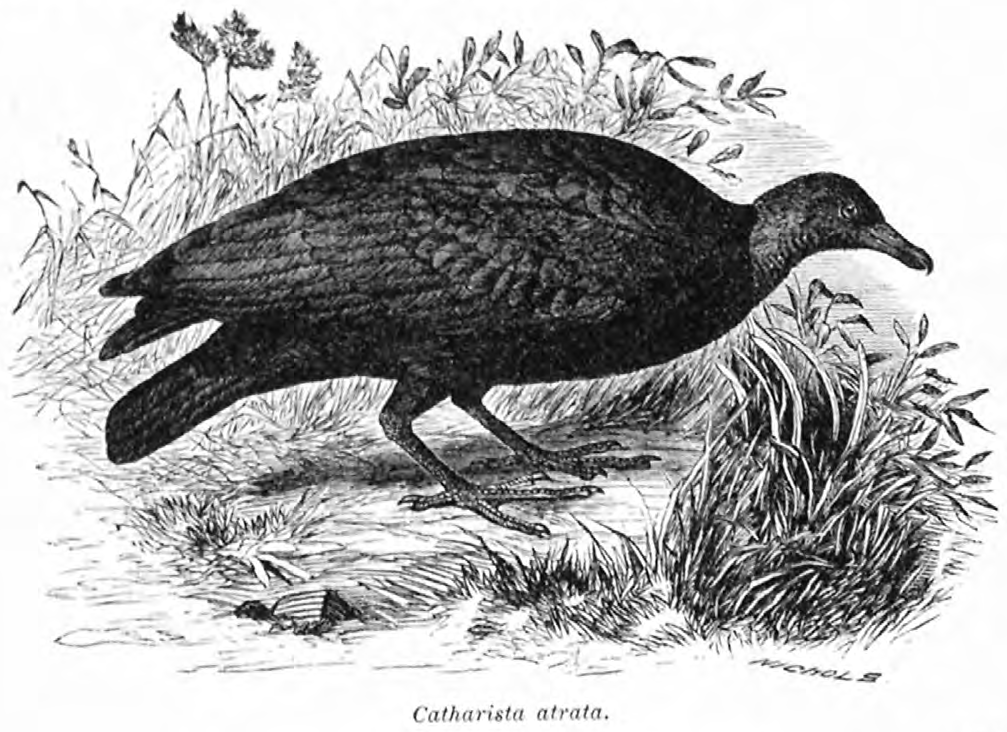

downwards and backwards in the mesial plane, to become consolidated with the extremity of the basi-presphenoid, below. Behind, by extension of its median osseous plate, it assists to complete the orbital septum, while laterally it develops on either side alar productions that amalgamate with the lacrymals, as pointed out above. On its anterior face we have presented us a sharpened edge, extending up and down the bone in the mesial plane. The lateral wings in C.aura are removed far to the back, and they have from their lower boundaries horizontal plates developed that reach forward beyond the basi-presphenoidal tip, to the 
anterior base of the bone. This is a constant character and is only to be observed in Cathartes aura. The palatines are broad plates of bone, witb a wide fissure separating them; anteriorly their extremities are wedged into the anchylosed articulation in common with the lateral processes of the premaxillary and the maxillaries. The posterior and upper thirds of their inner margins are fashioned to glide over the interior and rounded surface of the sphenoidal rostrum, the articulation being a re. markably free one. Their posterior ends turn outwards and accommodate themselves to the entire crown of the heads of the pterygoids (Plate XXII, fig. 120), constituting the usual pterygo-palatine articulation. Descending lamina are developed from the inner margins of these bones, along the posterior half of the palatine elefts in all of the species. There is a disposition on the part of these plates to curve downwards, so that their outer margins are in a lower plane than their inner ones, their surfaces being smooth, and as a general thing their salient angles rounded. G. papa, in comparison with its size, seems to possess the largest and widest palatine boues of any of the Cathartida, while $C$. atrata has the narrowest.

The sutural traces of the three primary segments of the infraorbital bar have all disappeared, and we have remaining only the strong style that bounds on either side the orbital cavity below. On the inner side of its posterior end we observe a conical tooth-like apophysis placed at right angles with the continuity of the bone that fits deeply into a socket intended for it on the lateral aspect of the quadrate. The distal extremity of this malo-zygomatic link is firmly wedged into the articulation described above, being superior to the palatine, and slightly dilated in the horizontal plane, as the maxillary usually is. This bar has a gentle fall from before backwards until it arrives at the os quadratum. In Pseudogryphus it is much compressed from side to side, and presents a decided vertical swell in its anterior third. (Plate XVI, fig. 106.)

So large are the quadrate bones in the skull of any of these Vultures that they form one of the most prominent features on the lateral view of the cranium. The "mastoidal process" looks very much as if it might originally have been a broad lamina of bone, facing directly forwards, but subsequently had been seized by the condyle, twisted one-third upon itself, and its articular facet placed in the concave depression in the squamosal; the long diameter of this latter lies in an oblique direction, and if its imaginary line were produced it would pass from the upper and outer margin of the auricular process towards the occipital condyle. This articular facet on the mastoid process is long and narrow, being convex from side to side, as well as from above downwards. The orbital process of either quadrate, though it looks very formidable from a lateral view, consists merely of a very thin, though broad, oblong lamina of bone, projecting at a right angle from the stouter mastoid process into the orbital space. Its inner extremity is finished off by a little raised rim. At its base, above the inner condyle of the mandibular end, we have presented to us for examination the snb-elliptical convex facette for the pterygoid, a special elevated crest being thrown out to support it. In all, with the exception of aura, a marked depression occurs just anterior to the artieulation and immediately above the inner mandibular condyle. The Californian Condor seems to have this characteristic best shown. The condylar surface on the under side of the quadrate intended for the lower jaw is, as usual in so many birds, divided into two irregular, undulating facets, separated by a mid-depression; the long diameter of the whole being situated trans- 
versely. Quite a decided constriction exists between the mastoid and orbital processes and the mandibular end. The portion bearing the outer condyle is produced, outwards, forwards, and upwards, as a subcylindrical, stout apophysis, having in its extremity the deep, conical pitlet for the reception of the process upon the squamosal end of the infraorbital style.

The pterygoids are horizontally compressed and exhibit upon their mesial edges the elongate facettes for the pterapophysial processes of the basi-sphenoid; these facettes are towards the anterior and broader ends of the bones. The posterior extremities of the pterygoids are constricted and twisted upon themselves, so as to bring their articular facettes to meet those that were described for their reception upon the quadrates, while the anterior ends are dilated to afford the necessary articular surface for the palatines. These bones do not meet anteriorly in any of the Cathartide, but form the usual palato-pterygoidal articular apparatus for the rostrum of the sphenoid.

We cannot state at present with any degree of confidence whether the orbito-sphenoids develop in these birds from separate centers of ossification or not; at any rate, as a general thing, the orbital septum is quite complete in the smaller varieties of the family, but in the Condors and $G$. papa large and more or less circular deficiences, most usually only one, exist in this partition, about its middle. This sometimes fuses with the perforation that is found just anterior to the optic foramen. In all of our skulls of $C$. atrata this inter-orbital wall is entire and quite thick, but in all, with the exception of this Vulture, it is in either orbit, produced out, by division above, in connection with the ethmoidal wings, to the vault, and in so doing leaves a covered duct (double in Pseudogryphus) for the passage of the first pair of nerves from the rhinencephalon to the rhinal chamber beyond. So deficient are the walls of this osseous duct in $C$. atrata that it is really reduced to a canal. Even in Cathartes aura we occasionally find foramina, due to the too great thinning of the walls, present, and opening into the passage. In the back part of the roof of the orbit we find the usual circular foramen for the orbital vein, with a shallow groovelet leading from it in all of the Cathartida.

In Neophron this arrangement is like it is in the Falconide, i. e., an open channel is provided for the nasal nerves.

The orbital septum sustains one other perforation, already referred to, and can be best described by saying it is a piercing of the partition immediately in front of the orbital foramen proper, thus allowing very nicely the passage of the branches of the crossed optic chiasma. Uther nerrous foramina are found to be distinct. The only example of the sclerotal plates that we have are a set from the eyes of a specimen of C. aura. In this Vulture they number fifteen in each eye, are very broad, overlapping each other by about one-fifth of the extent; their corneal margins are turned outwards, while their sclerotal ones are reflected in the opposite direction. We have but little doubt that when opportunity for examination offers, this description will apply very closely for these platelets among others of the Cathartida.

All of the cranial segments, or rather such of them as usually go to form the brain-case, have become thoronghly anchylosed in this family. Original sutures, boundaries, and land-marks have disappeared in the adult birds, leaving not a trace behind them to acquaint us as to the position of the primoidal elements. A study of the superior aspect of the skull has already been submitted to the reader and its leading features sufficiently well dwelt upon; now, viewing the cranium from a lateral 
standpoint (see plates of skulls), it presents for our examination, in addition to other points that we have already considered, 1 . The entrance to the organ of hearing; 2 . Two prominent processes; 3 . The general sur. face.

The posterior boundary to the aural aperture is formed by a strong, raised, semi elliptical rim, the upper border of which is produced forwards in all of the Cathartide to terminate in a horizontal and eonical apophysis, one of the two mentioned above. (Fig. 113, Plate XX.) This flaring entrance to the ear gives us a very good opportunity to examine into some of the osteological features of this organ as seen in the vulturine head. We observe the fumnel-shaped opening of the Eustachian tube; the foramen leading to the inner ear, as well as several vascular foramina.

In fact, in our California Condor, so shallow is this outlet that by the inexperienced it might be easily overlooked as not forming any part of the aural apparatus.

The remaining process found on the lateral aspect of these skulls is above the one we have just described, and is directed almost directly lownwards, having only a slight inclination outwards and forwards. We are of the opinion, and believe our reader will agree with us after m examipation of the segmented cranium that we presented in the Tetraonida, that this process was no doubt developed by the alisphenoid. It becomes compressed from side to side in Neophron, still more so in the Secretary Vulture, while it is positively wing-like in Aquila cana. densis and in the majority of the Hawks and Owls. The intervening valley between these two processes is roundly coneave, as the squamosal surface of this lateral aspect is generally convex outwards above and slightlv concave below, forming, as it does, the temporal fossa on either side, and showing a limital muscular line above. The uppermost of these two processes is called the sphenotic.

The posterior wall of the orbital cavity is quite smooth and concave from above downwards in $C$. aura and $C$. atrata, less so in G. papa, while in Pseudogryphus and the South American Condor it is nearly flat and slopes away rapidly towards the sphenoidal suture, being marked by several transverse lines or ridges. The "foramen ovale" is unusually large in these birds, and is to be found rather low down in the orbit, almost hidden in the shadow of the great quadrate bone on either side.

Passing to the basi cranii we find in Cathartes and Catharista the foramen magnum to be nearly eircular in outline, while in Pseudogryphus and Sarcorhamphus its vertical diameter is the longer. The bony walls of the back of the brain-case project beyond this important aperture in the median line and with a gradually lessening amount on either side, due to the fact that these birds all have long and markedly prominent "cerebellar prominences," which rise, dome-like, above the foramen of the occiput. This is strikingly the case in Pseudogryphus, in which, as among others of the Cathartide, the inferior border of the cerebellar prominence and the superior arc of the foramen magnum lie in the same line, which line slopes away on either side to terminate in the paroccipitals or lower angles of the raised ridges that bound the ears. This line or ridge forms a striking feature in rear views of the skulls of the Cathartida, and is present to a greater or less degree in many of the diurnal and nocturnal Raptores. The condyle, situated at its usual site in the median line, fairly on the lower border of the foramen magnum, is broadly and transversely elliptical ; in fact, it may be said to be semi-ellipsoidal in form and nonpedunculated, though prominent. It has a faint median notch above in all except Pseudogryphus, where it is very feebly marked, if it occurs at all. We have specimens of $C$. atrata before us in which the occipital 
condyle is fully as large as in our specimen of Aquila canadensis ; indeed, as a rule it seems to be larger throughout the Vultures than in the Falconida.

In Polyborus tharus it is completely sessile and hemispheroidal in form, being still smaller, and in the Crows and Jays we know it is comparatively still more diminutive. The area that includes the foramen magnum and the occipital condyle, and is bounded laterally by the elevated aural ridges, is depressed below the surrounding points in the basi-cranii of all of the Cathartida. In this space on either side we dis. cover the usual venous and nervous foramina, the precondyloid foramina, and those for the vagus and jugulars, the latter group occupying the base of a special depression for themselves.

We find in many birds, beyond the condyle, on either side, a descending tuberous process; they show pretty well in a fine specimen of the Canada Goose that we have at hand, while they are entirely absent in our skull of Circus, and only moderately dereloped among the Eagles. In the Cathartide, however, this pair of processes become the leading feature of the base of the cranium, though it must be remarked that they are not always equally well developed, for we have crania of C. atrata in our possession in which one would bardly be strock by them as worthy of particnlar notice. In one of our skulls of S. gryphus, however, and another of the Californian Vulture, these processes are remarkably well developed, being great tuberous projections that spring from extensive bases, taking a direction downwards, outwards, and a little backwards. Their inferior extremities seem to be designed for muscular and ligamentous attachment. In the accompanying cut, Sp designates this pair of processes, and $T p$ a quadrate bone. This figure is life-size from the smaller skull of the two specimens we have of our Californian Vulture; it illustrates many of the points that we have just passed over in our description of this view of the cranium. These basal processes form the outer angles of an isosceles triangle, the apex of which is the lip beneath the Eustachian tubes (Plate XXII, fig.120, C. aura), and the sides, the

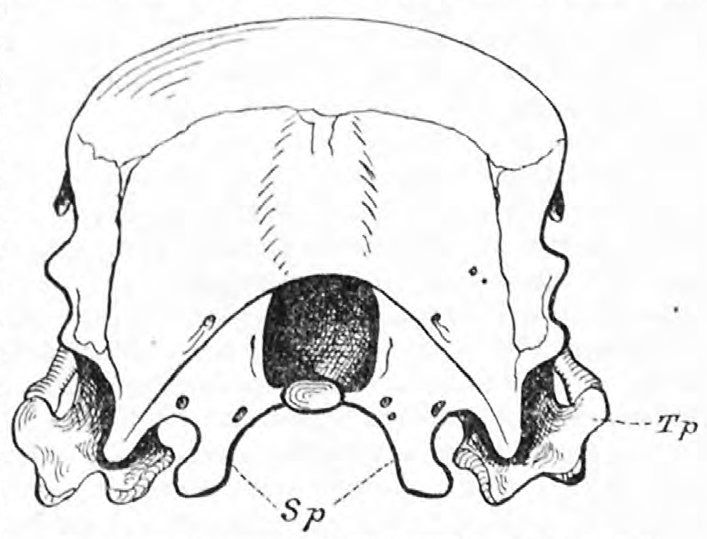

Rear view of cranium of Pseudogryphus californianus. lateral portion of the basi-cranii. The Eustachian tubes open at their usual site in one capacious common aperture, the gutter leading from the entrance of which is seen on the basi-pre-sphenoid. These tubes are conical, the apices being at the anterior opening; it is not uncommon in C. aura to find these passages not closed in by the anterior bony wall, and the general aperture is quite wide in Psendogryphus. The foramina for the passage of the carotids are found near at hand in the recess. On either side of the Enstachian groove, jutting from the base of the sphenoidal rostrum, we observe the pterapophysial processes; they are directed forwards, outwards, and a little down wards, each being crowned by an elliptical facette, the major axis of which in each case is nearly in the horizontal plane. We have already dwelt upon the fact as to how these apophyses meet and articulate with the pterygoids. They are 
more prominent in Gypogeranus than they are in the largest of our Condors, while in Neophron percnopterus the pterygoids stand well away from the basi-sphenoid and no such processes are present. In Polyborus not the slightest evidence of them exist, but in Aquila and Circus we find diminutive sharp spines jutting from the usual points, but they do not possess articular extremities, nor do they ever meet the pterygoids in these birds. It will be remembered that we found them in quite a num. ber of the American Owls, and we believe the r are present in all of them.

Gently inclined upwards, very long and robust, we find the basi-presphenoid in all of the Cathartida, carrying out its functions in the me. dian cranial plane. Above it has become thoroughly blended with the interorbital septum and the mesethmoid, below it is rounded and smooth, and aifords the common articular surface for the pterygoids and palatines. In Pseudogryphus it has a length of four centimeters, and in $C$. aura develops a little spine anteriorly that projects beyond the meseth. moid.

We show in our cut of the rear view of the cranium in Pseudogryphus how the region of the occiput is bounded by the superior muscular line, both laterally and above; this line is well marked in all of these Vultures. The lines at the sides are quite ridge-like in the California Condor, parallel and in the vertical plane, while the line forming them above is a long, shallow arc, with its concavity towards the cerebellar prominence; this is also the case in C. atrata. In Cathartes aura the side lines are curved outwards, while the superior line is broken at its middle point, which point is carried down on the cerebellar prominence for about one-third of its distance from above, in the median plane, where the extremities of the broken line join it at a gentle curve on either side. This is nearly the pattern as seen in $G$. papa, but in S. gryphus we again find it as we described it in the Northern Condor, only we have in the former a slight inclination for the point to come down on the prominence.

If we remove a section of the vault of the cranium, and this has been done here in $C$. aura and Catharista, in specimens of skulls of these birds that have been in collections for several years, * we find that the internal and external layers or the cranial tables are very thin, and that a fair amount of diplöic tissue is placed between them, especially towards the occipital region, where, as we approach the locality of the internal ear on either side, it becomes several millimeters thick; the cellular network being more or less coarse in texture. The internal walls of the brain-case as thus exposed are smooth, being traversed only here and there by vascular tracts and grooves for the exit of certain nerve branches. The fossæ designed for the reception of the different cephalic lobes are moderately well separated, the one that contains the epencephalon being the most distinct, aided as it is by the internal concavity of that external feature of the occiput that we described above as the cerebellar prominence; the usual transverse groovelets do not mark this section here on the internal table. This distinctness is further assisted by thin horizontal off-shoots from the united bones of the earcell. The internal auditory foramen is unusually large and predicts a correspondingly good size for this important nervous branch; the same remark applies to the trigeminal and its orifice of exit. Remarkable depth and space is allotted to the fossa for the lodgment of the hypophysis, the "sella turcica," as this receptacle is known by in anthropomy,

\footnotetext{
* For changes that may possibly take place, see author's remarks in Osteology of
} Lanius ludovicianus excubitorides (Bull. Geol. and Geogr. Surv. of the Terr., Vol. VI, No. 2). 
its posterior wall being as high as the anterior, and the carity having a depth of three or four millimeters or more. In our specimen of $O$. atrata, an elliptical perforation exists in its hinder wall near the bottom; the carotids seem to invariably pierce its base within, by two openings. Immediately above and anterior to it we find the optic and other nervous foramina spoken of when engaged with the orbital cavities. Passing to the rhinencepalie fossa, we are not disappointed in finding that this cavity is also equally spacious and well developed, and lodging as it does, the encephalic lobe that presides over the sense of smell, this fact becomes particularly interesting, insomuch that it may indicate extraordinary powers on the part of this faculty. The orifices of exit for the olfactory nerves are double in the Cathartida, which is an exception to the general rule. Professor Owen found the same state of affairs in a Vulture that he dissected, and this able anatomist made this remark upon what he observed: "In the Vulture the olfactory nerve is single on each side, and continued from an olfactory ganglion or "rhinencephalon" along the upper part of the interorbital space to be distributed upon an upper and middle turbinal, the latter being the largest."-(Anat. of Verts., Vol. II, pp. 123.)

Along the roof of the eranial cavity, in the median line, the "longitudinal crest" is seen to pass. This may become grooved as it approaches its anterior termination, or for its anterior half, which indeed is the ease in the majority of these birds; the groove dilating, and the whole merging into the general surface immediately before arriving at the conical rhinencephalic recess just referred to abore.

Fig. 115, in Plate XXI, gives us a very accurate idea of the hyoid arch, taken from an adult specimen of Cathartes aura. Like the other subjects presented the reader, it is life size; in it we notice that the glossohyal remains in cartilage during the life of this Vulture, and that the ceratohyals, as two slightly curved, elliptical osseous plates imbedded in it at its base, articulate by the margins of their posterior ares with facettes on the anterior aspect of the basihyal; they are also tangent to each other at their middle points in the median line. In its turn, the basihyal seems to share largely the requisite support for the broad fleshy tongue in this bird; to do this, it has been given an extensive horizontai plate that is further strengthened by a keel below. This horizontal plate is concave above, dilated at its extremities, more so at the posterior one, where it produces a rounded process, mesiad, that is continuous with the carina beneath. This keel is deepest behind, sloping gradually to the anterior part, where it merges into the horizontal plate and the thickened, elliptical facettes for the ceratohyals. Posteriorly, it is produced downwards as a long, slender apophysis, terminating in cartilage, that no doubt represents the connate urohyal. At the sides of this keel, opposite its deepest part, there are, on either lateral aspect, cup-shaped depressions to receive the expanded heads of the hypobranchial elements of the thyrohyals that articulate there. These latter are found to be two rather robust, long bones, with upturned and cylindrical shafts, that articulate in their turn with the ancerior heads of the ceratobranchial elements behind them. The ceratobranchials are still more curved than their stouter companions, and gradually taper off to cartilage-tiped points posteriorly.

In contradistinction to the Falconide and the Old World Vultures, the members of this family are armed with much more powerful lower maxillæ, this increased strength lies principally in the greater depth of their rami and consequent breadth of the symphysis, as well as the ponderous articular extremities, that these jaws possess. 
The vacuity, forming such a characteristic feature on the sides of the jaw in so many of the class, is here rarely or never present. In Pseudogryphus its location is merely indicated by a shallow slit, that does not penetrate to the bone, though in G. papa it does for a limited distance along the base of a similar slit, but in our specimen of $S$. gryphus every trace of the locality of the foramen has been obliterated; again in Cathartes and Catharista narrow and faint groovelets are the sole indicators of its position, or the margins of the elements that origin. ally bounded it.

Deep pits are found in the centers of the upper surfaces of the articu. lar ends; these are bounded externally by narrow, longitudinal facets, as do the inturned conical processes support more irregular ones. In the Californian Condor there is a predisposition to develop from these articular ends quadrate apophyses behind, in weak imitation of the spur-like affairs that we found so characteristic of the Tetraonida; this effort does not seem to be so thoroughly entered into by the others. The under surface of either articular end is divided into two by a longitudinal ridge, continuous with the lower ramal border; of these two surfaces the lesser and outer faces outwards and downwards, while the inner and larger faces downwards and towards the median plane.

Almost an unbroken smoothness characterizes the internal and external surfaces of the sides of the jaw; this is extended to the entire dentary region beyond. Even the ramal borders bounding these surfaces above and below are notorious for the nice manner in which they are erenly rounded off, there being scarcely any evidences of the coranoidal projections to interrupt this general smoothness; it is only in the superior one, that for its anterior third on either side, and as it sweeps around the curve of the symplysis, that it becomes sharp, to correspond with the tomial edges of the mandible above.

The depth of the symphysis in Pseudogryphus is about two centimeters, and the deepest part of the jaw, the ramus just beyond the articular ends, is $1 \frac{1}{2}$ centimeters; for aura and atrata the measurements are equal. The curve that is continuous with the lower ramal borders, limiting the symphysis posteriorly, is parabolic in outline. Viewing the mandible in the Cathartida from a lateral aspect, when it has been articulated with the cranium, we observe that it is bent downwards from a point a a little posterior to the distal end of the maxillary, from which point it is obliged to accommodate itself with the superior mandible. A row of foramina is always present just within the sharp edge of the superior border beyond, and still within these a few others are scattered about; one or two isolated, though parial, nutrient and vascular foramina are found at corresponding points, along the sides of the mandibles of all these Vultures.

Having now passed, and we trust with sufficient thoroughness, over the osteology of the vulturine skull in general, and the osseous portions of its sense organs, may it not be in place and an advantage tous to ask the question here, Where have we detected any differences among these birds, so far as we have carried the subject? To present, or really to recapitulate, these for our reader, we will here arrange the most prominent departures among the species in a tabulated form, or at least such of them as we deem worthy of reconsideration. This method we shall follow, after the discussion of each of the parts or divisions of the axial skeleton or its appendages that may be thus separated, grouping as much as we can into one table, without jeopardizing its utility, deferring, however, general conclusions and comparisons for the concluding paragraphs of this monograph. 
Of the vertebral column.-The manner in which the vertebral columm of birds should be divided has been differently viewed by ornithotomists. The two principal reasons for this difference of opinion, no doubt, has arisen from the various arrangements assumed by the free ribs at the anterior part of the column, and the equally diverse manners in which the innowinate bones of the pelvis attach themselves to the column. Without entering very extensively into the literature of the subject, let us first examine into the question as to where the line shall be drawn between the cervical and dorsal vertebræ. We seem to have presented us here two very uncertain guides; the first being whether the first free ribs are connected with the sternum by sternal ribs or hæmapo. physes, and the second upon the character of the vertebre-that is, whether ther have the appearance of dorsals, as we usually find them, or cervicals as we usually recognize them. Professor Huxley sharply de. fines the line when he says: "The first dorsal vertebra is defined as such by the union of its ribs with the sternum by means of a sternal rib; which not only, as in the Crocodilia, becomes articulated with the rer. tebral rib, but is converted into complete bone, and is connected by a true articulation with the margin of the sternum." (Anat. Vert. An., p. 237.) Professor Owen takes a different view of the subject when he states that "In the first and second dorsals the pleurapophysis (1 and 2) terminate in a free pointed end, like the "false floating ribs" of Anthropotomy; in the third the pleurapophysis, $p l .3$, articulates with the hæmapophy. sis $h$; which, in connection with its homotypes, constitutes the bone called 'sternum,' $f$." (The letters given refer to a cut showing the first three dorsal vertrbræ and scapular arch of a bird, in diagrammatic side view. (Anat. of Verts., Vol. II, p.15.) It will be remembered that when we examined into the osteology of Eremophila we found sometimes that the second pair of free ribs, or rather freely articulated ribs, were connected with the sternum by hæmapophyses, so that in this case some would claim them as true dorsals, or as dorsals any way (Owen); while others could but say that the number of pairs of dorsal ribs varied. This state of affairs in Eremophila is no more an impossible thing or unusual occurrence than the occasional presence of cervical ribs in man. (Owen, Anat. Verts., Vol. II, p. 298.)

Now, among the Tetraonide we found another condition that proved equally puzzling; with them it will be recollected that there were, in the backbone in the dorsal region, four vertebræ that in the adult were completely fused together, and that the pairs of ribs that articulated with the anterior vertebra of this compound bone did not connect with the sternum by hrmapophyses. Here we must, if we consider the floating ribs in this region as cervical ribs, consider that a cervical vertebra has become anchylosed with three dorsals, together forming a bone that we believe every one would, as the writer then did, say was composed of dorsal vertebræ alone, in spite of the anterior ribs not joining the sternum by sternal ribs. One other ease, and let us take a specimen of Asio vilsonianus to illustrate it. In this bird we discover, passing from before backwards, that the first pair of free ribs hang from beneath the transverse processes of the vertebra as diminutive bonelets, as we found them in Speotyto. Now, the next vertebra behind this one has all the appearances of a true dorsal vertebra, (possessing the lofty neural spine, etc.); but the ribs still fail to connect with the sternum by sternal ribs. These three varieties may be again divided when we come to consider the appearance or non-appearance of uncinate processes upon these ribs, a condition which likewise varies. At present I do not propose to definitely state my views in regard to this matter, but it will be seen 
from what follows that I consider the free ribs in this locality in the Cathartida, as well as the Falconida referred to, as cervical ribs. This may be my final opinion.

Now, so gradual is the passage from the processes on the cervical vertebræ from which the ribs are formed to free ribs among the Vultures, that indeed, the first cervical rib has more the appearance of a bony plate than a rib, yet it freely articulates with its vertebra as the rest of the dorsals do, and its presence makes the number of cervical ribs in $C$. atrata reckon three. Again, the vertebræ possessing these free ribs are situated opposite the clavicles and other parts of the scapular arch, and form the "root of the neek," being so far removed from the dorsal region that we can only regard them as true cervical vertebræ, The rudimentary manner in which these ribs are first exhibited on these vertebræ is well shown in Plate XXI, fig. 114, cy, cy, for Cathartes aura, while in $C$. atrata, as we have remarked, the par-pleurapophysial plates are free as ribs in the vertebræ beyond these even.

This arrangement reduces the number of dorsal vertebræ in Sareorhamphus and Pseudogryphus to only three; that is to say, that in these genera we find three tree segments in the mid-column, where the pleurapophrses are connected with the sternum by the sternal ribs, while the vertebra immediately posterior to them is with these birds firmly anchylosed with the ossa immominata. On the same page, then, we have just quoted from Owen's Anatomy, it will not surprise us to find the statement in regard to the dorsal vertebræ that "they have not been observed to be fewer than four (in some Vultures) nor more than nine throughout the class; the latter number obtains in Apteryx; the most common numbers are six and seven." Now, if we accept this, and also this anatomist's arrangement that the free ribs are dorsals and the vertebræ bearing them dorsal vertebræ, and there being "usually two of them," then it would leave us a very limited number of vertebra between them and the sacrum that were connected with the sternum by sternal ribs (at the most two) in the Vulture referred to; so we are compelled to think, knowing as we do the usual condition of the ribs in these birds, that on this occasion the distinguished zoötomist himself reckoned his four vertebræ as those that were articulated with the sternum by the intervention of sternal "hremapophyses," and for the moment did not note the free ribs. This would give the same formula as $C$. aura and others.

With the exception of the vertebræ that are grasped by the pelvic bones, these segments in all of the Cathartida are freely articulated with each other. This is likewise the case with Gypogeranus and Neophron percnopterus, and obtains also with our Circus hudsonius, in which species five vertebræ are allotted to the dorsal division of the column. A gain, we find it in Accipiter cooperi, while in Tinnunculus sparverius and Polyborus tharus at least four of these vertebræ form one solid bone in the adult specimen; in Micrastur brachypterus there are again five dorsals, and all independent segments.

Unfortunately, all that remains of our specimens of Pseudogryphus, so far as the vertebral column is concerned, are a few of the free ribs and several scattered vertebra; two of these are the third and fourth cervical, another one from the middle of the neck; one of the last cervicals and lastly the ultimate dorsal-this latter we have devoted a fig. ure to, representing as it does no doubt the largest avain vertebræ of any living form to the northward of the range of the South American Condor-nevertheless, we think we may predict, almost with certainty, that even from these few fragmentary pieces it will be found to be the 
ease, that when the opportunity offers for an examination of a perfect skeleton of this bird, that the number of segments in the spinal column will be the same as in Sarcorhamphus; we have been assisted in arriving at this conclusion by a critical examination of the ribs we have, as well as the sternum and sacrum, that come very near to S. gryphus.

We have carefully counted the vertebre in the different species before us, and in order that the reader may have them for easy comparison, we present the various results in the form of a table, here subjoined, in which will be found other important and useful data. The number of sacral vertebræ must be accepted with a due amount of caution, as we all know it is quite difficult to decide on the number of segments de. voted to the "sacrum" in adult birds, after anchylosis has thoroughlv been accomplished.

Table for the comparison of the vertebre.

Species.
$\ldots$

The specimen of Micrastur shows an interesting phase on the part of the "hrmapophyses" of the pair of sacral ribs, for we observe the one on the left side articulates with the sternum by expanded extremity on a perfect facet as the other sternal ribs do, while on the right side the "hæmapophysis" of the sacral rib does not reach the sternum, but on the other hand lies along the posterior border of the sternal rib next beyond, as it does in many other birds. This gives us in this bird six facets on the costal border of the sternum on the left side, and only five on the right.

Then, in our skeleton of Neophron we find a pair of sternal ribs, the last pair, springing from perfect facets on the sternum, that do not meet corresponding sacral ribs coming from above, but are apparently held in their position mainly by the intercostal muscles aud membranes. Such facts and instances as these must make us necessarily a little wary, when we have only parts of skeletons in our possession, from which we have to decide as to the number of vertebræ or ribs in any particular instance.

The Cathartide being large-boned birds generally, we find that this feature is extended to the segments of the spinal column. The vertebræ are large, and all their various processes well marked and strong.

In the cervical region or division of the column we find the vertebral canals as usual, passing from vertebra to vertebra, along on either side; in each segment the tube remains throughout more or less subcircular, and is closed in the ordinary manner by the parapophyses and pleurapophyses of each vertebra. The protection afforded the vessels is markedly complete, for it is ouly in the atlas and axis that we discover slight 
deficiencies in their lateral walls. The neural canal as it passes through the vertebræ of the upper half of the neck is nearly cylindrical, but as we approach the middle of the neck it gradually becomes compressed from side to side, and assumes the rertical ellipse, to become circular again before arriving at the dorsal region. In the atlas the facet for the condyle of the occiput is semilunar in outline, and the neurapophyses are broad above, but as usual exhibits no sign of a neural spine. Below we commonly find a well-marked hypapophysis, though this feature is absent in C. atrata; laterally we have the unclosed vertebral canal of this bone, the processes receding from each other as sharp spiculæ. These points are still nearer together in the axis, and in this segment we find a thick, quadrate, neural spine occupying the center of the arch above. Below, the hypapophysis is carina-like in character, traversing in the median line the entire centrum of this bone. The odontoid process is an insignificant tip, being quite broad from side to side, while the postzygapophyses are tuberous lateral projections, with the facets on their under aspects in the horizontal plane, looking directly downwards, with the anapophysial projections above, elevated into prominent though blunt tuberosities.

The facet for the third vertebra is convex from side to side, and looks almost directly upwards, it facing slightly backwards; the similar surface for the atlas, anteriorly, being much more extensive, twice as broad, continnous with the articular surface beneath the odontoid process, is directed forwards. Solidity and great breadth marks the third cervical vertebra; in it bony leminæ connect, on either side, the pre-and postzygapophyses, an elliptical foramin being found in the surface near each laterai margin.

There is a conspicuous neural spine with thickened crest, while below we have a quadrate hypapophysis. The vertebral canal is completely closed in, and parial parapophysial processes begin to make their appearance, being directed backwards; in all of the Vultures these spine-like appendages are long and styliform in mid-neck, to become broad and tuberous as we proceed dorsalwards.

Facets upon the pre-and postzygapophyses of this vertebræ are elliptical in outline and comparatively large; the former are directed upwards and a little forwards, the latter almost directly downwards. The anterior facet of the centrum, below and immediately outside of the neural canal, partakes of its usual ornithic characters; it is very narrow from above downwards and decidedly concave from side to side. In this vertebre, the last remnants of the carotid canal are present in all of the Cathartida; it is formed in its usual manner as we pass down the serial segments. In S. gryphus its first appearance is made in the eleventh cervical, but in the tenth in G.papa, as is also the case in $C$. aura and Catharista. More or less complete interzygapophysial bars are found joining the process laterally in the fourth vertebra. The hypapophysis of this segment is reduced to a low ridge beneath, while superiorly the neural spine still projects from the lamina, mesiad, as a vertical peglike process. The articular facets are about as we found them in the preceding vertebra.

As a rule, the hypapophysial process throughout the cervical series, after passing it when it is double for the carotid arteries, is found better marked on the next two or three ultimate vertebræ. Those cervical vertebræ that possess free ribs rarely show a distinct hypapophysis, but in them the centrum beneath is broad and oblong in figure, with a faint ridge mesiad at the usual site.
Another suppression takes place on the part of the neural spine 
among the vertebræ found in mid-neck; it is but feebly developed in the tifth segment, still more so in the sixth, and is nearly lost in the few following vertebræ as we proceed down the neck. It soon reap. pears again, however, as a broad, knob-like apophysis, to become com. pressed from side to side, quadrate, and finally like the anterior dorsals.

In the Cathartida we find a diapophysial process jutting out from the wall of the vertebral canal, laterally and at the anterior part of the ver. tebra; this character is best marked as we approach the dorsal region, and we find that upon those cervical rertebræ with the free ribs it is quite broad and exhibits a metapophysial ridge.

Upper cervical vertebra show long postzygapophysial processes, and thronghout the series the arms bearing these articular facets are shortened or lengthened in such a manner as to preserve the decided sig. moidal curve so characteristic of the vulturine neck. As we arrive at the middle of the cervical chain of segments, we notice that the anterior articular facets are barely concave, face directly inwards, and so, each other, occupying a position, on either side, on the bony ridge that spans the vertebral canal above.

Epipleural appendages are never found upon the free ribs of the cervical vertebræ of the American Vultures, and this condition seems to obtain pretty generally among the Falconida, though these ribs become more and more like the true dorsal ones as we advance in that direction.

In a communication just received from Mir. Frederic A. Lueas, Ward's National Science Establishment, Rochester, N. Y., we learn that this observer found in Otogyps calvus "fifteen cervical vertebræ; two pair of cervical ribs, first very small, both without uncinate processes. No uncinate process on last rib." This last remark probably refers to the sacral rib, which rarely bears an epipleural appendage. This observer further states that he found "a bony internasal septum (in this bird), with a skull proportionately shorter and higher than in Vultur cinerea." From the sketch he kindly presented me the nostril has its long axis inclined nearly vertical rather than longitudinal. And, further, for Vultur cinerea we find "fifteen cervical vertebræ; two cervical ribs, first smaller than in O. calvus, both withont processes, small uncinate process on last rib" (sacral?). "A bony internasal septum" was found in V.cinerea.

Then for Gyps bengalensis, "Cervicals seventeen; last two cervicals bear a rib, the tirst of which is 4.5 millimeters long, being 40 millimeters longer than same rib of $V$. cinerta, and 38 millimeters longer than in 0 . calvus. Second cervical rib with long uncinate process. Last rib with uncinate process" (sacral?). "A nasal septum, but no bony projection within nostril, as in $V$. cinerea and $O$. calvus. Skull much more like Cathartes in its shape than any other large Vulture I have examined." No doubt means general contour, as Cathartes, we know, has not a nasal septum present.

Lateral wings are seen to project horizontally from the centrum of the ultimate cervical beneath, and so we pass to the first dorsal, in the majority of the Cathartida, these wings still persist, but are not so farspreading, and are, as it were, drawn downwards at the expense of the centra, the latter becoming more compressed, the former, now attached by a quadrate pedicle, are true hypapophyses with flattened and expanded extremities, which latter contract, and the pedicle becomes longer as we approach the sacrum. These are very prettily shown in S. gryphus, and in all of our Vultures are a striking characteristic of the dorsal series.

Rim-like projections are observed to bound the facets of articulation among the centra in this portion of the column; these latter are sub-com- 
pressed at their middles and quite deep-this does not seem, however, to influence the form of the neural tube in this region to any great extent, as it remains almost uniformly circular throughout, markedly so in $C$. aura. Piccings into this passage on either side for the exit of the dorsal nerves are made at the expense of certain parts, both before and behind, in each vertebra, giving rise to rather small irregular openings for this purpose. At the base of the transverse processes of the dorsal vertebræ, and again at their extremities, semi-circular facets exist for the capitula and tubercula of the dorsal ribs. Those at the bases are upon slightly raised elevations and look almost directly outwards, those at the extremities look downwards and outwards, in aura and atrata, but in S. gryphus and the California Condor almost directly outwards, especially in the last dorsal.

The diapophyses become progressively longer as we near the sacrum, at the same time more inclined upwards; they are compressed from above downwards, being dilated at their outward extremities, where they bear distinct and styliform connecting metapophyses, the last pair being extended to the pelvis in Cathartes.

Close and mutual locking is accomplished in this region, principally by a shortening of the pre- and postzygapophyses, the facets upon the former facing upwards and slightly inwards, upon the latter downwards and slightly outwards, so as to be nicely approximated in the articulated skeleton.

Sharpened ridges beneath the transverse processes connect the facets for the capitula and tubercula of the ribs; this feature is best marked in $O$. aura and next in $G$. papa, less so in the others.

Vertically elongated but shallow depressions occur above the centra on the anterior and posterior margins of the neural spines, for the insertion of the broad connecting ligaments; the spines themselves spring almost abruptly from the neurapophysial arch, are uniformly quadrate plates of an equal height, with thickened crests above, that become united at their anterior and posterior ends by a modified arrow-head joint, such as we described in speotyto, where the points were more acute.

Mr. Lueas tells us, in the same communication cited above, that he found five dorsals in the spinal column of Vultur cinerea and Gyps bengalensis, six in Otogyps calvus.

Owen clearly defines the condition of the hypapophyses in some of the Old World Vultures in the following words:

From some or most of the dorsal centrums inferior processes (hypapophyses) are sent down, for extension and favourable origin of the flexor museles, longi colli and recti antici, of the neck. In a Vulture (Gyps fulvus) the hypapophysis is a low median ridge in the first and second dorsals; to this, in the third dorsal, is added a pair of ontstanding depressed plates; in the fourth the pair of plates are smaller, and, with the medial ridge, are supported on a common stem; in the fifth dorsal the hypapophysis is again reduced to a median compressed plate, but it is expanded at the end; the vertebra, which by anchylosis has become the foremost sacral, has a similar but stronger and slightly bifurcate hypapophysis. In both Vultures and Eagles the parial hypapophyses are seen to be due to modified parapophyses, which descend and are progressively lost in the median hypapophysis of the fourth and fifth dorsals (Harpeya, Cuv.); the sixth and seventh have only the low median ridge. (Anat. Verts. vol. If, p. 17.)

The caudal vertebræ are very much modified, as they are as a rule, throughout the class; the number possessed by each species has already been given in one of the tables accompanying this monograph. They are considered next in order after the dorsals, as the author believes, and the reader will surely agree with him, that in the present subject 
the sacral rertebræ had better be taken up with the pelvic bones as an entirety and treated under the section devoted to the pelvis.

In the South American Condor a complete arcade is formed by the nenrapophyses of the coccygeal vertebræ, over the ultimate division of the myelon, and even the pygostyle is pierced for a short distance to allow the entrance of the nervous cord. These bony arches are surmounted by knob-like tubercles throughout the series, that show a very feeble disposition to become bifurcated at their summits. Many of the lateral elements of the vertebræ are combined to form diapophysial processes, which, in this bird, are heavy and broad projections jutting from the centra on either side, bent downwards, and becoming wider and wider as we near the coccyx, to be suddenly suppressed in the ultimate seg. ment. Very faint indications of a hypapophysis occur in any of the first three caudals ; in the fourth a cleft but sessile tubercle is seen, that leans forwards to rest upon the under surface of the centrum of the vertebræ beyond; in the last two this process becomes much larger, and is evidently made up of the hæmapophyses of the vertebræ, for in each case it is pierced by a delicate hæmal canal, while the true hypapophysis is still below and still exhibits the disposition to overlap the vertebræ beyond. The centra of the coccygeal segments of the spinal column in the Cathartidce, as among the class generally, are procolian. In the coccygeal vertebræ of $G$. papa we find the same general characters present that we have just attributed to $S$. gryphus; the prineipal differences are that the neural spines are more lofty and only the ultimate hypapophyses form a perfect hæmal eanal, the anterior ones being only grooved. Among the Vultures there is sometimes an extremely intimate relation existing between the first caudal vertebræ and the last sacral, amounting to, in some cases, positive anchylosis.

In Cathartes aura the neural canal is complete throughout the chain and enters the pygostyle for some little distance; the hæmal canal does this also below, but this latter only passes through two of the hypapophyses of the last two caudals, these processes being but feebly developed in the others. The diapophyses in this Vulture become gradually broader and shorter as we leave the sacrum. Catharista exhibits about the same peeuliarities with regard to its caudal vertebræ as we see in Cathartes aura.

Mr. Lucas tells me that he counts seven caudal vertebræ both in Otogyps calvus and $G$. bengalensis; he also kindly furnishes us with outline sketches of the pygostyles of these two Vultures, which we give below as we compare them with others.

It will be observed that, as a rule the coccyx among the Cathartide is more or less parallelogramic in outline, with well-defined angles ; on the other hand, among the Falconidee and the Owls and their allies this bony plate is drawn upwards and backwards into a rounded point; we give examples of this in the cuts, as well as exceptions to the rule.

Neophron has a strong tendency Falcon-wards in this respect, less marked in Gypogeranus.

We also present the reader, in each case, except in the two outlines from Mr. Lucas, with a posterior view of this bone, which will show the great variability of outline of the pygostyle, better than any descrip)tion could do, however elaborate it might be made. An elliptical foramen, in some cases two (Gyparchus), pierce this plate at about the locality the last coccygeal vertebræ fused with the one next behind, forming, as it were, a point that the process of osseous amalgamation failed to fill in. This feature is rare among the Falconida. Among 
Pygostyles of various Old and New Wobld Vultures and Hawrs.
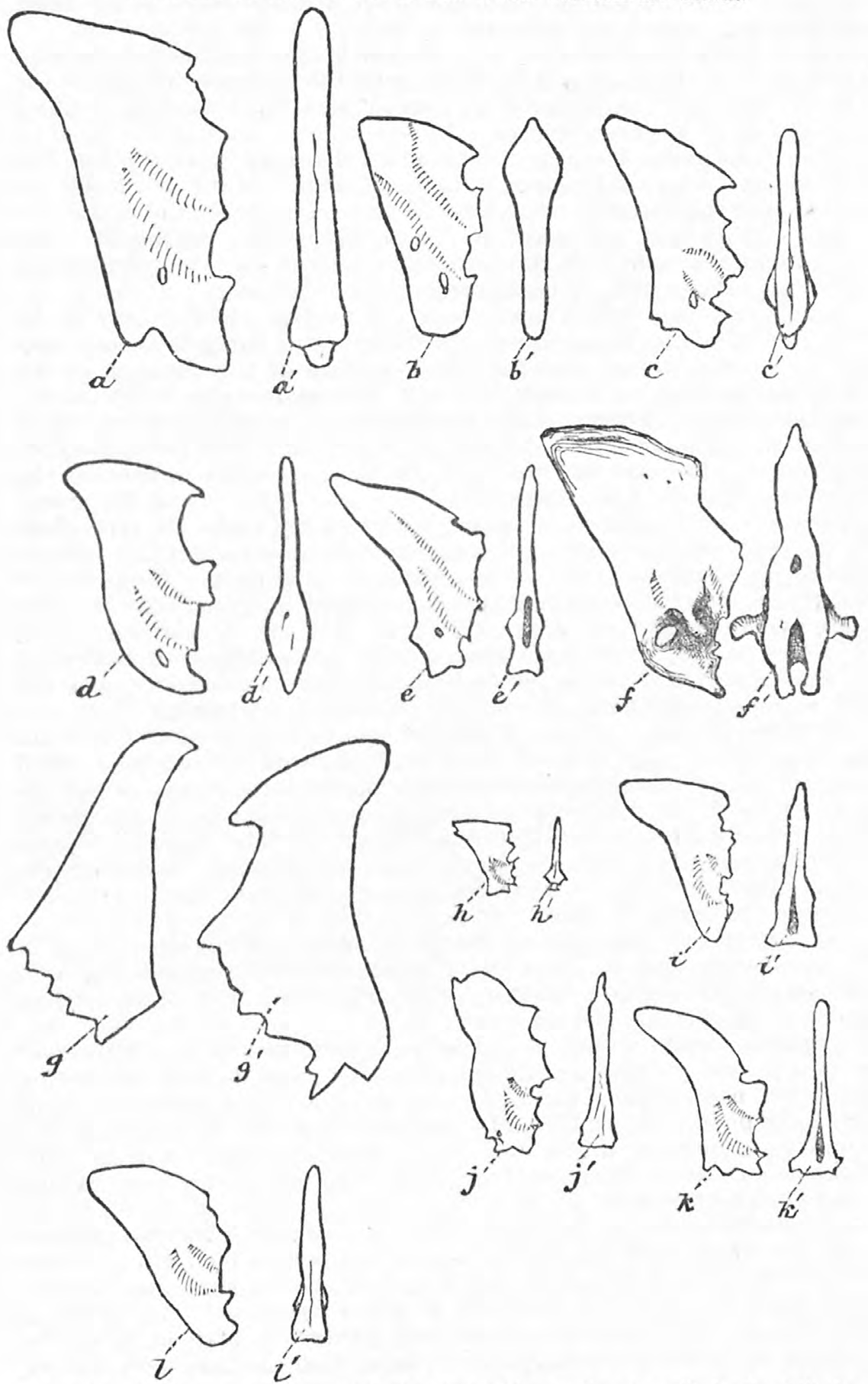

$a$ and $a^{\prime}$, lateral and rear view of pygostyle of Sarcorhamphus gryphus, respectively: $b$ and $b^{\prime}$, the same for Gyparchus papa; $c, c^{\prime}$, for Oathartes aura; $d, d^{\prime}$, Catharista atrata; $e, e^{\prime}$, Neophron perc. nopterus ; $f, f^{\prime}$, Gypogeranus serpentarius; $g$, Otogyps calvus; $g^{\prime}$, Vultur cinerea; $h, h^{\prime}$, Tinnunculus sparverius; $i$ and $i^{\prime}$, Accipiter cooper $i j, j^{\prime}$, Micrastur brachypterus; $k, k$, Circus hudsonius; $l$ and $i$, Polyborus tharus. 
the cuts, $a, a^{\prime}$ is an outline sketch of the pygostyle from Sarcorhamphus gryphus; it shows very well, and is, in fuct, typical of the parallelo. gramie form this bone assumes in the Cathartida; $b$ and $b^{\prime}$ is the lateral and posterior view of the bone from Gyparchus papa; in this Vulture we observe that the upper portion of the bone, ur rather the upper and josterior angle, is very much thickened.

Cathartes aura, shown in $c$ and $c^{\prime}$, still retains the usual outline of the other Vuitures of this family, while in Catharista atrata, $d$ and $d^{\prime}$, the lower and outer angle is rounded off, but the common form is still very decidedly retained in its upper half. In Neophron percnopterus, seen in $e$ and $e^{\prime}$, we discover a marked leaning towards the form of the bone as it is known to us among the majority of the Falconida.

Eccentricity of form stamps nearly every part of the bony frame. work of the African Secretary Bird, Gypogeranus, so we are not so much surprised to find the shape the coceygeal vomer takes on, a shape that we present in $f$ and $f^{\prime}$. That the diapophyses of the anterior vertebra that assisted in making this bone have been retained with great prominence is very evident to us, and they are shown both from lateral and posterior aspects. The size of the usual foramen still fur. ther individualizes this vertebra.

Approximate outlines of the bone for Otogyps calvus $(g)$ and Vultur cinerea $\left(g^{\prime}\right)$ are next in order given, and we note that in the first the tendency is decidedly to partake of Falco-form type of the segment, while just the reverse is seen in the second, where it assumes a shape quite like the Cathartida.

The two more common patterns, as seen among the vast majority of Hawks, Owls, and Eagles, we find sharply portrayed in Circus hudsonius $\left(k, k^{\prime}\right)$, and in Polyborus tharus $\left(l, l^{\prime}\right)$. On the other hand, we give notable exceptions to this triangular style in Tinnunculus sparverius ( $h$ and $\left.h^{\prime}\right)$, Accipiter cooperi ( $i$ and $\left.i^{\prime}\right)$, and in Micrastur brachypterus ( $j$ and $\left.j^{\prime}\right)$. So we see that among these Vultures, as well as the Falconide, the form that the pygostyle takes on can only be utilized as a distinctive mar $\mathrm{k}$ in the question of differential diagnosis, when taken in connection with other groups of characters found either in the bird's external topography or its internal structure.

The number of the dorso-rertebral ribs in any of the Cathartida can easily be ascertained by consulting the table of vertebræ (the second accompanying this monograph), as, of course, every dorsal vertebra has its pair of free dorsal ribs, these being articulated in the usual manner with the sternum, by the intervention of the sternal ribs. The ribs as found among the American Vultures are very robust and strong bones, representing, as they do, fit accompaniments of a skeleton notorious for its general massiveness. As is most usual in the class Aves, the neck bearing the capitulum of the rib at its extremity lengthens as we pass backwards towards the pelvic end of the body, in due proportion does the one bearing the tuberculum shorten, until in the latter we have the transverse process of the vertebra, in the last dorsal resting for the outer third of its length against the true neck of the rib apposed to it, and the tubercular pedicle has become sessile with the body.

The ribs of the Cathartida, or such of them as are found in the dorsal division of the column, are very broad throughout their entire lengths, the broadest part being found at their superior thirds; this transverse compression gives rise to sharp anterior and posterior borders, and long elliptical facets, placed longitudinally below for the sternal ribs.

All of the dorsal ribs support epipleural appendages, in this family, anchylosed to the posterior margins of these bones, below the middle 
of the shafts. We believe that this is the case in the vast majority of the Falconida, inclnding the Old World Vultures. These unciform oftshoots are very wide-spreading and prominent, more so among the American Vultures than in any of the Hawks or Eagles, and as a rule overlap the rib immediately behind them, but never two consecutive ones, as in some birds.

There are some very interesting and distinctive differences between the ribs of the Cathartidce and these bones, as found among the Falcon$i d a$ and the vulturine Raptores of the Continent; these differences are largely due to the form assumed by these very epipleural appendages, taken in connection with the greater breadth of the pleurapophysial bodies as already referred to, and shown to be characteristic of the family we are describing.

We present a few outline, but accurate, sketches of these bones, chosen from several species, given in life size, as the best way to demonstrate these very striking and really diagnostic features. The first, marked $m$, is the rib from the anterior dorsal vertebra, taken from the left side

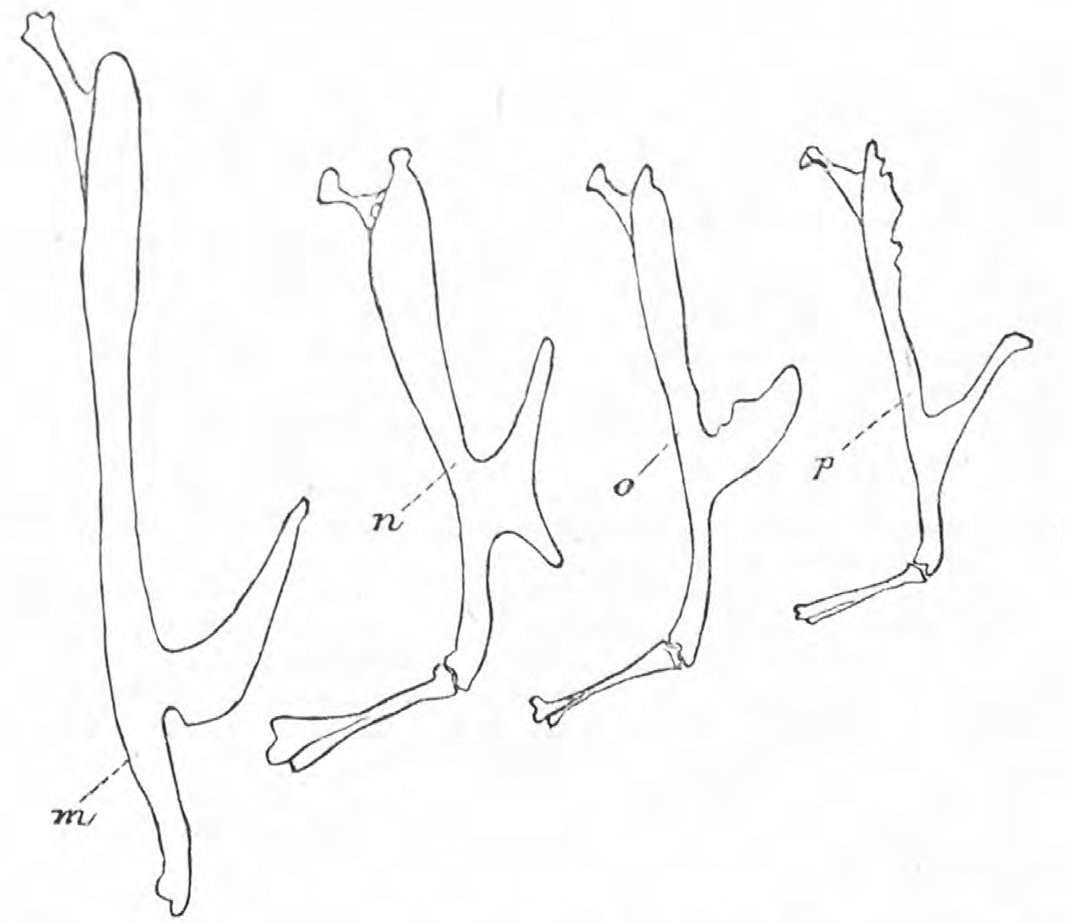

of Pseudogryphus; $n, o$, and $p$ are the ribs, from the same side, of the second dorsal vertebræ of Catharista atrata, Neophron percnopterus, and Circus hudsonius, respectively. The feature which we desire to direct the reader's attention to particularly is the descending process of this pleurapophysial appendage, here best seen in $C$. atrata $(n)$, though it is no better marked in this Vulture than in others of the family to which it belongs. This peculiar form of the epipleurals of the ribs in the Cathartida is most decidedly marked among these bones chosen from the middle of the series, though it persists in a less degree in the first dorsal rib, as seen in $m$ (Pseudogryphus), as well as in the appendage when it 
necurs on any of the sacral ribs. We know of no instance among the Falconida where it erer assumes such a form; and its outline as seen in Neophron (o) leads us to believe that this is only an additional ex. ample where these birds depart from the Cathartidie and tend towards the Falconida.

The first dorsal rib in Gypogeranus serpentarins bears no epipleural appendage; in the second it is broad and short, with a minute descend. ing process below, very close to the margin of the rib; in the third this unciform appendage is long and narrow, and is in contact with the rib for its entire length, sloping away below; in the last dorsal it appears only as an increased widening of the rib for a certain distance along the usual site of its occupancy. Sternal ribs that in descending meet the dorsal ribs are, like these bones, strong and robust; they possess quite extensive quadrate facets for sternal a: ticulation at their lower ends, that when placed in situ in the.skeleton cause these bones to be turned outwards, so that their anterior faces are visible from a direct lateral view. Their posterior ends are progressively from before, backwards, curved in such a manner as to preserve the oval form of the chest walls, and are very much dilated as we proceed in that direction; at their distal extremities they support the usual facets for the vertebral ribs. In the Secretary Vulture they become very much compressed from side to side as we examine them successively in the order referred to, and in this course, too, in some of the Falconida, they become curved in an anteroposterior direction, the concave margin being in front. In these birds and in our specimen of Neophron the sternal ribs are seen to be much slenderer than corresponding bones in the Cathartida.

Additional protection is afforded the contents of the thoracic and ab. dominal cavities by ribs descending from the sacral vertebræ; by free sternal ribs in other species, and by the meeting and articulation of both in others. To complete the description of these important and serial auxiliaries to the stability of the chest walls, we will say what we have observed in regard to these sacral ribs here, so that we will be left comparatively free to deseribe that bone as a unit.

Sarcorhamphus gryphus has three of these ribs on either side; the first two pair support epipleural appendages and articulate with the sternum through the agency of well-developed sternal ribs. The last pair are devoid of the unciform projections, and their sternal ribs in turn articulate by their distal extremities and a small portion of their distal and anterior margins along the posterior borders of the sternal ribs in front of them, their points coming within about a centimeter of the costal border of the sternal body on either side. We believe, after an examination of such parts of our skeleton of Pseudogryphus as refer to this region, that the arrangement will be found to be the same as we have just attributed to the South American Condor. Gyparchus possesses two pair of these ribs, both articulating with the sternum by sternal ribs that are the largest and longest of the series. The first pair have unciform processes. Sometimes in this species an additional rudimentary pair are found to exist, and belong to the next vertebra beyond, but ail the distinctive characters of the upper part of a rib have been absorbed by the under surface of the illium, so that this pair almost has the appearance of being offshoots from the ossa innominata.

In Cathartes aura we discover two pair, the first connecting with perfect sternal ribs coming from the sternum below, and support epipleural appendages; the last are withont them, and otherwise behave as we described the ultimate pair in Sarcorhamphus. Passing to Catharista, we find the same arrangement present as in $C$. aura, but in addition a 
pair of rather long styliform rudimentary ones are found, with their capitula, tubercula, and necks absorbed as we saw them when they occurred in Gyparchus, though evidently belonging originally to the next vertebra in order. So that among the Cathartide the variations observable among the plans for the sacral ribs resolve themselves into the following four classes: They vary as to the number of pairs; as to the presence or absence of rudimentary ribs; as to the method of articulation of the last pair of sternal ribs, whether these descend to the sternum or articulate along the posterior border of the pair in advance of them, thus constituting what might almost be termed "floating sternal ribs"; and, finally, as to the arrangement of the unciform processes.

Turning to such specimens of the Vultures of the Old World as we have been able to learn anything abont in this regard, we perceive at once that we have an entirely different set of "plans of arrangement" presented to us. In Neophron percnopterus we have a free pair of sternal ribs that articulate with their anterior ends on facets in the costal borders of the sternum, just as any other pair of the series do; no evidences of a corresponding pair of sacral ribs descend to meet them.

Mr. Lueas tells me that he found in Vultur cinerea and Gyps bengalensis that the ultimate pair of sternal ribs were still free as we found them in Neophron, but that the anterior extremities articulated with facets in the posterior margins of the next pair of sternal ribs beyond them. He further says that in Otogyps calvus "a very small floating rib is attached throughout its entire length to the last articulated sternal rib." This no doubt occurs on both sides, and is the same condition as we find in Gypogeramus, only the rib is longer in this latter vulturine Falcon. Cases of asymmetry no doubt occur among many or all of these various arrangements, as, for instance, in the skeleton of Micrastur brachypterus that we have before us we find that on the left side six sternal ribs spring from the sternum, while on the right there are only five, the last or sixth one articulated with the posterior border of the sternal rib beyond it.

Of the scapular arch, sternum, and pectoral limb.-As in the majority of the class Aves, the scapular arch of the Cathartide consists of its pair of scapule, its pair of coracoids, and its furculum, or the united clavicles. This group of bones enjoys the usual amount of independence that we find in nearly all birds, in being distinct from each other and from the sternum. There is a very great similarity, both in ontline and general appearance of this arch as it is found among the Cathartide, and to this we may add that when the bones forming it are in situ in the articulated skeleton they present a patterm that not only possesses a common resemblance, but is peculiar to the family, and differs very decidedly from the Vultures of the Old Work and from the Falconide. We find in our present subjects that the sternal extremites of the coracoids are very much expanded in a transverse direction, that they touch each other, mesiad, when articulated in the sternal grooves or beds designed for them. These dilated ends are scooped out on their posterior aspects where the pneumatic foramina oceur, and roughened, while in front the surface is smooth, convex from side to side, and continuous with the general surface of the shaft. The inferior side is occupied for more than its imner half by the facet for articulation with the sternum; this is broadest mesiad, narrowing in each bone as we proceed outwards. The outer angle is truncate and presents an upturned tip of bone, and a face that is directed outwards. Very little shaft can be boasted of by these bones, for no 
sooner do the fan-like lower ends commence to contract to merge into a shaft than dilatation immediately sets in again to form the great tuberous heads that constitute the opposite and superior extremities. More of a true shaft exists in Catharista than in any other of these Vultures,

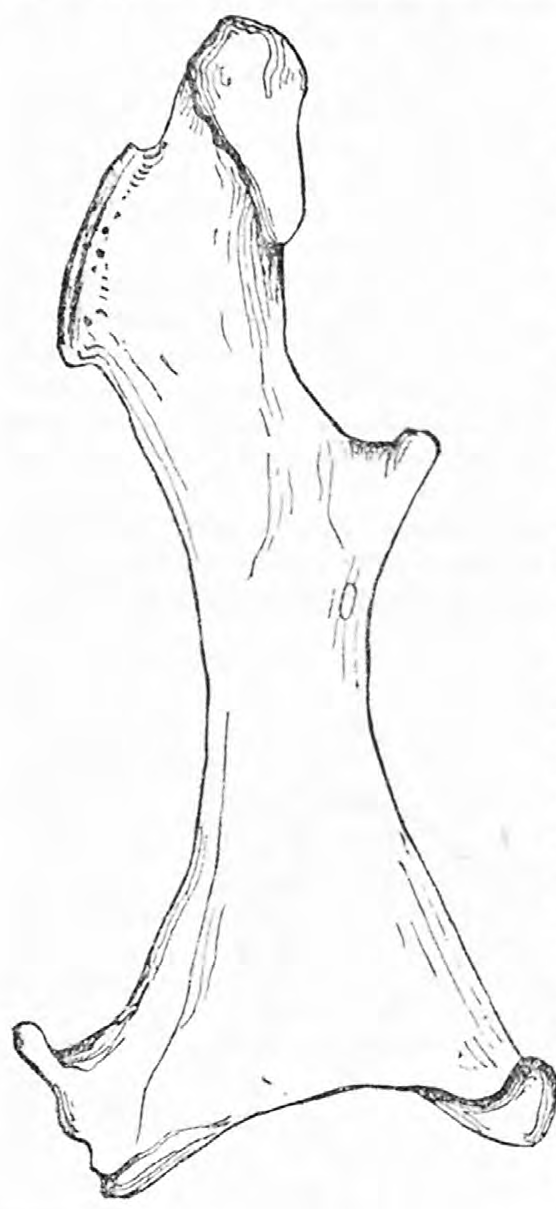
Right coracoid of Pseudogryphus, viewed from in is devoted to the articular facet for front; life size. longer in this species; in all it is more or less compressed from before, back. wards, rounded externally, sharper within, where in each bone it is pierced midway by an elliptical foramen, such as we found in speotyto. This last feature is scarcely perceptible in the Carrion Crow. In each the facet for the scapula is behind and rather to. wards the median plane; it is placed transversely upon the bone, oceupying the upper surface of the scapular process, and is continuous with the shallow glenoidal facet that is seen on the outer aspect. The coracoids terminate superiorly in rounded heads that are flattened from side to side, and present upon their mesial aspects smooth surfaces for the broad clavicular limbs. The bludes of the scapule are short and broad, being eurved outwards, with rounded points; they never reach back nearly so far as the pelvis, but generally overlap the last pair of dorsal ribs. The heads of these bones are flattened from above downwards, eurled up on their inner aspects, so as to afford surface to artieulate with the points of the clavicular ends, while externally they present raised elliptical facets that go to complete the glenoid eavities of each shoulder joint. The entire anterior margin of a scapula the coracoid. for the coracoids are proportionately

The glenoid cavity formed by the approximation of these two bones is quite deep and extensive, and thus far we have failed to discover the presence of the os humero scapulare, and its assistance is apparently not in demand as an additional aid to retain the humeral head in the socket in these birds (Plate XVIII, fig. 108), the usual ligament being substituted for it. Our figures for the representation of the os furcatorium show it to be the very type of the broad $U$-shaped variety or form (Plate. XXIII, figs. 123 and 125, C. aura), and such it pre-eminently is. Superiorly this bone presents for examination the great flattened ends that articulate with the coracoids and scapulæ on either side; these are drawn out into rounded points behind to reach the latter, while a limited smooth surface on the outer aspect of either limb comes in contact with a similar surface on each of the former. All of the surface within the $U$ is smooth and devoid of any points of particular interest. Without it, and above, in the expanded heads we find the eutrances to 
the great air passages, for they are more than foramina, that lead into the bone. No hypocleidium is found attached to the thoroughly united clavicles of these birds, below, but a little ridge occupies the usual site beneath and a characteristic tip projects from in front in all of them. Be. hind the borders are rounded, in front they are sharpened and produced out to the point of the aforesaid tip or anterior projection. With the scapular apparatus in position, we find that the axis of the shafts of the coracoids are in line with the long axis of the sternal body; that these bones diverge from each other at an angle that is equal to the angle of the clavicular fourchette. From behind their heads the articulated scapulæ spring out at nearly right angles, and pass backwards parallel with each other, to be deflected outwards only as we near their posterior points or extremities. After closing in the large "tendinal foramina" by its broad superior dilatations, the fureulum dips directly backwards to bring its lower arch into the recess of the anterior concavity of the carina of the sternum, but it never touches this bone at that point, and its near approach seems to vary for the same species; it is quite distant in the specimen of the King $\dot{V}$ ulture we present in figure 105, but in another it comes much nearer.

In the vast majority of the diurnal Falconide of this country, and, no doubt, in those of the Old World too, the clavicular heads have a much more extensive articulation with the superior ends of the coracoids than

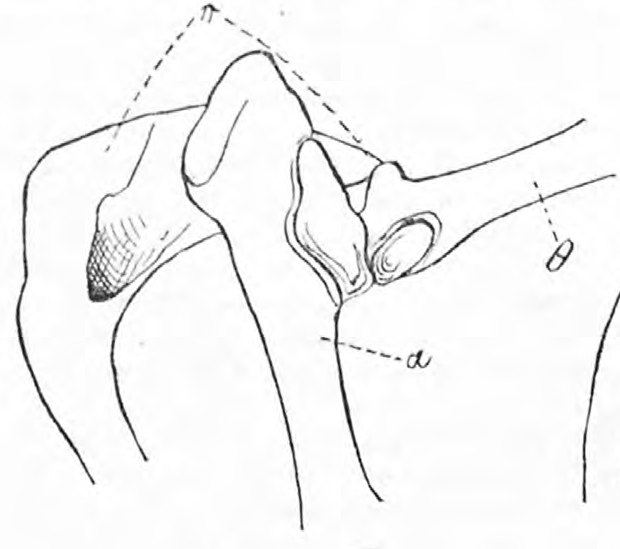

Catharista atrata.

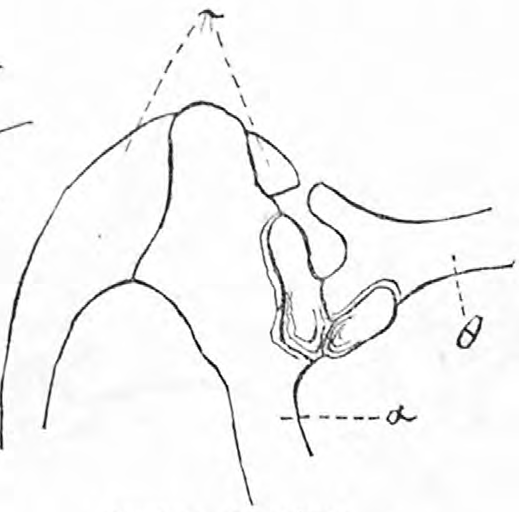

Neophron percnopterus.

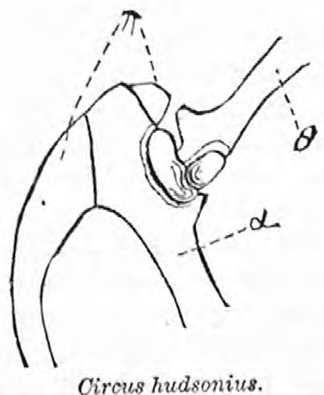

Cirous hudsonius.

we have just ascribed to the Cathartida; this arrangement is closely followed by Neophron, and, in short, the entire scapular apparatus of this bird is indubitably stamped with the well-known characteristics that mark this arch among the Hawks and Eagles. So interesting and 
important a matter is this, that we feel sure that our reader will be glad to examine the cuts we present illustrating these points in representative members of several of the families involved. The views are from an outer aspect of the joint in each case, showing the heads of the three bones of the scapular arch and the glenoid cavity. The bones are all lettered to correspond, and $\pi$ directs attention to the furculum, 0 to the scapula, and $\alpha$ to the coracoid.

The figure in the upper left-hand corner is of Catharista atrata, the figure below is of Circus hudsonius; the remaining one is of Neophron percnopterus.

In Catharista we see the common plan for all of the Cathartida, in which the clavicular head simply rests against the inner side of the coracoidal capitulum, while on the other hand, in Neophron and Circus, as representatives of the Falconide, the coracoid is actually molded to receive a corresponded surface on the clavicles.

Taken in consideration with other characters, we are compelled to regard this arrangement of the bones of the scapular arch as still another valuable and reliable character differentiating these birds from the Old World Vultures and still further establishing Professor Huxley's sound classification, as far as the Cathartida are concerned, in awarding them a family of their own. No one could be more disposed to draw family lines in birds with greater caution than the author, nor one more adverse to establish such lines upon any single set of characters, chosen either from points in external differences or internal structure; still such decided distinctions as this must have their due weight, occurring as it does, too, in a set of bones that, taken in connection with the sternum, have always been regarded by ornithologists the world orer as containing some of the most distinctive features in the avian sketeton, and even carried by some to such nnwise extremes as to be chosen for, and considered of sufficient importance to even construct and base a system of classification upon.

The scapular arch in the Cathartida is far more constant in its char. acters than the sternum itself, a bone we will now consider; and it strikes us, as we glance at the many specimens before us, still more forcibly how totally impossible it would be to take this segment alone as a criterion upon which to classify the class and yet have genera and species of known affinities arranged anything like approaching proper order. My views upon the value of such single characters coincide so well with those of Wallace, who so long ago as 1864 appreciated and recognized the truth of what we have been saying, that we give some of his sound remarks upon this subject:

* * * No one can be more convinced than myself of the utility of osteology, and especially of the sternum, in the classification of birds, and I sincerely trust that this great work may be bronght to a conclusion (referring to a paper of M. Blanchard's). I cannot, however, allow that osteological characters are an all-sufficing guide. Like every other character taken singly, osteology is a very uncertain and irregular test of affinity, and is, moreover, in almost every case accompanied by parallel external characters. Sometimes one, sometimes another part of the bird's organization has varied more rapidly, so that one group exhibits the most striking constancy of a part which, in another group, is subject to extremo modifications. The sternum is no exception to this rule, and by following it alone we should make the greatest errors in classification. For example, the sterna of the Finches and the Flycatchers are scarcely distinguishable, notwithstanding the great dissimilarity in almost every part of the structure of these birds-their bills, their feet, their plumage, their habits, food, and digestive organs. On the other hand, the sterna of the several genera of the Caprimulgide differ from ea h other more than do those of the most distinct families of the restricted Passeres. The Bee-eaters, the Barbets, and the Woodpeckers, again, are three very distir.et families, which, in a classification founded upon all parts of a bird's organization, camnot be brought in close contact; and yet, their sterna, according to 
M. Blanchard, much resemble each other. It is evident, therefore, that the whole structure of a bird and its corresponding habits may be profoundly modified, and yet the sternum may retain a very close resemblance to a common form; and, on the other hand, the sternum may undergo the important changes, while the general organiza. tion and habits are but little altered.

To prove that true aftinities indicated by the sternum are also in most cases exhibited in external characters, it is only necessary to refer to the paper above quoted, in which the relation of the Hummers to the Swifts, and the separation of the Hornbills, the Rollers, the Musophagida, and the Parrots, from the Passeres, were pointed out from the consideration of such characters alone. In that paper, however, I made two important errors, namely, putting the Todies with the Passeres (from the descriptions given of their habits) and including the Swallows among the Swifts. Tho character of the sternum is undoubtedly of great importance in finally settling such points as these.

I also at that time included the Psittaci among the Scansores; but I am now quite convinced that they deserve to rank as a primary division of the class of Birds, a rank to which the great peculiarity of the sternum, the large brain-cavity, and highly organized craninm fully entitle them.

With regard to M. Blanchard's determination of affinities from the body of the sternum only, without its appendages, I must remark that it often leads to erroneous results. For example, he says that the sterna of Merops and Tamatia do not differ enongh to deserve a separate description, and he includes Megalama with Tamatia in one section as having the same form of steruum. He notices some differences in the Picida, but remarks on their resemblance to Megalama and to the Toucans.

Now in all these points an examination of the entire sternum, with the furcula, coracoids, and clavicles attached, leads me to very different results. * * * These remarks are made in no spirit of depreciation of this very interesting and valuable work, bnt for the purpose of showing that isolated characters may lead to erroneous conclusions from whatever part of the organism they are chosen, and that in this respect osteological have no positive superiority over external characters. M. Blanchard tells us, in the introduction to this first instalment of his work, that he proposes to examine successively each separate part of the bird's skeleton. His future researches may therefore seriously modify the conclusions he has hitherto arrived at.

I cannot but think, however, that he would have produced a more satisfactory work if he had based it upon the comparison of the entire sternum, with its appendages attached, and also on the cranium, these two parts being of the greatest importance in classification.

It has been well observed by Professor Owen that those parts of an animal which have the least immediate connection with its habits and economy are exactly those which best exhibit deep-seated and obscure affinities. The wings, the feet, and the beak in birds may undergo the most extraordinary modifications in the same group in accordance with differences of habits and of external conditions, while at the same time snch apparently insignificant characters as the general coloring, the texture of the plumage, the scaling of the tarsi, or the color and texture of the eggs remain constant and reveal the true relations of the species. Thus it is that the form of the sternum is of such importance, since it has no immediate dependence on external form and habits. The Sparrow, the Flycatcher, the Wren, and the Sunbird all have one characteristic form of sternum, while between those of the Swallow and the Swift there is the greatest diversity.

It is evident, also, that the modifications of form immediately dependent on habits and external conditions are generally to be seen in the skin even better than in the skeleton of a bird. These are principally changes of form, size, and proportion in the bill, feet, and the wings, which are excellent characters for distinguishing genera and even families; while for determining the true affinities of isolated groups we must have recourse to those characters which, having no direct dependence on habits, \&c., are often persistent in a remarkable degree. Of these, no doubt, the sternum is of the highest value; but there are many others of almost equal importance. * * * Now that true principles of classification are becoming so much better understood, we may, I think, hope that the chaos which has so long existed in ornithology will soon give way to a truly natural system which must obtain general acceptance. - (Remarks on the Value of Osteological Charaeters in the Classification of Birds, by Alfred R. Wallace, Ibis, Lond., 1864, pp. 36-42.)

In some birds the coracoids and consequently the coracoidal grooves on the sternum decussate; now such a marked character as this would certainly have to be taken into consideration should we lay too great a stress upon this bone as a means of differential diagnosis in classification alone; and we might add to Mr. Wallace's examples such problems as how we would treat or dispose of Polyborus tharus and Ardea hero- 
dias by the decisions of such a system, as the condition just referred to is found to be present in both of these birds.

There is no distinct manubrium in the sterna of the Cathartida, as we find in Neophron and among the Hawks; this feature being supplanted by a massive and tuberous promontory in the median line, over which the broad concave coracoidal groores meet at the middle point above, to be produced shallower, narrower, and less distinct to the deep pneu. matic fossæ that are found on either side, just below the facet of the first sternal rib in the costal border, in all of these Vultures. The body of the sternum is oblong and deeply concave, being wider behind than it is anteriorly, and longer for its width in Catharista than any other. The general internal surface is very smooth, and so evenly distributed is the concavity that marks it that no distinct furrow defines the po. sition of the carina below, as in so many other birds. All of the borders are sharp and thin, except the anterior moieties of the lateral ones, that are more (Pseudogryphus) or less (Cathartes) occupied by the facets for the sternal ribs. These are small parallelograms, varying in size according to the rib they support, placed transversely and tipped slightly outwards, being separated from each other by subelliptical depressions that show the pneumatic openings at their bases. Beneath, the body is likewise smooth, and presents for examination the prominent pectoral ridges on either side, originating in eminences in the middle of the costal borders to be produced backwards and terminate just anterior to the mid-xiphoidal process, at the base of the keel. This lat. ter is very deep and strong in all of the Cathartida; commeneing be. low and within the manubrial prominence, it is carried out, mesiad, to the very posterior end of the bone; its anterior margin is always thickened, but in the Condors and Gyparchus the entire inferior rim is fonnd to be very much more so; in this latter Vulture, too, we observe that the anterior carinal margin is wider above and scooped out throughont its extent, having the fine median line passing down from the manubrial eminence to the carinal angle, that is present in all of these birds. A well-marked muscular line is found on either side of the keel, a few millimeters within its inferior boundary, extending from the carinal angle to be gradually lost before arriving at the posterior termination of this plate. It is less distinct in Gyparchus and the Condors.

There seems to be no exception among the Cathartide as to the fact that the xiphoidal end of the sternum exhibits many patterns for the same species; a circumstance that may be due to slight differences in age, but which certainly robs this bone in this family and in others where it may occur of a great share of its importance as possessing distinctive character in this respect. It is not strange, then, that scarcely two drawings agree as presented us by divers authors and ornithologists, much less any two verbal descriptions, so that, as far as these Vultures are concerned, a question of accuracy has arisen on many occasions, on the part of one observer examining the work of another, when, perhaps, a mistake very rarely occurs with any of us in one description of the con dition in which we found the notches or foramina at the xiphoidal end of the sternum in any of these American vultures.

One pattern is shown for $C$. aura in Plate XXIII, fig. 122, from a specimen seeured in Wyoming by the author, and we will give a few outline sketches here as the best means of showing the wonderful diversity that may exist, not only for the bird we have just mentioned, but for all, and even this characteristic is extended to the Old World Vr ltures (Neophron). 
For Cathartes aura we present the reader with the principal variations that we have found to exist, carefully selected from various sources and collections.

Mr. T. C. Eyton, in his Osteologia A vium (London, 1867), in a half view of the sternum of this Vulture, found it as in spec. No. 692 , here given, only the foramen was a little larger (Pate I, fig. 2, of Eyton's work). We, however, read in the text of this book, page 19-20 (C. aura), "Sternum in general shape similar to Sarcorhamphus, but with two large fissures on the posterior margin next the keel, and two fissures exterior to them; the remaining portions of the skeleton

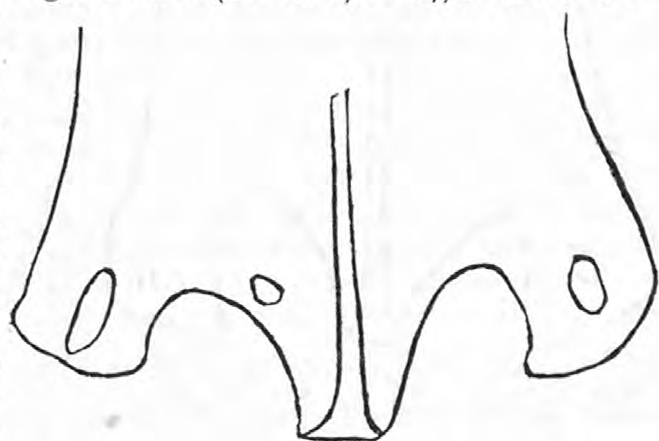

Cathartes aura, No. 6897 of the Smithsonian collection. are very similar except in measurements." Now here is a writer that actually contradiets his own drawings by the statement he makes in the text, and we can only believe that Mr. Eyton could have been led into such an apparent mistake by having several specimens of the sternum of this bird at his disposal, availing himself of one for his plate and another for his description, perhaps at a later date.

This gentleman found his specimen of "Cathartes niger," as we see from an examination of the plate presented, with a large cathartes aura, No. 3102 of the collection of the Smith. elliptical foramen on either side; while, on the other hand, in a specimen we received from Florida, and shown in the cut, the arrangement is seen to be entirely different. Gyparchus papa apparently shares the same fate that $C$. aura does in this respect, for in one Ecuador specimen (Plate XV, fig. 105) the xiphoidal margin is encroached upon on either side of the keel by a broad and rather deep notch, each being of the same size, while, in a specimen of this Vulture from Mazatlan, this is the condition of the bone on the right side of the keel, the left having an additional small notch to the outer side of the large one. Mr. Eyton found his as in our Ecuador bird, and describes it as having "two large open fissures," op. cit.

Referring to these matters, Professor Owen says:

In diurnal Raptores the sternum is a large elongate parallelogram convex outwardly, both transversely and longitudinally. The manubrium is short and trihedral; the 
lower border of the keel is convex; the front border concave; their angle of union rounded off. The instances where the sternum is entire have been cited; in other

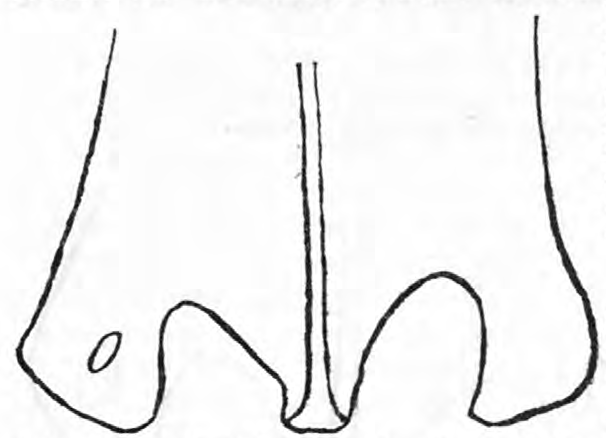
birds of prey the arrest of ossification is limited to very small parts of the hind border, usually a foramen, rarely a notch (Sarcorhamphus) on each side, one of which may be filled up, wholly or partially. Eyton figures two small notches on each side of the posterior border in Hierax bengalensis; and both hole and notch on each side in Cathartes aura.

In our specimen of Sarcorham. phus gryphus a faint indentation marks this posterior border on each side, but in Pseudogryphus trwo well. defined notches of equal depth are Cathartes aura, No.692 in the Smithsonian Institution. observed on either side of the keel.

Eyton states for the South American Condor:

Sternum:- * * Posterior margin in a young bird with two indentations, which are nearly obliterated in the old one.-(Osteologia Avium, p. 18.)

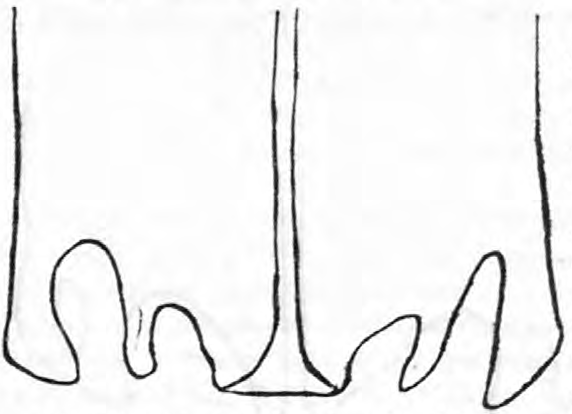

Catharista atrata.-Specimen from Florida.

Mr. F. A. Lacas, who kindly examined the specimens of the Old World Vultures in the Natural Science Establishment at Rochester for us, writes me that, "You will notice that the right sternal foramen of Neophron is closed (referring to a specimen sent to the Army Medical Museum); this was also the case with a second specimen, while a third, somewhat younger, had the foramen open, but much smaller than the left. A specimen of Ne. ophron from $\mathrm{N}$. India has both foramina open, and there are a few trifling differences between its skull and that of the Abyssinian specimens."

The keel of the sternum in Gyparchus has the antero-posterior curve along its lower margin, as we find it in Pseudogryphus and Sarcorhamphus (Plate XVII, fig. 107, P.californianus); this ontline is faint!y imitated by Catharista, but in this bird the border is not nearly so thick even in proportion. Cathartes has a convexity peculiarly its own, as distinguishing it from others of the family. The sternum is eminently falconine among the Old World Vultures in its general form and outline.

Professor Owen, contrasting the relative lengths of the segments of the pectoral limb as observed in the class, refers to it as found in the "powerful Raptorial flyers," as showing an intermediate and more harmoniously balanced proportion of the several segments. This is the ease, in a marked degree, with our American Vultures, for here we find almost a perfect condition of relative equipoise among arm, forearm, and pinion, not only as regards lengths, but calibers of the interested long bones. To place the former property in a more satisfactory manner before the reader, we present a table of the lengths of segments of the pectoral limb, given in centimeters and fractions of the same, of the members of the family under consideration, and add also measurements taken from Gyporgeranus and Neophron percnopterus simply for the sake of comparison. In all of the long bones the straght line joining the points furthest apart in distal and proximal extremities was taken 
as the line to measure upon; in the pinion, it was the straight line let fall from the highest point in the metacarpus to the extreme tip of the distal phalanx, the limb being closed.

Table showing the length of the bones of the pectoral limb in the Cathartida, given in centimeters; also of Neophron percnopterus and Gypogeranus.

\begin{tabular}{|c|c|c|c|c|}
\hline Species. & Humerus. & Radius. & Ulna. & Pinion. \\
\hline 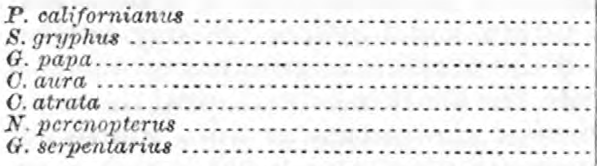 & $\begin{array}{l}27.8 \\
27 . \\
17 . \\
14.5 \\
14 . \\
14.5 \\
18.5\end{array}$ & $\begin{array}{l}31.2 \\
30.3 \\
20.4 \\
16.6 \\
15.1 \\
16.7 \\
19 .\end{array}$ & $\begin{array}{l}32.8 \\
31.6 \\
21.6 \\
17.5 \\
16 . \\
17.1 \\
19.8\end{array}$ & $\begin{array}{l}24.5 \\
23.5 \\
15.1 \\
14.5 \\
14 . \\
14 . \\
18.3\end{array}$ \\
\hline
\end{tabular}

In considering the relative position of points upon these segments during the course of our remarks, we must consider the bony framework of the wing as drawn up alongside the body in a state of natural rest, as seen in the King Vulture in Plate XV, fig. 105. The head of the humerus is bent not only downwards, but anconad, the reverse being the case in the distal extremity of the bone; these deflections, gentle as they are, and extended to a certain share of the haft, give to this segment, both from superior and lateral aspects, the usual sigmoidal curvatures.

At the proximal extremity we find a well-developed "greater tuberosity" in the form of the ordinary smooth convex and curling facet for the glenoidal cavity of the shoulder; below this occurs the tuberous and projecting "ulnar crest" or "lesser tuberosity" overhanging a large subcircular fossa, at the base of which we note the many pneumatic perforations, to allow the entrance of air at this end of the bone. The radial crest occupies a position for nearly one-third (Gyparchus) or more (C. aura) on the superior aspect of the shaft, proximad, exhibiting all of its most usual points of interest. It is quite vertical, turning outwards but very slightly, and strongly marked at the common sites by elevated muscular lines; this crest terminates over the greater tuberosity in a special broadened prominence, the continuation of its platelike portion beyond. (Plate XVIII, fig. 109.) From the dilated humeral head, we pass to a smooth and even shaft, that presents but little for our examination; it is elliptical on section throughout, the long or major axis being vertical, while below and nearly midway between the extremities we observe a minute nutrient foramen that pierces the bone from before backwards. Nearing the distal end of the humerus, the shaft gradually expands in a vertical direction, to support at its termination all of the characters commonly found there; these, like the ones we have just left at the proximal extremity, bear out their ordinary ornithic types. The external condyle is raised above the bone as a tuberous projection for muscular insertion; both internal and external condyles are produced anconad to form outstanding and lateral boundaries to a shallow olecranon fossa, into which pass longitudinal muscular groovelets. Beyond the prominent and strongly developed "oblique tubercle" and "ulnar convexity," we find in all of these birds a triangular depression on the palmar aspect of the bone, which lodges pneumatic perforations already referred to. These bones are very much alike in their general characteristics, among these Vultures there being no very decided points of difference in them beyond their size; this ap- 
plies pretty generally to the remaining segments of the pectoral limb. On the palmar aspect of the bone, at the base of the greater tuberosity, in Gyparchus, we find a deep pit that is not observed in the humerus of any other member of this family, though its site is marked in all by a very shallow depression.

In the Condors we find the radius straight and nearly parallel with tine ulna; particnlarly is this the case in Pseudogryphus, where for the distal two-thirds of its extent the interosseons space is of nearly an equal width; on the other hand, the bone is very much bent in $C$. aura, but here it corresponds with a compensating curvature of its fellow, and little change is experienced in the interosseons space. Strong muscular lines and decided development of the ornithic characters of the two extremities mark this bone. As a rule, the shaft is subtrihedral throughout, this being due to the prominence of the muscular lines aforesaid. A transverse facet occupies the entire extent of the distal aspect of its expanded outer end, and articulates as usual with the scapho-lunar of the carpus. The facet for the oblique tuberele on humerus is seen to be an elliptical concavity, placed vertically, with a broad, articulating surface, to its onter side for the ulna. One of the most striking features of the $u$ ln $a$ that attracts our attention upon first examining this bone is its well-defined and donble row of elevated quill-knobs for the bases of the quills of the secondaries; these are placed at about equal dis. tances apart, along the palmar aspect of the shaft for nearly its entire length (Plate XV, fig. 105, Gyparchus), the fainter row being seen beneath them, the knobs being placed opposite each other. About its proximal end we note that the olecranon is but feebly produced, being nothing more than a general extension of the shaft, just sufficient to afford the necessary surface for the circular facet for the ulnar convexity on the humerus, the radial one being continuons with it, quadrate in outline, and much shallower. Upon the inferior face of the subtrihedral or proximal end of the shaft, we find in all of the Cathartida a long ellipti. cal depression, that is quite characteristic, and is absent in Neophron and the majority of the Falconida. Beyond this locality the shaft soon assumes the subcylindrical form, becomes gradually smaller in caliber to bear distally the trochlea surface for the remaining bonelet of the carpus.

All the members of this family after they have attained their full growth possess but the two usual carpal segments, the scapho-lunar (radiale) and the cuneiform (ulnare); these articulate with the long bones of the antibrachium proximad, and the trochlea surface afforded by os magnum, anchylosed with medius metacarpal, distad. Their general form varies but very little throughout the species, they bearing the common characteristics as we find them described for the class generally.

These remarks apply with equal truth to the metacarpus (Plate XV, fig. 105, and Plate XIX, fig. $110 \mathrm{~m}$.), a bone that is strikingly similar among the Cathartida, except in point of size, which, of course, varies with the species. It is constituted, as the bone usually is among birds, of the three united metacarpals; the short and projecting anterior one, or the poll'x metacarpal, being the first of the bird hand; next, the stout and largest of all, the second or mid-metacarpal, forming, as it does, the proper shaft of this compound bone; finally, the compressed and arched third metacarpal, thrown across, as an osseous span, between the proximal and distal extremities of the latter at its posterior aspect. On the palmar side of the second above, we find a prominent projection in all of these Vultures, that in the Tetraonidae was de- 
scribed as the pentosteon* that became anchylosed at this point as the bird advanced towards maturity. This is a characteristic feature in Neophron also. The trihedral and robust pollex with its undulating and superior facet for articulation with its metacarpal, bears below, in all of our American Vultures, a freely movable ungual joint; this appendage we have already described elsewhere, as well as the circumstances attending its diseovery. (Am. Nat., Nov., 1881, p. 906.) In the prepared skeleton, freed from all ligaments and soft parts, this joint consists simply, and in general terms for all of the Cathartida, of a compressed, usually from before, backwards, curved, and pointed bone, articulating upon a facette found just below the anterior margin of the pollex.t (Plate XV, fig. 105, Gyparchus, and Plate XIX, fig. $110 \mathrm{~K}$, Pseudogryphus.) Now this terminal phalanx of pollex may be found covered by the common integuments, and not visible when the wing has been stripped of its feathers, e. g., in Limosa freda and Numenius longirostris, or it may pierce the skin to be covered by a horny sheath, e. g., in many of the Ducks, Geese, and Swans.

The particular interest which attaches to the joint in the Cathartidce is, that it passes through the integument, up as far as its base, to be covered with a horny sheath outside, and so armed bears a very close resemblance to any of the claws of the feet. This is not the case among many other birds, as we have cited above; at least the writer, who has had the pleasure and opportunity to examine a large number of these birds in company with such an astute ornithologist as Mr. Ridgway, failed to find it, and we are indeed moreover compelled to acknowledge here that it

- I have proposed elsewhere the above term for this ossicle when free; I first detected it in the carpus of Centrocercus; it is the fifth segment of the avian wrist now recognized. It formerly bore the name of the pisiform, which I gave it, and with which it must not be confused, nor with a bone so termed by Dr. Coues in his osteology of the Laride. (Birds of the N. W., p. 600.)

tThe discovery of this claw excited not a little interest at the time. Mr. Forbes, of London, kindly noticed it in the following letter to the editors of the American Naturalist, which contains so much of interest on this particular point, that I take the liberty in republishing it.

\section{To the Editors of the American Naturalist:}

[December 7, 1881.

Gentlemen: I real with much interest Dr. Shufeldt's article in your journal for November last, on the claw on the "index" of the Cathartida, to the existence of which he had previously called my attention when I had the pleasure of making his acquaintance in Washington last month. Dr. Shufeldt certainly deserves great eredit for being the first to detect a structure, which has previously, so far as I am aware, escaped the notice of all observers. I may add that since my return I have been able to confirm the truth of Dr. Shufeldt's statements on specimens of Cathartes aura and C. atrata in my possession.

Allow me, as one perhaps more favorably situater than Dr. Shufeldt has been as regards the Jiterature of ornithology, to call my friend's attention to Nitzsch's "Osteographische Beiträge zur Naturgeschichte der Vögel," published at Leipzig in 1881 . In that $^{2}$ he will find an excellent account of the claw and phalanx in question as it exists in many other birds.

Nitzsch does not seem to have observed it in the Cathartida, but found it in Haliäius albicilla. Tinnunculus alaudarius, and some others of the Falconida. It is very conspicnous in Pandion. In fact the occurrence of such a claw is of very frequent occurrence in the class Aves, though by no means universal amongst them. Amongst birds in which it may be well seen, I may mention Struthio and Rhea, Cypselus, Caprimulgus, the Rallide and Parride. Such a claw must not be confounded, as has been done by some writers, with the long "spurs" covered by epidermic tissues, formed by out grow ths from the metacarpal elements, of most birds, as Parra, Palamedea, Plectropterus, \&c. In fact, the two may, as in Parra or Plectropterus, co-exist. Believe me, yours very truly, W. A. FORBES,

(Am. Nat., Feb'y, 1882, p. 141.)

\section{Prosector to the Zoological Society of London.]}

'The digit of the Avian manus, called "index" by Professor Owen, is now universally recognized by anatomists as really the pollex.

${ }_{2}^{2}$ Ueber das Nagelglieh der Flügelfinger, besonders der Daumen," pp. 89-97. 
was only very recently, and when in the study of this accomplished naturalist, who was present, and to whom the fact was also new, that this characteristic occurred in Fulica, Gallinula, and no doubt in the Rallida generally, not only those of our American avi-fauna, but among their cousins on the other continents. Mr. James Bell, of Florida, an excel. lent observer of the habits of birds in their native haunts, had that same morning (Dec. 28, 1881), narrated to Mr. Ridgway how, when he was in Florida, he had noticed that the young of Ionornis martinica actually put these claws to practical use by holding on to twigs in climbing ont of their nests, and sometimes even suspended themselves like bats do.

Professor Owen distinctly states that the Swan does not possess an external clan, when he says, after describing various claws and spurs as they occur among birds: "Although the instances of these weapons, and the occasional use of the wings in birds not so armed, $e . g .$, the swan, show them in the light of means of attack, the bones of the pectoral limb in birds are modified mainly for volant action."-(Anat. Verts, Vol. II, p. T4.)

Mr. J. A. Jeffries does not state exactly whether in the birds he examined the clano made its appearance through the integuments or not, in his interesting paper, upon "The Fingers of Birds." (Bull. Nutt. Ornit. Club, No. 1, p. 6, 1881). This writer remarks towards the close of his article, that "also where there are two or three joints respectively in the finger there are often claws on the end, thus pointing to ungual phalanges."

Since writing the article in the American Naturalist just referred to, I have, after more careful seareh among the specimens at the Smithsonian Institution, found this claw in Neophron perenopterus, Gyps fulvus, and Vultur cinerea, and it, no doubt, oceurs in all of the Old World Vultures, so that denying this fact was the most serious oversight that I allowed to ereep into that paper.

So far as our knowledge carries us at the present writing, however, we know of no author who has directly attributed this character to the Cathartida except ourselves. At the time the above paper appeared in the Naturalist such able ornithologists as Dr. Coues and Mr. Ridgway were macquainted with its existence, the author having the pleasure to call Dr. Cones's attention to the fact himself in a specimen of the Californian Condor; and Mr. William Brewster, an ornithologist whose knowledge of the external characters of birds and ability the writer holds in the very highest esteem, writes to me as follows:

"Your discovery of the claw on the index digit of the Cathartida is most interesting and unexpected. I am no anatomist, or I might have anticipated you, as I have had the pleasure (?) of shooting and skinning both the Black Vulture and Turkey Buzzard."

The second metacarpal supports its usual number of phalanges, the upper one presenting the ulnar expansion, common in so many of the elass and here well developed, affording below a broad facet for the most distal phalanx of manus, the second of this metacarpal being very much like the one representing pollex, only shorter and more delicately constructed. A phalanx is also freely suspended from the last metaearpal. This is the smallest one in the hand, being about half the length of the broad one of the second metacarpal, alongside of which it lies. This sometimes develops a tuberous process from its ulnar border, a feature that becomes quite prominent in Neophron.

of the pelvis and the lower extremity.-We have already enumerated, in our table of the number of vertebræ present in the different divisions 
of the spinal column, the number of the sacral segments as they occur in these Vultures. In every instance they form a thoroughly anchylosed "sacrum," which in turn combines with the ossa innominata by perfect osseous amalgamation along the borders, more particularly anterioriy, for posteriorly or in the post-acetabular region the union with the ilia always is visible, and in some species allows a thin knife-blade to be inserted in the interstice by moderate force (Pseudogryphus). The complete pneumaticity of the sacrum has already been cited and dwelt upon, and the facets for the sacral ribs, and how these ribs in some species unite with the ilia, has likewise been referred to in sufficient detail.

Viewing this compound bone from above, we find that it is only in C. aura of the species we have before us where the ilia fail to meet in the median line, and thus conceal the common neural spine of the pre-sacral vertebræ (Plate XXI, fig. 117). In this Vulture quite an interspace exists between the ilia, 8 millimeters at the narrowest place, which is filled in by the much compressed and very broad neural spine. Gyparchus makes the next nearest approach to this condition. In all the others of the Cathartides the ilia meet for a greater or less distance mesiad, and also slope downwards more rapidly from the line of junction, these bones in the pre-acetabular region of Cathartes being quite in the horizontal plane anteriorly. Without exception, the neural spine of the first saeral vertebra juts out beyond the anterior borders of the ossa innominata, as the anterior moiety of the segment does below.

Cathartes aura, from the arrangement just deseribed, seems to be the only one of the family that has a posterior opening on either side for the "ilio-neural" canals, the close approximation of the Sacrum of Catharista atrata; viewed from ilia in others of the group precluding it.

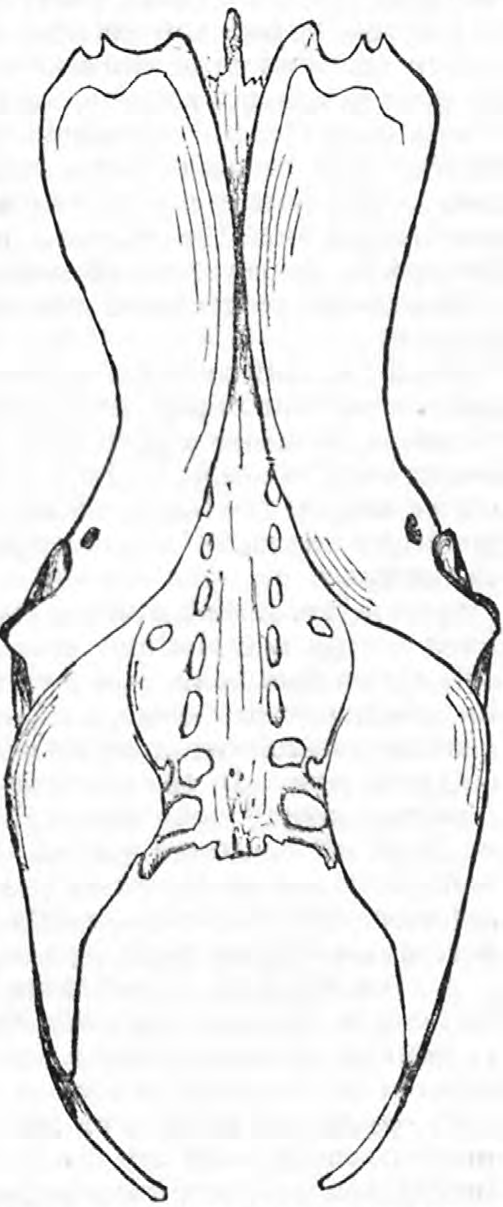

The thoroughly united neural spines on this their superior aspect in this bird are also broad and flat from one extremity to the other, while in Catharista and Gyparchus such portions of them that show behind are slightly rounded from side to side, a condition well narked in the Condors.

Referring the reader again to Plate XXI, figure 117, we observe how complete is the series, on either side, of interapophysial foramina in the Turkey Buzzard, and how an additional row of smaller ones exist outside of these; then by examining our cut of the sacrum in Catharista atrata (and the condition obtains next best in Gyparchus), we observe how it occurs among others; they are confined almost to the few ultimate vertebræ in Pseudogryphus and Sarcorhamphus. The anterior margins of the ilia are finished off abore by a smooth-and raised border, which 
seems to be produced over the extremities of the diapophyses of the first sacral vertebræ in Cathartes and the Condors. This border is ear. ried backwards a certain distance to be lost in the true gluteal ridge, of which it is the anterior extension. It is less prominent in Gyparchus, as seen in a good life-size figure of the sternum of this Vulture given by Eyton in his Osteologia Avium. Posteriorly, and where the sacral vertebræ are visible from above, the outline of the area they appropriate, is lozenge-shaped, the anterior angle being in the locality of the point where the ilio-neural canals terminate posteriorly in most birds; the posterior angle is in the last sacral vertebra, while the lateral angles are about opposite the acetabula, corresponding to the longest processes thrown out from the vertebra below as abutments at this important point. The last sacral vertebra, in all of the Cathartide, although well anchylosed with the one next beyond, is never completely grasped by the ilia, its transverse processes always projecting a little beyond.

The gluteal ridges meet then at a point, mesiad, in such of these Vul. tures as we have described the ilia meeting at a greater or less distance beyond the antitrochanters, they diverge to form bounding lines to the post-acetabular region, being carried in their course above the antitrochanters, in whose neighborhood they form lateral angles to be direct ad backwards, to terminate behind in the produced processes, or process on either side, of the ilium. Such part of the superior pelvie surface as is generally known as the pre-acetabular is carried or continued backwards to the space between the antitrochanter and the lateral angle of the gluteal ridge, on either side, consequently, for description's sake, slightly back of the acetabulum. This well defined region is formed on each side by an iliac bone, and confining ourselves to one side, we find it to be concave from before, backwards, as well as from side to side, the general surface being smooth and its narrowest part just beyond the cotyloid ring. In the Condors, less so in the rest of the family, the posterior moiety looks almost directly outwards, only slightly upwards, while in all the outer side of the anterior portion is directly upwards, and the inner nearly as in the posterior half; in Cathartes all of the anterior portion looks directly upwards, this Vulture having a much flatter aud broader pelvis generally than the others of the family.

As among Eagles and many other diurnal Raptores, the posterior half of the pelvis of the Cathartide, as well as the Old World Vultures, is bent downwards from a vertical plane passing through the bone tangent to the anterior arcs of the ischiatic foramina; this causes the post-acetabular surface or region to face backwards and upwards, it being bounded anteriorly by the gluteal ridges, posteriorly by a rounded border concave inwards, composed of the iliac margins and the last sacral vertebra.

The under side of the iliac surfaces, or such portions of them as are seen upon an inferior aspect, are in the horizontal plane anteriorly, and up to that point, as we proceed back wards to where the pleurapophyses and transverse processes of the first four or five vertebræ are thrown out to abut against and anchylose with them. The anterior face of the first sacral vertebra possesses all of the necessary elements to articulate with the last lumbar; its neural spine is quadrate and produced beyond the ossa innominata; the prezygapophyses look upwards and inwards; the entrance to the neural canal is elliptical with the major axis vertical. In all of the Cathartide the first sacral vertebra supports more or less of a well developed hypapophysis; this process is very large in our specimen of Pseudogryphus, possessing lateral wings and upon its anterior face bearing a small facet for articulation, with a similar process upon the last dorsal. This plate-like hypapophysis, merging with a more feebly 
developed one on the vertebra next behind, in this Condor, added to the marked lateral compression of the centra of the first three or four sacral vertebræ, give this bone an extremely odd appearance for its under and anterior half, the bone dipping far down into the abdominal cavity, a characteristic that is more or less evident among others of the family, but we do not find it so in Neophron, an Old World Vulture that pos.sesses a pelvis very much nearer the Falconida. Branches of the sacral nerves, the motor and sensitive roots, make their exit from the sides of several of the middle segments, the foramina being placed one above another, the largest apertures occurring in the mid-series, becoming smaller as we advance anteriorly or posteriorly.

The margins of the anterior, and at the same time horizontal, portion of the iliae bones are quite sharp. They converge to points at a greater or less distance beyond the acetabula, depending upon the species, where they suddenly become robust and rounded and continnons with a similar surface belonging to the "heads" of the pubic elements, or that portion of these bones on either side which complete the cotyloid rings. Opposite this, the constricted portion of the pelvis, or rather its narrowest part, we observe the greatest amount of enlargement of the neural canal to accommodate the ventricular dilatation of the myelon; here, too, short parapophysial braces come from the vertebræ, to be directed upwards, the anterior one abutting against the ilium on either side, the posterior rarely, if ever, meeting these bones.

Viewing the under side of the bone, we note that it is justbeyond this locality that we drop into what really may be designated as the "basin of the avian pelvis," and here usually the next three vertebræ throw out only their superior processes as braces to the ossa innominata, while the last five (Pseudogryphus, Cathartes, Catharista) or six (Gyparchus) sacrals have strong parapophyses that unite at their outer extremities with each other, and with the other processes coming from the vertebræ all along. the iliac borders on either side; of these, the first pair is the longest and are the ones opposite the cotyloid rings, the last two having all of their processes run more or less together, forming two pairs of strong rounded braces that are extended nearly horizontally to the "side bones." This pelvie basin is very commodious and deep, more particularly in the Condors and the Carrion Crow; this condition is much enhanced by a sort of reduplication that takes place from the posterior and united portions of the ilia and ischia, forming a concave recess on either side just within the ischiadic foramen.

Upon a lateral view of the pelvis, we find the acetabular ring nearly circular, the peripheries of the inner and outer boundaries coming nearest together in their upper and anterior ares, while at their posterior and upper arcs they form the outline of an extensive antitrochanter, whose surface is directed forwards, downwards, and outwards. The greatest amount of surface for the articulation of the femoral head, between the internal and external ring, is found anteriorly and below. A stout osseous pillar separates the cotyloid ring from the much larger and subelliptical ischiadic vacuity, which is posterior to it. Below and between the two we find the long, oval obdurator foramen, its major axis nearly parallel with the pubic bone, and a deficiency occurring at its posterior are, where this latter element fails to meet the ischium. The separating and outlying bone about these lateral openings in the pelvis of the Cathartides is thick and strong, more particularly about the acetabular ring, affording ample support for the powerful pelvic limb of these birds. The pubie style, after passing the obdurator foramen, is a moderately wide strip of bone, compressed from side to side, nearly or quite touch. 
ing for its entire length the lower ischial border, except in Gyparchus, where quite an interspace seems to exist. Its outer or posterior extremity is produced well beyond the other pelvic bones, to curve inwards towards its fellow of the opposite side, from which it is separated by a varying space two and a half centimeters in our specimen of Sarcor. hamphus, nearly one and a half in C. aura and Catharista. That portion of the outer and lateral surface of the ilium that is posterior to the ischiadic foramen, and below the continuation of the gleuteal ridge, looks downwards and outwards; opposed to it, below, is the ischial surface looking upwards and outwards; these bones thus form a longitudinal and shallow furrow between them, the anterior extremity being in the posterior are of the ischiadic foramen, the posterior extremity terminating in the apex of a notch that is found between the ilium and ischium in the posterior pelvic margin. This notch is acute or angular in the Condors and the King Vulture, but rounded in the Turkey Buzzard and the Carrion Crow; it is very distinctive of the Cathartida, none of the Old World Vultures or the Falconidce apparently possessing it, it being absent in all of the representatives of these latter birds that we have before us, the nearest approach to it being in Gypogeranus.

In reviewing the forms of the pelves of these Vultures and comparing them with each other we find, of course, for size, that the bone is largest in Pseudogryphus and Sarcorhamphus gryphus, and indeed in these two birds the pelves are very like each other. In general outline, and differing from the Condors, we find the pelves of Catharista and Gyparchus to be nearest alike, and to this couplet the pelvis of Neophron percnopterus approaches quite near, while Cathartes aura has a pelvis of a form differing from all the rest, and peculiarly its own, being at once recognized by the separation of the ilia anteriorly by the broad neural spine, and by its greater width as compared with its depth and length.

As already hinted, the pelvic limb of these Vultures is a very well developed one, and in every respect equally so with the pectoral extremity, which we have described above.

Among the species there are but few and trifling differences, except in point of size, though we note some departures from the typical form assumed by the Cathartide in Neophron, a Vulture that has a lower extremity more like the true falconine birds, as it did an upper one.

We find the pelvic limb in the Cathartida to consist of the usual number of bones for birds throughout the class, and, as a matter of some interest and no little importance, we insert here a table showing the comparative lengths of these segments, given in centimeters and their fractions, just as we did for the pectoral limb, choosing the same species and specimens to measure from, so that the two tables can be compared and the balance between the two limbs of any species taken into consideration; this will show at once the well-known discrepancy existing in Gypogeranus.

Table showing the lengths of the bones of the pelvic limb in the Cathartida, given in centimeters; also of Neophron percnopterus and Gypogeranus.

\begin{tabular}{|c|c|c|c|}
\hline Species. & Femur. & Tibia. & $\begin{array}{l}\text { Tarso-meta- } \\
\text { tarsus. }\end{array}$ \\
\hline 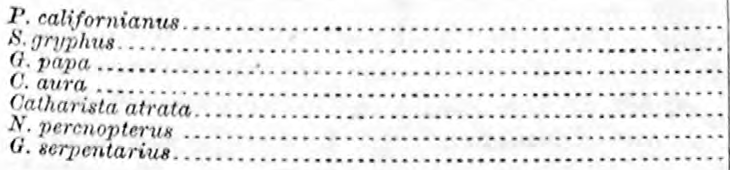 & $\begin{array}{r}13.6 \\
14.8 \\
10.1 \\
7 . \\
9.3 \\
7.3 \\
11 .\end{array}$ & $\begin{array}{l}22 . \\
\text { 17. } \\
\text { 11. } 9 \\
14.8 \\
11.8 \\
30.1\end{array}$ & $\begin{array}{r}12 . \\
12.5 \\
9.2 \\
6.4 \\
8.6 \\
7.5 \\
29.1\end{array}$ \\
\hline
\end{tabular}


These measurements show us that among the Cathartida, the Condor of our western country possesses the greatest extent of wing, although the South American one (Sarcorhamphus) has the longest legs; the same condition is also seen to exist between Cathartes aura and Catharista atrata. Also, in comparing $C$. aura with $N$. percnopterus, we observe that

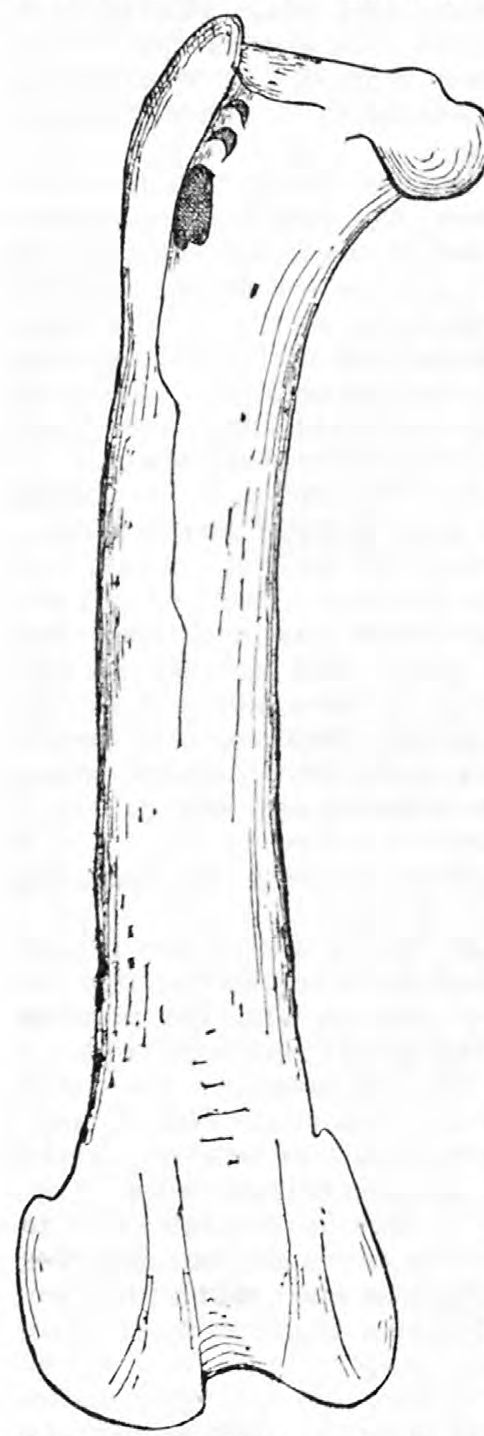

Anterior view of right femur from Pseudo. gryphus californianus; life-size. although the measurements of the segments of the pectoral limb are very nearly alike, the latter bird has a longer tarsometatarsus in comparison, even where the femur and tibia are nearly as in the first: here again we find in this old World Vulture a balance among the segments of this extremity that similates the Falconida.

The femur is so bent that a longitudinal line drawn along its anterior surface is convex outwards, the greatest curvature existing at the junction of middle and lower thirds of shaft. $A$ similar line drawn down its inner aspect is found to be concave.

The upper surface of the semi-globular head is in the same horizontal plane with the extensive articular facet at the summit of the bone for the antitrochanter of the pelvis, while above this rises the broad and prominent ridge of the great trochanter; below and to the outer side of which we find the pneumatic foramen ( $C$. aura) or foramina (Pseudogryphus), for generally the species show more than one.

The femoral head is eminently sessile with the shaft, and presents for examination above an extensive though single excavation for the ligamentum teres. Below the characters we have just enumerated as pertaining to the proximal extremity of the bone, the shaft rapidly becomes subcylindrieal, to dilate transversely at its distal or condylar end in the usual way. Near the middle of the shaft behind we observe the medullary orifice, and the ordinary muscular lines are tolerably well produced.

The rotular channel on the anterior aspect is moderately deep, rather wide, and of nearly the same width throughont; it passes beneath into a shallow, intercondyloid notch. In the popliteal depression, above the condyles behind, a deep pit exists; a few foramina are found at the bottom of it in Catharista atrata that may be pneumatic. The fibular cleft at the back of the external condyle is very decided, the inner half formed by it being produced well backwards in all of the Cathartida, as a prominent process to be applied to the internal aspect of the fibula in the articulated limb. Slight depressions are found, one on either side, in the broad lateral surfaces of the condyles, intended for ligamentous insertion. If a plane 


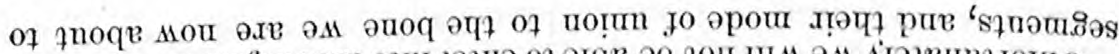

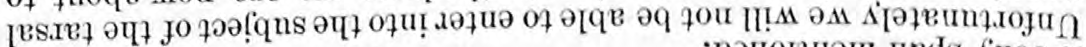

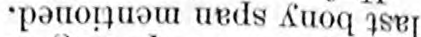

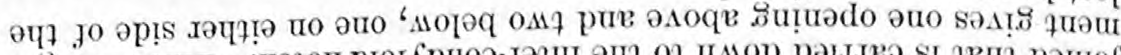

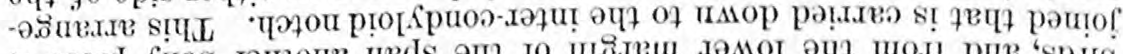

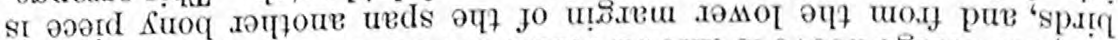

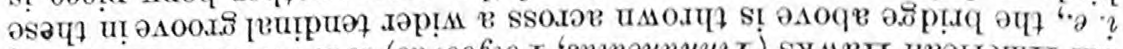

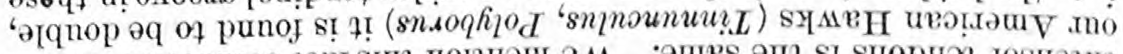

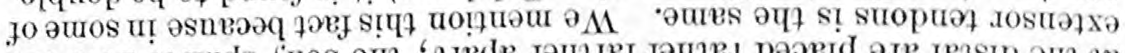

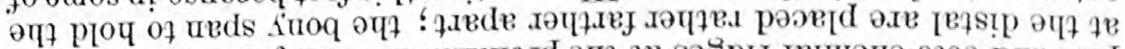

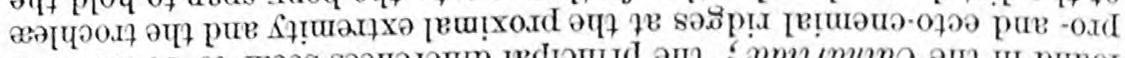

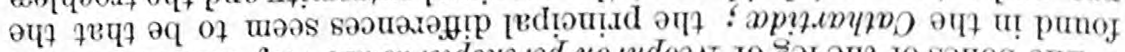

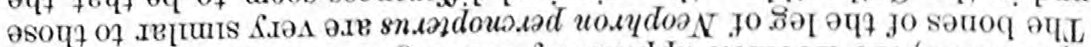

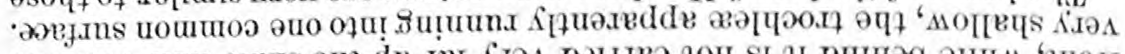

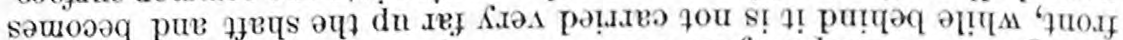

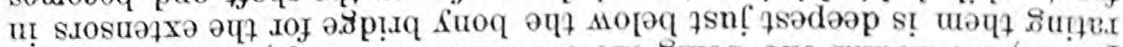

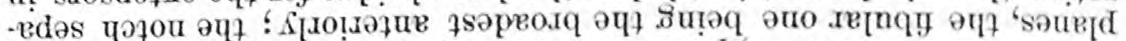

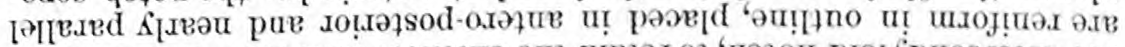

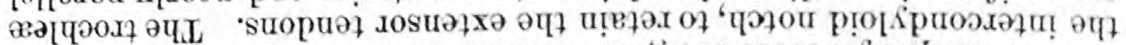

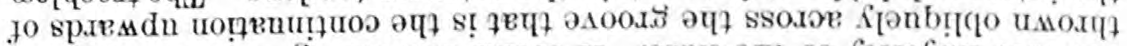

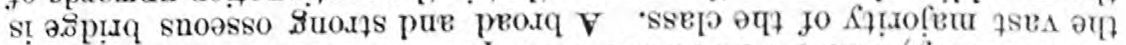

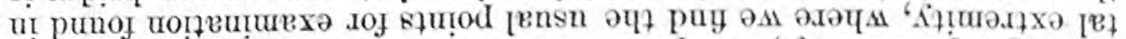

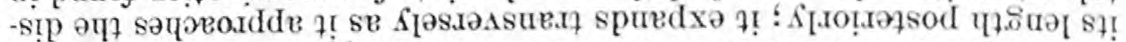

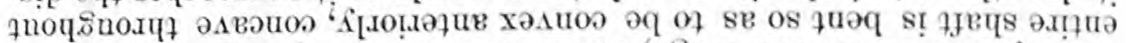

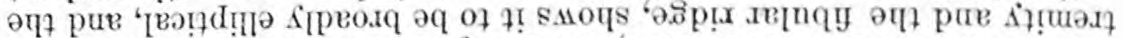

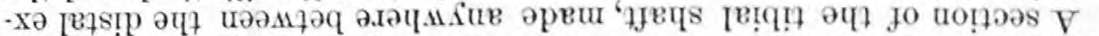

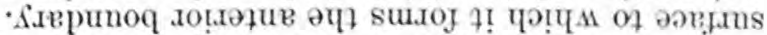

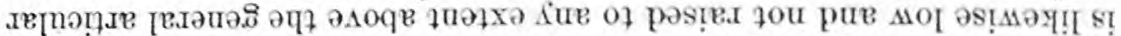

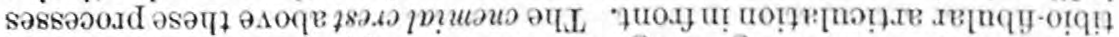

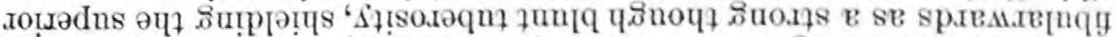

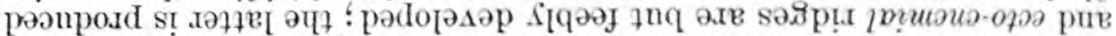

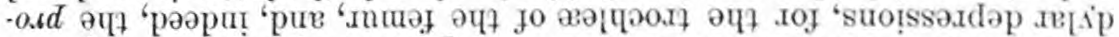

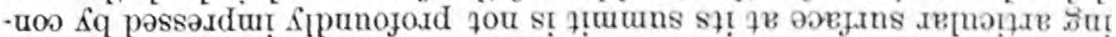

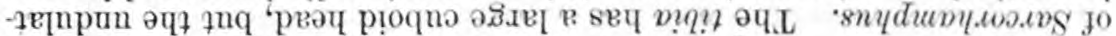

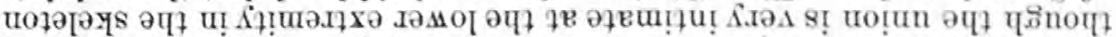

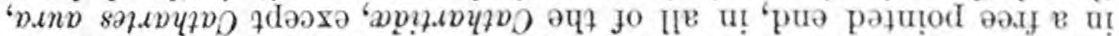

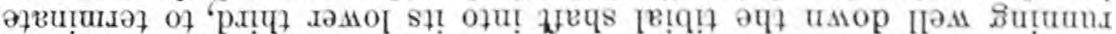

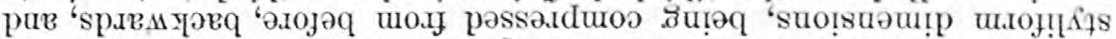

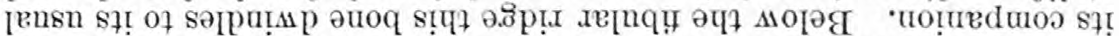

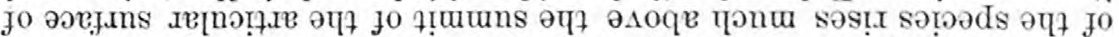

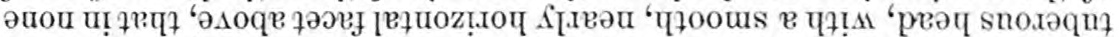

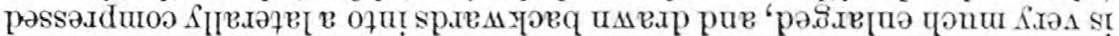

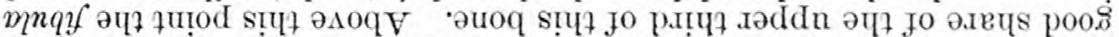

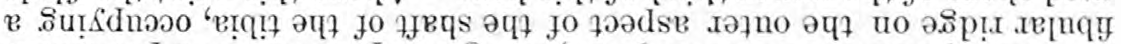

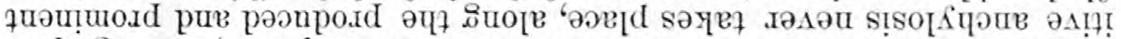

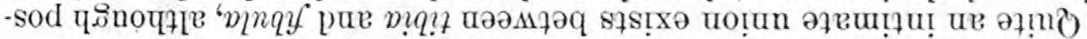

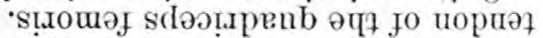

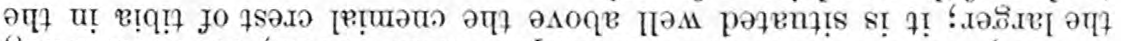

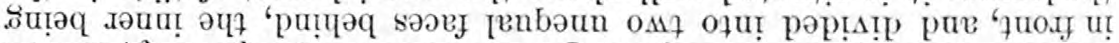

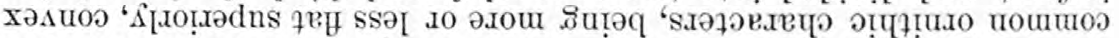

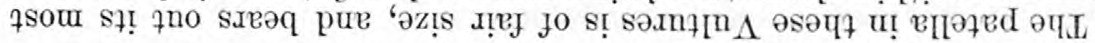

-spita

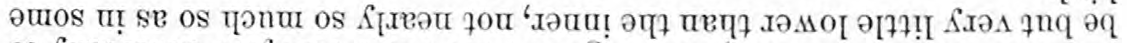

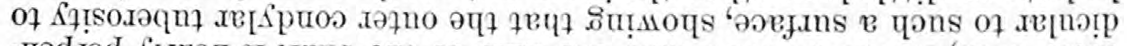

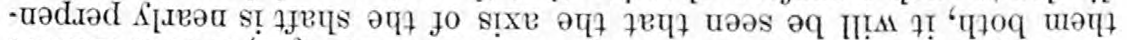

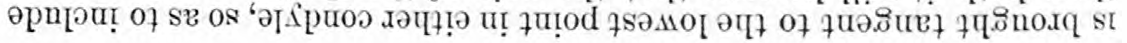


describe, and to the distal end of the tibia, as this requires the skeletons of the very young of the subjects in hand, material that I unfortunately do not possess.

The study of the forms assumed by the process or processes at the proximal and posterior aspect of the tarso-metatarsus is extremely interesting, and as important as many of the results are, the author is obliged to confine himself here to a hasty sketch of the general appearance of this tuberosity as it is found in the Cathartides and some of the Old World Vultures and the Falconida. Among all of the American Vultures it is a broad cuboidal process, placed at the extremity of the posterior aspect of the shaft, mesiad. It has leading away from it below a raised crest, that soon merges into the shaft, or the amalgamated mid-metatarsal.

In Cathartes this process is sharply grooved in a vertical direction behind. This is also the case in Catharista; the King Vulture has the process broader transversely, the grooving shallower, with its outer and posterior margins slightly produced. This condition is still further advanced in the Condors, while upon turning to Neophron we observe that it has been earried still further, so much so that the mid-vertical groove is now a broad concavity and the lateral productions appear as separate and rounded processes.

In Polyborus tharus it is a distinct, broad quadrate plate at right angles to the shaft. In Tinnunculus, this plate is not distinct, or rather it is carried far down the shaft to merge into it in the lower third; an intermediate form between the last two is presented by Micrastur brachyp. terus.

Gypogeranus presents it very much the same as in Cathartes aura, only rather longer for its width, which is quite natural in this bird of a stilt-like tarso-metatarsus. An instance of its being apparently double is seen in Buteo cooperi, one stout and quadrate lamelliform process, crowned by a transverse, subelliptical plate, standing prominently out from the fibular side of the bone, while absolutely separated from it on the tibial side we find a smaller though eminently distinet apophysis with its summit slightly bent outwards, the intervening sur. face being broad and only moderately concave between the two. Other Hawks also assume this form, as Circus. A tough piece of cartilage is placed over this process in the Cathartida, through which many of the flexor tendons pass. The summit of the bone presents two lateral concavities with a median anterior rounded tip, all for the accommodation, in the articulated skeleton, of the trochlex of the tibia.

Horizontal sections made at almost any point of the shaft are more or less parallelogramie in outline, and this portion of the bone is markedly straight in all of these Vultures, for we know that in many of the Falconida, and the condition is slightly observable in Neophron, that the tarso metatarsus is often more or less bent in the reverse direction of the tibia above. The shaft of this, the last long segment of the hinder limb, is very much scooped out on its anterior and upper surface; this disappears as we approach the distal end of the bone, where we find the large foramen for the anterior tibial artery occupying its usual site. Behind, the shaft is doubly grooved, in a longitudinal direction, markings that are about equally distinct throughout their course, each groove pass. ing down alongside the plate that was described as coming from the process at the upper and hind end of the bone. Two foramina pierce the bone at its upper part, appearing posteriorly on either side of the plate just mentioned. The three trochlear projections that terminate this bone distally are large and well separated from each other, the mid one being the largest, standing out in front of the others, and possesses 
a very decidied median groove that passes clear round its entire sur. face; this feature is usually absent on the lateral processes, of which the outer is the smaller; these are placed slightly to the rear of the middle one, particularly in the Condors, least of all in Catharista, in which Vulture all three are nearly in the same transverse plane. The concave facet for the os metatarsale accessorium is more than usually distinet, and this bone in the recent skeleton is attached after the common rule by ligament merely; it is twisted upon itself, rather long, but not so long as in Neophron in proportion, and supports its ordinary toe, of a joint or phalanx and an osseous claw.

Perhaps there is no better way of calling the reader's attention to the points of interest that are to be found in the feet of these birds than by comparing such a Vulture as Gyparchus papa, that has represented in these parts all of the characters of the Cathartide, with Neophron percnopterus, that as far as we know possesses in its foot all of the striking characteristics of the vulturine birds of the Old World. The joints of the toes follow the usual avian rule of $2,3,4$, and 5 segments to the first, second, third, and fourth toes, respectively. In the first or hind toe of Gyparchus, and in all of the Cathartida, the proximal joint is long and about equally dilated at either extremity, while in Neophron the end that artienlates by its concave trochlear surface with the os metatarsaleaccessorium is very much expanded transversely, while at the same time it is compressed from above downwards. The bony tubercle found at the under side of the proximal extremity of all of the claws is quite an insignificant affair in our Vultures as compared with the protuberance we find in Neophron, and, moreover, the claws are very much more curved in this latter bird than they are in the Cathartida. The proximal joint of the inside toe of Gyparchus is long, having all the characteristics of the other long segments of the foot, while in Neophron it is a markedly short and irregular bone, having, to be sure, its ordinary articular surfaces, one at either extremity. This difference can be made more evident by simple measurement; the first and second joints of the inside toe of Gyparchus measure respectively 2.2 and 2.5 centimeters in Ncophron percnopterus the same segments .7 and 2.4 centimeters, respectively. It is very interesting for us to know that in this matter of the shortening of the first joint of the inside toe Neophron follows all of the Falconida or their American representatives that we have been able to examine. Differences in the hind toe are not so striking, the segments in both birds being long and proportionately balanced, but in the outside toe again we discover a leaning on the part of Neophron towards the Fal. conida, while Gyparchus, in common with the rest of its well-marked family, still adheres to a proportionate equipoise in length of the internodes, this time it occurs in the second and third joints of the toe in question. These we will also compare by measurement: in Gyparchus, first, second, third, and fourth segments measure 1.8, 1.4, 1.1, and 1.6 centimeters, respectively; in Neophron the same segments measure, in the same order, $1.2, .5, .4$, and 1.5 centimeters.

In closing this monograph the writer did intend to give a general synoptical table, but upon second consideration believes the various tables already presented will sufficiently illustrate and compare, not only the decided generic differences among the Cathartida themselves, both as to external characters and the more deep-seated internal and osseous distinctions, but also serve sufficiently to individualize the group as a family ; so that, upon reviewing all that we have endeavored to present upon the osteology of these birds, we firmly believe that the reader will agree with us that our investigations have not only confirmed the fact that the Cathartide are widely distinct from the old World 
Vultures but enough so among themselves as to certainly warrant the family divisions into genera that we have followed in this paper. We further believe that the time is not far distant when the fact will be generally acknowledged, and Professor Huxley's admirable arrange. ment is this regard followed, that the old World Vultures are only entitled to the rank of a sub-family under the Falconidas. It is hard to perceive, even, how Mr. Sharpe can still adhere to his classification as given in the catalogue, where both New and Old World Vultures have been placed in the same family, Vulturida, and then divided into the two sub-families, I. Vulturince (Old World Vultures), and II. Sarcorhamphine (New World Vultures.) (Cat. Birds of Brit. Mus., Vol. I, 1874.) Let us take the very good example of Gyparchus papa from the second of these groups, and Neophron percnopterus from the first; snow-white skeletons of both of these birds, mounted upon their museum perches, are now standing before me, silent attestors, as far as their osteology goes, of the violence perpetrated by such an arrangement.

In Gyparchus papa we have the pterapophysial processes of the basi. sphenoid, the peculiar arrangement of the lacrymals, and the absence of the nasal septum, cranial distinetions of great importance and weight, while in Neophron a complete septum narum exists, and the pterapophysial processes are missing, characters it has in common with the Falconida.

Then, again, the differences in the scapular arch and sternum, the pneumacity of the skeleton on the part of the King Vulture, a condition not enjoyed to any such extent by Neophron, the arrangement of the sternal ribs, and, in short, down to the very toes, these two birds are stamped with characters that compel us to acknowledge that they belong to two very different families, and to such, along with others of their kind that possess similar and such undoubted differences in structure, they must eventually be assigned by universal consent.

Washington, August 31, 1882. 

PLATE XV.

Fra. 105.-Skeleton of Gyparchus papa, \&, one-third the size of life. 

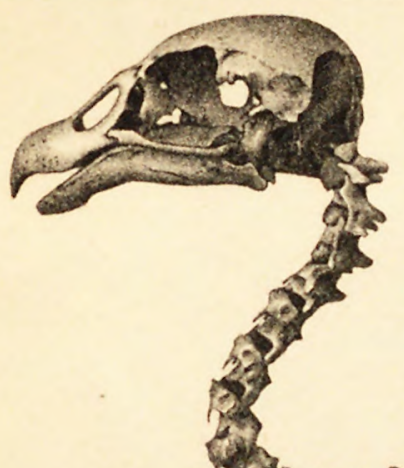

a.d. 5 ?
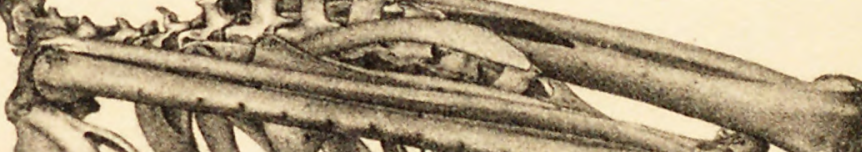
Dan
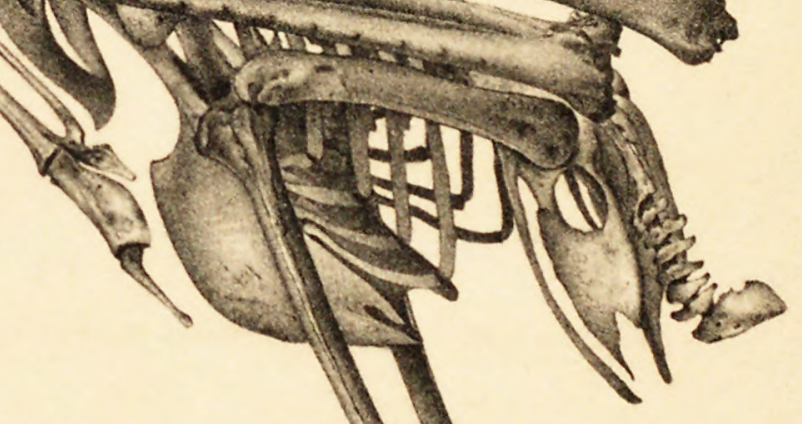

Fis 105
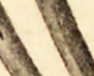


PLATE XVI.

Fra. 106.-Skull of Pseudogryphus californianus, left lateral view, life size. 


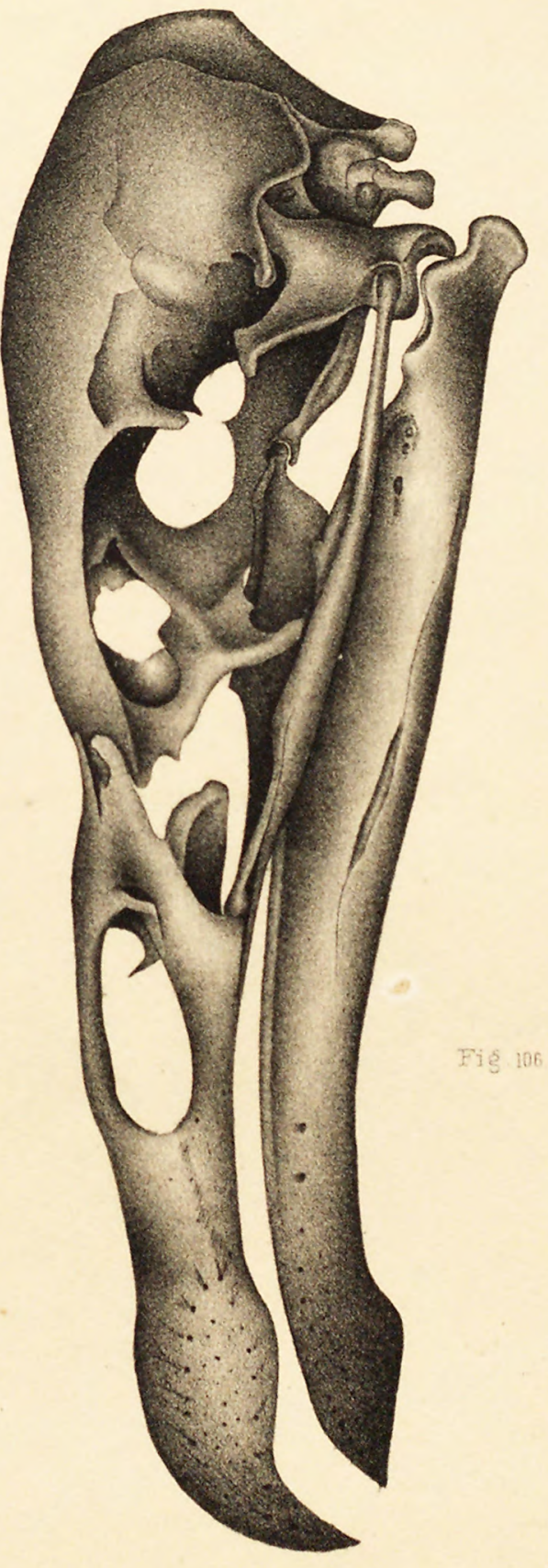

SHUFELDT ON THE OSTEOLOGY OF THE CATHARTIDAE. 


PLATE XVII.

FIG 10T.-Right lateral view of sternum of $P$. californianus, from same specimen as figure 106; size of life. 


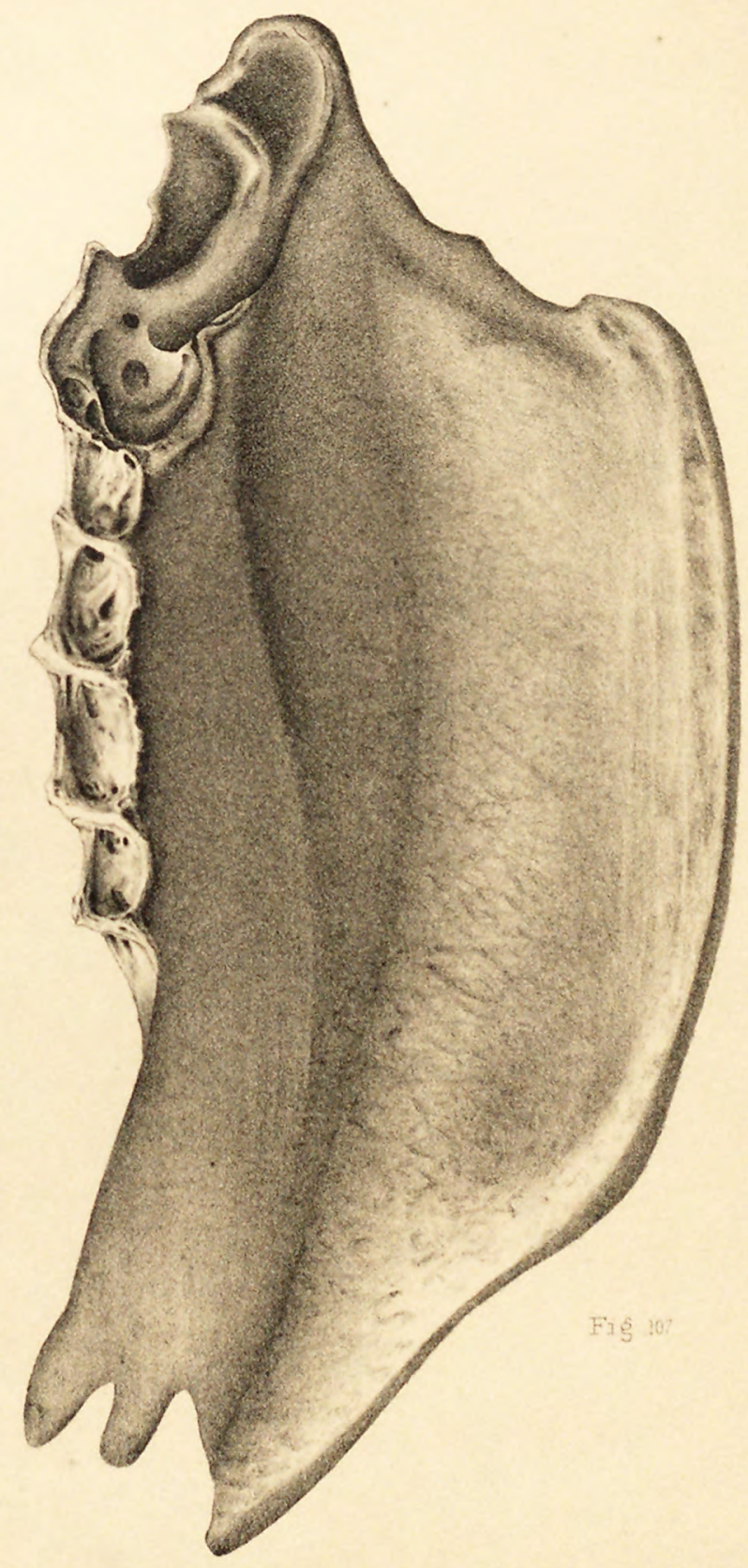

T. Smclax \& Son Lath. 


FIG. 108.-Right coracoid and scapula of P. californianus, size of life; the dried tissues, stretching across the glenoid cavity, assist in retaining these bones in their proper position.

FIg. 109.-Right humerus, anconal aspect, from the same individual; life size. The dark pit at its lower side shows the entrance to the largest of the pneumatic fossæ. 


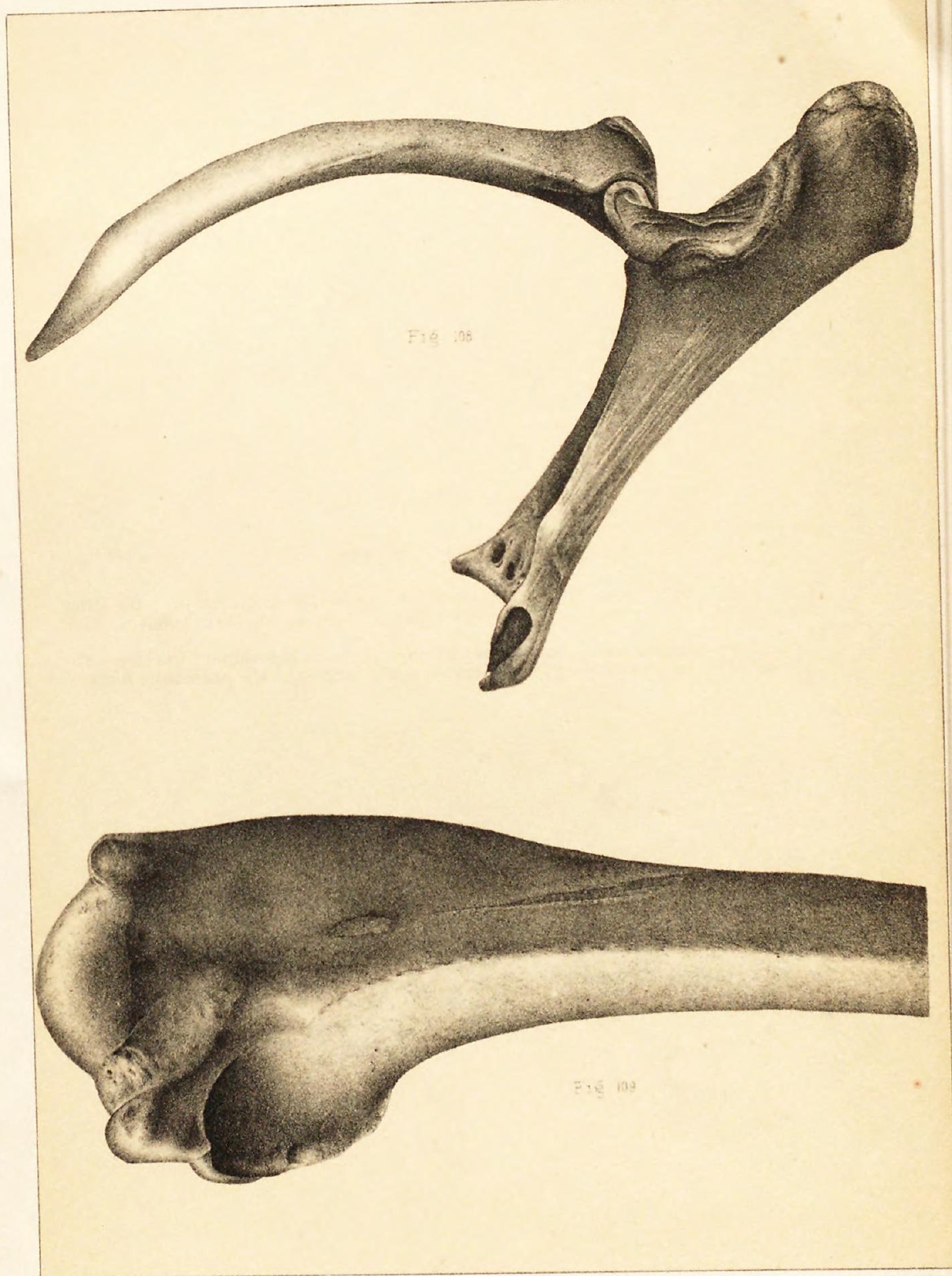

SHUFELDT ON THE OSTEOLOGY OF THE CATHARTIDAE

Hincian 2 Son Lith.

\section{SHUFELDT ON THE OSTEOLOGY OF THE CATHARTIDE.}






\section{PLATE XIX}

Fig. 110.-Outline sketch of the left metacarpus, $P$. californianus (same bird), with pollex $(\mathrm{K})$, and the bony core of the claw it bears, in situ; life size. $m$, metacarpus; d, pollex.

Fra. 111.-Furculum of Pseudogryphus californianus, size of life, from the same specimen; viewed from the left side, showing the positions of the pneumatic foramina and the roughened surfaces for the attachment of ligaments.

Fig. 112. - The last dorsal vertebra, from the same bird, life size, posterior aspect, showing the facets that articulate with the first sacral vertebra. $p f$, large pneumatic foramen. 

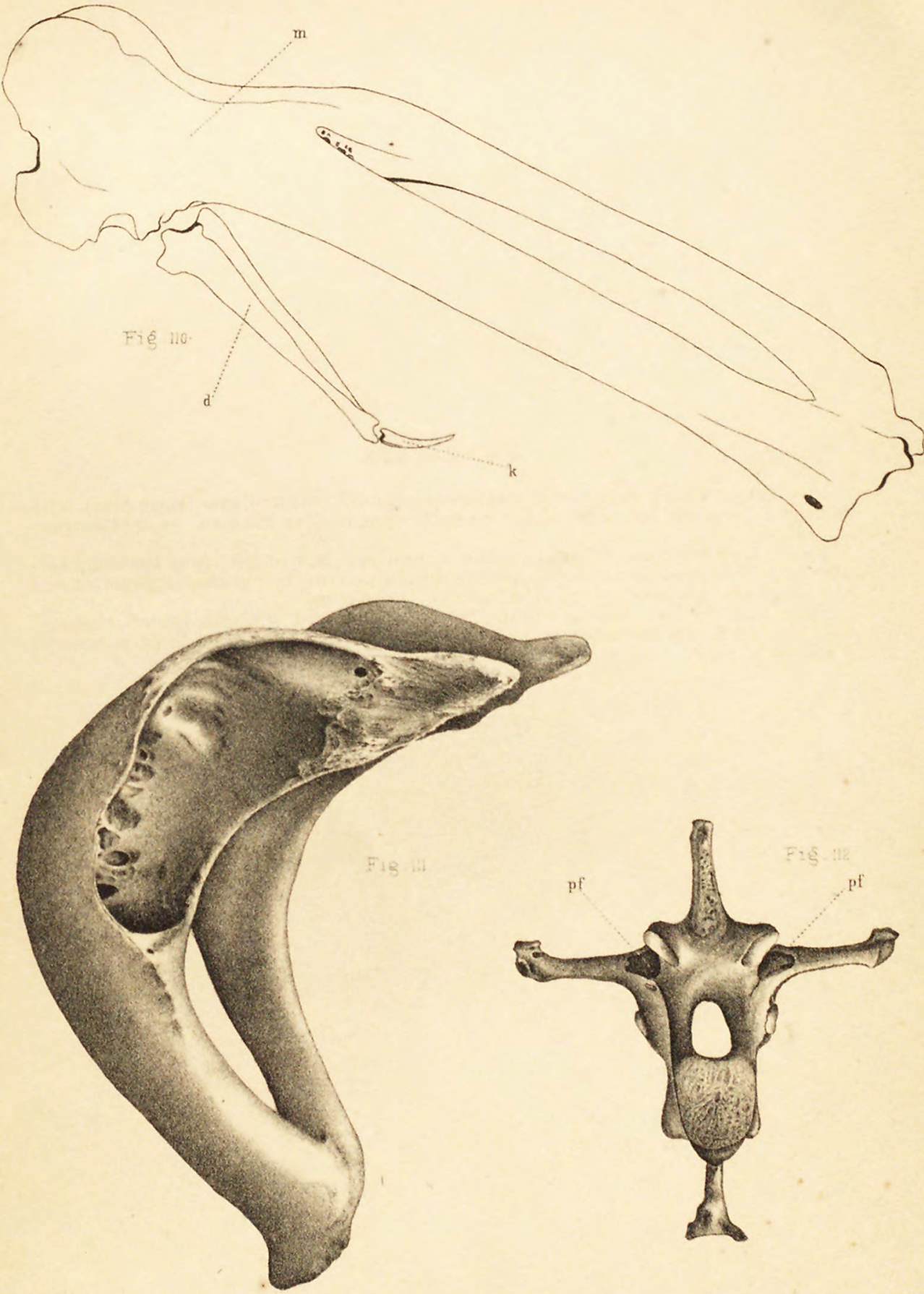

I Sinciorr \& Son Lish. 


FIG. 113,-Left lateral view of life-size skull of Sarcorhamphus gryphus. 


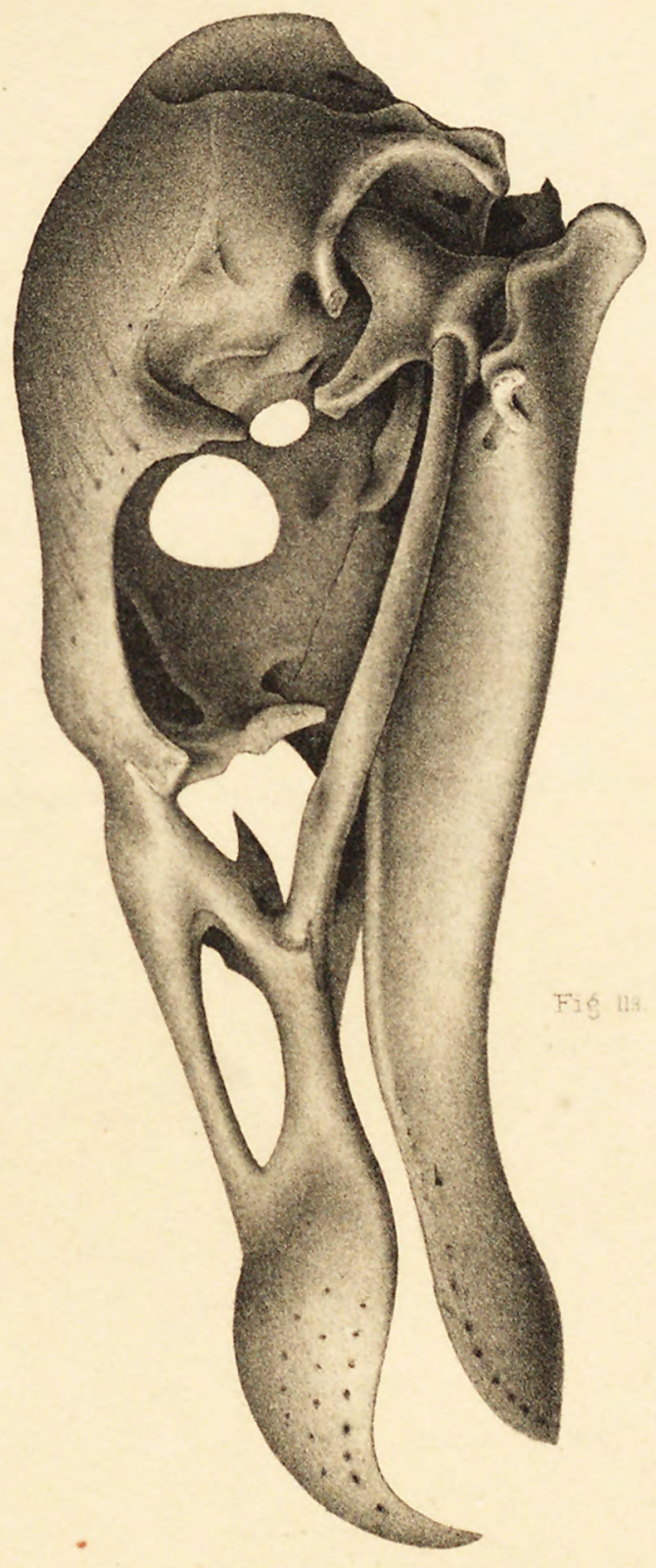

E Sinclair \& Son Jath 


Fig. 114, - The three last cervical vertebræ from Cathartes aura, seen from below, showing the formation of the cervical pleurapophyses from the processes of these vertebræ by gradual metamorphosis as the bird passes from young to maturity; specimen size of life. cy, ribs that remain free in the adult and after the change just referred to is complete.

Fig. 115.- Hyoid arch of the same bird.

Fig. 116.-Left lateral view of the skull of Gyparchus papa; size of life.

Fig. 117.--Superior aspect of pelvis of Cathartes aura, life size; candal vertebræ still in situ. 


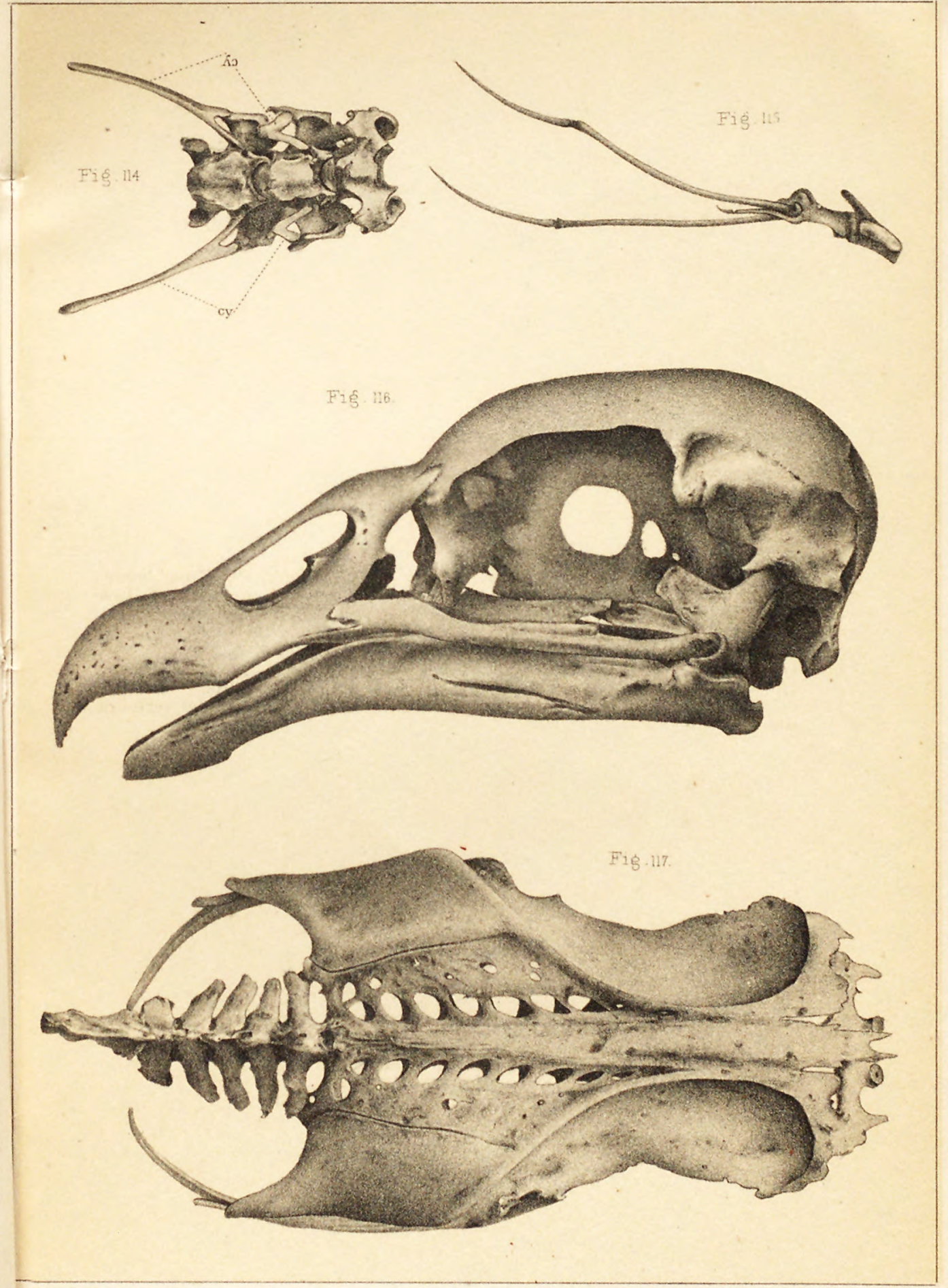

SHUFELDT ON THE OSTEOLOGY OF THE CATHARTIDAE. 


Fig. 118.-Left lateral view of skull of Cathartes aura, size of life; same specimen from which the parts referred to in the other plates were chosen.

FIG. 119.--Same, viewed from above.

FIG. 120.-Same, viewed from below. 

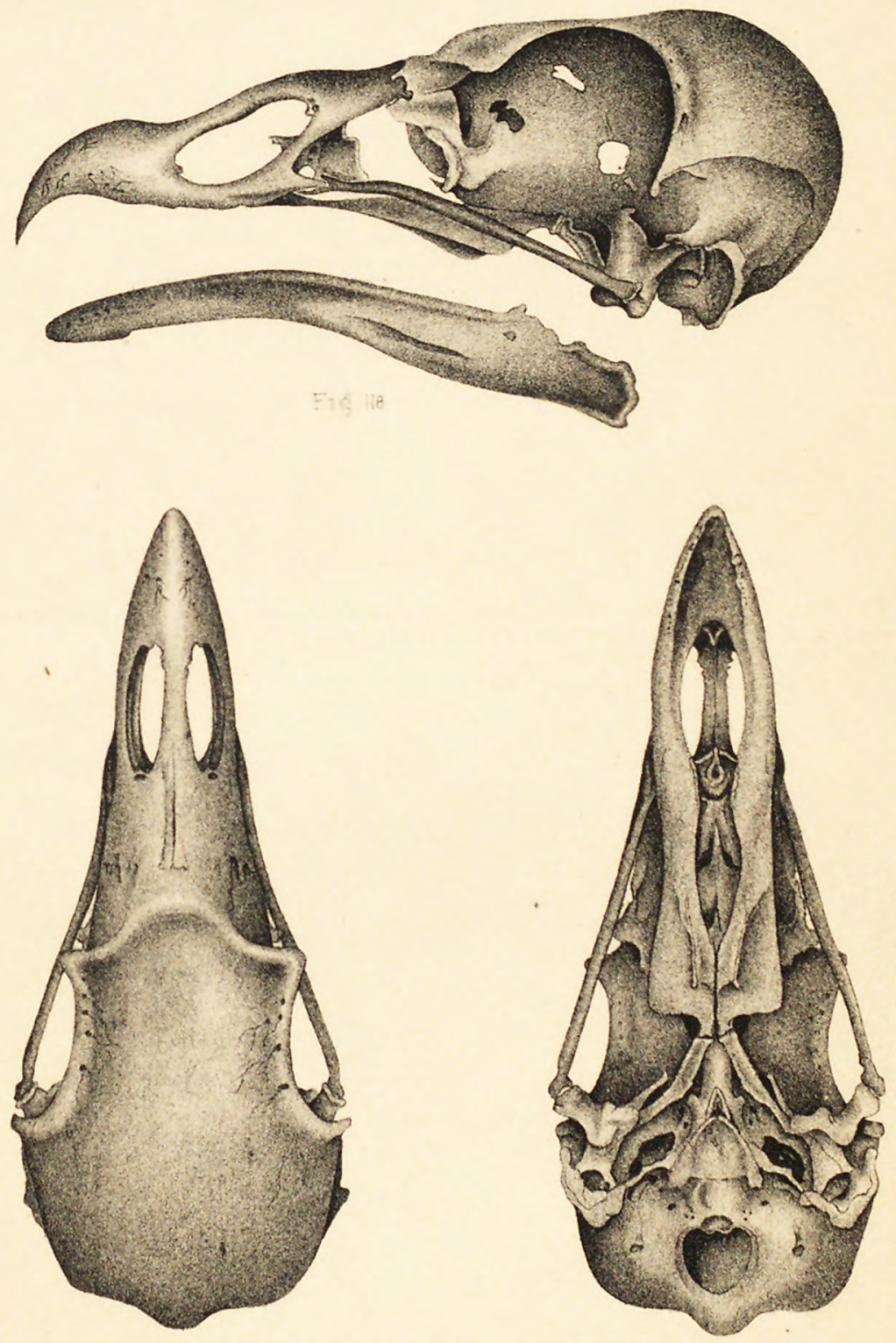

Sinclar \& Son wath 




\section{PLATE XXIII.}

FIG. 121.-Cathartes aura, same as in Fig. 118; right lateral view of sternum; size of life.

Fig. 122.-Same, seen from below.

FIG. 123.-Same specimen; dotted outline of furculum, life size, from in front; giving the general outline from this aspect of this bone as it occurs in the Cathartida.

FIG. 124.-Same specimen (C. aura) ; right outer aspect of coracoid and scapula; life-size. The bone is represented as resting on the plane of the paper.

Fig. 125.- Same specimen; right lateral aspect of the furculum, size of life, showing entrance to pnenmatic fossa, and the distribution of the smaller foramina. 

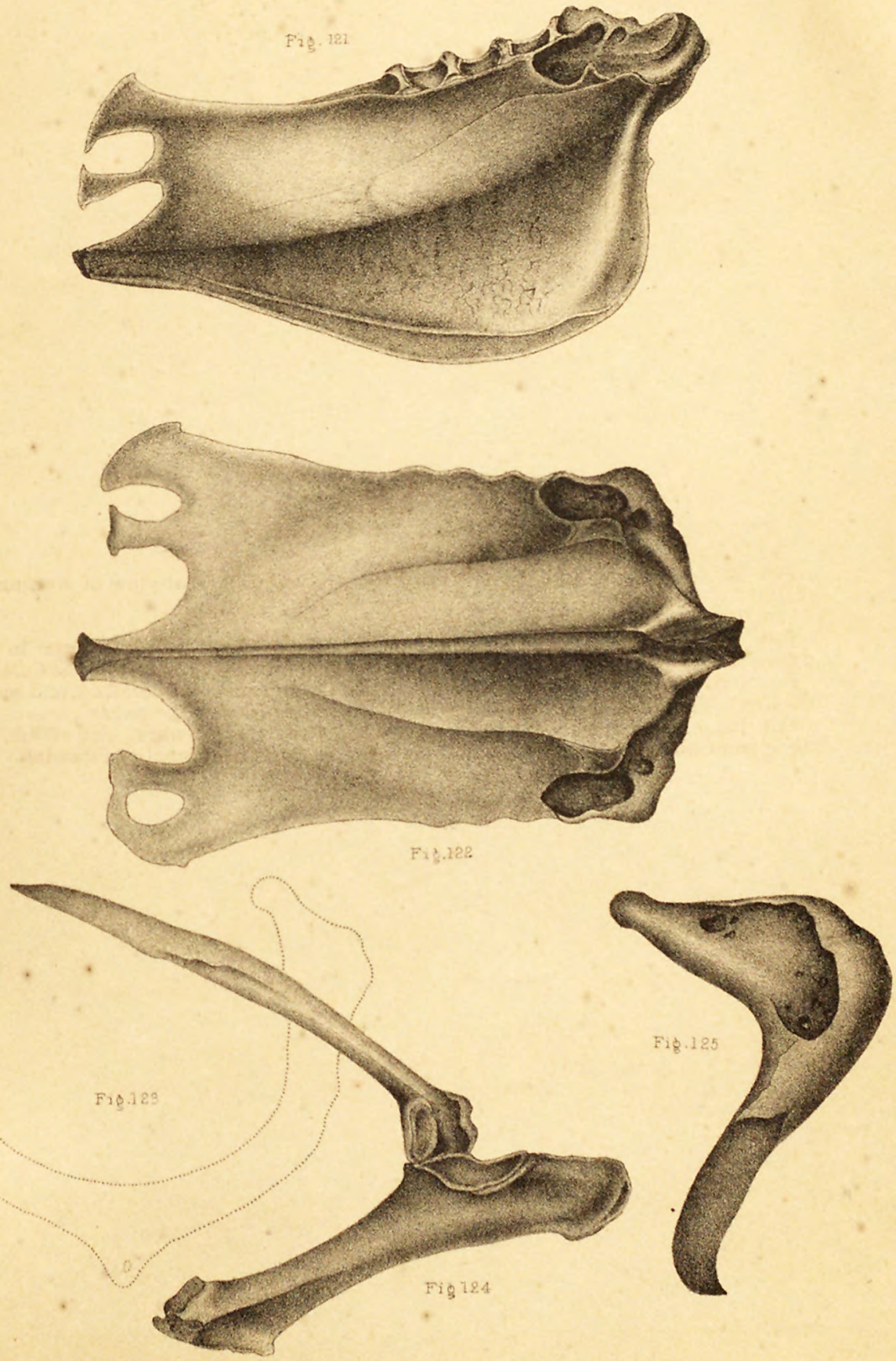


Fig. 126.-Left lateral view of the skull of Catharista atrata; life size. Fig. 12\%.-Same, from above.

FIG. 128.-Lower jaw, from above; same specimen.

Fig. 129.-Same specimen; the skull from below; life-size. 

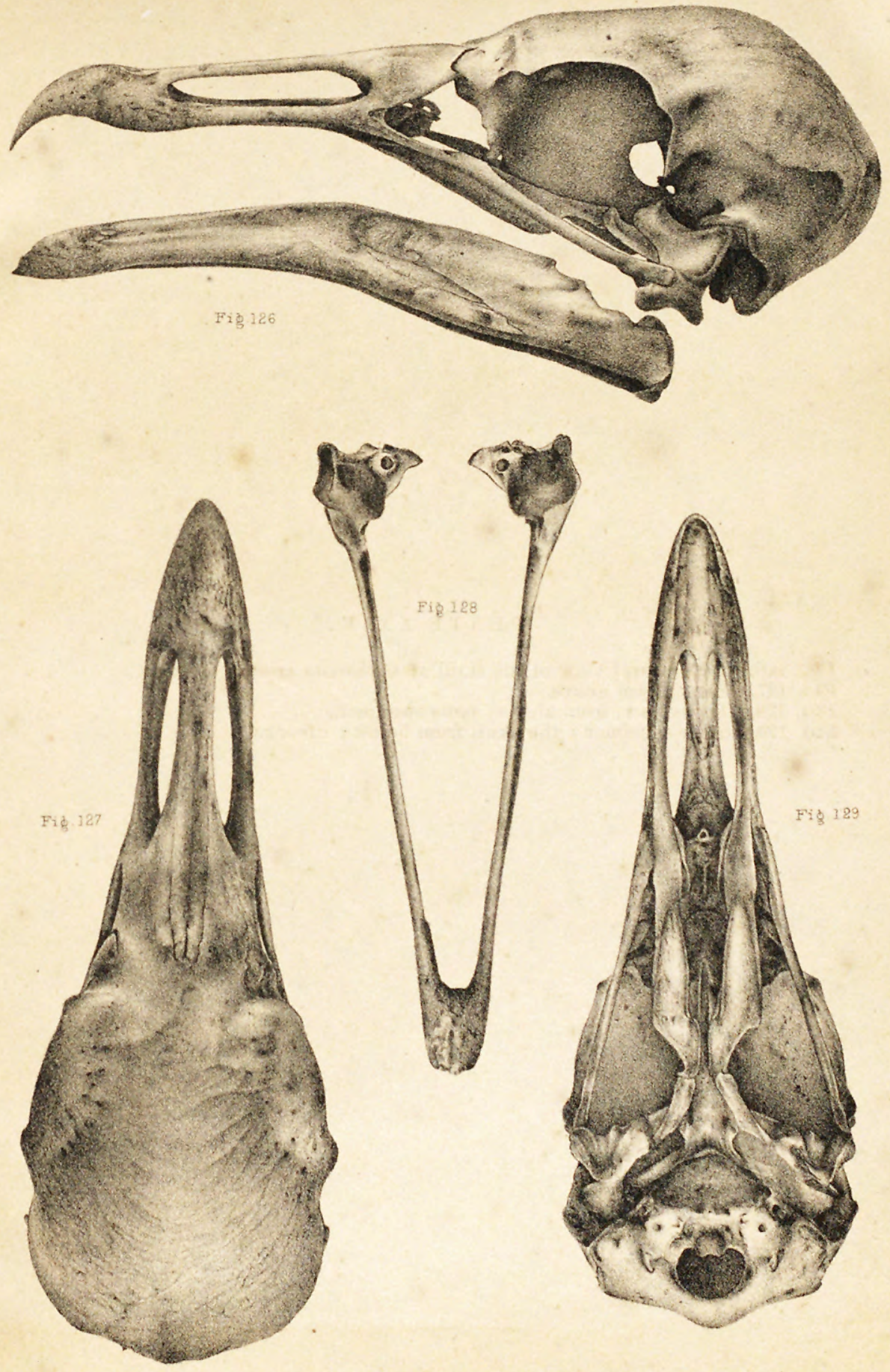

SHUFELDT ON THE OSTEOLOGY OF THE CATHARTIDAE 



\section{N D E X.}

Allen, J. A., 69

Alpestris, osteology of, Eremophila, 627

Apodida, 315

Apus, 319

sequalis, 320

domingensis, 326

dukianus, 327

guildingii, 326

himalayanus, $32 \%$

longicandatus, 324

lucasanns, 322

newberryi, 321

Apus cancriformis, nanplius of, $\mathbf{4 1 6}$

Apus lucasanus, eggs of, 426

Argus, 444

larval stages of, 428

Artemia, 329

$$
\begin{aligned}
& \text { fertilis, } 330 \\
& \text { gracilis, } 330 \\
& \text { guildingii, } 334 \\
& \text { monica, } 330 \\
& \text { utahensis, } 330
\end{aligned}
$$

Artemia fertilis, parthenogenesis in, 459

Artemia salina, parthonogenesis in, 461, 462,463

Artemia arietina, 466,501 muelhausenii, 466

Artemia salina, relation of, to $A$. Milhausenii and to Branchipns, 466

Artemia, character of, 509,513

Artemia koeppeniana, 506

Artemia, influence of change of external conditions on, 473, 491, 501

Bowditeh, F. C., 271

Brancbinecta, 334 coloradensis, 335,338

lindahli, 339 paludosa, 336

Branchipodidæ, 328

Branchipodidø, reproductive habits of, 420

Branchipodinæ, 328

Branchipus, 340

$$
\begin{aligned}
& \text { arietinus, } 466 \\
& \text { characters of, } 509,514 \\
& \text { ferox, influence of change of } \\
& \quad \text { conditions on, } 474 \\
& \text { spinosus, } 487 \\
& \text { grubei, } 496 \\
& \text { serratus, } 343 \\
& \text { stagnalis, nauplius of, } 416 \\
& \text { vernalis, } 343,420 \\
& \text { larval stages of, } 428
\end{aligned}
$$

Broadhead, G. C., 155

Brine shrimp, 330, 459

Carboniferous fossils, 119, 155
Carthartidæ, osteology of the, 727 pelvis and lower extremity of the, 776 pneumaticity of the skeleton of the, 736

pygostyles of the, 761

scapular arch, sternum, and pectoral limb of the, 765 skull of the, 740

species representing the, 729 table of cranial differences among the, 753

table of external characters of the, 732

vertebral column of the, 754

Ceratiocarida, 499

vortebral ribs of tho, 762

Ceratiocaris, 444, 450

Chirocephalus, 351

holmani, 351

Chirocepbalus holmani, larval stages of, 424

Chlamidomonas dunalii, 489

Cladocera, limbs of, 404

Clark, Frederick C., 173

Conditions, external, influence of, on Phyllopod crustacea, 473

Cope, E. D., 69

Cretaceous fossils, 5

Crustacea, classification of, 446,448 eyes, 414

genealogy of, 416,418

limbs of, 414

morpholoyy of logs of, 387, 404

Crustacea, Phyllopod, 295

$$
\begin{aligned}
& \text { fossil, } 355 \\
& \text { geographical distri- } \\
& \text { bution of, } 362
\end{aligned}
$$

Crustacea, Phyllopod, eyes of, $3-0$ morphology and an-

Cyclops bicaudatus, 479 atomy of, 370

Cyclops bicuspidatus, 499

Cyzicus, 303 odessanus, 499

Dall, W. H., 10

Daphnia, degenerata, 478 magna, 478,479 pulex, 4\%o

Daphnia rectirostris, influence of change of conditions on, 475

Decapoda, limbs of, 405

Dictyocaris, 444, 451

Dithyrocaris, 444,451

Dorsal vertebre, sternum, Eremophila, 637

Echinocaris, 450 
Endlich, F. M., 134

Eremophila alpestris, 627

Estheria, 303

Estheria belfragei, 309

californica, 304

caldwelli, 306

clarkii, 306

compleximanus, 305

dawsoni, $35 x$

dunkeri, 306

jonesii, 310

mexicana, 306, 354

morsei, 308

newcombii, 305

ovata, 356

watsoni, 354

Estheria compleximanus, larval stages of 426

Eubranchipus, 340,342

Eulimnadia, 311

$$
\begin{aligned}
& \text { agassizii, } 311 \\
& \text { antillarum, } 314 \\
& \text { stanleyana, } 311 \\
& \text { texana, } 312
\end{aligned}
$$

Evolution in Artenia and Branchipus, 466

Geographical distribution of Phyllopods, 362

Gilbert, G. K., 119, 136

Gissler, C. F., on reproductive habits of Branchipodidæ, 420

translation by, $459,463,466$, 473

Gros Ventre Range, 208

Gros Ventre Basin, 219

Gurley, W., 155

Hayden, F. V.:

Letter of transmittal, xvii

Hedessa, 298

Hoback River, 180,202

Holmes, W. H., 60, 131

Hyatt, A., 288

Hymenocaris, 444, 449

Hyoid arch, Eremophila, 634

Hyoid arch, Lanius, 720

Isaura, 303

John Day Ridge, 187

Jurassic fossils, 143

Lakes, Arthur, 5, 271

Lanius, 719

Laramie group fossils, 49

Leaia, 356 leidyi, 358

Lepidurus, 315

$$
\text { angusii, } 319
$$

bilobatus, 316,318

couesii, 316,317

glacialis, 316

viridis, 319

Lepidurus productus, nauplius of, 416

Lesquereaux. Leo, 174

Limnadella Kitei, 313

Limnadia, 311

americana, 311

coriacea, 313

Limnadia hermanni, naupliius of, 415

Limnadiadæ, 297

Limnetinæ, 298

Limnetis, 298

brevifrons, 301
Limnetis gouldii, 299 gracilicornis, 302 mueronatus, 300

Limulus, affinities of, 411

limbs of, 407

Lobster, limbs of, 405

Lower mandible, Eremophila, 634

Ludovicianus, osteology of, 719

Marnoch, G. W., 6

Monas dunalii, 489

Morphology of Phyllopod crustacea, 370

Monlting in Phyllopod crustacea, 377

Mushbach, J.E., 114

Nebalia, 444, 449

Nebalia, anatomy and development of, 433,440

Nebalia, palæozoic allies of, 443 limbs of, 407

Nebaliadæ, 445

Nicholson, H. A., 6

Osteology of the Cathartidæ, 727

Eremophila alpestris, 627

Lanius ludovicianus excubitorides, 719

North American Tetraonidæ, 653

Speotyto cunicularia hypogæa, 593

Packard, A. S., jr., 149

Packard, Prof. A.S., jr., on Phyllopoda, 295

$$
\begin{aligned}
& \text { on the order of } \\
& \text { Phyllocarida, } 432 \\
& \text { report of, } 294
\end{aligned}
$$

Paleontology, contributions to:

No. 2, by C. A. White.

No. 3, by C. A. White.

No. 4 , by C. A. White.

No. 5, by C. A. White.

No. 6 , by C. A. White.

No. 7, by C. A. White.

No. 8, by C. A. White.

Paranebalia, 449

Peale, A. C., 115, 174, 271

Peltocaris, 444, 449

Pelvis and the pelvic limb, Lanius, 723

Peivic limb, Eremophila, 648

Perry, Nelson, 173

Phyllocarida, character of, 447

Phyllopoda, 297

limbs of, 407

order of, 432

brain, 400

heart, 399

liver, 397

mouth, 397

nervous system, 400

ovaries, 398

stomach, 397

Phyllopoda, crustacea, 294.

fossil, 355 .

geographical distribution of, 362

geological succession of, 355

histology of, 361

Phyllopoda, development of, 415

genealogy of, 415

histology of, 370,372

morphology and anatomy of, 370

moulting of, 377 
Phyllopoda, nomenclature of, 372

reproductive habits of, 420 , 423

Powell, J. W., 153

Rachura, 451

Sacral vertebre, pelvis, Eremophila, 640

Salt Lake brine shrimp, 330, 459

breeding habits of, 489

winter eggs of, 462

Scapular arch, Eremophila, 643

Scapular arch and pectoral Llimb, anius, 72:3

Schmankewitsch, W. J., on the influence of external conditions of life upon the organization of animals, 473

Schmankewitsch, W. J., on the transformation of Artemia in to Branchipus, 446

Scudder, Samuel H.,Report of, 271

Tertiary Lake Basin at Florissant, Colo., 271

Shufeldt, R. W., osteology of Eremophila alpestris, 627

Shufeldt, R. W. :

Osteology of Lanius ludovicianus excubitorides, 719

Osteology of Speotyto cunicularia hypogæa, 593

Osteology of the North American Tetraonidie, $65: 3$

Osteology of the Cathartida, 727

Siebold, C. T. :

On breeding habits and egrs of Artemia 1ertilis, 459

On parthenogenesis in Artemia salina, 463

Skull, Eremophila, $62 \tau$

Skull, Lanius, 719

Speotyto cunicularia hypogæa, osteology of, 593

dorsal vertebræ, sternum, 604

hyoid arch, 599

lower mandible. 600

pelvic limb, 616

sacral vertebræ, pelvis, 608

scapular arch, 611

spinal colnmn, cervical portion, 601

upper extremity, 613

Spinal column, cer ical portion, Eremophila, 635

Sternum, Lanins, 722

St. John, Orestes, report of, 173

St. John, O., 1:21, 144

Streptocephalus, 344,348

floridanus, 350

similis, 350

texanus, 345
Streptocephalus texanus, larval stages of, 426

Taste, organs of in Crustacea, 384

Tertiary fossils, 41

Tertiary Lake Basin, Colorado, by S. H. Scudder, 271

Tetraonidæ, ostenlgy of the North American, 65:

of the pelvis and pelvic limb, 691

of the scapular areh and pectoral limb, 686

of the skulls, 661

of the sternum, 681

of the vertebral col-

Thamnocephalus, 532 umn, 675

Triassic fossils, 105

$$
\text { platyurus, } 353
$$

Trilobites, limbs of, 408

Upper extremity, Eremophila, 545

Vertebral column, Lanius, 721

Wachsmuth, C., 155

Wadsworth, M. E., 276

Walker, D. H., 33

Western Territories, distribution of life in, 364

White, C. A., 174

Contributions to Paleontology, No. 2. Cretaceous fossils of the Western States and Territories, 5

Contributions to Paleontology, No. 3. Tertiary mollusca from Colorado, Utah, and Wyoming, 41

Contributions to Paleontology, No. 4. Fossils of the Laramie group, 49

Contributions to Paleontology, No. 5. Trassic fossils from Southeastern Idaho, 105

Contributions to Paleontology, No. 6. Carboniferous fossils from the Western States and Territories, 119

Contributions to Paleontology, No.7. Jurassic fossils from the Western Territories, 143

Contributions to Paleontology, No. 8. Carboniferous fossils from the Interior States, 155

Whittield, R. P., 37

Winchell, Professor A., 121

Wind River District, 175

Wind River Range, 228

Wind River Basin, 255

Wyoming Range, 178

Zoogeography, 362 